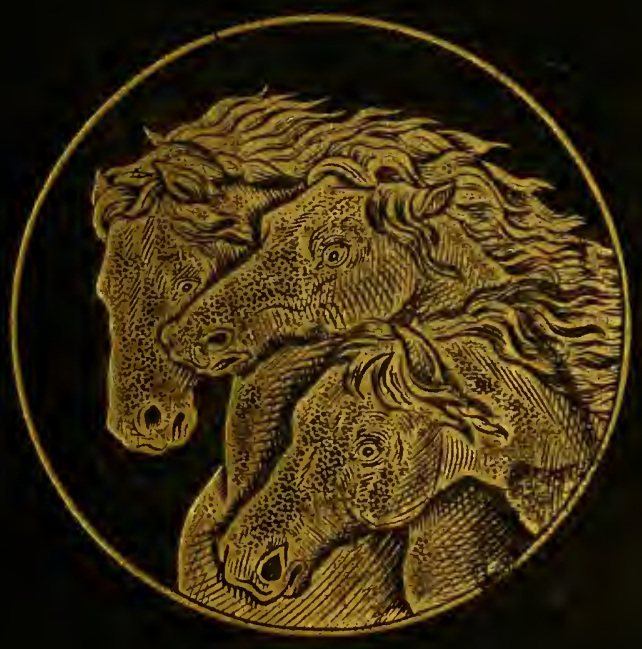




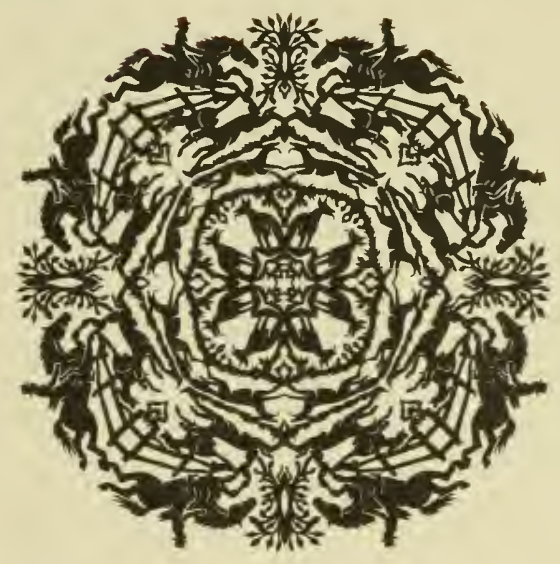

JOHN A.SEAVERNS 
$=-\div \equiv$

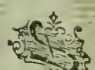

I

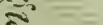

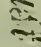

de

$+=0$

I

$=$

s. 






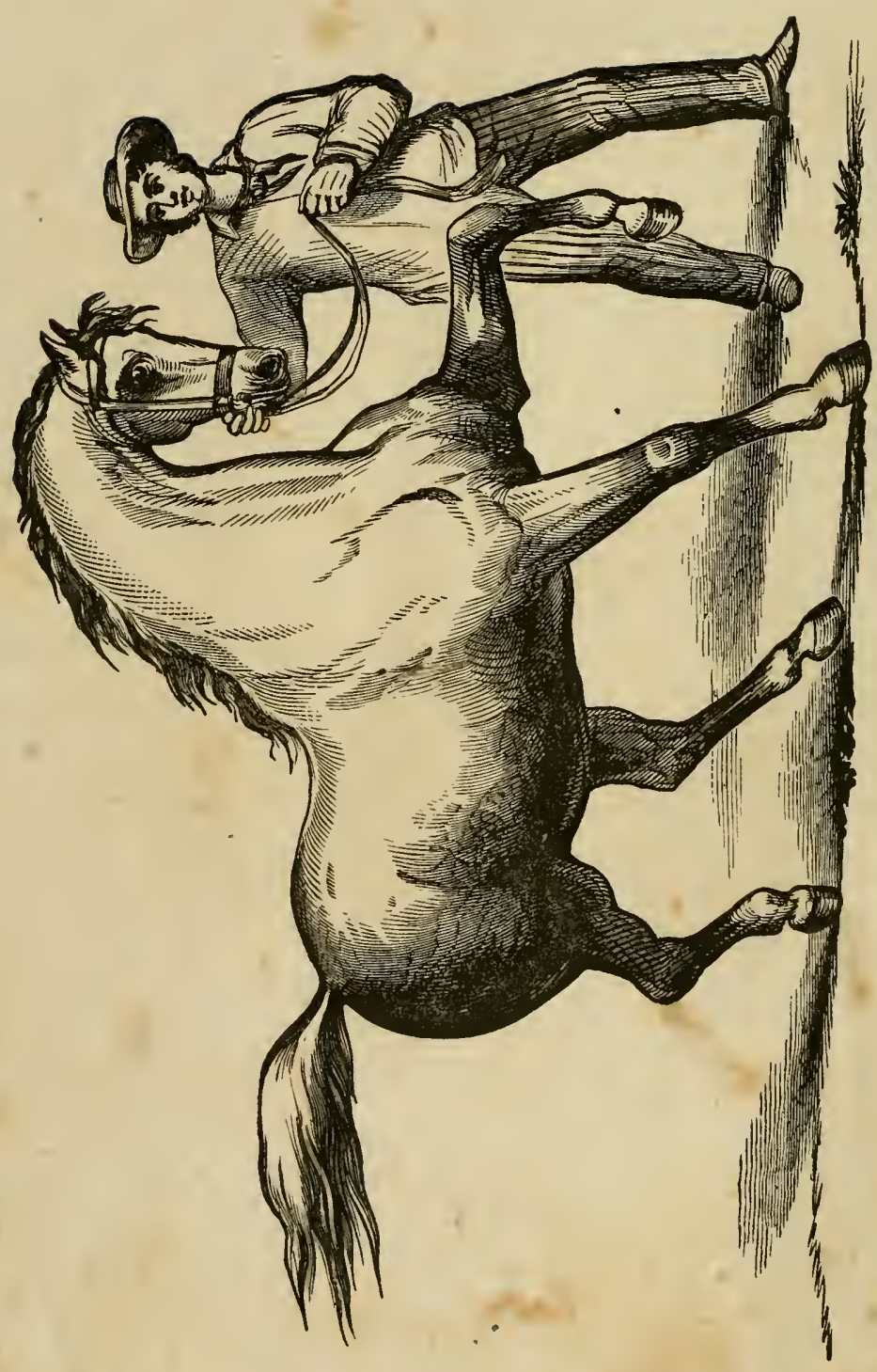




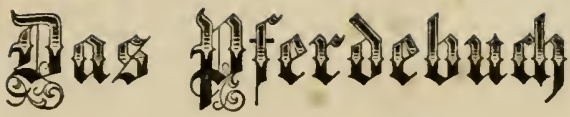

oct

\section{amerituatschen fratmers,}

enthattent

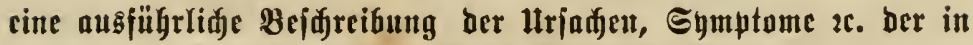
Amerifa borfummenden Pierbefrautleiten,

fowie elne

einfactie, erforgreicfje und originelle Anweifung jur Befjanofung derfel6en,

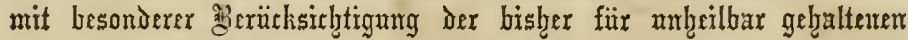

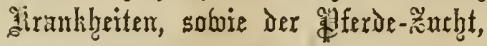

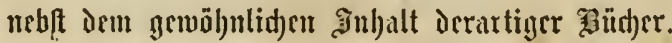

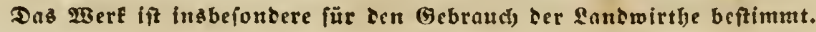

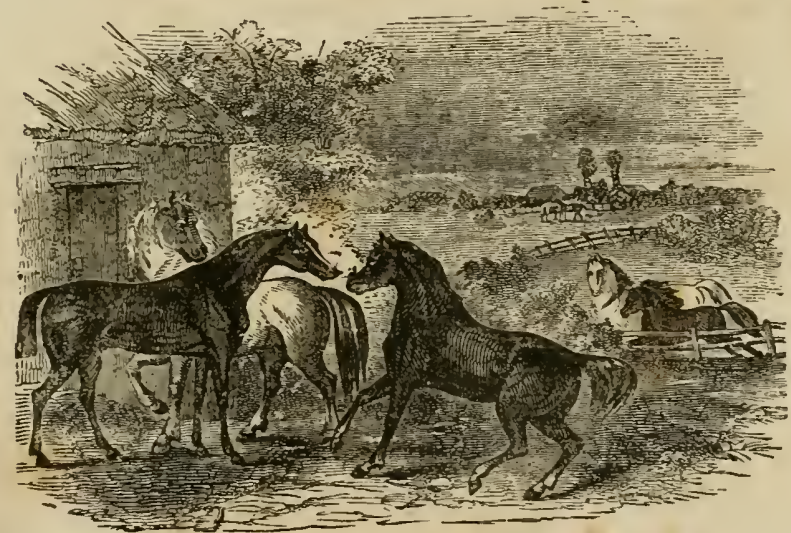

Bon

Doftor ser Mebizin unt Ibierargt.

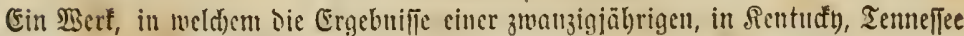

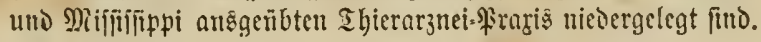

\section{Cinciunati:}

C. E. V v

Chicago: 3. 5. Gooðman \& $\mathfrak{C} 0$.

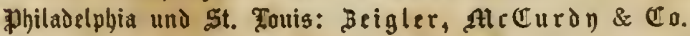
hidumond und atlanta: Nlational lublishing Company. 1868 . 
Entered according to Act of Congress, in the year 1866, by

C. F. VENT \& CO.,

In the Clerk's Office of the District Court of the United States for the Southern District of Ohio. 


\section{Worwart ore Werleyer.}

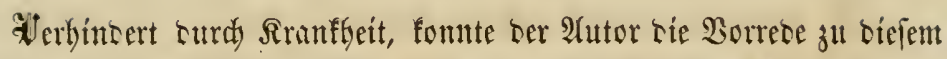

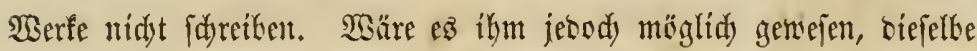

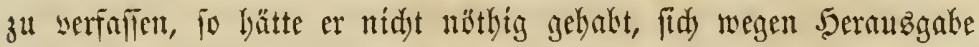

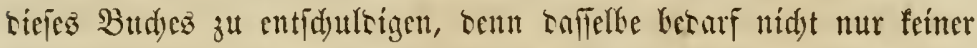
Entfduldiguttug, foutern entfpridyt unjern Gädjiten Erwartungen uno

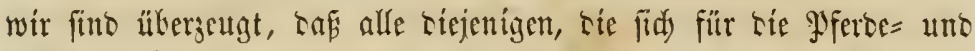
Mianthierjud) interejïren, siejem Budde ibre herglidje Buftinumung uno Interftüțutg nidyt worenthaltent werben.

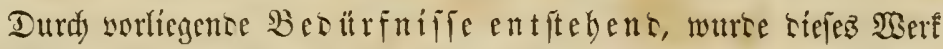
nad) uno nady weiter gefülyrt tub fortigejest uno erft sann ber Deffent= lidufeít ühergeben, alz ftänoig war. Sor etwa zwantig Sabren ridjteten Fiftel un $\mathfrak{B} i g$ 5ead unter ten Pfercen bes Shtors grope Berheerutugen an mo

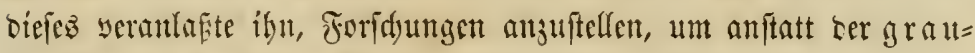
famen un grofaentheils erfolglojen Behanolungäweíe, síe

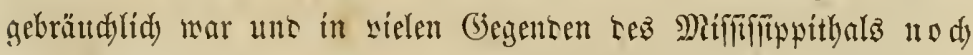
all $\mathfrak{g e m e i n}$ gebräud)lid ift, rationeflen Sutrmethoren bie $\mathfrak{B a b n}$ ju

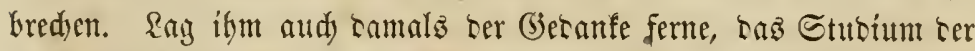

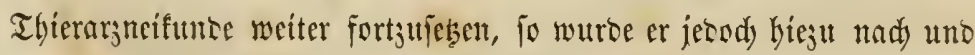

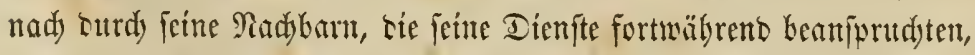

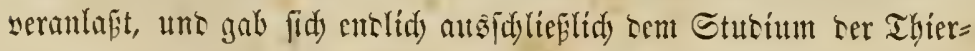
argnei=\$Si Prariz bin, wäbrento weldyer er vicle ber alten Theorien volfitïndig wiberlegte uno anjtatt ber graujamen, unmenidjliden Rutumethoben einfadjere, erfolgreidyere und billigere einführte. Seime Praxiz er= 


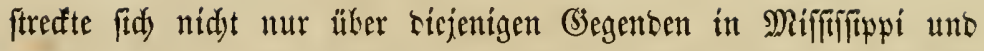
Tennefiee, wo man ber Pierbezudit bejontere 2lufmerfjamfeit identt, fontern yom Dhio bis jum Rio Grrante.

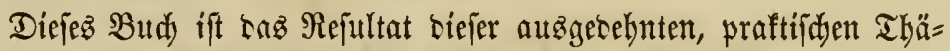
tigfeit, uno wir übergeben eż ber Deffentlidfét mit ber feften Ueber=

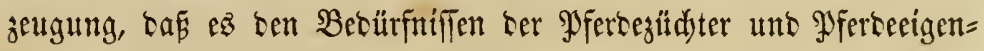
thüutter befīer entipridyt, alz irgend ein anteres, ober alle antern

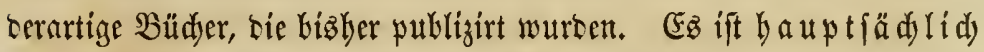
für $\mathfrak{A} \mathfrak{m}$ erif $\mathfrak{a}$ geidurieben uno enthält eine volfytändigere, eingehen= bere Beidjeibung uno Bebantlungşweife ber ben amerifanifden Pferben eigenthü $m$ lidyen Sranfleiten, alz irgend ein anberez

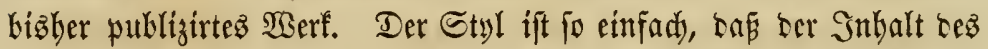
Budb yon Sebem verftanden werten fonn; bie Erflärung Der Fremt:

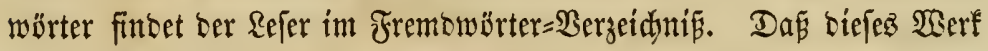

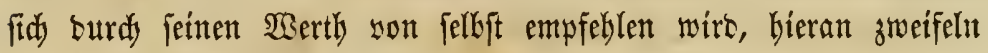
wir feinen 2fugenblide.

Diejenigen, die (3iebraud, Dayon madjen, werben unz zum Danf

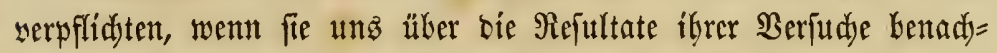
ridytigen, benn hierburd) werben wir im Stante fein, Jrtthümer, rie fid) möglidjerweife eingeidjliden, ober yon benen, weldje bie vorge= idjriebene Methobe befolgten, begangen wurhen, zu beridtigen.

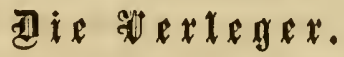

Cincinnati, den 1. Sanuar 1867. 


\section{I $\mathfrak{a b a ~} \mathfrak{l}$ t.}

\section{1. $\mathfrak{R}$ piter.}

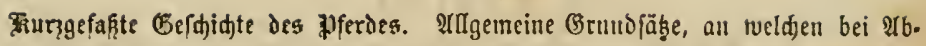

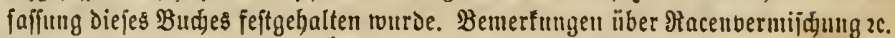

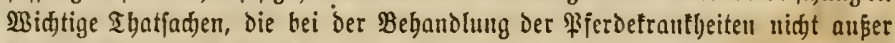
ád gelaijen werden bürfen

\section{Rapitel.}

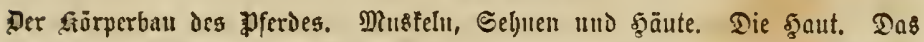

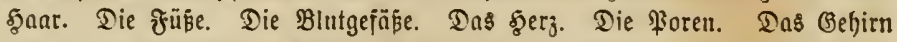

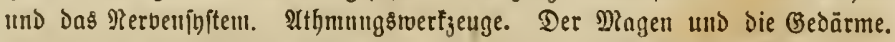
Die Reber. Die Bautjpeideldriife. Die Mil

\section{3. $\mathfrak{i}$ a $p$ it $\mathfrak{e}$.}

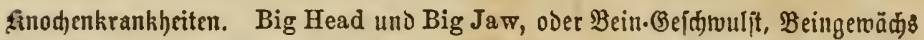
aın Sopf ober Riunbađten. Swinney (eine Entjündung), Edfulter.Entzünoung.

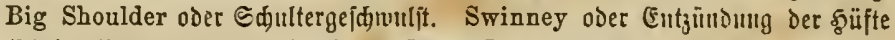
(hip). Berreutte oder gebrodgene şiijte. Silroderipat (bone spavin). (Einige

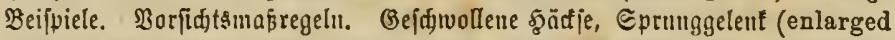

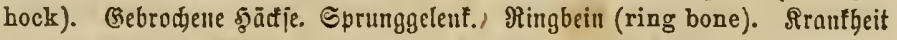
Der Iniefdeibe (stiffle). Splint, oder Srantheit Des (Briffelbeins. Suriebrud, Etolpern. Sentrücten (sway-back).

\section{4. $\mathbb{R} \mathfrak{a}$ itel.}

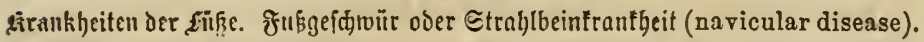

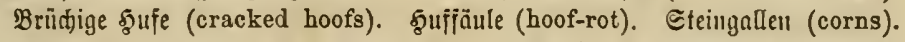
Bollfuf (contraction of the hoof, of narrow heel). Serlestungen De§ Єtrabls, aud Gabel (frog). Die Relye, હteifigteit (inflammation of the feet, or founder)

\section{Sapitel.}

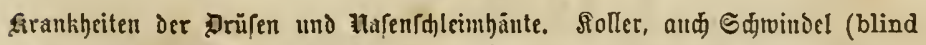

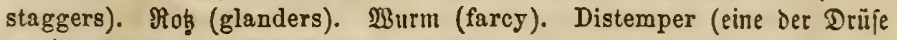

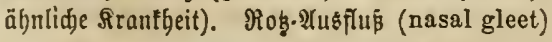

\section{6. $\mathbb{R} \mathfrak{a}$ ittel.}

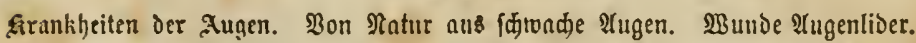
Monto. nuth Monatblinobeit (moon eyes). Etaar (cataract). Blas.2lugent. Ent jünomg Des britten 2A (ugentios (inflammation of the haw, or hooks). Blösindtigteit (dimness of vision). Wie man bie Arantfgeit ber \&ugen entbeftell tanul.................................................................................. 


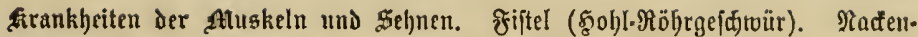
(Genicfififtel (poll evil). Da) fenipat uno Blutfpat (bog and blood spavin). Flußsgallen (wind galls). \$̧ajent)ade (curb). ßiphacten (thorough-pin). Dianlflemme, aud) Maulfperre, Starrframpf (tetanus, or lockjaw). Diuster.

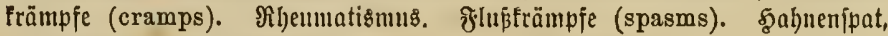
nud fुabuentritt oder నిuffus (string halt, or spring halt)

\section{Sapitel.}

Earankbeiten Jer sfaut und der obren. Edrammen (scratches). Fliepende Stral)lfäule (thrush). Maufe (cracket heels, or greese). Beingejđunulft. Gejdfwollenes feficlgelenf (swelled ankles). Surfeit (eine Durd) umreines Blut

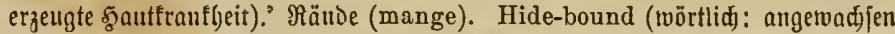
mit Der Şaut; eine Şautfranfheit). Steifbeit (stiff complaint). Warzen.

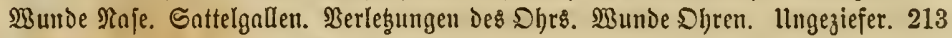

\section{9. $\Re \mathfrak{n} \mathfrak{i}$ t $\mathfrak{e l}$.}

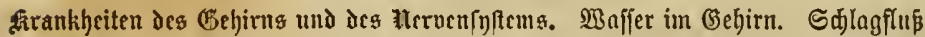
(apoplexy). Wanferidell, Wuth (rabies, hydrophobia, or madness). శ్all. fudt (fits, or epilepsy). Şirnentzünoung. \&ähmung (palsy). Iollbeit,

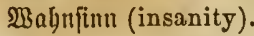

\section{0. $\Re a p i t e l$.}

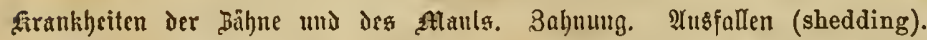

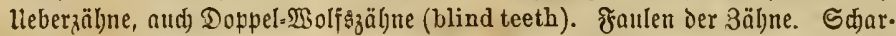
bodf, aud) Eforbut (scurvy of the teeth). Stump-sucking (an Baumitumpen jaugen). Crib-biting (an der Srippe nagen). Wind-sucking (wenn Das अferd, indem es an einem Stumpen ober an Der Sirippe nagt, Die Ruft gewaltfam ein- uIID alisatbmet). Frojø (lampas)

\section{Rapiter.}

Atrankbeiten des falles. Erfältungen. (Befd)wollene Drïfen (enlarged glands). (Bejd)wollener Sুals (swelled throat). ร̧uften. Malignant epidemic (die bösartige Seuthe). Şartjđunaıfigfeit (difficulty of breathing). Dämpfigfeit, Baud)(d)lag uno Reidjen (broken wind, bellows, and heaves). Thick Wind, Wheezing, etc. (Surzatlymigfeit). Roaring...

\section{Sapitel.}

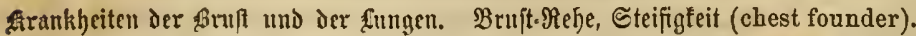
Bronchitis (Entzuntoung Der Brondjien). Inngenentzünoung (pneumonia,

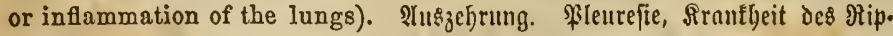
pen-Rungenfells (pleurisy).

\section{3. $\mathfrak{R}$ apiter.}

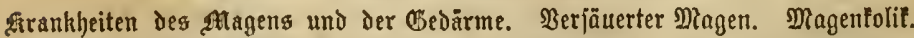
\$ïrmer (bot). (Gedärm.Entzünoung (inflammation of the bowels, enteritis). Msimbtolif (fiatulent colic). Entzimbung Desి Brimmbarms (inflammation 
and rupture of the colon). Entjünoung uno Bluten Des Maftiarms (inflammation and bleeding of the rectum). Wunber unb juffender affer (soreness and itching of the anus)

\section{4. in $p$ iter.}

Sirankbeiten der feber, der Garnorgane u.F.m. Ballenfieber, Belbjudyt (jaundice or yellows). Bergröberung Der $\mathfrak{M i l}_{3}$ (enlargement of the spleen). Rieren. entjuindung (inflammation of the kidneys or nepheritis). รatnflup (profuse stalling or diabetes). Blutbarmen (bloody urine or haematuria). Edyleim. barnen (thick and albuminous urine). WEeiper oder falfiger f̧arn (white or limy urine). Sarnblajenitein (gravel or stone in the bladder). ßerbaltung

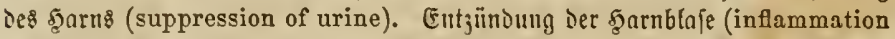
of the bladder). MBmber Sdjlaud (foul sheath). Colt founder (EntzünDung Der Bebärmutter 2c.) Arantheiten junger Foblen

\section{5. $\mathfrak{A} \mathfrak{i}$ it $\mathbb{E}$.}

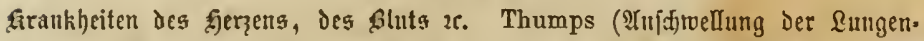

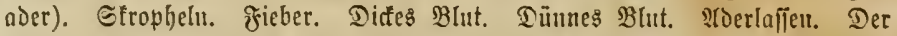

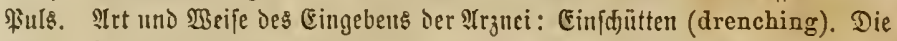

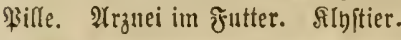

\section{6. $\mathfrak{R} \mathfrak{a} \mathfrak{i t e r}$.}

Gifte, giftige Siblangen und In/ckten 2e. (Bifte, veld)e Den Drganisిuns nergiften, weun fie genolfen werben. Bifte, weldye Durd, Die şaut einoringen. Biftige Thiere.

\section{1\%. Sapitel.}

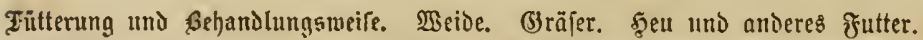
Getreide. Grïnes Futter fïr Binter. Gtalleinridtung uno Behaublung im Stall. \&uft. Bentilation und Iemperatur. Fuśboden. Stren. Reinigen und StriegeIn. Beränderung Der $\mathfrak{B}$ itterung und Der Iemperatur. Ieppichbedectung. Desinfeftion. Bervegung....

\section{8. $\mathbb{A} \mathfrak{a}$ it $\mathbb{C}$.}

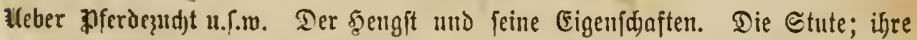
Eigenjajaften uno ibre Bebandlung. Sas Foblen und jeine Behandlung.

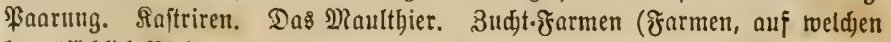
Gauptiädjlid) Bieb gezogen roird)

\section{9. $\mathfrak{R} \mathfrak{p}$ iter.}

atterkmale, an weldjen man das alter und stlifhandlungen erkennen kann. Die 3äbne. Die Sippen. Das fुaar. Der llntertiejer. Die Augen. Die Miß̄.

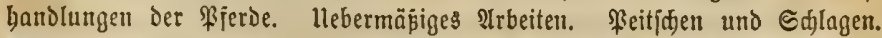

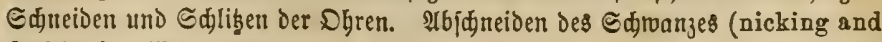
docking). Bettrennen 


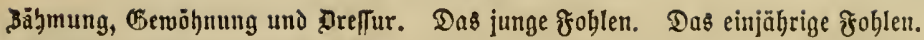

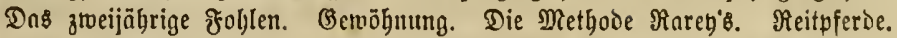
Chnifenpferde. Bugpferde. Roadsters (\$Ferde fïr Dmnibuffe ze.). (Getwölyung, Drejfur 2r. Des Maulthiers.

\section{1. $\Re \mathfrak{a} \mathfrak{p}$ iter.}

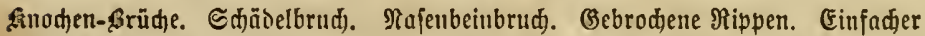
Beinbrud. (Berifift (frame). Mothitall (pen). Eintidten Des Beins. Be. Gandtung der Brudjwutde. Die 3eitoaner der Sur

\section{Sapitel.}

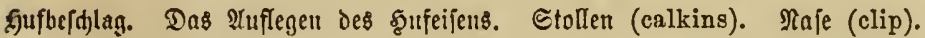

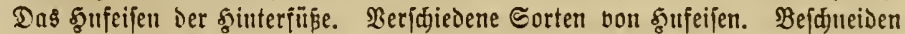
Der झुufe (paring the hoofs). 'Abuegmen der झुufeifen. Wie lange diefelben gebraudjt werden fönturn

\section{3. $\mathfrak{R} \mathfrak{a p i t e r}$.}

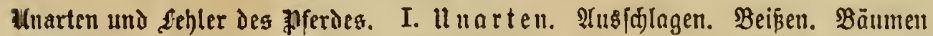
(rearing). Sđeumerben. DavonIanfen. Störrigfeit unb 3urürtweiden (balking and backing). Nagen an Den Riemen. Reipen an Der f̧alïter uno Loßreißen

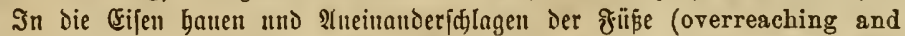
interfering). II. ₹̛̣

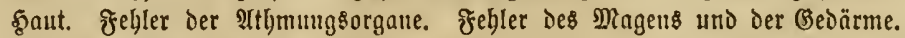
Die şarnorgaute. Edflubbemertungen .................................................. 54

\section{4. $\Re \mathfrak{a p i t e r}$.}

Ziecepte zur Arz̧nei-ßereitung............................................................ 559

Xlphabetifdes frembmörterverzeidnif ............................................. 571

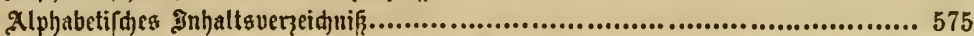

Angabe Der \$nmptome Der ver[diedenen farankheiten................................. 584 


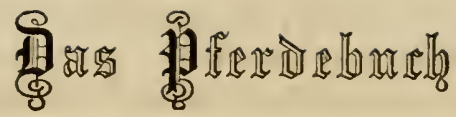

des amerikanischen frarmers.

\section{Sirftes carapitel.}

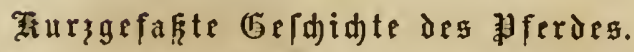

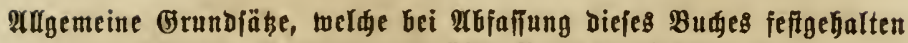
tordoen. Bemerfungen über Bacenbermiidung zc.

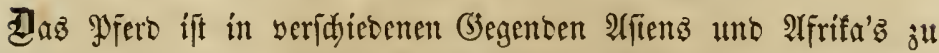
5atre; aud) fintet man im jübliden Sibtrien sa unt cort grofe 5eer=

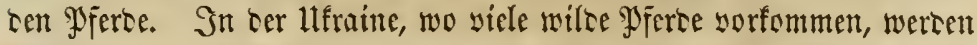

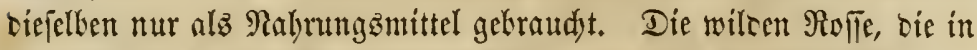
Seeroen auf beiben Uiern Les Don leben, finto bie Radjfümmlinge ter

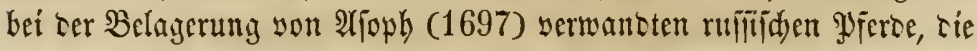

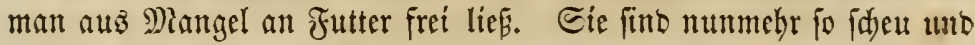

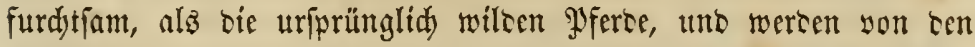

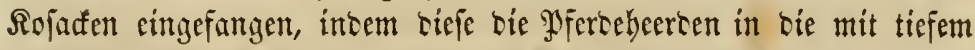
Ednee gefüllten Ihäler treiken, wo man ter Thiere leid,t babhaft wirt.

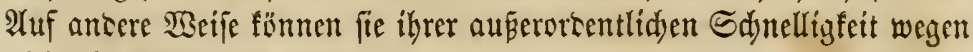
nidyt eíngejangen werten.

Die in Süßamerifa yorfommenten Seersen fino fpanifđen Hriprungs

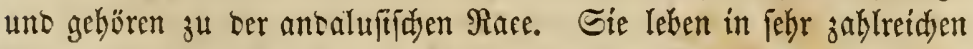

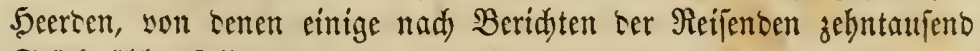
Stüđ zählen jollen.

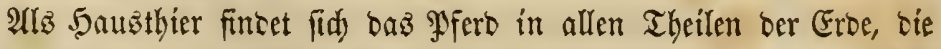

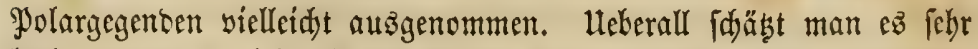
hod, verwentet viel Zeit uno Mïhe auf feine Zudyt uno Drefiur uno

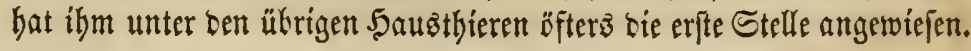




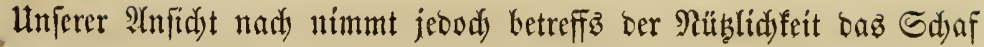

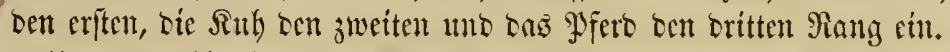

Unter ben bis jest entoeften fed)s PJerocraecn bat man nur ente in uripinglidy uno yolffonmen wilsem 3uitano in ber neuen welt tuo

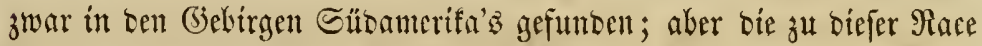
gebörenoen Pofle haben gejpaltente 5utfe.

Das Pferd ift bem Menfdyen binfichtlich feintez Stolzez, feimer \&after uno (bicbrechen fowobl als bejitglich) feiner. Riebe jur Inabbängigfeit uno Stürfe ähnlidy. Gifon im Prltertyutue bahen Didyter ben Math uno

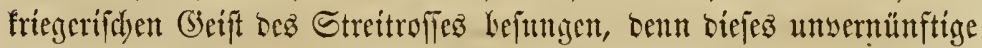
Thier, bas fidh mit fübuem Minth in rie Gdyladyt ftürst, ift in bicfer

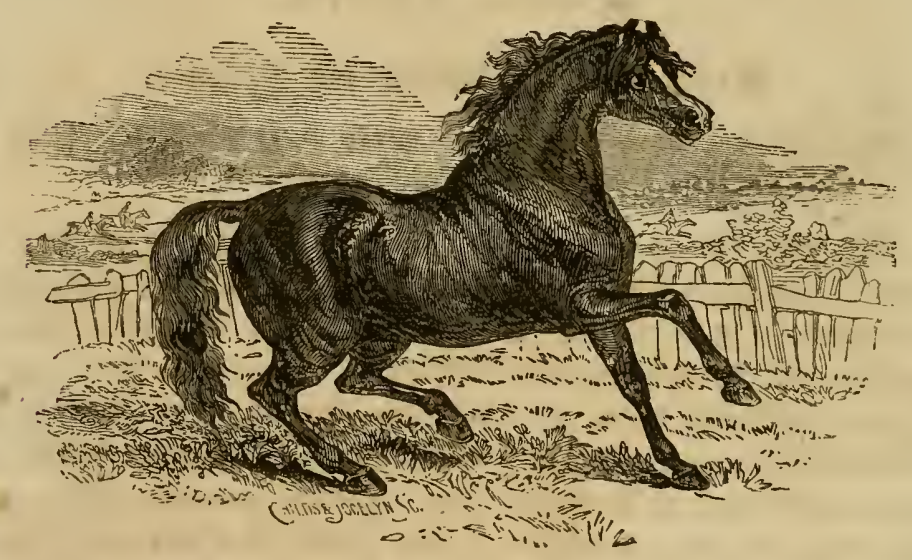

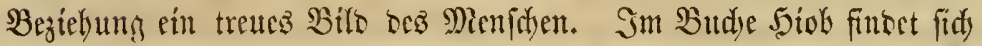

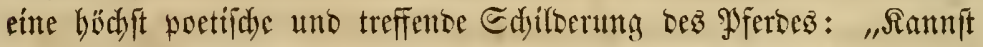

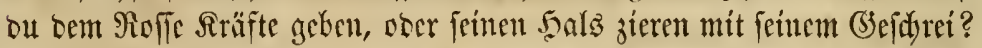
Sannft bu es̃ futreden wie bie 5cufdreden? Das ift Preis feiner Naje, was fdyredfich ift. EB ftampfet auf ben Boben und iff freutig mit Sraft, uno ziebet aubz Den (Sebarnijd)ten entgegen. Ez jpottet ber Furdjt unt eridyrifft nidyt, tmo fliebet yor bem Edywerte nidyt, wenn gleid wioer

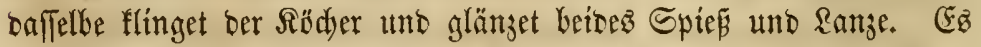
gittert umb tobet und fdjarret bie Croe und adjet nidyt ber Trompeten Salf. Wenn bie Irompete ftarf erflinget, fpridyt $\mathfrak{c z}:$ Sut; ried)t ben Streit son ferne, das Sdyreien ber Füriten unb Gaudjzen." 


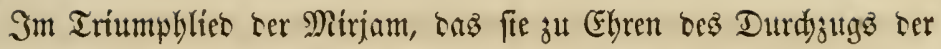

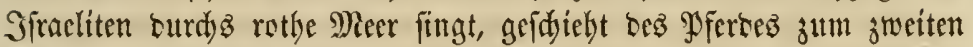

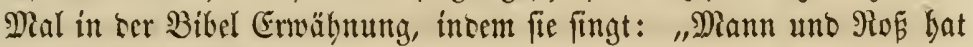
er in'? Meer geftürs̆t." .

Das Pfero wiro in ber beil. Edyrift faft immer in Berbinoung mit

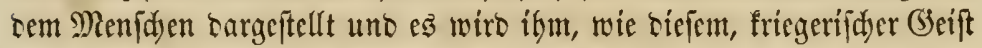
uno Ruft zu Streit uno Rampf jugeidrieber. Dod) muÉ ez, wie ber

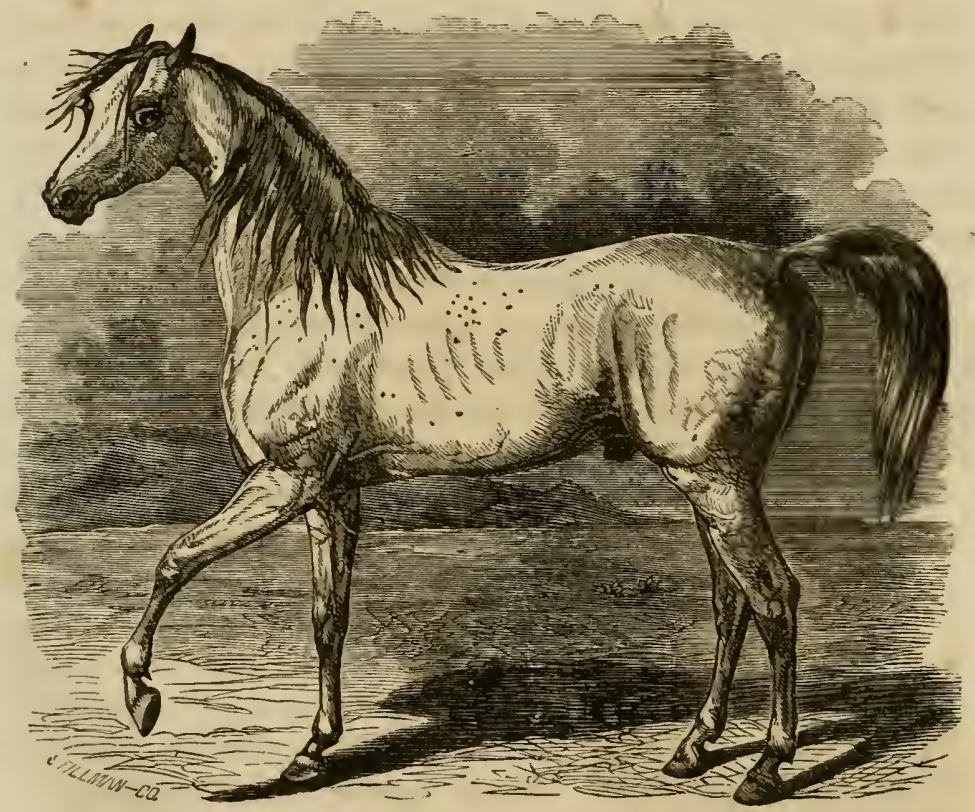

Arabifdeg olferd.

Menid) mit groferer Sorgfalt fïr sen blutigen Rampf berangebillot mer= เon, wozน

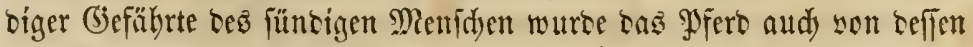
Sranflgeiten - cine unfehlbare Folge ocr Sïnbe - befallen, uno cż mag gcjagt werben, ba bezüglid) feiner Sranflyeiten sem Menidyen näher ftebt, als irgeno cin anteres $\mathfrak{I h i e r . ~}$

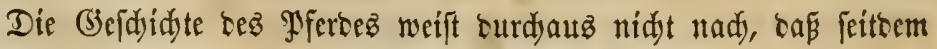




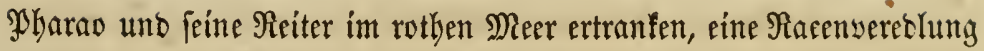

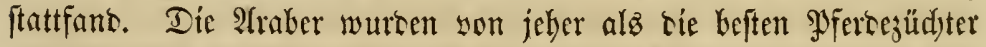
unb als foldye anerfannt, weldye bie fdjönjten Pferbe kejiţen uno sie=

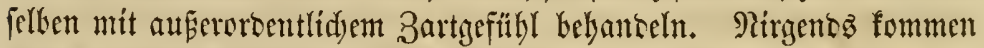
fo wenige Roǵfranffeiten sor, alz unter ben arabifden Wferben, uno büdjtens fönnen sie Ponics (Wfersden, Rlepper) ber weftliden $\mathfrak{I n}=$ rianer fid in biefer Shinfidyt mit ibnen meffen. Sieraus geht herwor,

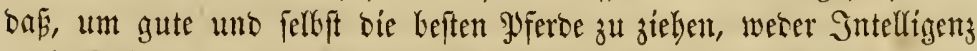

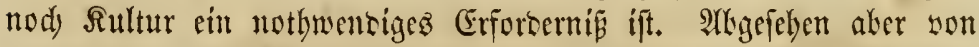
ber Frage, ob bas Pfero mit ber 3eit wereselt wurte oter nidyt, ift es

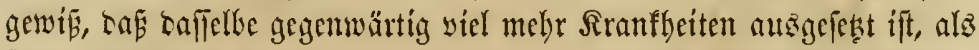
früler unb zwar namentlidy in tenjenigen Räntern, wo men ser Yjerse=

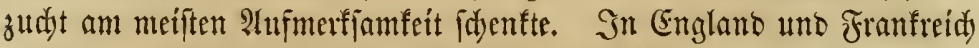

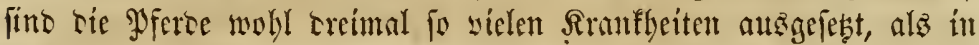
A(merifa, uno in sen älteren Ctaaten riefes Rantes foument wohl zelyn=

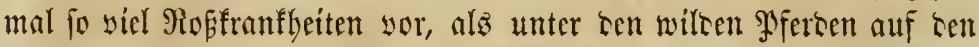
Prairien in Teras ober unter ten Ponté ter Sncianer. Beitcez,

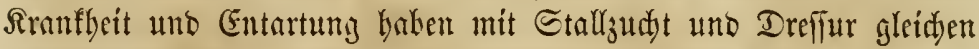
Sdyritt gebalten.

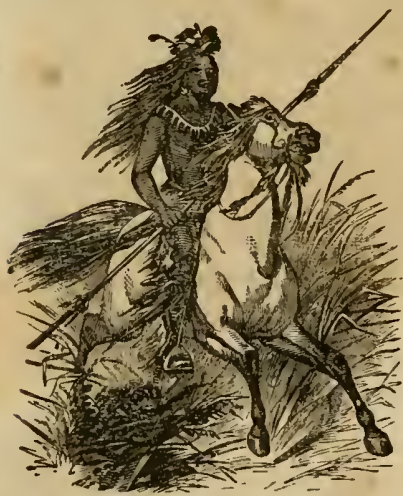

Pur wenigen Plerjonen ift es befannt,

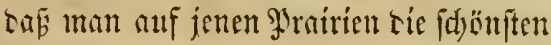
Prerte fintet, bie eş ülerthaupt githt, utho

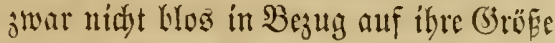

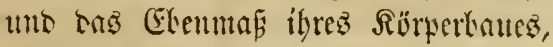

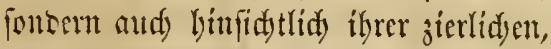
tem $\mathfrak{T}$ tuge gefölltigen $\mathfrak{B}$ ewegungen. Mandje berfelben übertreffen bierin bei Siseitem foldhe Pferte, auf teren Budt uno Dreffur tie grö́s̆te Eorgfalt yer= wentet wurte.

Aflz ber Berfafier einft mit einem

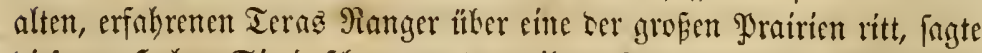

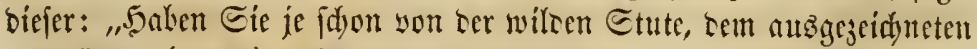

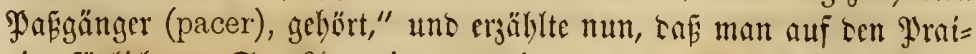

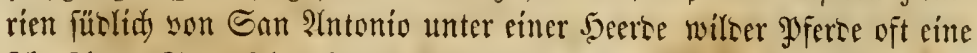
fehr fab̈ne Stute fehen fönne, tie immer nur, fo hisig fie aud serfolgt

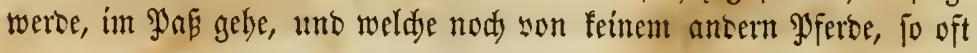


man bieş aud fadon yerjudjt habe, eingeholt worben jei. Dieje $\mathfrak{B} e=$ Gaurptung Gürte id ipäter yon andern beftätigen.

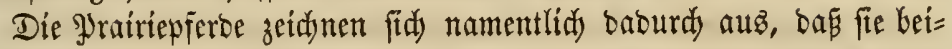
nake niemalz frant werben, uno sieje ifgnen eigenthümlidje Eigenfda aft

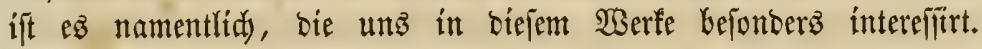

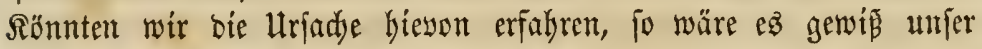
Bortheil, unz son biejen ftummen \&ebren unterridsten zu la|len, uno

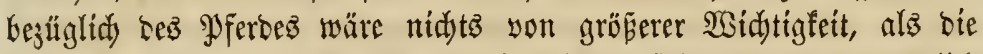
Entbefung biefer Urjadjen. Serody fteht ez feft, bas ez namentlid) zwei Hriadjen Finto, weldje bie zafinen \$ferbe io vielen Siranfheiten unterwerfen: 1) Das Futter, weldes im Stall gefüttert wird, utnd

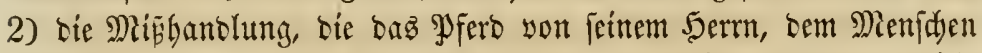

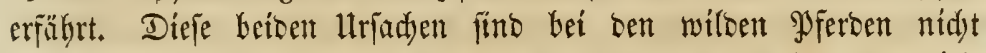

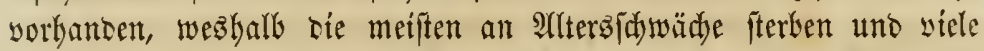

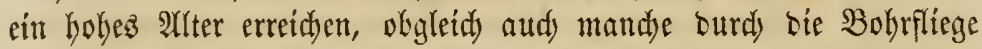

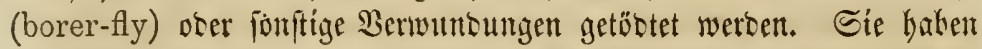
bie ifrem Drganisెmts angeme|jene Freibeit, folgen ifrem Snftintt,

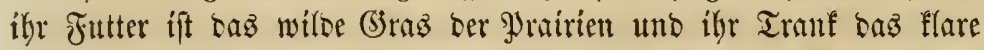

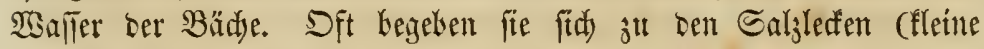

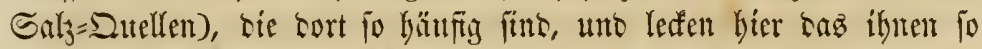

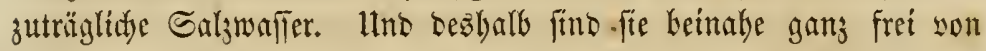
jeglider Srruffgeit, wäbrent fie fid zu gleidyer Zeit naturgemäs biz

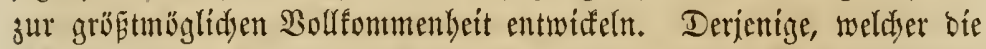

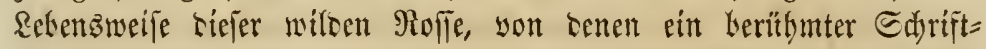
fteller *) jagt, daj fie sie beften Cavalleriepferse übertreffen, uno ifre

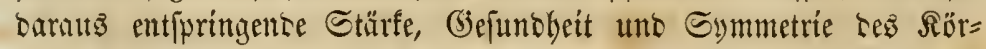

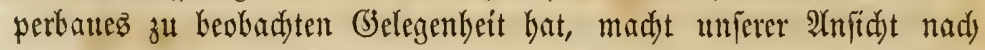

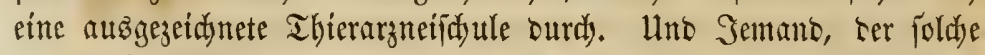

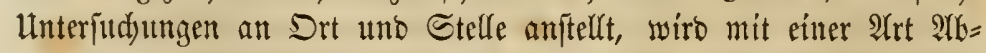
foheu gegen bie fojledten in sen Etallungen unt auf ben Rantgütern gebrüud)lithen Methosen zurüdfommen.

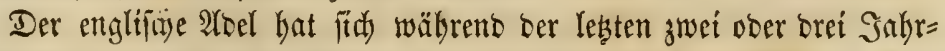
hunberte ermftlid) und vielfad) mit ber Beredlung des Pferbes abge= geben uno bat bierourdy, ohgleidy er alle guten Eigenfdaften beriélben entwiffelte, im (Ganjen bod) nur währeno biéer ganjer Zeit zu befîen

*) Bafjiugton Sroing. 
Entartung beigetragen und fomit Riatefdritte in ber Pferbegutdyt ge=

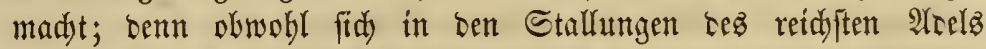

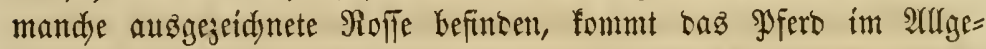

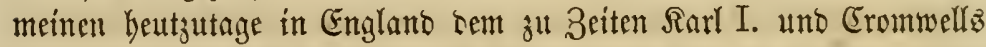

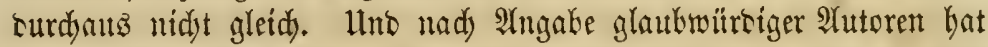

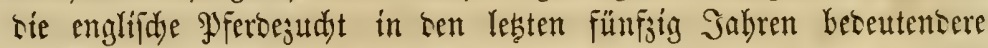
Rütđidyritte gemadjt, als in irgent ciner vorhergehenben Periobe. WWir

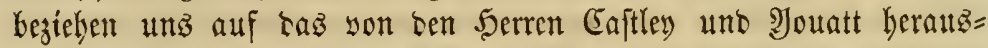

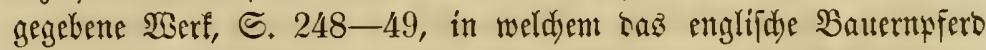

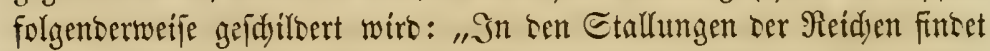

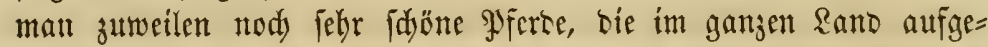
fauft wursen; aber siefellben fint fo felten geworben uno wersen ju

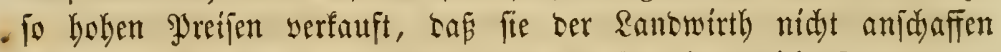
fann; ja, bie \$yferbe mandjer Erellente fint jeste nidjt fo gut unto

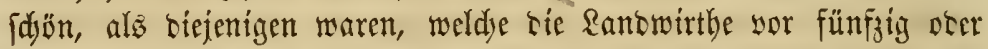
Guttert Sahren gebrauddent, Lemn bie Tage, wo bie englif́den Bauern

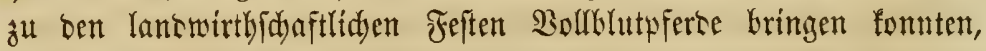
fint vorüber; biefellen fint in ben Sä̈noen ter wentigen Reidyen uno ber Borrath war umo ift immer geringer als bie Siadjfrage."

Daflerbe iff in Epanien ser Fall. Bur Blüthemseit ber Fanifden

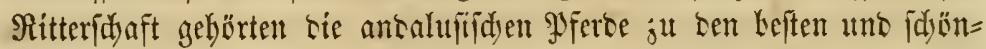
ftent, bie man bamalz fannte, umo ber Sircujfahtrer ritt tas ecelfíte

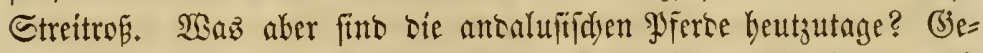

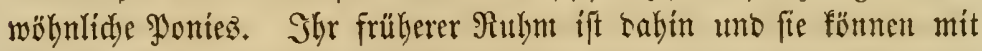
ibren Sorfakren "Lutdaus nidjt ntebr sergliden werten. Sian hat fie von ten Bergen uno Thälern in bie Etallungen gebradjt umo ter Civilifation bienfitbar gemadyt, waz zur Folge hatte, saj fie in $\mathfrak{B e r}=$ geffentyeit gerathen fint uno beinalye autsgerottet wurten.

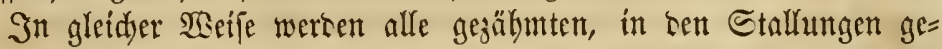
baltenen Mferbe auzarten. Durdy Budyt unt Mijdung ber Racen probucirt man nete Unterarten, aber nur eine aนื fünf fann eine Berbefierung ber żwei uriprünglidjen Racen genannt werben, unt bic antern werben viel werthlojer fein, währent aufercem bas seken ber Thiere burdy bieje Mifdjungen bebeutent abgefür $r_{3}$ t wirb.

Die nämliden Raturgepetse - ticz jeigen bie Thatjad)en auf'z Deutlidyte - find in unferm Rante gültíg. Da aber bie Pferbe in Atmerifa gewäbnlidid befler bebanbelt werben uno fie auf unjern farmen 


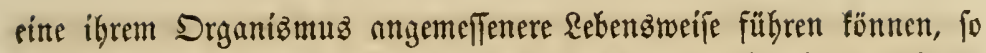

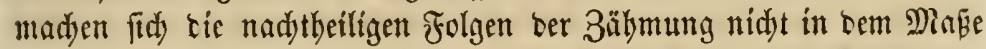
geltent, wie in antern Räntern. Sevod) Galten unfere Plerto mít

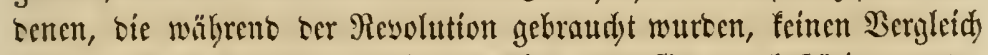

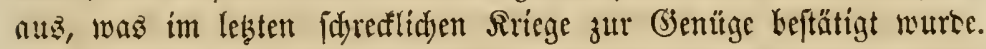
Die won Marion uno McDonalo benübten Cavallerievferte über=

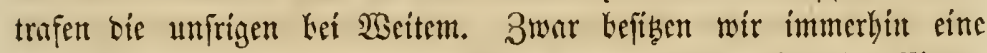

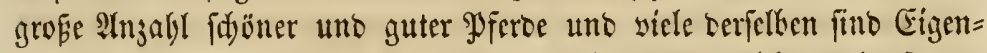
thum ber frarmer; trobsem aber finto bie Pferte nidjt mebr fo gut aไz früher. Ia Thatjadye; jerody fint fie nidyt mely fo fein uno fejt, fontern lojer

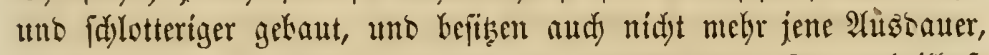

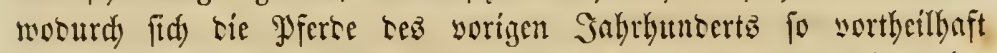

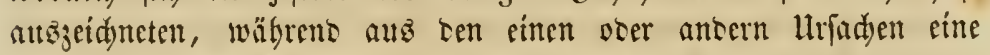

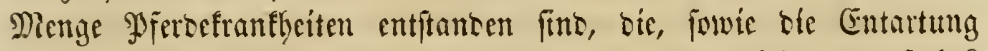

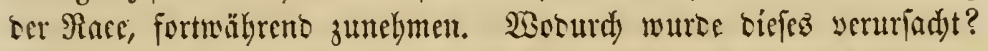

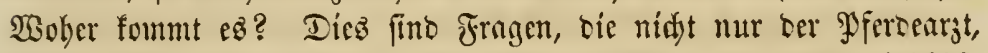

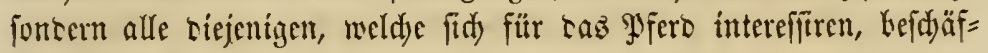
tígen follten.

Bur menigftens theilweifen Beantwortunt tiefer Fragen fdalten

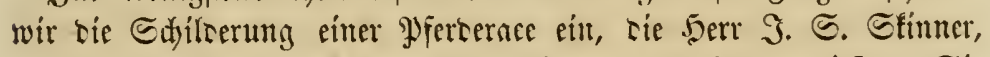

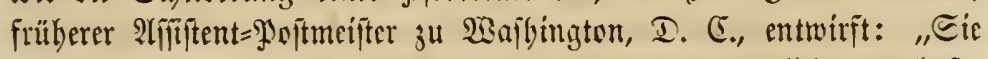
fimb," fagt er, "jeble flein, feft gebaut uns auperorocntlid) bauerbaft; man fintet fie an ber Eefeiifte Marylants uno Birgíniens, wo fie

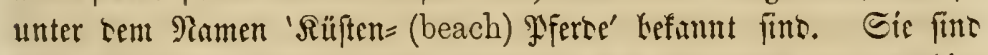

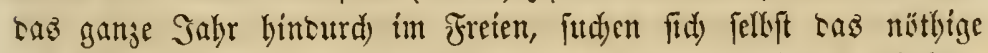
Futter uno fajarren oft ben Edynee weg, um baffelte zul erhalten. Dbgleid) auferortentlid) flcin, jeidjnen fid siele unter ibnen bennod)

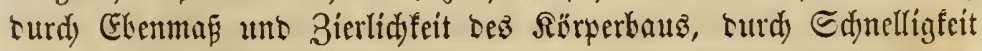

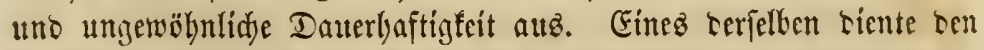

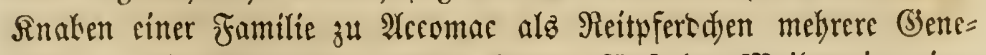
rationen bindurd); ein anteres fonnte fünfzegn Meifen in einter

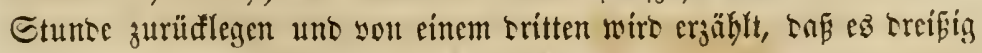
Meilen in jwe Etutuben jurüaflegen fonnte."

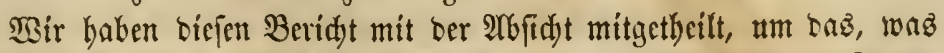

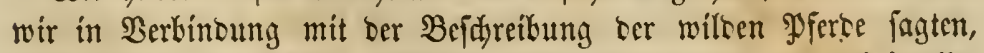

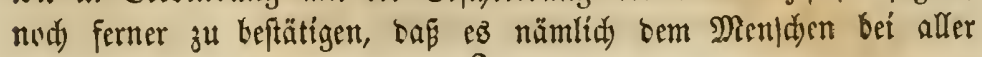


angewanden Mäbe nod nidyt gelungen ift, bie Pferbezudd in poldyen Grabe zu versolffommnen, baj bie erzielten Rejultate benen gleid fommen, weldye dic Ratur Gerworbringt.

In allen 3eitaltern bat fid, Ser Menidy abgemüht, saz fut thun,

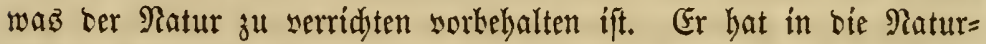
gejebe cingegriffen uno verjudyt, biefelben zu beherridyen uno bie Natur ift, wenn man ifgr entgegen trat, ruhig ibre Babn gegangen, hat Sdyönes, Symmetrifdes uno Rräftiges erzeugt uno ren Menidyen

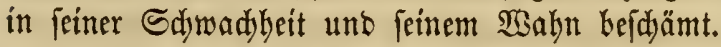

So vft ber Menid es unternimmt, in bie vom Sdyopfer niecer= gelegten Raturgefese ftöreno einzugreifen, fo serbirbt er tie Sdjönbet

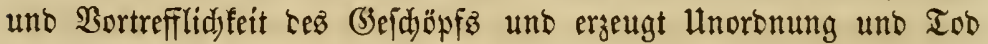

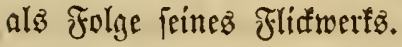

Das Rüftenpfero ftammt son ben canacifaen PPonies ab, weldye uriprünglid) aเธิ sem füsliden Jranfreid famen, uno gebört zur

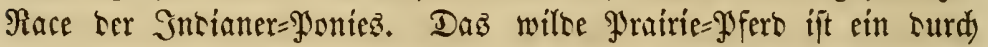

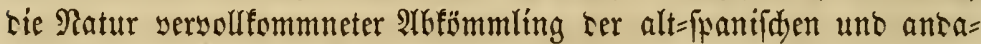
luftidjen Race. Die Bollblutpferse in Englano uno ŶAmerifa fino

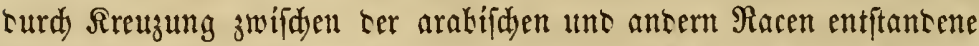
lnterarten, son Eenen feine Ier uriprïnglidien Race gleid fommt.

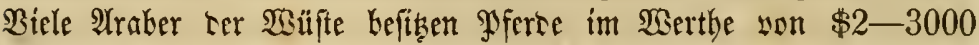
per Stüaf, mäbreno mandye Sengite ber beseutenteren Säuptlinge (Sheifs) wahrhaft fabelhafte Preife bringen.

Ste unb ba trifft man in Epaniens fdyỏnen Thälern nody ein

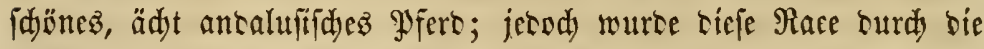
volftäntige Racenmifaung früberer Zeiten beinabe sertilgt. Die= jenigen Pferse, rie von untermifduter Race abftammen, itbertreffen

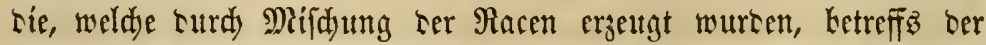
\&ebensbauer bei \$Seitem. Ein Pony lebt treimal, unt ein wiltes

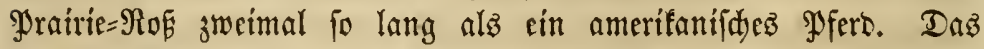

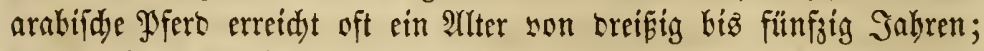
rie Sncianer=Ponies wereen nidyt felten fïnfrig bis fedysig Jabre

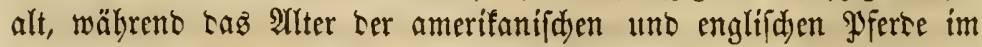

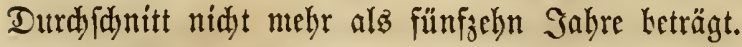

Wer fid mit ber (Sejdidyte ber Stalfpferbezudyt uno ber Bermifdung ver Pfferberacen Eefannt madyt, ber wiro bie Uraadjen ber Pferbefrant= beiten uno Racenentartung leidt entceđen fönnen. Die idjlimmen 
bieraus entfftebenten Folgen fino unzählig uno unberedjenbar. Diefer

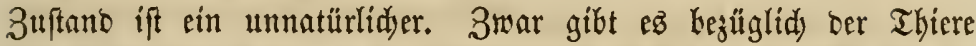
fein befitimmtez (bejes ber Blutidjante unt bod fetht Mifd,ung veridjectener Racen, fowie bie Rreuzung ber Mitglieter ein unt berjelben Familien aud bei ben Thieren bie idlimmiten Folgen nad) fid) jieken. Die reinen Racen waren uno fitto immer befier als bie gemifdjten. Der Flud, weldjer auf ber memidjlidjen Racenser= mijajung rubt, ift audy auf bie Thierwelt ülergetragen worben. Gira bejeidynet bie Bermifdung ber Sirneliten mit ben heibuifogen $\mathfrak{B o b l f e r n}$

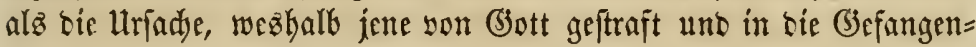

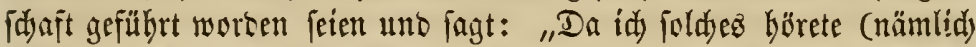

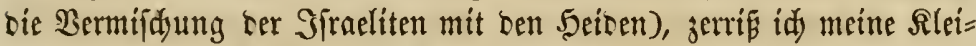
ter uno meinen $\Re$ of uno raufte mein 5aupthaar uno Bart aus uno

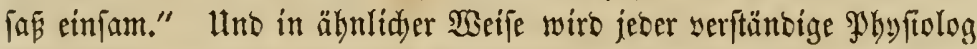
fdumerglid, berührt werben ob ber Thorkeit, Unmiffentheit uno Süno=

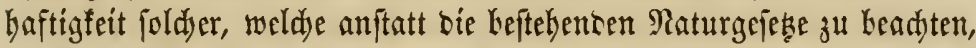

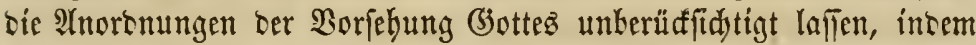

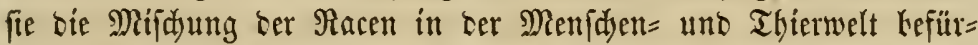
worten. (3ott hat, nadjem Dą erite (jeidjled)t ten Erwartungen

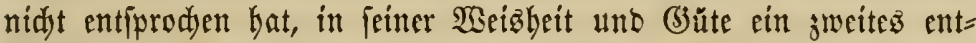

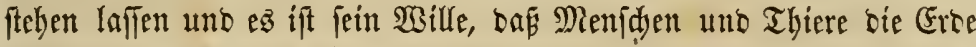

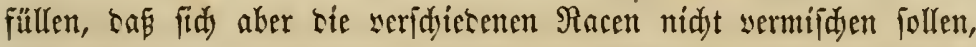
was surdy ben verliekenen Smftinft ober Berftant, burd) weldye bie Fingelten regiert Jwerben, beutlid) ausggeprägt ift. Die Beobadtung

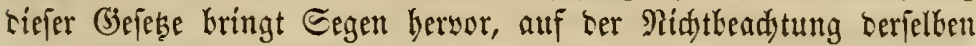

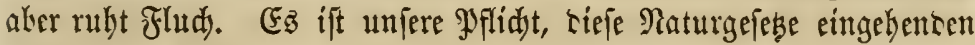

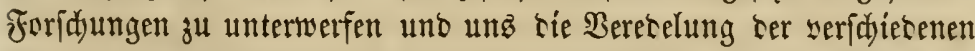
Racen - Ler menjdliden forwohl alż Ler thierifden - uno nidjt teren

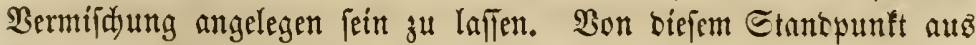
ift tiefez Budy ahgefapt.

Es ift nidyt umpere 2lbfidyt, bier auf bieje Thema's näber einju= geken, wab in ten ketreffenten నapiteln gefdelenen wirt. Wir baken

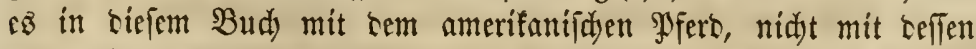
allgemeiner (3ejedjidjte 2 ., fontern mit Seflen Sranfleiten, ibren $\mathfrak{u} r=$ fadben, ten ju befolgenoen నutmethoden uno ber zu beadtenten, menfdi)= lidaen und yernünftigen Behandlung zu thun. 


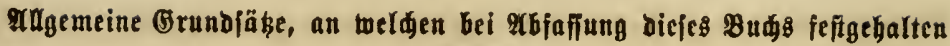 tourde.}

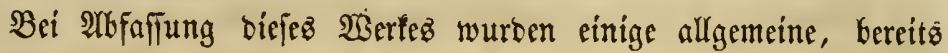
bewäbrte (Sintmojäbe fejtgebalten uno ba eine furge Heberfidyt oerjelten

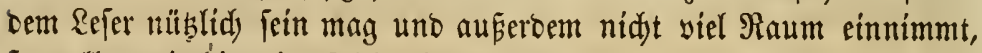
fo wollen wir bier cine joldye cinfualten.

1. Dag Pfero ift uriprünglid) ein willoes Thier uno wurbe nur ourd) Zäbmung in eill Saubithier ungerwanoelt.

2. Im wilten 3 uftano ift $\mathfrak{e z}$ am glüdfidjten, erreid)t ein bỏberes IIler uno entmidfelt feine natürlidjen sräfte uno fäbigfeiten am beften.

3. Whie bei ten Menjuen, jo gab Sfersen verjhietene Racen, bie man nie mijhen, fontern ftetz yon einanoer getrennt balten jollte.

4. Im wilden 3uftand vermijiden fid die veridiebenen Pferberacen nie unt würse man bem Inftinft oer Pferbe freien Sauf laffen, fo würbe nie eine Racenvermijchung vorfommen.

5. Das Pfero ift in natïrlidem 3uftano nur wenigen ofer feinen

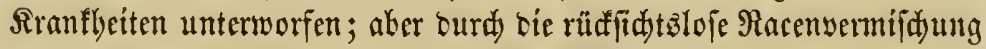
wurben bie Pferbefranfleiten auterorbentlid) vermebrt uno Entartung ber Diijuungēracen ergettgt.

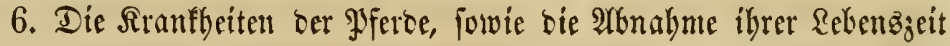

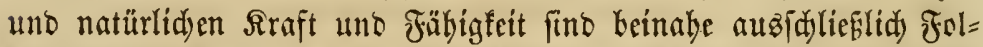
gen ber Mitíhanolung uno unzwectmäfigen Bebandlung yon Geiten Der Dienid)en.

7. Je beffer man die Beoürniffe oes $\mathfrak{P}$ ferbes verftebt uno je na= turgemäfer feine Bebandlung ift, befto beffer uno braubbarer wirt caffelbe.

\section{Widtige Ilyatjaden, bie bei ber Behandung ber Pierbefranlbeiten nidt

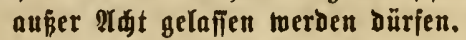

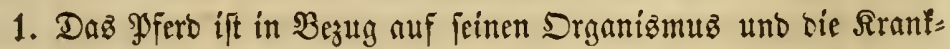
beiten, benen ein anberes I hier.

2. Bei Menidjen wie bei Pferben erzengen die gleidjen uriadjen aúđ Die nämlid)en Sranflgeiten, für weld)e bei beiben bie nämlid)en 
Mittel erfolgreidy angewendet merben tönnen. Sebody gibt esิ aud Itušnabmen yon biejer Regel.

3. Fine Srantheit ift entweder eine allgemeine ober lofale; (be=

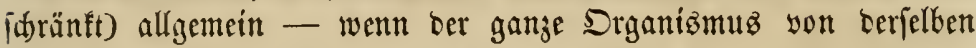
angegriffen ift; lofal - wenn fie fid auf biejes ober ein anderez Srgant,

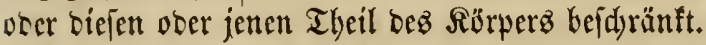

4. Beinahe alle Rrantheiten, fei $e s$ bei Menidjen ober Thieren, entffehen, was aud immer bie jonftigen uriadjen fein mögen, burdy Itnorbnung uno Berftopfung bes Saft= uno Blutumlaufs uno ber

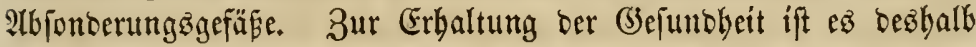

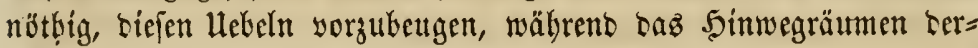
felben bie Bebingung ber Mieberherftetlung berfelten ift.

5. Shgleid bie Rranfleiten ihren Uriprung nidjt im Blut baben, fo ift taffelbe body baz Dittel, woburd) fid) biejelben im Srganišmtis serbreiten.

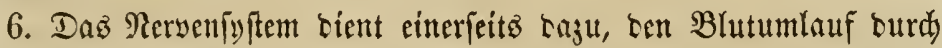
sie $\mathfrak{A}$ sern zu berwirten, weathalb irgeno weldye ltnoronung in bemfelben sen Blutumlauf beeinflust, und biejer wiecerum auf jencż Einfluß aแลืนี่เt.

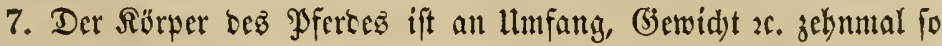
grof alz der Les Menjden. Sein Rörperbau ift ein viel groberer uno

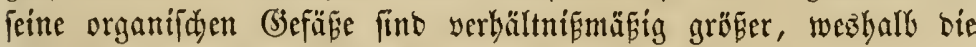
Duantität ber $\mathfrak{A} r_{3}$ nei biejer Proportion entipredjen muß .

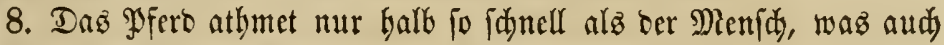
in $\mathfrak{B}_{\mathfrak{c}}$ แt

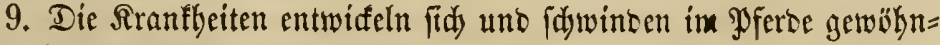
lidi siel langfamer alz im MRenidjen.

10. Ridjt alle $\mathfrak{2} r$ z̧neien bringen bei ben veridjebenen Iljeren bie nämliden Sirfungen hervor. Mandye Subftanzen, bie ben Meniden vergiften, fino bem $\mathfrak{P}$ ferbe un[düblid uno umgeffhrt.

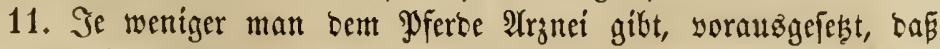

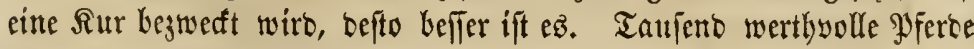

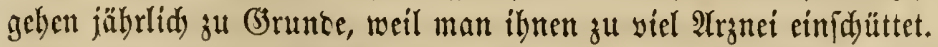

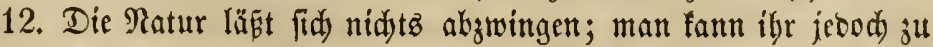

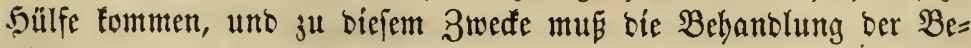
ifjaffentheit ber Rrantheit entipredjen.

13. Da es feine Folge obne urjadye gibt, fo barf man bei Ent= 
becfung einer Siranfleit fidjer fein, baj bie Urjadye berjelben niddt weit fu judjen ift, und was immerhin biefelbe aud) fein mag, fo polute man fo fanell als möglid biefelbe aufzufinben uno womöglid zu ent= fermen fuduen.

14. Sbgleidy berientige, weldyer ein franfez Thier bebandelt, ba biefez nidjt fpredjen fann, mit grofen Sdyierigfeiten zu thun bat, fo fommen ifm bic beutlidben $\mathfrak{A}$ euferungen beffelben bennod) zu Jülfe

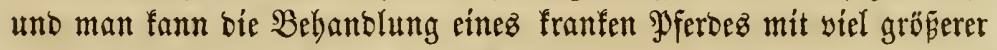
Soffnung, eine gute $\mathfrak{\text { Rur }}$ zu bewerfftelrigen, unternebmen, als bie eines Denfduen, benn bie నur fann mit yollfommener Sidjerbeit beim Pferbe zu einer viel entidjebeneren gemadjt werben. 


\section{3meites Eapitel.}

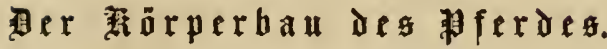

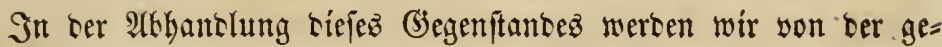

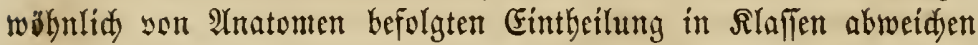
unt ben Gegenftand furg unt bủntig in Feiner natürlidyen Dronumg Earjtellen. Sowobl bem farmer wie bem gुfertehändler fann eż yon feinem praftifjen Interefle jein, zu wifien, welde Stellung saz Fferd

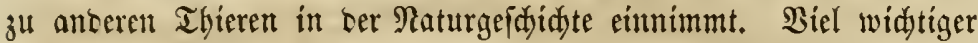
ift ifnen bie Befdereibung bez Pferteg felbft, cine S5inweifung auf feine Braudbarfeit zum Dienjte; eine Ânleitung zur bejten 9 Trt unt

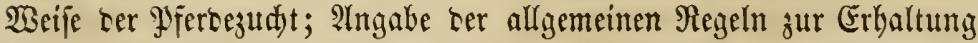

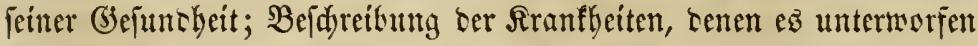
ift, uno iłre geeignete Bellantlung, fowie bie palfenten Mittel jur

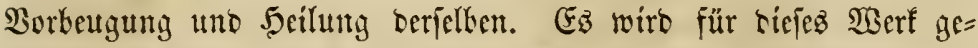

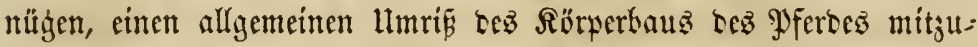
theilen, bamit in ter Befantlung son Rrantfeiten bie erfranften

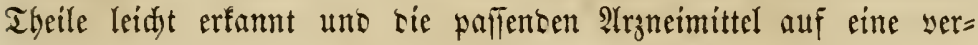
ftünrige $\mathfrak{B e i f e}$ angewant werben fönnen.

Uujer $\mathfrak{T b h a n d l u n g a ̈ p l a n ~ w i r o ~ b e m ~ b e s ~ B a u m e i f t e r z ~ a ̈ h n l i d ~ f e i ́ n , ~}$

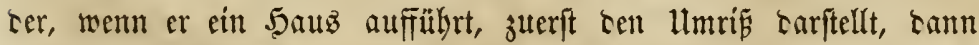
tenjelben mittelft אIammern unt Bolzen zujammenfügt, focann bebeçt

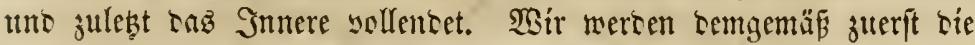

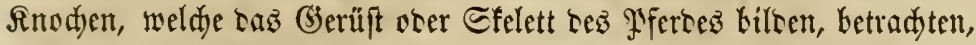
cann bie Mugfeln und Sehnen - bie Bintemittel, weldje bie $\mathfrak{G}_{r}=$ fteren zufammenfügen, fobann bie 5aut uno 5 aare, weldje bie $\mathfrak{B} e=$ Leffung auṡmaden, uno guleşt bie innere Einridtung - Qungen, Ser3, Eingeweite, 5̧arnwerf nebjt tem Drüien= uno Rersenigitem.

Eine furze Bejdreibung jeber biejer atbtheiltungen wiro unierem

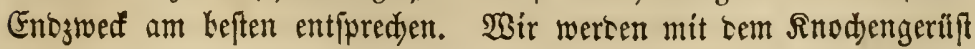




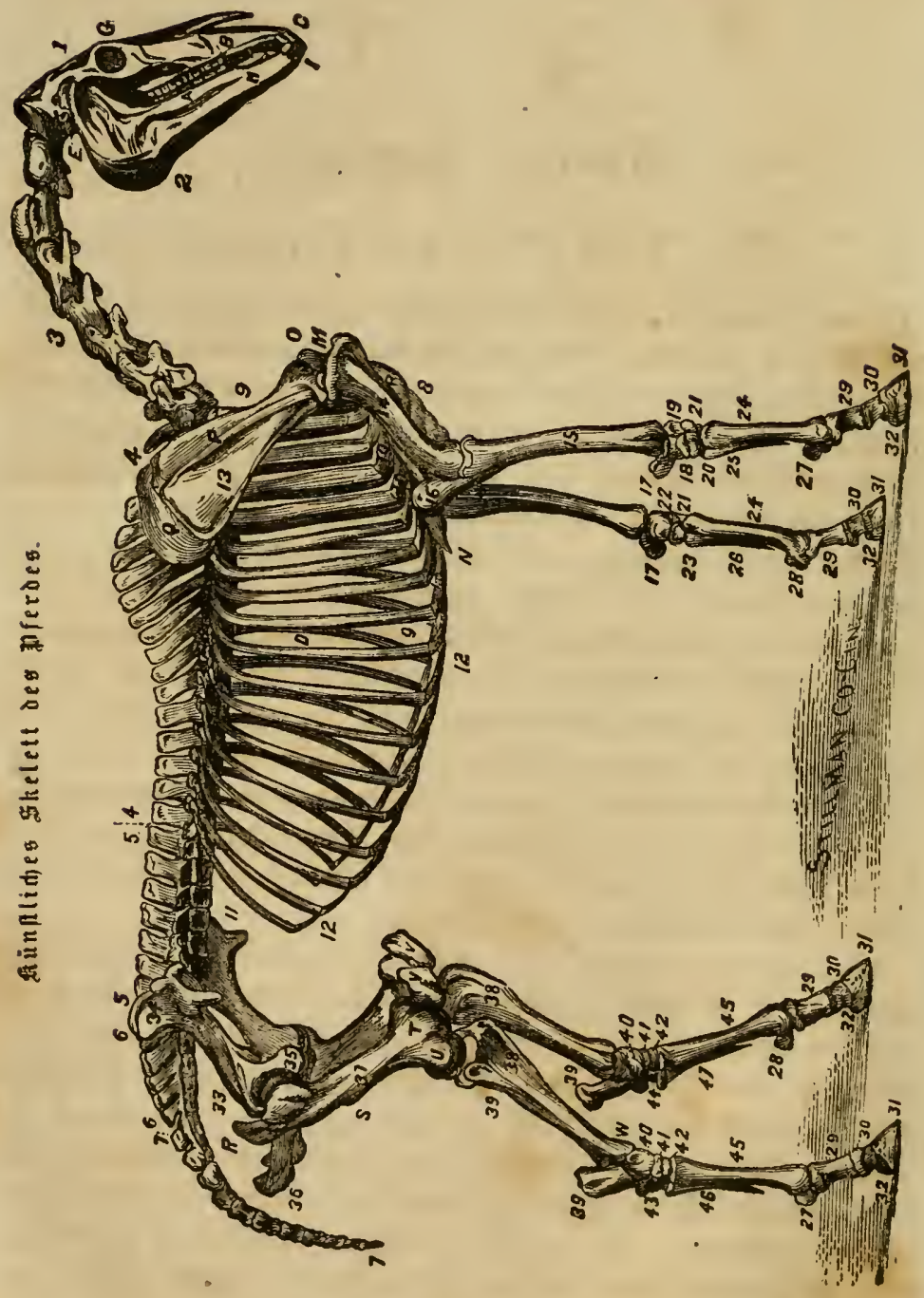


1. \$̧irnfकäbel (brain pan or scull).

2. Sinterficfer (lower jaw).

3. ફूalş

4, 4. Riufentuirbel (dorsal vertebræ).

5, 5. Relloeluvirbel (lumbar vertebræ).

6, 6. Ireuzbein (sacrum or sacred bone).

7,7 . Sdiweifwirbel (coccy geal vertebræ or tail bones).

8. Bruftbein (breast bone or sternum).

9, 9. Die wahren Rippen (true ribs).

10,10 . Rippenftuorpel der $\mathfrak{w}$. $\Re$.

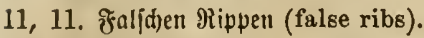

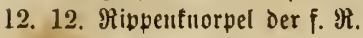

13. Sdjulterblatt (shoulder blade).

14. It rmbein (humerus).

15. Borarmbein (radius or arm).

16. Ellenbogenbein (elbow).

17. Şatfubein (os pisiforme).

18-23. Iniefnodycu (carpal bones).
24. Stienbein (shank bone).

25, 26. (Briffelbeine (splint bones).

27, 28, (Bleidjbeille (sesamoid bones).

29. Zeffielbein (upper pastern).

30. Aronbeill (lower pastern).

31. \&ুufbein (coffin bone).

32. Strablbein (shuttle bone).

33-36. Beđenterine (pelvis bones).

37. Sberidentelbein (femur or thigh bone).

38. Broker Ilnteridgentelbein (tibia, flute or pipe bone).

39. Ferfenbein (os calcis).

40. Rollbein (astragalus).

41-44. Eprunggelentstofnotien (tarsal bones).

45. Sdjienbein (large metatarsal bones). 46, 47. Griffelbeine (small metatarsal bones).
A. Bađţäbue (molars).

B. H. ร̧atfelıălune (canine teeth).

C. I. Sducivezähue (incisors).

E. Ittln\& oocr Träger (atlas).

G. Ingenlüble (orbit).

M. Sd)uabel- oder fुabidt\$ftiorpel (carniform cartilage).

N. Ediwertfuorpel (ensiform cartilage).

0. 3iz̧elffortfal (coracoid process).
P. Sdultterblattgräte (spine).

Q. Ed)ulterblattfnorpel (cartilage).

R. Obere llmbrelyer (trochanter major).

S. Samm des Dheridentelbeins (subtrochanterian crest).

T. Rolffortfats (trochlea).

U. Belenffuopf (external condyle).

V. Iniricheibe (patella).

W. Eprunggelent (hock joint).

ober Sfelett beginnen. Shgleid eine fefr genaue Befdreibung ber Snodent aufer unferem 3wede liegt, Kaben wir bennody eine Figur

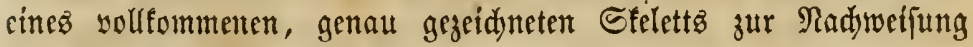
uno zum Eturium beigefügt.

Daz Efelest bejteht aแz 247 Sinoden, welde mittelit ber Belente verbunoen, ben Rüfgrat, sen Brufterb, bas Befen, ben Sdimeif uno bie sorberen uno binteren (3)liebmaêen billoen. Der Rüfigrat

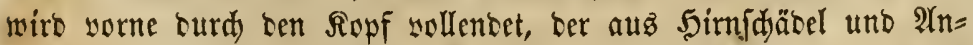

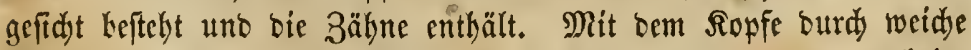
I beile verbunben, binter ber Zunge, finben wir baz 3ungenbein, weldẹ bic 3abl ter Sinodjen solffändig madt. 


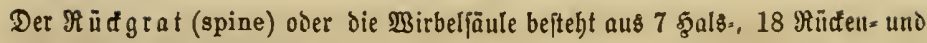

6 Rendenmirbel, zujammell.

Der $\mathfrak{B}$ ruft forb (thorax or chest) wird ourd) die Rüfenwirbel nebft 18 Rippen

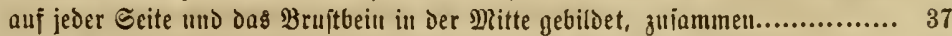

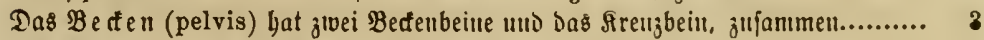

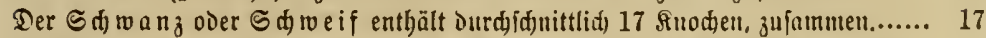

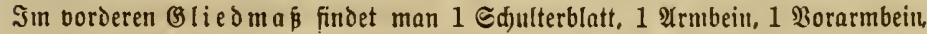

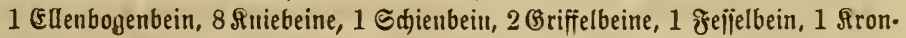

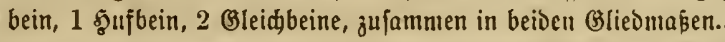

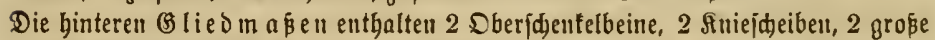

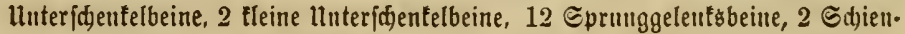
beine, 4 Griffelbeine, 4 Gleidbeine, 2 Jeffelbeine, 2 Fronbeine, 2 รुนfbeine,

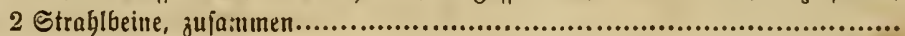

§irnjळädelbeitre ................................................................. 10

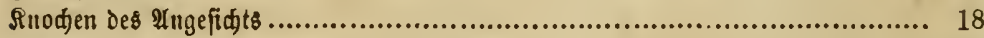

Bähne................................................................... 40

(Behörtnöd)elduen, 4 in jedem Dhre ............................................... 8

3ungenbein, aus 5 Ibeile bejtebend.............................................. 5

Summa................................................................ 247

Die 5ornidube ober Sufe (hoofs) bilben fojufagen die (5runto=

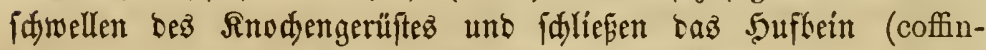
bone), ber erfite Rnodjen Cer (3)liebmap̃en, vollfommen ein. Sber=

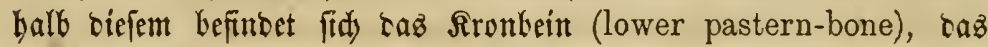
yorn auf bem 5ufbein ruht, binten aber mit einer (Stube verjeben

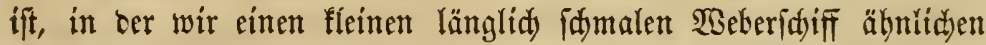
Inoden, baz Strablbein (shottle-bone), finben. Sid) nad binten

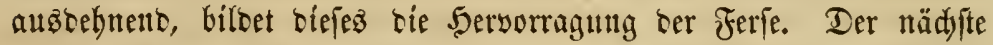

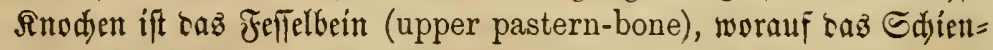
bein (shank-bone) mit Den (Gleidjbeinen (sessamoid bones) ruht.

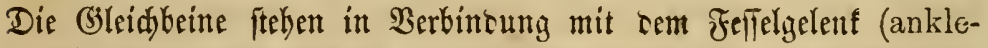

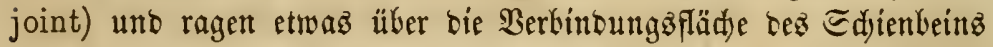
uno bes Feflelbeins berwor. In tem Iniegelent fino adjt Inodjen. Sinter sem Rnie unb gerabe unterbalb eriftedfen fid ju beicen Geiten bes vorberen Shienbeinz, faft feine ganje \&änge binab, zwei tüntte, 1a)lanfe Rnodyen, die man bie Griffelbeine (splint-bones) nennt. Sherbalb bes Rniegelentes befindet fid) Ser widtigfte Rnodhen ber

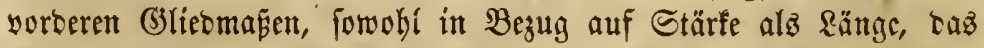
Borarmbein (arm-bone). Theilbz über, theillz binter bem Boraut= bein uno mit ifm unberweglid verbunben, finben wir baz Gllen= 
bogenbein (ulna or elbow). Sherthalb bem Ethenbogenbein unb mit

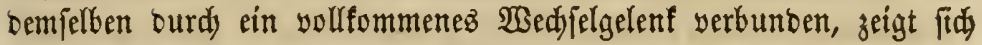

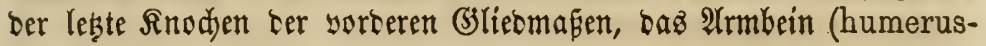
or shoulder-bone).

fig. 1. fig. 2 .
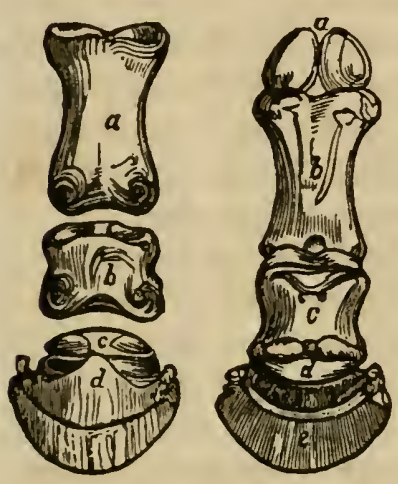

stig. 1.

$a$ Feffelbein (upper pastern).

$b$ Rroubein (lower pastern).

c Strablbein (shuttle or navicular bone).

d ईufbein (coffin-bone).

fig. 2.

$a$ (Gleidbeine (sessamoid bones).

$b$ geffelbein (upper pastern).

$c$ Rroubein (lower pastern).

$d$ Strablbein (shuttle or navicular bone).

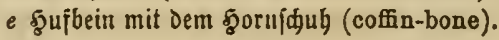

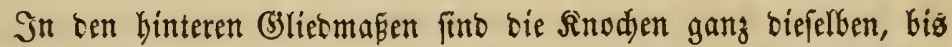

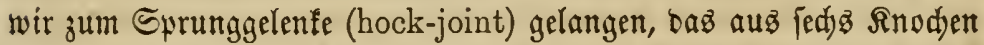
befteht. Die Ferworragung am Eprunggelent wirb burd) bą Fer= ientein (os calcis or heel-bone) getiltoet. Heber bem Sprunggelenfe

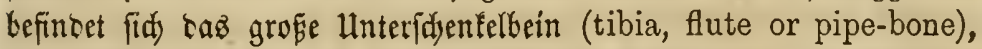

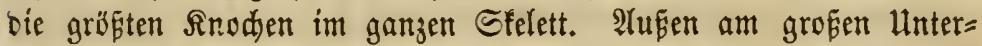
idjenfelbein fdjmegt fid ein langer fdjmaler Rnoden feit an, bas fleine Unterif)enfelbein (fibula). Daz Rniegelent (stifle-joint) wiro gebiltet oben burdy bas Sberidentelbein (femur or thigh-bone), unt unten surd) bas grofe Unteridentelbein uno ift sorme yon ber

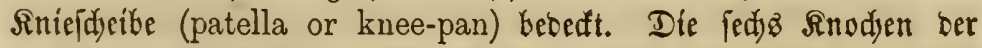
ber Şüften (hips), brei auf jeber Seite yerwollftändigen bie Inodjen

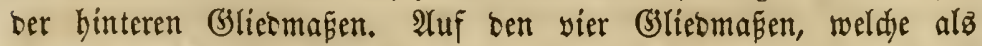

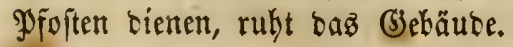

Wir mögen nun bie אopffnodjen anfübren. Bon biejen finto bie

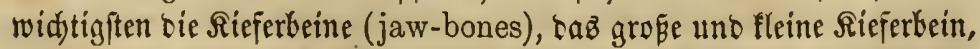
ber. untere uno obere Sinterfiefer. In ben Rieferbeinen fino bie Bähne befeftigt, 24 Bafłähne (molars), 6 auf jecter Seite beibes 
oben uno unten; 12 Sdnneibezähne (incisors) ober vorbere Zähne, 6 oben uno 6 unten; uno 4 Şadenzähne (canine), einer auf jeber Seite, forwobl oben alş unten.

Die Sdjäbelfnodyen (skull bones) befteben aub breiten gebogenen Platten, bie unbeweglid mit einanber verbunoen fino burd fägejäkn= förmige Ränoer, bie genau in einanter pa|fen. Die widjtigftell wer= ben nad) ibrer Rage Sberbauptbein (occipital), Rajenbein (nasal bone) uno Stirntein (frontal bone) genannt. Unterbalb bes. Stirn=

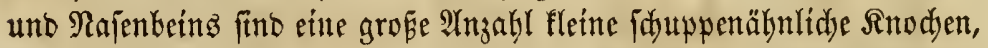
wovon einige nidht mit anberen Inodjen verbunben, bie meiften aber mit ben Sdyäbelfuduen vereinigt fint. Dieje find fo anemanber ge=

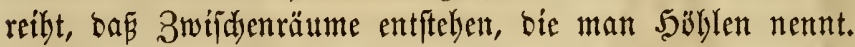

Im oberften Theil bez Ropfez, wo ber Salsz beginnt, finben wir Daż Dberbauptäbein (occipital bone), mit weldem ber erfte 5als = wirbel ober Träger burd ein eigenthümlidbes Bano serbunben ift. In biejem Banbe hat bas Uebel, (3enidffittel genannt, feinen Sis.

In ber Mittellinite bes Rörperz som Ropfe nadh Ginten laufent,

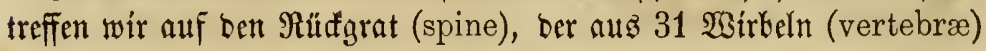
beffelyt, bie miteinanoer mittelft Bänoer vereinigt fint. Die fieben, bie fid) im $5 a l z$ Gefinten, nennt man bie Salzmirbel (cervical vertebræ), bie $18 \mathrm{im} \Re u m p f e$ bie $\Re$ üfentrirbel (dorsal vertebræ). Die lebsteren befiłen bebentende nad) oben gefebrte Servorragungen, beren Ränge in ben seridyecenen Theilen bez Rü(fenb ungleid) ift. In ber Sdultergegent beträgt fie niemalz weniger alz brei Zolf uno und in mandjen Pferden fommt fie auf $4-5$ Boll. (siegen bie Mitte dez Rüfens wiro fie weniger, etwa $1 \frac{1}{2}$ bís 2 3oll. Die näduften 6 Sirbel, weldye ifren Sis in ber Renbengegeno haben unb beshalb Senbenwirtel (lumbar vertebræ) heif́cn, vervollftänbigen ben

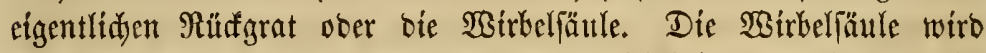

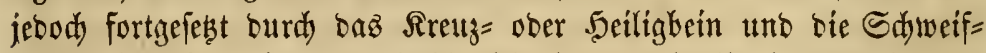
wirbel (tail bones), beren 3 ahl nidyt immer biefelbe in veridstebenen Pferben ift, burdjidnittlidy aber 17 beträgt. Die widhtigften 5üft= fnodyen (hip bones) verbinben fith mit bem Ireujbein (sacrum) unb Rüffgrat, wo bie Senbenwirbel aufbören.

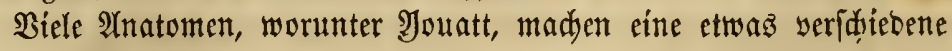

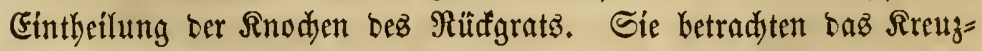
bein als aus 5 Theílen beftebend, weldje fie Sireugtwirbel nennen. 
Einige Autoren behaupten aud, bas bte burdjpdnttlidje 3 abl ber Edjweifwirbel 15 hetrage.

Iluf jeber Eeite ber Edjulter befinbet fid ein bebeutenter Snodjen, oer unter tem Ramen Edjulterblatt (shoulder blade) befaunt iff. Er ift unten mit sem STrmbcine yerbunden; yon biejem Gelente aus wiro er bünn und breit, unt zeigt aut ter Mitte Der äuß̈ern Fflädye cine Jervorragung, die man bie Saulterblattgräte (spine) nennt. Er erftreçt fid) nabezu biz zum Rüffgrat, womit er burd) Musfelm serbunten ift. Diejer $\Re$ nodjen ift zutweilen mit einer furdstbaren Rranfheit, Edultterent jündung (swinney) bebaftet.

Die Rippen, teren fidj) 18 auf jeber Seite befinten, geben nidut

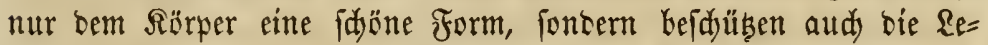

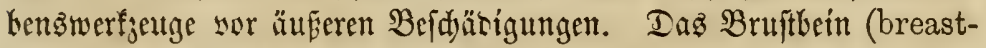

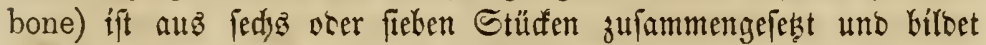
sen Boben ber Bruft. Er ifít eín langer đajwammiger Sinoden, ber burd) die Rippenfnorpel ser fieben yorberen Rippen - bie beshalb wahre Rippen Keisen - in feiner sage erhalten wirb.

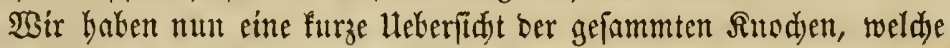

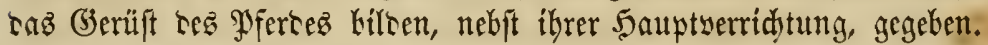
Die Rranflyeiten berfelten werben wir in einem anteren Rapitel be $=$ ¡dreiben.

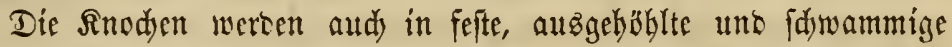
eingetbeilt. Die, weldye man bie feften, audy breiten, glatten nennt, werben hautptiäd)lidy zut Bilsung son 5öblen serwentet uno fomit bejonters im Ropfe unt im Bedfen gefunten. Die Sohlhnodyen, bie

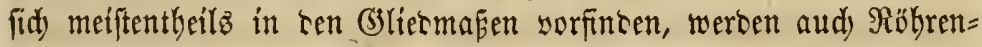
fnoden genannt. Dieje Benennungen rübren son sem Ulmftante her, ¿ấ bie langen Snodyen ber BSliebmafen in ihrer Mitte einen boblen mit Snodenmarf gefüllten Raum enthalten. Sie fino bie

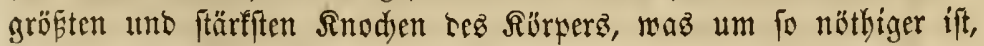
ta fie beftäntig ter grösten Epannung uno bem fidsweriten Drưt

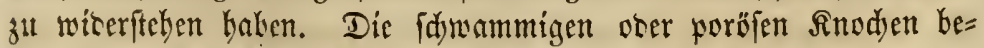
ftehen aus ben fleinen in ben (Jelenfen befintlidjen Snodjen, bem Edylterblatt, sen Rippen, sen oberen unb hinteren Iheilen ser Riefer uno überbaupt ben Enten aller Sinodjen, bie fid miteinanter zur Bilteung yon Gelenfen vereinigen. Rnodjenfranfleiten unb Inodjen=

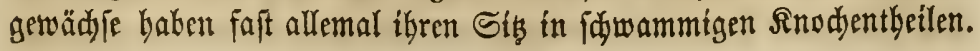




\section{Die Mugfén, Gelgnen und gäute.}

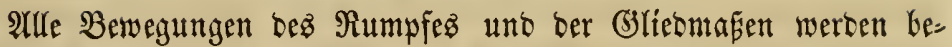
werfftelligt burd) eine befontere, unter Raten alz Fleifd befannte, yon 2Ynatomen aber alz Mugfelgewebe bezeidunete Subjtanz. Diefe bildet bie Sauptmatie aller auperball ber Sirn=, Bruft= unb Baudjhöble

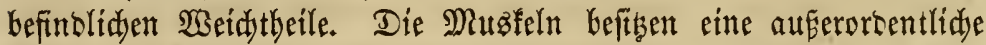

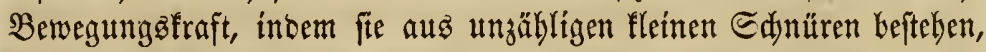
die man Fafern nennt, yon benen jeoe cinzeln eine eigene elaftifdye uno zulammengichente Rraft befitht. Sbgleid) jebe Fafer eine unab=

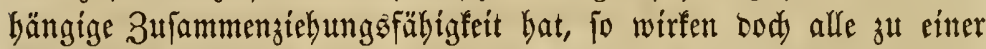
Musfel verbuntenen Fafernt ju gleidjer 3cit, fo baf ihre vereinigte Siraft erftaunlidy grofi wiro. Shierson fann man fid leidst eine $\mathfrak{B o r}=$ ftellung madyen, wenn man becenft, baj bie wunberbare Siraft bes Poerbez yon ben Mutsłeln abbängt. Eine bemerfenswerthe Eigen=

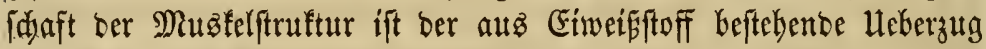

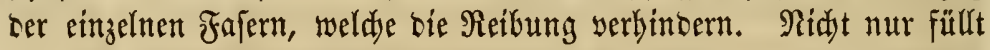
biejer bie Räume zwifjen ben Fajern aus, fonbern bient audy burdy feine flebrige wadjartige Eigenjd)aft alz ftarfez Binbemittel ber Fajern uno Fajerbündel untereinanber.

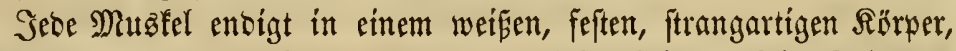
die Selhne ober Jled)je. (Utnter ber Heberidhrift: "Die Sehnen," wiro ber Rejer eine bejdreibung berfelten finben.)

Die Empfintungşähbigfeit ber Musketn ift unbebeuteno. Sn ter

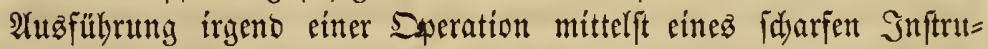

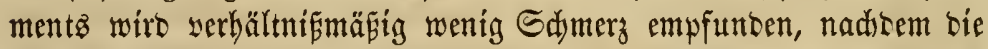

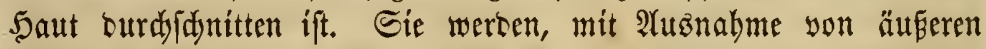
Berleb̧ungen, äuß̈erft felten yon franfhaften Etörungen beimgciudjt.

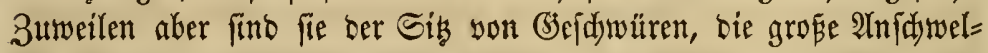
lung serurjadjen uno auperorbentlidje groṕe Suantitäten (Eiter ent= laben.

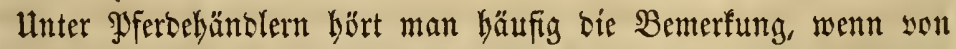
ben Eigenid)nften irgento eines Pferbes bie Rebe ift, "bies Pfero bat

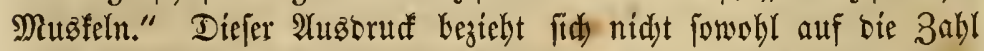

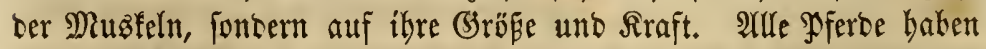

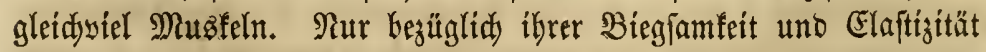
ift irgento ein Interidied wahrzutehmen, uno zwar mag berfelbe febr

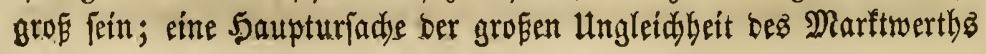


weridiebener Pferbe. Die Rraft bes Pferbes wirb jebud wentiger

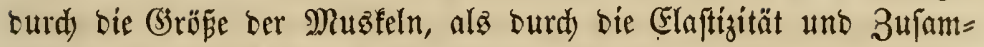
menzichungsfähigfeit ber Musfelfajern bebingt, woyon bie "größere Stärfe und Edjnelligfeit gewiffer Pferbe bauptlädylid abłängt.

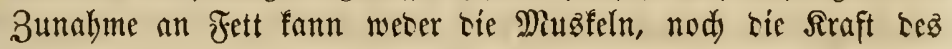
Pferbes yermebren. Daburd entfteht aber bie solle abgerundete From, welde fo hod geidjäbt wiro uno mandye bebenflidje Febler verceeft. Sit bie Fettiztunabme allzugrof́, fo legt fie ber Musfeltthätigfeit be=

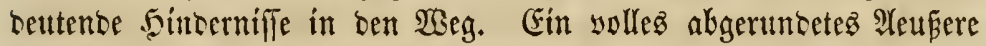
ift fein Bewciz für gute (Eigeniddaften, aud) zeigt Magerfeit nidut beren Mangel an. Ein gut gefïttertes, gejuntez, magerez YFerd

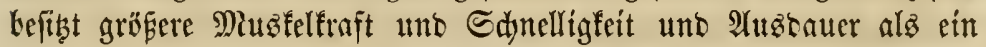
allzufettes. Thu Dhgleid biefe Thatjaden allgemein anerfannt fint, fo bleibt $e \bar{z}$ nidjtz=

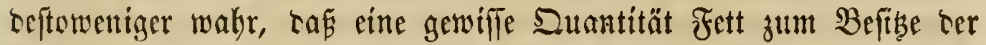
hisdjten Iraft und Energie wejentlid) nothwentig ift.

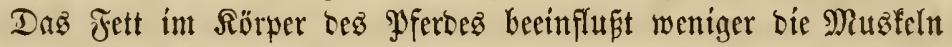
als bic 5aut und bie Saare, beren 3uftand wejentlid bayon ab=

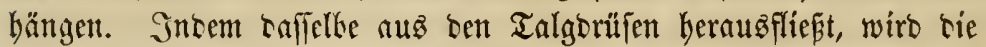
äufere 5aut weid) unt geid)meibig uno bie 5aare glatt uno glän= zent, worin eine 5auptidjönlyeit bez Pferbez befteht.

Einen fehr widjtigen Einflup auf bie Thätigfeit uno Rraft ber

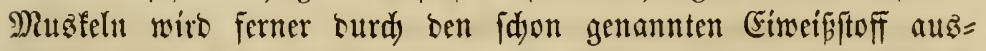
geübt. Bon ber (s)üte uno frinen Gigenjidjaften hängt bauptädblid

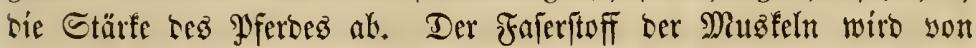
bemielben solffommen umgeten uno in jeiner \&age erhalten. Ez ift ser in unreifem ober fehr jungen fleif gefundene wadjarartige Stoff, ber ben Fingern fo gern anflebt. Seine (3)üte unt Menge fint yon

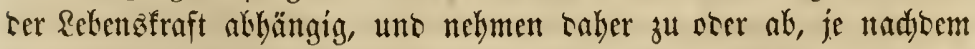
rie Rebengfräfte verminbert voer gehoben werben. Tluf ber anberen Eeite übt befien 3uitano wieberum einen widjtigen rïdwirfenten

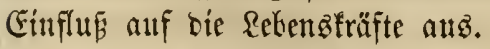

SSiro cin Pfero in Folge ciner Siranflyeit ober ungentigenter Früt= terung fehr mager, fo erleitet ber Eimeisiftoff eine bedeutente $\mathfrak{B e r}=$ änberung. Ridjt nur nimmt er an Duantität ab, fonbern wirb audi) fefter und flebriger. Die Fafern rüđen in Folge einanter fo nahe, báp ibre Ihätigfeit gehemmt wirt. Der unteridjied zwifden ber 
Reidtigfeit ifher Berwegungen im gejunben Buftante uno ber ge: bemmten Thätigfeit, wenn bie Rebensfräfte bez Thierez bebenflid; abgenommen haben, ift etwa wie ber, Den man wahrounthmen (b3e= legenlyeit hätte, wenn man taujeno cínzelne Sdynitre łu gleidyer Beit erfit burd) Del, hermady burd Thran zieken würte. Bei bem fdwadjen balbwerthungerten Pferbe if́t eine fehr läjtige, quälende $\mathfrak{A}$ uftrengung erforberlid, um bie unzägligen Mutbelffafern feinez $\Re$ s̈rperz in bem

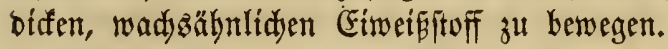

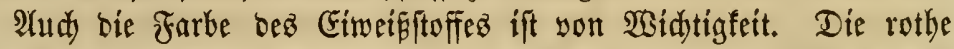
Farbe ber Muzfeln Gängt nidjt vom Faferftofi ab, ber eigentlid weí ift, fonbern yon bem im Eiwcisfitoff befinolidjen Farbeftoff. Bei ge= funben Pferden doer Rinbern ift bie Farbe bes Jleifdez eine bell=

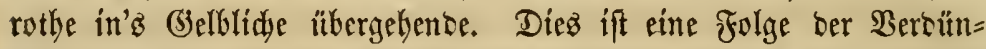

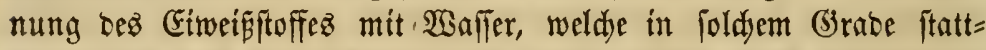
fintect, bás ber Eiweiffitoff feinen Beftanttbeilen nady bem Rahm älinlidy wirb. Rommt aber baffelbe Thier burdy sunger ober Rarant= beit fehr beruuter, fo erhält baz fleif cine sunfelrothe, an'z Braune grenzente Farte, unt ber Fimeisftoff wiro bif uno fletrig wie Theer.

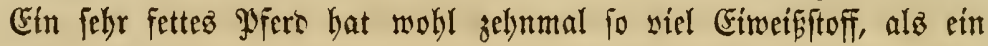
felbr magerez.

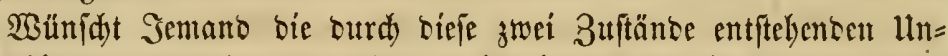
teridjiebe zu erproben, fo nebme er in eine 5ant ein Stüt ntageres Fleifid) son einem fetten Rinte uno in bie antere 5 ano ein äbn=

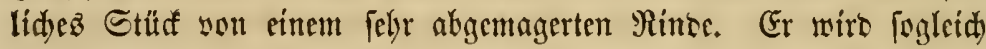
verftehen, waz wir flar zu madjen wüniden. Man Gärt Eoltoaten

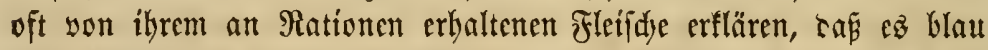

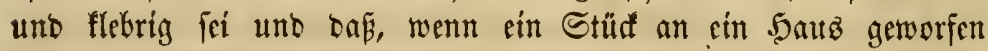
wirt, ez foft flebe. Diez ift ein Berweiz oer îtemagerung, weldye

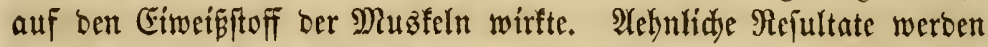
burd) Rranflyeiten erzengt. (Es mag bem Rejer viefleidyt yon Snterefle

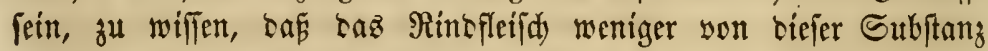

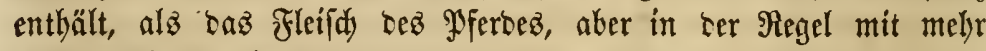
Fett burdyogen ift.

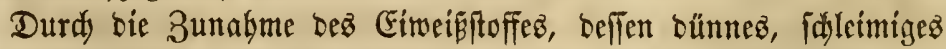

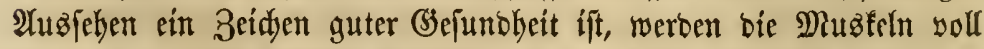
unt runt. Die $\mathfrak{D u s f e l f a j e r n ~ m e r b e n ~ a u f g e l o c t e r t ~ u n o ~ f a l u ̈ p f r i ́ g ~} g e=$

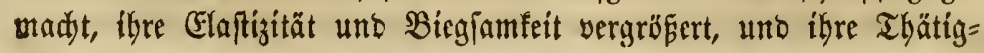




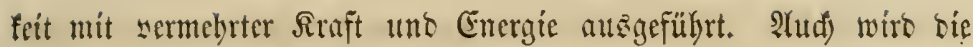

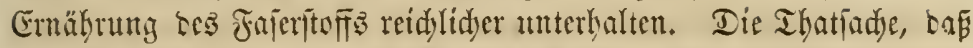

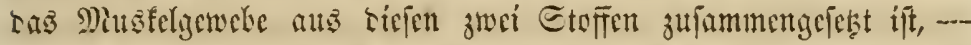

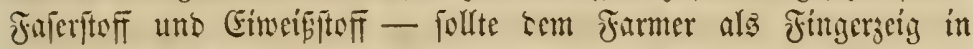

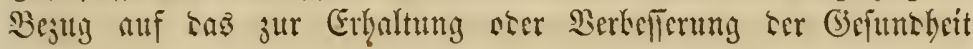

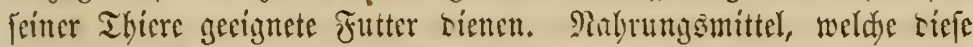
Etoffe reidylidy uno in einem leidyt serrauliden Buftano entlyalten, follten jur Fütterung feimer PJorke sorgejogen wersen. Dicjer OBe genftand miro in cinem anceren Rapitel auşfübrlid befyantelt.

\section{Die Ge}

Es gikt seren fehr viele; wir tënnen bicfelben jecod) ebenjo wenig

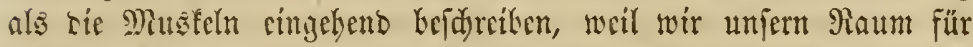

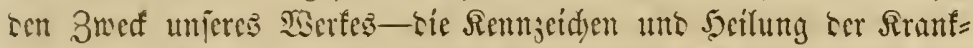

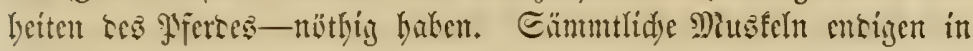

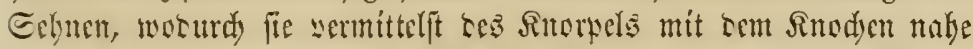

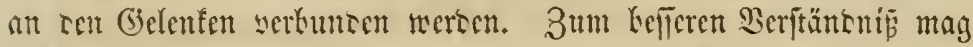

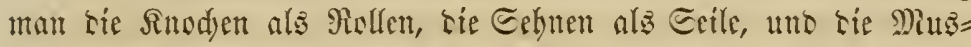
feln als sic an ten Eeilen zielentere Siraft betradyten. Shgleidy tie

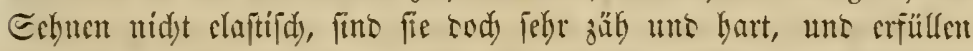

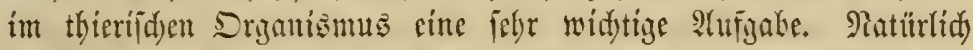

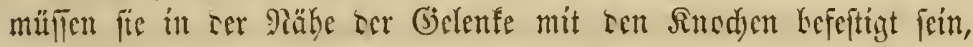

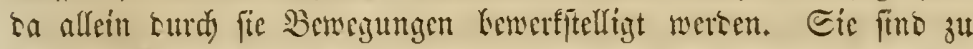

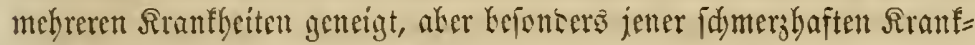

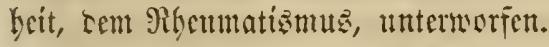

Fiffeln, Gejonters Lie Rituenfiftel (poll evil), siefe futddtharent

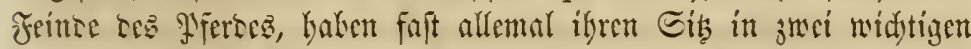
Eebnen. Die Befdreibung einter terjelfen wiro für Keite binreiden,

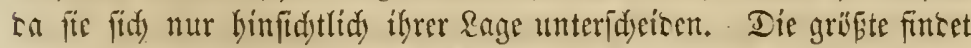
man mif ten oberen Theil ter Edyulter. Dis Fajern seriethen haten

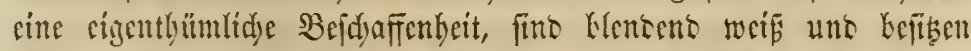
nidjt mur bie auserorsentlidje Etärfe ser übrigen Eehnen, fontern

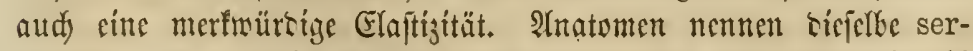
ratus major (rörttlid) grope fägenförmige), aker unter sen Raien if

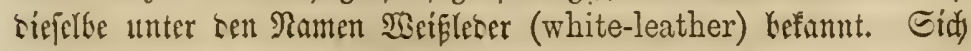
unterbalb tem sberen Ente teş Edjulterblattz erfitrefent, fdyeint fie

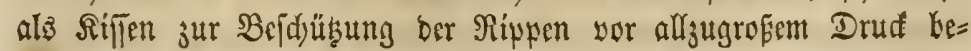


fitimmt 3u fein. Borne ift riefelbe mit bem Bruffforb unt ser interen

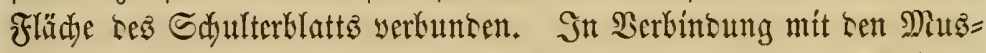

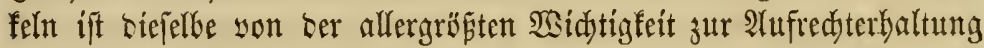

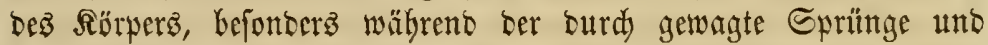

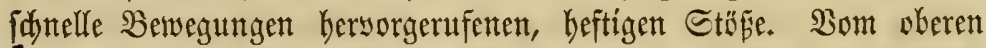

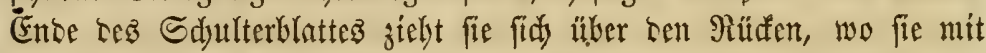

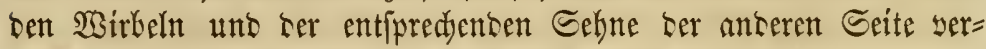

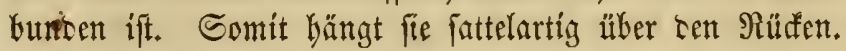

Die Fifitel, weldye wir eingeheno im fiebenten Rapitel bejdyreiben werben, ift eigentlid cine Anjdywellung uno Eiterung hez serratus

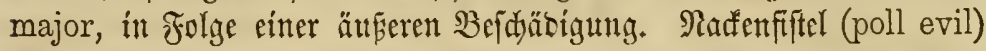

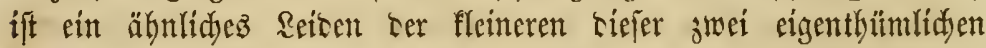

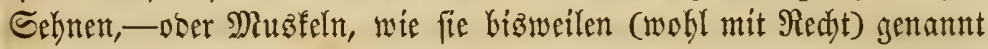
werben,- - (ber serratus minor,) bie ifhre Rage nahe bem vberen I I heile

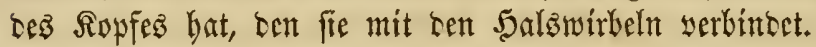

\section{Die $\mathfrak{g} a ̈ \mathfrak{a t e}$.}

Die Säute bilben sen Sünnen glatten Hekerzug ber Snodicn unt

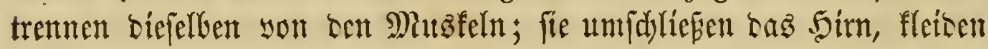

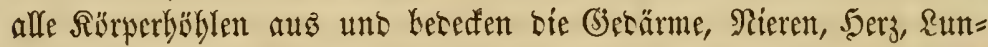
gen uno antere Drgane ähnlider Rage. Sie überzieben ebenfalls

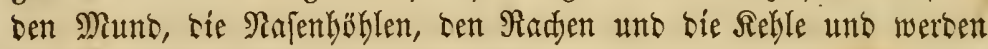
an allen Reillesöffrnungen angetroffer.

Se nady ifrer Rage uno tent Drganen, bie fie einthüllent voer über= zieken, fino fie benannt worten. So nennt man ten Heberzutg ter

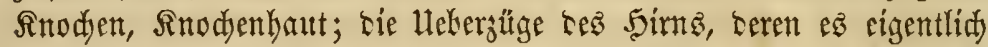

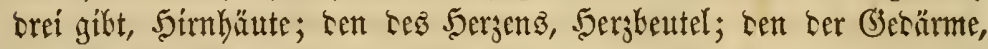

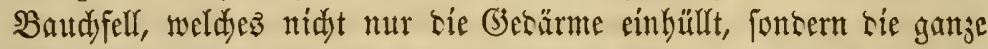
Baudböble überzieft. 2 atd tie bie Rungen umgebente Saut, Brutt=

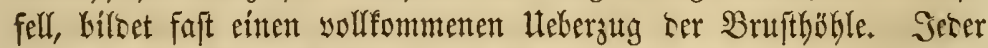

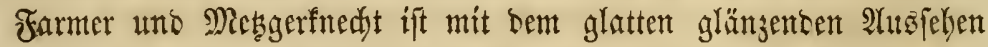
ber bie \&ungen unt bebärme fowohl alsె einige anbere Drgane bç

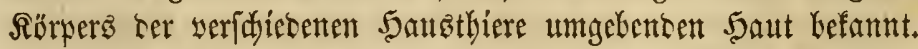

Die Säute finto zum Sdyute ber von ibnen überjogenen Drgane

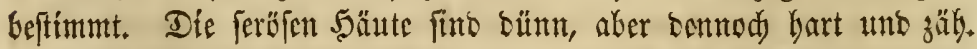

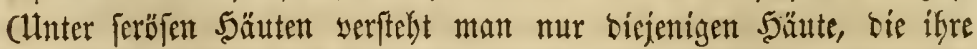

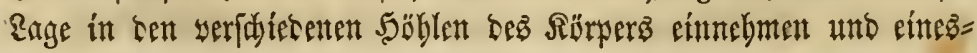


theils sic Picilung unb ten Drud Ler cingelnen Ifeile an einanter

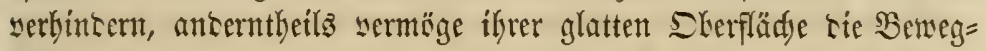
lidfeit ter Srgane an einanter unterftüben.) Eie wercen wentger leidyt surdyjuntten ofer Eurdjorungen, als irgeno cin anterer Rör=

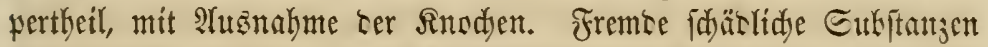
gleiten in Folge ifrer glatten Skerfläd)e fechr leidjt ab, menn nämlid

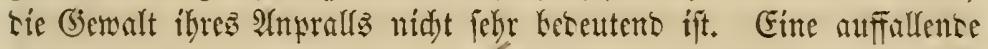

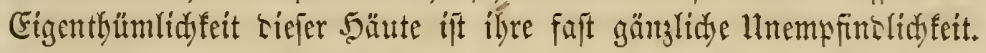

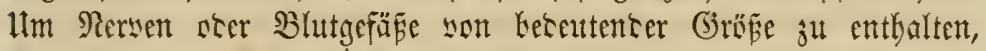

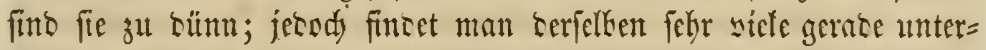

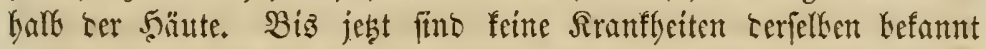
getworsen, aber fie find natürlid, wie alfe anseren Ibeile, Berleşungen unterworfen.

\section{Dic äน вิย}

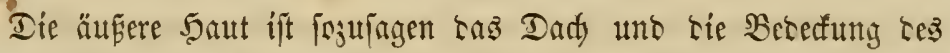

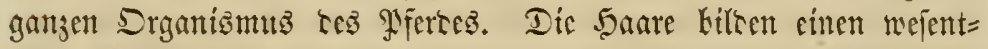

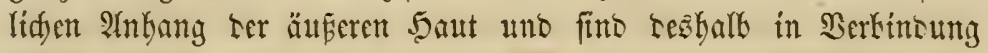
mit berjelben zu betradyten. Sie fins eigentlid sie son Sathr zu

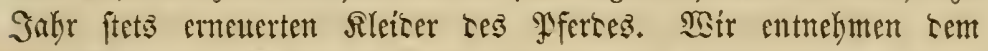

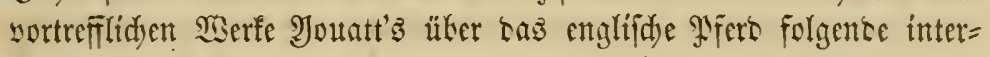
eflante Bejdreibung fer äuferen Şaut uno íber Funftonen.

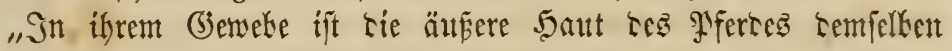
Drgane in anteren Ibieren ähnlid). Cie beiteht aus trei üterein= anter liegenten Gdjtden, melde mejentlidy in ifrer Banart und

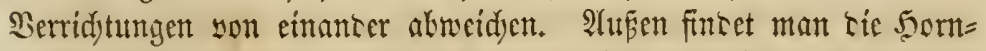
baut epidermis, scarf-skin, tie ณนเ vielen Edjidten unjähliger

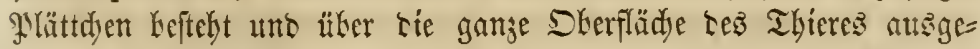
sebnt ift. Iluterjudyt man rie Sornhaut mittelft eines Ditfoftops, fo werten sie SHlättdyen, sie sen Eduppen ser Fijdye ganj äbulid fint, leidt erfannt. Durdy tie Sirtung eines Fliegempflapters twer=

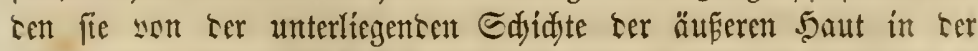

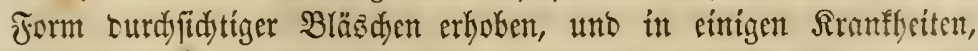

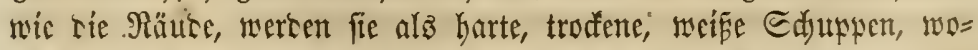
won siele ftetş übercinanter liegen, abgeworfen. Die Sorthant ift in jecem Theile res Sörpers son utzäbligen Poren surdyzogen, won welden einige ben Durditritt fer Saare geftatten; anere bilsen sic 


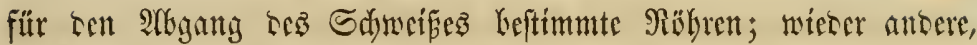

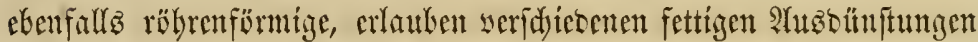

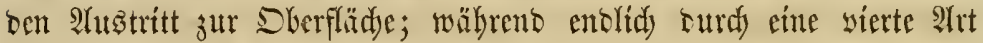
viele veridyicsene (baje unto Flinfifgfeiten cingejogen werben.

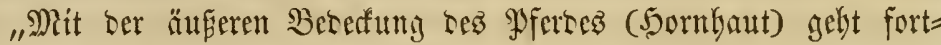

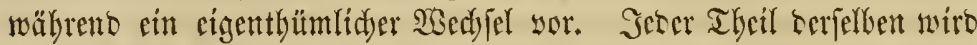
beftändig umgeänoert wno crneuert, aber fie ift mit fer unterliegenten Rererhaut mittelft ber Poren uno fobr viclen fleinen Grboblungen,

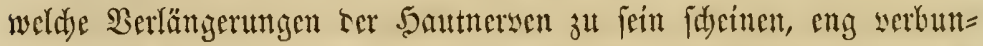
Den. Die Sberbaut felbft ift gefilibllos, ifre widytigfte Funftion ift aber bie unterliegenten Ibeile zu Kejdüțen, bie bäufig allzuempfino= (id) find.

"Itnterlyalb ber Sornhaut (cigentlid) bie unterjte Edjichte berjellen bílsent,) finbet man eitte weidye, oünne Subjtanz, burdy weldye tie

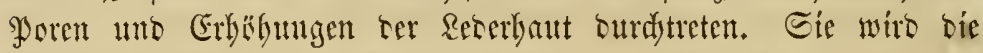
Sdyleimidhidyt genannt (rete mucosum) wegen ifter gewebten Banart uno fajleimigen Beftantlyeile. Sie idjeint zur Bebedung uno jum

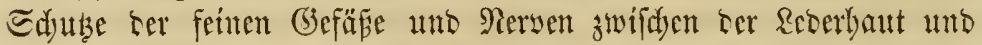
Sornlyaut beftimmt ju fein. Die Sautfarbe bat cbenfallz bier ilbren Sib. Bei weifhbarigen Pyferon ift sie Sdyleimjuidyt weif; fie ift yon brauner Jarbe bei Kraumen Pfersen, fdwars bei ton fdwarjen

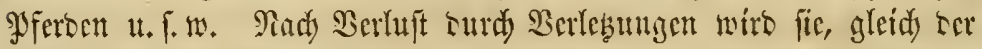
Sombaut, wiecer entment.

"Die Reberbant liegt unterbalb tor Sdylcimidyidyt. Sie bat cine fajerige Bauart, ift elaftifd, nidyt leidyt zerreipbar, auperorsentlidy gefäpreidy uno febr cmpfintidy. Sic Kilset Den Tlyeil ber äuferen

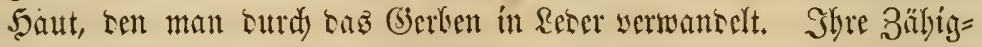
feit ift febr grof́, weshalb fie aud zur Bufammenlaltung aller Theile

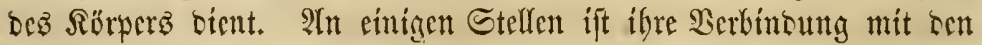
unterliegenten Drganen fo eng, baj faft feine Betwegung terfelten

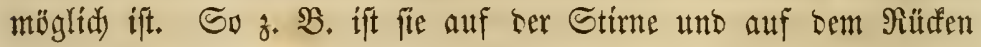
felor eng mit ben unterliegenton Ibeilen vereinigt, aher im (s)eficte, oen Seiten utto ten Mseidyen billoet fie lofe Falten. In ten zu $\mathfrak{B} c=$

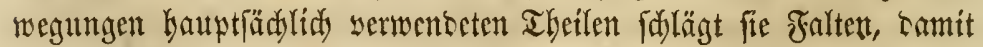
bie Thätigfeit bes Thícres nidyt gebenmt werbe. IYm dümnten uno claftifdyten ift bie Reocrbaut an sen am wenigften mit Saaren be beffen, ober ganz yon benjelben entblöften Tlyeilen, wie bie Rippen, 


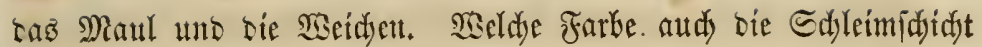
baten mag, ift rod) bie Reserbaut inmer yon blap weifer Farbe. lleberfaupt ift bie Farke ber 5aare ntedt yon ter Reterbaut ab= Gängig.

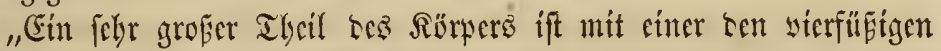

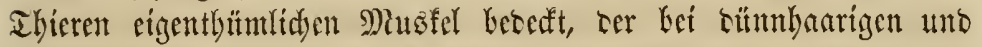
sünnhäutigen Théerent viel frïftiger uno auszgebréteter ift, als Ket foldyen, bie cine ftäifere äufere Bercedutug baken. Som Sointerfopf

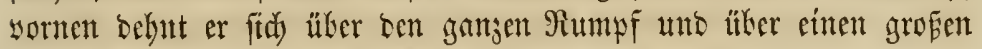

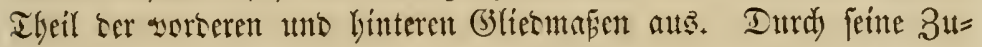

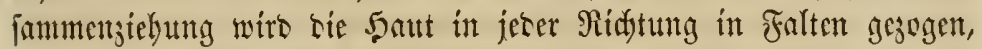
utto ift feine Thätigfeit entergifa, fo fann bas PFero nidyt nutr alle

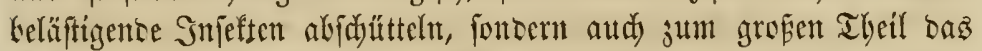

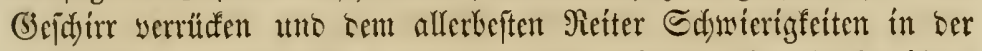
Bebratptung feines Eiljes madyen. So weit er jid erftrect't, ift er

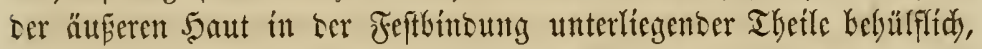
uno ftärft aud wohl bic anliegentoen Mitsfeln. Man nemut ifhn ten Sautmug̈fel ober bie Fleifdylyaut panniculous carnosus.

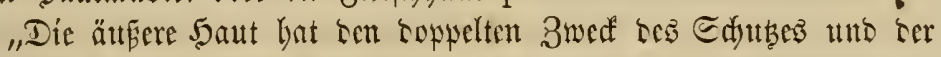

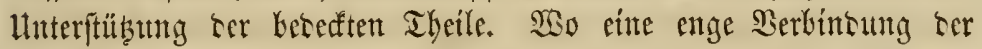
I Geile unteremanter nöthig ift, flebt fie febr fejt an. 3. 3., bie

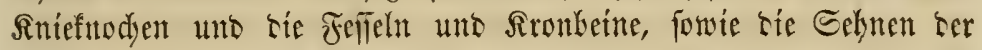

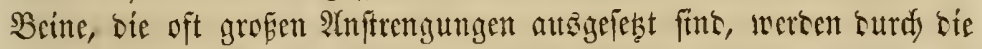

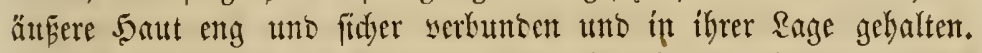
Bon ibrer grofen Etïrfe baben wir vielfade Bancife fowobl im lebensen alz tobten Ihtere. Shre Fafern finto mit cinanter Had)

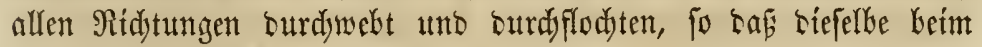
lebenben TGiere faum zerreipbar, beim torten zu ftarfem Reber ver= mentbar ift.

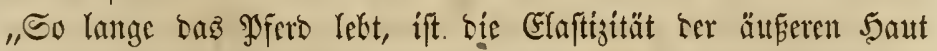
auscrortentlid grof. Pid

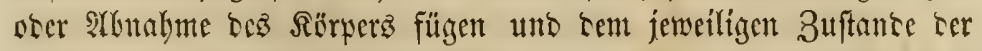
Fettleibigfeit ober fetettartigen âbmagerung gleid) gut antafien, font= bern wenn irgento ein kejonterer Theil terfelten bis zum bödjftent (brate burd) Musfelthätigfeit ausgeselynt worsen ift, ziebt er fid

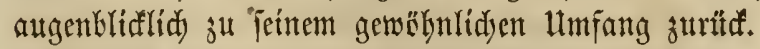

Diefe Elaftizität befitht fie hauptfädylid in Folge ter son umzäb= 


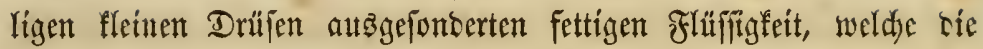

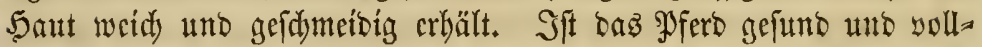
ziegt jedez Drgan feine Funftionen ridutig, fo wiro cine getwilie Dutantität biefez öligen Stoffez auf ber Sberflädye ber äuß̃eren 5aut angetroffen, fowie audy in allen an ber Skerfläd) auṡmilntentoen

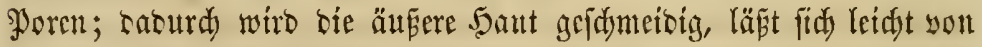
cen unterliegenten Theílen aufbeben, unt zeigt jene eigentbüntidye

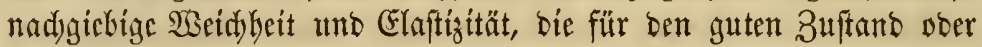

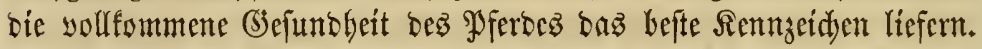

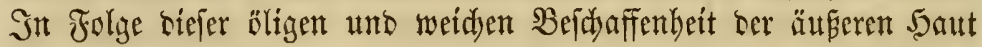
liegen bie 5aare glatt uno bejitgen einen febr fäbnen woblgefälligen

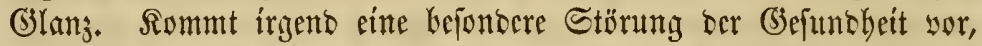

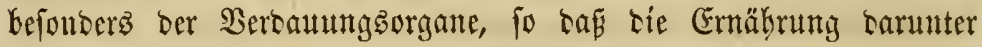
leibet, io merft man bälo Den (Einflue auf ber Dberflăd)e. Daż Del gelangt nidjt mebr zur Dberflädje; bie äunere 5aut verliert ibre

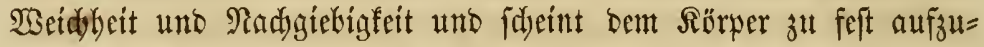
fiben; ein 3uftant, Den man mit bem 2 tušrut "angetwadjen" (hidebound) bejeidinet.

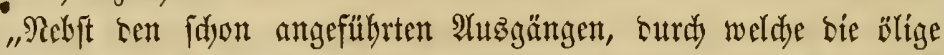

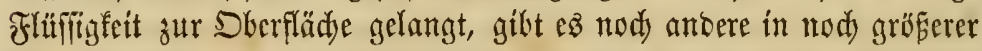

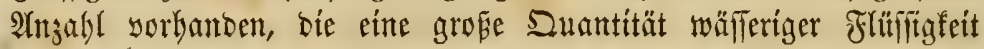

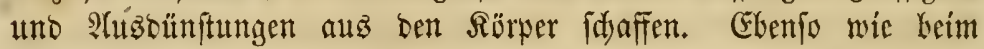

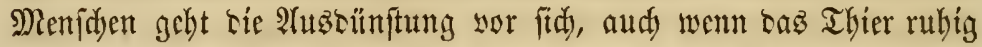

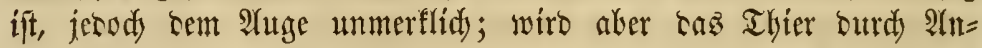
ftrengung altigeregt, fo gebt biefelle fo rafd sor fids, baf fie in ter

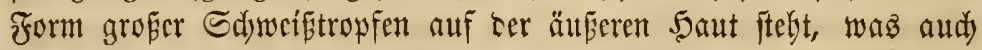
bei gewiffen franflyaften Buftänoen ber Fall ift.

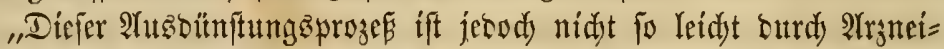

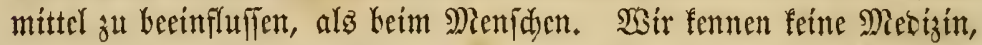

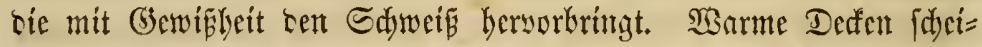
nen benfelben zuweilen zu erzengen, aker bies ift nur fajeintar uno nidyt wirflidy oer Fall. Der unmerfliden ftets yor fid gebenten

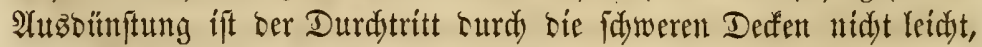
wezhalb fie fid alz grofe Edjweíftropfen anjammelt. * * * Sir baben genügente (birünte anzunebmen, baßs audy noch eine andere

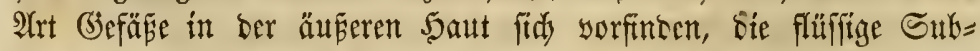

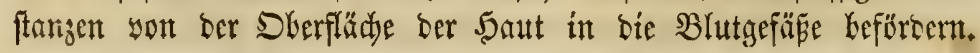




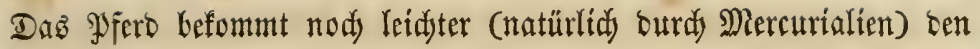

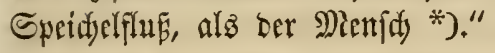

\section{Dic $\mathfrak{g} \mathfrak{a} \mathfrak{a} \mathfrak{r}$.}

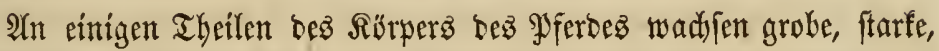
fteife 5aare, hauptiädlidy am Sarje, wo fie bie Miälnte bitloen unto

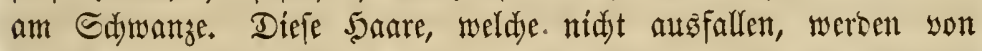

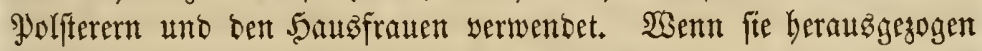
werben, wadjen fie wieber, jebod febr langiam.

Aber you weit gröserem Snterefie ift uns bie allgemeine $5 \mathfrak{a} a r=$

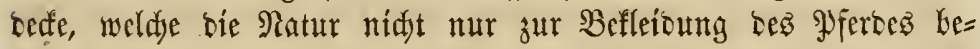
ftimmt, fonbern aud to eingeridtet bat, bas fie fid ben veridjieden=

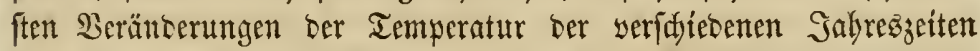

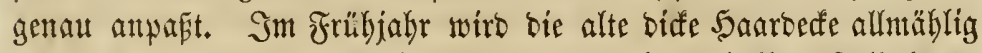
abgemorfen, während fid eine neue, etwa einen halben Boll lange bereits zunt Erjatae ber alten yorfintet. Diefe Saare fint viel feiner แnt bünner, als bie abgeworfenen, und für ben Iemperaturwedjel auperorbentlidy gut gecignet. Sît baz \$feró geiunt, fo Gaben fie ein

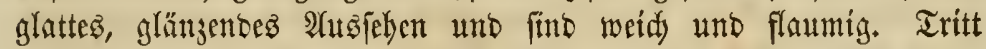

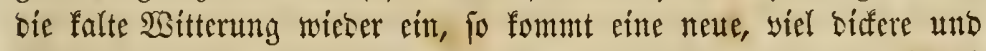
grobere Edjidjte zum Sorjdein. Die Sommerhaare fallen jectody

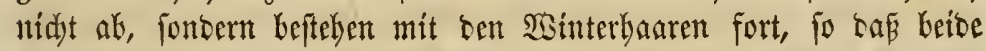

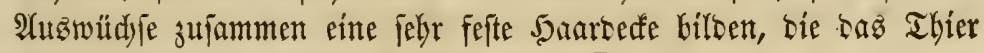

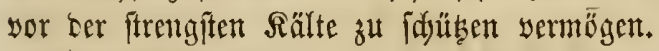

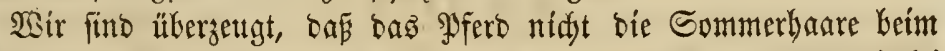

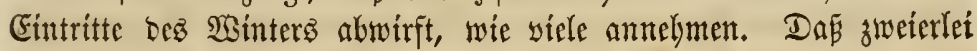

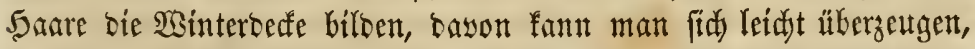

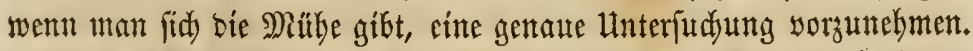
Es fint gute (3rünte zur Âtnabme sorbanden, bap aud) bie Eom=

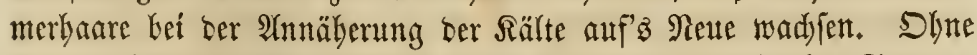
3weifel hat tas \$fero immer zweierlei 5aare. Selbeft im Eommer trifft man unter ben längeren und gröberen Saaren cine viel feinere

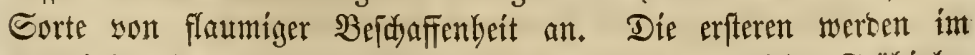

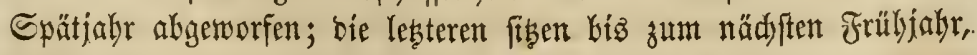

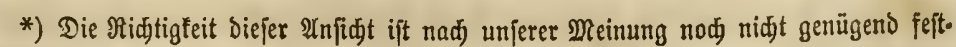
geiftellt. 


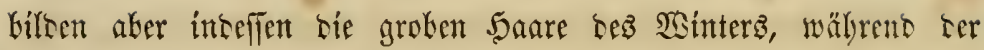

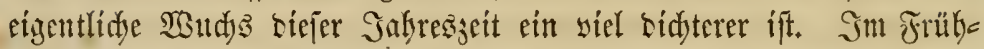

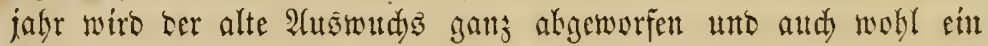

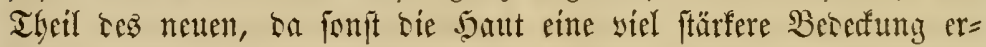

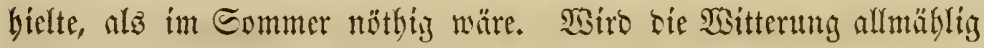
heiser, fo wirb sie alte Edjidyte von ser neten yerbrängt. Comit fängt Lic im Spätjahr erforberlidye 5aartedfe im Frïhjatgr ju wadjen an, und im Spätjalyr sie im nädyften Frülljabr nöthige. Durdy

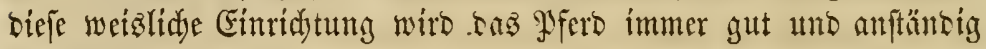
befteiret.

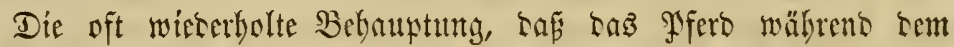

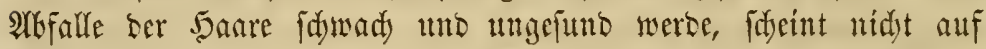
Thatfadjen hegrüntet ju fein. Sonmen Kei irgento einem Prerte wäbrend biefer Weriobe joldse ungünftige Erifdeinungen sor, fo fino fie wobl mit siel melye Redjt entweber bem ju siejer Beit worfom=

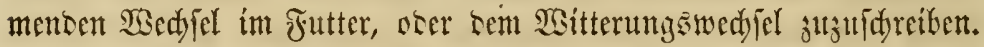

Sn oer äuferen baut finten fid ölige 2tbjonserungen sor, mie

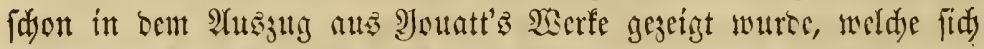

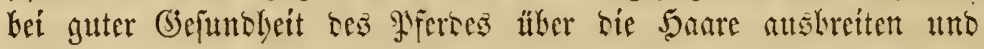

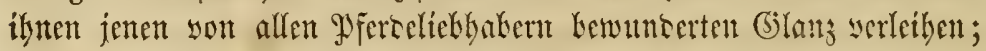

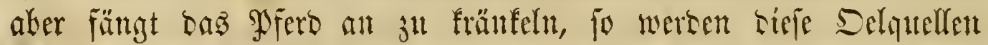

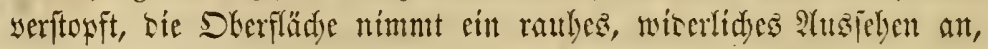
und tie 5aare fteben fteif, trofén uno borftenartig zu Berge.

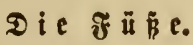

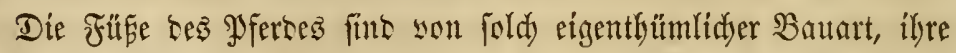

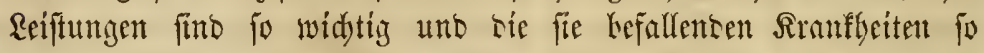
zahlreid, tak wohl cint ganjer. Bant ilfer Betradtung genismet

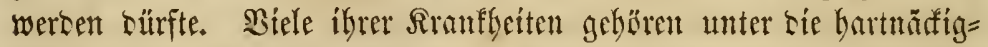
ften uno besenflidjfen, benen Las Pfero unternorfen iff. Der an=

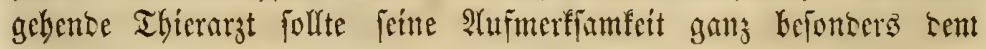
Sturum Derfelben mismen, sa fie in feiner zufünftigen Prariz cinen grofen Theil feiner Beit in Thiprud. nebmen werben.

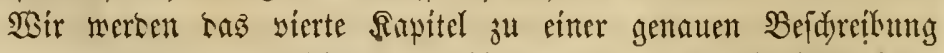
berfelben verwenten. Wir mollen bier nur einen Umrís ifyer fom= plijirten Bauart geben, fer Dem Rejer leiduter verftändlid fein wirs, wenn er bie hierauf bejüglidjen Figuren za Saülfe nimmt. 


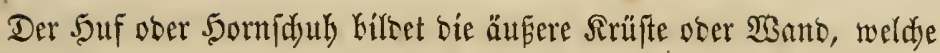

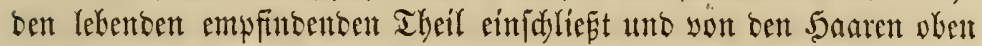
bis jum unteren auf ber Eroe ruhenten Rante fid erfifredtt. ITm längften ift er vorme, wo ber untere Rand mit bem Rament "Bebe" (toe) belegt worten ift. Shinten ift er vffen; hier enoigt berfelfe in einer biffen, fojwammigen 5aut, weldye hinten am Fune surd eitne Epalte orer Siluft in ber Mitte getrennt unt jut Keísen Seiten alz

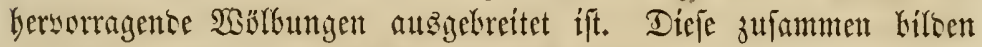

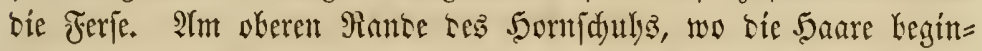

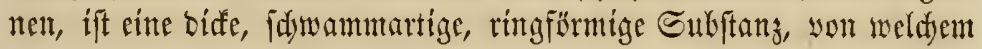

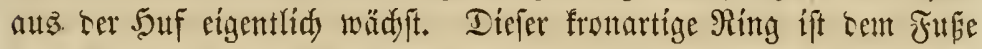

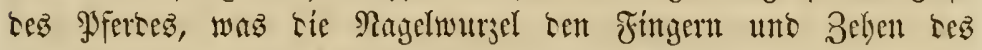

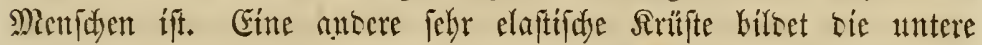
Fothflädye voer Soble, beren untere ber Groe zugewantste Flädje ser=

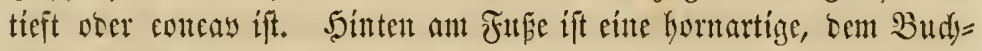
ftaken $V$ ähnlidje Sersorragutmg, teren Deffnutng ber Ferfe auge= wentet ift. Die Seiten biẹer 5ervorragung, welde cinten SSinfel son etwa 45 Graben miteinanter biften, werben Giffteben (bars)

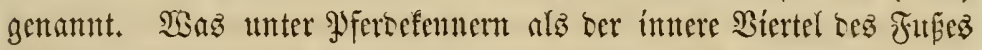

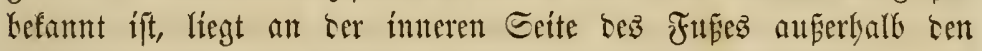

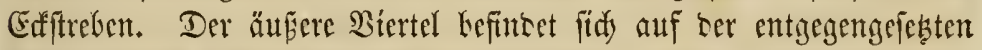

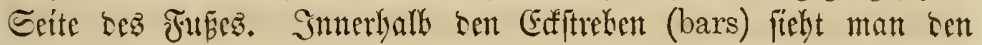

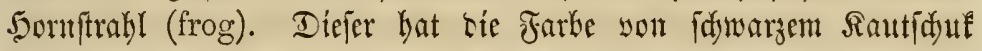
(india-rubber), bem er audy wobl an Bähigfeit uno 5ö̈tte, aber nidyt an Elaftigität gleid) fommt. Der 5ormftrabl bejibt fein Gefüht, aker etwa einen halben Zoll höher ftö́pt man auf ben Fleifdjftrahl, ter sufierorontliad) empfindlid) uno mit unzäbligent fleinen 2ietsen uno Błhtgefäšen angefiulllt ît.

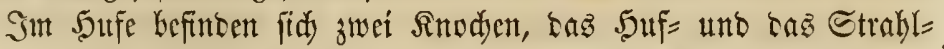
bein, weldye zuweilen sou fehr Gartnätigen Rrantfeiten Gefallen wer= rent. Diefe nebment faum mebr alz bie 5älfte tes im Sufe kefint =

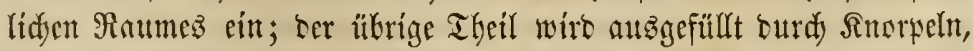

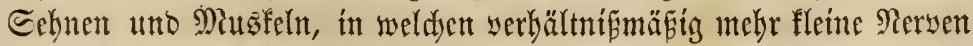

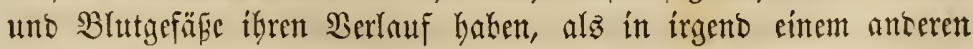
Rörpertbeil.

(Fine febr midatige Selyne (bie Bettgefehne) erfitredt fid som bin=

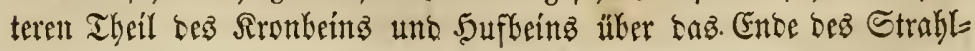


beinz, wo fie fidy in zwei Theile trennt, weldje auf jeber Seite ber Ferie uno bes Sornjtrablaz Ginablaufer uno fid an ben unteren Entoen bes Sufteines befeftigen. Durd bas Etrablbein und biefe Sehne, welde unmittelbar auf bem empfindliden Fleifajtrahl liegt, wiro eigentlid bie Servorragung Ler Ferfe gebilteet. Folglidy wersen Berlebungen bez Fleifdjtrafis faft allemal aud) bieje Sehme uno tå weidye Strablbęin treffen.

\section{Dic $\mathfrak{B} \mathfrak{l} \mathfrak{u} \mathfrak{t} \mathfrak{b} \mathfrak{f} \mathfrak{f} \ddot{B} \mathfrak{B}$.}

Duntglijon in feinem Mesical Dictionary beidnribt baz $\mathfrak{B l u t}$ als

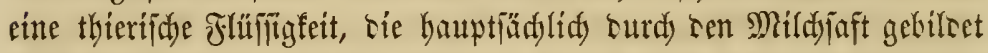
miro, nod) weitere widjtige Gigenjadaften mittelift zentes erbält, burdy bie Círeulation in jebes Drgan einoringt, jescm Gerwebe sie nahrhaften Etoffe zuführt uno bie Sutelle aller 2 bbon=

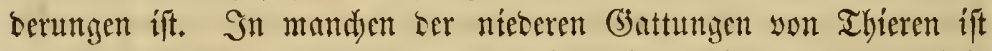

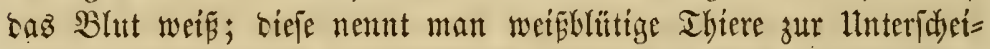

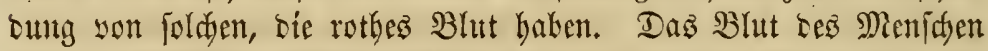

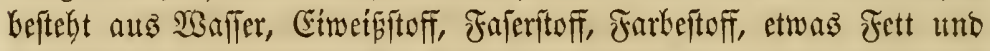

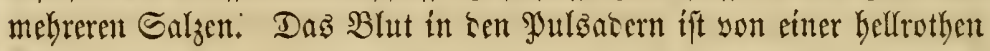
Farbe; bas in ben blaten Blutacern hat cine braunrothe ober bun= felrothe Farbe.

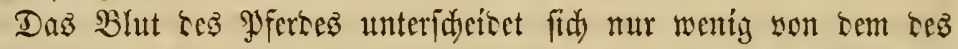

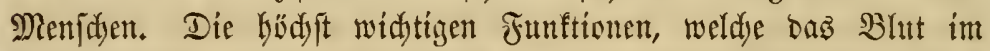
Srgantömus verridtet, finto fidon angejeigt in ber Miannigfaltigfeit feiner Beftanttheile; die alle zum Eriatbe bes beftünsig im Rörper worfonmenten Stoffycrhijtes beitragen. Se nad) Lent Bufftante Les

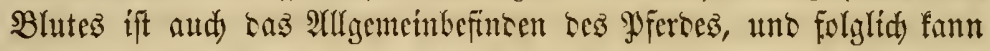

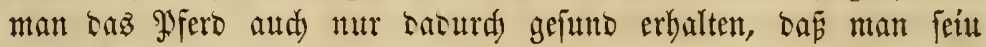
B̧ht rein uno naherbaft erbält.

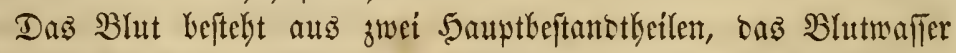
und oer Bhattfuctyen. Im lebsteren fintet man bie rothen Rörperdyen,

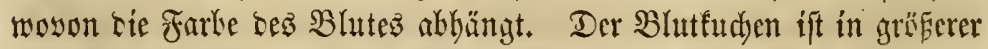

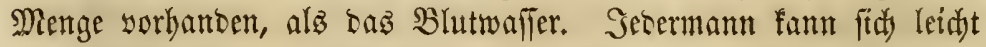
mit bem Utnterjojtede zwifden biefen zwei B̧luttheilen befannt madyen.

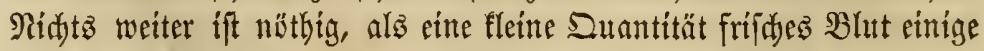

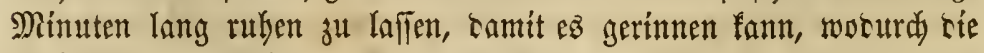
zwei Theíle yon einanter getrennt werben. 
Der Rreislauf bez Blutez läpt fid mit einem See vergleidjen,

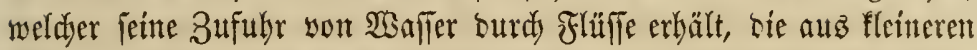
Baädjen gebildot wurten, uno bieje wieserum aus Bäd)leitt uno fleinen Sisäfierden, weldye in bent fleinen foft unmerflidy ter Erte entiprin= genten Tropfen ifren 1 triprung Gaken; Dann fid wicoer serliert burd'

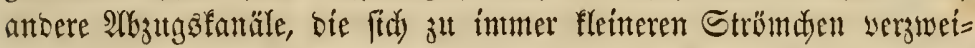

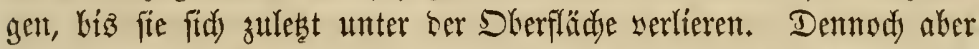

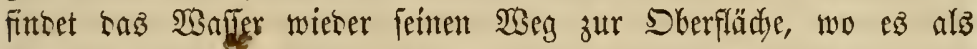
Iropfen eridjeint, weldje fid zu immer gröferen Etrömdjen utmo

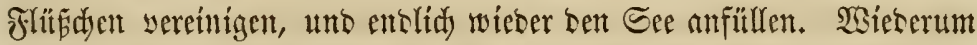

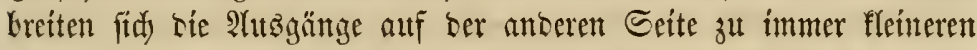
Verjweigungen auz, biz fie von ter Sherflädye verjdylungen werten. So wieserbolt fid) ber Rretżauf beftînoig.

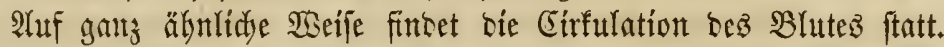
Dả Serz ift ber Bebälter. Dic Błutabem fint die zufiührenten

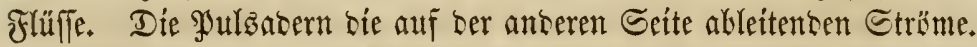

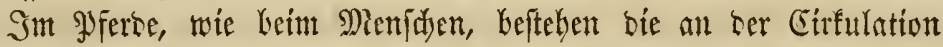

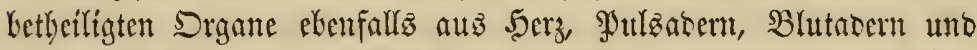

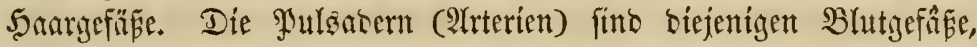
tie tas rothe mit Sauerftoff angefitllte Bhut yom 5 erzen nady allen

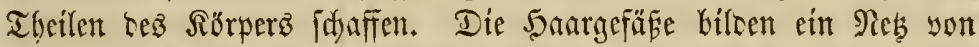

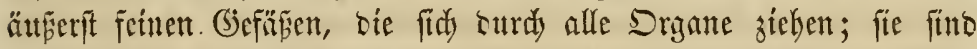

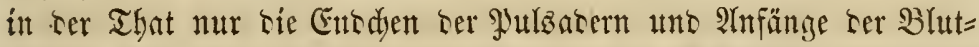

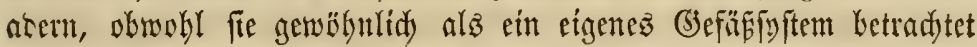

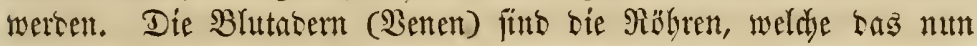

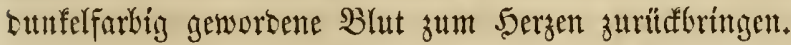

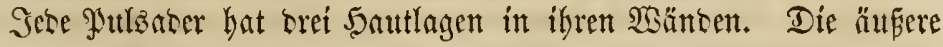

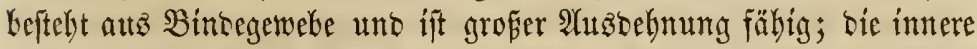

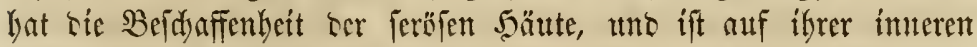
Fläd) auferortentllidy glatt, bamit bas $\mathfrak{B l u t}$ in feinem gewaltigen Rauf feitte Reibung erfahre. Die mittlere 5autt ift größtentheits aus

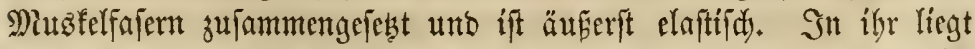

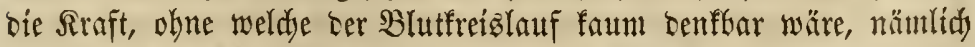

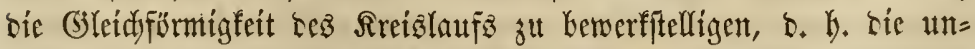

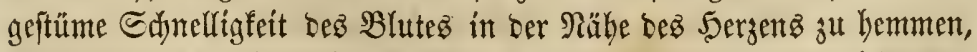
aber feinen \&auf in weiter Entfermung yon ber gropen Central=\$umpe bez నörpers zu bejdleunigen. 
Die Blutatern Gaben efent jovid 5autlagen, ithre Sänte find aber

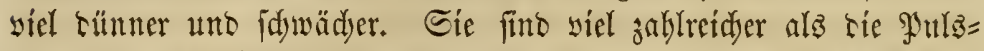

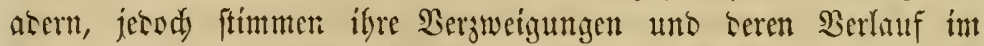

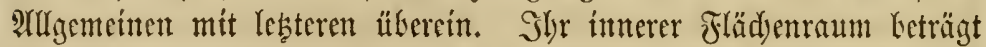
fait soppelt fo siel, alz ter fer Poulzabern. Sie fteben natürlich nidyt fo viel unter sem Einfluf ses 5erzens, folglid pulfiren fie nidyt, and) fliefst ibr Blut langfamer. Eine Gigentfünllidfeit oer Blutabern ift ser Befis son Rlappen son febr meridjectener Con=

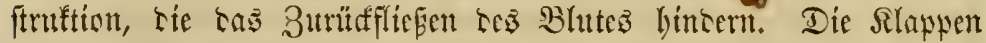
fint zuweilen soppelt, uno bie uno sa aud wohl tret= ofer vierfach miteinaner sertunsen; in sen meiften, jecody nidyt in sen gröbten SBlutarern fint Slappen sorlyatten.

Wir Gaben foweit nur sen allgemeinen ober grofen Rreișlanf be= tradjtet. SBent wir sen idbönen Borgang im Röper, ben man fen

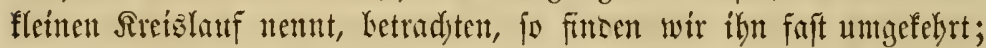

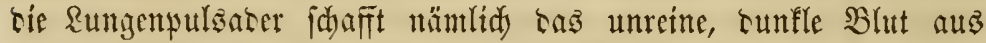
fer recten Serjfammer in sie Rungen bintin, wo es gereintigt ofer. mit Saueritoff veriechen wirt. Diejes werbefierte Blut, weldyes in

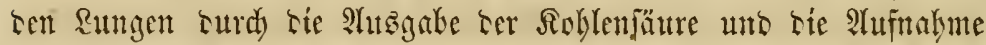
won Gauerftef in ein befrothes serwantelt worten ift, flief̂t nun mittelft ter Rungenblutatern in sen linfen Borbof Les Serzents. Atuserorsentlidy interefīante Eridseimungen fintet man aud) in Sent

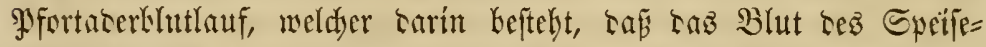

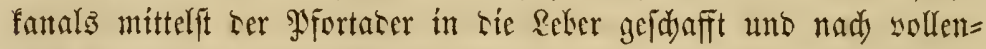

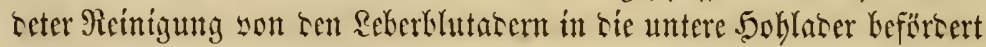

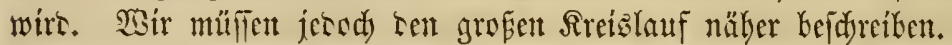

Nadicem tas in ten Rungen gereinigte $\mathfrak{B l u t}$ surd bie Rungen= blutabern in Ien redjen Sorbof Ies 5ergens geidjafft worten ift,

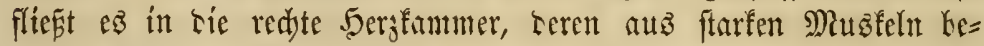

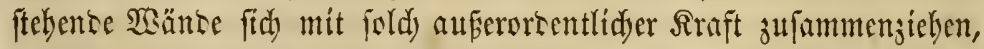

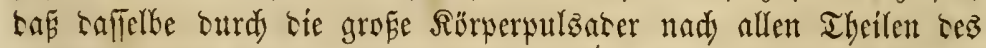

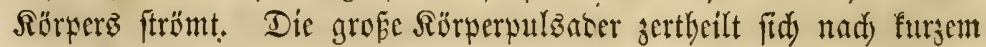
Berlaufe in simei grofe Aefte, son senen ter fleinere, nad) siclen Berzmeigungen im Ropfe unto ben vorseren (bliesmafen, ter gröfere in bem Rumpfe uno binteren Grisermaken verläuft.

Das fo som 5 crien auşgetrietene Blut entyält sie mannigfaltigen Stoffe, weldye jur 5erftellung bes Subftanjwerluftez ber veridjecten 


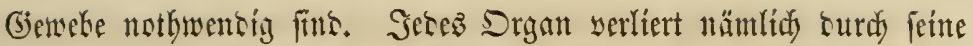
Thätigfeit gewifie Theile, weldye suth Las in allen. Drigaten fein=

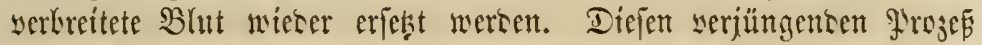
nenten sie \$ogyfiologen cen Etofinedjel. Diejer fintet hauptfüdylidy

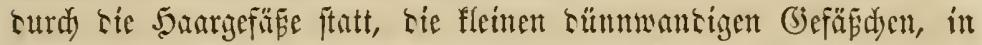

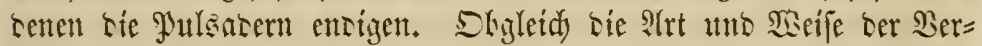
kreitung Ser Sarargefüpe in hen seridjecenen Sriganen, wie sie Drüjen,

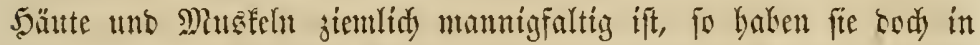

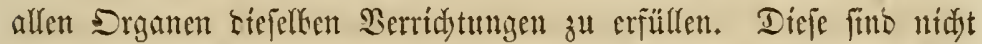

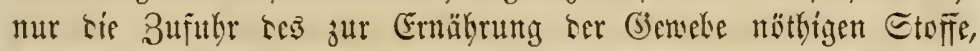

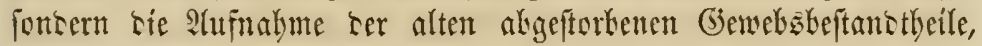

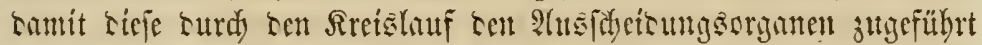

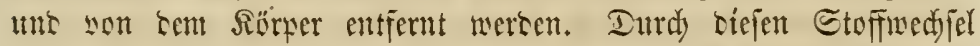
verliert bas $\mathfrak{B}$ hut bic in sen Sunigen gewonnene bellrothe Farbe unb

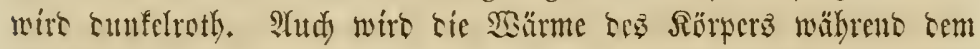
Etrfinedjel ergengt.

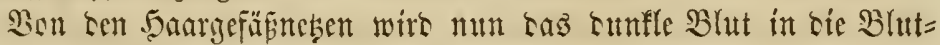

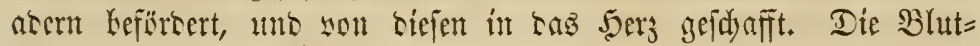
asem sereinigen fid ù untereinmtser immer metr, je näber fie tem berjent fommen, Ki

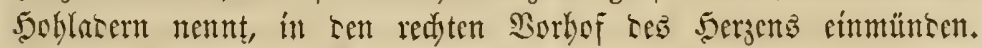

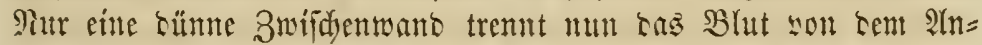

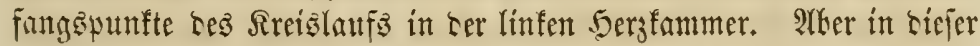

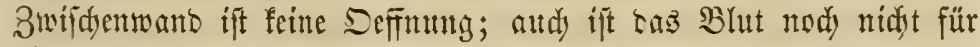

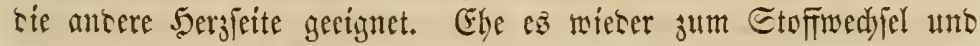

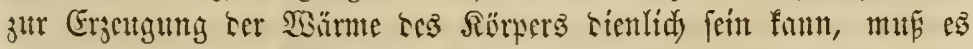
gereinigt wersen. Nidjt nut mü̈jen bie son allen Srganen aufges

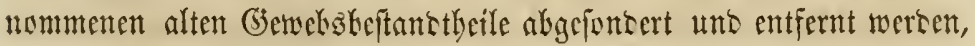

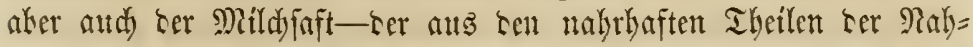

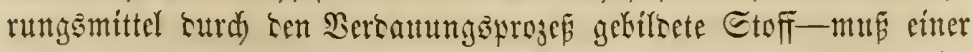

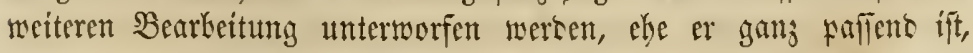

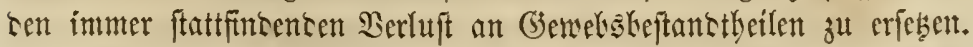

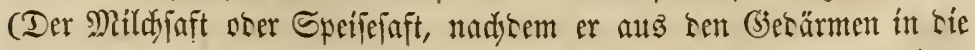
Saugatern ükergegangen ift uno in ben Unterfeibastrü|en eine weitere (Berälynlidfung mit sem Blute) Borbereitung erfahren hat, wirb yon tem Mildebruftgange, in sen tie Sangahern entigen, in cine ber

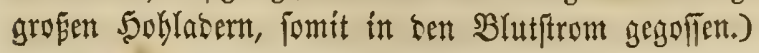




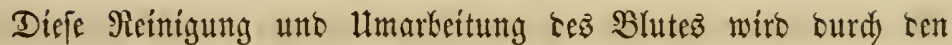

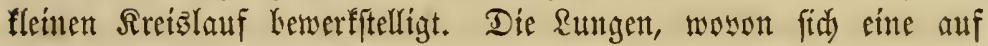
jeser Seite im Brufterbe befindet, haben ein fdjwamntiges Growebe,

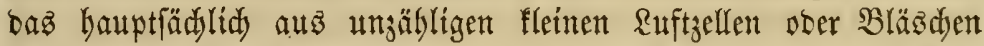

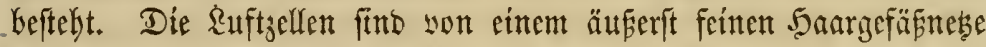

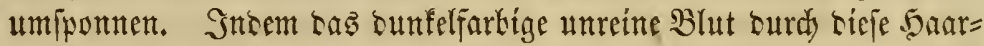

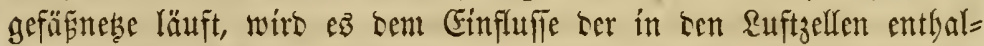
tenen $\mathfrak{Q} u$ ft $\mathfrak{a}$ a meten Ruft kefindliden Eauterfoff in fid auf, theilt aber zu gleidyer 3eit ber Ruft eine grofe Dutantität Roblenfäure mit. Die Roblen= fäure ift bas 5auptprosuft ser Berbintung bes Sauerftoffz mit ben alten Berwebseeftantheilen, folglidy auth ber unreine, ment er fid übermäfig im Silut ankäuft, fogar töttlidje Stofi, ser mittelfit sor

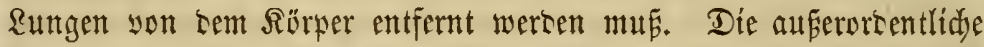

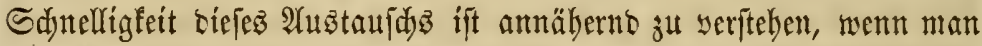

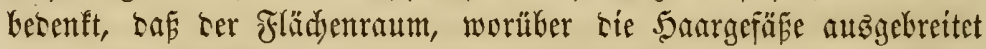

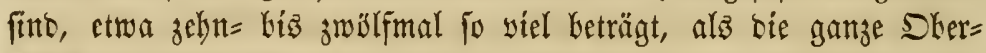

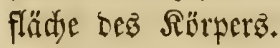

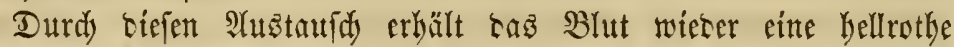
Farbe und wirs nun yon sen \&ungenthlutabern sem 5erjen jugefübrt,

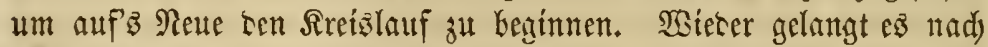

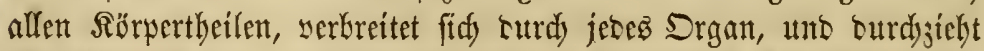

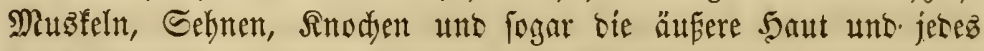
barauf befintlidje Saar. Eaz gibt feinen Theil, fei cr atd nod) fo flein, entfernt veer unbereutent, weldjer nidjt yom Blute yolfommen burdjogen wirs, mittelft ter auperortentlidy feinen Derbreitung ser

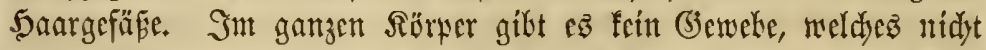

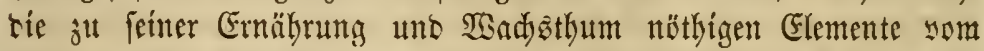
Blute erbält. Utno nadjem

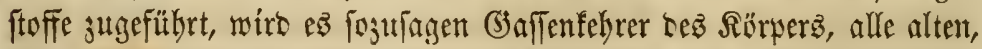

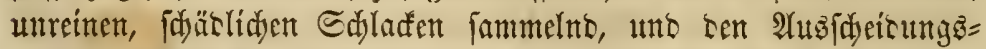
organen zufführent, Lamit fie yom Rörper entfernt werten fismnen.

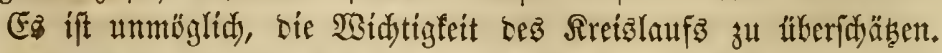
Dhme sentelken fönnte feine einzige Funftion solfogen wersen unb

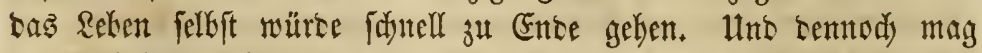

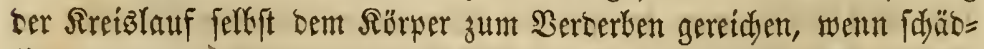
lide giftige Subftanjen in bą $\mathfrak{B l}$ ht gelangen. Deshalb follte grofie 
unb beftäntige Sorgfalt auf bie in ben Magen cingefübrten Nah= runggimittel ober Merizinen serwentet wetsen, ta fie fo fdundl uno

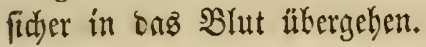

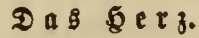

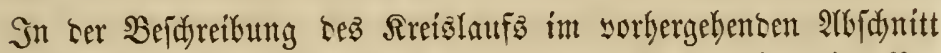

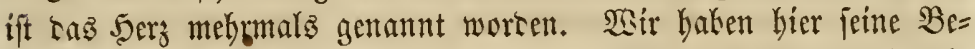

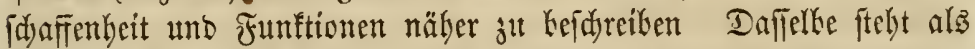

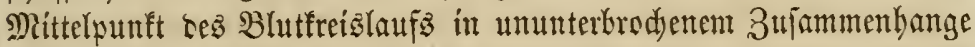

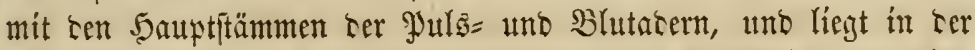
Brujtböble jwijden Keicen sungen binter sem Bruftbeine, umgeken son einem cünnwansigen Gaff, sen man Serbeutel nemnt. Ser

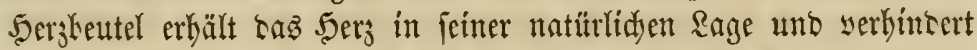
irgento weldye Reibung zwifden tem 5erzen unt ten angrenzenten Ibeillen.

Im 5erzen befinten fid) vier Şbhlen, zmei oben, Lie Borfammetn,

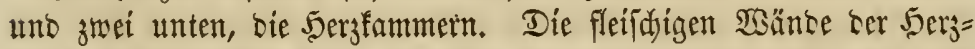
fammern fint viel biđer als sie fer Borfammern; aud) fint cie

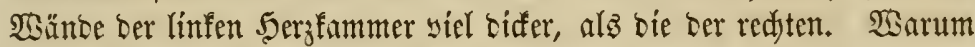

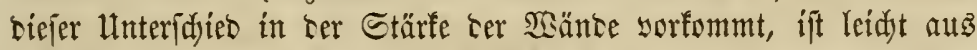
ben Funftionen tes Sersens zu erflären. Die Serjfammern bilken

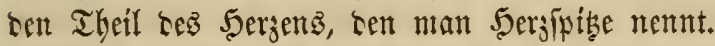

Sn tem redten $\mathfrak{B}$ orbof münten bie jmei grofien Soblaben und

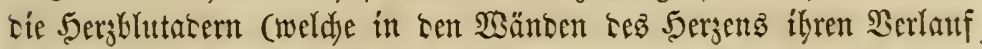
Gaken) ein. Bom redten $\mathfrak{B}$ orbof fübrt eine mit fegelförmigen Slap= pen weriebene Defrumg in sie redjte Sergfammer. Aud) bat rie redite Serjfammer eine runce Deffmung, ebenfalls mit Rlappen ser= ieben, sie aber in rie Rungenpulşater fübrt. Das sunfelrotbe Blut ber red)ten Sersfeite wiro mittelft ftarfer 3 uammenjiebungen ter

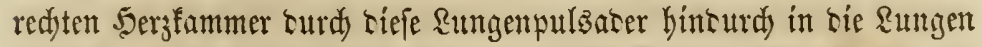
geidotien. Nad) ber in Len Rungen ftattfintenten Reinigung bes

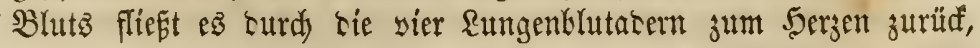

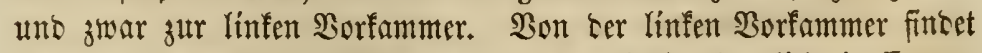

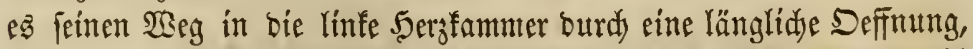
bie man cie Borfofỉ=Sersfammermünoung nennt. Die Deffnung ift

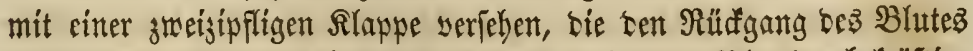
verbintert. Non ter linfen Sergfammer wiro bas $B$ lut burd fräftige 


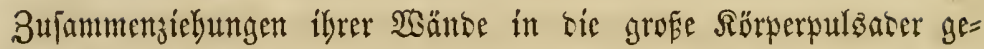

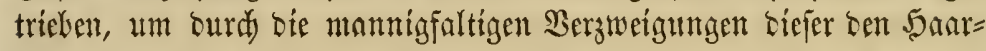

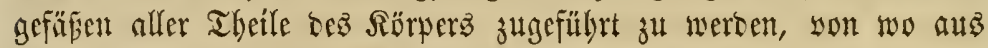

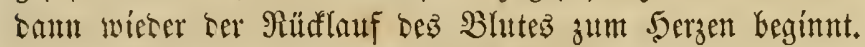

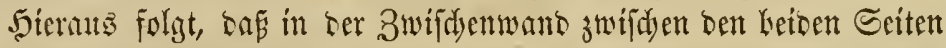

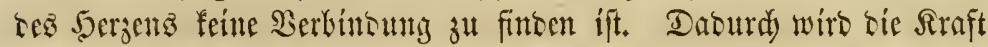
ter 3ufanmentiebungen, weldhe auf beiben Seiteng gleidzeitig fittt= finden, แm Biclea erböbt.

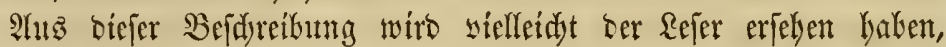

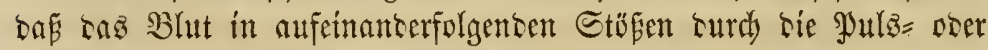

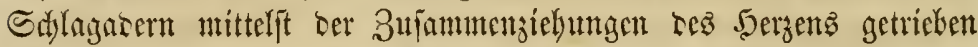
wirb. In ben nahe ber Rörperoberflädye verlaufenten SJulşatern

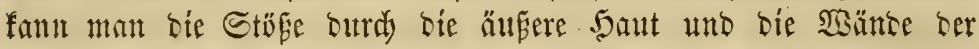
(3efäpe sentlid fehen, oter sody mit sen singern wahrnebmen. Sier=

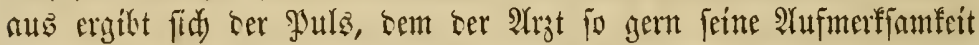

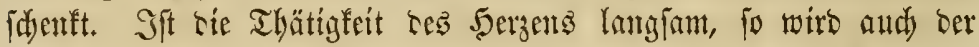

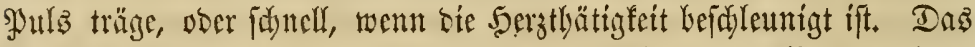

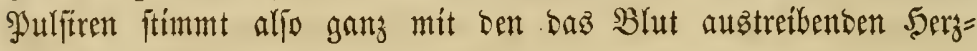
fơllägen überein.

\section{Die $\mathfrak{P}$ ren.}

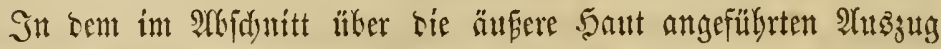

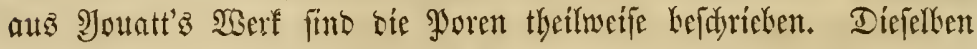

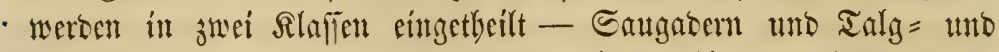

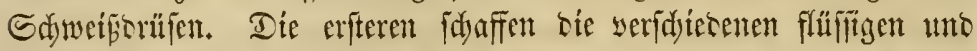

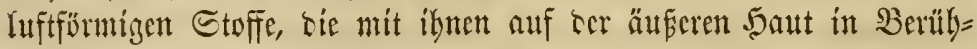
rung fommen, in ben Bhutftron. Die Talgorüjen entleeren eine ölige

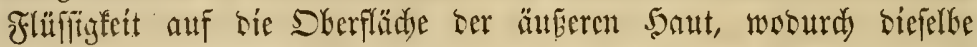
weidy uno biegfam wirt. Die Edyweifstüfen fülyen eine bebeutente

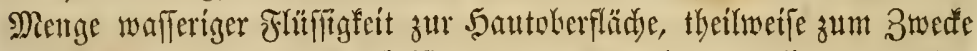
ber Serrünmung utto Derflüfifigung bes ausgeleerten bligen Stoffes,

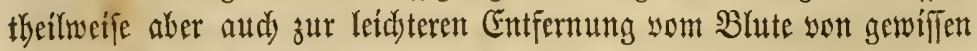
idjäblidjen Subfanzen.

\section{Daร สำ}

Sbige Figur, weldje einent (entredst son worn nad) Kinten burdd)=

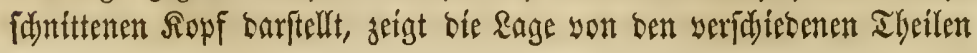




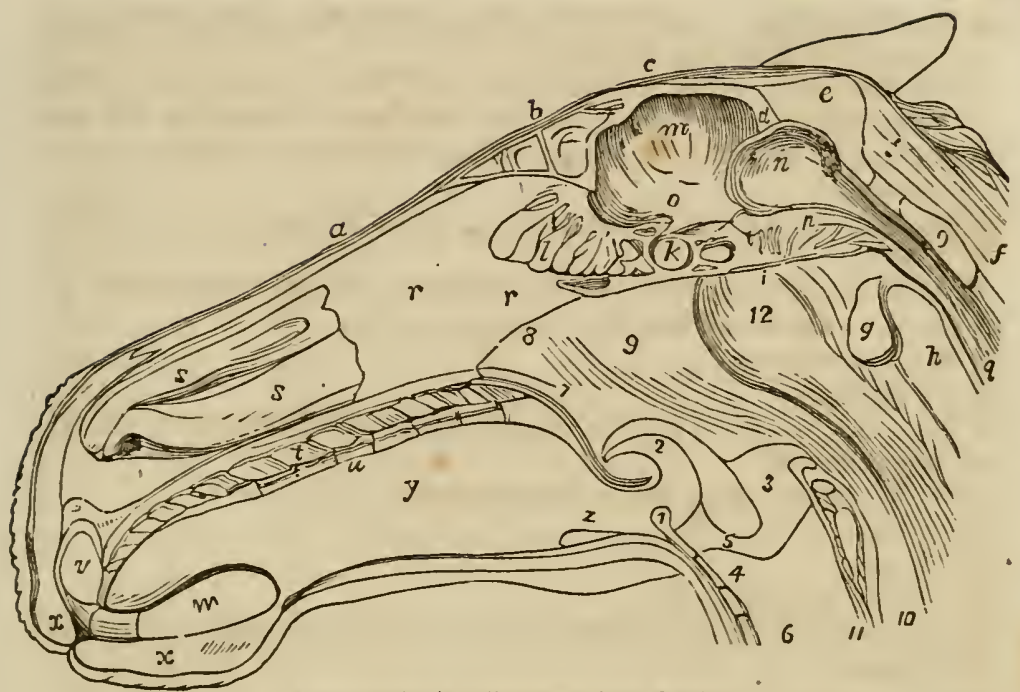

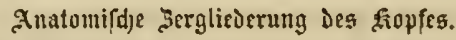

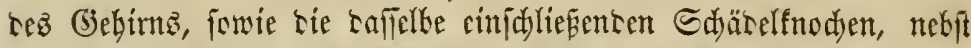
ben antoren Theilen res Sopfes uno Saljes. Sie wito rem Rejer

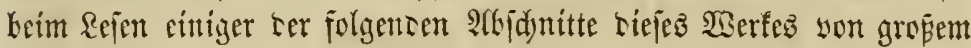
Nuben fein.

a Das श्रjenbein.

$b$ Etirnbein. Die unterliegenden ફ̧öhlen werden હtirnböblen genannt.

c Die Gräte Des BorDerbauptšbeine\&.

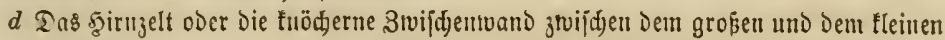
Behirn.

e Taส Duerlyauptşbein.

$f$ Ins Ractenband (whit-leather), wodurch Der Siopi bauptiädylidy in feiner Etellung erbalten toird.

$g$ Ter जtlas oier Träger. Der erite Şalsiruirbel.

$h$ Die $\mathfrak{i}$ (a) je oder Der zueite şalsmirbel.

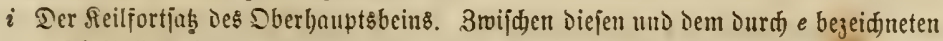
Sheil liegt Das grope Dberbauptślod, mas zum Durdgang bes berlängerten Marfes oder Rüufeumarfes dienl.

$k$ Das Reilbein mit Den Reilbeinhöblen.

$l$ Das Siebbeil mit den Siebbeinzellen.

$m$ Das grope (Bebirn mit der weisen und grauen Rerbenjubitan\}.

$n$ Das fleine Gebirn.

- Der mittlere Ilyeil Dez gropent (5ehirns und Defien Berlängerung, wovon Die meiften Nerben entipringest. 
$p$ Das Mittelgebirn, - Der Berbindungstheil zwifden bem gropen (Bebirn, Dem

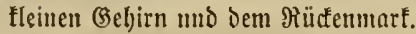

$q$ Daร Rïlfemmarf, weldyes in einem in Der Mirbeljäule, Dem Rrenjbeine und Den

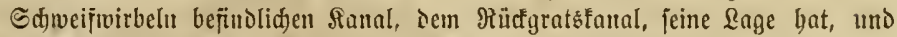

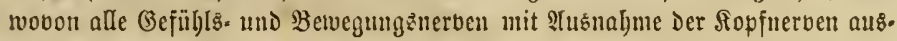
geben.

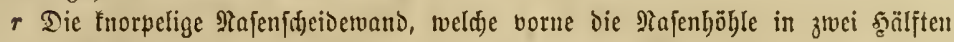
trenut.

s Diejelbige unten abgejduitten um bie fdjwammigen Rnodgen, Rajenmu[dyeln ge nannt, welde in bie ?tajenböhle bincintagen, zu zeigen.

$t$ Der harte Gaumen.

$u$ Die Badżälute.

$v$ Die fleinen Rieferbeine mit Den Sduneibezäbnen. Der Şadenzabn ijt von Der 3 unge berdedft.

$w$ Der sinterfiejer unit ben binteren Єduneidezälynen.

$x$ Die Rippen.

$y$ Die 3umge.

$z$ Ein Iyeil Des 3ungenbeins.

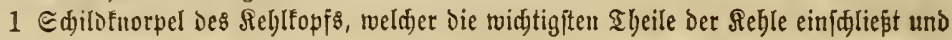
bejditist.

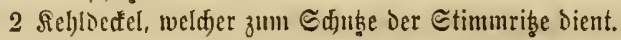

3 Die Bieffannenfnorpel, zwifden weldjen fid Die Stimmritge befindet.

4 Die @timumbänDer.

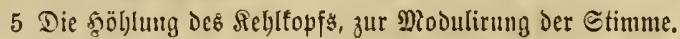

6 Die Ruftrölyen mit iljen fnorpelringen.

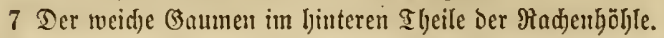

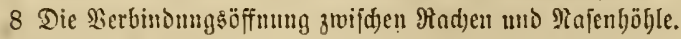

9 Ein Den Eingang Der Dhrtrompete bebecfender Rnorpel.

10 2ie Speijerölyce.

11 Der Ringfnorpel Desీ Reblfopjä; unten mo binten ijt er mit Dem Edjildfnorpel verbutioen.

12 Ein bon Der Radenjdyleimbaut bededter Minftel.

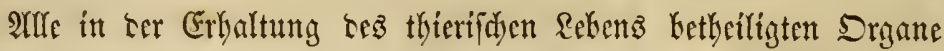

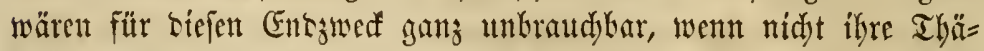
tigfeit surd) cine benegente $\mathcal{R}$ raft angeregt uno georenet würte. Eine foldye atregente tuto orontente Rraft fdut ter gütige Edjöpfer

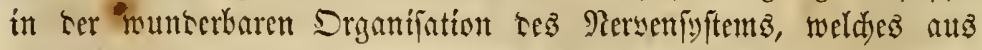

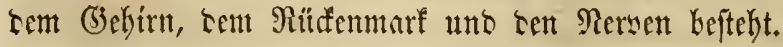

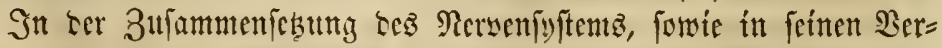

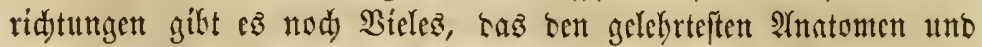
\$Shyfiologen sunfel ift. Jesod) tann ter aufmerfjame Eejer cinen fehr guten Begriff son tem Nersenfyttem surd) folgente Befdreibung 
erhalten, wenn er bie Figur auf Seite 49 jur bejieren Seranjdan=

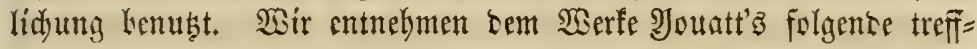
lidje Befdurcitung:

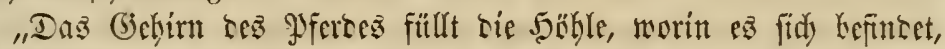

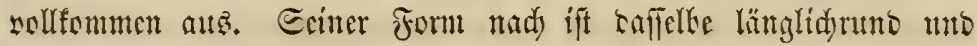

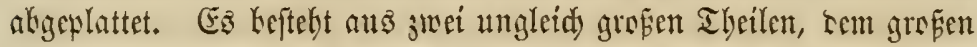
Gechint (cerebrum, fiche $m$ in ter Figur) utto sem fleinen Giekitn

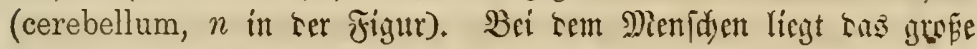

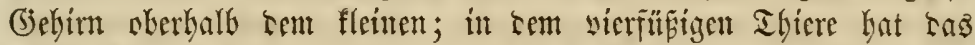

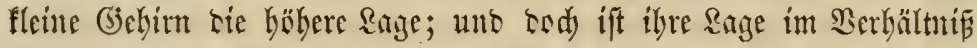

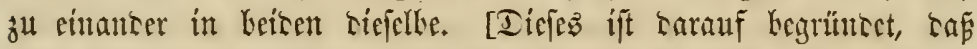

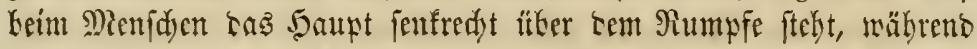

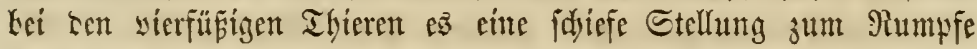
cimnimmt.]

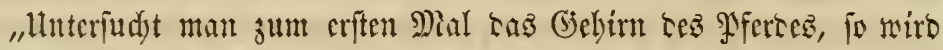

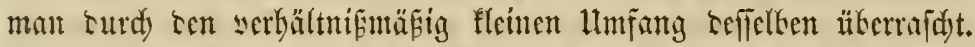

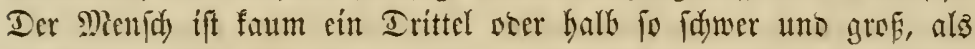

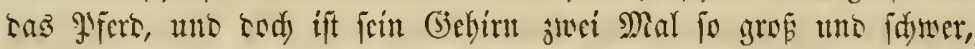

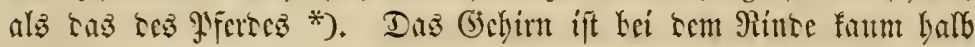

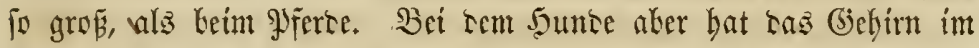

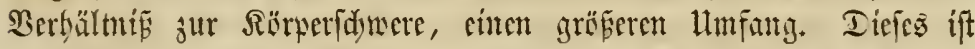

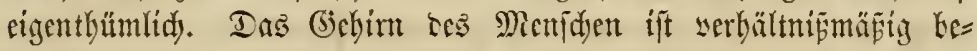

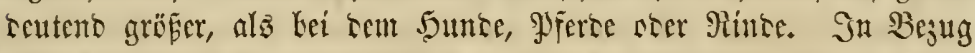

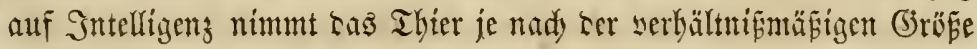

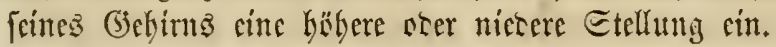

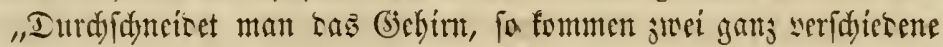

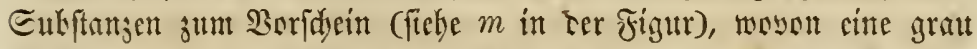

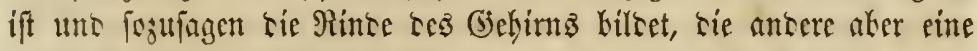
weipe farte bat und ten imeren son ter grauen Eubjtans um=

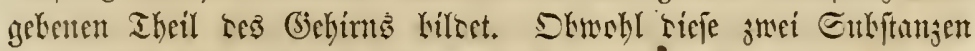
ancinanter liegen, fo sermilityen fie fid nidjt miteinanter, fontern Gleiken getrent in ifrer Rage, forwie fie in ifrer Etruftur und Ser= ridftungen wont cinatter wejentlidy werfadicsen finto.

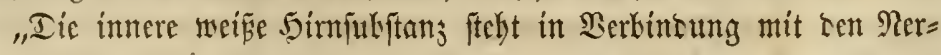

*) Diejes ift eine jebr fonberbare Angabe für einen to forgfältigen Alutor. Da\$ Be.

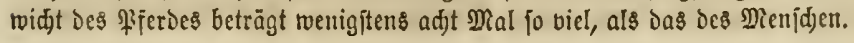




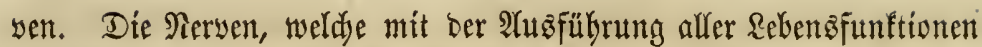
beauffï angejeben werben. Soon ben Rerwen bängen alle Bewegungen ber

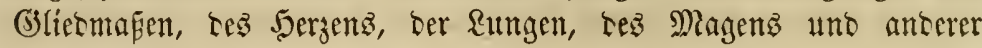
Drgame ab. Durd) biefelben werben äunere Einbrüffe Lem (belyirne mitgetbeill; felbjt ber (beift erbält sutud) fie bie Materialien, weldye er ju biebanfen werarbeitet.

-Die grate Simfubftants hat nidt mut eitte anbere Farbe, fonbern aud) einte gant antere Bejedaffentyeit. Miand ba ben angenommen,

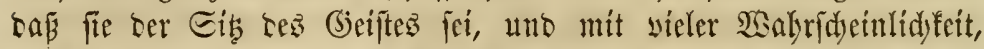
weil fie bie auf tie Sinnesorgane gemadyten unt bem (Behirm Sutd

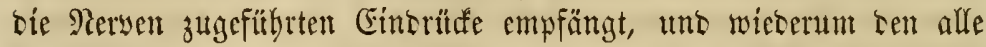

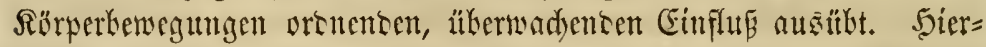
mit überctnjtimment, wiro höbere Sntelligenj in Berbintung mit eíner

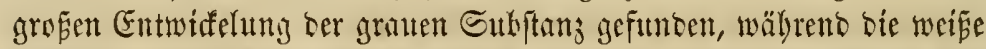

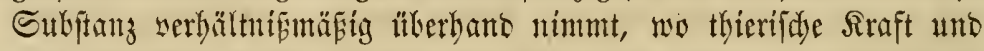
ftarfe fimnlidye Irtehe herwortreten. Bei Lem \$yerse finset man wer=

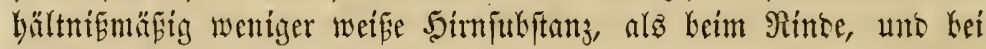
bem Şunte weníger, alz kei tem Syjerbe.

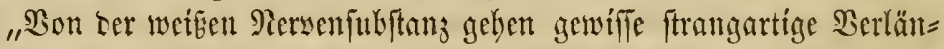
gerungen aแล, bie man Rersen nemnt. Diefe fint bie Trïger ober

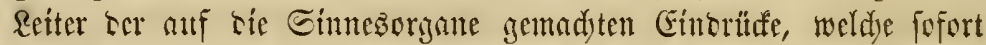

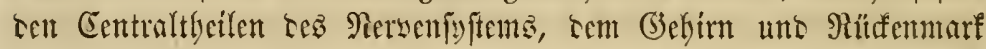

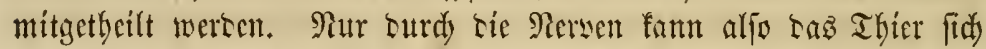
mit ben umgebenten Begenftänten befant madyen uno sie Freure

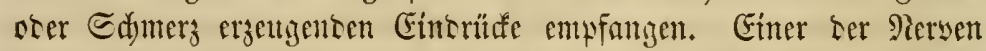

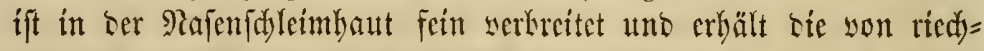
baren Rörpern gemtaden Gintrütfe, er rícdyt; ein anterer ift im

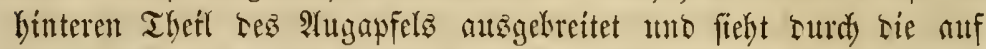

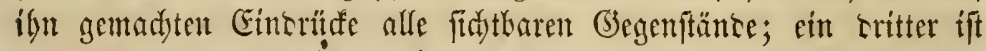
bem Gebörorgane mitgetheilt, wo er bie Eintrüfe bürbater Töne empfüngt unt sem (bebinne juffübrt. ITnere Rersen theilen fid ten

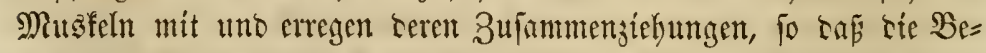

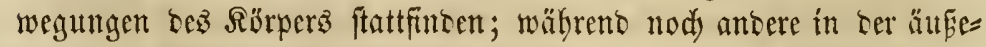

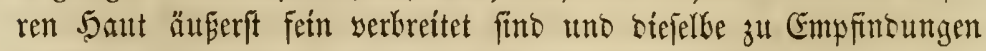
befäbigt.

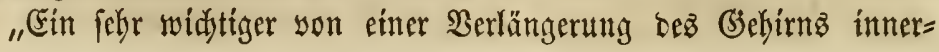


Galb ter Edyäbelfoble entipringenter Ners theilt fid tem Edylunt= uno Reblfopfe, ber \&uft= uno Epeiferibue, bejonters ater ten Rungen, tem 5ersen utto semt Mlagen mit utto wirb Laber audj Rungen=

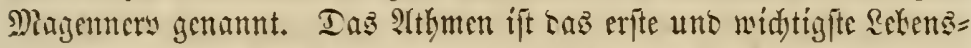

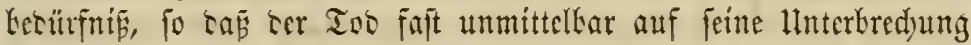

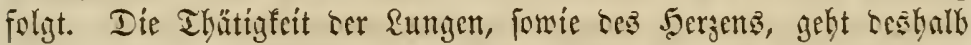

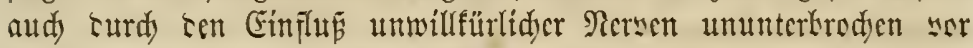

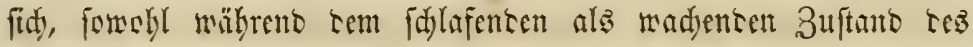
Thieres.

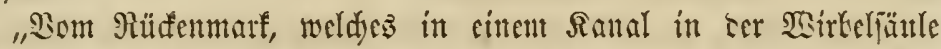

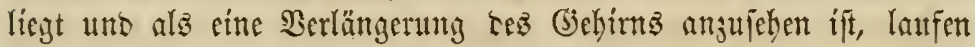

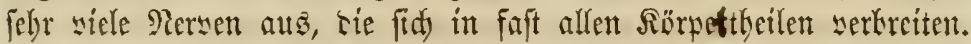

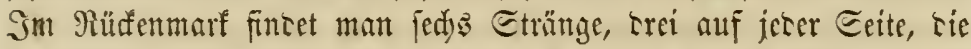
eng miteinanter verbunten, aker surd) sie jut heisen Eciten feidyt, aber sken uno unten tief cintringenten Einfduttitte ju unteridjeiren fint. Iie zmei okeren Etränge fint mit tenjenigen Ihcilen tes

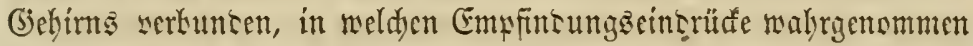
werten. Son biejen Etrïngen entipringen zul keiten Eeiten jabl= reidje Siersenfajern, tíc fid miteinnter serbinten, surd) eine fleine

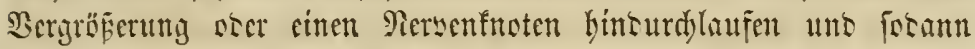

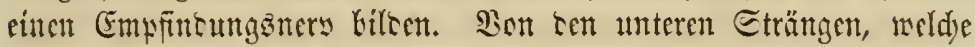

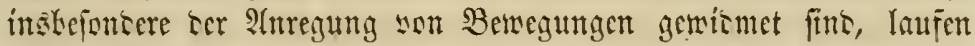

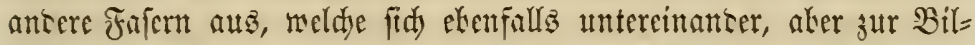

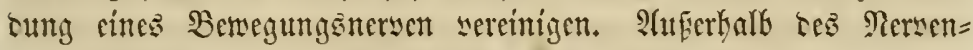
enoten vercinigen fid siefe jwei Mersenturtrelyt ju cinem gemeinfamen Nerscnftamm, ser Giernad) beitez, Entfintungs: unt Bemegungez= nersen, enthalten muß; ; fie fino jmar unter einter Sülle miteinanter sertunten, aber senmod) getremnt, ta jeter Piery son ciner eigenen fernigen Edjeise umgeten ift, unt feine bejontern Funftionen ser= ridytet.

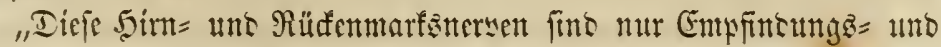

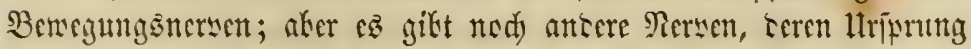
auEerbalb ธẹn Centralorganen, โem Bichirn unb Rüdenmarf liegt. Dicie tilem tas 'Eympathifde Rersenfyitem,' meldes fo genannt wurte, weil es ten Eympathien su Grunte liegen follte. Cie ent=

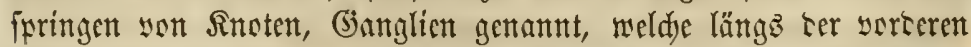
Jläd)e ter Wirthelfäule herablaufen. Sie theilen fid tem Serzen mit, 
uno Defīen Thätigfeit geht yor fid); fie serbreiten fid im Magen,

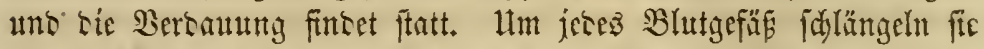

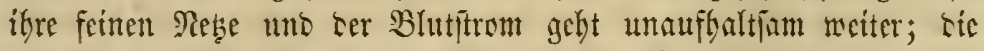

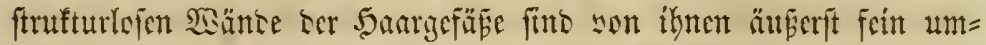

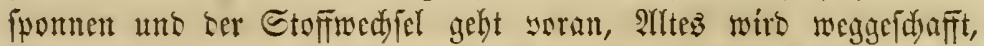

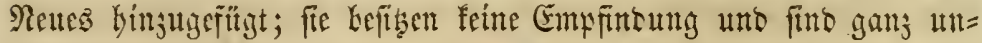
nkGängis stom 然iflent."

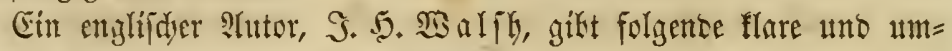
faflette 1teberfidyt toื Mersenjy temts :

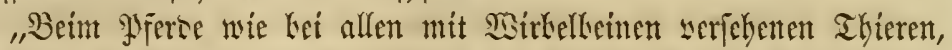

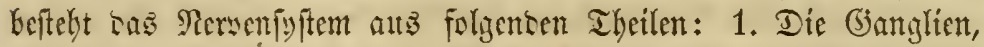

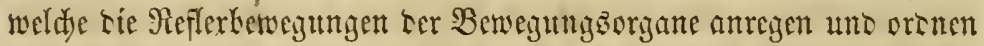

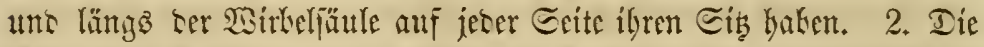

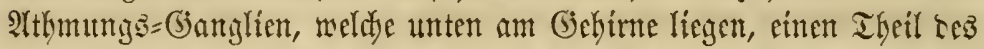

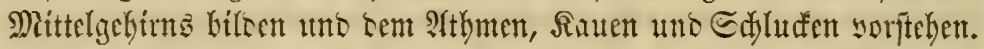

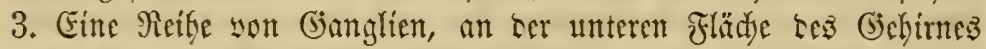

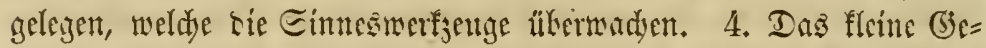

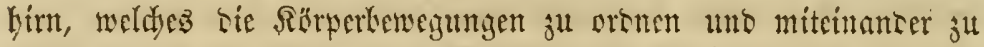

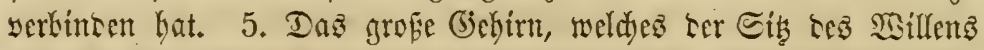

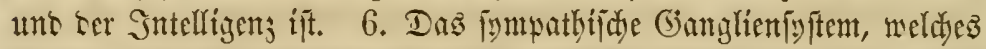

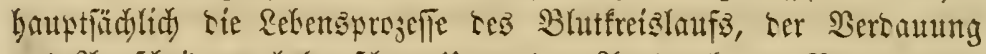

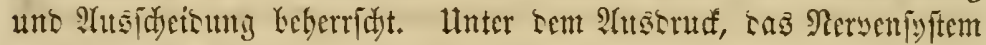

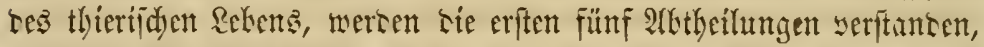

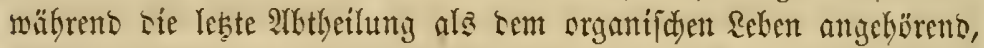
betrad)tet wirs."

Eke wir auf ten nädjten Gergentand ükergeben, wollent wir tie Giebirnbüute Ketractent. CEs fino ihrer trei ükercinanter gelagert,

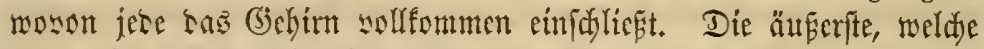
man bie harte Soirnhaut nent, ift fehr ftarf, feft uno jefung;

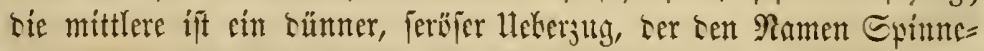

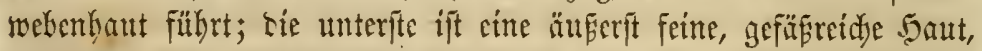

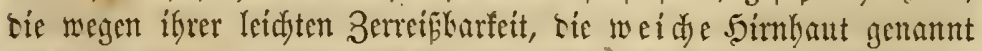

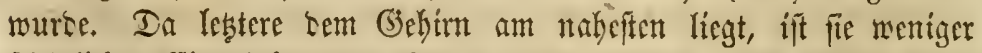

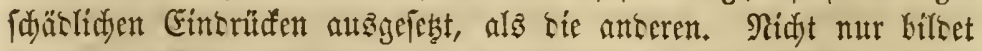

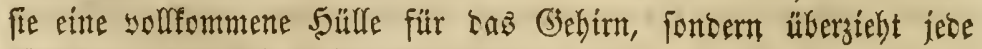
Erbohung und cringt in jece Serticfung hintein. 


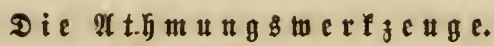

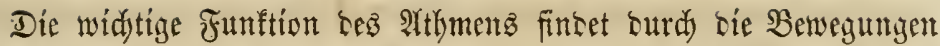

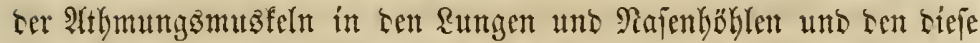
Theile serbinsencen Ruftröbren ftatt ullo fteht unter ber befonteren Aufitdit ter $\mathfrak{2}$ thmunganerven.

Die sungen fint von einer feinen, glatten, feröfen Sautt befleitet, ธaริ B̧ruftfell, weld

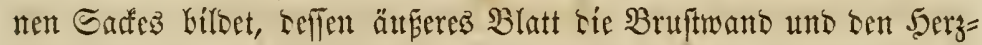
beutel ükerjielyt. Cie baben eine fegelförmige (jeftalt, beftelyen aus

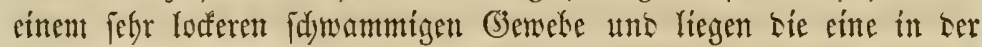
redten uno bie anbere in ber linfen Butuftyalffte. Sie werben buth

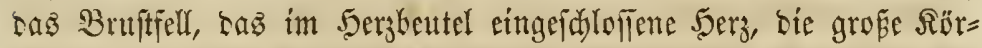
ferpulsoser und bie untere 5oblvene von einanber getrennt. Die

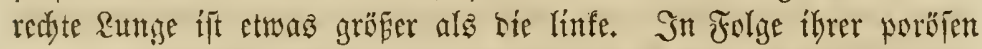

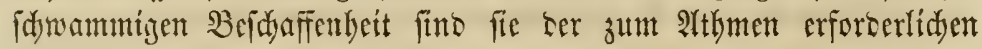

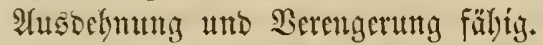

Das Rungengemete bat im gejunren 3uftante eine felor fdjöne, bellrothe Farbe. Es ijt äuferft weid, jart uno fein, jecod) fo ftart

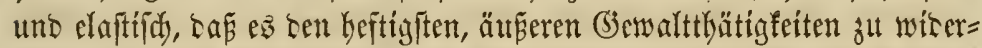
fteben sermag. Itnterjudyt man sas sungengewebe genau, fo fintet

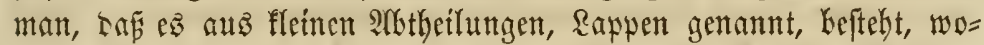
yon jeres yon allen anteren yollfommen akgeidyloflen ift. Iie als Dämpfigfcit ster Reidyen Kefannte Ropfranflyeit (broken wind) wirb Durd) tie Betreifung fer Rappentwänse verurjadyt. Secer Rappen $\mathfrak{c r}=$

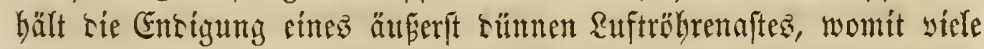
länglid) runse, traukenförmig miteinanser sereinigte Bläs̆den, \&uft= jellen, serbunten fint. Die Ruftallen, seren es beim Menidyen gegen 1800 Millionen gibt, fino mít einer äuterfit bünnen son Den 5aar=

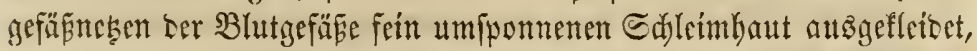
surd) weldye binturch โas $\mathfrak{B l u t , ~ i n t e m ~} \mathfrak{e B}$ in sen 5aargefäpmezen fliefst, ten Eaueritoff ser Ruft cinfangt uno rafür sic som cunfel= rotben Blut auz allen Rörperthcilen in rie \&ungen gefübrte Soblents

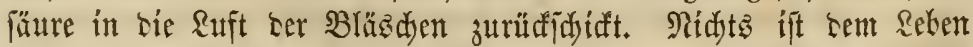

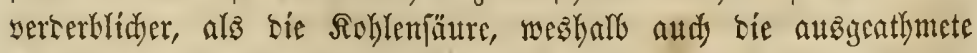
Ruft jo wibrig uno unangentehm ift.

In ben Najenthölen wito hie frijo einzuathmente \&uft gemärmt

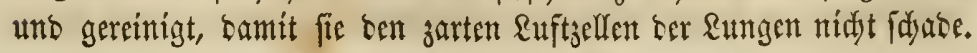


Sft tie \&uft fehr troden, fo mag fie audd. mehr ober meniger freud)-

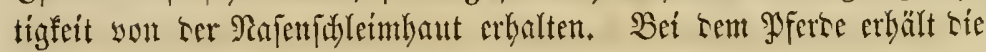

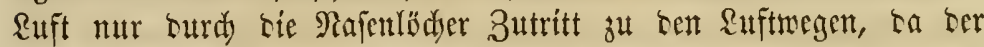

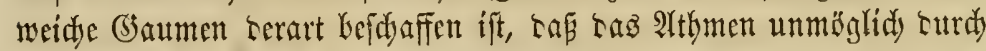
bas Maul ftattininen faum; aker bennod vermag baffelle mit beceu=

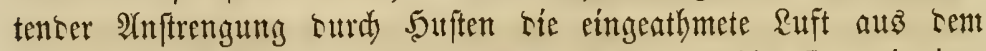

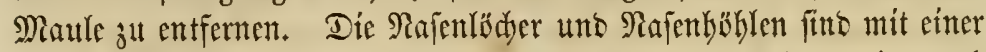

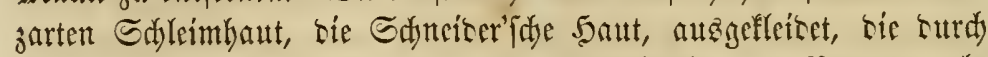

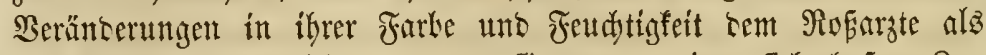

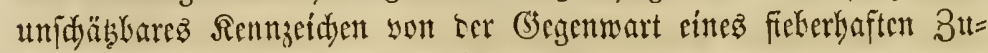
ftanbes uno befien Sierlaufes sient.

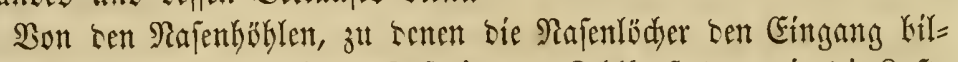
Len, oringt bie cingeatlymete Rufft in Den Reblfopf, Lamu in sie Ruft= röbre uno teren 2 efte, uno entlid) turd sie lesten Berzweigungen

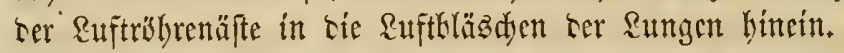

Der Sillffepf bient nidjt nur zut Beförterung ter Ruft, fontern

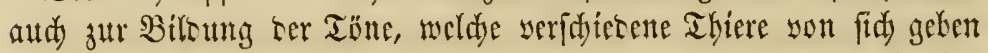

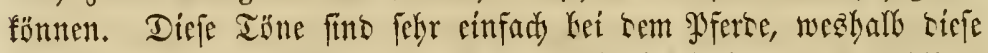

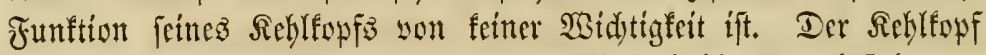

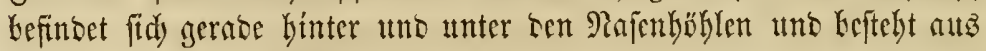
fünf ftarfen burdy Bänter ancinanter gehefteten Rnorpeln. Giner

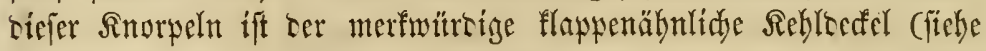
2 Figur 5. 49). Diejer ift io befejtigt, Laf wenn bas Theier fein Futter serfadingt, er fid nady unten uno bínten orängt utto fo tic

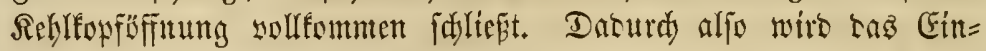

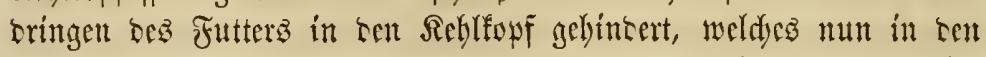

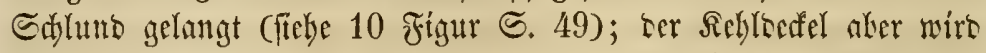

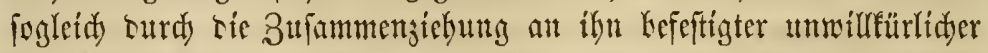

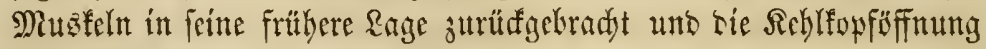
ift wieser frei.

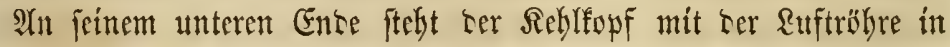

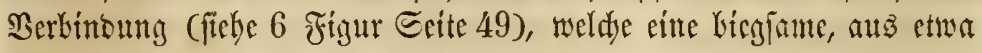

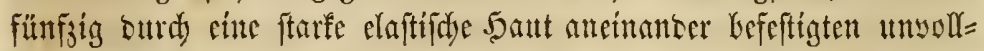

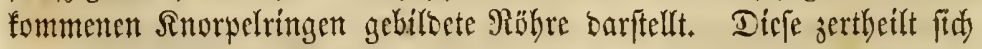

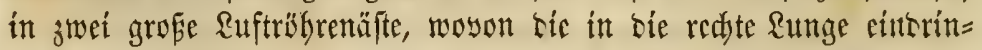

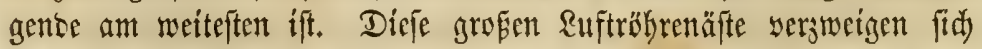
baumförmig zu immer fleineren \&uftröbrenäften, beren leḳten Entó 


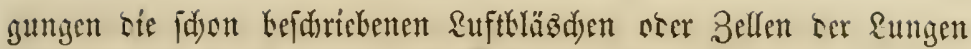
Gilten. Die fid fo serjweigenten Mäbren erlyalten mit jeser weiteren

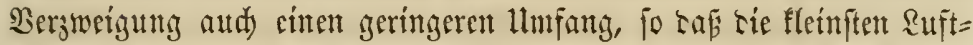

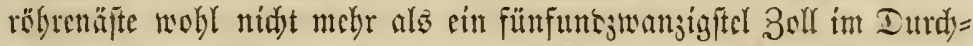
mefïer baben.

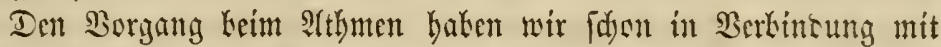

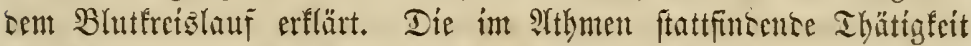

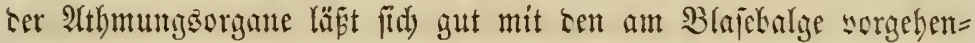

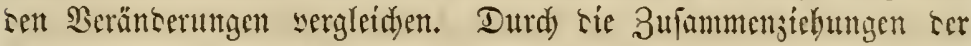

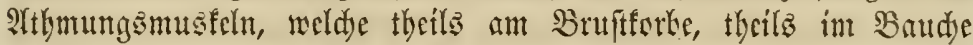

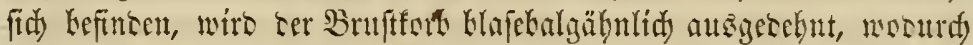

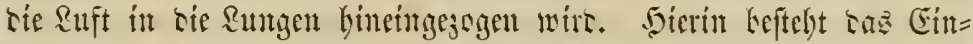

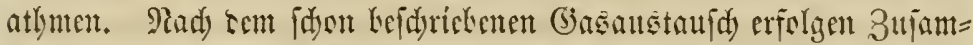

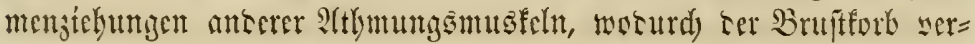
engert tuto sie Rungen zuf

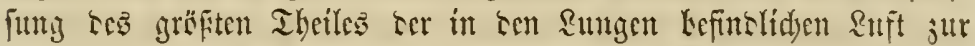

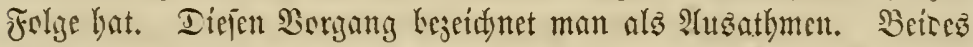

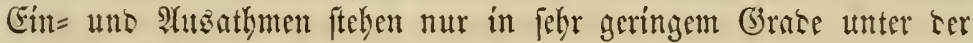
Sisillfür.

\section{Die ธpei西eldrü}

„Itnter Drïfen serfiteht man Siejenigen Srgane, meldje yom $\mathfrak{B}$ (ute eine eigenthümlidge flüfítige Eukjtang abjdetren und surd) cine ent=

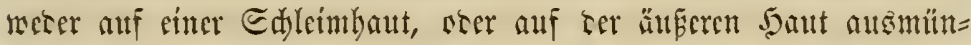

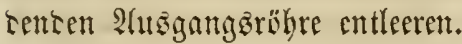

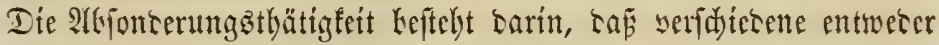

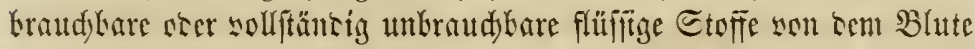
afgejontert merten, uno die surd tie Drüicn fo erbaltenten Flüffig =

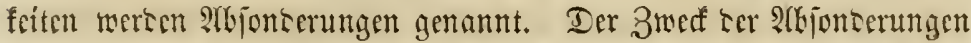
ifte cin Soppelter: erftettz merten fie ju irgeno einer anteren Thätig=

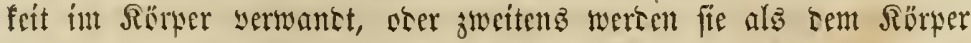

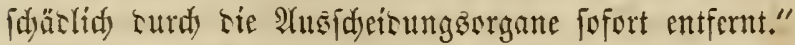

Man unteridectest aud) siefe Funftion je nad) tem einten ster antern siejer 3weffe. Co wiro sie Funftion, wenn nod) Krautdikare Stoffe abgeiontert werten, $\mathfrak{A}$ b fonderung (secretion) genamnt; fönnen aber tie abgeidjiesenen Euteftanjent nidjt mehr innerbalb tes

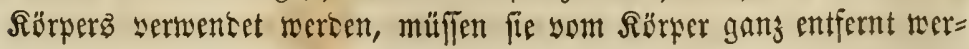




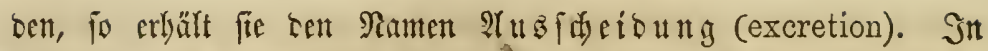

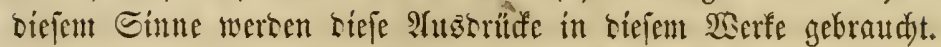

- Sn ter Radjen= veer Maulbable teg Pfertes gibt es eine Menge

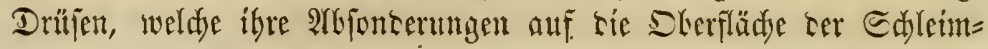
haut als Speidyel entleeren. SWwobl sie Dunntitüt siefer grlinfifigfét

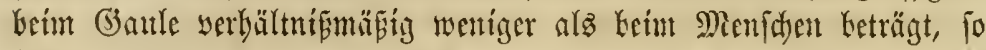
ift ifre Menge, bie auf niaft meniger als 4 bis 5 Gallonen in 24 Stumben foumt, bod auferorsentlidy grof. Der Epcidjel sient Gaupt=

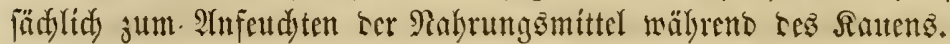

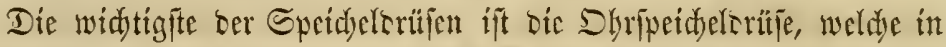

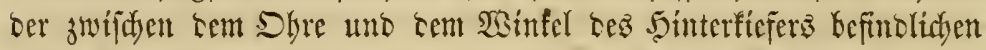
Bertiefung liegt. Cie kefteht atts vielen fleinen âbtheilungen orer

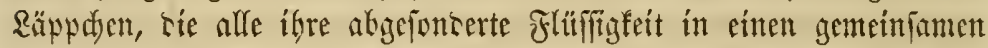

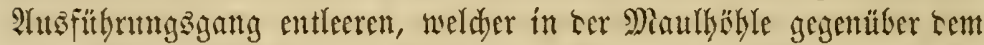

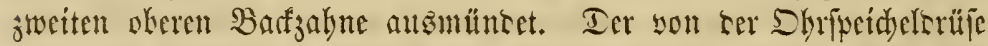
allein argefonterte Speidfel wiro auf nidht weniger als cin \$oint jere Stunte uno wälreno ter Berfautung tes Futters auf Loppelt fo viel

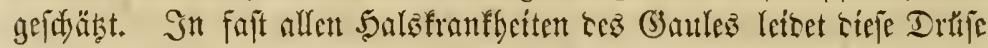

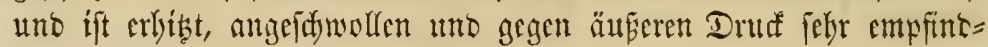

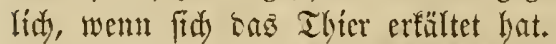

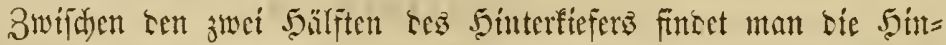

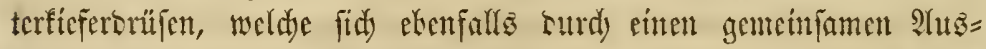

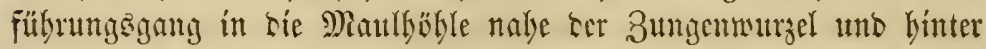

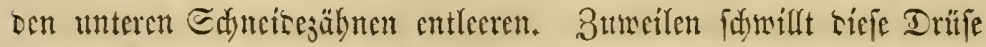

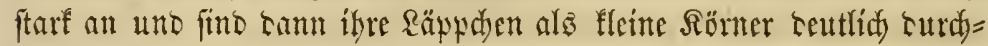
zufüblen.

Bon ten betcutenten Epcidyeftrüfen ift tic Zungenfpeidyelorüfe tie

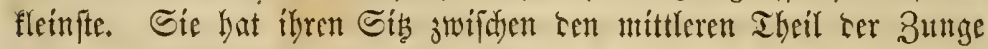
uno ser Ecitemfläd) tes Sinterficfers uno mäntet sutrd mebrete

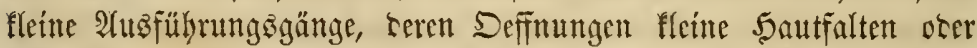

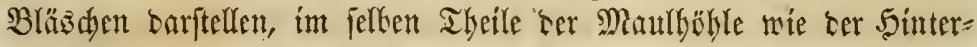

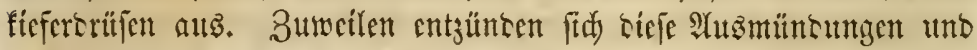

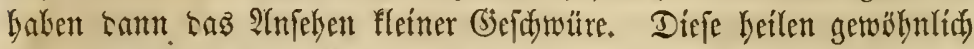

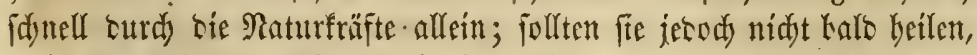

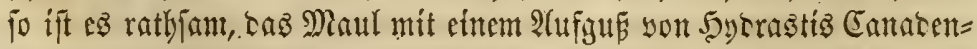

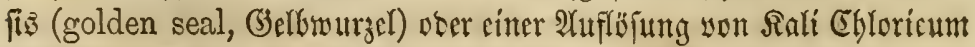

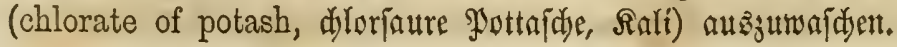




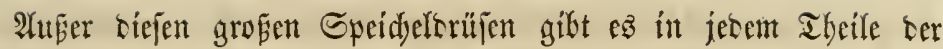
Sdjleimbaut ter Radjentg̈ble, fowie ter Rippen, SWangen tho Bunge wiele fleine Drüjen, Seren âbjonterungen einen beftanttheil bes Epci= d)

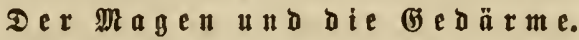

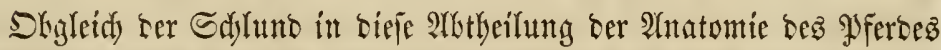

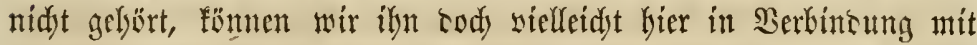

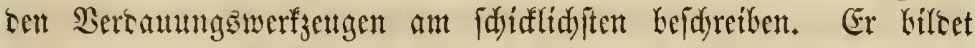

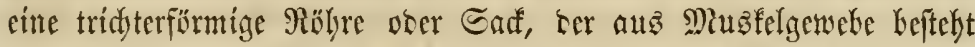
uno mit einer Edjleimthaut übersogen ift, welde ter bie Maul= unto

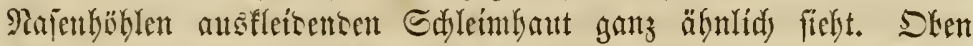
ift er mit sem Edyluntfopf, meldyer mit Iem binterften Theil ber

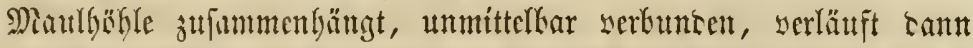

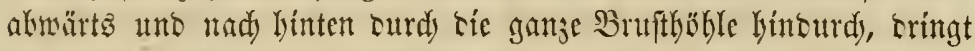
surd) cine Definutrg im 3werdfell uno sercinigt fidy mit sem Magen. Im 2̂nfange feines Derlaufez liegt er gerate hinter bem ßeflfopf, nimmt aber weiter anten eine ctrwas zutr linfen Seite gewentoete Stel= lung jutr Ruftröhre ein.

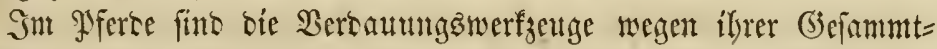

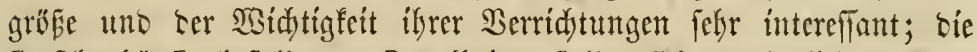

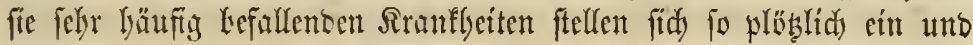

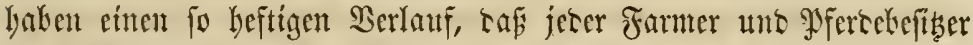
einen ridtigen Begriff ihrer Struftur uno Funftionen fid antzleignen

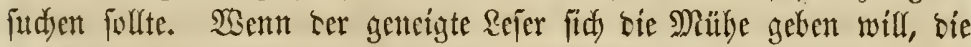

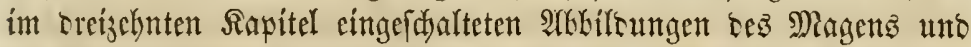

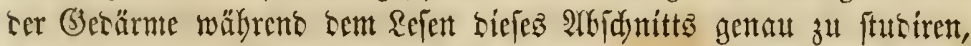
fo wirt er leidyt bie folgente Beidreibung verfteflen uno feinem (bse $=$

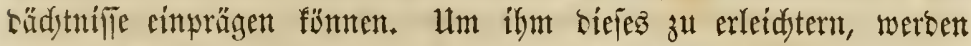

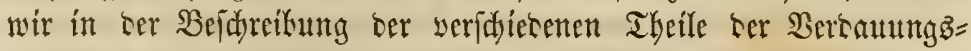
organe auf bie ketreffenten Stelfen tor Figuren bínweifen.

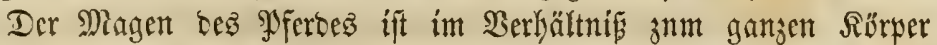

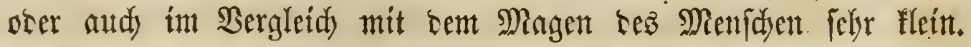
(Er vermag sutdjidnittlid) brei (ballonen jut faffert; währeno im Ma=

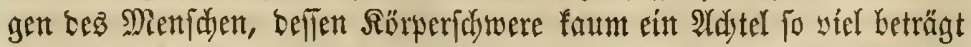

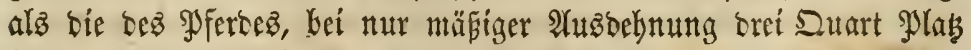
baben. Da aber bie pflandliden Stoffe, welde bemt Roffe zur $\mathfrak{R a b}=$ 


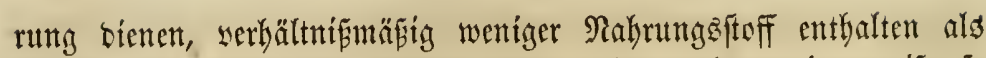

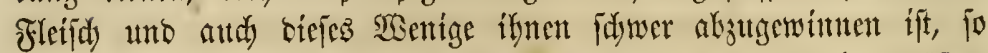
mtte ber Berbauungşapparat bes Thieres länger feyn und cine gröfere

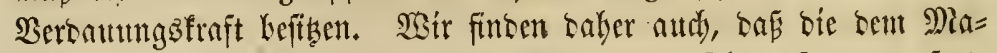

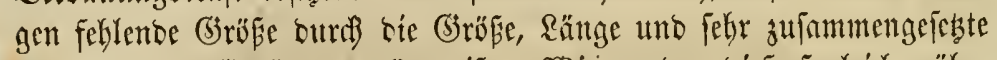
Struftur ber (sebärme ergänłt ift. Wirr werben bieje fogleidy näber bejdureiben.

Sn einer oberflädylidyen Betrndytung bes Mragens fiebt man zwet Deffnungen uno zwei factartige Erweiterungen. Die obere Deffnumg ftebt mit bem Edylutise ober ber Futterribre in Betbinbung. Man nennt fie ben Magenmuno; in ber bezüglidyen Figur ift fie surdy $b$ bezeddyet. Yjoutat befdreibt Den Magenmuno ober bie Fimmünoung tes Sdylunbes wie folgt: "Wo bie Futterröbre in ten Magen itber= gebt, bat fie cine etmas getrogene Nitytutng. Sic verläuft idjräg

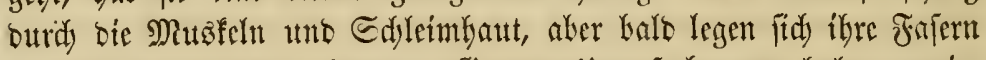
um ben Magenmunb Gertm. Genaue Interjudutngen baben erwie=

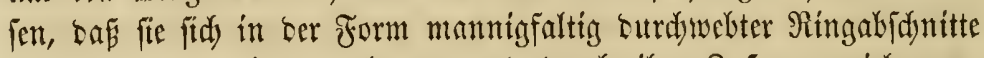
um ben Magencingang lagern tno burdy ilyre 3ufanmenzielyungen

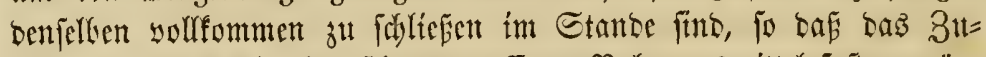

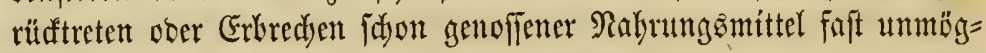
(id) iff."

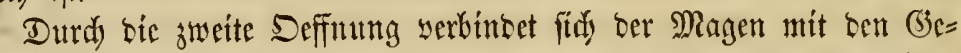
bärmet. Man nennt fie Ien Mförtner Lez Magent. Sn ber Figur ift fie ctiwas unwollfommen rargeftell, fiche $f$. Folgente Befdurci=

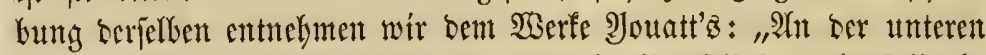
Magenoffnuttg ober Lem Pförtner fino sie Musfelfaiern ebenfallz in

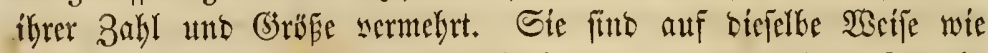
an Miagenmumbe angeoronet unt ftarf gentig, bem Druta bes 3werdy= felfs zu wiberfteken und ben Mageninbalt fo lange in bem Magen ơ balten, bís berielbe ơur weiteren Befürbertung burd) ben Berbau=

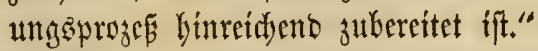

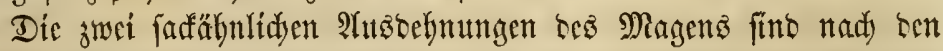
Magenöfnumgen benannt worben. Dieje 3ertbeilung bes Magent

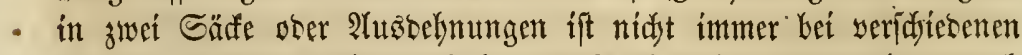

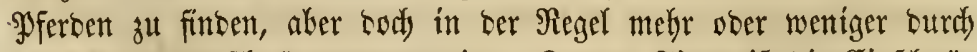

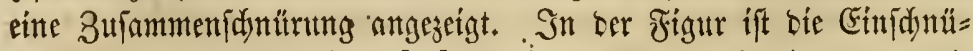
rung vei oen Bathjtaben $d d$ ourd) cine ounfelfdattirte, unregel= 


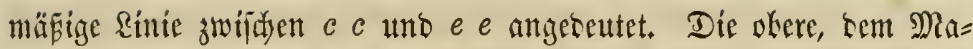
genmuno am nabeften gelegene A(uscebnung ijt eigentlid nur ein

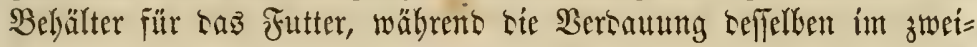
ten Gadfe won Etatten gcht.

Sn ben Magenwantungen fintet man trei Şattlagen. Die äunerite

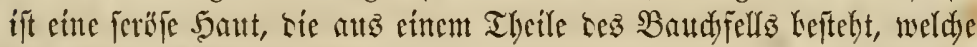

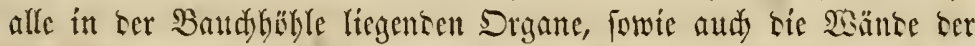

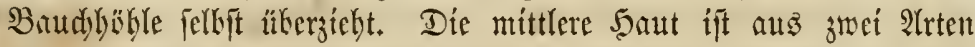

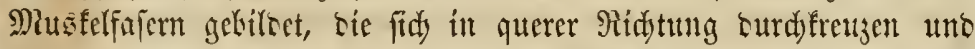

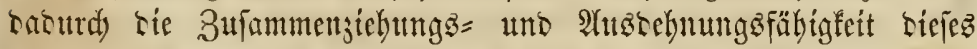

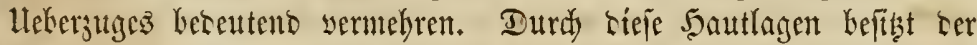
Mingen tie fdumingenden, wellenfötmigen Bewegungen, wosuth tor

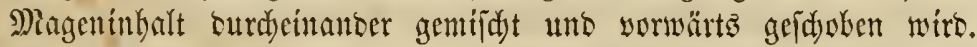

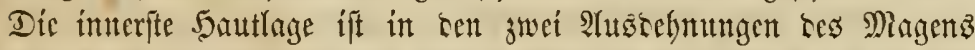
etwas serfidecen. Sn Ier vferen Erweiterung bat fite mebr ober weniger bie Bejdaffenheit ber Sornbaut unt wiro bie unempfint= lidye Sautlage genannt (ficbe $c$ c in fer Figur); wäbrent fie im unteren Gafe als tie fammetartige Saut ober Sdylembaut befannt ift (fieke $e e$ in ter Figur).

Der Gornbautabnlidye ofer unempfinclidye teberzug ift eine Fort=

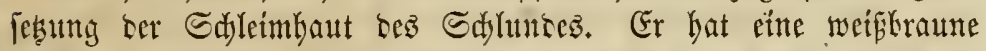

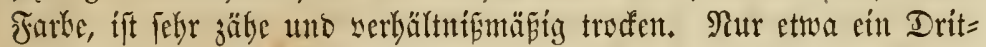
tel Ics Flïd)enraums bes Magens wiro son ithm beceft. Eein

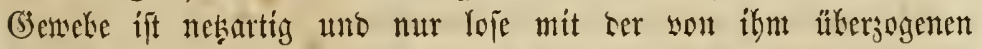
Miteffelecfe vertunen, wowon er fid) nad) bem Toce äuperit leid)t trennen läft. Er bat, nadjocm er gerwajdyen und gereinigt woroen

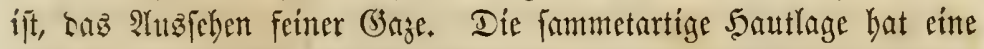
roth(traune, mit belleren Edattirungen strd)zogene Farbe und befist cin auterorentlid zartes, leidyt jerreiplidyes (sewebe. Sie bat nur

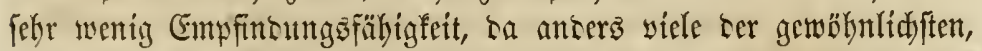
als Jutter gefrefienen Sukftauzen wäbreno ber Serbautng wobt

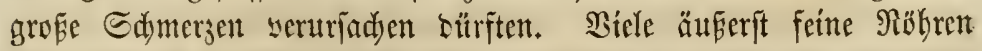

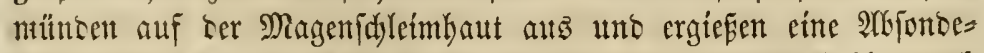
rung cigentbümlidyer 2 rt, weldye bie fowon in fer Maulfoble surdj sen Epcidyel kegonnente Erweidung feg Futters fortjeb̧t. Dicfe Flüf= figfeit, fie cincn fauren (Sierud) unb (bejdmad bat, nennt man ben

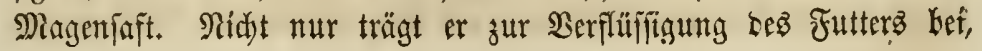




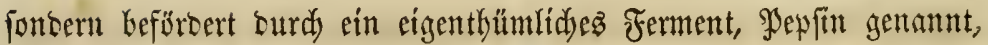
bie Untwantlung tes Mageninfaltes.

Daz genvifene Futter wiro alfo burdy ben Magenfaft verflüfirigt und yerünbert, yerbaut ober in Fintterbrei umwantelt, welder butdy

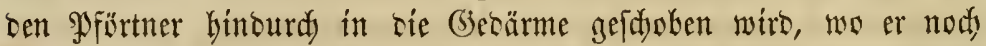

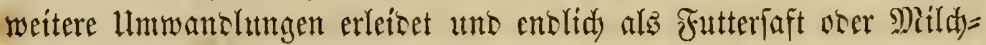

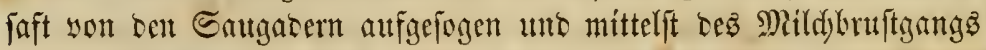
in ben Blutftront gefdafft wirs. Der unvertaulidye, umuafrlyafte Theil bes Futters, ser nidjt won ben Saugaten cingefogen werben fann, wiro surdy bie wurmfürmigen. Bewegungen mit anteren som Bhlte abgeidjicbenten, unbrattd)baren Stoffen weiter gefdobent uno entitid) Lurd) ben Miaftoarm yom Siörper entfernt.

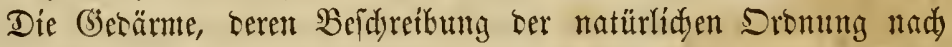

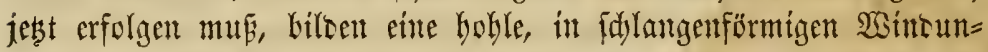

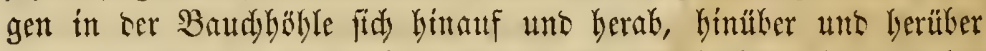

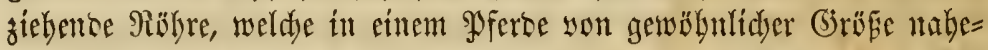

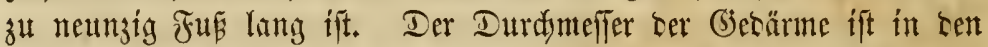
veridjicoenen Theilen Durdjaus nidyt berfelfe. Whie ber Mingen, fo haben audy, bie (3)crïrme brei 5autptlagen in ifrer Etruftur, jebody

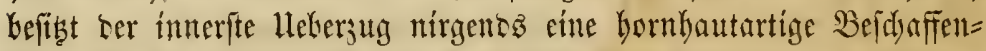

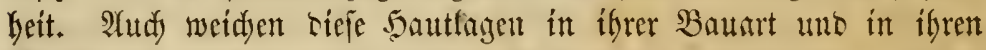
F̧unftionen in ten weridjetenen Theilen tes Darmes you cinan= ber ab.

Die mittlere Sauttlage ober bie Mubferfhaut befteht aus zwei nady

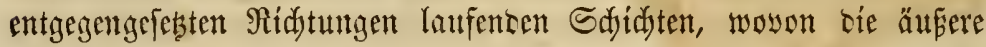
längs tem Darmfanale bintablätft, bie innere aber ringfürntig fid

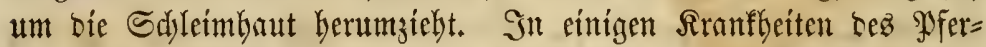

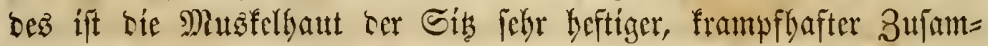
mengiehungen, weldye tie iogenannten Etriftutren verurfad)en. In ber innerftent 5autlange ober ber Edjletmlyaut befinten fid unzählige an Der Dherflädje ausinüutonte Saugabern, weldje bie vertauten, zut Errährung bes Rörpers tauglidyen Stoffe eitrfaugen utto in ben

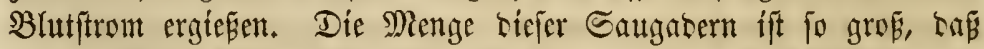
man audy nidyt bie feinfte Nabelfpibe irgentwo in bie Sdjletmbaut einbrüfen fann, obne eine ber Saugabern zu berübren. Llnter ge=

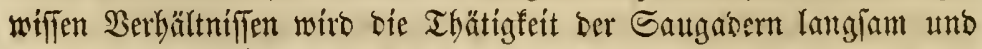
träge, weldes balo ben Sumgertod zur Folge hat, reent burd) bie ge= 
eignete Bebantlung eine Kähere IGätigfeit her Saugadem nidyt ge= wefft werten fantu.

Der Darmfantal beftebt aus nut zwei natürlidjen âththeilungen, Ler Dünndarm uno ber Diafarm. Sebod) wiro jerer teiejer Theile son

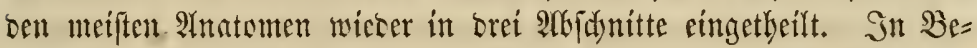

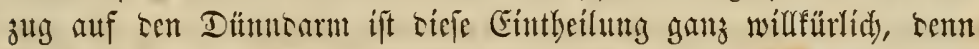

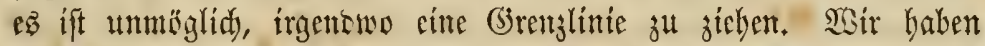

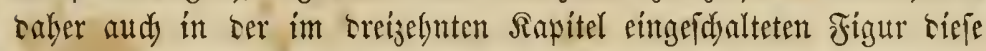

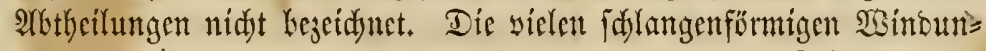

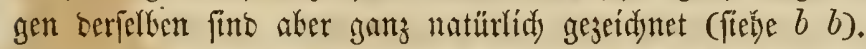

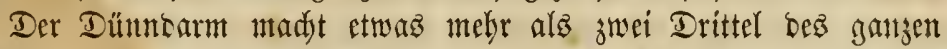

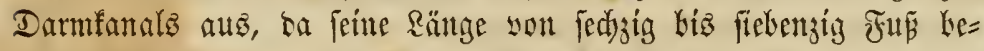
trägt. Er ift jebody fo viel enger alz der Diffoarm, bas or nur ctwa

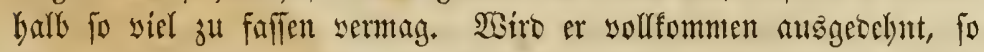

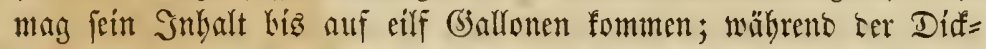

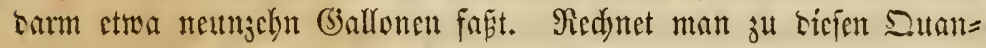
titäten bie trei som Miagen gehaltenen (Jadlonen, fo ift bie Mienge,

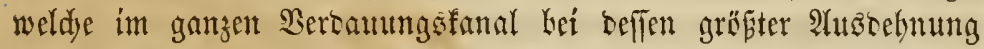

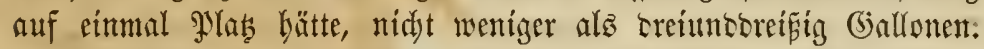

Die brei Ilyeile, in weldye nady ben meiften 2 (natumen ber Düntn= sarm 3uf̈̈llt, werten 3mölfingertarm, Reercarm und Sruntmbarm ge= nanmt. Der Znölffingeroarm wurbe fo genannt, weil er im Menfdjen ungcfăhr tie Ränge son zwölf nebenteintanter gelegten fingent hat.

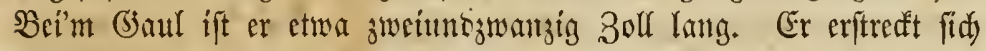

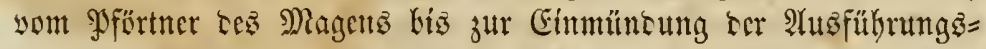

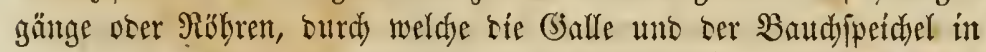
cen Darm gefdafft wercen (Fiebe $a$ in ber Figur).

Der Reertarm erbielt feinen Ramen, weil er nady bem Tobe beş Thieres faft imnter leer gefunten wirb, was wohl yon bem ltmitante abbängt, Dáp ter Darm feinen Snhalt fehr iadnell sotanidiebt. Er ift etwa enger als ber 3 wölffingeroarm, fann fid aber viel freier in ter Baudbäble kewegen alz biefer, weil er nidyt fo feft an bie Baud $=$ wano burd bas Baudffell angeleftet ift.

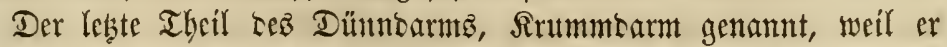

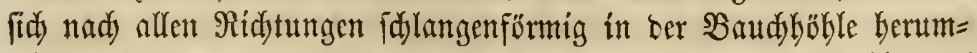

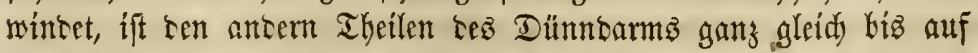
feine Muşfellage, weldje sifer und ftärfer ift. 


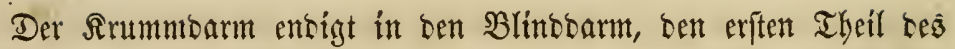

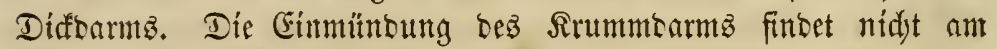
Infunge bes Blinboarmz ftatt, fontern nahe sem Ente teffelten, wie in ter Figur bei $e$, wo ser Blinbsarm ftarf Gersortritt, zll fethen ift.

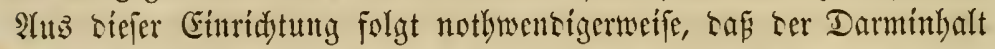

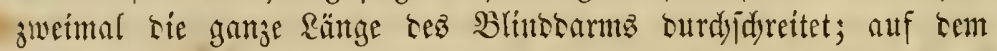

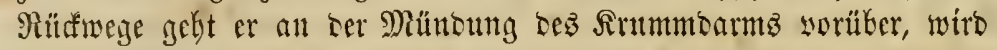
aber surd) eine cigentlyüntlide $\mathfrak{i l a p p e}$ yon bemielben abgejd)

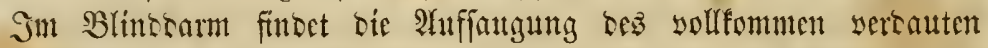

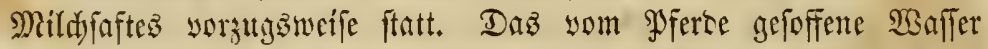
gelangt fofort int biefe Flotheilung bes Darmfanals ohne weiteren 2lufenthalt im Magen und Dïmbarm.

Der Blintearm if mit sem nädjten Theile bes Didformts (fithe

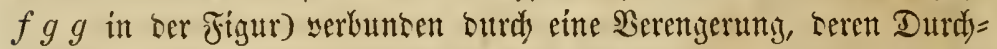
mefjer aber immerlýn nody bebeutender ift, als ber bes Düntroarms.

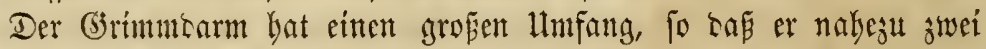

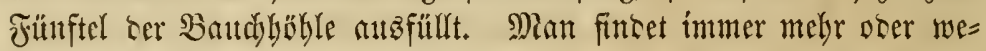

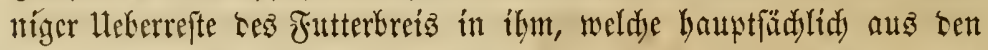
gröberen, unverbaullidyen Bejtanththeilen bes Futters beftelyen. Se meiter ser Darminlyalt voraniefdoben wirs, je mebr verlert er alle flüifiigen uno nabrbaften Stoffe uno gelangt entolid) alz immer feftere

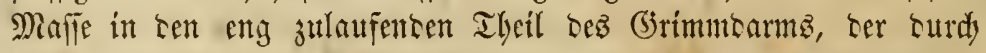
freisförmige in ocn Darm Kineinragente Bänter ber Edyleimbant in Albtheilungen getheilt ift. Sn biejen wiro mun ber fefte Darminthalt in runte Mafien geformt, bie immer weiter uno entridid in sen Maft= Darm gejdyben wersen, son weldyem fie nad) reidylidyer 2 (ntyäufung aโż P̧

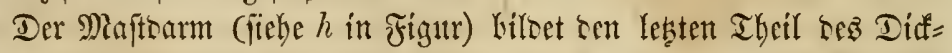

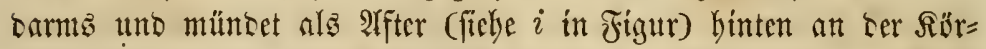

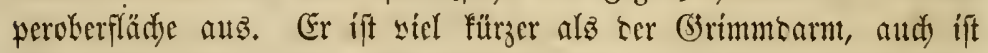
fein $\mathfrak{l n m}$ fang wohl um trei Biertel wentiger. Da feine weitern nabr= baften Etoffe zur 2 lufiangung übrig fint, went bie Futterüherrefte in ben Maftoarm gelangen, fo hat audy feine Edyleimbant feine

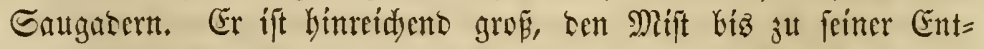

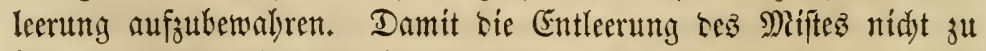
jeber Zeit, je nadjoem er in bet Maftearm gefdoben wirs, sor fid

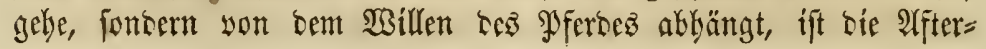




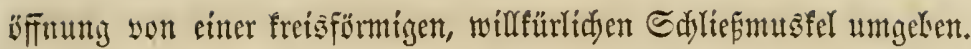

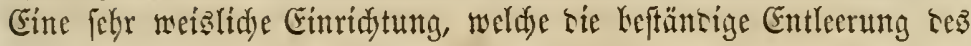
Mijtez verbintert.

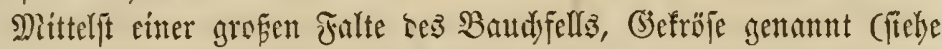
$c$ in ter Figur), wiro ter Dünntarm an sie hintere $\mathfrak{B a n d}$ mand kefeftigt uno in feiner jwar febr kenegliden $\mathfrak{E} a g e$ gehalten. Durdy antere Falten merten tie ütrigen Theile tes Darmftentals in ther ganjent Ränge entweter gans verer theillweife eingejdlotien unt ant bie

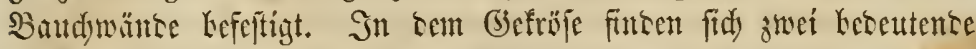

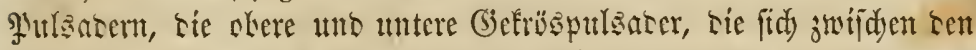
Fatten โeร Bă

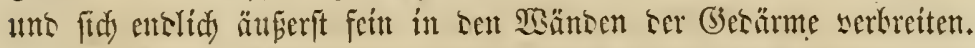

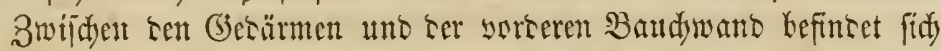

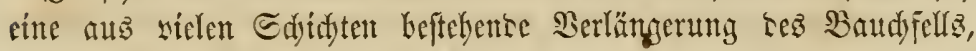

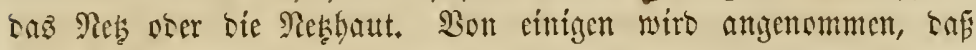

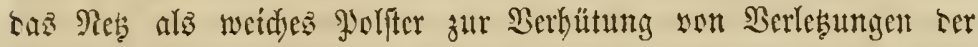
Gescïme siene, weldye jonft surdy heftige Eridjütterungen ver surdy

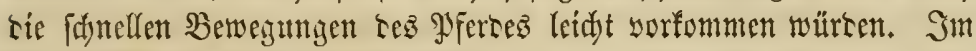

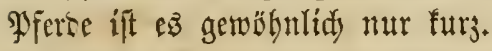

\section{Die Leber.}

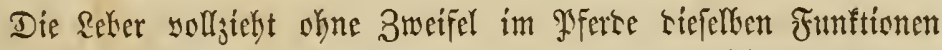

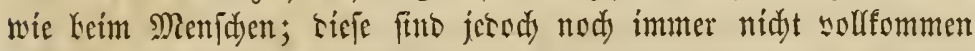

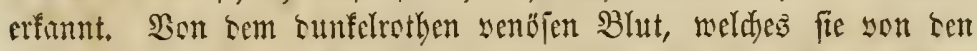

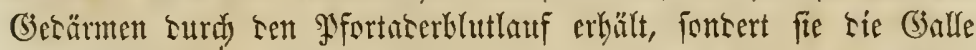
ab, Leren Beftantetheile, wenn fie nidyt surdy Sie Reber ans ter Cir=

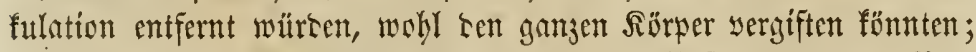

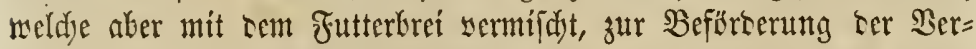

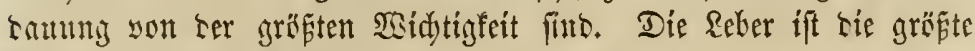
Dritic im ganzen Rörper.

Dic Reker hat ihren Sit hauptiädlidy int Ler redten Seite, wo fie an ser binteren flädye tes 3werdffella liegt. Sie hat eine eigen=

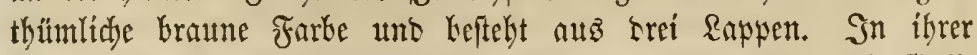

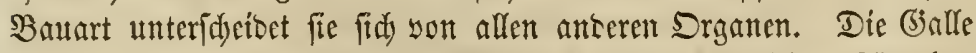

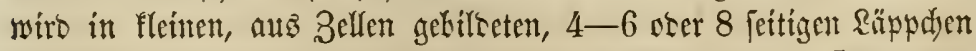
yom Blute abgeiontert. Sdjnetoet man sie Reker auf, fo fintet man

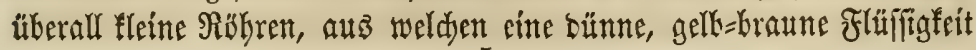


berautsfliefit, weldye sí fogenantte Galle billeet. In ben meiften Ifieren wirb an ter unteren Fläd)e ter Reber eine länglidye Gatlen=

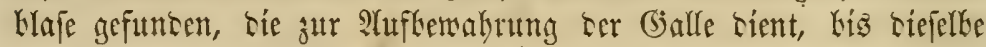
im Berbautungäprojefle nöthig ift; im Yyferte fintet man aber feine

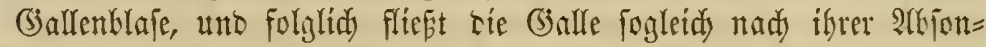

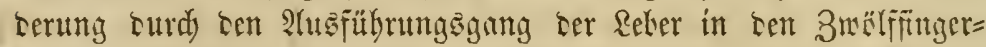
onrm, einige 3oll unterbalb bem Yyförtner (fiethe $a$ in ter Figur)

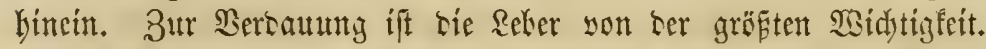

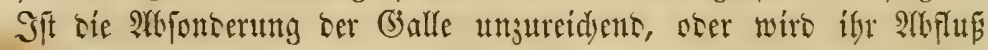
gebintert, fo leitet ter ganje Drganismmu barunter. Färt aber tie (Ballenabjonterung gants auf, fo wirb Las $\mathfrak{B l u t}$ butd bie Beitebal=

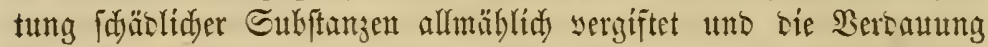

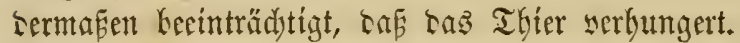

Die Reber wiro Keim. OJerre nidyt fo oft son Rrantheiten Getroffen,

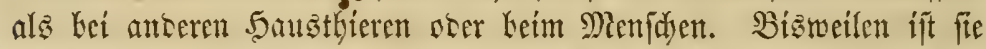

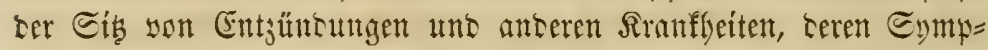
tome nod immer sumfel fims. Sie utte da miro in Folge son હtö=

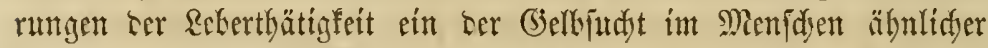

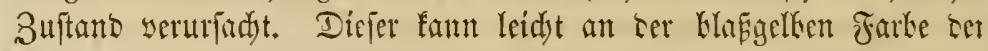
Edhleimbant, weldye Raje, Rippen, Maul uno Bunge überz̧ieht, be=

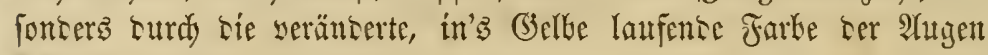
erfannt wercen.

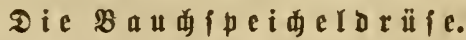

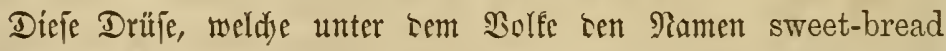
fühtht, Gat ihre Rage zwijdjen sem Magen unto ter linfen Riere. Eie

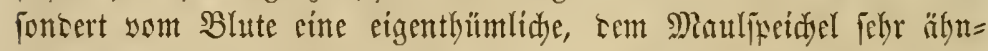

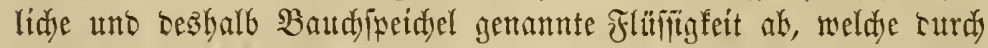

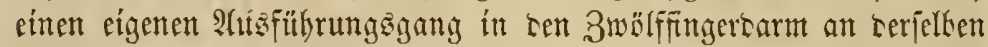
Stelle, wo ber Bjallengang ausimitntet, entleert witr. (Eiche $g$ in

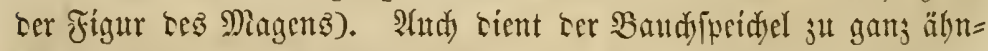
liden 3weften wie tor Mautipeidyel. Sn feinen Beftanstheilen fintet

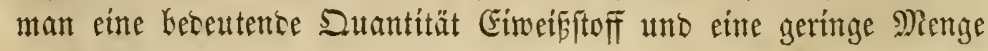
freier Gäıte.

\section{Dic $\mathfrak{M}$ i 3 .}

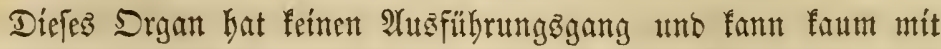
Redyt eine Drïje genannt werben. Sie kefindet fid zwifden hent 
Rippen ter linfen Eeite unt sem Magen, meldyen fie ferye fefit anliegt. Cic ift son länglidyer Form, breit an eintent Ente, am anteren aker

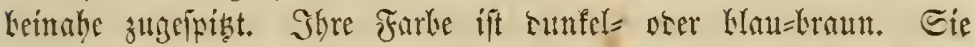

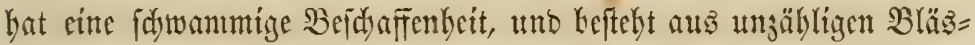

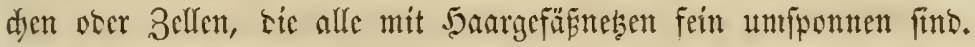

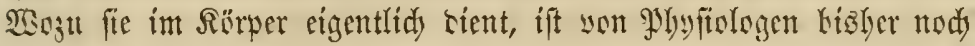

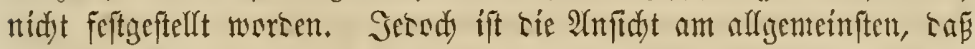

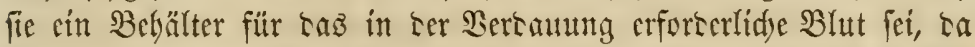
fic audd mit bem Miagen turd) viele Blutgereäpe eng vertunten ift,

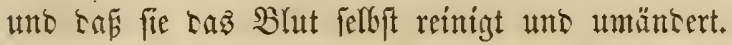

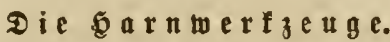

Die 5arntwerf 5arnleitern unt Ler 5arnröbre. Die Rieren fateisen sen Utrin oter

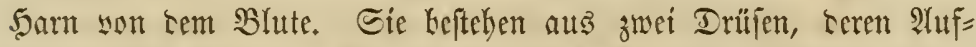

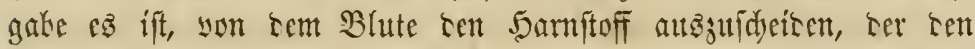

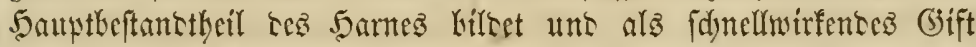
Gald Len Ioo verurfadyt, wenn er nidyt som Blute entfernt wirs.

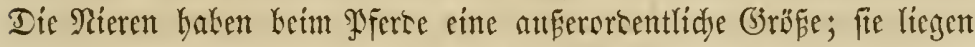
in ter Rentengegent; tie redjte unterbalb ter Reter, afer etwas weiter nady yorne alsె tie linfe, weldje hinter tem Magen liegt. Sn jere

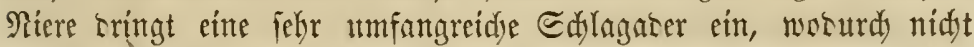
nur sie Nieren Felbft, fontern aud, tie anteren Sarnwerf

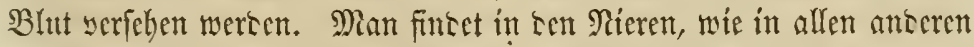

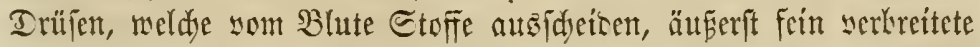

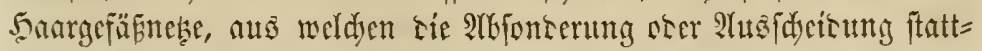

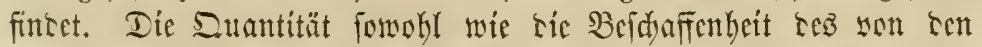

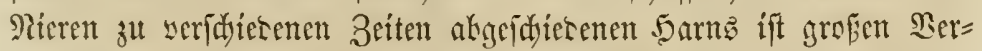
änterungen bei alfen Thieren unterworfen, aber siefleidjt Kcim \$Jferse in cinem nody häheren Grotate ałs kei irgents einem anteren Thiere.

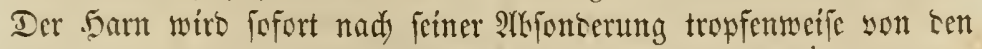
5arnfeitern, moson einer mit jecer Nicre yertunten ift, in sie 5arn= Waje gefdafft.

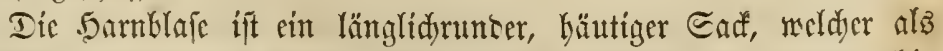
Bchälter โe

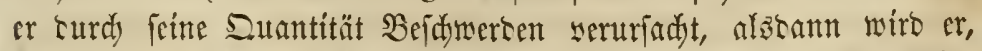

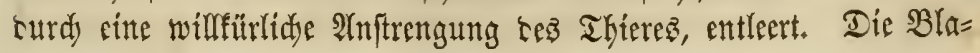


[enwano Gat orei 5autlagen, woyon sie äuberite, weldye oer yom Bauddfell erbaltene feröje llebersug ift, nut etwa rie Sälfte ser äuferen Flüdye cinfüllt. Itnter riefer Rage fintet man tie Mitsfellage, weldye am unteren uno Ginteren Theile Der Blafe sic aud äutere Dberflädye ser Blaje Killeet; fie beftebt atto zmeierlei fid freuzenten Fajem. Der intere Ueberzug ser Sarnblaje ift eine Shleimbaut, weldye aud bie innere $\mathfrak{B a n b}$ ber Sarnleiter ausfletset und fer alle Soblorgane aubi=

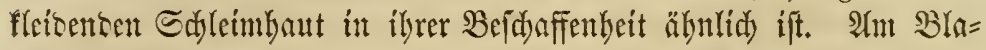

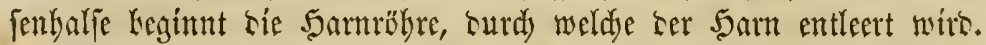

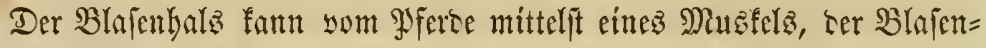

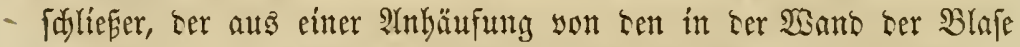
serlaufenoen Muğfelfajern bejteft, fo feft geidloffen wersen, saf aud fein Tropfen ltrin unwillfülidy entweidyen fann.

Die Sarnwerfiettge wersen Ieidyt son gewij̄en Iranfleiten befallen,

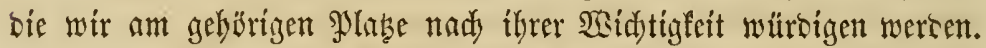
Siermit haben wir sem Rörperbau bes Pferses fo viel $\mathfrak{A}$ thmerf= famteit gefdyenft, alz unjer Raum erlaukt, unt aud wobl fo viel, •

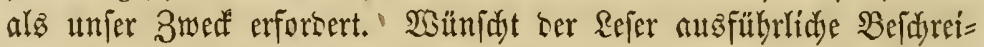
bungen zum weiteren Stubium, fo fant cr foldye in folgenten wiffen= fdaftlidyen uno wertboulden Sierfen finoen: Percisal's "Anatomy of the Horse" uno "The Horse in the Stable and the Field," yon 3. 5. $\mathfrak{Z} \mathfrak{a l} \mathfrak{i} \mathfrak{h}$, (Stone-henge). 


\section{Drittes sapitel.}

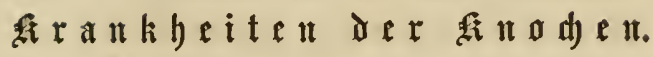

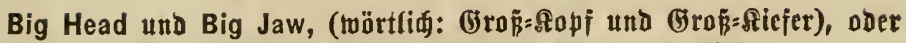
Beingeidmulit, Beingemä円s aut Sapf ober Sicfer.

Dicje Siranflect hat eine eigen= thümlidye (J)eichidte; fie ift aus

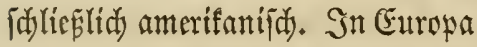
fàteint fie gänjlid unbetannt at fein. Eninglifade und fransöfitide

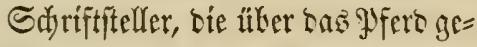
fadrieben baben, erwäbnen fic nidgt; eine Tlyatiadye, weldye zeigt, Dá fite ihnen, fowohl alz sen artent

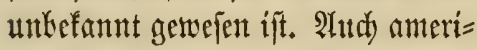
fanifde Sdyreiber Gaben ifr wentg Ittfmerffamfeit geidentt, wahts (ideinlidi weil fie wentig mit ser $\mathfrak{N} a=$ tur, nod) mit her Bebandlungs= weife ter Srantfyeit Gefamt waren. Sie herrifte meiftens im Micifififppi= thal, in ben Staaten Iennefiee, Irfanias, Mifififitppi, Rouifiana uno ITahama. Se weiter man fid son siejem mäd)tigen frlus ent= fernt, seito melor nimmt bie Rrant= beit $\mathfrak{a b}$; rod) tritt fie in cinjelnent

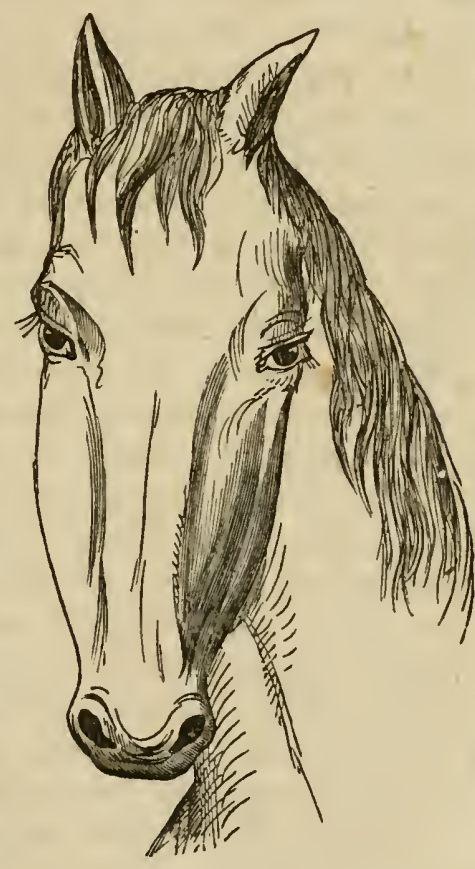

faig Fead. Frallen in allen Theilen tes Rankes auf. 3erftörento berridyt fie im

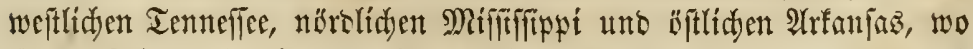

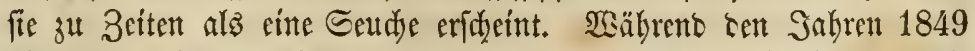
bis 1858 reifite ber $\mathfrak{2}$ utor burd) jente (Jegenten, unt mit biejer Sirant= 
Keit genau befantnt zau werben, uno wenn möglich, ifgre thrjadje uno

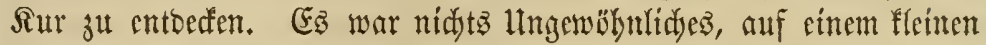
Rantgut von cincm biz fünf Mfersen und Maulejel ju finten, bie mít igr Kebaftet waren, währent auf grofien Rantgütern yon zwölf

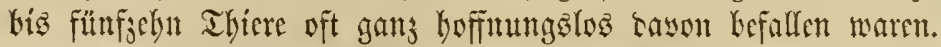

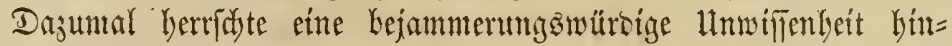

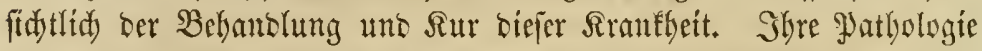
wurse won Niemanoen yerftanten. Einitge \$ferceärste battent ibre

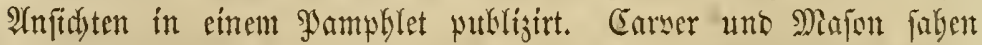
fie als unbeifbar an; tod werfdyrieb ein jeber ein Syeilmittel, weldyes fith) aber alz gant und gar untanglidi criviez.

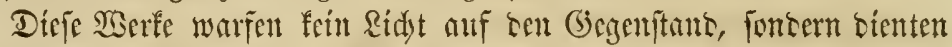
vielmehr baju, benfellen in Finfternis zu verbülten uno cine ridjtige

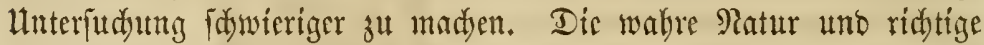

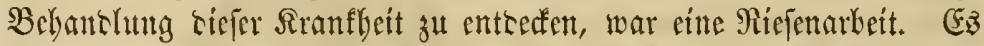

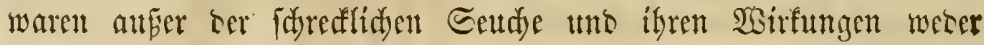

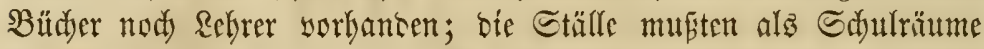

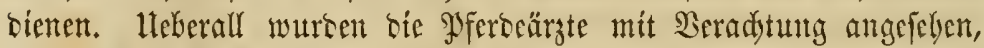

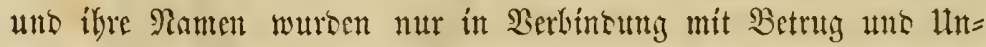

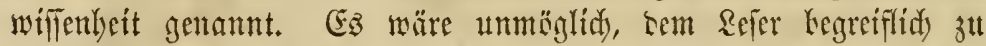

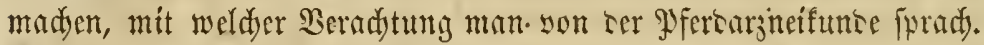

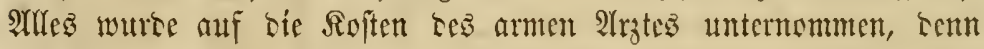

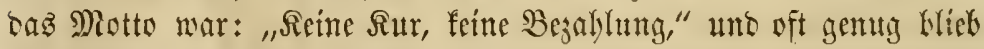

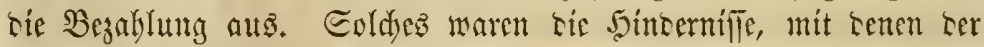

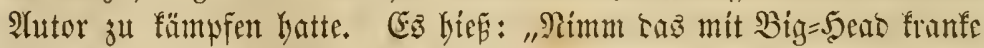
Pfert, probire seine Sumft an bemreflen; famrit bu biejes furiren,

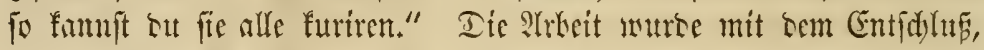

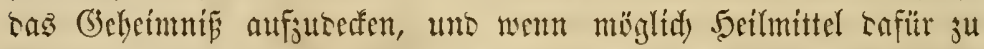
finten, unternontmen; sof biefes ju Etantse fant, ift nutnmebr That= fadje unt Taujerte in Süren fönnen sieg Kesettgen.

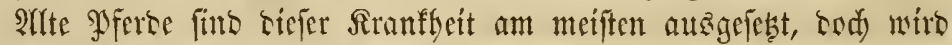

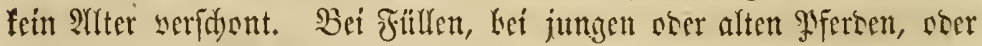

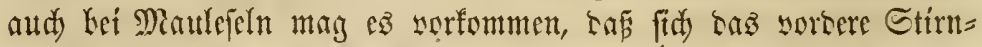

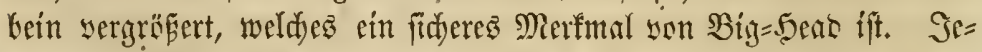
ood) mö̈gen fid), bies hat fid Sem Ifutor surd Erfahrung beftätigt,

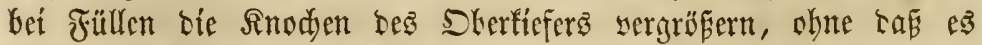
Big= Saw iff. Die Siranffeit fajeint bie Füllen in geringerm Mafe 


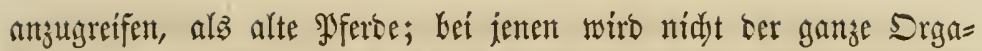

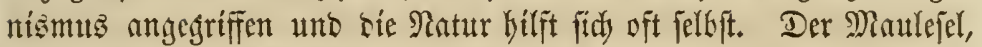
wenn audi) bicjer Rrantfeit weniger unterworfen, wiro bod oft son terjęlben befallen, aber er ift immer leidyter ju Geilen. Der $\mathfrak{A}$ th

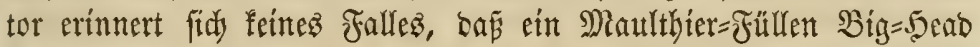
hatte.

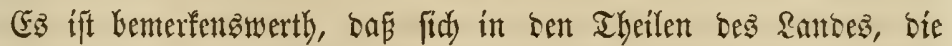
fitt sie אultur ser Baumwolle geeignet fint, sieje Rranffeit šfters uno mely entwiffelt, als andersెwo. Sie wüthet am beftigften in (B)egenten, wo fodled)te Ruftaušbünftungen vorfommen, ja, man fann

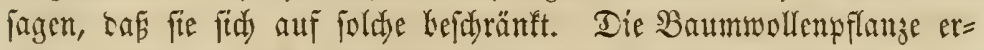
reidjt gerabe in siejen Diftriften ifte gröfte Bollfommentheit. I In Salfjeingegenten fontmt fie nidyt fo bäuffig yor, wenn aud alle antoern Einnirfungen biejecleen fint.

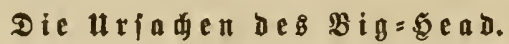

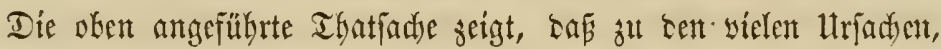

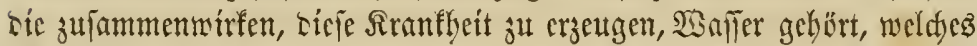
in biefen Bjegenten gefunten wiro, uno weldyes ftarf mit Edywefel, Gijen unto antern Míneralien geid, wängert ift, aber. Eeinen $\mathfrak{K a l f}$ ent= Gält. Der Salf ift cin 5autptheftantetheil ber Snadjen; tenn fie $\mathfrak{b e}=$

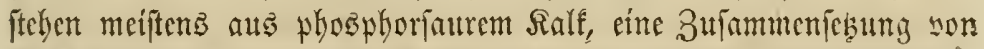

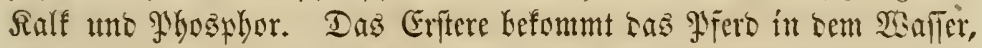

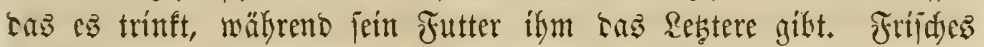

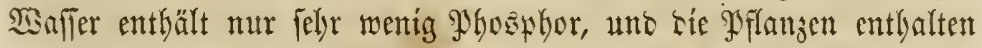
nur fobr wenig Ralf. Der Salf in mandjent Sajper ift nidyt rein, fontern mit antern Eufftanjen vermifodst, uno in foldyent Fälfen ift

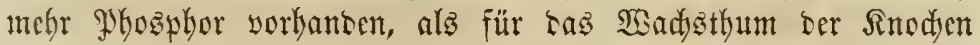
nothmentig ift. Sisaffer bient als auflöpente Eubftang in ten Ser=

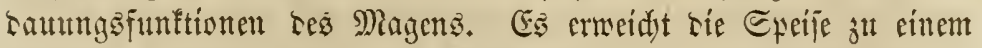

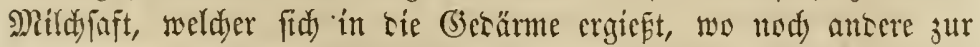
Berbanung bientidjen Mittel binjufonment. Die nahrbaften Ifrile swersen nídyt entfernt, fondern getyen in sas Blut. Ralf ift verbun=

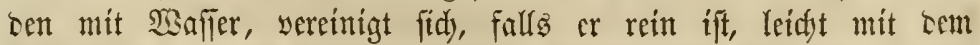

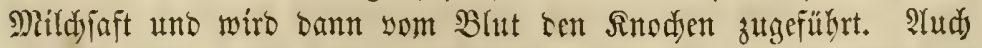

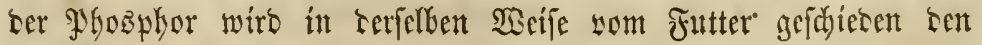
Sinoden zutgeführt. 
Das :

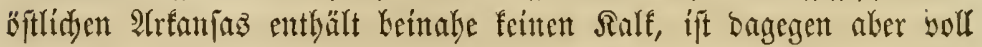

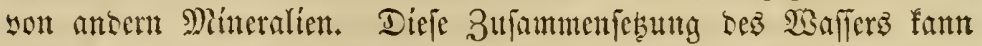
jesody nidyt allein als bie ltrjadye ber Stantbeit betradytet wersen; senn in sielen Theilen Sez Ranrez ift now wiel wentiger Ralf im Waffer, uno biefe Sranfleit ift Sajelbft unbefannt, wäbrent aud in

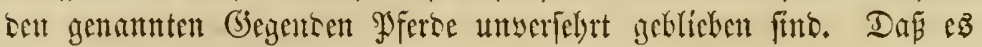
aber eine ber lltiad)en ift, fann nidyt bejwcifelt wersen.

Fine andere widjtige Ermägung im Erforidyen Ser ltrjadyen Siefer Srauffeit, ift saz Jutter รes Pfertes. In, wo vicl (Gras wädy, fommt sie Rrantbeit nur felten wor uno Yferte, weldye gute (Sras= weiren baben, werben felten son ser Seudye Gefallen, felbjt went Diefelfe in ber betreffenten begento berridyt. Destalb wetren viele

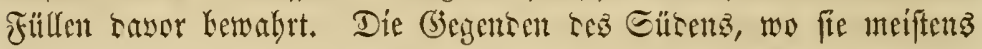

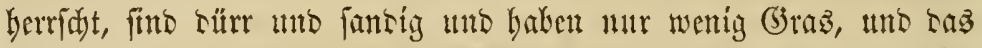

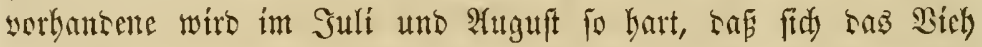

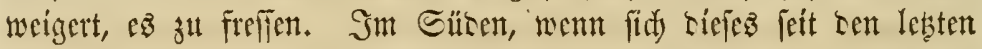

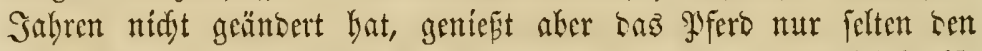

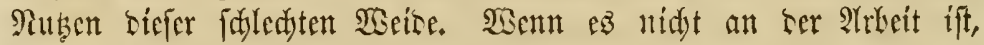

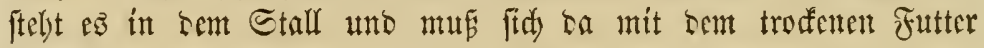
begnügent.

Whüre eine antere Finridytung in riefer Jinfidyt getroffen werten,

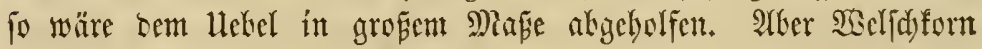

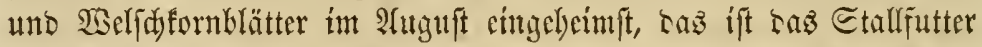

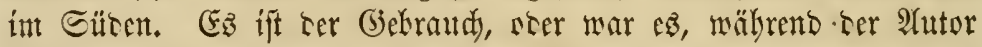

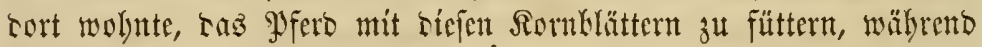

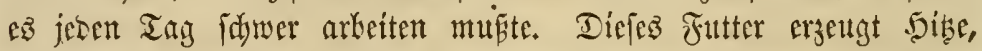
und wenn fortwäbreno gebraudyt, verurjadyt mebr ofer wentiger Ficter.

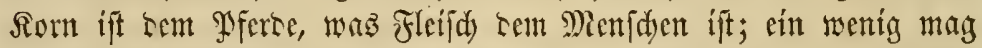
mit Nuben genofien wersen, aber went nidyt nod) antere Etoffe gefüttert wersen, serurjadyt ez Rranfleit. CEin Pfers, Das bejtïndig Romfutter frifít, ift folten ganz frei son Ficher.

Nidytz ift Sem Pferse fdüllidyer, als Romfutter, wentigftens in

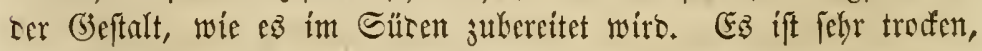

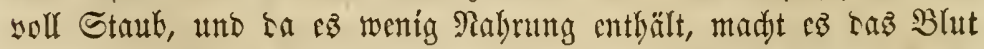
bid und troden. Es wiro aud febr oft surd Regen versorben; in vielen Fällen wito es gar nidyt yor Sinter eingebeimft und oft liegt 


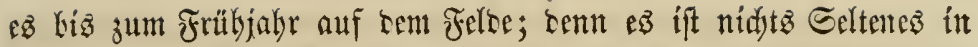

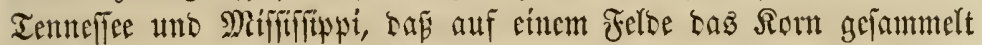

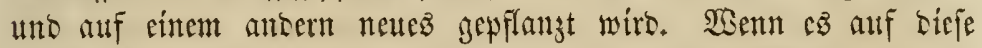
Siscife übermintert, muß

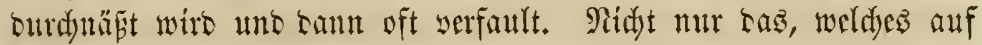
tie Erbe fäht, wiro werterben, fontoen die Aehre wiro erweidyt uno vermobert. Daffeclbe gill yon anterm Futter; es fteft in Büntefln auf tem Felto unto wiro feudidt unt fajtmutelíg.

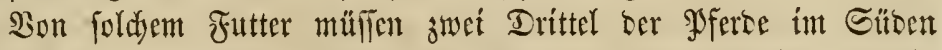

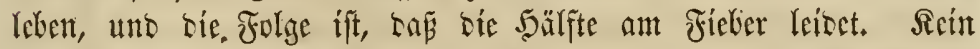
SBuncer, saf fie ant Bitg=5

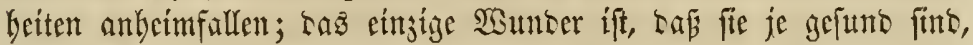
ober safi fie gar nod) leben. Sie mit Rorn allein ju füttern, iff fdylimm genug; went aker tiejes Sorm nod faul uno feudjt ift, fo fint Lie arment Thiere wirflid) 3ut bedatem.

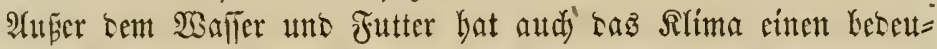
tenoen Einfluf auf sic Entwifflung bicjer Rrantfeit. Daf fie fith

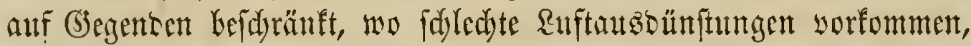

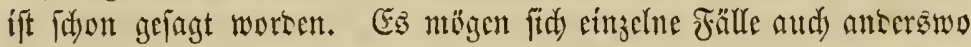

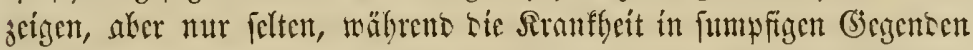

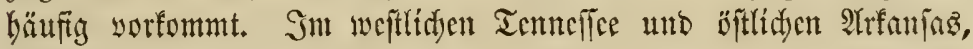

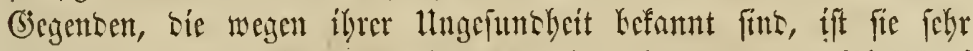

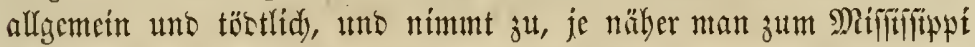

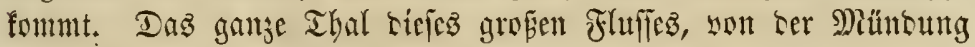

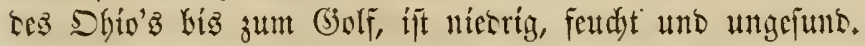

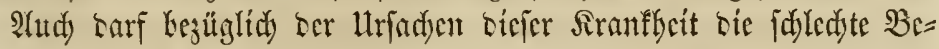
hanthung bes Pfertes nidjt überfehen wersen. Seser, Ler biejem

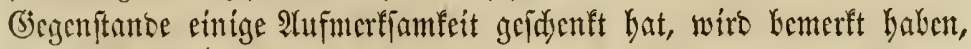

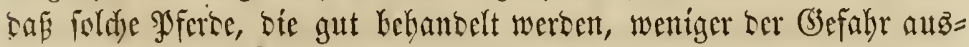

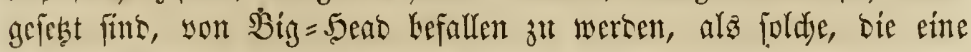

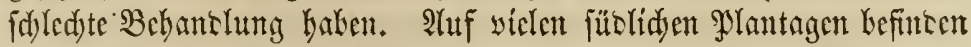
(id) Eeine Stülle; uno auf viclen antem war eż niddtż Seltenez, síe

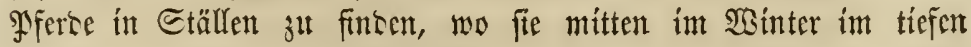
Soth unt Salier, und im Sommer auf tricfentem Mifithaufen ftan=

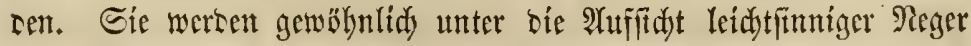
geffellt, benen wenig an ter \$ferbe Sohl und Gefuntheit liegt; biefe

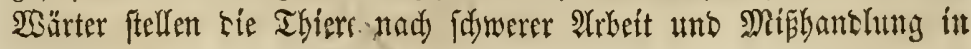


bieje folledten Stülle, füllen die Srippen mit Sorn und wäbnen, bie=

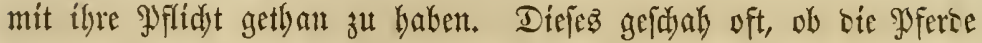
franf orer gejutto, erbigt ober nidjt erbigt waren. Utro jwar börte

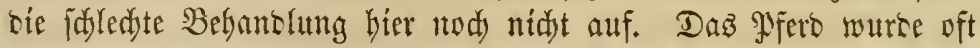

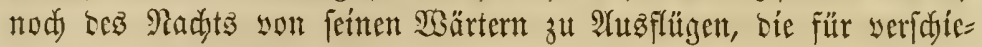

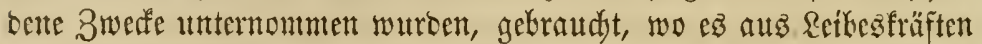
laufen mufite, alsbann an einen Baunt getunten murbe, obne Sdybs

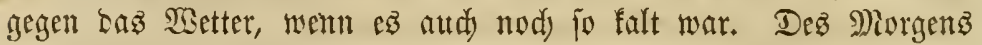
wurbe Beit genug hatte, feit Rom zu freffen und wieber an bie $\mathfrak{A}$ ibeit zu geben. Soldye Bebandung erfubren taujente son Pferben in Güben yor etwa zebn ober zwanzig Jabren. Tatürlidy ridyteten Rranflyeiten jdrectldye $\mathfrak{V e r b e r u n g e n ~ u n t e r ~ i f n e n ~ a n . ~}$

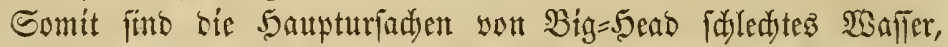

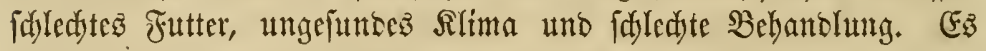
follte aber serfitansen weroen, saś nidyt alle bieje llrjadyen immer zur gleidyen Beit wirfen. Pferte, Lie gut bebantelt wurben, baben rie Sranfyeit gebabt, uno in Giegenten, wo fidy gutes șaffer mit viel Ralf vorfinoet, fint Fiălle sorgetommen. Dody wiro es geglaubt, Iafi werer Pferoe nod, Miaulejel gelitten baben, went ibl Futter nidyt meiftens aus Sorn beftant, falls fie in einer gejunsen (siegeno lebtent.

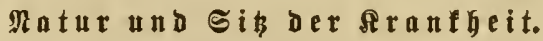

Bitg=5eab ift cine Sranfleit ber Rnodyct. Sie fängt an, inbem

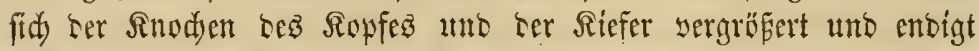

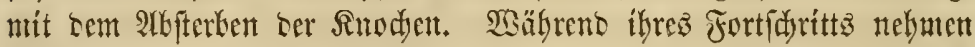

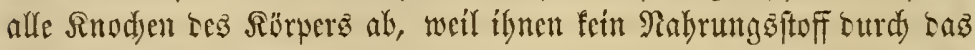
Blut zugefitgrt wirs; fie fint bals mur halb ooer ein Biertel fo grofi, als fie in cinem gejtmeen 3uftand fint. Sie weroen wie इdyoten obne Marf, uno fo mürbe, bafi fie lcidyt getrodyen wersen fönnen. Sefters bredyen bie vorteren (sliesmafen, ba fie nidyt mebr ftarf gentg fint,

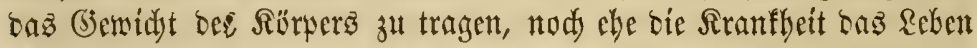
zeritört hat, wnter Ler Raft zufammen.

Wie oben bemerft, zeigt fidy bie Rrantfeit zuerft im Sopf und Riefer; ibr unmittelbarer Sis iff im Marfe Les obern uno untern

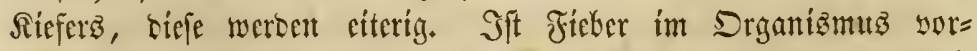
banden, fo zeigt ftd cine ftarfe Neigunar saf fid bie Sranfbeit 


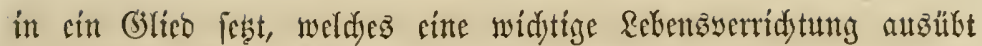

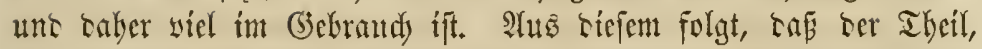
ser in ftetem Dientite ifit, am leidteften Velyaftet wirs, unt saber folgt

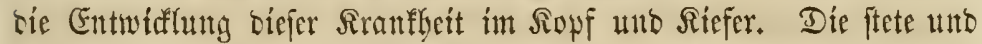

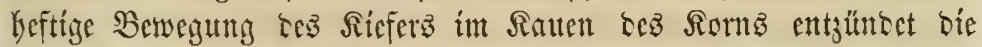

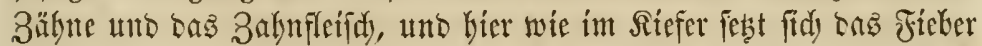

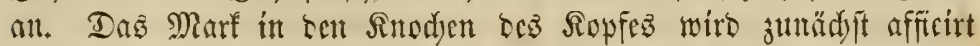

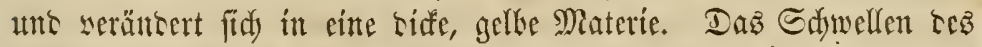

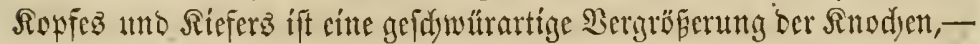

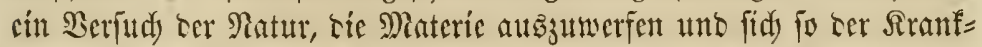

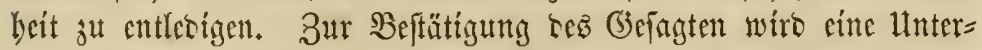

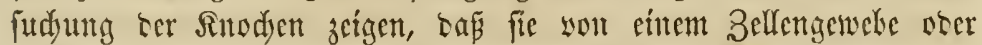

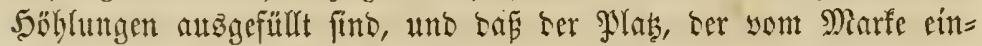
genemuten mutre, son eítem id)uppigen, fdyanmmigen Rnodyenge=

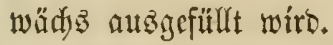

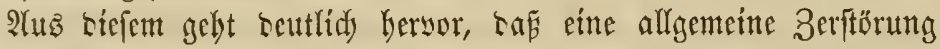

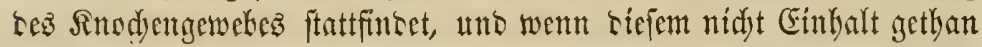

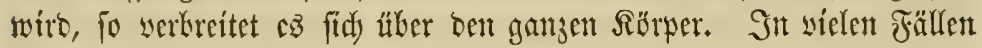

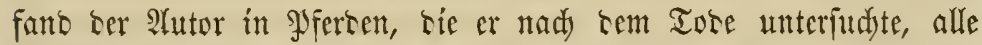

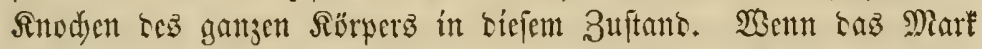

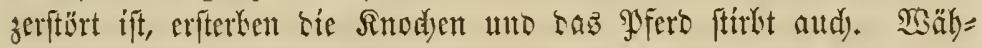

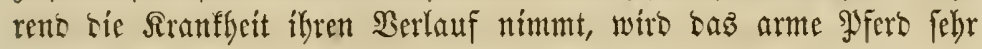
mager.

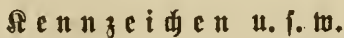

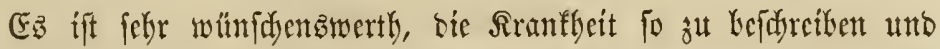

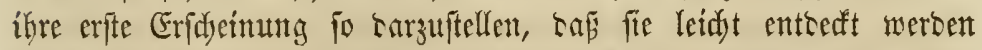
möge unt man yor Täufdunt bewahrt Greibt. Diefez wiro nidjt

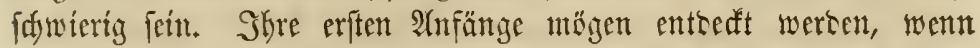
man sen Daumen unter sie untere Sippe, neten tem untern Riefer, jwifden sen Bähnen uno or Rippe hinaufidjebt. Die Ecite bez Simubafens follte mit ben Zühnen beinabe in fenferdter Rinie ftchen.

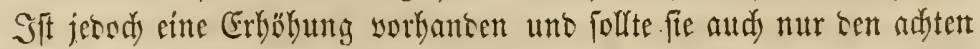

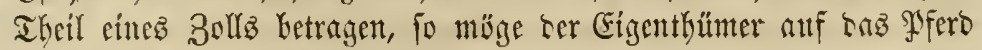

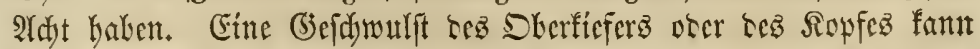

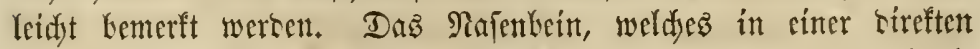

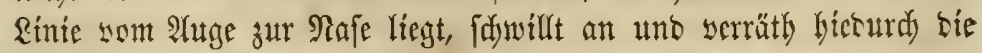
Siranflect. 
Die Saut utto Mußfeln bes Siopfez werten ftarr uno bewegen fid nidyt, wenn man an Sen Rippen jielyt. Ein gewiffes Zeiden ter

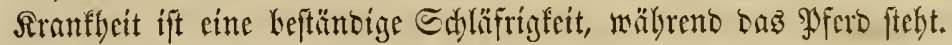

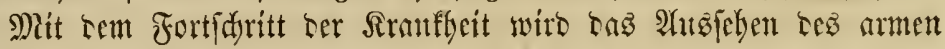

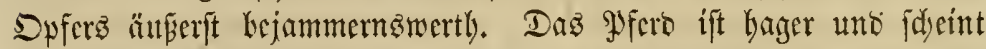
zufammengejvigen zu fein; feitte Sinter= uno Borberfübe ftelyen beinabe bcieinanber; fein Ropf bängt bernb uno bas Saffer lïuft ilym aus

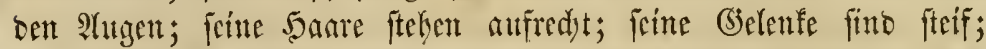
feine Saut ift troden uno Gart uno faseint fehr ftraff zu feir. Dí

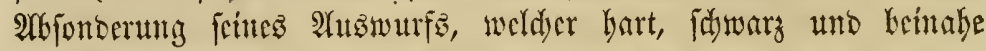
obne Feudtigfeit ift, verurjadst ifm Sdymerzen.

Wie angeoeutet, ift sie Sranflecit in ibrcm $\mathfrak{A n f a n g}$ für ein tnge=

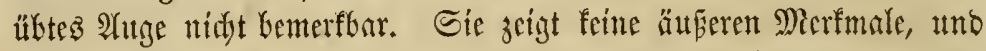

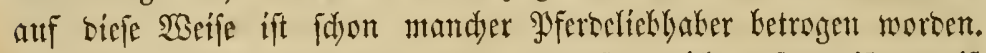

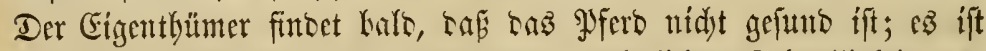

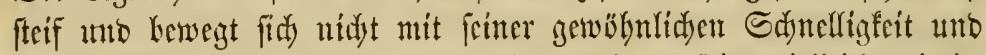
Bebensigfeit. Serodh ift fein Itppetit gut, ja es frift viclleid)t gierig, uno bierourdy wiro man wieser berubigt. Cin PFerb, bas ben Big Seat bat, frifst bis zun lesten 2 Hugenblid. Senn ez nidyt melyr im Stanse ift, feinen Ropf aufredst zu balten, bettelt $\mathrm{eB}$, fo gut ç fann, um Rorn; uns, fo fonterhar es fdyeinen mag, Rorn - bic

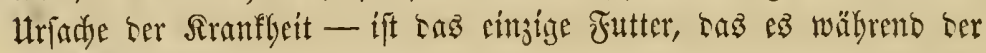
Sranfloit liebt.

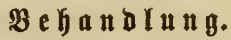

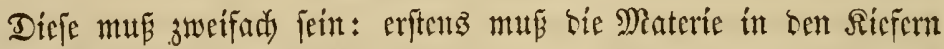
und bem Sopfe ansigetroftuet werten; und zwcitens muß ber ganje

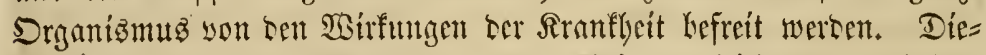

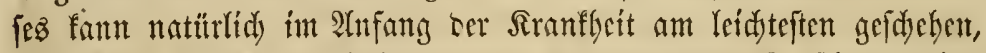
bod fann biefelbe aud bezmungen wersen, wenn fie fidson weiter vorangeforitten ift. Jebenfalls ift es tor Mäbe werth, einen Ber= (ud) zu madyen, fo lange fid ein Plfert auf ben Beinen balten fonn. Yrorlaffen ift bas erfte und nothwentigfte, was zu thun ift. Das

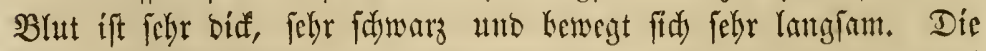

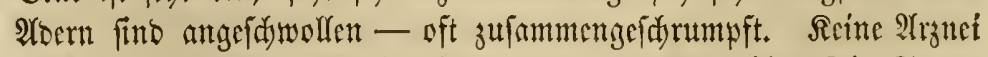
wirft, fo lange oaz Blut in cinem foldyen Buftand ift. Die Saug= abern ber (3)ebäme find beinabe gejdloffen und bie Speife fontert 
(id) untersaut ab. So lange tie $\mathfrak{B e r b i n t b u n g ~ b e r ~}$ Serbaunngäorgane

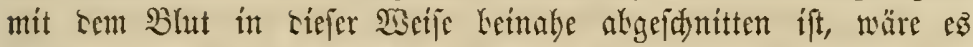

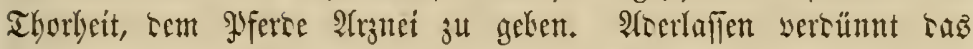

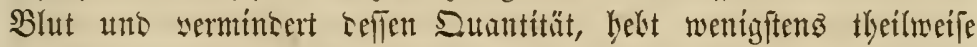

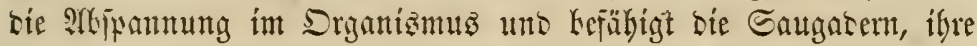
Funftionen wieter ơl verridjten, unto fo fann $\mathfrak{A}$ raznei wieser auf

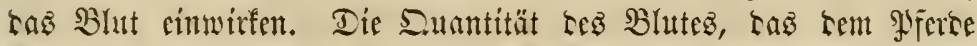
abgejayft mersen follte, Veeträgt won zmef biz vier Suart, je nady

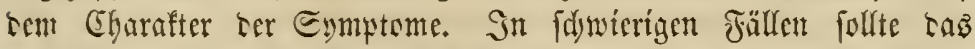
Trerlaffen alle fed)s Tage wiecerholt werten; tod werten zwet biz

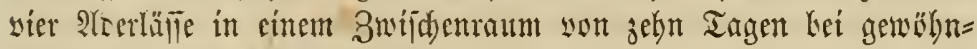

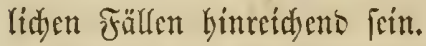

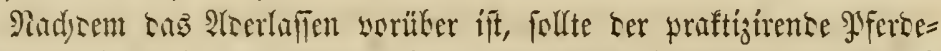

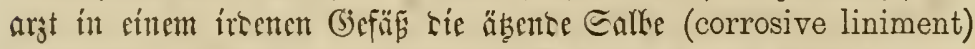
zutereiten. Mit siefem wiro ser franfe Theil mittelfit eines an einer Santhate kefejtigten Raptenz gut keftriden. Gin Ggloffel soll an jeser Eeite bes Ropfes wirt genty fein. Dite Flüfiligfeit follte zut= vor gut aufgejdüttelt unb tie betreffenten Etellen mit tem Riniment wok kefendftet unt sam mit einem glühenten Eijen bineingetrod:=

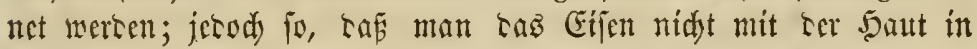
SBerübrung bringt, ta ticies bem liferte unnöthige Edymerjen ver=

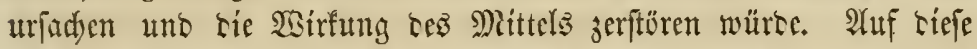

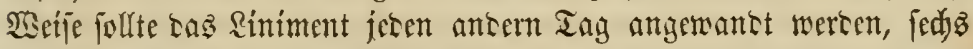
ober adyt Mal; in fdywerigen Füllen mag man fo lange alz noth=

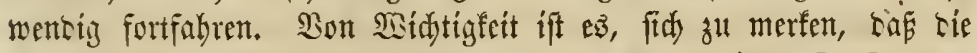

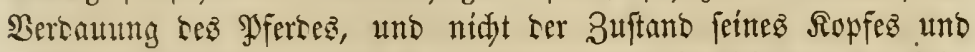

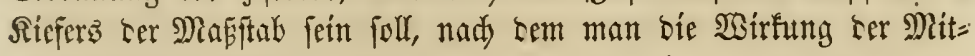
tel Keurtheilen mup.

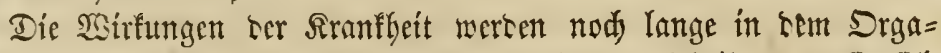

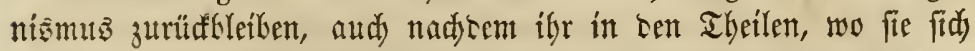
meiftens zeigte, Einhalt gethan ift. Zur Entfernung diejer sirrfun=

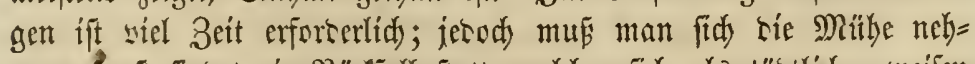

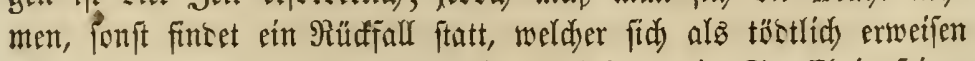

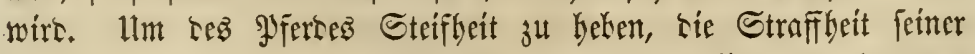
Saut zut milleern und feine Berbauung zu reguliren, wente man

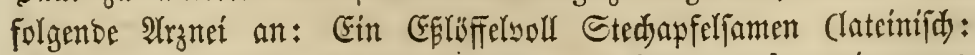
Stramonium; englifd): jimson weed ober thorn apple) mít etwas 


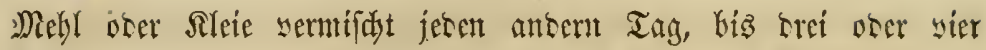
Dojent ritrgegeben fint. Man mag ramit audy jwei bis erei Iage

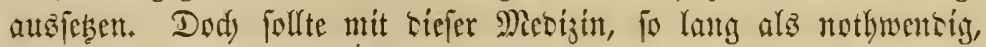
fortgefathrent wersen. Biele Reute, weil fie bent Stedjapfel für giftig balten, weigern fid anfangä, iłn cinjugeten. Ës ift aker nidyt bie

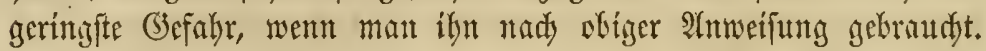

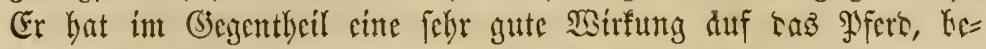

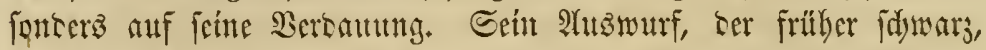
trofen unt hart war, wirb jest weidy unto von ciner gefunten, gel=

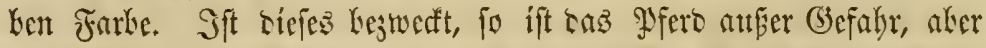

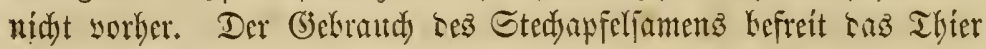

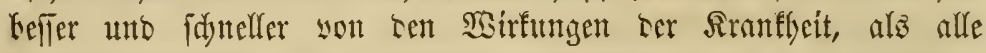

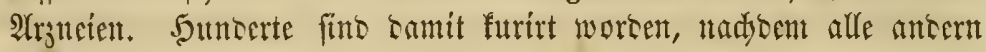
Mittel fefl gefdlagen butent.

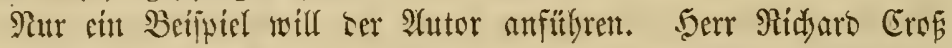

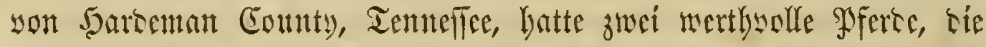
jebody burdy biefe Rranelysit Keinahe rutuirt waren. Er trieb fie in

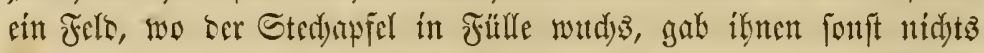

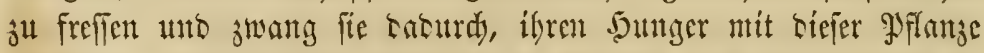

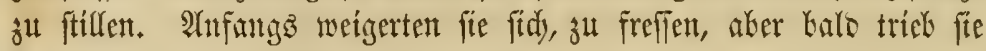

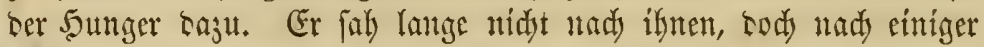
Beit fally er wieber nady ifyen und fant fie ju feinem Erftantuen

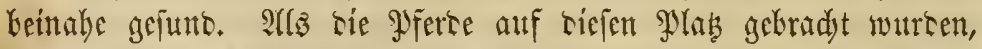

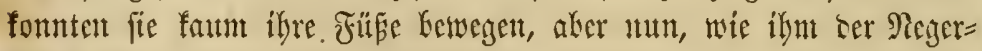

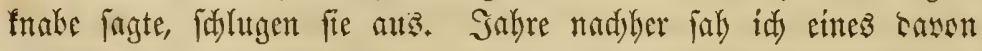
fo ftarf uno fatt, als man es matr wünfdyen fonnte.

Solfte ter Stedjapfelfante ntidyt zut Gefommen feyn, fo gebe man

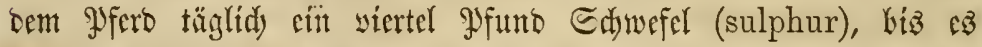
ctwa brei biz vier gy funt eingenommen hat. Sn Berbintung mit bem Sdywefel gabe man ifm nody eine Ifloe gille (aloes pill) jeten

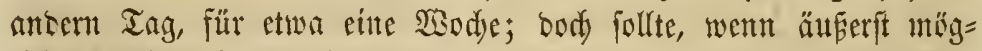
lid), Stedjapfel angeidafft werben. Ittu fein anterez Mittel fum man fo fityer redjuen, uno biefem hat Ser Plutor meiftens feínen

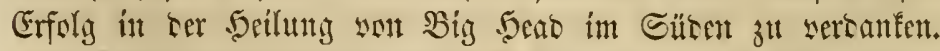

Die (̧eíd) sie Beculen wercen jesody nod lange bemerfbar fein, aber nady cint= gen Sabren werten aud fie veridswintent. Die Mutsfelt unb Seb= 
nen mersen fid an sen neuen 3uftano fer Dinge gewoblben, fo

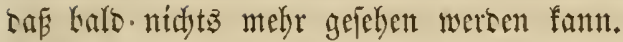

Pídyt wentiger alz jebntaujeno PJFerse uno Manlefel, son Lenen ber Futor meifj, frno in ten Salyren 1850 rís 1858 surd bieje Befbanslung furitt worben. Dic Sur ift rasifal. Sft fie soll=

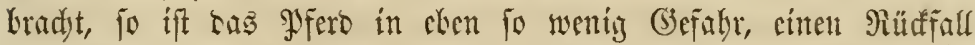

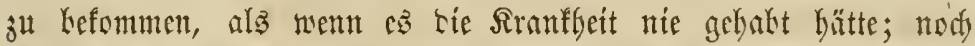

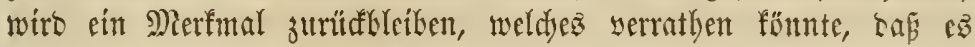
jemals franf mar. Zur Bequemlidyett folf éme Sistecerbolung rer Bebanslung keigefügt mersen:

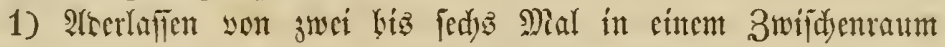
yon fect) bis zebn Tagent, je nath ten Gymptomen.

2) Gebraudye cie äbente Galke (corrosive liniment) jeren antern Ing, nady ?tuweifung.

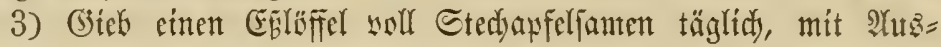
fesung, wie angerentet, fo lange als notlywentig.

4) In Ermangelung tes Etedyapfeliaments gieb sie sorgejdrie=

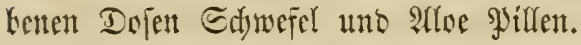

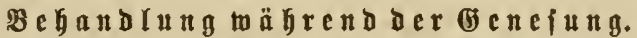

Diefe folfte serftüncig unt sorfidytig fein. Co lange sno Pfero

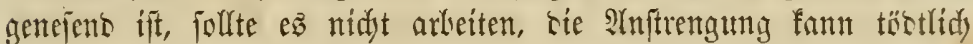
mersen. Sft rie sittenung rauly uns ungitnftig, fo follte es in cinem warmen reinlidyen Stall gebalten mersen. Sit es Seseisezeit, fo follte

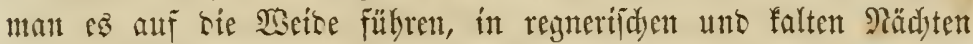
aber im Etalle balten. Sit taz Sacter feudst unt falt, fo werfe

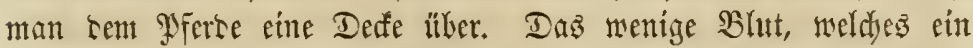

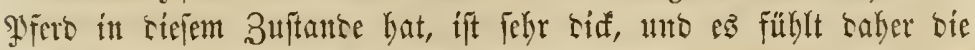
Rälte viel mebr als in gejuntem 3 utante.

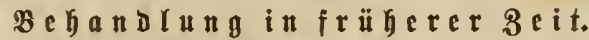

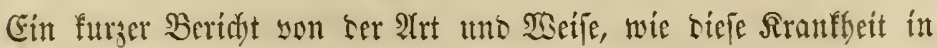
fritherer Beit bebanselt wurte, twirt Sem Refer wobl nidut uninter= eflont feyn. Dicie mar offt äuserft Karbarifa, wno batte fonft feinen

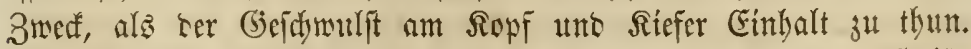

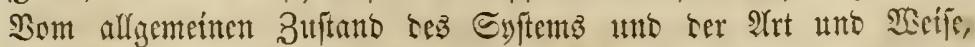

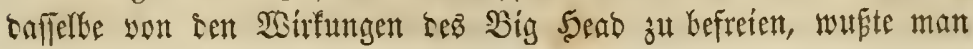




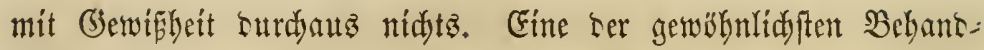
lungsmetboen mar bie uno ra erfolizreidy, gewöbnlid aher (d)lugen

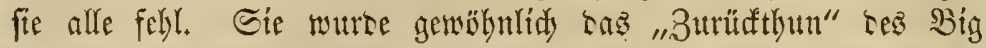
Sead gentannt. Solfte etwas zH Stante gebradyt werben, fo mufite

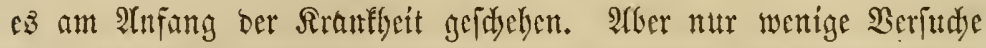
gelangen, uno gewbinlidy erlagen bie auf bieje Siseife furtrten Pferte

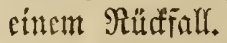

In ber fdyredfidyen Rifte Ier graujamen Bebanthngszmethosent mag

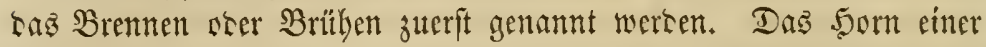

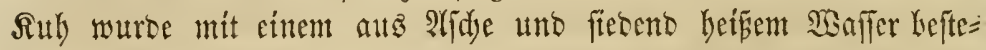
benten Brei gefüllt uno cann an tie franfe Stelle gefbalten. Ier Sopf res Pferdes wurbe feftgebunten, fo baj es ifn nidyt kewegen fonnte, und man bielt tas 5orn jo lange an bie betreffente Stelle,

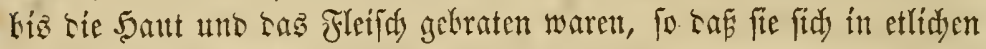

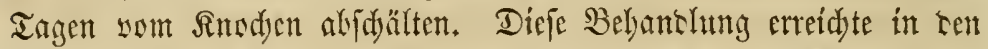

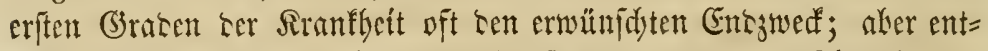
ftellte Das arme Thier nidyt mutr febr, foncern tiotete es fefre oft.

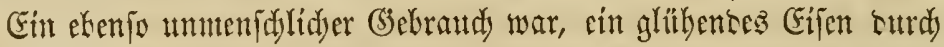
ren Sitefer su bohren. Diefes that Ser Rranflyeit in mandjen Fälfen ethenfallz Einbalt, erjengte aber ein laufentes (je) gebeilt meroen fonte. Der Sdyreiber fab vicle Pferse, tie auf tiefe Scife Eelbantolt worten, uno einft wursen jwei foldbe Spfer unter feine Sbhut getban, um einige Derfudje mit ibnen zu madyen, es fonnte ifunen jesody nidyt gelyolfen weren. Das cine wurbe aus

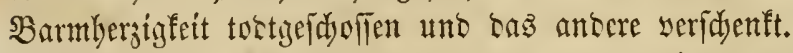

Gin anberer Gebraudy war, einten ober zwei tor gröften Baden=

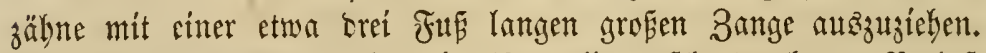

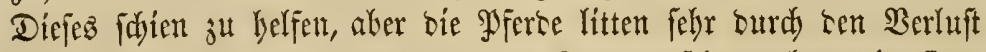

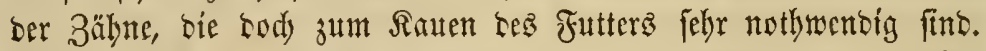
Der $\mathfrak{A}$ tor fah wenigitens fïnfluncert Pferbe, seren Zähne auf steje

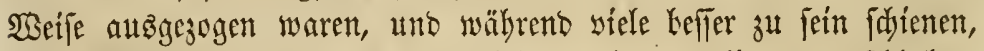
war feines ganz gefuno. Sie blieben fteif uno lítter an foledster Dersautung.

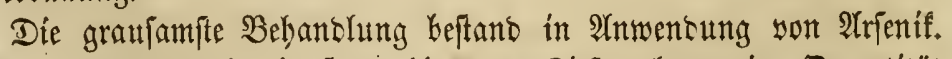
Man fantitt Durdh bíe Saut kis zum Ritefer, legte cine Duantität

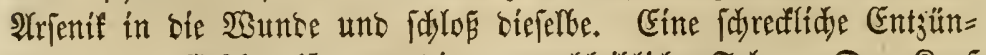
oung uno Gefdroulft war bie unausbleiblide Folge. Der Siopf 
wurbe oft io grof, wie ein Bufbelbaşfet. Es entftand ein unteil=

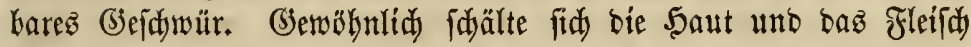
ab, fo bá ber Riefer bloṕ gelegt wurbe, und nur burdy bie äuperfte Befqutjamfeit fonnten bie Maben, frlegen uno ber $\mathfrak{T}$ ob ferme gehal= ten werben. Diefez Mittel war fablimmer benn bie Siranfleit felbeft

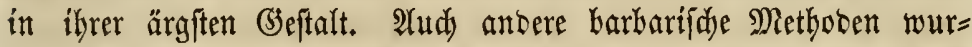
ben angewant, bie angefülyrten jebod) find genügent, und es ift

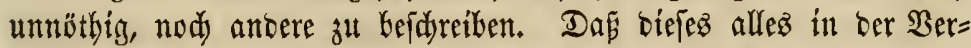

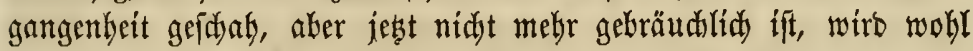
jeren mitteisigen Menidgen freuen. Ȩ war wernünftigen Männern

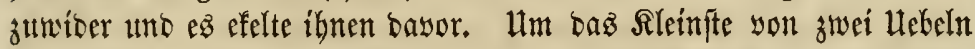
zu wäblen, wurben bie \$yerbe oft bem Iob überlafien, ofhe einen

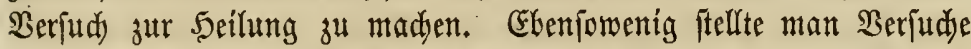
an, burd) sernünftige Mittel eine $\mathfrak{R u r}$ zut betwerffeteligen. Die PFerbe= ärzte jener Zeit fonnten nad) Sefefallen fajalten und walten. Die Reute

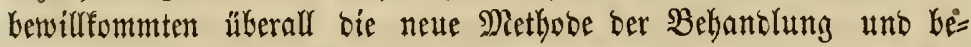
żeugten bem 2lutor Ebre und 2ldytung.

\section{Swinney ober efnt}

Den Utrprung biefez Ramenż (Swinney) vermögen audd bie ge=

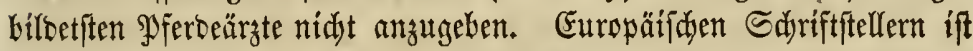
er völlig unbefannt, uno von amerifanifden 2futoren wiro er felten

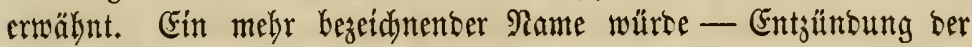
Sdulter fein - wie aus ber folgenten Bejdyreibung erfidytlid ift. Die unter bem Ramen Swinney voer Sweeny) befannte Rranflyeit fommt in allen Theilen ber Bereinigten Staaten vor, bod Kerridjt fie vorgüglid im Sübreften, und befonbers im Minfirfipppittal.

Sie wirb ohne 3weifel burd beftige 2 Mfftrengungen ber Sdutter

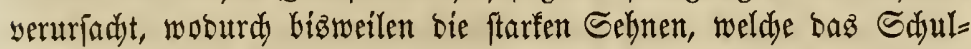

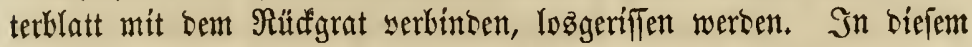

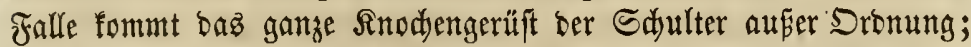
baz Sdjulterblatt fenft fid etlidye 3oll uno ber obere Theil ber

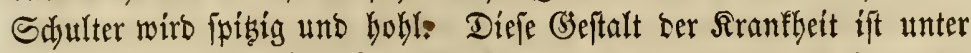

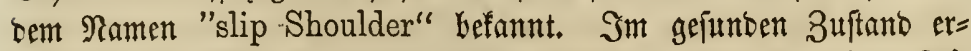

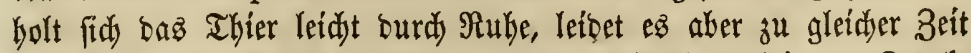

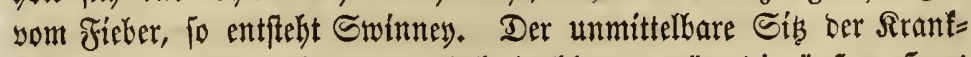

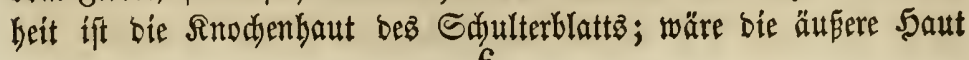


bebaftet, fo fönnte man es fehen. 2Bäre ber Snochent affirirt, fo würoe bies burd eine genaue llnterjudung ober gewis burd) Sef= tion zu erfenten fein, uno wäre ber Sis ber Rrantbeit in ben Sdyul=

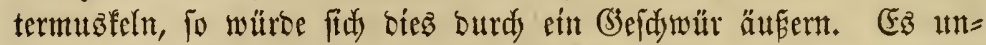
terliegt nfor feinem 3weifel, bap die Snotpeln uno bie Eebnen, weldje baż Edulterblatt umgeben, yon ber Sranfleit ergriffen werben, benu fie fterben oft ab, wenn bas Thier an Sminney letbet.

Die Rranfleit hat zwei weridjiebene Stufen, eine Thatjadye, weldye fid) ein Seber merfen und genau beadsten follte. Die erfte Stufe

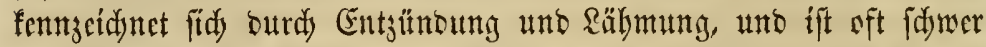
yon gewiffen Siranfleiten ber Füpe zu unteridheisen. Dft fdyeint bie Räkntutg ibren Gis nur in ben Beinen uno Fünen zat baken. Daz Pfero fest oen einen Fuß beim Steben inmer vorwäts uno greift unit bemlelben nidyt genug yor. Die Edulter ift febr ent=

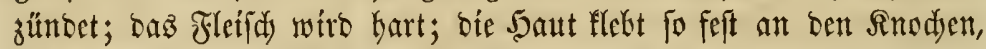
bajs fte nur mit Sdywerigfeit bewegt werben fann; bie betreffenten "Theile furumpfen zujammen unb bie ganze Sdulter hat ein bobles,

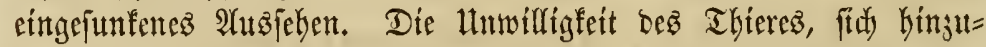
legen, ift ein ftarfes Symptom, benn bie bierburdy verurfadyte 2 (n=

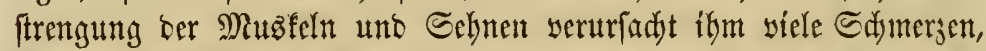

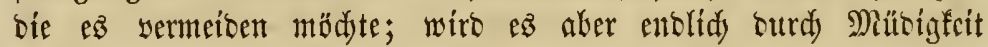
zum Rieberlegen gezwungen, fo ifte fein Sdymer ntdyt zu verfennen.

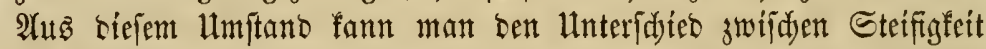
(bie Rebe) und Ewinney beutlidy erfennen, Denn letbet bas Pofero an Der erifgenannten Rranflyet, fo fann es fidh leidyt nieberlegen uno liegt aud bie meifte Beit.

Die zweite Stufe ift eigentlidy ber $\mathfrak{A}$ nang jener Sranfleit, weldye bie Farnter big shoulder (mörtlic) (3rof $=$ Sdulter) nennen, ein fdwe= res Reiben, wowon weiter unten abgebandelt wiro. Eg ift bie Folge einer lang anbaltenoen Entzïnoung, ooer ungetwobnlidy fdwerer Berleb̧ungen. Die Seknen, bie bas Sdjulterblatt mit bem Rüdfgrat

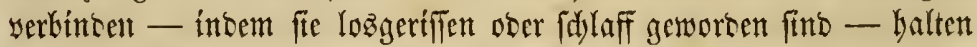
Daffelbe nidyt mebr in Feinem SOlnb, fo bafi

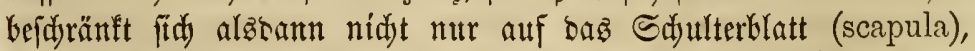
fonbern fie afficirt baz $\mathfrak{A}$ rmbein (humerus). Der obere Theil bicies.

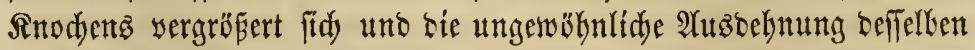
madyt bets Fall nod) fdwieriger. Atud bas (selent yergrösert fith 


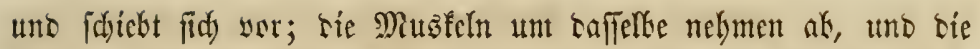

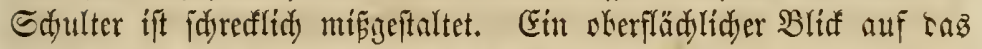
\$JFero jettgt teutlidi savon, was frattgefunten hat.

Díc unter Sem Rament Eminney Kefannte Siranfbcit wiro unter

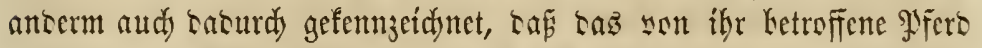

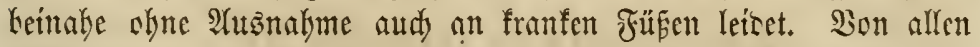

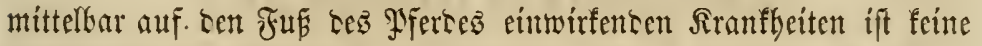

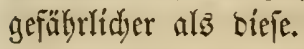

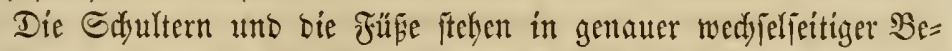
ziefyung ju cinanter, unt went jene erfranfen, fo fint biefe leteent. Bejonters wiro tie Suffüule oft son Envinney werurfadyt, uno er= fortert sirefte Beluantlung, wie an cintr antern Etelle keidjrieken

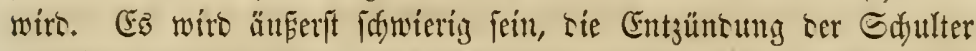

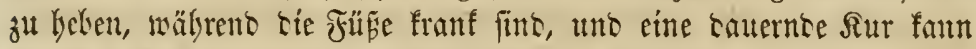
unter biejent Utmitäntent gar nidyt gemadjt wercen.

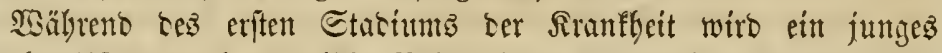

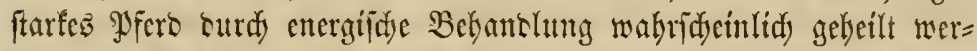
oen; aber bie alten tmo fidwadyen Ihiere merten idywerlidy son allen Sirtungen ter Rranfleit fret werten. Sn bem jweiten Streium fann man in feinem Faalle viel leiften. Man mag baz Yjferd jur

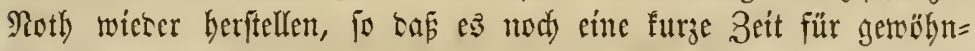

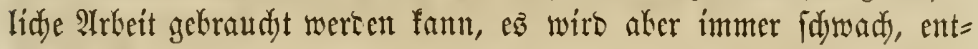
ftellt uno kei Etrapazen unzuverläpipg fein.

\section{B e $\mathfrak{h} \mathfrak{n}$ ป $\mathfrak{u} \mathfrak{u} \mathfrak{g}$.}

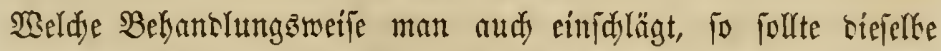

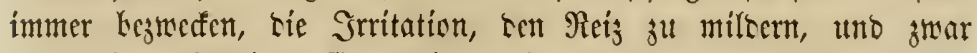

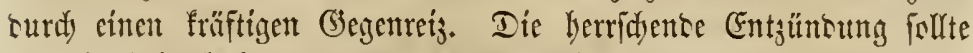
an bie Dherflathe gejogen werten. Diez wirs burd tas correfits Siniment Gerwirtt. Man fallte es täglidy, für brei woer vier Inge

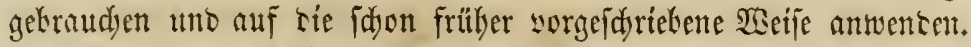

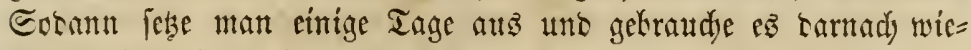

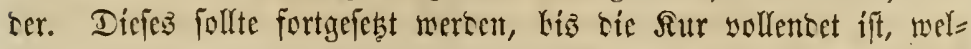

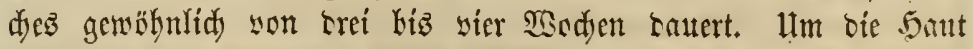
loz jut maden, follte man fie jeben Morgen reiben tno mit ber feant bearkeiten. Ifud) biejez mag fortgeieste werten, felbit nadjeem man

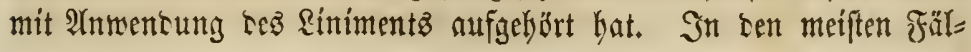




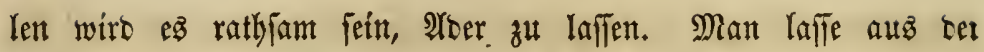
5aläaber yon zmé \$uart zu einer (Gallone Blut ablaufen, je nady

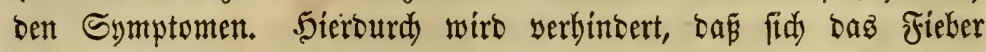

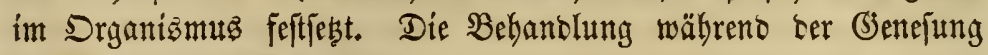
fet wie bie beim Big Sheat.

\section{Beba n⿺ I}

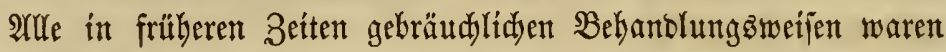
barbarifdde $\mathfrak{B e r j u t b e , ~ e i n e ~ ( s e g e n r e i z u n g ~ ( c o u n t e r i r r i t a t i o n ) ~ z u ~ e r = ~}$ zeugen, ba biefez bei Bebandlung diejer Rrantheit baz 5aaupterfor=

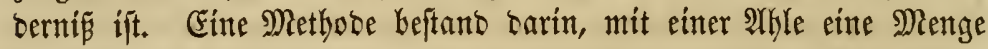

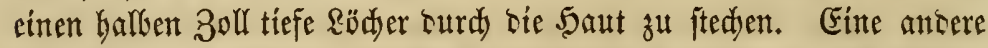

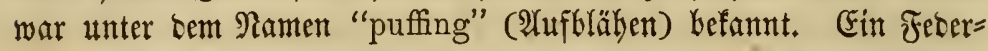
fiel wurbe in bie Saut geftef̆t uno burd bieje Ruft eingeblajen.

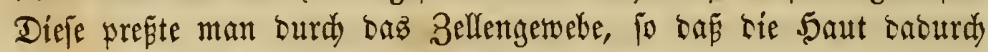
loşgetrennt wurbe, biłz bie Sberfläd) ter ganzen Sdjulter wie cine Blaje auşăh. Giner britten Methore folgeno, brannte man bíe betreffenben Etelfen mit einem glühenten Eifen, ober mit Dampf, ober mit hei

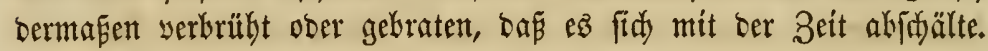

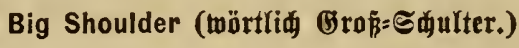

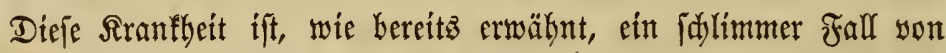
Sminney. Daz Fleifh unb die Sehnen ter Bruft fowobl alz bie ber Sdjulter finto afficirt uno idjumpfen zujammen. Der franthafte

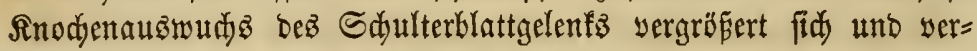
mebrt dic Berumftaltung und bülflofigfeit.

\section{ஜำ}

Dieje mus natürlid Lerienigen, bie bei Swinney befolgt wirt, gleid) Fein. Gine yolffänoige Rur fteht jebody aufer Frage. Die

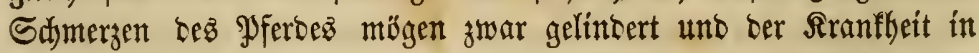
geniffem Mafae Ginfhalt gethan werben, aber in ben meiffen Fällen if baffellbe zur $\mathfrak{A}$ rbeit unfähig.

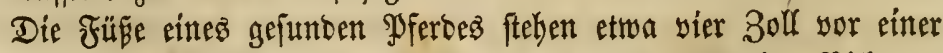

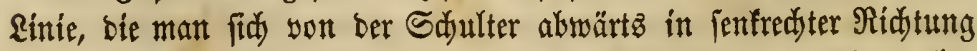
gezogen benft. Bei bem an biejer Iranffgeit leibenden $\mathfrak{P} f e r b$ aber 


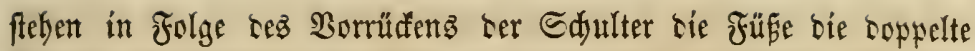
Entfermung hinter biefer Rinie, woourdy es in Ler Bewegung fehr gebintert unt um wenigftens sie bälfte feiner Siraft keraubt wirt.

\section{(E)}

Diefe Rranfbeit fommt wiel feltener yor als bie oken befdurtekene, gleidyt siejer jebod in allen Eymptomen, bejonters in bem Edjuin= ten Ler Muğfeln, tem Fieker uno ser Lamit verbuntenen Siranfleit ter foüpe. Weil fie aber fo wenig yorfommt, wiro fie audy nidyt redjt veritanten. Einige nettere amerifanifde $\mathfrak{A}$ utoren auşgenom= men, ift tiefe Siranflgeit nie befdyrieben worten.

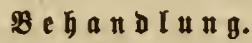

Die Bethanthung follte terienigen, bie bei Swinney in sen Sdjul= tern kefolgt wirt, gleidf fein, wiro fid aber wirfjamer ertweifen. Die äł̧ente ভalke (corrosive liniment) verfehlt felten, eine völlige Rur zu berwerfftelligett.

\section{Berrente ober gebrode a e}

Man foulte meinen, sie $\mathfrak{x a t u r ~ h a ̈ t t e ~ g e n u ̈ g e n t e ~} \mathfrak{B o r f e b r u n g e n ~ g e = ~}$ troffen, bas büftengelent ju bejdühen. Die Berbinbung ber crei Snodjen ser Shüte surd) ftarfe Snorpeln, weldye fie auf jeser Seite

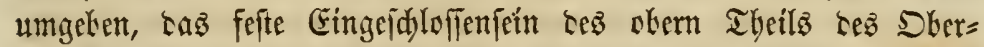

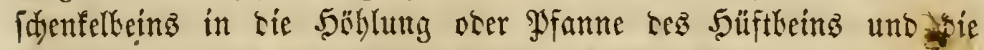
Berbinsung aller siefer Theile mit sen ftärffiten Bänbern - sieß, po follte man senfen, würte irgend weldje Berleşung zur Utnmögliduleit madjen. Uno sod) mag surd) eine heftige Eridjütterung eine Kereu= tente Berrenfung erseugt wersen. Dab obere Edjenfelteín wiro aus

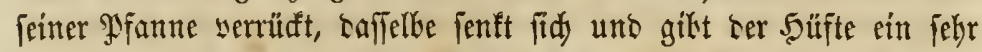

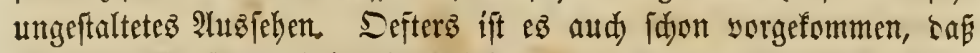

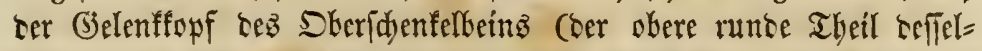
ben) zerfplittert wurse. Sierwon wirb aber in bem betreffenten Sapitel abgefantelt werben.

\section{8 с $\mathfrak{b} \mathfrak{a}$ o $\mathfrak{I} \mathbf{u} \mathfrak{n} \boldsymbol{g}$.}

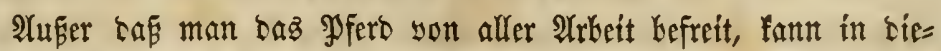
fem Fall nidjt weil mehr gethan wercen. Eine orer zwei 2tnwen= 
bungen bes corrofiven Riniments werben bebülflidy fein, ber Entzün= Dung zu ftettern und Räbmung zut verbüten. Die Sitfte aber in ibrer sorigen (3eftalt wieber berguftellen, ift unmöglido.

\section{$\mathfrak{A} \mathfrak{n}$ 过 $\mathfrak{e} \mathfrak{n} \mathfrak{p} \mathfrak{a t}$ (bone spavin).}

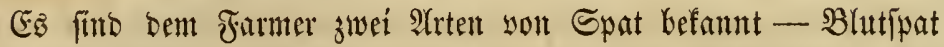
und Snodyenipat. Ulber ben lesteren wirb bier abgebandelt. Der Erftere ift in 7. Rapitel bejdrieben. Snodyenjpat ift eine Bergrö=

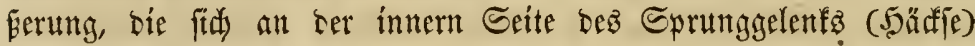

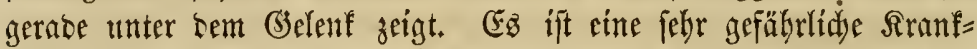
beit, die, wenn fie nicht orbentlid bebantelt wirb, bas Pferd gămz= líb) ruinirt. In mandyen Fällen fdyeint fie feinen wejentlidyen Sibaben anjuridyten, bringt aber Berunftaltung berwor, währent in

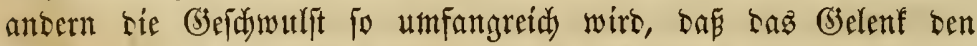

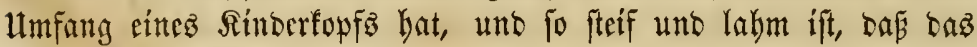
Pferb faum auftreten fann.

Einten ber Inodyen Des Sprunggelenfiz (Den mittleren) beif́t man feiner (3) fitalt wegen Wiurfelfnodien (cube-bone), Der auf zwei altoern yon ganz veridyiedener (s)ftalt rubt. Den einen berjelben, sen ätfern, nennt man Sdyenbcin, Sen andern, fleinern und innern, Siriffelbein, wegen feimer Dünne, uno weil er wie eit zugeipitster (5)riffel ausz= läuft. Der Sopf Des Biriffelbeins ift febr poröz und viel umfang= reicher uno weidjer, alsz bie anoern Theile, nimmt aber an Didjtig=

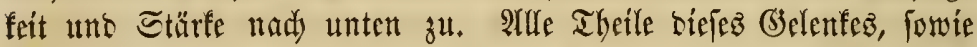
alle anbern im ganzen Sörper, werben mit einer öliduen Flüfitigfeit: (von ben $\mathfrak{A}$ ergten synovia, (3elenfiaft genannt) veriorgt, weldbe fie fatliipferig madyt und Reibung yerbütet. Diefe Fliiffigfeit verridytet auferbem nod einte widytige funftion, inbent fie bas Mittel ift,

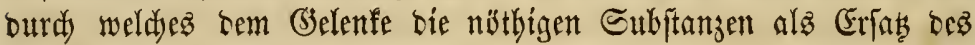

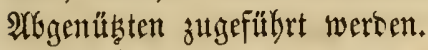

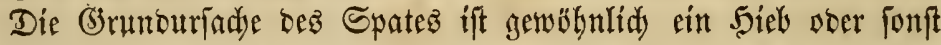
einte Berlesung. Sierburd entftebt ein fieberifder uno angejunoer

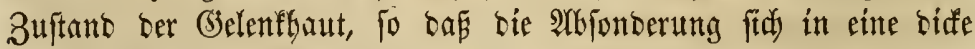
citerige Subftanz werwandelt, weldye sie Natur zt entfernen futdt. Die Saut aber ift zäbe und ftarf, oa feine Deffnung entfteft und Die Flüfrigfeit alfo nidts ablaufen fant. Diefe fest fids nun in bem

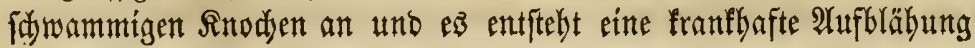




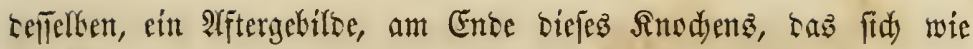

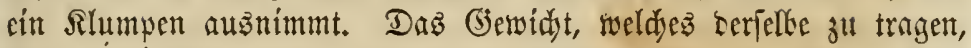

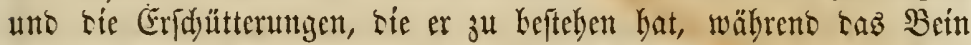

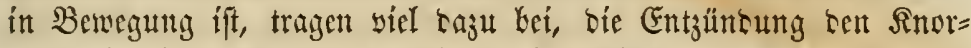
peln, rie ricien Sinodyen umgeben, mitłutheilen.

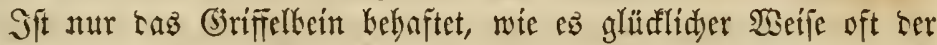

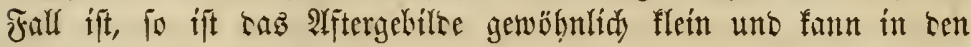
meiften Făllent leidyt futrint wercen. Sfit aber wiro baz oberbalk

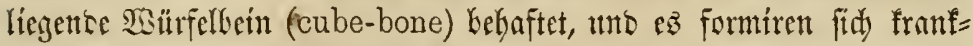

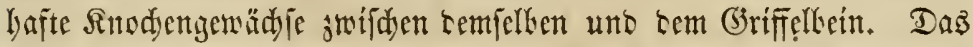

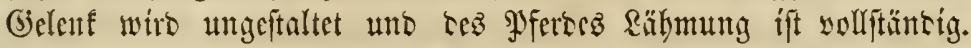
Bei einem foldyen Jall ift feine Rur mäglidy. Trrgteien täment nidyt

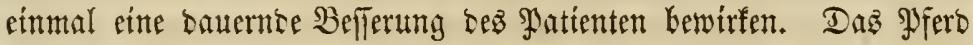
ift ruinitr.

\section{$\mathfrak{B} \in \mathfrak{b} \mathfrak{a} \mathfrak{d} \mathfrak{I} \mathbf{u} \mathfrak{g}$.}

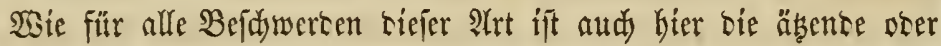
fdinrfe Ealte (liniment) tas befite Mittel. Sic pollte auf bie bes treffenten Theile auffeefst wersen, uno zwar in tor Siseife, wie es

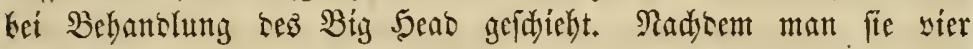
ober fünf Iage lang gebratdyt hat, fann man ebem[o laing bamit

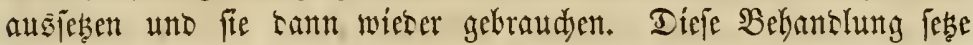
man fo lange als nothwentig fort. Die Beit ser Beflantlung wiro Durd) Lie Zcitsauer, währento weldyer fid) Die Siranfheit entwiafelt,

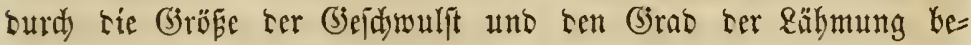
ftimmt. Sit sab Sürffelbein (cube-bone) afficirt, fo werben alle Berjudje sergeblidy fein, uno bas \$fero ift als unbeilbar za be= traditen.

Ein anteres Mittel für Sinddenfpat, weldes ziemlid) werthyd ijt, ift sic Merfurial=Salke (mercurial salve) (fithe 24. Rapitel). Die Theile okerbalb ter Spatflumpen follten jesen Morgen mit ber Ealbe entweser mit bem Fintger ofer mit cintem sappen eingeríken werben, worauf man bie Ealke mit eintem glühenten Eijen cintrod" =

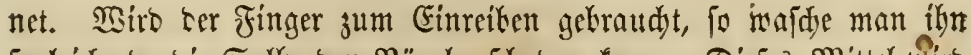
pogleid, ba bie ভalke sen Mägeln fdjacen fann. Diefe Mi Mittel wiro erfit trad) einigen 2 sodjen wirfen; man fahre samit fort, febe aber bamit auf tie nämlidbe Weife, wie mit bem corrofiten Riniment, auz. 
Die Befandhung während ber (Sonefung befteht nur in forgfälttiger Behandlung :

Die Belyandung bes Spates ift einfach und beutlidy, aber nidyt immer son Erfolg. Sn feinem Fralf follte ber GigentGümer ten

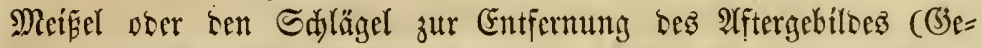

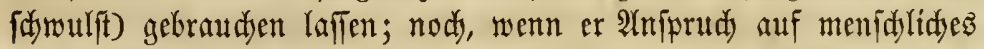

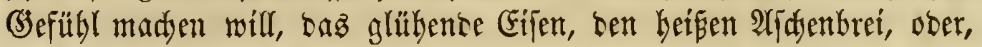

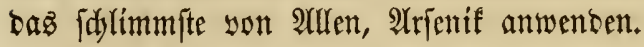

\section{CẼ}

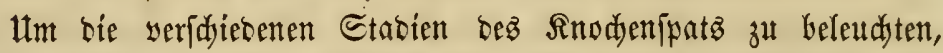
will ber $\mathfrak{A} u t o r$ nur zwei Beifpiele aus feiner \$rariz anfühten. Sm Sahr 1852 behandelte er ein fajönes, jungez, bent Serm Soleph

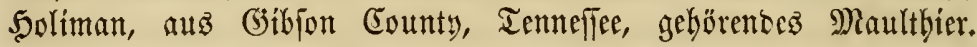

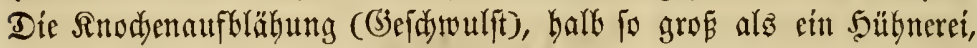
zeigte find auf tem linfen Sinterbeín unt war ziemlidi fidlimm, sabei litt bas Thier son Fieber, jonft fehlte ihm aber nidtes. Es wurten

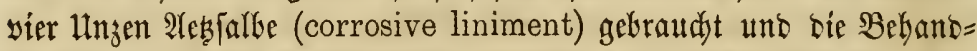
lung wurde cinen Mionat lang fortgeeptst. Das frante Thier batte

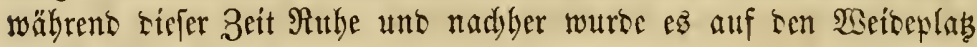

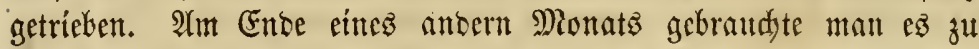

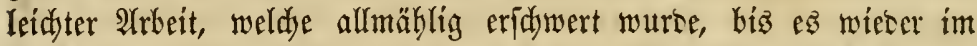
Stanbe war, fdjwere $\mathfrak{A}$ rbeit zu verridjten. Man bemerfte fpäter nie an ifgm bie Spatlähmung.

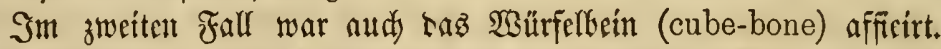

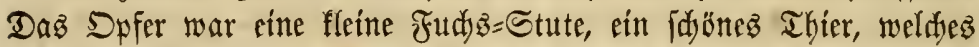
ein Freuno fürşlid in übergrofém Selbftyertrauten, ben Spat beilen za fömen, eingehandelt Gatte. Daz belent war breimal fo grop, als ez gewöbnlid ift. Sobgleid) Las corrofize Rinintent cine lange Zeit gebraudyt wurbe, blieb ber errounjidte Erfolg bod atţ. Daz̉ \$Perb be froh, ez veridjenfen zu fönnen.

\section{$\mathfrak{M} \mathbf{a} \mathbf{n} \boldsymbol{u} \mathfrak{\pi} \mathbf{b}$.}

Ein Pfero ift oft mit Spat behaftet, währeno feine (3ef dynulit, ober bödffens eine fehr fleine zu bemerfen ift. Radjem es cine Beitlang ftant, trítt ez zwar lahm auf, aber wäbreno bem \&aufen 
werten bie franfen Etellen erhibt, bie Bänber erweitern uno beque= men fid ben gefdyollenen Theilen an, bie Rälgmung verfobsintet uno

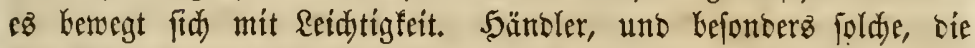

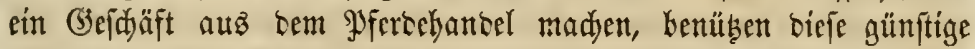
3eit, um foldje 9ferbe los zu werben uno sen Unwifienten $\mathfrak{j} \mathfrak{b} \mathfrak{b}=$ trügen. Daz Pfero wiro mit nadi 5auje genommen, unt nadjem

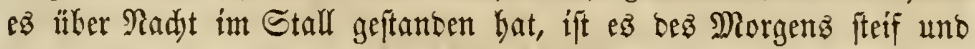

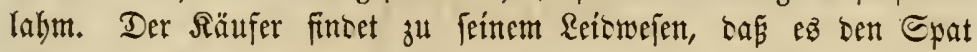
hat unt baf er betrogent ift.

$\mathfrak{u m}$ fid̀ sor biejen $\mathfrak{B}$ etrug zu büten, follte ber Räufer bie Beine beforters genau unterfudjen; fintet er bie geringite unnatürlidse BergröÉcrung ober antere versädtíge Merfmale, fo beftebe er barauf,

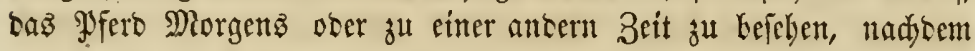
es etlidje Stunben geftanten hat. Sine andere Miethose beftegt

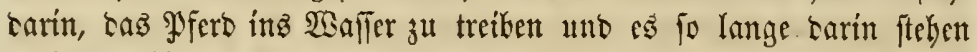

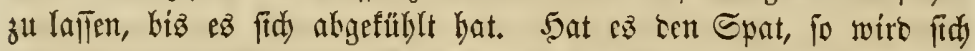

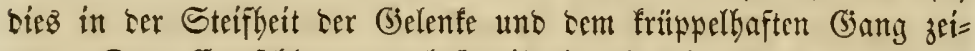

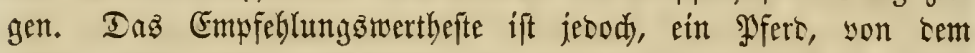

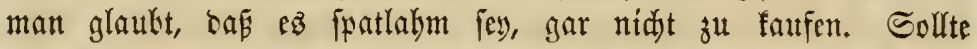

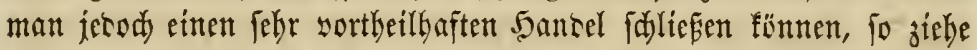
mant einen Freutto ju Rathe ober laffe fid Bürgiduaft geben.

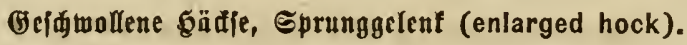

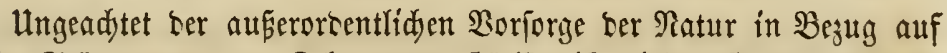

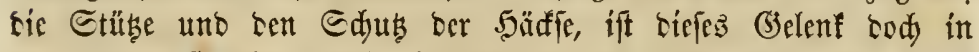

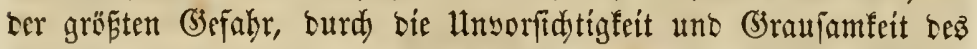

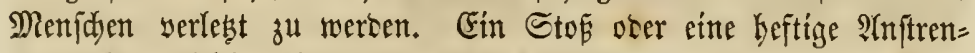
gung fann leidjt Entoüntoung ober Eähmung verurfadyen. Diefé mag zwar nidyt lange anhalten, uno $\Re u b e$ fann wieber allez in

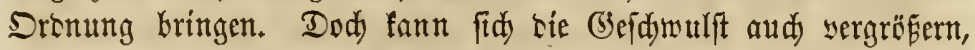

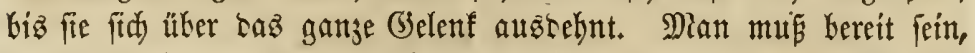

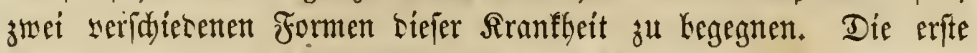
ift biejenige, wo nur bie Selgnen und sinorpeln behaftet fint, in

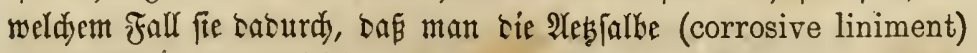
eintige Mal anfest, leidjt gebeilt werben fann. Die antere form

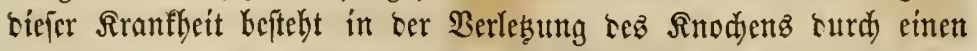
Etop, Edjmís over fonftige Erifjütterung, wobei bie umbüllente 


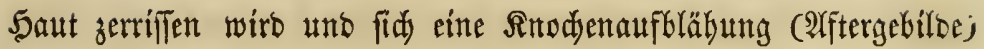

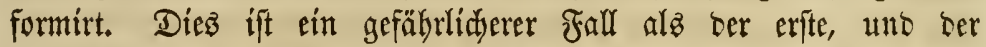
Eigenthümer mag find glütlid fajäben, wenn

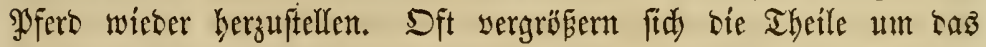

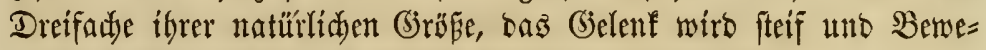
gung ift fommershaft uno im bödjten (3rab fdwierig.

\section{$\mathfrak{B} \in \mathfrak{b} \mathfrak{a} \mathfrak{u} \mathfrak{\mathfrak { I }} \mathfrak{\mathfrak { a } \mathfrak { a } \mathfrak { g } .}$}

Die Befandlung follte ber beim Epat befolgten ăhnlid fein, boch braudt man bas glïbenbe Eifen zum Cintroduten nidyt anzumen= ben, auşgenommen, wenn ber $\mathfrak{m}$ nodjen behaftet ift.

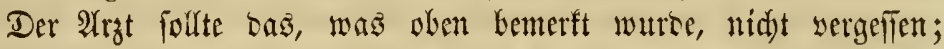

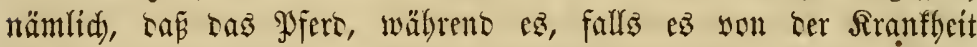

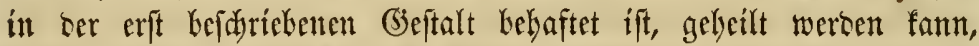

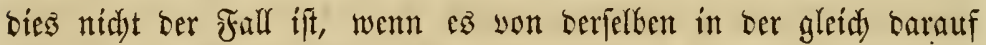
beidriebenen Form befalfen wurte. Zwar fann man bem Hebel

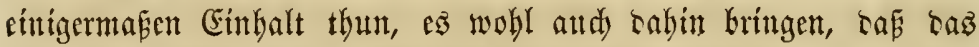
\$Fero zut gewöbnlidyer Farmarbeit getraudyt werten fann, für ben

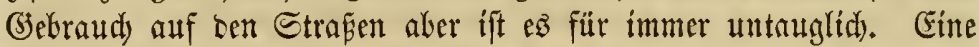

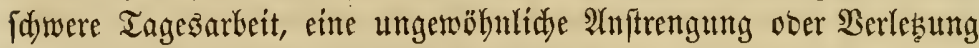

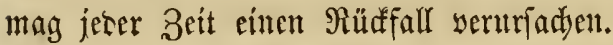

\section{(G)}

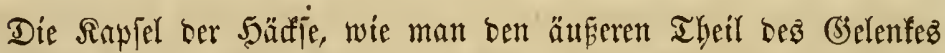

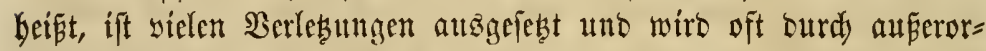
bentlidje Sdjläge, Sdymifie zc. gebrodyen.

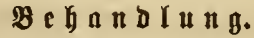

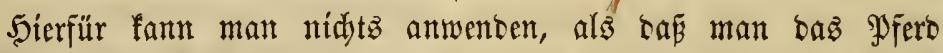

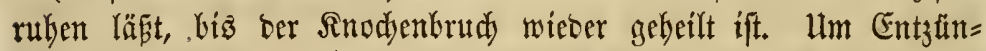
oung zu verhüten, getraudje man bie 2 ebjallece.

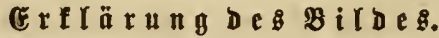

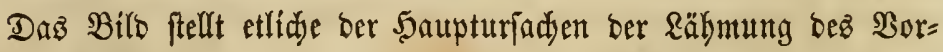
berbeinez yor.

$a$ Sergröperung bes (Ellenbogengetents.

$b$ "Einbug" (tying in) Deß Beines unter Dem Sinie. 


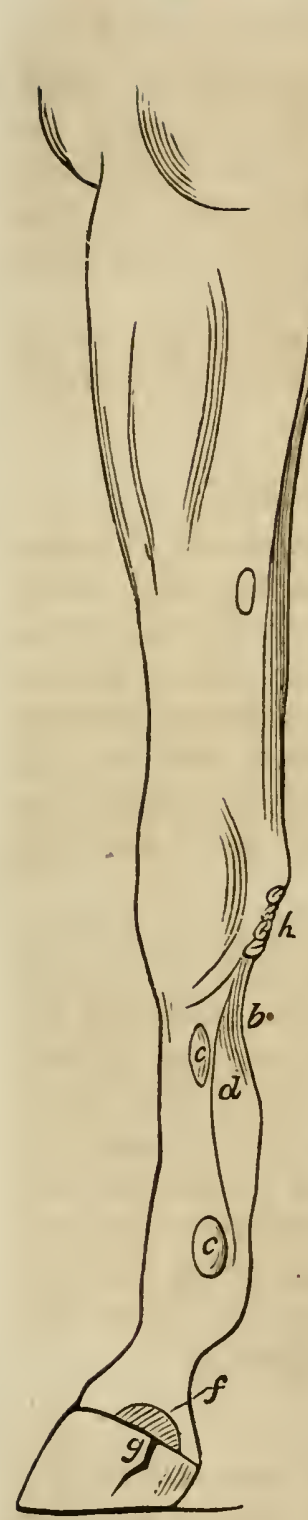

c Der Siz̧ Der unter Den Ramen "Splint" befann. ten Arautheit.

$d$ Ein follimmer fall bon Bejdivulift.

$e$ Der Siş Der flup̃gullen. .

$f$ Das Ringbein (ङanle, Reijten) im erften Єta Diutu.

$g$ Brüd)iger 5ूแf an Borderbein (sand-crack, cracked hoof). Siele 4. Sapitel.

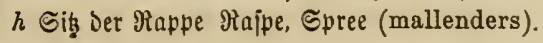

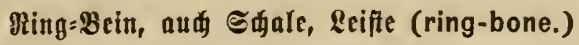

Daz Sufbrin (coffin-bone) ift sor Sino= d)en เes Fufes, weldyer son sen 5omiduben umidyloffen wirt, uno bilicet in Berbintung mit ben ifn amgebenten Traghüntern uno

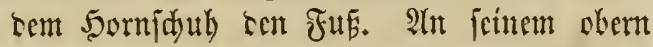

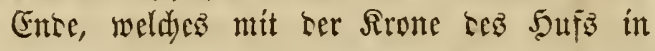
glcidyer Rinte liegt, befintret fit) รas (sielenf bicjez Situdacns. Derjelte ift febr weid) uno

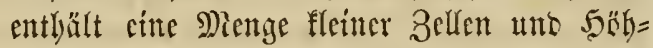
Iungen, sutd welde die Blutgefäpe res Fufez laufen. Das Sufteit ift fomobl Rranfbettent

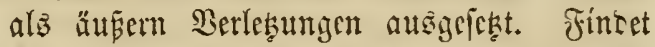

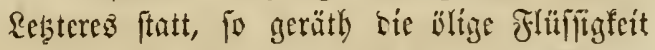
(synovia) tes 5ुufbcins in cincn flanfbaften

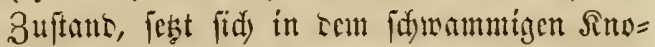

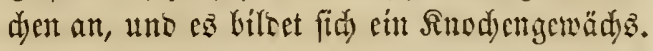
Da, wo raş Saar an Sen Som zeigt fid nun ein Plftergebilte, uno sie Entwiaf=

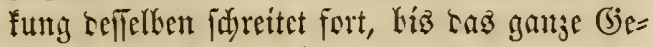

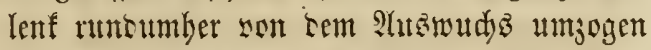
ift, Saber ser Name Ring=Bein. Die unter

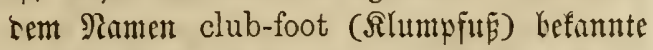

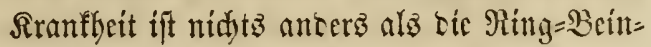
frantheit im bödjten (jrabe. In joldyer Rage

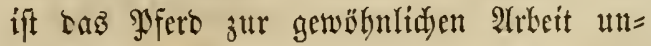
braudbar, wäbreno es io unwabridjeinlid ift,

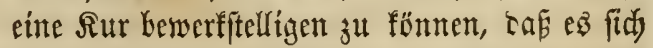
faum lobnt, eiuen $\mathfrak{B e r j u d j ~ z u ~ m a d y e n . ~}$ 


\section{$\mathfrak{B} \mathfrak{e} \mathfrak{b} \mathfrak{n} \mathfrak{d} \mathfrak{\mathfrak { n } \mathfrak { n } \mathfrak { g } .}$}

Ringbein fant nutr in ben eriten Stabien gebeilt werben. Selbfit bann ijt bie Seilung fajwierig uno fann nur felten alz bauerno an= gejehen werben, ba eine bejonbere $\mathfrak{A}$ njtrengung ober Erijdütterung

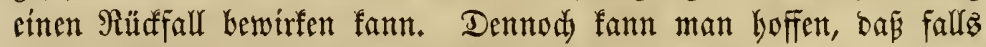

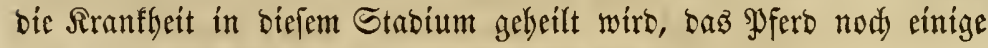
Jalbre für gewöbullidye $2(r b e i t$ gebraud)t werben fautn.

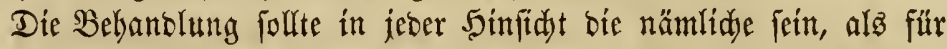
Spat yorgeiduriebene. Bor $\mathfrak{A}$ lem follte bas Pfero lang uno ununter= brodjen ruben.

\section{Rranfbiten ber Rnief由cibe (stifle).}

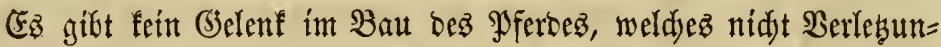

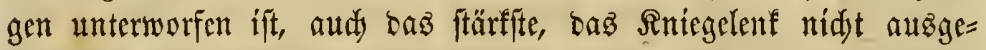
nommen. Es wirb oft fehr fallimm verrenft unt jwar gewöbulida

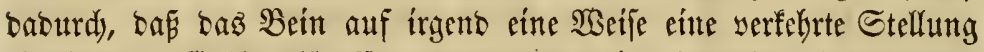

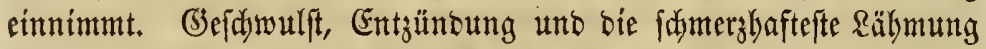
entffehen baraus. Sn mandien Theilen bez Ranbes nennt man biez

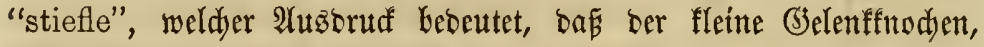

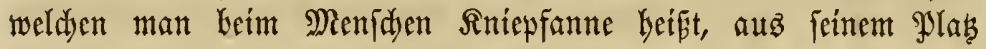
getreten fei.

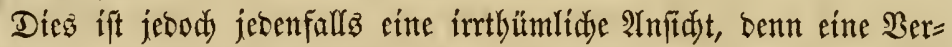

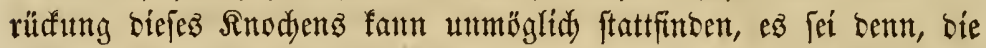

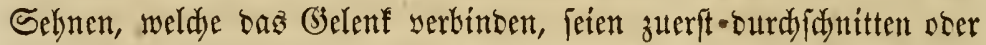

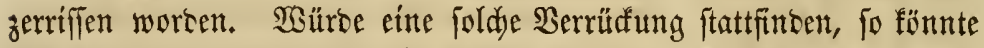

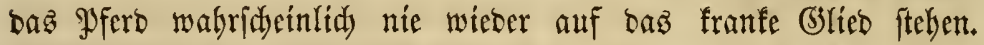

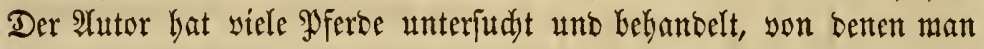
fagte, bie Sintefdeetbe fei verrentt, aber in feinem cinjigen Falfe fanto

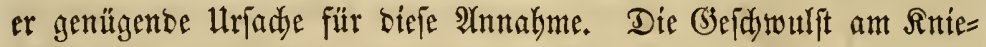
gelenf miro jebr grof́; uno burd) biefes, zufammen mit ber lang= famen Genejunt bez Pferbes, fomment bie, bie mit ber Sadje unbe=

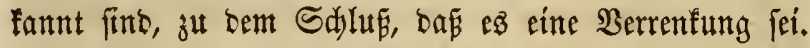

\section{$\mathfrak{B} \mathfrak{c} \mathfrak{b} \mathfrak{a} \mathfrak{b} \mathfrak{l} \mathfrak{a} \mathfrak{n} \mathfrak{g}$.}

Nur eine $\mathfrak{B}$ ebandlung, weld)e (Jegenteifung (counter-irritation)

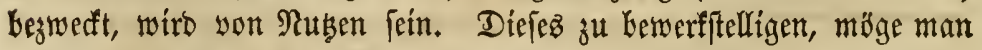
bie Stellen mit corrofisem Riniment jeben folgenten $\mathfrak{T a g}$ gut einreiben, 


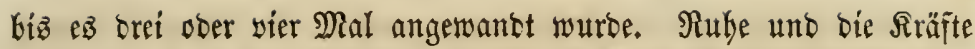

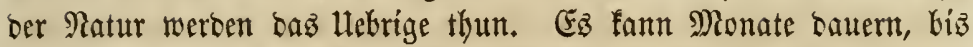
bas Pfero wieber zur 2rrbeit braudjbar ift; aker in biejem wie in

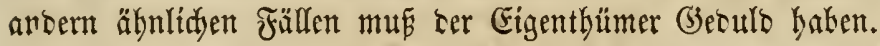

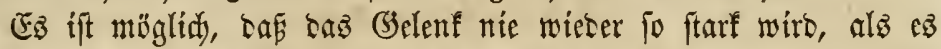

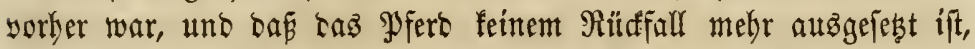

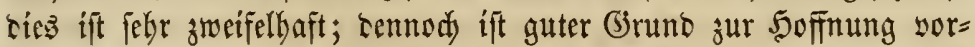
hanten, bemn nidyt wenig fogenannte "stifled" Paerbe find roieber söllig hergeftellt worten.

\section{Splint ober Rrantheit bes (Griffelbeins.}

Diez ift cin Inodyengewäd) am innern (splint) Briffelfein, Saber auty ber Rame. In Uriprung, Eymptome uns Entwiflung if bieje

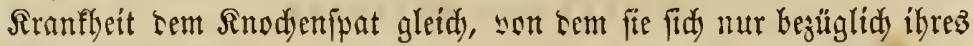

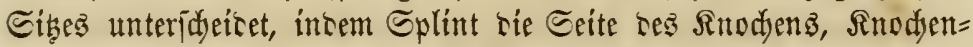
fpat aber bas Ende teflelken afficirt. Splint ift jecod eine weniger

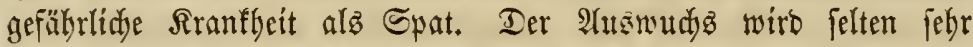
grof́, unt in hen meiften Faülen fint feine ser widdtigen Bänder be= haftet. Die Siranfleit fommt meiftenz an Len Borserbeiten, todt

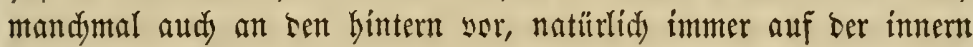
Enite.

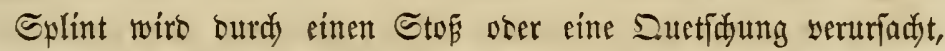

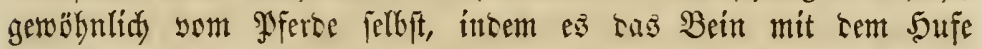

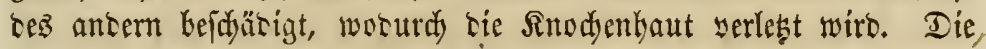
Frunftion biejer Şaut ift, sie äutere 5 aut vom $\Re$ nodjen zu trennen,

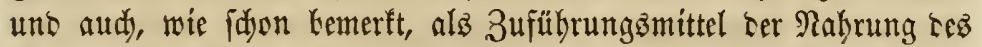

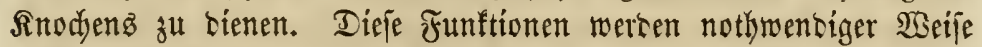

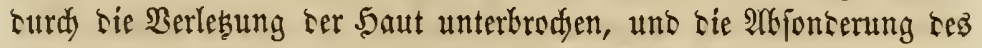

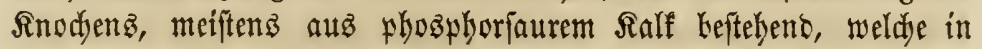

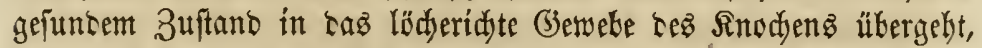

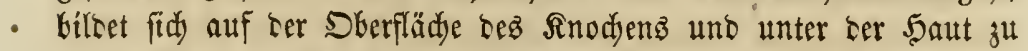

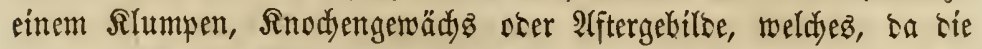

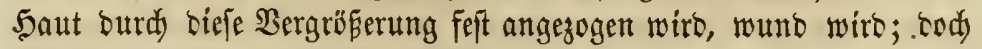
bie Ratur bequemt fid an biefen neuen 3uftano ber Dinge, fo caß diefez mit ber 3eit vergeht.

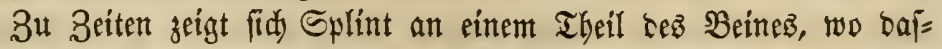
felbe mit einer grofen Selgne in Berührung fommt, ober er mag 
gerabe am Sislent feine Gridseinung madyen; in betoen Föllen ift natürliduer Seife Räfmung bie Jolge; aufer bem uno ber ergeugten Berumftaltung idabet die Rranflyeit nidyt.

\section{$\mathfrak{B} \mathfrak{e} . \mathfrak{b} \mathfrak{a} \mathfrak{n} \mathfrak{b} \mathfrak{l} \mathfrak{a} \mathfrak{n} \mathfrak{b}$.}

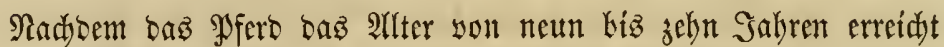
bat, seridumbet bie burdy Spint serurfadte Berunftaltung, uno es ift in oen meiften Fällen unuötbig, fernerbin Mittel anzuwenton. Entidyliefst man fid jebody, bie Bebantlung fortzlieben, fo gebraude man bas corrofive Riniment, nad) ber beim Spat gegebenen 2 nwei= fung, zwei ober orei Mal, um bie Sdymerzen uno bie Räbmung zu beben.

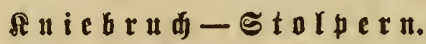

Stolpern fann nidyt mit Redyt zu ben Unarten bes redunet werben, bennody züblen ift jebod die Wirfung ciner Sdulterfranfleit ober beB untern Fust:= gelentes, ober eime üble (biewobntheit, weldye sie Folge feblerbafter

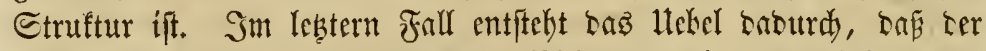

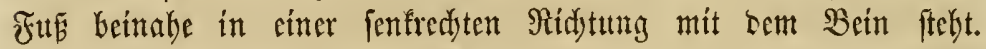

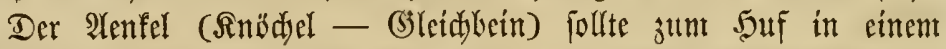
Witufel you etwa sierzig (5raben fteben; mandumal aber fintet man Pferbe, beren ânfel ganz fenfredyt über bem 5uf ftebt, in werl= d)em Fall berielbe eine aufredste Stellutg einnimmt uno rutio ift.

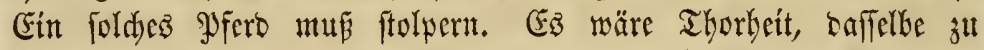
faufen ober einzubanteln, obne zusor feime Sinies unteriudt uno genau nad) feinten (sicwobntyeiten gefragt zu baben. Eit ftolperndes PFero ift nidst nur langlam uno unlider in feinen Bewegungen, fonbern ez ifit gefäbrlid, Daffelke zu gebraudjen. Der Reiter ftebt in Keftänoiger Giefabr, ïber feinen Sopf geworfen uno verlez̧t zu werben. Bor bem Sagen wirb es gewís, fokalo ber Weg bergattf fübrt, wo feine Dienfte am notbwendigften fint, fallen. albgejehent

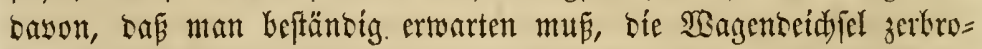
d)en zH ieken, wiro man mit einem Stolperer, namentlidy an Drten, wo viele Menjuden find, in bie unangenebmften Serlegenlyeiten fom= men. Denflben mit cinem jungen Pferb zulammen zu fwanten,

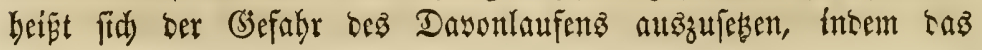


junge Thier, fallz daż Pranfe fallen follte, făeu wirs. Ein Etolpercr fann utr jum riflügen getrauddt werten, senn bier ift

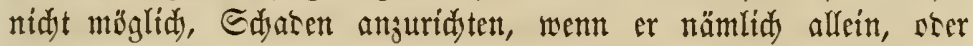
mit eittem alten, rufigen Yferse angejpaunt ift. Man büte fid sor einem Etolperer. Sein Eigenthümer ift Getrogen, aud wenn er ihn für eine geringe Summe cinthantelte.

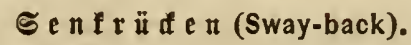

Diefez ift feine Siranfleit, fonbern eine Serunftaltung, welde ba=

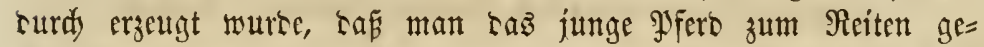
braude, che d)en, แnausgebiltseten Rüafenwirbel Kinakgetrüăt uno seren okern Enţen zufammengeträngt, tie untern aker gemaltjam auseinanter gerifien wutren. Der Miüfen ift nidyt getroden, aher fadrectlid ein=

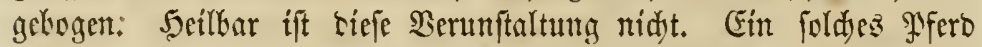

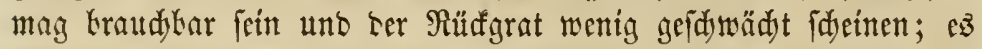
wiro fidy aber nie rafd forthemegen fönnen, uns feine Serumftaltung

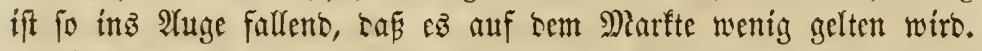

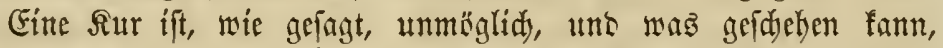

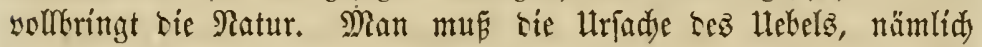

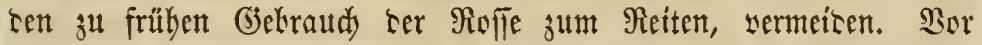
sem Ente tez żweiten Jahrez̧ follte man auf feínem Fohlen reiten uno aud bann follte mur ein Rnake sen Beriudy madyen, währent cin auşgewadjenter Mann erft eintge Monate fpäter haş Syferb zum Reiten gebraudien follte. 


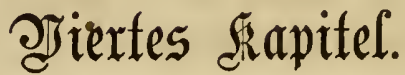

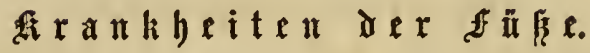

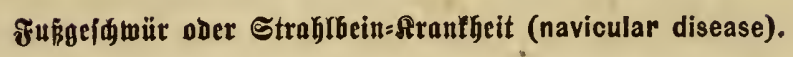

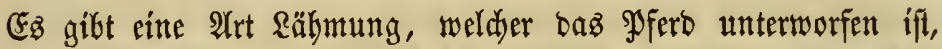
bie bem Farmer, wie ben Sadjfunsigen fajon oft nidjt geringe $\mathfrak{B e r =}$

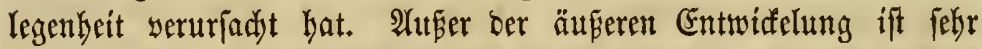
wentig bayon befannt. Sic fommt wobl nidft fehr oft, bod mand $=$

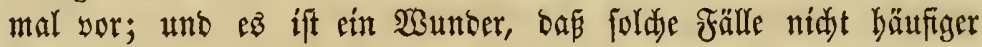
fint.

Man entbed̆t, ba griffen if, Gleibt lange unentiditeden. Biszmeilen idueint bie $B_{e}=$

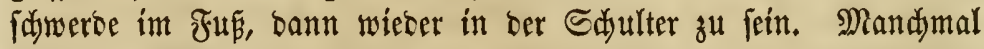
binft baz Thier, alz wenn $\mathfrak{e}$ vernagelt wäre, bann verfdminbet bie Räbmung aud wieber, fo bafis fie faum bemerfbar ift; fehrt aber, fajlimmer alż je, wieber zurüd. Snbeffen bat fid eine Rranffeít

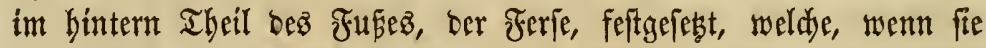

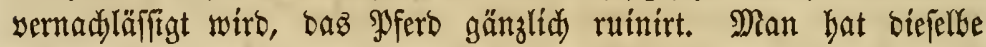
bie Sranffeit dez Strablteingelenfo genannt.

3wifden bem Suftein (coffin-bone) uno Rronbein (lower

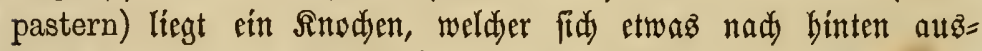

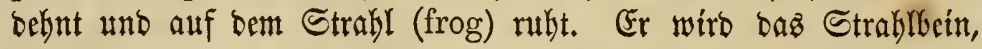
autd) Sdjiffbein (navicular bone) genannt, weil or bem Gerippe

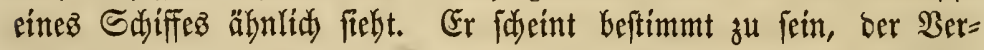
binsung zwifden bem 5 ufbein uno dem Gelent werbalb beflelben

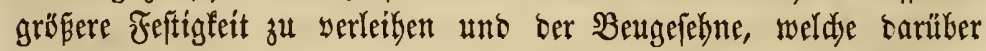
bingeht und unten im Soufbein eingeidelofien ift, mebr నraft uno

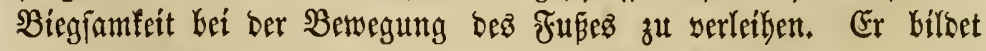

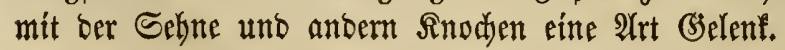

Das Strabltein uno (Belenf fint mandjerlei Bejdäbigungen,

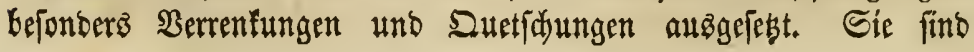


ebenfallz febr leidyt affiritrt, wenn ber Strabl bejdätigt ift, waz vft ter Fall ift. Er wirb gejduitten neer verbällt Surd) (beben auf

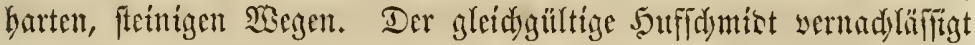

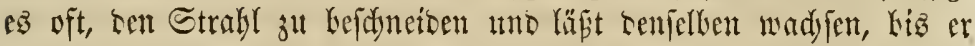

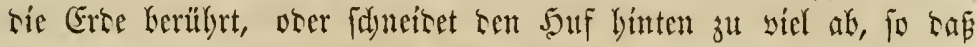

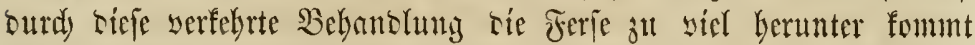

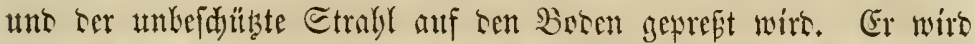
and) oft surd) fdarfe Eteine, bab (jechen auf gefrornem Boben and bergleidyen verwuturet.

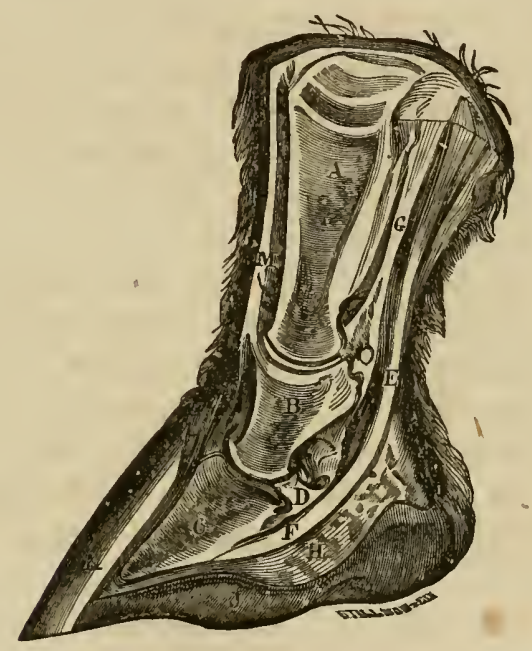
A. Jelfielbein (os saffraginis.)
G. Das Fleinere (Bleidbein-Band.
B. Rronbein (os coronae.)
H. Şufmulit (Cleft of frog.)
C. S.ufbein (os pedis.)
I. Soble.
D. Strablbein (os naviculare.)
K. Iritite.
E. Beugeiffnen (perforans \& perforatus L. Eubftanz des STronrings. tendons.)

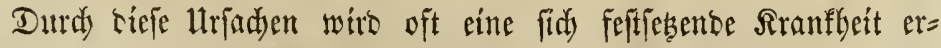

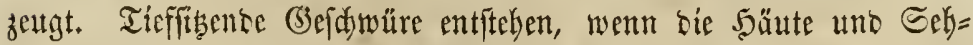

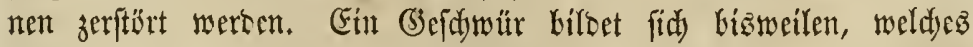
mit ter Zeit aufbridut, altz weldyem oft lange Beít Eiter fliefst. Stellt biefez fid ein, fo mag baz \$fero nod gekeilt merben; und bei jeber 2 frt ber bebandlung follte man fudden, folden Eiterab= 


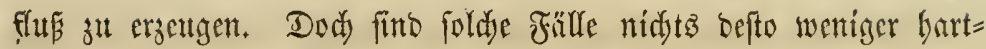
näđig. Sn viclen Fällen nimunt bie Sirntelleit aber auth) cine gans

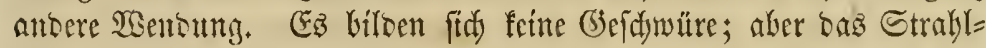
bein wiro franf tnto fängt an zut verfaulen; Der Sutf fdurumpft cint,

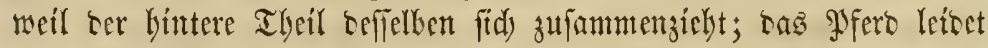

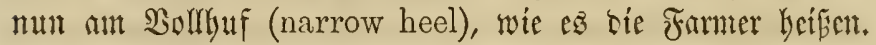

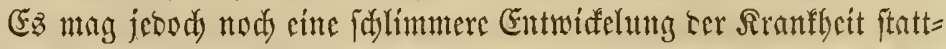

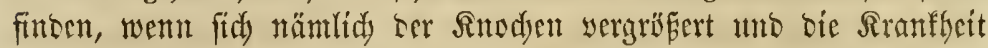
biefelbe Geftalt wie bei Ringbein uno Snodyenfpat (ringbone and spavin) antummt. Das Etrablecin wädjft in biejem Falle mit

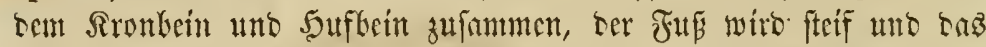

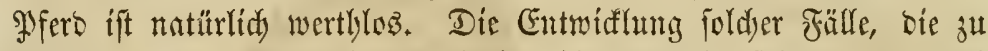
beobadjen cs ber Mathe werth ift, ift ungefälyr folgente: 3uerit

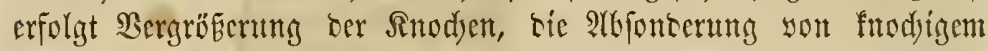

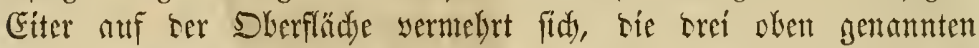

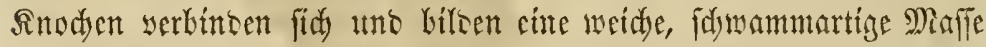

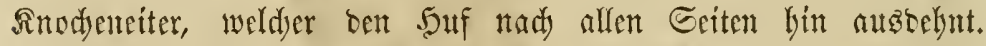

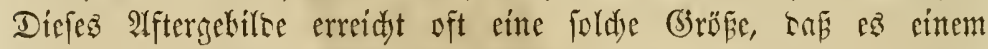

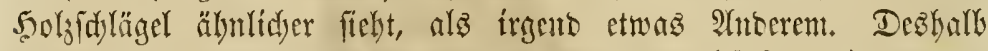

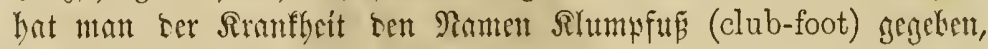

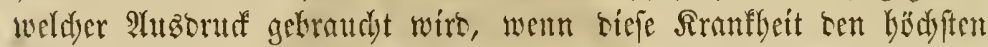

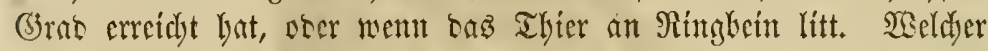

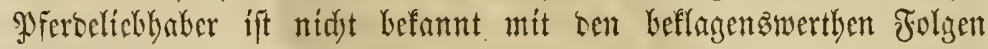

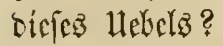

\section{$\mathfrak{B} \mathfrak{\in} \mathfrak{b} \mathfrak{a} \mathfrak{n} \mathfrak{d} \mathfrak{\mathfrak { n }} \mathfrak{\mathfrak { g }}$.}

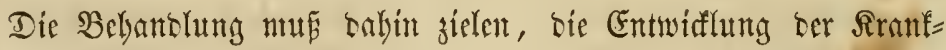

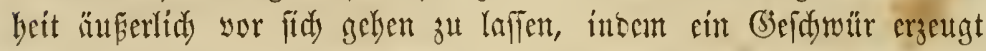
wiro, weldjes fich nake genug an tor Dberflädye befintet, um ten

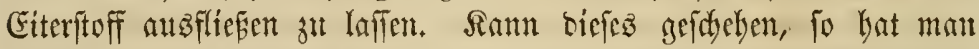

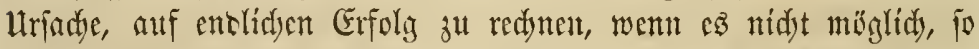

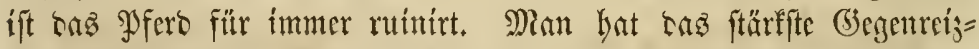

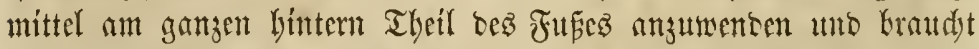

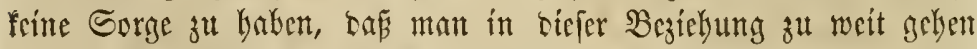

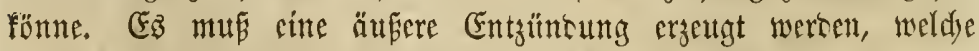

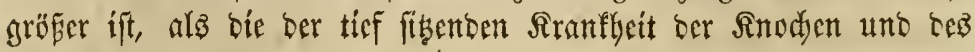
(J)clentfez. 
Sein Mittel fann für biefen 3 wed fo erfolgreid) angewentet merten, al: bie $\mathfrak{A}$ ețfalfe (corrosive Liniment). Nebft ter fduelfen,

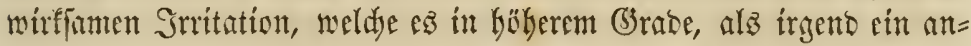
Leres Mittel Kersorruft, ift es termisge feiner Eigenjadaft, fdnell

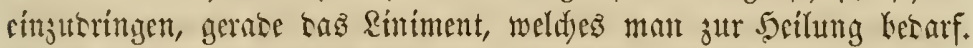

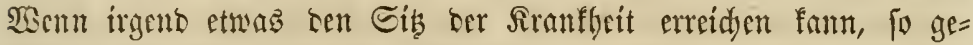

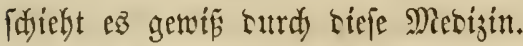

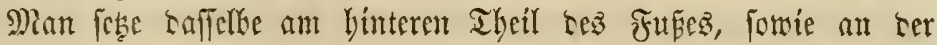

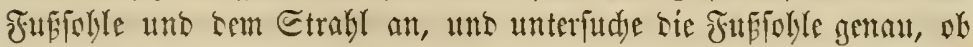

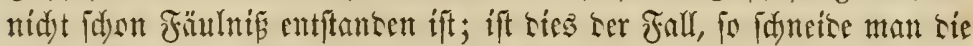

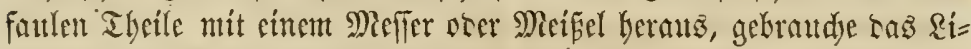
niment uno trodne es mit cinem heifen Eijen gut ein. Die Bremife

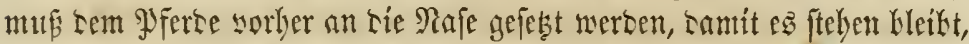

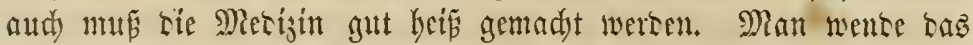

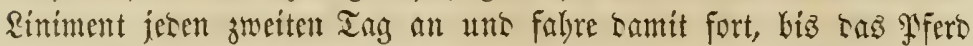

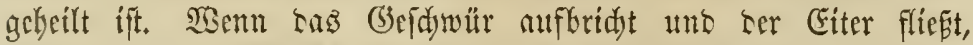

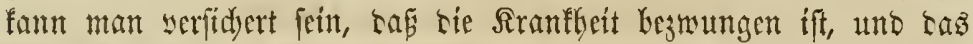
Thier Kesarf tann nutr nod) Beit jur yölligen (jenejung.

Man halte โas Mferb in rinem trodnen, füblen Etall, oter wonn ein Sisciceplats sorbanten ift, fo lafie man es Lenjelthen benüben.

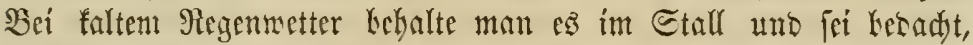

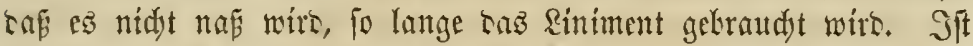
fén allyemeiner Sörperjuftand cin franflyafter, fo lafie man ibm cin= mal jutr $\mathfrak{2}$ (ser unt gebe ifm ein Pfund Edjwefel (sulphur) in an=

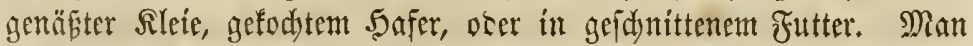
madye sier (5aben (Dojen) aus sem Edjwefel uno gebe semielfen

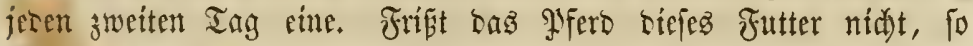

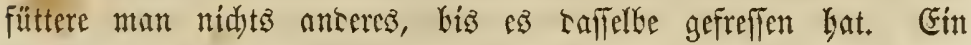
mentig bungern mag nüblitid feír.

\section{Diefe Sranthe it ift bic uriade mander anderen.}

Dieje Rranffeit ift gewöbnlid bie Utradje son mandjen anteren Beidymerten an sen Fünen. Sie entwiafelt fid auf gar mandjerlei S⿱⺈⿻コ一心

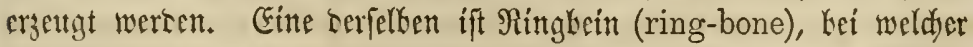

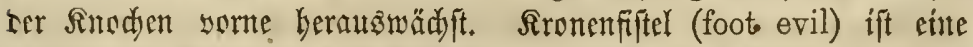
antere. Sotebei fliefft ber Giter oben am Jü rutbumber auz bem 
Sronturing (coronary ring). $\mathfrak{B o l f h u f}$ (contraction of the hoof,

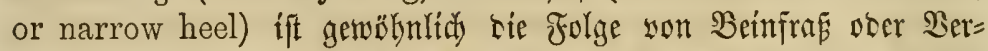

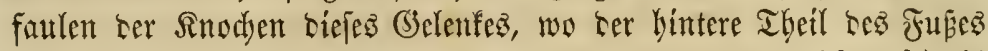
tann cinfült ober zufammenfdenumpf̣t. Etrablfäule (thrush) ift sur ber 2Anfang won Rronenfiftel (foot evil), ser eiterartige Etoff, welder fid im (stelenf fammelt, fltept surd) bie Ferje und Strabl aนt

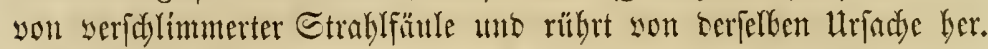

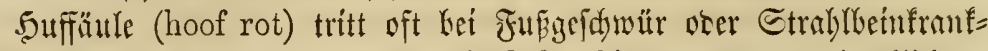
beit ein. Brüchige Shufe (cracked hoofs) fommen son bröutlidyent,

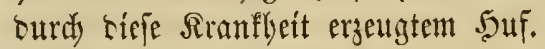

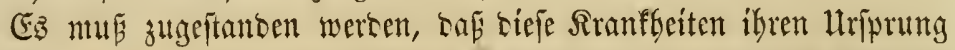
fonftwo, als in ten angegebenten ltrjadyen baben mögen, aher in ben meiften Fällen werben fie in Berbintrung mit ber genannten Sirant= beit gefunten unt in vielent Fälten burdy siejelbe erzengt.

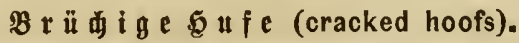

Diefe werben autdy vft jantbrüdige 5 ufe (sand cracked hoofs)

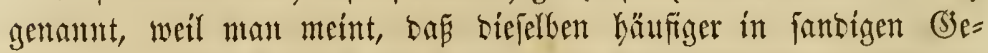

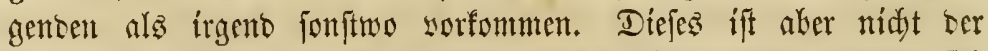

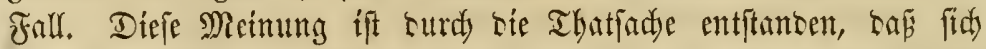

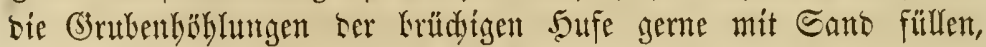

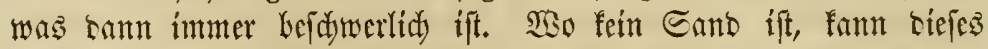

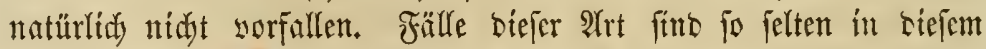
Rante, เás ez faum ber Mühe werth ift, Gierauf einzugehen.

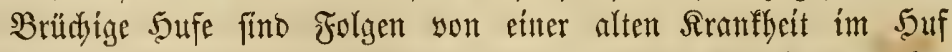

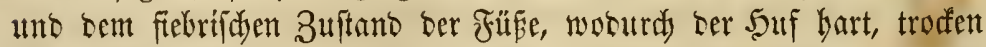

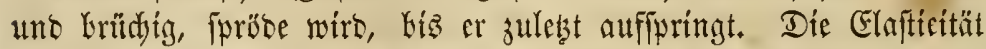

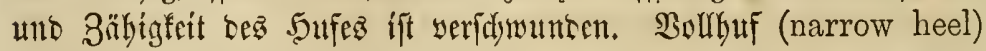
ift eine antere Hrjadye yon brüdyigen Sufen, nadjem baz Fieter biefelten hart uno troden gemadyt hat. Der hintere Theil her Ferfe

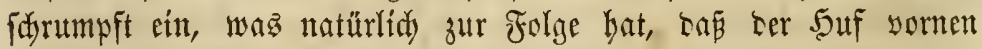

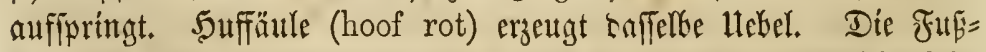

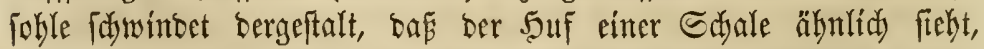
weldye bart unt brüdyig ift. WSenn bas Pgero eine geraume Zeit

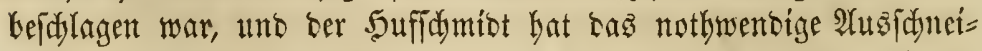

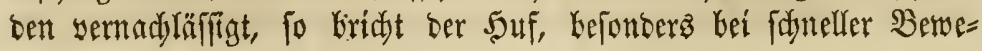




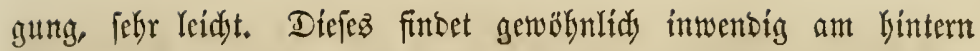

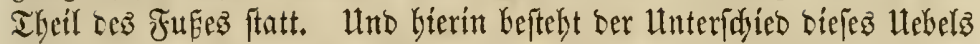
yon ben burdy Bujammenzielyung erseugten Brüdjen, weldje, wie wir gefelyen baben, gewöbutlidy yorten fitto.

Die sorteren Fü̈ße werten leidjter brïdjg, alż bie binteren.

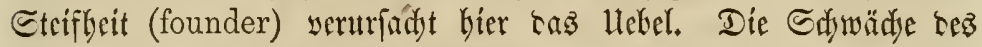
5ufs verurjadyt bie 3ujantmenjiefung beffelten uno erjengt bie

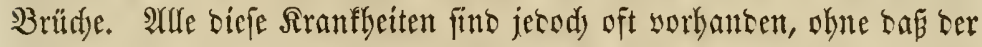
Suf Grüdjig wirb; aber joldje erfranfte Sufe wercen viel Yeidjter Grüdjig

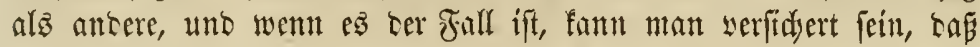
es yon ten bier angegebenen ltradyen berrïbrt.

Die Brüdje in tem sortern Theil bes 5ufz zielen fidy oft biz oben an ten Sironing; fie fint nidyt won gleider Tiefe uno butdy= fanteiten fie ben Shuf oft mur theifweife. Sn foldyen Fällent thum fie wenig Edjaben, uno mit einem guten 5ufeifen veriehen, thut Las Wyfero bei mäfigem (biekraut) nodj jalyrelang gute Dienite. Die

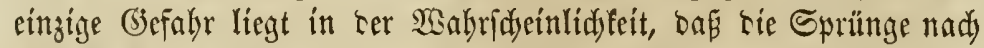

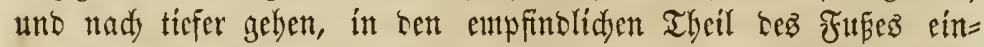
fdincicen uno tann Räbmung verurjaden. Wenn fie fid in ben Tradyten (Duartieren) befinten, erfitreffen fie fid felten weiter, als balkwegs am Sufe Ginauf, aber fie mügen tief unt fegr wunt feín.

\section{$\mathfrak{B} \in \mathfrak{b} \mathfrak{a} \mathfrak{\mathfrak { d }} \mathfrak{\mathfrak { u } \mathfrak { n } \mathfrak { g } .}$}

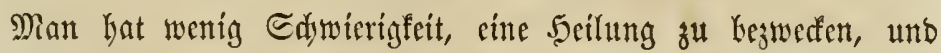
mus fich nur Beit baju nebmen. Man kemülye fid, sie sie Bitüdye

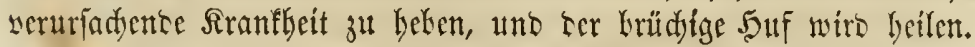
Sind rie Gruben vornen am 5 uf, fo feille man rie Ränecr ter fel= ben ab, lege ein ungefählo ein Zoll langez Etü̆d Eegcltud) ben langen 绝g tarauf, uno nadjoem es mit 5 eft falfe (adhesive salve)

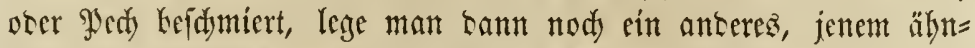

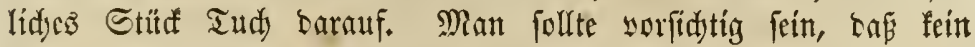

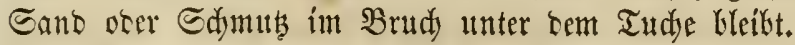

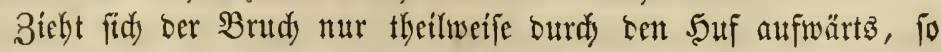

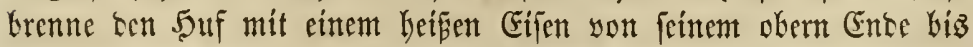

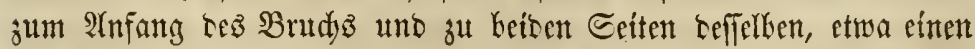

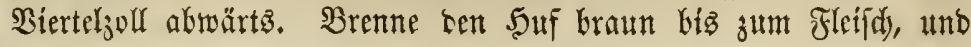




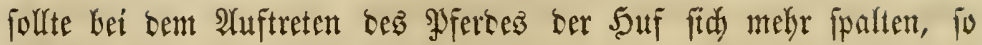

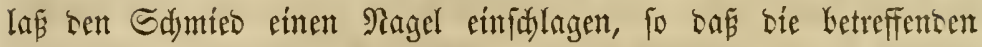
Tbeile zufammengebalten wersen. Der Ragel follte auf biejelse Weije wie beim 5uffeidslag verntetet unt die Cnen follen glatt gefeilt weroen. Mandymal mag es nothwettoig fein, zwei Plïgel einzuld lagen, ben einen etwas böber als ten antern. In tiejem

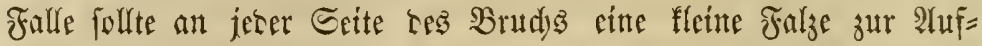

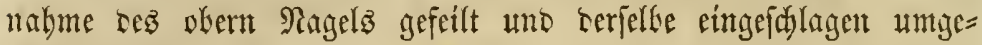
ritetet werben.

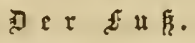

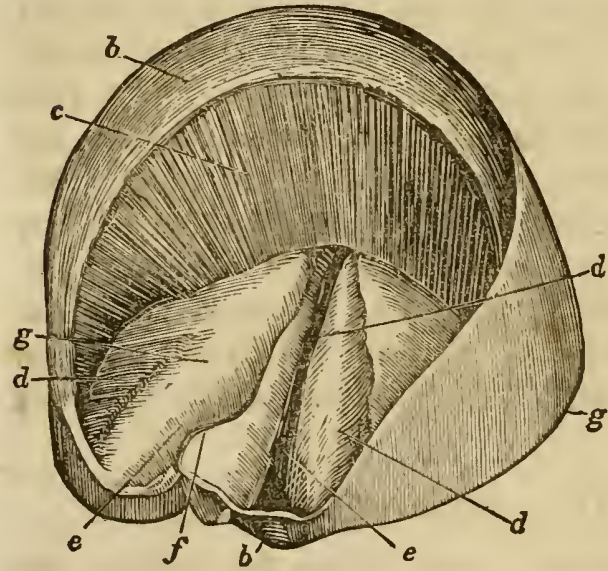

a Die äแpere Srufte.

$b$ Der frronring (coronary ring.)

$c$ Die fleinen hornidyten şrn̈tt. d) cu, welfje Die Srujte ïbergie. belt.

$d$ Diejelben, wie fie fid über die Edfitreben fortietsen.

$e$ Tie beisen anğgehöblten Sberfläd) Des sooruitralls.

$f$ Die sufiuulit (Epalte Des $g$ Strabls (cleft of the frog.)

$g$ Die Editreben (bars.)

$h$ Der runde zum Strabl ge. hörende gheil Der ferfe.

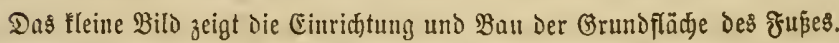

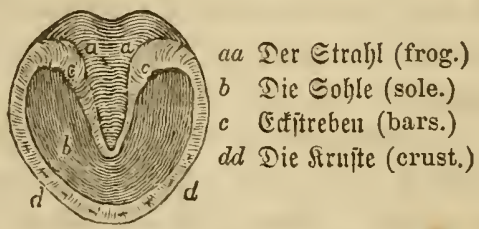

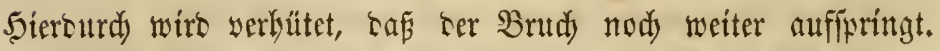
Sein Wfers, cas an brüdigem Sufe leitet, follte gebraudjt werten,

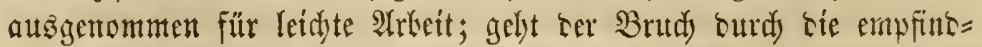

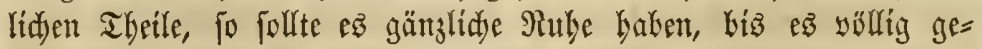
Geilt ift. 


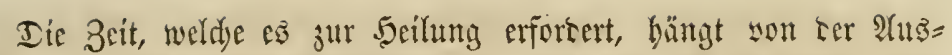

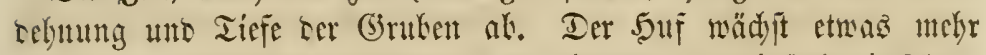
als cinen halken 30 If im Monat, uno intem man einfad sie Ränge

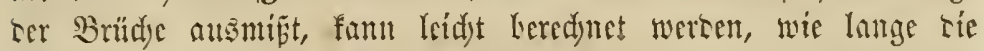

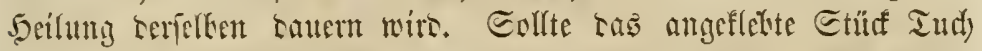

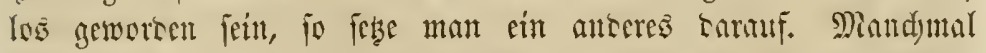
mag cas gut fein, tie Eifen aufjuld lingett. Dutd) tie alt tent Irad)= ten (Duartieren) befuntliden Brïhe follte inmer an seren Ence citr Ritgel orer Riete eingejdjlagen werten.

\section{$\mathfrak{g} \mathfrak{u}$ ¡ f ä u $\mathfrak{l}$ e (hoof root).}

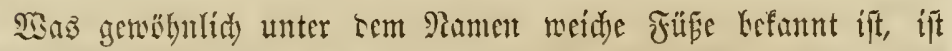

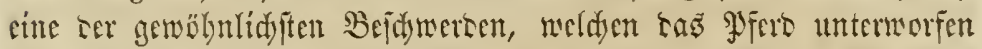

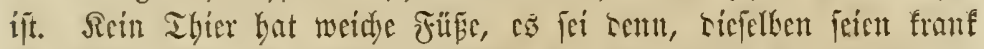

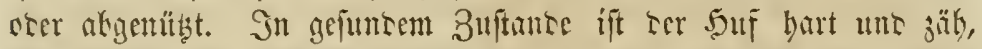

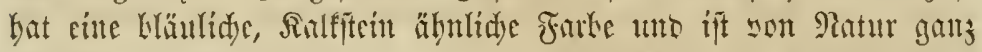
gecignct, sic Beidärigungen unt Erjdütterungen ju crtragen, wel=

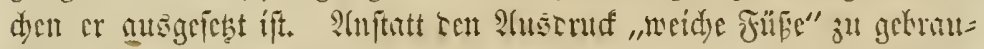

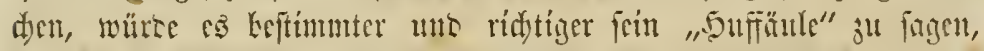

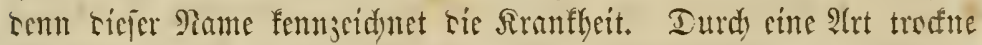
Fänle, weldye einen fickerifden 3uftant in allen Theilen herwortringt, serfault ter buf utto fajwitrset. Iie anfünglidye thriadye bason

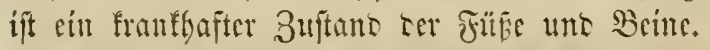

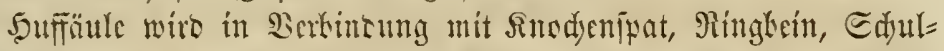
terentjüntung, Sironfittel (foot evil) uno aud) sfit mit ser Etrahl=

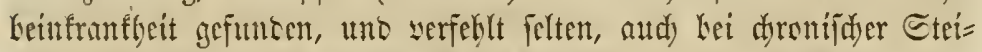

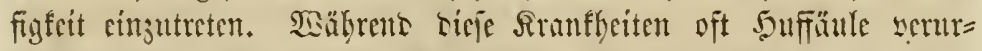

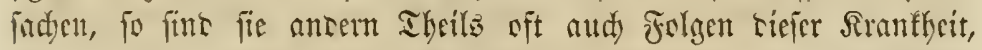

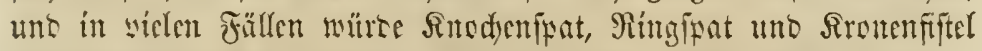

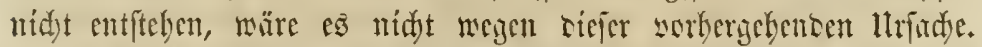

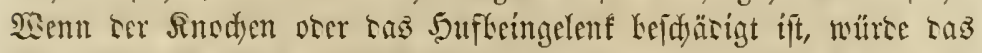

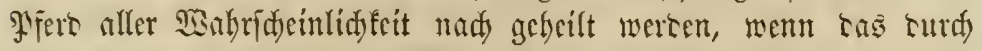

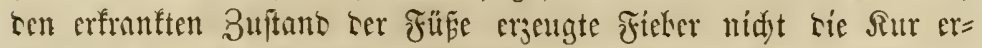

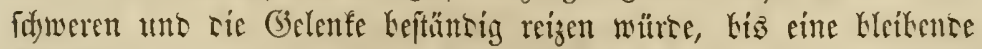

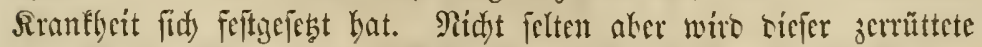

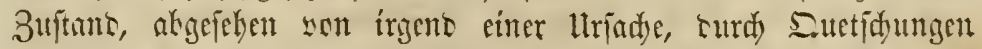

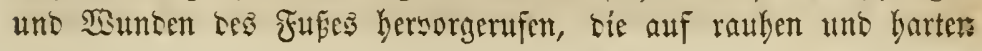




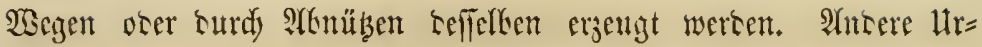

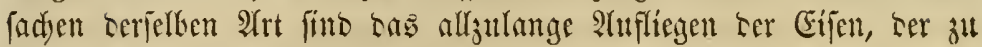
sft wiebertgolte 5uffbejdlag unt nafle ungefundo Ställe.

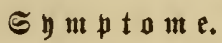

Die Rramfleit mag erfantut werten an sem trofenen, Sircite äbn=

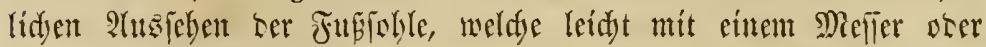

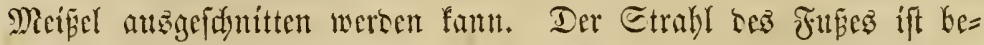

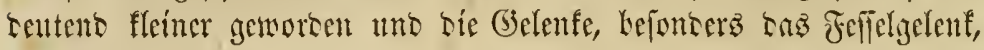

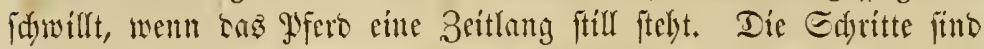

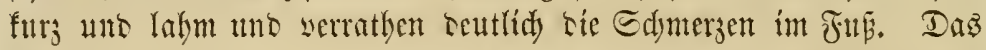

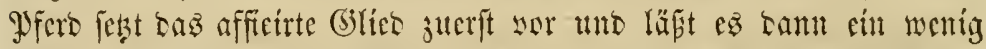
ruben, ocer, went beire Finfe frauff fint, wiro ter gJatient juerft sent

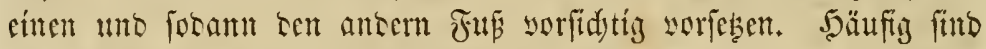

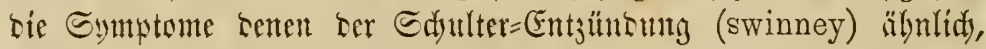

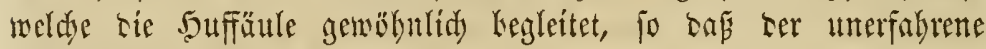

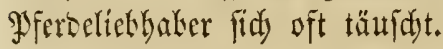

\section{$\mathfrak{B} \in \mathfrak{b} \mathfrak{a} \mathfrak{n} \mathfrak{d} \mathfrak{u} \mathfrak{n} \mathfrak{g}$.}

Sit sie Rranffeit nidjt mit einer antern verbunten, fo Kewirft bie Treşalke (corrosive liniment) tie Sceilung; ift fie aber mur bie Folye ciner anbent, fo mup sieje erfit gelyoben werben, ehe man erftere tireft bebandelt famt.

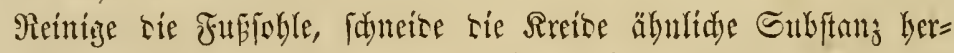

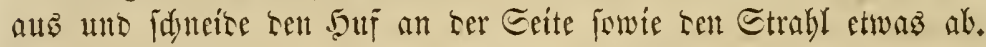

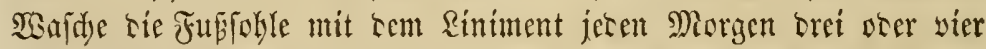
Tage bintereinatter unt trefene $\mathrm{eB}$ mit einem beipen Eijen gut eint. Eetbe die Bebantlung jwei Tage aus und beginne micter, wie sorber.

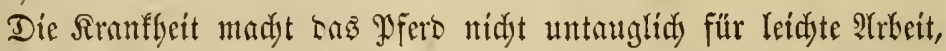

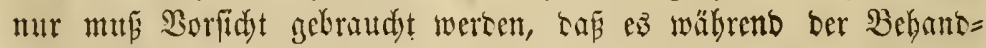

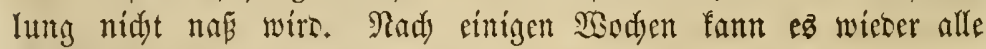

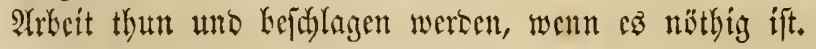

\section{Steingafle $\mathfrak{n}$ (corns).}

Dies ift cinte grofép Plage ber Stallungent. Rähmung in ton

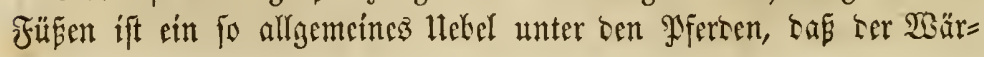


ter uno Etalfeigenthümer ç nidst überwinten fönnen, fokald ein $P$ ferb

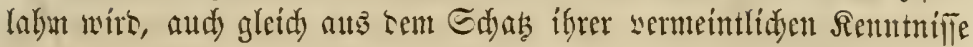

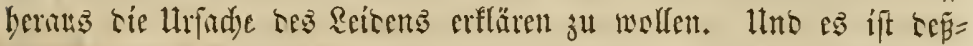

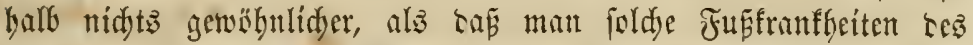

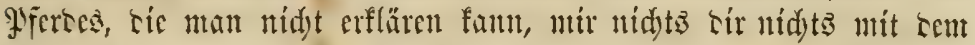
Namen Eteírgallen (corns) Kejeidunt; cin Srrthum, weldyen aud

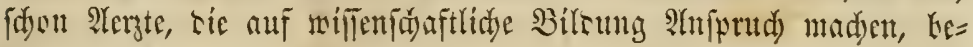
gangen baten.

Ein terartiger Fall fam mir im Friblyabre 1866 sor. Ecit einer geraumen Jeit war eine pradstwolle Etute, meldye eittem 5 crm in Cillcimnati gehörte, megen "Stcingalfen" unter ärstliduer Bebautlung,

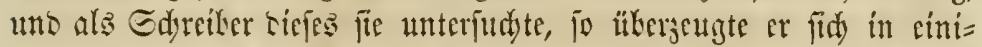

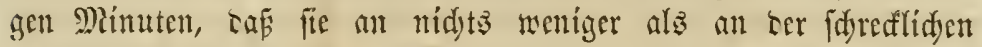

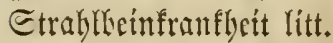

Sír baben nod nif etwas an ten Füfen Ler Pferce gefuncen, meldyes mit Redjt "Eteingallen" (corns) genannt werten fomnte, baten aler fdon siele Fïlle lebantelt, wo fid cine cigentfiumlidye

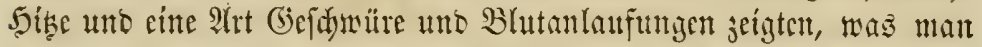
intit tent Ramen corns Kezcidjnet. Dian nimmt an Ten Eoblen ent;ünte rothe oser gelblide Fledfen wabr, sie gemsibnlidy zuerft in ren Iradyten (aud) Suartieren), an beiren Eeiten tes Etrabl: ent=

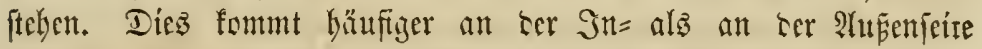
ter Trudyten sor, unb aud öfter an ten Borter= als Sinterfüfen. In allen Fällen, weldye mir unterfudyt baken, war Suffäule tabei im Epicl. Die Eoble tes 5ufes fault, bis rer empfinclidye Igeil

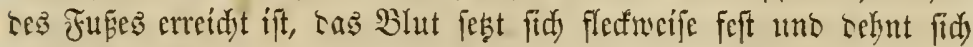
nad) allen Ridutungen linienteis aus uno gikt ben Theilen cút khtut=

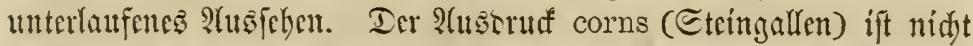

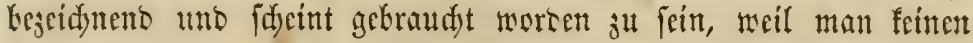

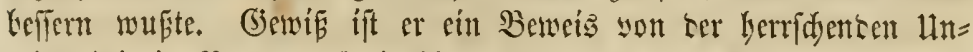
willentyeit in Bejug auf rie bier Feidrietene Sranflycit.

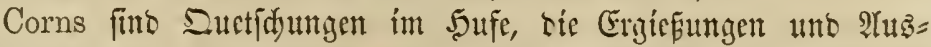

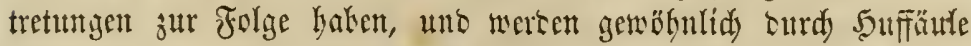
berworgerufen. Eie gebören ju serfelten Familie und baten to ju lagen benjelken Etammbaum, wie Etrahlfäule, Raufe, Rronenfiftel uno Bolbuf.

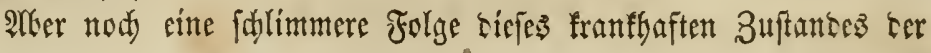




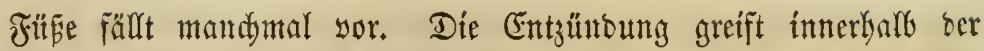

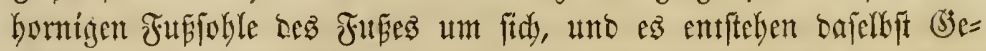
fdywüre. Der Eiter, welder fid fantutelt, ergmingt fid mandymal

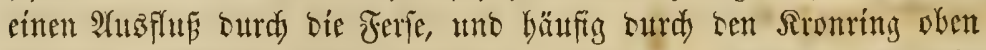

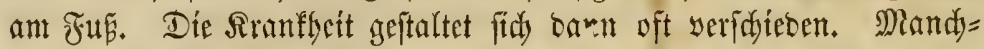
inal entfiftgt Sronenfiftel (foot evil) ur.o behnt fid um ben ganzen

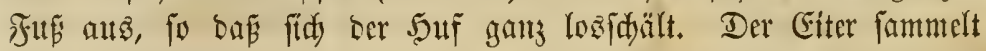
fid) oft yeridiebene Mial uno mag Monate lang laufen.

\section{$\mathfrak{B} \mathfrak{e} \mathfrak{b} \mathfrak{a} \mathfrak{d} \mathfrak{I} \mathfrak{u} \mathfrak{n} \mathfrak{b}$.}

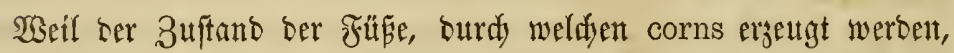
you 5uffäulle entipringt, fo milifen biefelben Mittel, wie bei lebterex, angewand werten. Man beile sie Suffäule uto corns yeridywinten

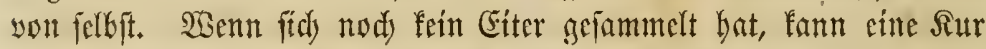

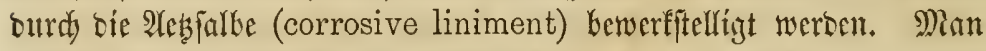

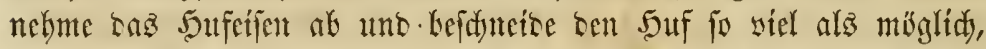
ebento ben Strabl unto grabe ben fautlen Stoff aus bem $5 \mathfrak{5}$, ge=

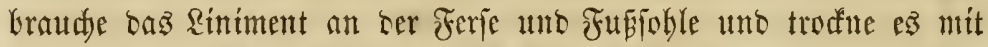
cinem Keifen Eifent gut cin. Wistererhole ijit nidyt nothwentig, bas heifie Cifien an ber Ferje mebr als cinmal

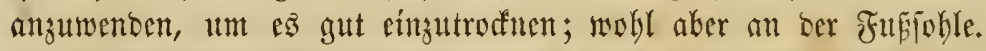

Sm Sommter 1866 belbanbelte ber Edyreiber cinen Fall an bem Sofert. Dez berm Carly in Fetersburn, Boone County, Rentud"y, weldjez ciner ter fdylimmiten Frälfe war, sie er je fah. Die faule,

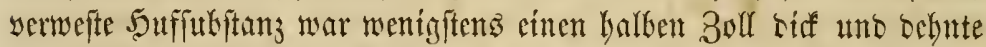

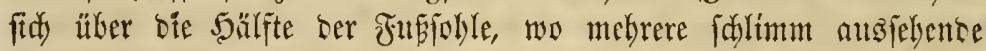
Stellen waren, auż, währeno bie Sohle an ben Enten ber Irndyten roth unt entzüntet war. Die Rennzecthen seuteten bercitzs barauf

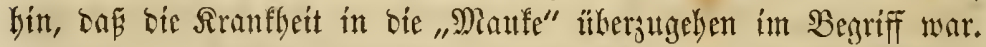
Das Bein war iefr gejdyollen biz ans Eprunggelent. Sisegen oies

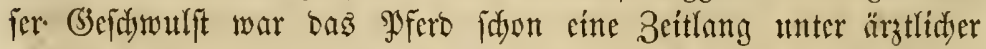

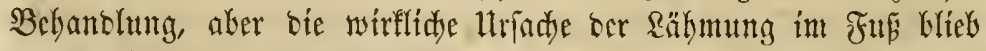

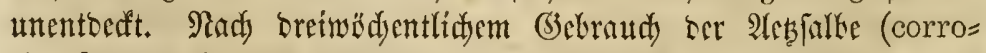

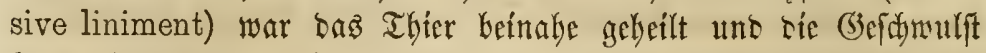
faum bemerftar. Die Fortfetsung berfelben Bebantlumg bewirfte yolfommene Scilung. 
$\mathfrak{B} \circ \mathfrak{I} \mathfrak{l} u \mathfrak{f}$ (contraction of the hoof, or narrow heel).

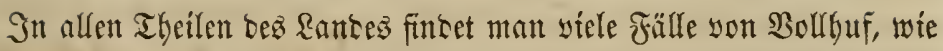

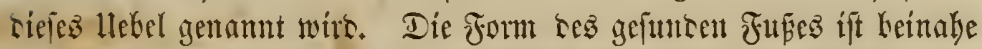

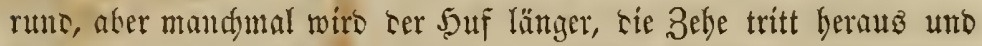
ter lintere Theil jieht fidh zufammen. Afllgemein wito angenommen, inj sie 3ujanmentiehung tie Folge son tem Befdulagen ift, aber

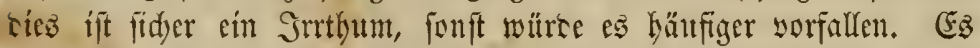
gibt feinen (3runt, warum biejelbe liriade, auf siejelke \$seife witfent, nidjt Gäufiger uno allgemeiner biejelben Folgen baben follte. Niddt

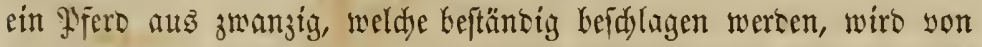

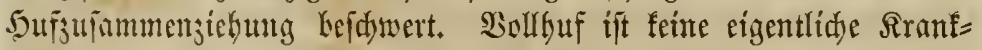

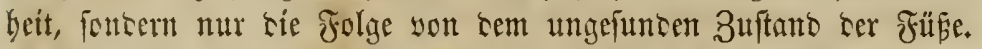

Eo lamge als afle Theile im 5ouf in ithrem natürliden Buftamb

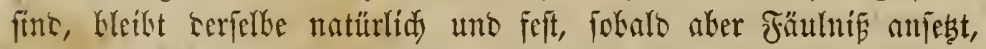
mas aud immer sie Hrijadje savon fein mag, fo zieben fid sie Theile

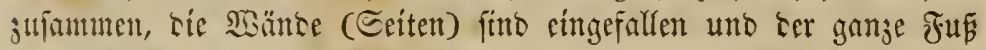
ift mifigeftaltet. Dicfes ift ter Berlauf tes Boufufä. Der Suf

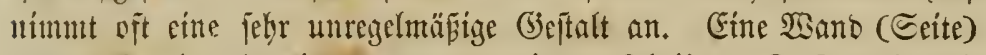
fält mehr cin als bie antere, Ier nietere Theil ter Ferje treht fid nad) Smnen orer audd nad) Itufen uno tie Zehe verlängert fíd

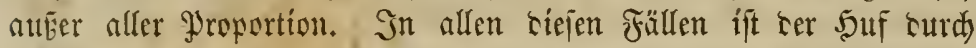

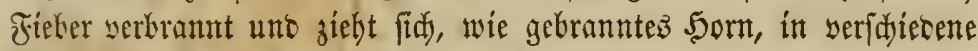
Formen.

\section{$3 \mathfrak{B} \mathfrak{c} \mathfrak{a} \mathfrak{n} \boldsymbol{b} \mathfrak{l} \mathbf{u} \mathfrak{n} \mathfrak{g}$.}

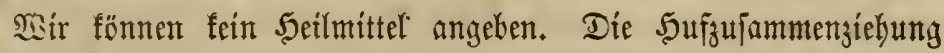
hört auf, wenn sie Sranffeit, welde siejelke hersorbringt, geheilt

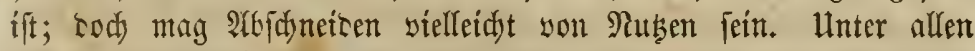
bejonters eittgeriditeten Soufeifen, tweldje emproblen finto, ift feintes

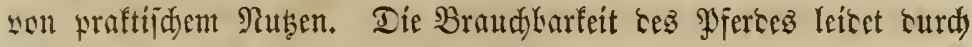
Solfhuf nidjt immer erheblidjen Edjaten; pbwohl zu fajnellen $B_{e}=$ megumger untauglid, mag Dienjte thun.

Berleţurg Des Etrahls, aud Gahel (injuries to the frog).

Der Strahl (frog) ift ein Theil bes Fukez, meldher bejonterz

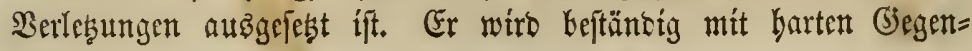




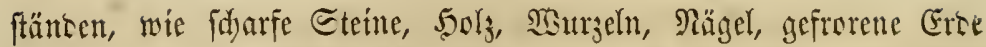

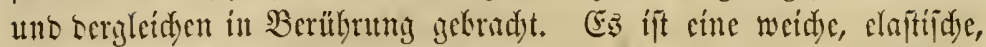

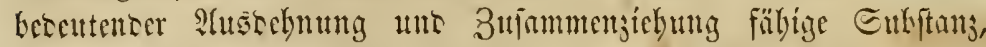

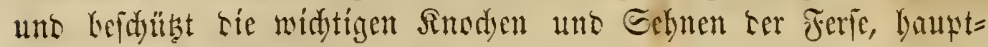

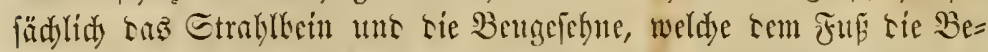

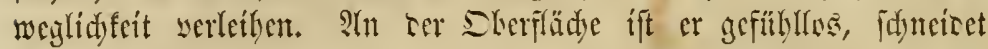
man ater ctwas sayon ab, fo wirs ter emprintslidje Theil kalo er=

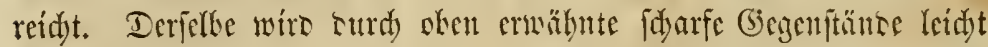
verlest, Ficher unt Entyüntung serbreitet fid) üler sie nabe liegen= ten Theile uno fringt nft tiefe uno bartuäatige Gejdymitre bersor.

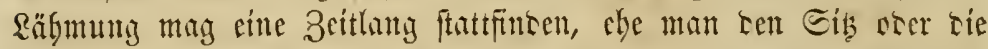
urfadje ber Sranflyeit entredt. Der Etrahl follte gut leidutten

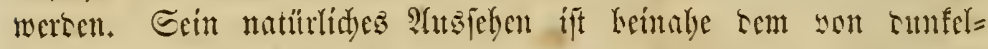

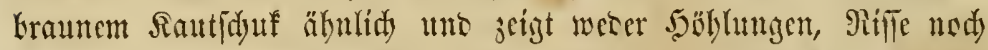
Spalten irgeno weldjer Art. Sistro irgeno cin fajmarjer fleft im

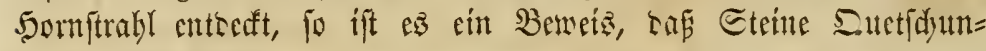
gen ergetugt bahen.

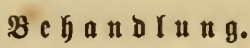

Die Áthliflfe (corrosive liniment) entfernt alfe Epuren ticjer

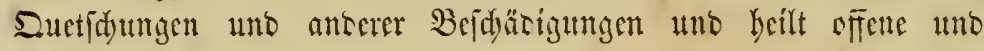
wunte Stclfen.

\section{Die Miche, Etcifigfcit (inflammation of the feet, or founder).}

(3)

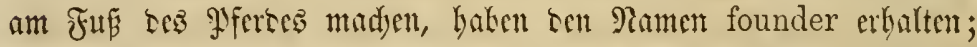

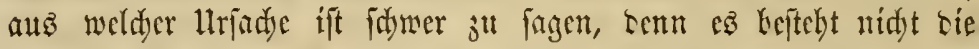
geringfte Serbintung 3mifden tem 2 tustrutf uno ten Symptemen

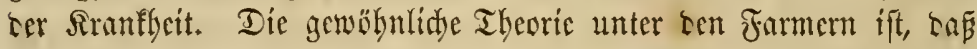

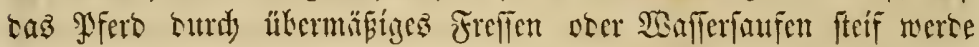

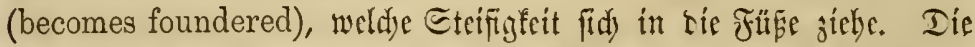

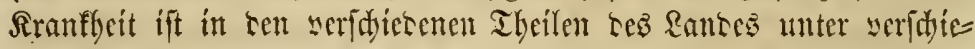
benen Ramen Kefaunt, i. $\mathfrak{B}$. corn-founder, water-founder, grassfounder etc. (

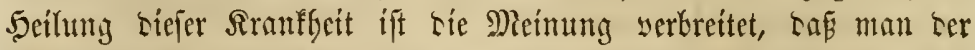

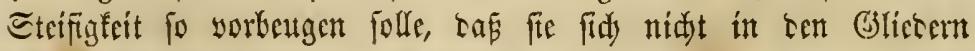
feftétst. 


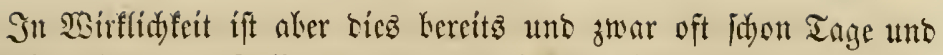

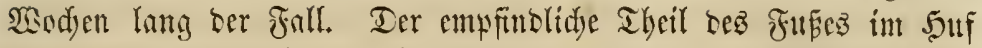

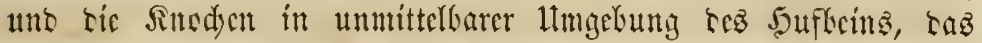

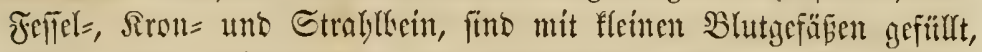
meldye riefe Theile mit Rabrungegfuthitanzen werfehen. Die Entzün=

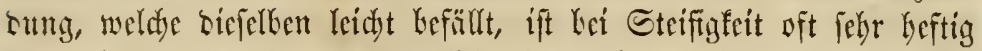

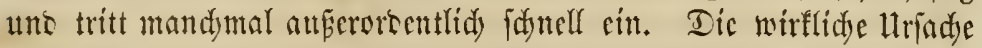

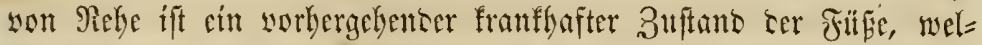

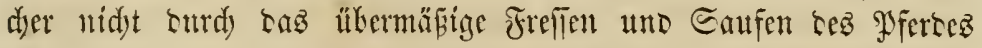
bersorgerufen, wobl aber biersurdy veridylimmert mutse. SBie bei

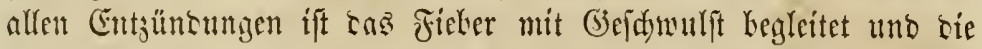

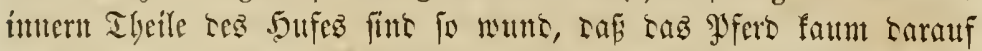

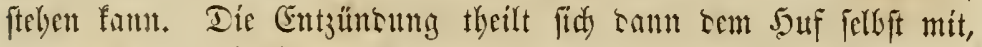
weldjer surd) sic iunere (bejd)wulft anseinantergetrieten uno ganz

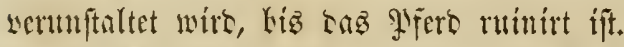

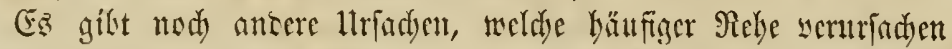

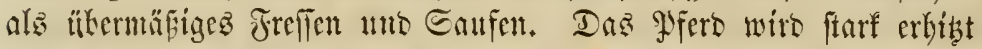

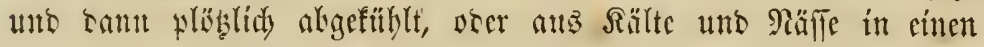
warmen Etall gebracts, no feite Finfe im Etrob oter marmtem

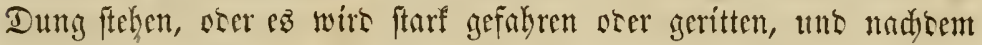
ca an cintem Syfoften angebutren, in fuictiefem Dreff geftanten, in einen warmen, feftserfdylofenen Stall getradyt. Ein Pfero, weldez

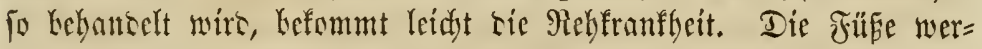
ธen crausen falt unt im Etalle erbib̧;

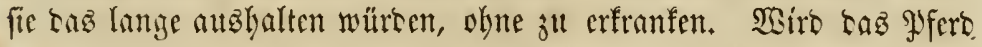
gut kefandolt und ift ez fonft nidyt franf, fo befommt es nie bie Rebfranffycit.

Gine Rranflyeit ber Füüe, yon weldyer gewöbnlid Lie yorbern

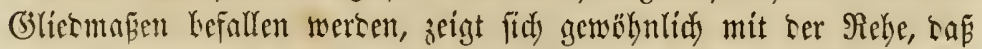
man faum umbin fann, nidyt in riejen ltebel sie 5atupturfadye zu fudden. Sut hutnerten Fällen yon Eteifigfeit, weldye ber Edyreiker un= terîtute, war nidjt ciner ganz frei yon 5 uffä ule. Sn tent mei= ften Frällen war bicje fdyon șodjen umo Monate lang yorbanten. Die üblen Folgen tes 3uftantes folder Fäpe fint nur zu bäufig ükerfeten morsen.

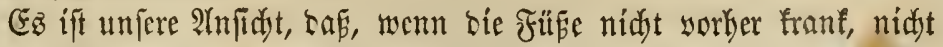

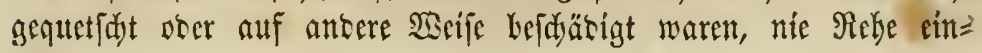


tritt; รaf baş, was unter bem Namen Founder befannt tif, nur einc

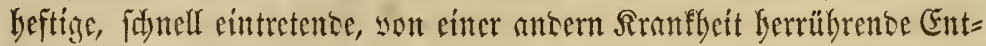

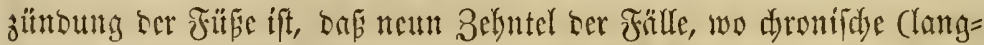

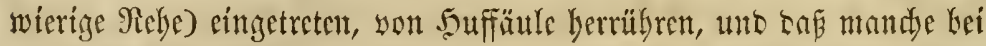
ben Pferoen yorfommente Rälynuth, die won sem Eigentbünter nidyt beadytet wurbe, Der Beweis eines franflyaften 3 uffandes ift, weldyer

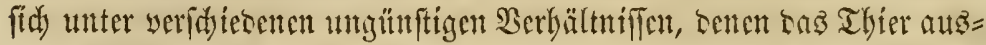
gefebst ift, zut dyronifdyen Relye entwidfeln mag; nidyt ju crwäbnen ser Uebel, weldye Durdy sie unnatitrlidye Form uno Bergröperung ter Füfe bersorgerufen werten.

\section{ธ $\mathfrak{m} \mathfrak{p} \mathfrak{t} \mathfrak{m}$.}

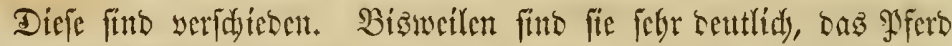
jeigt bie Befdaffenbeit feiner Sdymerzen unwerfentuser an; oft aber

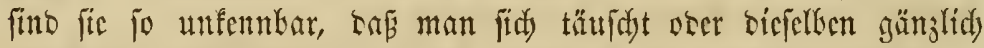

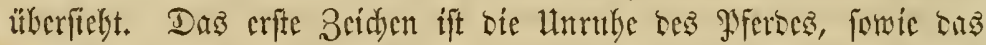

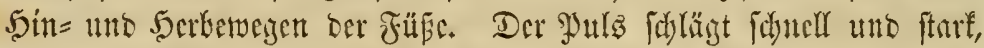

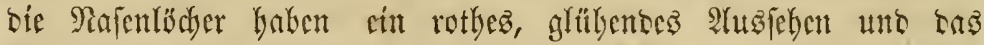

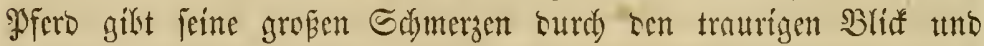
bäufigę fdweres Stöbnen zu erfennen. EG bleibt ntdyt lange auf oen Füfen fteben, fann fith aber andy nidyt anf bie geroblynlidye

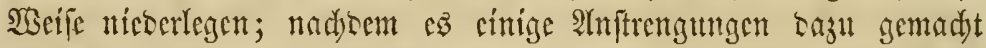
bat, ftebt es wieber auf, orebt fid wieter um, yerüntert feine Etel= lung und probint wieber, fid zul Iegen. Diejes wiebcrbolt eg oft

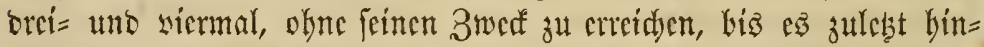

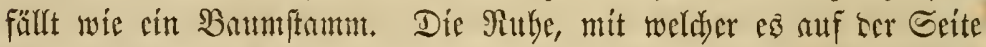

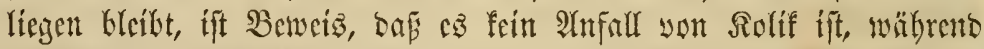

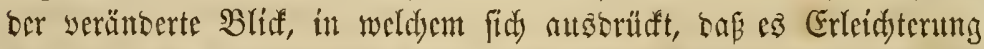

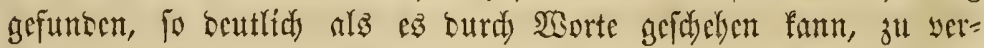
fteben gibt, woldyer $\mathfrak{T}$ rt bie Sranflyeit ift.

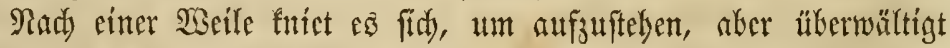

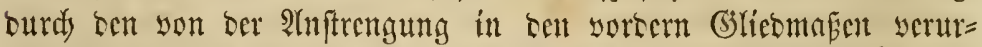
jadten Gdymers fält co weber auf tie Scite. Den Sopf nady ben

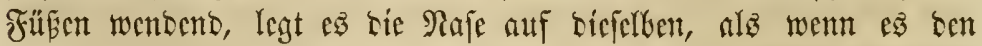
Srt ber Sdymerzen anteuten und um Sällfe anfpredyen wolle. 


\section{$\mathfrak{B} \mathfrak{c} \mathfrak{b} \mathfrak{a}$ b $\mathfrak{l}$ u $\mathfrak{a}$ g.}

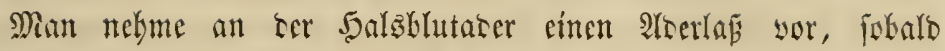

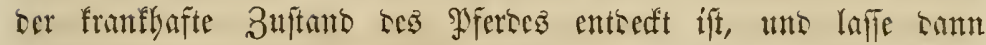

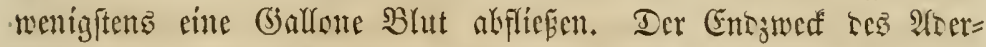

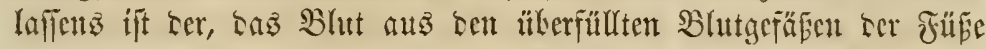

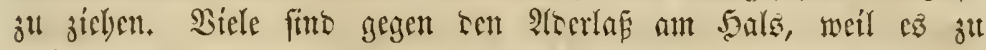
weit entfernt won bent Sils ocr Rranflyeit fei; aber Lie Erfabrung

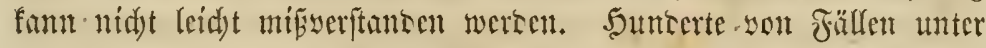

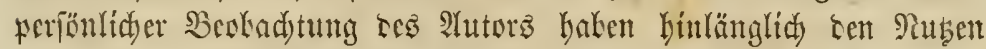
cincs foldyen Berfalyrens bemiefen. Sisir fint gemif, tafj die er=

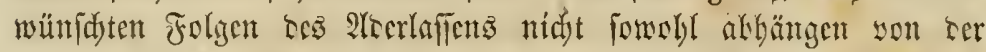

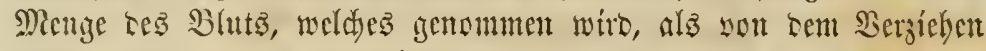

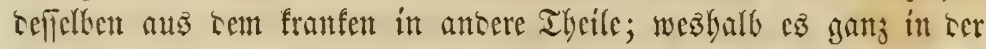

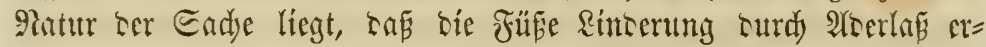
balten.

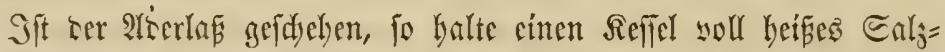

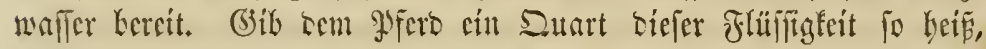
กไ: Rethe fie gut mit cinem rauben Iud) ober ciner Bürfte. Wieser= bole siefes im Berlauf ciner Etunte trei= bíz viermal, uno fobalo als tie Füpe troden fint, benetse diefelten an ten Gnoen ber Saare

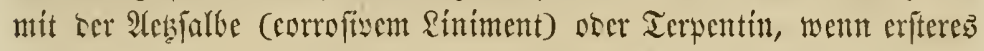

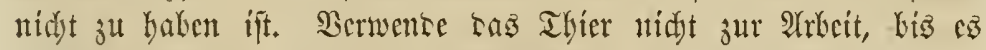
vollig geftud ift. Füttere angenǟte Sleie, gefod)ten Safer, geidnit= tenes Jutter ofer etwas angebritytes Sornmebl. Sann es aber gute TEcise Gaben, jo braudyt taz Keite Futter, fontern aud rie Merizin in ser Ratur, unt bei

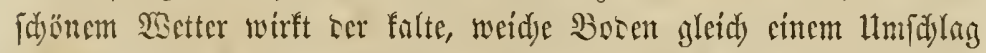

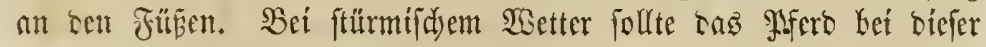
wie bei allen ansern Siranflyeiten in cimem guten trofenen Stalle fein.

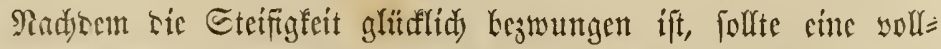

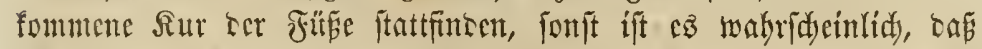

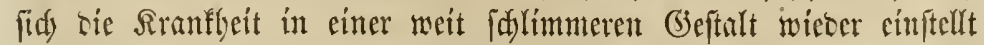
als vorber. Suffäule ift eళ̉, gegen weldye man fidh jest vorichen muí, intem man bie gegebene $\mathfrak{A}$ nweifung genau befolgt.

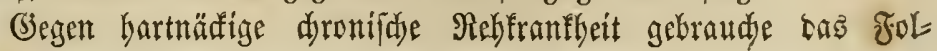


gente: Fin Syfund Edjwefel (flour of sulphur), cin Tiertelpfund

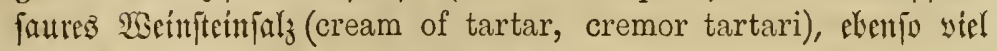
Salpeter (saltpeter) uno eine balbe ginte pulverífirten Stedjapfel=

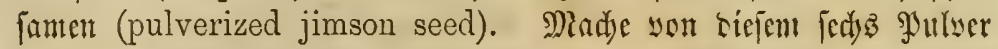
uno gib täglid cinz, biz fie alle fint. Zur felben Zeit mus cine

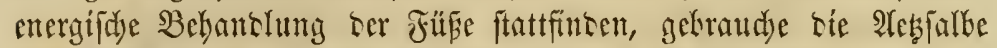

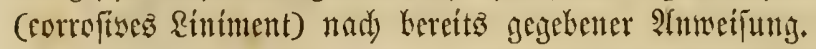

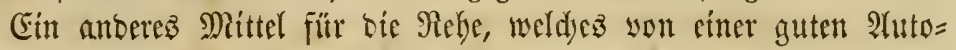

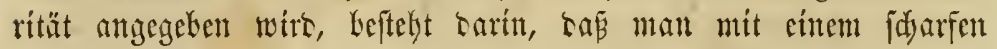
Meffer bie fleitie Epitie ober Sitropf, weldye in ten langen Saaren binten an ter Risthe (fetlock) fid befintet, aufidjnetret. Diefez ford autgenthlieflictye Rinterung seridjaffen.

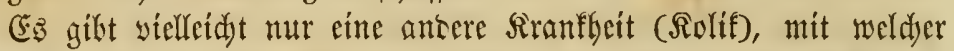
Soerte io allyemein geplagt fint, als mit Strifigfeit. Die Rebfrant= beit ruintirt mebr Pferbe, alz alfe anteren Rranflyciten zufammen. Dodis faun biefent Hebel vorgeteugt werben, wenn mit ber $\Re$ ur früh genug kegonnen wirt, tmo in allen fä̆llen mag bcocutente Rimbe= rung verfdjaft werben, aber es bleibt immer ntefir ober weniger eine

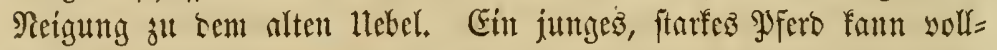
fommen Gergeftellt weroen; ift bas won ter Siranfleit befallente Ihícr

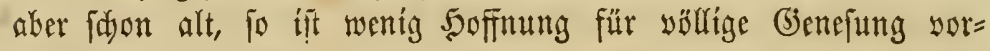
banten. 


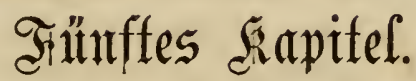

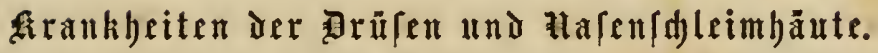

Solfer, au而 ๔utwindel (blind staggers).

Blind Staggers fommt namentlidy in Sen fütlidjen Staaten yor, unt wirs in ber Form, weldye bie Rrantheit bort annimmt, nörslid

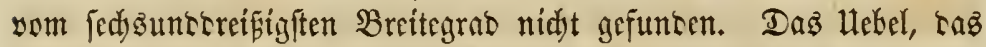
man in Europa unt sen Roreftaaten mit biejem Ramen bejeidjnet, tift mit ser furdetbaren Rranfleit, tie man im Süren Blind Staggers nennt, faum fau vergleiden uno wiro nur burd) einige ber Symptome berielben gefennjeidnet. Sn Europa, fowie in ben nört = lidyen Elaaten nennt man alle Sdjmintel = ober Roller $=\mathfrak{2} \mathfrak{2}$ fä̆lle Staggers; wbghleid) aber biejelben ein Sin = und Sertaumeln beim (jeben sertrfaden, fo nimmt man bei benjelten rod nidyt tie

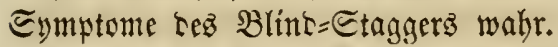

Dás weter sie Bemohner ser nörslidyen Etaaten, nodj jelbjt wohlunterridytete Edyriftiteller, sie üfer Perbearjneifunte gefdrieten haken, mit biefer fürdyterlidjen Serdye Ler Baummollenftaaten, wo fie in frïheren Sahren fdrreflide Berbeerungen anridytete, befannt waren, ¿avon fitto wir yolftäntig überzengt. In ten Sahren

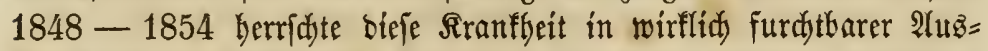

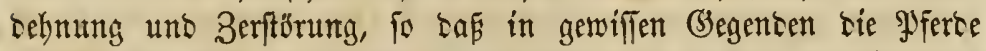
yöllig ausftarten, und zwar leiter meiftens in foldyen, wo bie Reute ten Berluft am wentigften zu ertragen im Stante waren. Die Siranffeit brady auf neuangelegten uno erft furre 3eit cultivirten Mlantagen sffters als in ältern uno fajon länger bebauten Diftrif= ten aมี

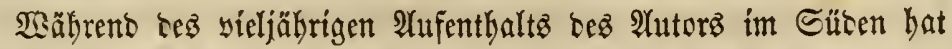

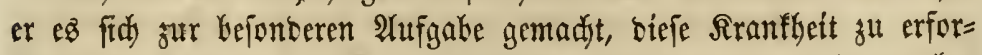
fajen, fu weldiem 3twede alle Gegenten ser Baummollenftaaten be=

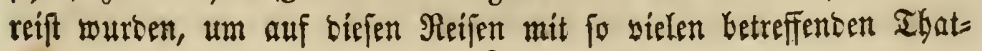


fadjen alz möglid befannt ju werben. Bei biejen Nadfforjdungen waren ifm bic gebotenten Filfomittel yon nur fehr geringem SSerth, Lenn bie beften Befdyreibungen anerfannter $\mathfrak{A}$ utoritäten in ser Thier=

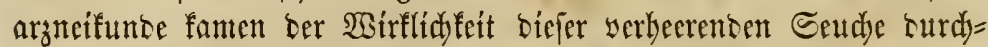
auz nidyt gleidy. Bwar hatten bíe Bemohner ber beimgejudjen

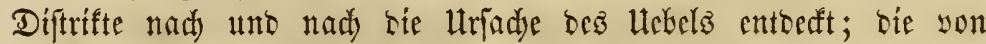
ifunen befolgte Befhantlungšneife war aher chenjo graujant als mir=

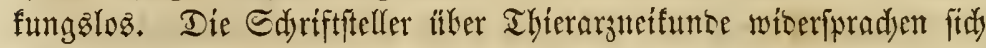

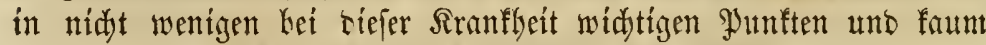
einer son ibnen fam einer getreuen Edjeltberung ter im Süben yor= fommenten $\mathfrak{B l i n t}$ Staggers aud nut nahe. Der Name Etaggerz fommt in ifren Befdreibuttgen alo bödjt unbeutlider, allgemeiner

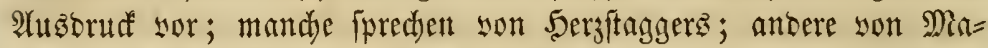
gen $=$ ober (behiruftaggers, orer son id)lifrigen unb wathenten Stag= gerz, Ât ber Siranffeit abgeleitet fints.

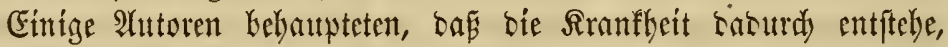
wenn bas PFero bie som Thau bentegten, Morgens am (3̈rą hän=

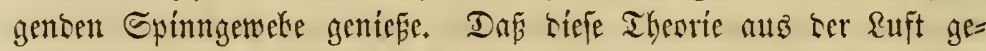
griffert ift, gebt aber barats bervor, bas aud Pferte, tie immer im Stall gefalten wurten, biefe Rrantfleit befamen, uno zwar häufiger

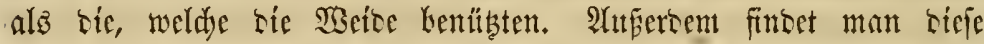
Spinnengewebe in énigen Giegenten Mifififfippi's, wo die Seutde fo

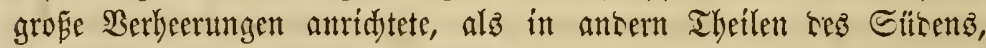

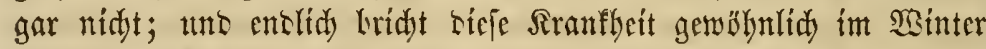

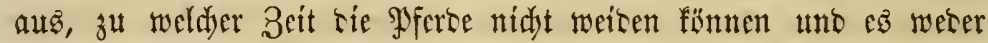

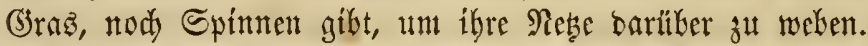

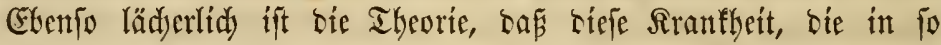
furdtbarer (Seffalt auftritt und ifre Berbeertngen uber Geinalye bie

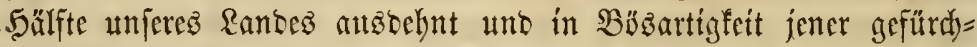
teten Seudje, ber Cholera, gleidjtommt und Pferoe, Maulthiere, Gel uno felleft Sdyweine jecen alters nidjt seridyont - son übermäfiger Fü̈tterung unb einem frantfaften Magen berrüfre.

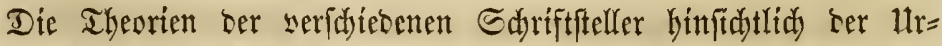

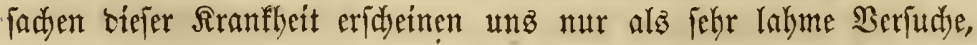
baz, waż fie nidjt verftehen, zu erflären. Die Bewohner ber Keint=

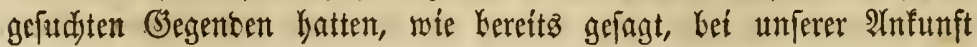




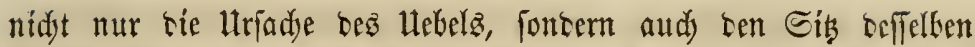
entbeft, was bem 2Yutor in ber weiteren Erforfdung oer Sranflett bebentenben Boridub leiftete. Dafi bie angemante Bebandlungs = weife höd)ft graufam und febr wirfungslos war, wurbe ebenfallz fidon angecentet, ragegen batte man ser Sranfbeit einen felgr be=

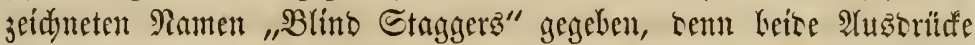
fenngeidunen zwei Wirfungen tes Uebels uno bezeidynen miteinancer tie Natur זeflelben.

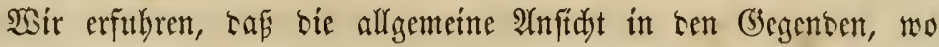
Blind = Staggers Berbecrungen anridytete, bie mar, tap tas son ten

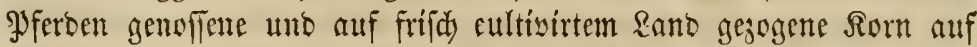
bie citte ober antere Setje mit ber Sranflyeit in Berbinoung ftebe; benn biejclke trat an beftigften zur Zett anf, in weldyer foldyes Sorn eingecrutet wurbe, unb namentlicy in foldyen Sabrgängen, wo bie Suantität beffelfen grofi war. Durd) bieje Untfänoe seranlafit, fitellen wir cine linterjudyng an, tm wo möglid) berauszuffitten,

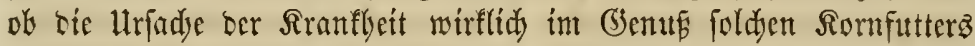

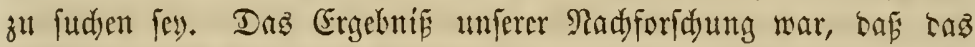
auf neu ungebrodyenem Rantoe gejogene Sorn bătifig yon eincm grünlid $=$ gelben $\mathfrak{X}$ sum jerfreffen wiro, weldyer in ser Sornäbre feinen

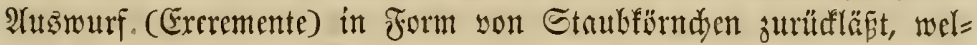
dyer febr giftig ift. Tud) ธaรี auf fdon länger cultisirtem Ranb gezogene Sorn ift z̈fters, ferody nidjt in joldjem Mape ben Serbee=

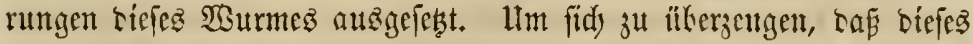
"Wurm = Mchl" giftig ift, sarf man tur cin Pflajter cason madjen, intem man bie Exeremente mit Eifig vermijat, uno biefes Pflafter auf sen äufern Theíl ber Sanb legen, wo es Kalo eine Blale zie ben wirb.

Dayon, baja fer Magen uno feine Funftionen nur míttelbar auf

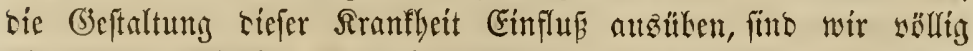
liberseugt, wesbalb man aud) nad) einer andern Hrfadye ibrer Ent= ftelyung ju fudyen bat. Diefelbe ift olyne 3meifel tas "SBummebl," weldyes fitd am Rorn vorfintot, aber auf cine ganz andere 2 seife

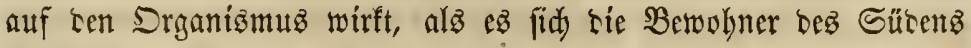
vorftellten.

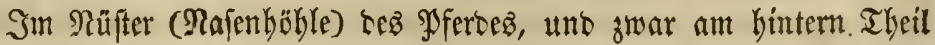
cerfelben, etroa pinen 3 oll von befien Münoung, befinbet fid näm= 
lid) eine fleime Deffnung, weldye bei verfdictenen 3 fercen son ver-

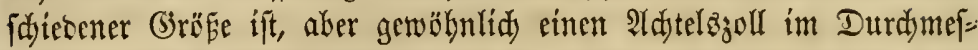
fer hat. Diefe fleine Seffnuttg, fowie eintige antere, bie weiter innen

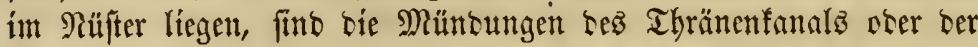

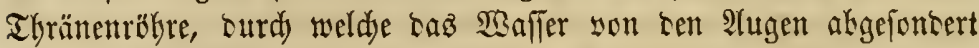

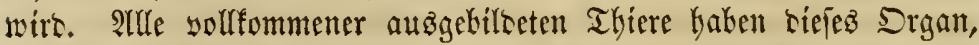

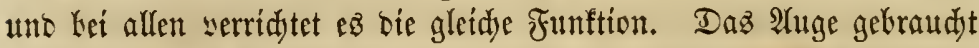

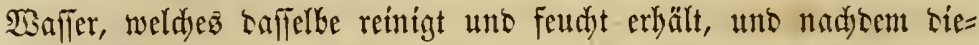

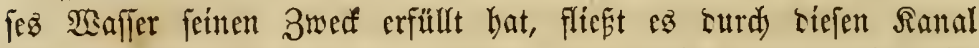
uno bie fleine Seffinung im Rüfer ak. Beim Pferbe wie beim Maultyier liegt biefe Canalmündung viel weiter unten in ter $\mathfrak{R a j e n =}$ höGle uno fann namentlid beim lebtern gand seutlid gejelgen werten.

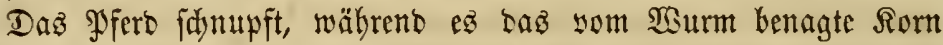

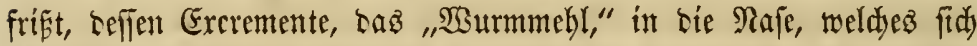

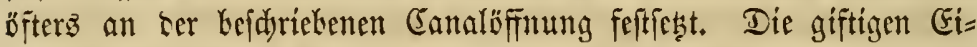

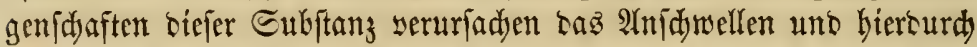

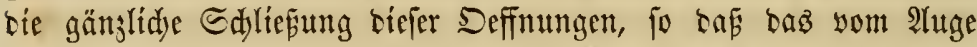

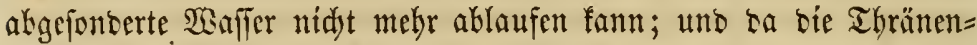
röbre mit uno itgre Deffnung im Räfter aud) mit ben nad) bem Sopfe fübrettoen Rafentyöblen in Berbindung fteft, fo werben aud

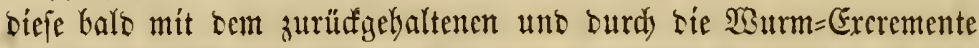

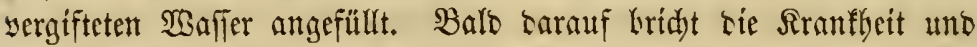
bie Entzünsung in aller Sheftigfeit aus. Zutädft fint ez sie nabe liegenten Theile, sie entzüntet werben, bann greift bie Entzüntung immer weiter um fid uno endlid werten bie Eehnersen afficirt unt Blindkeit uno Taumeln treten sann zugleid) eín. Das Gehtín uno überbaupt alle Theille bes Ropfes, fowie aud ber Magen, fammt bem Darmeanal gerathen in franflyaften Zuftand; ja, bas fatreflidje (sifit wirft auf alle Şauptorgane uno beinahe auf alle Theile bez Rörperß̄.

$\mathcal{D a} \tilde{\beta}$ baz Rlima, jowie verfdjiebene andere ungünftige lumitänoe bas ltebel beteutent verfdimmern mögen, ift ungmeifferfaft. Dod fint wir feft tayon überzeugt, caf Blino Staggers won einer Ent=

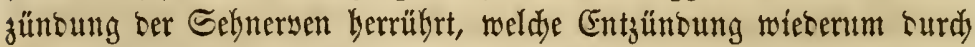
SBurm=Excremente ergengt wurbe, bie auf sie bejdrietene Weife in ben Drganismus eintraten unb bie von benen, welde man im Rorn bes Rorbens fintet, wejentlid verfajteden fint. 
Biele mit rem Gebnery gleidy nady eingetretenem Toce angeftellten

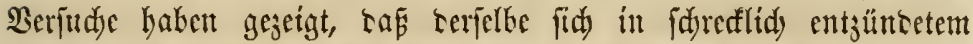
3uftance befand und bereits anfing, in Berwejung überjugeben.

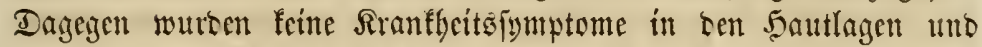

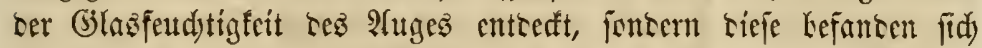
im Bujtano solfommener (Sejuncheit; aber tor junädyft rem 2tugen= nery liegente unt mit Ienfelfen in unmittelbarer $\mathfrak{B}$ erbintung ftelyente Theil tea (jebirns war fehr entzüntet uno rothe flecten zegen fid

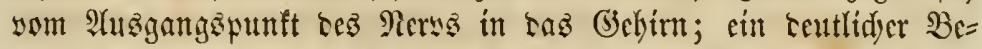

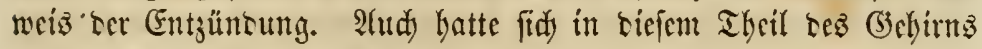

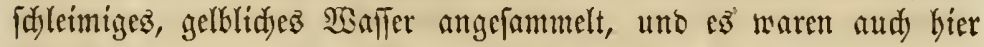
¡don Zciden fer Berwejung bemerftar. Die Entjüntung, Iurd

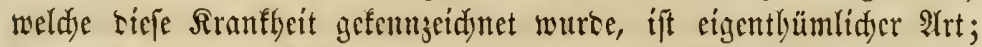
fie entfteht curd) (Bift, cas unmittelkar jum (3) birn gefübrt wire.

Mandimal fintet tie Berfopfung Ics Thränencanals nur auf ciner Sette tes Ropfes ftatt, in weldyem Fall fid sie Entzïntung für eine Zcitlang nur auf riejen Theil bejdrünfen wirt, unt taz betreffence Pfero wiro alštann an cinem Iuge ganj uno am antern, weldyes ourdy รasె franfe 2tuge natïrlidy aud) angegriffen wirt, theil= weife blint. In riejem 3ujtumo ridjet ras

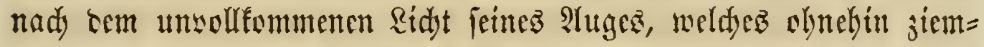

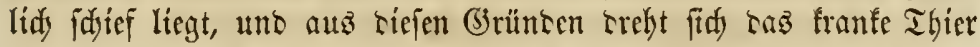

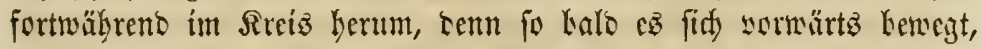

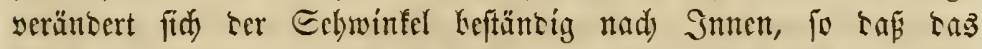
Pfert, anftatt cine gerare Ridytung cinjuldylagen, fth Keftänsig in einem Sreis yon etwa fedbs $F u s$ im Durdimeffer berumbencigt, und zwar fo lange, alsz es jeine Rräfte erlauken. Das yon riefer Eeudye befallene Thier ift aber nidyt allein beintake Glint, fontem audy taub.

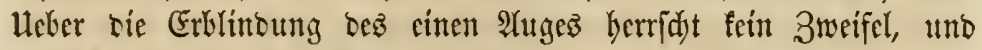
man fann auf oer Seite, mo riejes liegt, Jum Thier bintreten unb rie Santo an teflen Ropf legen, obne taf man son thm lemertt

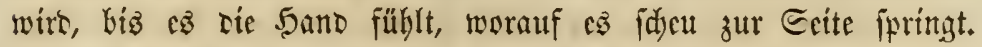
Räbert man fidy ifm aber auf rer ancern Seite, fo gebt es beftün=

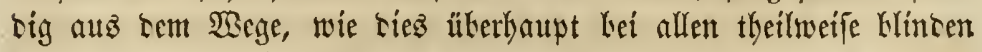

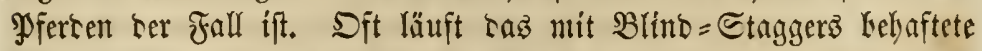
Pfero fo lange, bis ter $\mathfrak{P}$ fad sollommen bart getreten ift, uno fo oft man ein foldes franfes Ibier in fetnem Sreislauf unterbred)en 
roill, geht Stelle benfelben wieber.

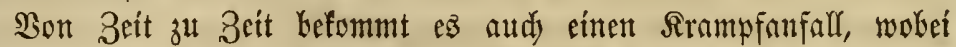
[อ gleid) cinem betrunfenen Miann bin= uno hertaumelt uno zutam= menftürzt. Dieje Srrämpfe bauern yon zwanzig Minuten biz zu ciner Stunde unto öfterş audd jwet Stunten lang. Innfänglidy tre= ten fie nidjt öfters eín als etwa cinmal ben $\mathfrak{I} n$; im $\mathfrak{B}$ erlaufe ber

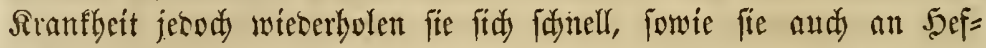
tigfeit junnebmen. Die Reiben bes armen Thiers währento siejer

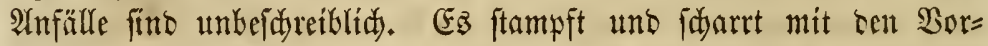

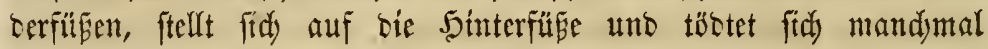

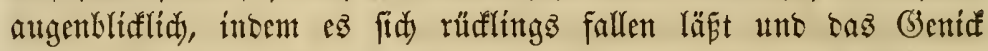

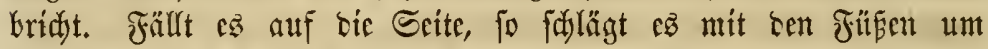

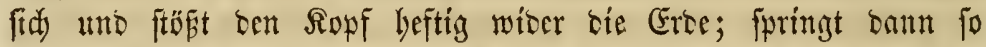

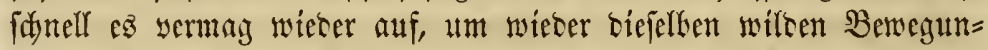

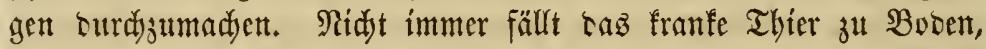
fontern taumelt und fdywanft zuweilen, incem as mit ben Futsen

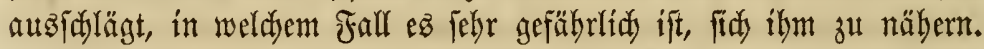

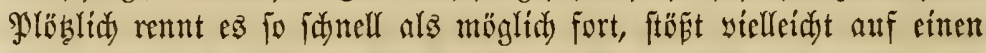
Baum, cine Fente ober cin 5aus uno ftürzt bant zufammen, und

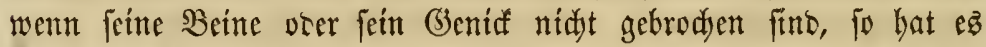
fid) gerwi jonftige bebeutente Beföäbigungen jugefügt.

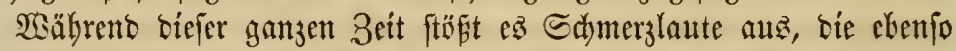
jammersoll, als für ten 2 Tnweienden peinigeno fint. Nur zu Beiten

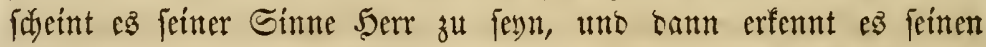

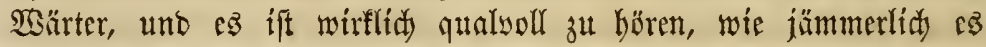

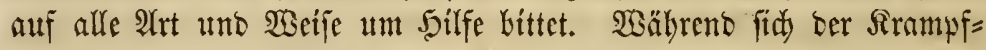

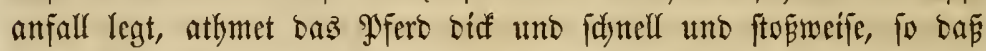

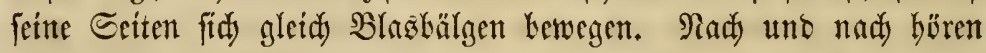

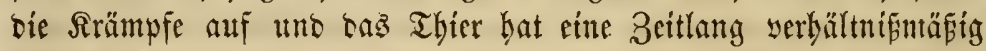
nidjt mehr io wicl jull leiten. Riegt es gerabe auf ber Seite, io

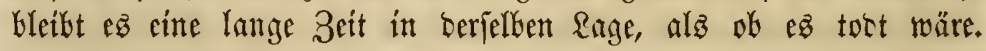
Sehr bäufig fdcinen bie Rrämpfe plöblid zut veridyminten, und wenn bas Thier in biefem Fall fid in ftebenter Stellung Kefintet, fo Gleibt

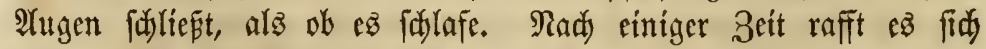
wobeber auf unb bewegt fid abermalz im Sircis berum. 
BSerten beise $\mathfrak{2}$ ugen afficirt, waz bft ter Fall ift, fo wiro baz Yjero völlig blino uno jteht zitterno betent mit herabGängentem

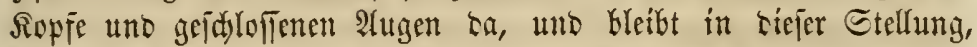

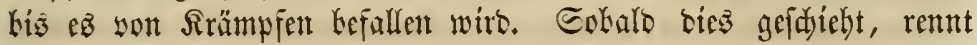

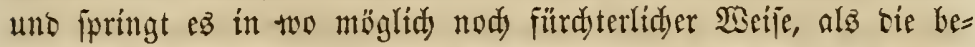

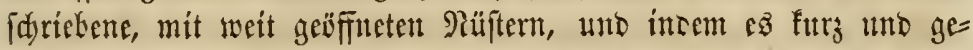

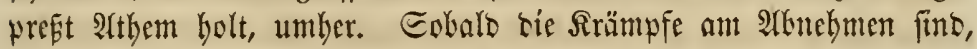

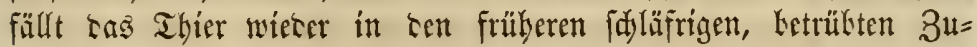

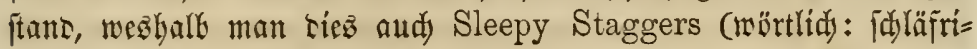
gen Iaumler) genatunt hat.

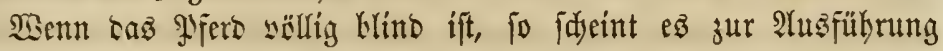
jeglider Bewegung untwillig ju fein, tulo fängt erft bant an fid ju kemegen, went

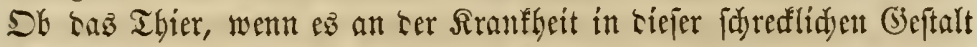
leiset, irgeno weldue Sinne benüben lann, ift zweifellaft; gewín aber

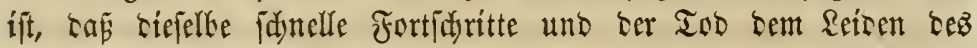
Yatienten balo sin Entre madjt.

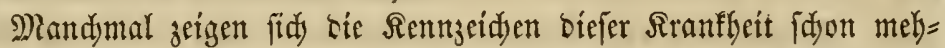

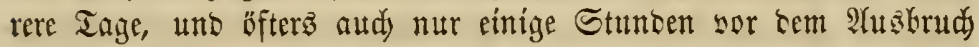

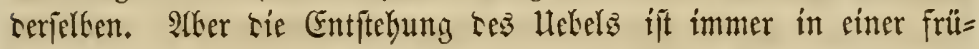
beren Zeit zu fudjen, und baflelbe war vielfeidyt idjan wodjenlang

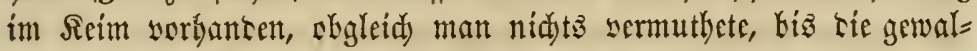
thätigen Eymptome yon tem Dafein ser Rranfleit zeugten.

\section{Die alte Bchanblungstocile.}

Die früher im Cü๖en allgemein gebräudjlidje Behandlungşweife biejer Rranflyeit liefert, obgleid) fie graujam uno gemaltthätig war,

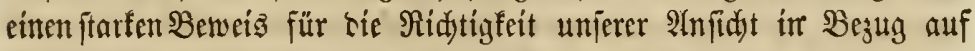
Lie Mrjadye und Entitelyung son Blind= Staggerb. Durd) eine trau= rige uns unwillemmme Erfahrung hatten bie Bemobner ser heim=

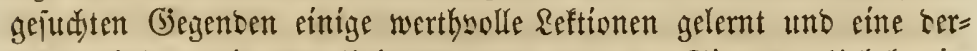

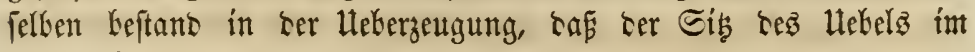
Ropf jét.

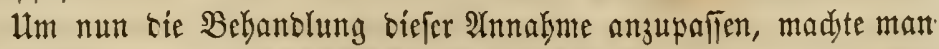

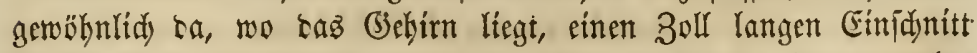
in tie Saut, in welden man irgentoweldes (sift kradjte und als= cann sie 2 Bunte wieber verbanb. Shieburd entfand eine offene 
WBunbe, bie wiel Eiter 2 . abjonberte, uub obgleidy biefe $\mathfrak{B}$ ehantlung weife fehr fdmerzhaft fürz Thier war, fo weridyafte fie ihm bemnodj zatweilen Errcidyterung.

Fine antere Methode beftant tarin, Lafi man einen bümen Mieífel

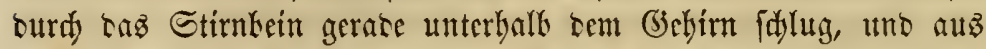
ber Deffnung bie angejammelte, versortene unt vergiftete Flinfifgtét

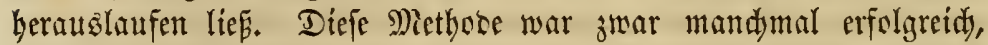

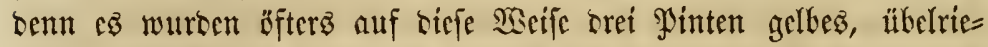
dyendes $\mathfrak{x a f f e r}$ aligezapft; aler bie Speration war tody immer mit

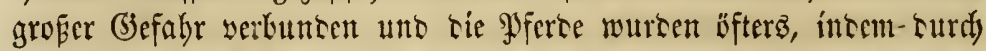
ben Sdjlag bie 5imfdale geipalten wurbe, wohl getöstet, aber nidut furirt.

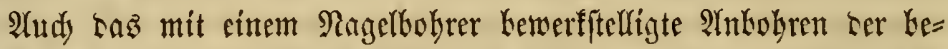
treffenten Stelle erriez fith alz febr gefährlidy, intom auth hiersurdy bie Sirmidale oft gejprettgt utto baz Pfero getöbtet wurbe.

TSaz bie Befandlung ter mit Blint= ভtaggerż behafteten Wferbe fehr fdywierig madjte, war sic auperorcenlide, oft zur Tolfwutb wer= bentbe Raftlofigfeit sez Thicrş, weldye nodj surdy bie graujame,

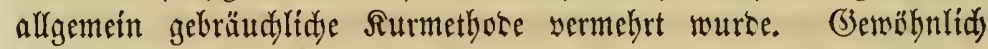

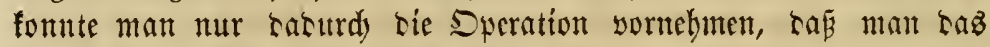
Pferd niecerwarf, weldyez nidjt felten burdy ten fall uno bas bar=

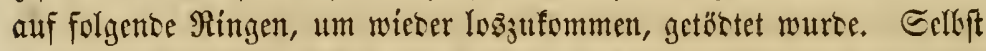

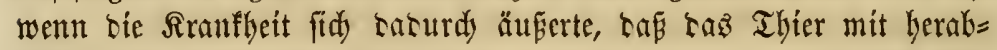

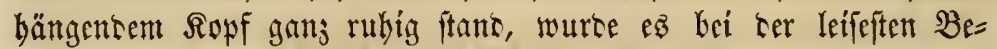
rührung yolffommen raftlos unt öfters rajent.

Die cingeld)lagene Behandlungşweife beweift beutlid, bas man im alfgemcinen Gegriff, bie Rranfleit fei ourdy $\mathfrak{A}$ mfammlung genwaffers im Sopf entftanton unb haf, fofern baffelte akgejappt

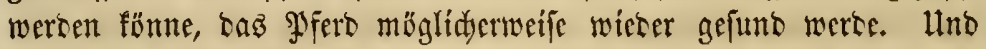

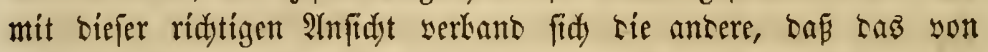
Bürmern benagte Rorn auf bic eine ober bie anbere $\mathfrak{B e i f e}$ - auf weldye, biez fonnte man fid nidjt erflären - bie Grontour|adje ser frantfaften Störung jeí.

\section{2 or be u}

"Borjorge verbütet Radjorge;" biefez Sprüdywort läft fid in feiner yollen $\mathfrak{B a} a b r b e i t$ auf $\mathfrak{B l i n d}=$ Staggerż antwenden. 
Pyerse und Fohlen, bie fortmährent auf ter siseibe fint, werten

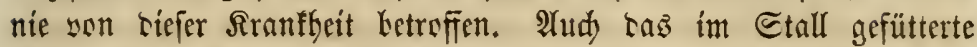
Ffert, fofern man ibm fein Forn giekt, Kleibt beinake gan frei son

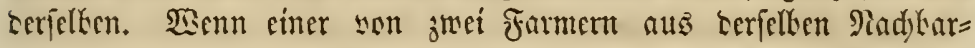

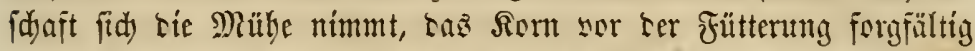

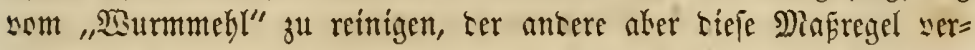

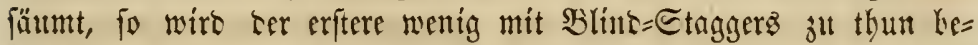

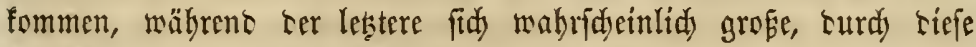
Siranfbeit hersorgenufene Berlufte zusiegt.

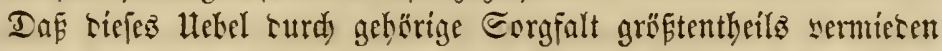
wereen fann, ift flar uno surdy Thatiadyen keftätigt. Sann ter

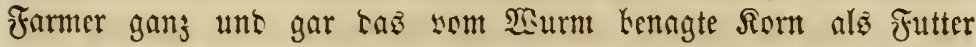

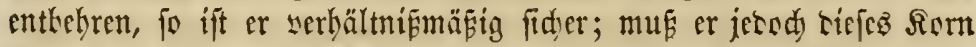
füttern, fo follte cr Laflelbe sorber aufo jorgfältigfte reinigen.

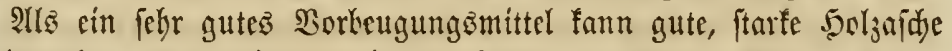
gekraudit werten, bie man in sen Futtertrog ftreut. Son nod) kef= ferer Sirfung aher ift fein geriekener, in tie Rrippe geftreuter $\mathfrak{I} \mathfrak{a}=$

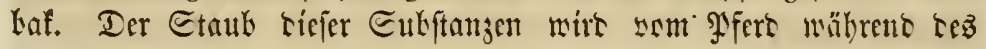

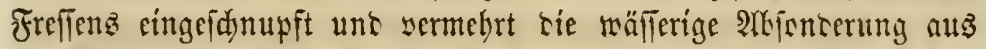
ser $\mathfrak{R a f e}$, wosurd sie Sanalmüntungen sffen gekalten wersen.

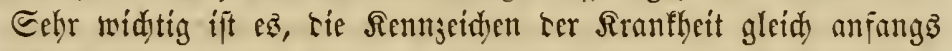

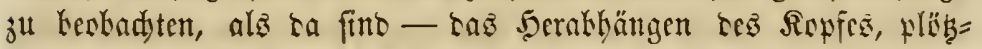
lidjes beftiges 2uffiahren, wie

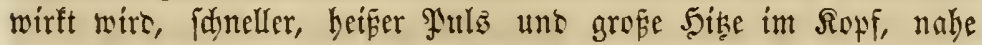
beim Giehim fowohl, als am Etimkein uno gerace unterlyalb ter

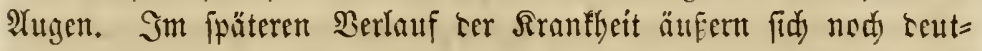
lidjere Symptome. Sisenn man tem gejunten Ffero mit tem Sinö= del auf sie Simidale flopft, jo ift ter sarurd entftebente Ion flar unt bobl; nunmebr aker ift er tumpf uno tem ähnlidy, Ler erjeugt

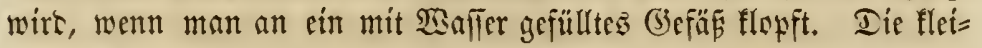

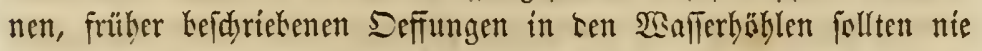

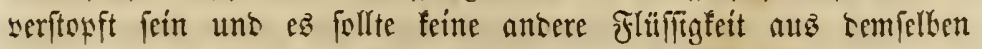

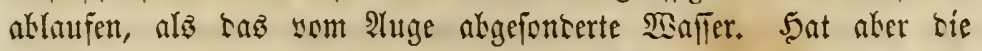
Rrantheit einmal Fortidyritte gemadjt, fo fino tieje Deffnungen ent= weter ganz oter theilmeife verftopft, uno cỏ brängt fid) aus senjel= ben mehr ober meniger Eiter. Die Rüftern fint grinsig unt ge fdyollen, uno ser bintere Theil berjelben ift fehr roth uno entjüntet. 
Sobalo fid biefe Symptome zeigen, fo Darf man verfidert fein, Daj

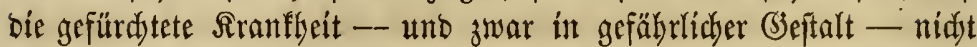
fern ift. Man follte, um folde) üble Beidhen bei Beiten zu entoecten, bie Rafe öfters unterjuden.

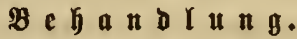

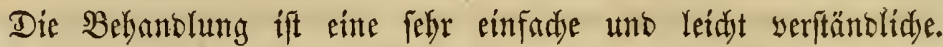

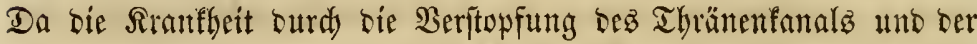

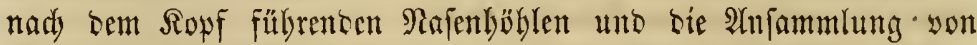

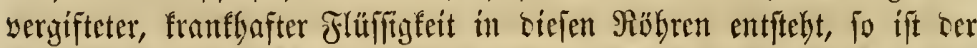

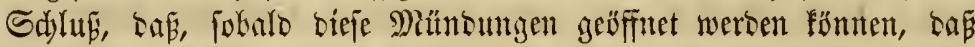
diefe Jlüfitigfeit ablüuft, wemigftens bebeutentoe Erleid)terung ein= treten muß̈, eín jelyr natürlidyer uno unbeftreitbarer. Unto bies wiro burd) bie Thatjadye beftätigt, bem jobalo bieje Speration glüflity

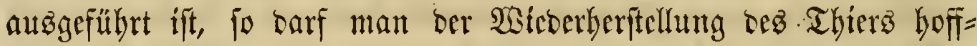

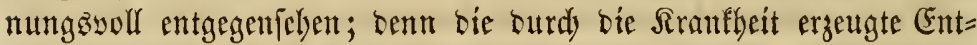
fündung, fowie andere Frolgen, mögen burdy geeignete Behantolung geholen werten.

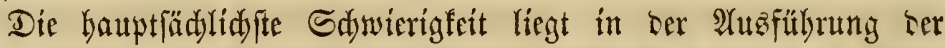
Dperation. In vielen Fällen madyt bie Sranffeit jo fanelle Fort=

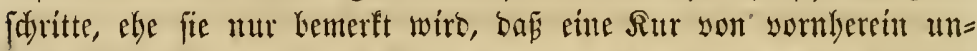

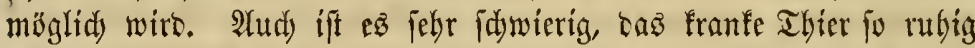

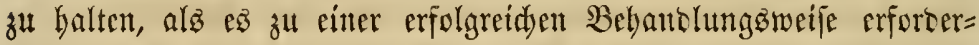
lid) ift, und jelbeft wetn bies bewerffelligt werben fann, erweifen fith

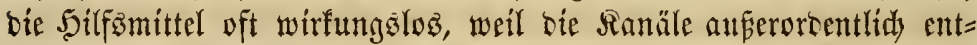
züntet unb angejdwollen und yolr won Eiter fint, welder burd, bas eintretente Fieber nidjt felten in eine bidjte, beinabe fefte Mafie wer= wandelt wirb.

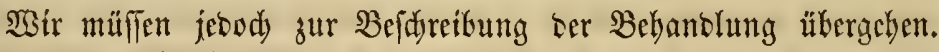

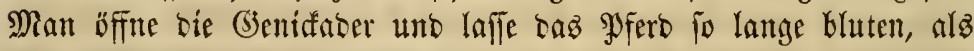

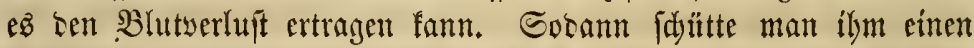

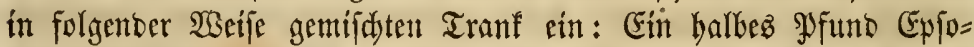

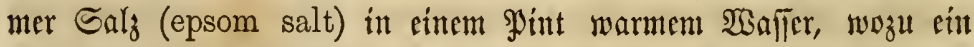

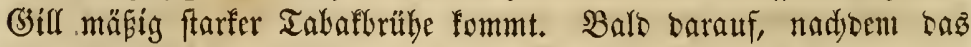
PFero bieje Mebigin eingenommen, wirb es fid fo übel befinoen, baß biejenigen, bie bieje Mebizin zum erftenmal gebrautden, ber Meí= nung fein werben, bas \$orb werbe fterben. Dbgleid) aber bie $\mathfrak{A} u=$ 
gen bes Pferbes gläjern werben, und okfdon baflelbe bin= unb ber= wanft, wobl aud mandamal zufammenftürst, fo ift fod viel weniger (5efabr ta, als yorbanten wäre, wenn man biefe Mírtur cinem

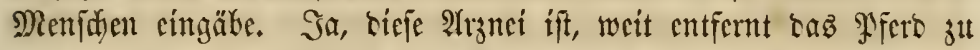

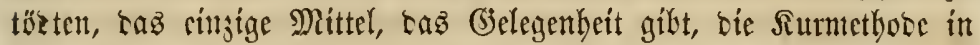

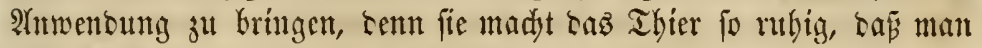
nad) (bicfallen mit ibu umgelyen fann.

Elye nod cie Sirtungen biejer Mirtur soritter fint, gebe man

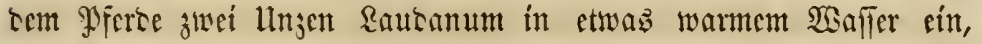

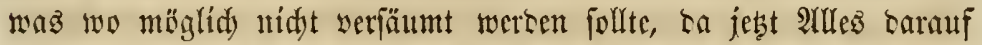

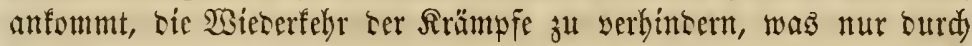
ein fdumersitillentes Mittel kewerffelligt weren firm.

Sunithjt nebme man nun einten etwa zmé Fü langen Steffent, an befien einem Ente man einen weidyen Edywantm gut kefejtigt, über weldyen man ein weides Stüd Iud) ober Rinnen jiebt, Lefien Ente über bie Janbbate berunter Gangen follte, fo toff, follte fer

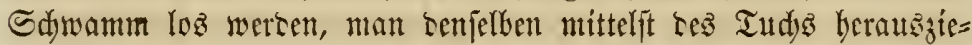
ben fann. Diefen wifder taudbe man in fdwadbe, ganz warme Ta=

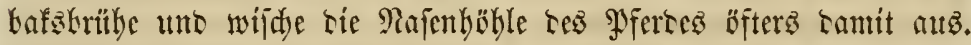

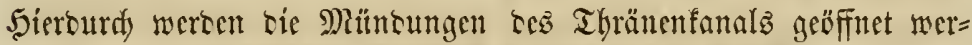

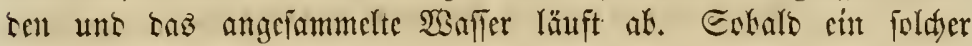

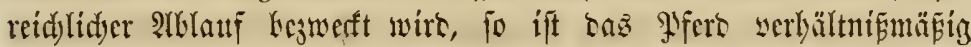
aufer augentliffidyer (sefobr, uno wire bei guter Bebanclung wie= ser gefuno wercen. Defters ftrïnt tie wertorkene, wäfrige flüfïg=

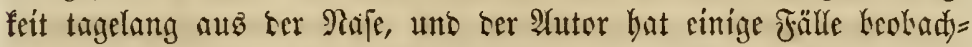

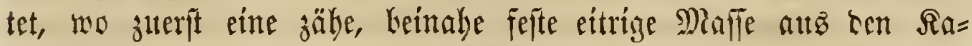
nalöfinungen georängt wurbe, worauf โaร̇ : frömte.

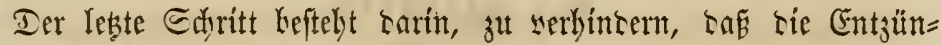
fung aud โaร Giebirn angreife, ober fallz ties bercits gefdeben,

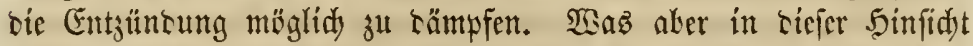

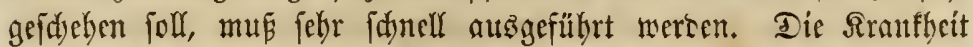
wiro gewif nidyt surd langiam autgefübrte Mafircgeln üferwältigt werben. Man muß augenblidflid), โa, wo bas (Sebirm liegt, cine

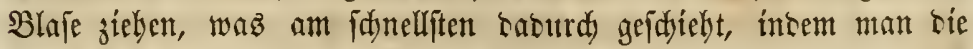
Saut mit tor 2 etsfalbe (corrofivem Riniment), ofer falls ties nidht zu baben ift, mit Terpentin einreibt, und auf bie cingerietene Stelle 


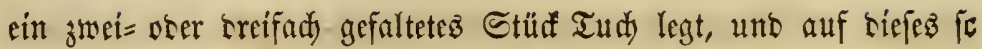
lange ein heifez Bägeleifen ftellt, biz sie Blaje gejogen ift.

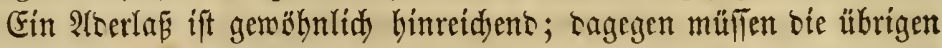

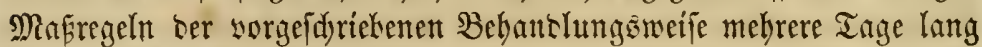
offers wicterholt weroen. Dakei ift.jerody ju kemerfen, saf́ es viel=

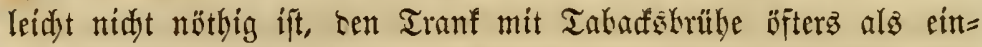

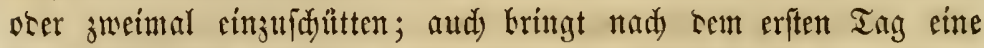
Unze Raubanum gemöbnlid sie gemündote Sirfung bersor.

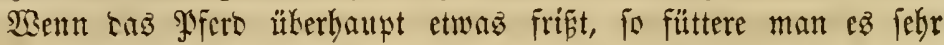
leidyt uno gete ifm fein Rorn. Grüntes Gras ift tas Hefte Futter. Mant halte tas Thier mebrete MEoden lang volffäntig rubig.

Sft yergeblich angewentet, unt ber Tod wirs tas leitente Thier bald

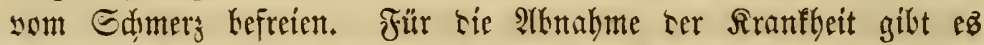

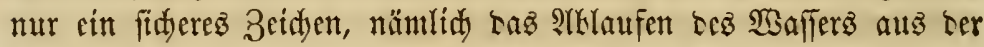

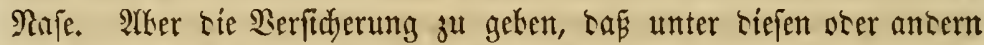

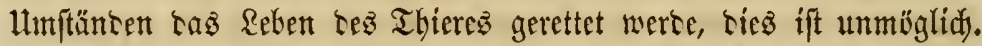
Darum ift es̊ um fo widftiger, eines ber yon unz angegebenen Bor= beugungsmittel anzumenten.

\section{Bieberbolung ber Bebandungstocife.}

1. Man laffe rem Pyero fo lange ju Yhor, alz ez bíes ertragen farn.

2. Man gebe ten Tabafizbrübetrant mit ten Galzen.

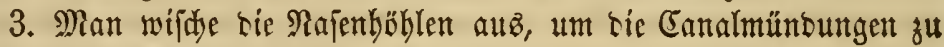
öfrnen.

4. Man ziebe eitte Blaje über Dem Gebirn.

R o b (glanders).

Shgleidy sicie Srantheit son ten Thieräräten öfters nidyt fo flafî: ficirt wirt, wie sies bier gefdiebt, fo trült ibr Rame sod gerace

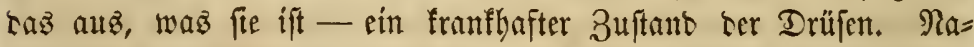

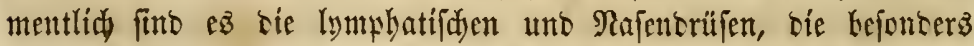
afficirt werten, uno hier mag bie Sranfhcit im Reime monate= ja jabrelang exiftiren, ebe man beren Borbanbenjein gemabr wiro. Bon biefen Drîfen fonoert fidy eine fhleimartige Flüfigfeit ab, bie surd bie Rajenboble ablätft und fpäter tie Rajenjd)leimbaut eitrig uno 
geid)würig madyt. Darum weidyen wir in ter Clafitficirung biejer Siranfleit yon beinabe allen ansern Pyerceärsten ab.

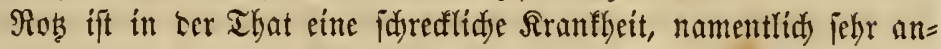
fteffent uno, falls fie fith sóllig entwidelt hat, beinabe unbeilbar. Im Serlaufe Ler Sranflycit fann man, wie aus tem Folgenben her= sorgebt, beutlidy srei Stufen berfelben unteridsetisn, uno blos wäh= rent fer erften unt mandynal auds währeno ber jweiten ift eine Sur möglidy; aber unglüflidyerweife idyenft man sem llekel gemöbnlid

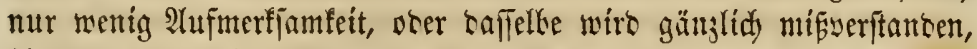

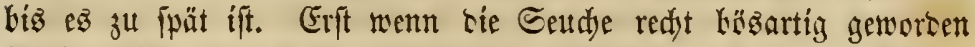
ift, Gemerfen tie meiften Eigenthümer uno SËrter teren Borbanten= fein uno finto alżsann sft nod nidyt millig anjuerfennen, bap bas

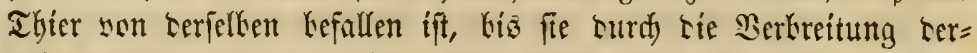
felten uno antere Renngeidyen fid enslid tiberjengen laffen.

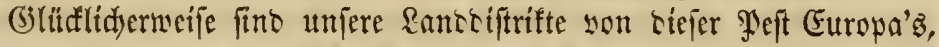
riejent llebel ser engliftyen Etalungen meiftens seridgont, tenn in unjerm Sante bejdränft fid tie Sranfbeit grofientheils auf bie Stäbte,

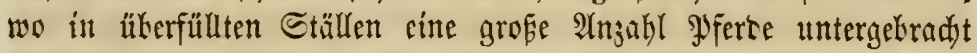
fint.

Durd) genaue Benkadtung fant man fith thkerzeugen, baf $\mathfrak{A}=$

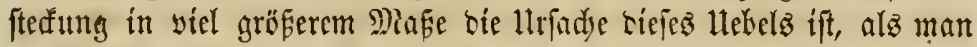
gemsibnlid annimmt. Setody liegen aud nod mebrere antere $\mathfrak{H}_{\mathrm{r}}=$ fadten sor, welde sie Sirantheit aud ba bersorrufen mögen, wo $\mathfrak{A} n=$ ftedung ganz uno gar unmïglid mar. In tiejem fall fint gerwibnlidy Sdumus uno unridytige Bebandung, weldye rie Ceudue verurfadyen, uno bauptfädslidy an fumpfigen uno ungefunten Srten

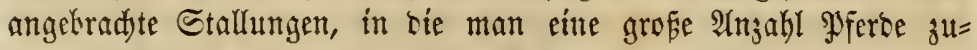
fammenpferdit. Unter Ien mannigfadjen Ulrjadyen, Lurdy weldye ter

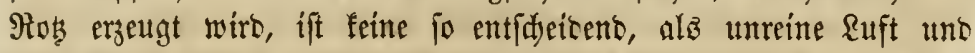
vercorbenes ofer ungefuntes Futter uno Waffer, alles Dinge, weldyen

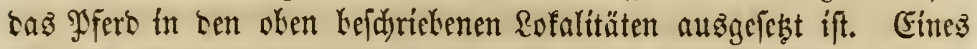

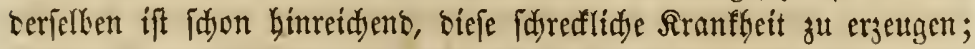

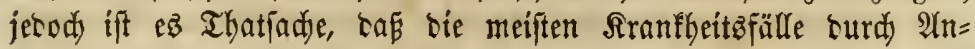
ftectung entfteben.

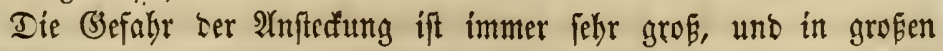
Stallungen, wo immer yiele Pferbe $a b=$ uno jugeben, if

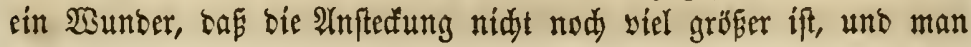


fant fid) bies nur burd) ben ftarfen, gefunten Rörperbaut ber Thiere

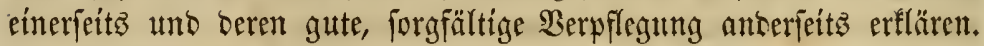
Die Bentilation, sie gute Dronung uno Reinlidyfeit, tie man in sielen grofent Stallungen antrifft, find nidyt weniger empfehlungs: werth, alş bie Sorgfalt, mit weldyer bie Befitizer uno Aufieher ber=

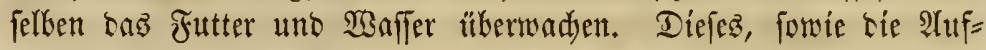
merffamfeit, bie ber Reinigung und bem $\mathfrak{W a f d e n ~}$

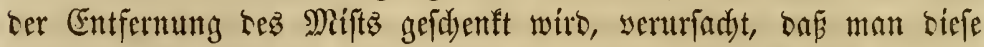

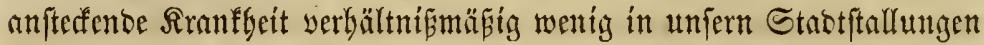
vorfintet. Sn ben leţten fünfaig Sahren erfuhren die Stallungen

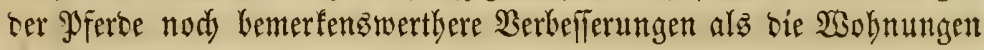
ter Mienidjen.

Sebod) mag ein Pfert, trob allen Borfidt tömaßreegeln, yon bem

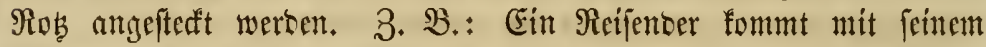
Pfert, weldes er für sollfommen gejuno hält, in einer Strobt an unto ftellt baffelbe in einem Stall cin. Es frifit aus ber Srippe, wo

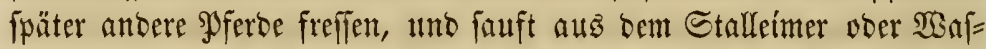
fertrog, ber für alle Thiere benübzt wirb. Sierauf reift ber Mann

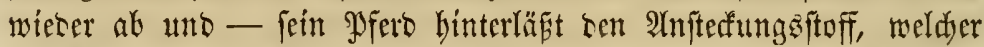

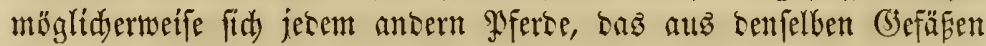
fríst ober fauft, mittbeilen mag. Bielleidyt wersen nidjt alle yon

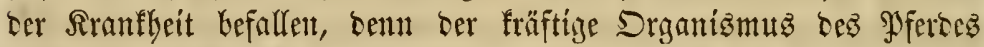

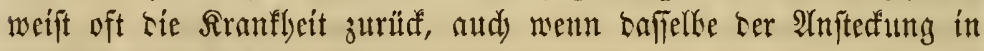

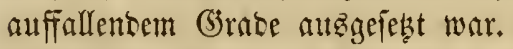

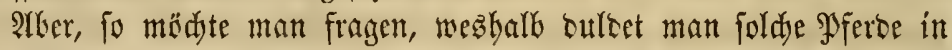

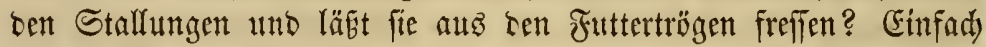

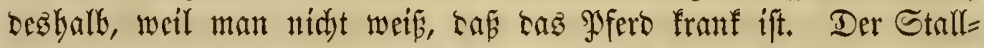

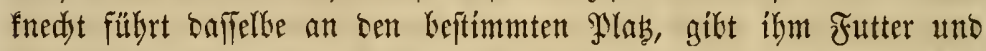

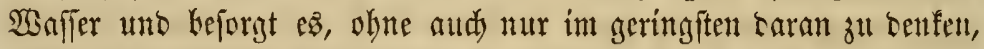
baf er es mit einem franfen Tbier zut thun hat. Selbft bann, wenn

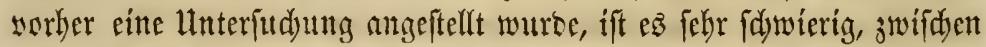

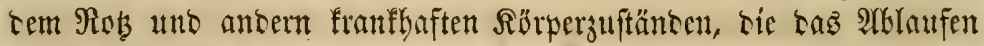

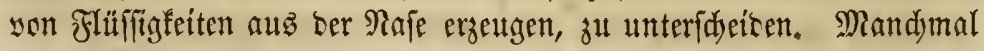

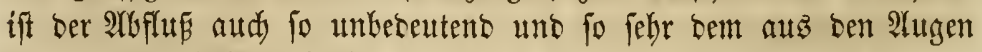
fommenden $\mathfrak{B a} a$ fier ähnlidy, Laf er monatelang gemährt haken mag, vhne bie AYufmerffamfeit zu erregen, währent weldyer Beit bie Rrant= beit natürlich Fortidyritte madd. 
Sft madyt ez ben gefuidfeften SPferbeärsten auferorbentlid siel

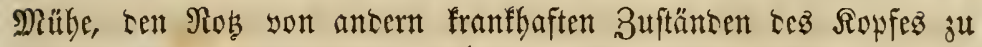

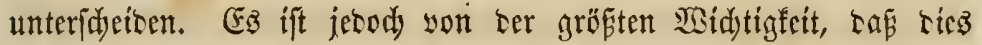
genau geidebe, uno gemoblulidy mus ber Farmer folbft tie Entidei= bung geben. Sir werben bei Befdyreibung fer Rranffeit nidyt alfein uniere Beobadytungen, fonoern aud) bie anterer nicberlegen, bamit ser Rejer fo siel Ridut als möglid) über ten (sicgenftant erbält uno fo unterridytet wirb, safi er im Stanbe ift, sas Hetel bei Beiten ju erfenten unb die geeigneten Sdyritte futhun.

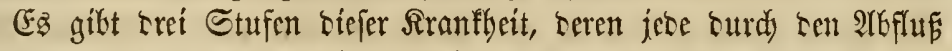
aus ธen Naiftern gefennjeidnet wirb. Sn bent erften Starium fiefyt

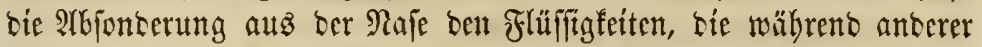
Rajentranfbeiten, ober felbjt im gejunsen Buftand ablaufen, fo äbnlidy,

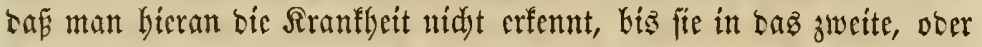
logar ras sritte Stabium getreten ift.

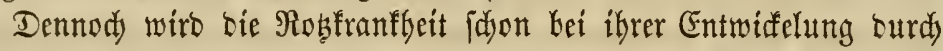
zwei Merfmale gefennzeidynet, Iurdy weldye fie son ansern Siratt= beitsfällen unteriduesen werben fann. Das erfte biefer Merfmale ift bie Thătadye, โấ bie Akfonberung aus ber Naje flebriger ift, als bie Flüfifigteit, bie fonft abläuft, uno bas anbere befteht Larin, Daf Der 2rbfufi faft immer nur auf eine Nafenboble befdränft ift, uno jwar auf tie linfe. I ie luradye bieson anjugcben, find wir nidjt in Ctante; baf cs aber Thatfade ift, bayon find wir ubberzeugt,

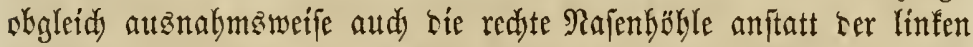
afficirt wirb; beite zugleid) aber zeigen anfünglid) nie Spuren eines franfliaften Buftaners.

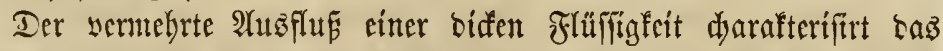
jwcite Stasium ser Robfranflyeit. Diefelbe ift nunmebr febr id)leimig uno fehr zäh uno. flebrig; Die Farbe serfelben ift Sunfler, oft etwas

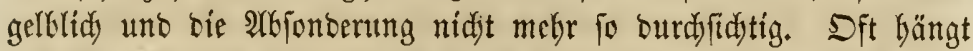
biefe Mafle in langen Slumtpen, gleid Budbinterfleifter son ben Niiftern berak. Die Nafenidycimbaut bat ein bleidyes, bleifarbenes

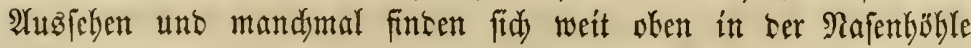
(3)ẹdymüre.

Das britte Stabium ber Rothfranffeit entroidelt fidy febr langlam uno biejelbe wirb, pobalo fie in ibrem Berlaufe siefe Etufe erreidnt Gat, nady bem allgemeinen Dafürbalten guter $\mathfrak{2}$ utoritäten als unbeil= 


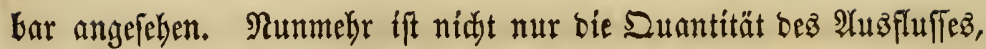
fonbern aud befien Sdyleimgehalt unt Bähigfeit bebeuteno vermebrt; bie Farbe ber Flüffigfeit ift um vieles bunfler und gelber uno oft mit $\mathfrak{B l u t}$ vermi jutt.

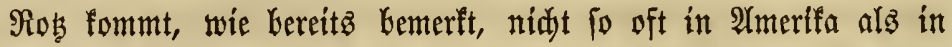
andern Rändern yor. Aluf einen Fall in ben Ber. Staaten fomment wenigftenz zwei ober brei Fälle in Englano ober Franfreid; wie

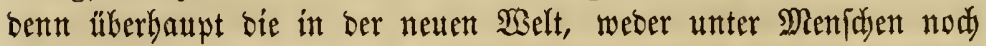
Thieren, anftedento Seudjen je joldje Bertheerungen angeridjtet Gaben,

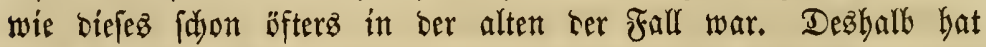
man aud in Europa viel befiere BJelegenbeit, biefe Rranflyeit mit ihren Symptomen 26. ju beobadjten.

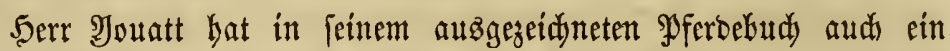

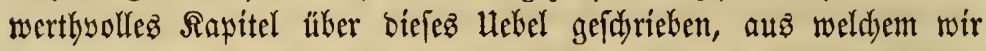

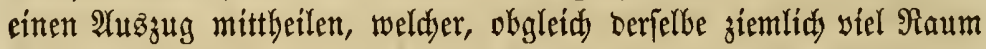
cintefmen wirb, und obwobl berfelbe bann und wann lungenauig= feiten fowie Trugid lü Y⿹ountt mit grofer Sadjenntnif und Sorgfalt zut 2 serfe geht:

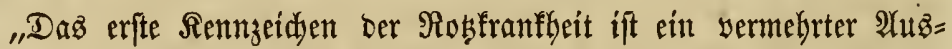

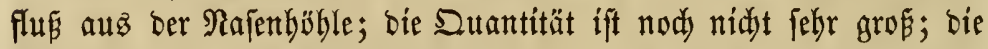

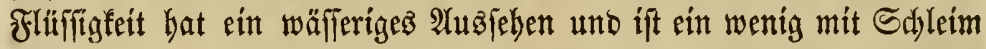
yermifat.

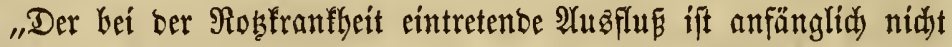

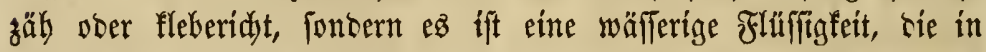
fleinen Duantitäten beftänsig abläuft uno unteridyeibet fỉ biersurd

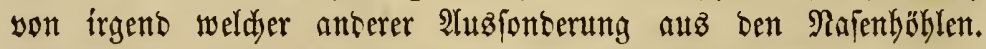

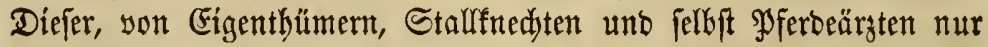

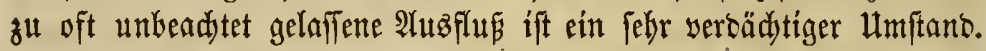

, Mimmt man bei einem yöltig géfuncen und wobl gefütterten \$ferbe

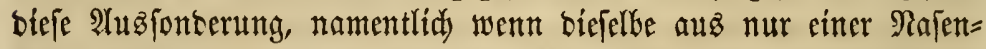
häble ftattfintet, wahk, fo follte man feine Beit verlieren, baffellke yon ben anbern Pferben zu trennen. Diez fann jebenfallz feinen Sdja=

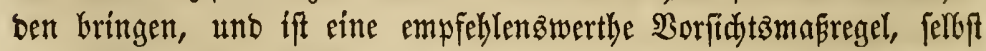

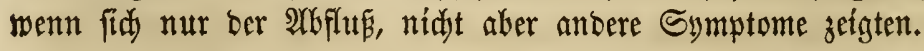

„Díe eigenthümlidje 3äbigfeit uno Rlebrigfeit, welde bie bei ber

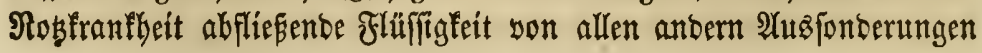


ber Najenbïblen unteriduetret, zeigen fid) erft im zweiten Stabium, uno ehe man bies wabrnimmt, mag รas Hebel in febr küzartiger

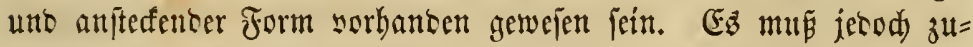
gegeten werten, saf in ben meiften Füllen fer צYGflü wenigftenz etwas flebrig und zăh ift.

"Ein fonberbarer Hmftant, weldjer nod) niddt binlinglidy aufgetlärt

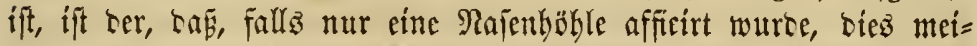
ftens mit ser linfen ser Fall iff. Serr Dupuy, ber Direftor ber

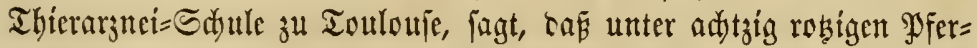
ben er nur cines gefunten bake, beffen redte 2ajenböble afficirt gewejen fei. In Englano ift biejer Unteridieb jwar nidyt fo bebeu= teno, bod) ift aud) cort bas Berbältnís jwifden sen Pferben, beren

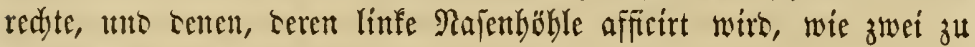
Erei vecr wie trei ju vier.

"Dic Flitifigfeit, fallz die Rrantheit yon $\mathfrak{A}$ nftecfung berrübrt, mag fict) cine lange Zeit, vielleidyt Monate, ja Jabre lattg in Elemen

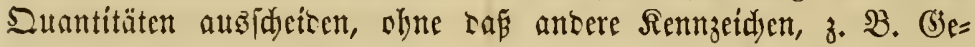

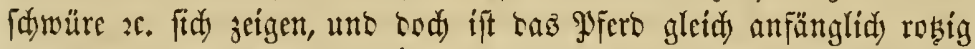
unb fann bie Eeude verbreiten. Mit ber Beit aber vermifidt fid

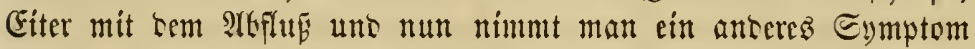
wabr. Diejer Eiter afficirt nämlidy bie Drüjen uno verurjadyt, tą

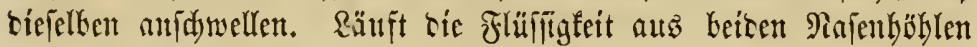

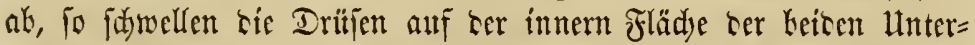
fiefer an; flieft aker bie Shfonterung nur aus einer Rajenboble, fo wirt tie Drüje mur auf bicjer Seite anjdwellen. Serod mag bie Rothfrantheit fajon eintge Zeit sorbanten gemejen fein, obne baf Driffen = Stnfdwellungen ftattfinten, wäbrent auf ber antem Seite auch antere franflafte 3uftänce, 3: $\mathfrak{B}$. Ratarrh öfters bieje $\mathfrak{A} n=$

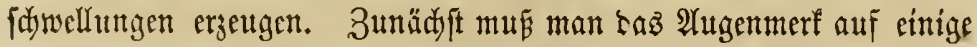

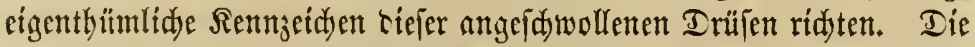
Inidyellung mag anfünglid etwas grof fein, fowie aud mebr ober meniger um fid gegriffen baben. Ballo aker wiro fid tie (j)efdyuljt ber umliegenten Theile legen unt man wiro einen ober jwei leidyt fu unterideicente \&ymphenfnoten, nidjt in ser Mitte bez Reblgangez,, jontern an Eem Hnterfiefer wabrnchmen, auf welder Seite ber $\mathfrak{A} b=$ flue frattfinot.

„Nunmebr follte sie Rajenfdleimbaut genau unterjud werten. 
Man wiro siefelbe balo blaf uno Gleifarben und balo withernatürlid geröthet, uno überbaupt febr seridjiebenfarkig finten, nur nidyt fo,

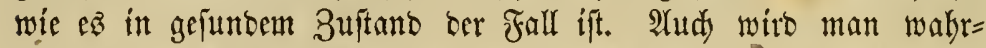

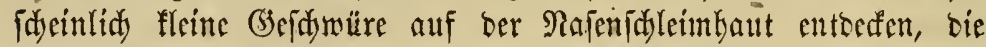
balo gräßere, balo fleinere gufteln biltoen, cine runbe Geftalt baben unt Fefrer erfentbar Kervortreten. Sobalo fid biefe Rennjeiden ein= ftellen, braudft man üher die Ratur ber Rrantfeit feinen 3weifel nethr ju hegen. Dody follte man eine forgfältige lunterjudung an= ftellen, um ausfintig zu madjen, ob aud wirflidye (bejdyüre yor= banben fint, bent man bat fdon oft fleine Sdylein= ober Giter=

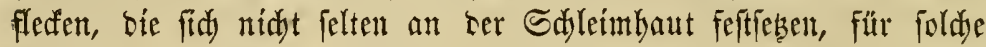

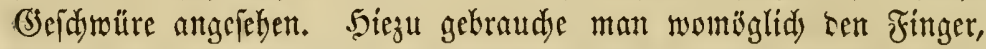
intem man mit bemfelten über bie betreffente Stelle fährt, um zat erfahren, ob fid ber Fled megmifden laffe oter nidjt. STudy follte

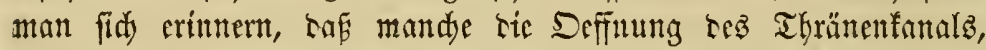

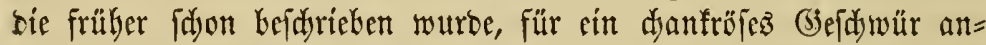
gerchen baben. Dieje Eanaloffrnung befintet fith an ter Fortiesung

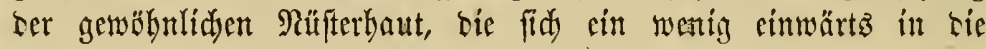

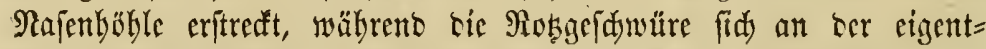

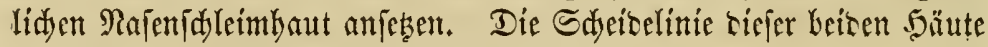
zu erfennen, fällt burdjaus nidyt fodwer.

"Sokalo auf ber Rajenfdyleimbaut Gejodmüre entftelyen, fo wiro die Gefuntheit bes \$ferdes angegriffen. Der Patient magert ab; fein Baud erideint heraufgesogen; feine 5aare baben cint fiimmer=

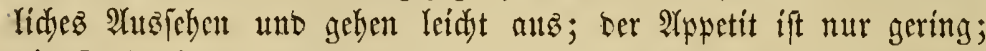

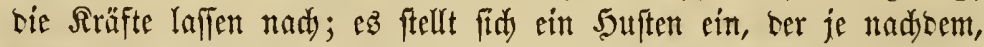
milter ober heftiger ift; sie Dutantität Lez Rajenabfluffez sermebrt uno entfärbt fidy, ift fterf mit Blut wermifat unt serbreitet cinen

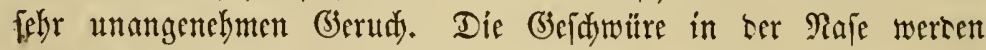
gröfer uno nelymen an $3 a \mathfrak{b l}$ zu, unt ba bie \&uft hicourdy nidjt mehr

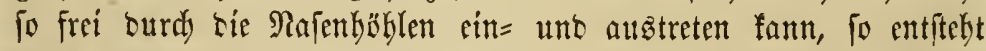

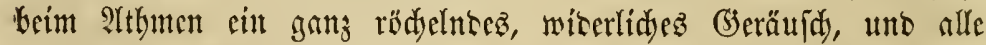

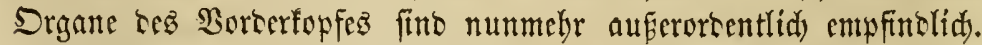
Die Sdhleimbäute her Stirnbäble (frontal sinuses) entyünten fidy

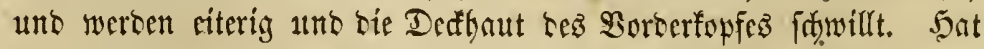

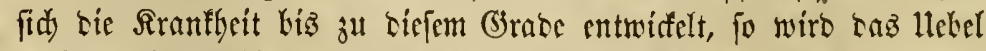

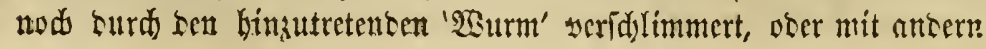




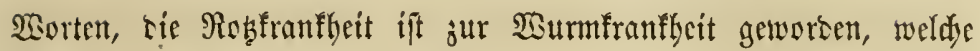
nod) mebr Edjleimbäute afficitt.

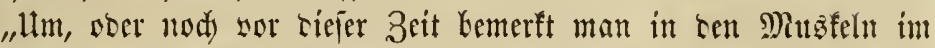

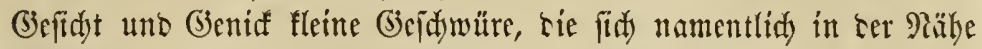

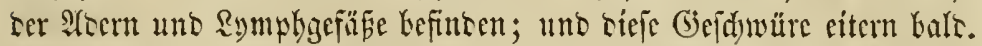
Itud) ntadjen fie ifre Erideinung, intem fie fid immer ba anjeţen, wo fid) STern oter Symphgefäpe bingichen an sem innem Theil ber

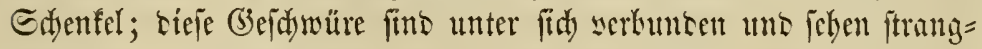

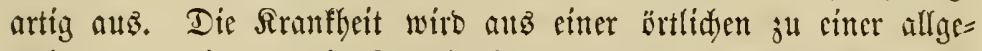

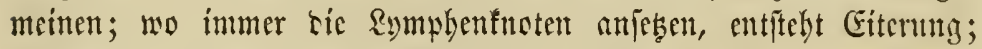

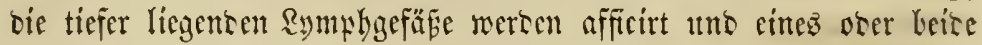

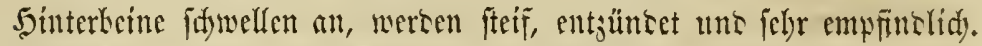

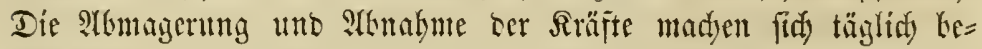

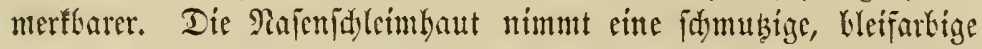

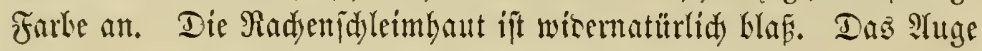

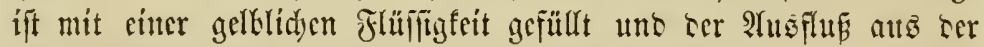
Raje sermebrt fich une ried) unausfteblid unangettehm. Iaz Thier

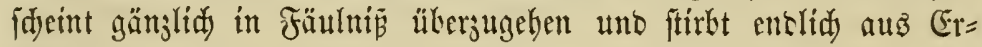
mattung.

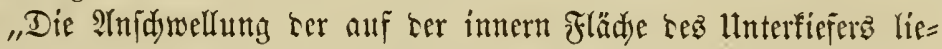
genten Driifen erforsert siclleidyt einige Errläiterungen. Dieje Edywel=

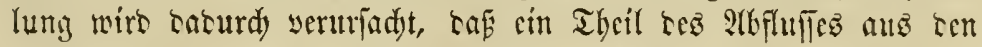

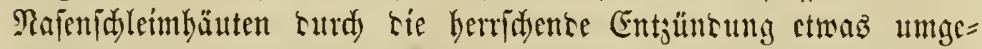
wanblt uno bierauf akjorkitt wirt; intem mun siẹe Eubjtanj natur=

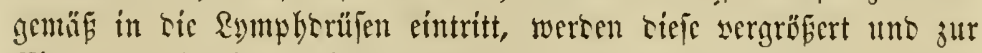
(Eitertng getradyt. Dieje Drüjen finto jesod) nur anfänglid) (jeltene

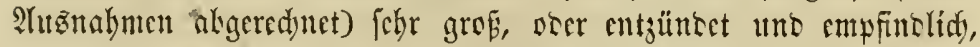

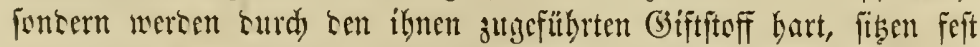

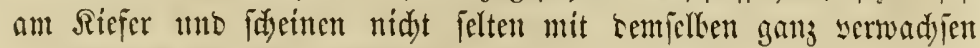
3t Fein. Dicies Sertwadjenfein wirt surdy sic Entjüntuny ser Drü=

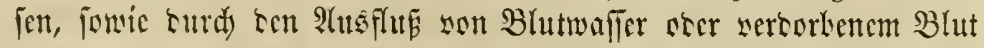

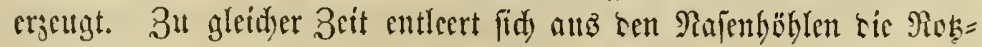

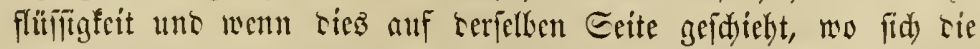

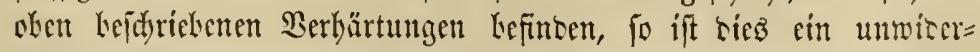

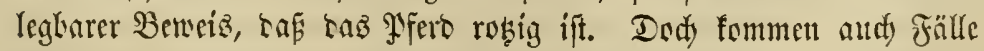
sor, wo bie Drülen weser bart nod) angeidndllen fint, währent.

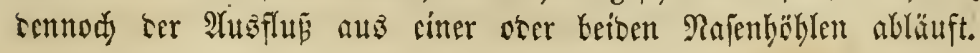


Der Thicrarst wiro aud in biefem Fall aus ben Symptomen tif Robęranfleit leidjt erfennen.

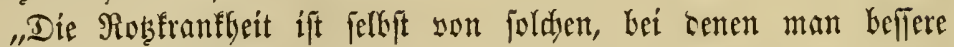
Renntnís yorausjegte, mít ser Druje (strangles) verwedjelt worsen. Die Drule. fintet fid namentlid bé jungen Pferten. Das erféte Stabium diejer Rranlfyeit ift surdh Erfältung mit etwaz Fieber,

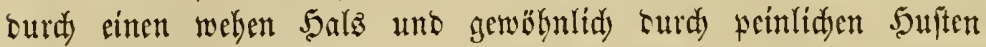

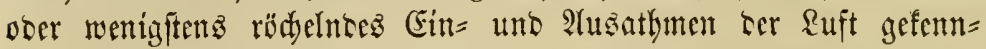

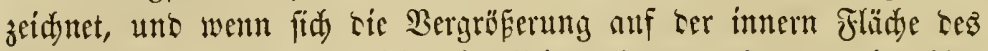

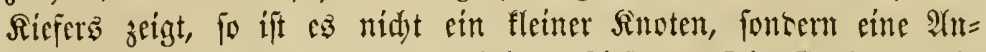
fabwellung aller Theile zwifden beisen Riefern. Die Gejdywlfit ift in ber Mitte härter, entbält cine Flüfïgteit uno bridyt auf. Díe

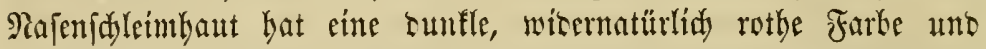

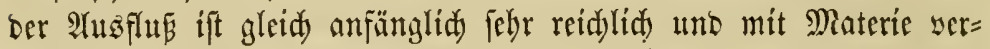

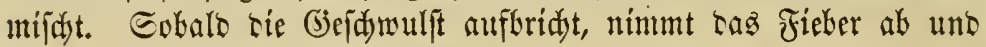
Daษ Prero wiro wieder gefund.

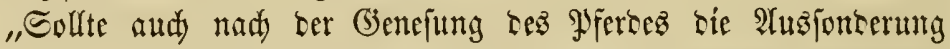

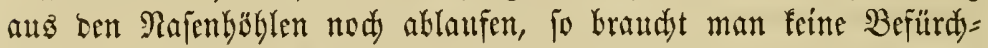
tungen ju begen. Stuz ser gemölynlidjen Irufe mus nidjt noth=

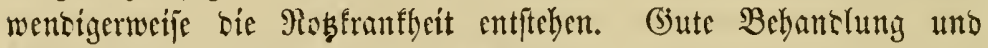
fleine (Jaben ftärfender (tonic) Medizinen werten sie Rur nad) und nad) sollentsen.

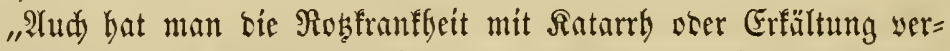
wedjelt, ofhgleid dic "unterfdeirenten Merfmale sentlidy gemug fint. Eine Erfältung wirs suld Fiteber, wehen 5als, Futterserneige=

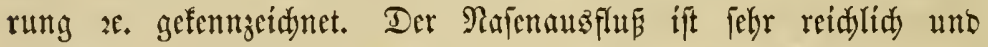

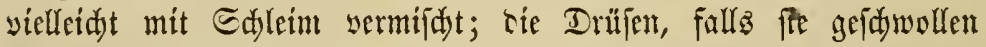

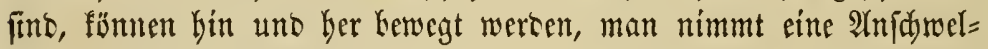
lung ber fie umgebenten Theile wahk, unt fie find febr weid) uno heis.. Bei guter Bebandlung nimmt bas Fieber ab, Ler Suften wer=

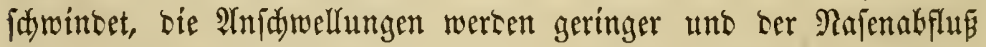
hört nadi uno nad) auf; ober wenn berjelbe ftattfinbet, fo unter=

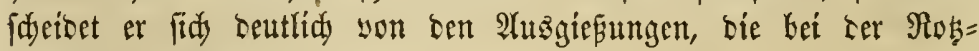
franffeit ftattinden.

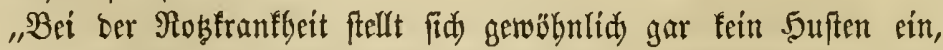
ober berfelte ift yon nur geringer Bebeutung. Radjem ser Ratarrh bereits geheilt ift, fliep̧t aus ber Rafe öfters nod) eine geringe 


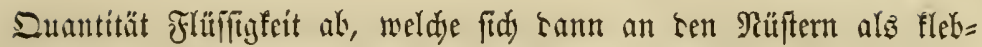
rige Malle fettegt; Liez ift namentlid) Ier Fall, wenn tie Thiere im Frühjabr an Snflutma (Ģrippe) Ieiren. Dieje llebel nebmen

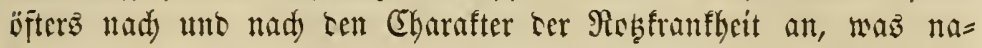

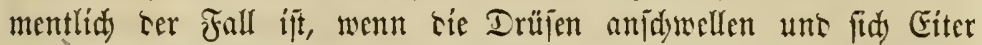
in ten Rajenbäblen anjetste. Eokalo ser Ratarrh terartige Remn=

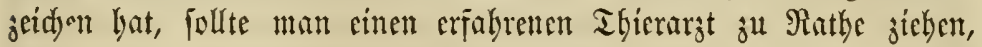

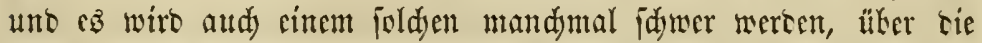

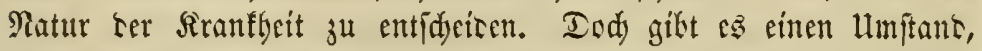
weldjer ifgm biçu Gehifflich icyn faum. Sein franthafter Buftand

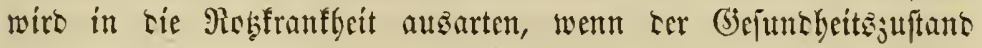

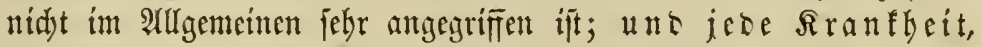
welde einen folden allgemein im Drganismus ver= bréteter franfaften 3 uftano bervorbringt, wiro ben

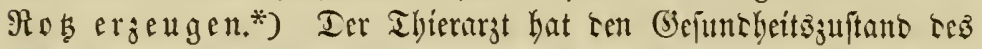

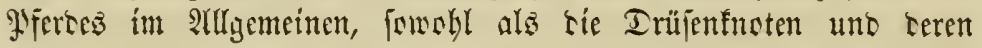

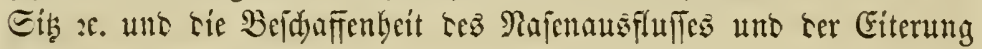
genau ju unterfudjen.

, fints, fo mag cin Berjud) angeftelft werten, weldyer mit Medjt grau= fam genannt wurse unt jut tem man nur greifen jollte, went $\mathfrak{c}$

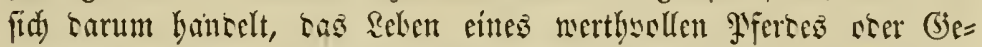

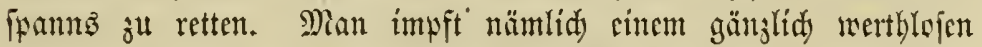

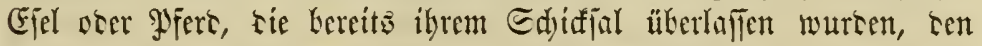

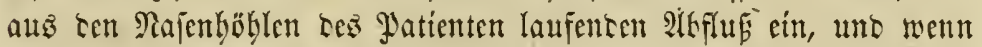

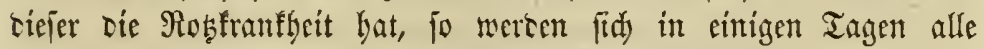
Beidyen terjelken bei sem "geimpften" Ibiere einftellen.

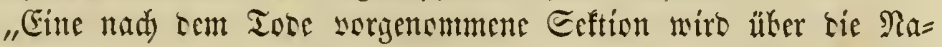
tur ter Rrantfycit feinen Zmcifel übrig lafen. In ten Rajenbäblen finten fid mehr ofer meniger febre entjüntete Etcllen, sie fid ent=

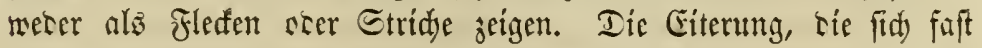

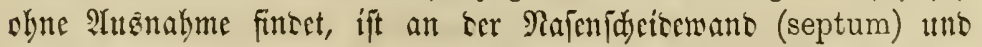
sen Giekbeinen (ethmoid and turbinated bones) dyanfross. Iis

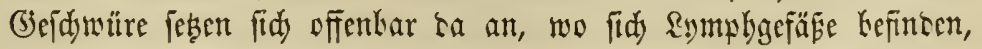
unt tie Siebbeine fint oft förmlich) mit Giter angefüll't unt wersen

*) Mir halten Dics für cine zu gewagte Bebaupturg. 


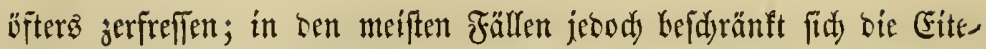

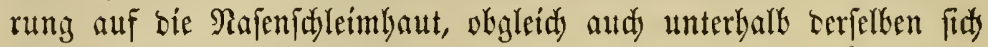
Eiter befinten mag. In febr idflimmen Fathen yerbreitet fid bie

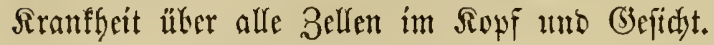

"Int bem Reglfopf und ber Ruftröbre ift tie Rranflecit beutlid 3tt

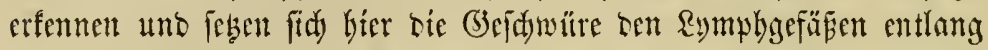
an uns wersen in fehr foflimmen Frällen felthit nabe bei ten Rungen grejutten. Sie ergettgen in biefem Drgan Entzüntung, bie in man=

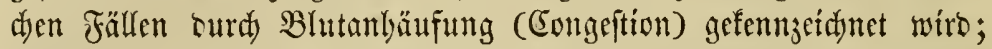
mandymal gebt aber bie (Eongeftion aud) in Eiterung über, jo ba bie Euft bie \&ungen nidyt melyt futrdjoringen fann (hepatization), woourd) tas 3ellengewebe tor Rungen zerftört wirt. WSiro bie Eunge afficirt, fo finten fid meiftens franthafte Snoten in beriflben

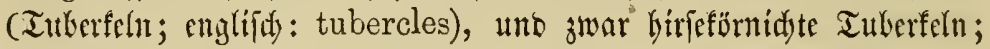
(miliary tubercles) fleine Rärner auf ober in ber \&unge, wobé nidjt viel Entzünoung herridt. Sn cinigen Fällen entfithen grofie Iuberfeln, welde vft weid) werden, fït) entleeren uno Şöblungen

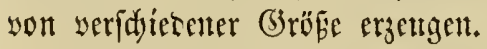

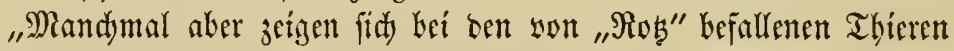

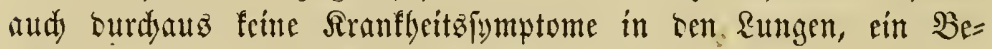

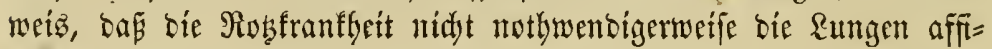
círen $\mathfrak{m u} \tilde{B}$.

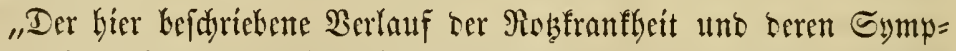

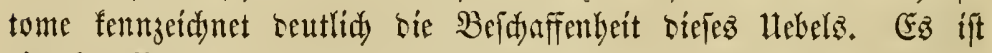
ein frantfafter Bultano ber Rafenjolfeimbaut. Mandje jagen, ber= fellbe werte yon fleinen Tuberfeln ooer Befdymüren in ben obetn Zellen ber Rafenböble erjengt, weldye lange sorbanten fegn tönnten,

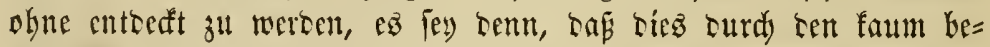

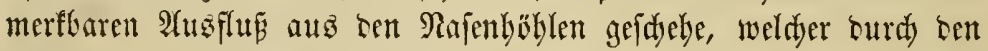

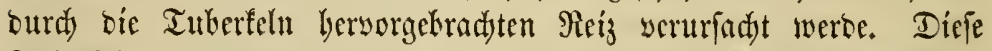
Tuberfeln vermetren fid nady uno nad, bautfen fid büfdelweife an,

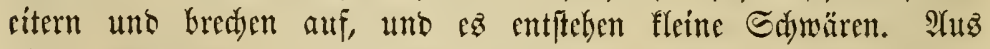

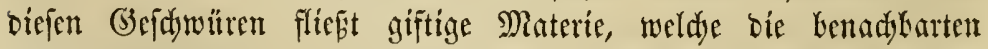
Drüfen auffaugen, uno hierourd) wiro frither vber fpäter ber ganje Drganiżmus franflaft uno anbere Thiere fünnen yon ser Geude angefteflt werben. Mandye geben fith mit ber Bekauptung zufriesen,

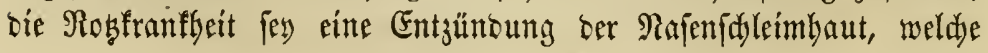




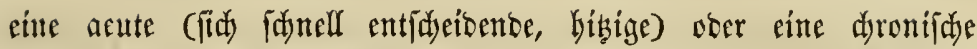
(langwierige) Form antebme, voer früber ober fpäter in Citerung übergebe.

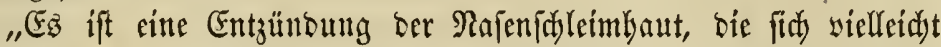
Monate ullo felbit Jabre lang auf biefelbe ober aud nur einen Theil berjelben bejaränft, obne bie (5ejunokeit oocr Braudbbarfeit Des Thieres im geringften zu beeinträdytigen. Dicfe Entzünsung wito aber nady und nady beftiger uno sie Sdyleimbatt ber Naje citert. Die Entäunsung verbreitet fid) an beiben Eeiten ber Raje= id)eirewand (septum) uno nimmt forann nad uno nad jene eigen= thümlidye Geftaltung an, weldye burd) bie Entzünoung ocr Rymnth=

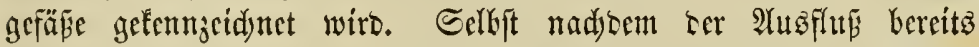
flebrig geworten ift und dyanfröle (jejedyuare fid angejebt baben, fdecint bas Pfero oft nod) ganz gejuno fu feyn. Eg gibt hundert roţige Pferbe im Ranbe, son benen aud nidjt ein einjiges ju ben 'franten' gezäblt wirs. Mionate uno felbft Jahre lang mag biefes Ulebel bie Gefunobeit nicht befdäbigen. Die Entzünoung ift blos lofal und nur ourd) bie immer mit Entzünoung eintretenten 1 lm=

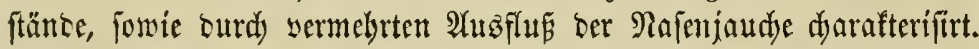

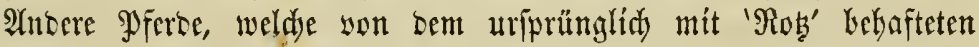
angefteft wurben, fterben; dicies aber bleibt gejunb. Entlid aber verbreitet fid bie Entzünoung über ben ganzen Drganis̄mus; bie Rranfleit, bie man ben $\mathfrak{L}$ urm (farcy) nentt, trítt eitt uno ter Too madyt ben Reiben bes Patienten balo ein Ende.

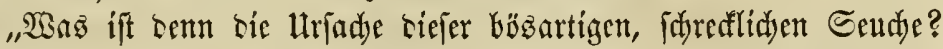

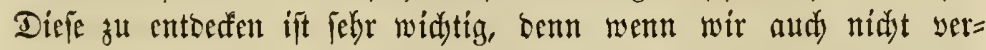
möget, in allen Fällen, bas rosige Pfero zu beilen, fo werben wir, falls die llriad)e bes Uebels uns beutlid ift, wentigitens mandjes Borbeugungsmittel in Anwentoung bringen fönnen. Utno in biefer Sinfidyt wutre aud fdyon viel geleiftet; benn die Roţfranflet ridytet gegenwärtig bei weitem nidyt foldye Berberungen an, als bies yor Ereipig, viersig Jahren ber Fall war, uno wiro meifteng nur nod; ba alz eitne verberento Seudje vorfommen, wo Sdymtb, nadyläfïge Bebandlung uno fallechte Bentilation bie Rranfleit Keföroen.

"Die Mobfrantheit entfeht entweber Durd) fdyledte Bebanclungs = weife ober $\mathfrak{A n f t e d u n g , ~}$ und über biefe zwei Punfte werben wir nod, reben. 


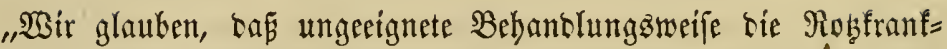

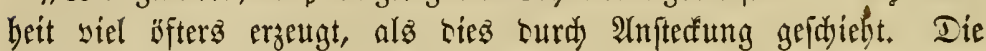

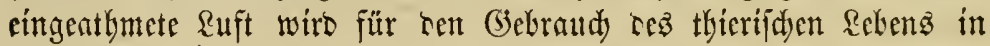

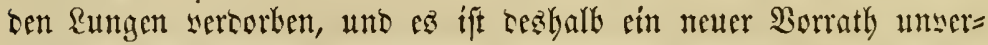

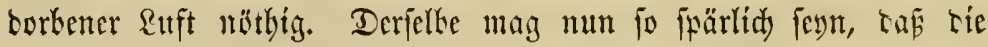
yerborbene Ruft immer wieber cingenthmet werben muf, in bie Run=

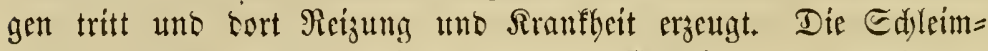

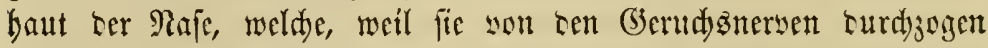
wirb, febr empfintslid ift, wirb ethenfalle leidjt turd bie vercortene

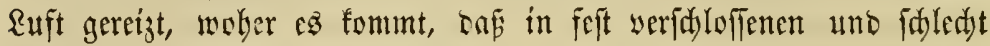

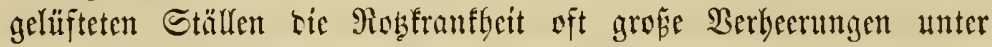
ben Pfercen anridtet. Frofefīer Coleman fübrt einen falf alş $\mathfrak{B}_{\mathfrak{C}}=$

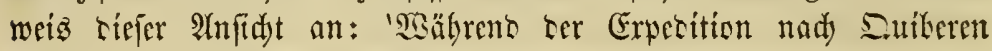

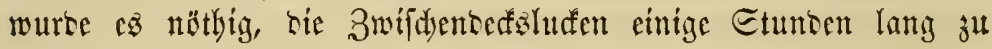

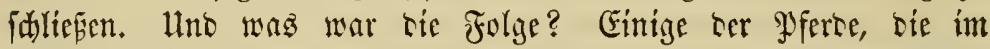
Zwifdenteff ftanten, erfitiften, wäbreno alle übrigen ausgeidifift

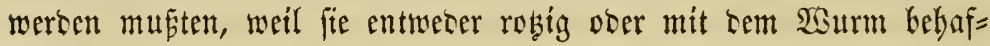
tet waren.'

"Sn einem feit yeridlofitenen Stall wiro tie Ruft, ba fiè immer

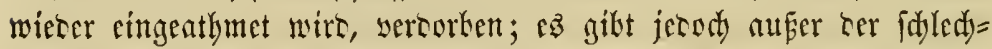

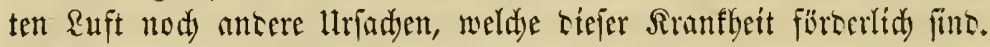
Wonn man midjt tarauf firht, bap ter Ctall yon Inng uno farn

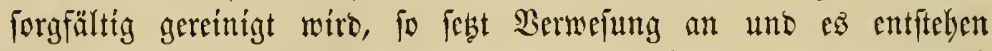
fajledyte Dünfte. Dap man auf Daz verborbene und nafie Etroh bann uno wann ein wenig frifdes wirft, diez ift durdyaus nidjt genügent uno werbirgt bie Rrantfeit wirfente thradje wohl ein wenig, entfernt fie aber nidjt.

"Die Stalfungen Ler Reiduen' werten gewöhnllidy warm genug gehalten, ja fie fint nur zu warm, obgleidy man in vielen terreflben nummebr nady vernünftigeren Regeln bantelt; fie find aber immer läftig unt geräumig uno man beobadutet bie forgfältigite Reinlid) feit. Die Folge ift, bafi in foldten Etallungen bie Robtranfheit nur jelten ausbridyt. Die Etallungen ber Farmer find zwar idmutig genug,

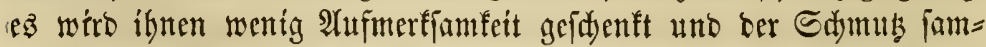
melt fid oft wodjenlang, bis Laz Pforo förnlid) vom Dutng um= geben iff. 2(ther audj hier findet fid ber Rob fehr felten, tonn bie

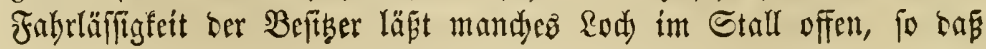


gefunce Ruft cintreten fant und ber Bind sen fürdyterlidien (serud menigftens theilmeife fortfübrt.

"Iie Ctallungen ber Pyerbehäntler fint jwor fehr warm, aher $\mathfrak{e z}$ berridyt in senjelben bie jorglamfte Reinlidfeit, moher ez fommt, La tie in tenfelken febenten Prerte felten som Rob Kefallen werben. Dagegen fint tie Stallungen ser Soft= uno Canalpferte gemblutid fo nierrig, tap ein grofes Thier nidyt aufred)t tarimnen ftehen fann;

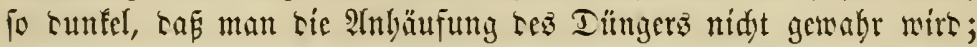

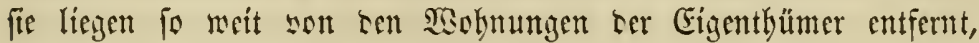

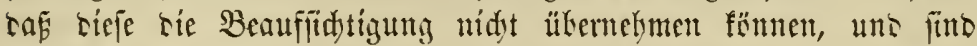

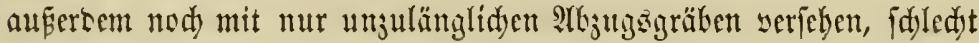

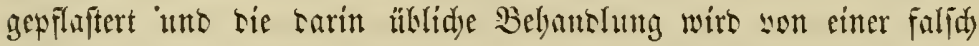

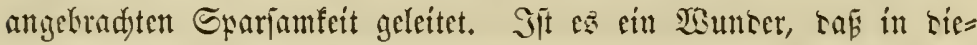
jen Etalungen ricje Eeudje fdyceflidje Berberungen anridytet unb viele serjelten nie son Ler Sranflyeit frei fins?

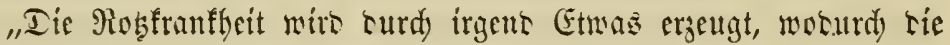
Ed)leimbaut Ier Paje bejdätigt, orer woturd) fiejelle für längere Beit in ifren eebensfunftionen geidmädut wirt. Iic Eeudye ift mandunal idon surd) eituen Rajenteinbruds, surds cinen beftigen

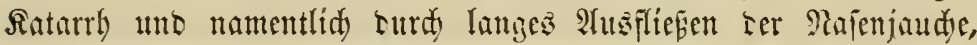
forte aud surd) sas Einsrimgen ftimulirenter ober faurel Eulftan= zen in sie Rajentöblen entftunten. Srgent Etmas, woturd ber

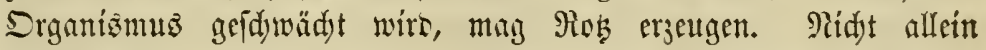
id)ledte Bebantung im Etall, fontern aud) Etrapajen uno Er=

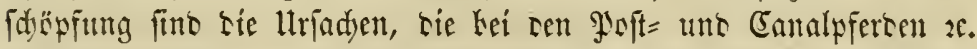
rie Rogfranfleit nady fid jichen, uno es gitt faum eine bisige

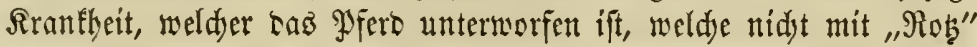
entigt.

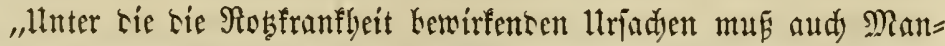
gel an regelmäétger Bewegung gejählt werten, shgleidy man vielleidyt

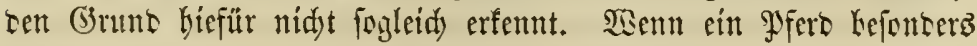

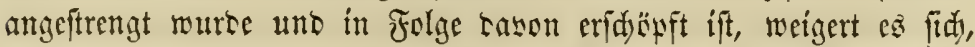

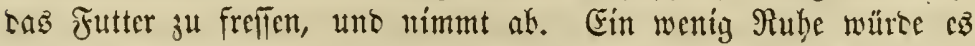
wicser juredyt fringen; ftatt Ieffen aker will ser Etallfnedyt mit Cordials (ftärfente, bergftärfente $\mathfrak{A}$ rgneien) nadjhelfen uno giét bie= mit Sel ins Feuer, benn tas Kereits angereste Fieker wirb biecturd

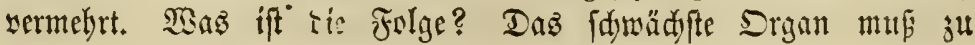


Grunte gehen, unt bas Fieber afficirt entweber bie \&ungen, ober

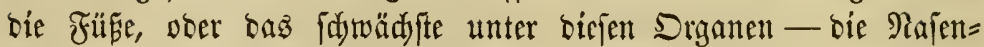

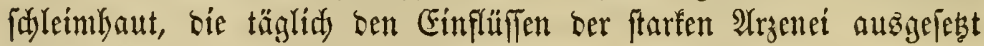
ift, franf wirb uno entlid alle Zciden bor Robfranfleit zeigt.

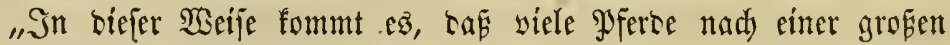
Etrapaje von ber Rob̧franlfbeit Gefallen werben. Zwar maj ber Seim ber Sendye bercits vorthanten fein; aber beren Fortiduritt

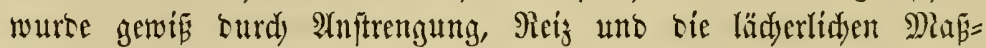
regeln, weldje bả fieber nidjt bämpften, fontern begünitigten, bes föroert.

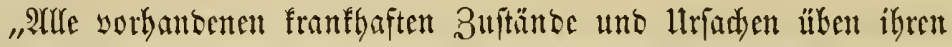

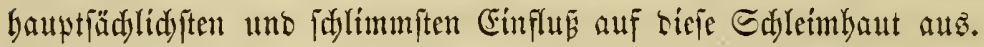

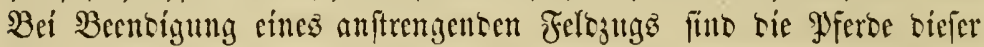

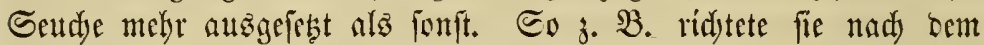
sem Feldozug in Epanien idyreflidje Berbeerungen an. Sere Rrant=

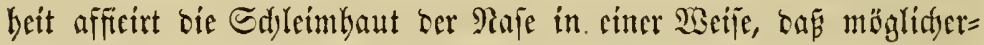
weife Pob entiftehen fann, uno vicle Sirantheiten thun bies in un=

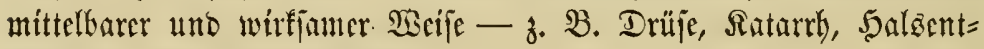
zünoung, \&ungenentgünoung.

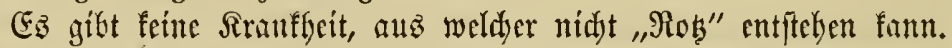
Wodden, Monate und Sabre*) mögen zwifiten bem Eintreten ter

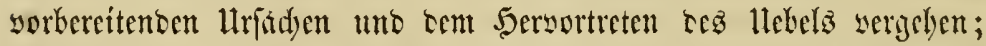

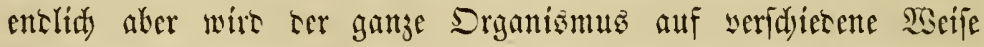

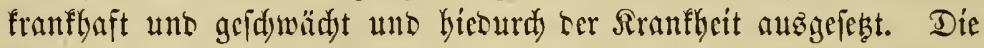
Beichaffenbeit ber Ruft üft auf baz Gintreten oer Rob̧ranfheit einigen

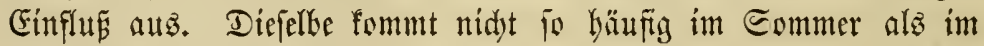

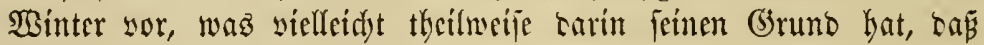
im Eommer bie Rnft in ten Etallungen weber fo verborbent ift, nod) io grofer Temperaturwedyicl vorfoumt.

,Dap bie Feutdtigfeit in ber Ruft oft cine ber mitwirfenten $\mathfrak{l t}=$

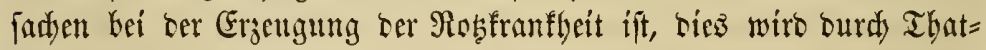

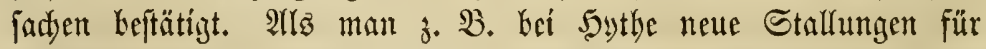

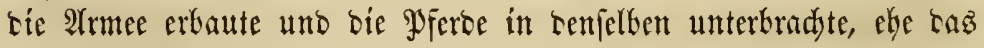
Mauerwerf gehörig ausgetrofunet war, wurben viele PFerbe, weldye an bie freie, gejunte suft gewöbnt waren, robgig; nad) eíniger Zeit

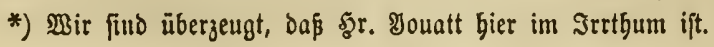




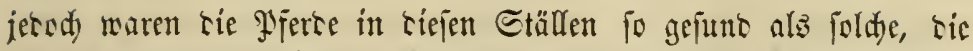

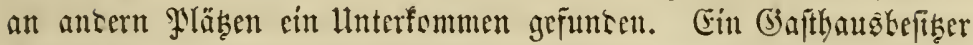
in Safefiels, welder grof́e Etallungen für jeine Pjerre erbaute uno riejelken ju früb in rieje (5etrüte kradte, erlitt grofe 23erlufte surd

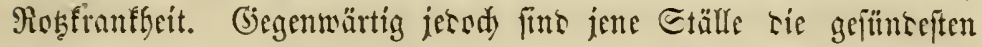
in jenter Etart. Dergleiden Beipiele fünten nod) Biele angegeken werten.

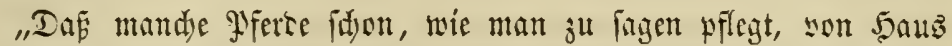

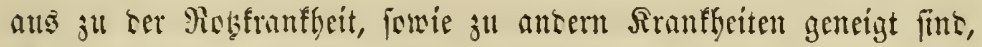
ift nody nidyt gebörig berüfifdigt moren. Fo gikt faum eine Rranflyet, rie fid nidyt son ten alten Pretsen auf tie son ifinen erjeugten jungen, mentigftens in ifrem Seime forthflanjt; fo 3. 3 .

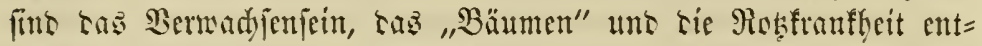

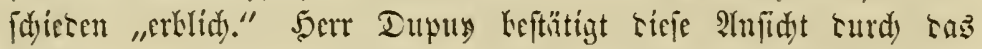

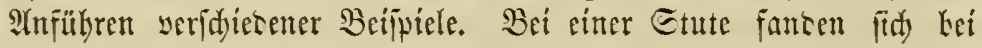

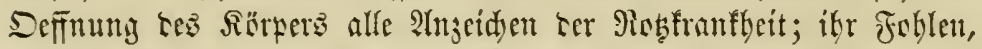
weldyes ibr forohl rem äuferm Injeben nady, als bejüglidy ibter

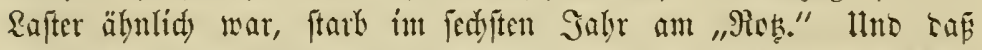

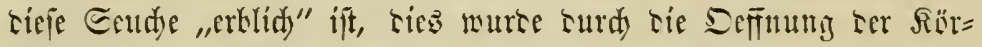
per yon nod mebreten Etuten, jowie sie Sirantyciten ibrer Foblen solftommen leftütigt.

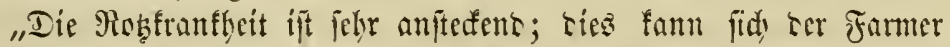

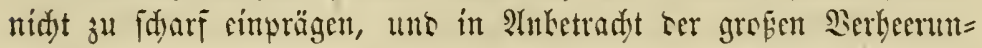
gen, weldye sicje Eeudje oft antidytet, würsen bic (jejesgeber solts=

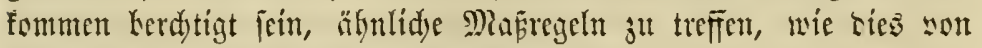
ifnen binfidtlidy Ser Blattern gejdeben ift.

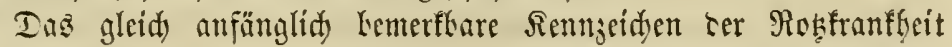

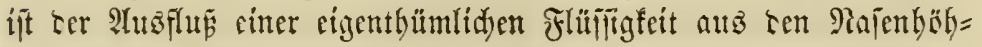
len, weldye, fotute fie in eine Sinte seer auf cime antere Sdyleim=

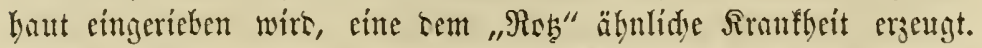
Sären tie Yjerte fo son cinanter akgejontert, saf fie fid nidyt

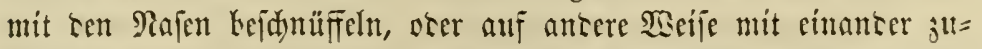

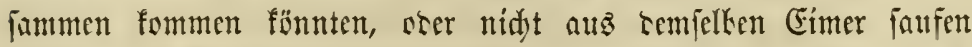
witrsen, fo tönte möglidermeife ein gefuntes Pfero jabrelang in rer Pähe eines roţigen fein, obne angeftect ju merten. Mian bat

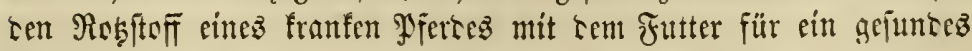
gemilidt, obne sas biefes robig rutbe; mande Pferte haben cas 
yom "robigen" Thier übrig gelaffene Seu gefreffen, vhne angeftedt worsen ơ fein, wäbrent anbere unter äknlidjen lumftänsen frant

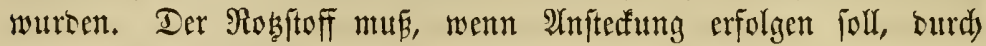
eine Wunbe ober eine büne Sdyleimbaut, bie Senjelfen leidyt auf=

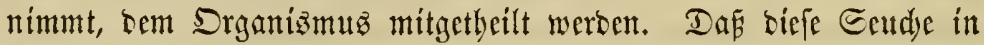
Etallungen, wo febr viele Pferbe ftehen, die beftäntig mit eituanter in Berübrung fommen, aus ciner Srippe frefín uno aus cinem Fimer faufen, leid)t ausbredyen fann, ift nidyt fobwer zu erflärent.

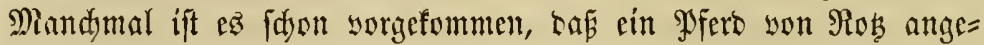
ftedt wurbe, wäbrento ez ein anderes, weldyes gerabe fduanbte, pai =

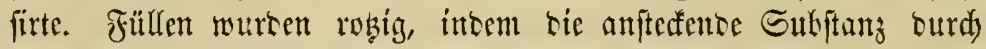
Den Sitno you cinem Felo jum antern getragen wurbe, wäbreno fid benadbarte Pferse, wieberno uno fdnaubento, fid ibnen ju näbern

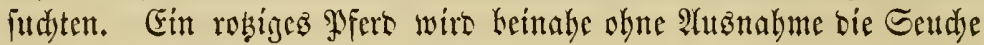
in sem betreffencen Stalle verbreiten.

„Dap Mandye tie (3efabr nidyt gebörig beadyten, fommt Saber,

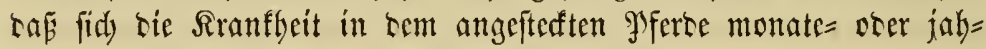
relang nidst äufert, uno wenn fie jid bann zeigt, vielfeid)t antern Urfachen zugeidricten wirb. Man follte ein robiges PJero weter jur Farmarbeit, nod zu irgento etwas anberem gebraudyen, nod onf=

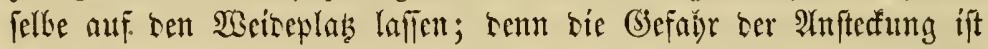
fo grof́, โa Thier entweber getöbtet, ober einem Ihierargt, ober ciner veterinäri= iden Seilanftalt übergeben werben follte.

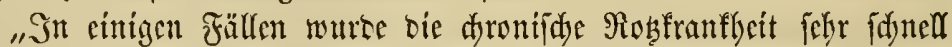

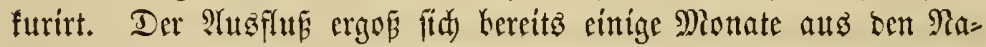
fenböbleu, nabm nady ans nad) ab uno börte entlid ganj auf; uno

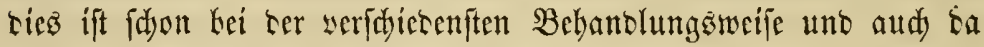
ser Fall geweien, wo gar feine Mittel angetwant wurten; aber in oen meiften biefer Fälle wurse bie Flüifigfeit turd) irgento eine 1 tr= fadje nutr eine Beitlang zurüfigebalten uno begann nad) eimiger Zeit nur in um fo gröperen Sunntitäten zu fliefen. Soer aker, fallz

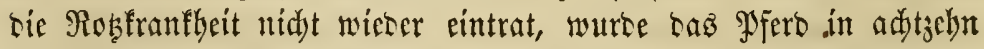

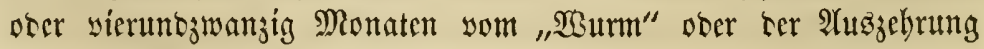
befallen, uno ftarb. Diejer Fälle fino febr wenige uno fie mülfen mit febr grofer Borfidst aufgenommen werben.

"EB gibt faum eine Metezin, bie nidyt fajon zur Scilung ter 


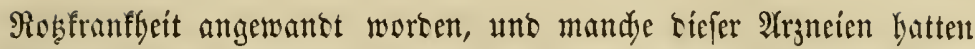

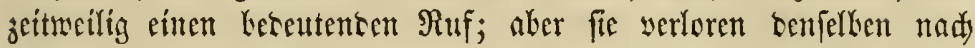
uns nad, uno beute fpridyt man nidjt mebr son senfelfent. Der

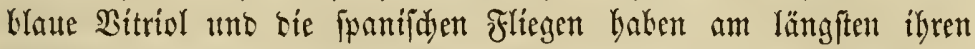
Ylats alz Surmittel erbalten, นกర

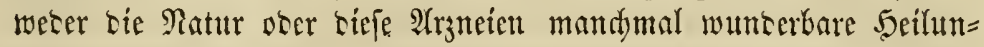
gen yolforadten; in ten meiften Fällen jeoody waren audy biepe Mit=

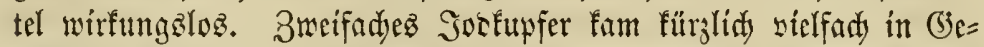

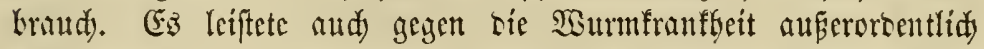
gute Diente; man fann jebody Kei Ros nidyt auf riefez Mittel ver= trater.

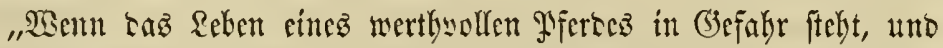
ter Eigenthümer trifft alle Borfidytzmafregeln, tapj fidy oie Eeudye nidjt verbreitc, fo mag taz Pfero ärgtlidjer Behandung übergeten

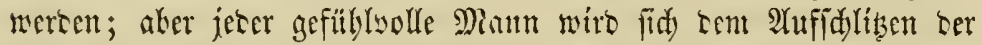

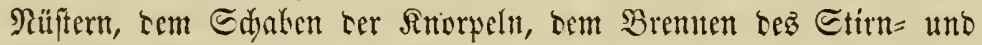
Rajenbeins uno bem Einfprisen ocer Einlegen yon Senf, Pfeffer, freflentem Sueffillber= Sublintat (corrosive sublimate) und Sitriol,

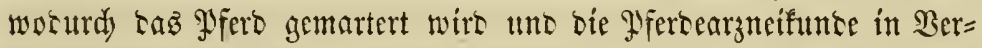
ruf fommt, miserjesen. In ier Beterinitidulte ober yon oem Pfer=

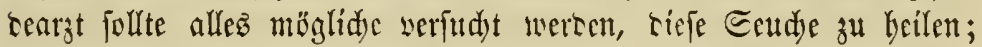
in antern Fällen ater erfüllt Ierjenige nidst frine gegen feine Nad)= barn ibm nuferlegte Pfflidyt, wentn er nidyt Iurd) surdigreifente Maf́= regeln die Serbreitung ser Sinnffeit zu verbintern fudt.

"S⿱: geiorgt wercen, daj Das Pfero an einen Plats fommt, wo genug reine \&uft ift. Die Pferse, welibe meiften im Stall gebalten werten, fino

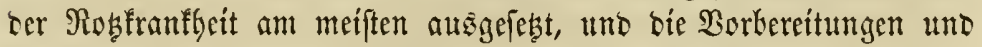
(5)

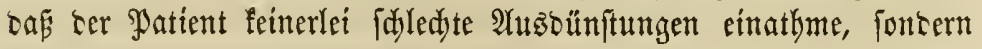
gentig füble uno reine \&uft babe.

"Ein fog. "Saljgrumb," D. G. ein Stita \&ano, baz mit falzigen Eubftanzen gefdwängert ift, uno wo cas fog. "Salzgraz" wädjt, ift für ein mit Robfranffeit bebaftetes Pferb cine auszezcidnete Weise. Dod mus man genau barauf 2(d)t baben, bap fein geiun=

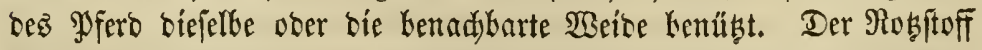
mag fid an fer Fence ober bem Thor anjeten, fort hart werben the 
nody viele Monate Sarnad Die Rranfleit verbreiten; ja, felbft Las

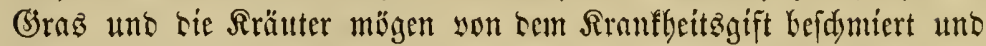

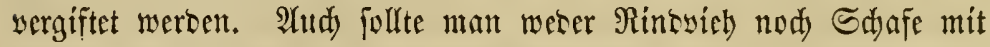
bem franfen Pferbe auf tiefelbe Sacioe laffen, benn es ift feinesine=

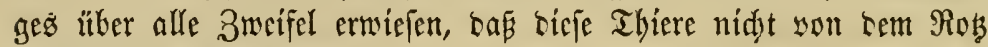
angeftedt werben fönnelt.

"Sft, fo fönnte man fragen, nadyem ein Farmer tas yon ter Robfranflyeit befallene Pfero entweser entfernt ofer getöbtet bat, nod

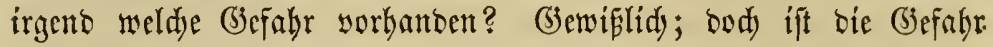
nidat mebr fo grofi, als man gewöbnlid wermuthet. Die Srippen uno Raufen, ober ber Stnlf felbjt - wie bies non Manduen gefdah nbjutred)en; bies ift nidyt notbwentig. Die Injtefung geidiebt nidyt burdy bie yom Patienten ausigeatbmete \&uft, jonoern burdy sen

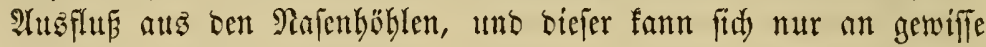
Theile ter Stałung anlängen. Went bie Rrippen, Raufen, Stän= oer 2e. titd)tig akgeidabt uno grüntlid mit Ecifenwaाfer uno sann mit ciner श(uflifung von d)lorfaurem Salf (chloride of lime) - eine

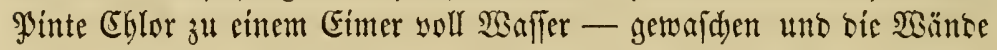
Dann geweipt, uns Łas Salfter ober Sopfgefdirr vertrant, und an= Deres (3)efdirr, meldes ber Jatient geliraudst, nebft ten Deffen tüd)= tig gereinigt uno bie Eimer frifh angeftriden, uno bie Eifentlyeile ser Stallgeräthidaften glühento gemadyt werben, fo ift bie (3) fubr yoritber.

„Sinfid)tlidy ber Borbeugungszmittel läpt fid menig befriebigentes fagen. Das erite und fid)erfte Borbeugungänittel beftebt barin, sie Ctallungen fubl zu halten uno gut auşวulüften, tenn bie erbibste und verborbene \&ujt nicterer uno feft serfdsloffener Etïlle ift cine Saupturfadye biefer Rranflyeit.

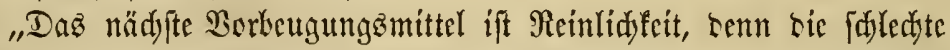

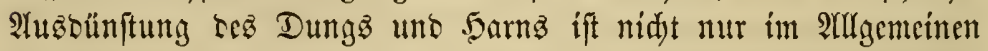

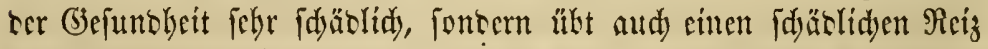

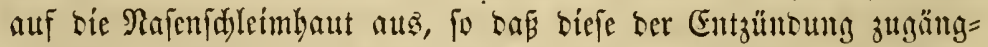

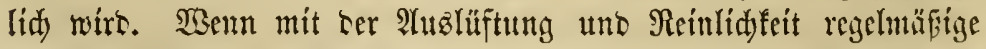
Bewegung 5and in 5and gebt und Dabei im Sommer bic uno ta grüne Futter uno im $\mathfrak{B}$ inter Sielkritben gefüttert werben, fo bat man zur Berbütung fer Geudye taz feinige beigetragen.

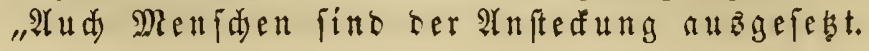




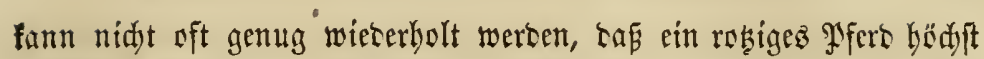
wahridseinlidy antere, sie gefund find und mit remielben in Berüb= rung fommen, anferfen wiro; ja, aud Ier SBärter cines foldyen Pa=

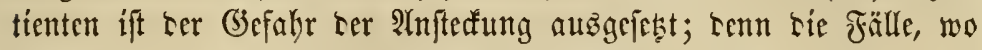

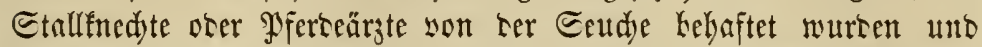
ftarken, fino nur ju jablreid. Beim Meniden ift jesody eber cine

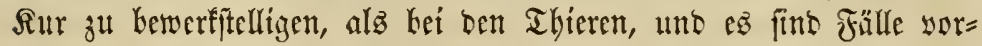

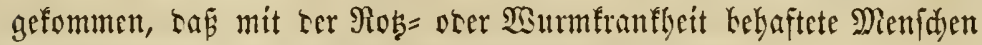
gebeilt wurcen; jebod) find bieje Fälle fehr jeltent."

Sntem wir ticjer mit vieler Eadjenntnif unt Rlarbcit afgefafi= ten Darftellung gerne eine Etelle in riefm Bืudye einräumen, müfien wir befennen, saj wir in siefer Bejiebung nidyt fo ganj boர̄nungs

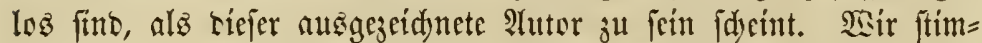
men nidut Samit ükerein, Iaj̃ sie Roţfrantbeit unter beinabe allen Ulmftänten unbeilbar ift. Rod fönnen wir ser Bebauptung beiftimmen,

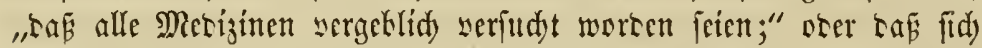

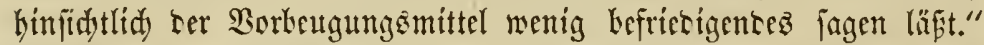

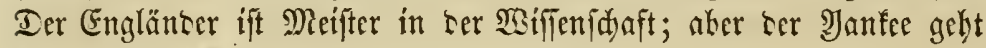
einen Edritt meiter unt wentet riejelbe an.

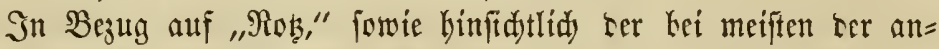

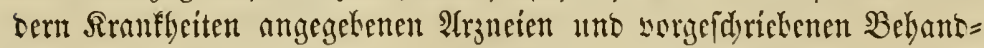

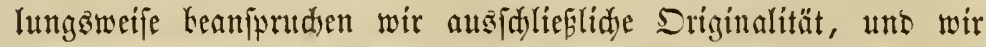

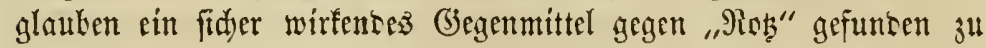
baben; es ift aufercrsentlid einfad), Ieidyt ju balen unt ten 2 (erz= ten rer alten Siselt, sie ohne Zweifel tüdtig getilret fint, unkefannt. Ramentlid wirft es als Borbeugungsmittel febr gut, uno bewoirft im erften Etarium Ier Sranflyeit gewiff, uno im zweiten febr oft

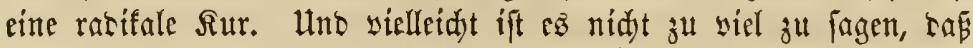

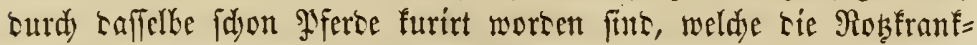

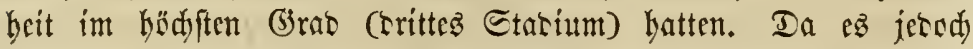
fajmicrig ift, rie Sdyciclinie jwifden biefem Starium uno sen sor= Gergebenien ju entbeffen, fo wollen wir nur sas kebaupten, woju wir surdy feftitebende Thatjadyen beredtigt fint.

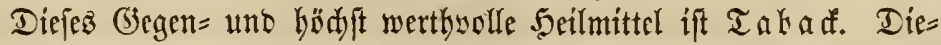
fez Kisber untraudbare Itnfraut hat nämlid sie Gigenfdaft, baz rurd bie Reijbarfeit im Blute verbreitete (Bift zu neutralifiren uno

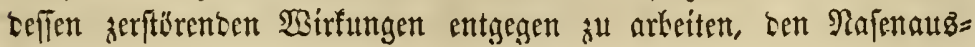


flü aufzutrodnen und endlid - nid)t blos bie Sranfleit zu berwäl= tigen, fontern aud beren (d)äblid)e Wirfungen im Drganišmus zu entfernen.

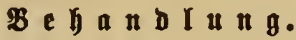

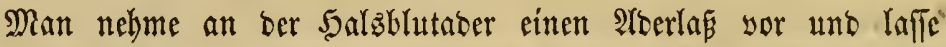

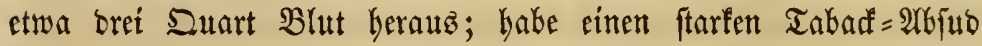
bereit, yon weldem man eine $\mathfrak{B i e r t e l}=$ \$inte in eine \$inte warmes

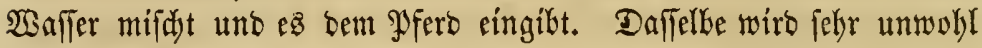

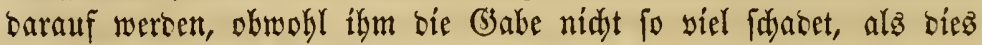
ber Fall fein mitroe, wäre es gejunto; ja in biefem Fall ift biefe Dofiz burdjaus nidjt gefälrlidy. Man wafde bie Rajentöblen mit

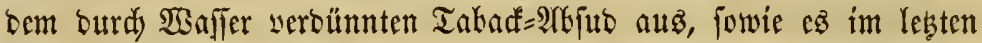

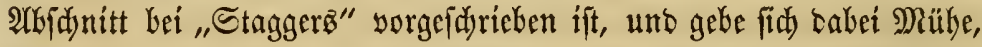

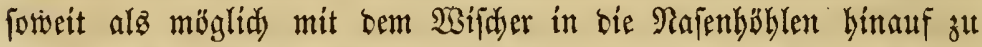
reidjen. Die Míf fann.

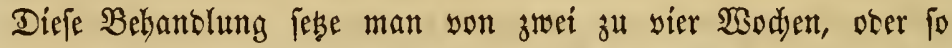
lange fort, biz günitige Ifnzeidjen bemerffar werben." Man wifdye

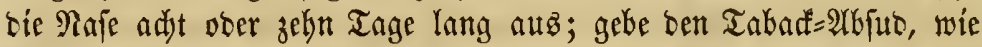
oben angegeben, alle brei Tage, fo lange wie oben bemerft ein und gebe bem PJatienten fo viel Edywefel (sulphur) uno Sarz (resin) alż er frifít, für ben Zeitraum yon zehn Tagen. Eine yolle (batbe befteht in vier Unzzen Edjwefel uno zwei Ulnzen $\mathfrak{5 a r z}$, beibes pul=

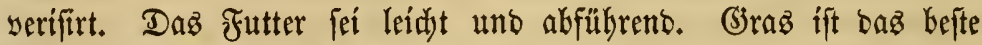

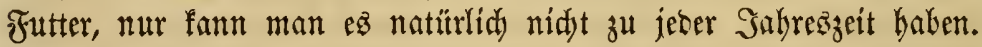
Benn ber Yatient auf bie SBeibe getallen wiro, jo jebe man barauf,

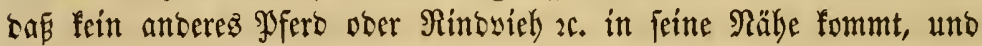

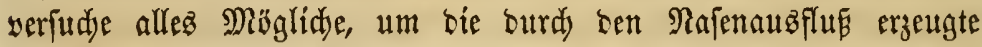
Anftedung zu verbüten. Man bringe bas Pfero bei Radjt, ober bei

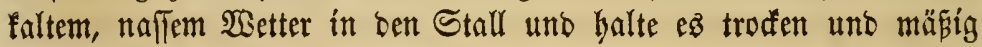
warm.

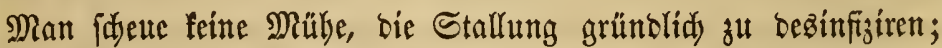

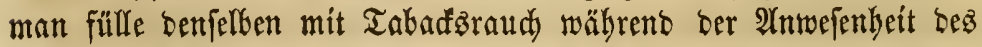

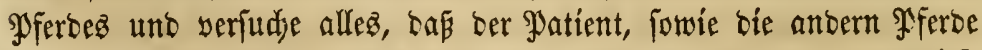
fo viel als möglidy yon biefem Raud) einathmen; fo lange mué biefe

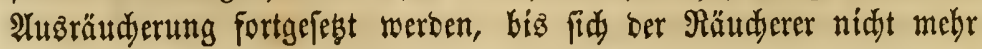


im Etall aufbalten fann. Man majdye ben ganzen Stall uno na= mentlich bie Sirippen mit einem ftarfen Tabad =2Ab/ub uno balte zer=

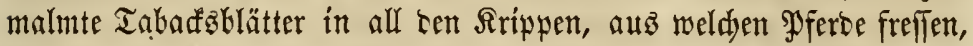
bie ser Sranfleit ausgefebt waren. Wer biejer Behandungštweife

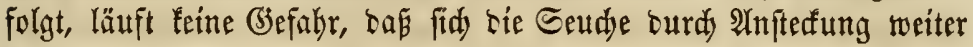
serbreitet.

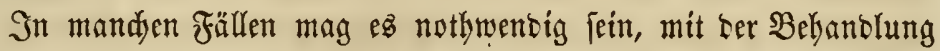
länger fortzufahren, als oben angegeben wurbe; wenn jebod ber hier gegebenen Anweijung genau Folge geleiftet wiro, fo wirb man die Robfranfleit, ehe fie inz britte Stabium getreten, beilen fönnen.

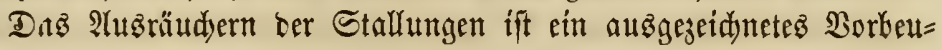
gungsెmittel, weldyes namentlid, bann öfterş follte angewanot wercen,

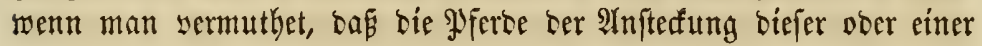
antern Rranfbeit ausgefegt waren. Der Tabaf wiro alb Borbeu= gungsిmittel gegen alle Sranfbeiten gute Dienjte leiften. Neben Douatt bebaupten aud andere adtungswerthe श्dutoren, baf (Befabr yorban=

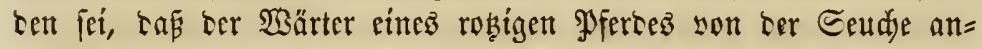
geftect werbe. Dies mag ber Fall fein, wo man fein Borbeugung $b=$

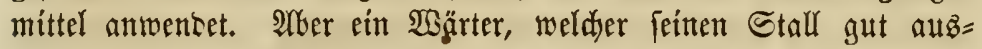
räudert ttto wäbrent feimer $\mathfrak{V}$ erridutungen eime Pfeife ober eine gute Cigarre raudat, braudyt feine Furdit zu baben.

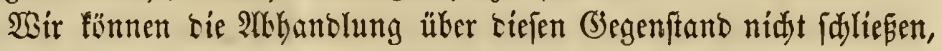
obne einige emfte $\mathfrak{W}$ orte an PJerbecigenthümer zu ridten.

Die Prerte in einem nieberm, feudten, fdumbigen Etall zu halten, welder son faledter \&uft angefült ift, in weldyem grofie Saufen Dampfenter Dung liegen, nno weldyer widyt allein fdjledyt gelüftet, fonbern oft aud ganz finfter ift, - bies ifit ein Sdjanbfled, mit bem fidy Riemano bejubln follte. In ber veroorbenen, verpeiteten \&uft eines foldyen Stallz fönnen fidy weber Thiere nod Menfdien lange aufbalten, obne frant zu werben.

Wenn irgend einer biefer Hebelftände fid in euren Stälfen findet, jo bitten wir im Namen bes cigenen Sntereffes, ber Danfbarfeit unb Barmberzigfeit, đdufft biefelben ab und bereitet euren Pferben, diefen treuen Snedten ber Menjuen, ein befferez Unterfommen. Bejdafft einen geräumigen lüftigen Stall mił gentigenoem Sidt. Wenn bie:

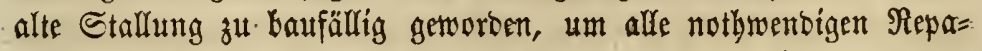
raturen befteben zu tönnen, fo reift fie ab uno baut eine neue, unb 
feit werfidjert, Dap ihr hiemit eurem eigenen Sntereffe bient uno zu=

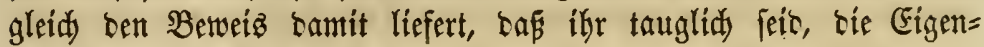
thümer yon Pferben fu fein.

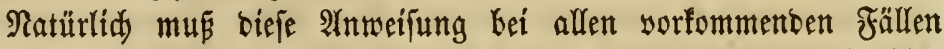
befolgt werben, benn wollte man fie nur in fefre fajwierigen in $\mathfrak{A} \mathfrak{n}=$ wentung bringen und babei feine Sur bewerffetelfigen, fo wäre es

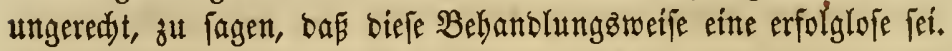

\section{E}

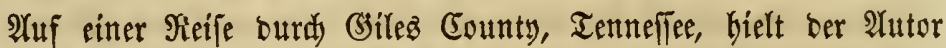
yor einem Rauflaben, wo fid Jugleid bas \$oftamt befano, in tem

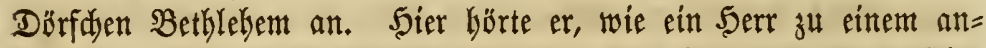
Dern [agte, er fei beinabe ruinirt, benn Poferce und Maulthiere burd) eine Rranfleit serliere, bie burdantz unbeilbar fei. Diefer Serr war eit Farmer uno bebeutenter $\mathfrak{B}$ ieb)

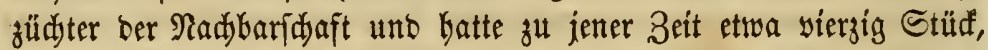
meiftenz junge Mjferbe und Maulthiere, bie er bald auf ben Marft

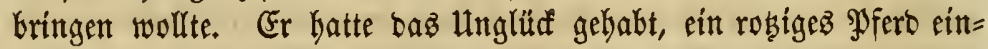
zufaufen; bie Siranfleit verbreitete fidd unter ben jungen foüllen, yon weld)en einige bereits geftorben waren.

Diez war natürlidi ein fehr bebenflider 3uftand und fonnte zut einem Berlufte yon mehreren taulent Thalern führen. Utno cas war zugleid ein Faall, in weldem fid bie Wirtung ber von unż benühten und empfohlenen Seilmittel erproben fonnte. Die (jelegenteit mutro

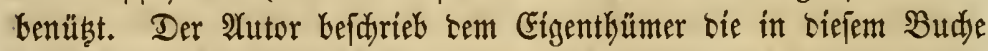
mitgetheilte Behandlungzotwife unb biejer veriprad), biefelbe genau zu befolgen. Unto Giemit fajieben wir yon Serrn 'Soleph Eomonston.

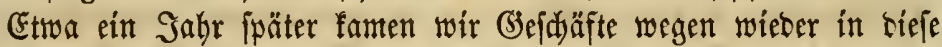
(3egend und ba wír yon bem ausigezeidjeten Grfolg hörten, Den Sherr Eomonzton mit ber yon unz angegebenen Methobe hatte, gingen

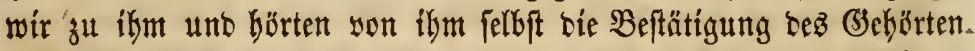

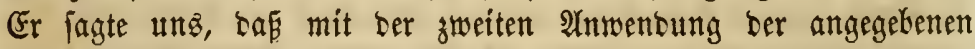

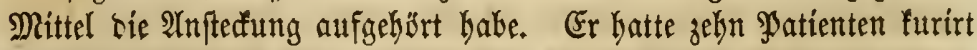

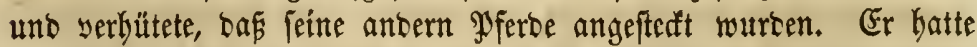
weber feine Stallungen abgebrant, thod einez feiner Thtere getöbtet

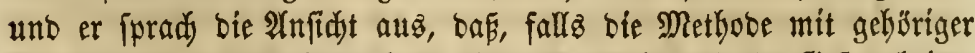

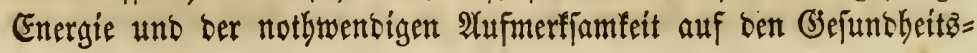


juftano bes Patienten überbaupt befolgt werbe, bie meiften Falle ber

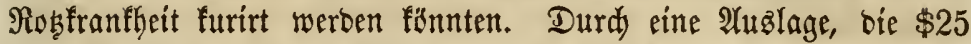
nidjt überftieg, Gatte er Pferbe und Maulthiere gerettet, bie $\$ 5000$ werth waren.

\section{$\mathfrak{W}$ и $\boldsymbol{r} \mathfrak{m}$ ( f a r c y).}

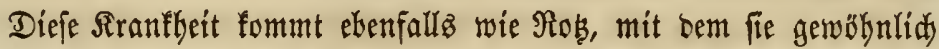
in $\mathfrak{B e r b i n b u n g ~ a u f t r i t t , ~ v i e l ~ b a ̈ u f i g e r ~ i n ~ b e r ~ a l t e n ~} \mathfrak{B e l t ~ a l z ~ i n ~ t e r ~}$ neuen yor, uno Surmfranfleit ber englijaen uno franzoffiden Etallungen befannt. Desbalb find bie (jelegenteiten, diefe Seude zu beobadyten, bierju= lano nid)t fo bäufig uno unjere Ihierärzte fino mit berjelben roeniger befannt alş ifhe Collegen über bem Meer. Dennod) tritt biefe Rrant= beit cann unb wann in veridfecenen Rofalitäten auf, uno wirb ge=

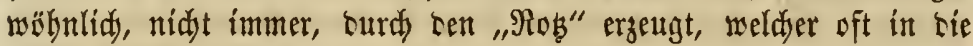
Wurmfranflyeit übergebt.

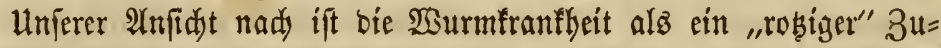

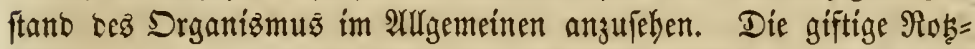
jubftanz gebt ins Blut über unb zeigt fid endich in (Bejdyüren (खেurmbeulen) auf ber Saut, weldie aufbredten uno aus weldien

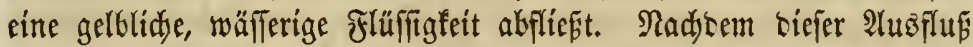
einige Beit ftattgefunber, geft eine wejentliche Beränterung vor. Die Flüffigfeit wiro nämlia mehr materienartig, flebrig uno übelried)ent uno if mit Blut vermifdt. Die Eiterbeulen fommen meiftens am

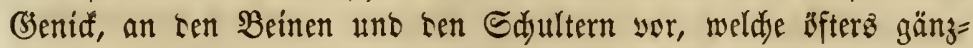
lid) yon benjelben bebeăt fino. Anfänglid fino fie mandimal nur auf bie Füfe uno sfters nur auf einen berjelken kejdränft. Die Beulen vergröfern ftd uno laffen eine übelried)ente Flüffigfeit auģ= fliefen; bie Sranfleit verbreitet fid, biż Ler ganje Sörper einer Fiter= maffe gleidy fieft unt entlid erlöft oer Too bas Thier yon feinen Reiben.

Die $\mathfrak{3}$ urmfranfleit ift, wie fdon aub ifter Bermanbtidjaft mit

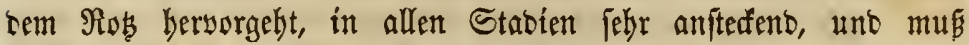
meiftens als eine Folge ber Bernad)läffigung uno (a)ledsten Betiano= lung bezeidnet werten. Wo immer bie Stallungen feudst, fdimusig und nidht gelüftet fint, ba ift Bsefabr, bas cieje Siranffeít eqtiftebt, : 16 fann bon biejer Seudje nod mit mefr Redyt als yon bem 


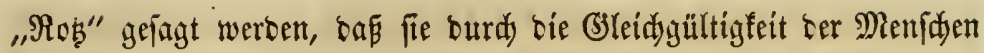
erzeugt wirt.

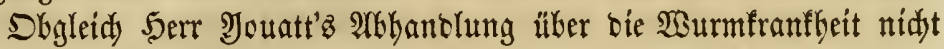
in alfen Punften mit unferer 2 Infidyt übereinftimmt, fo jualten wir biefelbe bier cin, benn fie fdeint unz ber Şauptiadye nady auf ridy= tiger $\mathfrak{A}$ njdyautung fu beruben:

"Die $\mathfrak{3 u r m f r a n f f e i t ~ i f t ~ m i t ~ b e m ~ ' \Re o g ' ~ s e r w a n t . ~ G i n e ~ b i e j e r ~}$ Seutyen, ober aud ibre Symptome geben in bie ansere ïher uno che bie eine ober antere Rranfbeit ifr töstlidyez Ente erreidst, wito fidy bie Bermanotidaft ber beicen beinabe immer auf bie eine ober anbere Weife äufern. Ein yom $\mathfrak{W u r m}$ befallenes Thier wirb oft

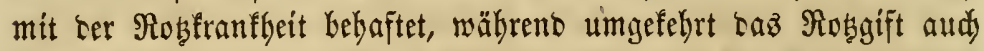

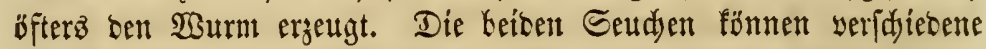
Erfdyeinungen ober Stufen einer unb berjelben Rranfleit genannt werten. In ifren Symptomen fowie in ifrem Derlauf nimmt man jeood) einen wejentlidjen Itnterjdjeb wahr uno jwar befteht berjelte

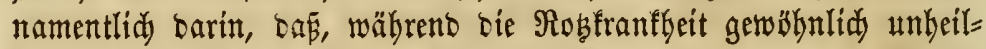
bar ift, ber \$urm in feinem eriten Stabium uno wenn bie Seudje in milloerer (S)eftalt auftritt, furirt werben mag.

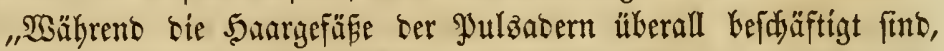

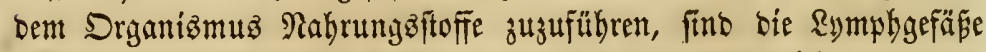
nidjt minber thätig, bie nublofen unb abgenübten Subftangen aus=

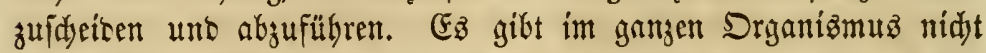

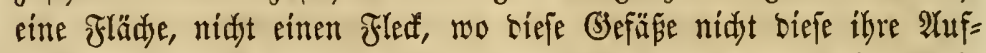
gabe verridsten. In cer Erfüllung berfelben entfernen fie nidyt alfein nublofe uno oft aud gefunbe, fonbern eben forobl giftige uno zer= ftörence Stoffe. Sie befincen finh an jebem dyanfröfen (siejdwür, an jeber Eiterbeule, faugen einen Theil beż Fitergiftż auf uno wer= ben burd befien giftige, beipente (Eigenidaft mebr ober minter be= fhäbigt; weabalb diefelben (bie \&ymphgefäpe) anjdyellen.

Sn ben Rymplygefäpen befinben fidd ba unb bort Rlappen, weldye ourdy bie fliepenten Säfte auf bie Seite gebrüdt merben, fo bap bie= felben (bie Säfte) gegen die Bruft bin burdjfliefen, aber nidht mebr zurüdgehen fönnen, Denn bie Rlappen iffnen fid nur nad) einer Rid)= tung. Die angefdwollenen symphgefífie in biejen Theilen, forwie bie bier entfandene Entzünoung fann fowohl mit bem 2Yuge als mit bem Taftinn in böberem ober geringerem Brabe wabrgentommen werben. 
Man bemerft biejelben gemöbnlidi zuerfî an sen Rippen, ber Naje, tem (3)enif und ben Süfften. Sie fino hart und oft verhärtet, mehr ocer weniger gegen Drud empfindlidy uno erribt.

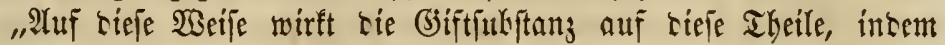
fie auf biejelle befdränft ift; $\mathfrak{e B z}$ folgt Eiterung uno Beulen ent= fteḩen. Dieje Beulen find ben Drüjenfnoten ähnlid, bie auf ber

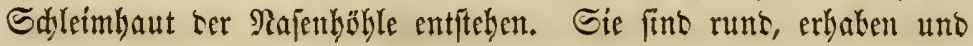
baben ein bla

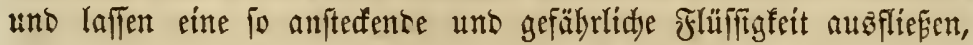
alz bież bei ber Rob̧franflyeit ber Fall ift. Co lange fie bart finto

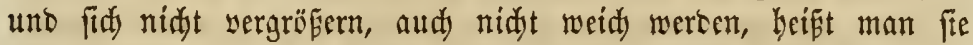
Wurmbeulen (buttons or farcy buds) uno fie fint miteinanter yer= butten, fo dấ fie oft lange Etränge bilten.

"Manthmal nimmt man beim Pferbe Beiden cinco franflaften Buftantez wahr, ehe fid sie Beulen ober Etränge zeigen. Seine Frefluft ift eine nur jeflr geringe; feine Saare fints ftruppig;

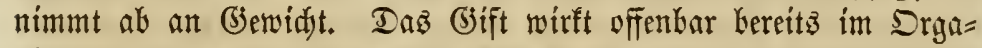

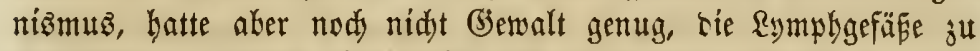
vergröß̈ern. Sefterz eitern bieje Beulen aud) gar nídt, fontern

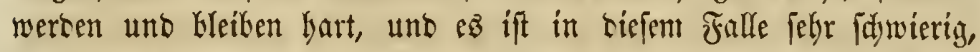

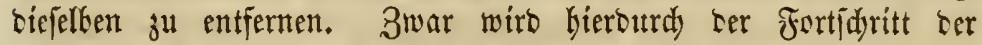

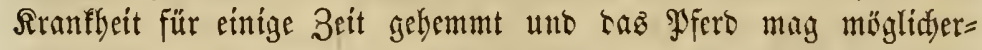
weife Monate lang gänjlid) gejutto ideinen, trägt jerod ben Seim

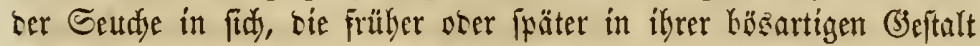

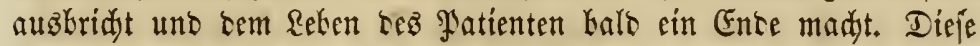

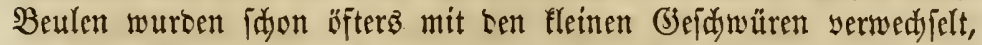
bie bei Ser Rrantleit vorfommen, bie man mit rem Ramen "Surfeit" (eine surd) unreinez Bhut erseugte 5autfranffeit) bejcidnete. Die

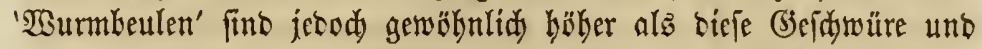
nidyt io breit als bie lestern; aud) baken fie cine envtenartigere Form als biefe und fommen gemölynlidy an ber innern flädje ber (3)tiermafen, anftatt an ber äufern vor.

"Die yeridiesene Beftalt, weldye bieje Sranlfeit oft annimmt, be=

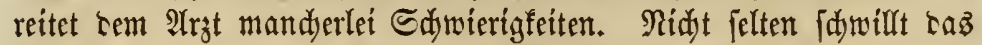

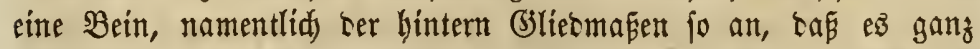
unförmlid wirb. Radjtz fdjeint ber Patéent volfommen gejuno zu feyn und Morgens ift eines feitner Beine breimal fo grós als bas 


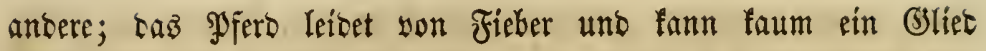
rühren.

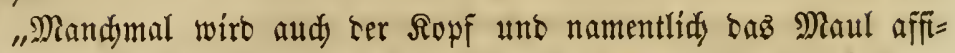

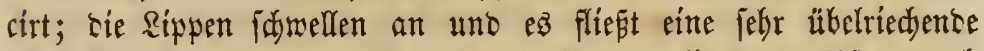

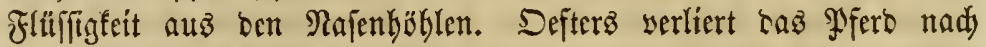

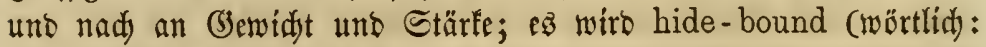

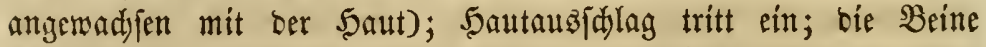
idjwellen an; bie 5 sufe werben brüdig, uno eine unerfabrene $\mathfrak{P e r}=$ fon mag in biejen Beidjen niddtz weiterez erfennen, als einen ge

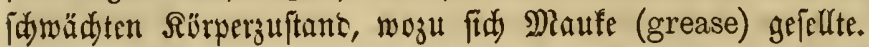

,19ad) und nad) verbreitet fid bie Sirantbeit im ganjen Drganiz=

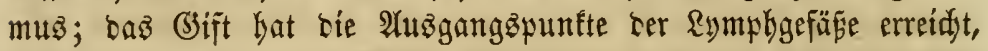
vermifajt fid mit ben Säften uno wiro burdy bas Blut in allen

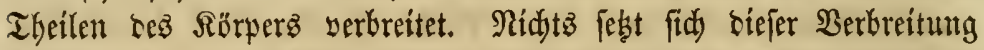
mehr entgegen, uno man nimmt nun feine $\mathfrak{B e u l e n}$ mebre wahkr, fon=

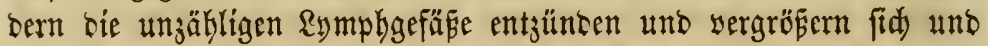
yerriduten ibre Fanftionen nidjt megr. Sicraus entfteht bas $\mathfrak{A}(\mathfrak{n}=$ idjwellen ser yeridjecenen Theile - ber Beine, ber Brutt, bes Ropfę,

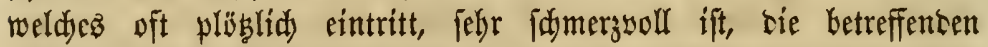

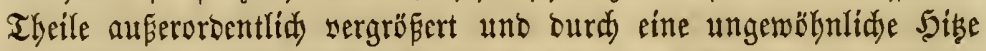

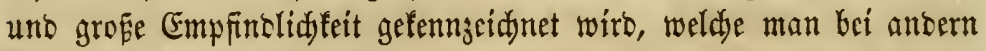
$\mathfrak{A}$ nidjwellungen nidyt fintet.

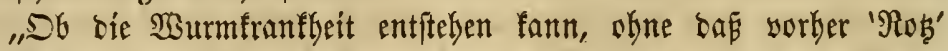
yorbanben gewejen, ift eine nidjt leidjt ju beantwortento Frage.

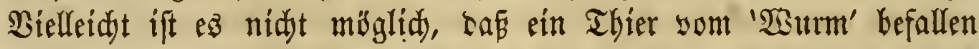
wiro, obme yorker rotzig gewejen zu fein. (E⿱亠乂 mag fein, baß burdy

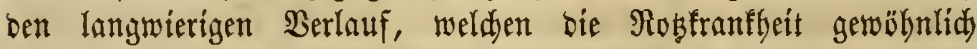
nimmt, uno zwar ohne Laß gewaher wirb, bie Eiterung auf ber Edjleimbaut ter Raje idjon ein=

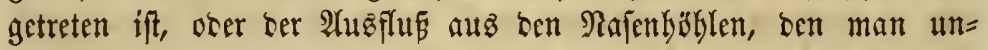

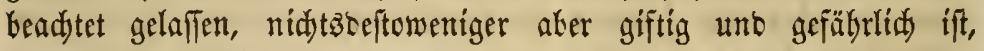
idon längere 3eit ftattgefunten bat und fid bie হiranfleit über ten Dryanismus verbreitete uno entlidi in (Beftalt ău药te.

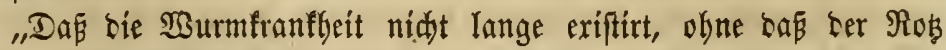

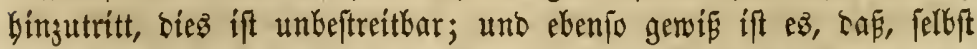

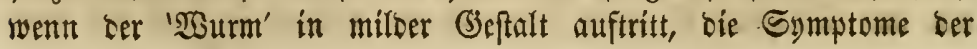




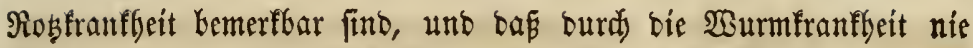

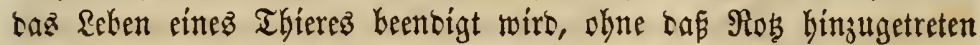
ift Die beiten Eeudjen fino Stabien einer uno berfelken Siranfleit.

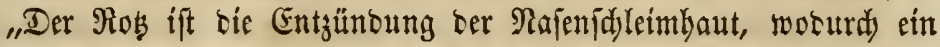
giftiger $\mathfrak{A}$ แตflu länglidye Duantität biefer yerborbenen Cubftang yon ben \&umphge= gefü̈en aufgejaugt wurbe, fo entfitebt bie :

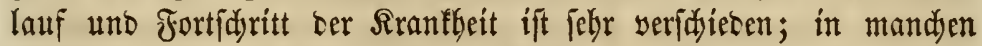

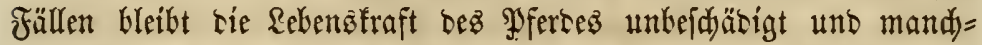

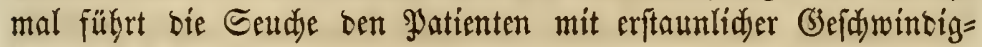
feit sem $\mathfrak{T} 0$ be gut.

"Die $\mathfrak{S u r m}$ jeudje wurbe fdjon oft mit antern Siranfleiten ver= wedjelt; wer biefelbe aber mit einer $\mathfrak{B}$ errenfung ber (J)lente ver= wed) felt, ber muß auÉ

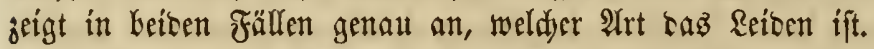

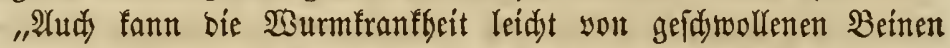
ober ber Maufe (grease) unteridieten wersen. Díe Maufe wiro

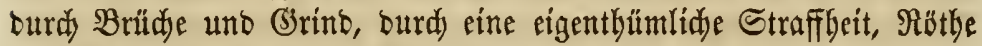

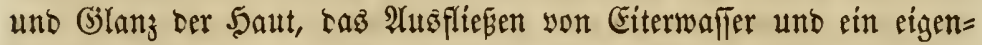
thümlidjes 马ưfen bes Beins gefennzeidnet. Bei ber $\mathfrak{s u r m f r a n t h e i t ~}$ fommt oft nod viel gröfere (Jeffdyulft yor, alz bei ber Maufe.

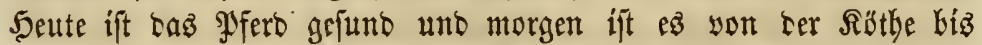

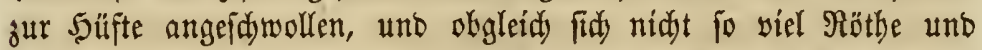

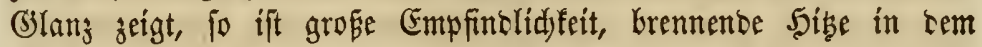

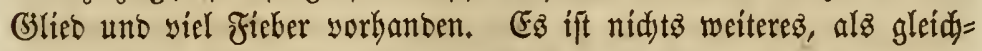

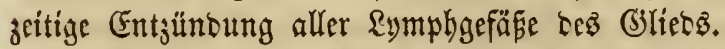

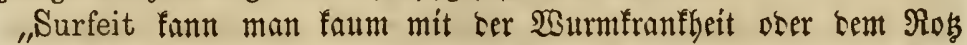
verwedjeln. Der Finnen=5 bei Eurfeit yortommt, "entigt nidyt in Eiterung, fontern in 2(fbidup= pung (desquamation), uno folgt nidyt ben \&ymphgefäß̈en, fonbern ift über bie ganje Saut yerbreitet. Mandynal wiro saz Bintes geweke uno namentlia teffen Bergrößerung unter ber Bruft yon Walferjudt befallen, weldjer Srantbeit man ben fonterbaren Ramen Water-farcy (2Ba feine Symptome ter $\mathfrak{B}$ urmfranffeit zeigt, fontern in nidjtz anberm

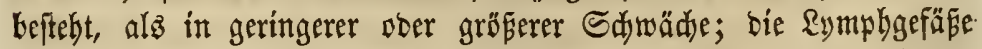
fino bakei burdauts nidjt entjüntbet, unb beí orbentlider Befanto= 


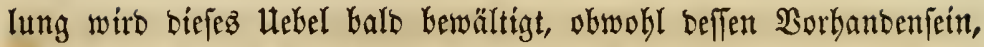
nadjem bas Thier eine fdyere Sirantheit überftanben hat - aud)

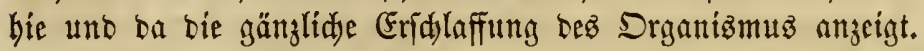

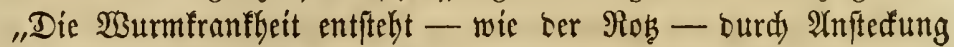

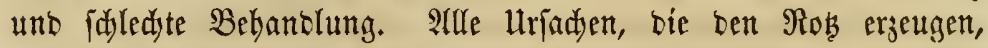
geben autch) Beranlaffung zur Entftehung bez พsurms, mit nur bem

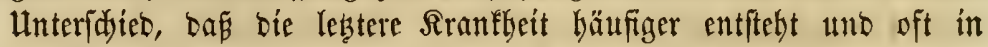

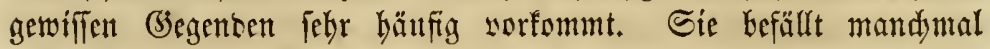
mebrere in einer Stallung ftehente Prerbe, fowie anbere in ter

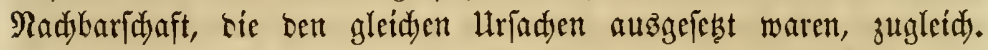
Mandje haben Gehauptet, bicje Rrantheit jei nidjt anftedent, und

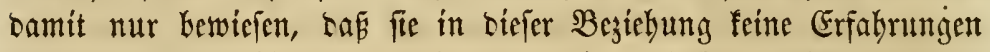
fammelten. Esz ift zwar wahr, báp bie anfteffente Wurmiubftanz

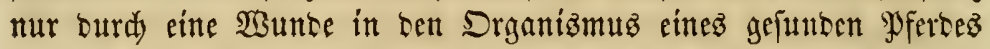
cinbringen fann; ba jebod) bie Pferbe häufig mit einanber fpielen,

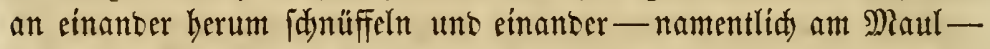

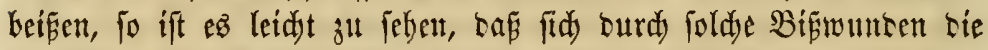

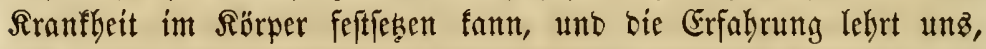

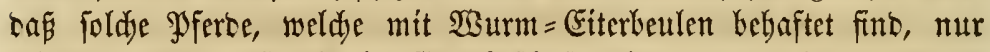

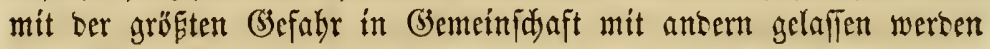
fönnen."

(Es gibt nod) cinen anbern 5autaus] biejem Rante bfterz unterworfen fint, unto ber mandymal mit ter Wourmfranfheit werwedjfelt mirb; wäbreno berfelbe jebod) nur bie

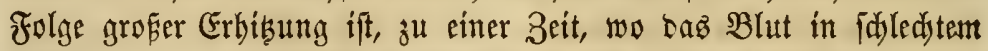

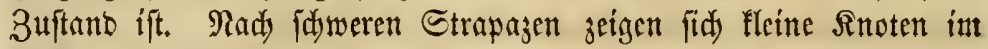
(B)eniff, ben Edyultern, an ber Seite, weldye an ihren Spiben ein

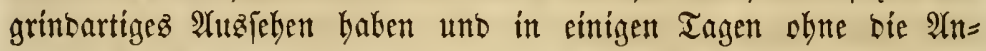

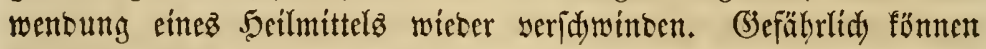

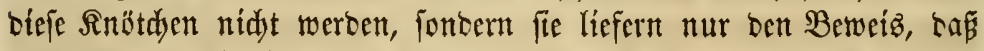

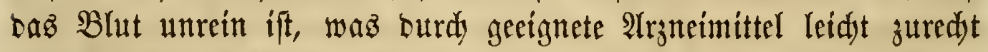
gebradyt werten fann. Es ift nur eine 9 Art fänell sorïbergebenter

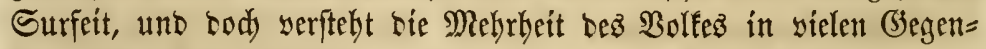
ben unter bem 2 Uț

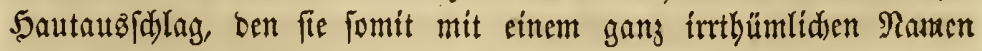
belegt. 


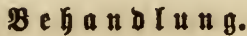

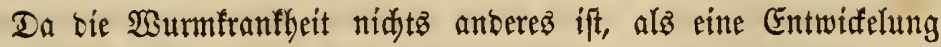
Der Rogftrantbeit im ganzen Drganiżmuz, ober wenigitens eine

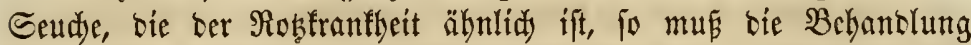

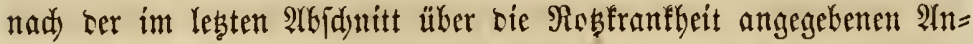

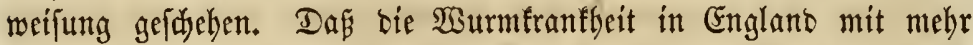

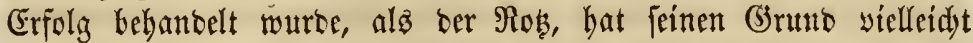
barín, weil man bie $2 r_{3}$ neien auf eine unmittelbarere uno umfaj=

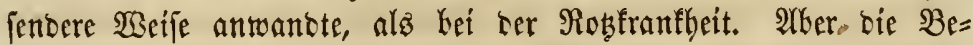

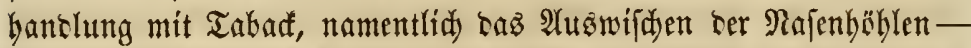
fübrt Lag Seilmittel bei beisen Seuden unmittelbar zum Sibs ber Rranfleit.

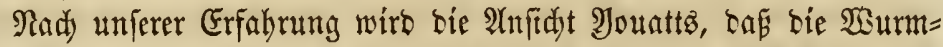

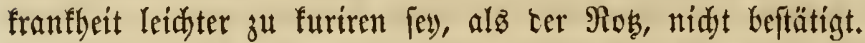

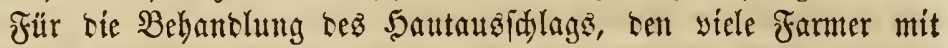

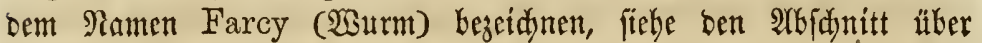
Surfeit, Rap. VIII.

\section{Distemper. (Gine Der Drule, Єträngel äbnliđe \&ranffheit.)}

Biele Symptome bicjer Sranflyeit fideinen barauf binjubeuten, bas

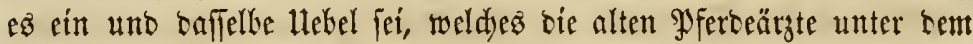

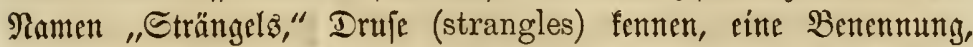
bie obne 3meifel baher rübrt, baf tie bayon befallenen Pferte teim Freflen ourd Suftenanfälle beinabe erfitift wurben. Englifde $\mathfrak{A} \mathfrak{u}=$ toren bejdreiben biefe Sranflect nod beutzutage unter bem alten Ramen; aber in siejem Ranbe ift terjelbe beinake ganj unbefannt, uno bie Farmer unb Pferbeeigentbümer gebraudjen ben nur alfzu befannten Ramen Distemper.

Dod) gibt $\mathfrak{e}$ weldye Symptome biejer Rrantheit, bie wir in ben yon curopäifden $\mathfrak{A}$ lutoren gelieferten $\mathfrak{B}$ efduretbungen ber Strängelz nidyt fincen. Youatt fagt, bạ bauptfädlidy bie jungen Pferbe, fage yom vierten bizz fedyften Jahr, yon ben Strängelsె befallen werben. Distemper verfdont jebod fein Ulter, obgleid ez auf oer antern Seite wahr ift, bafi die jungen Pferbe mehr bavon leiben, alz bie

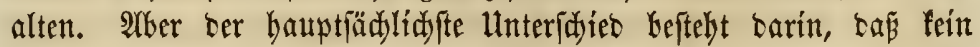
Autor bie Strängels als eine anfteffence Sirantheit bezeidynet, wäh $=$ renb Distemper im bödften Grad anftefent ift. 
Fä gibt veridjiebene Stufen biejer Sranflyeit. Daz erje Stabium

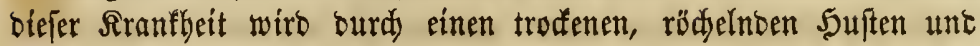

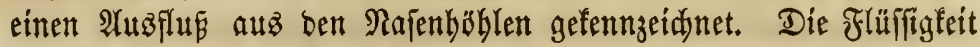
wirb nad und nady bid uno flebrig, uno hat immer eine weíflidye Farbe.

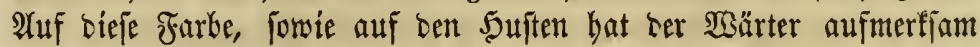

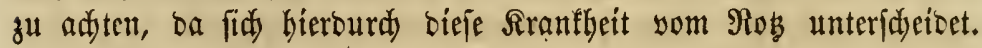
Diefe Symptome fino jebod nod nidyt befrierigeno; aber ez wer= oen anbere folgen, weldje feinem Zweifel mehr Raum laffen.

Das zweite Stabium tritt fehr fonell ein. Der Sals bes Pfer= bes fdiwillt an, und eine Unteriuduung zeigt, bap bie Mandeln und Speidyelorüfen afficirt fino. Sie waren gleid anfänglid entzünoet; bie Drüfen fino nun geidlofjen uno febt fid Materie in Denjelben an; benn bie Natur will auf bieje Weile bie Sranflyeit bemältigen. bierauf entitebt eine Eiterbeule in Salje, in weldyer fid bie Eiter= abjoncerungen ber Drüjen anjănmeln.

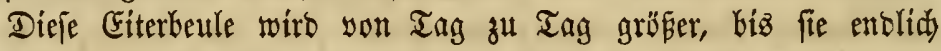

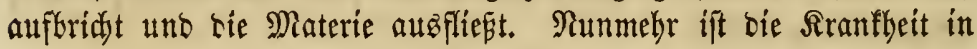
baz britte Stabium getreten. Die Materie mag Woden uno vie! $=$ leidut Monate lang aublaufen; aber won biejer Zeit an wirb tas Sfero gewöbulid beffer.

Währeno beв Fortidyrttz oer Srantheit hat ber 'Patient viel Fie ber, und ber Suls ift jehr erregt uno hart. Die Frefluft mangelt

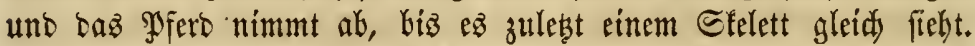
Mit rem Fortidyritt Ser Rranflyeit nimmt aud bie Seftigfeit biefer Symptome zu. Daß Fieber wiro ftärfer, Ier Puls geht fduneller uno bïrter, bie $\mathfrak{A}$ ugen fino gläjern uno matt, bas Saar ift frup= pig, trocen uno wie abgeftorben, uno ber Sopf bängt beinabe be=

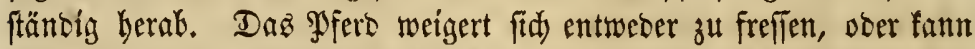
bies nur mit viel Shyterigfeit thun; $e \mathfrak{B}$ wiro auferoroentlich töl= pelbaft uno fein 3uttano if in ter That ein jämmerlidder. Ent= ftebt leine Giterbeule, fo tritt ber Too beinabe gewif ein, uno ofters

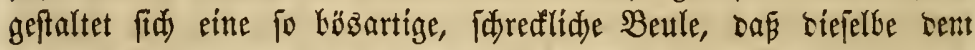
Leben Les. Patienten ein (Enbe madt. Mandymal baben fid aud)

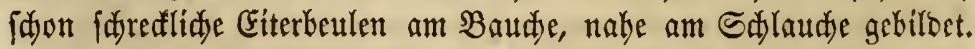

Wir haben bereits erwäbnt, daés dieje Sranfleit auferorbentlid anftefend ift. SPferbe, bie ziemlid weit yon einander entfentt fint,

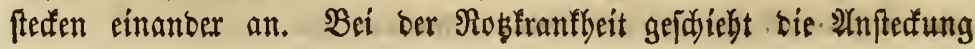




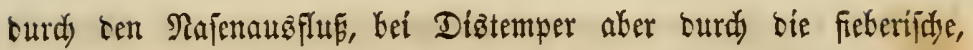
auşgeathmete Ruft, uno fann auf eine viel gröfere Etrede frattin=

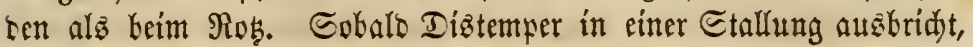

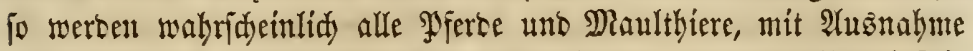
serer, weldye rie Siranfleit fdon früber hatten, son terielten befal= Ien; Senn gleidjuie bie Blattern bei Denjden, fo fino bie Ihiere mur einem $\mathfrak{A}$ nfall von Diştemper untertworfen. FFohlen uno jüngere Wferse werten von älteren angeptedt, ftefen aker nur jelten biefe an. Serod) fann man nidjt Larauf redjnen, Laf́ irgent ein Pjero ober Maulthier, weldes sie Eeude nod) nidjt batte, Lason verfidont bleibe, jobalo biejelbe in einer Etallung ausgebrodten ift.

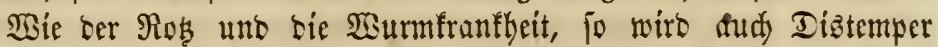

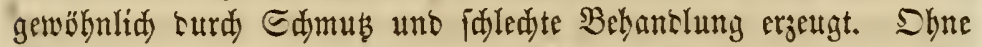

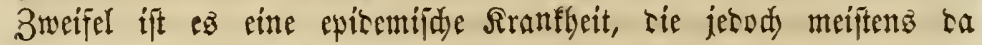

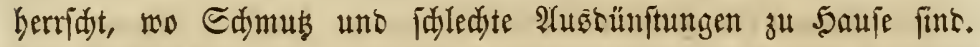

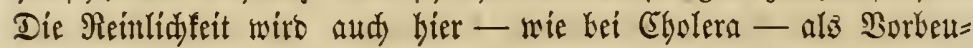

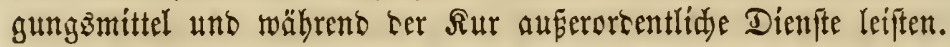

\section{จำ}

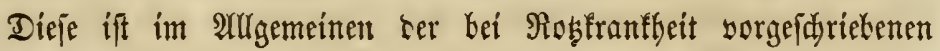

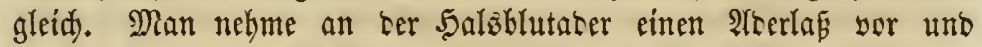
laffe etma brei \$inten Blut aušlaufen. Cocann mifaje man einen

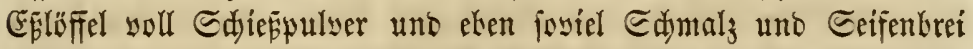
(soft-soap), zwei (Eplöffel voll Theer uno cinen Ëplöffel voll pulve= rifitrte Myrrhen (gum myrrh) gut untereinanter und, jajieke einen

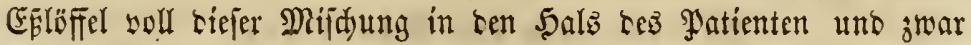

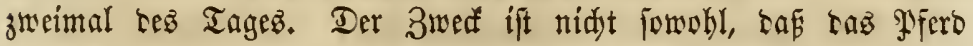

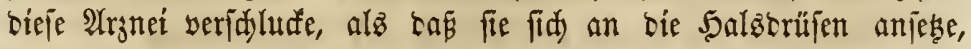
uno fie wito bemirfet, bafi fid tie Drüjenabjonterung vermetrt, worurd) sie Drüjen felbjt piffen erhalten wetren. Zur felten Zeit

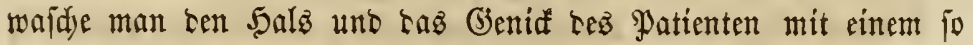

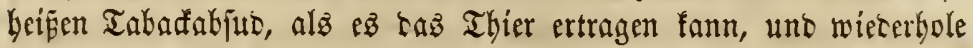
tiez żwei= beer breimal

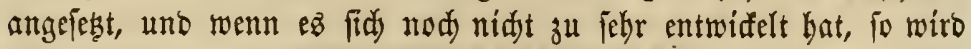
biefe $\mathfrak{B}$ ehandlung baffelbe entfernen, uno überhaupt wiro baz \$fero,

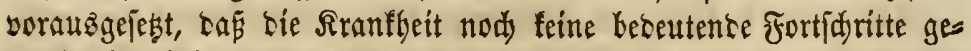
madjt, in einigen Iagen wieber gejund fein. 
Reben ber oben angegebenen Medizín gebe man bem Pferbe io

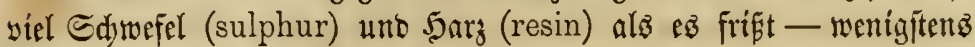
ein Bicrtelpfund jeden Tag, uno jwar nehme man zwei Theile

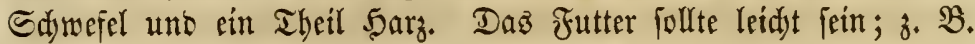

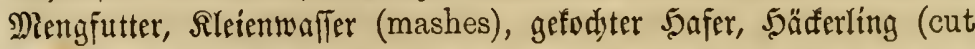

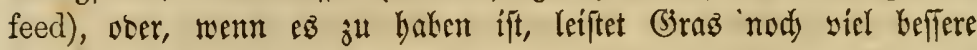
Dienfte. Sorn füttere man erft tann, wenn tas Pofero solffommen bergeftellt ift, uno in feinem Falle follte baffelke sor feiner völligen

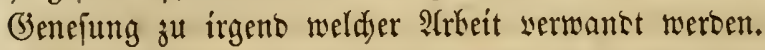

Man räudjere ben Etall gut auş uno getraudje ten Tabad aud

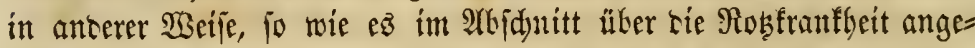

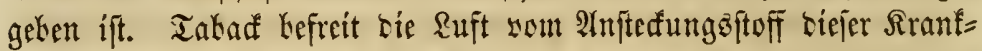
heit, uno wirt, wenn ridtig gebraudst, verbintern, baj bie gefuncen Thicre son ber Seudje angefteft mersen.

Der $\mathfrak{A}$ utor bat hunderte mit Distemper kehaftete Pferbe unb Maulejel mit fehr gutem Erfolge kehancelt. Sn bré Foüllen ausz

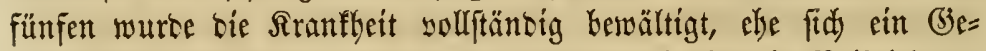
fdjwür gebilteet hatte, uno zur Erläuterung jei hier ein Beifpiel an= geführt :

Dr. 5. Saroifon yon Marihal Co., Tenn., hatte jebn Mantlthiere

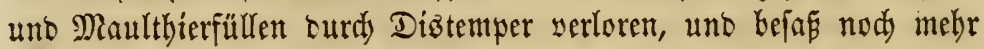

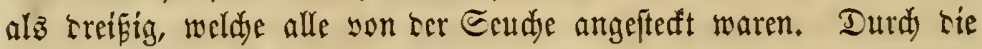
bier angegebene Bebantlung wurten alle furit, uno er benadyridy=

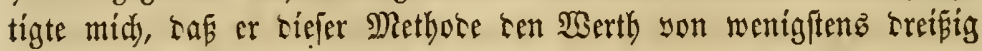
jungen Maulthieren verbanfe.

\section{Bieberbolung ber Bchanblung.}

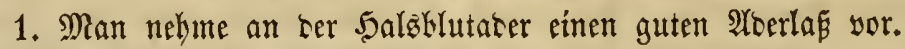

2. Man gete tie Distemper=Mixtur, wie yorgefdrieben.

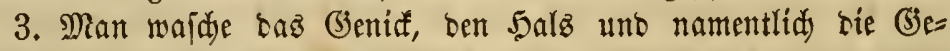
gent, wo bie Ruftrb̧bre liegt, mit tem Iabaftakjut.

4. Man räudjere bie Etallung aus uno gebraudje ben Tabad in

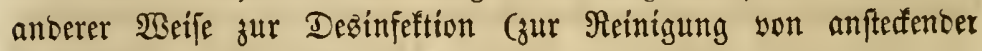
Materie).

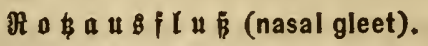

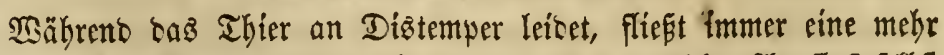

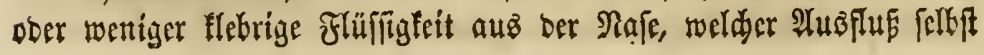




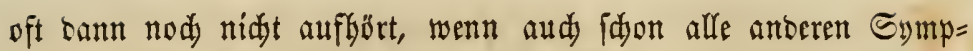

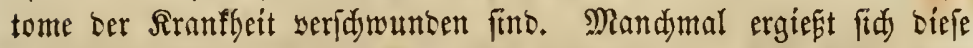

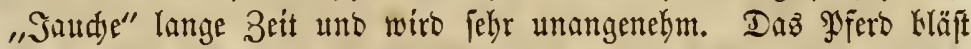

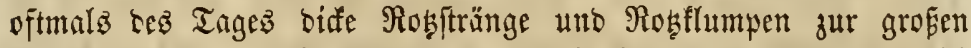
Beläftigung Ierer, bie gerate um taffelbe herum fimt, aus. Sold

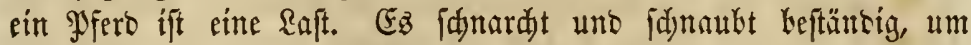

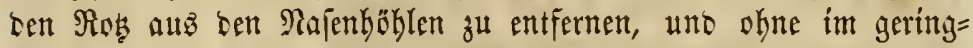

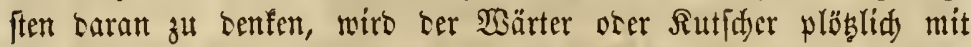

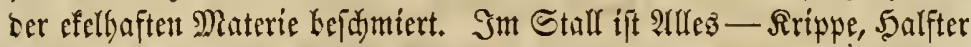

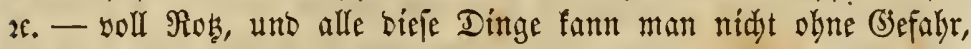

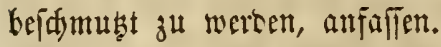

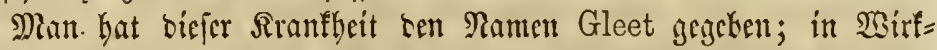
lidjeft ift Fieber, weldes bei Distemper in ter aeuten Form cintritt. Mand)=

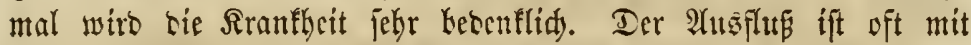
Blut sermijat, nimmt bie Farbe tes Futtters an uno wirb - grün,

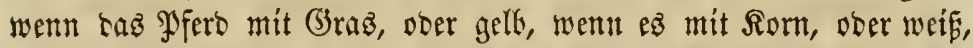

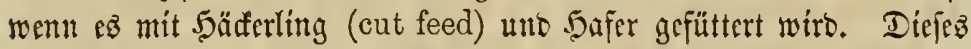

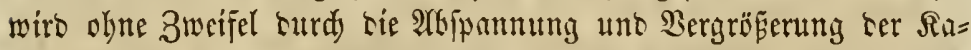

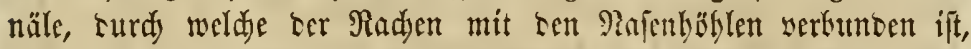
verurjadyt, woburd) etwag you frutteriaft, wäbrento ber Sorbaumg in sen Rajentäblen rintreten fant. Ein joldyer 3uftano biejer $\Re \mathfrak{A}=$ näle fommt surdjauz nidyt felten vor. Sesermann faun fid sayon überžeugen, wenn mun bie \$jerbe beim Snufen beobadjtet, währeno

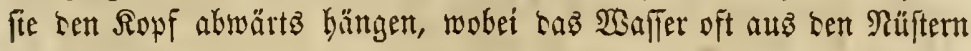
berautร̆lăuๆt.

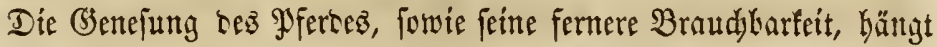

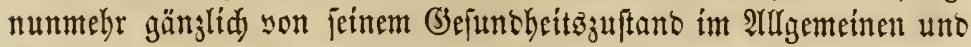
oer auf $e z$ yerwenteten Sorgfalt ab. Rä einem nieberen, feudyten, fidled)t erleuduteten Stall ftehen, jo wiro bieje

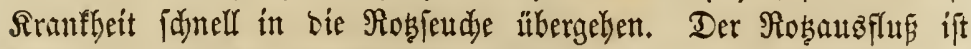

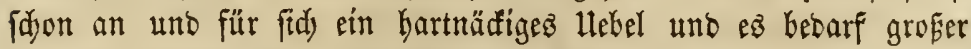
Sorgfalt fowie jiemlid viel (3edulb, baffelbe zu Keben. Wenter man jebod) die gehörige 2 Uufmerffamteit an, fo fann in beinake allen Fällen eine Sur benerfftelligt werben. 


\section{ห⿻}

Diefelbe mus natürlid berientgen, bie bei Diztemper yorgejdrieben wurbe, fehr ähnlidj fein. Man wajd)e die $\mathfrak{R a f e}$ mit bem in bic

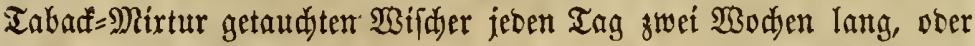

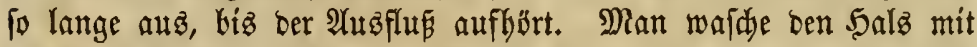
berfelten Mixtur, welde fo heif alz möglid, whne ben betreffenten Theil zu serbrühen, angewentet werben mus. Dies mus jeben $\mathfrak{T} \mathfrak{n g}$

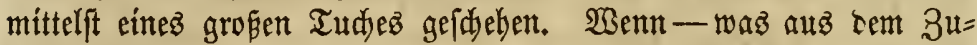

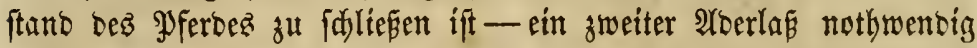
getworben, fo nehme man einen foldjen vor, laffe aber nidjt mehr alz orei \$inten Blut aus. Man gebe ein \$Pfund Ediwefel (sulphur)

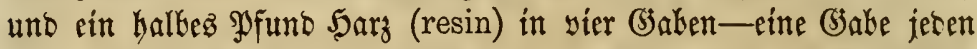
Iag. Sollte fid Syuften cimftellen, fo gebraudjt man bie Distemper Mixtur fo lange, alsె $\mathfrak{e B z ~ n o ̈ t h i g ~ i f t . ~}$

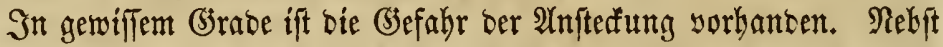

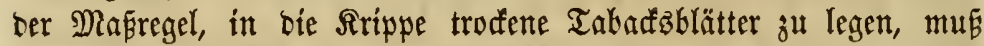

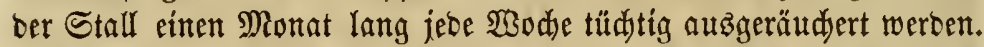

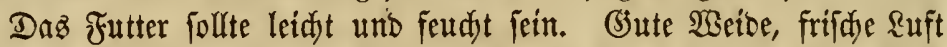
unt mäpige Berwegung werben bie (benejung febr keförbern. Man

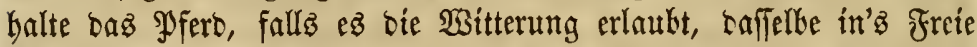
zu Lafien, nidyt im Stalle. Sm $\mathfrak{w i n t e r}$ füttere man dem $\mathfrak{P a t i e n t e n}$

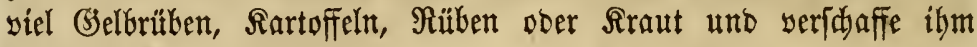

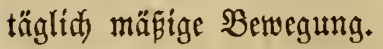

Bei allen ben in siefem Rapitel bejajriebenen Rranfleeiten wird

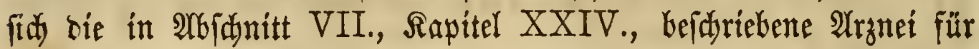
die Blutreinigung felfr geeignet unt werthyoll erweifen. 


\section{Sechistes diapitel.}

\section{A $\mathfrak{A} \mathfrak{g} \mathfrak{e} \mathfrak{k} \mathfrak{x} \mathfrak{a} k \mathfrak{b} \in \mathfrak{i} \mathfrak{t} \mathfrak{n}$.}

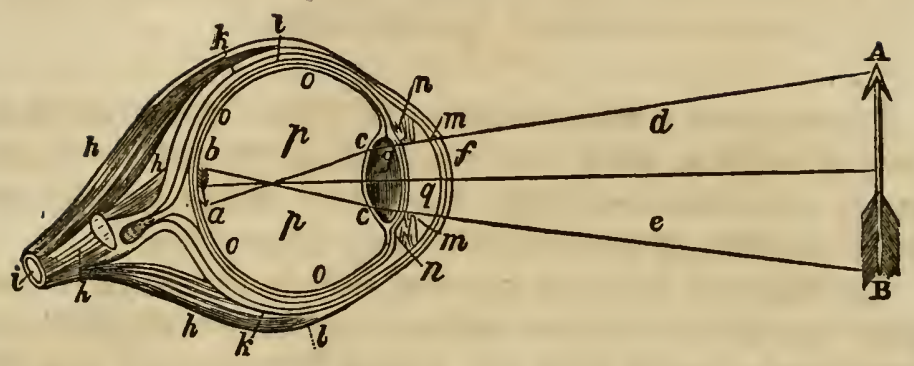

Sbige Figur ftellt ein fenfredjt won wom nad binten burdidintit=

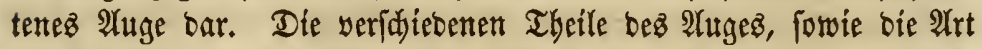

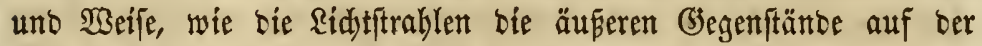
hinteren 2 Yugenwant abbilden, fint Yeidjt zu erfennen.

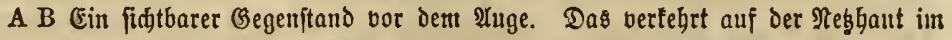
hinteren Iheile Des $\mathscr{H}$ uges itehende Bild $a, b$, Des Gegenftandes.

c c Die \$untte, two die \&idfftrahlen, nahiem fie burd) die sornbaut und die Sry. ftallinfe bindurăgebrungen fund, zufammenlaufen.

$d e$ Die von ben Enden bes (Segenftandes in's Ange fallenden Ridiftrablen.

$f$ Die Durdhfintige \$ornhaut. Diefe ift im natürlidjen 8 uftande von einer feinen Durdffiftigen Sdfeimbaut, Der Binbebaut, überzogen.

$g$ Die Rinfe oder Rryftallinfe, binter Dem Seb̧lod (ßupille) und vor Dem (\$las. förper.

$h$ h श्agenmustein.

i Der Sehnert.

$k$ Die barte Arugenbaut, welde die binteren 5 Sedjstel Des Augapfels übergiegt und fth vorne mit Der Das vorderfte Sedgstel bebectenden ફornhaut ber. bindet.

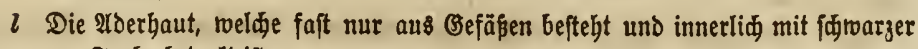
Farbe bedect ijt.

$m m$ Die Regenbogenbaut, welde gleid Ginter Der f̧ornhaut liegt (nur Durd) Das Waffer ber borbern $\mathfrak{A}$ ugentammer von biejer getrennt) und einen platten 


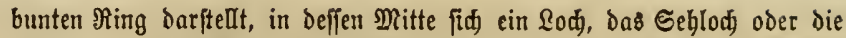

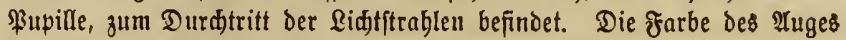
hängt von ber Regenbogenbaut ab.

$n n$ Der Faltenfranz ober Strahlenförper, ein faltiger, bom borderen Rande ber

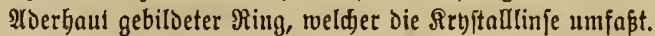

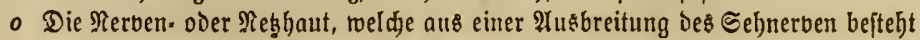

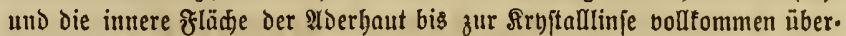
zieht.

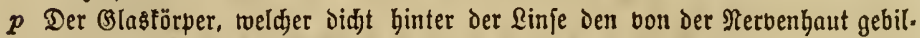
Deten รูoblraum ausfïltht.

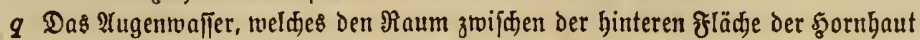
und Der vordern fläde ber Rrbftanllinfe ausfüat.

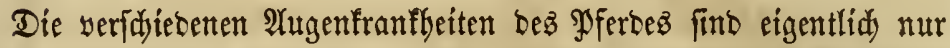
bann zu serftehen, wenn man einen ridjtigen Begriff Der Etruftur unt ber Funftionen bes ?luges erlangt hat. Nimmt ber \&ejer obige

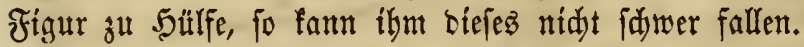

Der Aługapfel ftellt eine aus brei um einanber berum liegente

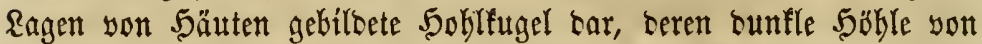
Durdjfidytigen, fowohl feften wie flüfifigen Materien, bie man aud

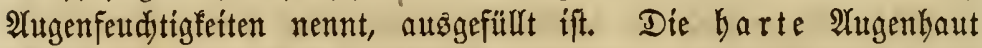

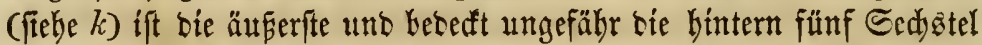

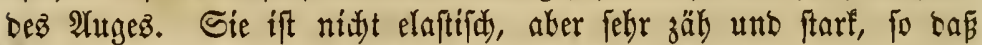

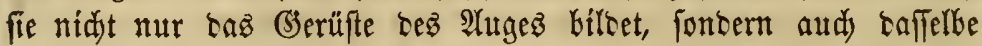

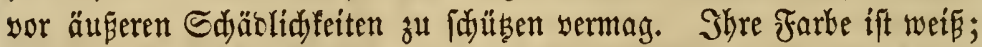
ba fie yon ben Sautlagen bie äuferfte ift, fo freft man ben yorbern Theil ibrer äubern Fläd) beim Meniden immer, aber beim Pferbe

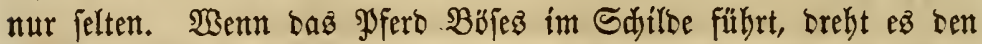

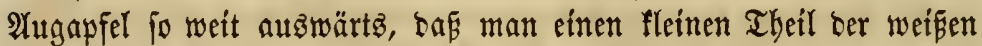

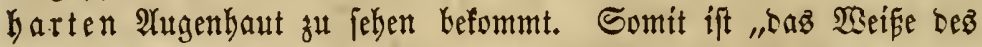

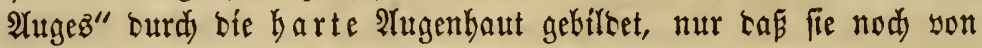
ber bünnen, burdjfidtigen $B$ inbehaut bebectt ift.

Borne am 2 lugapfel fintet man bie 5ornhaut (fieble $f$ ), weldye

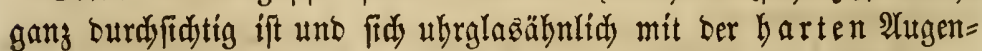
baut yerbinbet. Sie ift yon einer feinen Sdjidte ter Binbehant überzogen.

Die 2 berbaut (fiehe $l$ ) ift bie mittlere 5autlage bez 2 Augapfelas

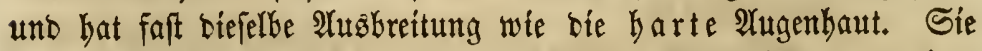

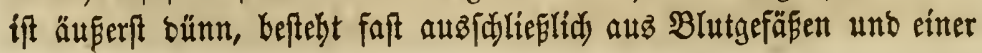




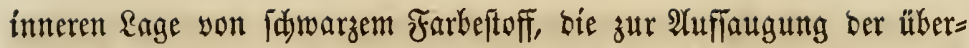

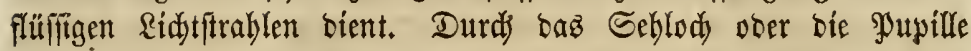
zeigt fie bei ber Dämmerung, wenn die Ridutftrablen nidyt mebr fo

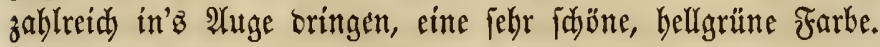

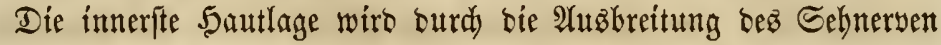

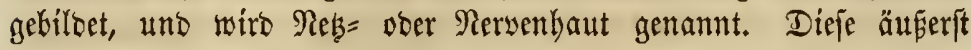
feine, zarte utto fajone 5autlage crbält bie yon ben Ridutfrablen

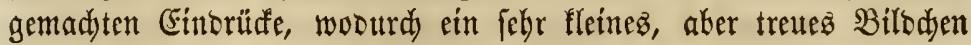
yon bem (biegenftante, wowon bie Ridutfitrahlen autzgehen, auf ber

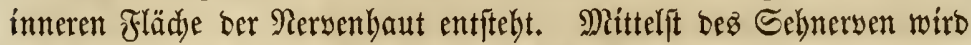
ber. fo erbaltene Einorute fofort dem Gehirn mitgetbeilt, wo bas Thier

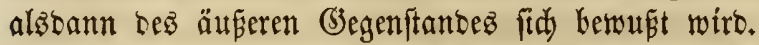

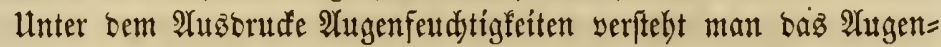
waffer, ben Gjtazförper unb bie zwijhen biejen befindlide Sryftall=

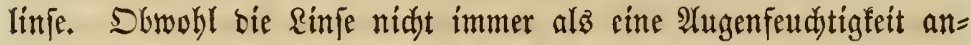

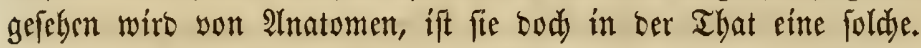

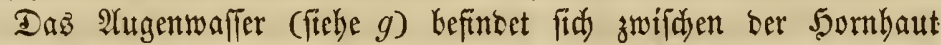
yorne unt ber Rryjtalflinje binten. Daffelbe bejteht aus einer yoll= fommen burdjichtigen Flürifgfeit, bie mittelift einem auferorbentlid

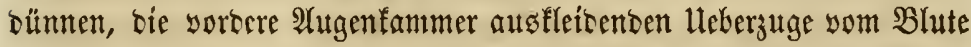

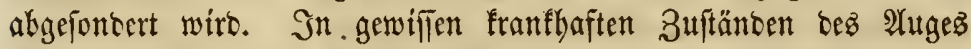

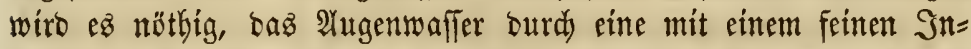
ftrumente gemad)te Deffmung auzz̧ulaffen; baffelbe miro aber balo wie=

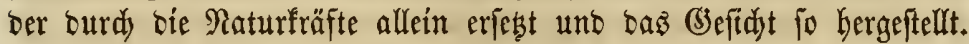

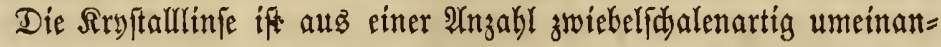
ber berum gelagerter Edjidten gebilloet. Sie hat bie Conjiftenz son (3)elee unt ift linjenfürmig, wie fie in. Der Figur bargeftellt ift. In= bem bie Ridutfrablen burdy bie Siryftallinfe hinturd bringen, werben fie fo gebrodyen, baf fie ganz genaute Billoer ber yor bem 2 luge be=

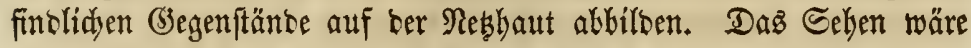
obne Sryftarllinfe unmöglid. Sebod haben aud bie Sornhaut, bas

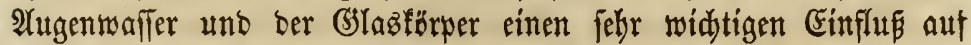
bie Ridutung ber \&idjtftrahlent.

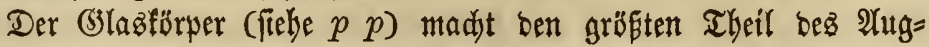
apfelz aus. Er befteht hauptfäblidy aus einer flaren fłhüfiigfeett, weldyer aber bie Comfriftenz yon (J)lee hat, weil fie in vielen gants burdjidtigen Bellen eingeidlolfen ift. 


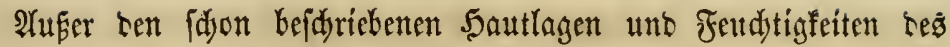

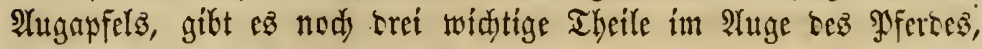
weldje eine furge Beidreibung erforsern. Hunter biefen finten wir zuerft bie Bintebaut, weldye auz einer äuferrft feinen, fowolyl ten

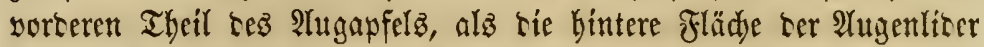
übersiehenoen Edjleimbaut befteht. Eo lange rie Bintehaut gans gefuno ift, beftht fie eine vollfommene Durdyfidtigfeit, wiro aker fajleimig uno mit $\mathfrak{B l u t}$ angefüllt, wemt fie erftanft. Wise wir in ber Beidreibung ber 2 tugenfrantbeiten fehen werben, ift fie febr oft ber Sils yon Entzüntungen.

Einer ber wunterbarften Theile bes 2 Uuges ift tie fogenannte $\Re e=$ gentogenthaut, weldye ticje Benennung erhielt, weil fie ber Sib ber

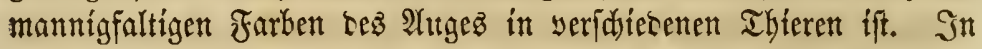
ber Frigur fitht man nur bie Rage, weldje bie Regenbogenfiaut im

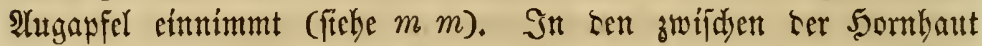
uno ber Siryftalllinie befintlid)en, mit bem $\mathfrak{A}$ ugentwa Raum hineinragend, bient biejelbe mittelit ihrer Berengerung ober Erweiterung zur Mosiffifation ber Riduftrablen, je nadjem riejelben

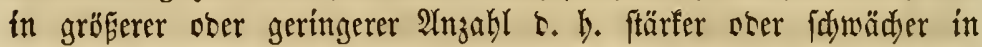

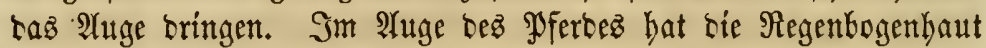
gemöbnlid cine braune Farbe.

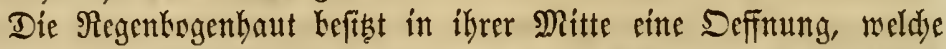

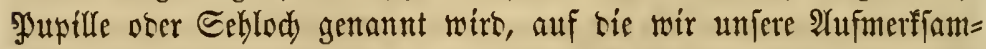
feit Ienfen wollen, ebe wir zu ben 2Yugenfranfleiten ükergehen. Sn Ler Regenbogenhaut fintet man eine Sdyidite son Mitüelfajern.

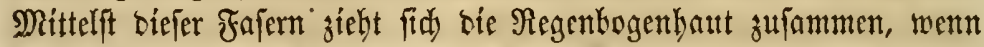

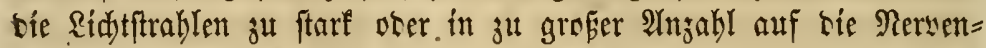
baut fallen, folglid) wirb bie \$utullle verengert; ift aber bas ant bie

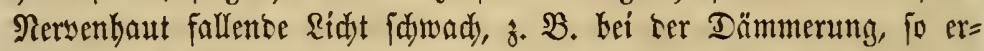

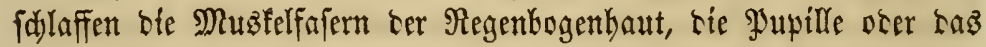
Sehlod wirb erweitert, bamit fo viele Ridhtfrahlen alz mäglid in haz

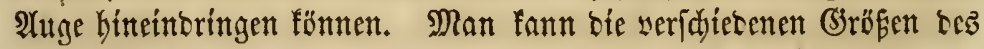
Seblodis redit leidjt beobadten, wenn man bas 2 tuge einez gefunten

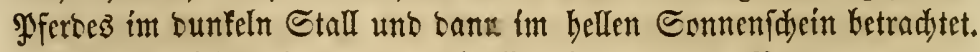
Rod) viel leidter fann man bie (Erweiterung uno Berengerung Ler

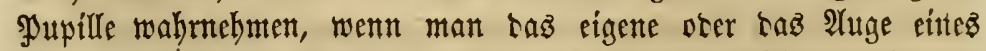
₹rreunbez unter tem Einfluffe ftarfen ober fdywadjen Rídtes beobadjtet. 


\section{utrjađen ber 9:ugenertrantung.}

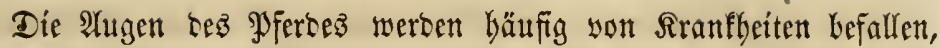
bic, obrobl nur wenige an ser $3 a b l$, tod unter ben gewöbulidyen

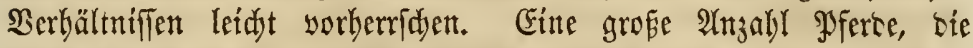
einen $\mathfrak{W e r t h}$ son vielen Taujeno Dolfar: haken, werben alljäbrlid

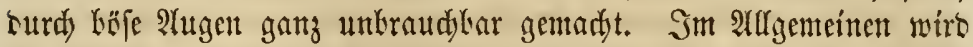
angenommen, รap bie Erfrantung ser 2 ugen fajt tnotbmentigerweife eine Erblinoung zur Folge bat. Dafer ift es won ser gröftent

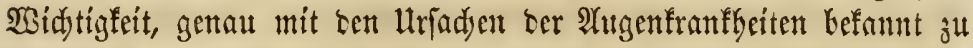
werben.

Shite Buteifel fint falledte Stallung unt gramfame Befhandung

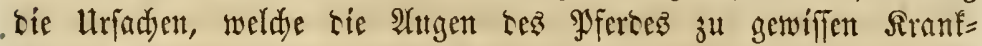
beiten geneigt madjen. Sisir fönnen faum umbin, über fie erfte

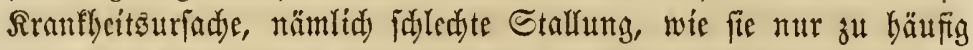
in siefem sanbe angetroffen wiro, ein recht crnjtes 20 ort ju reben. Serody tft eine graufame und bumme Bebantlung ser $\mathfrak{A}$ tugen cine nod) viel bäufigere ltrfache. Beibe erjettgen nur alfu oft febr bög̈=

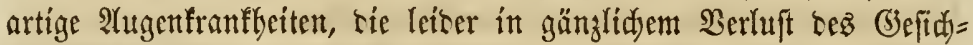
tez gewöbnlid ifren $\mathfrak{A}$ (sigantg finten.

Wie mandye Gtälle baben wir fdon befudd, wo tas flüdytige

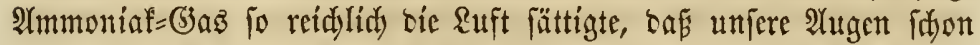
nad) eintigen Minuten mit Thränen angefüllt waren! Sönnen die

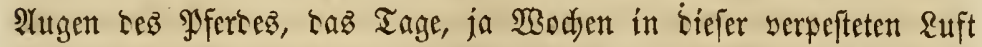

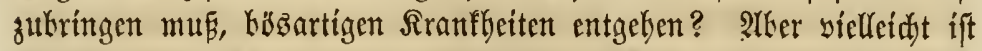
ber Mangel an Ridyt eine nidyt minter wirffame llifadje. Faft alle Ställe fint bürftig mit sidyt verfehen, unb in weldyen oringen bie

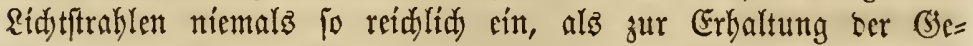
funbbeit erforberlidy ift. Das belle Tageslidat ift befanntlid zum Sadjethum ber Pflanje abfolut notbwentig. Fud gebeibt ber Menid) nidyt, weber förperlidy nod geiftig, obne ben (Einflup bes Ridyes. Sft fu erwarten, baf bas Sfferb unbefdabet bas sidyt faft ganz entbebren fann? Die bellen Sonnentrablen üben eitnen auper= orbentlid ginfitigen Einflus auf Ibiere, fowte auf Pflanten aus. Welden Unterfdeted in ber Farbe swifden in sunfeln Sellern wadh=

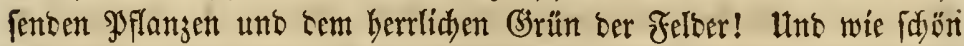
finb bie bon ber Sonne auf bie Wangen bes Ranbberwobners ge=

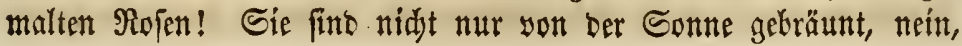


fie fint reidylidjer ntit eftrem guten, nabrhaften $\mathfrak{B l u t}$ angefüldt. Rann

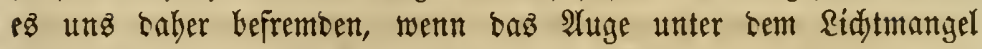

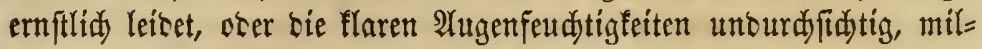
dig werben?

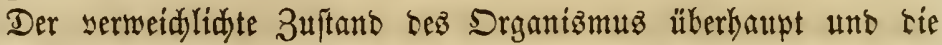
dronifhen comfititutionellen Sranfleiten, weldje auf bie oben ange=

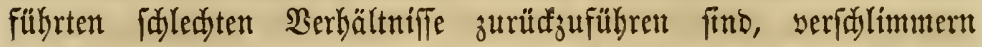

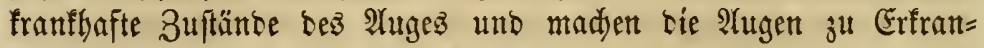
fungen yon ben geringfügigften anterweitigen urjaduen getreigt.

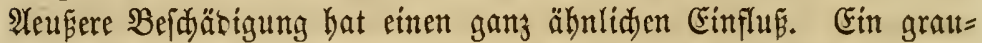

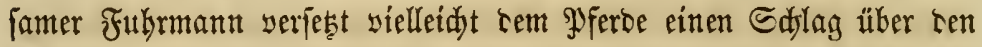

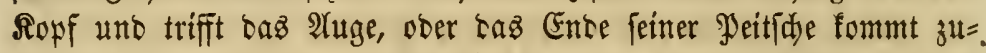
fällig mit bem $\mathfrak{A}$ uge in Berührung; eine (3emebsftörung ift bie unmittelbare Folge uno zeigt fid redit balo alz eine Entzünoung

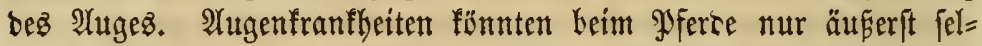
ten ftattinton, wemn Dafielbe gut gepflegt unt tem Ridjte und ter freien Ruft ausigeicbt würbe. Bei guter Stallung mit binreid)enter Ruft würsen biejelben ebenfallz fänell abnebmen.

Die angeführten Serbältniffe fönnen, bejonterz went aus irgento einem Grunte ein fieberi放er 3uftanto eingetreten ift, eine entjünto=

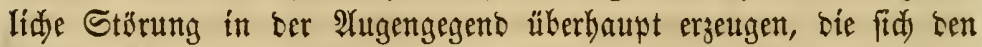

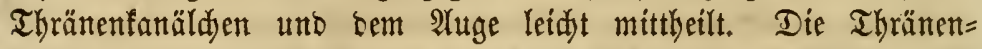

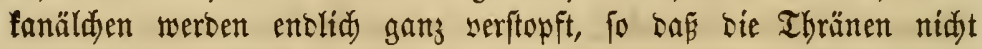

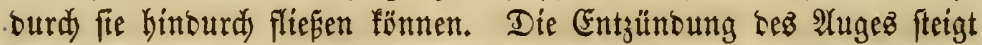
immer mebr uno endlidy folgt gänglidje Erblindung, wenn bie $\mathfrak{u r}=$ fadje nidjt entfernt und eine vernünftige Behandlung ser Sranflyeit eitigeleitet wirb.

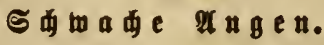

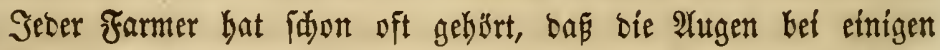

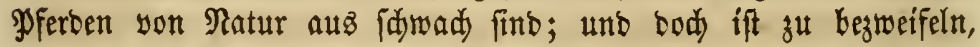
ob bie angeblid)e Sdymäde eine natürlide ift. Heberbaupt tif eine

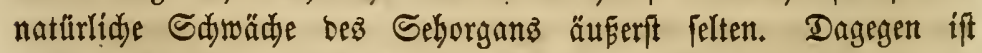

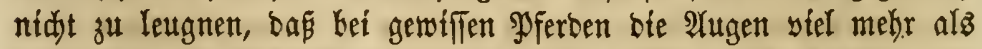
bei anberen fut Erfranfungen geneigt fint. Woenn bie Thränen an

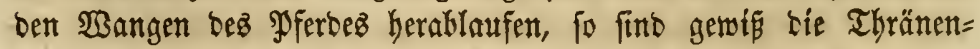
fanälden, burd) welde ste Ilyränen im gejunben Zuftanto in bie 


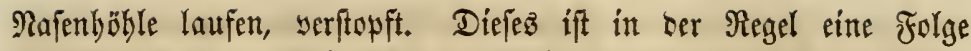
einer Entzütroung ber ketreffenten Theile, weldje fid leidut bem $\mathfrak{A}$ ug $=$ apfel felbft mittheilt.

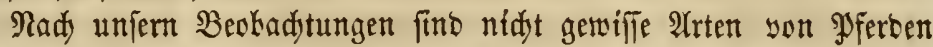

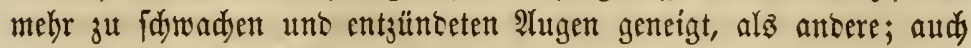
fommen biefe franlhaften 3uftänte nidjt vorjugşweife bei irgent

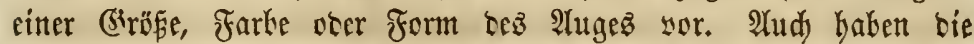

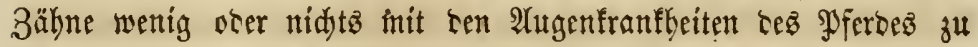
thun. Man hat sorgeidlagen, geroilie Zähne, bie trem Yjerce

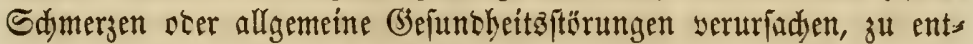
fernen. Diejes ift aber äup̌erft felten nothmentig. Man überlaffe fie ihrem natürlidjen (3ang, ta fie gewöbnlidy zur gebörigen Zcit jum Durdbrudy lommen. Die 2 (nnakme gewi i kejontere gegenfeitige Beeinflutiung zwifden sen $\mathfrak{A}$ ugen utb sen

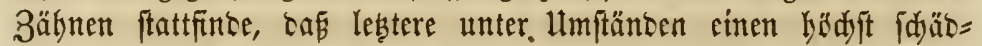

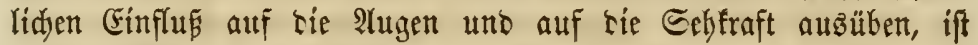
nidyt auf Thatfadjen begrüntet.

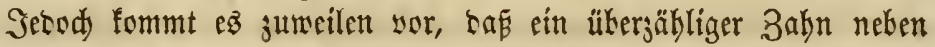

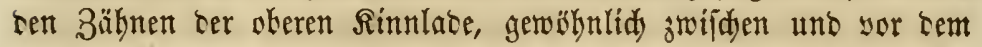

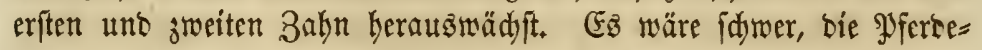

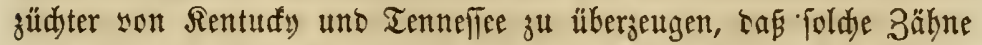

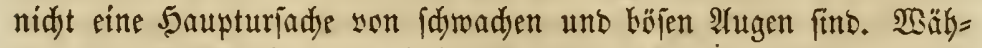
reno ibre $\mathfrak{A n}$ fidjt cine ganj irrige ift, follte sod ter unnöthige $3 a \mathfrak{h n}$, weil ar Kei ber Zermalmung bez Futterz im 2 sege fteht, entfernt wercen. Diefés läpt fíd am leiduteften mitteljt ciner ftarfen Zange thut.

Während bem Durdtritt ser Zähne entzünten fid zumeilen bie

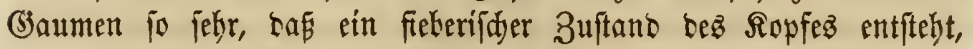
ber fid leidyt ben 2 tugen mittheilt. Serody gibt $e \mathfrak{B}$ audd siele antere

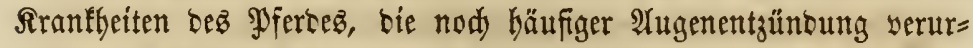
fadjen. Rnodjengewädje am Ropfe, Radenfiftel, Rot uno ter alz

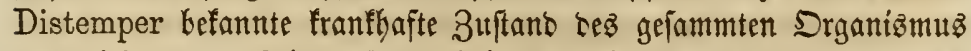
unt viele anbere Reiben find faft immer mit fieberijder Störung hez

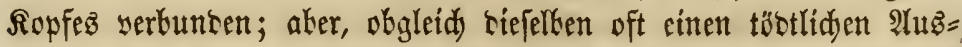

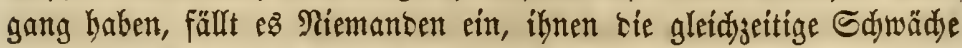

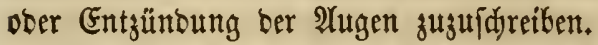

Diefe Theorien, weldye in bem Durdtritt ber Bähne ober anbern 


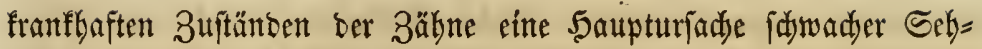
fraft voer gänglider Blintheit fintsen, müffen als veraltet antgefehen werben. Ez gibt gar feine Thatjadyen, bie safür ipredyen; audj)

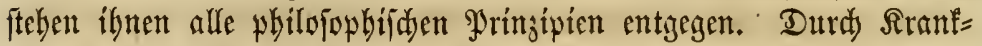
hciten mögen bie leften 2lugen zerftört werben; bagegen lebt man=

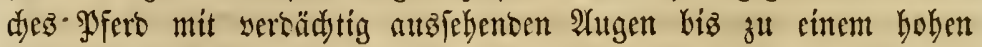

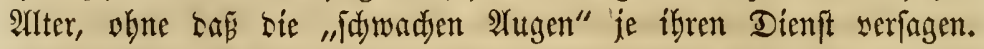
Rati unferer Erfahrunt barf man faft unbebingt annelymen, ba

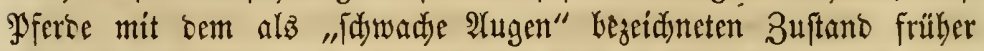

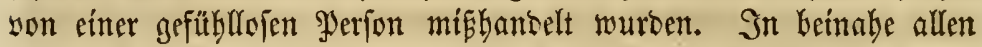

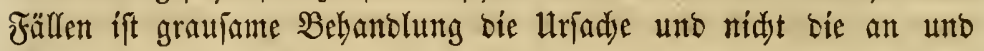
für find gan unjääblidjen, notbyentigen Beränberungen im Drga=

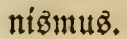

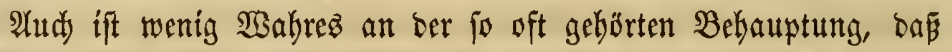

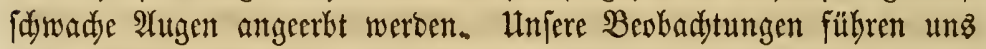
jum Sduluffe, bapi bie Theorie ber angebormen Sdywähe yon ben

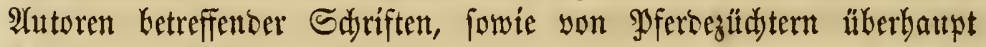

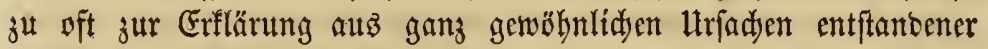
Sd)wäd) mif̧Graudjt wirb. Siernit ftimmen aud viele ter bebeu=

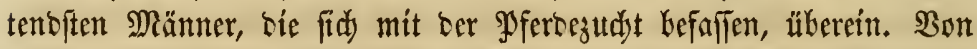

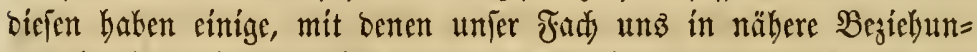

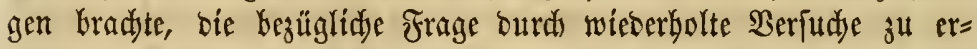
grünten gejudyt. So ftellte ein Freunt in Temter|ee Beobadtungen mit vier blinten Mäbren an, woyon jebe inturbalb brei Sabren zwei voer orei foüllen warf, beren 2 ugen aber yollfommen gejunto waren. WSír haben fie felleft lange genttg beobaditet, um von ter

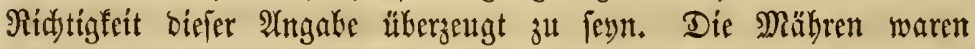

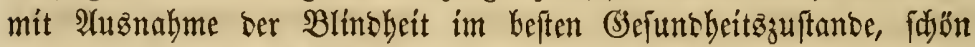
und wohlgebaut. EGbenio batten bie Fülten einen fobönten uno fräf= tigen $\Re$ s̈rperbaut uno nethenbei gantz feblerfreie 2 tugen.

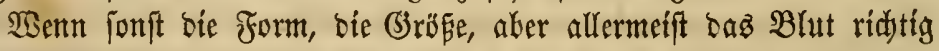
beidjaffen ift, fo hat man feinen guten (Jrumb, bas Borbantomjein be=

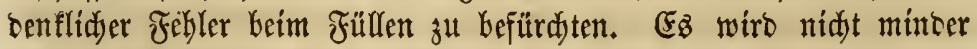
gejuno fein in Begutg oer 2 ugen, fowie anoerer Sörpertheile, als wenn feinz ber Eltern einen Febler gebabt hätte. Dícz mag Cini= gen unthattbar idjeinen, ift aber sollfommen begrüntet, ba, wie fojon

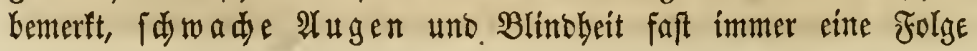


äup̃erer Bejdäbigung orer Mi nidjt langer Beit jahen wir bei einem fehr fdjönen Stallpjero ein angeidjwollenes Eprunggelent, in Folge Lefien bafielte mur mit gro= Eer Sdywerigfeit im Eduritt geben fonnte. Der Figentbüner garan= títe. aus entifehenoen \&eiben behaftet fein würoe, waz er aud obne be= jontere $\mathfrak{B}$ efürdtutungen riştiren fonnte.

Sinodjenfpat, Ringbein und einige antere Miffftaltungen fino ebenfo-menig ertilid. Sie werben beinahe immer surd Beiduasti= gungen oeer graujame Bebandlung verurjadyt uno baher nur febr felten won einer Generation auf bie nadjfolgente ükertragen.

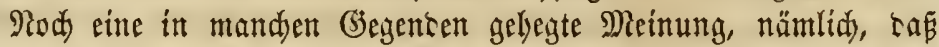

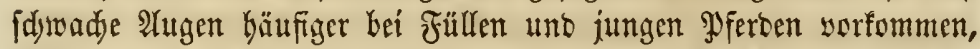

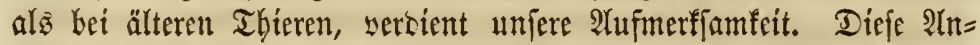

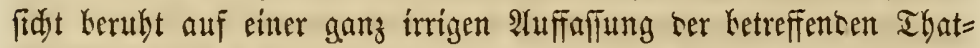

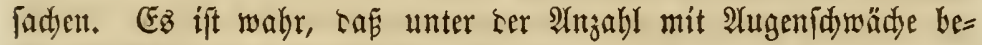
bafteter $\mathfrak{Y}$ ferte bie meiften jung fint; aher biez ift mohl nur barauf begrüntet, dás in allen (B)egenten faft hoppelt io viel junge als alte Pferte angetroffen werten. Berenft man tie Berjdiesenbeit in ber

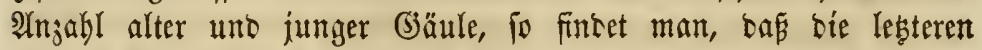
chenjo oft yon böfen $\mathfrak{U}_{\text {ugen }}$ befallen werten, alz bie erfteren.

Eine Ilyatjadje versient bieadtung. Jü̈llen, ckenfo wie Rinter, erfinnfen leidy; aber ipäter, wenn ihr Rörperbau uno ihre Rräfte

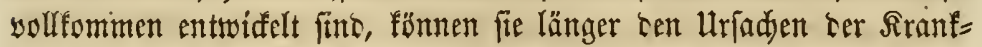
heiten witserjteben. Mande langwierige, entidid mit bem $\mathfrak{I} v$ be aug=

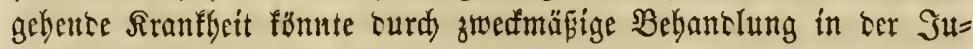
geno gan werhütet werben. Ier Same ber Edjwädje und bes

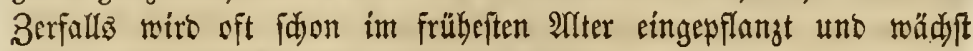
alşbann mit bem herantwadjenten Rörper.

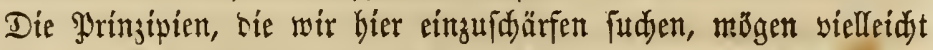

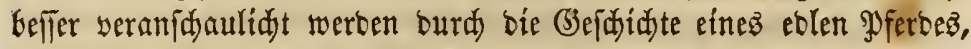

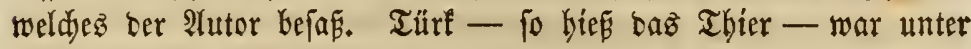
bem Sattel ocer im Buggy eingefpannt, unübertrefflid. Er batte

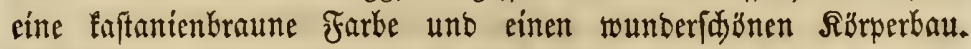

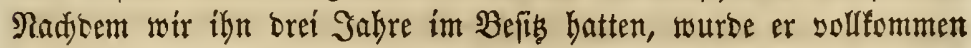

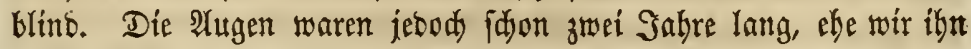
erbielteri, beftig angegriffen. Wäahreno biefer fünf Sahre nahm bie 


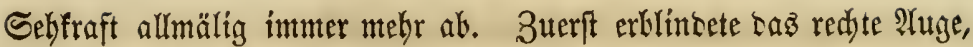

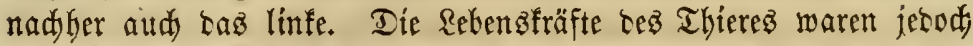
fo ftarf gewefen, baf ez biefe lange 3eit binturd) gegen bie beftige $\mathfrak{A} u=$ genfrantheit fämpfte, uno erft nad) YUGlauf ber fünf Sabre waren

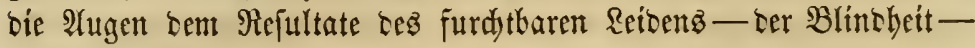
antheimgefallen.

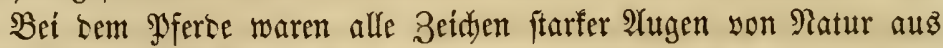

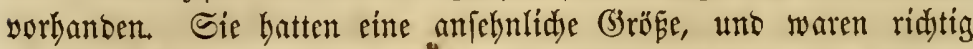
in Len weit yon einanter entfernten, reidjlidy yertieften 2 (ugenbäblen

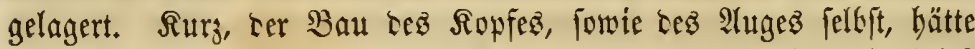
nid)t güuftiger fein fönnen. WSorurd) entftant aber bie Blintoheit?

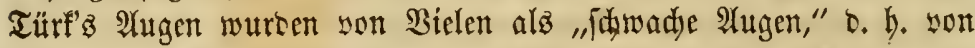

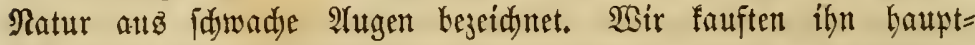

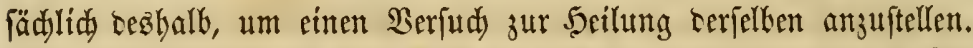
Skgleid) die Rranfheit bierju fdjon zu weit sorgerüft war, fo fimb wir sod überscugt, burd eine geeignete Behandlung bas (befiddt um einige Sabre verlängert zu haben. WBie wir ppäter erfubren, be=

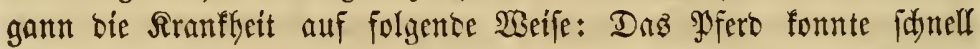
laufen-uno war oft jum Settremen verwant worben. Eas fam in ben Befits eines forglofen, wilten, jungen Mannes, oer es oft

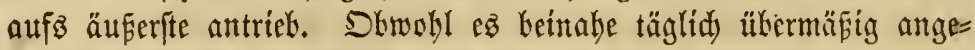
ftrengt uno erbitst wurbe, nabm es ood ber unsernünftige Eigen= thümer, wälyrento Daz $\mathfrak{B}$ hut nod in hödffter Sisallung war, in ben

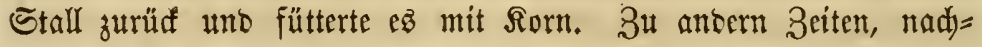
bem ez in bie Shise gejagt worten war, wurte $\mathfrak{e z}$ ftuntenlang im

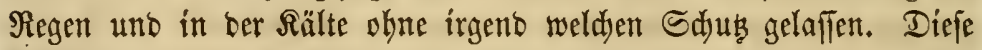
Mífbanolung batte fojon brei Sahre ftattgefunten, alz bie erften Zeidjen ber 2lugenfdjwäd)e jum Borridein. famen. Beitweife nahm

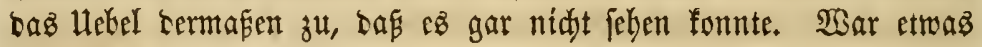
anberes $3 \mathfrak{u}$ erroarten?

Sn faft allen Făllen ift ber Beginn uno Berlauf ber Sranfleit

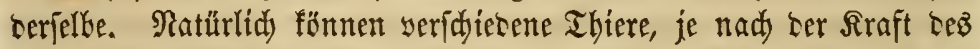

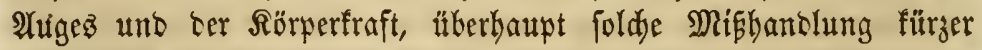
voer länger ohne fdjäblidje Folgen ertragen. Alber ber Farmer barf

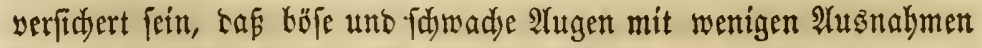
bie Folge yorbergebenter Mif́ghondung fint. 


\section{Die Bebandung ber $\mathfrak{A} a \operatorname{bcn}$.}

Bet einigen Pferben fino bie श्Yugen ju gewiffen Rranfbeiten ge= neigt, bie gewöbnlid ourd einen fieberifden 3uftano ober in Folge

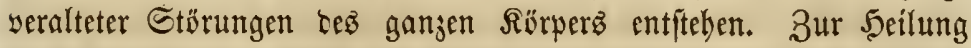

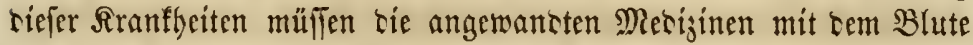
felbit in Berührung fommen, ramit riejes fo veränoert uno verbef= fert wirt, oaj ez cen Etoffwedjel auf einen ber (3ejuntbeit entipre= duenren $\mathfrak{B e i f e}$ unterbalten fann. Arlterirence Dittel foueinen nidjt

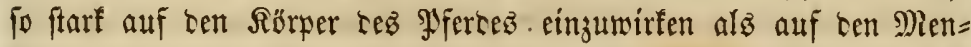
iden, fint aber teflen ungeadtet nidt ganj żt verwerfen. Sn fer Regel fino fräftige Mittel erforterlid, um eine grünolid) Sceilung

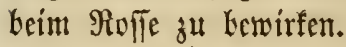

In sen betreffenten Fällen wersen $\mathfrak{B}$ lutentziebungen yom gröften Nuben fein. Man laf̣e trei Slint aus̄ Ler Sals̈blutaber alle zebn Tage zmei Monate lang ver nody länger, wenn es̉ im Berlaufe ser Rranfleit nöthig ideint. Was innere Mittel betrift, ift @dyefel alz bie befte zu verwenbente alterirente Medizin für sag \$pfero ju betradj= ten. Zwar wirft terielbe langlam, aber tringt leidjt in tas Blut eín uno bebnt frine Sirfungen vollfommener üter cas \$aargcfäp̄yftem

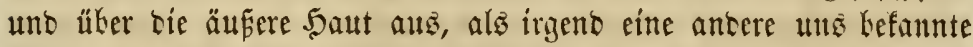
Mesizin. Die Sdyefelblüthe ift für ben Farmer bie zwedmä= bigfte Form riefes Miitels, ca fie auz einem feimen Эulser befteft, Stangenfdwefel aber erft sor cem (3ebraud) zu Pulver gerieben merten muf. Dayon gebe man eine $\mathfrak{S}_{\text {adje }}$ lang alle zwei Iage trei Dofen, wovon jese aus einem Biertelpfuno befteben follte. Nad) Itblauf Der jweiten $\mathfrak{B o d j e}$ wieberbole man bie Dojen auf ricjelke Weife uno fabre alcann mebrere Donate lang fort, biefelben alle zwei :

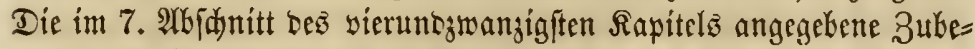

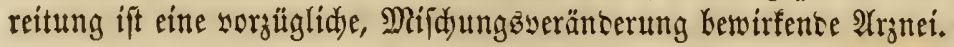

Im Sinter füttere man mit frifđem, grünem Futter, z. B. Sobl, rotbe uno gelfe Rüben, fo lange foldes zu baben ift. Heberbaupt follte bas Futter auts leidyt verbaulidyen, feudten Stoffen befteben, mit

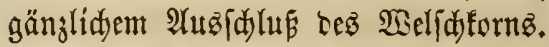

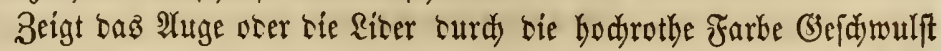

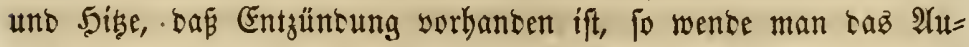
genwaffer redyt bäufig an. Sit bie Sd)leimbaut ber A̛genlioer (näm= lid) ifre innere, fammetartige Flädbe) bebeuteno entzünoet, fo follten 


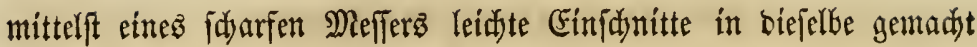
werben. Man bremie bie Rafe bes Sferbes, bamít ez ftill halten

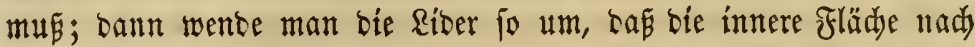

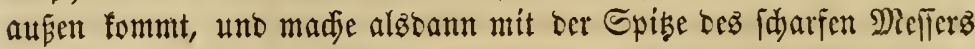
mehrete furse unto oberflädlide Einjdynitte. Diefe follten ihren Blut= gehalt reidjlid auskeren. Daburd) werben tie frobent mit Blut

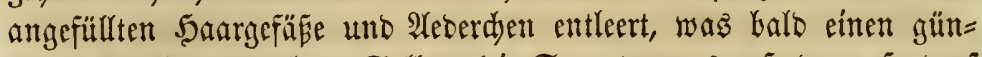

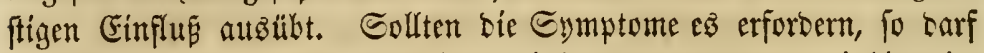
bieje Speration melyere $\mathfrak{M a l}$ in 3wi Tagen wiederholt werden.

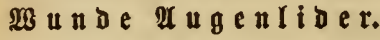

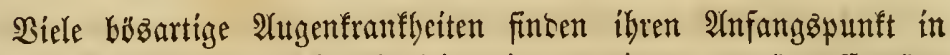
weben 2 ugenlibern. Dieje Gegleiten immer tíe auşgeprägte Ent jün=

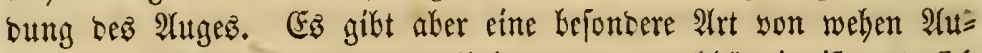
genlibern, bie yon andern Siranfleiten gants unabbängig ift uno fíd

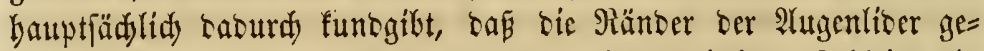

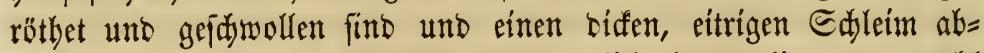
werfen. Dicfe Siranflycit ift auferorbentlid bartnätig, was wohl

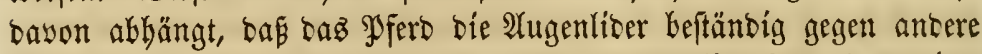

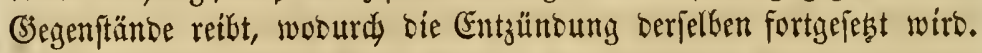

\section{B十 $\mathfrak{b} \mathfrak{a} \mathfrak{n} \mathfrak{b} \mathfrak{l} \mathfrak{u} \mathfrak{g}$.}

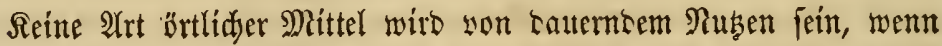

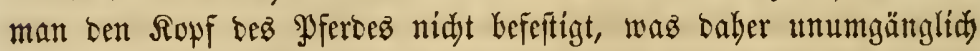

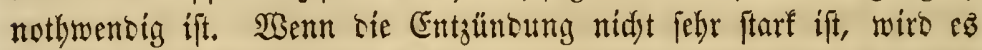

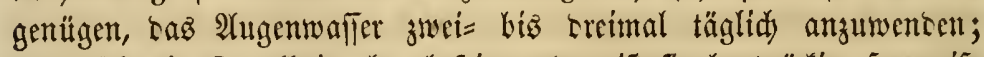
zeigt fid die Sirantheit aber beftig, ober iff fie hartnädíg, fo greife man zur Merfurialjalbe, bie man in fleinen Duantitäten redjt forg=

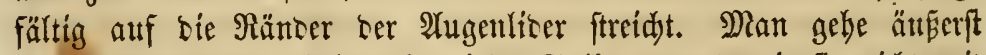
forgfältig mit bem (s)traudje diejer Salbe um, bamít fie nicht anit bem $\mathfrak{A}$ the felbit in $\mathfrak{B}$ erülyrung fomme.

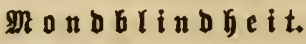

Die unter Farmern alz Mondblinbbeit, aber unter wiffenfidaft=

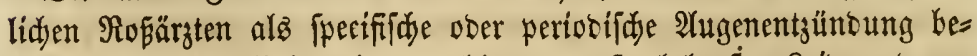
fannte 2 (ugenfrantheit gehört wohl zu ben furdjtbariten Reiden, tenen 
baz $\mathfrak{A}$ uge unterworfen ift. Sie beftebt in einer Entzünoung ber barten Augentaut, Bintebaut unb Regenbogenhaut. Weil die Re= genbogenbaut oft am ftärften angegriffen ift, hat man bie Rranfleit audi) Regenbogenbautentzünoung genannt.

3uerft bemerft man bie furdutbare Entzünoung in oer Bincebaut. Der weife Theil tes $\mathfrak{A}$ (ugez wiro geröthet; bie (3)arbaut fiteht neblig

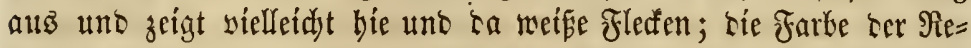
gentogenbaut ift getrübt; tas bie 2ugenfammer ausfüllente :affer

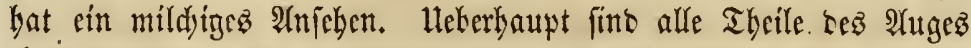
eitter langfamen Berrüttung verfallen. Sebody ftrengen fidy bie Ra= turfräfte an, bie Etörungen gut ơ madyen, fo taf oft eine plöblidye

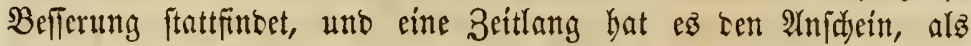
wenn tie Rranfleit gebrodjen wäre. Slber ber Fortbeftano fer erften Uriadyen läft feine cauernte Befferung zu, To safi balo wieber ber

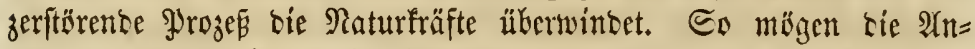
fälle ser Srantheit, weldye Donate, fogar Jahre lang, $a b=$ uno zu= nebmen, jebes $\mathfrak{M a l}$ jduneller wiecerfebren, länget bauern uno einten böछartigen Charafter annebmen.

Bei ter erftmaligen Befferung täufdit fid ber Cigenthümer tes (3)aules gemöhnlid mit ter Soffnung, โafi tas Reisen gänglidy be= fiegt fei. Bald aker wito er feinen Jrrthum gerwabr. Die 2Yugen

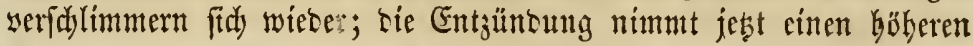
(S)ab an; bie 5ornbaut wirb uncurdyfidstiger uno bas meife, mil=

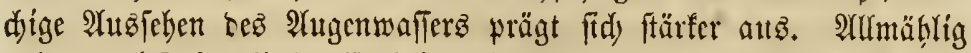
nehmen bieje franflyafte Eridjeinungen wieber ab. Sebt bemerft man aber, taf ber $\mathfrak{A}$ lugapfel merflidy abgenommen bat uno etwas abge=

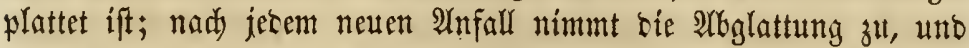
bas 2 Ugentwafler wito weiffer uno bider.

Dicje periobifdyen Ritufälle trbmen fo lange an Syäufigfeit uno

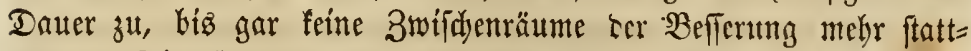
finben. Die Servorragung Les $\mathfrak{A}$ ugapfels veridymbet ganz, Las Yugenwaffer wirb vollento eingebrült, was ben Durdtritt ber Ridyt= ftrablen hemmt uno cauernoe Blinokeit verurjadjt. Dieje Rranfleit ift unter Raien als Monbblinbbeit befannt wegen ten periobifid wie=

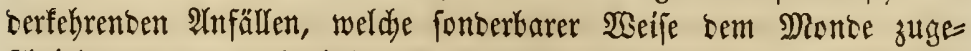

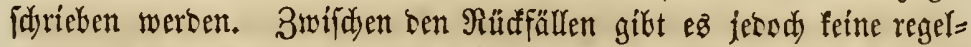
mäpigen 3wifd)enräume. Im weiteren Berlauf ber Iranfbeit fom= 
men fie viel bäufiger yor, als im Beginne berielben, getwöbnlid in 3wifa)enräumen yon fed) bis fünfłż Tagen.

\section{$\mathfrak{B} \in \mathbf{b} \mathfrak{a} \mathfrak{n} \boldsymbol{d} \mathfrak{\mathfrak { u }} \mathfrak{n} \mathfrak{g}$.}

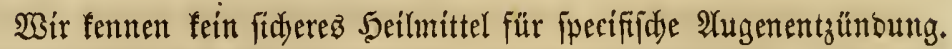

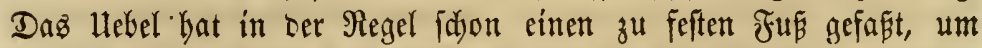

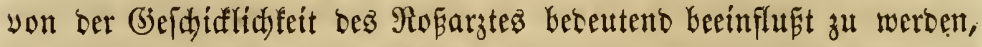
uno für eine erfolgreidje ärztlidje $\mathfrak{B e b a n d l u n g}$ ijt baffelle zu weit

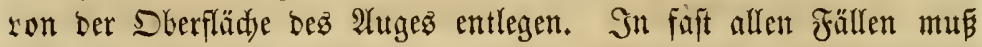

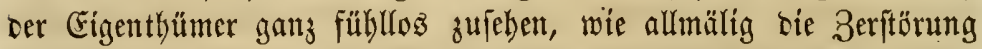

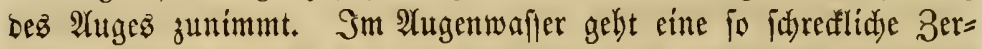

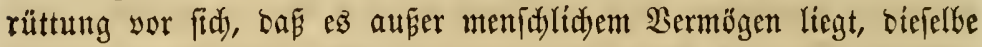

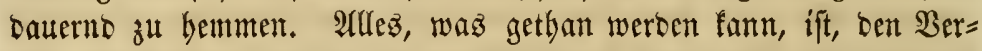
lauf ber Rrantfyeit etwą zu verzögern uno zeitweilige Rinterung zu

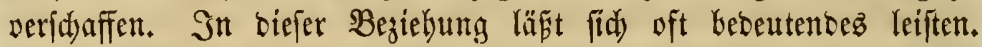

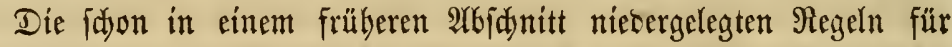
oie Bebantolung erfranfter $\mathfrak{2}$ ugen follten ftreng beobad)tet werden, fo

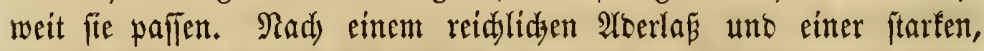

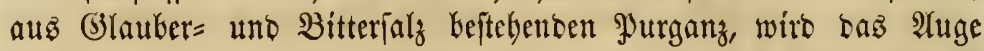

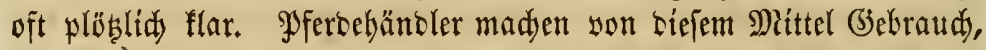
wenn fie eín nodj nídt ganz erblintetes \$pero zum $\mathfrak{B}$ erfauf anbie= ten wollen.

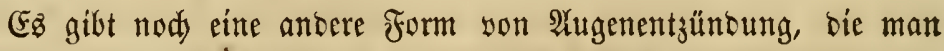
iłres günftigen $\mathfrak{B e r l a u f e s ~ w e g e n ~ e i n ~} f$ a d) e $\mathfrak{A}$ higenentzünoung nennt, weldje aber nidjt immer leidjt yon bem $\mathfrak{B} e$ ginn ber fdon bejdriebe=

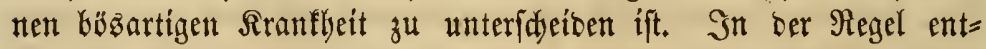
fteht fie in Folge yon Erfältungen, voer wiro surd bie Giegenwart

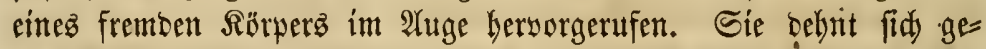

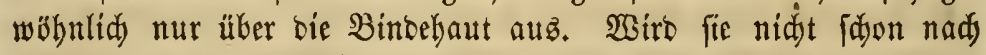
einigen $\mathfrak{T a g e n}$, wenn bie anbern Symptome ber Erfältung veridjwun= ben fint, ober bie frembartige reizenbe Subjtanz aus bem 2 tuge ent= fernt worben ift, you jelbjt beffer, jo folgt faft immer fidnelle bei= lung auf bie örtlidje $\mathfrak{A}$ mwentoung von einfadjen 2 (ugenwaffert.

\section{ธ $\boldsymbol{t} \mathfrak{a} \mathfrak{a} \boldsymbol{r}$.}

Diefe Sranffeit hat igren Sils in ber Rryftaulfinfe, bie immer un= mer unburdfiddtiger uno endlid für bie sidutftrablen ganz undurd)= 


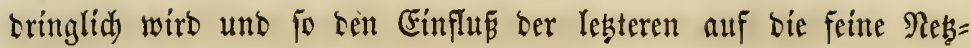
ocer Rerwenthaut zulebgt ganz abjdneibet. Eehr oft ift fie bie Folge ber Montblinbleit, bod) entfiteft fie audy ofne anterweitige Stönun= gen im $\mathfrak{A}$ uge. Shat fie fid solffommen entwifelt, fo ift bas (5)e=

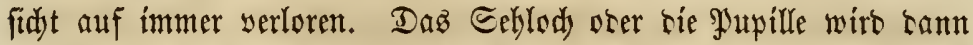

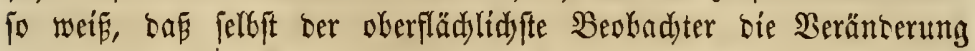

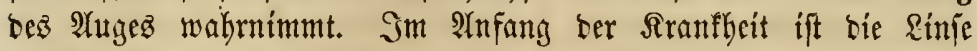
neblig, wirb bann mildjig, hat aber in ser hödjten Entwifflung bez

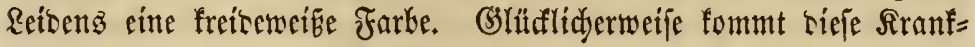
beit Gierzulanbe nur felten yor.

Unjere Farmer haben siel B̈fter Obelegenheit, eine anhere Störung

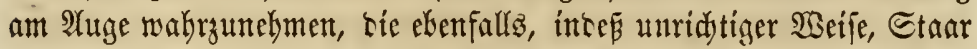
genannt wirb. Bon einigen Rofïraten wito fie alż falfder

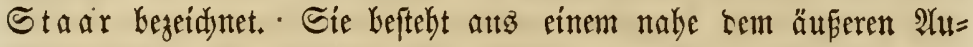

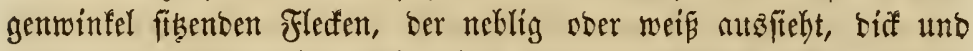

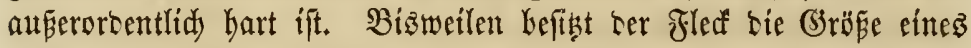
halben Seeizenforns, bat aber in ber Regel einen siel geringeren Utrrang. Gr wädjt nidyt tuto wiro mit her Beit obne Radjfilfe

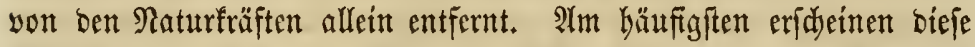

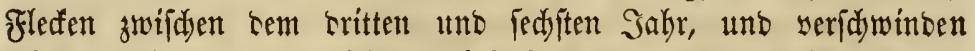
wieber währento ben nädjften orei Salyren. Shre Dauter ift fehr ver=

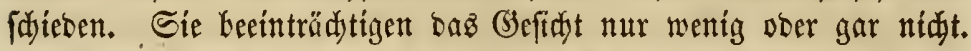

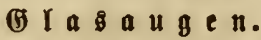

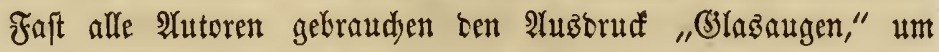
Den fdjwarzen Staar zu bezeidnen, ber in einer \&ähmung voer gänz=

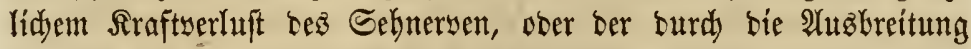

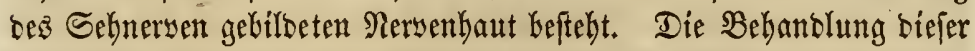
Iranffeit wiro nur fëlten uno bann nur im $\mathfrak{2}$ nfang mit Erfolg

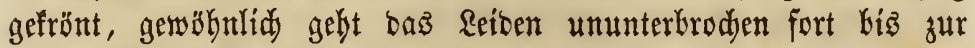
gänglidjen Grblintung.

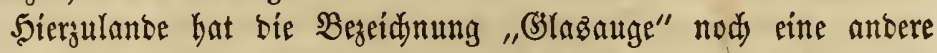

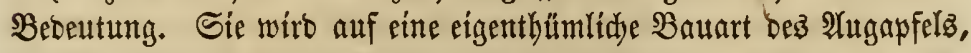
bie aber feinen ftörenten Ginflup auf bie Sebfraft auşübt, angetwandt.

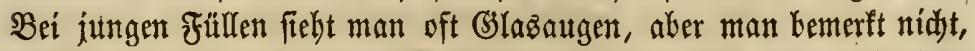
bas in Folge berfelben eine Ertranfung jpäter ftattfindet. Nadh alfem

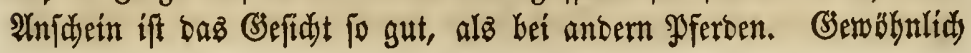


zeigt nur ein $\mathfrak{A}$ uge siefe eigenthümliche Form uno ift baffeltbe mit

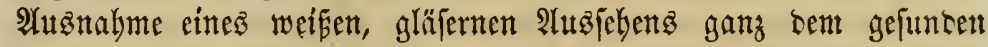

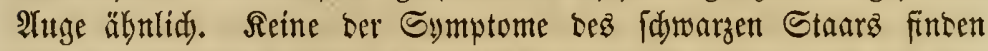

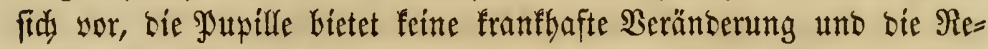
genbogenbaut hat ifre natürlide Farbe uno Form. Der bie 5orn=

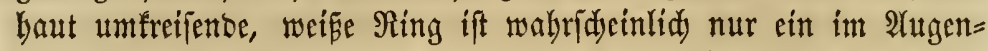

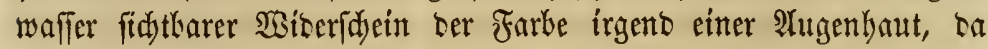

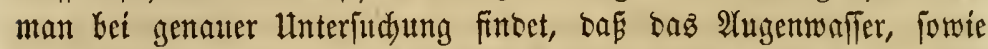

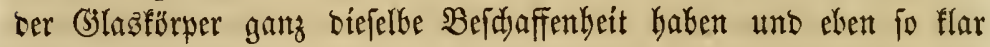
แno burdfichtig finto, als im andern 2 tuge.

Der Eigenthümer eitne gląäugigen Pferbez würbe fid feht wan=

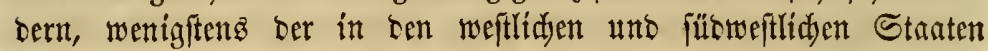

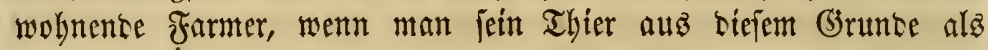
weniger werthyolf betradjen wollte. Woüre überbaupt ber $\mathfrak{B}$ erfauf baburd) becinflust, fo wäre ez allenfallz nur wegen bem auffallenten

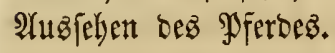

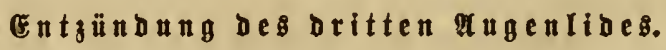

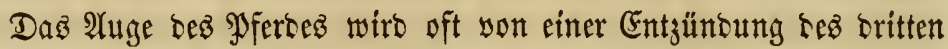
Iugenlibes voer ber halbmontbförmigen Falte ber Bintelyaut befallen, eine Rrantfeit, bie in allen Theilen biefez Randes als "hooks" befannt ift. Buweilen wiro sie Rranffeit aud "bone hooks" unto "fatty hooks" genannt. Biele bezweifeln sie Exiftenz Der "hooks" unt man hört oft bie Frage, ob fie wirflid vorfomme, eine Frage, für

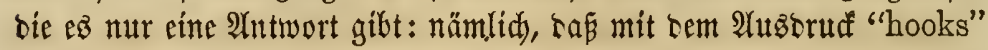

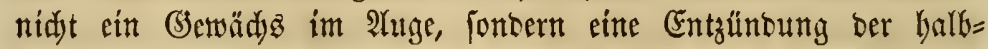
montoförmigen Bintehautfalte, bie fid im inneren $\mathfrak{A}_{\text {ugentwintel be }}=$

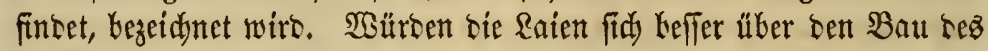

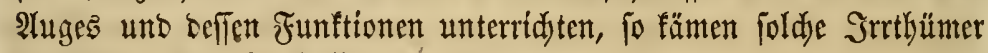
in Beług auf "hooks" nidut leidjt vor.

Die balkmonsförmige Binbehautfalte enthält cinten fleinen brei=

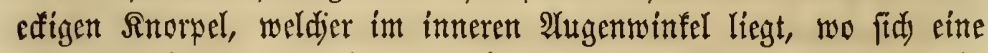

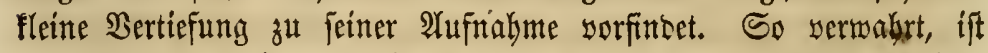
nur ein ganz geringer Theil berfeltert im gejunben 3uftande fidjtbar.

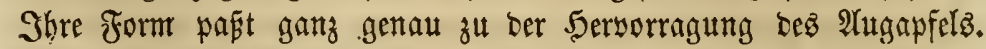

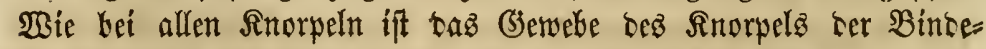

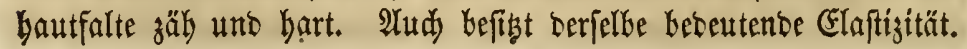




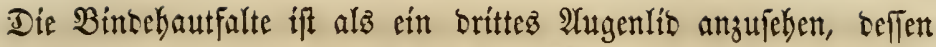
bejontere Funftion Dariil befteht, fremte ßörper, wie Staub, Fliegen,

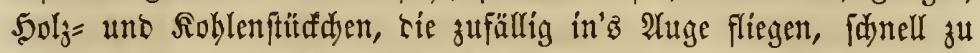

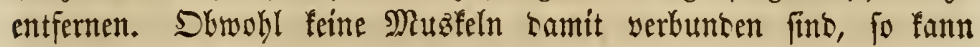

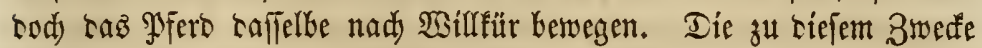
beftehente $\mathfrak{B o r r i d j t u n g}$ ift in ber That berwuterunganürtig.

Sn ber 2ُugenbäble befintet fid eine bebeutente Duantität Jett,

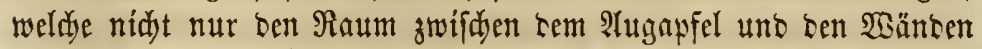

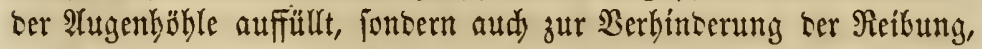

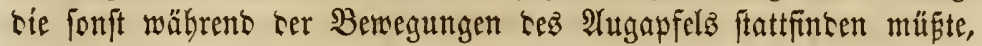

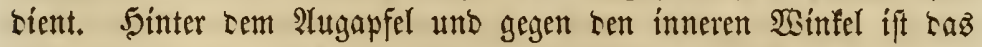
Fettpolifter am reidylidjten sorkanten. Der 2 lugapfel ift yon mehreren

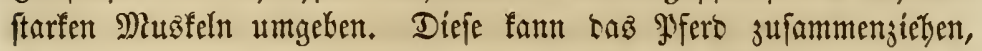

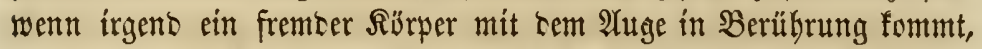

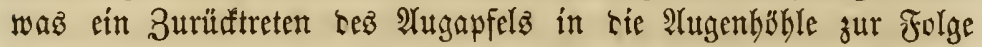
hat. Daz Fettpolfter, weldyez Gierourd) nady allen Seiten aubeinan=

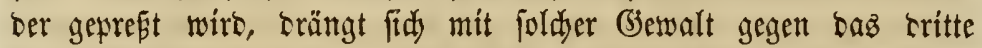

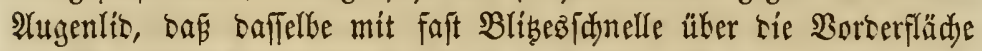
bez 2 Lugapfelż fliegt uno ben fremten Rörtper entfernt. SoLann er=

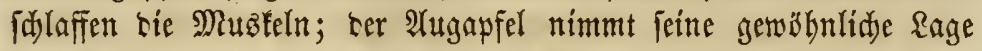
mieber ein, bas Fettpolfter febrt in jeinen gुlat zurüf, uno taz

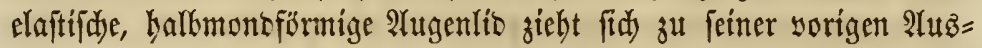

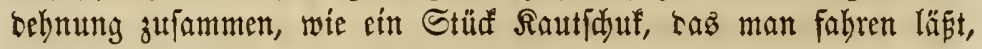

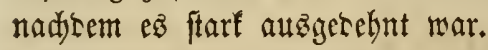

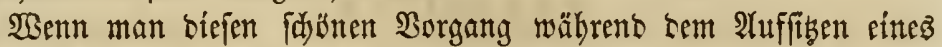

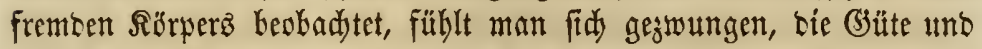

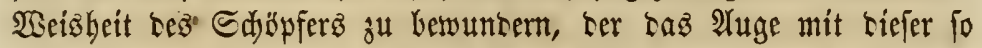
auserorbentlid) solffommen ihrem Enfzwed entipred)enten Borridytung verjah. Man hat am beften Gielegenheit, Lie Thätigfeit tez britten

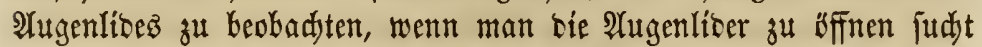
ober bie Fingerpitge mit tem 2 tugapfel in Berübrung bringt.

Die Entjünbing ber balfmontfürmigen Bintehautfalte entfteht hauptfäd)lid in Folge ber 2 tt SYugentheile. Rady langer Entz̧ünoung wirb bas fnorpelige, britte

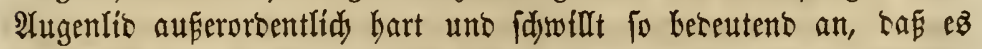
auz bem inneren 2 Itgenwinfel wie ein grofer אlumpen herworragt,

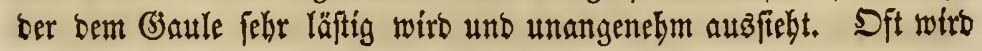




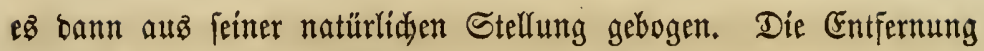

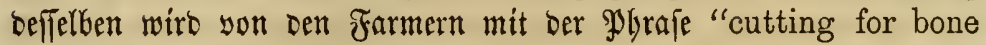

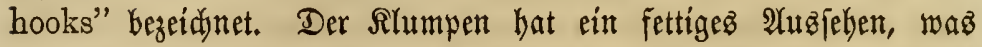

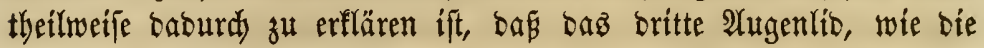

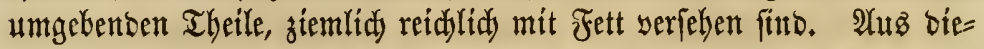
fem (3runbe wirb ber Ilumpen aud) "fatty hooks" genannt.

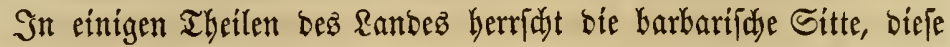
Rlumpen mit bem Mefîer zu entfernen. Bęüglid folder $\mathfrak{B e l}$ and $=$ lung ift eine Thatjadye getwín, nämlidy, bá bieje fleine, yom Sdjöpfer zum Sdyute bez Sefyorganz beftimmte Borridytung burd) eine Dpe= ration gämglid zerftört wirb. Daburd) empfängt bas $\mathfrak{A}$ uge einen

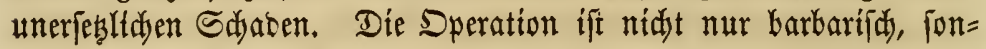
bern beruht auf unwifientheit. Sebe verftänoige Serion, bie ben 3wed ber halbmonoförmigen Bindehautfalte zu veriftehen vermag, mus bie Dperation verwerfen, und fie follte unter feinen $\mathfrak{t}$ miftänoen geftattet werben. Woenn biejenigen Pferbeärzte, weldje biefe Speration yolle zieken, gezwungen wären, ben ganjen $\mathfrak{T} a g$ in ber Sitze unt im Staube fu laufen, obne irgent weldjen Sdjus yor ben blententen Sonnen= ftraflen ober ben idymerzerregenden Staubartiffeldyen, würben fie ben bem Pferoe burdy biefe Speration zugefügten unerfeslidjen Sdjaben befier verftehen. Die Dperation if ganz unnöthig. Beit uno ent=

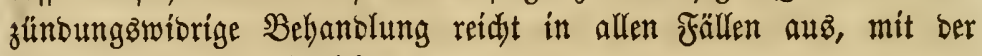
Beit bas $\mathfrak{H e b e l}_{\text {zu }}$ bejeitigent.

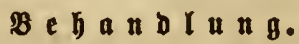

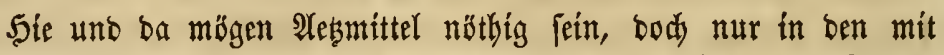

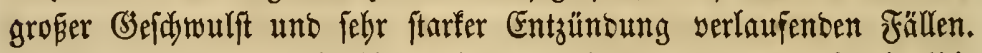
Das $\mathfrak{A}$ ugenwaffer zwei= bis breimal täglid) angemant, wirb in bei= nake allen Fällen fidjer zum Biele fülyren. Diejez follte warm mit= telfit weidjer Rappen ober an Stefen befefígter 'Baummollenbüfdel

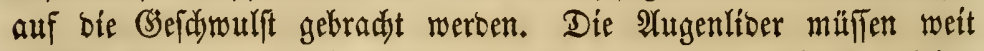
gesffinet werben, um bie entzündeten I Iyeile gut zu erreidjen. Sind

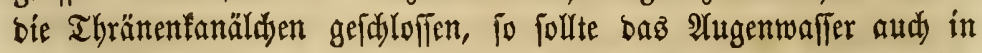

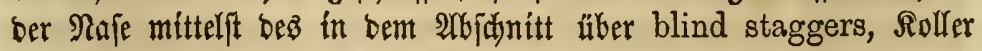
ober Sdywinbel angegebenten 2 (pparates beigebradit werben. Reidjte

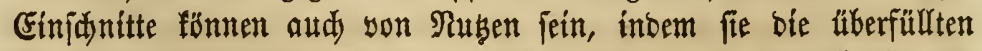
Blutgefäpe entleeren; aber man benfe nidyt baran, bą Wa Waffer für 


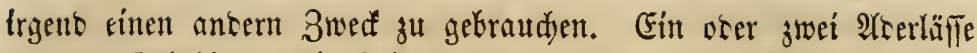

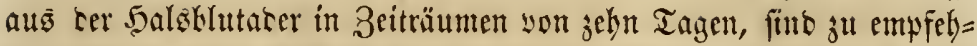
len. Beim erften $\mathfrak{A}$ (serla nadber nur tic 5älfte ricjer Suantität.

Durdy siefe Behanclung wiro sie Ent

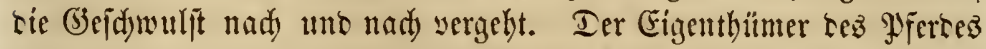
wito es foif unerwartet finten, sa

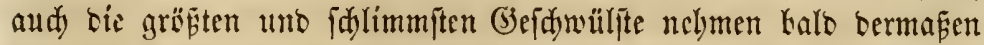
ab, bá fie wicrer in sem für fie beftimmten winfer Raum gentig fincen.

\section{B I}

Ez gift Plferte, bie nidft gut feben, obwohl man feine Fehler an

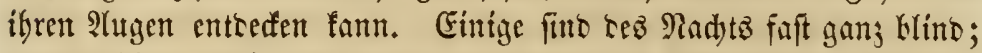

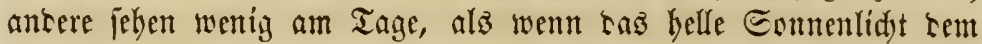

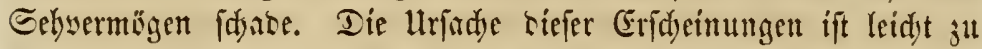
finben; entweser jint tie 2 lugen zu flad oter ju bervorragent. Mon

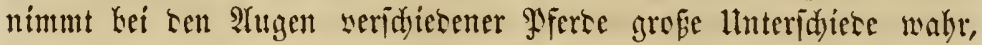

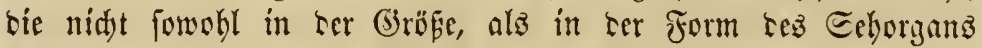
bejteken.

Die 5yornhaut ift nidft bei allen 9 ferten wolfommen surdfidytig, aud hat sie lidjtbredyente Sryftulltinje zumeilen mehr, juweilen we= niger Sirummung unt Durdffitdtigfeit. Die Folge savon ift, onf

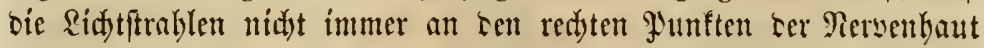
jufammentreffen, ober sie Rersenbaut felbft mag cine foldi) geringe

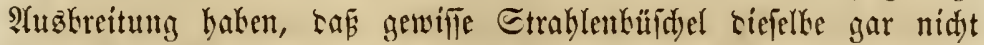

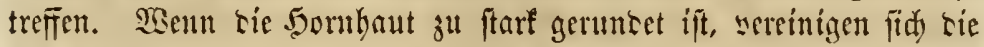
Ridytitrablen, elye fie sie Persenthaut erreidjen, bas Bilo liegt bann yor ter Mersenthant; ift aker siejelke jul flad), fo sereinigen fie fid

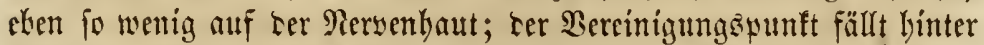
berielken. Dieje, sie Eehfraft becinträdtigente Buftünthe fünnen ohne irgent eine sorthergegangene $\mathfrak{2}$ tugenfrantlecit vorfommen.

Bei alten Wertsen fommt cie Blösfidstigfrit am bäufigiten sor, weil sie 5ornhaut mit sorrüfentem IYter leidyt akgeplattet miro unt

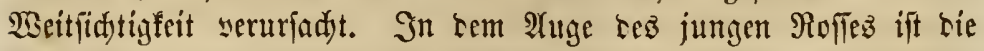

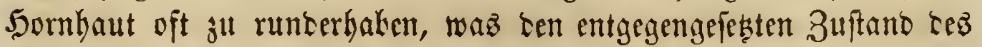

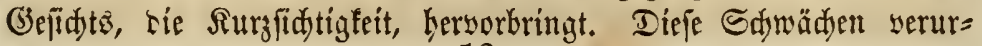


factyen gewöbnlid sie plöblidyen Sprünge uno antere unangenebme Concerbarfeiten. Man bat oft (Belegenleit zu bcobadyten, baj ein

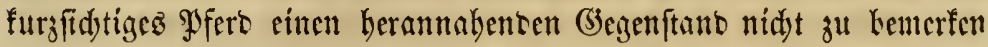
facint, bis berielbe cidyt sor ifm gefommen ift, sann aber ton Sopf eriduroden in bie boble wirft uno ängftlid) aușueidyt. Soldy cin (Saul ift in Der Regel ein unheilbarer Etolperer, weil or fid in ter Entfernung oer Giegenftänce keftünoig tïufd,t.

Bei einigen Pferten fino bie 2) waffer fadcint bif unt ounfel ju feitt, fie fint aber feiner weiteren Beränoerung unterworfen, fo LaE feine Befferung erwartet werben fann, eine $\mathfrak{B c r i d}$ limmertutg aber audy nidyt ju befürdyten ift. PFer

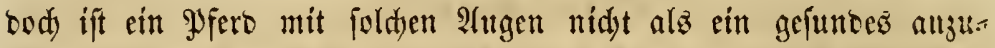
jeben; bent unsolffommene Eebfraft ift ftets ein bereutendes (bis= bredyen. 2Tuf offentlidjen Segen ift ifm gar nidjt zu trauen. Dez=

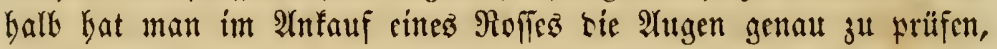
bamit man nidyt mit cinem blöbjidytigen Pfero \#̈bervortbeilt wirb.

Für Blöbfidytigfeit gibt

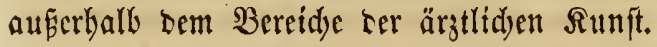

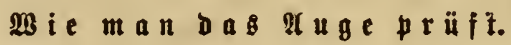

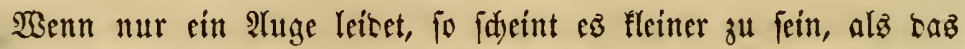
gefunoe, uno sie 2 (ugenlisipalte ift verengert. Diefes ift jecod) nidjt

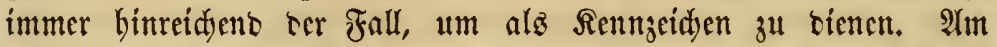

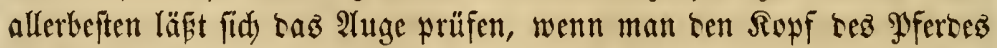
fo ftellt, baf er zwar im Edatten, aber bod ten Somnenitrablen zu=

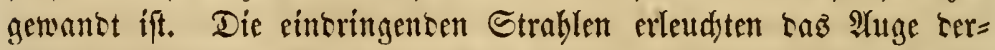
mafen, saf man jebr gut feben fann, ob baffelte nebelig ober flar ift. Ein mit fdywadyen 2 lugen bebaftetes Pfero ift immer ummuthiger

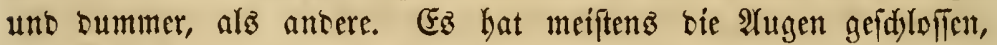
wenn es fteht, uno gewabrt berannabente (jegenftänte weniger leidt,

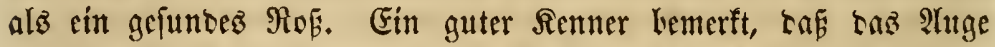

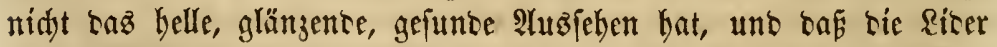
in ber Räke ber Tugenwinfel etwaz eingetrofnet uno runjlid fino. Rebteres sarf man jecody nidjt mit bem im alter natürlidjen 3uftano serwedjfeln.

Jrgent cine Entzüntung offenbart fid obne Wseiteres. Nur bei rem periosifden Radylaffe terfelken in oer Monblintbeit läuft man 


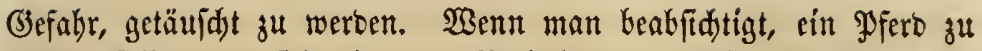

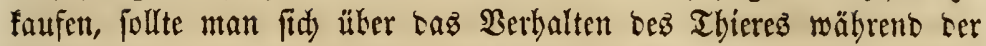
leststwergangenen Safire genau erfuntigen, uno wenn irgent weldye

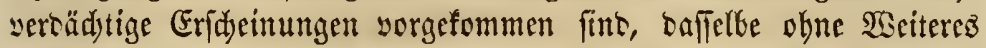
serwerfen.

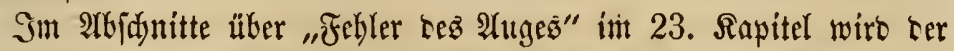
sejer nod) weitere Bemerfungen über biejen Öegenftano finten. 


\section{Giebentes sinpitel.}

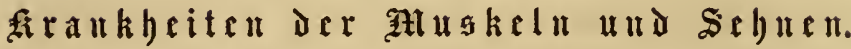

\section{Eifit (fistula).}

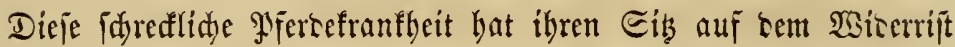
(withers), gerace am Ente sez Edyulterklattż uno zwar anfänglidy gewöbnlidy mur auf einer Eeite tez Sisterriftz, son mo fie fid aher in sen meiften Füllen aud) auj sie antere Eeite verbreitet. Sin=

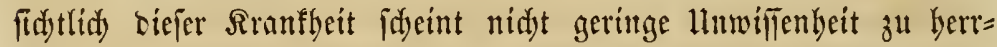
fajen, benn währeno bie Meiffen sie Urjadye unt and im Itlgemeinen ben Sib rerjelben anjugeben vermögen, fo fragen fid bod) mur 被= nige: weldye Theile fint $\mathrm{ez}$, sie won biefem llebel affiritt werben uno weldes ift ber genaue Berlauf ser Rranfbeit? (Bembihnlid) wirb sie Fifitel burdy ingeno weldye Duetidung erseugt, sie auf verifficsene

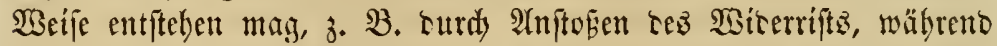

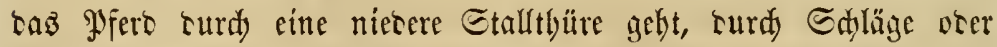

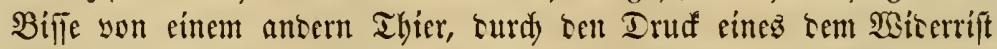

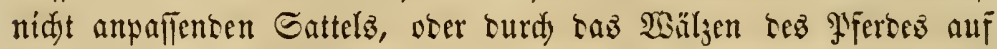
Steinen orer $\mathfrak{T H u r z e l n}$.

IUf sem sbern Theile ter Edyulter, unmittelbar unter sem okern

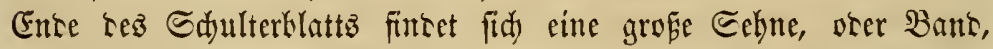

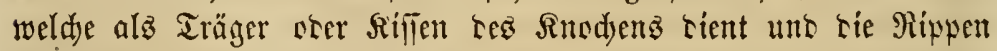
yor alljugrofem Drud bejübst. Der wijienjdaftlidje Rame siejer Selhe ift serrates major (wörtlid): grofé, fägenförmige), cine $\mathfrak{B} e=$ nennung, weldye fie yon ifker fägeartigen (sejtalt erfalten hat; aber im gewöhnliden Reben ift biefelbe unter bem Ramen 2 sei 3ählecer (white-leather, though-leather) befannt. Diefe Eefhne

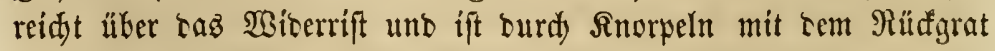

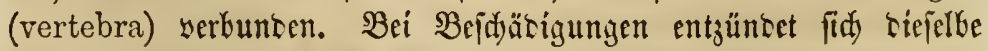

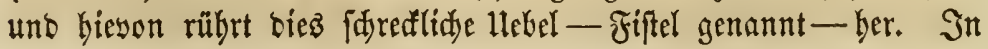


gejuntem 3uftant Fehen bie Fajern biejer Sehne fleinen Eträngen

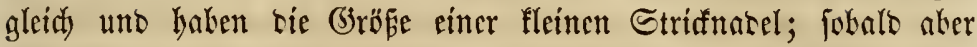
Entzünoung cingetreten, io werben fie fo bif wie bas Moks ciner Takadöpfeife. Dic Schne jomillt fort uno fort an, bis entlidy tie

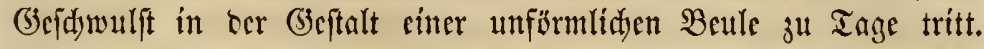

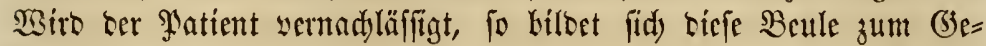

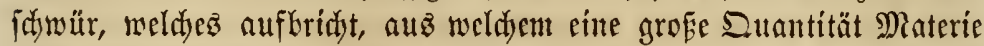

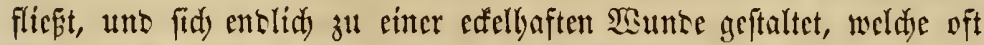
Monate, ja felbjt Jathre lantg citert. Da fid ser Eiter beftünoíg mehr

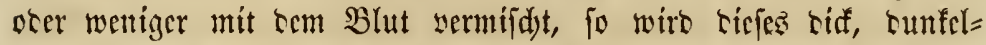
braun, ser Blutumlauf wiro theilweife gehemmt unt ber Suls ift febr soll. Daz Pfero witro immer magerer utto fdjwädjer. Daz

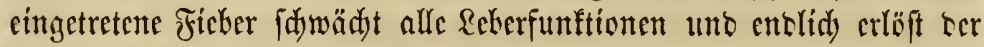
Too ten Patienten won feinen Reiben.

Defterz verbreitet fid bie Entzüntoung auf bic antere Seite ter Sdjulter unt as mersen sie Rnorpeln uno sie Enten tes Edul=

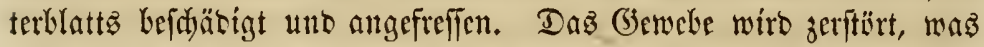
ein Bufammenfinfen ber betreffenten Theile unb cine fdrefflidy Ber= unftaltung zur Folge hat. Dieje Mifigeftaltung helt fid) aud bann

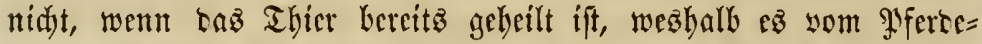

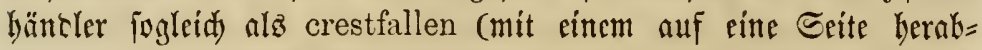

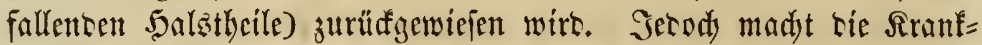

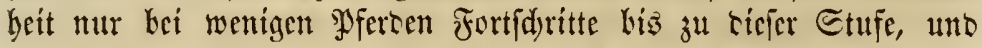
nody mentiger \$atienten, bei benen tas llebel fo weit sorgefdritten ift, werten gebeilt. Die früher gegen Fiftel angewante Behant:

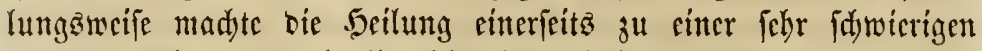
uno antericits war bicfelbe fehr langwierig uno mühesoll, fo rafi

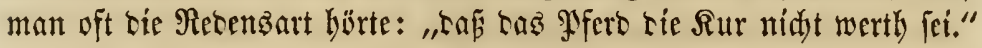

\section{$\mathfrak{B} \mathfrak{e} \mathfrak{h} \mathfrak{a} \mathfrak{n} \mathfrak{d} \mathfrak{u} \mathfrak{n} \mathfrak{g}$.}

Ez merben zwei brilmittel emprohlen, bie man bei zwei yerijdie= tenen Stufen ber Rranfleit anmentet. Bon ser Beit an, wo man

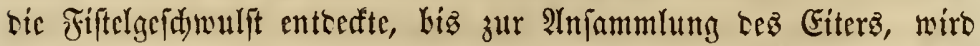

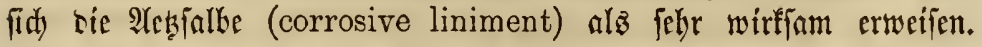

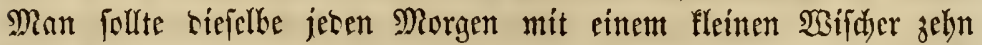

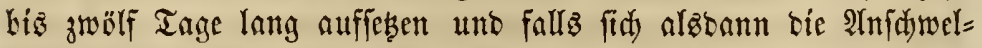
lung wod) nidst vermintert hat, fo follte bie Fubblatt= (aud) Enten= 


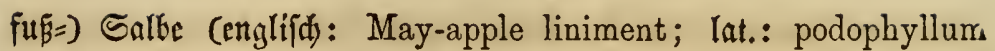
peltatum), wie unten angegeben, gebraud)t werben. Die Ateglalbe

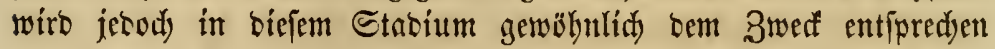

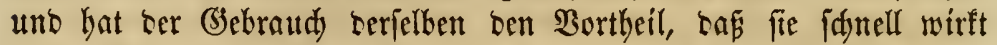

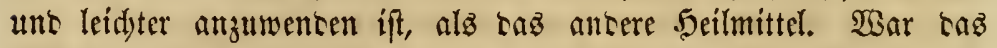
Siftelgefdywitr jebody fdjon lang im Entfethen begriffen, ober ift baf=

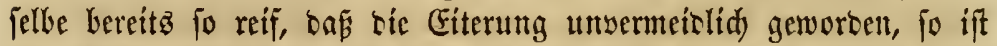
bå̇ May-apple liniment baz gecignete Mittel. Mit biejem follte man jeben Miorgen bie Beule sünn bejtreiden tmo ant 2 tbent bie= felbe (bic Beule) forgiam abrwajden, wonady man irgent weldyez

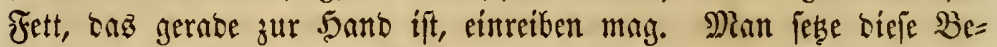
bantlung brei ober vier Iage, voer fo lange fort, biz fid in ben

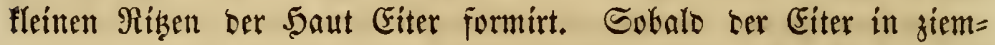

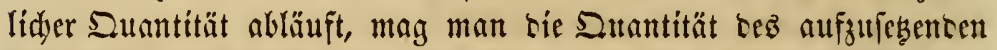
Siniments nady uno nady yermelyren, uno man fann baffelbe auth

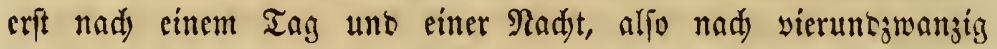

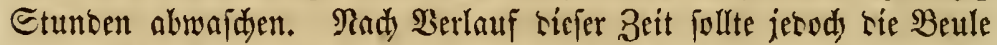
ahgewaiden werben. Nadbem man vientubzwantig Stunten aubz= feste, fann man taz Riniment abermalz in ziemlicher Duantität auf= feben, obne bie Beule sorber gereinigt zu habert. Eghe man jetod) bas Fett einreibt, mun sicielbe immer tüdtig mit sinem $\mathfrak{T} u d$ uno warmem, farfem Eeffen=2lefut gewajd)en werben.

Dic Wistunngen bez Rinimentż. werten temjenigen, ber biefelten nod) nie ju beobadyten (belegenbeit hatte, wirflidy erftaunlid worfom=

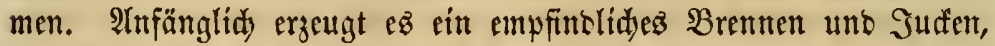

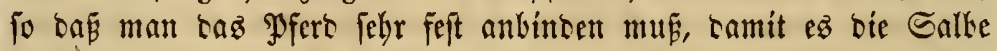
nidjt abreibt. Sobalo jebody tie Eiterung eingetreten, fteht ber $\mathfrak{P a}=$ tient oft ftuntenlang auf einem F!labs fitíl und man faun beutlidy fehen, Laf ihm bebeutente Erleidterung gemorber ift. Die Dutan=

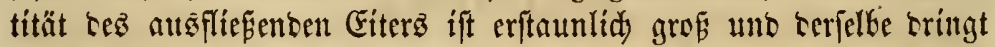
oft 10, reidylidy aแz ben ermeiterten Poren ber Şaut, Lap er an ben

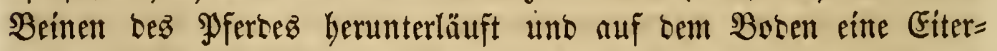
ladje entftebt. Sobalo dież (eine reidjlidye Giterabjonberung) einge= treten ift, ift bie (befabr vorïber uno man braudyt fur Rur nur nod)

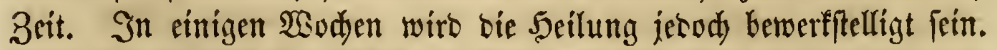

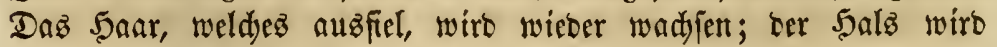
niddt crest-fallen (auf ber einen Eeite berabGängent), uno taz p̧fero 
wirt überbaupt fo gefuno alz vorber fein unb fann wieber jur Âtrbeit gebraudyt wersen.

Sbgleidy aud bei bicjer Bebandlungämeife Beit ju ciner yolftän= bigen 5eilung erforterlid) ift, fo wiro curds biejelbe in jesem Eta=

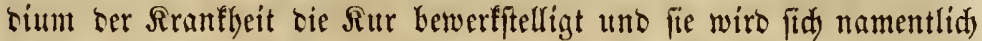
bann fehr erfolgreidy beweijen, wern fidy bereitż Eiter angejammelt

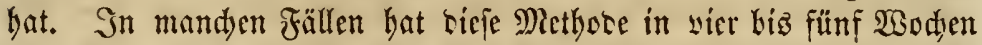
mebr ausgeridstet, als antere Scilmittel in jo wielen Mlonaten. Cie wirft bauptïalidy bešwegen fo erfolgreidy, weil fie eine idnelle Eite=

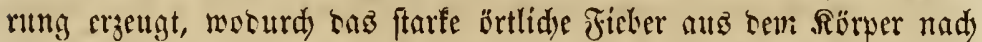

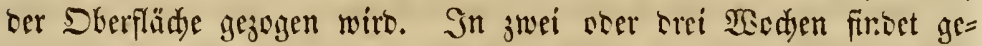

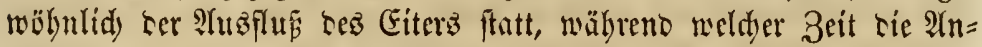
fdyellung zugleid, critaunlich abuimmt.

Anfünglich muß man fehr beîorgt fein, saß man nidyt eine zu grop̧e Suantität Riniment auffekt, noty Iaffelbe ju lange auf rer

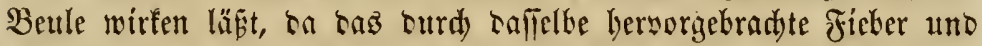
ber yon ifm ergethte Reiz jiemlid) beftig fint uno bem Pferbe fdäs=

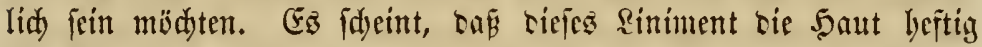
erbitge (scald), ehe es auf bie Sanrgefäfe uno bie Theile wirft, wo ber cigentlidye Sis ser Srantlbeit ift. Eelbft menn biefez Scilmittel

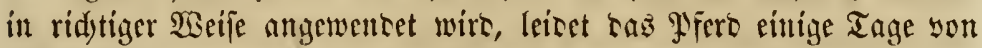

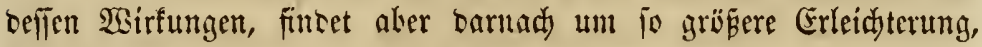
jobalo bie Eiterung begomen hat.

In einigen Fällen bat man mit ter bier befdriebenen $B$ ebant= lungşweife aud feinen Erfoly gebabt. Dies war jecod) nur cann ser Fall, wenu bas May-apple liniment unridtig angewanst wurte. Bei hartnädigen Fällen wiro eine Iltwed)b̆lung mit beiten Seil= mitteln, fo baß man einige Tage bas corrosive uno einige Tage

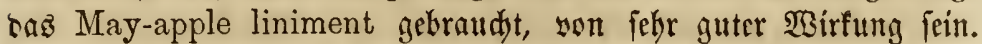

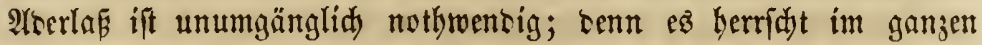

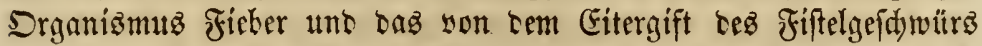
vertorbene Blut ift bif uno läuft langiam in frinem Umlauf. Daf= felke mus besెmegen surch fdunellwirfenbe, alterirente Mittel verbeffert

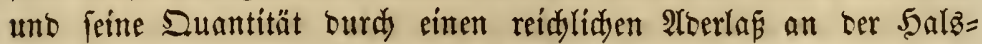
blutaber verminbert werten. Das erfte Mal mag man eine (ballone,

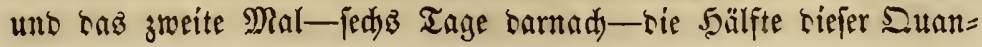


tität ablaufen lajen. Darnad) wiro Edjwefel nebft grüntm Futter unt ser gewöbulliden Bebantlung binreident fein.

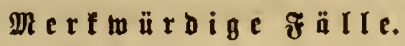

Dic $\mathfrak{A n f u ̈ h r u n g ~ c i n i g e r ~ m e r f w u ̈ r s i g e r ~ F a ̆ l l e , ~ w o ~ b i e ~ F i f t e l ~ m i t t e l f t ~}$

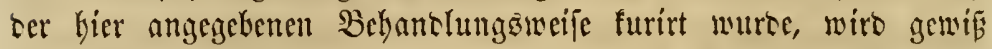

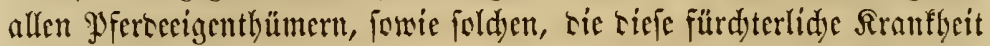

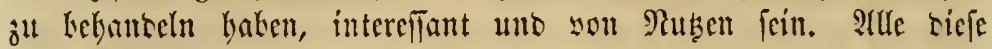
Fälle famen in meiner Prariz in ten Jahren 1847-1851 vor.

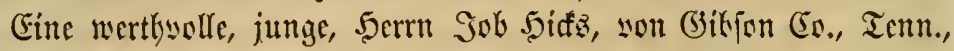
gehörige Stute litt fdon etwa adjtyehr Monate lang an cinem grofen Jriftelgeidwüre auf ber linfen Sdyulter. Dic beule war mit atrienif atşgen̈bt norsen; cine jiemlidue Dutantität Giter batte fid entleert; nunmebr aber bärte sic Entleerung gänjlid) auf mit bic Theile wa= ren idreftlid) angefdimollen uno entzüntet; aber auf ter Beule hatte

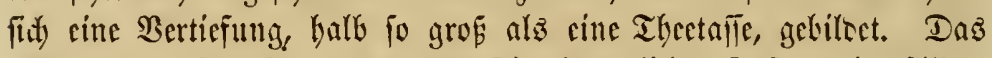

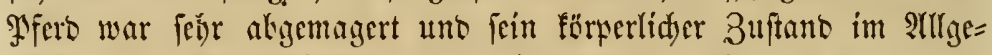

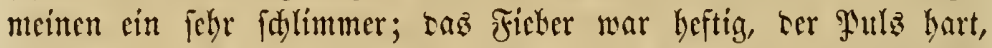
sie Saare troden unt ftruppty. Dies war cin Falf jur Gurokung โes May-apple liniment, weld)e rid)tig unt forgfältig augewant wurte, währeno ber grotient nebftem foldye Bebanclung erfuhr, alz

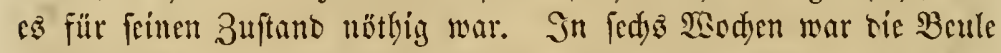
serfidyunten uno nut nod cine fleine Sisunte sorbanten. Dis Sur war cine yolffonment, tenn mit StuẼtahme ciner fleinen Sdyramme an ser Stelle, wo rie Berticfung entftanten war, fonnte man aud feine Epur ser Rranfleit entseden.

5err Sofeph Eharp, weldyer in Serfelten RadjEarfdaft moknte, batte eine alte Stute, kei welder fid Jiftelgefduüre an beisen Eeiten

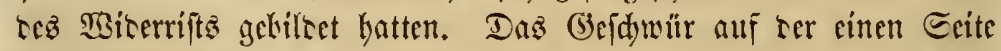
war zoweimal, ras auf ber ancern cinmal mit STrenif ausgeäht wor=

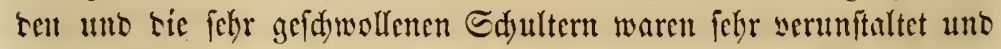

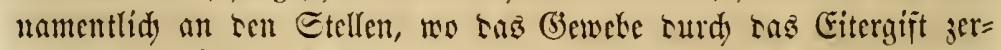
ftërt war, auifer aller Proportion. Da taz Pfero faon brei Sakre lang franf war, fo bewiç jid) bic Rranflyeit alz cine jefr bartnädige. Dentud wurse sic Rutr, chgleid) man fedjz Monate saju Kraudde, volftradit, unt co fano fcin Rüđfall Etatt.

Bcim näd)fen Fall, ben id) anfïthren mill, war tie Behantlung 


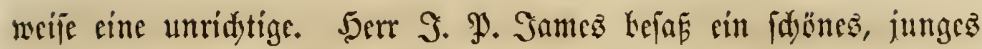
Pfert, weldes ein Fifitelgeidiwür auf ter Edjulter hatte, tas fid an beisen Eeiten berjelben aušrchnte. Dic Gitrrammlung batte nod) nidjt begonnen uno saz Fiekter war fajteflid. Sd) verorencte ton

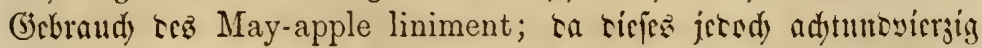
Stunten ling auf ber Beule werblict, ohne akgerajdan jut wersen, fo bilscte fidf eine barte Sirufte utto nadyecm fid bicic abgeidyält, zeigte fid cine zäbe, gläictute 5aut, anf weldje tas Siniment nidjt wirfte. Zu jenter Zeit (1848) war baz corrosive liniment nad) nidft im (jebrand unt man founte mr nad) fünfmonatlidyer, forgy

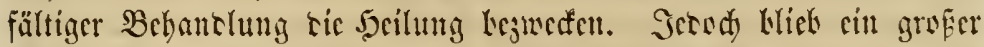

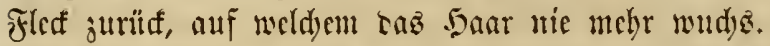

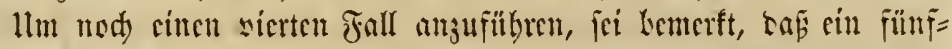

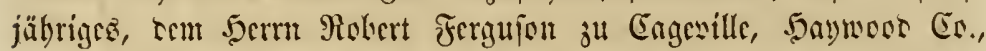
Ienn., (wo ter Ałtor tamalz wohnte) gehörentez 1 fers, mit cinem ungrheucr grofen Fiftelgcidynür behaftet war. Ias May-apple

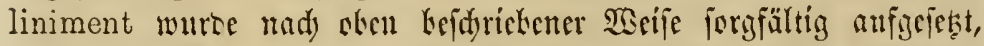

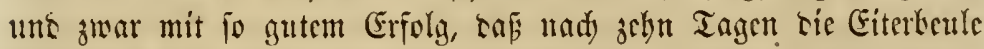

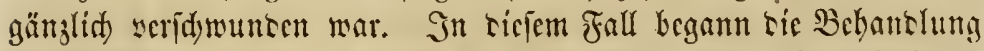

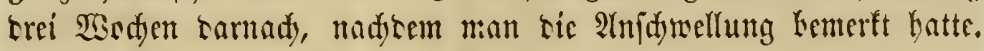

\section{Fribere Methoden ber $B$ ebandung.}

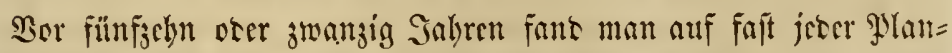

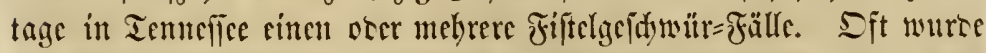
sem ISaticnten surdyaus feine 2tufnerfiamfeit gefdyenft, oser man

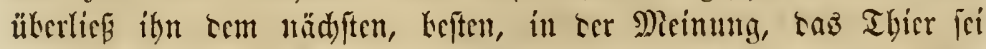
obuchin werthlos. Nur wenige Farmer waren kercit, cin mit Fiftel

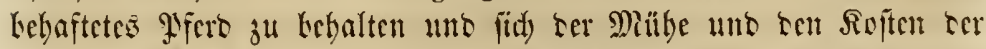

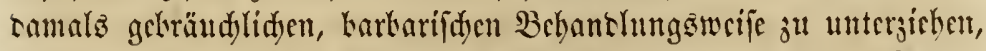

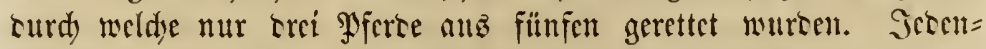

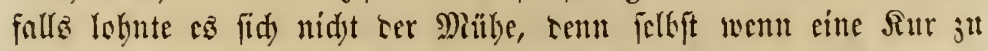
Etante fam, war tas Pforo anberorsentlid) misigeftaltet, uno fah mit crest-fallen (auf cine Eeite herunterbängenten) Edjultern uno

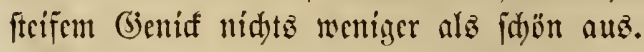

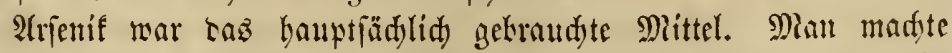
cinen tiefen Ginidnitt in sie Epite ser Beule, in wolden Einjdntt mittelft cinç Jeterfielz ber Arranif eingellajen wurte, worauf man 


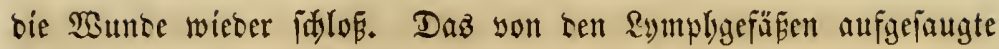
(3ifift wirtte nidyt nur balb auf bas Fiftelgefdmult, fontern aud auf bie benadbarten Gebnen uno Maźfeln, uno erjeugte cine Citterbenle,

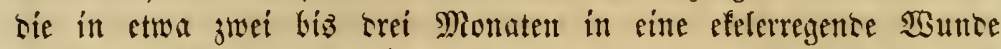

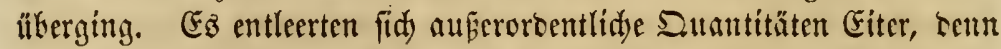
ธaร weit cingebrungene (3ift griff viele Theile nad) allen Ridytungen bin an uno zeritorte zumeilen Sehmen, Ruorpeln umo mandimal

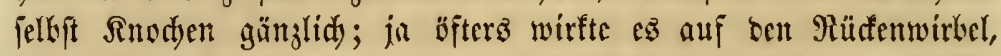

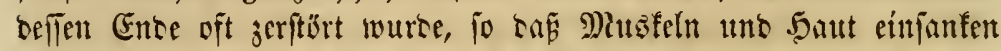

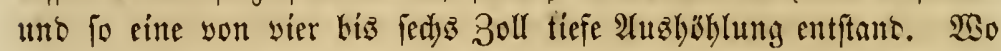
Das Bift bintrang, ridytete es feine Berbeerungen an. Enolidy, nady=

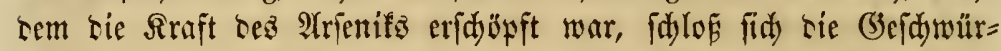
wunce, uno onz Pfero wurse mit feinen Berunftaltumigen uno oft

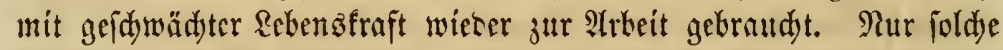
Pferte, Seren Rörperbau ein auferortentlid ftarfer uno beren $\&$ s. benştraft eine ungewöbnlidye war, fonnten diefe Bebantlungsiweife, bie oft monate = uno jabrelang sauerte, aushalten.

So jduredtlidy tie Folgen Ser hier befdriebenen alten Methobe fint,

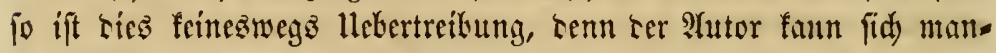
d)er Fälle erinnern, wo bic $\mathfrak{B i r f u n g}$ siejer barbarifden Bebandlung cille nod siel fürdyterlidyere war. Gr hat Ifiere gejeben, Seren oberer

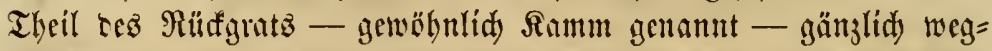

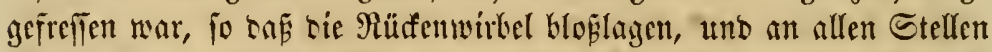
jener Theile entlecrte fiit) jull gleidjer 3eit efelerregente Materie.

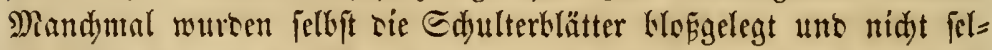

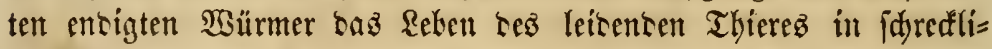
(j)er $\mathfrak{i e i f e . ~}$

linter bie alten Methoden fer Bebandlung gebört aud โaß彐 Bren= nen mit einem glübenten Eifen, ober einem 5orm, ober heifem aidjen= brei; oft ftad) man aud mit cinem bünnen, ipizigen Fifen, weld)es glïbeno heif gemadyt wurbe, bie Beule ourdy uno surdy; ober man Iegte \$olfroot ober corrofises Sublimat in einen in bie Beule ge= madten Einjanitt; was äbnlidye Sirfungen, wie bie oben bejdrie= benen, zur Folge batte.

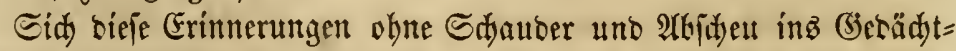

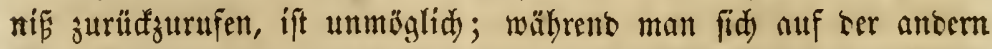
Seite freuell sarf, bap sie Unmiflenbeit uno Graujamfeit nicht länger 


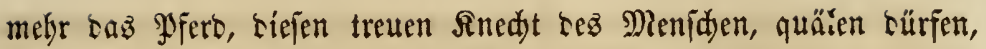
fondern bas baffelbe eine befiere Bebandlung erfälyrt.

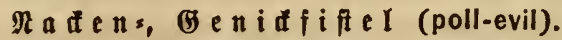

Der Sis biefez llebels ift oben am 5alfe uno gewöbnlidy einige Finger breit binter Den Shren; ricie Srantfeit wirt aud Gentid"=

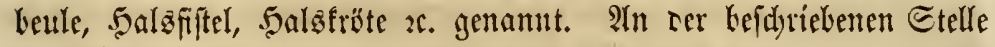

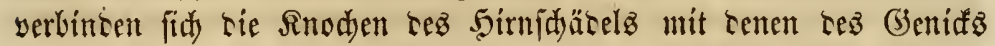

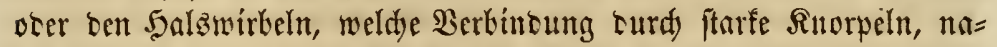
mentlid) aher burd) bie Eehne, weld)e man serratus minor. (mört= lid): fleine lägcfürmige) nennt, hergefteft wirt. Eiche ten atbid)nitt über Mutsfeln uno Eehnen, forwie $\mathrm{E}$ auf bem Bild: Rünftlides Sfelett Les Yjertez im jweiten Rapitel.) Durd bieje Rnorpelt uno biefez Bano wiro ser Sopf getrigen uno gewinnt einen feften Salt,

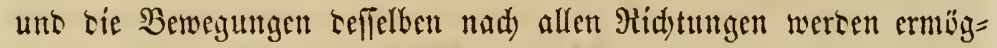
lidyt. Den Gintern Theil teg Ropfez (Şinterfopf), wo tic Gentidfifitel entjtcht, heíst man in ber englijuen Spradje poll, Laher Ier Name

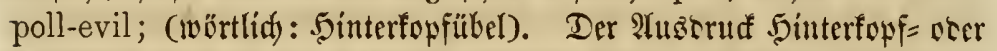
Sopffiftel (poll or head fistula) würoe jerody bejeid)neter foin; benu

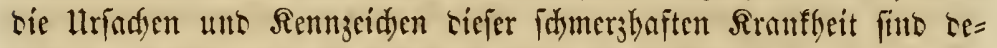
nen ter Jiftel auf tem Wiberrift souffommen äbnlid.

3wijden ten zwei Eehnen, weldye man mit serratus major unto serratus minor benannt hat, befteht eilte genaue 2 ecdjelbeziefyng,

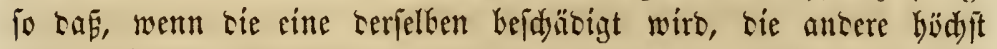
wahridseinlid) aud) mefgr ober wentiger leiset, unt oft fann man sie

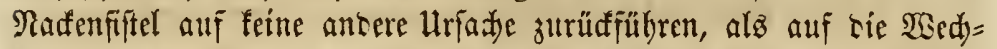
felbeģifhung mit ser serratus major, fallz biefelbe nämlid franf= haft ift.

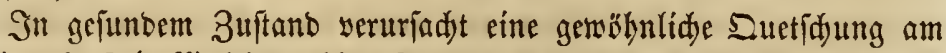
Shinterfopf (poll) feine üblen Folgen; fino aher sie Theile in fieberi=

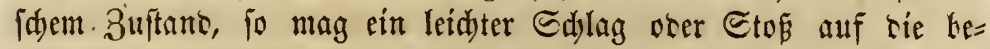
treffente Etclle iebr siel Unbeil anridten. Rädift ten Edultern uno Gelenfen ber Gliebmaf́en wiro währeno tez Gehenz orer Rau= fens bez Thierz fein Theil feinez Rörpers in foldem Mape ange= ftrengt, alz bic Muzłfeln und Selynen am Sinterfopf.

Es ift nidjt nur ein gegen Drud, fonbern überbaupt ein febr em=

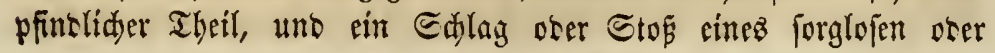




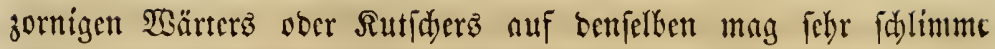
Folgen nady fich zieben. (Entfeht feine id)limmere Rranfbeit, fo jeugt eill Sinoten ober Gernusitretenter Rlumpen, weldyer längere Beit nidjt veridwintet, gewöhnlid) won ter tem Thiere wiserfabrenen Bebant= lung, weldye aud plöblidyen Tod jur Folge baken fann. Einft fab

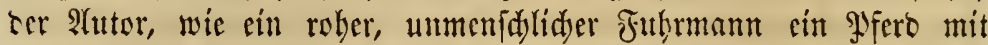

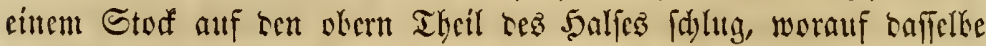

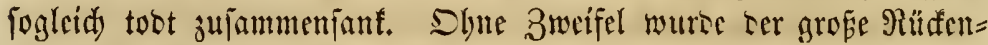
marfōtery cntweber fdwer lochärigt ober auseinanter gerifien.

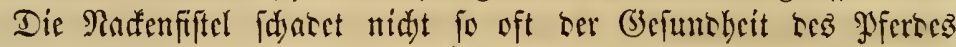
in bett (3rabe als tie Fiftel, und jmar teswegen, weil ber Sis ter erfteren yon ben bauptiädlidyften Drganen, ten Rungen uno rem 5er=

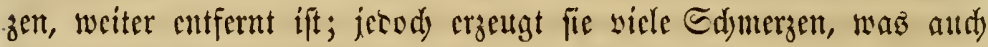
bem oberflädylidyen Beobadter nidjt entgeben fann.

\section{B ค}

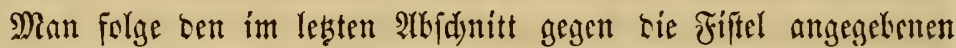
2)

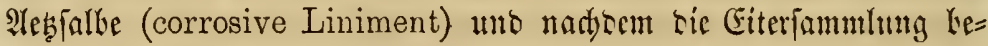
gouren, wente man bas May-apple Liniment (Entenfufjalbe) an.

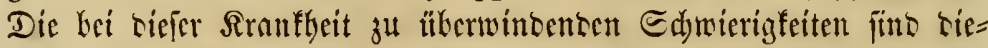
jelben, wie ç bei ber Fiftel ter Fall ift, uno man griff früber zur $\mathfrak{B}_{\mathfrak{e}}=$

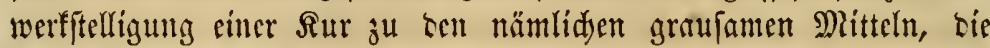
gegen lebtcre Siranfleit gebraudst wurten.

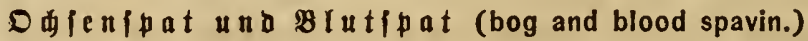

Sd) fempat (bog spavin) befteht in einer weidyen, runten (3eidwulft an ber innern Srite เes Sprunggelents; affizint aljo namentlid) bas Sprunggelent uno rie flcinen mit ciner öligen Jeudytigfeit gefüllten Bebälter, bie fid in ticjen Theilen fo zablrcidy vorfunen. Shgleid wir wicherbolen müfien, was int sritten Rapitel gcjagt wure, fo wirt eb, ehe wir weiter gehen, nitblid) fein, sie Etruftur tes Sprung=

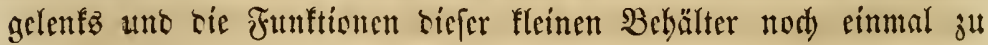
betrad)ten.

Dicjenigen (3) lenfe bes Rörpers, bie am meiften SInftrengungen ausigejęt fint, fino mit ftarten grofen Sebnen werfeben, sie fie febr nisthig baben. Ân ben äuEerften Enten ter Eebnen uno jwifdyen 
ricjen, fowic zwifden ben Eebnen uno Snoden, befinten fid rie mit oct öligen (jelenffeud)tigfeit gẹüllten fletnen Bebälter uno baben

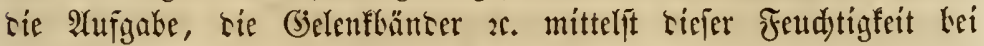
fantller Bewegung oser ftarfer Anjtengung vor Reibung zu lemab= ren. Die Eethen auf ser innern Erite res Eprunggelenfiz, am Enre เes inmeren (s)riffelkeins (splint-bone), weldye tas Edjienbein und tip (j) riffelbeine (jietge Bilo auf Ereite 24, Bif̄er 45 uno 46) mit sem grofen lunteridyenfelbein (fielye Bifier 38 auf semjelben Bilt)

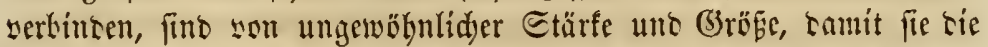

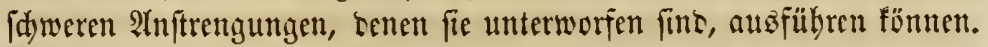

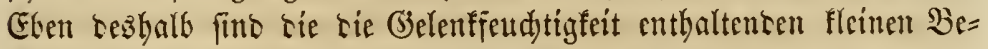
bälter bier nod zableidjer, als irgentwo anters, sent gerabe bicr ijt mebr Gefabr ter Reibung vorbanten, als an irgent cínem antern Theil เes నörpers.

Durd) anftrengence Ctrapajen uno Keftige, plöblidye $\mathfrak{A}$ mitrengun=

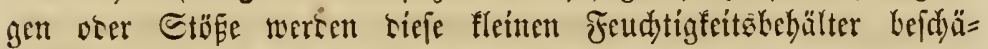
bigt uno vergröfern fid), B̈fters aber nod weren fie gewaltjam ge=

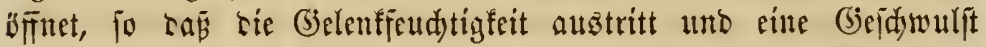
unter fer Saut und fem Bellengemebe entftebt. Soldyem llnfall fimb

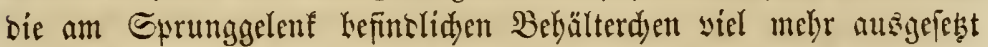
als sie, weldye antersino angebradjt fint, uns weil fie an rie = fem Eselent, wie jhon bemerft, aupersem febr jablreid fint, io ift

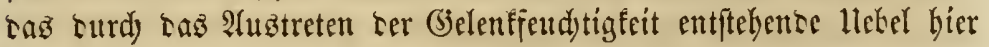

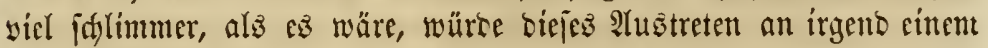
anern (Selent ftattinten.

Die Abjoncerung fer (5elenffeudytigfeit nimmt aud), nadjem tie Bebälter jerrifien fints, nidyt nur ibren Fortgang, fonterm yermelyrt fid), weil rie Natur sen Gdjaben gerne gut madjen würte. Sn rie=

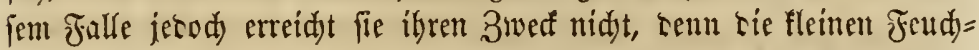
tigfeitsbebälter beilen nidht, bagegen fonert fid bie (Belenffenditigfeit (yon ben 2 (ergten synovia genannt) fort unb fort ab und fer Epat= flumpen, sie (s)eddwulit nämlid, fdwillt natürlid immer mebr uno.

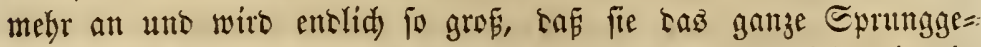

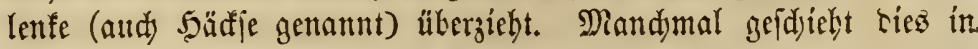
eriftaunlich furger Beit. Diefe (S) jedwulft serunftaltet fas SIfero un= ter allen IImftänten uno mandje siejer Spatflumpen fino fdon to grof geworben wie ein Mannstopf, in weldem Falle fab Eprung: 
gelenf, ba die Berwegung ber Sebnen uno Mlubfeln volftommen ges Gemmt ift, gänjlid) fteif wirt.

Senn eine fleine Blutaber gevrodyen ift und sas Blut in sent Spatflumpen tritt, fo Geī̄t man ras lletel Blutipat (blood-spavin). Ilno bierin beftebt ber einjige llnteridied jwijden biefem Hebel uno tem Sdy[enfpat, ter audy einfady Spat, ocer aud weidyer, feuditer Spat genannt wirb.

Ddjenjpat uno Blutipat bringen nidjt immer Răbmung hersor, uno cicfe tritt gewölndid) nur ein, went bas Pyero febr angeftrengt wirt, jeigt fid jerod bei unbereutenten $\mathfrak{A}$ idjwellungen nur jelten.

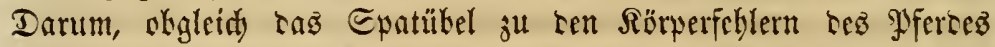
geredtnet werben mus, fant eit ramit behaftetes I I ier für gemöbn= lidje $\mathfrak{2}$ rbeit nod lange gute Dienfte leiften; 今. 23. vor bem Plflug,

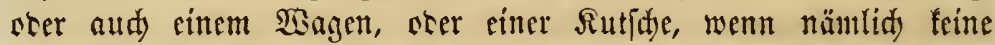
idnelle Bewegung erforterlid) ift; hiełu aber ift ein fpatiges Soro nidyt tauglid. Mąąige Berwegung wiro die Sirantbeit nid)t wejent= (id) seridslimmern uno aud) nidyt verurfadsen, rap Der Epatflumpen um Bebeutentez anidwillt, fowie riejelbe aud bie Räbmung nidjt auf bie Dauer vermebrt.

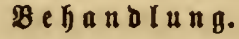

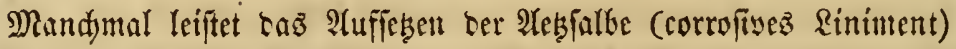
auf bie betreffenten Thcile ausgejeidnete Dienjte, intem bierturts

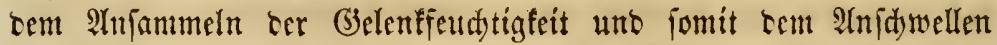
Finbalt getban wirt. Sm erften Stabium ber Sranflyeit ift ter Spat= flumen febr flein uno mag burdj siefes Dittel ganj utto gar aufgetrod"= net werten; jecenfalle ift es cer Mäbe werth, eitten Berfud ju ma= den. Man barf jetod feiner Behantungsmeife unberingt vertrauten,

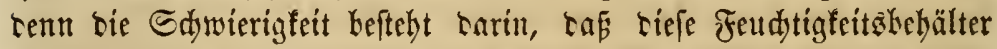

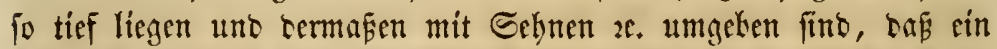
äuferlich angemantes Seilmittel faum bireft auf fie wirten fann. Da cie Rranfleit cas Pfero nidt ganz unbraudbar madt, aud fei= nen (B) tor intelligente Eigentbümer entid)eten, ob eine Rur unternommen werben foll ober nidat.

Die alte lädjerlidye Methoce, oen Spatflumpen anjuzapfen (tapping), woburd cine unbeilkare Sisune entftant, aus weldyer beftän= 


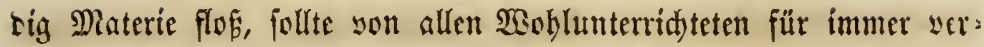
micben werten. Wentigften boffen wir, ton feiner unjerer Refer it

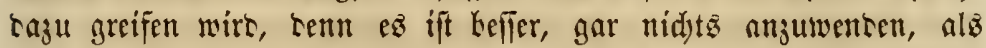

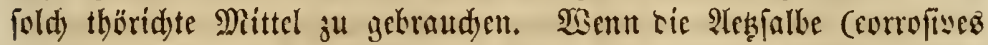
Riniment) feine Rur bervirft, fo werten alle anderen Mittel vergeb= lid) angerwentet werben.

\section{$\mathscr{F} \mathfrak{l} u \mathfrak{B} \& \mathfrak{a} \mathfrak{l} \mathfrak{l} \in \mathfrak{n}$ (wind-galls).}

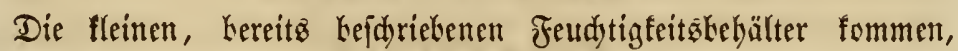
shgleidid fie am Eprunggelenf, tem 2fenfel uno sem Sinic am jahl=

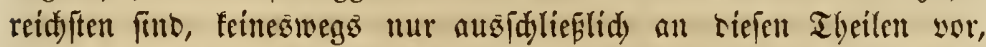

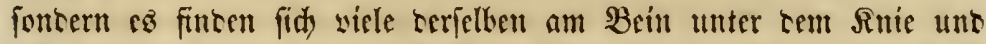
Eprunggelenf uno an sen 2 tenfeln. Die 2 tnjdwellungen, bie surd ric Bejdärigung uno Sefjnung' siejer an riejen Theilen liegenten

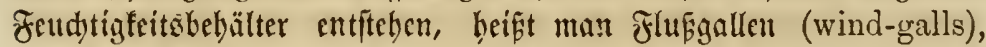
meil rie Suffddmicte glaubten, biefe Gefdunulfte feien mit Euft gefüllt.

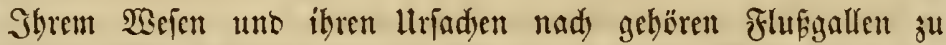

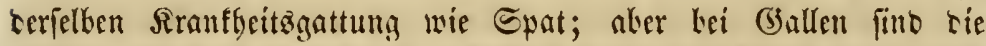
bejdärigten Feudjtigfeitābebälter nidjt fo zahlreidy nlä beim ভpat, uno

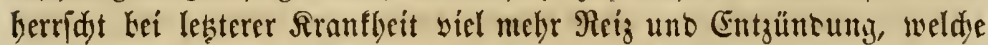

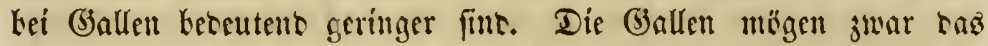
PJero cinigermafen serunftalten, aud) zeugen fie won barten Stra= pazen uno fajledter Befbantlung; gefäbrlidy aber werben biejelben nie unb bas mit biejem llebel bebaftete \$fero ift für ben praftifacen

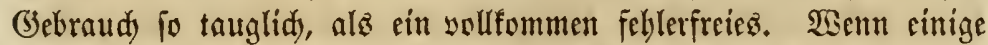
Gallen nabe bei einanter entfteben, fo wiro biersurt) sie Biegjam= feit ber Gelente becinträdtigt; aber felbit in biejem foalle ift taz

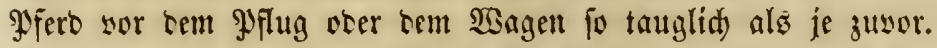

Bie bereitz bemerft, entffthen Gallen entweser surd cine Suet=

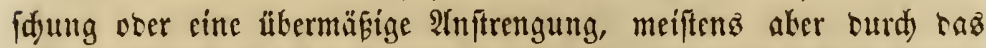

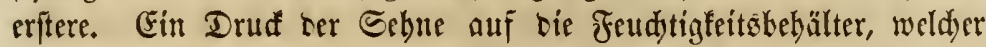
riejelbe zerreist, fann nur burd) rine nufergewoblanlidje 2 Inftrengung

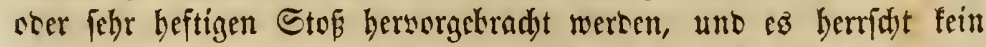

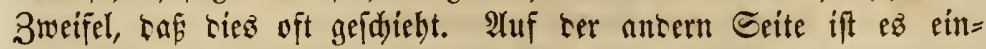

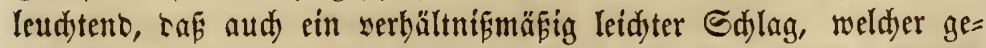
rate ben auf einem Sinodjen ofer auf ciner ftarfen Eehne ruhenten 
Jeudtigfeitabehälter trifft, Ulnhyeil anridyten fann. Gin ten langen

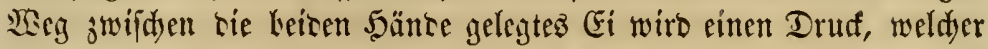

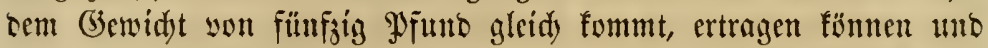
anterfeitz fann man surd) cinen leidjten Edylag tefien Edyale zer=

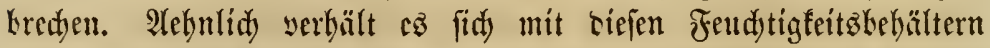

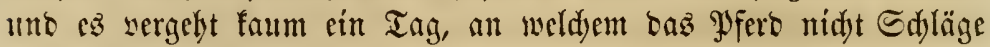

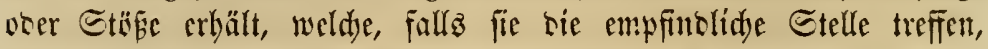
nidjt Bejdübigungen er

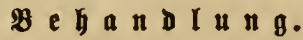

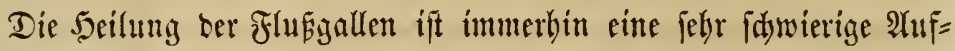
gabe uno vft mersen tie bejten uns mit grofer Eorgfalt angewanten

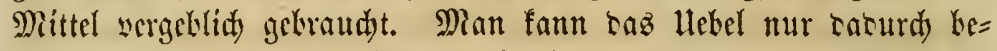

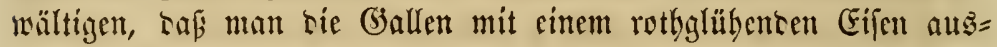
brennt. Sicsurd) wiro nid)t nur sie angejammelte Flüffiigfeit auf= getrodinet, fontern ser Grunt ber Sranflyeit wirb aud) geboben, intem

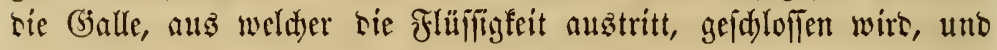
fo wiro sfters eine sollitänoige Rur bewirft.

Iic alten Ihierärate haben immer biefe Mietthobe befolgt, fie ift jecody mit grofer (3efabr yerkunten. Durd) bas Bremnen entjebt

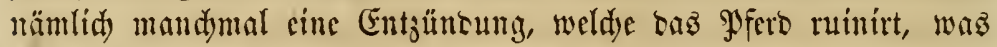

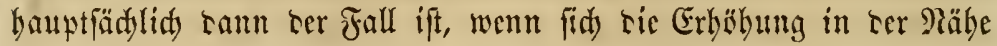

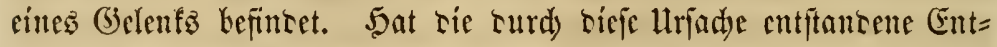
zünsung cinmal bereutent um fid gegriffen, fo wiro eine unlyeilbare Giterthenle erjengt, uno Befétigung ricfez Eiters, fowie zur Wieterberftellung sez yertor= benen Bellengemelez, woburd) ricfes ldebel gefennzeidnet wirt, ent=

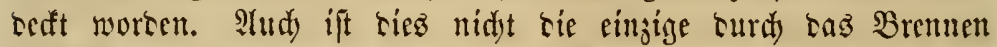

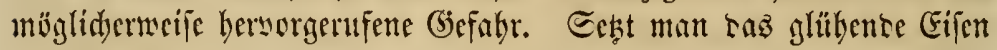
auf cinen unbe beim (belenf fid) befintenten Gallenfnoten auf, io wiro tie beinabe immer eintretente Entzüntung fo heftig, baß โaz Gelenf fo fteif wirt, เฉa tauglid) ift. Sisir fömen bieje Methlore nidjt empfeblen; fie ift auferortentlid) graufan, unto man läuft bakci (Gefahr, sie Braud)= karfeit bes \$fertes auf immer zu ruiniren.

Miandye unwifiente \&eute baben tie Flügallen (wind-galls) an=

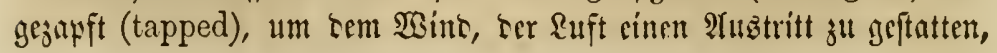


unt fanten zu ifrem Erftaunen, baß biefe Euft in ciner gelfliden, etraz ridften flitifigfeit beftant, tie aus ber gemadten Deffnung beraus= lief; unt was rieje Reute nod) mehr in Etaunen fethte, war sie Thatfade, baj fie eine Deffnung gemadit hatten, tie fie trob allen angewanten Ditteln nidyt mebr fadlieseen fonnten. Itno biemtit entigte tas llnbeil nod) lange nidjt. (E⿸z brad eine Entzüntung

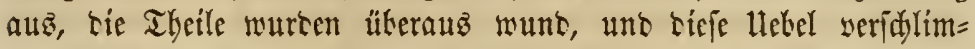

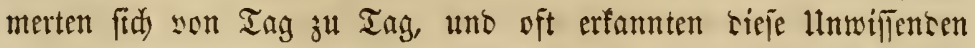

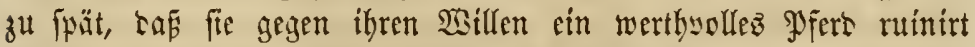

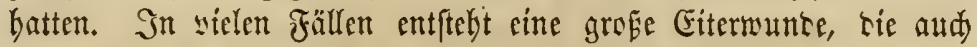

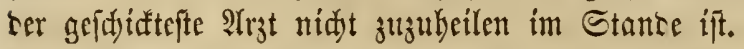

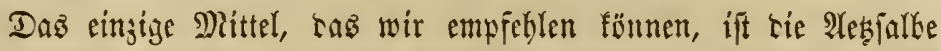
(corrosive liniment), weld)e man etwa vier veer fünf Iage lang jecen Tag auffest unt bann tamit chen fo lang aușest, um fie jetesmal nad) yier orer fünf Tagen in serfelben siseife witeser po lange zu gebrauden, als es nothwenrig ift. Ias Riniment follte

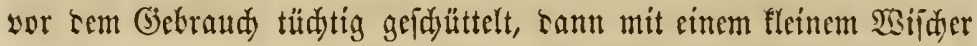
aufgejetst uns mittelft eines glüfenten Eijeng cingetrofinet wersent.

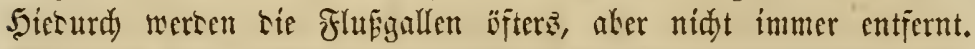

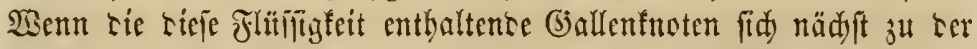
Defbaut Kefinten, fo fann eine Sur ohne grop̧e Edywerigfeiten ju Etante gebradjt wersen. Einto riejelfen jerod unter tem Bellen= geweke, weiter son ser Iefthaut entfernt, wie ties meiftenz ser Fall ift, fo belfen äuferlid angemants Mittel wemig.

Bei \$Sintrgallen eine Sur vorzunebmen, Entgüntung unt \&ähmung zum tetelel gejellt, lohnt fid faum ter

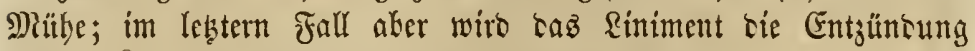
beken und follte seskfalb fogleidi gebraudit werten.

\section{gafenhate (curb).}

Tiez ift ter Rame einer längliden (Geid)mulft, tie oft am bintern Theil tes Baintez, nahe unter tem Eprunggelenf, sorfommt. Tic=

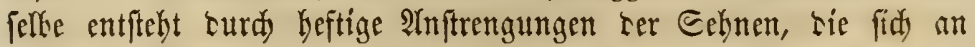

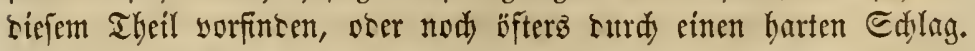

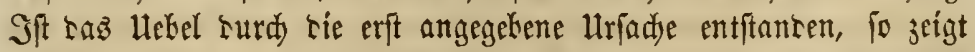

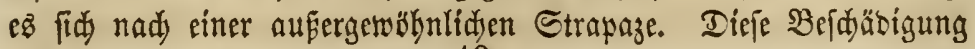




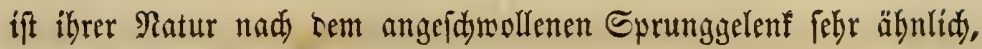
worüber im britten $\mathfrak{R} a p i t e l$ abgebandelt wurbe.

\section{$\mathfrak{B} \mathfrak{e} \mathfrak{h} \mathfrak{a} \mathfrak{n} \mathfrak{d} \mathfrak{l} \mathfrak{u} \mathfrak{n} \mathfrak{g}$.}

Bei ter Bebandlung wirb tie $\mathfrak{A}$ etjalke (corrosive liniment) nad)= haltig angewant, forwie ez bei geidyollenem Eprunggelent vorge= idfrieken ift. Daz Pfero wiro surd biejes Hebel fehr labm wersen

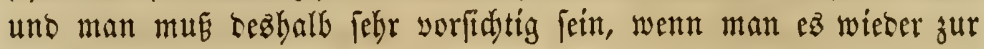
2Trkeit gebraudft.

\section{Piphaten, aud Steißghafen (thorough-pin).}

Diez if eine antere (B)efdymulit, weldye auf ter inmern Seite ter 5ade, Eprungbein - aud) mandjmal Ferfenbein genannt (fiebe Bitlo Seite 24, 3iffer 39) sorfommt unto fid yon siner Seite surdy bie

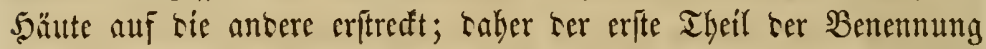
thorough-pin; weghalf man biefem Hebel ten Ramen "Pin"

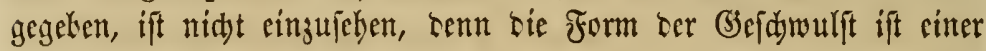
Strannatel butdauz nidyt gleidy.

\section{:}

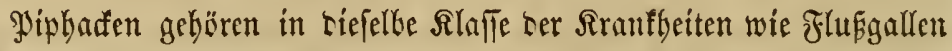
uno Epat, uno man mur baher bie gleidje Behantlung in $\mathfrak{A}$ mwent= suntg bringen. .

\section{Maulflemme, aud Maulfperre, Etartframpf (tetanus or lock-jaw).}

Der Rünftler hat hier ein son biefer Rranfbeit befalfenez Thier mit grofer Treue uno (Jienauigfeit Largejtellt, unto unjere Rejer wer=

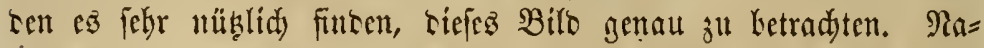
mentlid follte man bie $\mathfrak{T}$ hufmerffamfeit auf bie Etraffbeit ber Mitsfeln,

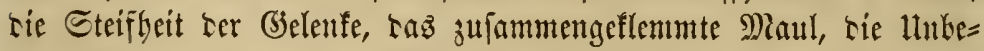

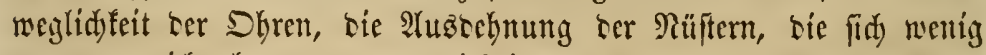

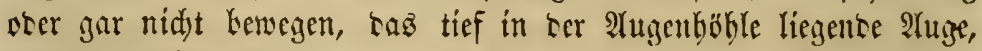

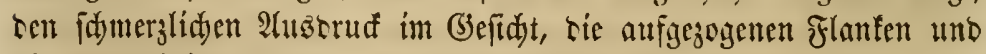
tie jpertbeinige Etellung ber (s)licomap̃en, ridyten.

Der Starrframpf ift eine ser idjecflidjiten Pferbefrantbeiten, und

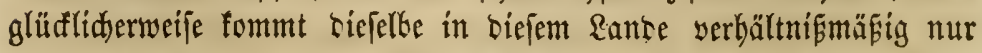
felten vor, was aus ser Thatjadje hersorgeht, baf Taufente, sie 


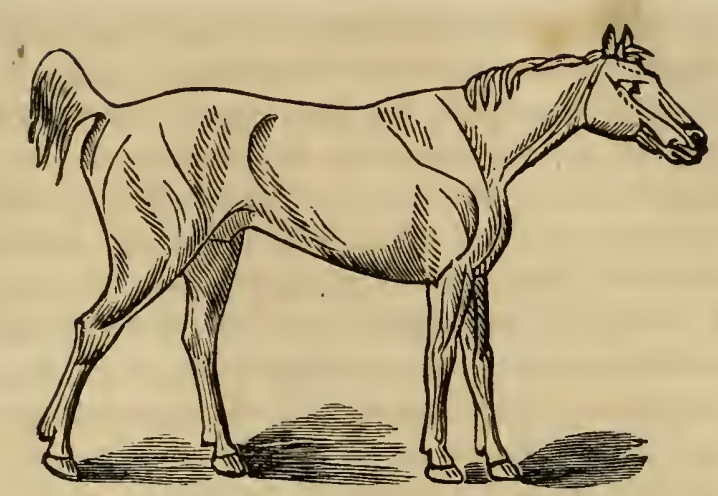

Gin Bferd, wold)es mit ataulklemme bebaftet ift.

beftäntig mit Pferen umgeben, in ibrem ganjen Retten nod) fein einzigez geieken baben, weldyes die Maulfperre batte. Sn einigen \&äncern Europa'z war bicje Rranfleit bagegen zu Zeiten jebr bäufig

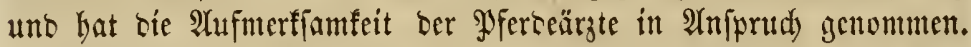

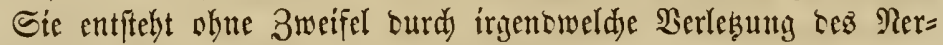

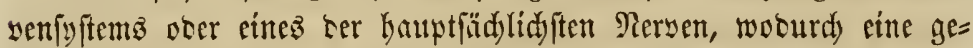

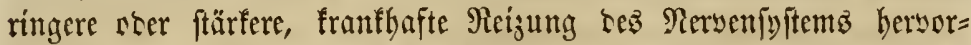
gerufen uno entlid) (d)redtidje Srämpfe aller Rïrpermusfeln erzengt

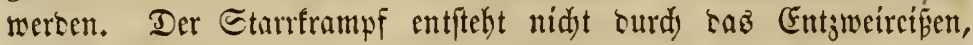

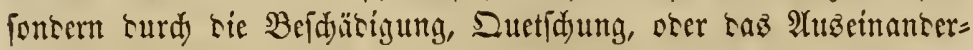

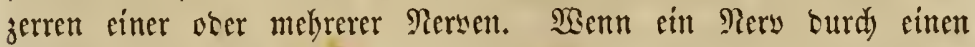

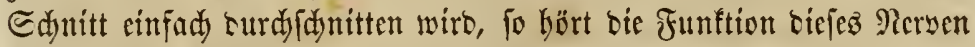
fogletid aus uno nad) uno nad) beilen bie getrennten Theile wiecer zufammen. Dies ift bei alfen Sdynittrunoen ber Fall, ohne baj

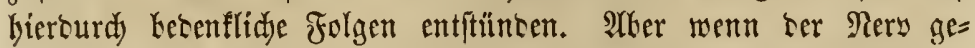
quetidt ooer auseinanbergejert wire, fo vermebrt fidy beffen Ifätig= feit, berfelke wiro gereigt uno entjüntet, uno fallz tann Fieber im

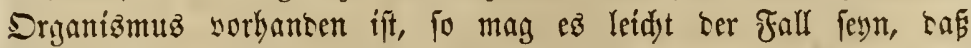
Startframpf entftebt, welder mit bem Tobe entiget. Ienn Eayon,

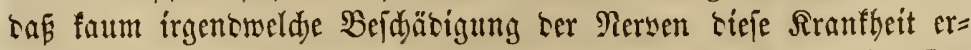
zeugt, wenn ber 3 uftand Lez SPfertez nidyt ein franflafter ift, fino wir voullig überzeugt.

Biebt fid jebod cin Pferb Lurd ingentwelde Utradien eine Er= 


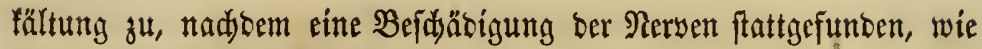
oben befdrieben, fo fann febr leidst Starrframpf entifeben. "Natürlid' wiro unter allen Umftänben ber Berwundung einez ఇerven melyr ober weniger Entzünoung folgen; ift aber nur bies unt fein anteres binzugetretenes $\mathfrak{H} \mathfrak{c}$ el $\mathfrak{z}$ bemältigen, fo wersen bie Naturfräfte Gierju youllig aubreidyen, unb bas Uebel ift in furzer Beit geboben. (Se= ftattet bagegen ein binzutretender franflyafter 3uftano bes Drganismus,

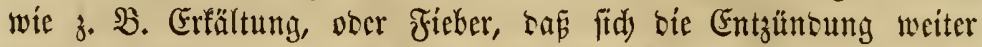
yerbreitet uno zunimmt, fo oríngt biejelbe idjnell mittelft bes Merven= 19ftems fum grof́cn Senforím bes Drganismus, bem (5)birn. Don

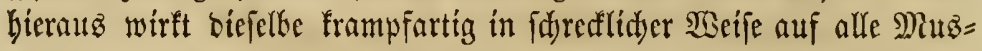
feln uno Sefnen, wobei bie Spannung berielten in jebem Ibeil tes

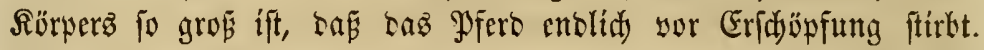
Währeno bez Berlaufz der Sranflyeit werben nicht nur bie Muşfeln und Sefnen immer mehr zujammengejogen, fonbern bie Şaut wiro

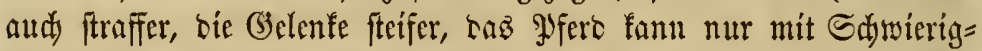
feit atlymen uno fann fid faum berwegen, biz rer bentitleibenswerthe Patient ju Booen ftürst, um nicht wieber aufäteben.

Infänglid) fino bie Rentzeidyen bes Starrframpfo nidjt leidyt ke= merfbar, benn fönte man biefelben fogleidy erfennen, fo würen bie geeigneten, red)tzeitig angewandten Mittel felten verfeblen, cinen guten

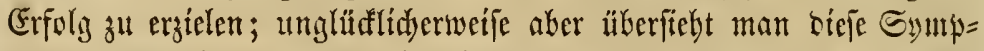

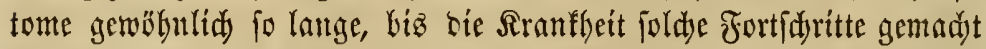
bat, Dafi bie Scilmittel entweber gar nidyt mebr angewand wertent fönnen, ober biejelben ganz uno gar wirfungs̆loz fino. Die Rrant= beit zeigt fidh zuerft in ben Riefern und verbreitet fith yon bier in

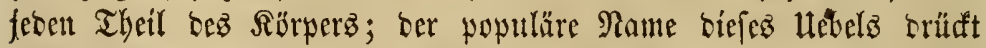

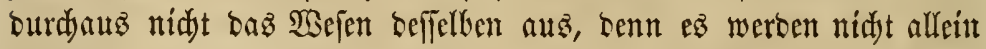

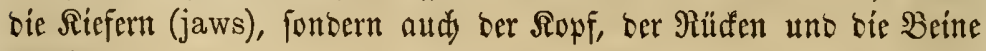
afficirt.

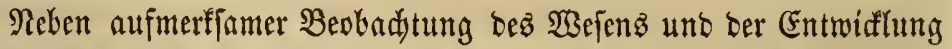
Diefer Rranffeit, haben wir audy bie Grgebniffe ber Grfabrung an= Derer, namentlid folder, meldye fid einen beredytigten Ruf in Furopa ermarben, wo biejes Hebel die Thierärste in viel gröperem Maf́e in

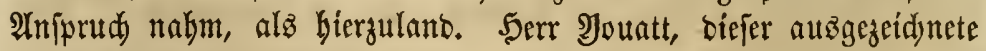
yeterinärifdye Sdjriftiteller, fagt:

„Der Starrframpf rübrt offenbar yon einer franflaften Störung 
Des Rervenjyftemz ber. EEs wurbe cine fleine Fajer ober Rery be=

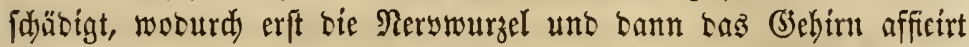
wiro, uno entlid allgemeine franflyafte Thätigfeit erfolgt. Bei Starr= frampf werben nidjt Gloz bieje ober jene Musfelpartíct, fontern aud) beren Gegenmusteln yom Srampf Kefallen. ** * Ctarrframpf ift gerröhntidy tie Folge einer Mersentepdäsigung, moburd, intem fid,

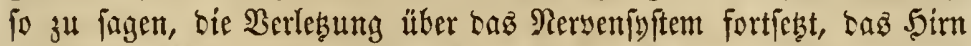

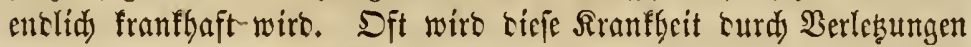

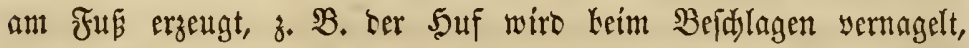

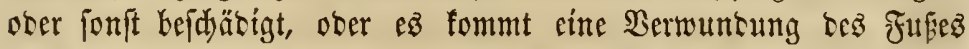

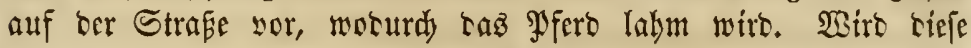
Beidäbigung nun entweber gleidgültig bebantelt, ocer ganz unbe= adjtet gelafien, fo mag es fein, bas tie Rähmung nady unt nady

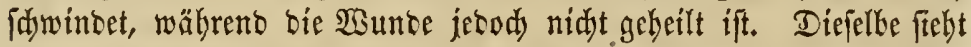

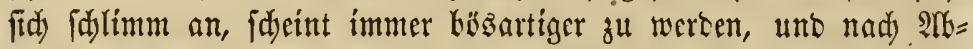
lauf you etra adjt ocer zelh $\mathfrak{T}$ agen trít Starrframpf ein. Gine Rervenfafer wurbe gereizt uno bejdäbigt, fo. gering aud tie bieju yeranlaffente Uradje fein mag."

5iersulant entigt ter Starrframpf meiftens mit bem Iote unt zwar weil baz erfranfte Thier gewöbnlid fo lange yernadjläfitigt

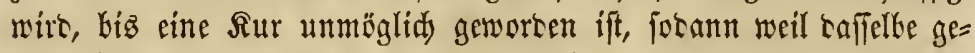
wöbnlidy burd Sounger umfommt. Eelten mur kegreift ber Eigen= thümer, baf ein joldjer Syatient ebenfo wohl Futter bebarf, uno eż vielfeidyt nod nötbiger hat, als in gefuntem 3uftant. Siranflyeit

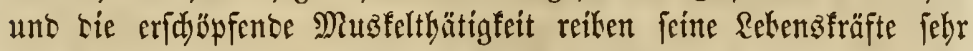

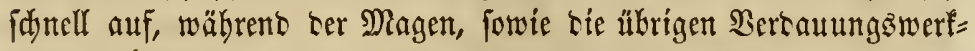

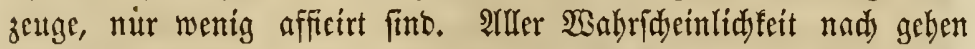
febr siele \$yferte surd) Starrframpf zu Grunte, tie mäglidjerweife

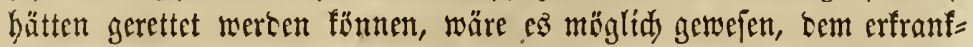
ten Thiere irgent weldes nahrbafte Futter beizubringen. Fin som

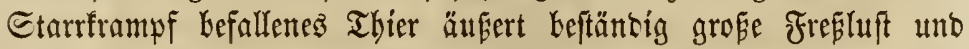
jollte wenigftenz alle zwei biz brei Stunben gefüttert werben. Diez mag geid)ehen, intom man bem

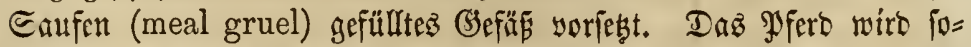

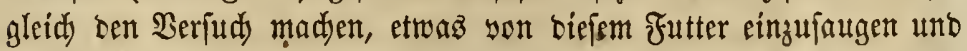

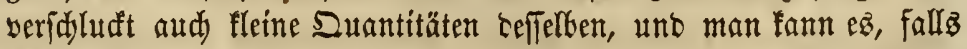

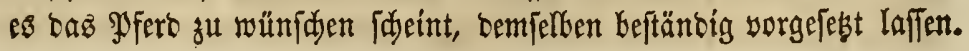




\section{$\mathfrak{B}$ с $\mathfrak{b} \mathfrak{a}$ ๖}

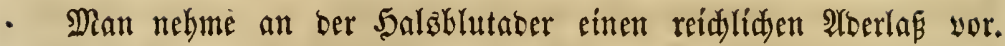

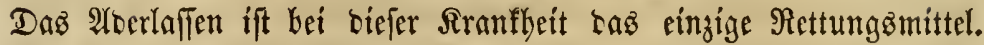
Die Blutgefäfe uno Rersen fino über ben ganzen Rörper verbreitet, liegen überall nahe beifammen uno üben eine $\mathfrak{s e d j p e l m i r f u n g ~ a u f ~}$

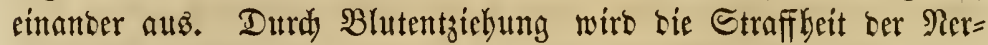
ven uno fomit aud bie ber Mugfeln, weldje von benfelben burdyso= gen werben, sermintert.

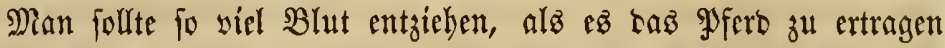
im Stante ift; benn eine Sur wiro nidyt möglid fein, $\mathfrak{e B z}$ fei benn, bieje wejentlidye Manregel ber Behandlung werbe ausgefü̈brt. In ben meiften Fällen wiro ez ratbjam fein, fo viel B̧lut abzuzieben,

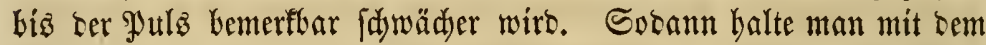

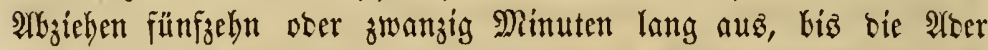
wieber volf ift, uno laffe bann zum zweiten Mial bas Blut fo lang

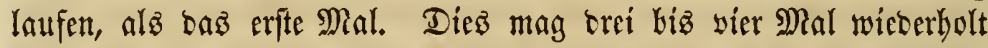
werben, worauf bie Spannung in ben Riefern unt Measfeln nad)=

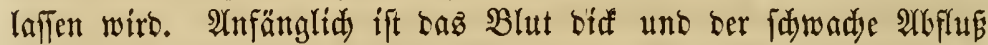

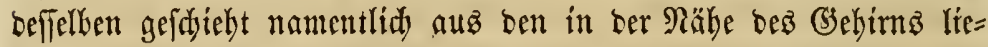

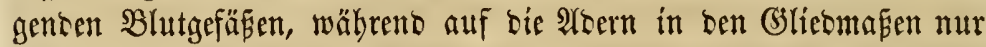
wenig eingetwirft wirb. Daburd jebods, baf man bem Entziéten

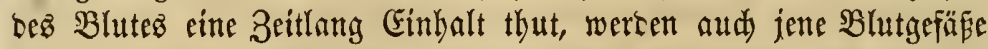
angereigt, uto fdjon beşwegen, aber aud barum, weil burd) ben un=

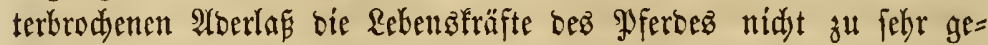
färädyt wersen, ift biefe Methode empfehlengiwerth. Foährt man aber mit bem Blutabzug obne lunterbred)ung fo lange fort, biż bas

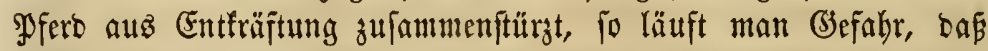

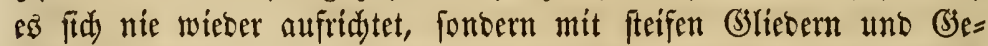
lenfen liegen bleibt, bis ber $\mathfrak{I}_{0 b}$ eintritt. Die hier anempfoblene Itberlapmethooe entfpridjt bem 3wed - bie Spamnung unb Straff= beit im Drganisెmus zu vermintern - vollfommen, währent bie Funftionen ber Rebenzorgane baburd) nídjt geftistr werben.

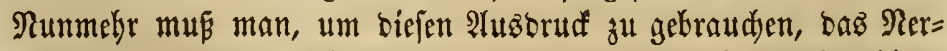

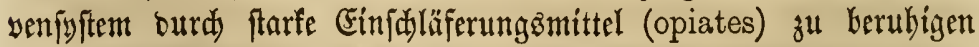
uno Durd) Arfü̈brunggentittel eine fernere Berminderung ber Span= nung $z^{u}$ Stanbe zu bringen fudjen. Ein Kalbez Bill Sautanum ift in

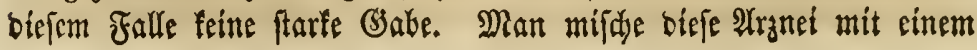


halben Mfunt in einter Sinte marmen $\mathfrak{s a f j e r ~ a u f g e l o ̈ f t e n ~ S a l z e n . ~}$ Dicie Mebizin wiro bem gyferbe mit einem an beiben Enden offe= nen 5orn eingegeben, Leffen dümteres Ente man sem Patienten

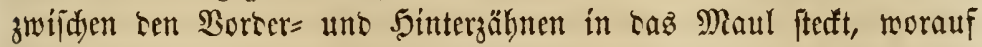
man baz \$räparat langlam einfdüttct. Rad Berlauf yon fed)z Stunten gebe man bie 5 älfte ser Gabe, Sals in terrelben SBeife.

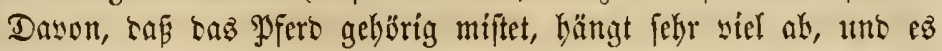

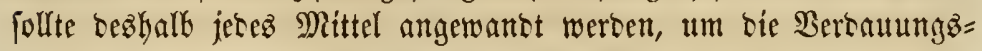
crgane zur Thätigfeit zu bringen. Man brítge tem Yatienten alle fünf biz jeds Stunten cin Rlyfticr yon cinem Dutart Maismehl= waffer (meal gruel) bei, waza ihm zu gleider Zeit io viel $\mathfrak{R a h}=$

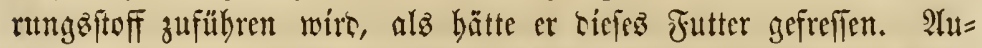

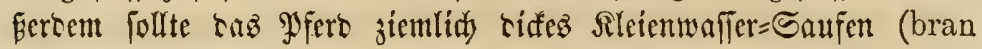
mash) ober büntrz Maímeblivajfer = Eaufen (meal gruel), wie when angegeten, vorgeicht halen.

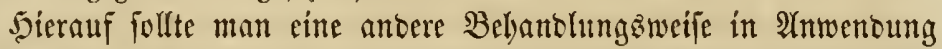
bringen. Man fodte ein Wed baffer woer grobe Sileie in einer (baal= lone $\mathfrak{S a j f e r , ~ i n ~ w e l d e s ~ c i n e ~ P i n t e ~ R o m p l e r g e i f t ~ ( s p i r i t s ~ o f ~ c a m p h o r ) ~}$ uno cine (sill Tabaffaft (tobacco juice) gentijitt wurbe, intem man ben Safer ober bie Rleíe in einen Ead icjüttet unt senferfen auf

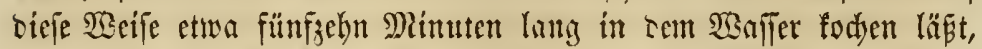

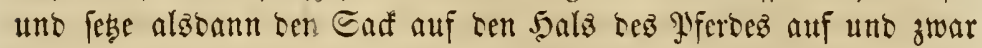
40 heî́ alz Bintfaten, fo gut als möylid, bas baz Thier bemfelben nidyt $a \mathfrak{b}=$

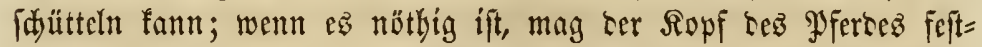
gebunten werben. Zu gleidjer 3eit beteffe man ez mit einer war= men, grof́en Deffe ober Duift unt befeftige biefelle. Sierourd wiro gewöbnlid reidjlider Sdywei er ereugt, waz fehr midjtig ift. Man ermetere ben $\mathfrak{H}$ midjlag (poultice) zwei Tage lang alle fedjz Stunben uno halte baz Pyfero mit einer Deffe ober Duilt gut besedt.

Şenn bieje $\mathfrak{A}$ nweijungen genau befolgt merben, fo mag baz Pfero

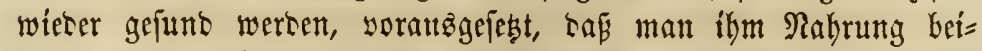
bringt, ober beibringen fant. Die Sur fant leidst bewerffeteligt werben, went man gleid anfänglidy, ehe bie Rranthett bebeutente Fortidyritte gemadjt hat, bie geeigneten beilmittel anwentet.

Wir wollen nody ein anberes Mittel gegen ben Starrframpj an= geben, obrobl wir nidjt für ben Erfolg bürgen tönnen, ba wir nod 
nie eine (3)legenkeit batten, baflelbe zu prüfen. Man nimmt bie Sdabe (scab) yon den Sorderbeinen bez Pferbes und pulberifirt riejelbe febr fein mittelft einer (5robjeile uno bringt sann je eimen Theelöffel yoll biefer pulverifirten Subjtang in jebez Shr bes SPferecs unb blaje etwaz son terjelben in jeine Raje. Dies, fo fagt man,

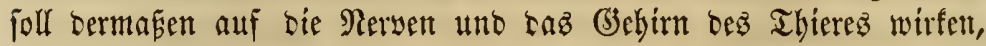

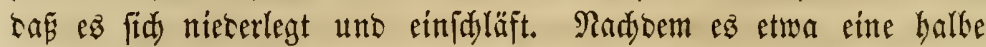
Stunte gelegen, jteht $\mathfrak{c}$ wieber auf uno ift allem $\mathfrak{Y}$ widein nad) ge= funo; bie Straffbeit ber Mušfeln bat nadjglaffen uno bas Thier zeigt

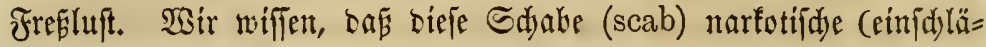
fernte, betäubente, engl.: narcotic) Subjtanjen entbält, uno ta รaร Mittel yon einer ber beften Autoritäten im Silsen empfoblen wirb, To ift es ber Mülye werth, einen Beriud bamit zu madyen.

\section{Ein mertmüroiger fơll.}

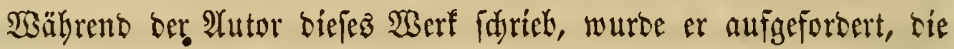
merfwürsigfte Starrframpffranfleit ju behandelti, die er je bei einem Peroe zu beobadten (Selegenbeit hatte, und zwar in Petersburg,

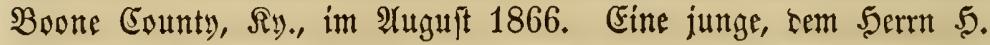
Mexithy gehörente Stute, weldje nodj nidjt youfommen gemöbnt uno brefint war, wure währent eines febr beifen Tages einem Fubr= mann fur Dreflur übergeben. Sie mar febr fett und früber nur felten zur Arbeit vermant worsen. Bon fleinem Rörperbau, wälyx rent bas mit ify angejpannte Pferb grof uno ftarf war, erwies fid rie $\mathfrak{A}$ rbeit- Wegfabren umberliegenter Baumftämme - albz viel zu (d)wer für dieje. Stute.

Fines Tages wurben mir eilig abgerufen, um fte zu bebanteln, benn fie batte ben Startfampf. Shr 3uttano war in ber That

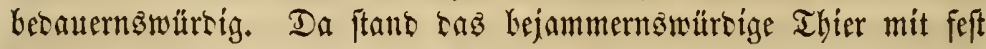
zufammengefniffenen Riefern, ftraffen, geipannten Musfeln und fo

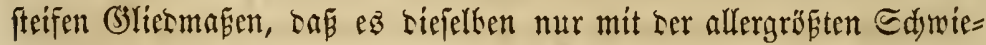
rigfeit bewegen fonnte. Die bie Rranflyeit erseugente Urjadye in rie fem Fall ift febr felten uno geiduebt terifelben in feinem Pfercearjnei= butye Erwäbnung. Wir werben cie Bebantlungsweife, fowie Ien Berlauf oer Sranfbeit eingebeno bejdreiben, weil es vielleidst nüblid

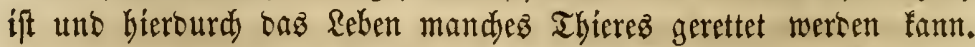

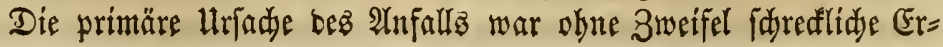




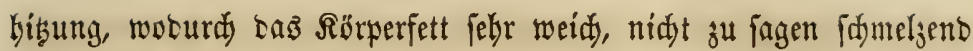
wurte uno fid feft auf Sen Rerven uno Blutgefǟ́fen gelagert batte, waร sie Rersentbätigfeit aufbob unt sen Blutumlauf Gemmte. Jeser Rers war gefpant uno jese Mubfel uno Eebne fo zujammengezogen, als bies möglid ift. Die Riefern waren nid)t allein feft une tutles

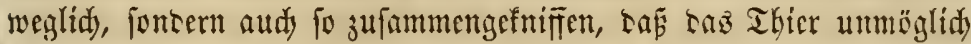

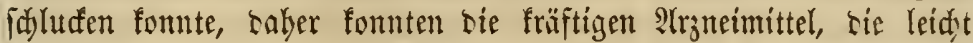
iu baben waren, nidt in sfnwentung getradyt wersen, tenn man

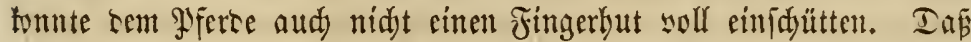
bie Stute fid nur nod furje Beit in aufredter Etcllung balten föne, sies mar augenjofinlid, uno safi, fohals fie cinmal zufam= mengeftürt, nie wieter auffeben weree, fonnte man leidst sorber=

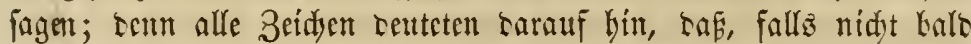

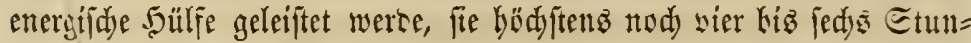
cen lelen tonnte. Der Pulz war bart, aing fürdyterlidy fannell unt

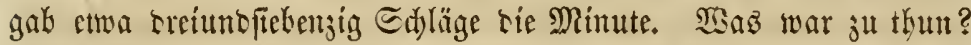

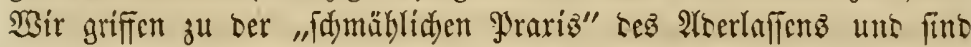

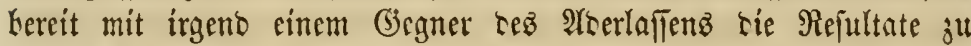
setgleiden.

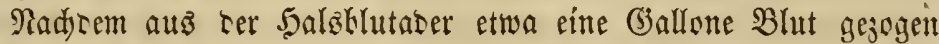
war, fhien Las SPferb fdwach zu werben uno fann beentigten wir sen Blutallauf. Daz Blut war baz ridffte uno fdyärylidyfte, saz wir je fahen - mit $\mathfrak{A}$ usnahme mandyer Fälle yon Big=5ear = Erfran= fungen - uno lief mefrere Minuten febr langjam ab, okwobl rie Deffmung grof genty war. Die burd) sen geringen Blutserluft Gervorgerufene Sdymädye เes Thiers war erftaunlid erflät fid aber

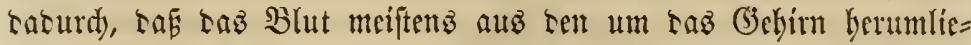
genten (jebilten gejogen wurte, wäbrent sie weiter entfernt gelegenent Blutgefüfe nod) nidut angeregt waren. Siäbreno siejer 3eit mar ter

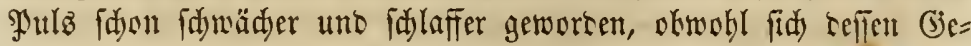
idywintigfeit nody nidst sermintert batte. Mandje ser Ulmberitebenten

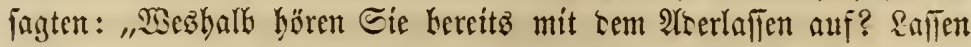

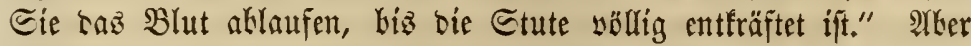
wir wuEten kefler, weldye Metbobe in Anwensung gebradt merben mufte; benn würse sie Stute in tem tamaligen Buftano aub Ent= fräftung zujammengeftürzt feyn, fo wäre fie liegen geblieben, biz ber Tod ifrem Reben ein Enbe gemadyt bätte. Unjer Streben war, bie 


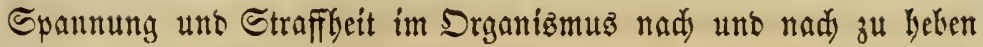

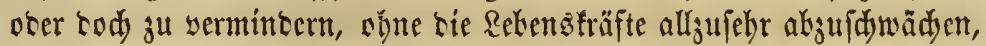

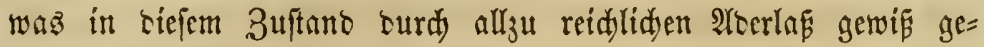
fajechen wäre.

Sn etwa jwanjig Minuten roffte fie fid wieber auf unb ber $\mathfrak{B l u t}=$ umlauf wurbe wieber soller uto ftärfer. Nunmehr murce zum zoweiten Mal ebenjo siel Blut afgezogen alz baz erfte Mal, uno in sicjer

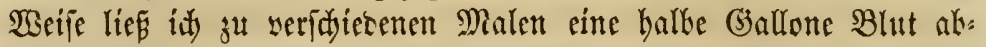

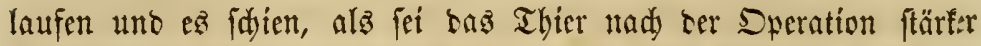

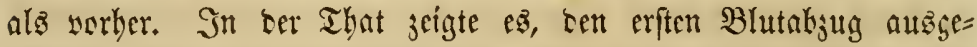
nommen, fpäter feinerlei Edjwäde. Untersefien hatte audi bie Etci=

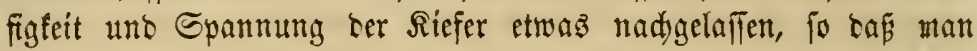
fie etwa cinen 3 ort son einanter entfernen fonnte. Hnd zu all biejem war stwa ein uno eine halbe Stunte erforterlidy.

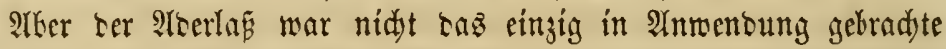
Mittel, fontern währento berellbe sor fid) ging, wurte eine grof́e,

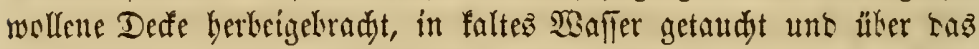

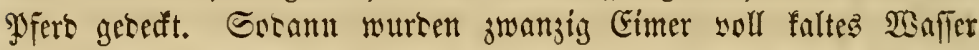

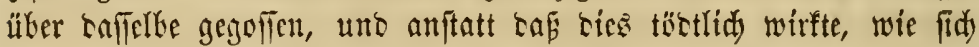
viele yorftellen wercen, erroiez e

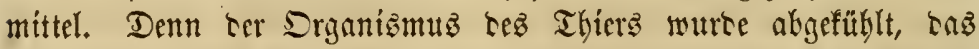
Rörperfett wurbe wécer bart utho jog fith, um biejen 2 tustrut ju getrandaen, jufammen uno fomit erhielten sic Nersen uno Blutgefäpe wieterum ben gebörigen Spielraum jur Thtşülkung ifrer Funftionen.

Rad) brei Etunten waren rie Riefer wieser fo bemeglid, ba bem Thiere möglid) mar, mit 2 (njitrengung 3 ut fhlưfen. Nun wurbe

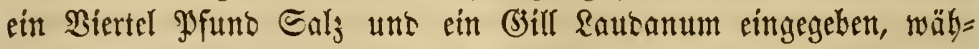

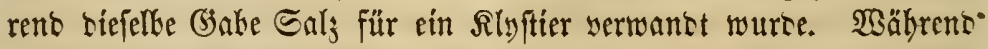

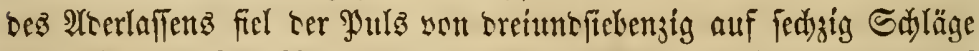
bie Mijnute. Der 2lutor behantelte baş Thier zwei Tage, worauf

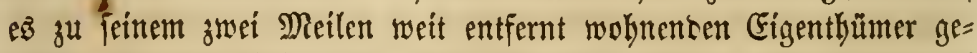
fant unt nad einiger Beit wöltig hergeftellt wurte uno heute-gwei Monate barnad-if

\section{Mu f clträmpfe (cramps).}

(Finige Pferbe finb Rrämpfen unterworfen. Man verfeht barunter

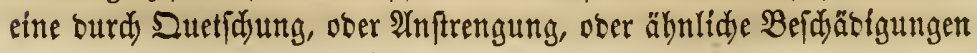




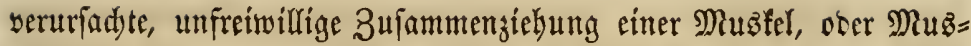
felpartie. Pferce, weldye sen Iag üter ütermäfig angeftrengt rour= ren, febr fdwer jieben musten unt tann in eitten engen Stalfitant geftellt werten, fitto Srampfanfällen in ten Beinen febr leidyt aubs=

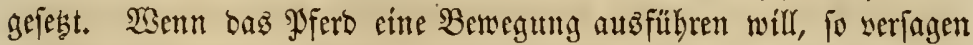

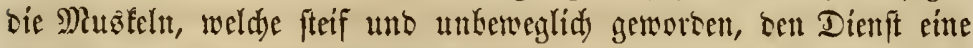
Zeit lang, líz bie Nersentbätigfeit mieser hergeftellt ift, unb if bies gejdeben, fo werten fie ju frampfbafter Ibätigfeit angeregt, woburd

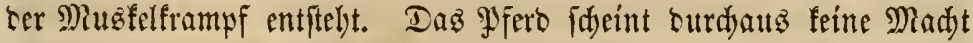

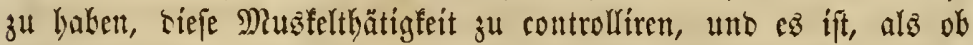
bie Musfelt won irgeno etważ hin= uno hergezerrt würoen. Der Blutumlauf, weldyer surd sen Srampf theílweife gehemmt uno auf= geboken wurce, wit' burch bieje Bemegung fduell wieber bergeftelft, unt fobalo rie betreffenten Theile wieber warm weren, fo läpt bie Epannumg tadh uno sie Musfeln weren wieter fo geidmeisig uno elaptijh wie juwor.

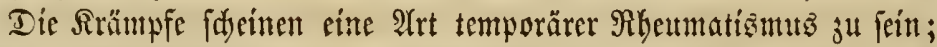

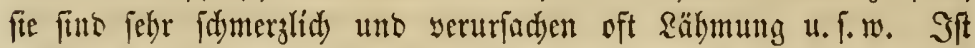
bies ter Fall, fo follte man feite Dühe fdeuen, tie afficirten Theile

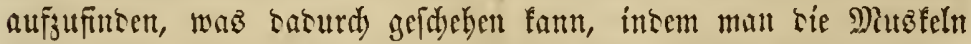
bes Beines mit ser 5ano unterjudyt; Senn fohulo tie betreftende

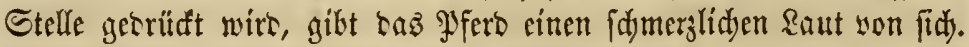

\section{$\mathfrak{B} \in \mathfrak{b}$ a}

Man nebme einen Srorlaß sor uno entziebe brei Suart Blut;

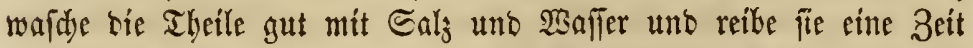
lang mit ser Sano oter einem groket $\mathfrak{I} u d$; ift bie Stelle getrodnet, fo febe matt bas corroftye Riniment auf.

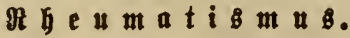

Sekr wenige Perionen ahnen, wie oft has Pferb riefem Reiten unterworfen ift; utto aud bie Thierärs̆te baken biejer Siranfleit im

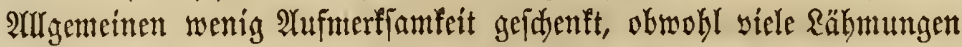
sorfommen, unb zwar. Fehr famerzhafte und becutenbe, bie auf feine anbere llrjadye zurüdgefübrt werben fönnen, alz auf bieje Sranflyeit.

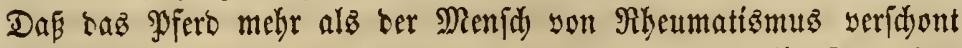

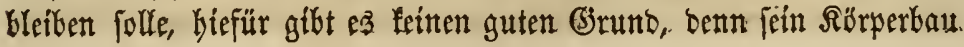




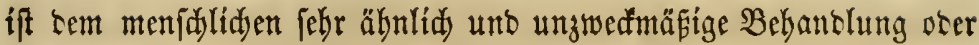
Erfälung wirb biejes ltebl beim Pferbe fowobl alz beim Meniduen erzeugen.

Namentlid fint alte Pferbe biejer Sranfleit unterworfen uno zwar bauptjäd)lid dann, wenn fie mifbraudyt ofer übermäfig angeftrengt wurben; junge SPferbe baben mur felten von rheumatifden Uebeln

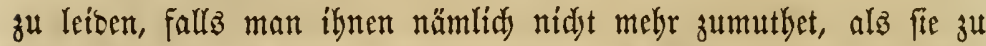
Ieiften und zu ertragen im Stunoe find. Erfältung uno übermäpige

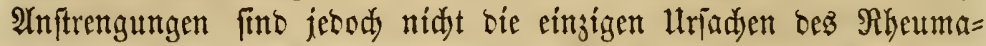
tiвmus. Das magere, aber jonft gefunbe Pfero befommt nur aแs = nakmsiweife tenjelben, wäbreno bas gut gefütterte, yolnblütige uno uno idylidythaarige Pfero oft son rhetmatifden Infüllen leicet. Dis unmittelbare Uriadye biefer Siranfleit ift tie 5emmung res SBlutum=

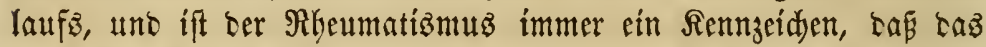

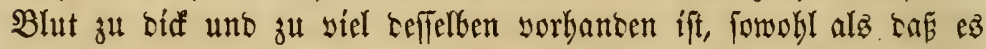
in feinem Umlauf langjam uno unregelmäsig ift, weldyer Zuftuno

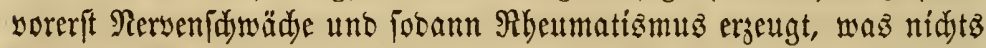

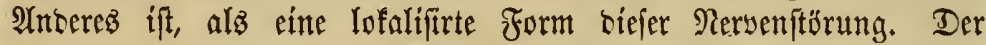
Starrfampf ift eine yerfärlte uno allgemeine Entwidfung beriflen Störung.

Der Rheumatiomuz afficirt bie Sehnen uno Gelenfe uno ez ift

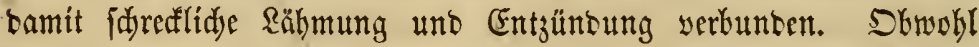
namentlidy sie Süften uno Cdultern rheumatijden 2Ynfällen am meiften autigejest fino, fo werben bod aud mandumal bie (Belenfe uno Bcine yon benfelten kefalfen. Srampf ift nur eine antere (3ie ftalt biejer Rranfleit, nämliò): đdunell yorübergebenter, frampfartiger

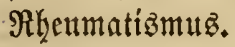

Man Gat barauf zu adyten, bas man ciejes lebel nidjt mit antern Sranfleiten verwedjelt. Das, waz man gewöbnlid Steiffeit (stiff

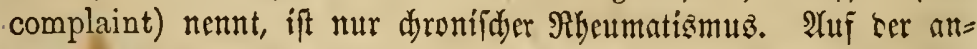
bern Seite fino fdjon viele Fälle als Rolif ofer Rebe (founder) behantelt worben, wäbrent ter Patient an nidjts 2lnberm litt, alsె

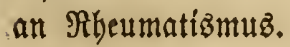

\section{Mer t to}

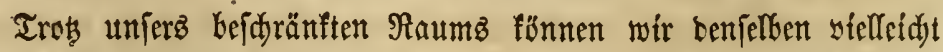
nidyt befler benutzen, als incem wir einige mertwürbige Fălle an= 
fübren, weldye ber $\mathfrak{A}$ utor yor einigen Sabren belbantelt hat. Sie beweifen, wie leidyt fid ber Ridytunterridtete binfidytlid ber unter=

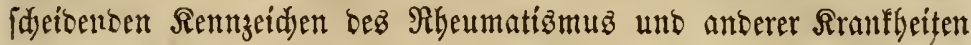
täufden ใann.

Serr Sartifon yon Mittel= Tennefiee bejudjte einft mit feiner Fa milie einige Freunbe in (bibron County in felben Staate. Die Ent= fernung betrug etwa cintuntertunbfünfzíg Meilen uno ber $\mathfrak{B e g}$ wurte mit feinem vor sie Siutidje befpantent Ruttidentperd jurüffgelegt. Dicies soar eine grofé, gut genährte, volfhblütige Etute unt trug alle Merfmale, bafi fie yon ihrem Eigenthümer bie aufmerffamite $\mathfrak{B}_{e}=$ banthung erfuhb. Diefe Reife auzgenommen, war fie niemalz unge= möhnlidy angeftrengt worben, fonbern wurbe gewölgnlid nur zu furzen Epazierfahrten werwentet.

Cintz Morgenz, alz man erft eine furze Strecte yon bem 5aus, wo fid 5acr 5ardifon aufbielt, weggefabren war, wurbe fie plökllid

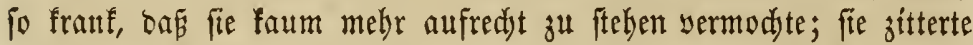
am ganjen Reibe; grof́e Tropfen Sdyweíf ftanten auf ihr unto träu= felten auf bie Croe und in etwa jwanjig Mínuten war fie som

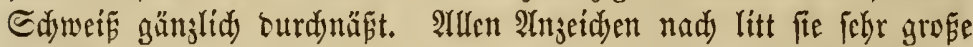

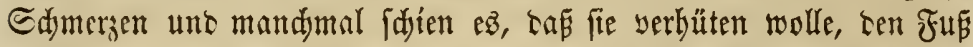

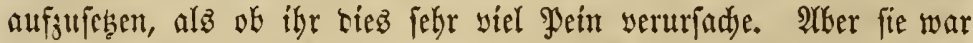
eterifo menig gentigt, fid nieberjulegen. Die 2tnwefenten erflärten,

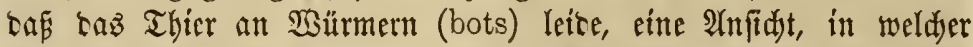

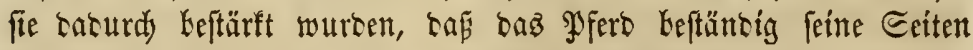
unt Borterkcine befdunuffelte, wo fid ju gleidjer Beit aud) ein eigen=

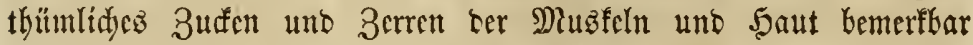

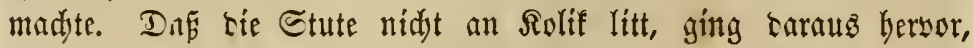
oafi Ler Unterleib nidjt aufgetricben war.

Der 9 tuttor erfannte in ben Symptomen eine ganz antere Rrant= heit. Es wurne an ter Salzblutaber ein 2Yterlas yorgenommen uno

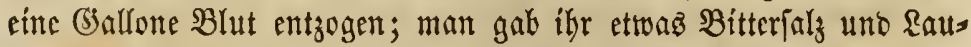
banum, uno in zwef Stunten war Erleidjerung geidaft.

Wenn bie Frage geftellt wirb: Wonaum wiro biejer Fall alz ein

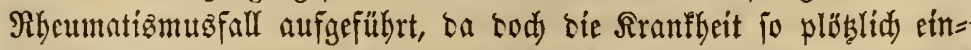

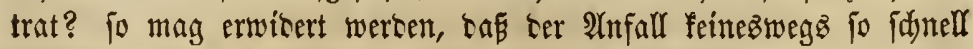
gänglid) gehoken wurbe, benn eż tauerte zwei Monate, biz Laz PFerb wicter fo weit hergeftellt war und man bie, Seimreife mit ihm unter= 
nehmen fontte. Çs war ohne Zweifel ein fehr ftarfer 2 anfall yon frampfbaftem Rheumatismus, Leffen erftaumlidy idntelle Entroides

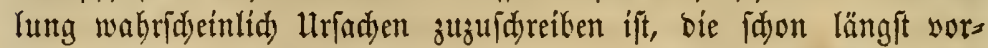
hanten waren. Diejes Beifpiel jeigt, wie furditbar zerftërento eine

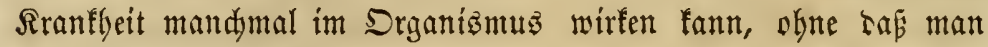
eine. Thnung Layon bat.

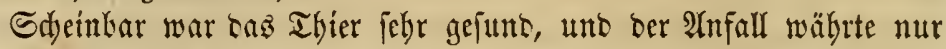
jwei Stunten, che er kerwältigt nar, uno bennod fam bafferbe fo

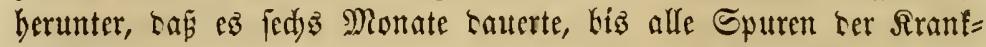
beit verwifht waren. Seine Beine, Sdultern unt Jüfte waren Monate lang fteif unt fehr empfintlid), ttho man tarf woll in Zweifel zieken, ob es je wieser fo gefund wurbe als früher, ster

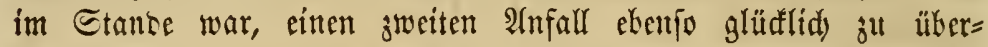
ftehen.

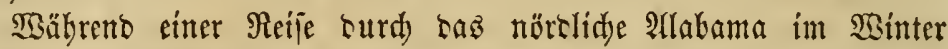
$1858-59$ traf ter 2 tutor cinen antern Fand, welder, whigleid) in

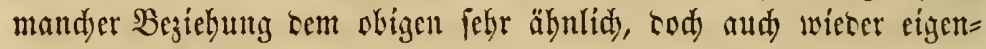
thümlidje Merfmale zeigte, wešbalb eín näberes Eingeben auf sen= felben cbenjowogl nüblid, als interefiant fein wirs.

Wir Iogitten in cinem (Gafthaus, wo gewöhitlíd) siele gyfertebänto=

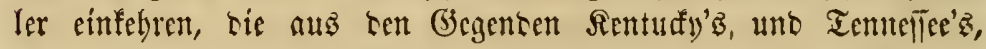
wo fo virle \$ferse uno Maulthiere gezsgen wersen, grofe 5 ecerten berfelfen nad) ten Baumwollenftaaten bringen. Sjier fam untz ber

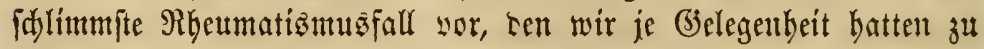

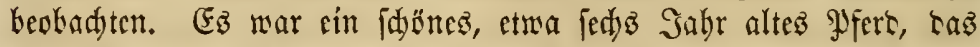
in silliamsaburg County, Ienneffee, getauft morsen war. CEs war

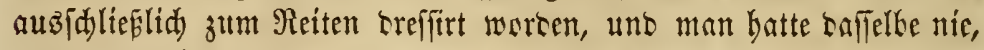

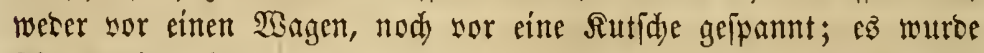
fehr mäfig gebraudjt uno hatte immer eine gute $\mathfrak{B}$ ehandlung erfahy= ren. Sn ten fieken ober adyt vorkergebenten Iagen batte $\mathfrak{e z}$ mit

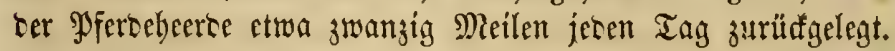

Sisosurd) wurte sem, fo misdte man fragen, Ler llnfalf serur= fadjt? Das \$gfero war jung, fehr fett und biz yor wenigen Etunten

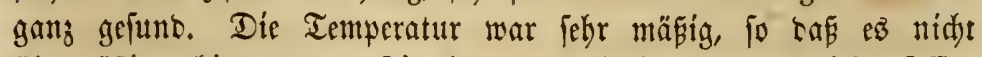
übermäßig erhist worben feín founte, nod) batte

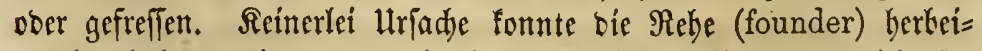
gefübrt baben; wie bent aud) sie Unterjudung zefgte, baf nidjt fo= 


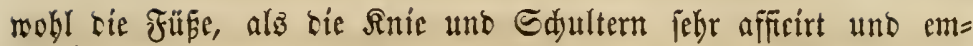

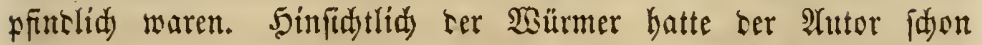
Sabre lang rieje unjalsuligen Rreaturen gegen ten Borwurf ver=

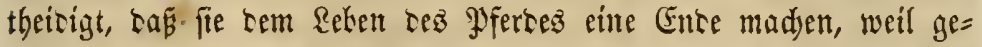
nügente Beweife sout (begentheil vorlagen. F(ud) war es fein Rolifanjall, benn tie Remrseiden, son tenen man hätte auj eine Ctörung ber ઉ̉ecärme hätte fdhlię̧en fännen, fehlten.

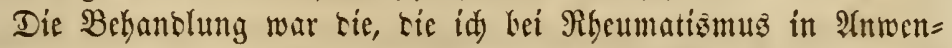
sung bringe; und biefelke war erfolgreid). Ein Atretlap wurbe vor= genommen uno ten übersbllen Blutatern eine Gallone Blut ent

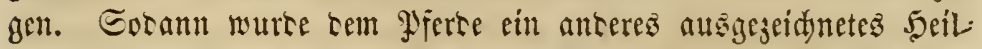

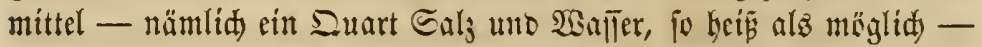
eingeidfüttet, uno ju gleider Beit wurten tic Beine mit cerferlben Mijdung tüdtig gewajden. Edyon nad) einer Etunte war tor Watient beseutento befier und idjen feime Edjmeraen mebr ju baben.

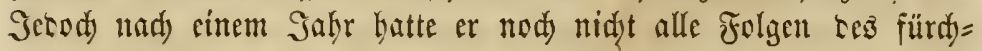
terlid)en $\mathfrak{A} n$ falls üleritantent.

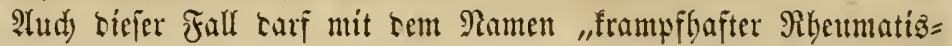

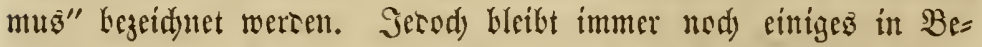

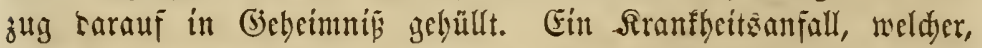
okwohl er nur sier furje Etunten mäbrte, foldje fadlimme Folgen hinterlieह̃, fonnte nidft in einigen Etumsen orer Tagen entfitanten fein. Die wirfenten Urjadjen mürīen idjon Woodjen, ja Donate lang yorber vorbanten gewejen jein, mittlerweile fid) tie Srantheit im

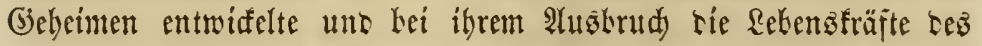

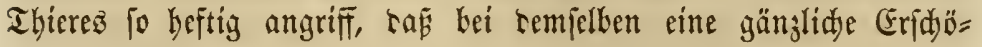
pfung eintrat.

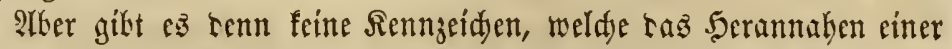

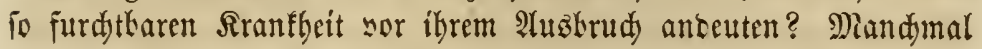

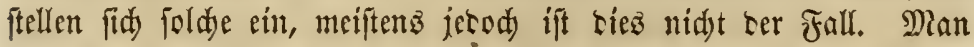

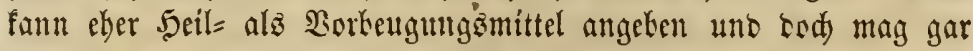

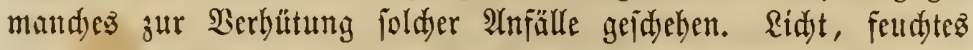
Futter, gute $\mathfrak{B s e i t e , ~ o t e r ~ i ́ r g e n t w e l d e ~ R a r i r m i t t e l ~ w e r b e n ~ f u r ~} \mathfrak{B e r}=$

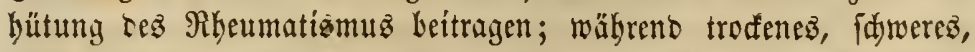

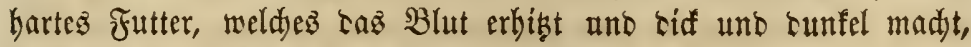
Denjelben berbeiführen voer beförbern wirb. 


\section{B}

Dicfe wurbe bereits in ben angefülyrten Beifpielen autgegeben. Sie

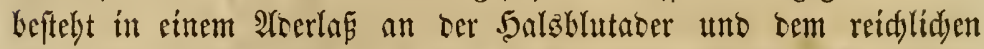
(3)ebraud) bes Galzes uno beifen Wafferş, fowobl interlidy als äน= Ëerlidy, intem die afficirten Theile bamit gewaidyen werben.

\section{$\mathfrak{F} \mathfrak{l} \boldsymbol{u} \mathfrak{i} \mathfrak{r} \ddot{a} \mathfrak{m} \mathfrak{p} \mathfrak{f}$ e (Spasms).}

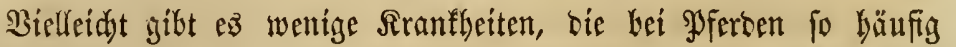

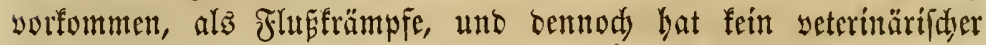
Sibriftitelfer biefelben in Feimen Sranfbeitşbejdyreibungen aufgefübrt;

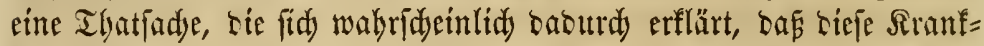
beit, obfdon fie allen benen, bie mit Pferben umgeben, wohl befannt ift, gerwobnlid in Berbintoung mit anoern yorfommt, fo bas man fie nur als eill Syniptom anoerer Hebel betrad)tet. Mandymal $j e=$ Dod) fommen Fluffiämpfe aud gant felbftitüntig vor, ofne alle Symp= tome anterer Sirnflyeiten boer Bejdäbigungen, fo bap ber intelli= gente $\mathfrak{A}$ iğt biefelben unmöglidy irgentweldyer lofalen Störung zufarei= bent fann.

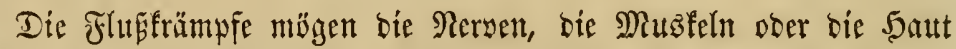
afficiren. Ilno obwohl nur bie zweite $\mathfrak{A}$ rt in bies Sapitel gehört, fo ift cs wobl am bequemften, hier alle orei Âten zugleid zul be=

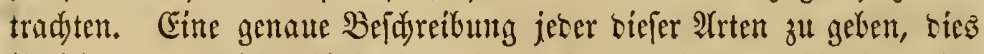

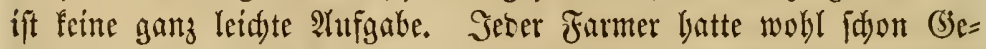

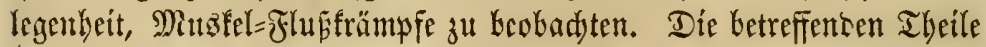

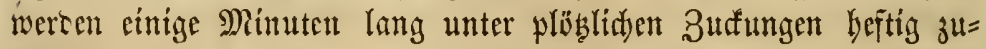
fammengezogen, focann yerziebt fid ber Stampf wieber tmo bas Pfero fiebt fo geiuno aus als je.

Rod) öfters fommen nervöje Rrümpfe vor. Daz Pfero wirb plöb= (id) beftig erregt, jittert am ganzen $\Omega$ örper unb fein Blide ift ein

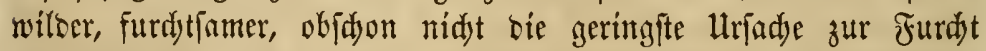
uno Sdjreden worbanben ift. Einige Fugenblide lang bebt ber ganze Rörper yor Errejung, wav jebod fogleid wieber mad)läft, morauf Das Thier wieber to rubig wiro wie frilber. Solde Falle find vf=

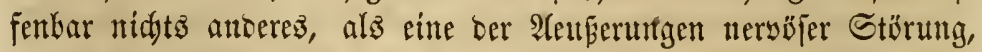
worin all bieje Uurube uno Furdht ifren (3ruto bat.

Sebermann weif, baj nervïje Reute ungemöbntid furdutjam fitto uno fich immer voritellen, cinem "Ereignis" oser ter Giefabr entge= 


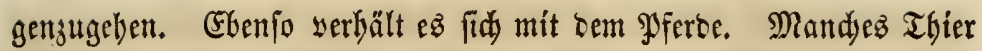
wurbe fdyon unartig genannt uno empfing futdutbare Sdjläge für feitte bem Fubrmann unerflärlidje Erregung, feine Seigeruti, vor=

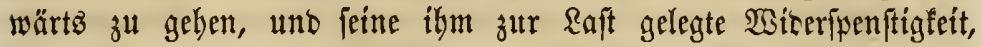
wäbreno all biefez nid)tz anberez war, alz eine Neryenftörung, bie fid in (Seftalt ber Fluffrämpfe äuferte uno cen ganzen ßörper afficirte.

Solder 3uftand wirt gemöhnlid caburd erzengt, baf baz Blut in zu grofer Suantität sorbanben, biaf uno ungefuno ift. Das Rervenfyftem bient neben anberm aud jur Beförterung bes Blut= umlaufz, und wenn bas Blut in sem oben angegebenen 3uftano ift, fo müljen bie Rerven übermäpig angeftrengt werben, um ifre AHfgabe zu erfüllen, uno eż zeigen fí bie bereitż angebeuteten, bem Fubrmann fo rätbjelbaft sorfommenoen Eridueinungen.

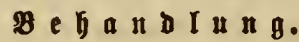

Nur ber Unwiffente und (Sraufame wirb fein Pferb peitictien, wäbreno ez einen foldyen Infall bat, weldyer gewobbnlich burd bie

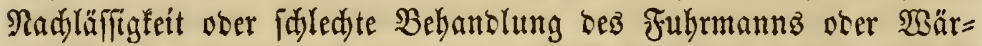
ters erzengt wurbe, und man alfo bem Pferbe siel meniger Edulto aufbürcen barf, alz fich felb/t ober beffen Wärter. Man bebantle ein berartigen $\mathfrak{A}$ fä̆llen unterworfenez Thier gütig uno mílbe, uno

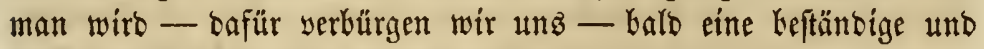
erfreulid) Beränoerung wafhrnebmen.

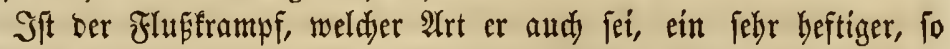

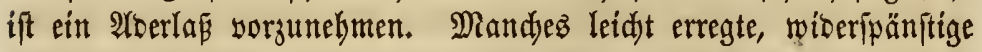
Yjerb wirb solftommen berubigt und wieber lenffam werben, fobald man ben überfüllten Blutabern eine (Sallone Blut entzogen bat. Selten jeood) wiro es nöthig fein, fo siel Błht abzulafien. Man

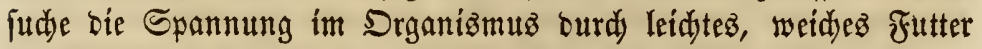
zu verminbern, was jebody nidjt bahin verftanben werben barf,

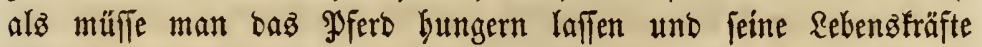
[đł

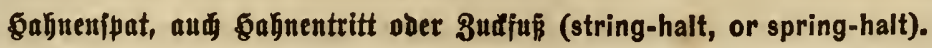

Sedez .Sebilde im Rörper bat feine Rerven, obne weldye weber Ibätigfeit, nod) Betwegung ber betreffenden Theile möglid wäre. 
Die 5üften uno Sinterbeine erhalten $\Re$ raft zur Bemegung burd) ten

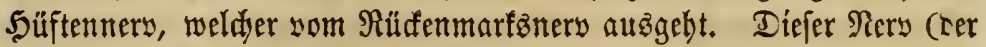
Süftennery nämlid) wiro yon ben nteiften Thierärsten als ber Siks

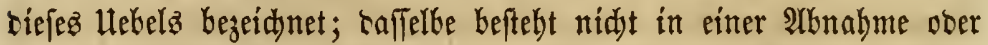

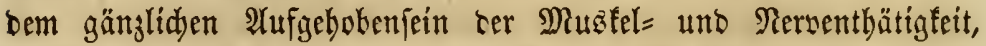

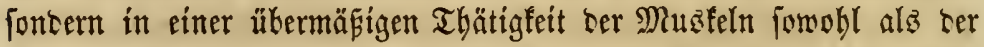
Rersen, fo Laf, wemn das Pfero geht, baz Sinterbein frampfbaft emporgebober unt viel böber aufgezogen wirt, alz biez gerwöbnlidy cer Faall ift, ja oft wiro ber Sinteridenfel biz zum Baud empor= gehoben unb gegen biejen mit ziemlidjer Rraft geftof́en. Die $\mathfrak{M}_{\text {uga }}=$ feln fint nur bie Diener ber Rersen unb zeigen nur foldhe 3ufam= mengiehungen unb Zudungen, bie ihnen von ihren 5erren, ben Ner= wen, mitgetheilt werben.

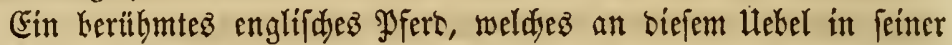
fdilimmften Form litt, wurbe von Mrofeffor Epooner, son ser fänigl. Thicrargnei[dule, geöffnet, um einigrs lidjt üker tie Utrajaen riejer Rranflyeit zu erhalten. Das Rejultat biejer wiffemidaftlidjen Unter= fudung ift folgenbez:

"Die Mugfeln waren in volffommen gejuntem 3uftant, unt man

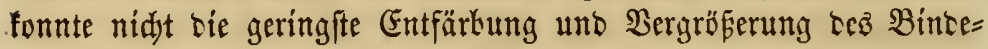
gewebez wahrnehmen. Die Muăfeln ber vorrern uno bintern Błlies= mafen wurben ganł genau unterjudst, wokei man namentlid) Sen Muafelnfajern jeglidje 2Hufmerffamfeit identte. Cie, Lie Mušfeln, waren alle aufó fdönfte entwifelt uno zeigten nidjt bie geringite

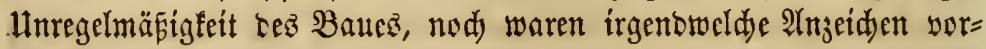

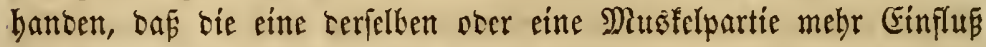
als bie antere attsilke. Der einjige auffallente umitano war ter, baß bie Musficln eine sunfelgelbere Farbe batten, als man bies ge= wöhnlid fintet, unb zwar war biez mit allen uno nidjt nur mit einzelnen, ober biefen uno jemen Musłfelpartín ser Fall.

Die \&enten=, Edjenfel= uno Süftemnersen wurten unter[ud) uno

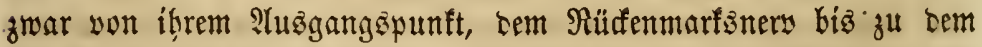
Sunfte, wo fie fid) verzweigen. Der Renten= unt Edjenfelnery waren volffommen gefunt. Der Süftenters tagegen war an ter Deffruttg,

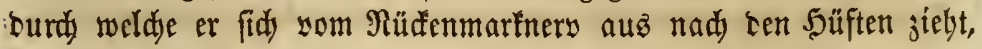

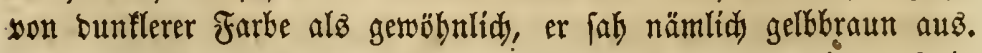

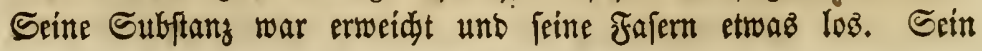


Ulmfang war ser gemobnlidye; aber in ten Theilen biefes Nerven, bie fid surd sie Musfeln ter Şüfte zieken, fano man mebrere mít Blut unterlaufene Etellen, uno zmar bauptfädlid sa, wo er mit bem

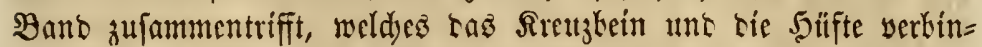
bet. In rer Begeno Lez Eprunggelentz jerod batte ter Rery wic=

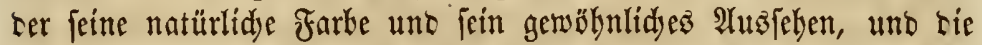
yon ify sem (jelenf fu aubigebenten Fajern befanten fid in soll= fommen gefuntem 3 uftant.

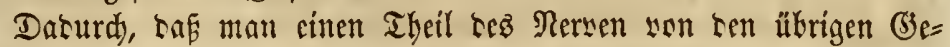
bílben berausfidnitt, ergat es fidy, raf fid sie Blutunterlaufungen

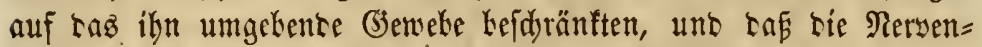
fubftanz felbft in solfommen natürlidyem Buftano war,

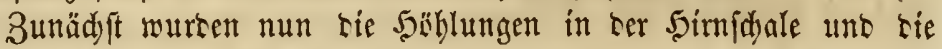

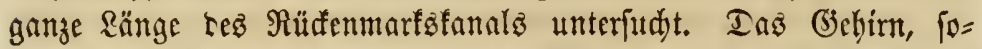

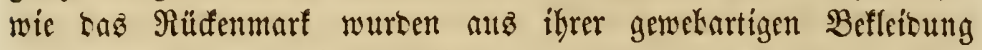
genommen unb alle biefe Ibeile genau geprüft, unb man fano we= wer fier, nod) in ten senten irgent weldye Berlebung.

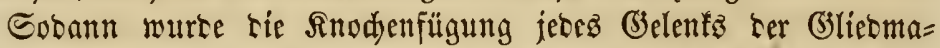
Ben aufz genaufte unterjudt uno in feinem terjelben eine Erfran= fung yorgefunten.

Profeflor Spooner war ser Anjidyt, Łaf riefes eigentbümlidye

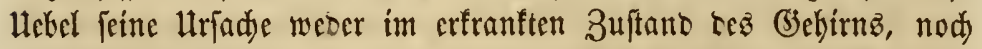

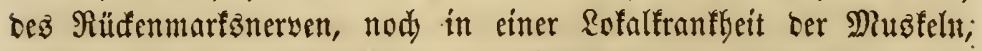
foncern in ciner Erfranfung tez Şüftennersen habe. Bei jerem nut Şaknentritt kebafteten Pferce, weldes er s̈ffnete, fano er biefent Rers, weldyer hauptfädlid Len bintern (Sliecmafen bie Saraft tor Bewegung verleibt, erfranft."

Der Sabnentritt ift felten fo fdlimm, sap er sie Dienjtfähigfeit

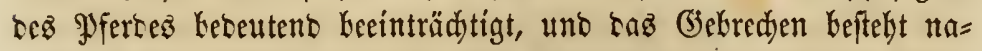

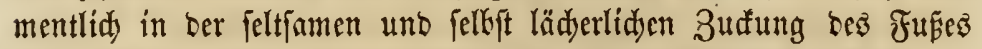
beim Gang. Iaks aber taffelfe ein Beiden bejonterer Sraft fei, wie Mandbe behaupten, bicz ift gerwif ein Irrthum; ez ift eber ein

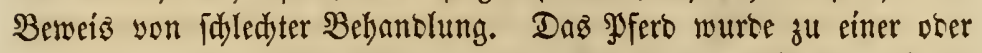
ciner antern Beit üker Bermögen angeftrengt, und bie baburdy er= zcugte Muäfelfeidäbigung wirfte auf ten widtigen Süftentery วurüd. 


\section{Bebandung.}

Man nehme einen mäsigen 2Tberlä́ yor, inbem man nidyt über brei Pinten SBlut entzieht, und man wieberlyole bieje Speration

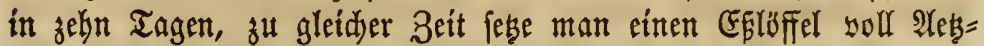
falbe (corrosive liniment) auf ben Theil ber Saüfte auf, weldher bem $\Re$ üffgrat am nädften liegt, fowie auf ben bintern Theil bez Futeres. Man halte bie Shüfte, fowie bie Ferie wenigftens einen $\mathfrak{M}_{0}=$ nat mittelft des Rinimentz wunt, intem man baffelbe täglidu ge= brautdst.

Diefe Bebandlung - woz̧u nod brei biz yier Ģaben Stedapfel= faamen geyeben wurben - furitte ein \$oferb, weldjez ben Sahnens tritt im Göbdfen Grabe hatte. 


\section{Aldftes siapitel.}

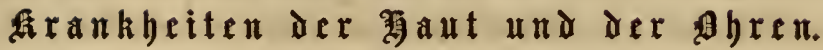

Da alle ungünftigen, äuß̣eren Einflülie, weldyen bas Pferb auz= gefeģt ift, zuerft mit ber 5aut in Berübrung fommen, fo ift leid)t begreiflid, warum biefelle to häufig ber Sis yon Siranfletiten ift. Betradjten wir bie (d)refflidje Bebantlung, weldhe oft bem armen Thier zu Theil wirb, fo ift ez ein Wounber, baj bie Folgen nidjt id)limmer fint. ATher bie eigenthümlid)e Bauart ber 5aut, wie fie

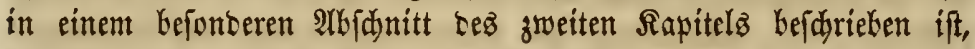

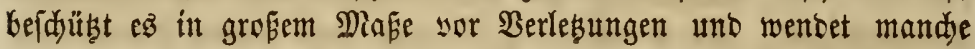
idlimmen Folgen einer fajledten Bebandlung ab. Die manderlei

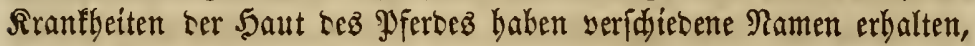
je nady ihrem Sil uno ber veridiebenen Gridgeinungen, weldje fie

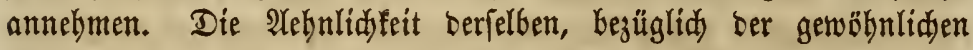
Symptome fowohl alz ser Hrfadjen uno ber Beflantlung, ift fehr grof. Man fann fie in zwei Siafien theilen: Eritenz poldje, weldhe yon fdiledter Bebantlung berrühren; zweitens foldhe, weldhe Folgen.

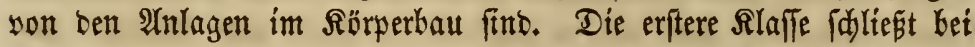
Weitem bie gröste $3 \mathfrak{a b l}$ in fid.). Gine ber bezeidnentiten biefer Rrant= beiten Find bie

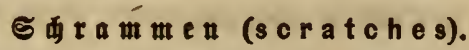

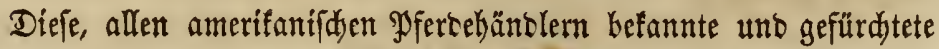

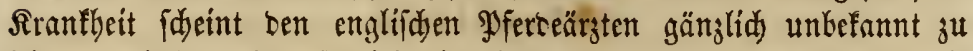
jein; wenigftenz bat, fo viel wir wiffen, feiner biefelthe erwähnt. Sie

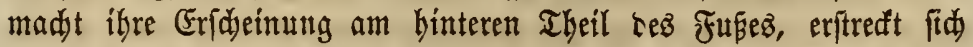

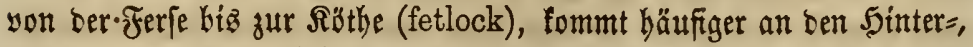
alż an ben Borberbeinen vor. Sn fdlimmen Fä̆llen hat fie fid

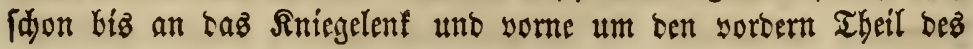


Juß mít einem trof̉nen, biađen (strint auf ser Saut, inbem fid berfelbe ba und bort ftellentweife aniest unt bann um fid greift, bis bie ganże Sberfläde zu einer feften Ma\|le yon Grino uno Saaren ge= worten ift.

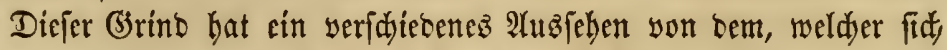
bei antern Rrantheiten ber Saut uno ben Füßen zeigt. Er erzeugt auferortentlidjez Sucten, fo ba ift, bie Theile oft reibt, biz biefelbent wunb and bluteno fint. Daber fonmt ber Uriprung bes Ramenż-Edyranmen (scratches).

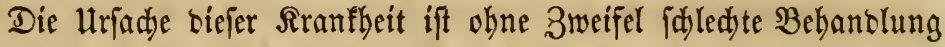
und fdjled)te Stallung. Man madhe eine (Betrobnheit Laraus, baz PSfero im Dref unt Moraft, ober im Stall auf einem 5 aufen Keifen, raudenten Miffes ftehen zu laffen, uno ehe ber gleidgülttige $\mathfrak{A}$ uf = Feher ez yermuthet, haben fidy bie Sdyrammen entriácelt. Diefez

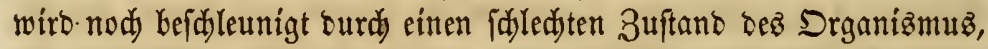
unreines Blut, Utoronung ber Berbauungsorgane unt allgemeine

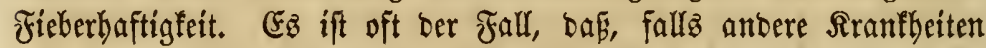

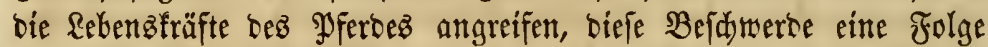

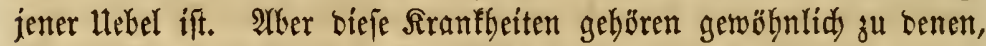
weldje ber errwähnten fdjledten Behanolung folgen. Sdjledjte \&uft uno Unreinlidfeit haben baz $\mathfrak{B l u t}$ vergiftet uno ben ganzen Siga=

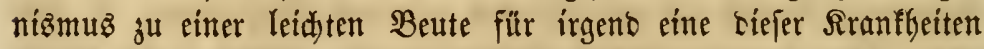

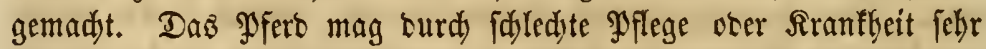
mager werten, obne Sdyrammen zu befommen; aber wenn riefe $\mathrm{Ut}=$ fadien vorhanten fino uno ez jugleidy im Dref unt Moraft, ober auf einem Saufen weiden, faulensen Miftes ftehen mus, io ift es ein Wunber, wenn ez yon biefem llebel veridjont bleibt. Gin Yjerb, weld)ez fid in einem trodnen, rein gehaltenen Stall befinbet, befommt felten Sdyrammen.

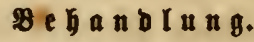

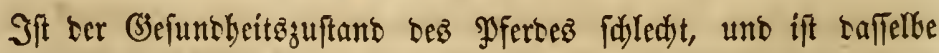

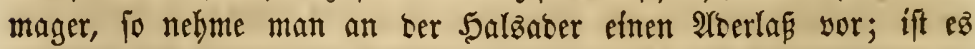
aber fabwady und elent, fo barf man mur eine fleine Duantität $\longrightarrow$

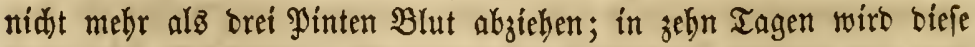
Dperation wieberkolt. Sit $\mathfrak{e}$ az aber nod) ftart, fo braudjt man nur 


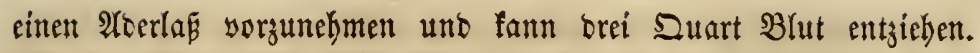

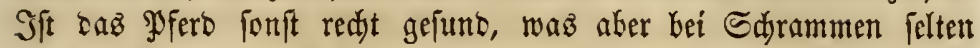
ber Fall ift, fo ift gar fcin Alverlás nöthig.

Das anzumentenbe Sheilmittel ift faft io unfehlbar, alz irgento

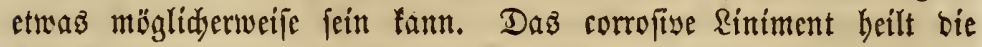
Srantheit in jebem Stabium und faft unter allen Berhältnifien.

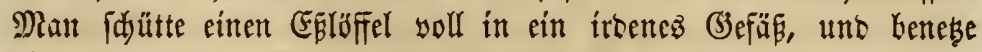
bie angegriffenen Theile gut mit einem barein eingetaudsten Rappen.

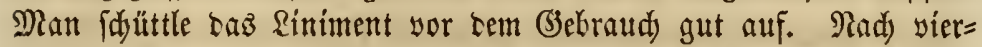

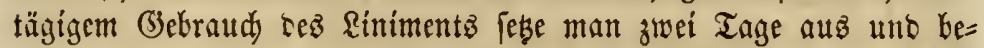

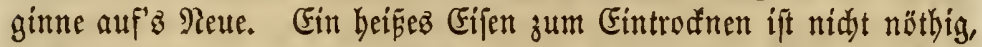
weil biejez einer von sen Fä́llen ift, in welden baz Mittel auf ber Dherfläde erfolgreidjer wirft. Man büte baz Mfero währeno bem

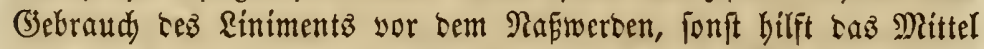

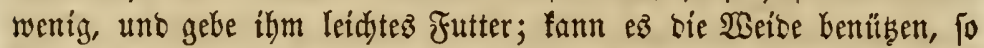
braudjt weid)

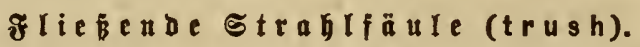

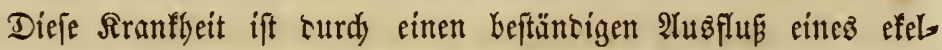
haften Citerz aus bem Strabl (frog) uno ber Ferfe gefenniseidjnet. Die Spalte im Strabl ift yon einem yiertel bíz zu cinem balken

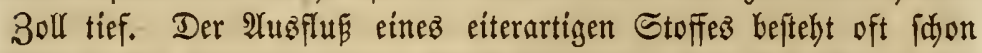
längit, ehe ber unadjtame Eigenthitmer Strablfäule nidyt in Berbinsung mit einer antern Rranflyeit als lofalez llebel yor, fo wurbe fie gewöbntidy turd baz Stehen in einem

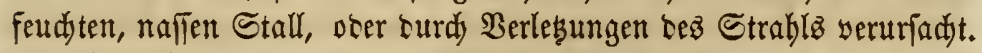

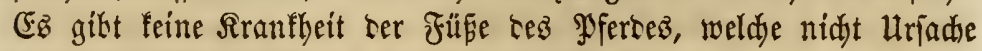
son Strahlfäule fein fann uno aud oft ift.

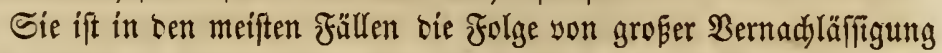
uno (d)ledjter Bebantlung, uno würoe in unjern Ställen felten vor= fommen, wenn biefelfen reiner uno trol̈ner gehalten würcen. Die Gavalleriepferbe baben fie felten; uno ez gibt burdjauz feine Utriadje, warum bie Farmer häufiger bamit zu fämpfen haben follten, alz bie Reiter. Wir hoffen, bá nur bei wenigen unjerer Rejer ber folgente. Rath anwertbar ift, aber foldje, benen eż gilt, fönnen nidjt zu fajmell banbeln. WBerfe ben gróen 5 aufen Miff, welder fith in beinem. 
Stall angebäuft uno auf weldjem baz Pfero zum grofen Radtbeil feiner Gefunbheit cine geraume Beit geftanoen bat, hinaus, uno git ihm ftatt beffen ein gutes sager von troctnem Etrob ober Sägemehl. Thue biefes uno ou braudjpt menig Furdyt zu baben, ter Mübe uno

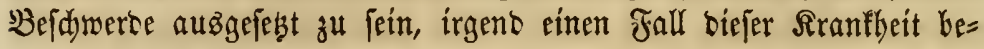
banteln zu müffen.

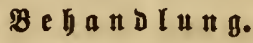

Das corrofive Riniment wiro fid) etenio erfolgreid bei Strablfäule zeigen, als bei Sdyrammen, wenn oie Sranfleit örtlid) ift uno nid)t in $\mathfrak{B e r b i n o u n g ~ m i t ~ a n b e r n ~ a u f t r i t t . ~ S S e n n ~ e i n e ~ a n b e r e ~ R r a n f f e i t ~}$ bes Fufe fie verurfadyt bat, fo beile man ricie. Man benebe ein Stüdduen Tud ober Seil mit bem Riniment uno lege $\mathfrak{e B}$ in sie Spalte bez Strablz tho die angegriffenen Theile oer Ferfe, ino zwar joll ties $\mathfrak{A}$ bendo gefdyeben uno Morgenz nimmt man baz Rappden wieber weg. Mit biefer Bebandlung fäbrt man fo lang fort, als es nöthig ift, febe jebod immer ben britten ober vierten Iag aubิ.

\section{Ma f u (cracked heels, or grease).}

Diefes ift nur eine anbere Form ber Sranflett, son weldyer wir fdon zwei Entwidlungsformen betradytet baten. Sie ift jebod) ber Strablfäule äbnliduer, alв Den Sdyrammen, unb beiduränft fid gänslid auf ben binteren Theil beż Fuęez, Die Ferfe genannt, ein Drt, weldyen bie Sdrammen felten afficiren, jebod) gerabe ber Sibs ber

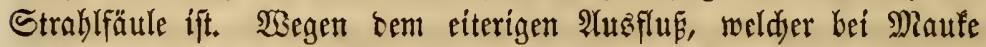
borfommt, ift fie lebterer nod) ähnlidier.

Fine antere, vielleidyt mebr serborgene Sranflyeit bez Fufes if febr bäufig oer Ulriprung riẹç Hebelz. In vielen Fällen if feine örtlide Sranfleit, fontern eitt bünner EiterauşfluE, weldyer fid) ourd) bie Poren Srängt, fo wie er gemöbnlid bei ber im vierten Sapitel beidyriebenen Strablbein= ober Strablgelenffranfbeit sorfommt. In ben meiften Fällen tif lebstgenanntes (3elent ber wirflid) ange= griffene Ibeil. Aber aud bier rübrt bas Uebel oft son benfelben

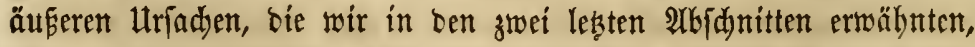

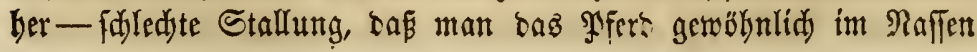


ober Dreâ,, Dber auf einem Şaufen verfaulten, mit laugenjalzigem Urin genesten Strohes fteben läst.

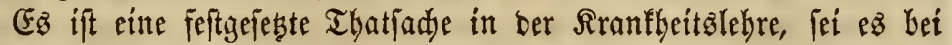
Menjuen ober Thieren, daṕ biejelben Urjadjen, weldye auf ben Dr= ganiżmus einwirfen, unter veriđjiebenen Berbältnif\}en, ganz veridje= Dene Wirfungen berworbringen mögen, uno Gieraus ergibt fid eine antere Thatjache, baf nämlid) mandye Sranfleiten zu berfelben Rlaffe gebören, aber mekr ober weniger in ibrer Entwidflung veridieben fino, audy mit ganz veridiebenen Namen bejeidjet werben unb bod oft zu bemielben Uriprung zurüdgefübrt werben fönnen. S\$arum

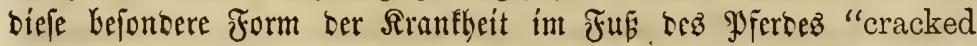

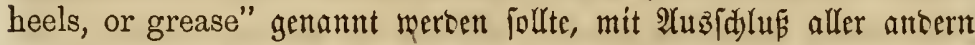

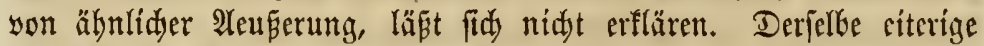
Stoff fliést bei Strablfäule und Sronenfiftel (foot-evil) aus. Dieje Sranfbeiten find fiderlid febr nabe verwant. Sie offenbaren bie= felben, ober beinahe biejelben Symptome, uno sine gebet oft in bie antere über; aud) mögen fie genau biejelben Urjadyen baben, forwie fie atth riefelbe Bebandlung beilt. Man wäre bezbalb beredytigt,

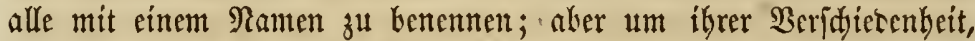
fowie um ber befferen Berftündlidfeit willen werben fie je tadj ibren battptiädlidyiten uno veridjebenen Symptomen veridjiesen Kenannt. Die anfrallenbjte Figentbümlid) feit biejer Sranfleit, fowie bas einzige, weldyez fie yon allen antern unterjdeicet, fint rie aufgeprungenen, offnen Ferjen. In biejem Berf wirb fie beghalb Maufe (cracked heel, wörtlid): aufgeiprungene Ferie) genannt.

2Nn ber Ferje bez Pferbes ift die Saut yon eigenthümlidyer $\mathfrak{B e}=$ ida affenbeit, wie bies an feinem andern Theil fcines Rörperz yor= fommt. Bei gutem (Bejunbheitşzuftand bez Pferbes gebt eine be

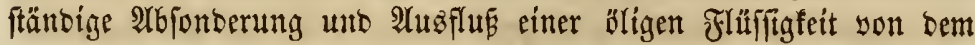
unten liegenten Bellengemebe vor. Diefes madyt bie Sberflädye ber Ferje fallüprrig uno erbält fie weidy uno biegfam, bemabrt tie Saut, bafi fie nidut hart uno troden wirb, uno ebenjo wobl yor bem 2 uf = pringen, waz jonft leidut geidiebt.

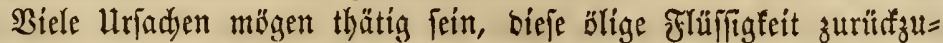

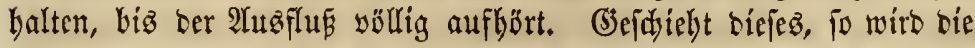

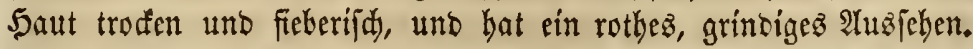

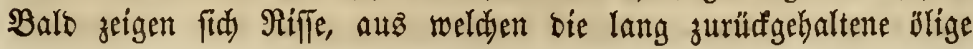




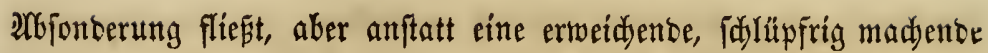

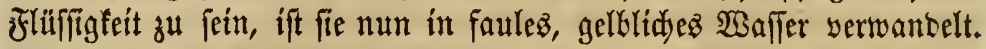
Wiro ber Rranffeit nidyt Eingalt gethan, fo geht bie ganze Ferfe

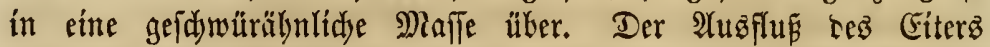
nimmt zu und wiro immer bider utto fteifer. Eine foldse Entwid =

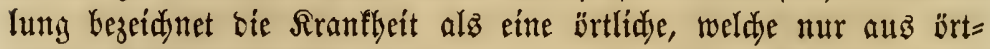
lidjen Urifadyen entipringt.

Maufe ift nidjt anftedent, wie viele meinen; wenn aber ein Pferb biejelbe hat, fo werben bie antern, woldde in temeelben Stall fint, früher ober jpäter in biejeltbe sage fommen, weil ibre $\mathfrak{l l m}=$ gebung bieferbe ift. (BTreidye Urâdyen baben gleide wsirfungen. Durd, einen naffert, ungejuttoen Stall voer brectigen 5ofraum be= fommt ein Pfero die Rranfleit fo gut wie baz anbere.

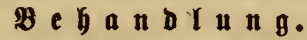

Wie fdjon vorker angebeutet, ift faft biefelte Bebandlung noth= wenbig, wie bei Sdyrammen uno Strablfäule. Eìn anhaltenter

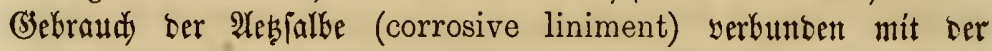
nothwentigen Borfidyt uno Sorgfalt, heilt tie Rrantheit gemí.

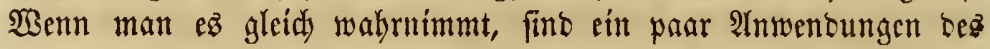
Rinimentz zur Syeilung binreidyent. Beftebt bie Sirnefleit aber fdjon

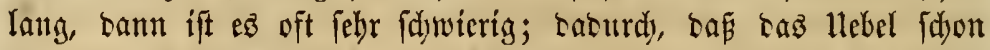
längere Zeit Fortfdyritte mad)te, ift nidyt allein bie Ferie fdyon auf= gefprungen uno bat jid nidyt nur bereits eine fijwammige Mafie

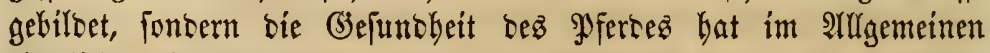
żiemlid) gelitten.

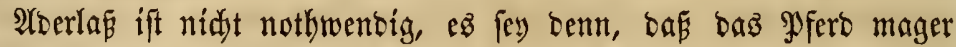
ift und fein (3efuntheitż̧uftano burd) bie Befdiwerbe gelitten hat. In foldem Fall entziehe man zroei Duart Blut aus ber 5aläblut= aber uto gebe ihm jeben britten $\mathfrak{T a g}$ Sdjwefel (sulphur) uno 5arz (resin), zwei Theile son erfterem uno ein Theil yon Tetsterem. Bier

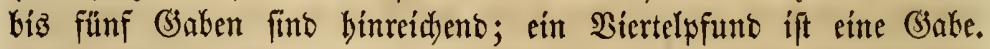
Man faüuttele baz corrofiwe Riniment gut, giefe etwas in eín irbe=

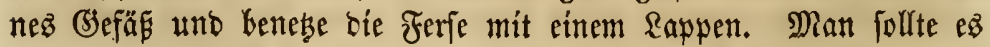
einen um ben anbern $\mathfrak{T} a g$ gebraudben, biż bie Siranfleit bewältigt if und alle Spuren von Entzünoung, fowie ber fadwammige $\mathfrak{A}$ ug =

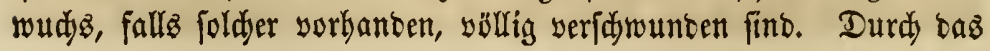


Siniment entifebt oft ein bifer Grino auf fer 5aut, fo bif unb

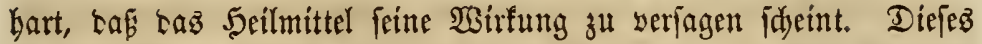
ift ein fidjerez Zeidjen bayon, Laf bie Rur gelingt. Man jeşe Len

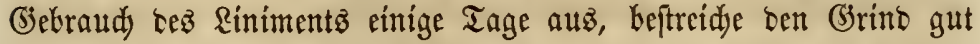
mit Fett, biż Lerjelbe veridnintet, uno gebraudye tarnad Laz Rini= ment wiecer uno fabre auf bieje $\mathfrak{B e i j e ~ f o ~ l a n g e , ~ a l z ~ e s ~ u o t h w e n t i g ~}$ ift, fort.

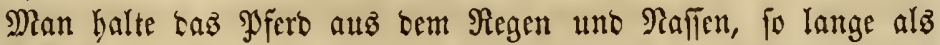
ธas Riniment gebraudjt wirb, ober wenigitens für fedjz Stunten

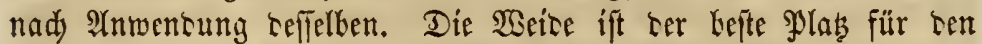
Patienten wäbreno โez Tagez, aber er follte nidt auf Len Weibe= plaş gebradyt wercen, ebe Der Ihau weg ober Las Graş nad eín= getretentem Regenwetter wieber troden ift. Zur Jahreszett, wo ez

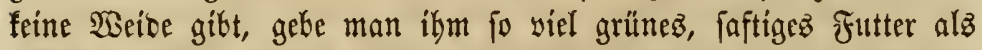
möglidy. Radytz balte man bas $\mathfrak{P}$ fert in einem reinen, trodenen Gtall.

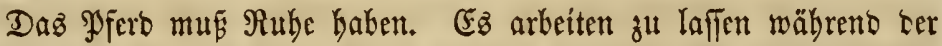
Rranflyeit, if nidyt allein unbarmbergig, fontern bringt fein seben in (3)efabr und verhinbert gewíp die Seilung. SAber manche fagen

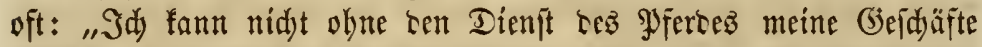

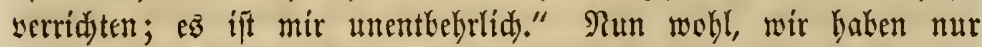
Diez zu fagen: Shr habt cure Mabl, entweser eine furje Zeit, weldye

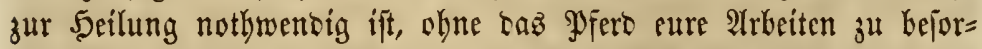
gen, ober es ganj ju verliereth, was gewiép ter fall feyn wiro, wetn Eer Sranflyeit nidjt enterifidy Eingalt gethan miro. (jebraudyt ibr oaz Pfero zu irgeno einem Dienft, fo fönnt ifr nid)tz anteres er=

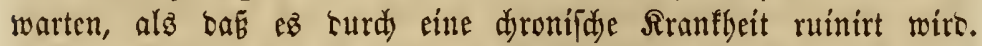
uno eins ît gewíp: "Würbe ber Cigentbümer nur balb fo viel lei= ben, fo würte er auf irgeno eine $\mathfrak{s e i j e ~ w e r f u d y e n , ~ o f n e ~ f e i n e n ~ e i g e = ~}$ nen Dienit leben żu fönnen, bizz er gejunt wäre."

Ein bejonbers Gartnätiger Fall yon Maufe wurte burd tie eben angefilhrte Bebandung in Peterbłurg, Boone Co., Sy., im Eommer 1866 getheilt. (Fin jungez PFero, weld)ez oem Pojtmeifter tajelbit, Serrn S. Nelion (Sreen, gebörte, batte die Sranfbeit im hödjten Grab. Der Fall war yon einem praftizirenten Pferbeargt eite ge= raume Zeit bebantelt unb zulest als unbeilbar aufgegeben worben. Shreiber biejes begann bie Bebanblung mit bem corrofisen \&ini= 
ment. (E⿱ d)ung mit Fett entfernt wurte, worauf fosann bas siniment ange= wanot wurbe. Nadjem biefes abwedjelno viermal gejdeben, war

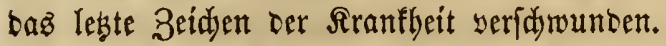

\section{Beingelditulft (swelled legs).}

Eine antere Rranflyeit, weldye in enger Berbinbung mit ser Maufe

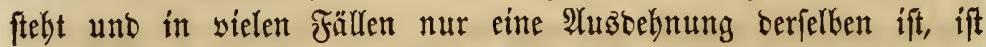
unter bem $\mathfrak{R a m e n}$ Beingeidiwulft befannt. Die Ginteren uno biz=

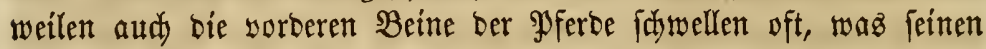
urjprung in bem zellenförmigen (Bewebe, weldyes unter ber 5̧aut

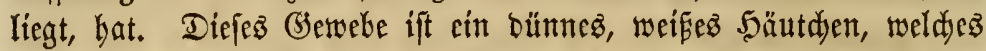
bie Saut an bie Miusfeln befejtigt, uno finoet fid) nidyt allein in ben Beinen, fontern eriftrefft fid über ben ganzen Sörper.

Die Ratur hat alle 3wifđjenräume zwifden bem fleifdigen Theil

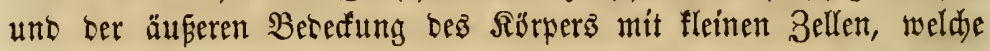
eine wäfferige 2(bjonberung enthalten, auşgefüllt. Diefe zellenförmige

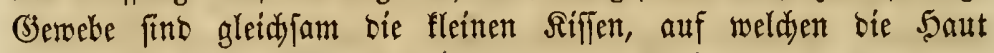

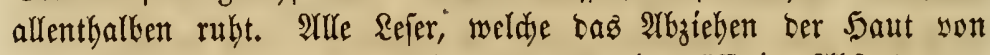

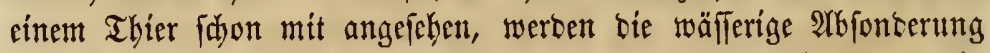

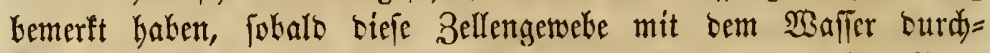

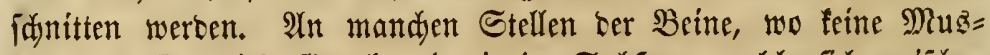
feln fint, fint bicfe (Jemebe bie einjige Subftanz, welde fid zwifden

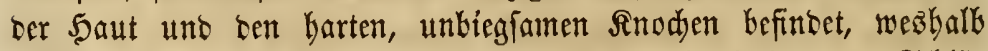
bieje Theile bejonters leidjt bejdäbigt werben in Folge von Salä=

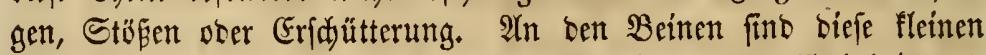

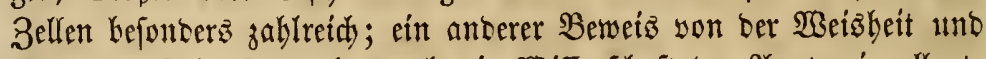

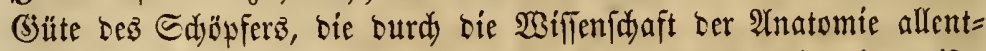
balben geoffenbart werben, und auf's Reue müjifen wir bie weifen 3wede uno Bolfommentheit einez jesen Gegenftantes in ter $\mathfrak{R a}=$ tur, weldye Eeiner bänbe $\mathfrak{B}$ erf ift, berwunbern.

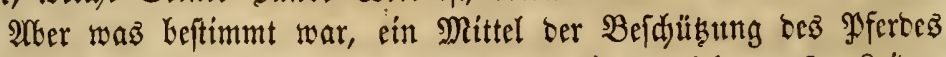

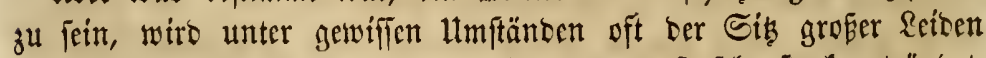
uno Edymerzen. Dieje Bellengewebe werben oft fehr fiarf entyüntet,

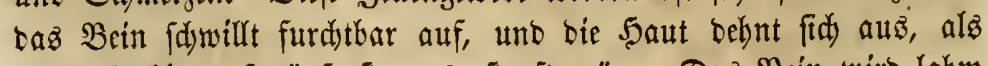

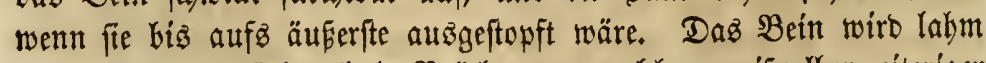
und fteif; 
Stoff flieft, ähntlid bem Eiter bei ber Maufe. Rebteres fommt ge= wöhnlidd, aber nidyt immer bei ber Beingeidinulfit yor; bäufig gehen biẹe beiben Sranffeitent in einatter über.

Mandymal tritt bie Beingeidywulfit erftaunlidi fidnell ein - vicl=

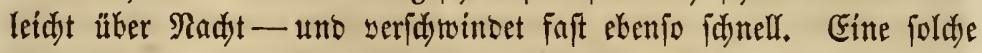
Erfideinung zeigt gemöhnlid) bie Wirfung an, weldje Störungent in

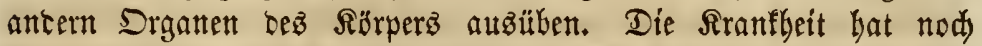
feine dyronifde (Beftalt angenommen. Es iff nur eine $\mathfrak{B a r n u t h}$ yor etwaz Edjlimmerem, weldes nod) fommt. WBüren bieje $\mathfrak{S a r =}$ nungen nut verftanten unt beadtet, wie fie follten, fo tönnte eine

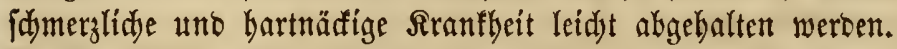

"Ein Unglüă fommt feltett allein," fingt זaßz alte Spridwort, unb felten berweift biefe Rranfleit baz Bjegentheil son bicjer Befauptung. Beingejdmulft ift fo eng mit antern Srantheiten verbunten,

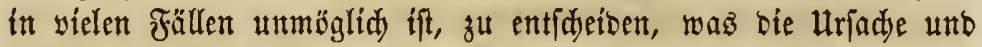

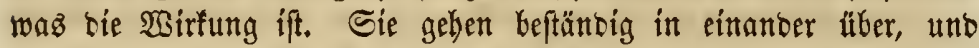
bie eine veridylimmert bie antere. Die (Jrundlage yon allem aber finto, bies fann tem jorgfältigen Beodbbadter nidjt entgehen, zweí ober brei primäre Sirantfeiten; bie Siranffeiten bez Strablbein= unt Sronbeingelenfiz uno bie fruthtbarfte Dutlle aller Reiden in oen

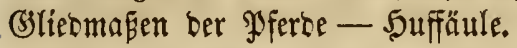

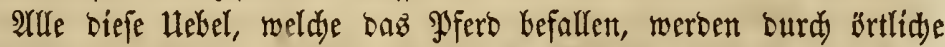

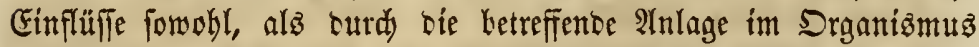

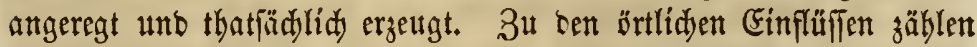

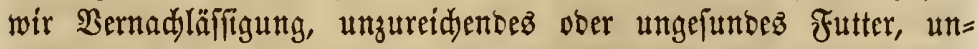

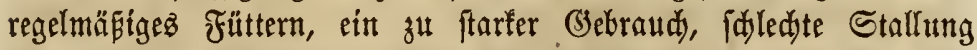

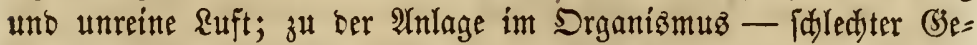

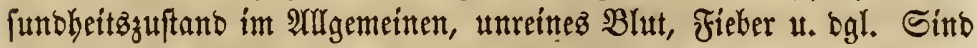
eintige biefer urjaden yorbanten, fo verfeblen fie nidjt, einte voer mehrere biejer Rrantfeiten berbeizufübren. Zmei berelben fint hin= reidjent, auf bie wirffamite Weife Sdaben anzuridten.

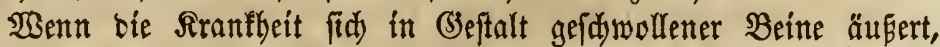

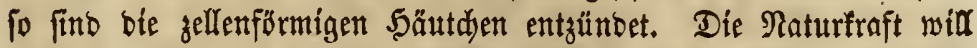

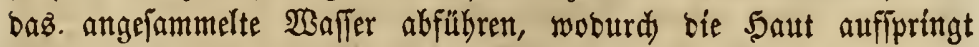
und baz $\mathfrak{3 a}$ affer alżbann an ben Beitten herunterläuft.

Diefes if nadi unjeren Heberzeugung eine getrette Sdiftberung btejes $\mathfrak{u}$ ebels, fowte mandjer ăhnlidien. 


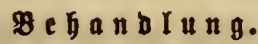

Dasi cin fold)er Fall bartnäđig uno bie Befferung nur allmäblig geideben fann, ift leidjt cinżuleben. Man begime tie Bebantlung

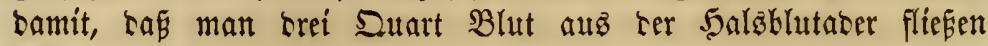
läft; wente bas corroftze Riniment mit einem Rappen auf siefelbe Weifje an, wie bei ser Maufe, nutr saj ez bier jeten Morgen ohne

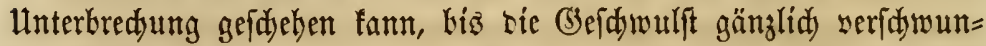
ben ift, utho gebe brei ober vier Tage lang täglíd) eint Biertelpfunto

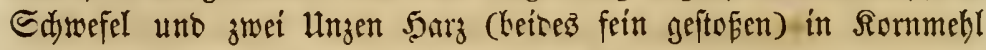

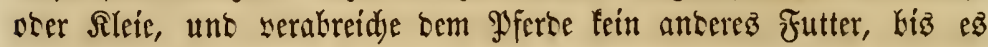
biefes gefrefien bat.

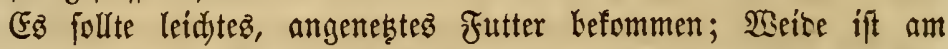
beften; audd) nüb̧t $\Re$ ube in einem reinen, trofenen Ctall bem $\mathfrak{P a}=$ tienten febr viel. Man lebe ibn, bejonterz währeno ser Behant= lung, ja nidjt ber naाাen WBitterung auts.

Dbige Bebandlung ift zuverläfitg; fie hat fdjon Seilung betwirtt, nadisem alle anteren Mittel fehlgeldylagen haben.

\section{Ein Beifpier.}

Alz Beleg für bie gemadjte Bemertung wollen wir nur ben $\mathfrak{B e r =}$

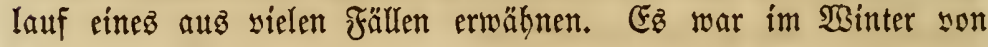
$1856-1857$.

Sherft Sarmon, welder in $\mathfrak{s i l f o n ~ C o u n t y , ~ I e n n e t l e e , ~ w o h n t e , ~}$ hatte ein jungez Ctallpfers, weldes eine fehr grofie Beingejdmulft hatte. Die Sirantheit hatte tie idlimmfte (3eftalt angenommen.

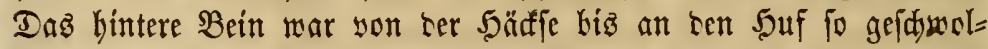
len, Iafi jente Theile eine Maffe ftinfenten Giters bilheten. Die

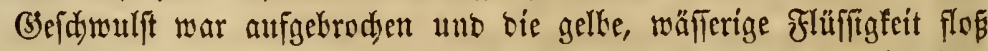

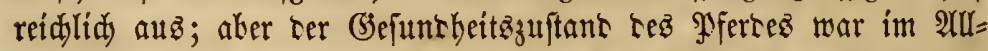
gemeinen ziemlid gut; aufer ser fieberbaften Grfranfung, weldye son tem Bein herrïbrte, hatte $\mathfrak{e z ̇ ~ n u r ~ w e n t g ~ F i e b e r . ~}$

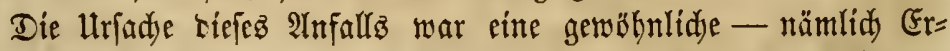

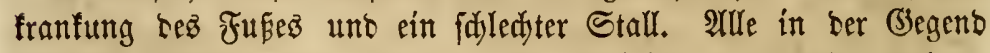
befannte Mittel waren Monate lang erfolglos angewant worten; bas $\mathfrak{H} e b e l$ wurse immer fdlimmer, biz man allgemein zur Heber= zeugung fam, baj eine weitere Behantlung sergeblid fey.

Zu biejer Zeit wante fid Sberft Sarmon an ben $\mathfrak{2} u$ tor, unb 
La biefer taz corrofine Riniment empfabl, rourse fogleidy ein Sincht nad) Najbuille gefojidt, wo bie Mebiain nad) unjerer Antweifung zubereitet unb tann auf bie Farm getradyt wurte. Die bejontere (sebraudfonantwetjung, welde gegeben wurbe, ehe id wegging, wurbe ftreng befolgt uno taz $\mathfrak{P}$ fero warb vollig gebeilt uno fo gefund und wobl alß̈ je.

\section{Gef}

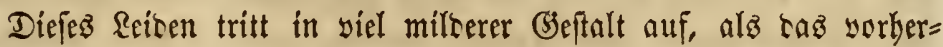
gebenbe, unb bejdränft fid), wie ter Name allecttet, nur auf Las Feflelgelenf; fod fteht $\mathfrak{e E z ~ i n ~ e n g e r ~ B e r b i n c u n g ~ m i t ~ B e i n g e f d y u l f t , ~}$ yon welder es faft immer ein Borbote ift. Cinige Plferbe find fehr geneigt taju. 2lkente fiebt man nod feitt $\mathfrak{A n}_{j}$ eidjen, afer tesె Morgens find bie (3elenfe ftarf gefdrwollen uno erbibt. Die Eymps tome werfdwinten jesod) wäkreno tes Tages wieser, uno alles fdeint in Sronung zu fein. Diefer 3ujtanto fer Gelente mag Monate lang wäbren, tho bat fdon PJerbe Gabre lang geplagt. Dap biefes Ulebel mit grofer Unrube uno wirfliden Sdjmergen ver= buncen ift, beweift bie Anfitrengung, weldye bas Pferb madt, um Rube ju finten, feine Reigung jum Nieberliegen uno bie Rincerung,

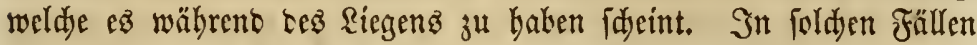
ift unfeblfar ein tranfhafter 3uftanto ter füfe rie ltrjadje.

Selten nur bat gefdwollenes Feflelgelent feinen llriprung in ter

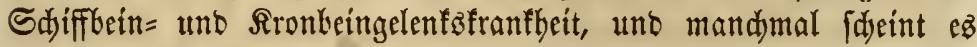

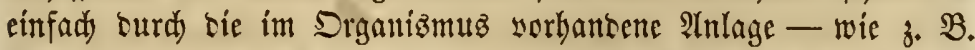
Bollblütigfeit in Berbinbung mit beftiger 2 (nftrengung uno fdwerer Yrbeit, erjeugt worben zu fein. Waber in netn Fällen aus jebn rübrt

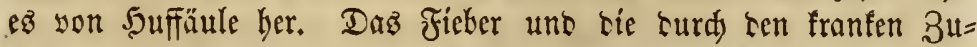
ftanb ber Füfe crgeugte Sige zieben fid weiter nady oken unb ent=

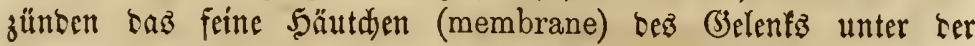

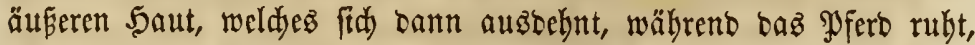
aber wäbreno ber Bewegung feine Thätigfeit wieber verridytet, fo bafi die (Sefdiwulif veridyinbet.

Wirb ben Symptomen bes geidwollenen Feffelgelenfes nidyt burd)

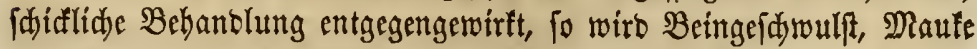
ober Sdyrammen fid früber ober fpäter gewín einftellen. 


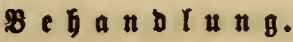

Daż Erite, waż gefdehen follte, ift, Ias man bie Urjadje bet Sranfleit burdh bie Seilung ber Fuffokle entfernt. Man wente bas corrofive Riniment jeben Tag vier bis fünfmal reidjlid an, uno nadjoem inan zwei ober brei Tage ausgejęt hat, fange man auf's Reue bamit an. Man unteriutbe bie Ferien, ob diejelben weh ober

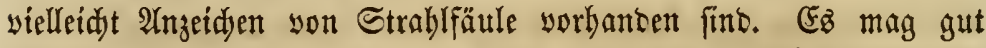
jein, baz Riniment audy an ber Ferie aufjujeben, bamit man gemíp ift, Lafi man irgeno eine Sranflyeit erreidt, weldye cafelbit verborgen jein mag.

Went die Fuffoblen gefuno fint, werben bie Fefielgelente nidjt

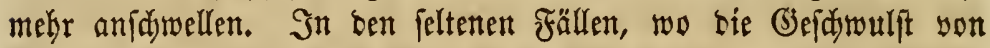
Dolnblütigfeit berrübrt, if Arerlafi am Plabe.

Dan füttere foldye Subftanzen, weldye etwas abjdyädyen. Fin alterirentes (miloernteş) Mittel wiro in sen meiften Fällen wohl=

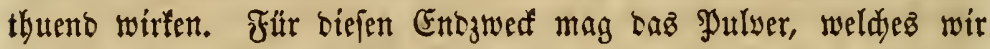

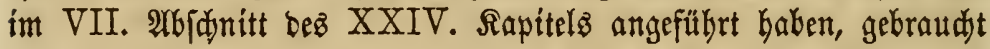
werben.

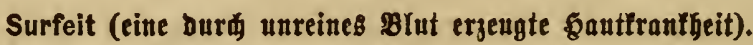

Surfeit if serfibeden son sen in biefem Sapitel angefübrten Uebeln; es if eine allgemeine Sranflyeit ber Şaut uno fein örtliches Reiben. Sie tritt in biefem \&and gèwobntid in millorer Form auf uno ridjtet felten befonteren Sdjaben an; wenn bas Pfero gute Weibe baben fann, fo seridyinbet Surfeit gewöbnlid son felbft. Die Rranflgeit madyt ihre Erfdeinung meifent im Frähjabr, ent= weber zur Zeit, wenn bie 5aare aub̧fallen, ober furz nadjber, wenn bie Şaut beinabe blos, ober metgr entblöpt ift, als zu irgeno einer Zeit im ganzen Jabr.

Surfeit zeigt immer einen biffen, unreinen 3 uftano an; felten aber ift biefez Hebel ein Bemeis bayon, baj ber Drga=

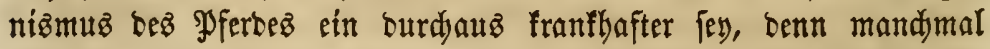
fino bie beften SPferbe bamit geplagt. Dagegen beutet Surfeit febr oft nad)läfige Beriorgung uno fdjledte Stallung an, obwobl mand)=

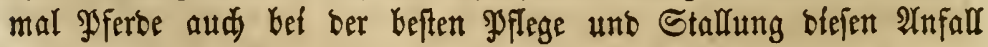
befommen.

Wenn, währent bie Şaare aug̊fallen und ber Rörper ben Fin= 


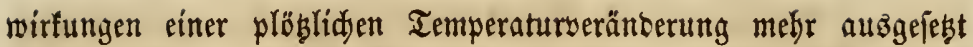

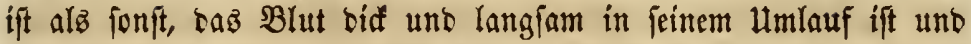
baz PFero fid erfältet, fo entfeftit eine leidjte Entzüntoung, uno bie ăufere Sdjidte ber 5aut, 5ornfaut (cuticle) genannt, wiro burd

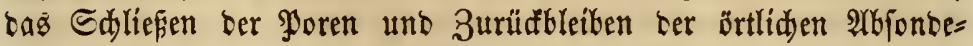

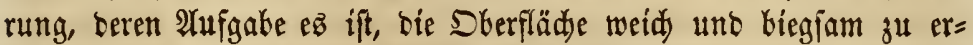
balten, hart uno troden. Sileine Sodjen erjedeinen auf ber Saut, aus weldyen ein bünner, weiflidjer uno Bliger Giter flieşt. Dié

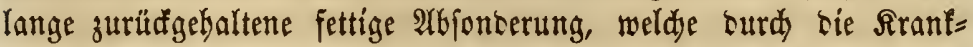
beit fid etwas seränbert hat, entleert fidd. Sie fließst in nur gerin= gen Duantitäten aus, níd) viel melyr alsz in gefunbem Buftant. Die fleinen grinbigen $\mathfrak{s} u$ fteltn, weldye fid auf ber Saut gebilbet, bebecten ben ŞalE, bie Sd)ultern, Seiten unb ben hintern Theil ber Borberbeine.

WBenn bie 5aut fid in bem fieberifden Zuftand befinbet, momit

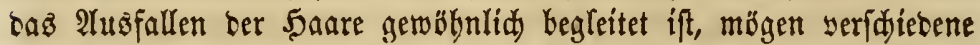

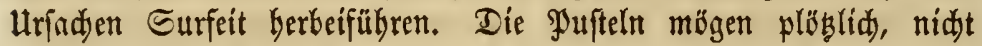

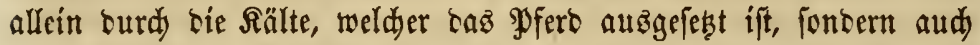

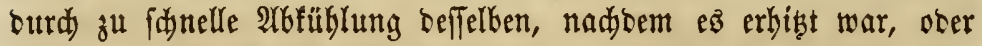

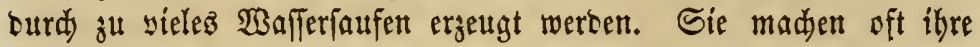
Eridjeinung in einer Radt.

Gin Fad son plöblidjem Surfeit ift fadon oft Beranlajiung zur größten Bejorgni bei ben Unerfahrnen geworben, inbem man be=

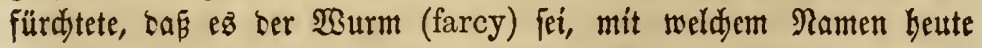
nod) taujente amerifanifde Farmer biefez $\mathfrak{H e b e l}$ (Surfeit) benenten; aber ez hat feine yon ben unyerfennbaren Symptomen jener fatred"=

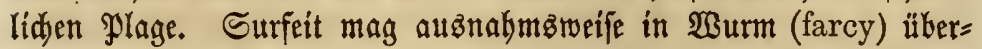
geken, aber biefes fann nur gejdeken, wenn antere mädtige yorbe= reitenoe Uriadjen barauf Ginwirfen. Beridjiebene andere Sranflyeiten geben viel eher in 2 surm (farcy) über, als bieje einfadje 5autfrant= beit. Diejem Bjegenftant if fidon bie nöthige Beadtung geidjenft worben in bem arbjdnitt über ",Wurm" im V. Rapitel.

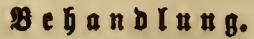

Surfeit madyt feine umftändidide Behanthung nöthtg. Man nehme

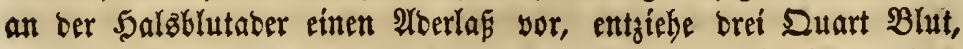
uno gebe zrwei gewöbnlide Ģaben yon Sdyefel (sulphur) uno Sarz 
(resin). Sit ber Fall ein hartnädíger, fo beidjmiere man die Stel= Ien, wo bie Pufteln aufgebrodyen find, mit Sdurefel unt Edweine fett, yon jebem einen Gefloffel yoll. Man thue diefez Des âkentos ein = ober zweimal, laffe baz Pferb auf bie Weibe uno nad einigen Tagen ter Rube wiro alles in Dronnng frín.

\section{$\mathfrak{A}$ ä u de (Mange).}

Răube ift bie cinzige Rranflyeit, in weldye Surfeit leidjt autzartet.

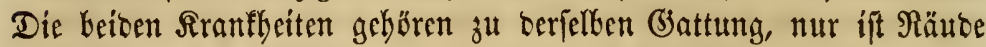
viel fdjlimmer alsె Surfeit, uno ebenpo febr anjtedeno. Sie wersen ourd) Diefclben Ginflüfle erzeugt; wäbreno aber Surfeit in Räute übergeben mag, ift raz umgefebrte nidt möglid. Diefe Rranfbeit

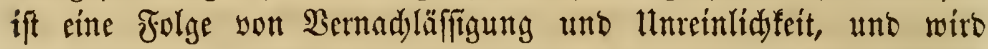

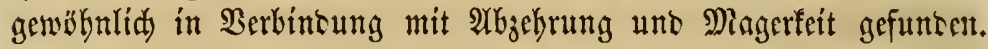
Fin gut gefüttertez, gefundes Pferb mag Surfeit baben, uno jalbit yon cer $\Re a ̈$ be angefteft werben, aber es fann nie in einen fo elen= ten 3uftant fommen, weldyer von unfern Farmern gewöbnlid) mit Räube bezeidnet wirts. Sobalo man yon cinem räutigen Ibier bört, ftellt man fid) aud) fogleid cin abgezebrtez, clentes Syfero wor, unt ber alte, akgemagerte, an biefem Hebel letente Patient, weldyer auf bem offenen (3emeinteftü (commons) orer eincm idjled)ten Felo

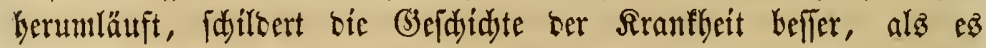
TSorte 子u thun vermögen.

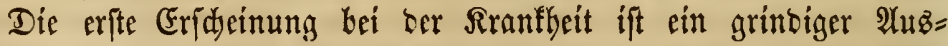
fajlag auf ber 5aut. Die Borbaut (cuticle, or scorfskin) bridjt in fleine Stüdfden wie Eduppen, weldye fid) abfdălen, woourd) basె robe, oft blutenbe Fleifd fidtbar wirb. Die Saare geben fdyon vorker

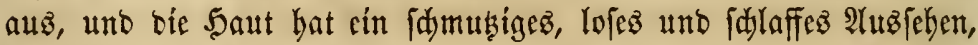
uno ift beoedt mit Eduppen uno woll roben uno rothen Flecten. Ein fdureflid brennentes Sutfen begleitet bieje Symptome, weldyes

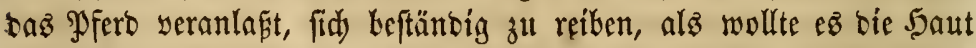
abreiben. $\mathfrak{B o}$ immer $\mathfrak{e z}$ fid reibt, läft $\mathfrak{e B}$ sen Sdyorf uno (3)rino zurüd, uno jebes Thier, weldes fid an berfelben Stelle reibt, ift oer

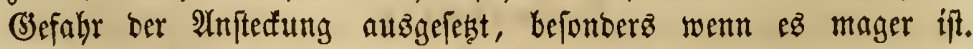

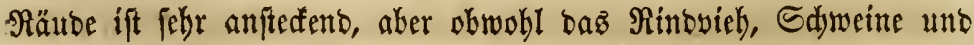
Saunbe siefelbe som Sfero befommen mögen, fo befommt fie biejes nie yon jenen. 
Die geringfte Berührung aker ift hinreident, ba位 ein 9 fero baz

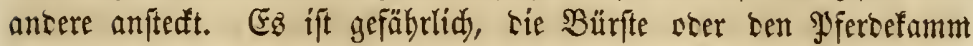
für gefunte $\mathfrak{P}$ erse zu gebraudjen, weldje bei einem räusigen gebrauddt

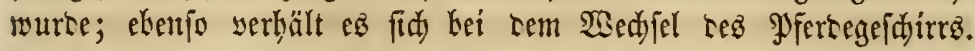

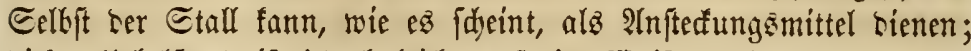
biejem Uebelftano ift jerod leidjt auf sine 2 seife ju begegnen, weldje wir bejeidinen werten.

Diefe Rranfleit fonmmt gegentwärtig feltener yor alz frïber, waz wir ber vermebrten $\mathfrak{A}$ ufflärung ter Farmer uno sem kefferen 3 uftanto

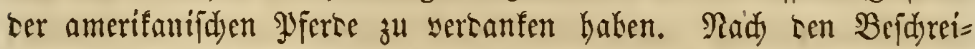

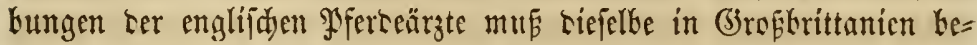
bentento fajlimmer fein, als in tiejem Rante. Mandje fä̆lle finto

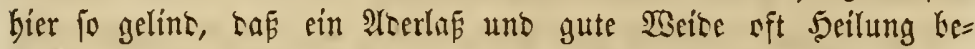
wirft. ohne bap Mericin orer jonjtige Behantlung in Anwentung fommt.

Bei einem magern, elenten Siprse liegt bie Siranfleit im 5 rga =

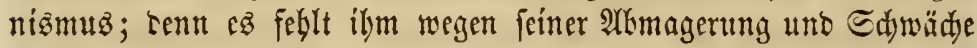

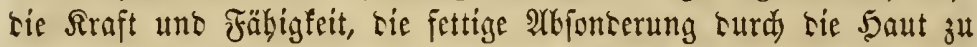
treiten. Daz Blut un ter ganje Srganiżmuz werten hierturd ftarf afficirt. Durdigrcifente Syeilnittel fino in folden frällen abjo= lut nothmentig. Sft ras PJfero jiemlid gut im Etano uno fouft

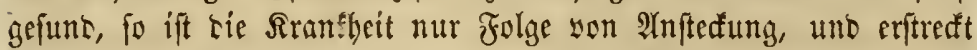
fidj felten weiter als auf sie Saut. Dertlide Bebantlung ift aläbann binreidend zur Entfermung tes Hebelz unt, wie sorhin angebeutet, fo bifft rie Raturfraft fid oft felbit, obne (betraud) írgeno cinez Mittel'z.

\section{B ヒ}

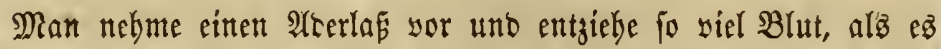

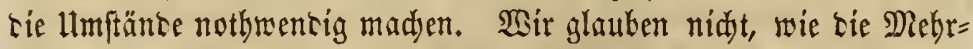

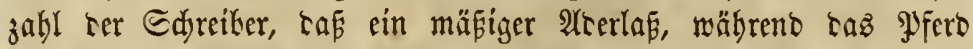
franf ift, ba|felbe iahmädjt. Unjere Erfahrung hat uns ju bem ent=

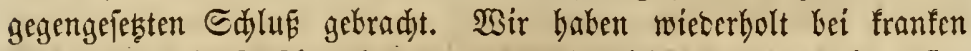
Syerben, welde fo fdwady waren, bas fie nidyt auf ben Beinen fte-

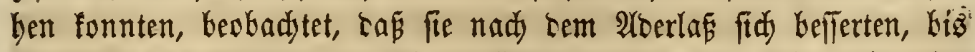
fie volltig gejunt waren. Diejen Begenftano werten wir weiter be=

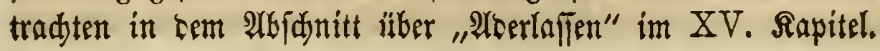




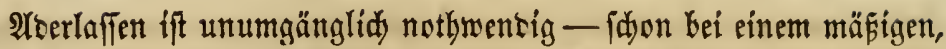

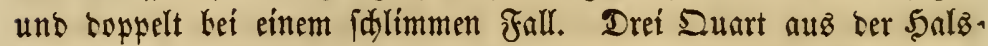

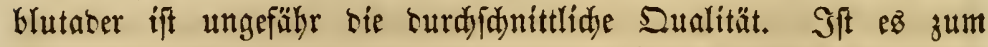
zweitenmal nothwentig, fo follte sie Speration zehn Tage ipäter ge= idethen.

Beftreidje alle räubigen Pläke mit Mercurialjalbe uno reibe bies $=$ felben mit einem Rappen gut ein. (bebraudie nur po viel Salke, alz

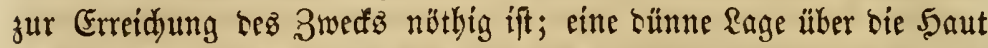

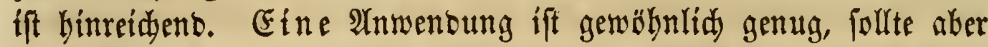
eine WSieberkolung nothwentig fein, fo wajdye man alle räubigen

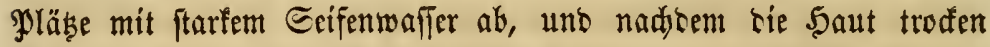
ift, gebraude man bie Salbe wie yorher.

Ein anderez Míttel ift eine Salbe, weldie man auz gleidjen Ihei= len yon corrofitem Siniment, Sdyefel und Sdjweitnejdmals bereitet. Diefez gut gemengt uno angewantst nad ter 2 (nwweifung im yorigen Soaragraph bei ber Mercurialfalbe, entfernt bie Rätoe. Daz Rini= ment jollte sorber gut aufgeidüttelt werben. Es ift am bejten, wenn man erft eine fleine Poortion siefer Salbe einreikt, uno bann eine größere Duantität anwentet, obne fie einzureiben. Der nädjfte Sdjritt in der Behandlung ift, sấ man saz alte zuverläffige Mittcl, Edjwe= fel uno Sarz, gibt. Ein $\mathfrak{B i c t t e l p f u n o ~ E d y w e f e l ~ u n o ~ z m e i ~ U n z a n ~}$ 5ary, fein geftoren, madjt eine Bake. Man gebe biefez jeben britten Tag, zwölf biż fünfłzhn Tage lang.

Man laffe bas \$yferb auf einer mit gutem (3rą bewadjenen

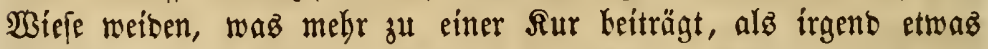
anteres; AKentz bringe man

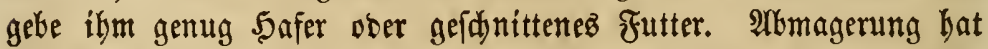

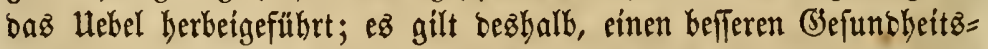
zuftano herbeizuführen uno barauf zu wirfen, bie loje, lappige Saut

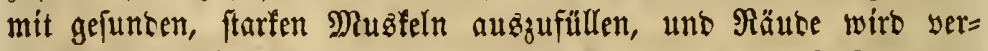
idwinben. Sie fann bei nöthiger \$plege uno gutem Zuftano bez Pferbez nidjt beftelent.

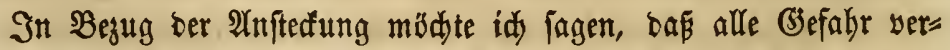

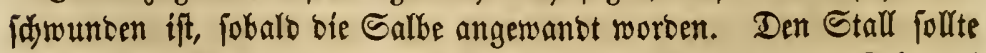

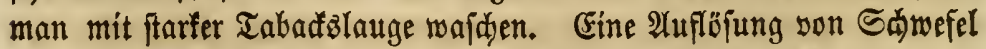

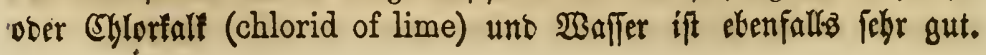




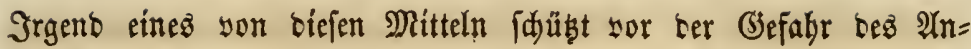
ftecfent.

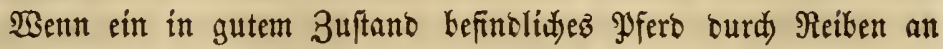

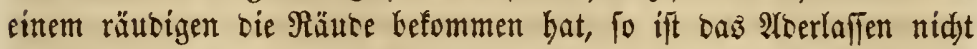
nothwentig. Im Hebrigen follte bie Behandlung biejelke feit, aus= genommen, dáp in riejem Fall zwei Gaben Saywefel uno Jarz binreident fint.

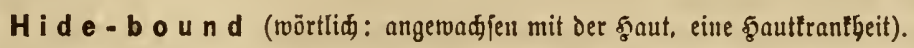

Diefes ift eine Saautfranfleit yon befonterem Charafter. Dbgleid

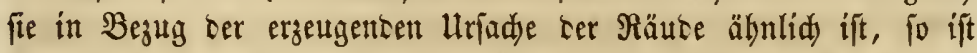

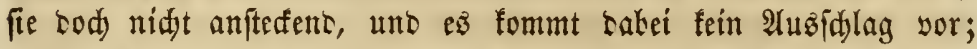
bie 5aut ift in einem 3uitant, ber tem bei ber Räute gerabe ent=

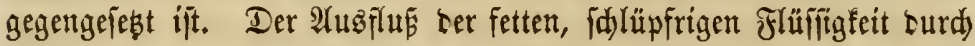
bie Poren hat aufgebört, unb die Jaut wirb trođen uno hart, ähn= lid), als wenn man fie abnehmen uno auf einen $3 \mathfrak{a} u n$ zum $\mathfrak{I}$ rod:= nen bängen würte. Währento hide-bound ein fehr bezeidjnenter

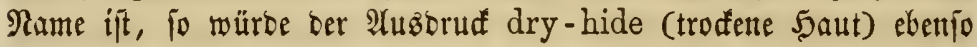
idjiflid) unt nod paffenter jein.

Ea ift nidft allein eine Befdwwerse in bem zellenförmigen 5äut=

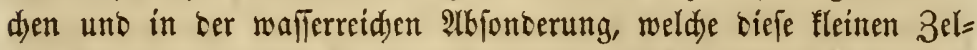
len entfalten, fonbern aud in ter 5̧aut jelbjt: Diejelbe faum nidjt lange bart utto trofent fein, ebe fie ibre Biegiamfeit verliert. Sie

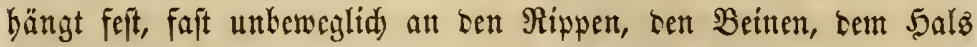

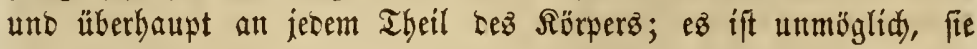
mit ber 5ant zujammen zu ziehen, wie man es leidt bei einem ge= funten Pferbe thun fann. Die Saare fint ihres Gilanjes und ibrer Sdjönheit beraukt unto fehen rauh uno troden aus, wie es beí tenen einer tooten Saut ber Fall ift.

Dieje Rrantheit zeigt einen franflaften 3uftano bez ganzen $D r=$ ganis̄mus, eine allgemeine 3errüttung ser widtigiten Drgane an.

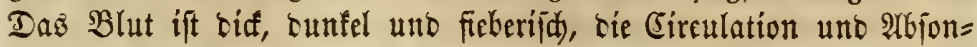

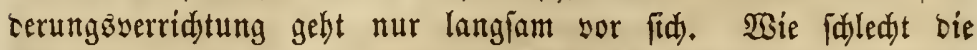
Berbauung vor fid gebt, zeigt ber Mifit, weldyer troden, hart uno iffwarz ift.

Sibebound ift nidat fowohl eine Srantbeit an unto für fid), alz

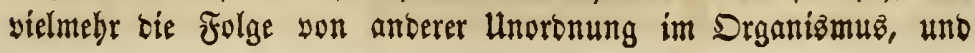


fommt unfelflbar in Berbindung mit bem Beingewäd) am am Ropi

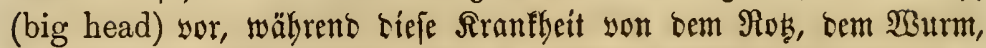
oer Rete uno Diztemper erzeugt wiro. Bei idlimment Fällen son Enţ̧ünoung ber Süfte, Edjultergeidywulft uno Etarrframpi zeigt fid

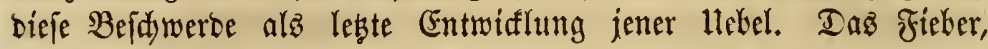
weldjez biefe fajredlidjen Rrantheiten begleitet, trodnet bie wäjerigen atbonberungen auf, fo basi bie 5aut zufammenja)rumpft uno feft ant Rörper anliegt.

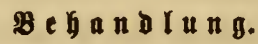

Die Behandlung ift eine langwierige uno bie Seilung geht lang=

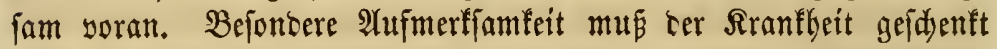
werten, weldye baz Hebel berbeigeführt hat, uno nidyt eher fann man

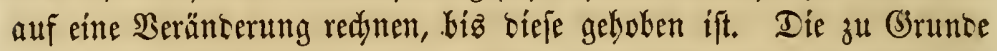

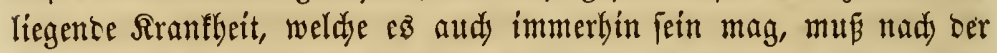
Ânweijung, weldje tort gegeben ift, belyantelt wetben. Man laffe

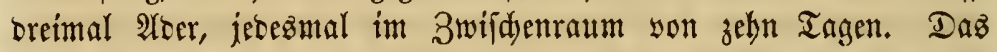
Erritemal entziche man vier, nadher zwei Duart $\mathfrak{B l u t}$; gebe einen

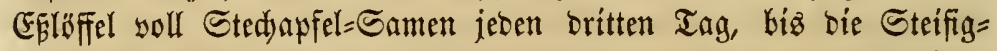

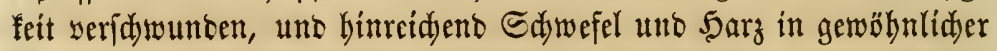

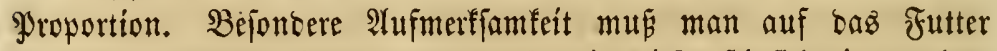

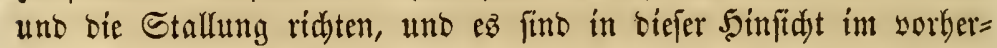

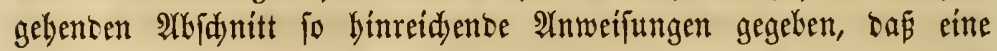

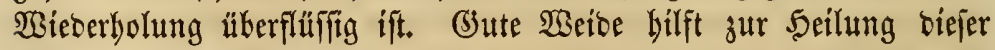

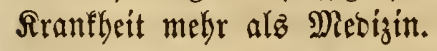

\section{G t e if fig it (stiff complaint).}

Dirfe Rranfleit fadeint bejonbers häufig in ben füblidyen Staaten vorzulommen. Es ift eine antere uno fallimmere Entwiatung ber bei Sibebouno fid zeigenden Symptome. Die 5aat ift fo troden uno zulammengezogen uno liegt fo feft an ben Gelenfen an, bas bie

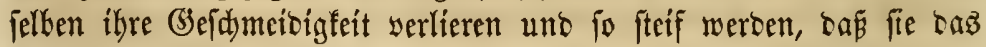
Pfero nidjt ofhe Sdymerzen bewegen fann. Die Muafetn und Sehnen, bejonbers bie ter Beine werben fteif unt ideinen zujam= men gezogen zu fein. Die Bewegung deż sperbeg, weldye badurd febr erfdawert ift, ift langlam uno folperig. 


\section{B c $\mathfrak{b} \mathfrak{a} \mathfrak{n} \mathfrak{d} \mathfrak{a} \mathfrak{n} \mathfrak{g}$.}

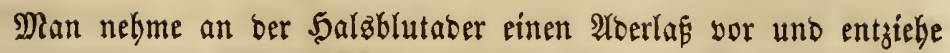
wenigftens eine (3)allone Blut; bies yerminbert die Spannung im Srganiżmus uno treibt bie trägen ober aufgebörten Drgane zur $\mathfrak{A b}=$

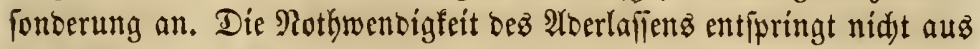
oer Menge bes Bluts, fonbern aus bem franflaften 3uftanbe tef= felben, welder die nöthige Circulation beflelben verbinbert uno Fie= ber uno Entzünoung veranlap̧t. Die Eymphgefäpe verridjten ibre Yufgabe mit foldyer Beidyerbe, bas Mebizin zur Blutreinigung we= nig bilft. Sa, unjere Erfabrung bat unz gelebrt, baßj jogenannte "Blutreinigung" zur 3eit, wenn bie Srgane ibre Funftionen nidjt verridten, mebr Sdjaben als (3)utez thut; oenn foldbe Mittel fönnen nidyt in bem Mafe, wie es nöthig ift, auf ben Srgantīmus ein= wirfen, fonbern fie bleiben im Magen uno Len Eingerweiben, weldje fie reijen, liegen, uno anftatt, dap fie bas Fieber heben, vermebren

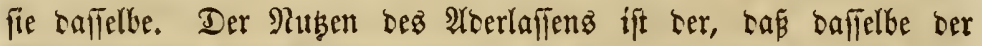
Blutreinigung ben Weg bahnt, um fo viel erfolgreiduer zu wirfen.

Der Sted)apfelfame (jimson), welduer vielleid)t bas ftärffte Blut= reinigungsmittel ift, waz woir befisen, entipridyt bem Zweef. Denn bieje $\mathfrak{H}$ rznei gebt fdnell ins $\mathfrak{B l u t}$ über, regt bie (3)efäpe an, öffnet bie \$oren und treibt bie zurüdgebaltene 2 bjonoerung aus, woourd bie Saut ermeidst wirt. Man gebe einen Gibloffel woll Gamen in Sornmebl ober Rleie jeben Morgen, bis Beflerung eintritt. Zut gleidyer 3eit gebe man genug Sdywefel uno Sarz, jeben andern Tag bie gewibnlidye Dofiz ebenfalls in Sornmehl ober Rleie, uno füttere nid) a a

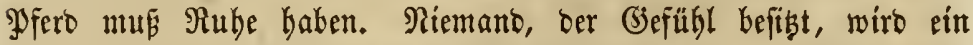
Thier, tem jebe Bewegung Sdjmerzen verurjadjt, zur Artbeit ver= wenten

\section{$\mathscr{B}$ a $\mathbf{z} \in \mathbf{n}$.}

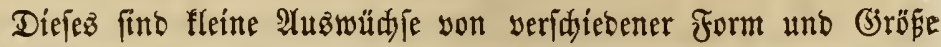

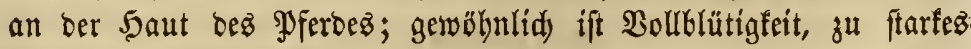
Füttern uno wenig $\mathfrak{A r b e i t ~ b a b e i ~ i m ~ S p i e l . ~ S u n g e ~ P F e r o e ~ f i n o ~ b a ̈ u = ~}$ figer bamit geplagt alş alte. Maulthiere find felten frei bayon. gibt zwei $\mathfrak{A}$ rten - bie Samen= uno Blutwarzen (seed and blood warts.) 
Die Samenwargen fint gewöbnlid flein, maden ihre Errateinung an ten Augenlibern, ber $\mathfrak{R a f e}$, bem Sajlaud uno ben angrenzenten Theilen bez Reibez. Sie wadjen plahweife bei cinattber; haben fleine, barte Spizen. ober Rörner, weldhe Samen genannt werben. Sie ftefen in ber 5ombaut (cuticle) feft und belnnen fid bis ju

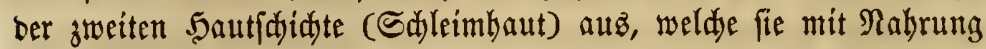
jum $\mathfrak{B a d}$ sthum veriorgt. Sn biejer 5aut befintet fid bie $\mathfrak{B a r}=$ wurzel, weldje vernidjtet merben muf, wenn man bie Beidswerbe beben will. Samenwarzen beuten einten ungefunden 3uftatto ber Saut an, thun aker wenig Sdjaben und yergehen oft yon felfit. Blutwarzen fint fdon falimmer. Sie fint ein fidwammiges fleif

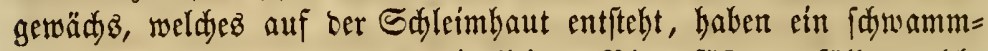

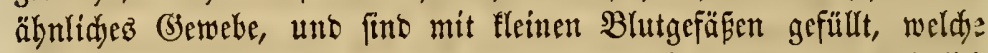
bei bem geringiten Reis ziemlid) bluten. Sie fommen gewöbnlid an ber Saădfe, bem Snie uno bem Fetilelgelent, biżweilen aud) am Sdilauth uno ben angrenzenten Theilen wor. Sie entitehen am

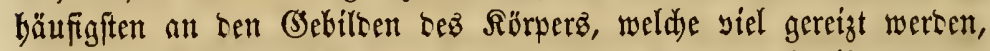
ober wo fid Unteinigfeit irgento weld)er $\mathfrak{A}$ (rt finbet, bod) gibt es ber= felben, gleid) wie Samenwarzen, an allen Theilen tes ̊örperb.

Die Blutwarze wiro leidyt febr grof und greift oft um fid, am Sinie ober Feffelgelent behnt fie fid) oft um baż ganje (Selent herum aนz. WBenn eine berfflben heraugigetreten ift, fo mag biejellbe immer alż ein Sorbote yon althern betradtet werben. Sm Winter 1858 biż

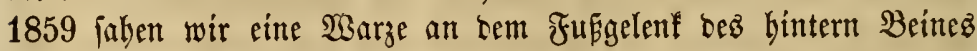
cineż গুferbes, weldje beinahe zwanzig Zoll im umfang war. Sie

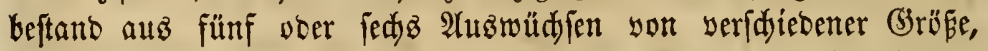
uno jeber war weh, roh uno blutete. Daz Thier war ein fijünez,

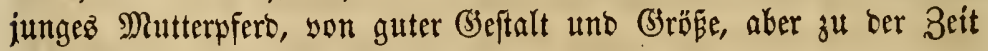
burd) Fieber in [ajledtem Stant.

Die Blutwarze hängt bižmeilen wie ein Ball herab, uno îf buth

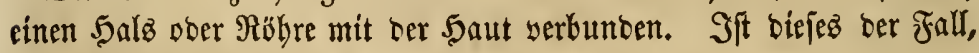
fo fann fie leidyt bejeitigt werben.

\section{Be}

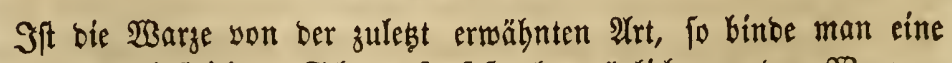

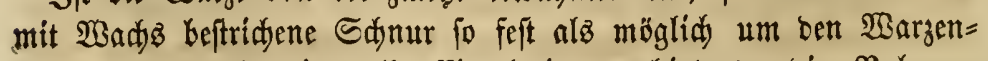
bals. 5ierburd) wiro alle Circulation verbinbert; bie Rahrung 


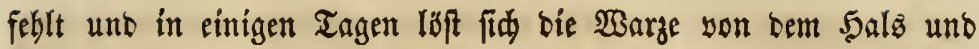
fällt $\mathfrak{a b}$.

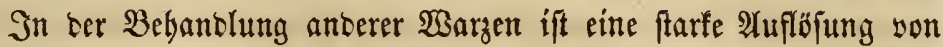
äbettoer \$ottafdbe (caustic potash) bas befte Mittel zur Entfernung

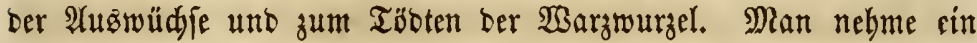
Y) funb rohe Pottajde (crude potash) uno laffe biefelbe an ber $\mathfrak{E}$ uft liegen, biz fie zerfällt, mifaje bann etwaz waffer barunter uno be= ftreidye bie Enoen ber $\mathfrak{3 a r z e n}$ jeben Morgen - ober nod beffer,

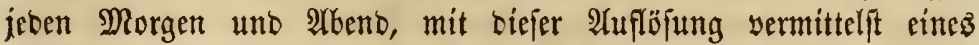
Eappens. Rad jebem (sebraud) follte man bie torte Maffe auf ber Waarze abjdaben ober abwajden. Rad brei= veer viertägigem (j)e braud feb̧e man zweí Tage aus und beginne bann aufó Reue.

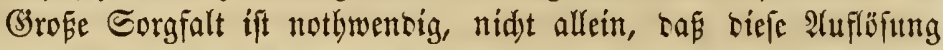

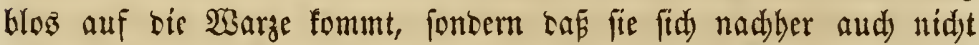

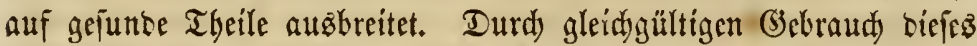

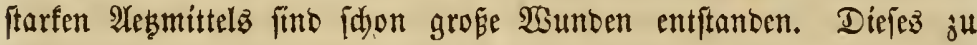
verhüten, nehme man ein Ctüaf ftarfes Sapier, fdneibe ein $\mathfrak{d} d$ d

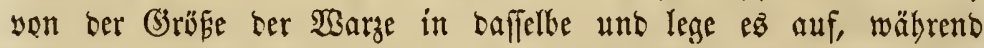
man bie $\mathfrak{A}$ uflojung aufiest. Eine nod) befiere Metbore, welde immer bei Blutwarzen lefolgt werben follte, ift, bas man runt um bie $\mathfrak{B a r z e}$ herum einen halben 30 lf biffen $\mathfrak{H}$ midlag mit $\mathfrak{T a l g}$ madt, ehe bas Âabemittel gebraudyt wirb.

Bei Błutwarzen mag man mit ber Bethantlung jeben Morgen

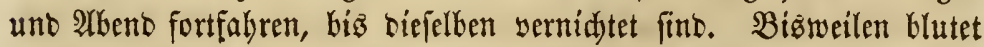
tie Warze wäbrent. Der Behandlung ftarf; in idlimmen Fällen mag

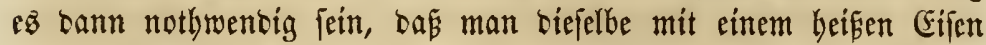
brennt. Sebe bie Behandung nadb Dem Brennen zwei Tage aus, ebenlo wenn bie Beine, weldses oft ber Fall ift, ftarf anjdyellen.

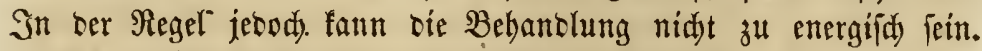
Sn febr fablimmen Fällen beginne man mit 2toerlaffen, um bie über=

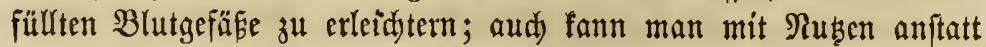

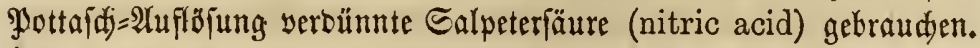

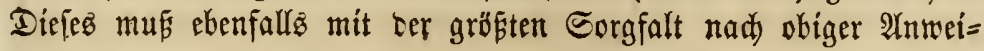
fung angewant werben.

Shat bie Bara ziemlid) abgenommen, io beftreide fie mit einem. in corrofites siniment getaudten Eappen. Rad viertägigem (bes braud fege man ebenio lang aus, und fange alşann wieber an. 
Sn ber Zwijd)enzeit beftreidje bie Wsarze mit Del, Wetroleum (coa. oil) ift $b_{\mathfrak{a}} \mathfrak{u}$ am beften. Fhe man bas siniment wieber anwentet,

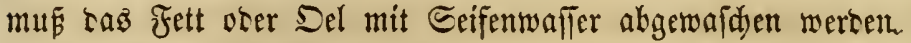

Die Sur Der fleinen Samenwarzen erfortert feine fo burdigreifen= ten Maßregeln, als tie Sheilung ter Blutwarzen. Arerlaffen an ter Saläblutater uno einige (baben Ediwefel uno 5arz fino gemöbnlidy binreident. Sft veriduminten fie whe alfe Behandlung. Sisen fie nidit in sen Bielenfen, fo ifte nidit nothwentig, fid samit ju be= mühen. Dic gewäbnlid ganj fleinen Samenwar sen an ter Raje

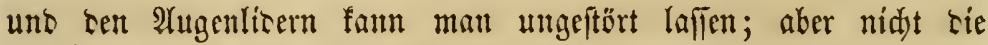
Blutwarasen, wie flein fie autd anfangs fein mägen. Man behantle fie fogleíd, ba anfünglid nod) eine Sur möglid) ift, was fpäterbin nidjt mebr ter fall fegn rürfte.

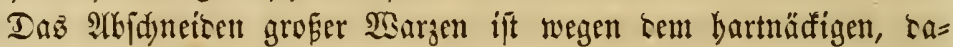

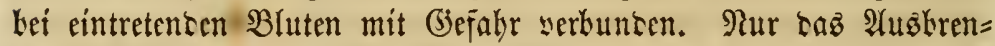

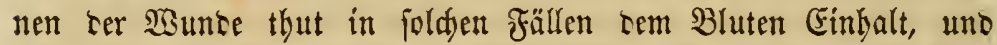

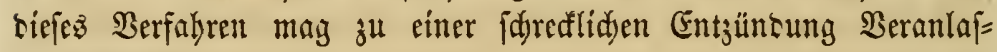
fung wersen.

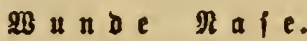

Die Rafen mandier Pferte wersen oft wund und fino mandimal mit (brino übergogen, wäbrent bas Yyferd fonft gejund ju fein fueint. Diefer Buftano mag bie Folge von organifajer Edywädje fein, wiro aber in Ien fürlididen Etaaten Gäufiger von einem gif = tígen Ulnfraut, weldyes bafelbft wädjft, uno megen feinem eigenthüm=

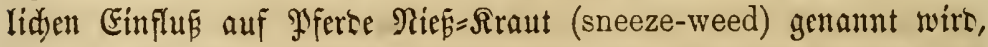
ergeugt. Fs ift eine Pflanze, weldje ein uno einen halben Fus bod wiro, fteht fehr ridyt bei einanter uno ift zur gewillen Zeit mit ben alten Blättern ser gelken Blüthe beteât. Die feinen Iheile terfel=

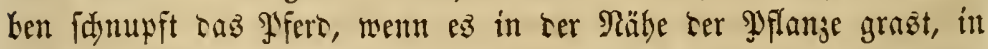

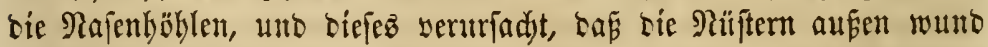
werben. Befonterz ift elye ber Thau weg ift, an foldjen gläten weiret. 3̆u biefer 3eit wirft felbft baż grüne Unfraut alş (sift. Junge Foblen fino ten

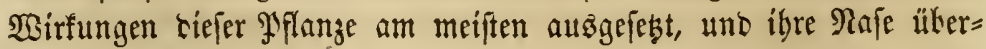
ziebt fid) gang mit (Brino. Die Meinung, bas siefes unfraut nidjt allein ben Pferben, fonbern aud sem Rinssieh töstlid fei, war ein= 
mal alfgemein serbreitet, bod hat man feinen hinreidjenten Gruno bieju.

Dic Raje wiro oft Surd ancerez Unfraut uno Ranfen vergiftet,

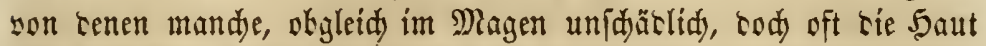
reijen, fo tá fie idjwürt. Eo 3. B. sergiftet Etedjapfeliamen (Jimson weed) tic Raje tez Rintutehz uno ter Edjaje etemjowohl, alz tie ber अierse, und tod haten alfe idjon eine jiemlidje Suantität yon Blütben uto Sinożpen beflelten nidjt allein ohne Edjaben, fon= terti jum Beften ter B̈ejuntheit gefrẹjen.

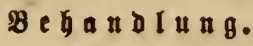

Merfurial = Ealfe (mercurial salve) ift in foldem Falf ein pai = fentez Mittel. Beftreidje tie munten Etellen ramit uno reibe fie mit einem fleinen Räppdyen gut ein. Eş mag am Keften jein, sie Ealbe mit gleidjen Theilen yon Edjmals uno Edjucfel ju vermen= gen, ehe man bicjelbe braudyt. Man keptreidje bie betreffenten Theile jeten Morgen, biz alle wunte Etellen, jotwie ter Grino geheilt fint.

\section{S a t te $\mathfrak{l} \mathfrak{g} \mathfrak{a} \mathfrak{I} \mathfrak{l} \in \mathfrak{n}$.}

Rid ungleiden Druff tes Gattels erhiţt uno muno miro, uno biejes

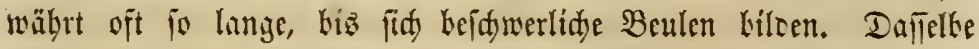

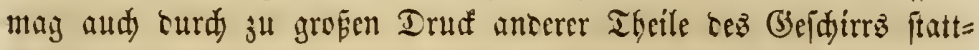
fincen.

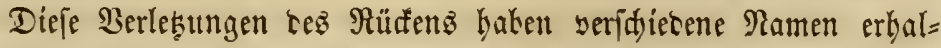
ten, je nady ber Gejtalt, weldje fie yon bem Eintritt ter Bejdywerte

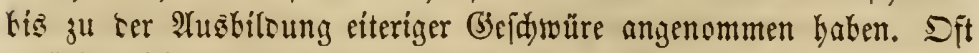
entiteken flecten auf ser 5aut unter bem Gattel, weldye tobt und obne Blutt ju fein fdeinen; bieje nennt man barte Sattelgallen

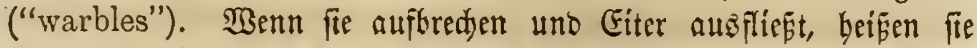

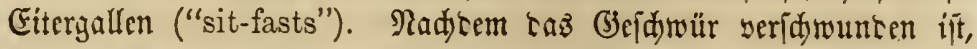
wiro oft ter Eattel, ehe völlige beilung bejmeatt uno cie Etelfe nod) reidy ift, ž früh aufgelegt. Daz Reiben serurjadyt num einen

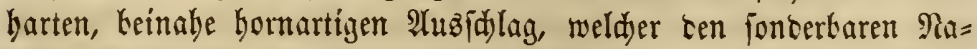
men ,'Mabelgallen" ("navel gall") crbalten hat, weil er alf bem

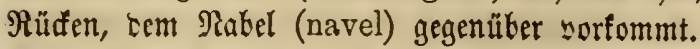

So viele Ramen für ein und ta|jeltbe Hebel gereidjen nur zur 
Verwirrung unt fint äberflüfifg, uno man mag das lebel in allen Feinen Entwiălungen einfad) alı̈ "Sattelgallen" bezeid)nen.

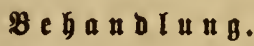

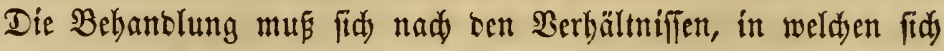
bas \$ferb, ober ber, weldter ez gebraudjt, fid befintet, ridjten. Sit

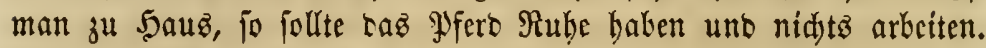

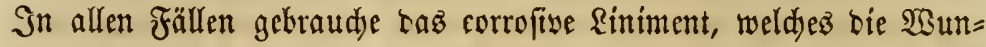

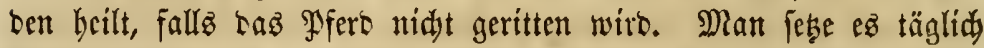

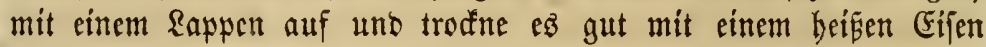
ein, biz bie Seilung vollfradyt ift.

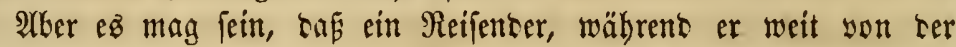

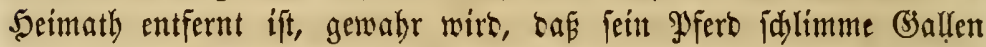
bat, bejonter bei warmem Wetter, ober dá burd) ben (Jebraud)

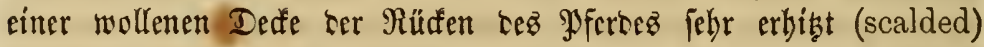

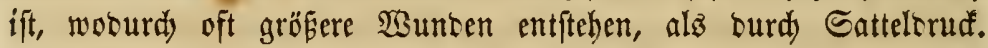
Das Pfero ift nidyt im Etante, ben Eattel zu tragen, uno sod) muÉ ez gebraudjt ober mit Berluft serfauft werben. In eituer pol= d)en $\mathfrak{E a g e}$ ift sie Befanntidjaft mit einem Mittel, weldes entweser sen Rüđen heilt oser sen Drud tes Sattels verhinbert, ein grofer Buttbcil.

Wir mödten Folgentez empfchlen: Sobalo man bie wunte Stelle gewahr wirb, wajde man fie mit reinem, faltem $\mathfrak{B a}$ aler; nadjocm fie troden ifit, lege man über bie gange Stelle ein Seftaflafter. Daz= felle follte warm gemad)t twerben, fo haß bie Salbe Larauf fdjmilyt uno bas \$flafter anflebt, worauf man es mit ber Sant feft auf= trüdt. Die bejte Methone ift, heife Roblen oter ein heífes Eifen

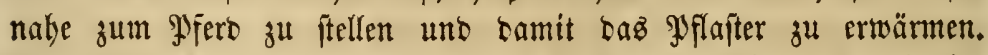
Sit ber Rüden geidjwollen unb hat fid) Eiter gebilbet, fo fdnneite

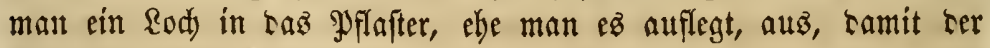
Giter aus̆laufen fann.

Ein foldees Mflafter werbintert bie Reibung burd) sen Sattel orer

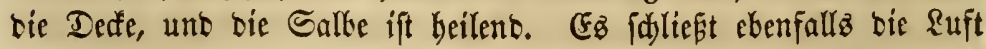

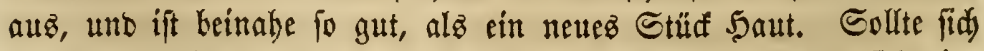
onfielbe abjojieben, fo lege man ein anberez auf. Sollte fid eine Beule gebillbet haben, fo mag man cin sod) in sie Dede fdnneiten, ober fie fo zu[ammenlegen, sap bie Stelle som Satteltrud frei if. 
Bei biefer Bebantlung mag man baß \$perb beftänbig gebraudjen, uno bie Sattelgallen werben nidjt allein nidjt idjlimmer, fonbern beilen aud langfam. Diefez fann aber nur auf Reijen empfohlen

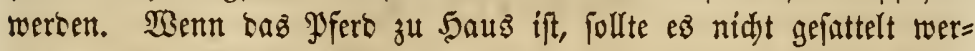

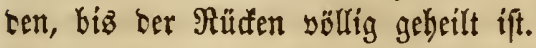

\section{Derlekung bes Dbrs.}

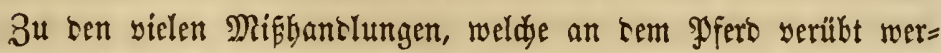
ben, gehört taz Inneifen uno Reifen ter Shren. Sft baz Pfero unruthig ober witeripentitig bei sem Beidlagelt, fo baben mande

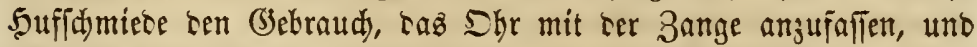
gibt fid bag Thier nod) nidjt jufrieren, fo zieht ber Sdjmied ober ein (ઉ̋ebülfe wäbrento bem Bejdlagen mittelfit ciner Zange mit aller

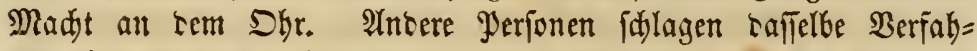
ren ein, wenn fie ein wiltes ober witeripenftiges \$yfero bänbigen wollen.

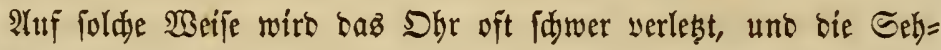
nett, welde bie Dhren in ihrer aufredten Stellung erhalten, werben manddmal abgebrodjen, fo tás fie herakbängen. Daż Pferb hat über biejelben feine Controlle mehr, fontern fie baumeln bei jeber $\mathfrak{B} e=$ wegung ses Sopfez herum. Cdlimme (sejdmüre fint oft bie Fol= gen yon riejen verwutteten Muzfeln uno Rnorpeln tes Shrż; fino fdyon fällle vorgefommen, wo burd) biefecten urfaden eine flie=

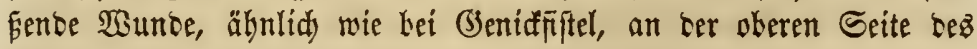
Dhrz nake bei bem Ropfe bervorgerufen wurbe.

Ather foldye Mífbandlungen baben oft nody fdlimmere Folgen.

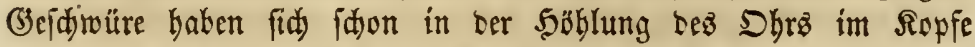
gebilcet, befonterz surd Sdjläge auf ben Ropf in ber Räbe bez Shrz. Mande Perfonen fint io heftig uno hisig, baf wenn tas

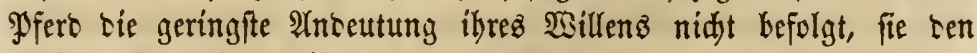
näd)fen Prügel ergreifen uno bem $\mathfrak{P f e r b}$ über ben Ropf íblagen.

Durd) foldje Gicwaltthat miro oft bleibente Inubbeit verurjadt. Ez gibt viele Pferbe in biefem Rante, weldje entrober ganz ober theillweife in einem ober beiten Shren taub fint. Wie allgemein if

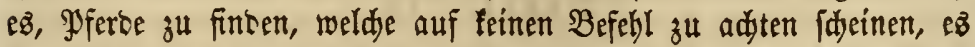
fei benn, berfelbe werbe gang laut gegeben, unb bann geben fie fo

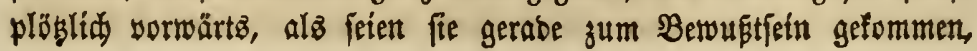




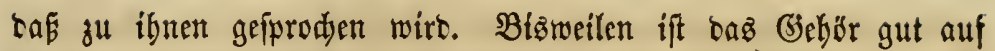
ber einen Seite, auf ber anberen aber yolllig verjdwunben.

\section{B}

Sft bie Befdwerte cine äufere, fo follte bie bei fifitel vorge= fartiebene Bebandlung befolgt werben. Sit ez nidjtż anberes als

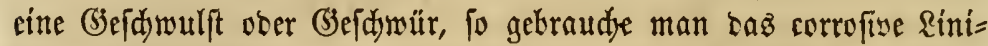
ment; gebraude aker Entenfú (May-apple) Siniment, wenn fid

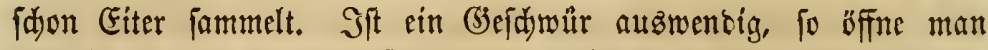
baffelbe an bem unteren Ente uno Durdjftedje baffelbe mit ter $\& a n=$ zette you unten nad) oben.

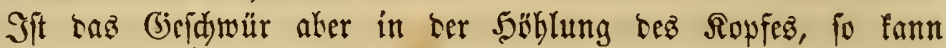
weber zur Sinberung nod) zur Siur viel keigetragen merben. Biz= weilen aber fann man Rinberung surd) Einfpritzen seridaffen, in=

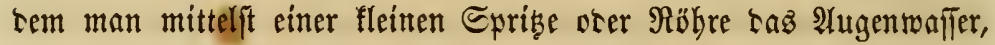
weld)es man nad) ber Ifnweifung im XXIV. Rapitel zubereitet, in taz Dhr einjprigt.

\section{Ba n}

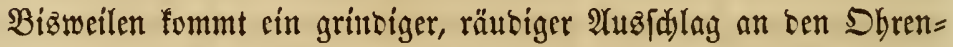

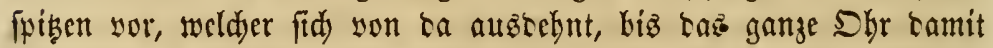
ülerjogen ift. Diefez ift cine edjte 5autfranflecit, weldye einigen

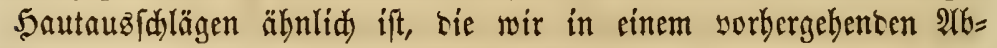

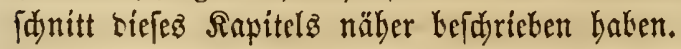

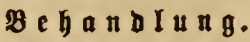

Man madje gutez, ftarfez Eeifenwafler, wajhe bie Dhren mit Demfelten ab unt fdmiere fie mit Edjwefelfalbe (sulphur ointment). Tadjcem man biefez längere Beit ohne Erfolg angemandt, fo nebme man etwas Merfurialijalbe uno beftreidye tie betreffenten Stellen zwei biz brei Tage lang cinmal bes Tagez. Radjem man ebenio lang aušge jebt, fann man wieber Damit anfangen. Dod) ift $\mathrm{ez}$ fel= ten nöthig, bieje Salbe zu gebraudjen.

\section{un geziefer.}

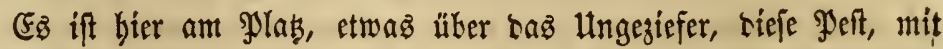
welder in ber einen voer anbern form bie ganze thierifde Sdyp̈ping 
geplagt ift, zu. [agen. Früher nahm man alfgemein an, Laf nur

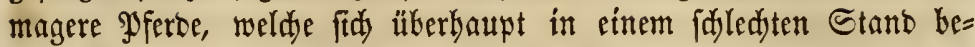
fänben, bamit geplagt feien; aber wir mifien, Lá während tem Sirieg viele Pferbe im beften 3uftand bayon befallen wurben. In folden Fällen murbe bie Plage wohl yon einem \$ferse auf antere übergetragen, uno baz lngeziefer war uriprünglidy fonftwo gebrütet morden.

Dhne 3weifel entftand ift ein Fflud), welder fdiledten Stallung, unreiner \&uft, Itnreinigfeit uno Bernadilaffigung folgt. Sbgleid) Utngesiefer autd bei Pferben, welde suf ber Weibe geten, yorfommen mag, fo wirb ez todj in neum Fällen aus jehn in fdjledten Ställen erseugt, uno ift faft whate $\mathfrak{A t a z n a h m e ~ b a ~ y o r h a n t e n , ~ w o ~ t i e ~ T h i e r e ~ u n r c i n ~ u n o ~ u ̈ b e r h a u t p t ~}$ fajledt befantelt werten, und Larum immer cin Betweiz, Lafi ez am

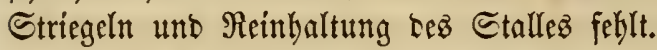

Es ift immer follimmer im Frühjahr, gerabe che has baar alts= fällt; wirb ez aber aud tann nidet weggeidafft, fo bleibt ez bei mandien alten feelettenartigen $\mathfrak{Y}$ ferben bas ganje Sahar. SIlte Pferce fino bamit mekr geplagt, als junge, rifftige. Es ift bejonter eine gylage für junge Foblen wäbrento bez $\mathfrak{B}$ inters, unt mandjer arme, magere, Galbtobte Sährling ift idjon Surd Ungegiefer fehr herunter=

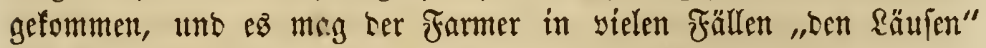

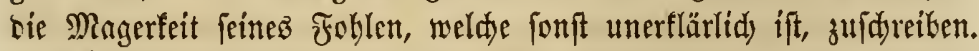

In' einigen Fällfen ift biefe glage bie Folge son Rrantbeiten;

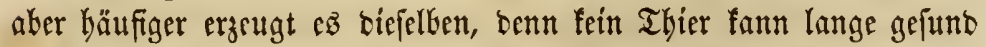

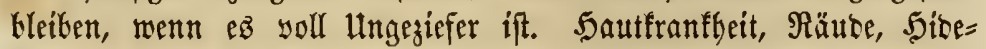
bounb unb vielleidjt anbere Hebel werben saburd hersorgerufen.

\section{$\boldsymbol{B}$ с}

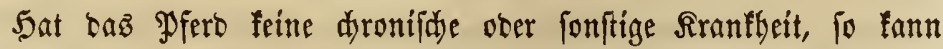
man taz Ungeziefer vertreiben burd) bloféz Beftreiden ber 5̧aare mit Merfurial= Salbe, ober ber nieberfdilagenten ober Sdjwefelialbe. Tabad yertreibt baß Ungeziefer; aber biefez Mittel töbtet aud

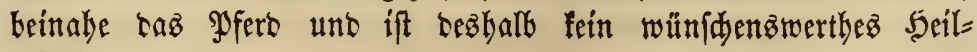
mittel.

In Berbindung mit ber Salbe, melde man braudjt, follte bas

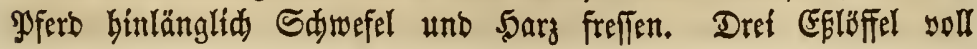




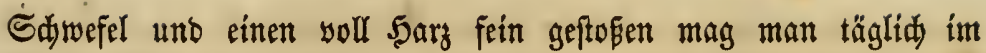
Futter geben.

Fin Bedjel aus bem Stall auf bie Weibe ift nadber bie beite Mebizin; fann biefer nidjt frattinten, io gebe man bem Pfero bin= retejent gutez, gejunbez Frutter.

In allen Sautfranfleiten, wo alterirenbe Mittel nothwentig finb, fann man bie Zubereitung, weldhe im fiebenten 216fdnitt bez XXIV. Rapitelz erroähnt ift, mit Bortbeil gebraudjen. Sn mandjen Fällen

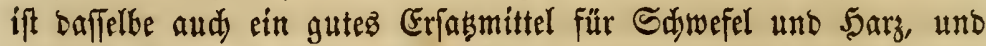

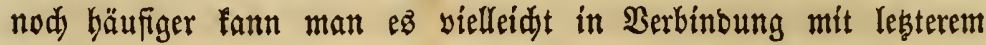
gebraudjen. 


\section{OClentutes Sapitel.}

\section{ffrankbeiten des Gebirng und des \#ernenfyftemg.}

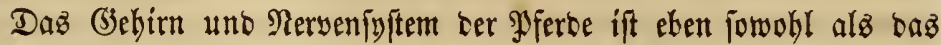

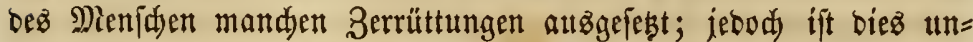

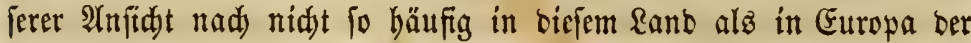
Fall. Mandje- Dicjer אiranfleiten fint Folgen von Berlebungen, an=

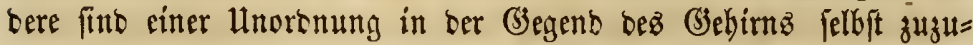

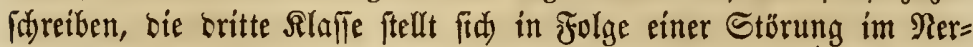
yenjyftem cin. Berleşung Tob.

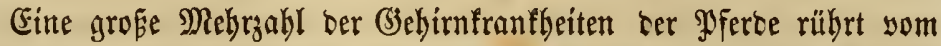
Druff her, ooer es fintet bei allen Sirnfranfheiten menigitenz mebr voer wentiger Druff ftatt. Diejer Druff auf baż Ģehirn mag auf breierlei

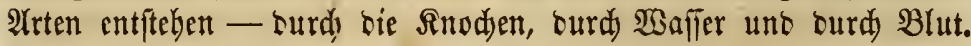
Auf ber innern Seite ser Sdjäbelfnodien entftehen oft Sinodenge=

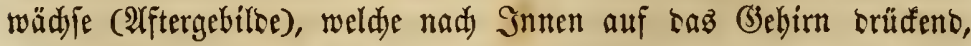
Rrampf uno Tob yerurjadjen. Alehnlide Folgen werben bizineilen yerurjadyt burd) graujame Sd)läge auf ben నopf, bejonberz bei Foblen, bei weldjen ber Iinoden nod) weid) uno biegjam ift.

\section{Ifaffer im (B) bitn.}

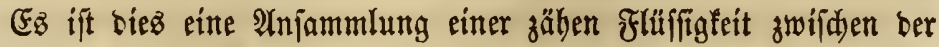

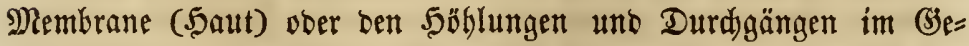
birn. Bei ausgerwadjenen Pferben fommt ez felten yor, wohl aber bäufiger bei jungen Foblen. Diẹes lebel verurjadyt faft immer

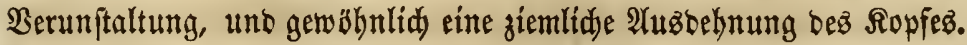
Das bamit behaftete Fohlen jtirbt gemöbnlid bet ber Geteburt ober furz nadiber; mandimal aber falleppt lang bin. 


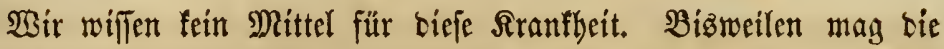
Natur ftarf genug fein, saz Reiben zu überminton, bierauf fann man jecod) feinerlei 5offnung grünben.

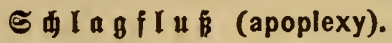

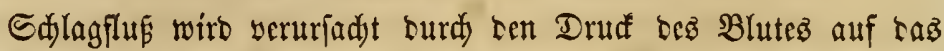
(jebirn, uno ifit bei sen Menfdyen etwas gewöbnlidjez. Dí Farmer werben felten etwas bamit $\mathfrak{z}^{\mathrm{u}}$ thun befommen, uno fie würben siel= leidyt erftaumen, wenn fie wüsten, wie viel \$y ferte jäbrlid baran

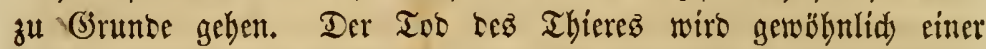
antern SiranfGeit zugefdrieben, unt bie Bebantlung, in Uebercin= ftimmung mit ber verfebrten 2 (n)idd, bcid)leunigt in neun faülfen aus

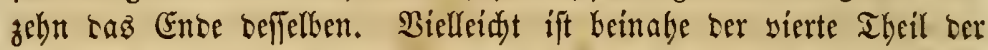

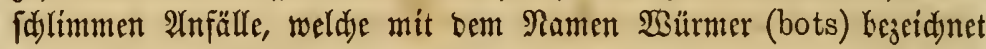

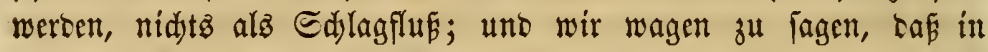

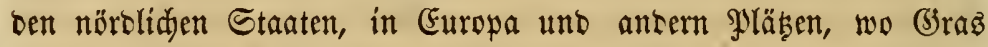
genutg wädjt, bie Sranfleit, weldje yon Thierärz̧ten, bem farmer uno Anteren Roller, aud) Edjwintel (blind staggers) genamut wirt,

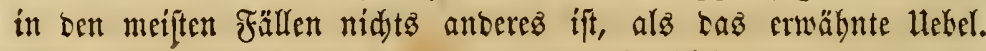

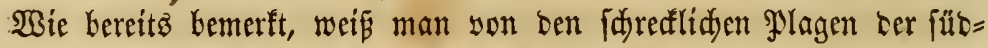
liden Etaaten (blind staggers) nörolid) yon bem 36. Brreitengrabe

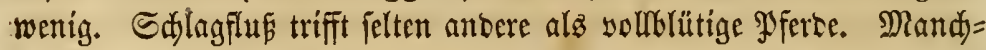
mal mag biefe Sirantheit aud) bie Folge einer anderen fein, unb

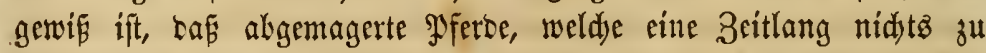
thun batten uno gut gefüttert wursen, leid)t einen Edjlagflukanfall befommen. Daffelbe ift mit jungen Foblen währeno bez Zahnenz

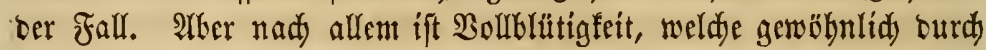

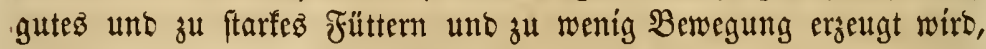
bie 5aupturfadje yon Edjlagflup.

(3)lüfliderweife berridjt jebt, hinfidtlid ser zur Sdjönheit Les Pfertes erforberliden Jleifdymafle, eine son ber früberen veridjiebene

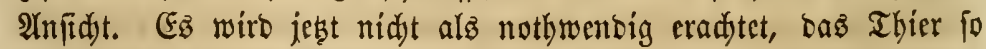

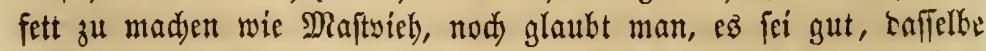
faft bic ganze Beit einjulperren, ohne ihm Bewegung zu madjen. Sdjlagflue ift ourd) Edjwindel unt wilbe Bewegung, unt beinahe immer burd) einen ftolperigen (bang gefennzeidnet, weshatb tiefe Sranfleit aud to oft für Roller angefehen wiro. Dis fallimmften 
Symptome in ber nädften Stufe fino ein ftarfer Sdyneif, ein 3it=

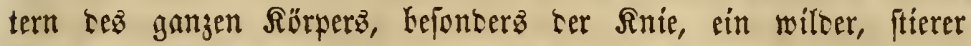
Bliđá, ein Zưfen ter Saut uno Zerren ter Shren. Die Mebrjahl ber Farmer und die Sälfte ber mobernen Pfertetoftoren würten allez

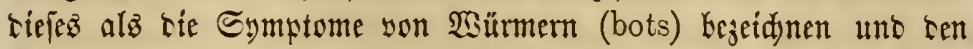

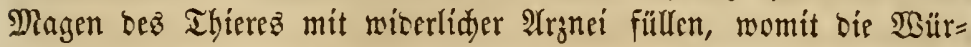
mer entfernt wercen follen, was aber nur bie Cdmerzen sermebrt, wenn nidjt jogar cen Tob yerurjadt.

2llles biefes ift reiner llnfinn. Das Pfero Graudyt feine-Arantei.

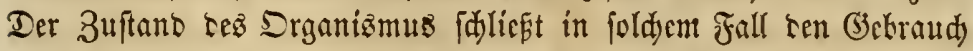
yon Argnei aub. Die Rranfbeit entjteft rurd Aufregung ber Rer= ฟen, Laz ganje Nerwenfyftem ift in faredlid)er Hnorenung uno sas Gebirn - ter grofe Empfintungs̄its aller Nerwenfräfte - ift zufam= mengepreft. Fine grofe, plöslidue Zufübrung son Blut im Sopf bat ftattgefunien. Das ganje (befirngemebe son Nerven uno Blutge=

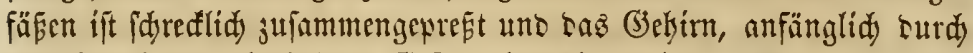

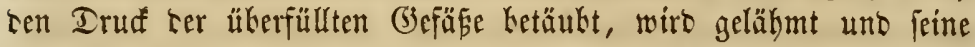

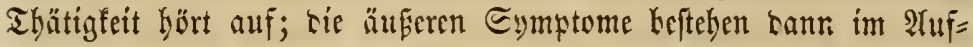
bören fer Gmpfintung uno milleürlityen Bewegung.

Die Urjadye cicjes Blutfluffe zum Ropf ift nidyt cine Deränterung ober Siranfleit im (j)birn felbit. Fine allgemeine Zujammenjiebung ber (jefäpe bat eine ungewöbnlid, Suantität Blut angebäuft; orer ez̃ mag aud fein, ธás gewaltfamer äuperlidjer Druff, wie ber burd

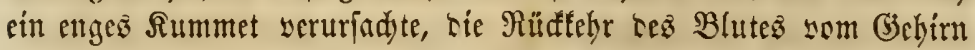
zum 5erjen serbintert bat. Die Injammlung son Fett ofer eine

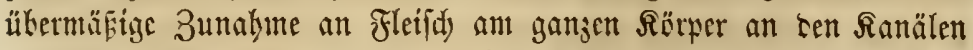

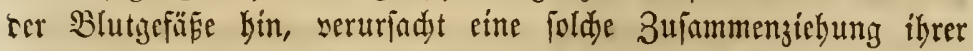

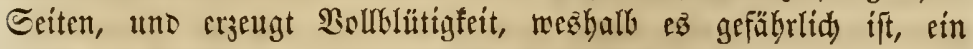
Ibier zu überfüttern uns alljuifer ju fdyonen.

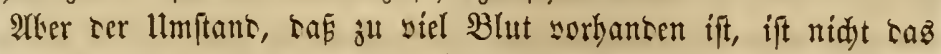
einjige Hekel, fontern Ias Blut ift aud sid uns son unnatürlidyer bunfelrother, faft brauner Fartie. Durd) tie 3ufammenziehung ter Blutgcfäp̧e twitb riẹç franflyafte Blut in gröperer Duantität tem Serzen jugefübrt, alz ez riefez Srgan ju ertragen im Etante ijt. Daz

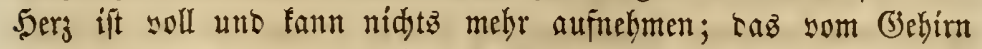
zurüffebrente $B$ lut fann nidt weiter, bie (Burgelaber an ber Seite

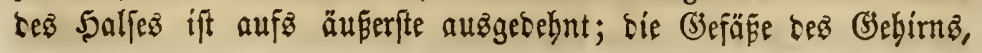


weldje ebenfallz ungebeuer aużgerehnt fins, srücfen ftarf auf bie

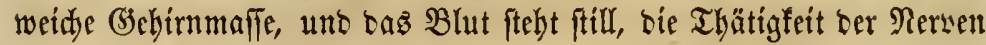
bört auf uno baz গPferb fällt tobt nieber.

Alles biefez mag nidjt mehr Beit erforbern, als wir zur Befdurei= bung gebraud baben, mandjmal mag es aber aud ftunbenlang rauern.

Das Hebel, weldes einen foldyen 2 tnfall berkeigefübrt bat, mag fid) faon Monate uno Sabre lang entwidelt baben. Jrgent Se= mant, ser fein. Pyero ftarf füttert, bis baz Thier redt fett ift, unt

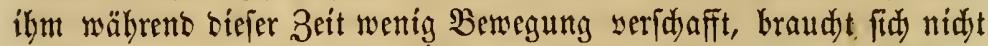

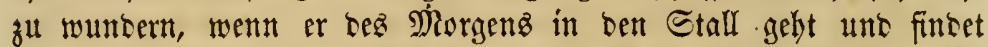
ben Riebling toot ober töbtlich 'am Shlagflus erfranft.

Der $\mathfrak{A n f a l l}$ tritt ofne Kebeutente Wamungżeiden, oft obne sie geringiten ein. Wenn baz, waz bie Farmer , Mürmer" ober "Stag= gers" nennen, Durdy bie bier bejdriebenen Symptome gefentzeidynet ift, fo ift ber Fall ein betenflidyer. Fine ber Sirfungen biefer Rrant= beit sersient befonsere Berüdfidtigung, unt jwar bie, baf, felbift wenn bie Symptome bes Salaganfallz nur đduad waren, bie $\mathfrak{A} u=$ gen bebeuteno Yeiten. Nidyt wenige Augenfranfbeiten uno felbft Blintheit baben ifren llriprung in Sd)lagflufanfällen. Tyouatt fagt: (5B ift nidyt bie gewöbnlidye, som grauen Staar erzeugte Blinobeit,

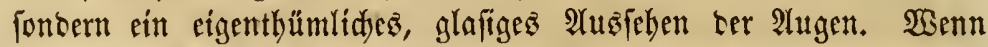

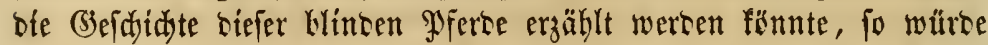
fid) zeigen, baf fie Âtüällen son Stumpfbcit uns Shnmadyt unter=

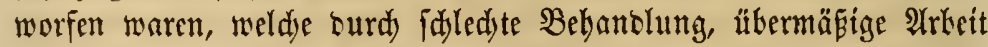
u. F. w. herbeigefübrt worben.

Wir haben zwar dic Symptome unb die Entwidfung bes Sdylag=

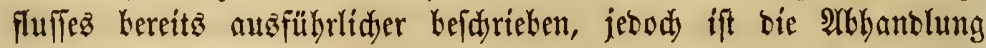
9jouattz über benjelben (Jegenftano fo sollftänbig uno befriebigent,

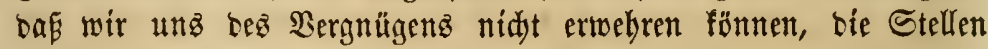
unjern \&efern anjufübren:

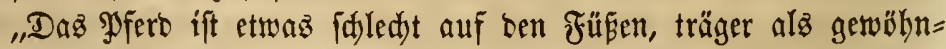
lid), uno oumm, uno hat gewöbnlid einen folpernoen (s)ang. 3wa:

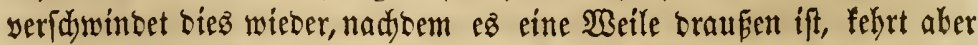

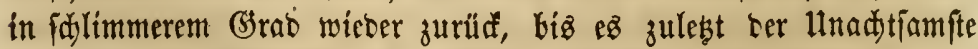
beotadytet. Das mirflidje STranffein bes Pferbes wiro vielleidjt zut= erft an Lem Rieberbangen beż Ropfeв erfannt. GE legt benjelben 
auf bie Srippe, ober ift geznungen, biefes zu thun, ober ben Sopf

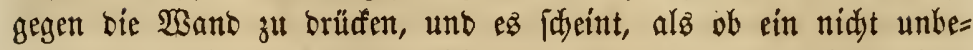
beutenter Theil bes Rörpergewidyt auf bem Ropf bes Thieres liege.

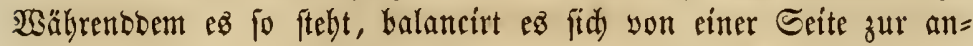

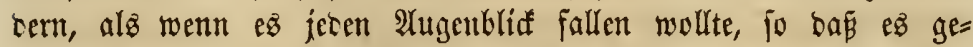
wöhnlich gefäbrlich ift, neben iłm zu fieben, ober ez zum (s)ang an=

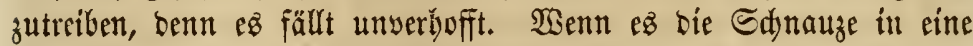
Ede bringen fann, bleibt es oft in biejer Stellung betwegungšloz eine

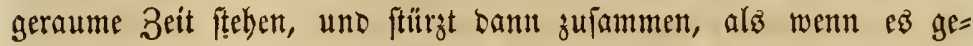

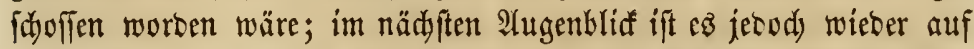
ben Fü ober ift ronigftens ganz uno gar betwustloz. Wiro es aufgedureaft,

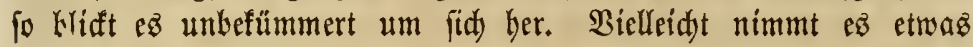
Seu. eş Die Augen uno fallät wieber mit bem Futter im Maul ein. Balb oarauf wiro ez vielleidyt nod eimmal aufgerwedt; es offnet bie Augen; aber ber Bliff ift ein ftarrer. Man bält ifm bie Sand vor,

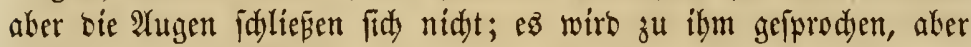
es bört nidyt. Die leste freimillige Betwegung, weldye es madyt, ift gewöbnlid, ein Berfuth zu faufen, aber ez bat zu wenig Sraft

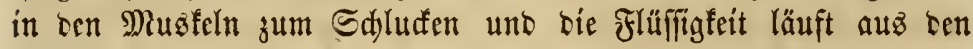
Rajenlöd)ern zurüđ.

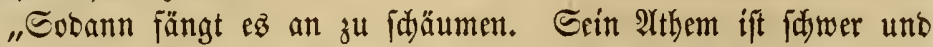
laut. Das $\mathfrak{A}$ thembolen fommt nunmebr burdy ben Cinflus organi= jher Nerven ju Stanoe, benn die beż animalijaen Rebenz yerjagen ibren Dienft. Der Pulz ift langiam und unterbrüct, bie Salząoer aber ift biz zum Berften aużgebebnt, bie Sdynauze ift falt, eB miftet uno harnt unwillfürlid); ę fnirid)t die Zähne, ein 3ucfen über= fommt oas (3)efidt uno befält bie (3lieber, weld)e oft in heftige Srämpfe übergeht, währent beren Dauer bas Pfert fid auf eine

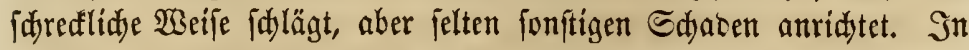
ben meiften Fällen bauern bieje Convulfionen nidt lange. Alle $\mathfrak{R e}=$ benşfäfte find unterbrüdt uno ber Tob-endet bie Reisen. fdnell. Bei einer Unterfudung nad) bem Tobe finbet man im ganzen $\mathfrak{B l u t}=$ abcriyftem Blutanbäufungen, und bie Stefäfe bes Behirns find yon ¡dwarzem Blut bejonberz aufgebunien. Bistweilen jebod ift feine Entzünoung im Sichirn ober Den (Sebirnbäuthen, aber ber Magen 
enthält entweber eine ungemabntide Mafle Speife, ober bie innerent Cingeweite fint mit fajledter fauler Subjtanz überlaben."

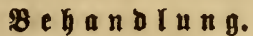

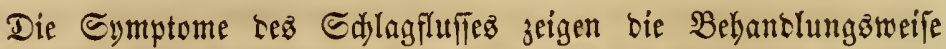
beutlid an. Der Magen felbjt besarf feiner 2 rajmei, mag aber alz Mittel gebrautd) werten, Lem Rervenigftem Sheilmittel zuzuführen. Da ber Tod surdy eine Blutankäufung in ber (Segent bez (3e $=$

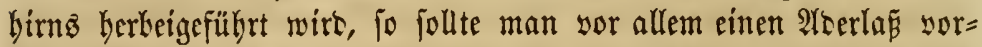

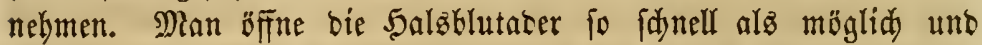
lafie taz Blut laufen, biz fidy bie Farbe - in belltroth verwantelt. Der Einjentitt, weldher mit Ler \&anjette ober Fliete gemadjt wirt, follte grof́ feín, bamit Las Blut reidlid ablaufen fann. Eine $\mathfrak{R} e=$

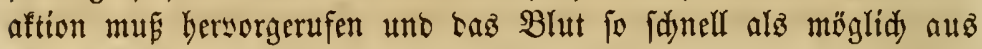

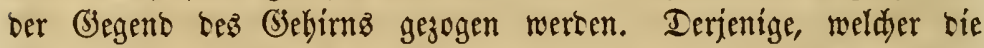
Speration sornimmt, mú felbjt beurtheilen, mie viel Blut er zu entżiehen hat, ba biejes jehr veridjieben ift in veridjiebenen faüllen;

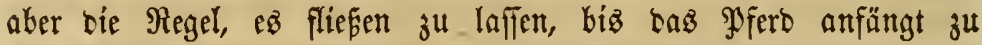

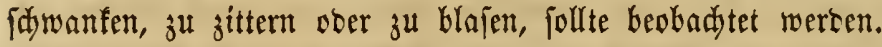

Dann gebe man eine Pinte heíke Salzwaller mit cinem Thee= lofffel rothen $\mathfrak{P f e f f e r}$ (Cayenne pepper) uno eine halbe $\mathfrak{H n}_{\mathfrak{j}} \mathfrak{e}$ Sauta num (laudanum) yermi idjt. Youatt veridjreibt Enjian (gentian) unb Ingmer (ginger). Diejes ift febr gut, aber fehr mill, uno bat in unjerer গুrariz nidjt ben Forberungen entjprodjen, wirft jebodj fehr

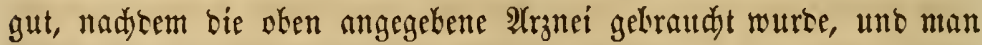
bereite tie Merijin wie folgt: Fine halke $\mathfrak{H}_{3}$ pulwerifirten $E_{j} n_{j}$ ian (gentian), ebenjo viel Sngwer (ginger) uno vier $\mathfrak{H}_{\mathfrak{j}} e \mathfrak{n}$ Bitterialz (epsom salt). Diefez reidjt für zwei Baben. Man gebe sie erfte Dofiz vier Etunten nady tem Raueanum uno tie anbere jwölf Stun= Len fäater. Ein Einjd)läferungżmittel ift nothmentig, fowohl als ein beruhigentes uno frampfitillentes. Artez diefez ift in tem ancm= pfoblenen Mittel entbalten. Der Pfeffer erwärmt unt ftimulirt, ธą \&aubanum idjläfert ein, uno alle bier angegebenen $\mathfrak{A} r$ raneien finto

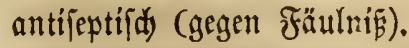

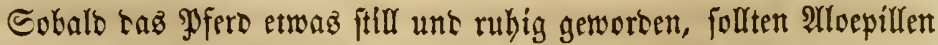
gegeben werten,--man nímmt yon einer balben biż zur ganzen un

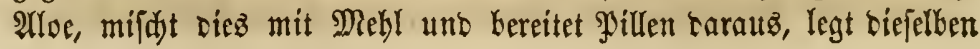


Ginten auf die Bunge, unb baz $\mathfrak{B}$ ferb wiro fie Ginunteridlufen. Auterbem ift nidyt mekr viel erforberlidy. Şat man bie Sranflyeit bibber erfelgreid bebanbelt, fo ift (J)runb yorbanben, auf eine Sur zut redunen.

Auf bas Futter muf grope Sorgfalt serwentet werten, uno man barf nur leidjtę Futter reiden, 3. B. Maifd, grünez Futter uno Weite. Pferte, welde viel auf rer Weioe geben, befommen felten Sd)lagflup. Es ift eine Stalltrantheit.

Nadj ber Seilung laffe man Das Pfero nidyt wieser fett und

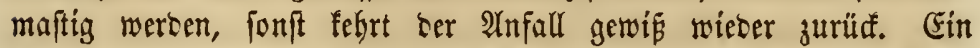

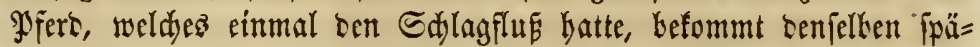
ter leidyt wieber. Die (Sencigtheit baju liegt in fer Zunahme an Fleija) uno Fett, weldye Uriadje man forgfältig ju vermeisen judien

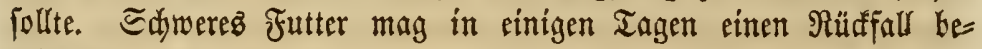
wirten.

Mafierfideu; $\mathfrak{Z}_{3}$ uth (rabies, hydrophobia, or madness).

Bon biejer furedfliden Srantfeit wifTen wír aujer bem, waz wir in Büdern carüber gelejen, menig. Sie fommt unter SPferten, be= jonters benen in Imerifa, febr wenig sor, uno wí fino überseugt, bá fie feinen anoern Uriprung hat aufer bem Bíf yon tollen 5̧un= oen. Alber felbit tolfe Sunte fino jelten, benn obgleidy fie bistweilen in Stästen gefunsen werben, fommt Sunbewuth auf oem Ranbe

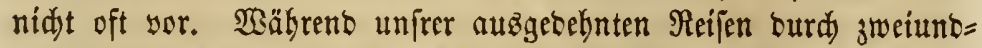
zwanjig Staaten ber Union fint wir nie einem tollen Sunbe be= gegnet uno baben yon nur einigen wirflidyen Fällen yon Sunbe= wuth gebört.

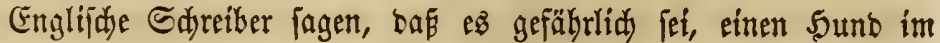
Pferceftall zu laffen, weil berfelbe toll werben uno bie Pferse beifen mödte. In unierm gefegneten sanbe begt man biefe Furdjt nidt, hat aud nidt bie geringfte. Deranla|fung Dazu.

Wir freuen $น ท 8$, baf wir beredtigt finb, biefe Siranfleit eine aub= ländifde zt nemnen, benn alle Ihierärgte ftimmen barin überein, baß fie unbeilbar jei.

\section{\&ีalfu西 (fits, or epilepsy).}

Sbgleidy man ifre felten begegnet, fo ift bie Falfudut bod in ben. 
Ber. Staaten nidyt unbefannt. Gin Pfert, weldję an Fallfudd

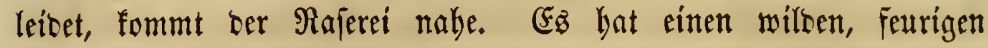
BBlifa, bäumt fid uno fallägt umber uno ift gewöbnlid) som $\mathfrak{A} \mathfrak{n}=$ fang biz zu Enbe bez 2 Mnfallz unlenffam. Mit bem Fortid)ritt ter Rrantfheit ïberfällt uno liegt in betäubenten, idjref̌lidłen Rrämpfen. Die Danter siejer

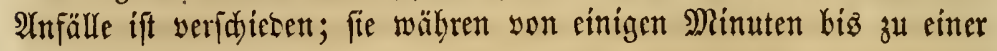
beträd)tlíden Iauer.

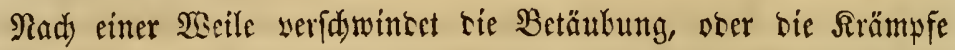
bören auf; baz Pfero ftebt auf, fduüttelt fid), alż ob nid)tż vorge= fallen fei, geht bayon uno fängt an ju freffen.

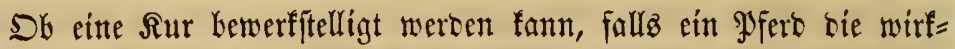

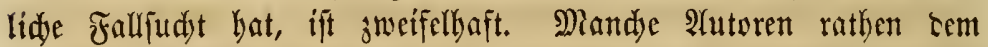
Farmer, auxifinbig zu maden, waz die Hrjadje ift, uno madjen ibm etwaz Soffinung zur Syeilung. Aaker wir haben nod) you feinem Fall gehört, wo eine 5eilung auf zufriescuftellente 2 seife nadjge=

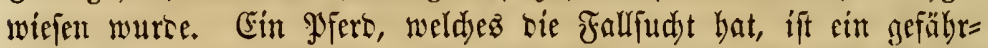
lidjez Thier, unto ein Farmer, meldyer feín eigenez Sntererle fowohl

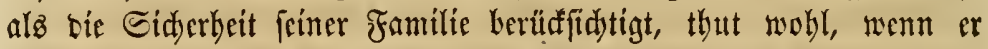
es Ginidaffit, wo es fcine Gelegenbeit hat, Utubeil amzuftiften.

\section{Girnentgïndung (inflammation of the brain, or phrenitis).}

Diefe Sranfleit, obwohl fie in biefem Rante nidyt allgemein vor=

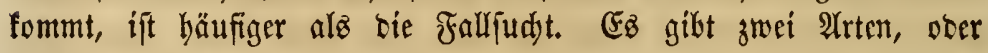
vielmelyr, (3ebirnentzünoung mag von zwei Urjaden berrühren. Erftenz yon bem Gsebirn felkft, in weldyem frall man fie willfürlidye Entzüntung beif́t; uno zweitenz von einer antern Rranflyeit, uno bann wiro fie ,fimptomatifi" genannt.

Die lektte $\mathfrak{A}$ rt ift bie einzige Erideinung ber Rranfleit, mit wel= der wir praftifd befannt find. E\& ift biefe, weldye bie enslidye $\mathfrak{l l}=$ fadje bes $\mathfrak{T}$ obes ift in allen fdlimmen Rollerfällen (blind staggers)

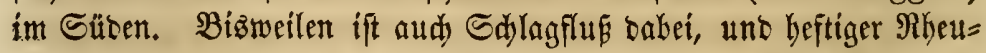

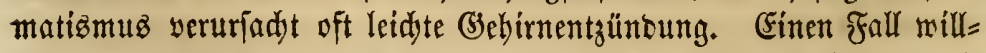
fürlicher (Entzüntung, voer Fieber bez G3ehirnz, haben wir nod) nie gefehen. Dieje 2Art ter Rrantheit mag ba uno bort in biefem Rante

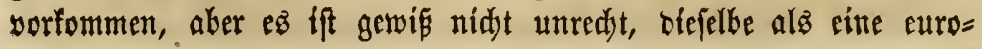




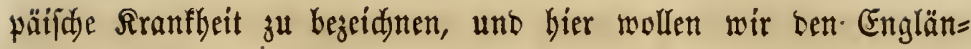
ter*) felbft recen laffert:

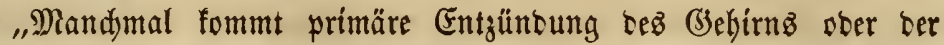
(Jethirnbäute, oder biżweilen aud beibez yor, Gäufiger jebod bie ber (bethirnbäute.

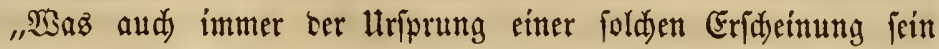
may, bie erften Spmptome fino faum seridjieben son benen bez

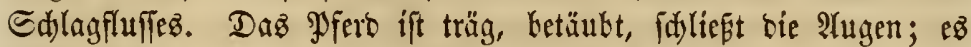

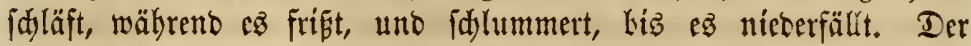

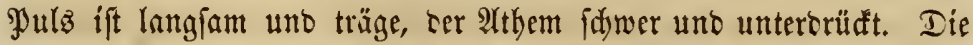
Symptome mägen bezüglid) ber Dauer uno (3rö̈ße verjdjeten fein, aber nidjt in ifrer 2 (rt.

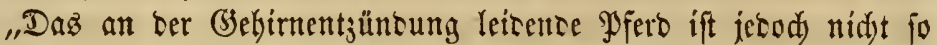

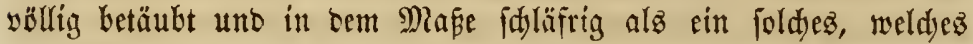

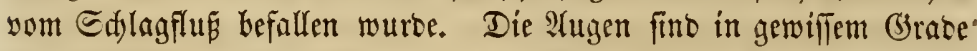
für bas Ridyt empfänglidy, uno baz Thier ift etwaz lenffamer ober

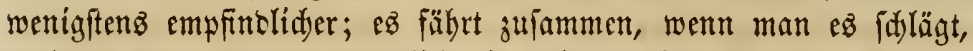

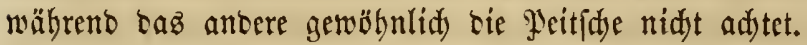

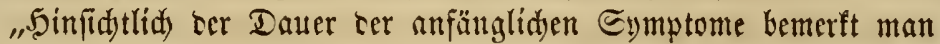

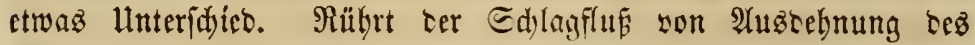

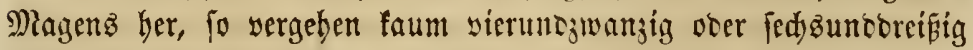
Etunten, ehe eine Seilung bewirft iff, ober ter Magen jeriprengt, uno bas Pfero iff verloren. Sommt es mehr son Unterorüfung ber Ber=

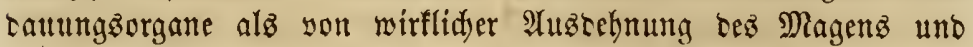
yon ber $\mathfrak{B}$ edjfelwirfung, weldye zwifjen bem Mlagen unb bem (3e $=$ birm befteht, fo farreitet bie Rranfleit fort - miro yon Stunte zu Stunte fallimmer, und biefer follummernte 3uftano bauert zwei ober brei Tage. Der Edjlagfluê bez mit Gehirnentzünoung behafteten

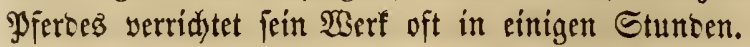

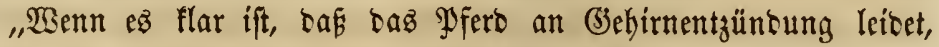

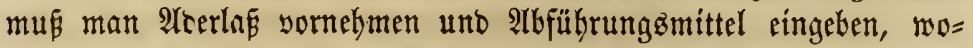

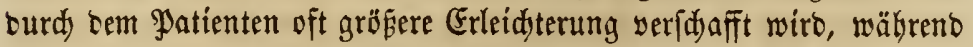
er burdy foldye energifdye Behanolung aud vielleidyt gebeilt merten mag. Sat man aber bie golsene Stunte verjdwinten lafien, ober bleiben bie angewandten Mittel erfolglos, po erfolgt bie idredtidjite

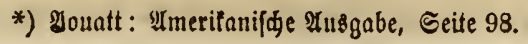




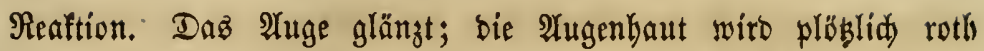

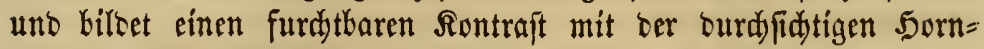
baut; ber $\mathfrak{A}$ ugapfel ift ausgebehnt; bie Rafenlöd)er, weldye vorber (id) faum berwegten, behnen fid auz, zittern uno fino thätig, sie Shren ftehen aufredtt oder fint nady sormen geridtet, alż ob tas

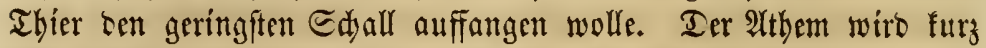
uno (đ)nell, uno bas \$fert, weldjez immer mehr aufgeregt wirt, zittert bei ber geringften Berwegung. Die $\mathfrak{A}$ ufregung tez Thieres

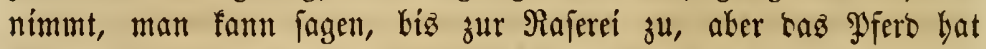

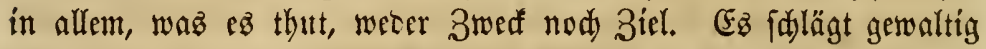

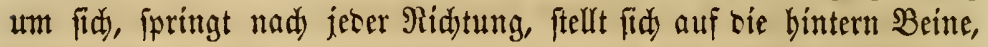

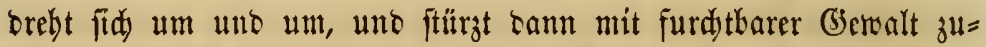
rüaf, uno bleibt eine Beitlang eridjöpft licgen. Dis Symptome ha $=$ ben nad)gelaffen, aber vielleid)t nur für eine Minute ober zowei, mögliderweife für cine Biertelftunse. ***

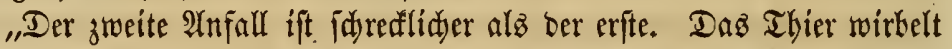

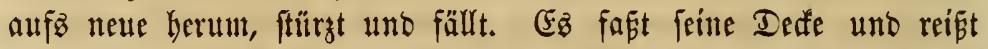

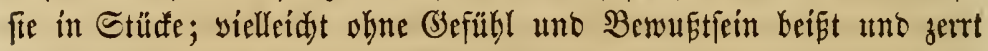

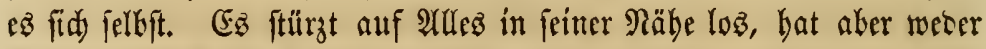

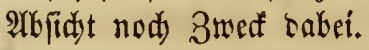

"Gine Unterbredyung und cin immer follimmerer $2 \mathfrak{A n f a l l}$ folgt bem

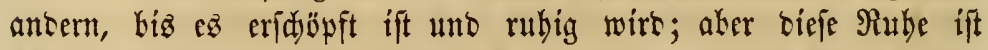
ridjt zurüafgefehrtes Bewustjein, jontern eine Betäukung. Dicjęs bauert eine Zcitlang, wonady bas Thier aufs neue anfängt, unrubig z̆l werben, aber vielleidyt unvermögeno ift, aufzuftehen; $\mathfrak{e z}$ bäumt

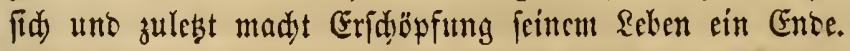

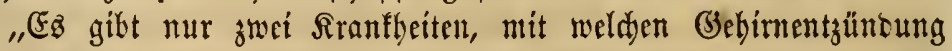

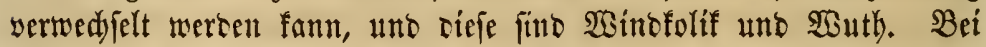

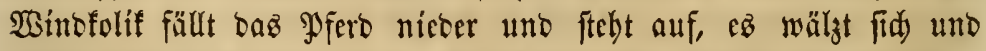

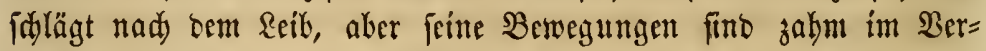
gleid mit benen, bie bas mit befhirnentzüntoung behaftete Ibjer aus= führt. Es hat feine willfürliden Rrämpfe in irgento einem (ST)

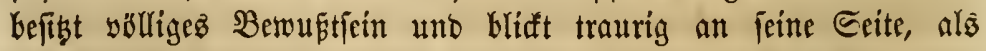
wollte ben Sib ber Samerzen anteuten. Der fab̈ne, aber färeftlid) aufgeregte Blid bez cinen uno ber mitteioige, bejorgte Blid bes andern fint fehr veridjeteden, uno wenn man zu ith fommen

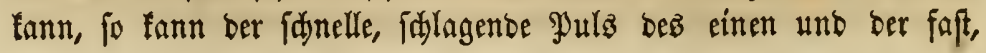


befonters im $\mathfrak{A}$ nfang, natürlidje beż anberen nidjt leidjt verfannt werben.

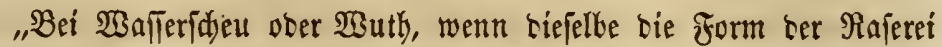

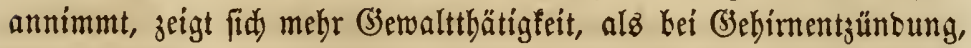
unt baz Thier verfolgt cinen 3medf Labei uno will Unteil anrid $=$

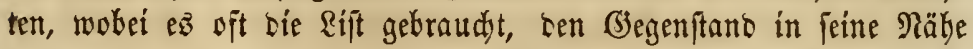
fommen zu lafien, um ign zu yernidyten. Dem wafierfdeuen giferbe

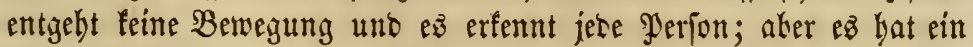

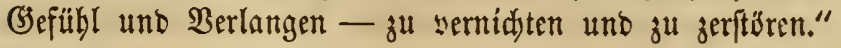

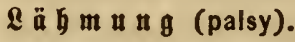

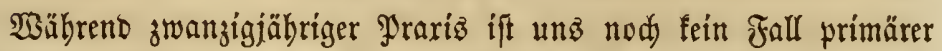
Rähmung yorgefommen. Die wenigen Fälle son Rähmung, weldde wir beobadtet, wurben alfe surdy andere Sirantbeiten veranla fat uno theilten immer taz Edjiffal berfelten. SBurte Laz Mfero yon ben anbern Hebeln gebcilt, fo veridwanto bie rähmung, im antern fall nidjt.

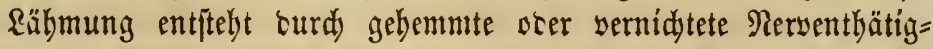
feit. Es wiro gewöbnlid angenommen, baj cieje Rranfleeit tie

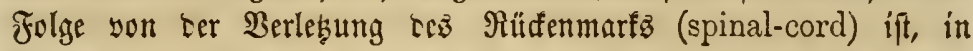
Folge tecien sie 5 hüfte unb Sduentel und anbere Theile tez Sinter= förpers theilweife gelähnt werben.

\section{B e}

Diefe wirb burd bie Befdaftenteit ser Siranfleit beutlid ange= zeigt. Man la je zwei= oter oreimal 2 ther in einem 3wijdentaum yout zetn Tagen; bas erftemal entziele man eine (jallone Blut, nad)=

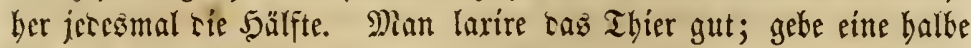

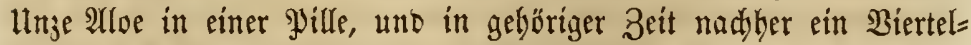
pjunt Bitterja (epsom salt). Man wente cann

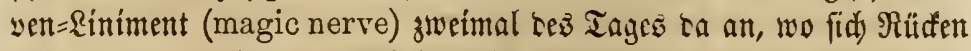
uno Şüfte verbinten. Sdeint biejez unjulänglidy zu fein, fo $\mathfrak{g} e=$ braude man ftatt befien corrofitez siniment jwei biz brei Tage lang.

Bei faltem $\mathfrak{B}$ etter bebecfe man Laz Pjerb mit einer guten wollenen

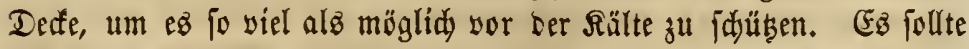
nur leid)tez abjührendez Jutter gegeben werben, yorauzgepést, baf baficlbe nidit Durdjall verurjadt. Starfez erbibentez Futter mag bas $\mathfrak{P}$ fero töbten. 


\section{$\mathfrak{B} \mathfrak{a} \mathfrak{h} \mathfrak{n}\{\mathfrak{i} \mathfrak{n} \mathfrak{n}$ (insanity).}

Soln Bull's Yferbe fowohl wie feine Sunte fajeinen nidyt allein

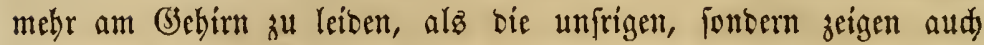
bie uno ta bie eigenthümlidjten, höd)ft überrafdenten Matureigen= beiten. Weurre irgento ein angefebener amerifanifäer Edyreiber fid

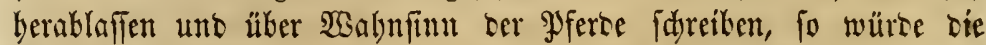

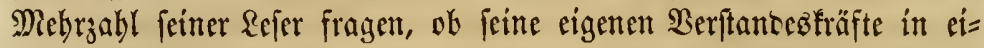
nem siel befferen Buftante feien; tod) als eine furiofe unterbaltente

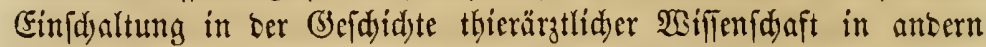

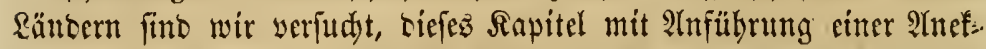

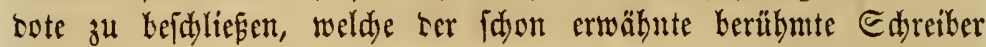

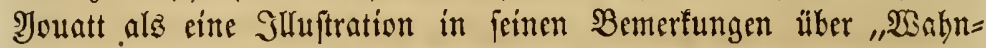
finn" gebraud)t.

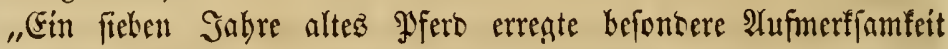
surd) Feine Dummbeit uno sen eigentbümliden wanternten $\mathfrak{2}$ tus =

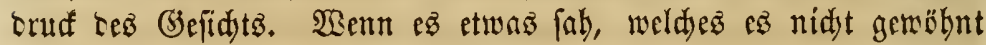
war zu feben, ober einen plötliden orer ungewähnliduen Edjalf

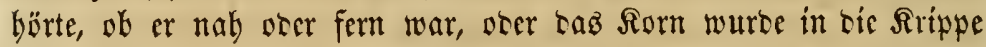
geworfen, whe safí $\mathfrak{e z}$ yorker geftreidelt oter ju ihm gefprodien

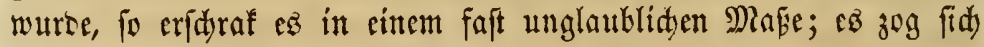
plöslid zufammen, jebes (bilico jitterte unt

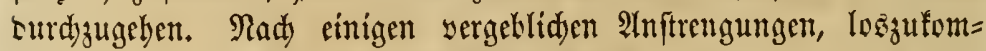
men, arbeitete $\mathfrak{c z}$ fid in foldye Raferé binein, ihm nabe zu fommen. Diejem aufgeregten 3uftant folgten bie bef= tigften Srämpfe, melde nidyt nadjléefen, biz entweber bie 5 alfter jerrifien war, ober ez auf fomfitige $\mathfrak{S}$ cif fam. Es wurbe sann wieser ruhig, liés fid) nad bem Etall führen,

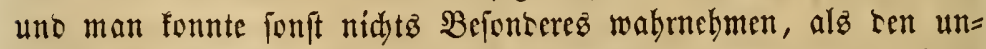

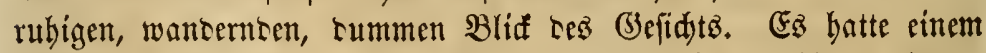

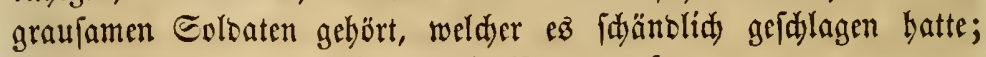
früher war

"Ein piemontelifider Difizier bejás ein pradtedvolles unt in jeber anberen $\mathfrak{B} \mathfrak{e z i e b u n g ~ b r a u d j b a r e z ̇ ~ M u t t e r p f e r b , ~ b a ̨ ~ a b e r ~ e i t n e ~ b e f o n t e r e ~}$ Eigenthümlidffeit an fid hatte, welde ez fehr gefährlid) madjte biez war ein entidjiebener $\mathfrak{A}$ bideu yor Yapier, weldes es augen=

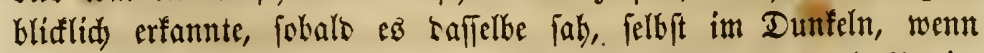
zwei Blätter zulammen gerielien wurben. Die Wirfung, weldye Papier 
auf riefes Thier herworbradte, war fo fanell uno gewaltig, baj ç veridiesene Male ben Reiter abwarf. Fz batte nidjt bie geringfte Furdyt vor Gegenjtänten, weldye tie meiften Pferte erfdredfen. EBz adjete weter bie Mufif, nod) Las Pefeifen Ler Rugeln, ben Donner

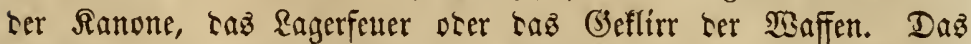
(B)răuja) und Durdjeinanter ber Sdjadyt madte feinen Einbrudf auf raflelbe, ebenfomenig โaż $\mathfrak{B a b m e b m e n ~ i r g e n o ~ e i n e z ~ a n o e r e n ~}$ meifen (Begenftances. Sein anterer Sdjall murte beadtet, aber baz 2)

„Ein Mutterpfero war ganj lenfjam, serrieth feine $\mathfrak{A}$ bneigung gegen ein menidlidjez $\mathfrak{W e j e n , ~ n o w ~ g e g e n ~ a n t e r e ~ T h t e r e ~ o b e r ~ P f e r t e , ~}$ ausigenommen, wenn fie son bellyrauer Farke waren; im Alugenblid,

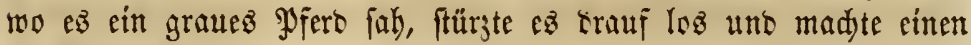

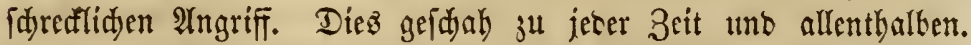

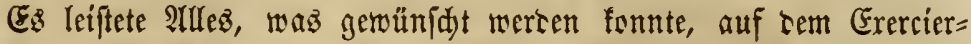

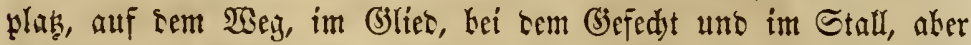

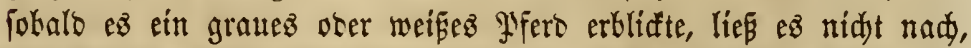
biz ez ren Reiter afgetworfen ober Lie 5alfter zerriflen batte, uno rannte Lann auf ben cingebilieten Jeind in ser gröften $2 B u t h$ los. "Ein anberes Mutterpfer wurse niemals erjareft, ausgenommen

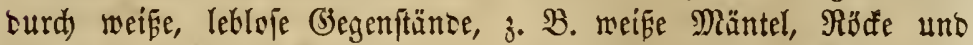

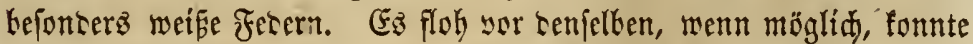

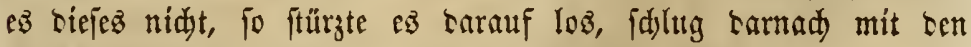
Borterbeinen uno jerrif fie mit ben Bähnen.

"Dieje Fälle find won antern ausigerwählt, weil fie sem, waz man bei einem menjaltden $\mathfrak{x e j e n ~}$ Wabnfinn nennen würbe, nabe fom=

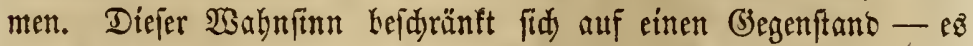
ift eine $\mathfrak{A}$ rt von Monomanie, unb Darf mit Redjt mit $\mathfrak{B a b n j u m n ~}$ bezeidnet werben. Ginsz yon ben erwähnten Pịersen, Daz zmeite, wurse burd) lange uno gütige Bebanolung yon ser wabnjmmigen Furd) befrett, unb wurte völig gelafien unb braudbar; bie anbern brei boten allen Mitteln zur Seilung, zu welden aud 3wang ge= börte, Iros." 


\section{Zefintes sinatitel.}

\section{Anankbeiten der Băbne und deg Aauleg.}

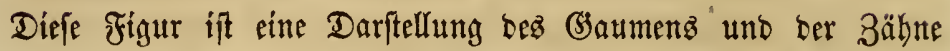

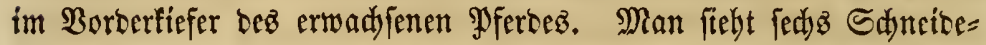
zäh̆ne, zwet Saafenjăhne, weldhe audh Saut= ober Fangzähne genannt

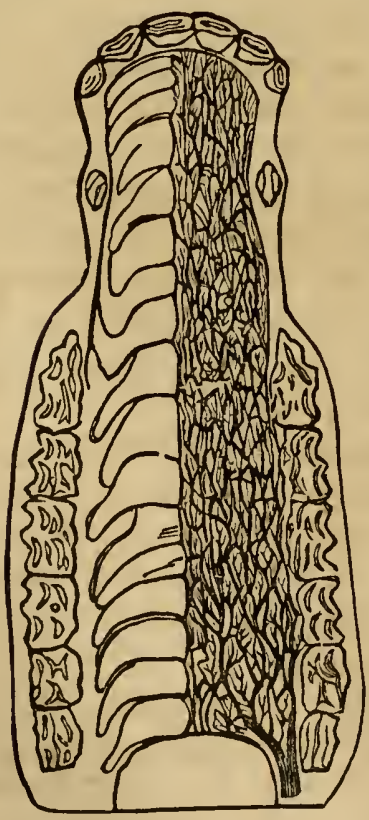
werben, und zwölf $\mathfrak{B a d f e n}=$, $\mathfrak{R a h l}=$ ober Stodłä̆hne. Âuf einer Seite ift baz Dad ber Maulbäble un= yeränbert bargeftellt, io baß bie Servorragungen ber Saleimbaut Dez Garten (Jaumenz beutlid) zu felyen jinto; auf ber anberen Seite fint bis 5ersorragungen entfernt, um bas unterliegende Brewele ber Blutgefäpe und Rerven zu zeigen. W3ir fino nad) porgfälttiger $\mathfrak{B}$ eot $=$ ad)tung überzengt, ba bie Zähne Dez Pferbez viel häufiger, alz man geneigt ift $\mathfrak{z} \mathfrak{u} \cdot \mathfrak{g l a u b e n}$, Sdymerzen unto Reiben verutradjen. Vyouatt fagt iuter biejen Giegenftant: "Man ift geneigt, baż Zahnen alż etważ ganz Unbebeutentes zu betradyten, uno benft nidst baran, baß aud) das MPero barunter siel leicen uno fogar ermitlid erfranfen fann; wer jebod) oft junge Pferoe beobadtet, wiro zutweilen einen fieberifden

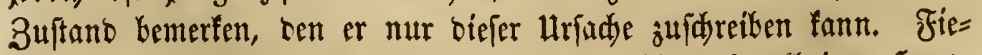
ber, 5uften, Entzünoungen ber Sd)leimbäute, 2Yugenfranffeiten, Shat= 


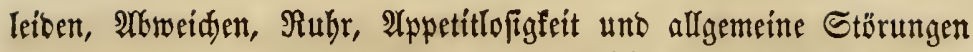

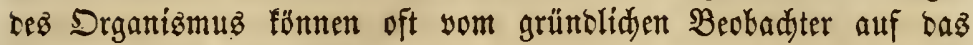
Zakgnen zurüufgeführt werber.

(Gz follte zur Regel gemadit werben, yon Ler nur felten abzuwei= d)en ift, bem jungen, zahnenten $\mathfrak{P}$ ferbe jebesmal, wenn ez von fie= bern befallen wirb, it bas Maul zu fafauen, unt im Falle bie 3äbne ftart hersortreten uno bas Zahnfleifd heif uno angeidnol= Ien ift, einen freuziörmigen (Sinjänttt über bie Zähne zu maden.

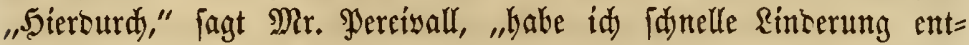

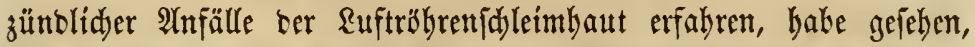
Daf Suften, lymphatifaje unto antere Drüfengcidinülfíte unt Saut=

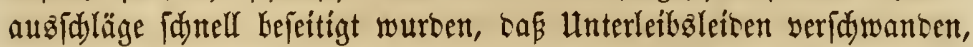

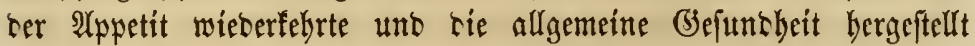
murbe."

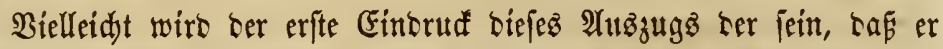
äbertrieben ift, unto bod) würben wenige erfahrene PJferbeärgte $e B$ wagen, bie allgemeine Ridutigfeit befielten in 3weifel zu żiehen.

Die erften 马ähne fommen febr früh zum Boridsein, bod) finto fie nidjt bauterhaft und werben beąhalb mit yorrüdentem altter bez

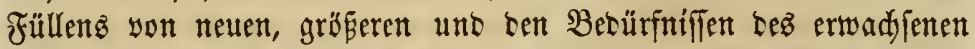
Rofię be

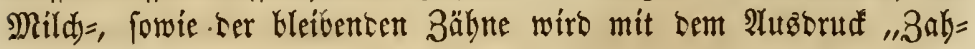
nen" bezeidjut.

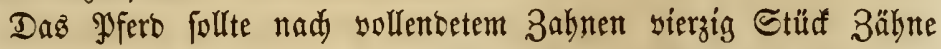
haben, woyon man in jectem Riefer fed) Ea Edneinezähne, zwei

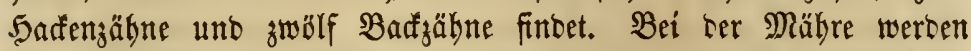
bie Sadenzähne entweter gar nidyt ober bod) erft im bohen âter entwidelt, obwobl ifnen entipredente fnöderne Servorragungen unter bem Zahnfleifd yerborgen liegen. Der Sadengahn, welder

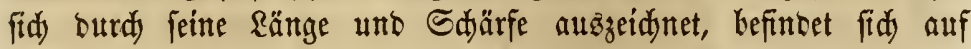

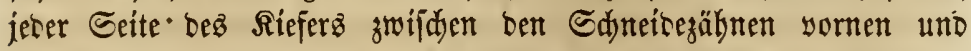
ben Badfzäbnen hinten, ift erferen aber am nabeften gelegen. (Bes=

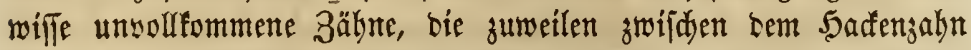
unt ben Barfiähnen berauginadjen, wersen yon bem Farmer ueberzäbne genannt uno folten bie utradje mandjerlei - Sranffyei= ten fein.

Die $\mathfrak{B e r a ̈ n b e r u n g e n , ~ w e l d y e ~ m i t ~ b e n ~ 3 a ̈ b n e n ~ f t a t t f i n b e n , ~ e l g e ~ f i e ~}$ 
ganz entwifelt find, und bie bacurd verurjadyten franflyaften (Er= fdeinungen werben zuerft unjere 2 Uufmerffamfeit in 2 nnjprud nebmen.

\section{Da $\mathfrak{3} \mathfrak{a} \mathfrak{n} \mathfrak{e}$.}

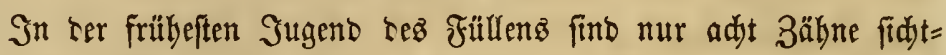
bar, bie erffen unt zweiten Badłzähne oben uno unten auf jeber

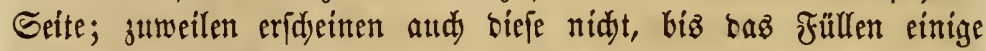
Tage alt ift. Die übrigen Bähne folgen nadeinanter in veridjiese=

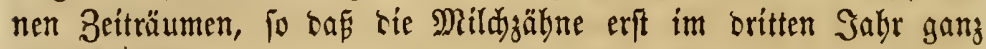
entwiafelt fint.

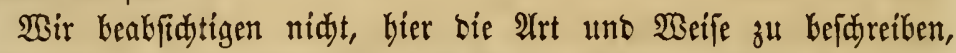

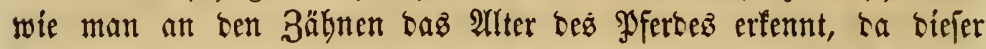
(Segenftant im 19. Sapitel eingehent behantelt werben folf. Unjere Aufmerffamfeit wiro hier allein ben Siranfleiten ber Bähne und bez Maulez gewibmet werben.

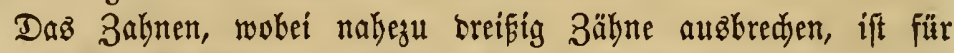
Das Fü̈llen feine to geringfügige Sade, alż

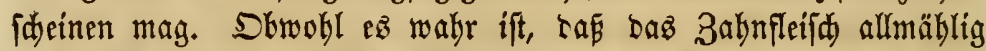
für ben 2(uzbrud) ber 3ähne yorbereitet wirb, fo finbet man bod wäbrent biefem Borgange, wenn man bas Zahnfleifa utto baz Maul unteriudt, bas bieje Theile febr heíp und fieberifd fint. So lange baz Frülfen nod) paugt, werben bie unangenebmen Folgen bez Zahnenz burd bie genollene Mild bebeutent gemiltbert, uno glüt=

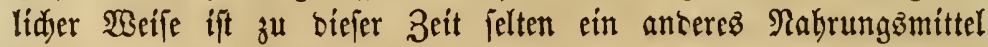
nöthig. Rad) ber Entwobnung ift bas junge Thier vielen Unan=

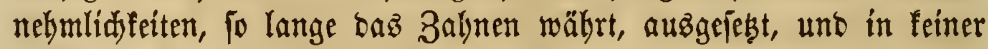

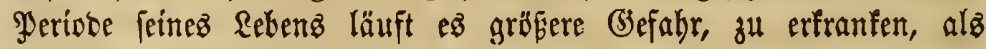
gerabe zu biefer Zeit.

Dhne Zweifel int es eine bädft weife uno gütige Einridtung, ba⿱ bas Fülllen nidjt alle Zähne auf cinmal befommt; benn ber Borgang würbe io ftarf auf die Giejunbbeit einmirfen, baf nur

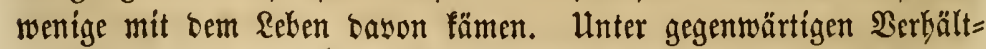

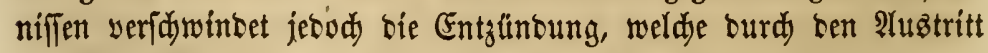
einez 3ahnpaarez verurfadyt wiro, uno bas Zahnfleifa fehrt gut bem

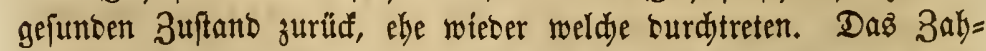
nen bat aber im 2̂tgemeinen bei'm (sejunbbeit, als bei'm Meniden und Syumbe. 
Die Mild $=$ ober Foblenzäbne finto nidyt mittelft $\mathfrak{W}$ urzeln, wie bie Gleibenden Zäbne in bem Riefer, nagelartig befeitigt, jonbern figen

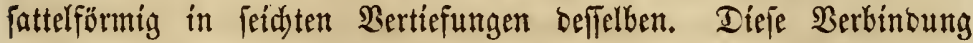
mit bem Riefer ifft jebod) feft genug, Daß fie zur Zerfleinerung

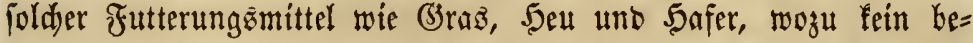
fonberer Rraftaufwant erforbert wird, gebraudt werben. A2ter bar=

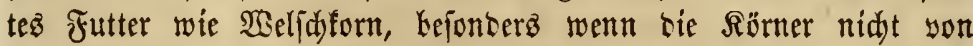
ben 2 ethren entfernt worden finto, idjabet ben Mildyzähnen. Durd)

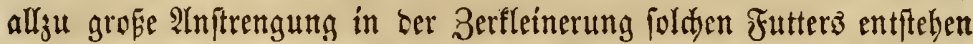
leidjt Entzünoungen in benjelben, und bieje franthaften 3ujtänbe

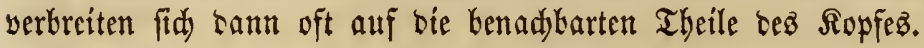

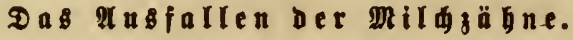

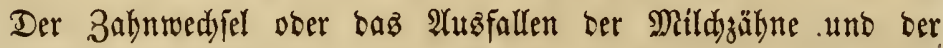

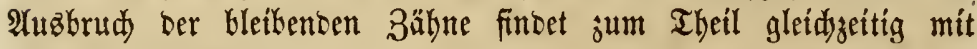
ben Yeşten Stabien bez 3ahnenz ftatt uno ift eng mit bemielben verbuntert. Bei bem Rinbe vernarben bie Deffinungen im Zahn=

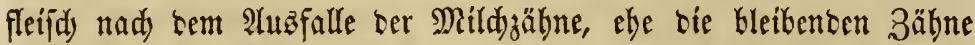
erideinen, aber bei bem Füulfen eridheint ber bleikenbe Zafin unmit= telbar unter bem Mildafahn uno bebt biejen fo zu jagen auz feinem

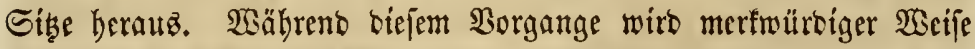
ber unterfte Theil sez Mildyzahnz allmählig abgetragen ober abge= rieben uno yon ben antrenzenten Theilen abjorbirt, io tap nur nod) wenig won bemielben übrig geblieben ift, wenn ber bleibente Zahn an ber Dberfläde bez Zahnfleifdez erideint. Se weiter ber bleibente Zahn aus feinem Fadte im Riefer hervororingt, je mehr wiro daz Zafhnfleifd, weldes den Milddzahn nody feft umfáft, emporgejdoben, bizz ber bleibente Zahn jo weit entwidelt ift, bas er

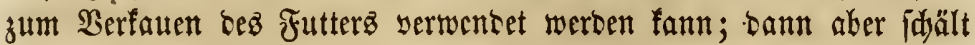

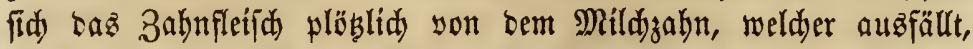
ab uno id)rumpft fooann biż untertyalb ber Dberfläde dez bleiben= Den 3ahnz zujammen.

Sdion eine geraume Beit, elye bie Mild zäbne aubsallen, fithen fie fefr loder auf, ba fie nur nod burdi ifre Berbintung mit bem Zahnfleif in ithrer $\mathfrak{L a g e}$ erthalten merben. Wenn fie mit barten Subftanzen in Berührung fommen, werben fie leidtt wadelig unb

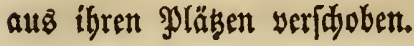


Faft immer ift bas $\mathfrak{A}$ uşafllen ber Mildyähne mit entzünbetem unt uno wunbem 3abnfleifd begleitet uno währeno ber ganzen Dauer

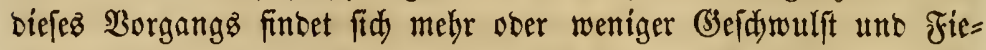

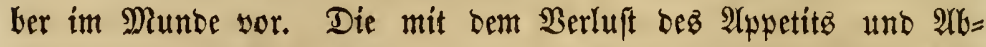
magerung verbunbene Störung Ler allgemeinen Gefunbbeit bei jungen

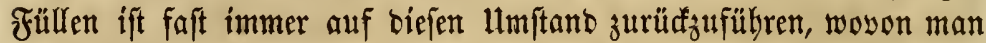
(itd) Febr leidyt burd) eine Unteriudung bes Maules unb bez Zahn= fleifdes überzengen fann. Die 2(ppetitlofigfeit ift jebod) nid)t bie

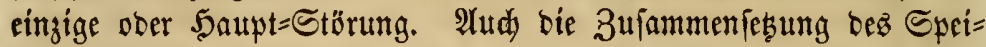
dyelz erleibet in Folge bez fieberifden Buftandez im Maule cine franflyafte $\mathfrak{B e r a ̈ n} b e r u n g$, fo baf fie nidjt mebr bie eigentlidje $\mathfrak{S e r}=$ bautung bez Futterz beförbert, fonbern ben Magen fekr balo in Un= oronutng bringt. Shne Zweifel entfteht während biejer Periobe mandfe bebenflidje Sranfleit bez Pferbez, weldje bauptfäd)lid bem Einflup

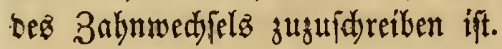

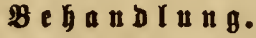

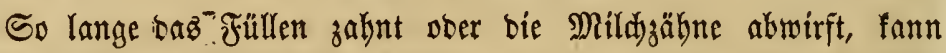

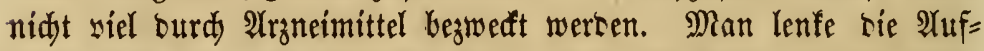
merffamfeit yorzugazweife auf eine gut gewählte Diät, benn bie fout= terungsimittel yerms̆gen einen unverfennbaren Einfluß auf rięen 3uftand augzuüben. Sely fefte uno erbibente Subftanzen barf man nid)t füttern und geftatte nur feudjte leidfte Futterung, wie fie in

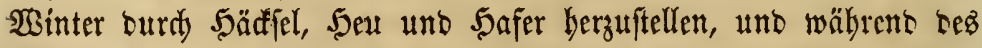
Sommers auf ber WBeide, weldje bas allerbejte Futter für alle Ber= bältnifffe bietet, zu finten ift.

In ben Baumwollen=Staaten, wo bie $\mathfrak{B}$ Beiben felten uno uner= giebig fint, ift $e \mathfrak{b}$ faft unmöglid, ein Füllen obne auferorbentlide Sorgfalt zu ergielen. Dort werben bie jungen Thiere gewobhnlid mit Welfadforn gefüttert uno bie Folge bayon ift, bas bie Mebrzahl berfelben crfranfen uno fterben. Nidjt felten werben fie von Bein= getwädjen am $\mathfrak{s o p f e}$ (big head) befalfen, bod) ift bie Rörperfraft kei ben jungen Thieren to groß̈, bas fie biefer Rranflyeit länger wiber=

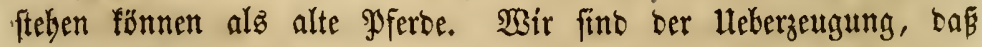

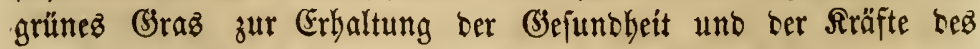
Dferbes in jebem 2llter wejentlid) notyyentig if.

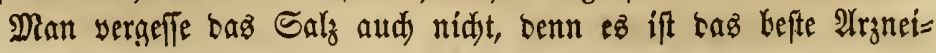




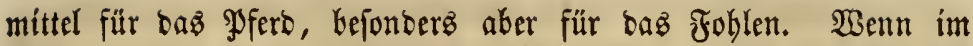
Stall gefüttert wirb, werfe man hin uno wieber bem yerfommenett Thiere etwaz Gibwefel vor, was jur Wieberberftellung ber (B)e= juncbeit uno Rörperfraft oft viel beiträgt. Secod) follte man vor= ber bas Maul genau unteriuden uno wenn bebeutende (Sefdroulft

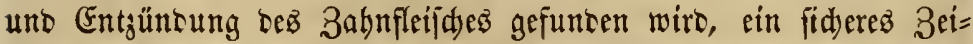
d)en bez 3abnens, zroei fid) freuzence (Finjdnitte in bas 3abnfleifd über ten yortretenten 3abn madjen, weldyes in ber Regel balo sin= berung verjdyafft.

Bei einigen Pferoen uno Fohlen fommt bas 2 (ufftofen yon Wint bäufig yor, was yon eimem fauren Dlagen herrübrt. Daż zafnente Füllen ift am meiften biergl geneigt, ofne Zweifel weil ber im fiebri= fajen Maule veräncerte Epeidjel leidt langfame Bercauung verur= fadt. Wenn bic Berbautng zu langlam yorangetyt, fommt im Dlagen

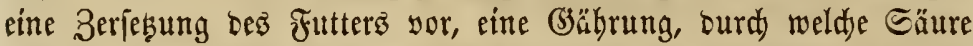
unt (3)ale entwidfelt werben. Hm die Beriebung im Nagen ju ver= büten, lege man etwas gute $50 l$ gajde mit bem Safer in Die Rrippe. In faft allen Fällen wercen bie in ber ardje befindlidjen alfalien bie Magenfäure volfemmmen neutralifiren, ebenfo wie biejes yor oer Entwöbnung burd) Die Muttermíld) geiduteft.

\section{teberzäbne oder Soppel=molfizzähne.}

Ueberzäbne fino nod immer ungebiloten Perionen eine Utradue zur.

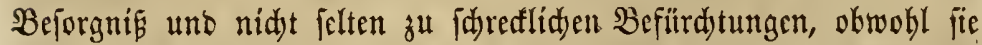
nid)t oft fdaben, uno nie in bem Mafe, wie fid unwiffende Reute yor=

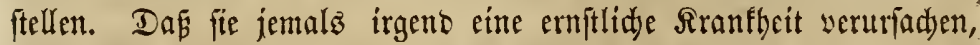

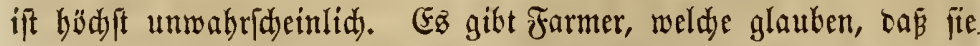
Die Bcingeidnulft bes $\Omega$ opfes (big head) verurjaden, bejonoers beim

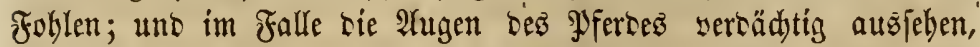
unterjuden fie fofort bie Bähne uno wenn Uebergäbne jufăllig vor= barisen fino, müfien fie fogleid, entfernt werben. Der Alutor hat fdon oft auf oa inftänoige Bitten abergläubiger Pfertebefiger Heberzälyne entfernt, weil alle Borftellungen diefelben nidyt zu überzeugen ver= modjten, daf eine foldje Dperation zur Berbütung yon Ropffnodjen= geid)wülften uno $\mathfrak{A}$ ugentrantheiten ganz unnöthig jei.

Bobl ift eb rabr, bafi biejelben futweilen im Wege fino und nic=

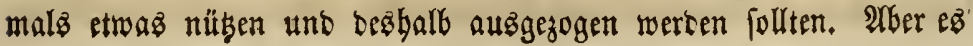




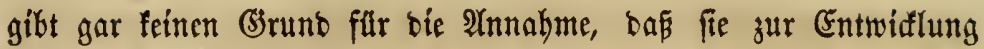
anterer Sranfleiten beitragen, mit 2 (tuznahme ber im Munbe burd) Fie bann unt wann verurfadten Entż̈ntsung $i$.

Bei Mähren fommen fie gar nidjt yor, wenn man nidyt etwa

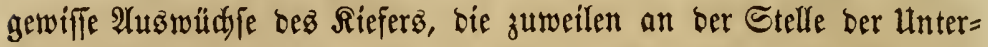
zähne gefunten werben, für foldje balten will. A(tud) fino fie nidyt

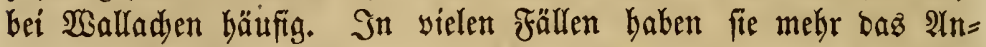

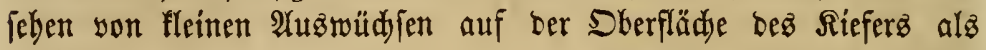
wirflider 3ähne und zutweilen treten fie gar nidft burdy bas Zahn=

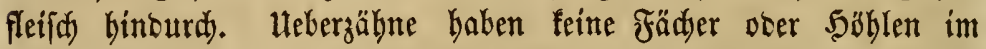

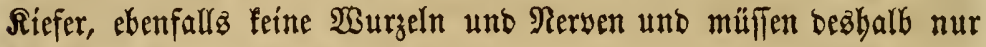
alż Einbringlinge betradjtet werben.

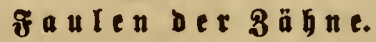

Bei Pferben fint die Zähne ebenfallz wo wie bei Menidjen dem Zer= fall unterrworfen. Nadj bem alltägliden Epradygebraud fa f len biefelken, weldyez ganz berfelbe Borgang ift, ben ber Zahnargt mít rem

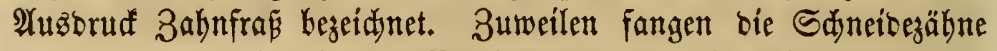
zu faulen an, aber in ber Regel fintet man bie Zeidfen bez Zer= fallzz zuerft an ben Băfenzäbnen.

Manden Farmern mag ez̉ etraz neuez fein uno bem in ífren

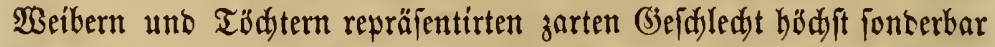

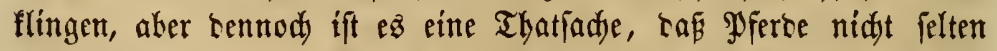

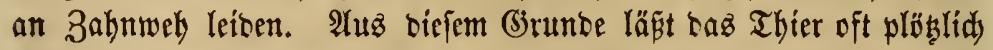
währeno bem Freêien Sorn uno anbere harte Subftanjen auż bem

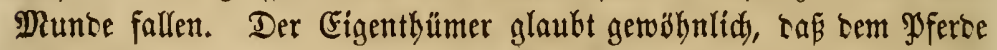
baz Futter zu folden Zeiten nidyt jajmauthaft jei, wogegen baz Thier vor Sdumerg nidjt freflen mag. Da baffelbe niddt burd eine an baş Maul gelegte 5and ober auf antere $\mathfrak{B}^{2}$ eife anzeigen fann, baß eż Sdimer empfinbe, yermutbet ber Farmer aud nidjt im entfernte= ften, warum bas arme Thier fein Futter fo langfam fríst.

Gin falledjter Magen ift eine ber Saupturiadjen bes frübseitigen

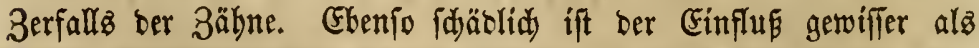

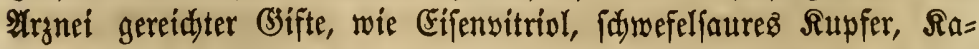
lomel, 2irjenif, Sublimat und andere mebr. Sie zerfreffen leidjt ben 


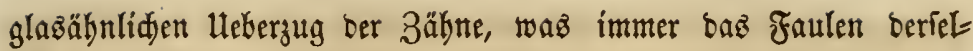
bett verur $[a d y t$.

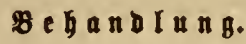

Bir wiffen nidjtz mit einem faulen 3abne zu thun, als ibn ber=

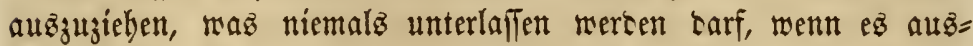
führbar ift. Man madje eine Zange nady sem Mufter bez alten befannten Zahnidjlüfiel

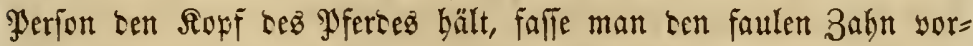

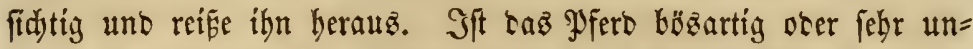
rubig, fo mus yorher ser Ropf mittelit einer Bremfe befeftigt wersen,

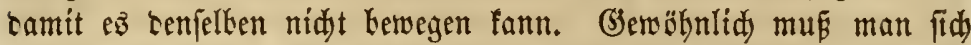
auf eine Rifte oser Banf jtellen, um baş Inftrument bejer hano= baben zu fönnen.

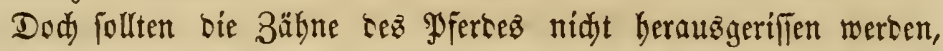
wenn nidjt heftige, turdh unnerfennbare 3eiden angebeutete Sdumer= jen ezs unumgänglidy nöthig maden. IHad barf tie barbarifde

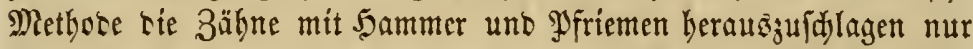
cann geoulset werten, wenn ein geeignetez Snftrument nidjt zu er= balten ift.

Da ein fajwader Magen oft ben Zerfall ter Zähne verurfadjt, follte temjelben siel altumerffamfeit geidenft werben. Sit ber Atthem heís uno ülelriedjent, hat sie Bunge eine bellpurpurne Farbe uno befist ber Speidyel grofe 3ähtgfeit, fo barf man fider aunehmen,

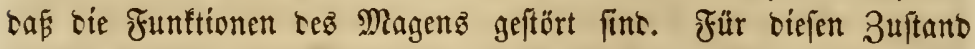
fino bie geeignetften Míttel Edjwefel uno Stedjapfelfamen (Jimson weed). $\mathfrak{B o m}$ erften gebe man alle zwei Tage vier $\mathfrak{U n j}_{j} e n$, yom lebs= teren eine Utnje alle trei $\mathfrak{I} a g e$. Bier $\mathfrak{D o f e n}$ vor jebem Mittel itt ben angegebenen Zeiträumen werben hinreidjent fein, bie Symptome zu entfernen. Die pultseriftrte Rinte uno bie grünen 3weige ber gelben Sappel leiften ebenfallz gute Dienfte und tönnen in ber Methobe, bie roir fogleid für bie Bebantlung ben wollen, gegeben werben.

\section{Stotbut bet 3 äbne.}

Zutweilen werten bie Zähne alter Pferbe, bejontbers bie Sduntbe= zăb̆ne, mit einem weisen Sdyorf bebeft, ober mit falfartigen Stoffen 


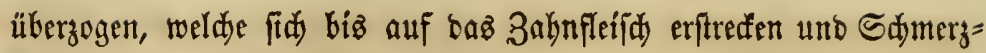
baftigfeit unt Entzünoung befielben verurjadyen. Dodh ift biejer

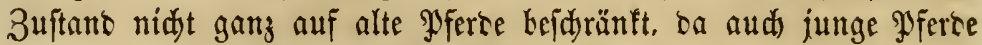
bin uno wieser von bemiclben befallen merben.

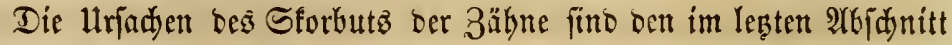
angefübrten faft gleich. Ueberbattpt fann man biejen 3ujtano alz eine Form bez Zerfallz ter Zähne betradyten, uno baß sie abfau= lenoen Theildben fil auf cer Sberfläd)e anjammeln. Wäbreno ter curd) idjledtes uno ungeeignetes Futter verurfad)ten (3ährung im

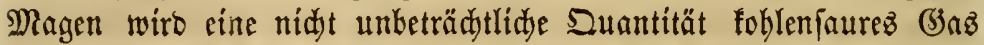

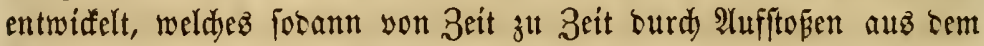

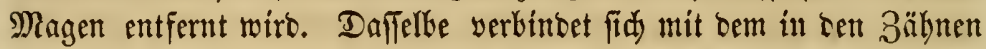
befintliden Salf, worauf fid eine Rrufte bes fo entitetenten foblen=

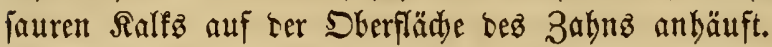

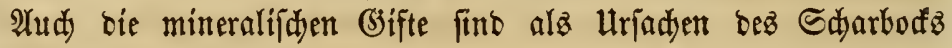
ber 3ăhne anzufübren.

\section{B e ba nor a n g.}

Die Bebanclung mú baburd eingcleitet rerben, baj man bie Berbauung, foweit biefelke im Magen vor fid gebt, genau regulirt uno rie ourd Die (säbrung entitebente Säure fofort tílget. Sduwefel uno Etedjapfelfamen fint bie gecignetfen 2 rzneimittel fur Sieber= berftellung bez Magenz, wie wir fidon im lesten 2(kid)nitt angeceutet baken. Im erfteren baben wír ein vorzüglid)es Alteratí (eine Mi=

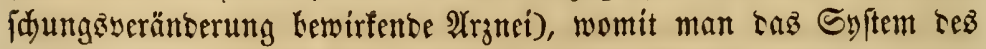
Pferbes beffer als mit irgent einem antern Mittel reguliren fann.

(5)ute Solzaldye follte beftünoig in fer Srippe liegen. Fein ge= ftofine gelbe Pappelrinde fann chenfalls zwedłäfig siejem Mittel zugefügt merben. Wenn ein fleiner Borrath beftünsig an ser Stelle liegt, wo man oas Pfero füttert, wiro baffelbe von Zeit ju Zeit bebeutenbe Duantitäten serzebren. In einigen fürlidyen Staaten ijt ę Sitte, Iange grüne Pappelzweige im Stalle cem Pferbe vorzulegen uno in furzer 3eit ift bann bie Rinbe ganz verif)lungen. Die Pappel=

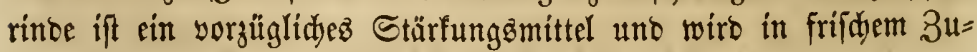
ftanbe gern yom Pferbe gefreffen. Seinem Injtinfte vertantt bas Thier huncert widtige Dinge, bie ber Menid nur nad) mübevolfen Foridungen uno Denfen entbeft. Sann baflelbe, wäbreno eż an 


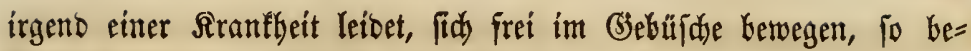
merț man, bá

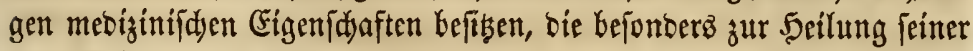
Srantlyeit geeignet fint.

So lange ber Magen nidft in guter Dromung ift, werben örtlidye Mittel an bie Zäbne jelbeft gebradjt, nidjtz nüben; wenn aber jenes

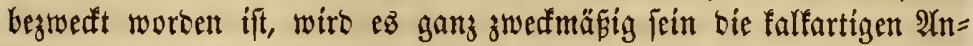
bäufungen zu entfernen. Dieję läpt fid am leidjteften burd Woein=

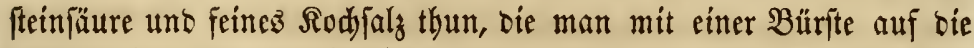

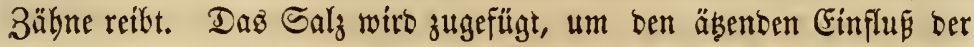

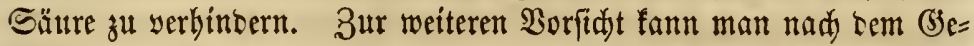

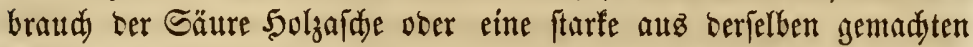
Rauge anwenten. Wir fönnen nidjt umbin emfte Eimwentungen ge= gen ben (Gebraudy ftarfer Säure uno fauffífđer Mittel für bie Zähne zu ntadjen. Da man ifre Wirfungen Durd) (Begenmittel nidjt ganz

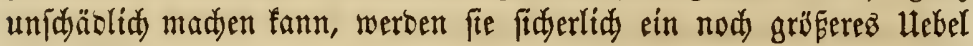
alż baz bejétigte eräeugen.

Bumeilen werben bie som Sdjarbod befallenen Zähne aud mit ber Feile gereinigt. Nadbem ber falfartige $\mathfrak{H e b}_{\text {erzy }}$ to entfernt worben ift, Gaben die Zähne ein raukez unebenez $\mathfrak{A}$ njeken uno fino nun im beften 3 uftante zur $\mathfrak{2}$ (ufnahme neter $2(6)$ agerungen. Durd eine zweite viel feinere Feile, ober burd ben (jebraudy yon Sanbpapier, wobei man yom gröbjten zum feimften übergegt, fann aud biejes leidjt beeeitigt werben. Es gibt jebod fein Mittel, wodurd man ben cinmal burd

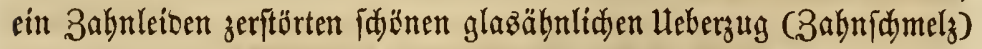
wiecter heritellen fönnte; aber bie Zahnoberfläde läpt fíd fein poliren, was einigermaken bafür einen Eraag bietet uno lange Zeit bem Zer= fall ber Zähne Wiberftand leiften fam.

Das Berfahren ift jefhr einfad) uno leidyt aubjührbar. Radjbem man bie Bremie angelegt bat, weldje ein Geehullfe Gält und bie Rippe Gerumtergieft, frabt man bie âtblagerungen yon ben 3ähnen mit cimer ftumpfen ober abgebrodyenen Feile uno polirt follieşlid, mit feinem Santpapier, monad etmas Baumöl auf ben Zahn gebradbt wirt.

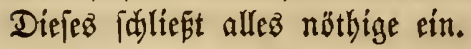

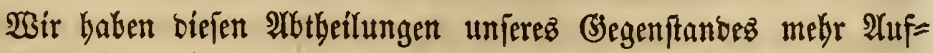

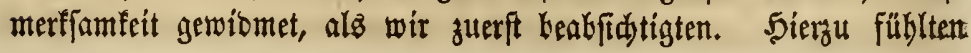


wir uns seranlaft burdy bie Thatjadye, baf bie alfgemeine (Siefundbeit bes Pferbes eng mit bem 3uftande ber Zälne verbunben ift, unb baj in ber Regel biefer Sadje gar feine ober bod zu wenig Aufmerfamfeit feitens ber Farmer geidjenft wiro. Sie fino inb= bejontere geneigt, die Reiben, weldje wäbrent bem Zabnen entiteben, zu überjeben. Wenn ber Farmer überlegen würse, wie äuferft fdumerz= baft daz 3ahnen feinem Rinte ift utto wie oft heftige Rranfleiten uno felbit ber Tob baburd serurfadyt wirb, unb bap sielleidjt bas

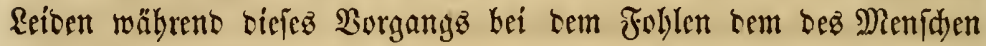

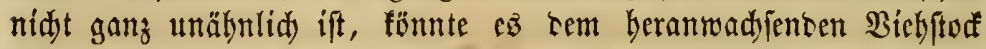
yon grofem Bortheil fein. Die armen fduwadjen Füllen, beren ratt= bes Saar, bünne Beine, fdwapenten (Sang uno 2lppetiflofigfeit

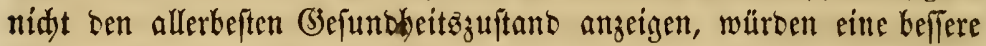
Pflege erfabren, wenn fie auf eine vernünftigere Cinfid)t gegrünoet wäre.

Folgente Methode baken wir bejonbers für Stodf=Farmen emtpfoblen, fie läpt fid aber ebenfowobl in fleinem Maṕtabe anwenben. Auf ber $\mathfrak{3 e i b e}$ ober im Stallfor fino lange Tröge anjubringen, in benen man beftänbig ocer cod wenigitens eimmal wöd)entlid) Sals, momit gute Solzalde gemengt werben follte, reidylid ftreut. In beinabe allen Fällen fann bie Neigung jur Unverbaulidjeit surd bieje Mittel befeitigt werben. 2Audy ser Sdjwefel foute zu gleidjer Zeit in bebeu= tenden Dofen gegeben werben; Denn reine Wirfungen alz Arlteratio find unübertrefflidy.

\section{Arippenbeißen, Etumplaugen, Binblaugen.}

Die fonberbare, alв "Stumpfaugen" (stump-sucking) befannte Sewobnbeit einiger Pferbe ift nod immer unerflärlid. Wir baben fdon viele Pferbe und Fohlen gejeben, bie biefe (Sewobnteit batten, aber müffen gefteben, Dá ben (3)runo berfelten zu fommen. In ben nörtidyen Staaten foll fie bäufiger sorfommen als in ben fübliden, am bäufigiten aber in eintigen europäijuen Ränbern. Die (Sewohnbeit hat im Süben oen Namen "Stumplaugen" erhalten, weil bort bie Stallhobfe, in wel= den bie Pferbe berum laufen, oft mit alten Baumftumpen befäet fino, an weldjen baz Pfero bie eigenthümlide (semobnbeit auzübt.

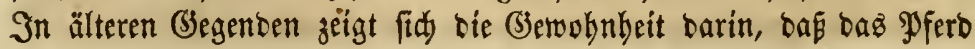


an ber Srippe nagt, Laber aud, bie Bezeidnung "Rrippenbeif́er."

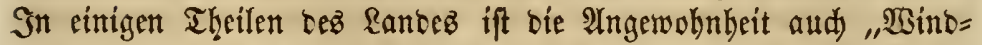
faugen" genannt worben, weil einige "Etumpjauger" rie Ruft ge= waltjam burdy bie Zähne einjaugen. Was alth immer bie Ratur biefer Rranfleit fein mag, fdeint fie zu unbeftimmten, fid nidyt $r e=$ gelmäsig wieterbolenten 3eiten ftattjufinten. Wirb aber bas arme Thier yon einem İnfall beimgefudt, fo ftürgt paffenten (3iegenftant, fei $\mathfrak{e B}$ ein Baumftumpen, ein Riegel, cine Siripe, ober ein Trog mit foldyer File, alz ob fein Reben bayon abbinge, uno, ben (Segenftano gemaltiam mit sen 3äbnen fa|lent,

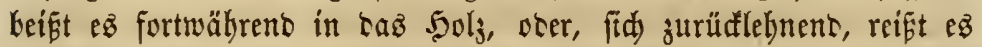
to heftíg am betreffenten (B)egenftant, als ę fann ober tie Zähne [Eี geftatten.

Das Winbjaugen finbet nidjt fo bünfig als bie antern formen oer Siewohnbeit ftatt, if aber sorfommenten Falls sem Bufdauer böd)ft peitulid. So weit wir wiाfen, ift callelbe nod son feinem Autor bejdrieben worten, wir haken aber (Belegenteit gebabt, bie Anfülle mebrete Rale zu Keobadyten. Das Pfero fdaut einen $\mathfrak{A} u=$ genblid lang will uno fdüd)tern um fid), cann ftürgt es auf irgeno einen barten Begenftano log und fapt senfelben mit ser grösten

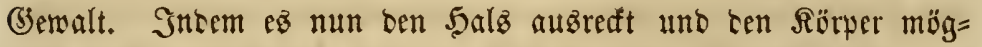
lidhft weit jurüdflebnt, fo taf

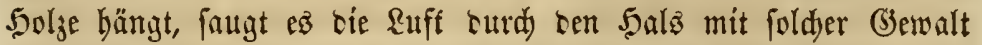
ein, Laf man ben caburd verurjadyten tokenten Rärm beinabe eine Biertelmeile weit bören fann. Dabei fröbnt unb ädyset rurdy fo furdtbar, als ob feine leb̧te Etunte gefdlagen bätte. In

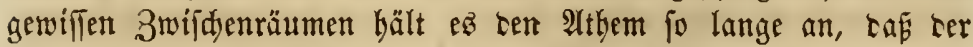
3ufdauter ernftlide Folgen befürbtet. Dann fängt es wieter mit einem langlamen akgemefienen (B)eftöhn, bas fid) balo zu cinem ent= fesliden (Gekrüll verfärft, an ben $\mathfrak{B i n b}$ einjufaugen. Diefez wirb fortgefebt, bis bie lippen beben, die Seiten jittern uno bie Weidjen blajebalgähnlid fid aubrebnen uno zufammenfallen wie bei einem PIferce, bas fid im Laufe aufz böhfite angeftrengt bat. Die Dhren

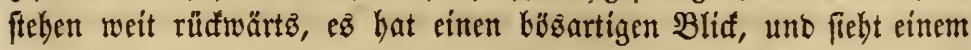
am 5alfter zurüfłiebenden, wiserpänftigen Maulejel fehr ăbnlid. (5) bebt, zittert, ftöbnt und faugt Wino zu gleid)er 3eit. Jerod unfähig, bie Anftrengung länger auछ̇łuhalten, öfnen fid bie Riefer 
uno baz Pferb taumelt willo umber ober fält erfdöpft zu Boben. Der 2̂nfall ift bamít beenoet; ez erbebt fid uno gebt weiter, ober bittet um jein futter, alż wenn nidjtż ungewöbnlidjez gejđjeben wäre.

Einige Pferbe laffen bie Epizen ter yorteren 3äbne auf irgent einem harten Rörper ruben, wobei bie Riefer nur etwa einen balben 3oll weit geoffinet find, swifd)en welduen oic Zunge liegt; fo wer= barrt cas Pfero yon 10 bí 40 Mimuten lang, die Bähne mit

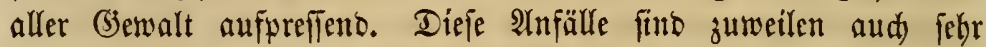

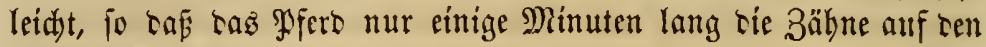
barten (5egenftano prefst oeer in ifn keift.

Der bartnätigite Fall, ben wir zu beobadyten (3)legenbeit batten, fam bé einem alten Pfert yor, weldez bem Serm Thomaz Băy

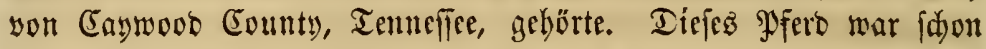
jeit vielen Sabren ein "Etumplauger" gewejen, uno wir haben ez

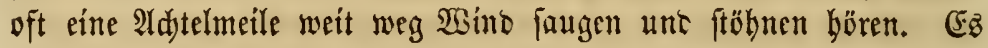
erlebte tas cinunozwanjigfte Jabr, uno war inmer in einem jum Arbeiten tauglidyen 3uftano.

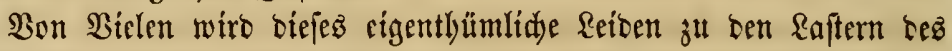
PFerbes gerednet, ofer bod) nur für eine üble $\mathfrak{A}$ gewohnbeit gehalten,

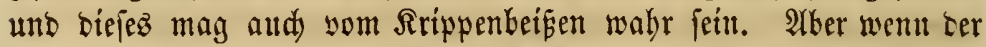
Atrall mit ben oben angegetenen Eridheinungen begleitet ift, follte

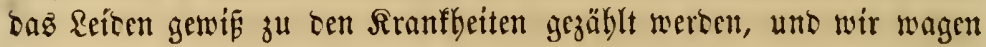

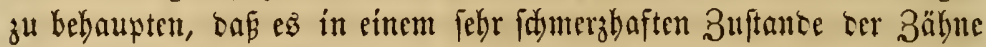
feinen (Sirund hat. Shne Zweifel bat bas Thier entedt, bas es Lurd)

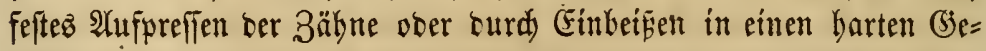
genftano uno 3ielon an bemielben fid Rinterung veridjaffen fann. Wenn man mít Epeidyelfluf behaftet ift uno bie grösten Edymerzen in bem wunten uno angeidyollenen Babnfletidy leitet, fann man fich augenblidflidye Rinberung taburd) veridaffen, baf man tie Zäbne feft auf ein Etüdd)en Solz zufammenbeift. Sudjt nidjt etwa bas PJfero zeitweife Rinterung von äbnlidyen ๔dymergen burd bas Winojaugen?

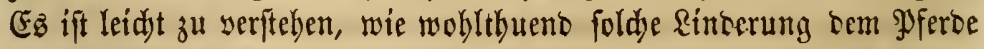
im leibenten 3 uftaltce fein würoe, unt wie angenebm ez fein fönnte, ben beifen fieberifden (5)aumen burd) baz anbaltenbe, fonelle Gin= faugen oer $\mathbb{R} u f t$ abzufüblen.

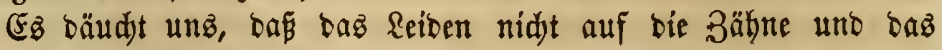
Bahnfleifd befdräntt ift, fonbern fid) auf bie Inodjentaut, weldye bie 
3ahnwurzeln übergiegt, uno auf bie Rerven ber angrenzenben Theile erftreft.

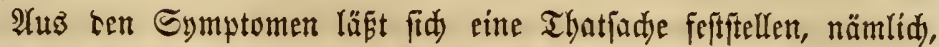

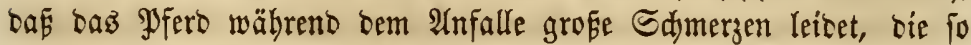
beftig fein fönnen, Laf fid Srämpfe einftellen. Itud nimmt es in

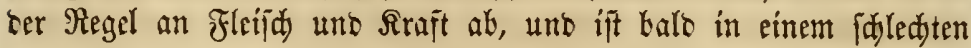

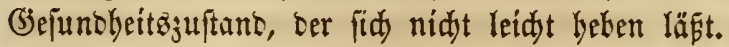

\section{Bebanolung.}

Die Bebantlung mus fidh befonterb auf bie Zälne uno bả Zahn= fleifid ridyten. Man wente juterft taz magifde Rervenliniment an, womit man bie sorberen 3ähne Morgens uno 2(6entz zebn Tage

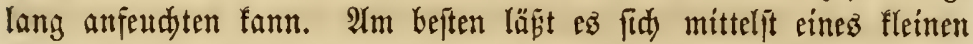
Sdjwammez an bie Zahnjpiben antringen; gewöbnlid) läuft sime

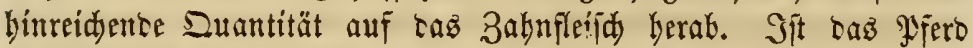

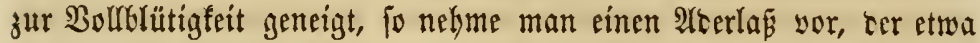
brei Suart betragen fann. In Yeidten Fälllen wiro biệe Behant= balo mit bem beften Eriolg begleitet fein.

Pierte, bei tenen bas Reiten eingerwurzelt ift, fint, was iłgre Braud)= barfeit betrifit, weniger werth alz andere Pyerte, uno folglidy bringen fie gewöbnlid im Marft einen jebr geringen Wretz. Wair haben biejem (3egenftand fo viel Raum gejdenft, weil wir hoffen, burd bie bier angegebenen 2 (njidjten anjuipornen, bie Ratur und urjadjen

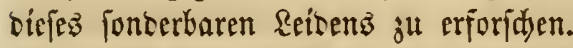

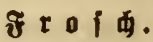

Diefe Uebel, weldes vor

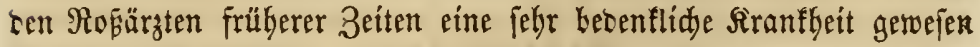
za jein. Es befteht aus, ceiter gewöbnlidjen Entjüntung son bem weidjen Theil tez (Saumenz, weldher binter sen Edyneitejähnen in ber vbern Mluntwand liegt. Der (baaumen hat bie Form auf ein= anber folgenter fleiner 5ervorragungen, wie ziemlid genau in ber am Beginne biefez Rapitels ftebenten Figur zu felen ift. Die Zunge

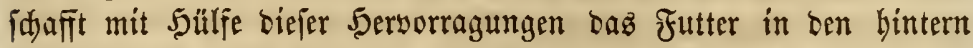
Theil ser Maulbäble, wo ez zwifden ben Bađenzăbnen flein zer= malmt wirb.

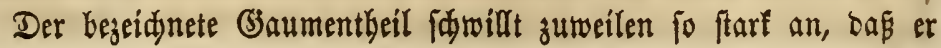


nidht nur biż zu ben Zahnipiben fid erftredt, fontern über bie Zäbne hinaugragt. Folglid wiro er balo wutto uno erjayert bem Pferbe

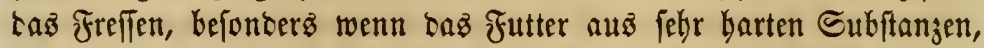
wie Welidforn, 5̧afer uno Thimotbeusheu befteht. Die Sdymergen fant man Daran wahmebmen, bá bas Thier bas Futter oft wieber fallen läst.

Diefe Entjüntung entftebt jiemlid oft in Folge oes 3abnens, und breitet fid son bem wunten 3abnfletid) auf bie 5erworragun=

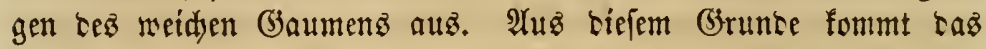
Uebel aud bei jungen Pferten am bäufigften yor. 2tber ez geben Beränterungen irgetlo eitter Irt im Mlaule ftets yor fidt); nad be= endigtem Znhnen werben sie Zäbne allnäblig algetragen uno fallen

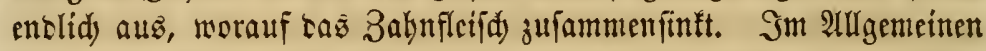
fincet bicies llebel nid)t jwifden rem fünften uno adjen Jahre ftatt; aber nadber gebt tie Albtragung ter 3ähne rafder yon ftatten; Las 3ahufletja fdrumpft jufammen und taz Hebel fommt wieber jum Boriducin.

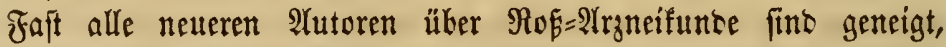

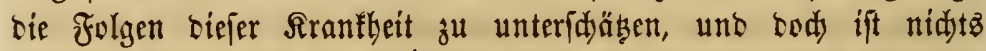
makrideitulider, alz oa eine fehr ketenflide Unorenung im Bertau=

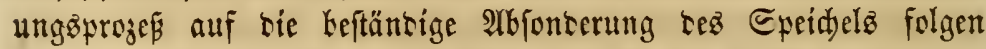
mǘ, benn serfelte ift, fonobl mas Dualität als Suantität betrifft, in Folge ธes Fiebers uno ser Şise im Maule reit som natürlichen

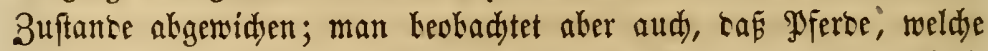
lange mit biefem Hebel behaftet waren, in Begug auf Rörperfraft abgenommen baben, bumm geworten find uno eine borjtenartige Saartede zeigen.

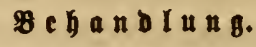

In manden Fällen vergebt ter Frofid yon felbft. Beigt er fid bartnädig, fo find balo feidyte Einfidnitte ju madjen. Dieje müifen

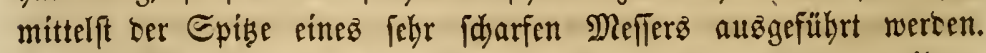
Der 3wed berfelben ift, bie ftrobeno gefüllten Blutgefäbe von ibrem

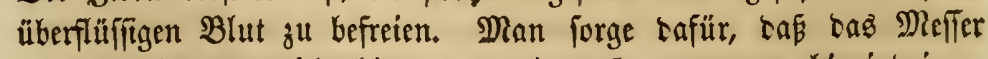
nidjt ju tief uno nidyt binter ber britten Serworragung hineinoringe, ba an biefer Stelle fid eine ziemlid bebeutente Pulbaber ber Sber= fläde näbert, bie nidjt leidyt unterbunoen werben fann. Sollte bie 
Ther zufälig burdifinnitten werben, fo fann man caz Bluten jogleidy baburdy fitllen, ba is man eine ftarfe Sdjnur hinter ben yorberen 3ähnen feft herumbinbet. Die 2loer wiro burd bie Ednur zufam= mengeprest uno fo weiterer Blutwerluft verbütet.

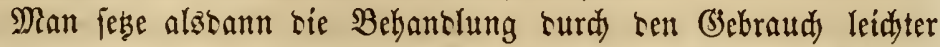

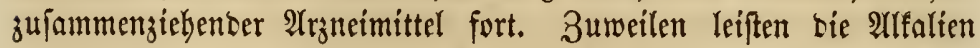
ausgezeidjnete Dientite, wenn alle anberen Mittel verjagen. Man madje eine frarfe 2luflöjung yon dilorofaurem Rali (chlorate of

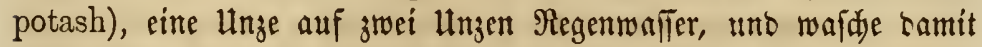
jeden Morgen Maul uno ahnfleif Beinige Minuten lang.

Wenn bie alfgemeine (3)

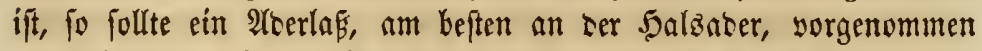
uno alşbann mit alterirenten Mesifamenten fortgefebt werben, be= jonterz Sdymefer uno 5anz, voer bie im vieruntozwanzigften Rapitel angefübrten $\mathfrak{P u l v e r .}$

Wir fitimmen wollfommen mit ber yon allen geadteten Pferbeär

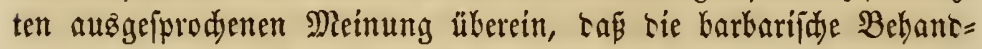
lungąmethobe, bie tarin befteht, dać man mit einem glühenoen (Gi=

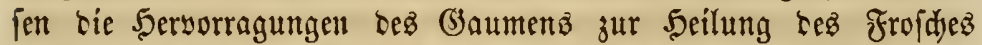
abbrennt, höd ft verwerflid) ift. Der (befdumadfinn unt folglid ter im Freflen empfuntene Benus hat wenigftens theilweife feinen Sib in biejem Theile bez Maules unt bie 5eryorragungen fimb, wie

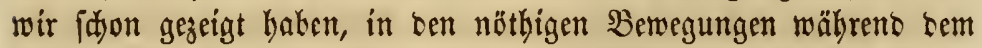

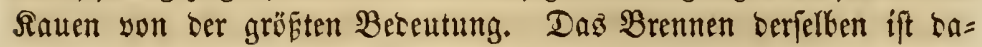
her nidjt nur bödjft graujam, fontern fügt bem goferbe einen uner=

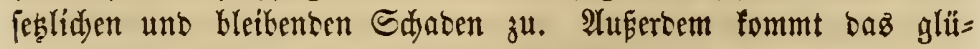
bente Eifen oft mit ben Bähnen in Berührung unt jertürt ben

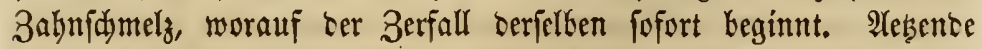
Mittel fint aus semjelben G̋runbe verwerflid unb fönnen ben Zäb= nen tod leidter fdjaten. Man bat aber aud gar feine turradje,

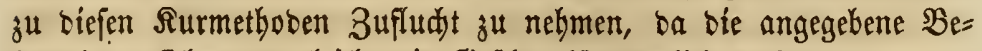

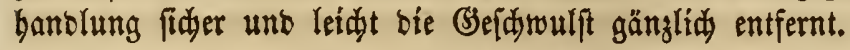




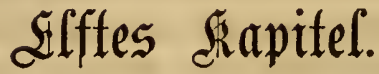

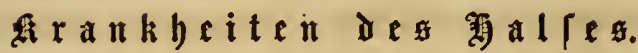

Die Siranfleiten beż 5alfez uno ber Bruftorgane finten bäufig bei ben \$ferben in un ferem Rlima ftatt, vielleidst wegen ber $\mathfrak{B e r}=$ änberlidffeit ter Temperatur, bie zumeilen innerhalb vierunzzmanjig Stunben yon ber größten Sommerbibe auf bie ftrengite Winterfälte berabfinft. Sn Sinfiddt Ler Temperatur ift vielleidst bas Mifififfippi= thal won allen Gegenten ber gemäfigten 3one Ler Beferuntheit am

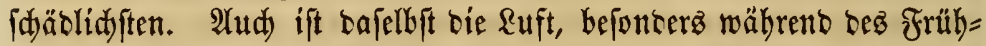
lingz uno Sinterz, mit Feudutigfeit angefüllt. Das Pfero fann nur surd feine ftarfe Ronjtitution biefe uno andere ungünftige Einflüfie überwinben, bie bei bem Menid)en jo häufige Sranfheiten veruriadyen, aker leiber wiro feine grofe Rörperfraft hadurdy, ba

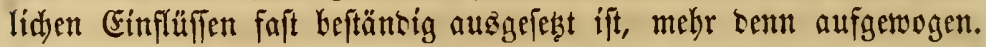
Daber finten wir, onf bie $5 a l a z=$ und $\mathfrak{B r u f t o r g a n e}$ ebenjowdhl wie andere $\Re$ örpertheile erfranten, unt jwar beinahe fo oft, wie bei ben in benjelben Simmelżgegentent lebenben Menjaden.

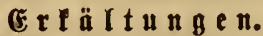

Die einfachjten und gerošbnlidften Erfältungen finto fowohl beim Wferbe, wic bei feinem 5errn, 5 aloz $=$ uno \&ungenfranfleiten. Ien=

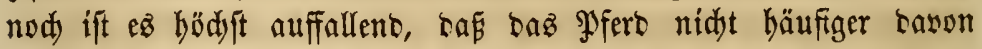
befallen wirt, ta ez oft lange Zeit ter grimmigften Rälte auşgefest ift. Ėa gikt noble Farmer - uno jeber ebelentente Menidy wiro

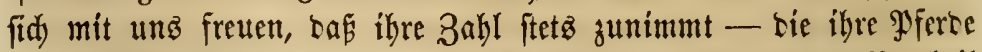
fo forgfältig behanneln, alz bie Ulmftänbe

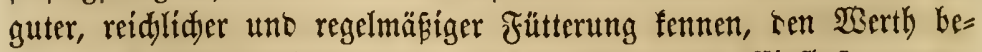
quemer Stallung fääben uno ben wohithuenten Einflú warmer Defen, wenn foldye nöthig fint, beobadtet babent, uno sicje prafí= 
iden Renntniffe in ber Behandlung ihrer Thiere immer zur Beltung bringen. Soldje bewähren bie $\mathfrak{B}$ orte ber heiligen Edrift: "Ein barm= bersiger Mann ift aud feinem Thiere barmbersig," uno werben fdon in pefuniärer Şinfid)t oreifad) für ibren (Ebelmuth), ihre Sumanität belohit.

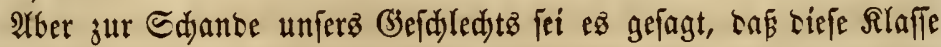

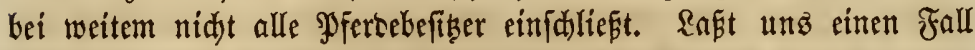

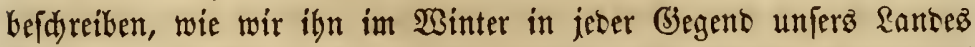

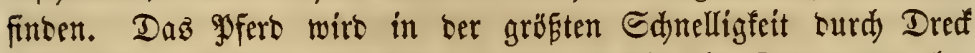

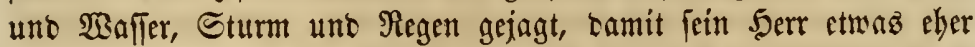
nad) Sauz fomme, wo er ben wüthenten Sturm uno burdjoringettsen Regen für ein bequemez Bimmer, loberntez zesuer unt weides Bett sertaufdyt. 2aber taz Pfero wiro entweder in einen falten, offenen Etall geftellt, ober im 5of gelafien, wo ez fnietief im Dreff fteht.

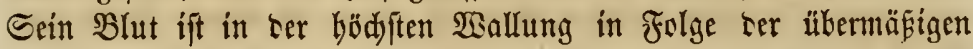

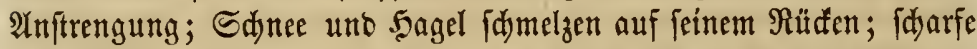
falte $\mathfrak{B i n b e}$ erftarren feinen ganjen Rörper, unt, bem furdjtbaren

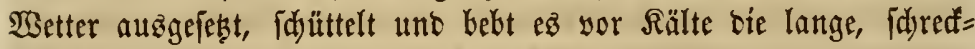

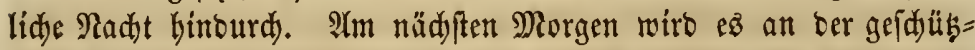

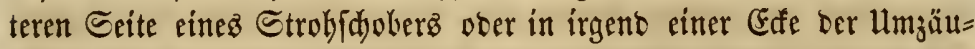

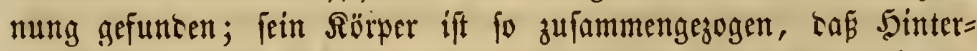
uno Borterfüfe faft neben einanber ruben, bie Shren fint weit Ju= rüfgelegt, uno überhaupt ftellt Benn endlid) zu einer fpäten Stunde tez Morgens ter gebanfentofe Eigenthümer (oenn wir wollen feine Ģraufamfeit jo gütig als möglid) auslegen) mit bem Futter feine (Erfdeinung madt, zeigen ber flagende

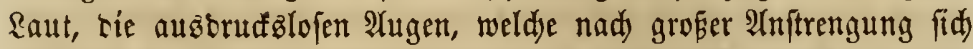
ein wenig aufbeitern, unt bie fteifen, abgemühten (Jliesmafen, weldje sen Dienft beinabe verfagen, baf sem armen Thier ein Gleibenber

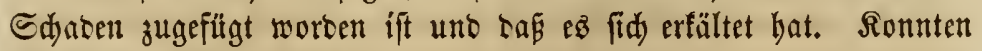
bie Folgen antere foin?

Das Wetter wirt jebod gelinber, bie Sonnenftrahlen erwärmen

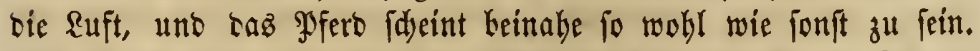
Die Zeit sergeht, jene furdtbare Radyt ift fdon längft vom Farmer oter Eigenthümer sergeffen, bem es aud nie im entfernteften einfiel, räi fie feinem Mferbe gefdabet haben fännte. Mit ber Zeit aber, vielleidt nur eine $\mathfrak{S O}_{0}$ e ober zwei, ober vielleidjt einen Monat [päter, 
bären wir ifn etwaz furditiam kemerfen: "Эđ wunbere, woher mein Sfero ben ftarfen Suften befommen hat?" Soer er fagt: "Mein

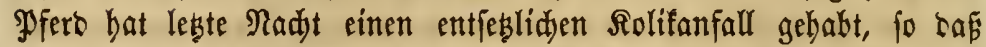
es beinabe brauf ging. Go war fonft nic mit biefer Rranfbeit be= haftet. Sd) wunbere, was tie Uriadje war?" Soer: "Id hake

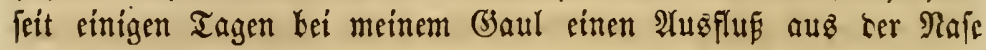
gefehen. Waaz mag ihm wohl fehlen?". Drer: "Mein Roḱ hat biejen Morgen cin furdtbar entzüntetes 2(uge. Sd befürdte, baf jeine

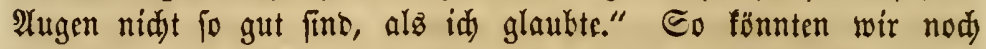
ein Dubeno Rranfbeiten berzäblen, sie unter ähnlidjen umftänten ben Eigenthümer in Erftaunen und 2 (ngit veriegen.

Mein theurer Freunt, ser bu jebtt vielleidjt cin tiefes Snterefle fühyfi, benfe ein wenig nad) uno weriude bie Urjadje biejer Siranf= beiten zu entrecten. GJelingt 2 bir nidjt, fo fomme, wir mollen

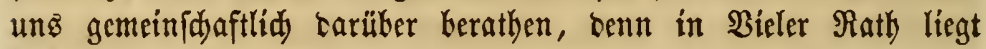
Weiz̄beit.

Bielleidyt fönnen wir zujammen bie WSirfung auf ibre $\mathfrak{t r}$ radje zut $=$ rüđfübren und fo bie Entftebung ber Siranflyeit erflären. Rafat unz

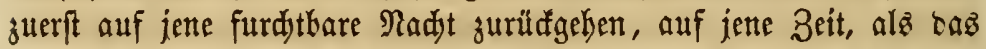

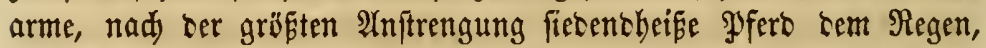
Sdinee, ber bittern Rälte cine lange Nadjt binburd) augegépht war, auf bic Zeit, alz bu baflelbe Morgenz an ber Eđe ber umzäunung, binter bem Strobjdjober, vor Rälte zulammengefauert uno bebeno fanteft. Betradjte baffelbe nod) cinmal, mein ehrlidjer zreunt, wie ez bort mit traurigen, Gittenten Blifen fteht, uno jenten flagenten, nad) befferer Bekanblung flekenben Raut, auşftié, Der in beine Shren srang, alz bu in ben jumpfigen $50 f$ trateft, um ihm baz futter in eine

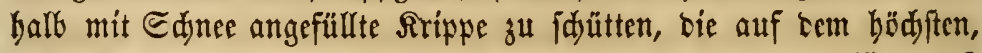

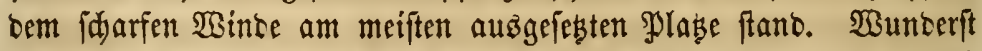

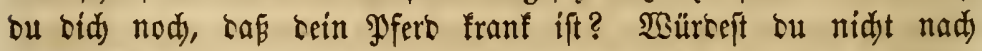

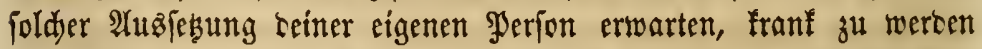

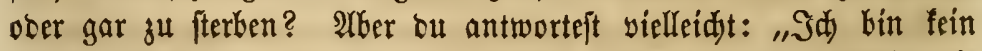

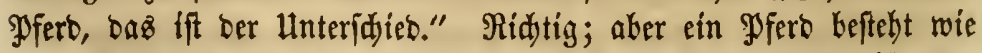

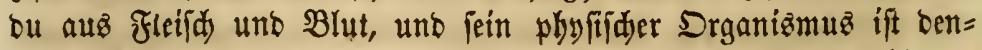
felten Gejeetsen untertworfen wie ber beinige, unt im Ganzen ift bas

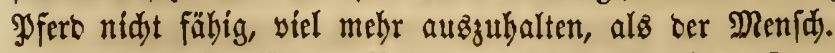

Erlaube mir aljo zur Befferung beiner fünftigen 5andlungòweife 


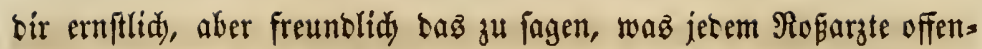
bar ift: "Du felbft haft Sdulto an ber Sranflyeit beines \$ferbez. Du bift verantwortlid, uno wenn bein (3aul in Folge feiner Rrant= beit serreft, haft bu ifn fo gewif umgebradst, als wenn bu ihm baz (3)eniä gebrodjen ober îm mit einem Beil ben Shirmidäbel geipalten hätteft." WBir fint zur Uebergeugung gefommen, ba za zwei Drittel

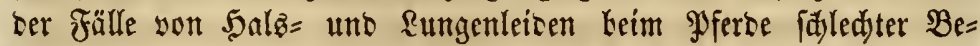

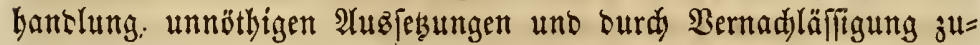
gefogenen Crä̈ltungen zuzujd)reiben fint.

(E⿱ binreidjenb zu erforfden, um einigermaß̄en zu verftehen, wie biefe

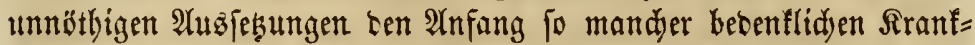
beiten biltoen. Die yon ber Natur gemadten 2 tnftrengungen, bie ¡jäblidjen Folgen-Ler graujamen Bebandlung ju entfernen, verbecten bell etwa geweften Bertadit. Itno rody fino gerabe sicje 2 inftren= gungen oft bas Mittel, weldez die lofale ober [pecifijale Rranffyeit hersorruft. Shre SBirfungen fonzentriren fith oft auf cin ober baz ant=

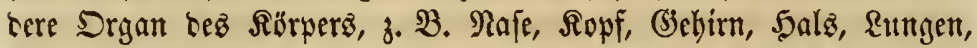

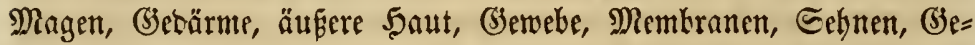

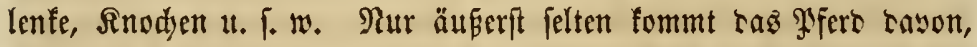
ohne baj ter eine ober anbere biefer Theile yon ciner Sranflecit be=

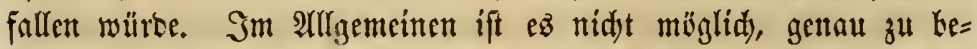
ftimmen, warum sin Drgan leidter nlsి bie übrigen erfrantt. Dft

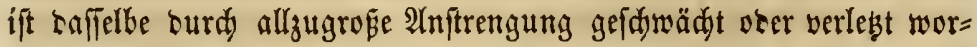
ben; Lod fönmen wir hieriber nidytz pofititiez angeben.

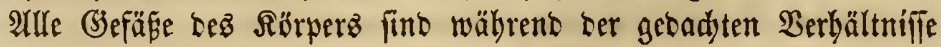
mehr ober weniger in ibren Funftionen geftört, wenn fie nidyt bauerno

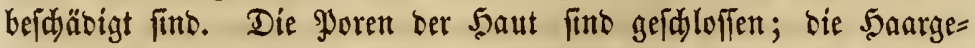

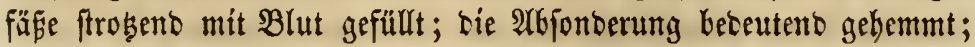
bas Blut ift bif unb in ben veridjiebenen Rörpertheilen unregelmäpig vertheilt; bie Drüfen fdjwellen an, währent bie Wänte ber Ruftrwege

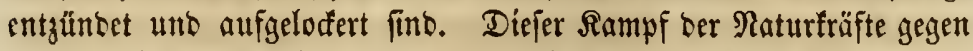

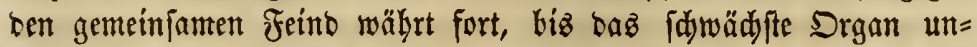
terliegt, unb in biejem freigt bann bie Entzünbung und \$̧ike auf ben hödjften Puntt. Daz in bem $\mathfrak{B l u t}$ burd bie genannten Stö= rungen entwidelte (sift flieft nun fidjerlid bem angegriffenen, ent= zünteten Theile entgegen, etwa fo wie fid baz Del ber $\mathfrak{a} a m p e$ burd) 
ben Dodjt zur lobernten Jlamme brängt. Wir haben unz lange mit biejem (̋̌egenftant aufgehalten, weil bier ber Uriprung bez Uebelż ift. Dies ift bie Duelle, aus ber bie Ströme flêfén, weldye bem פferbe fo bäufig zum Ruin werben. Sn fieben aus zelhn frällen werben bie אranfleiten bez Pferbes burd graufame Bebantlung,

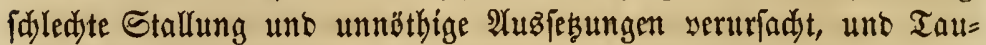

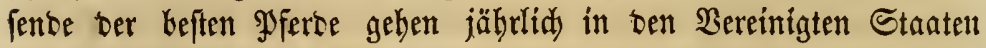
aแs biejen Uriad)en ż (3runte.

Diefes unnöthige Reiben unt bie nothwentig baraus folgenten

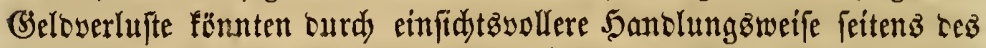

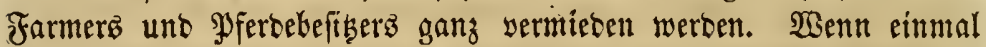
eine vernünftigere unt humane Befyantlung bez $\mathfrak{P}$ ferbez allgemein beobadtet worben ift, wirb baffelbe, felbjt im Dienfte bes Menfden, wieber feine uriprünglidye Siraft erlangen; unt bie Thätigfeit bes

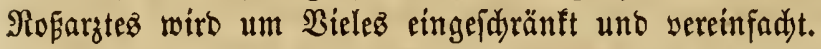

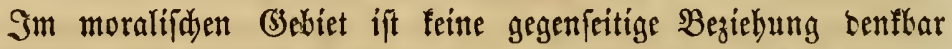
ohne übereinftimmenbe Berbinblidfeiten. Der Menfid ftebt in ser Beziehung bez Sherrn zum unvernünftigen Thiere, aber obne Zweifel liegt ibm bie Berbindlidfect ob, baffelbe zu beidjüben unt zu ver= forgen. Es ift aud feine moralifde grflidst, itsm felbft zum (3efese

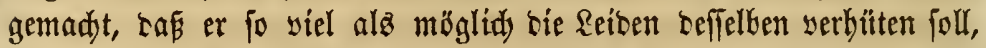
ant zwar yon bem Sdjëpfer, ber baz Thier ifm unterthänig madjte uno eigentlid zu feinem Dienfte fauf. Seber graujame 2 aft, ob wir

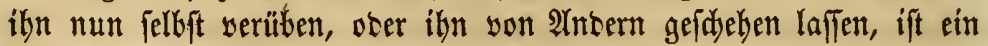
färectlides llnredyt uno sine Sünoe gegen (J)ott.

Wenn bei ungümftigem Wetter bas \$Perb ftarf angetrieben wor=

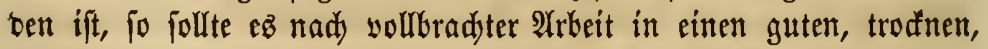
marmen Stall gebradyt unt für ein \&ager von reinem Stol geforgt

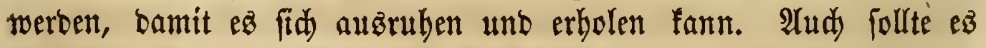
mit einer warmen, wollenen Dedfe bebefft werben, wenn $e^{3}$ fehr falt ift. Diejez ift nidjt mehr geforbert, als bu fdyon aus Rücfididten Der Danfbarfeit unt Sumanität thun follteft; ez wäre fogar beinte Yoflidst, wenn nöthig, eine warme Deafe yon beinem eigenen Bett $\mathfrak{z}^{\mathfrak{u}}$ nebmen, um bamit beitrent treuen Diener, ber bid mantde fummer= wolle Meile burdy ben futrdytbaren Sturm trug uno fidfer nady Saus bradjte, binreideno zu befdüben, felbft wenn bu alştann gezmungen 
wäreft, bie halbe Rad̆t aufaufizen, um bas Feuer in Detnem 3ims mer aufaubalten, bamit bu nidht frierft.

Man fann nidyt zu forgfältig fein in Bezug auf Futter. Unter feinen Umftänben barf bem erfibten Pferbe Rorn gegeben werben. Sollte unglülliduer Seife fein anderez Jutter bei ber Sano fein, fo

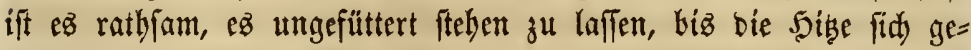
mäpigt hat uno ber Magen wieber in einem Buftano ift, in sem er 10ld) ftimulirentes Futter verbauen fann; inzwifden gebe ihm ctwas Waffer uno freue Salz in bie Srippe. Wenn Seu ober äbnlidiç leidtes Jutter im Stalle ift, fo follte es biefes zuerfit befommen. Sleie unb Säăfel fint am beften. Wir wieberbolen nod einmal, bá

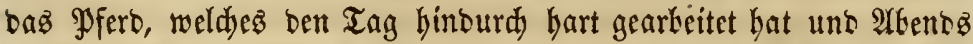
crmübet uno erhigt in ben Stall geht, vor bem näd) fiten Morgen fein Welfajforn befommen barf, wenn anberez Futter ju baben ift.

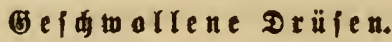

Fint Ler Sranflyeitżformen, bie in biefem Sapitel näher befdrie= ben werben, läpt fid am beften alz gefdyollene Drüfen bezeidynen. Wír veriteben bamit biejenigen Drüjengejdwülfte im Maule uno Salie, bie nidyt irgent eime anoere idwere Sranfleit begleiten, womit fie fonft bäufig alz begeidunento Symptome auftreten mögen. Sogleid biefer 3uftand nidyt auf einer fpecififden ober bleibenten Störung bes Drganiżmus berubt, fonbern bą Refultat einer vorübergebenden $G_{r}=$ fältung ift, fo hat er bod cine Neigung, in sine bauternbe Form überzigeben. Dann ift berielbe genau zu beobadten, und wenn er ungewobnlid lange währt, mus er bebanbelt wersen, wie im nädjten

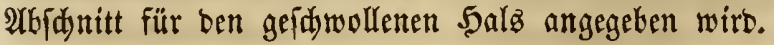

\section{(3) ef to ollenet}

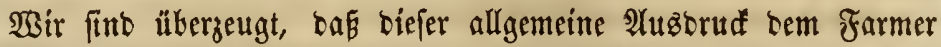
Dienlidaer fein wirb, als bie Eintheilungen tüdtig gebillbeter, wiffen=

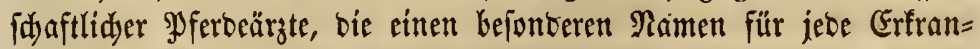
fung ber fleinften Salżheile haben. Dieje Rlaffe von Rrant= beiten bat fo viel $\mathfrak{A}$ ebnlidjfeit in Bezug auf urjadjen, Berlauf uno Bebanblung, bas, obgleidy fie anbere Theile bes 5alfes treffen, bier= ourd weber $\mathfrak{B}$ erwirrung nod Unbeftimmtheit entfteben fann. 
Währent wir an einem worhergehenten Rapitel arbeitteten, fahen wir einen foldyen fall auf $\mathfrak{W a l m u t ~ S i l l z ~ n a b e ~ G i n c i m n a t i . ~ D e r ~ S a l o ̈ ~}$ war in Folge einer ftarfen Grfältung uno entzünteten Drü|en bes beuteno angefditwollen.

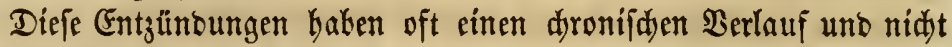
felten hat ber bem Eigenthitmer fowobl alz bem Yyferbe läftíge Suften

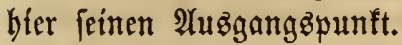

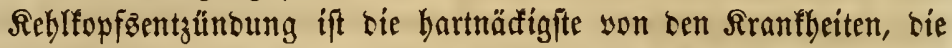

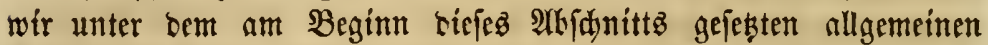
Namen betradten wollen. Serr Yjouatt bejdreikt biefelbe wie folgt: „Der Beginn ter Sranfleit ift bem einfadten (Satarrh febr äbnlid,

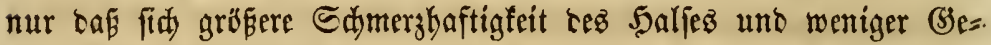

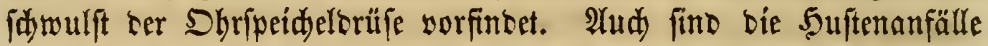
bebeuteno beftiger als bei ber einfachen eatarrbalifaden Entzintroung, uno fino oft mit einem eigentbümliden, son ber אeble ausgehenten Ton begleitet, ber bem surd) tas (3)urgeln von $\mathfrak{B a f f e r ~ e n t j t e b e n t e n ~}$ äbnlid) ift uno einige fus weit som \$ferbe weg gethört werden fann.

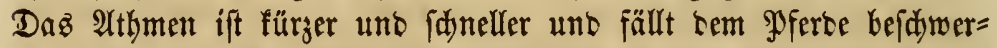

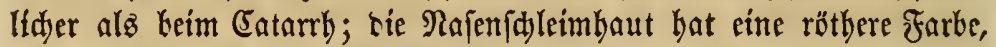
be in's Dunfelbraute übergeht; bas \$Pfero bebt fujammen uno gibt

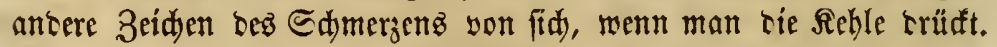
Die Suftenanfälle treten immer bäufiger uno beftiger auf, fo ba

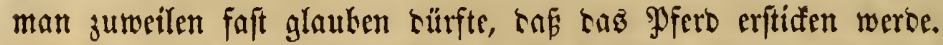

",Mit ber Zunahme ber Sdyner mehr ober weniger fteif uno ber Ropf fdeint meiter vorzuragen. Daz

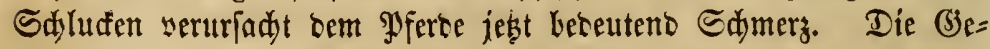

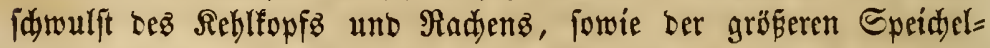
brüjen nimmt z̆u. Sm Fefben Grabe, wie jekgt bie Entzüntung tiefer greift, wirb ber Shuften beiferer uno fdwäd)er, unt wenn bie Rrant=

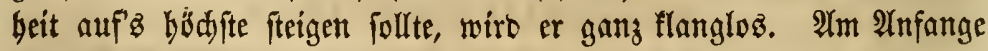

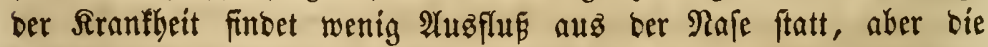
Affonberung geht balb vor fidy, entweber rein ober mit viel Speidel vermiffidt."

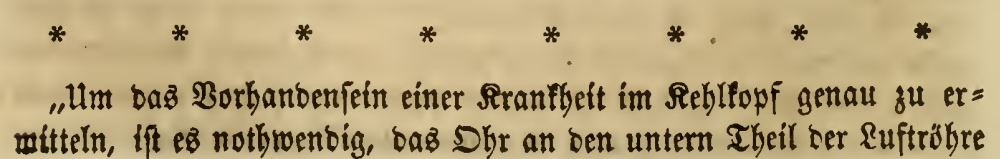


3u legen. ŞBrt man bie \&uft obne Unterbredyung ein= uno aubi= treten, fo barf man mit Sidjerbeit idjliesen, Das feine beceutende Rranfleit weber sie \&uftröbren nod bie \&ungen befallen habe, sa man anberz biejelbe pogleidy an ber Unterbred)ung ober Stodfung bez

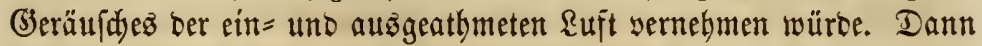
lege man bas Dhr ber Reble etwaz näber, aber nodj immer auf tie Ruftröbre. Bielleidjt vernimmt man jeşt ein Icifes gurgelndes,

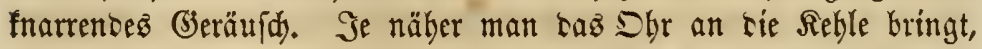
je bejtimmer Gört man sen Ion, ber zumeilen nrit einent zifidenten,

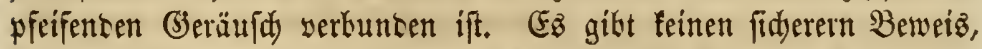
bafi ber Durdytritt Ser Ruft in Der Regle gebemmt ift uno jwar surd)

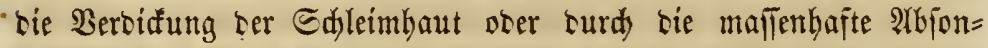
berung zähen Sd)leimes, weldes ten gurgelnoen, fnarrenten Rärm verurjadyt uno tie Reble verengt. Man wirt Kald im Stanoe fein, genau zu erfennen, ob tie $\mathfrak{B e r e n g e r u n g ~ b o r ~ R e b l e ~ t e n ~ z a ̈ b e n ~ S d h l e i m ~}$

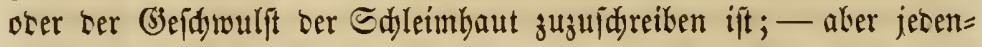
fallz bat man ben Sibs uno vielleidyt aud sen (3rab eitter beftigen

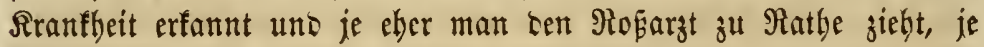
befier."

Diefe Salizentzünoungen fitto gemeiniglid son Frfältungen uno 5uften Kegleitet uno nidyt felten mit Bronduitis. In ber Megel

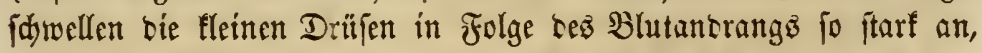

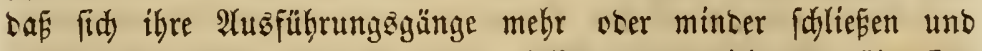
folglidy ibre Rbjonterungen fdwer abfliefen uno sid unt zälye fint

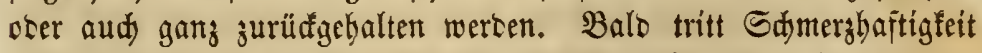
uno Entzuntung berjelben ein; fie fdwellen immer mebr an unb werten beutlid) füblbar, uno wenn fie nidat surd fa)leunige Şülfe son ihrem franflyaften 3 uftano befreit werben, geben fie in Eiterung ïber unb bilben $\mathfrak{U}$ cefle, bie mit bem Mefier geöffnet werben müfen.

\section{: e}

Die Bebandlung barf nidyt nergögert werten, ta biefe Jalätrant= beiten gemöbnlid einen [ajleunigen Berlauf haben. Man nebme fogleid) feine 3ufludit zu einem Xorlas, benn zur Beit oer (Ent= becfung bes Uebelz bat $e$ idjon gemöbntidy fo überbano genommen,

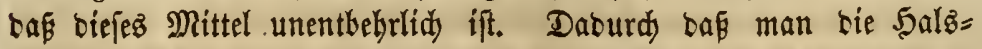
blutaber offnet, fann eine grofie Duantität Blut yon oer Umgebung 


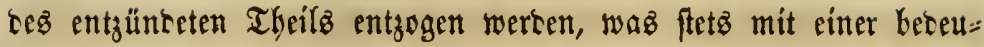

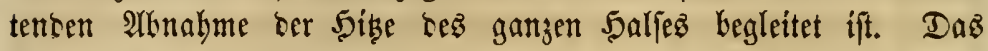

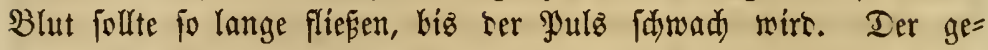

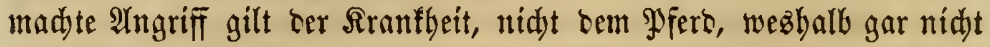

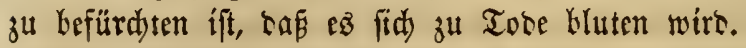

Shierauf wente man folgenbes Mittel an: Eine Unje dyloriaures $\mathfrak{R a l i}$ (Chlorate of potash), zwei Unjen Syydrażtiz Canabenfiz (Golden seal), viersig (Gran Bredjeinftein unt cine Pinte $\mathfrak{B a} a$ fier. Nadsem bieje Subftanzen gut untercinanber sermifdtt fint, madje man neun

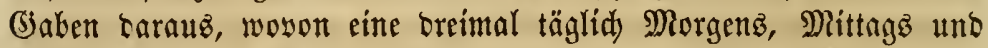
श्थ

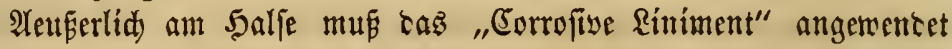
werben, weldyez immer gute Dienfte leiftet, wenn ber Şalż beheuteno geidswollen ift. Sollte ber entzïnbete Theil fidon in Eiterung überge= gangen fein, jo ift tas Entenfuş= (May-apple) Riniment sorzuziełen.

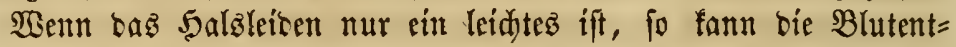
zief)ung unterlaffen werben, ebenio ber (3etraud) bes Corrofiwen $\& i=$ nimentz. Die Mirtur mus aber nad Boridrift gegeben werben uno

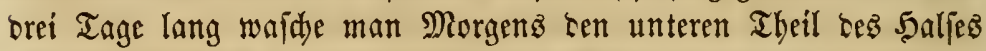

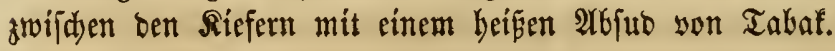

\section{Q}

Faft alle Rranffeiten ber Ithmungšorgane werben son meb'r ober

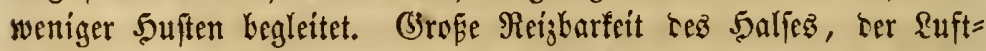
röbren uno ser \&ungen in Folge ser Enţüntung uno bes Ginfluffez ber $\mathfrak{R} u f t$ auf sen wumben unb entjünteten Theil ift immer ein Merf= mal biejer Sranfleit. Dem mehen Salje wiro eine febr falte 2 tmo=

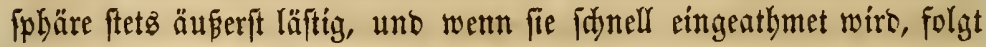
beinake immer ein 5uftenanfall.

Beim Menfden ift (3ejdywulft uno Empfintlidfeit ber Manteln eine, häufige Uriadye son Suffenanfällen. Dieje Srgane haben ihren

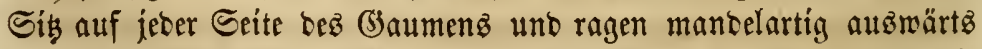
unb über bie Reblfopföffnung. Sn ten Manteln fintet man tie

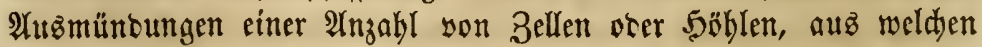

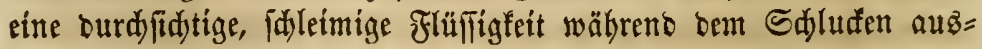

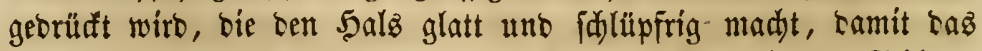

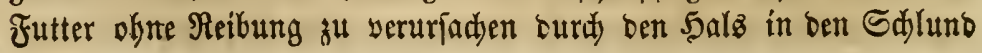


gelangen fann. Die Mandeln werben oft von (Steidjwulft uno Sdymerz=

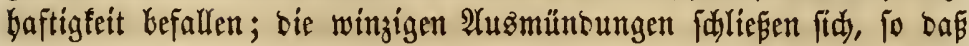
ber Saleim nidjt abfliesen fann; Maul uno 5als werben trofen und empfindlid), worauf balo 5ujtenanfälle folgen. Der 5̧uften ift nur als ein oft unwillfübrlider Berjud anjufeben, bie fdmerghafte Empfinoung im 5alje zu bejeitigen uno ben eingcidlofienen Sdyleim zu entfernen; fobald baber die Entleerung ber Sdjlcimbebälter hin= reidjeno burd) ben 5̧uften ftattgefunoen bat, um ben 5̧als glatt uno

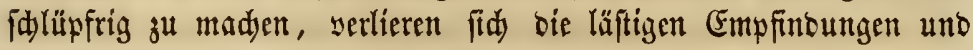
bie 5̧uftenanfälle lafien eine Bettlang nad).

Das Yfero befizt nidyt gerabe foldye Manteln wie ber Menid, uno folglid entitebt aud fein Suften nidjt gan auf biejelbe 2 seife, bod) aber werben biejelben 3uftänoe bura mangelbafte Sdyleimab= fonberung im Salje uno ben \&uftwegen Gervorgebradjt. Durd bie Albjonberungen ber Dhripeidyelorü[e uno ber fleineren Drüfen erbält bie warme eingeatbmete Ruft eine jiemlidje Menge Flüfigfeit, weldae fid) oer Saleimbaut oer Rafe, bes Maules uno ber Ruftwege auf= fest uno biefelbe befeudstet. Unter fieberifdyen uno entzünoliden $3 u=$ ftänoen yerounftet bieje Feud)tigfeit alfzufdnell, was eine läftige Irodenbeit ber Sdjleimbaut jur Folge hat. Bald entfteben num

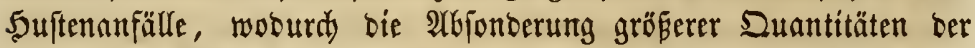
(đ)leimigen Flüfligfeit bezweăt werben foll, bamit bie Sdyleimbaut wieber hinreident glatt unt idflüprig gemad)t werbe.

Durdh bie 5 uftenanfälle werben alfo bie in ben Drüjen angebäuf= ten $\mathfrak{A} b$ fonterungen auf Die Sterfläde ber Sdyleimbaut ausgeleert.

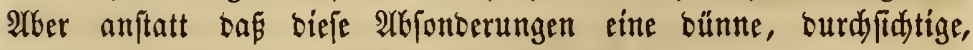
fàleimige flüffigleit barftellen, fino fie fäh uno unourdjfidtig uno befteben fo ju jagen auz einem gebiften ober geromenen Sdylem. Şierson werben oft grofe Mengen burd) ben Şuften entfernt, waz immer eine grofe Erleidjterung zur Folge hat. Wobl jebeşmal went ein Pierb mit 5uiten befallen ift, bat berfelbe bie $\mathfrak{A}$ ufgabe, ben maf= jenbaft in ben \&ungen unb \&uftwegen angefammelten läjtigen Sdjeint zu entfernen.

Dod) ift ber Şuften aud mit einer weiteren, ofwobl nur vorüber: gebenoen Rinberung begleitet, weldye barin bejtebt, bas bie fdnelf ourd) bie Suftenftöfe ausigetriebene Ruft tie brennenbe Sige ber

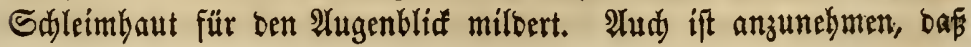


bie Reibung ber auszgebenton Ruft bie läftigen, judenten Empfin= bungen etwa fo linbert, wic äbnlidje Sdjmerzen ber äupern Saut ourd) leidtes Reiben ober Rraben bejdywidtigt werben.

Der laute Ion bes Suftens entfeht surd) bie heftige (Erifüutte= rung ber \&uft, intem fie son ben \&ungen mit grofer (3ewalt in. Sie Siehle uno jobann burd) bie enge Stimmribe getrieben wirb. Aluf ähnlide Beife werben sie Spradjlaute beim Menidyen gebillbet.

Trgeno eine Rranffeit Der Stthmungzorgane uno ber Ruftwege, ob nun bie Rungen, bie Ruftröbren, Iaz Bruftfell ober ber Salz baupträdlid leiten, meldye son einem fieberifdem 3uftano begleitet ift, wiro immer mit Suften yerbunden fein. Wenn die Rranfbeit dyronifa wiro, fo nimmt ber Suften benfelben Charafter an. Dods fönnen bie Shuftenanfälle nod lange fortbeftethen, nadjoem eine bef= tige acute Rranffeit längft befeitigt ift. Bon ten mannigfaltigen Sranflyeiten, in benen ein Şuften albु Eymptom auftreten fanm, wollen wir folgente anfïlfren: Wunbbeit oser Entjünoung irgent

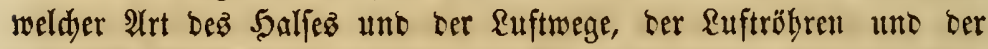

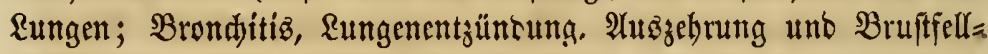
entżütoung.

Suftenanfälfe begleiten bin unt wieber aud) nod andore Srant= beiten, weldye einen fympathetifhen Cinflü auf ben $\mathfrak{S a l z}$ utto bie Eungen ausüben, bod yergehen biefelleen mit bem Berfdyinten ter heftigften Symptome jolder Rranfleiten. Unter biejen Rrauffeiten mus man folgente zăblen: Unverbaulidjfeit, Woürmer, Reberfranffheit und Distemper.

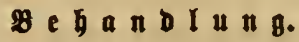

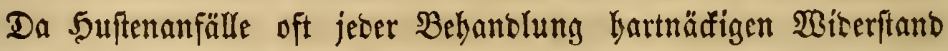
leiften, fo wiro $e B$ immer fajwierig, tiefelben gang zu betwältigert. Dod) fönnen biefelben bebeutent gemiltert werben uno gwar oft in furzer Zeit; aber bas Reiden ift beshalb nody nidjt ganz gehoben.

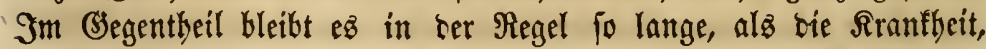

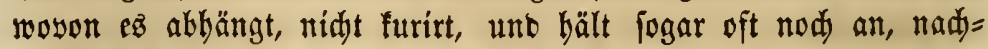
Dem biefeltbe grünolidy gebeilt ift.

Man fange bie Bebandlung cines aus Erfältung entffantenen Supenz fogleidy nady feiner Eridueinung an. Sobalo man bas Syfero huften hört, follte ter Sadje bie gröste 2tufmerffamfeit ge= 
fihenft und fo lange geforidyt werben, biz man bie Uriadje beffelben entbeft bat. Benn er burd frembartige Subjtanzen auf ber Sdleim= baut, wie Staub, Spreu u. F. w. entftanben ifi, fo wiro weiter

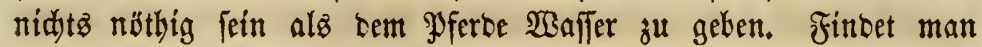
aber, baf berfelbe ein Symptom einer Crtfaltung ober einez bäfen 5alfes ift, fo mus mit einer energifjen Behandlung fogleidy ange= fangen werben. Man lege Las Dho auf ten Sals nabe bent Rie= fer, um auszufinten, ob bie Reble befallen ift, was fidy, wie faton

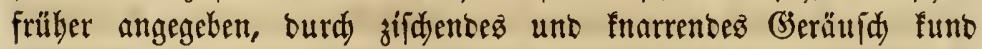
gibt; aud beobadjte man, ob baz Thier gieríg fäuft unb tann ten 5ुals aubffreăt, als wern bätte. Sollten folde Symptome entredt werben, fo fdjreite man pogleid zư $\mathfrak{B}$ ebandlung.

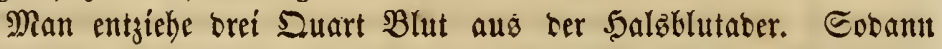
iff folgenbes Mittel zu bereiten: Ein Ef̣löfel yoll Sdjieppulyer, ebenjoyiel Sajmierieife, Theer unt fein pulverifirte Myrrbe, uno

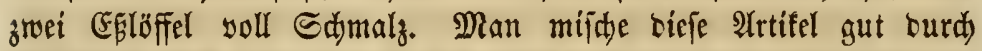
uno vertbeile fie alobann in fedjs Dofen, woyon eine jeben Morgen

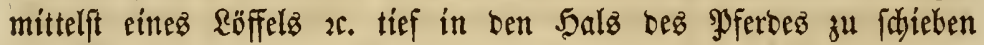

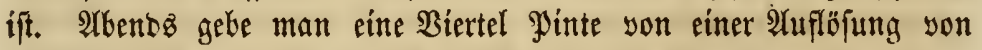
d) lorjaurem Rali (Chlorate of Potash), befteheno auz ciner Unze

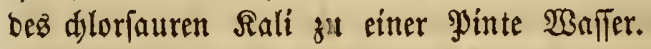

Sm F̧all bas \$Ferb im Stall fiteht, follte nadjher reiddid Edjwefel und Sarz gegeben werben; fann man bas Pferb aber zur Zeit

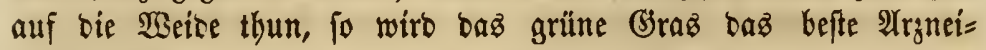
mittel jein.

Rommt bie Rranfleit im frübjabr yor, fo fann man bie $\mathfrak{B l u t =}$ entrieflung unterlaffen, wenn ber $2 \mathfrak{n}$ fall nicht fehr beftíg ift. In leiduten Făllen wiro fid ber Sulten bald yerlieren, wenn bie Mebigin für ben 5ă mal bes Morgenz mit einem $\mathfrak{A} 6$ jut yon $\mathfrak{T a b a f}$ gut gewajden wírb.

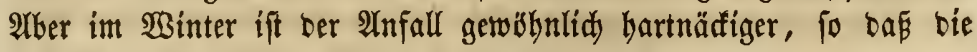
angrgebene Behandlung ganz ausgeführt werben muß. 


\section{Die bäsartige Seuमje (malignant epydemic). *)}

„Im Jakre 1714 wurbe eine bözartige Seudje som Sontinent beribergebradjt, weldye in bem fursen Beitraum von einigen Monatet 70,000 Pferbe und Rinber wegraffte. 2Uud bejudte tiejelbe antere sänoer in furgen 3wifdenräument uno berridte im ganzen etwa

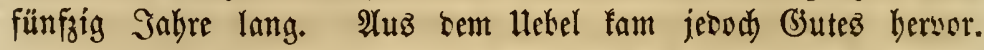
Die europäifden Rantwirtbe wurben bödhft bejorgt in Folige ser

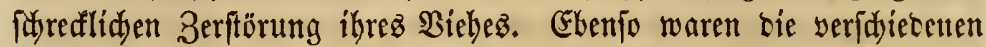
Regierungen von bem allgemeitten Edarefen ergriffen, was balo Beranlaffung zur (Strünung son Tbierarzneifalulen gab, wo man fid) genau mit ber Anatomie und Fathologie rez Thierez Kefannt madute uno aud halo sie Urjadhe ber bözartigen Seude unt rie befte 2 rt ber Bebantlung entoeffte. Bon ber Zeit an, alz man

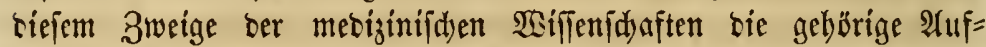
merffamfeit gervitmet bat, baben bicie Epiremien ibren bözartigen SGarafter verloren, fo baj fie jebt nur in viel milberer form auf = treten. Da fie aber bod nod immer bin uno wieber erideinen und oft grofe Berbeerungen anridten, follten wir unz genau mit ben Symptomen ber Sranfbeit und ben beften Mitteln zu beren Bcceiti= gung befannt madjen.

"Die bözartige Eeudje fing faft allemal mit einer Entjüntung ber Sd)leimbaut ber $\mathfrak{A}$ thmungzorgane an, ging aber toalo att an= bere Sörpertheile ïber uno zeigte fid enblid in ber form cinez Durdjfalls, ser ungeadotet aller Mittel ber Iunft unaufbaltjam biz zum Tobe anbielt. Dasె Fither, im IInfang ftart aušgeprägt, ver=

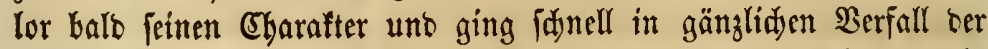
Rörperträfte über. Die Ent;ünoung theilte fid bem Binbegemebe mit uno es entftanten idymärenartige Beulen; zuweilen fah mau

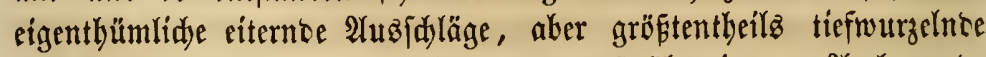

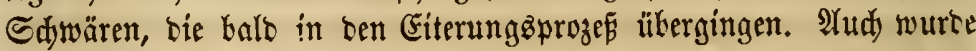
in furger Beit eine शeigung zur Fäulnif wabrgenommen, uno wenn

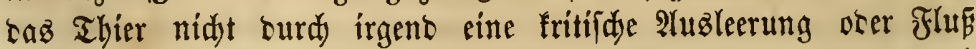
Sülfe befam, ftellte fid cin böbartiges typhöfez fieber ein, wobura baz Pferb fduleunig zu (Frunbe ging.

*) Die Betbeerungen diejer (Epibemie bilden eimen bödjt intereffanten, aber er.

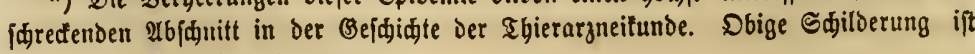
bem Berte Bouatt's entuommen. 
"Die befte Befdreibung einer foldjen Epitemie haben wir yon ter Feber son \$rofeffor Brugnone aus $\mathfrak{T}$ urin. Sie fing mit $\mathfrak{2}$ (ppetit= lofigfeit, zu Berge ftehentem 5̧aar, wiltem, unftetem Blif uno [d)wappentem (3ang an. Das Pfero legte fid, ftano aker fogleidy wieber auf, uno wieberbolte bies beitünoig, als wenn behaftet wäre; Dabei fahaute es balo nadj ber einen, bals nadj ter

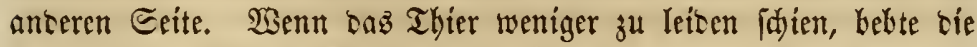

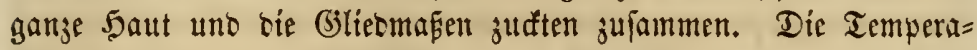
tur ber Dhren uno oer Fitiffe war serünterlidi. War irgento eine

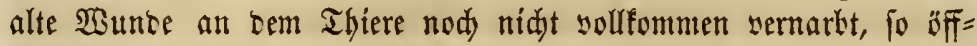
nete fie fid auf's neue uno entleerte eine Menge siafen, idywarzen

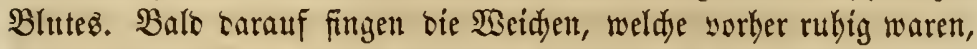

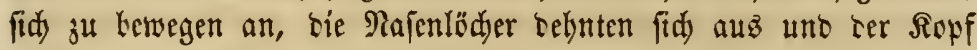
wurbe autögeftrefft, um befto beffer einathmen ju fönnen. Seţt war aber tab Pfero fo fdyad getworten, baf, wenn ez fith legte ober

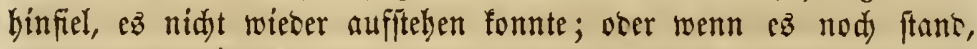

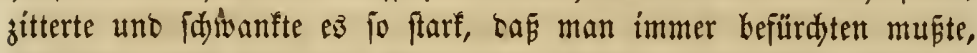
eż werte umfallen; taż Maul war trođen, bie Zunge weí, ber

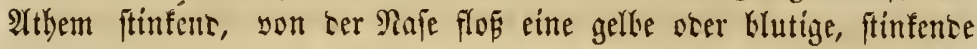

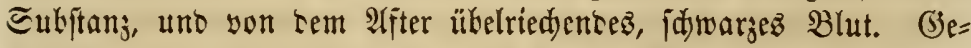
wöhnlid bauerte sie Rranffeit nidyt üker zwölf biz sieruntzmangig Stunten; orer wemn tags Thier nod) länger leiten müte, fajwollen

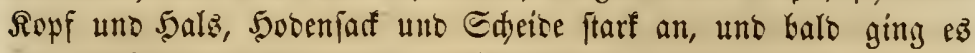

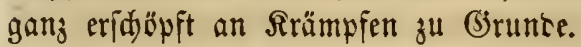

"In ten Bintemeken fanten fid fidmarze fleden yon auzigetre= tenem Błhte vor, fo aud im Magen uno allen 5äuten. Die (be =

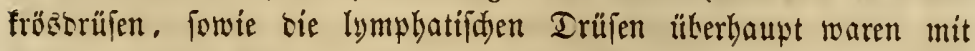
Blut angefülth, fajwarz uno brantig. Die Sdjleimbaut ter Taje uno bes 5 nalies war roth tmo angeidyollen, die sungen entbielten

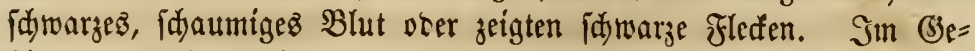
birn uno befien $\mathfrak{H e b e r z u ̈ g e n ~ f a n b e n ~ f i d ~ f e i n e ~} \mathfrak{B}$ eränberungen yor."

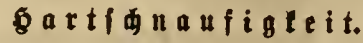

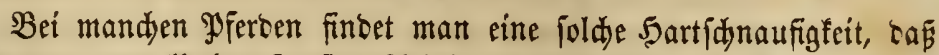
fie nur zur alferlangiamjten 2rrbeit taugliú) fint. Diejer 3uftano mag feinen Brtunt in einer Strufturveränberung in ben \&ungen baben, ober aud auf einem Semmní in ben \&uftwegen beruben. 
Man Kat bie Rranfleit mit veridiebenen Mamen belegt, je nad ber Etärfe uno $\mathfrak{B}$ iddtigfeit ihrer Symptome. Sn Englano bängt ber

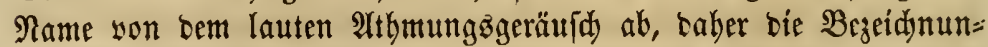
gen Pfeifer, Brüller, Edjnaufer u. 「. w. T(t) wirb baz llebel io=

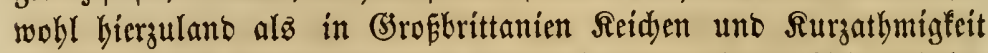
genannt. In ben fübliden Etaaten wiro baz fdjwere 2 thmentyolen alz "bellows" uno in ben nörtlidjen alz "heaves" bejeidjnet. Diefe Benentungen begieben fith alle gang auf benjelben Buftant, und entftanben bauptfäd)lid) in Folge yon ben idnellen uno mübjamen

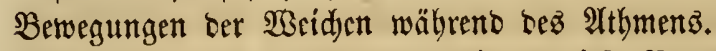

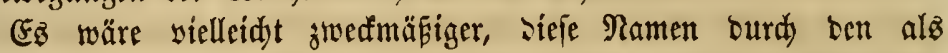

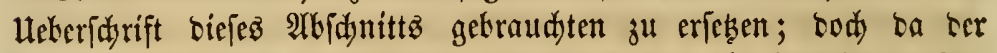
Farmer unter ben gewöbnlideren Benennungen bie franflaften $3 \mathfrak{u}=$ ftäntse am leiduteften erfennen mag, wollen wir bie serjdjictenen Berbältniffe Der Rranflyeiten, bie alz হeidłen uno Rurzatbmigfeit befaunt fint, einzeln bejdreiben. Die erfen zwei merben in ber

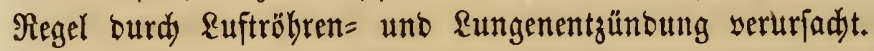

\section{Seifen, BeI}

Die Thätigfeit ber \&ungen finbet nady bemielben ærinzip ftatt wie bie einez $\mathfrak{B l a}$ lebalgę. WSenn fie in ihrer Struftur befdäbigt

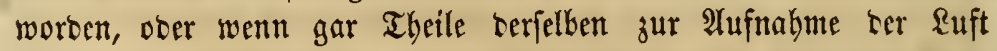
ganz untauglid) fino, fo wirb bie Thätigfeit, ber 2 (thmungżmus= feln um viclez gröfer. Bewegt fid aber baz Thier fdnell, io

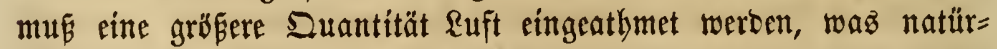

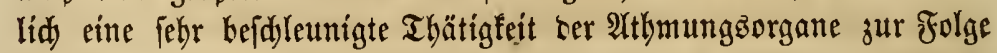

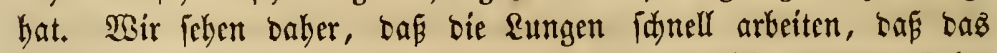
Thier bart fdnauft uno bie Seiten blafcbalgähnlid) gufammenfinten und fidh bann wieber fidnell auzbehnen. 2Yuz biejer Eriđeinung haben bie Süblänber ben Ramen "bellows" (B̊lafebalg); aud) ift bie in ben Neutengland=Staaten "gebräudilide Begeidnung "heaves" temfelben lumftande juzufdreiben.

Bei bem mit Reiden bebafteten Pferbe wirb bie Ruft viel idneller, aber aud bebeuteno mübjamer eingeathmet alz bei bem gefunben; wenn aber bie eingeatbmete $\mathfrak{e} u f t$ wieber burd) baz 3 ưfammenfinten ber \&ungen aużgeprest wiro, fommt cine eigenthümlidje, djarafteri= ftifde Erideinung yor. Dicje befteht io zu jagen in einer boppelten 


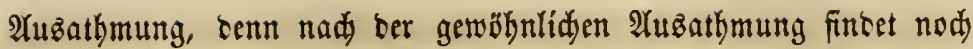

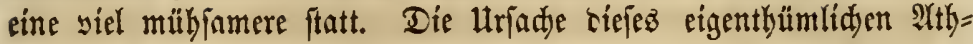
mens ift eine theilmeife Beränderung ber \&ungen, in weldjen man

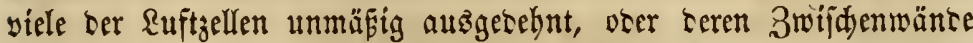

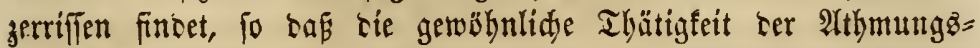

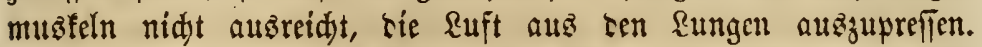

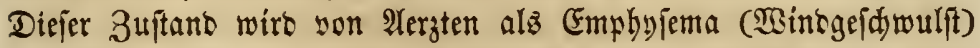

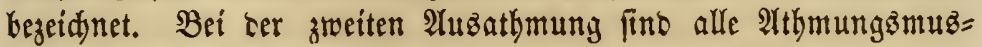
feln im bädften Groube thätig.

Stonehenge fagt: "Der Drua ber unerneuerten Ruft ïkt fortwäh= reno einen Reis auf bie Sungen aus, uno wetn aud leidjt genug

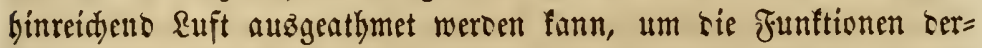
felben im gebörigen ઉ̉ang zu erbalten, fo lange ser $\Re$ örper rufht, fo

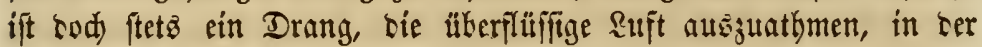
boppelten $\mathfrak{A}$ usaathmung bemerfbar. Sagleid) nad) ser zweiten $\mathfrak{A}$ zuz= athmung eridlaffen sie Musfeln, worurdy sie Meidjen zufammen= fallen; uno birs ift es, waz bem 3ufdauer auffällt. Bei ber Seftion fintet man sil Rungen weit ausgetehnt, aud fallen fie nidyt fo ju=

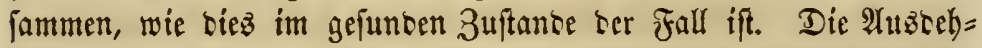
nung fincet ftatt, weil bie Bellen eine unnatürlid) grofie Suantität Euft enthalten; sics ift aber bejoncers ter Fnll, wenn sie überflüfifige Ruft im Bintegemebe, weldes die Bellen mit einanter vereinigt, jeinen Sils hat. In ber gewöbnlidyften form tiejer Srantbeit fino sie Bellentwänoe zerfallen, fo cas mehrere Bellen mit einanter verbuncen

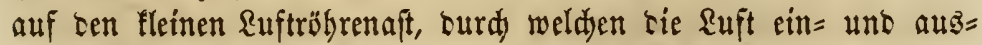

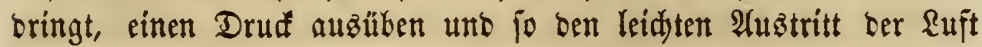
bintern."

\section{\$七}

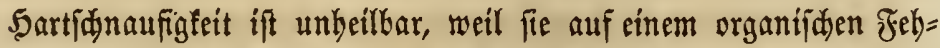
ler beruht. Die zerrifienen 3etlenwänte tännen surd feine menid)= lidje Runft in ihren früheren vollfommenen 3uftano zurüfgebractst werben. Dod fann aber baz seiben burd) eine geeignete Diät uno regelmäßige, nidjt zu beftige Rörperbewegung beseuteno erleidtert werben. Das $\mathfrak{P f e r b}$ barf nidjt innerbalb einer Stunte yor ber 2 (rbeit faufen, nod) zu hart angeftrengt werben, fo lange ber Magen voll Futter ift, ba bie \&ungen ben freieften Spielraum haben müfīen. 


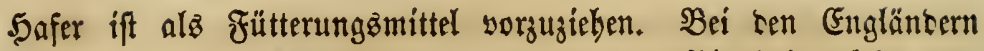

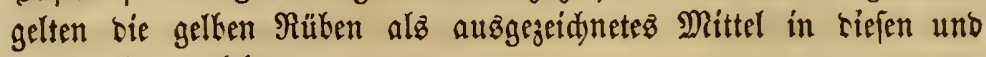
anbern \&ungenleiben.

\section{A u $\boldsymbol{x}_{\text {zat }}$ migteit.}

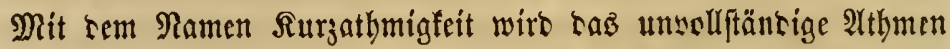
Lez Pferbes bezeidjnet, menn fein pfeifentes (Geräufdh gehört mitt,

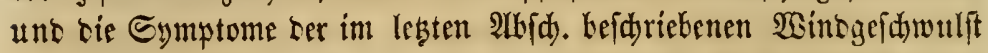

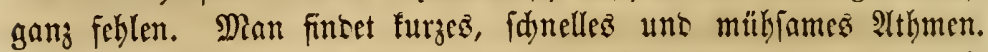
Diefes erftreftt fid aber jowohl auf bic Einathmungen, alş auf bie

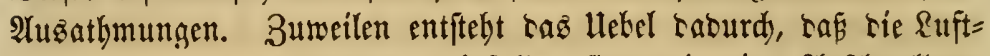
röbren yon einer Entzüntrung befallen fint, tie sine Ânfdwellung ber fie augleisenoen Edjleimbaut serurfadyt, uno folglid fo ten Durdjtritt Ler \&uft fintert; aber in ter Regel bängt Las \&ectrent won einer surd) Enţüntung verurfadten \&ungenverbärtung ab, Ł. h. viele ser \&uftzellen fint mit einem wäbrent ser Entzïnsung abge= lagerten Stoff ganz aufgefüllt, fo taḱ fie ihre Funftionen gar nidjt erfüllen tönnen. Die gejunben \&uftzellen müfien saker aud) sie \&uft, weldye in bie bejdäsigten Ruftzellen bringen follte, atfnebmen, was

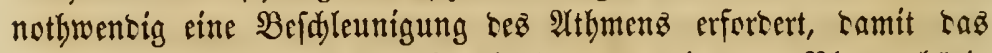
chen fo reidlidy als früber in tie \&ungen bringente $\mathfrak{B}$ hut gehörig gereinigt uno erneuert werben fann.

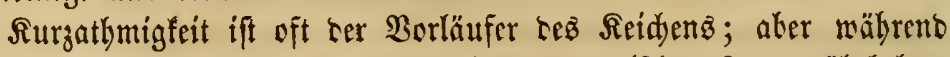
jencz llekel yon einem eigentbümlidjen organijden \&ungenübel ber= rübrt, fino faft alle \&ungenfranflyeiten mit אutrzathmigfeit begleitet.

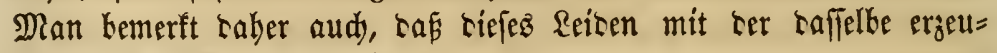
genten Sranfleit veridumintet.

\section{B e}

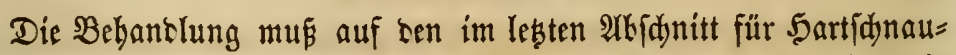
figfeit angegekenen \$orincipien beruhen. Dody ift nidytz meiter alz Sinnerung ser beftigften Symptome ž erwarten.

\section{Roaring.}

Mit siefem Ramen wirb in England cine Rranffeit bezeidnet, bie in biefem Rante äuferft felten, aber in einigen Begenten Euro= pa's red)t Gäufig vorfommt. Folgenbe 2Angaben entnebmen wir sen 


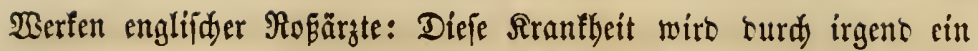

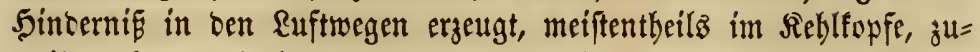
weilen aber aud in ber Ruftrible. Shin und wieser beftebt baz

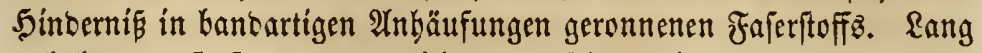

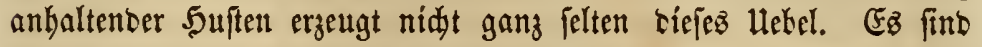
in ber Regel nut Zugpferbe bamit betaftet.

(3emitife Thatjaden beuten auf cine angeerbte Reigung zu biejen Reiben. Major Wilfon yon Diolington in Englano bejás ein jehr werthyollez Stallpferb, meldeez mit biefem Hebel behaftet war, Laz fid) aud) auf bie von bemfelben erbaltenen Foblen fortpflangte. Da gegen waren "Eclipie" uno "Ĩauruz," zmei berühmte englifaje : renner, beibe Roarerb, aber ifre Foblen hatten gar feine Symptome ber Siranflyeit an fidj.

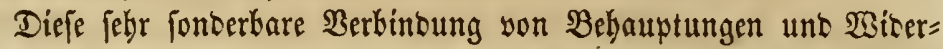
fprüd)en baben mir benfelben 2utoren entrommen. Damit wollen

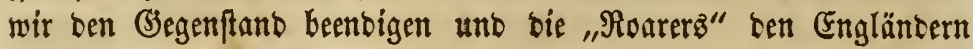
überla Ten. 


\section{Bwölftes diapitel.}

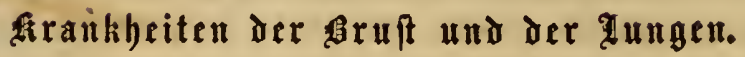

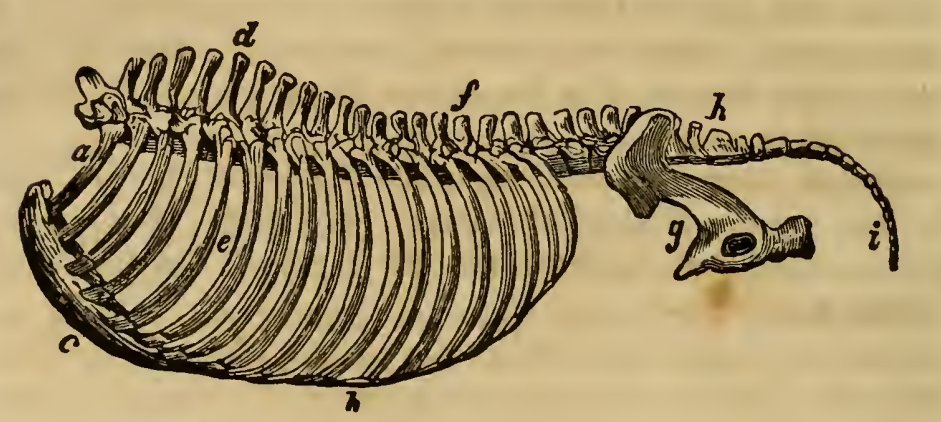

a Die erfte Mippe.

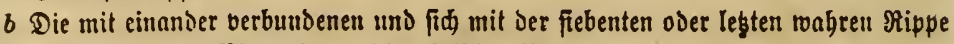

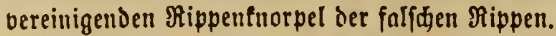

c $\mathfrak{D a s} \mathfrak{B r u f t b e i n}$ (breast-bone, or sternum).

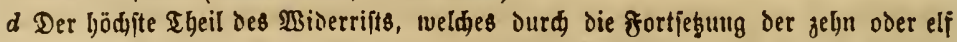

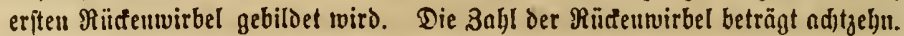

e Die Rippen, gewöhnlid adtzelyn an jever Seite; dic freben erften find mit bem Bruftbein durd Anorbel, Die \&norpel Der übrigen elf aber mit einander berbun. Den ; fiehe $b$.

$f$ Der aus den fechs Sendentwirbeln (lumbar vertebrae) beftehende Igheil des Rüct. grats, wo die \&enden anfangen.

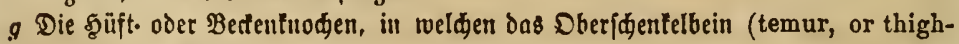
bone) befeftigt if.

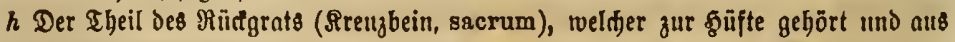
fünf İheilen befteht.

i Die Sdncifroirbel; getwögnlin find es fiebzebn.

\section{Bruft:Belie, Steifigleit (chest founder).}

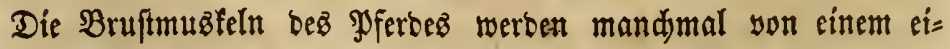

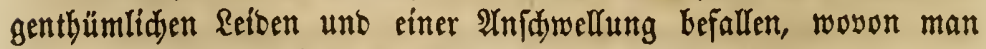
fi் biz jest nod feine genügente Erflärung geben tonnte, und wel= 


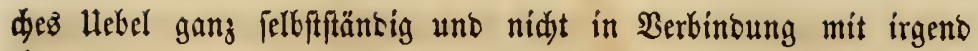

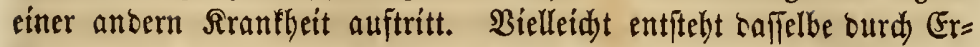
fâltung, bie fid aus einer ober ber anoern Urjadje in bieje Muąfeln Feftefst, vielleidst aud) burd) Berlebungen, ober basurd), baj bie mit ben Muşfeln in Berbintung ftehenben Sehnen franfhaft werben.

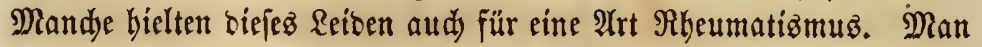
legte temjelben früber ben Namen "Gheiffounder" bei, unter weldher Benennung es aud beute nod) bei ben meiften amerifanifden far= mern befantit ift.

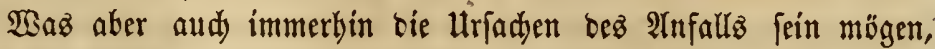
die Symptome beffelben fino nidyt zu verfennen. Das Pyfero hat offenbar viel Sdjmerzen zu leiben; ez ift in Sdjultern uno ben

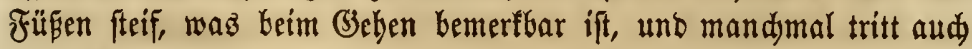
bebeutendeż fieber ein.

\section{$\mathfrak{B} \in \mathfrak{C} \mathfrak{a} \mathfrak{n}$ b $\mathfrak{l} \mathfrak{u} \mathfrak{n} \mathfrak{g}$.}

Man wajd) bie Bruft Morgenz, 2Abentz unt in ber Radjt mit warmem Salgwafler, uno fę̧e am ztweiten Tage bas corrofitye Sini= ment auf. Sobann gebe man bem \$atienten einen auz einer \$inte

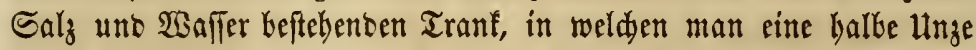
Ingwer (ginger) unt eine Dradjme (dram) Bredjweinjtein (tartar

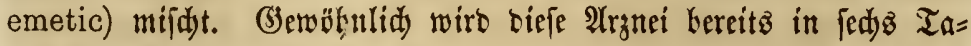
gen eine Rur bewerfffelligt Gaben; follte biefé jebod) nidjt ber Fall fein, fo fahre man mit bem (Gebraud) berjellen fort.

Sft die Rranfleit eine fehr hartnäđtige, fo nebme man einen mäß̨i= gen $\mathfrak{A}$ loerlá yor.

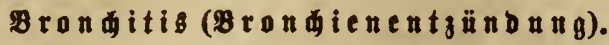

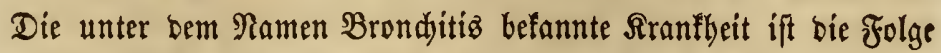

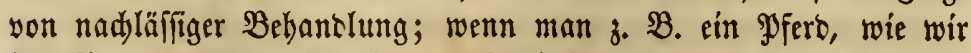
im Eingang bes vorbergehenten Rapitel' gefagt, nadjoem ez burd) Sagen uno $2 \mathfrak{n}$ ftrengung febr erhibst worben, währeno einer falten,

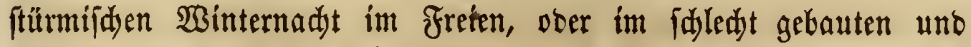

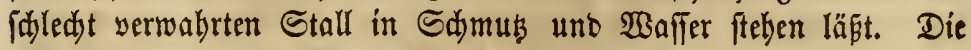
Folge foldher Behandlung wiro zunädjft eine Erfältung fein, fodann werben bie Drüfen uno enblid ber Satz anjdwellen, uno ber Ei=

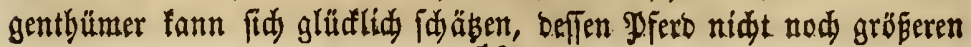


Seiten unterworfen wirb. Sft $e$ a audy nidyt immer ser fall, fo fommt

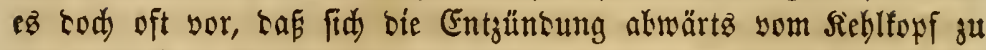
ter Ruftröbre, hen Brondjien (Bergweigungen uno Fortięţungen ser \&uftröbre) uno ben \&uftwegen ter \&unge verbreitct.

Brondjitiz ift eine Entjünbung ber ভdjleimbäute ber Brondien.

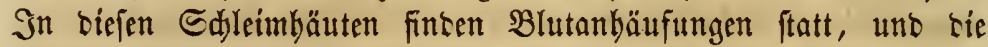
Röbre wirb baburd natürlid beteutend verengert, fo saf fowohl wer= mebrtez Itthmen, alsె Sdjwicrigfeit wäbrent beffellen bie Folge ift.

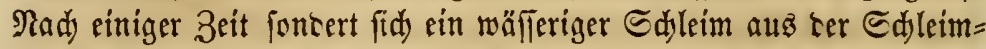

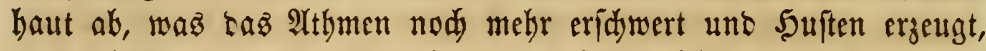
Denn bie Raturfraft mödte riejen Sdjleim befeitigen. Dieje Symp= tome, weldye immer wabrgenommen werben, fint bezüglid sez (Srabez, jowie binfidytlid ber (befdymindigfeit ihrer Aufeinanterfolge fehr veridiecen, son weldem Unjtano man bie Brondjitiz entweber sie dfute oter doronifde kenannt hat. Die Subftang, weldhe fich bei yon Bronditiz befallenen Thieren entleert, ift eiterig, faleimig uno mit Blut und Ros aus ser Raje sermifdt. Die Srantheit ergreift nad) uno. nad sie ganje Ruftröhre unt alle Ruftwege, ja felbft sie Rungen, fo taf sie Hnerfahmen siefelben nur mit Edywierigfteit yon Rungenentzünoung. (pneumonia), in weldje fir oft ausartet, unter= fideiren fünnen. Das yon tiejem Reiten befallene Pfero ift gegen Edmerz febr empfintlidy und feine Merven kefinten fid fortwäbrent in grofer 2 ufregung; fein Blid ift ein jebr trauriger, uno zu Beiten wiro baz 2rthmen bermajen cridmert, bas man glaubt, bas Thier fei bem Erftifen nabe. Der Suften ift troden uno peinlid, ser

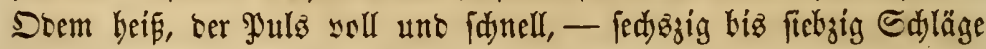
bie Minute - sie Rajenjdleimbaut ift hodjoth uno tas Cin= uno

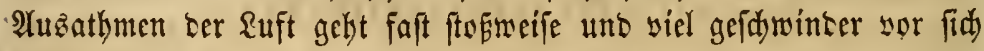
alz jon fit.

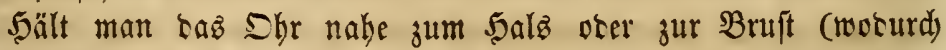
man fid am beften üher alle \&ungenfranflyeiten unterridyten fann,

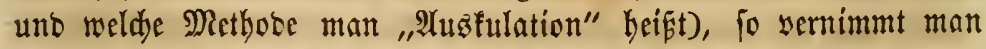

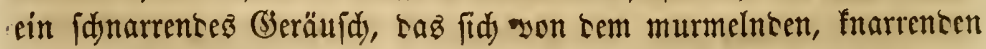
Ton, welder bei sem ton \&ungenentzüntung Befallenen gebört wirs, wejentlid unterideibet. Sobalo bie Edjleimabjonterung ju Etante gefommen, tritt baz jog. Burgdin ein, weldjez ein djarafteriftifalez Renngeiden ber Brondtitis ift. 


\section{O}

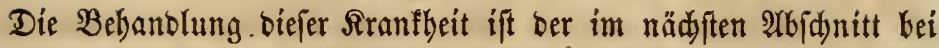
\&ungenentzünbung vorgefdrielienen fo febr ähnlid, baß ez genügeno ift, ben $\mathfrak{L e j e r}$ barauf zu verweifen.

\section{Eungenentzünbung (pneumonia or inflammation of the lungs).}

\&ungenent3ünoung ift in ben meiften Fällen, wo fie auftritt, fer Radfolger von Bronditís uno wiro gewöbnlid töetlidy; benn fommen verbältnifmäfig immer eine febr tleine 2 (nzabl Suren zu

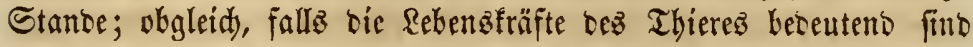
uno man pogleidy zu energifden Mittelı greift, eine Seilung ermög= lidbt werben mag; jecod) wirb bie Bebanclung immerbin viel Zeit, Mäbe uno Gebult erforbern.

Dáp primäre voer reine \&ungenentzün๖ung aud) vft allein uno nidyt in Begleitung von Brondjitio vorfommt, ijt getwís; aber ebenio

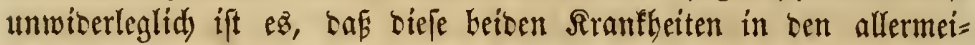
ften Făllen in Berbinoung mit einanter auftreten, uno vielleidjt serbinbet fid) Bronditiz mit ber reinen \&ungenentzünoung weit ifters, ober geht terjelben in viel mehr Fällen voraus, alsె man gewöbnlid annimmt. Alker bie Symptome Ler Sronditiz treten, meil die gefäbrlidjere Siranflycit viel beftigete Rennzeidjen erzeugt, nidft fo in ben Borbergruno uno meroen beşbalb überieben. Madit bie Rrantfeit jeood) nur langjame Fortidyritte, jo fint bie Renn= jeid)en ber Brondjitis beutlid) wahrzunebmen.

Das Thier friftelt beim Eintritt ber Sirantheit, worauf fogleid) cine unuatürlide Sibe in Sörper erfolgt, uno biefe wieber mit Froft afwed) jelt, weld)er ftärfer ift als ber erfte uno aud etwaz länger an= bält. Diefe Fieberidjauer mögen fid orei= biz viermal tvieberfolen, che fid ein anteres Symptom zeigt. Die Shliebmaficn fino gleid son $\mathfrak{A n f a n g}$ an eisifalt. Tadicem fid bie Symptome entroiffelt ba= ben, wirb bas 2 thmen erfdywert uno fdneller, incem auf jebe $\Xi_{e}=$ funte ctwa ein 2 themzug fommt ; rer $\mathfrak{P u l}$, obgleidy fduerfällig, ift

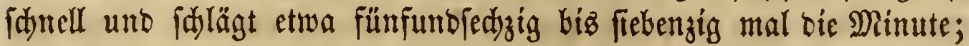
Das Maul, wie ber Soem fino feb: heif, ein feidjenter Sulten, welder bem Pferbe offenbar viel Sdmergen verurfadt, tritt ein, bie Borberfüfe fteben gefpreigt, weil bas Pferb inftinftmäfig bie Bruft ausizubebnen beftrebt ift, unb wenn man bas Shr an Bruff unb 


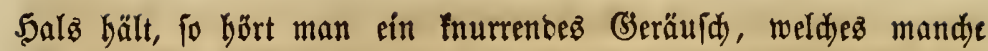
mit bem (beräuja verglidyen haben, bag bei bem 3ujammenlegen einer getrodneten Blaje entifebt. Diefes (Geräuja) woiro burd, Daz̉ Einbringen bes Blutes in bie Euftzelfen erzeugt. In ben \&ungen fintet eine fürdfterlidje $\mathfrak{B l u t a n b a ̈ u f u n g ~ ( c o n g e s t i o n ) ~ f t a t t ~ u n o ~} e \bar{B}$ ift oft ber Fall, baß eine Blutanbäufung, bie burd heftige, übermäß̧ge श्dnftrengung zu irgent ciner Zeit entfteben mag, bie \&ungenentzün= bung erzeugt.

"Die ungünftigen Symptome," fagt YJouatt, „finto - baz̉ Rålter=

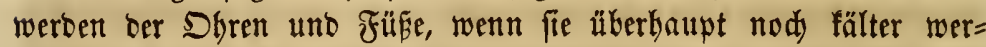
ben fönnen, alz fie beim Beginn ber Rranflyeit fint, etważ Sdiweiß,

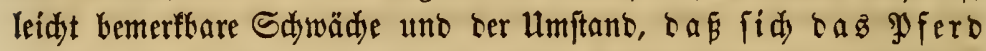

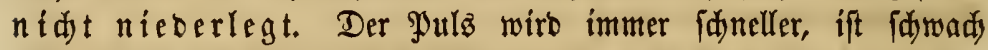
uno unregelmäfig, bie Rajenfalleimbaut wirb blaffer uno bat ein (đ) zujammen, raffi fid jecod fogleid wieber auf, um in ber nädyften

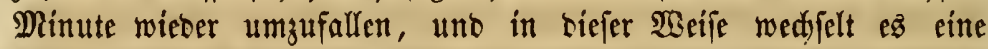
Beitlang ab, bis ez feine Siraft zum 2Huffteben mehr hat. Run= mebr fallägt es beftig um fid uno gibt fdymerglidje \&aute von fid);

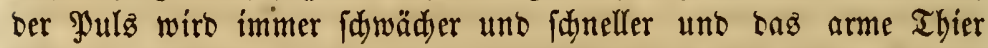
gebt an Fritifüung zu (srunte. Mandymal ift ter Berlauf biejer Rranfleit ein auferorbentlid rafder, uno es ift fdjon ber Fall ge=

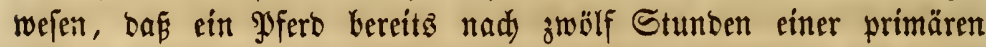
Rungenentzünoung erlag.

"Die günftigen Symptome fint - WBieberfehr ber Wärme in ben

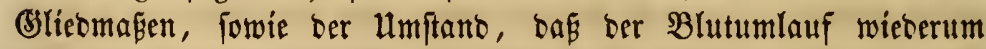
feinen natürliden (Sharafter annimmt, uno näd)fit zu biejen, wenn

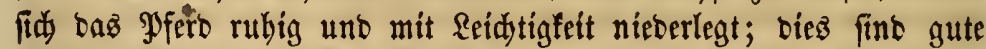
Symptome, weldje felten täufdjen.

"Sehr oft ift eż ber Fall, bap bie Rungenentzüntoung in Blutan=

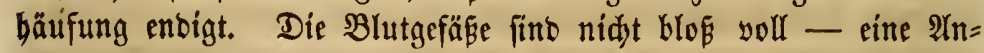
băufung, weldye bei jeber Entzünbung ftattfintot - forbern beren Wänbe find aud fo bün, bas fie leidyt berfen uno bie Zellen fid mit $\mathfrak{B l u t}$ füllen. Diefes ausgetretene Blut gerinnt, uno bie sunge

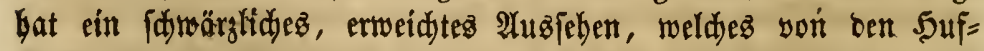

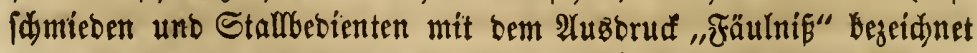
wirb und son weldem fie glauben, báp es cine alte Rrantlyeit an= 
zeige. Diefer Umftant ift ein Beweis yon ber Seftigfeit ber Sirant= beit, burdy weldhe viele überlabenen Blutgefäpe zerrifīen wurben, [o=

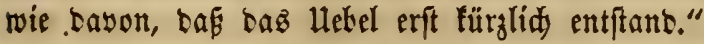

\section{Beband}

Wie bereitz bemerft, ift tie bei \&ungenentyüntung uno Brondjitiz fu befolgente Behantlung eine und riefelbe. Daz erfte Mittel, fu

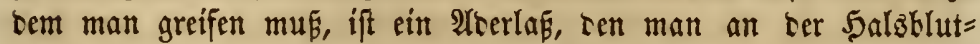
aber sornimmt unb etwa trei Pinten Blut entjieft. Bunädjit wa

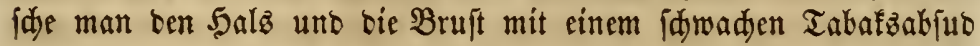
unt gwar wente man tenfelben to beif alz möglid an, und pobalt rie Bruft wieber trofen ift, wajd) man biefelbe mit bem corrofisen Siniment.

Sterauf gebe man tem Thiere einen beífen Trant - fo beí alż

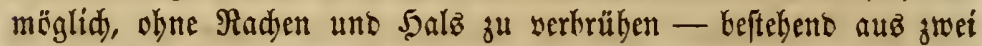

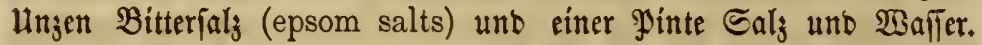

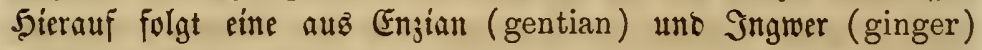
beftetente (bake. Man nehme eine Unje son jebem, fodje beibez

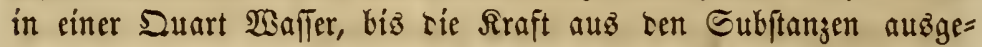

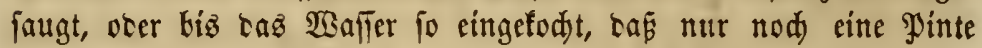
sorhanten ift, sieje theile man in vier Gahen ein und gebe bem

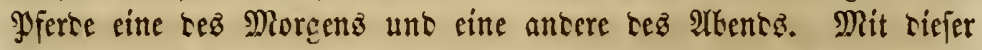
Argnei mag man to lange fortfakren, alż tie betreffențen Eymptome  abjuo (soap-suds) nady sem erfiten Trunf gegelen, wirt febr woble

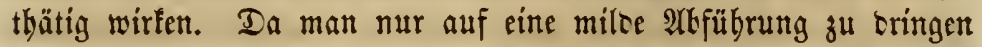

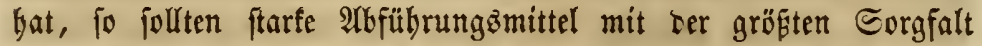
sermieben wersen; benn es ift leidft möglid, tá biefellben unter

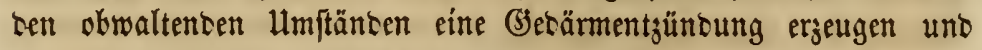

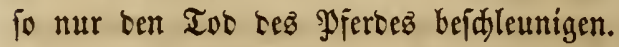

Unter alfen Eymptomen fint tie falten (S)liebmapen baz d)arat= teriftífifte Sennzeiden ber Rungenentzüntung; aud fann man fein anteres Symptom fo leidft erfennen, benn Dhren uno Bliecmą̧en fint öfters eisfalt. Ez wirb febr vortheillyaft fein, bie foüse in ftarfem Salzwa j]er, bas man to heíß madt, alz ez bas Pfero ertragen fann, fu baten uno barauf mit einem weid)en Tud fu reiben ober mit einer $\mathfrak{B u ̈ r}$ te zu bürf̧ten. 


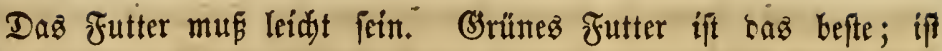
biez jebody nidjt zu baben, fo füttere man Rlciemajd)e (bran-mashes) ein wenig Rornmebl ober etwaz 5äafel. Ghe eine wefentlide $\mathfrak{B}$ ef= ferung eintritt, wiro bas Pfers feinen Berfudy madjen, etwaz zu

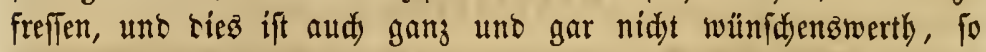

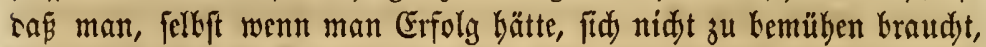

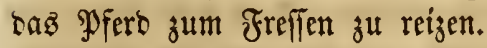

Sobalo ber Patient foweit hergeftellt ift, bafí man ihn in'z Freie

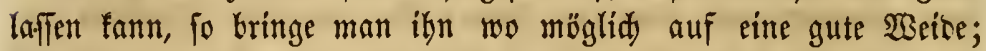
ift er aber baju nod) zu fapad), fo balte mant ikn im warmen Stall, biż er träftiger geworten, uno wenbe jekenfalls a alle Sorgfalt

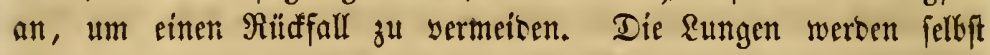
bann, wenn taz Thier furirt wirb, shne 'baz Reidyen zu befommen, nod) längere Beit fränfeln, unb nidjt felten greift ein berartiger $\mathfrak{A} \mathfrak{n}=$

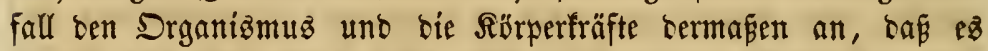
ben 2 nifjein bat, als ob fie biefelben bleibento entfräftet würben.

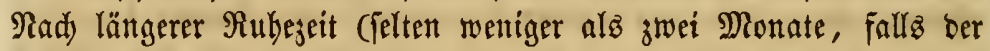
Tanfall ein afuter war) mag man bas Pfero zu leidjter uno nady unb nady mieber zur sollen 2 (rbeit gebraudjen.

\section{$\mathfrak{A} \mathfrak{u}$ z $\mathfrak{e} \mathfrak{b} \mathfrak{r} \mathfrak{n} \mathfrak{g}$ (consumption).}

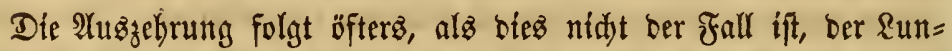

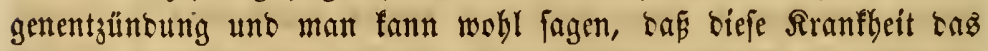
endlide Refultat vielfader, Ianger, Lurd) Bernadyläiligung herbeige=

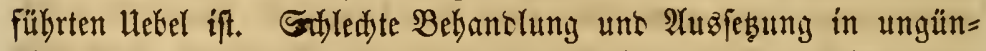

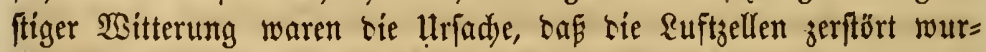

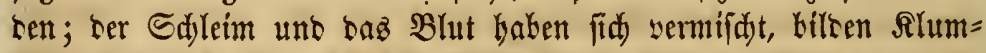
pen ober Sinoten, und aus biefer Subftanz formiren fid unter tem

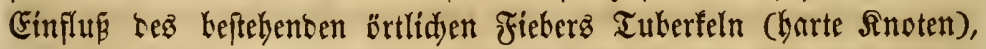
inbem Edjleim uno Blut gerinnen. Sie baben sine blafgelbe farbe,

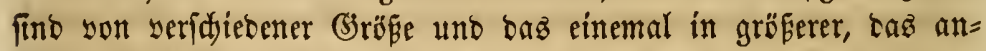
beremal in fleinerer 2 Tngahl yorbanten, je nad ber Zabl ber \&uft=

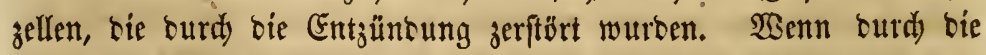
\&ungententzüntoung nur cinige biefer Fnoten in ben \&ungen ergeugt werben, unb biefe überhaupt fid nidjt in bejonberz gereigtem $3 \mathrm{u}=$ ftambe befinben, fo mügen bie Iuberfeln nad) uno nad) vertroünen, ober, um biefen 2Huzbrud ju getrauden, akfterben, ohne Sdjaben 
anzuridten. Sebod ift immer viel (3efahr vorhanben, baf fid biefe Sinoten vergröfern, uno bie log. Tuberfelmaterie, eine $\mathfrak{A r t}$ gelblid $=$

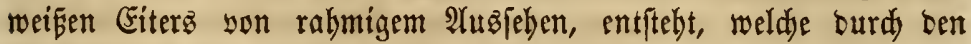

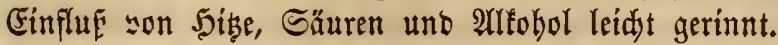

Fo werben in ben Rungen bäufig Tuberfeln gefunben unb biejelben find oft lange vorbanten, obne tas Pferd wejentlid zu kefoäbigen. Albet wir zweifeln, ob fie längere 3eit vorbanten fein fönnen, obne

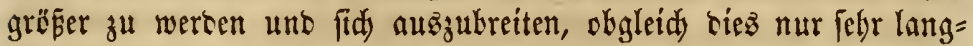

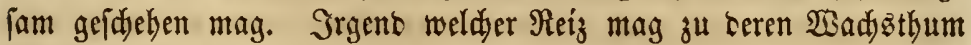
unD Alusbreitung beitragen.

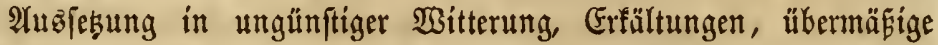
Anfitrengung, Unoronung im Magen uno ben Gerärmen, ein fiebe=

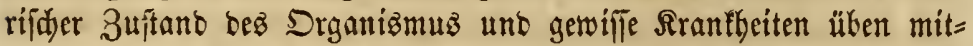

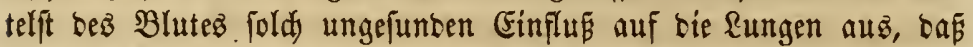
sie Iuberfeln gröfer werben, fid yerbreiten uno Iuberfelmaterie ent= ftebt. Rad) unb nad) wercen aud sie nod gejunoen Rungentbeile

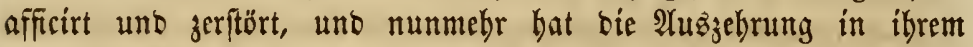
ganzen Umfange begonnen. Der gelbe, eiterige Sdjetm, ber fid yon ben \&ungen entleert, ift ber Iuberfeleiter, weldjer in bie Ruftrege ber sunge eintringt unb yon bem Menidyen burd fen \$als aus= gebuftet wiro, beim Pferte aber burd) bie Najenböblen abläuft.

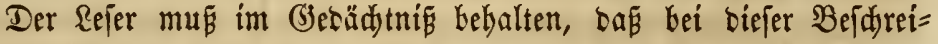
bung vorausige 3uftant oer Rungen in Folge von Rungenentzüncung, Brondjitiz ober Pleurefie entitancen fino. Siermit ifit jeoody nidyt gefagt, cafís auf biefe Rrantheiten notbwenbig bie Auşzebrung folgen müfle, ober aud) nur, baf bie oft burd jene bersorgerufene Iuberfelnformation bieje unter allen Umitänoen erzeugen. Ebenio mödten wir nidyt be=

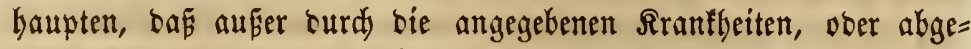
fehen yon allen ancern Reiben, feine Iuberfeln entftehen fönnten; benn wir find überzeugt, bafi fíd \&ungentnoten anieben mögen, obne

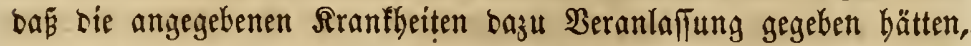

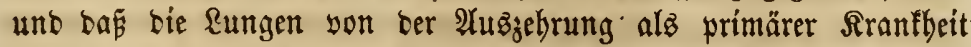
befallen werben fönnen. Bielfeidt ift bas im Sörper yerborgen wirlenbe Strophelgift bäufig, wenn biez meiftenz aud) nid.). geabnt

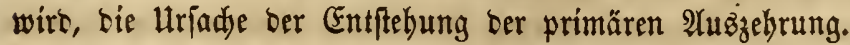

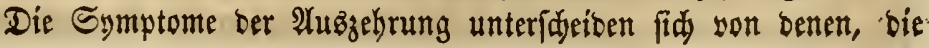


(id) bei \&ungenentzünoung zeigen, nidjt wefentlid) und find nur bef= tiger. Die \&ungen äußern eine langjamere uno franthaftere Thä:

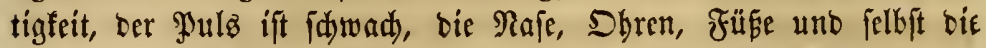
5aut find nid)t allein fühl, fontern sfters eisfalt, bie Rajenjoleim=

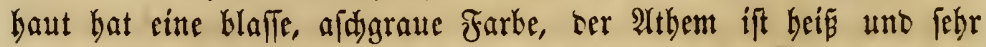

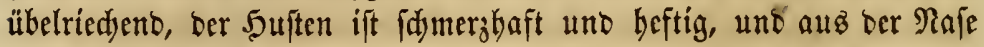
läuft fortwährenb cine eitrige, oft mit Blut vermi đate Malie.

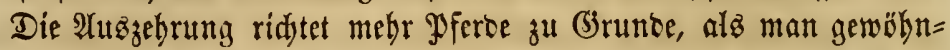
lid) annimmt. Sie wiro oft mit antern Rranfleiten verwedffelt uno bie Mebrzabl ber Mfercecigenthümer verjteht nody weniger von riejer Srantheit, alz son ben mit ibr serwanten - Rungenentżüt ung und Bronditiz. Diefelben haben offters einen fo rajden Serlauf, Dá ehe ber Gigenthümer ober Wärter ben Zuttand feinez Thierez erfant, aukerorbentlid viel Edjacen angeridytet wirb.

\section{$\boldsymbol{B} \in \mathfrak{b} \mathfrak{a} \mathfrak{n} \mathfrak{\mathfrak { l }} \mathfrak{u} \mathfrak{u} \mathfrak{g}$.}

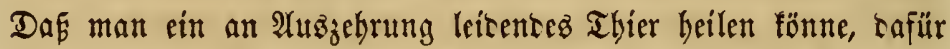
fann man fid nur febr wenig 5offnung madjen. Zwar fann man ez

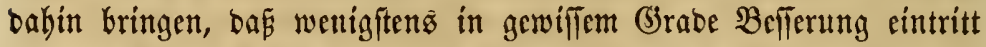
unt bas Reben verlängert wirt. Dies ift jecod) nur ein unterge

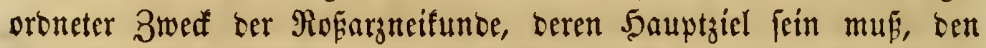
Patienten yolffommen gefund zu mad)en, fo bas er jum Dienfte fä =

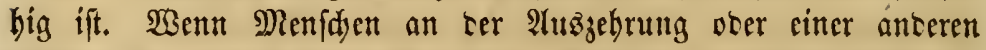
langwierigen, gefährliden Sirantheit leiben, fo unterverfen fie fid Monate und felbjt Sabre lang ärgtlider Bebantlung, nur um ihr leben etwab z̆ verlängern und bie Reioen zu lintern, zu weldjem

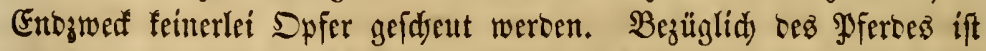
biefer Zwed faum zu berüffiditigen, und bod fann wenig, fehr we= nig barüber binaus betwerfftelligt werden, fobalo fid einmal bie \&ungenfinwintiudt bei eitrem Thier angefest uno entwidelt hat. Man mag eine zeitmeilige Beflerung zu Stanbe bringen, fo ba bas DFero wieserium fo viel Rräfte gewinnt, um zu leidjten Dienften verwentet werten jut fönnen, yodffommen gefuno unb ftarf wiro $e \bar{s}$ aber nie mehr werben. In neun Fällen auż zebn wärbe bíe Rutr, wie man fid auszorüatt, boppelt fo siel werth jein alz baz \$Ferb.

Radioem die Rranffeit einmal Fortfdritte gemadjt unt yom er= fen Stabium inz zweite uno britte übergegangen ift, ift nidbt mebr 


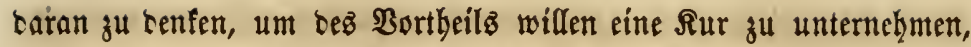
fonbern nur รas Grbarmen mit bem Patienten fann Beranlaflung tağu werben, benn sa自 seffen Reiben gelintert werben fönnen, bies feft feft, uno biez ift ein hinreidyenter (3runt, rie Bebantlung yor= junebmen. Jetod Ganteln bie meiften Farmer, uno jwar in sielen Füllen notbgeorungen, vom Stanopuntte pefuniärer Rüdfid)ten.

Fine sollftänbige Rur fann nur in ten erften Stabien ber Srant= beit ju Stante fommen; jeood) fdenft man ben Eymptomen ser= felben gewöbnlid) fo wentg Aufmerfamfeit, bas bie (3elegentyeit jur Seilung genöbnlid) unbenübt sorüber geht. Hno fobalo einmal bie

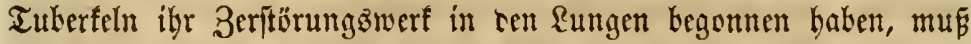
alle 5offinung auf eine beftünoige Beflerung aufgegeben werten. Den= jenigen jecod), bie ibre sunft an einem augigebrenten Thiere verju= d)en wollen, geben wir folgence $\mathfrak{A}$ nwcijung:

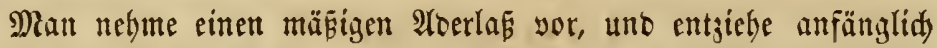
etwa srei \$inten $\mathfrak{B l u t , ~ u n o ~ j e d ) z ~ T a g e ~ D a r n a d ) ~ v i e j e l b e ~ D u a n t i t a ̈ t . ~}$ Um ben Drgantร̇mus zu ftärfen uno bcjonbers, um auf bie Saut zu wirten, gebe man Edwefel uno Jar (sulphur and resin), babet gete mau für ben $5 a l B$ uno fie Rungen tab̉ folgenţe Dräparat: Fine Pinte frijdye Mild), ein (3ill franjöfitdyen Branntmein (french brandy), ein (3ill 5onig uno eine balbe Unje fein pulyerifirte gum myrrh. Diejes mijaje man, made zwei (5aben saraus uno gebe

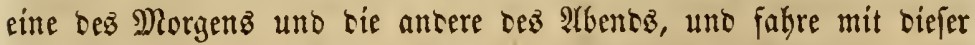
Arznei fort, bis bas Pjero wiecerhergeftellt ift, oter ftirbt.

Durd rieje Behantung wirb bie Seftigfeit ber Cymptome, we nigftens in ben erften Etarien ser Srantheit, beceutent geminbert werben, uno es ift oer Mübe werth, ju irgent weldyer Zeit einen Berjud mit riefer Metizin zu maden, on fie felten serfeblt, sen fo fdimerzyollen 5ujten ju lintern.

Fine gute Weire wiro fid) vielleid)t als beflerez seilmittel erwei=

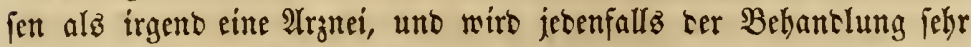
behülflid) (ein; rod) mue man febr jorgfältig fein, ben Patienten nid)t

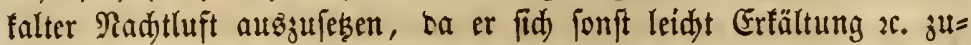
ziebt. Die mit bem franfen Thiere vorgenommene Bebanolung, um

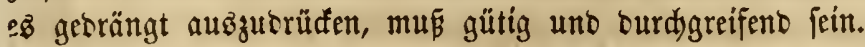

Sdlieflid fügen wir nod) bei, wab Jouatt in jebr yorfidtiger 
WSeife über bicfen (Begenftano bemertt, obgleid er nidft alle 5offinung, eine Rur zu begmefơn, abjprifyt:

"WSenn bie Srantfeit geeignet befantelt wurbe uno augenfdein= lid) am âtrebmen ift, fo barf baz Pferb nidyt fogleidy wieber zum Dienft verwentoet werben. Ez ift burd sie 2 tusazebrung sollfommen entfräftet uno aubzemergelt worben, ein 3uftant, welder lange an=

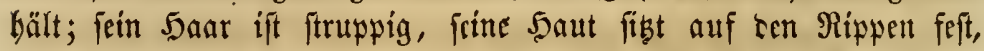
fein Baud ift, obgleid) eż genug Majd)e (mashes), Gielkrüben, grü= neż Futter uns Mesizin befommen mag, aufgezogen; fein früherer Muth febrt nidt wieser, ooer, wenn es fid aud bereitwillig zum

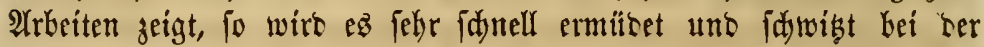
geringiten 2 tuftrengung uno zwar ift ter Sdjweí auf ber Bruft uno ben Eeiten am ftärffiten; feine Frefiluft ift febre gering, uno bei

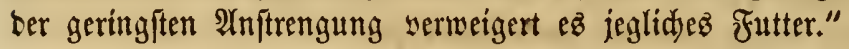

\section{Pleurefie (pleuresy).}

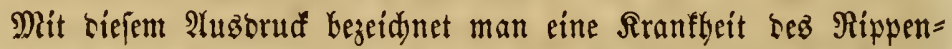
fellz (pleura), ser 5anut, weldje um bie Rungen gewunten ift uno bie gange $\mathfrak{B r u f f b a ̈ b l u n g}$ ausfüttert. Foleurefie mag auf $\mathfrak{B r o n d j i t i z}$ folgen, bringt oft \&ungenentzüntung bersor uno entfteht gemöbnlid)

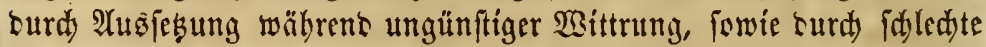
Behandlung. Diefe Rranfbeit mag betre Eeiten, ober nut tie eime ober anbere afficiren. Glüđllithermeife befommen tie mentigften Far= mer siejez Ranbes mit biejer Siranfleit zu thun, uns vielleidyt wer= ben nie mehr alz einer auz fümfhunbert unferer \&ejer (jelegentheit baken, einen fall biejer 9 rt ju behandeln.

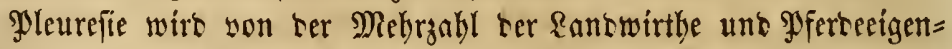
thümer mit \&ungenentzünsung ober vielfeidyt aud mit Brondjitiz verwedyfelt wersen; benn sie betreffenten Eymptome fino fith febr

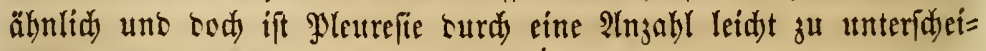
tenter Rennjeidjen djarafterifirt. Cines serielben ift bie eigenthüm=

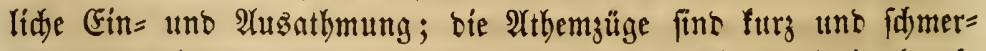
zen ten Fatienten auferorbentlidy, weil fid bas Rippenfell in frant= baftem 3uitano befinbet. Diefe Reizbarfeit wurbe burd Entzüntung

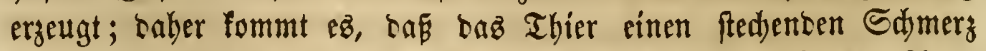

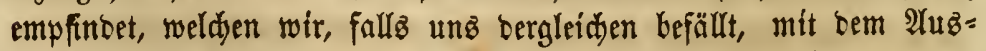
bruă "Etedjen" benennen. Daz Atbmenbolen wiro nad) uno nad 
immer gefdrwinter, fo baf son vierzig zu fünfrig $\mathfrak{A}$ themtüge per Mimute gemadyt werten. Der Pulz ift bereuteno beidyleunigt, bart uno frarf, wäbreno er bei \&ungenentzünoung untertrüăt uno oft faum bemerfbar ift. Dic Rafenboblen uno Augen Gaken ifre na= türlidye Farthe, oser biefelbe ift menigftens nidjt viel veränbert uno cie Nüftern fins nidyt erweitert. Die Füse, anftatt wie bei \&ungen= entzünoung uno Bronditio, gepreist zu fein, fteben nabe beieinan= ber. Der Ropf ift eber vormärtż gejtreeft, alz berabbängento; oer (je)=

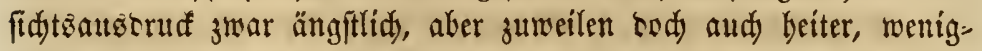
ftens währeno ser erften Starien, unt wenn ber Patient jeinen Ropf srebt, um gleidjam nady feinen Eeiten ju fehen, fo ift sie Bewegung plöşlidyer, frampfbafter als bei bem Thier, weldyez an

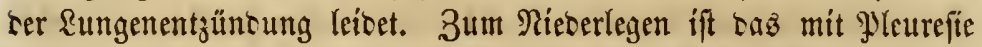
bebaftete Pferb ebenio wenig zu bringen als bas yon \&ungenentzün= bung befallene. Der Sujten ift furs und bejdleunigt, fann jebody yon ben meiften nidjt vou bem Sujten unteridyieben werben, welder bei anberen sungenfranflbeiten eintritt. Die Sïrpertemperatur ift febr weridjeten, mandimal ift biejelbe felbjt böher alz im gejunten 3uftand, gemöbnlid) if jecod) ธaz (5egentbeil bierson ser Fall; tie

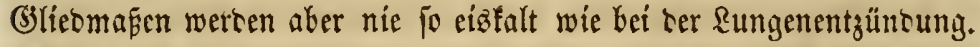

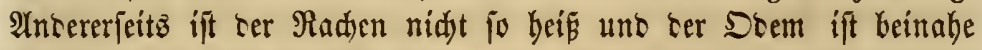
10, wie im gefunoen 3lifanc.

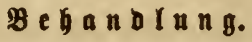

Die Bebanblung ift ber Sauptjadye nad) riefelbe, wie fie bei Brondjitiz sorgefdrieten wurte; nur nut man bier neten antorm ธaร corrofitse Siniment reidylid) auf bie Seiten aufiesen, uno zwar fiemlid) weit unten yor uno binter ben Sdyultern, fowie zwifden ben $\mathfrak{B}$ orberfüfen. 


\section{Dreizefintes sapitel.}

\section{farankeiten de atageng und der Gedãrme.}

Die $\mathfrak{B e r b a u n g s o r g a n e ~ b e z ~}$ Pferbes, namentlídy beflen Mager.

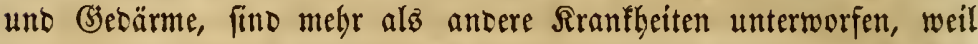
man mit beren $\mathfrak{R} a g e$, Struftur unt ben bejonteren Funttionen, welde

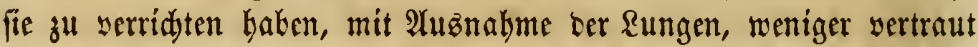
ift, als mit irgento anbern Srganen. Neben biefem Umftante fint aud) bie bei Magen= uno (Sebärmfrantlbeiten fid äusernben ভymp=

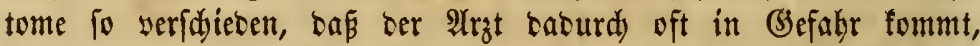

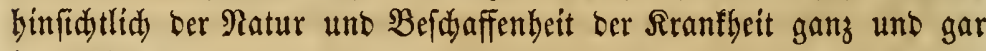
irrgefülyt zu werben.

Der Magen ift nidjt allein ber Futterbebälter bea Thieres, fontem

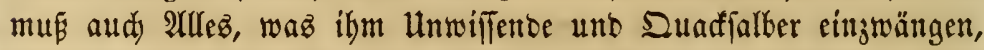
aufnebmen; uno nur zu vft werten bie eingegebenen Mittel gerare bie ltrjadye zu mandherlei Rranffeiten. Der weife Sdjopfer hat bie innere Magentyaut mit einer Unempfindlidffeit augegerüftet, bic, $\mathfrak{d} b=$ gleidy fie nidyt im Stanbe ift, alle Hebel zu verbinbern, in biefer Beziefung bod) bebeutentez leiftet. Uno bod) ift bie ftarfe Magen= haut nidjt immer im Stante, ben Srganižnuz yor ben bem Magen

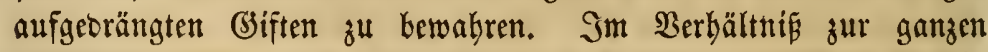

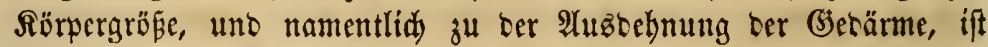

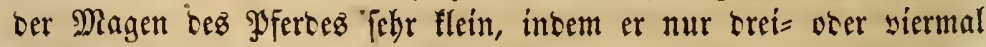
jo grop ift alz ber menfdlidje Magen, uno bod) beträgt bie Rürper=

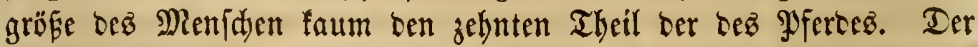

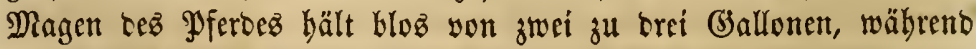

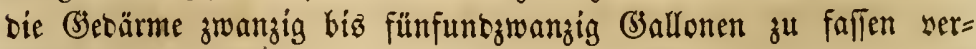
mögen.

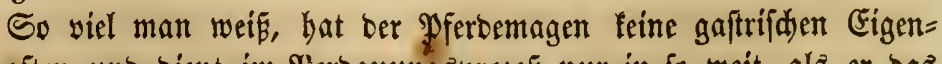

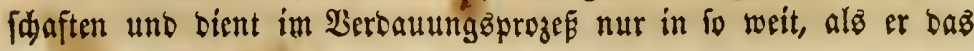


Futter erweidjt. Die übrigen Funftionen ber $\mathfrak{B e r b a u u n g ~ w e r b e n ~ y o n ~}$ ben (3ęcärmen verridutet, weldje sermöge ifrer gropen \&änge uno

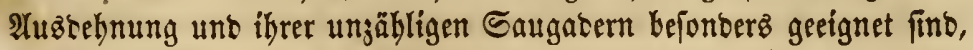
ríç auşufühtren.

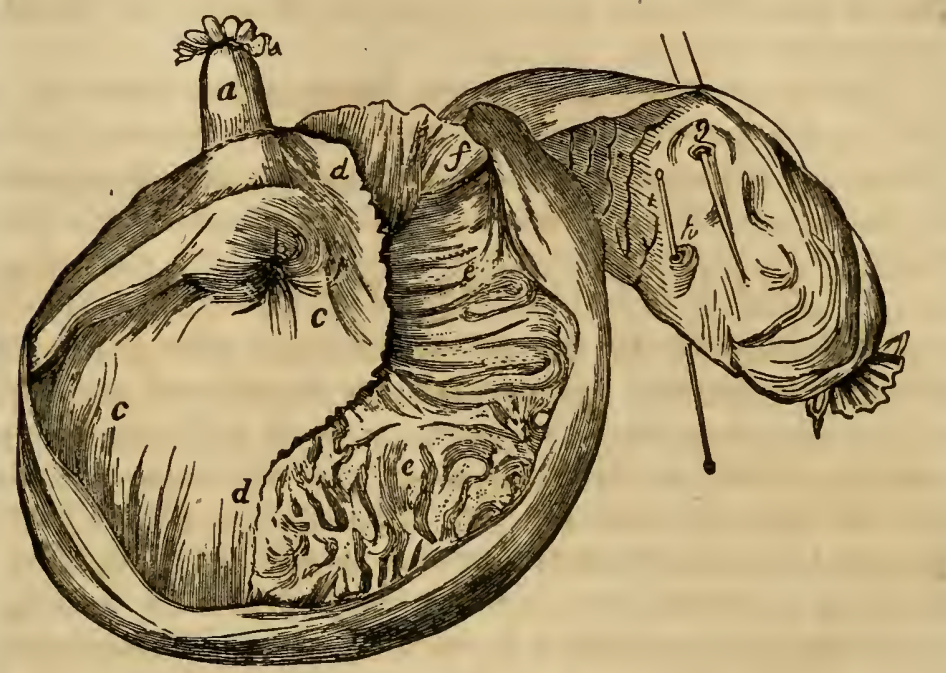

ger a

a Der હdluno (gullet), welder zun Mingen fïbrt.

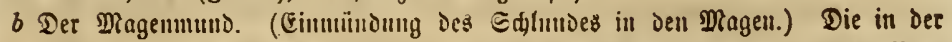
form mannigiad)er Ringabid)nitte fid $\mathrm{mn}$ Den Mageneingang lagernden Mus. felu fino fehr biat uno ftarf, uno vermöge ber Bufammenjielyung im Stande,

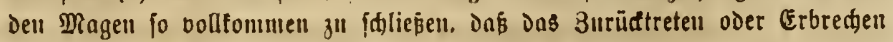
Des bereits genofieuen futters fajt unmöglich ijt.

c Der Sheil Des $\mathfrak{D a g e n s , ~ w e l d j e r ~ m i t ~ D e r ~ m i e m p f i n d l i d e n ~ s ̧ a u t l a g e ~ ( c u t i c l e ) ~}$ veriegen ift.

a Die Cinfdunüung, melde die beiden Magenfäde, den mit Der unempfintiden und Den mit Der fammetartigen \$̧antlage, trennt.

e e Der mit Der Sdleim. oder jammetartigen f̧aut berjebene \$heil Des Dagens, in welめem das gutter bauptjählich verdant wird.

$f$ Die $\mathfrak{B e r b i n d u n g ~ z w i j h e n ~ D e u ~ R a g e n ~ u n o ~ D e n ~ B e d a ̈ r m e n , ~ \$ f o ̈ r t n e r ~ g e n a n u t . ~}$

- $g$ Die Deffnung, Durd weldge Die Balle und Die Drijenabjondernng in Die Be. Därme tritt. Die beiden Stäbe bezeidnen Die hier verbundenen Röhren.

$h$ Gine fleizere Definung, Durdy welde die Drüfenabjonderung in die Bedärme tritt.

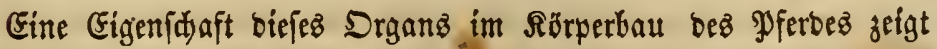

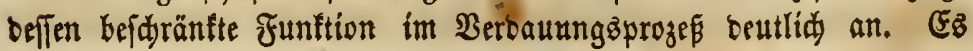


ift nämliady mohl kefannt, baj bie fammetartige Sdyleimbaut bes Magenz mit vielen fleinen Saugabern serjehen ift, beren $\mathscr{A}$ ufgabe ez ift, sie fleinen in Futterjaft verwantelten Futtertheile aufaufaugen uno fie in Cirfulation zu bringen. Wäbreno fid nun bieje Saat= lage in allen Gescärmen fintet, ift nur ein Drittlyeil tes Magenz mit berjelkent veriegert.

Dbgleid taz Ffert ideinbar von biliôfen Reiben befreit ift, fo

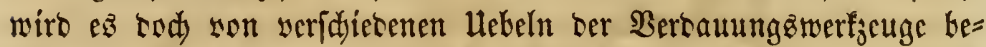
fallen, son tenen mandje oft jehr idjnell einen gefäbrliden Charaf=

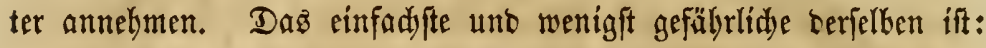

\section{Der ber Yä uerte Magen (sour stomach).}

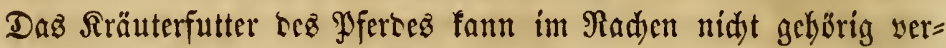
faut werter unt wiro nebftem burd ben Epeidel aud nur theil= weije burdffeuditet; in biejem 3uftano gebt unt Magenmunt in ten Magen, wo fid befintenten Musficln uno tem "\$ob̈rtner" (am Eingang in tie (Setärme) cingeidlofien wirt. Sier wirb tie robe zutterjubftang burth

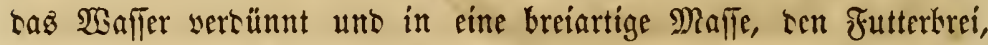

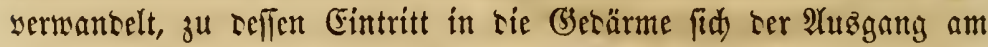
Magen (PFförtner) zeitweilig offnet, worauf jener (tor Magen) twie= Lerum nad) Futter kegebrt.

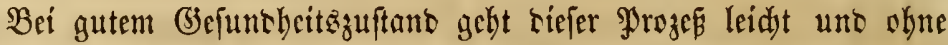
alle Beidjwersen yor fidd; aber unglïflidyerweife kefintet fid tab Wfero nidyt immer in sicfem 3uftant. Reis unt unnatürlide Sibc,

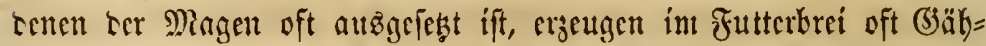

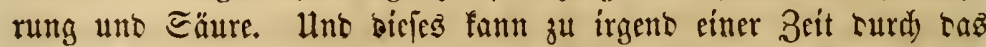
Freffen untaugliden Futters orer aud baburdi cntftechen, taf baz

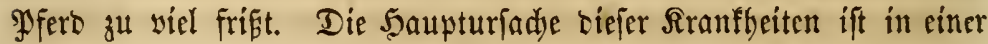

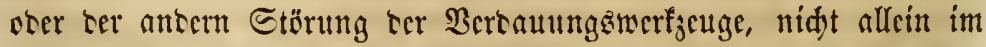
Magen, fontern aud in ten (Gesärmen, zu fudjen, unt saher rührt

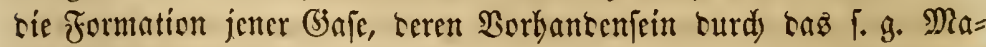
genfnurren uno anthere $2 \mathfrak{n}$ zeidjen angeteutet wirt, was immer $\mathfrak{l t}=$ rube unt "Edjmers und mandjmal aud) Wintofolif (flatulent colic) herworruft.

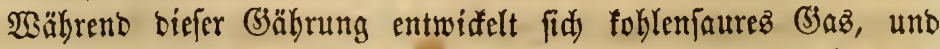

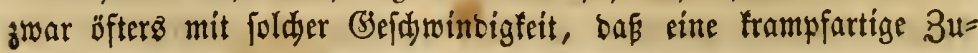




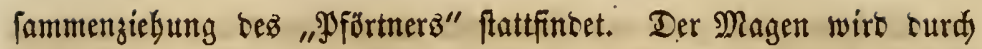

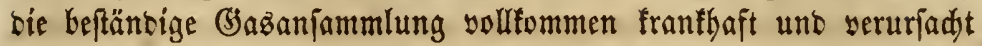

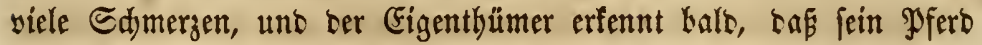
yon ber

\section{Magentolit (colic in the stomach)}

befallen murhe. Dí Symptome werben immer heftiger uno, fallż

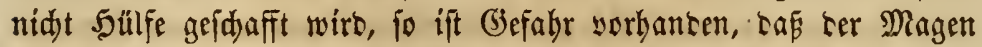

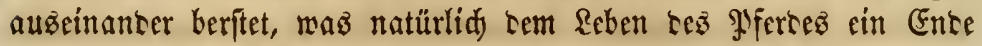
madjt. Nut wenige Perfonen abnett, wie oft ticz ber Fall ift.

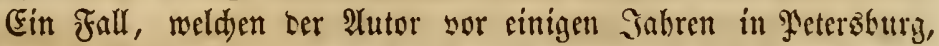
Sineoln (Eo., Tenneffee, zu beokad)ten (Belegentheit hatte, ift jo begeid)= nent, baß befien Bejdreibung bier einjujdalten fid lobint. Ein etwa zefn Sabre altez, gut gefüttertes Yjerb war zebn Iage franf gewejen, währent welder Zeit $\mathfrak{e}$ allez Frtter serweigerte uno fid bei ibm überbaupt alle Symptome tor Geshärmfranfheiten zeigten. Die Reute bes Sortz, mit Einfalulus bez Eigenthïmers, waren feft

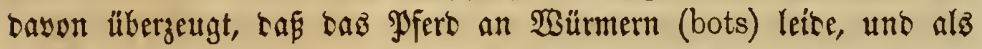
ber $\mathfrak{A}$ utor baz $\mathfrak{P}$ fero zum erftenmale fah, wurbe es yon einem grofen,

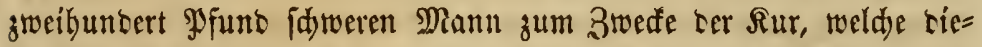

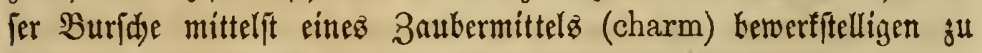
fönnen vorgab, berumgeritten. Nadj meiner $\mathfrak{A}$ niadt gefragt, antwor=

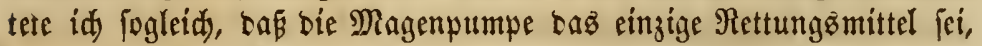
obgleid) sie Sranflyeit idjon io bebeutente Fortidritte gemadt babe,

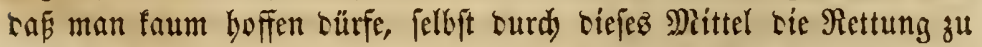

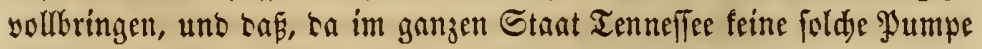

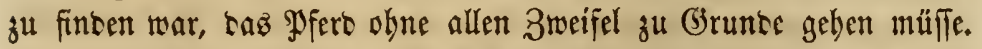

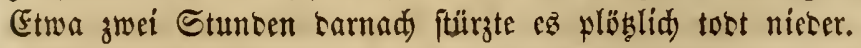

Giner ber llmitthenben behauptete, baßs, fallz man ben Magen

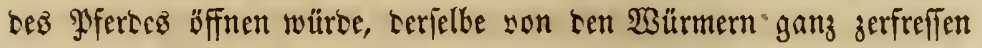
fein müßte. Die übrigen Yerjonen, etwa fünfzig an ter $3 \mathfrak{a b l}$, theil=

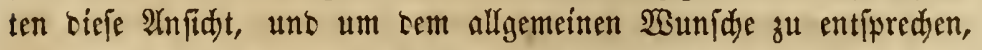

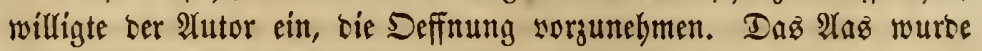
an einen paflidsen $\mathfrak{O l a g}$ gebradyt und als in einigen Minuten bie Seffnung solfbrad)t war, zeigten fid bie Urjadjen bez Tobez ganz Deutlid). Der Magen war budjtäblid in Feben geriffen uno fein Snhalt war in ber ganzen Baudbable veridüttet. So beftíg war 


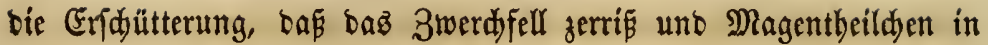
Ler Radbariđaft ber \&ungen uno bez Sergenz gefunten wurben. Dabei fonnte man in Den Magentwanoungen unb 5autlagen feiner=

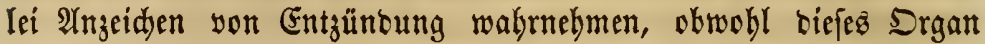
burd Rranfbeit beinabe zerftërt war. Die jammetartige Magenjaleim= haut war gar nidyt mehr yorbanten unb bie unempfinclitye Sautlage

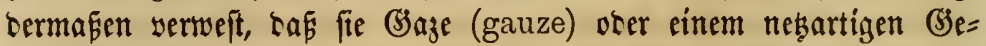
webe äbnlidy fah unt, alz man ben Magen yon ben mit. ilym ver= bunbenen Theilen auzidjnitt, heraugfiel. Die Magenmusfeln waren ebenfallz zu einer weidyen Maffe vertweft, fo daf man fie gleidy einem

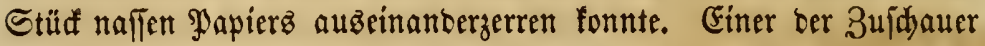
bejdrieb sen worgefunbenen 3uftant, inbem er bemerfte: "Da ift ja alles faul." Der "\$Pfürtmer" war feft gejdjlofien uno feine fürdjter= lide 3 ulammengiehung, woher all baz Uebel herrührte, nod fo ftarf alz sor bem Tobe.

In ben fleinen Gesärmen waren bie auf Entzünoung binteuten=

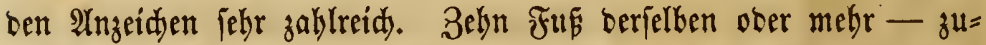
nädjt zu bem Magen liegeno - hatten ein blutrothez 2 Yusfehen, wäbreno an allen (3etärmen Blutfleđen gefunten wurben. Son bem Magen bis zum 2 fter war nidjt ber geringfte Theil $\Re a b r u n g s f u b=$ ftanj vorzufinben, unt biefe Reere fennzeidynet in allen $\mathfrak{l}$ mitänten berartige Fălle, ba fid bie (Sectärme febr fadnell entlecren unb aub bem Magen wegen ber Zुน brei auştritt.

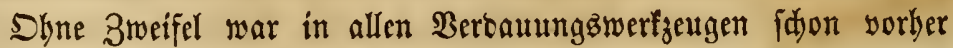
Entzüntung vorhanben; surdy baz Cingeben unglaublider Duanti=

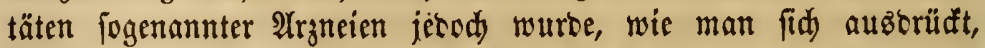
Del in bie flamme gegoffen. Der Magen mur wenigftenz zwei Gallonen siefer Mittel enthalten baben; 3. B. Salatöl, Caftoröl, Ierpentin, Bitterjalz, füße Mild), Molađers, Salbei= (sage) Thee uno antere mehr. Waahriderinlid) trug bą Eingeken ter grofen Duanti=

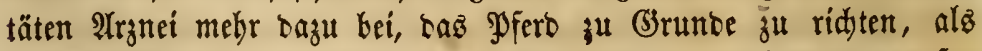
bie Sranfleit, uno อฮิ müroe viel mebr 5offnung vorhanben geweéen feit, bie Scilung zu Stanbe zu bringen, wenn man bem Thiere gà feine Mebizinen einge[duüttet bätte.

Die hier befdriebenen Magenfranfleiten mögen nod einmal twies berbolt unb in folgenter $\mathfrak{B}$ eife eingetbeilt werben: 


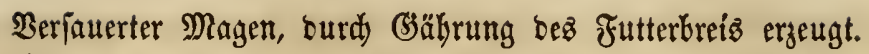
wirb.

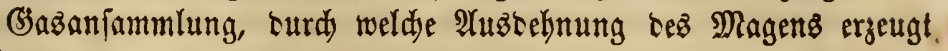

Entzünoung, bie auf Berwejung folgt.

Sirampf=Rolif, weldye beftige Sdimerzanfälle hersorrufen.

Berften ธยล̇ Magenż uno Tob.

\section{$\mathscr{2}$ ï $r$ mer ( $t h e$ bot).}

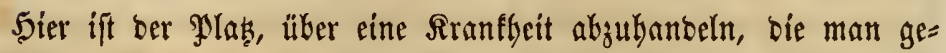
wöbnlid mit biesem Ramen beseidnet, unb bie, weil man wermuthet, biefelle fomme febr bäufig vor uno jei äuperft gefährlidy, bie $\mathfrak{A} u f=$

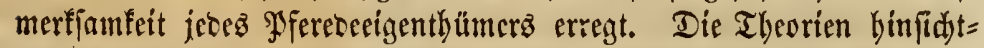
lidi ber Hrjadje uno Rur bieję Hetelz fino unzäblig uno fie werben alfe von vielen Bertheibigern aufä ernftlide vertreten, obgeid) nur

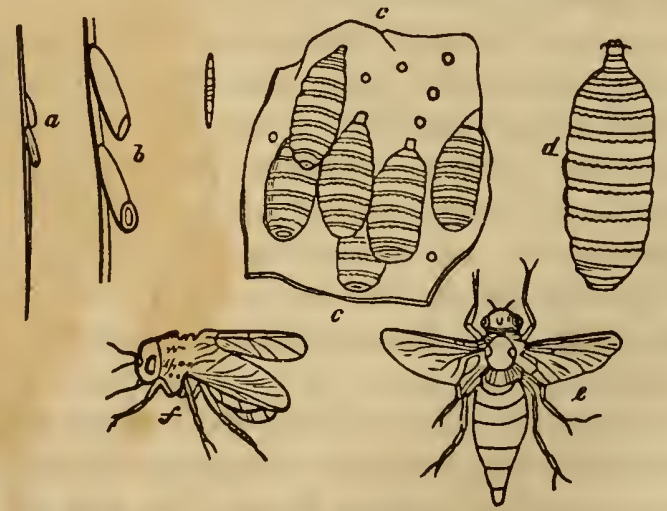

Bils bes Bot und der Gadfiege.

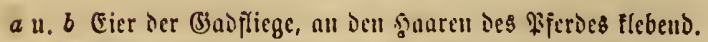

c Birmer (Engerlinge) an Den $\mathfrak{B a n d u n g e n ~ D e s ~ D i a g e n s . ~}$

$d$ Ein Engerling (bot).

$e$ u. $f$ (5a)fliégen.

felfr wenige berfelten nidyt bereit fint zu geftehen, bá fie yon ben bots, ifre. Entftehung, ben Folgen tez Borbandenjeinz biejer fleinen

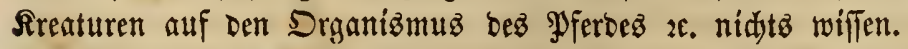

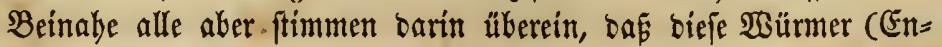
gerlinge) bie গুyerbe auf bie cine ober anbere Weife töbten. Die 


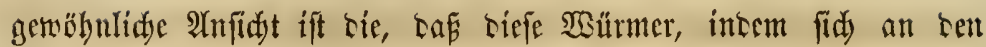
Magenwambungen feftetsen, fidi) öfters burdy bicfelben turdjfrefen,

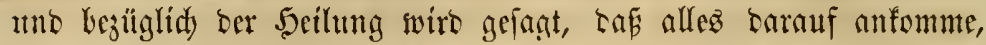
rieje \$Sürnter zu zwingen, ibren Sib auf ben Magentwandungen zu wertajīen, elye fie ifgr Berftörungšwerf begonnen bahen.

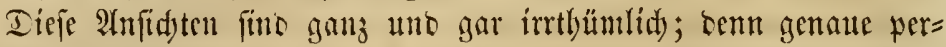

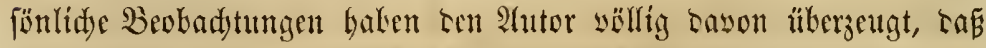
rie allgentein verbreitete Meimung nidjt mit sen Thatfaden üherein= ftimme, uno baf bie Etörungen uno ter Edjaten, bie man gewöbn= lida) bem "Bot" zufdyreibt, niduts anteres fint, als bie Folge irgent

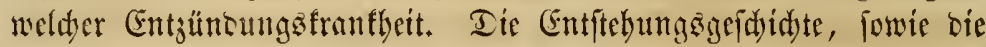
Sinturbejdaffenlyeit ciejer Engerlinge murbe bigher nie ridftig ver= ftanden. Sie fino bei tem Xlferte erblid uno werten mit ibm auf bie Sielt gebradjt, wowon man fidy bei ter Seffmung neugeborner Füllen überzengen fonn, Leren Magen siefe fleinen Thierdyen in soll= fommenemt 3uftant enthalten. Mian fintet fie an ber unempfind=

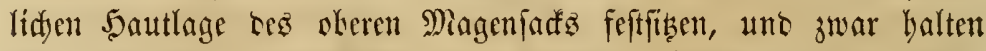
fie fid) nidyt mit tem Ropfe feft, wie gewöhntid) angenommen nirb, fontem mit tem Edywanzs. Inz Maul cinez folden Engerlingż

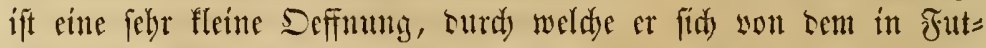

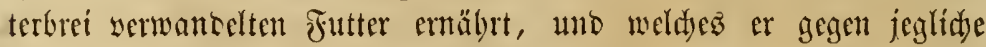
Rabung, die tem Femidnueder (tenn als Toldye tarf man biefe

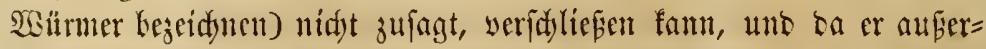
bem nod) mit cinem idjuppigten, harten $\mathfrak{l}$ leíb verielen ift, auf wel=

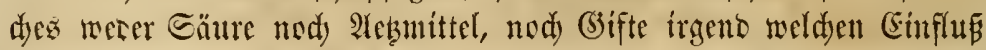

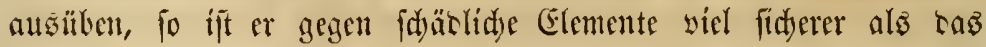

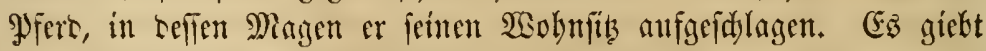

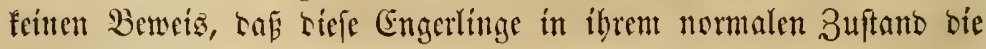
(3) e untheit tes Pferses im geringiten beeinträdytigen.

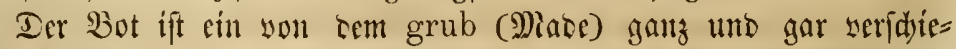
Dentes Snjeft, uno tie beiben finto turdaus nidjt mit cinanter

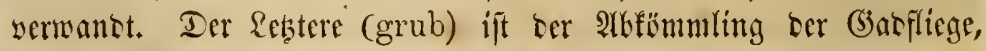

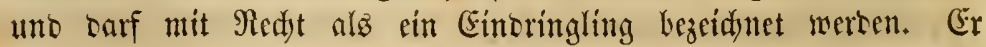
(grub) ift eine Gelfgelle Miabe, weldye in ten Monaten Suli uno 2luguft mit tem Mifit ausgemorfen wiro unb in bie Groe friedst, too fie zur \&arve wirb, aus weld)er mit ber Beit ble fliege entifdlüpft.

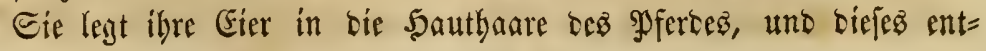


fernt biejelben burdy Refen mit ber 3unge, woburd) fie in ben Magen fommen. Shier entwifelt fid bie Mabe uno in biefer SBeife

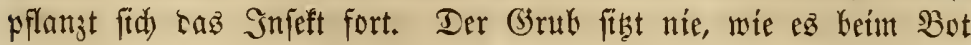
ber Fanll ift, an ben Magenwantungen feft, fontern bält fich im Zutterkrei auf, teffen barte, fajerige Theile er zerfegen bifft, uno in

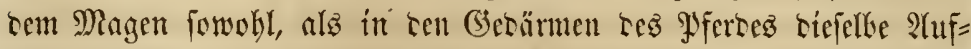

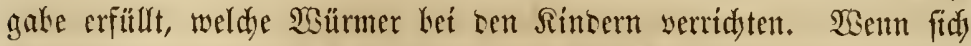

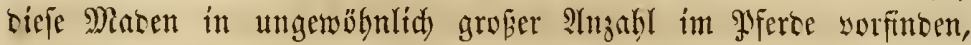

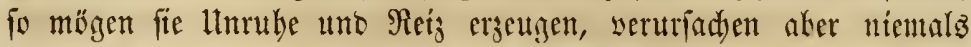
ben Tob ober audy mur cine erniftict)e Siranfteit.

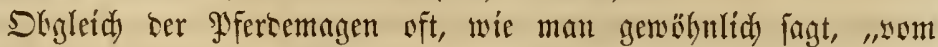
Bot ganj Surdjlödert ift," fo Sarf sod) angenommen wercen, sa

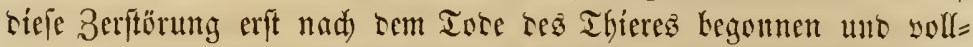

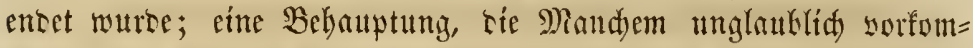

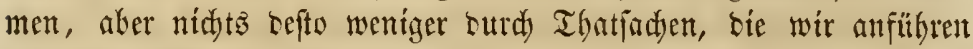
werten, beftätigt werben fann.

Die unempfintlidye 5autlage bez PFeroemagenb, an weld)er ber Bot mittelit eintiger hadenförmiger 5aare feftfitht, ifit beinabe, wenn

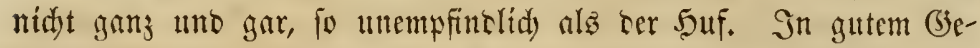

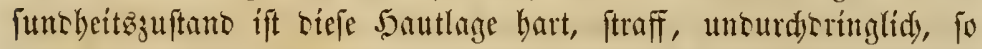
Dá

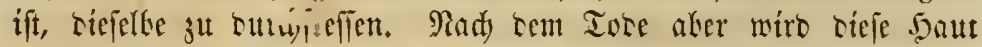

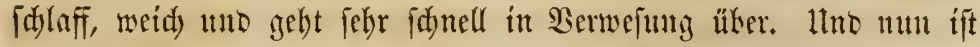

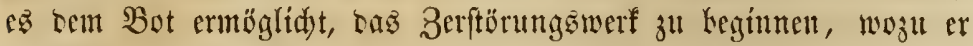

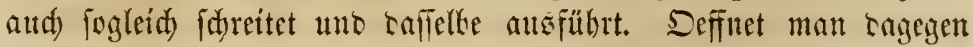
ein in gefuncem 3ujtano fid kefintlides Pfero, ooer wiro sie Eef= tion eine ober zweí Etunben nad) bem Tobe yorgenommen, fo wito man ben Magen in feinem einzigen Falle som $\mathfrak{B}$ ot "surdjfrefien uno surdlöd)ert" finten; eine That|ad)e, die burdy tie Defrnung

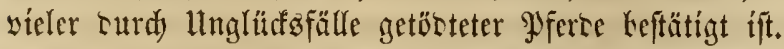

Dr. Sohn Franflin von Cummer $\mathfrak{S}_{0 .}$, Tenn., fǘtrt an, bá cin

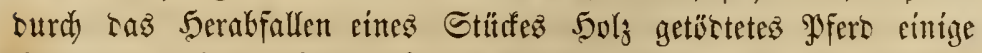
Stunten nad) tem Tobe mit ter 2 (thifidst geöffnet worben fei, um fid zu überzeugen, ob ber Bot in allen Fällen, aud) wenn feime Srant= Geit worthanten fei, ben Magen burdjliddere. Unt man fanto, wie

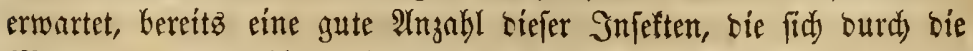
Mangenrwanoung Ginourdy gefrefien hatten. 
Der Bot madt ben 2Yngriff auf bie Ragenwanbung nidyt, um (iid) zu füttern, ober bem Thiere ङdjaten juzufügen, fonbern einfad besbalb, um felbit tem gewifien Iore zu entrinten; tenn biejelbe Sranfbeit, weldye tem Pुferte ten Ioo bringt, witb aud Iem Snjeft gefäbrlid. Derjelke Inftinft, melder ธaڤ (Sewürm uno Ungeziefer. überhaupt anweift, ein toetes Thier ju verlaffen, lebrt aud Ien Bot,

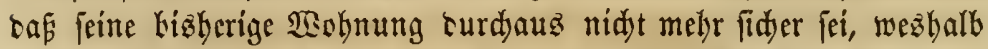
er senn serjweifelte P(njtrengungen madt, aus cerjelben zu cntflicljen. Man bat fdon wabrgenommen, caf er feime Fludt aus sem Magen ourd) sen Magenmunt unt Cdylunt, oser sic fleinen sictärme betwerffitelligte, uno wenn $\mathfrak{e z z}$ möglid wäre, würte er baz Pfero ganz uno gar serlaffer.

\section{(Gedürmenţ̧ünuntg (inflammation of the bowels-enteritis).}

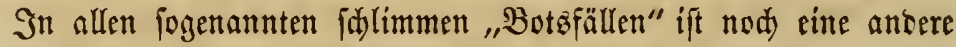
cen Too Kewirfence Hrjade sorbancen, nämlid faulence (putrid) Entzünıung fer (Sebärme, ober Enteritis, wie man jid wiflenjadaft= lid) aus̄trüt, weld) fid febr bäufig mit 3 uammenjiebung (stric-

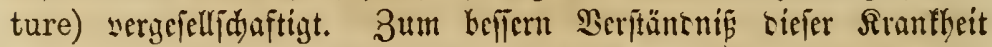

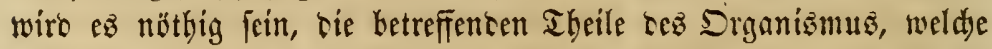
sen entipurdjenten keim Menjiden jefbr äbnlidy fint, etwas näber zu

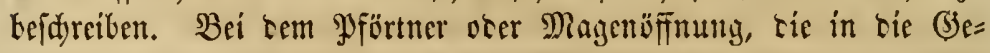
tärme müntet, beginnen tie fleinen (3etürme (Dünntarm), die beim

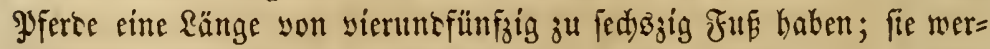

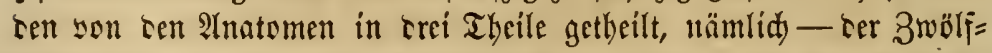
fingertarm (duodenum), fer Reertarm (jejunum) uno ter Sirumm= onrm (illeum). Der Jünffingerbarm erftrecft fich bom Pförtner Les

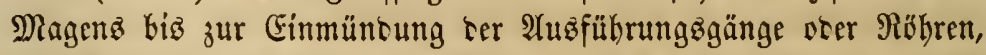
surd) weldue sie (Balle uno ser Baudifipeidel in ben Darm geidjafft werten, weldye Räbren beim Pferte etwa 20 3oll som Magen, ber zebn 3oll weiter entfernt alş beim Meniden, cimmünoen. Der Recr=

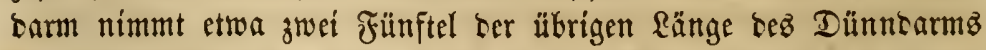
(fleine (Gebärme) ein, wirb, woher er feinen Ramen erbielt, nad bem Tobe Des Thierez fajt immer leer gefunoen uno ift nur mit suft gefüllt. Der Irummbarm hat eine ftärfere Mušfellage, als bie übri= gen Theile bes Dünnbarms, unb man fönnte ifn beshalb oen flei= fdigen İbeil ber Bebärme nennen. Er entigt in ben Blinobarm 
Srantheiten des Magens und der (Bedärme.

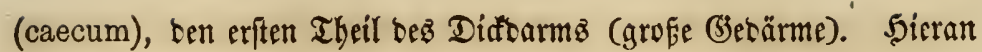
idjlieft fid ber (3rimmbarm (colon), weldjer unter allen (Becärmen ben grösten Ulmfang hat uno ben meiften Raum einnimmt, uno cer Daftbarm (rectum) biltet oen leşten Theil bes Difóbarmes (grofe (Secärme) unb münbet in ben After.

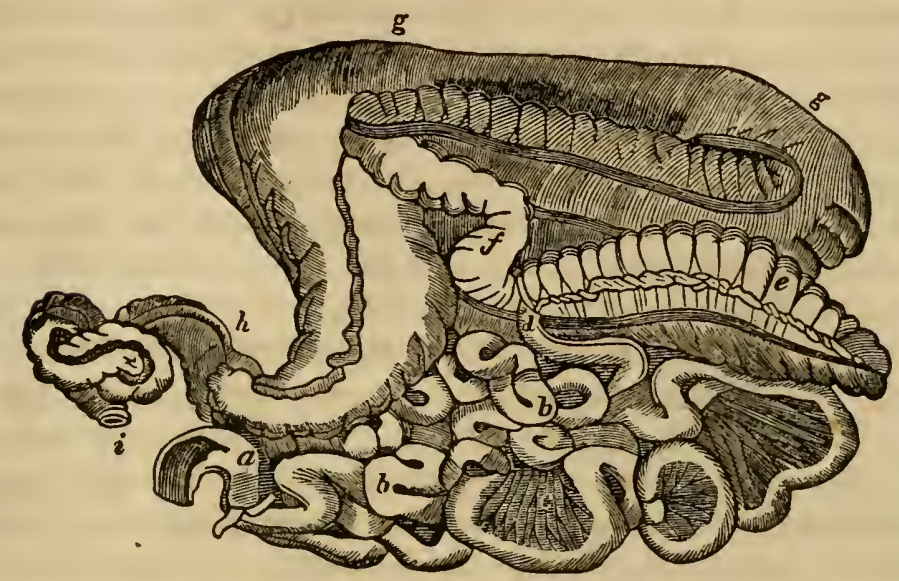

Die Be dảx $\mathrm{me}$.

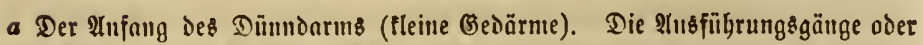

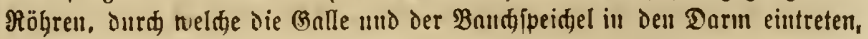
fint struns weiter unten angedentet.

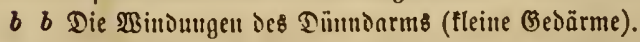

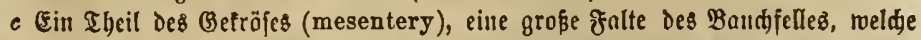
über ien größeren Theil Der (Bedärme herhärngt, mit viel fett verjeben und

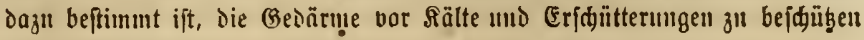
uno beren Ijätigfeit zu befördern.

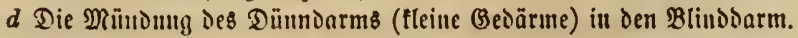

c Der in Bellen abgetleilte Blindiarm.

$f$ Der $\mathfrak{L}$ nuju

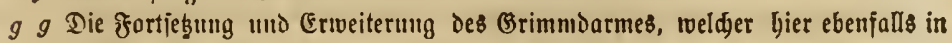
Bellen abgetheilt ift.

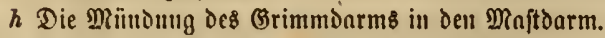

$i$ Die $\mathfrak{M}$ inndung Des $\mathfrak{M a f t o n}$ arms in dent 2 fter.

Die Bebärme befteben aus brei verfojiebenen 5autlagen: Die äufere, ober Darmbaut, weldye ben glatten, glaz̧artigen Ueberzug ber Sebärme bilbet; bie mittlere, ober Mubifellyaut, aus zwei nad ent= gegengejesten. Ridjtwegen laufenben Sdjidten bejtebend, bif einanber 
red)twinfelig Durdfreuzen; uno bie innere Sautlage, ober Sdjleim= baut, weldye fid nidyt nur in allen (Secärmen, fonbern, wie wir ge= foben baben, aud in eitem Theile teg Magens worfintet.

Die (Gecärmentjünoung bat gewöbnlich ikren Sib im Seerbarm (jejunum). Der Entjünoung folgt Bufammentebung ober Betíto= pfung, woburd) alşann (jebörmfrämpfe erzeugt werben, eine Stö= rumg, Lie man mit Iem Ramen Berürmfolif (spasms of the bowels) benannt bat. Durd Die. fympatbetifyen Eimflüfie bez fieberifden

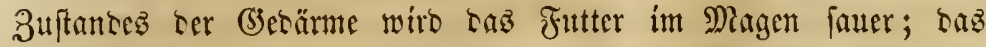
bicrsurd) erjeugte foblenfaure (5)a tritt in tie (S)erärme cin, wirb bier surdy bie in biejen Ibeilen Kerridente, unnatürlidye Shibe ver=

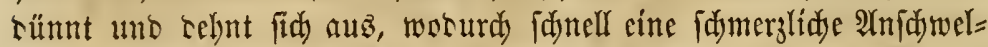

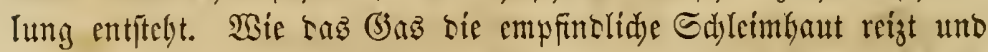
Saร Ficher sermebrt, fo trägt auf her anoern Seite bas Fieber jur

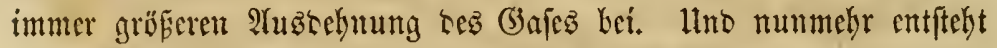

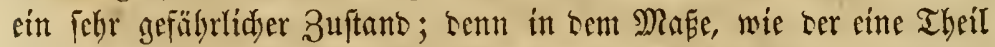
ber (3)cärme anfidwelft, ziefyt fid) Ler zunäd) finter ifm liegente zufammen, benn gerabe wie, wemn man ben eitnen Theíl eínes Pebez auscinanterjicht, ber antere fidy jufammenzicbt, fo mirfen biefe (be=

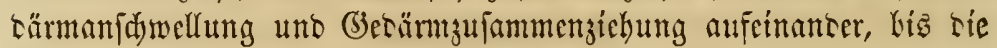

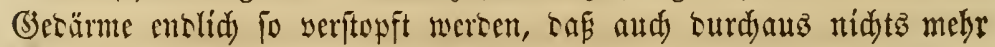
burdy Siefelben paffiren fann. Dies nennt man eine Zujammenjiehung (stricture).

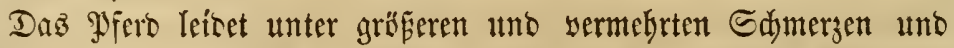
wirb balo yon Rrämpfen Kefallen, weldye zmar cnelidy zeitweilig nady= la fien, jecody fogleid wieber mit werboppelter Seffígfeit éntreten. Das berauernswerthe Thier fdwight febr ftarf, namentlid an ben

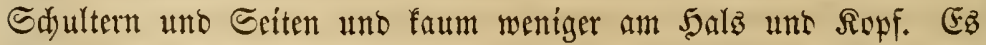
foüttelt fid und bebt fortwäbrents, uno feine Mugfeln werben bin= unb bergezert; $\mathfrak{e B}$ baft mit ben Borterfüben, fest riejelben yorwärtz und verjudyt fich auşujtreffen, uno wirft ben Ropf bejtänoig yon einer Seite zur anterm, albz ob

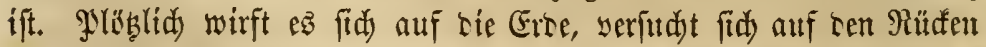

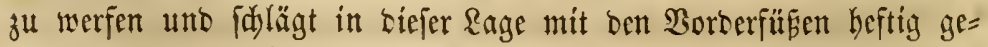
gen bie Bruft, fpringt aber fogleid wieser auf, legt feine Shren zu=

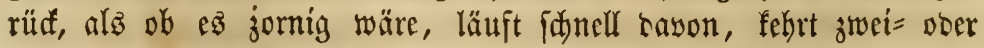
oreimal um und läpt fid wieber zur Groe fallen. AUle diefe Bewe= 


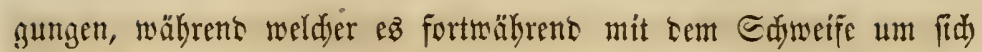
(d)lägt, wersen febr fdunell ausigefithrt. Beiden, tie auf eine $\mathfrak{U}=$ fdwellung binseuten, fino nidyt bemerfbar, aber rie Rippen uns $5 b=$

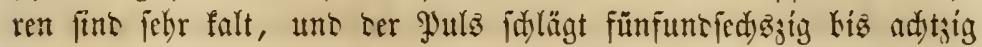
mal tie Mimute, wäbrento er nur treifig biz fed)ชืuntoreifig mal (i)lingen follte.

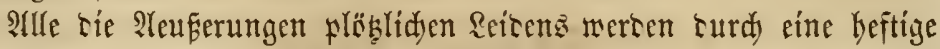
Entjüncung uno cie santit serbuttene 3 wammenjichung ofer Cin= flemmung ter (betärme, weldye raturd) leidyt zerrifjen merten fän=

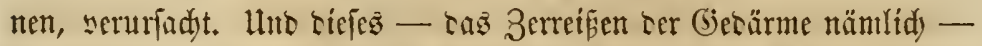
bat faft in allen sen Făllen ftattgejunten, wo sas Ibier wlöblid tort nicrerfälut.

Finoct ris 3uammengiebung soer Einflemmung jiemlidy weit vom Maijen entfernt ftatt, fo werten rie (5ecärme mohl mandimal rurd)=

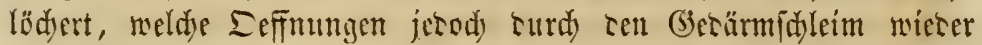

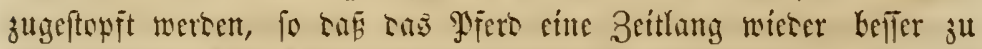

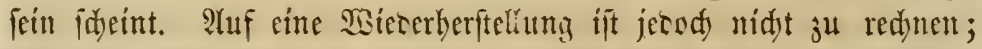

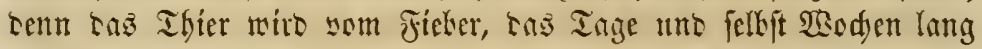
anbält, sergebrt uno gebst entlich ju Ginutes.

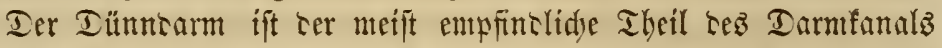

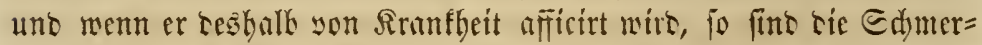

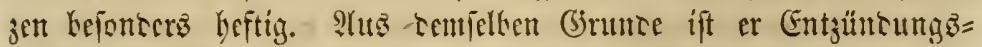

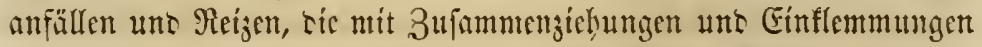

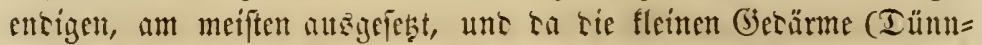
farmi) fo weit vormen in ter Baudböble liegen, taf fie Kcinabe ganz

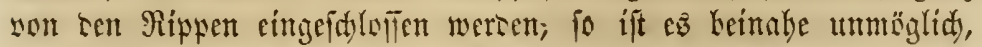

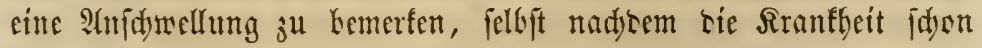
bereutence Fortidyritte gemadit bat.

Secod) entftebt aud in ten gropien (Secärmen (Didoarm) eft Reis, 3ujammenjiebung uns Einflemmung, uno tiefe Ibeile idwellen

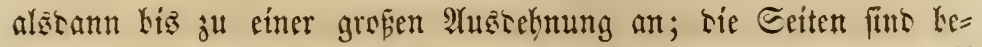

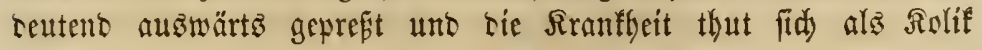
funt.

3wifden biejem uno sem oken kefdriebenen Fall fintet, auper in Bejug auf sen Sibs ser Sranfyeit, fein Unterider ftatt. Man fann bie eine nidjt mit gröferem Recht alb bie antere Solif nennen, uno in allen fällen wurte ber Artiall, wie fid berjelle aud immer 


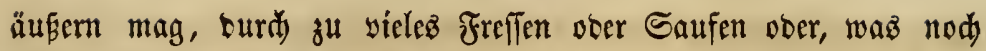
gefähtlicter ift, burdy beibes berbeigefübrt. Sn gefuntom 3 uftano mag fidy bas Pfferb vielleid)t butente mal überfüllen, ohne

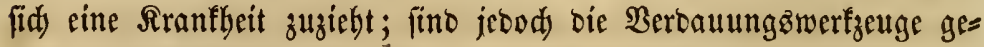
ftört ober franflaft, fo forbert bas Raturgefes feinen Tribut, ber entweoer in Reiten ober im Tob befteht.

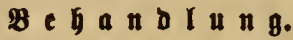

Sene thäridjte Metthobe, fu ber man gewöhnlid) greift unt bie

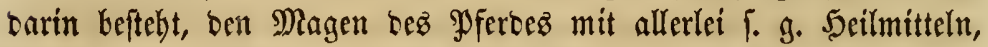
weldye yon Unwoiffenten uno Duadfalbern angegeben wersen, ju überfüllen, fann nidyt genug blożgeftellt werten, benn eż werten viel

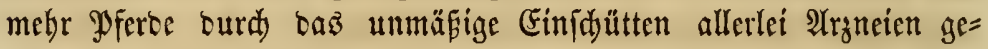

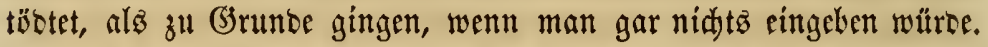
Der eine empfichlt biez uno ber andere jenez, biż endlid) ein suzento yerifiectene Scilmittel angewentet werben, son senen ieglidjes nady

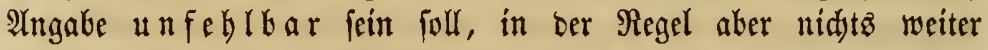

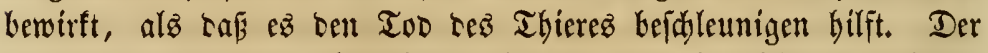
ängftlide, aufgeregte Eigentbümer befolgt, um ja nídtż unterlaffen

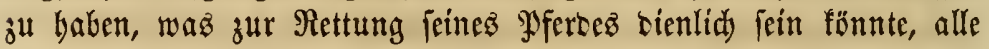

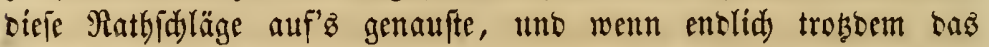
Thier ifym verloren grbt, wozu er felbft baz meifte beigetragen, io idjüttelt er yoll $\mathfrak{B}$ erwunberung über bie (Setwalt Der Rranflyeit ober

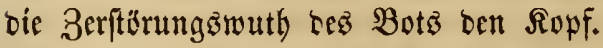

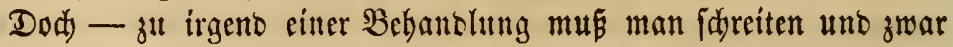

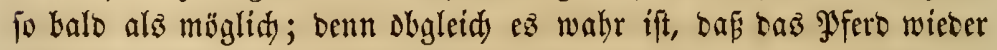

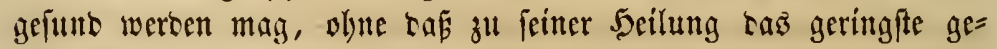
idehen ift, fo fann man barauf bod nidst rednen, fobann mus man

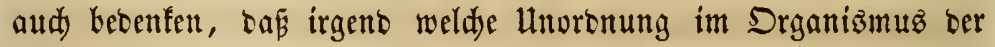
Menfaden fowobl als ber Thiere, tie anfänglide ganz unfdeintar

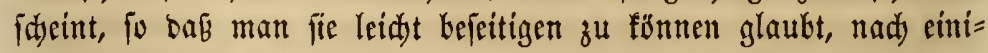

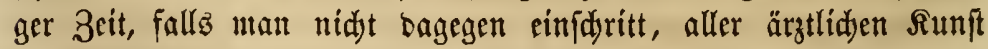
ipotten mag.

Die Methode ift, ob bie Rranfleit im. Diunn= ober Diftbarm

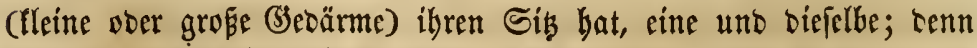
ber 5auptzyed in beiben Fällen befteht barin, eine Deffrung in

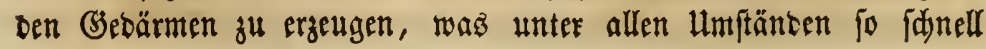


als möglid geideben mus. Jît biez geideben, fo fann man feft

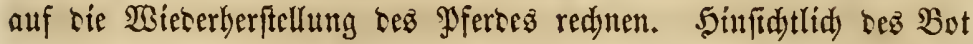
wagen wir getroft bie Bebauptung, baj biejes unjdäblide fleine Injeft nie balb fo sid Edjaten anridbten wiro, als bie Tböridyten und Intriffenten, bie gewöbnlid fo jebr freigebig mit ibren Ratb= idlägen finc. Bor allem mup inan babin wirfen, Laṕ tie Span= nung im Srganiżmuz nadlafle, bamit fid bie Bufammenjiebung

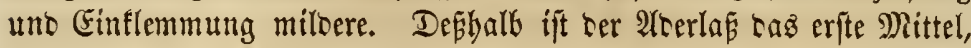

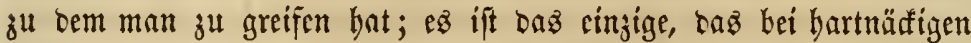
Fällen eine Rur ermöglidyt uno tarf in Bezug auf riefe Rranfbeit gewi mú Das $B$ lut füttert Medizin, fontern ift im (j)gentbeil füblid, fobalo es in ben Magen fommt. Nebftcem ift

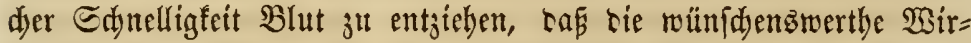
lung berworgerufan wirt. Donn โas Blut follte fdnell abfliefen, bamit bie gebörige Duantität fo idyell als möglid) entzogen wirs.

Dian bat mit sem Blutentjieben fo lange autubalten, bis eine

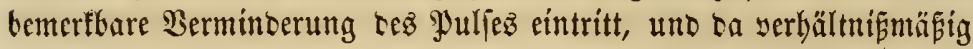
nut wentige Perionen oen Puls zu finten wifien, fo ift bier ter ge= cignete Plak, nod)malş eine Anweifung zu geben. Derjelbe fann leidyt gefuncen werben, insem man mit bem Finger auf bie Pruls= aber brüdt, bie unntittelbar über ren unterften Theil ธeв Unterfiefers binläuft, wo fid siejelbe wie einc sünne, über sie Rante bes Sno= d)ens binlaufente Shnur füblbar madyt. Sntem man ben Finger

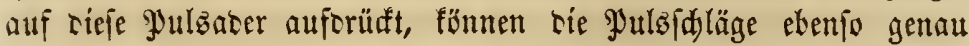

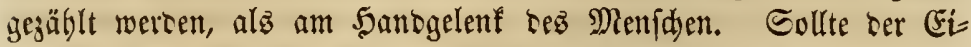
gentbümer zu ängftlid) feit, einen $\mathfrak{A}$ oerláp yorzunebmen, fo möge er fid erinnern, baj berielbe tem Pferbe burdyaus nidyt gefäbrlid wiro, tenn er wirft wobl gegen bie Siranflgeit, aber burdjaus nidjt gegent

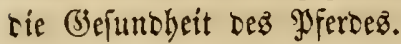

Bon $\mathfrak{A}$ rgtteien ift nidjtz nothwentig, als irgento weldes einfadje Seilmittel, weldjes bie Säure im Magen entfernt, benn obwobl bie= fes Srgan felbjt junädyit nidjt afficirt ifi, fo wiro baffelbe ourd iympatbetifhe (Einflüfe oennod) balo franfbaft werben; if aber in Folge yon $\mathfrak{B e r f t o p f u n g ~ ( S a ̈ h r u n g ~ i m ~ J u t t e r ~ b e s ~ M a g e n z ~ e i n g e t r e t e n , ~}$ 
io miro berfefte ber Sith groper Bejthmersen. Daz befte Mittel, weld)ez wir anjugeten vermögen, ift Chloroform, waz fdjon bezbalb fehr wertbyod ift, weil eine geringe Dunntitüt gentigt, bie gemünjd)=

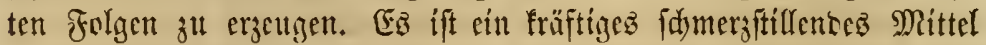
(anodyne) uno veridadft tem Patienten fogleidy Rinderung, intem ez augenbliflid) tie Edmmerjen hebt unt bie Epannung im Srga=

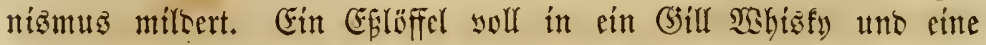

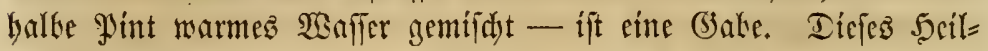

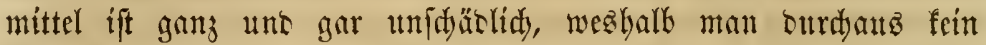
Betenfen tragen barf, baffelfe anjumenten, tenn objdon Ebloro= form gemöbnlid febr siel Shike ersengt, fo werten, wenn ber Magen in sem oben kejdriebenen 3uftanto ift, befien Eigenidhaften, ehe bie

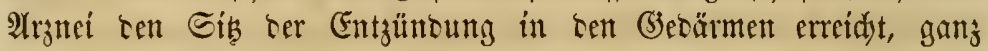
unt gar umgewantelt.

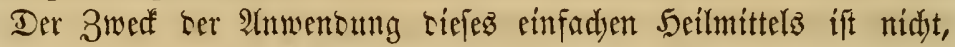

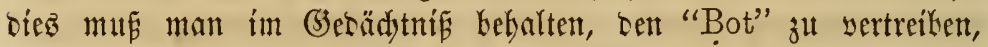
benn einmal erreidyt sie Mesizin jenen Theil tes Magens, wo fidy

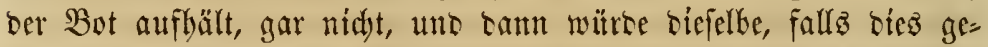

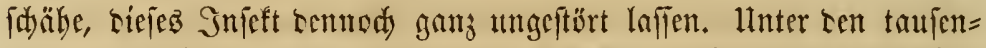
ten verberkliden Präparaten, bie sen Pferten eingefdjüttet merten, um ten "Bot" zu tösten, orer, wie man fid) gewöbnlid atšrnilutt,

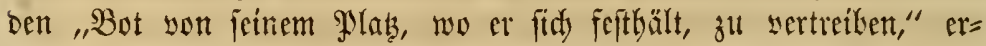

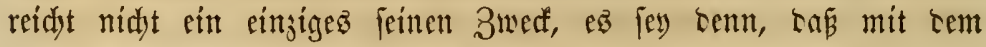
Bot tas Pyerd aud getöttet wirs. Dieje fogenannten Medizinen

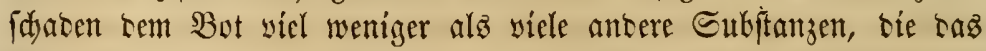

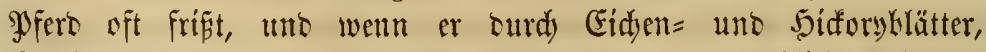
Sted)apfelblätter $=$ unt Beeren unt siele antere serberblidue PFlanzen nicht keläftigt wirs, fo wiro ithm gemís werer Salbeithee, nod Mild, nod) Miolafies uno bergleidyen idhaden, uno man mag all biefes ebenio wobl ten Edyweinen yormerfen; tenn bieje Mittel

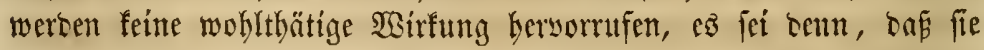
möglidyerweife in geringem (brabe baz̧u beitragen mïgen, bie Cäure im Magen zut vermintorn.

Fallz man Chloroform nidjt fogleid bejdaffen fann, mag ein ftarfer Seifenabjut, fdimadye Rauge, ober cin Efpliffer woll Soba, in einer Wint Mild) aufgelofft, alz Grjabmittel bienen; ja, felbjt bie

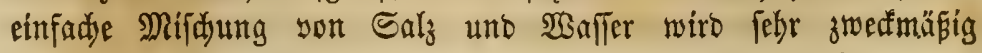


wirfen. Diefellbe follte folgenoermaßen bereitet werben: Man laffe

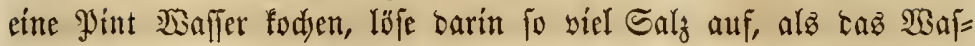

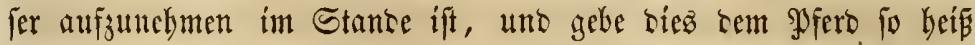

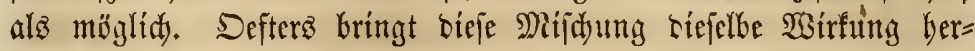
yor, wie Chloroform.

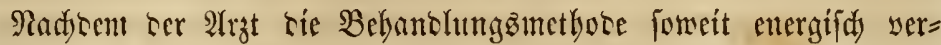

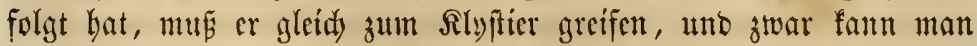

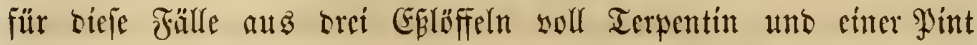

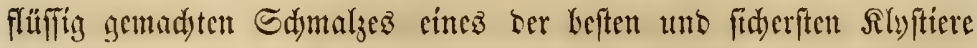
bereiten; chenjo mügen warme Eeifenabijute, sersümnte Etärfe ocer

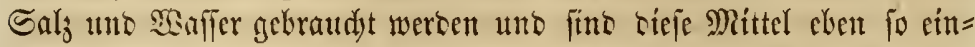

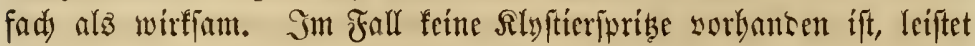
eine langhalfigge Flajthe siejelben Dienfte, benn wemn man ben bin= teren Theil berfelleen mälyrent ber Speration erbebt, wirt fid) ber

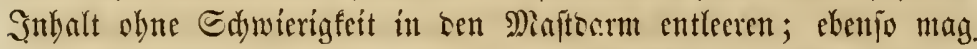

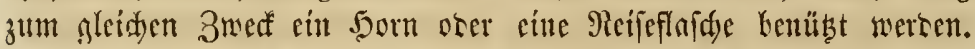

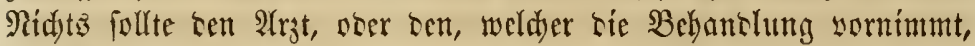
abhalten, sicie Dperation vorzunebmen, ober fie fo lange zu wieber= bolen, Kizz cin Miiftaligang erfolgt ift. Siser immer ein won cicier Siranfleit befallenes Thier Viebantelt, mus fidy zul ratben uno zu belfen wiffen, fo La er, went tas eine Mittel nidyt sorbanten ift, fogleid) jut cinem anterm greift; yor allem aber bat er sarauf ju feben, ta fontern grïndlid) ausgeführt miro.

Eobato tas PJero gemiftet hat, ift es yorterband auper (3efahtr. Dnz Futter follte leidyt fein, uno wenn mäglid, jollte tas Thter auf cine gute SBeibe gebradjt werten, benn biefe liefert igm bą Kefte Futter. Dabei bat man ibm täglidy angemeffene Bewegung zu serid)affen, sie man nady und nady serlängem fann, fo bá bas Pfers saran gewöhnt wirt. Altecrem gebe man tem Thier orei biz sier Tage lang foviel feingettopenen Edjwefel (sulphur) unc

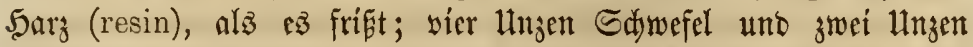
Sars fint cine Shake.

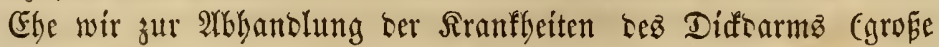

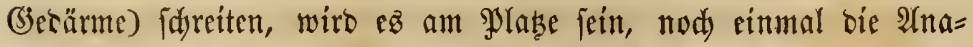
tomie biefer Theile, bie auf ber lețten arbbilloung sergeidnet find, sorzufübren. Der mit l bezeidunete Theil ftellt ben Blinbbarm 
(caecum), ber mit $\mathrm{f}$ gg bejeidinete ben (Brímmbarm (colon) yor,

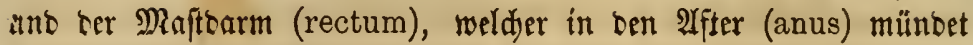
liegt zmifden $\mathrm{i}$ uno $\mathrm{h}$.

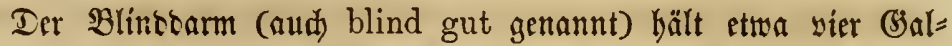
lonen uno ift, ba ber Mildyjaft namentlid) son hier auz in Cirfu= lation gebradjt wirb, mit unzähligen fleinen Saugabern verieken.

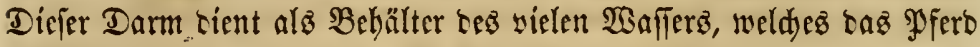
fäuft, uno befīen grö́perer Theil jogleidy bieker gelangt, ohne im Magen ober bem Dünnoarm (fleine Błesärme) zul verkleifen. Der (3rimmbarm, in welden ber leste Prozep ser Berbauung yor fid geht, ift fehr umfangreid) unt füllt etwa jweifünftel ber Unterleitbz= höble. Sm Maftrarm, sem lesten bes Darmfanals, fammelt fid

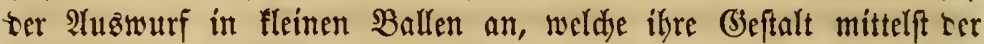
fleinen 3ellen bes Brimmbarm erbalten, unb verbleibt Lort, biz

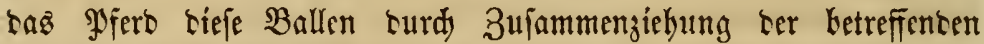
Mušfeln burd) ben $\mathfrak{A f t e r}$ hinaus brüđt. Bei einem Pfero mittlerer

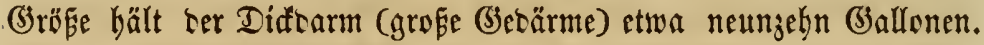

\section{M i n o t o I t (flatulent colic).}

Diefe Rranflyeit hat ihren Sit entweber im Blintoarm (caecum), orer im Grimmbarm (colon), ober mandjmal in beiben; jebod wirb ber lestere am heftigften afficirt.

Deriflke mag burdy fympathetifde Cinfluffe, bie cer erfrantte Magen orer ber franfe Dünntarm aušübt, gereizt werben, benn biefe Theifen fönnen fid nidjt entzünten, shne ben ganzen Darm= fanal zu afficiren. Die gemöhnlidjte urjade biejer Rranfleit jesod ift tas $\mathfrak{H e b e l}$ weldes man mit sem Ramen Bufammenziehung, Cin=

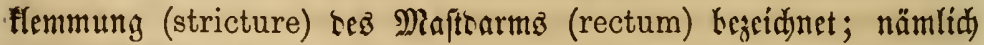
eine fold beftige Ginflemmung, baf bie verur fadjte Berftopfung to ftarf ift, baf aud nidyt einmal die angejammelten (ba aje auştreten fönnen. WButbe cine foldye Cinflemmung nidjt irgentwo ftattgefun= ben baben, to bätte nic Sintofolif entfethen tönnen, benn alle ergettg=

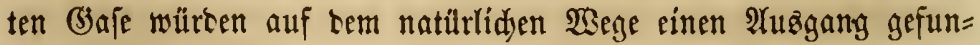
ben kaben.

WBir haben geephen, ba fid burd Störungen im Magen uñ bem Dünnbarm leidyt faule Baafe entwiafeln, unb biejelbe Wrirfung mag surd) bie (5ähbrung ber im Blitboarm oter (Jrimmbarm yor= 


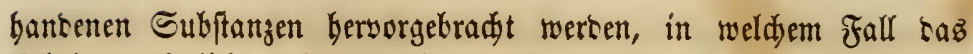
Uebel gewöbullid) nod baburd sermebrt wirt, bas fid bie im Magen

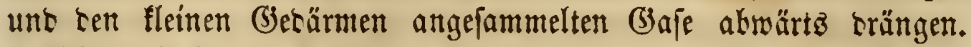
Wintololif ift ein Beweiz, baf in irgent einem Theil bez Darm=

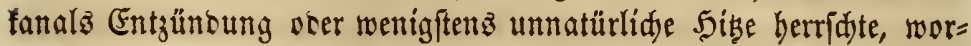
aus fid alzbann fidäbliche (3)aje entroiffelten. Diejelben verurjadjen eine

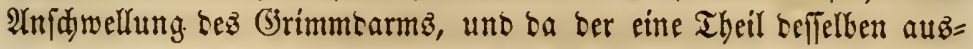
gebehnt wirs, zieht fith ber antere Theil zufummen; oter mit antern Worten, fobalo ser Grimmearm unnatürlid auşgecehnt wirb, entiteht an ser (Einmüntung Lez Maftarmz eine entfprediente Bufammen=

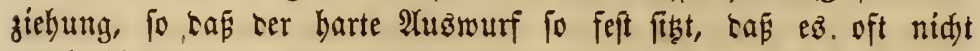
wenig $\mathfrak{A n f t r e n g u n g}$ erforbert, Lemielben zu entfernen. Diejer Buffunt

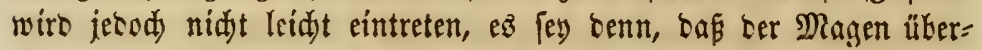
mäfig angefüllt wurbe unb bie Entroiflung ber Winte eine ent= ipredjento bebeutente war.

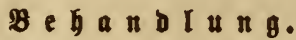

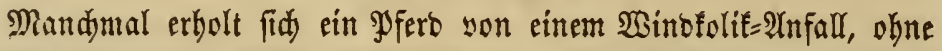

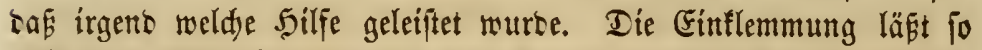

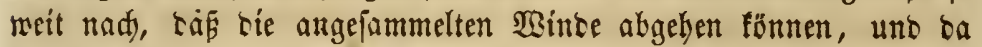
rie Berftopfung gehoken ift uno folglid bie (baje fid entwideln

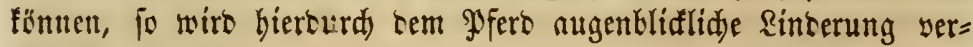
idafit.

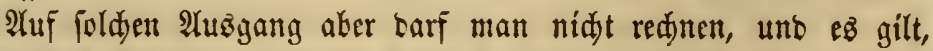

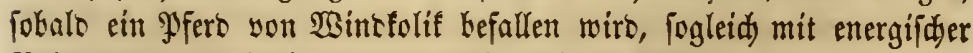
Behanslung ju beginnen, senn sie Zeit ift föftlidy.

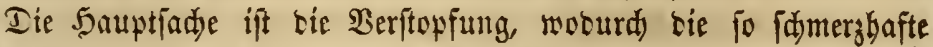
Anjidyellung ber (3etärme verurjadyt wirb, intem baburd bie (3a)

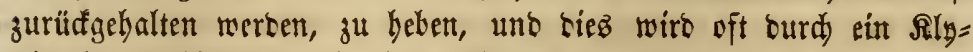

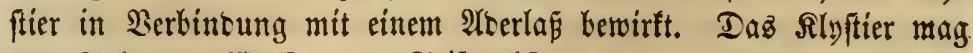

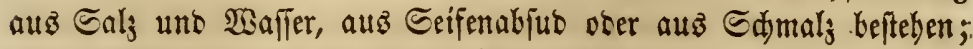
man nehme gerate bas, waz leidjt bejdafft werben fann. Durd. ciefe Mittel mag bie Spannung in ten betreffenten Theilen fo ge= millert werten, baf ein Durdgang gewonnen wirb, unt hat biez. einmal ftattgefuntert, fo ift bie Gefabr yorüber.

Das einģige zuverläfrige Mittel ift jebod bie Dperation, welde

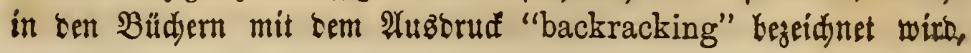


worunter man ganz einfad) bie Entfernung ser Miftrallen aus bem Maftearme mittelit ser Sand serfteht. Dic Einflemmung finset etra

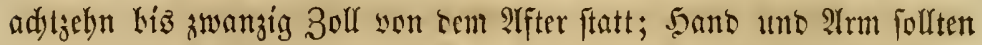

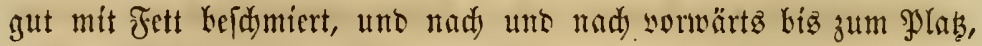
wo rie Reritopfung fattfinet, gejdoben uno rie Miffthallen forgiam entfernt werten. Wenn man sen 3eigefinger surdy einen Barllen ftedt, fo faun biefer leidyt mitgeidleift werten; jetody fint rie Mijt= ballen gemöhnlidy fo bart, raf ries nidyt geideben faun, uns in rie=

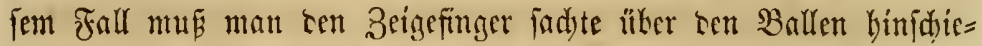
ben uno alšcann sorwärts rollen. Eebr beftig ift tie Bufammen=

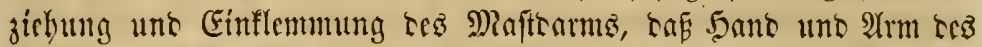
Dperitenten Lermafen geprefit werten cütften, sape heftige Edymer= zen empfintet und gezwungen ift, mit ter Speration ein wenig inne zu balten.

\section{(Enţündung unb Berften Des (Grimmbarms (inflammation and rupture of the colon).}

Falls tie Cinflemmung in Maftsarm nidyt Lefeitigt wersen fonn,

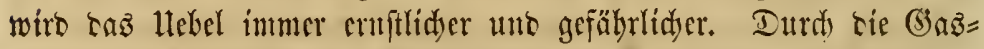
anfammlung idjwillt ser Strimmsarm zu ciner unglaubliden ?lus = bebnung an. Die Tseiden hes Thieres fino aufgetrieben uno Infelte

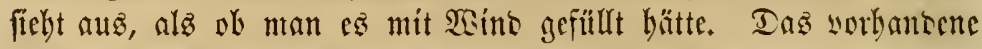
Fieber, fowie rie Sibe ftrigen fortwährento uno rie Symptome wer=

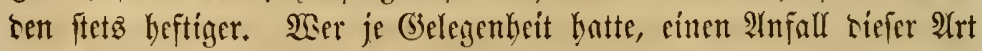

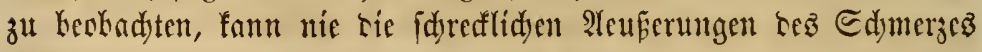
vergeffen, weldye basurdy berworgerufen werben.

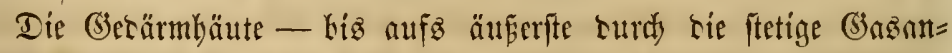
fammlung aแsgepannt uno turd) seren giftige Eigenidjaften afficirtfönnen enclid) tem ungebeuren Drutf nidyt mehr wiserftehen une wersen an vielen Etellen burdylöbert. Cobalo ties cingetreten, ift tas PFero unatänterlid) sem Tob verfallen. Die Zeit ciejer Iarmsurdy= lödscrung zu beftimmen, ift beinabe unmöglid, uno rab Iffer fdeint, nadyem ries geddeben, sielleidyt nidyt mebr fo frant zu feitt, wril

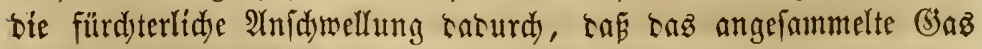
Durd) rie sielen fleinen Deffnungen am Darm entmid), bereutend geringer geworten ift. Eino ricje ctwas grïfer alอ fonft, fo wirb 
cas Thier balo fterben; fint fie flein, fo mag ę nod cinige Tage lang babinfiedyen, fann aber nidyt melyr lange leben.

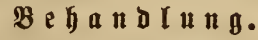

Da ber oben bejdyriebene 2(nfall im weientlidien terfelbe wie bei (3)ecärmentzüntung, ofer sielleidyt nur eitte antere $\mathfrak{A}$ euserung uno Form biefer Siranffeit ift, fo mur aud) bie Befandlung ber gegen bie Bebärmentzünoung yotgejdriebenen äbnlid) fein.

Daz erifte, was man sorzunebmen hat, ift ein 2rerlaf; tenn ra= burd) wirs bie Gpannung in ten betreffenten Ibeilen gemiltsert, waz burdy Medizinen nie zu Etanbe getradyt werben fann, weil ricje ten Sis ber Rranfbeit nidht erreidyen. Radjem jerody ein reidylidyer Atorlas yorgenommen, mögen $\mathfrak{A r j}_{j}$ neien zur ferneren wirffamen $\mathfrak{B} e=$ banklung febr zowedmäfig fein; uno zwar hat man foldye fu wäblent, meldse die giftigen (baje teutralifiren, ten Drganismus yon wer= berblidyen, anfectenoen Subftanjen befrcien (besinficiren) uno gezen Srämpfe wirfen. Die Chloroform= Mifd)ung, weldye gegen (Senärm= entzïnoung sorgefdricben wurse, bat alle ticje Eigenjdyaften uno ift

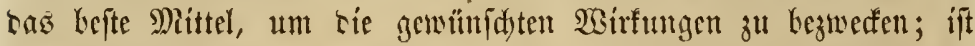
jecod) beftiges Ficber sorbanten, fo wiro bieie Mifdung, fowie alle antern ftarfen 2 trancien, fdärlidye Folgen nad) fid zieben. In ben meijen Fällen mag man jerod) biefes Seilmittel olne Bauben an= wenten, uno ift saffelbe nidst mur auferorsentlid wirffam, fontern

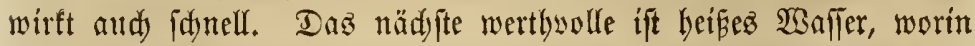
Salz aufgelöft iff; $\mathfrak{e B}$ fann nie serterblid) fein uno ift immer leidjt zul baben.

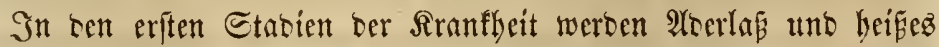

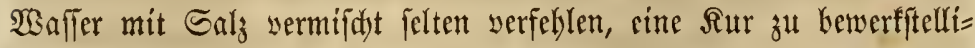
gen. Sit ber Fall ein gefäbrlider uno bartnädiger, fo wajhe man bie $\mathfrak{2}$ eidjen uno die Theile zwifden ben Sinterfüfen mit Sal; uno

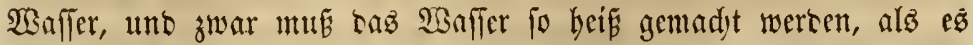

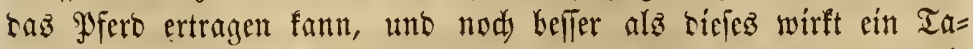
bafabiud. Sierturd) wirb bie Gpannung in Den betreffenden Thei= Ien bedeuteno verminoert. 


\section{Cintö̈übung und BIuten bes Maftbarms (inflammation and bleeding of the rectum.)}

Diez ift ein Uebel, weldję zน beiétigen wir währeno unjerer ve terinärijajen IGätigfeit jđon oft aufgeforbert wurben. Es vergefells fijaftet fich gewöhulid) mit ter (Srimmbarmentzünoung, ofer folgt berielben nad); mandymal ift es allem 2 Tnjajein nad beibes, eine Acußerumg uno ber Radufolger biefer Rranftheit.

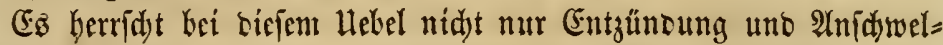
lung, fontern ez fintet ein $\mathfrak{B o r f a l l}$ bez $\mathfrak{A f t e r z}$ (prolapsus ani) ftatt, uno eв entleert find aแz ben Theilen eime bebcutente Duan= tittät $\mathfrak{B l u t}$.

\section{B с}

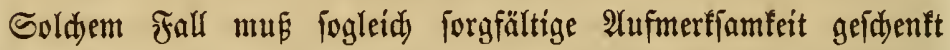
werben. Saltez, mit Salz vermifdtez Waajer ifit bas Sheilmittel, und man wentet Laflelbe alz Slyjtier an, uno wäjdy auperbem bie betreffenten Theile samit. Sn Berbinoung bamit wirb ein aus d)lorjaurem Rali (chlorate of potash) uno ber (b)elbrourzel (lat.

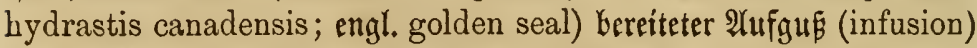
bie Wirfungen ber $\mathfrak{A}$ ragnei beförtern. Dies mag to oft gebraudat werten, als

Sm Fall biefes Hebel nidyt mit irgento einer anbern Ģcoürmfrant=

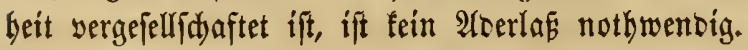

\section{Munber utb judtender $\mathscr{A}$ fter (soreness and itching of the anus).}

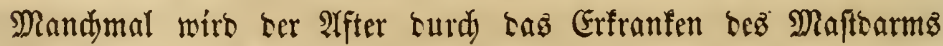
uno zeitweife aud surd, andere ltraden wunb unt gereizt, uno man nimmt Lann an ben betreffenden Theilen eine eigenthümlid)e Troden= beit uno Brindartigfeit wabr. Das \$Perb reibt jeinen Sdiweif oft

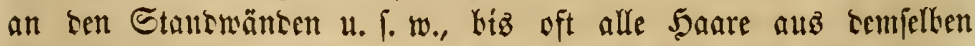

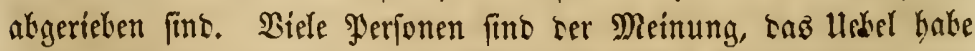

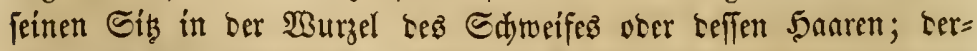

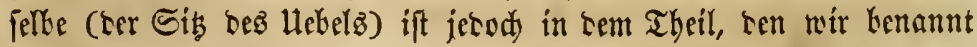
baben, und bie Theile, weldye baz \$ferb reibt, fino bie, welde erreiden fann. Mandimal mag jerod biefes Sưfen aud burd) Wuitmer erseugt werben. 
Sranlgeiten des Magens und der Bedärme.

\section{Bétandung.}

Man famiere bie Theile gut mit Sdunalz ober jonjtigem Fett eín, in weldes ein wenig feines $\widetilde{S}_{a l}$ gemijht wirb. Sierourd wirb caz lebel balo bejeitigt weroen. In einigen Fällen haben wir ge= funcen, baj cie Wuntbeit gerate am Beginn ces Dajtoarms íten Gis batte, uno wir baben alôtann bie Bebantlung bacurd erfolg= reid) vereinfadt, baj woir ein wentig ses mit Salz yermifduten Sdymal= 3eg, fowie ein wenig (Jelbwurgel in cen 2 ffer orüdten. 


\section{Dூierzefintes sapitel.}

efrankbeiten der feber, 每arnorgane u. . w.

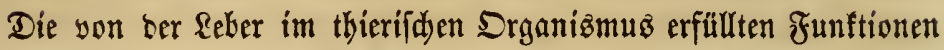
gebören zu ben allerwidtigften, benn bie (Sejundbeit bes Thierez

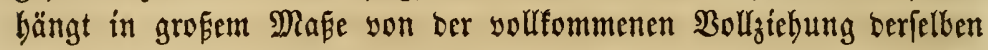
ab. Shre 5auptfunttion befteht barin, Dá fie bie Baalle aus bem

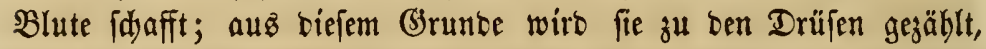
unter welden fie bei weitem bie gräfte billet. Nady ber auf Seite

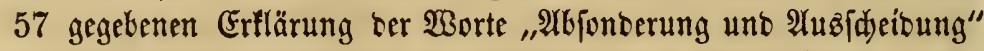

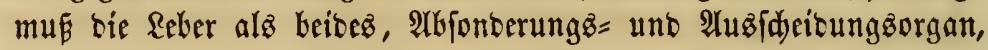
angejeben werben: 2 bejonberungsongan, weil bie Balle zur weitern

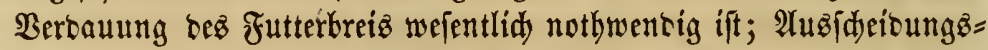
organ, weil bie Ģalle, fallz biejellbe nur mangelbaft auż bem Blute

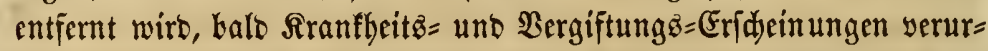

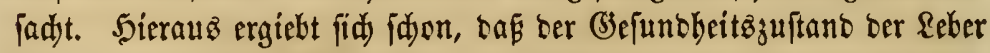
einen bebeutenten Einflü auf bie allgemeine Befjunoheit bez Rörperz aนsืủbt.

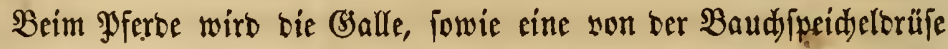
abge jonterte weiflidye flüifigfeit, am Enbe bez 3wölffingerbarms, etwa zweiunbzwanzig 3oll unterbalb bem Magenpförtner, in ben

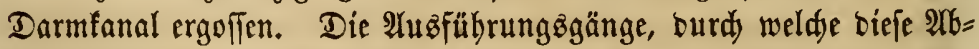
fonberungen in ben Futterfanal gelangen, finb in ber Figur ber (be= Därme im vorbergebenben Rapittel bei $a$ bezeidunet. Das gaferb hat feine Ballenblaje, fomit mus bie Balle, fo fanell fie in ber \&eber som Blute akgeponbert wirb, in ben 3wölffingerbarm gejdafft werben.

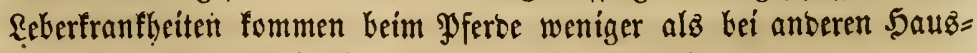
thieren ober aud bei feinem 5 errn, bem Meniden, sor.

Fä̈r biejen Umitano fann ber Ranbwirth redht banffar fein, benn unter ben yielen Srantheiten gibt es wobl teine, beren Eymptome 
in gröserez Dunfel gehüht unt bie bezhalb fdwerer $z^{\mathfrak{u}}$ erfennen

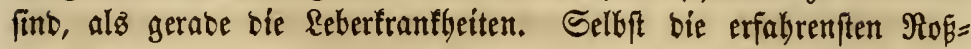
ärzte fönnen nur burd bie Seftion mit annähernber J゙ewifbeit bie Ratur einer Reberfranfbeit entbef̌en. Folgenber $\mathfrak{A} u g_{z} u g$ auz bem

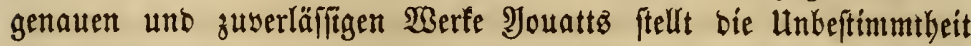

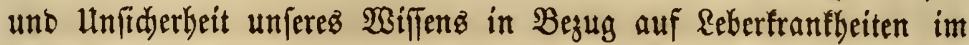
bellfen Ridute bar:

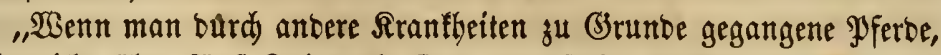
bie nidjt über fünf Sahre alt fint, unteriudt, to fintet man in ber Regel bie Retber gejunt, haben biejelben aber baz adjte, neunte ober

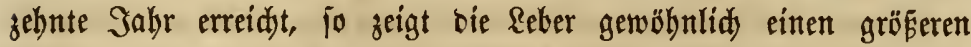
umfang, hat bie Elafticität eingebüßst und ein törnigez, zerfallenez

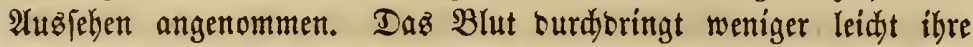
(Gefäze, fdywizt taher mebr ober minber aus biejen heraus unb bäuft fid in ben Baudbyöblen an, orer wird yon bem Baudjeelf eingeidlofien. Diejer Zujtanto wirb aber im $\mathfrak{A n}$ fang burd) feine be= fonberen Snmptome angefüntigt. Daz $\mathfrak{a f e r b}$ befintet fiit) wohl, frift fo viel als fonft, ift nid)t abgemagert uno fann beftänbig ar=

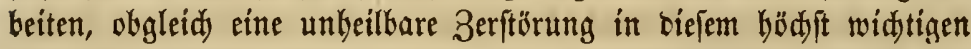
Drgane ftattintet; aber mit ber Beit reifst plöblid ber feröfe lleber: zug ber Reber; baz Baudfell unb baz yon bemjelben früber einge: fidloffene Blut überifemmt unerwartet bie Unterleibzorgane, ober ez fliest allmählig eine binreidjenbe Duantität in bie Baudbäble, um bie Funftionen ber barin befindlidjen Drgante beinabe aufzu= beben.

"Die Symptome biefer plöbliden $\mathfrak{B e r a ̈ n b e r u n g ~ i m ~ U n t e r l e i b e ~ f i n t o : ~}$

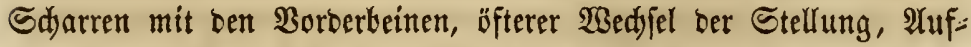
blähung bez Baudjez, 2Aufziehen ber Sberlippe, oft wieberholtez

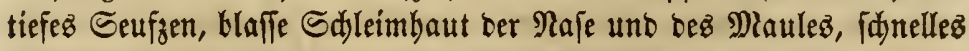
Sdynaufen, grofé Unruhe, Sdywäde, Shnmadten uno Tob.

"Deffnet man bie Baudbăble, fo finbet man bie Gedeärme mit bunflem Blut überjojwemmt. Die Reber bat entweber eine bellgelbe ober braune Farbe, ift äuterft leid)t zerreiß̧bar ober gang zerfallen."

Ez wirb behauptet, bafs ber fdimarge Staar entiftehe, wern eine foldje Blutung geftillt werbe, ehe baz Thier bebeutend baran gelitten bat; aus eigener Erfabrung tönnen wir jebod bieje Meinung nidjt beftärten. 


\section{Ballenfieher, (Belbjunt (jaundice or yellows).}

Zuweílen wirb bie Reber bez $\mathfrak{P f e r b e z}$ yon ciner Entzünoung be= fallen, bie unter anberm audh baz Symptom erzeugt, beffen Ramen

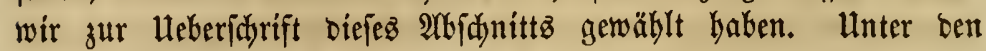
amerifanifden Raien wirb biefes Symptom aud "yellows" genannt. Die vorzüglidjiten Sdriftiteller neuerer Beit verwerfen sen Namen "(Sielbfuct)t" ganz, weíl leidyt Srrthum burd) beffen (Sebraud) ent= fteben fönne, on bie bellgelbe Farbe oer 2 ttgen uno ber Säute nidjt ben 3 uftano anzeige, ben wir beim Menjoden mit bem $\mathfrak{T}$ uzbrud (s)elbjud)t bezeidunen.

Yjouatto Beidyreibung ber Sranfleit, obgleidy er bie alte Bezeid $=$ nung beibebält, ift eine böd)ft gelungene.

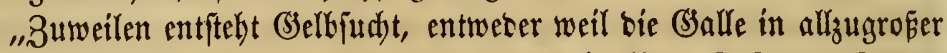
Suantität abgejonbert wirs, ober weil fie in ibrer 3ujammenjebung

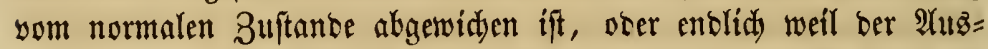
fübrungżgang geid)loffen ift. Man erfennt biejen Buftand leidat an ber gelben Farbe ber 2ugen, beş Maules uno ber äufern 5aut, wo biefelbe nidyt mit-5̧aar bebectit ift. Der Mift ift hart und wirb in fleinen $\mathfrak{B a l l e n}$ auggefonbert; ber Utrin hat eine Dunfelbraume Farbe;

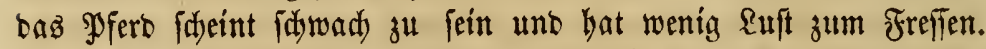
Wenn nidyt balo Saltlfe gefdafft wirb, zeigt ber (Saul gewöbnlid eine unverfennbare Untube; wiro aber fll antern Beiten summ, fablärig uno ftupib. Buweilen wirb tas rechte Borberbein labm, waz man, wie bie Sdymerzen in ber redten Sdjulter beim Menfdyen, wenn befien Reber erfranft ift, alz fennzeidnnenbez Merfmal zu

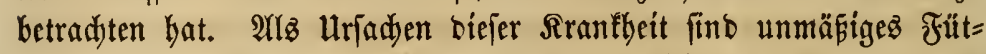
tern, allzugrope Ânftrenguttg bei brücfenter $\mathfrak{B i t t e r u n g ~ o b e r ~ a u t ) ~ z u ~}$ wenig Berregung bez Rörperz-anjufübren; audy ift fie ein Symp= tom son Crntzünoung uno antern Rranfleiten ser Reber.

,Bor allem ift $\mathrm{eg}$ nothwenbig zu unterjudyen, ob bieje Reberfrant= beit nicht in Folge ber Sympatbie ber \&eber mit einem antern er= tranften Theil entftanten ift; benn nidht felten begletten fie Entzün= bungen ber (Sebärme ober aud) ber \&ungen. Wenn in foldjen Fällen bie uriprünglidbe Sranfbeit bejeitigt worben ift, fo veriduminbet bie (Selbjudist allpofort. Sollte fidh aber feine anbere Sranflyeit vorfin= ben, fo wirb es ratbjam fein, ben natülid)en alfogang ber (salfe ourd ben (šbraud von 2nbfübrung $8=$ uno Reinigungämitteln, wenn 
móglid, berzuftellen, bie aber nidjt in allzugrofen Dofen gereidyt

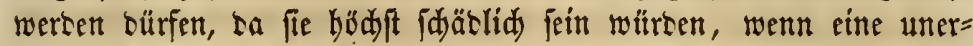
fannte Sungen= ober Darmentzünoung im Gang fein follte; aber man wieberbole fleine Dojen berfelben in furzen 3 wifdenräumen, biz ser Darmfanal gut entleert ift. Blutentzitehungen, beren Duantität

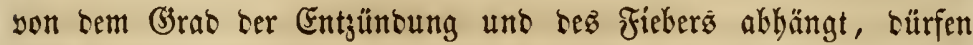
nidjt unterlaffen werben. Dem Thier muf reid)lidy $\mathfrak{B a f f e r , ~ z u w e i l e n ~}$ beffer lauwarm, boer büner 5aferfdleim ju faufen gegeben werben.

\section{8 c}

Die in biefer Rranflyeit anjumententen $\mathfrak{A} r_{j}$ neimittel müfien eber eine allgemeine als̈ d̋rtlidse Birfung baben; voer man fönnte fie vielleid) nod) befler alsె Borbeugungamittel bejecthnen. Sie befteken

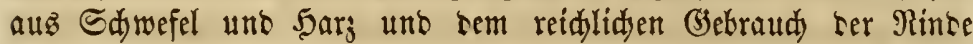
cer gelben Pappel (bark of the yellow poplar), entrocber alz $\mathfrak{P u l}=$ wer ober $\mathfrak{A}$ fjub eingegeben. Wenn man tie Ninte ter gelken Pap= pel in ber Form yon Sdyifden ofer feinem Pulver in bie Srippe

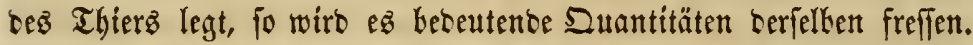

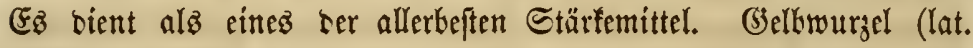
hydrastis canadensis, engl. golden seal) bat efenfalls eine yor= treffliate Birfung uno it Berbinbung mit Sdwefel uno 5arz ge=

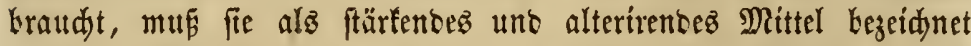
weren. Man fann bas Pulver in Dofen yon einer Hnje unter bem Futter geben, vier mit Sdywefel uno Sarg bermengen. Unter

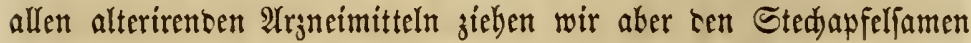
(Jimson seed) yor. Mit vollem Redbt barf man benjelben alsె bie Reber = uno Blutmerizin Les Roflę betradten.

马u ben oben angefügrten $\mathfrak{A}$ rzucimitteln fönnen wir nod Profeffors Dale'z Pulser (fielge 24. Sapitel) zufügen, bie einen grofen $\Re$ uf als jefr wirfiames Mittel für Blutfranffeiten uno allgemeine Stö= rungen genié̃en.

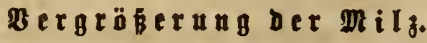

Die Funftion oer Mils ift nod immer in Dunfel gebullt. Nidst felten fälut biefes Drgan einer Bergrößerung ankeim, beren urfadje uno (5egenmittel bis jebst ebenfalls nod nid)t mit Sidjerbeit anju=

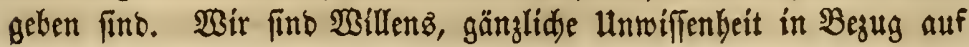


biefen Begenftand zu befennen, welder bem Farmer bod yon feinem

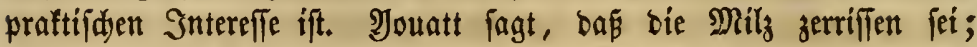
aber zur Berurjadung einez jolden Sdadens mürbe bie heftigfte Errfaütterung erforberlid fein.

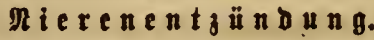

Die Rieren werben oft yon Siranfleiten befallen, unter benen siel= leid)t bie Entzünbung bie beftigfte uno idmerzbaftefte ift. Nieren= entzüntoung mag burd Manderlei verurjadyt werten. Bielleidyt fint

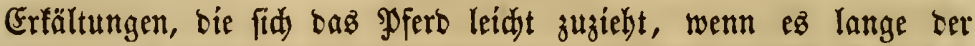

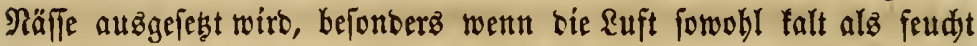

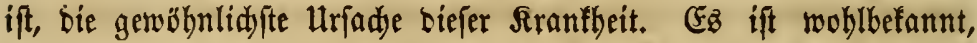
baß gewi i़ाe Subjtanzen, nadjem fie im Magen verbaut worben find, grof̧e Störungen ber Rieren bervorrufen. So entfteben bäufig Rierenfranffeiten in Folge von fadimmeligem Futter. Selyr viele ber ftarfen harntreibenten 2 razneimittel, beren fid unwiffente \$erio= nen gern bedienen, baben gleidfallz einen fo erregenben Einflufi, bás fie nie gebraudjt werten follten, aufer yon erfabrenen unb yor= fidtigen Thierärgten. (Eben fo fäablid) find aud gewifie minerali:

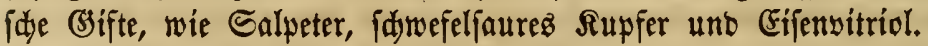

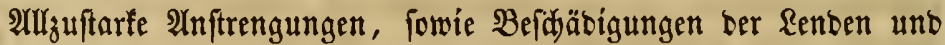
Süften faheinen zuweilen bie urradje von Rierenentzünoung zu fein,

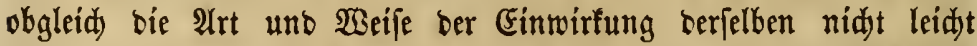
einzulfehen ift; man bat baher aud angenommen, baf bie Rranfleit

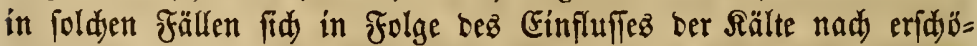
pfenber 2 Anftrengung entwífelt, ober baß irgent ein fleiner 3 weig ber Blutgefäffe in ben Rieren bei ber 2̂njtrengung verletst worben jei.

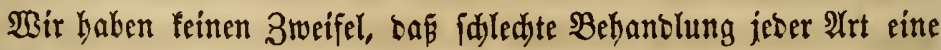
Neigung zu Siranfleiten ber Rieren hervorruft, uno zwar bežbalb,

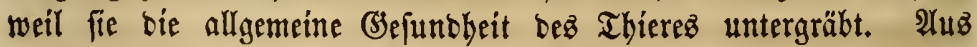
biefem Grunte baber, abgejeben yon allen anbern, follte man nie= brige unb feudite Ställe meiben unb foldie faule unb verpeftete Ruft, wie fie in vielen Ställen vorfommt, niemalz bulben. 2Rber bem Berbaununģapparate muß ebenfallz 2 (ufmerffamfeit gefdenft werben,

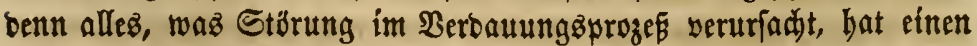
低äbliden Einflup auf bie Rieren, wie wir fidon oben gezrigt baben. 


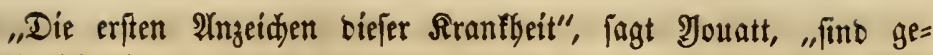

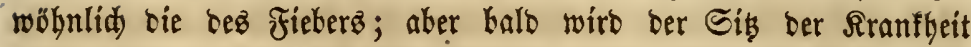

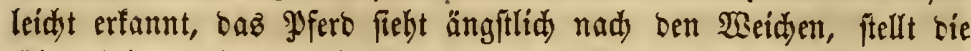
SSinterbeine weit aus einanter uno fpert biejelken beim Geben, legt

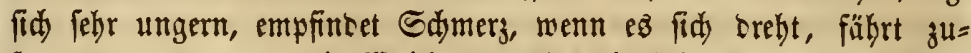

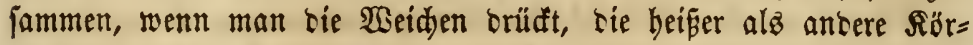
pertheile fint. Der Urin mirb in fleinen Duantitäten abgelaffen; terpelbe ift gewöbnlid) hodroth und zumeilen fogar blutig. Der

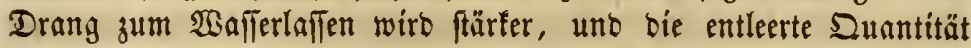
vermintert fid, biz ber Drang bödfif fammerbaft uno heftig wirb uno nur ganj fleine Mengen bodrothen uno brennenben 5arnz

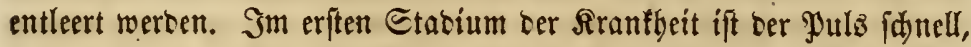
hart unt voll, wirb balo flein, werliert aker nidjt tie 5ärte. 2Yu biejen Eymptomen läpt fíd mit Eiderheit auf eine Erfrantung ber

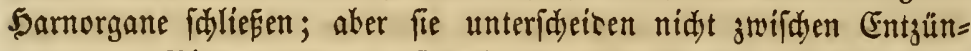

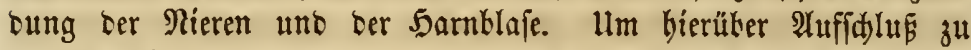
erlangen, ift ez nothwentig, bie $\mathfrak{5}$ ano in ben Maftbarm zu führen.

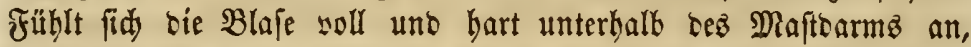
fo ift eine Blajenentzüntung vorbanten; fincet man oben bie Blaje leer, zeigt fie feine Edjmerbhaftigfeit gegen ben Drud, uno ift fie nidjt beifer als bie angrenjenten Theile, fo rübren bie Symptome von eimer Rierenentgüntung her."

\section{8}

Man nekme pogleid) einen $\mathfrak{A}$ berlá

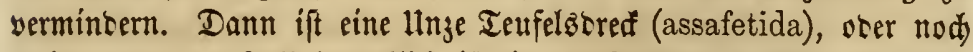
mebr, wenn ber Fall bebenflid ift, in ber Form einer Yille zu geben. Derfellbe 3rwed läft fid aud burd ein Drittel Pfinto Bitterjalz (epsom-salts) erreiden, weldes auf bie üblide $\mathfrak{B}$ Bife einzugeben iff.

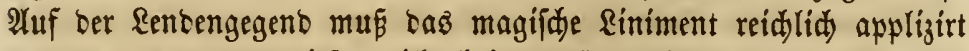
werben; ober wenn biefez nidjt bei ber Santo ift, fo fann man bas corrofive Siniment ebenfo wohl anmenben. $\mathfrak{A}$ ud jolte bem Patien: ten täglid eine fleine Duantität Sdjwefel uno Sar eingegeben werben. Resterez if ein millbez barntreibentes Mittel, und ift $b a z$ einzige, weldeb in folden zrällen gegeben werben jollte.

Wenn bie Siranfleit im Winter yorfommt, fo ift für einen wars

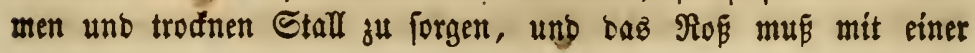


wollenen Defe bebeft werben, wenn fid fehr faltez Better einftellt. Das Futter barf nur aus leidtetwerbaulidien feudten Subftanzen be= ftehen, woyon grünes, wenn möglid), cine beteutenoe Portion bilten jollte. Sann man baz Thier auf sie Weite thun, fo miro fein anteres Futter nöthig fein.

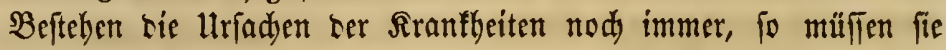
okne $\mathfrak{x}$ eiteres entfernt werben, uno in allen Fällen ridjte man bie Aufmerffamfeit auf tie Diät, bie faft immer ganz veräntert werben

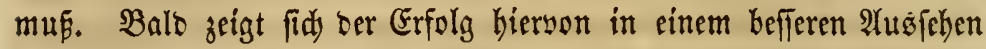
bes Urinz. Derjenige Pfertebefiber, weldjer feine Thiere mit ver=

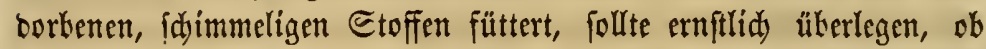
er nidyt jwei Dollar an feinem Syerte verliert, wo er einen baburd)

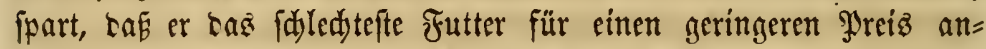

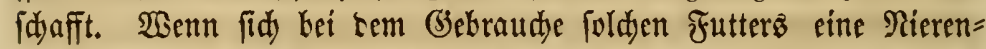

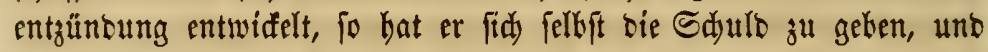

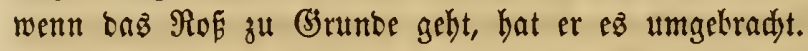

\section{$\mathfrak{b} \mathfrak{a} \mathfrak{r} \mathfrak{n} \mathfrak{l} \mathfrak{u} \mathbb{B} \quad$ (profuse stalling or diabetes).}

Bon biefer Rrantheit wiflen wir nidyt viel mehr, alż faß̧ fie bin uno wieber in ber Form einer läftigen uno maffenhaften Sarnent= leerung erfdeint. Ratürlid ift fie anf eine untatürlid vermebrte Thätigfeit ber Mieren kegrüntet, aber waz eigentlid tie Nieren bierz̧u seranlapt, ift ganz unkefannt. Buweilen entitelyt fie in Folge bez

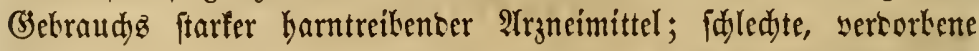
unt befonderz fdinmelige Fïtterungèmittel merben mit Redyt als

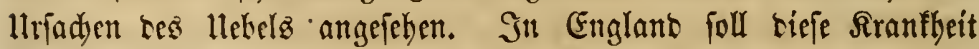
iek̨t viel bäufiger sorfommen, alz in früheren . Beiten.

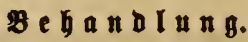

SBir cmpfehlen einen auz Scitelkeerthlättern (whortleberry) berei=

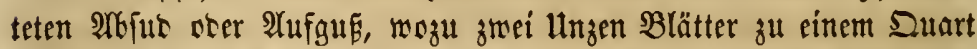

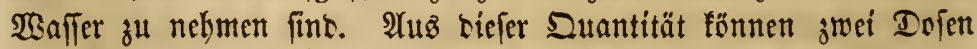
gemadjt werben, bie einen $\mathfrak{T} a g$ uno ben antern Morgenz gegeken werben tonnen. Mit tiefer einfadten Bebandlung ift fo lange fort= zufabren, biz fid bas läftige Uebel verloren hat. Bhlutentzichungen fino kei biefem Reiben unnosthig. Bon bem Frutter müffen alle 2 rrtifel, weld) gern bie Rierenthättgfeit vermebren, gänglid) entfernt wersen; 
bejonters wenn foldye nidyt volfommen frifa und gejunt fint.

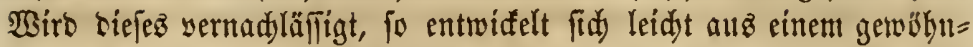

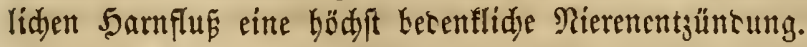

\section{PI utbarne $\pi$ (bloody urine or haematura).}

Zumeilen fintet fid $\mathfrak{B}$ lut im entleerten 5arn sor, uno juar gleidyiel, vb biejer vermebrt veer sermintert, ober in ter natürlid)en

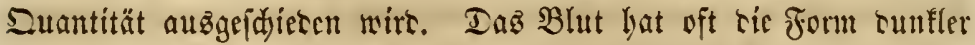
Slumpen, ift aber nod häufiger innig mit sem ltrin sermengt, fo caf Iesterer cine hodjothe ober braunrothe frarke cason crbält.

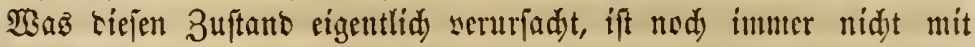
Beftimmtheit auşgemadt, sohil miro allgemcin augenommen,

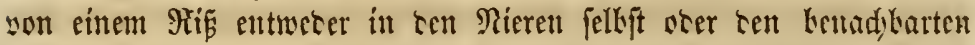
Theilen herrührt. Unter foldyen Umftänten flieft natürlid tas Blut langfam fort, biż ber Edjaben auछgebetîert ift. Durd sie Seftion

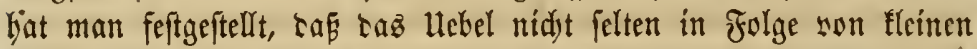
Baürmen, frebzartigen (3e)wädjen ober Rierenfteinen entftelyt.

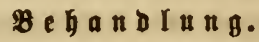

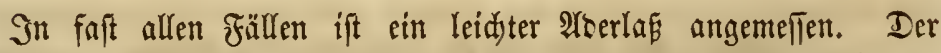

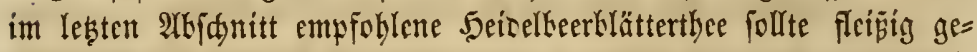
geben werten, uno mann tiejez nidjt aușreidjt taz lebel ju bejei= tigen, fo fann man effiglaures Rali (acetate of potash) in eincr

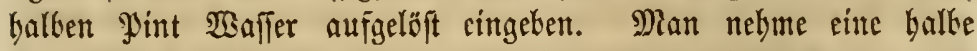
Unże yon ter Medizin zu ter angegebenen Duantität wanter. Sft

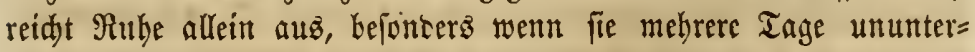

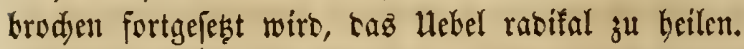

\section{ธ}

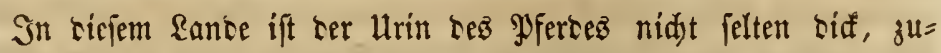
weilen hat er fogar tie Eonifitenz yon Sdjleim. Die leidtent Fă̈lle biejer Rranfleit zeidnen fid) Durd) einen, im 2 Anfang ter Entleerung,

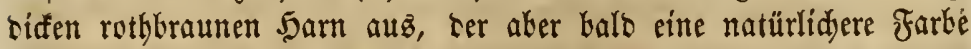

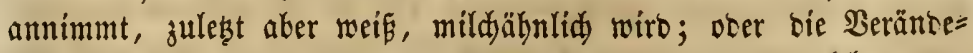
rungen in ser Forbe uno Confifterts fönten aud umgefelgrt vor fommer. Sat aber bie Sranffeit längere Zeit beftanben, io ift ber urin burdgängig biă und yon bunfler farbe und gibt bäufig einen 
ftarfen, unangenehmen (S̈erud) yon find. Shne Zweifel haben viele meiner \&ejer Fälle ber Rrantheit geielyen, in benen ser Şarn wie ein bifaer Strom von Syrup zur Grbe fiel unt beinabe fo fatwer war.

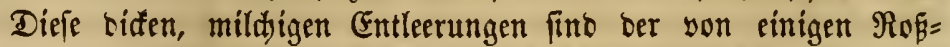

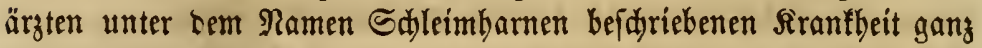

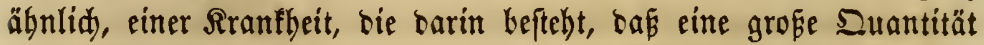
bez Eimeifftoffez surdy bie Rieren yom Blute abgejontert wirb.

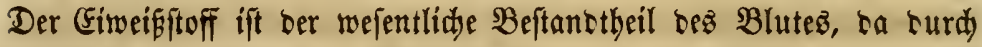
benfelben bie Ernährung beż Srganiżmuz yorzugämeife zu Stante fommt. Man bat ihn fo genannt, weil er feiner Ratur nadi bem im Ei befintliden weifen Stoff yolfommen äbnlid) ift.

Die Entleerung beż biffen, (4) leimigen Şarnez wirb sem Pfero böđj) läftig, waz befonters ber Borberbeine, funo thut. Bemabnlid ift bas Hebel mit mebr ober meniger Steifbeit ber Süften unt Sinterbeine begleitet, unt hin uno wieber entridelt fid beteutent Fieber. Wie wir io=

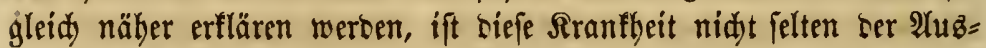

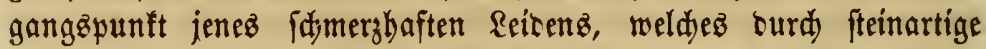
श्thbäufungen in sen Rieren ober ter Blaje serurjadyt werben.

\section{Meiper ober talfiger barn (white or limy urine).}

$\mathfrak{A}$ ud in ben gefünteften 5 armentleerungen finten fid falfartige Subjtangen, bie, wenn fie ungeftört yom Rörper entfernt werben, nie= malв Befdyerben yerurfaden. Selbft im Falle biejelben in unna= türlid grofer Menge yorhanten finb, entifteht baburd feine eigent=

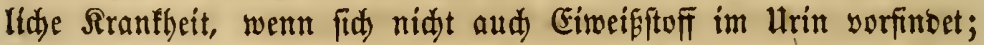
im lesteren Falle aber werten bie falfartigen $\mathfrak{P a r t i f f e l d j e n ~ b u r d ~ b i e ~}$

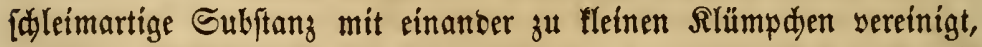

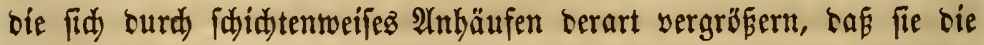
fogenannten Rieren= ober Blajenfteine biltsen. So wie gewiffe $\mathfrak{U m}=$

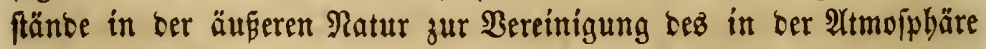

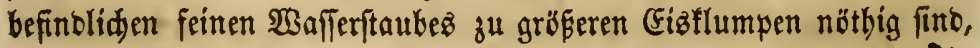

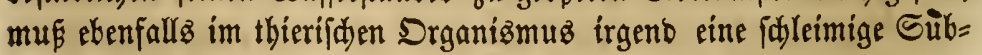
ftanz als Binbemittel vorhanben fein, um bie unifatbaren Ralttheile den $\mathfrak{z} \mathfrak{u}$ gröseren Steinen zu vereinen. Dies füłgrt uns auf eine năbere Beprectung ber 


\section{Blapenteine (gravel, or stone in the bladder).}

Unter ben Raien wiro bie Sranffeit nidjt mit biejem Ramen be= legt, bíz die falfartigen $\mathfrak{A n b a ̈ u f u n g e n ~ e i n e ~ b e b e u t e n t e ~ ( 3 o r o ̈ p e ~ e r r e i d ) t ~}$ Gaben uno furd)tbares \&eiben veruriaden; fie ift jecod nur eine $\mathfrak{B e r}=$ idjlimmerung beళ alsె Nieren= ober Blajengrię (gravel) befannten 3uftanters.

Der (Srunt biefez Reioens ift eigentlid) in ben Rieren zu fudjen; benn obgleid man bäufiger Steine in ber Bla ale als in ben Nieren fintet, fo ift $\mathfrak{e s}$ bod wabrideinlidy, bap fie nur in Folge eines un=

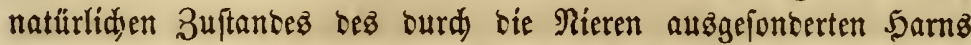
entftehen. Siernad bilten fid) biefelben zuerit in ben Rieren uno werben mit bem 5arn burd bie 5arnleiter, ehe fie einen grofen $4 \mathrm{~m}=$ fang erbalten baben, in bie Blaje geidafft, two fie alsbann imtmer mebr wadjfen uno zumeilen eine erftaunlidue (Stöbe erreidjen. Man Gat burd) operativez Berfabren Strine auz ber Blaje entfernt, bie mebr als vier Unzen wogen. Beim Menjuden ift rie Rage ber Nieren beinabe fenfredt über ber Blafe, woburd fdjon bie Sdjwer= fraft ben Alkgang ber falfartigen Maflen beförbert. Diez ift aber nidyt ber frall beim (Saule. Díe Sarnleiter baben bei bemielben eine beinabe borizontale Rage, fo Daf bie Saberfraft wentig Finflup atf bie Fortidaffung frembartiger Rörper hat, bie fid in ben Nie= ren gebilbet baben; baher bleiben Steine nidyt jelten in sen Rieren bes गुferbez, wo fie grofes Unbeil anridten. Dod) werben fie aud oft in bie Blaje gejdafft, wo fie baburd entieblide Sdmergen ver= urjad)en, bas fie bei cen Sarnentleerungen an Den Blajenbalz ge= idwemmt weren uno biefen theilweife ober ganz veridbliefen, fo oaj ber Ulín nur langlam ober gar nídst abfliésen fann.

Bir fönnen nidbt mit Beftimmtheit auf bas Borbanbenjein yon Nierenjteinen falliesen; wenn aber ber Sarn unyolfommen entleert wirb uno wir biejen llmitand auf feine anbere Sranffeit ter Blaje ober ber Nieren zurüđfübren fönnen, fo mögen wir Rierenftein vermuthen. Sind fie aber in ber Blafe, fo fann man fid babon leidjt baburds (3ervipheit verfdaffen, baß man bie Jano in ben Maftbarm einführt uno mit ben Fingern ben Stein in ber Blaje fühlt, tweldye unter= balb bem Maftoarm liegt. Durd biefez Berfahren fann oer Bla= fenftein immer entbedt werben, wenn er nidt zu flein ift.

Die burd Rieren= ober Blajenfteine verurjadjen S.jmerzen find 
benen ber frampfbaften Solif nidjt unäbnlid, unterfdeisen fid abet yon leţterer baburd, saé fie nídyt fo plöblidy eridjeinen, mentiger heftig verlaufen, unt bie Bewegungen bez Thierez auf eine weiter

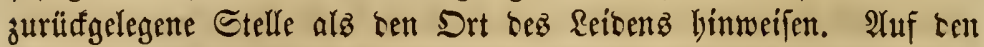

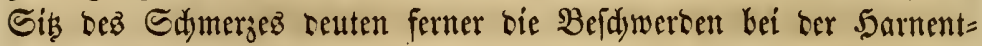
leerung, bie gewöbnlid mit bem beftigften Drängen uno ftarfen Sdymerzäuferungen begleitet fint, uno wie wir fdjon bemerft haben,

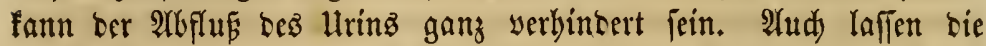
bunfle Farbe uno bie auferorbentlide Sitse tes 5amz bie Ratur

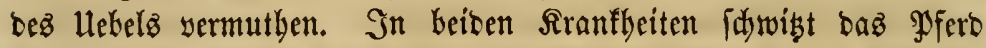
febr ftarf, was aber bei Blafen= ober Rierenfteinen in ber Renten= unt Weichengegent am ftärfften yorfoummt.

Die Sdjmerzen, weldje Blafenfteine verurfadyen, finto von ber ent: Feblidjfen $\mathfrak{A}$ rt. Werfonen, bie an biejem llebel litten, fagen, cas ibre Edjmersen unbeidreiblid) grof waren. F(td) felbit, wenn bie

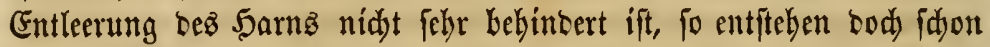

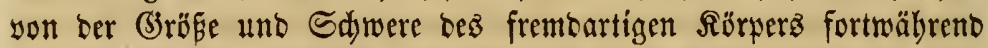
beläftigente Reizungsererideinungen, unb nidjt felten wirb bie ent= pfintlidje Edjleimbaut ter Blaje Durd) bie rauke unb uncbene Dher= fläd) ber Eteine bebenflid) verwunbet.

(3) lüflid)erwweife fommen fold) frälle nur äuserft felten yor, benn

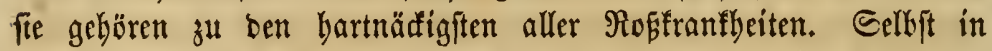
oen leidjten Fällen vergebt eine geraume Beit, ehe fid $B$ efierung

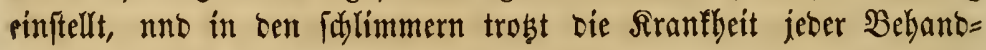
lung mit Mebifamenten uno läs̆t fid nur burd eine idiwierige Speration, ben Eteinjadnitt, bejeitigen.

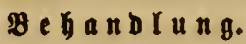

Wsir wenten jwei $\mathfrak{2}$ raneimittel an, woyon beibe beilfam getwirft, beibe aber audj oft ganj erfolgloz waren, waz fid yon jeber $\mathfrak{M e}=$ thoobe behaupten läst. Sm Folgenten werben wir bas Mittel zuerit anfübren, weldes fid in unjerer Prariz am beften bewäbrt hat.

Die erfte Metizin beftebt auz Etedapfelfamen (jimson seed).

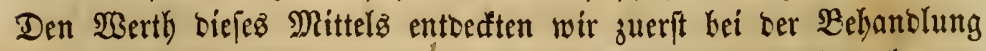

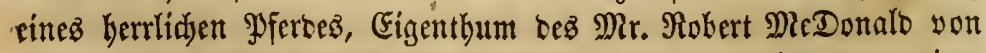
Salem, Tippah Coo, Miffififippi. Daflelbe litt an Diştemper, einer brüjenartigen Sranfheit, womit Rieren = uno Biajengries yerbun= 
ben war. Stedapfeljamen wurbe alż âteratís unb Stärfunģ̧= mittel angemants, unb furirte nidyt nur baz Dižtemper, fonbern aud baz 5̧arnleiten.

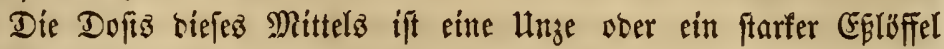

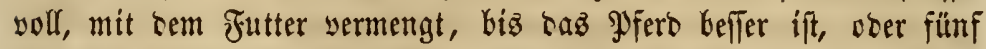

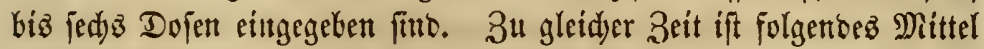
anz̧uwenten: $\mathfrak{B i e r} \mathfrak{l l n} \mathfrak{z}$ en Salpeteräthergeift (sweet spirits of niter),

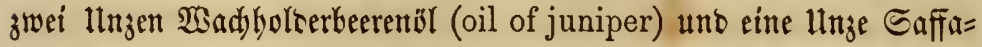
fraşbl. Siteraus finto vier Dofen zu madjen, woyon man eine Mor=

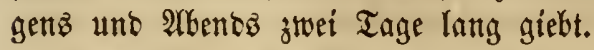

$\Im_{\mathfrak{n}}$ unjerer zwanjigjührigen Erfabrung haben wir nur einige auta =

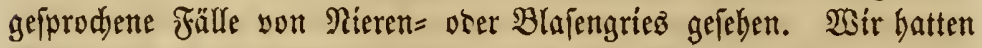
Gelegentheit fünf Fällfe zu behanbeln, wovon alle biz auf einen furirt wurben. Diejer Fall fant bei eitum gang beruntergefommenen Maul=

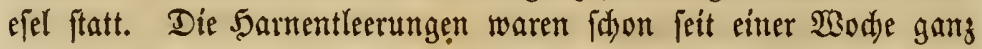
unterorüat, uno tie betreffenten Theile ftarf angeidwollen. Sb bie yon unz angegebenen $\Re e g e l n$ ftreng attägefülfrt tourben, wifien wir

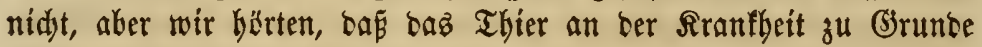
ging.

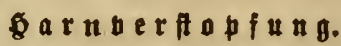

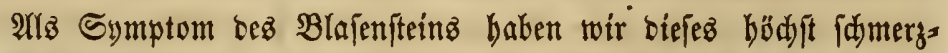
bafte Reiben fajon angeführt; aber obwohl eż febr oft son bem Blas ienftein abgängt, fo fommt ez bod) aud bäufig unter anbern $\mathfrak{B e r =}$

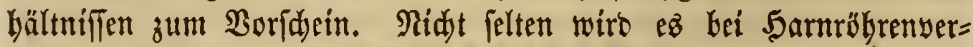
engertng beobaditet, bie oft in Folge von Berleksungen entfett. Der

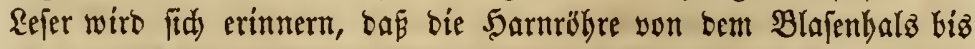

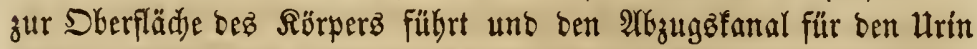

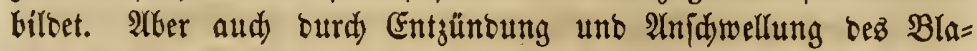

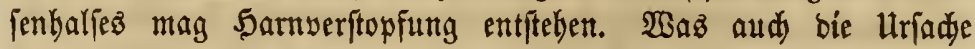
biées Hebelż jein mag, fo if Sdymerzen begleitet.

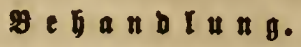

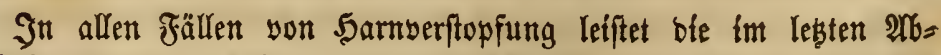
fantitt für Bla|engriez angegebene Mirtur, auż Salpeterätbergeift,

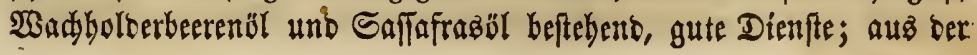




\section{4}

Das \$ferdebud des amerifanifden Farmers.

veroroneten Duantität follten jebod) nur brei amftatt vier Dojen ge= madjt werben, weldye in einer Pint warmen $\mathfrak{w a f f e r z ~}$ Morgens,

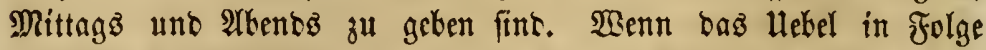
son Rieren = ober Blafengriez entftanten ift, fo follten aud bie übri= gen für sie Rranfleit angegebenen Mittel angewantt werben. Sino bie betroffenen Rörpertheile ftarf angeidjwollen, fo müffen fie orei=

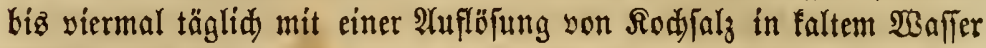
gewajden werben.

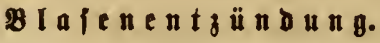

Beinabe immer miro Blajenentzünbung burd) Blajengriez soer Blajenftein serurfadt, entfelt aker juweilen obne sorbergebentes

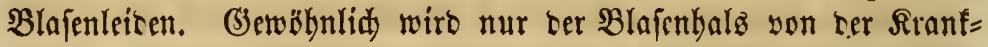
beit betroffen und felten bie im Snnern ber Blafe gefuntene Edjleim= haut ober aud) bie äuśere Muşfellyaut. Mebre ober weniger Ent= zünoung fommt beim Blafenfteine immer yor, ba ter frembe Sörper ftarf reizt. 2Ałuperbem giebt $e^{8}$, fo weit wir wiffen, feine anteren

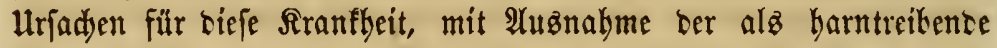
Argneimittel angewanten (sifte, unter weld)en ipanija) fliegen uno Bredjur ben erften Rang einnebmen. Ber folde giftige Sufjtan= zen alsె গTrzneimittel feinem Thiere eingiebt, verbient baffelbe zu ver= lieren. Wher wie fann er fid yon ber 2Ynflage befreien, baf́ er bie

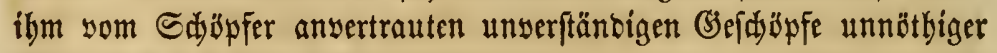
Weife gefoltert uno zerfitiont habe?

\section{B e}

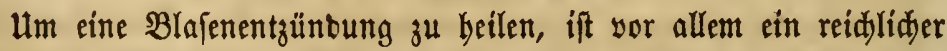
Itberla jogleid) entzogen werten. Radber idreite man zur 2Anwentung ter

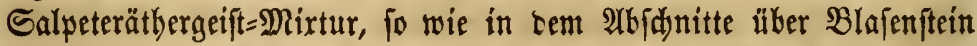
gelebrt wurbe. 2 (ud) gebe man bem Patienten treimal täglid eine sint Seinfamenthee, uno, wenn er überbaupt frift, leidfte, weidje Diăt, vorzuggeweife auz Roggenfleic beftekent. Renten, Sdlaud unt angremzente Theile fint mit faltem $\mathfrak{B a f f e r , ~ i n ~ b e m ~ \Re o d j a l z ~ a u f = ~}$

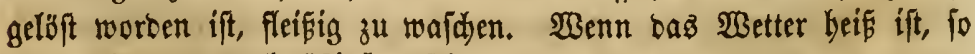

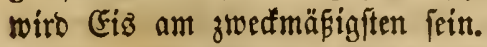

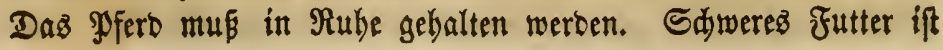


ifm auf längere 3eit ganz zu entbalten, uno wenn ber Eigentbümer fein Thier nidid verlieren will, fo hat er barauf ju fehen, baf ez̉ nidyt mit đatmmligem Seu ober anbern verborbenen Subftanzen gejüttert wirb. Bon Siseliabtorn ift auf längere Zeit nur ein febr fparfamer (5ebraud zu madjen.

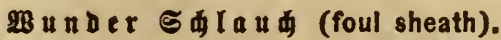

Der wunbe Sdylaud ift ein fprediender Berveiz futr bie Dumm= beit uno Sorglofigfeit bez Stallfned)tริ. Eв ift faft unglaublid, wie viele Pferbe Durd) biejé llebel berunterfommen uno zumeilen jogar zu Grunbe geben; uno nidjt minber jelten serurjadjt $\mathfrak{e B}$ an= sere beftige Sranfbeiten. Edon mandes gute RoF ift burd) ltn= adjtamteit in biejem \$unfte auf lange 3eit uno viele lebenglänglid unbraudbar geworben.

Unjere Silfe wurte idyon für wenigitenz hunbert Pferbe bean= fprudt, bie surd) biefes llebel biz zum Sfelett abgemagert waren;

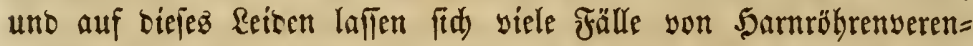
geruttgen, Sarnverftopfungen, Blutungen aนs ben Sarnwerfaetgen uno fogar Nierenentzünoung jurüdfübren. Daz fo vernadläfifgte Pferb hat oft Rolitanfäule, renn die im Cdylaud' 'entfantene Ent= günoung giebt fid balo ourd) einen unvertennbaren Einflus auf bie (3)ebärme fund.

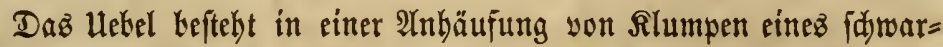
zen, wadbäbnliden Etoffes innerbalb bes Edlaudes. Sumeilen finbet man nur einen Rlumpen, gewöbnlid) aber zwei, orei, vier, bie

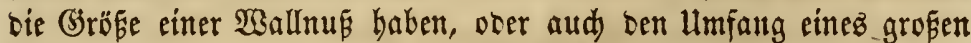
Sähnereiz erreiden. Ksenn- biefclben längere Zeit yorbanben fint,

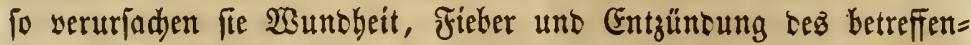
sen Theils uno ber Sarn fliest tropfenweife auz bem Sdjlaudje bervor. Balo fangen bie entzünbeten Stellen zu citern an, uno bods fino viele Pferbebeftier, wie wir idon zum gröften Erftaunen (bie $=$ legenkeit hatten unz zu überzeugen, zu. Dumm uno zu blino, bicien 3uftano zu beurtbeilen. Wenigitenz fünfzig arme, beruntergefom= mene Pferbe baben wir bebandelt, aus beren Sdyläudjen monatelang eine verfaulte, ftinfence Subftang geflofien war. Die Säule waren oft to fteif geworben, baj fie fid faum berwegen fonnten, uno sod wuften bie bummen Stalnfned)te nidht, was ben Thieren feblte. 
Der wunbe Sdalaudit if eng mit Fieber uno anbern Rranfbeitz: eridjeinungen ber \$̧arnorgane verbunten unt wirb oft son henjelken berworgebradjt. 2aber nod bäufiger verurfad)t berfelbe antere $\mathfrak{B}_{e}=$ fdhwerten. Bei alten Pyerben trifft man baz Hebel bäufiger alz bei jungen alt, vielleidyt weil ber Stoff, weldyer abgefontert wiro, um riejc Theile glatt unb fallüpfrig zut maden, bamit ihre Berwegungen

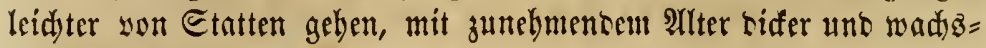
ähnlidjer wirt.

Der aufmerffame $\mathfrak{B e d}$ badjer fann bas $\mathfrak{H}$ ebel leidjt erfennen. Wäh $=$ reno ber Sarnentlecrung fommt bie Rutbe nidjt mebr aus tem

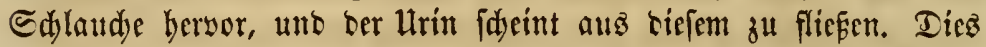
ift immer ein 3ridjen, baj an biefen Theilen irgento ein franffafter 3uftano fid yorfintet. Daz Ibier fdeint Sdymerzen in ten leiten= ben Srganen zu empfinten. Die Säften fint fteif und bie Sintre beine werben weit auseinanber gebalten, bamit bie entjünteten Etel= Ien nidyt gebrïdt werten. Sft baz Pfero gefunt, fa werben bie Sinterbeine nad binten uno zur Scite ausgeffrect, uno felbft in biejer Stellung fajeint baz Ihier mebrmalz gewaltjame Anftrengun= gen madjen zu müfien, che ber 5 arm in einem reidylidjen Ctrom abflieft; bei bem in Rebe ftebenten Hebel veräntert taz $\mathfrak{T}$ bier faum

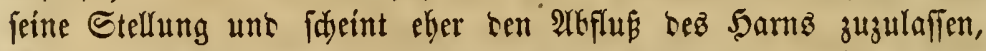
alz surd) Drängen herbeizuführen. Diez fintet barin feine Crfflä= rung, dáp jebe Bewegung unb bejonters 3ujammenjiefyungen ber mit biefen Srganen in $\mathfrak{B e r b i n t u n g ~ f t e h e n b e n ~ M u g i f e l n ~ b e m ~ \Re o f f e ~}$ Edjmersen verurjadjen.

\section{\&}

Dic Bebantlung ift bödfit cinfady. Bor allem antern ift ber Sdylaud gut zu reinigen. Die Rlumpen, wenn foldye vorbanten fimb, milifen mit ber 5anb entfernt werben; bann ift ber Sdylaud) jorgfältig mit Seifenwaffer auzzzuwajden; nadjer follte berjelle mit

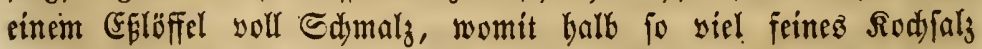
gemifdyt worben iff, eingeid)miert werben. Diejes bringe man forg= fältig mit ber ganzen inneren Flädje tes Cdjlaudjes in Berübrung, wo cz biz zum nädjten Iage gelafien wirb. Af(zbann ift her Єdjlaud

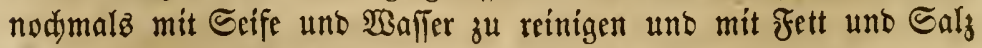
sinzufdmieren. Dieje Bebandlung mus io lange fortgejegt werten, 
biz sie betreffenten Theile gefund fins, ober kiż ber Saano oeer ben

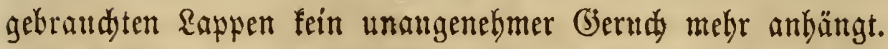

Das $\mathfrak{T}$ (euf́ere

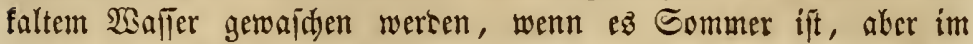

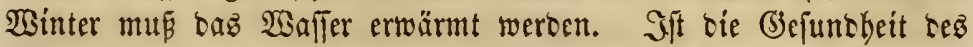
Pfertes anterweitig geftürt, ober hat ez beteuteno Fieber, fo fann

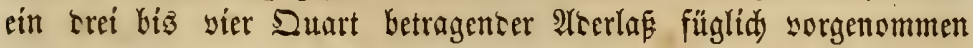
uno jugleid) reidjlide Dofen von Sdywefel uno Sarz gereidyt werten.

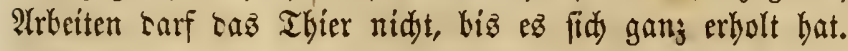

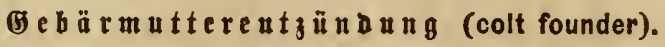

Wä̈hretto Sem Beitraume yon 1850 biz 1856 herrfate cine merf=

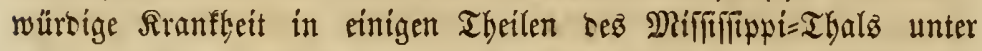

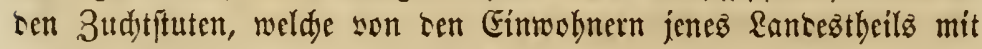

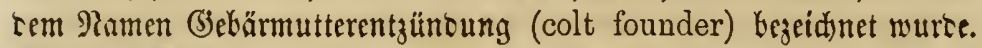
Die Sranfleit ftellte fid immer ein, wenn bie Stute mit einem Sungen ging, uno wurbe zuerft burd (Empfintlidfseit uno Edjmerg= haftigfeit in ter Rentengegeno uno allgemeinez ficber erfannt. Dås Thier wurte fanell äuserft fajwad) uno frepirte in auffalleno furjer 3eit. 3tuveilen war ter boffnungalolefte 3uftano idjon in einigen Iagen eingetreten, in anteren Fä̆len verzögette ter Too jeine Gr= idjeinung.

3wei Drittel ser befallenen Maăhren erlagen ber Rrantheit, unb mebr alz bie Sắlfte yor beentigtem Fohlen. Rebte. aber baṡ Thier biz nady tem Foblen, fo war etwaz 50 offnung auf $\mathfrak{B}$ efferung yor=

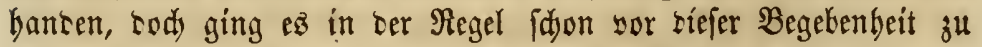
(5runte. Wir haben erfahren, aaf mehrere foblen zur Welt famen,

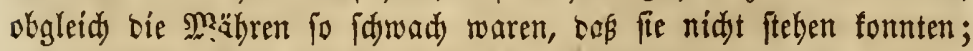
uno sie Sungen waren nidut nur am Reten, fonbern wudjen zu berr= lidjen Pyerten beran, obgleíd fie obne Muttermild ergogen werten

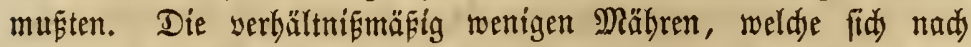
geidjehenem Foblen erholten, famen fehr lang jam zu Jräften, uno

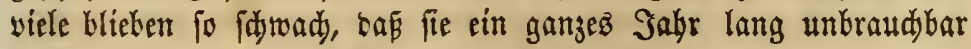
waren.

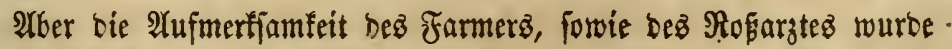

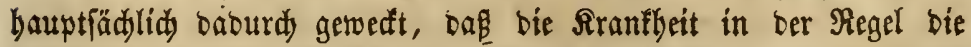

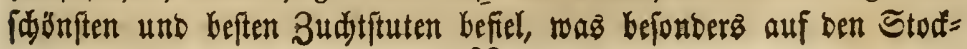


farmen uno im mittleren IKeil bcz Staatez Ienneflee beobadjtet wurbe.

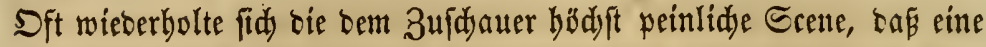
grofie, fdöne, fleifdige, bodjträdtige Zudjtftute fo yon ber Rranfbeit abgeidwädt war, tap fie bülflos auf ber Erbe lag.

Man bat biż jeşt fein ipezififd)ę Arzneimittel für (3ebärmutter= entzünoung entbectt. Biele Merifamente fint fdon probirt morben, woson einige aud Rinberung veridafften uno ohne 3weifel cas Reben bes Thieres retteten; aber bods fonnte man fid auf feines berielben alz fubereb Seilmittel verlaffen. Die Sdywerigfeit lag nidjt fowobl in ber ridtigen $\mathfrak{A}$ fffaflung ser Natur ber Rranfbeit, alz in ber Entsedung eimer Bebantlungsimethore, weldye fid mit Sidjerbeit tem llebel entgegenjeşen liep. Diejes fant feinen (s) in bem eigenthümlidjen $\mathfrak{A}$ fall ber Sranfleit uno bem allgemeinen (3)

Shne allen 3weifel beftant bie Sranflyeit in einer Entjintung

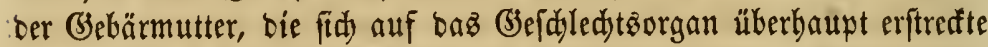
unb zumeilen fogar bie Nieren unb Şarnblaje befiel. Man fonnte - im Maftoarm leidjt die auferorbentlidje Sibe mabrnebmen; bie (S)e= bärmutter war furdstbar angefdyollen une entzüntet, fo tak fie oft aus iffrer natürliden Sage berwortrat uno (S)bärmutterborfall yerurjadite; batei maren bie äuperen Theile oft jo entfeglid aufge= locfert uno herworgetrieben, Das fie bödyft wiserlid auşáaben. Der Einflus tes Fieberz auf bie Sarnwerfjeuge liep fid bals in ber bod)rotben Farbe ser Sarnentleerungen wabrnebmen. Mit $\mathfrak{A}$ tönabme yon Roller (blind staggers) unb einigen anberen nur felten vorfom= menben Rranfleiten, gibt ez fein seciben bęz SPferbez, bei bem ter Pulz fo bod fteigt, nâmlid) auf fed)żzig, zumeilen fogar fiebenzig Sd)läge bie Minute.

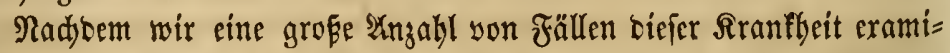
nirt unb bebandelt haben, fint wir zu oem Sd)lup gefommen, ¿á

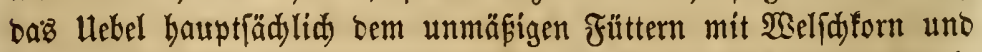
bem baraub entitebenben volnblütigen 3uftand ber Mäbre jujufdurei=

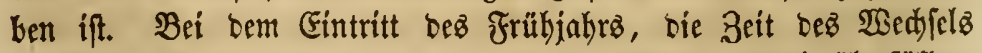
ber Şaarbede, war ber Drud bez fdweren Fohlens auf bie überfüllen

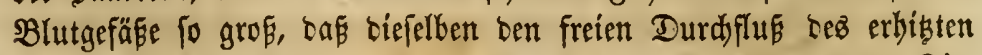
Blutes nidyt geftatteten, moraus balo ortlidje Entzünoung und Fic= ber entfant. Shne 3weifel wurbe biejes Refultat burd einen epi= 
remildyen Einflup, melder wäbreno ber okengenaunten Beitbauer berridste, bebeutent bejd)leunigt. Bor jenem Zeitraum wuste man wenig von ber Sranffeit uno nadber war fie balo faft gang yer= idmunoen. Âm bäufigften fam biefellbe im mittleren uno weftliden Theil von Tenneffee und im nöroliden Mififfippi yor; uno fo weit wir wiffen, berridte niemals eine Rranfbeit mit benjelben Eridjei= nungen in irgent einem antern Ranteztheil alz in ben genaunten

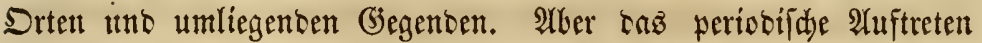
Der Sranflyeit in einer epibemifden form ift burdy fo siele That= fadjen feftgeftellt, bas es gar nidyt auffallent wäre, went bieję Ulebel in fünftigen Zeiten wieber bie ber PJerbezudyt obliegenoen (3ie= genten tes Sübens beimjuchen würte, niclleidht aber unter einem anbern als ben früber gebräud)liden Ramen "colt founder" betannt. Daher glauben wir, ba gegebene uno in vielen Fällen nit Erfolg angerwanote

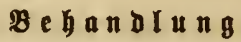

eingebeno zu befdyreiben. Wenn bie Bebanolung yolftommen ausgge= fiibut wirt, fo fann man erwarten, baf vier aus jedto ber befalfenen Thiere geheilt werben. Heberbaupt wurbe burdy- biefe Metbobe ein

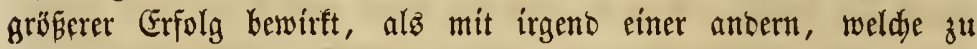
beobadyten wir (Sielegenbeit batten.

Daz a å̉gebrodjene Fieber uno bie ftarf aus̄geprägten Entzün=

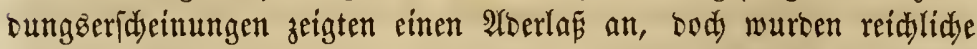
Aberläfle balo vermieben, weil fie leidt zu früber Foblen verurjadten, uno enclich muste bie Blutentziebung als bödyft gefäbrlidjes Mittel ganz unterlaffen werben.

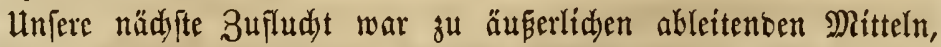
uno balo jaben wir eimen günftigen Einflus yon ber Inwentung bes corrofityen Rinimentz auf ber Renbengegens. Jene 3ujammen= jebung wirb als ableitentes saittel won feiner aucern befannten Mebiain übertroffen. In allen Fällen, bie wir nadjber bebandelten, madjten wir ftets mit bejriebigenbem (Frfolg bayon (Sebraud).

Wir lenften bann unjere $\mathfrak{X}$ ufmerffamfeit auf innere Mittel uno gaben ein leidt wirfenbes, Garntreibendes Mebifament, oa ftärfere Mebizinen feinen günftigen Einflup auzzuüben fdienen. WSir wen= Deten Folgendes an: " Fine Unze Belbwurzeln (lat. Hydrastis cana- 
densis, engl. golden seal), wurbe in einem Duart Manffre aufge= fodyt uno bann gefeift. Diejem wurken zwei grope Efelerfel yoll feines Sodjaja und cine Unze Ealpeteräthergeift jugefügt. Darauz madjen wir brei Dofen, woyon eine jecen Morgen falt eingegeben wurbe.

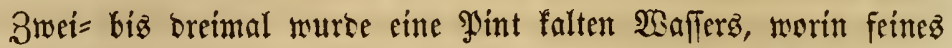
Salz uno Salpeteräthergeift enthalten waren, in bie Edyeite gegen

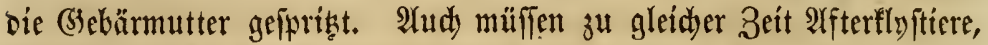
auz Ealzwajter beftebent, sorgenommen metten. Dem für bie Gese

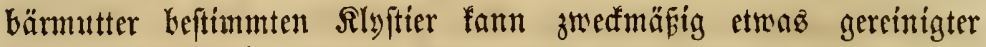
Weinftein zutgefeb̧t werben. Bei warmer Witterung folgte eine gün= ftige Wrirfung auf tas Hekergieß̧en ber Renbengegeno mit faltem Monfier.

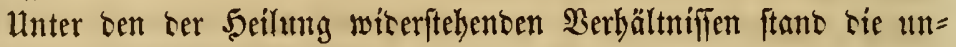
gemeine Sabwädye ter Şüften obenan. Sag eimmal bag fonnte ez nidyt wieser aufftelen, und wenn baflelke, fdon burd) cin brennentes Fieber abgezelgrt, ben fengenten Sonnenftrablen lange

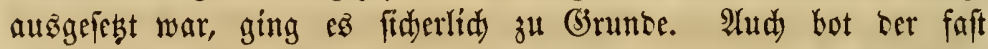

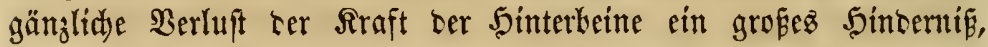
ba biefelben, je länger bag Thier auf her feudten Erre lag, immer fteifer uno hülflofer wurben. E\& war baber unerläplidy, ben Watien=

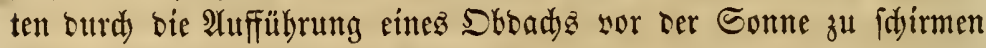
unb benjelben in ftebenbe Pofitur zul bringen, bamit er bod eini= germafen bie nothwentigen Bewegungen ber Sinterbeine sornekmen fonnte.

Yuf ten Budtharmen im mittleren Tenneffee, wo man bie yor=

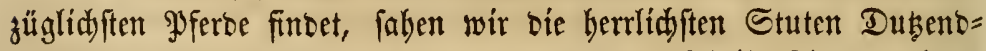
weife auf bem Grunde liegen, wo fie zum Theile fdon mebrere Wodjen lang bülfloz lagen, allen $\mathfrak{B}$ edyeln ber $\mathfrak{B}$ itterung, bem falten Regen, ben idmeibenten winten uno ber jengenten Sonme

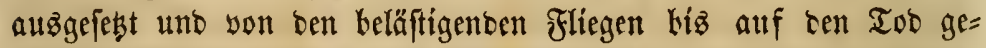

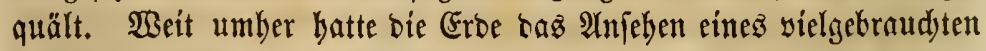

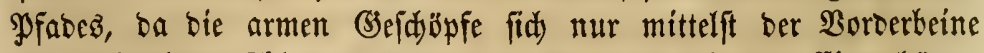
im Sreife berumidjleppen fonnten. Sft baten wir ben Eigentbümer emfitlid, etwas zur Rinterung ber Reiben ber hülflofen Thiere zat thun. Dod) nur zu häufig befamen wir von bem gwar in gering= fügigen Dingen fparfamen, aber für bebeutendere Intereffen blinben 


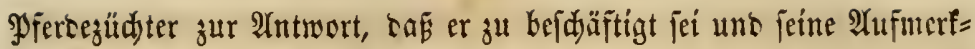
jamfeit won antern 2 ngelegentseiten zu viel beanjprutdt werte, siejen Thieren sie nöthige Behantlung angeseihen $\mathfrak{z}^{\mathfrak{u}}$ laljen, unt je cher

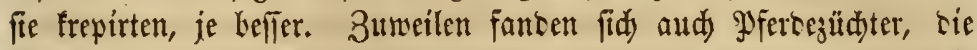
Serftanto uno (3efübl genug batten, sen armen Yatienten auj sie Beine zu belfen, unb foldye wursen oft burd) Sen erwünfdten Erfolg belohnt.

Das in jolden frällen angementete $\mathfrak{B e r f a b}$ ren ift leidyt ju ver=

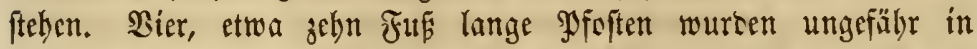
berfelken Entfernung son einanter in tem (Brunte befeftigt; auf rieje legte man Duerbalfen, weldhe sann mit Brettern betedt wursen, to

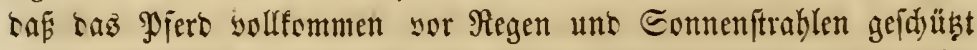
war. Die Pfoften, sie aud) mittelft Seitemitüfe miteinancer Kefcitigt wurten, eigneten fid aud jur Anbringung ser Mittel, weldje jur Ifufredterbaltung ber Mähre notbwensig warett; siefe Borridutung (sling) war im Wiejentlidjen ser im eimutrzmanjigiten Rapitel sar= geftellten gang äbnlidy. Die hierzu erforterliden Geile fann man über tie Seitenjtïfe werfen, uno entweber an bemielken ober an

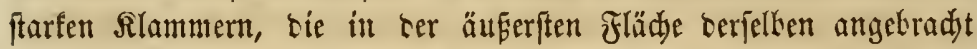
fins, bejeftigen.

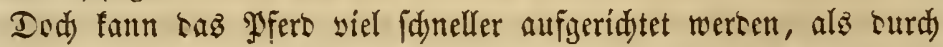

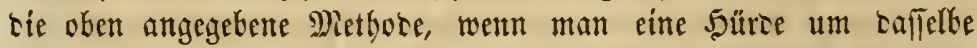
berumbaut. Daju hat man mur nebft Riegeln (rails) brei ftarfe Mlanfen uno fünf ooer fedjz gejdjifte Männer nöthig. Die glanfen follten nidyt weniget alz anterthalb 3oll bif́ uno minteftens zeln

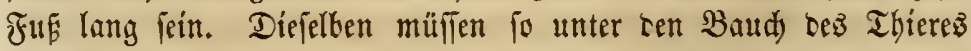
geidyoken wercen, há̈ fie auf beiren Seiten gleid) weit herworitehen.

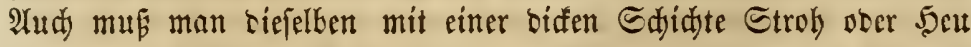
bereffen, worüber eine alte wollente Deffe ocer cin alter Teppid befeftigt wirt, bamit ber Baud wie auf einem weiden \$olfter ruben

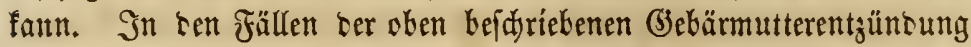

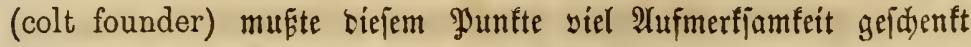
werben, ba ber $\mathfrak{B a u d}$ wutt uno äuferft empfintlid war. Sit bícz

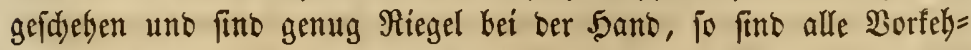
rungen getroffen. $3 \mathfrak{u}$ jeber Solanfe bat fidj ein. Mann $\mathfrak{z} \mathfrak{u}$ ftellen, einer mus bie Riegel bantbaben uno zwei fint nöthíg, um ben

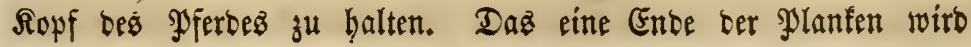


nun erbabt, bamit ein Riegel, ungefăbr ein Fuf yom Ende bet Planfe, barunter gejdoben werben fann. Sobann wiro bas andere

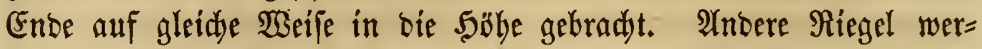
ben alżsann an ben Enben ber eriten gelegt, Samit bie Planfen surd) eine weitere Unterlage emporgerid tet werben tönnen. Rad uno nath, fo wie bie Stüroe erridutet wiro, wiro bas Pferb erboten, bis $\mathfrak{e z}$ enolid) binreidyend weit yom Boben entfernt ift. Daz Pferd fträufst fid gewöbnlidy, wenn es balb aufgeridytet ift, ba ibm eine foldye Stellung neu uno unbebaglid ift; aber bie am sopfe fteben= ben Männer baben baffebe fo ftill alz möglid fub balten, Damit bie Shürbe aufgefübrt werben farn. Die zwedmästgite 5öbe ift bie,

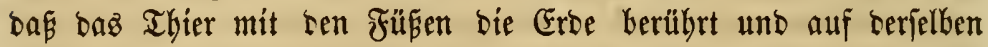
ruken fann, wenn ez will. Bor uno binter bem Pfero mup bie Sütre Gober uno febr nabe an ben Süften uno ber Bruft aufge= fübrt werben, ba jonft baffelbe auf ben Planfen bin und her wogen

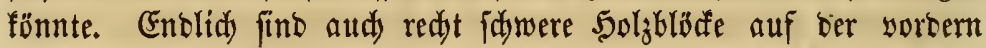
und binteren Theil ber Şürbe zu legen, um beren Feftigfeit zu fidjern, was aber bejonbers baburd) zut erreidjen ift, baj man an jeber Effe ber Şüroe einen PFabl in ben (Strund fdlägt. Dab Pferb fann man an einen yor ber Shüroe ftebenden Pfoften binben, uno mittelft einiger Planfen, weldye auf bie an biefem Enbe liegenoen Riegel gelegt werben fönnen, ift leidyt eime Rrippe anzubringen.

Der Roftenaufwand für eine foldye Borridutung wiro nidjt mebr alz zebn Dollarz betragen uno nidbt mebr Beit alz eimen Tag erfor= bern; aber abgejeben Davon, Dás biejelbe baż Reben bez Thierez retten mag, ift ibre Auffübrung bem Pferbezübuter wegen ber bakei gewommenen praftifyen Erfabrung minoeftenz fünfaig Dollars werth. Sie fann in mandberlei fällen angemanot werben, bie won ben mei= ften Farmern, weldye aud bei eimer fold' éinfachen 2 (ufgabe aus Dangel an praftifdem Taft unbetyolfen finb, fajon im Beginn alz boffnunggloz aufgegeten würoen. Bei Beinbrubden \%. B. ift man im Stante burdy eine foldye Borridytung vollfommene Sheilung zu erzielen.

Dod) geken wir auf bie Bebandlung ber (Bebärmutterentzän= bung zurüc. Nadbem bie Stute mittelft ber Sürbe binreidyeno vom (Srumbe erhibt tworben ift, muß ein gutes Sboach bergeridtet werben, uno wenn bas Foblen nody nidyt geworfen ift, fönnen bie 
für biefe Begebenheit nöthigen Borfehrungen getroffen werben. In Den meiften Fällfen fintet bie obengebadyte gänglide Sdawäde nidjt yor oem Foblen ftatt; wenn aber bie Mähre nod biz furz yor bie fem Borgang ftarf war, fo wiro am beften fein, bie Shüroe erít nady bem Foblen zu erridjten.

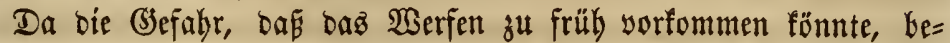
feitigt ift, fann man obne furd)t zu einem tüd)tigen \{toerlá zur Bejeitigung ber Entzünoung idjreiten. Daz Futter muk weid), mild

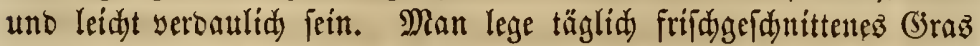
in bie Sirippe, uno gebe tüdtige Dojen yon Eduwefel uno 5ard. Wenn bas Thier an Stublveritopfung leibet und ber Mijit troffen, hart und fdywars ift, fo wirb ber Stedjapfeljamen bas zweefmääigfte Arraneimittel fein, wovon einige Dofen bas Hebel bejeitigen werben. Unter feinen Umftïnden aber barf biefes Mittel yor bem Foblen gegeben werben, ba ez bann hödjit gefährlid iff.

Befintet fid bas Pfero im Stall, fo fönnen alle oben angege= benen Mittel bort ebenjowohl angetwendet weroen.

\section{Rrantbeiten i nger ซoblen.}

Wir fönnen vielleid)t feine pallenbere Stelle finben alz biée, um gewille Sranfheiten zu betradjen, bie hin uno wieber junge Foblen befallen. Sie famen fehr bäufig yor in tent ber PJferoezudit oblie= genten (3)egenden in Tenne mutterentzünoung, nämlid son $1850-1857$, bajelbjt herridste. Zu jener Zeit waren es bauptjädylid bie gan furz yorker geworfenen Foblen, weldye erfranften, uno in ben meiften Fä̈llen endigte ber शrafall balo mit bem Tod. Die Foblen ber Maulejel blieben aber io wenig yon ber Sirantheit veridjont, als bie ber Pferbe.

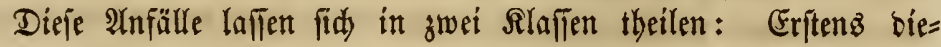
jenigen, weldye vorzugäweife in ben (Jebärmen ibren Siłb haben uno

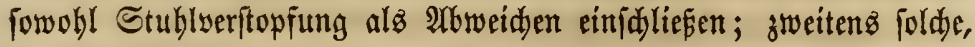
bie Kauptiädlid in Störungen ber 5arnorgane beftehen, uno fid burd) Sarnflus, 5arnvertopfung uno blutigen Urin funo gaben. 5arnverftopfung entftelyt zuweilen burd) medjanifaje Sinberniffe, wie. wir zeigen werben, wenn wir auf bie Bebandlung fommen; aberalle anteren Bejdyerben -junger Foblen entipringen irgento einem.

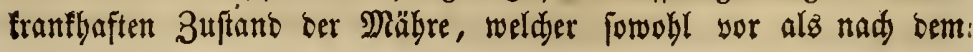


Foblen worbanden fein fann. Die Befdaffentyeit ber yom jungen Foblen yon ber Mähre erhaltenen Milda hat einen fidtlidjen Gin=

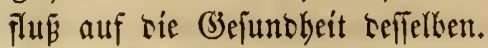

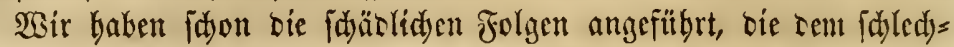
ten Selfdfforn und fdimunligem beu entipringen, bie bag Jutter

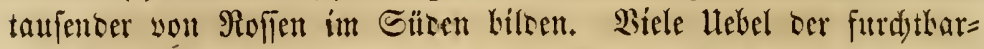

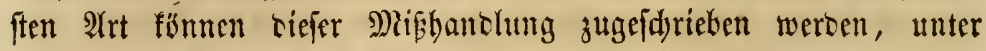
welden wir Beingefdyullfte am Ropfe, Sdymintel und Berbauungs:

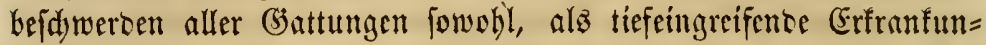

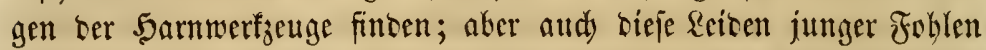
mülifen als bie Folgen einer foldyen naturwirrigen Diät betradytet werten.

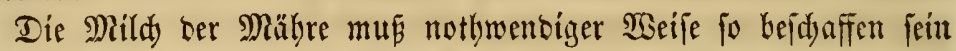
wie ons Futter, woraus fie gemounen wirb. Darauz folgt aber

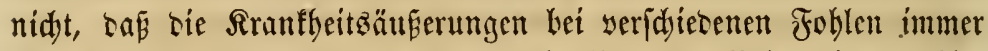

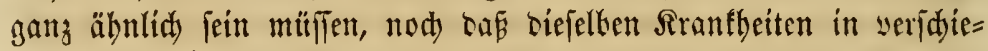
benen Thicren gleid) beftig. vorberriden. Diefge alz bie allgemeine Regel, ba

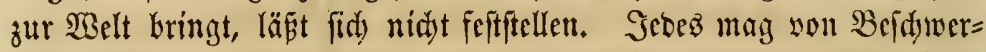
ben befallen werben, wowon beim altern feine Symptome fid zcigen.

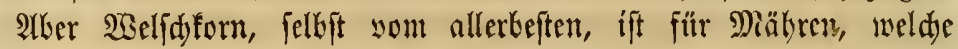

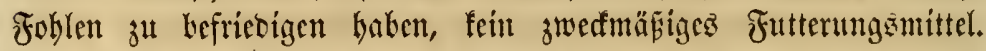
Bei weitem zul fräftíg uno erbizeno ift bic taraแв gemonnene Mild nidyt ben Beoürfnifien dez jungen Foblen entipredjent. Die Miăbre mag zwar unleejaadet baffelbe freffen, aber balo zeigt fid beim Foblen bartnäafige Stuflwerftopfung ober anoerweitige Bejdjwerden. Soldje Uebel fümen gar nidyt zum Boridein, wenn bie Mähre mit jwed"=

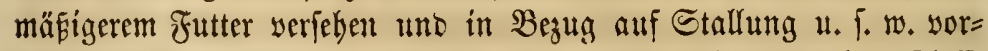

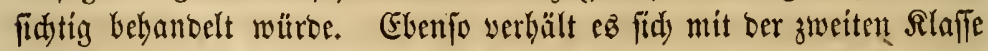
von Siranfleiten. Shgleidy bie Sarnorgane ser Stute in einige lun= oronung gerathen fönnen, fo ift bod ibre Rörperfraft zulänglidil, ge= gen bieje jääbliden Einflüffe anzufümpfen; Das weidlide Foblen unterliegt aber uno balo nimmt man wabr, tá ez ernftlid) erfinuft ift uno beftig leitet. 5arnröhrenverengerung, 5arnserftupfung, 5 arn= fluk und Sarnbluten mögen bie Folgen ber yon ber Maăhe erfabrnen faledten Behandlung fein. 


\section{Bย}

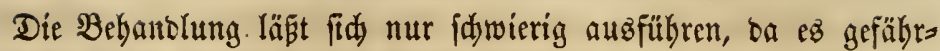
lid) ift, bem jungen Fohlen Mebizin ju geben; nidjt felten wutrbe baffelbe bebenflid) befdärigt, zuweilen fogar auf ber Stelle getöotet ourdy unvorfidjtiges Ginjwingen yon $\mathfrak{A} r_{3}$ meimitteln. Man follte allein ourd bie Mildy oer Maähre auf saż Fohlen einģwirfen fuchen uno leb̧terez nötbigenfallz nur mit Rlyftieren behanbeln. Bei Entylver= ftopfung bez Foblens wirft bie ter Däbre eingegebene Plrznei bei= nabe fo idnell auf ben jungen Patienten als auf tefien Plutter. Dod) faun man in bisfem Fall ein Slyftier, aus redyt warmem Galjwaffer bejtebento, bem etwas âloe jugefügt merten Larf, zwedoienlid) an= wenten; ftatt biejen Mitteln läp̈t fid) Las immer leid)t zu bejdaf= fence warme Seifenwajter benuben.

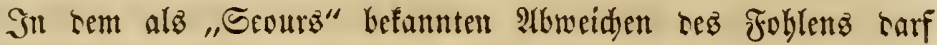
man weber ber Mäbre, um surdy seren Mildy ju wirfen, nod) tem Foblen jelbjt viel zujammenziebente Argnei geben. Der gelino wir= fence $\mathfrak{A}$ ufguf von Brombeerenwurgel wiro jecody ber Mäbre nidat fdaben. 3um Ilyjtier für Бaz Foblen löfe man eine Biertelunje Bitterfalz in $\mathfrak{B a f f e r}$ auf uno füge fünfjig Tropfen \&aubanum hinzu;

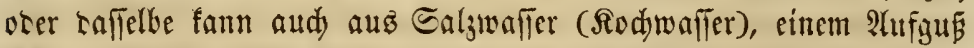

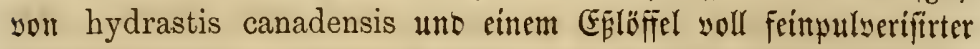
Soljtolle beftehen. Wirt rem Fohlen eine jujammenjiehente Deotzin eingegeben, jo mú man aud) ein gelino wirfentes Raximittel cagu ju thun, wenn nidjt Stublverftopfung mit Fieber entfteben foll.

Ev leidt laflen fid bie Beidowerten ber Sarmwerfzettge nidyt beilen. Sm Fall eine 5arnverftopfung fid eingeftellt bat, fo mü cine redt genaue Unterfudung sorgenommen merben, um auşufin=

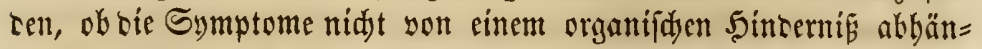

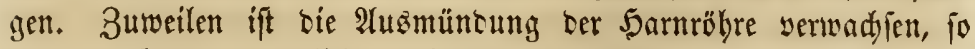

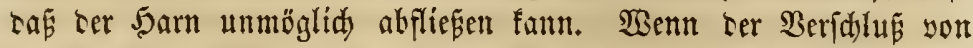
cinem grintigen Hebergug abbängt, fo wiro augenblialidje Rin= berung auf cine yorgenommene tüdtige $\mathfrak{B a j d u n g ~ f o l g e n . ~ S o l l t e ~}$ aber im (S)gentbeil เaz Uebel burd eine hautäbnlidye Bermadjung oer Sarnröbrenöfrnung erjeugt fein, fo fann man nur ourd cinen

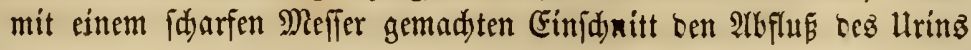
bez̧weden. Durd) Entzünoung entfantene Blafenbalozverengerung, die zuweilen aud) beim Joblen Urjade ber Samverfopfung ift, fann am 
Berlaufe Der Rranflyeit erfannt werben; aber antere Fefler, fowie Rierenfranflgeiten, laffen fidy nidyt näber beftimmen. Die Blajen=

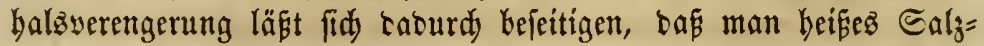
waffer äuẼerlidy um bie betroffenen Theile anmentet und in ben Maft= Darm einjpribt; man verfäume aber nidyt, täglid) ter Etute eine balbe Unje Ealpeterüthergeift in warmem Waffer einzugeken.

TSenn fid ber Sarn keim Foblen blutig jeigt, io entigt in ber Regel bie Rranffyeit wegen ber begleitenton Entzüntung uno sem allgemeinen Fieber mit rem Tor. Wajdungen nit Ealyadfer fint nüblidy; ebenio foltren Rlyftiere, aber mit faltem Salzwafler, sor= genommen werben; ter Etute ift ber Ealpeteräthergeift täglidi ju geben.

Vielleidjt fünnten diefe Beidmerten keteuteno gemilltert ater ganz werhinbert werben, wemt eine zwedmä̈fige Diät für tie Ctute vor bem $\mathfrak{W e r f e n}$ und fo lange nadjher, hiz baz Foblen entwöbnt ift,

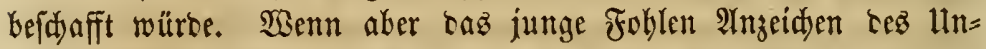

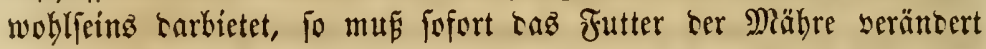
werben. Stelly fid Stublwerftopfung ein, fo ift eröffnentes Futter, 3. B. Rleie, yorzuggiveife Roggenfleie, ster nod) beffer grünez, mei=

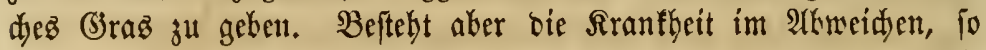
muf die Diät auz leidftem $\mathfrak{5 c u}$ uno reinem 5 afer beftehen. Dí

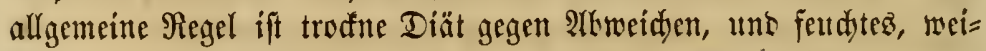
des Foutter gegen Etublserftopfung. Sn beicen Rranfbeiten follte ter Mähre fo viel Sdymefel uno Şarz sorgefebt werten, als fie nur im= mer frefien will. 5̧at cas foblen blutigen 5 arn mit Fieber, fo mus ein 2Toerlás an ber Mäbre yorgenommen werten, was eben fo ftarf

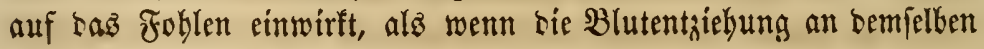
yorgenommen worben wäre. 


\section{马innfyefintes diapitel.}

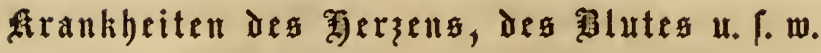

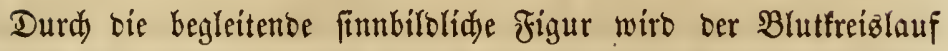
tem 2 luge bargejtellt, wie er ber 5auptiad)e nady bei bem Menidjen uno sen böheren Ifiergattungen yor fid geht. Sm obern Theile fieft man oen fleinen $\Re r e i z=$ $\mathfrak{l a}_{\mathfrak{a}}$ f ober bie Rungenblutbahn, unten ben gro=

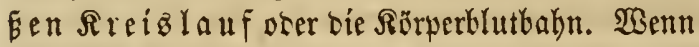

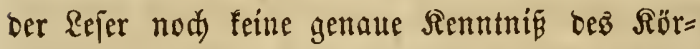
perbaues bat, io wiro es ifhm fowohl nüblíd)

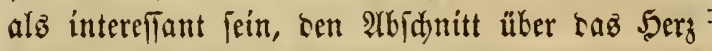
uno die Blutgefä̧⿻ im zweiten Siapitel in Ber= binoung mit biejer Figur red)t forgfältig ourd)ju= lejen. Daburd fann er fid bie widtigiten Rebren über ben $\mathfrak{R} a u f$ beż Błutez im Rörper leidyt inz

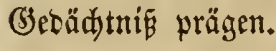

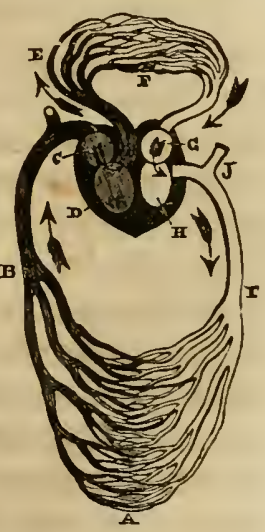

Entıurfamähige Darftellung des Glutkrriglaufs.

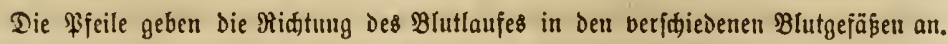
Diejenigen (Bejäse, welde Gellrotbes Blıt fübren, find weis; Die andern idjwargídjat. tirten enthalten oululles $\mathfrak{B}$ lut.

A. Die sanptgefäße, welde als fein verbreilete शekse in allen förpertleilen Die

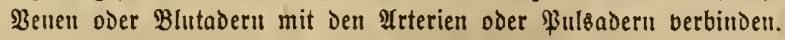

B. Eine Der Sুoblabern, Deren es zrei giebt, die Das onnfle Blut aus allen Dr.

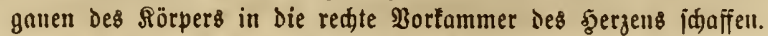

C. Die redte Bortammer, von weldyer bas Blut in die redte \$gergfanmer flieśt.

D. Die recte \$ुergtammer, weldje das duntle Blut in Die \&ungenpulsader treibt.

$E$. Die Rungenpulsader, von Der Das nod immer ungereinigte Duntle Blut in bie Rungell geidafft roirb.

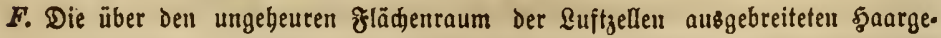
füpnege der Rungen. In diefen äuperft feinen ßeralveigungett wirb bas 
Blut gereinigt, meldjes in Der 2 bgabe Der Roblen[äure uno Ŝfuftume des Sauritoffes bejteht, wodurd daffelbe aus einem dunflen in ein beflrothes

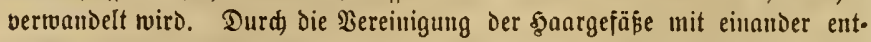
iteben Die $\mathfrak{R}$ ungenblutadern, movon eine auf Der redten Ceite Der Figur innerhalb Des oberen Pfeiles Dargeftellt, aber nicjt Durd, einen Buchitabent näber bezeidunet ift.

G. Die linte Rorfammer des Sgergens, meldye Das in Den \&ungen gereinigte uno Durd die Sungenblutadern jugefïbrte Blut erbält uno in die linte f̧ergfam. mer idafift.

H. Die linfe şergfammer, weldhe das bellrotbe Blut mitteljt fräjtiger 3ujummen.

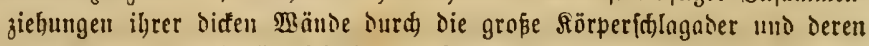
Bergmeigungen nach allen Theilen des $\mathfrak{R}$ röpers treibt.

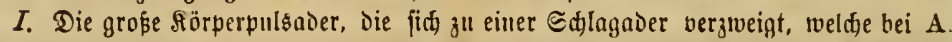

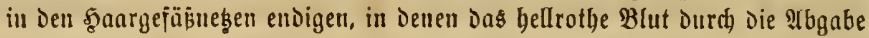

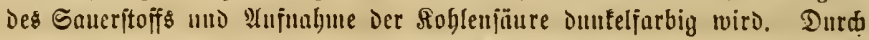
Den mit I. bezeidunten Thei! Der groß̈en S̈̈rperpulsaber wiro Der Interleib utio Die bintern (Sliesmajen mit $B$ Int verfegen.

J. Die vordere Albtheilung Der grosen Rörperpulsaber, welde bellrothes, reines

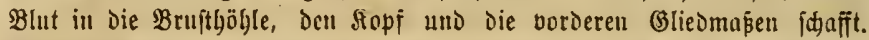

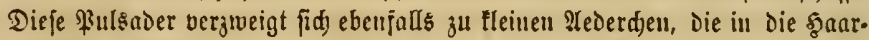
geräpe übergebeu.

\section{ger f $\mathrm{x}$ a the ite}

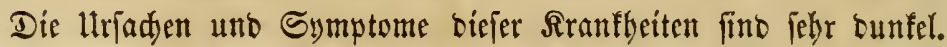

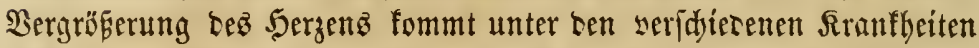
tiefes ऽrganz am häufigften sor. Bor mehreren Sabren bercidjerte Derr Tlompion son Bath; Englant, tie Thieraraneifunte surd cine

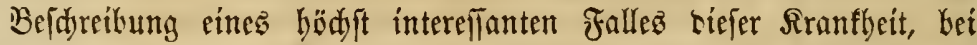
weldem baz $\mathfrak{T e r}_{3}$ in eine grofé zerrüttete, treiuntwier gente Marle verwantelt war. Sn biefem sante fint ähnlide fälle beridytet worben; aber bisher hat man wenig ober nidutz yon ben Uriaden, bem Berlauf uno ber Ratur ber Rranflyeit gemūt. (5)=

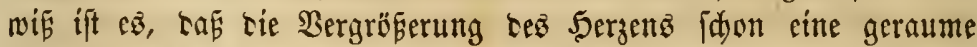
Beit yor fidh geft, ehe baz Reben baburd gefähroet wirb; bie Rrant= beit läfit fid jerod nidyt wäbrento bes Rethenz erfennen. WSenn die

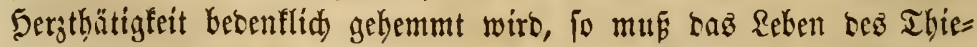

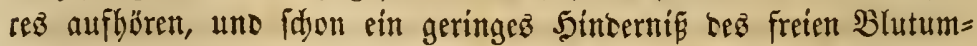
laufs verurjadjt beftige Beidjerten. Faft in allen fällen, in tenen

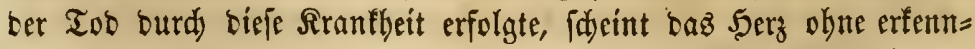

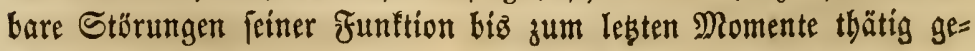
wejen zu jein. 


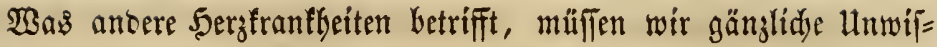
fenbeit zugeteben. Unter humberten von \$fercen, weldye wir zerglie= bert uno eraminirt baken, entôeften wir niemals bie Spuren irgeno

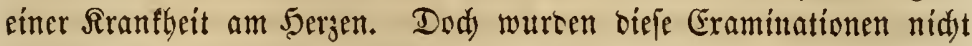
yorgenommen, um ten 3uftand sez 5 crojenz fritifa zu unterfudjen,

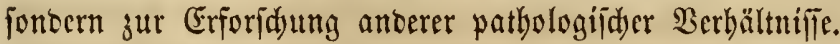

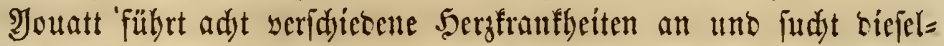
ben burd eigentbümlide Symptome yon cinntoer zu unterldeiben. In feinen Bejdreibungen fönnen wir jecodi feitte wejentlidjen $\mathfrak{B} e r=$

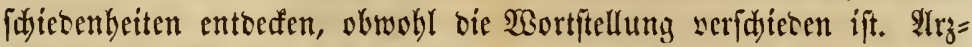
neimittel zur Seilung serjelten giekt er nidot an: Unter ten aner= fannten 2 Atoren uber Thierargneifunbe finten wir wenige, sic nur

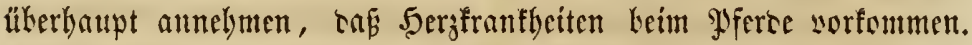

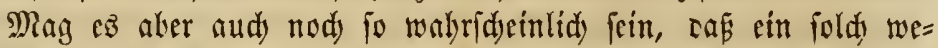
Fentlides Drgan, wie bas J్brz, mandyen franthaften Etörungen un= terworfen ift, fo wiro sem Farmer nid)ta burd) cine meitläufige $\mathfrak{B} e=$

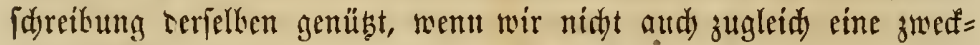

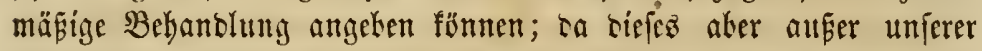
Maddt liegt, wollen wir biejen Giegenftant biermit keenten.

\section{Da Po de n (thumps).}

Diefe Sranffyeit, cie nidyt im 5 erajen, fontern in ber naheliegencen

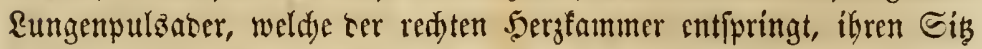

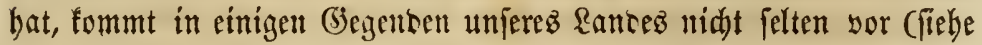
$\mathrm{E}$ auf oer sorbergehenten Figur). Sie befteft in ciner enorpeligen

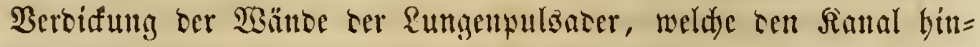
reidjeno beeinträdtigt, um sen freien Durd)tritt

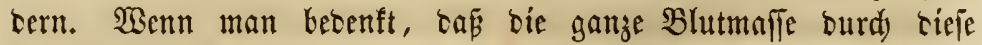
grofe \&ungenfajlagader von ber redyten 5erzfammer in bie \&ungen getrieben wirt, $\mathfrak{u m}$ bajelbft gereinigt uno verbefiert zu werten, io ift

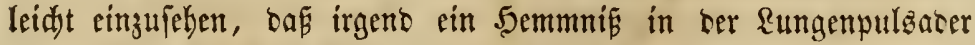
grope Störntng im Blutlauf uno im 5 ergen verurjadjen mußs.

BBie alle 2 toern, hat bie Rungenpulzaber brei Sautlagen in ifren Wänden, wovon bie äußere auz Binde= und elaftifitem Bestrebe, bie mittlere auz queren Muşfelfajern und bie innere auz Dberbautgemebe beftebt. Die Waänoe fino baber febr elaftija uno bieg= fam unt errweitern fid mebr ober weniger bei jebem \$olsidalag, wenn 
fie volfommen gefund fint. Buweilen wereen bie Sautlagen buras tranflyafte Störungen feft mít einanter yereinigt, verbiatt unb ser= bärtet, woburdy ber freie Blutlauf etwas gehemmt roirb. Serody beobaditet man bierson in ber Regel feine auffallenten Störungen im

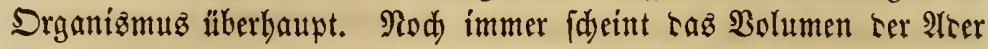

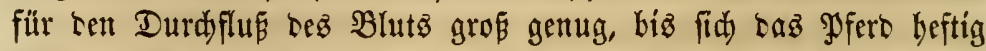
anftrengt ober ftarf aufgeregt wirt; Dann ftrömt baz Blut burd

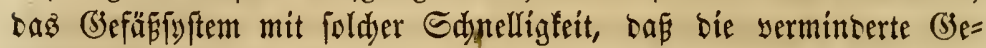

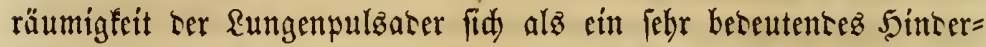
ni

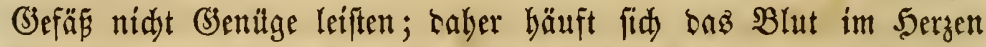
an uno reizt baffelbe zu nod größ̈erer Thätigfeit, um baz Shinter=

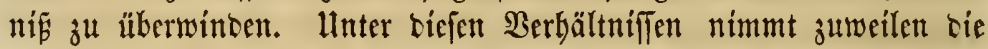

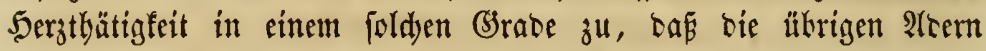
ftarf Geeinfluft werben, uno bie inneren Gingeweire überbaupt fräftig

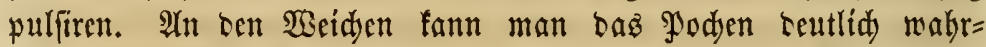
nebmen, baber aud sie unter sen Raien gebräudlidje Bezeidunung

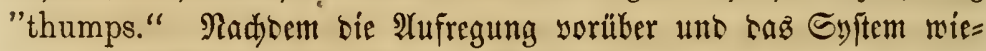
ber rubig geworben ift, bört bas

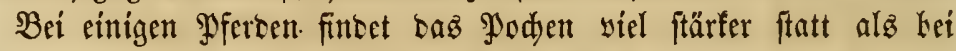
antern, wabrideinlid, weil in jolden Fällen sie Berengerung ter Rungenpulsater bebeutenter ift. Shin unt wieter gebt fogar saz Pfero an biefer Rranflfeit ju Grunte. Daz Serz leibet heftig, tenn

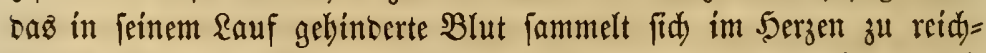
(id) an unb erregt beftige 3u[ammensiebungen, wosurd mit ber Zeit

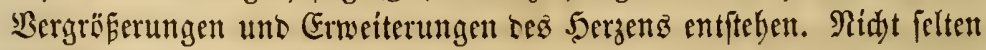

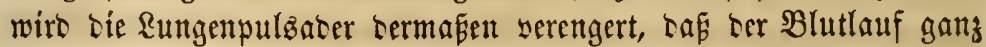
auflört uno bas Thier ploblid tost jur Erre fällt.

Einft fubren wir mit einer yor einem $B$ uggy gefpannten fetten Mäbre auf ber Chaulfee yon \$gulaźa nad) Columbia, Tenneffec.

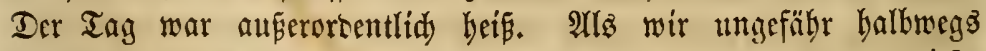
gefahren hatten, wurte baz Thier yon einem beftigen 2 tnfall riefer

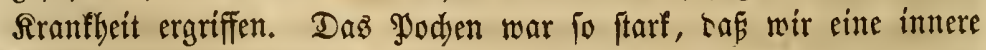
Beidäbigung befürdteten. Wir waren gezwungen, nidjt.nur tms aufzuhalten uno auszuruhen, jonbern pogar bas Thier auşzupannen,

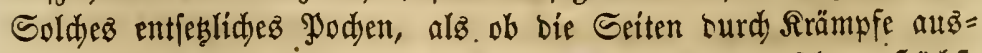

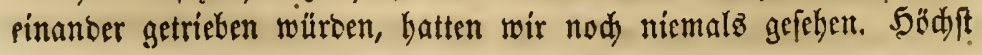


wabridheinlidy Gätten wir ten ganzen Tag bajelbit jutringen müfTen, wenn nidyt ber Zufall baz einfadje, aber erfolgreidje Mittel, weldjes

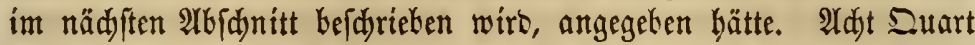
Waffer aus einer nabeliegenten Duelle, teren eż it siejer att $\mathfrak{\text { alt }}=$ fteinen reidjen (begent im Ueberfluffe gibt, in weldyes wir eime Sant yoll Sal' warfen, wurben bem Pferbe gegeben unt yon bemfelben gierig veridylungen. Nad Berlauf son oreifig Minuten war woll= fommene Rube eingetreten, uno wir gingen froben Mutbes langjam unjern $\mathfrak{i e g}$ weiter.

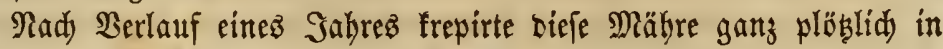
Folge bes franthaften 3 uftantes ber \&ungenpulsater. Sebr beftige Anfälle tes Podjenz batten fid) idon feit mebreren Sabren bäufig wieterbolt.

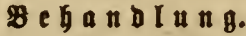

Man barf nidyt hoffen, biefe Sranflyeit grünblid) zu furiren, benn

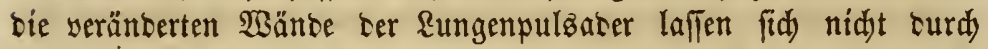

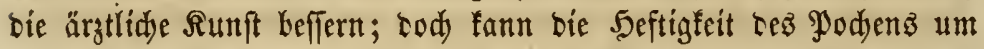
vielez gelinsert werten. Durd) einen tüdtigen 2(serlas tritt pogleid) fidjtlide Befferung ein, ba berfelbe ben Blutlauf um vielez vermin= bert; jecod) ift von biejem Mittel nur in ben allerbeftigiten 2 nfäullen (Sebraudy zu mad)en. Wenn ansere Seilmetboden nidjt genügt ba=

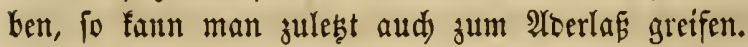

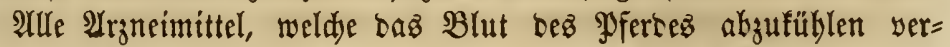

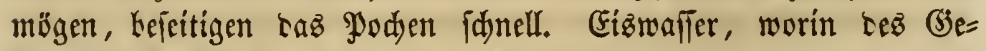
14mates balber, fowie einem Rolifanfall yorzubeugen, etwas Rod)= fals aufgelöft worten ift, idafft idyon nad einigen Minuten Rinbe= rung. Dies wirb alsె bas befte uno fiderfte Mittel anempfoblen.

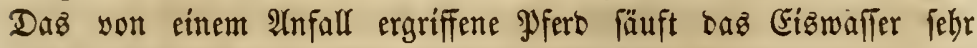
gierig, felkft wenn $e B$ ftarf verjalgen ift. Wenn ez aud nod fo biel fäuft, fann fein Shaben baburd entfeben. Sollte Daz Fiz= waffer nidyt zu baben fein, fo wirb redjt faltez Duellwaffer ober anberes füblez $\mathfrak{B a f f e r ~ b i e ~ B e i d w e r b e n ~ e b e n ~ f o w o h l ~ b e f e i t i g e n . ~ D a s ~}$ Poden läft jebody in ber Regel nad) furzer Zeit nady, uno wenn man เą̧ Pferb im Sdjatten aużruben läbt, fogar oft fdon nad) einer ober zwei Stunben.

Sdwefelfaurez Rupfer in Branntwein aufgeloft, ideint cinen 


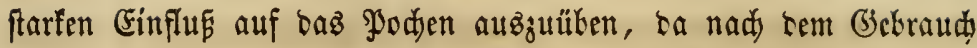
befferten nicht nur ber befitehente 2 mfall auffallento idjnell aufbärte, conbern aud) längere Zeit hinturd) fid feime neuen 2 Tnfälle jrigten.

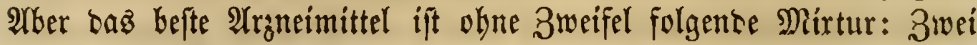

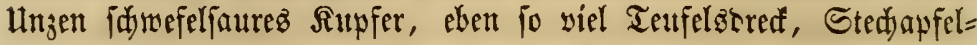
jamen (Jimson seed) beşgleidjen; nad)em bieje Artifel fein verftónen worben fint, müffen fie in eine Pint guten Branntweins gethan wer= ธen. Daraus fino jedjz Dofen zu madyen, woyon man täglidy sine in einer Pint warmen $\mathfrak{S a}$ aाter eingibt.

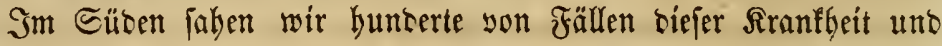
batten aud oft (Jelegenkeit biejelbe ju behanteln. Wir nahmen

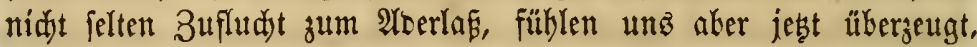

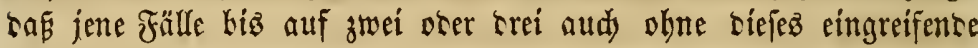
Mittel fid gebej]ert bätten.

\section{ธีtopeIn.}

Beyor wir bie Urjadjen unt Erideinungen bes allgemeinen Fie= berz voer ber Blutentzüntung näher unterjudjen, wollen wir sie

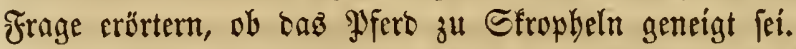

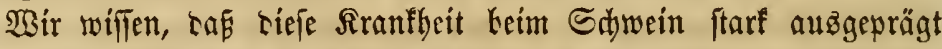
ift. Man fintet tie Merfmale teriellben in ter Reber, ben sungen, oer Baudjpeidjelorïfe, bem Zwerdfell, sem (berärme uno bent \&un=

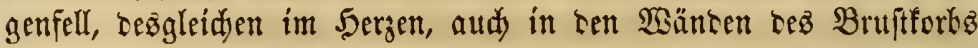

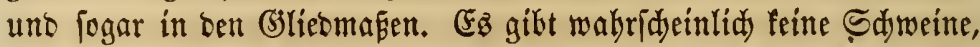

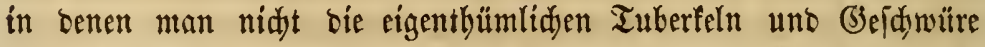
tiejez Reitens fintet. Beim Rinte fommt bieje Srantheit aud vor, ood) weit feltener. Shin uno wieber fintet man $\mathfrak{T} u b e r f e l n$ in ter Reber uno ben Rungen ser Ruh. Sdjafe fint bäufiger ffrophuläz

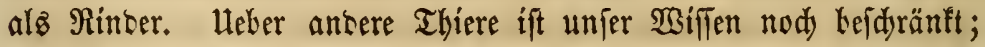

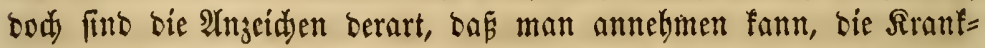

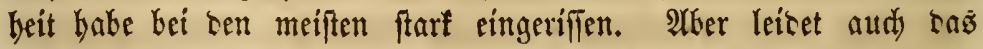

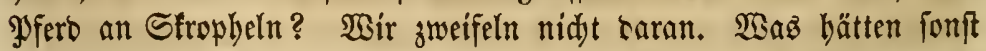

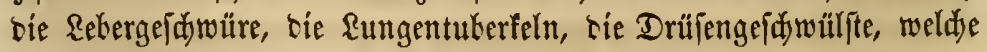
man ziemlid oft bei ber Section fiebt, zu bereuten?

Bei bem Sajweine, Sdjafe, Rinte uno Yyerbe baben $\mathfrak{I} u b e r f e l n$

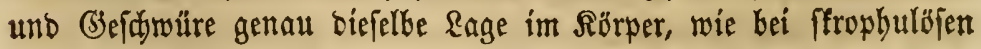

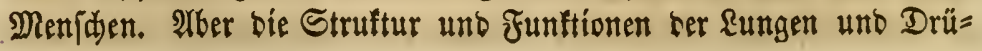


jen ift bei allen aud biefelte, obmogl fie ber form nad son ein= anter abweidjen. Die ffrophulöjen Rrantheiten idjeinen bei allen

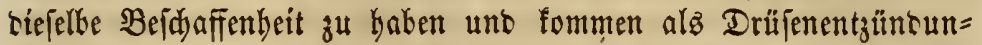

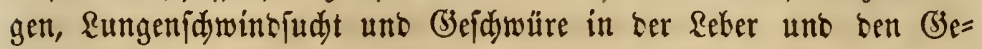
tärmen yor.

"Denn ez geft bem Menjđen, wie tem $\mathfrak{B i e h}$; wie biez ftirbt, fo "tirbt er aud); und haben alle eiturlei Drem." நat bieje Stelle

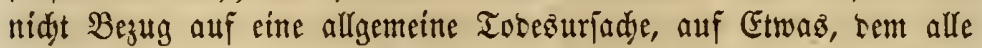
thierijd)en Rörper ohne Hnterfdied unterworfen fint, anftatt auf bie

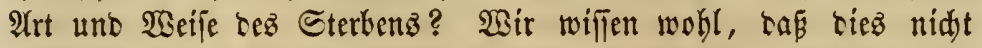

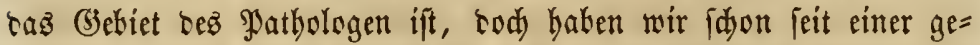
raumen Zeit bie Meinung gefabt, bas ber alz Stropheln bejeidynete 3uftano im ganzen Thierreid) angetroffen wirt, wo er fid wie ein (3)ift allmälig verbreitet, sie (bejuntheit zeritört unt oft ten Tob serurjadyt. SBir glauben bei bem \$yferbe eine ftarfe Reigung zu Stropheln gefunten ju haben; baher aud bie Erfolge einer altera=

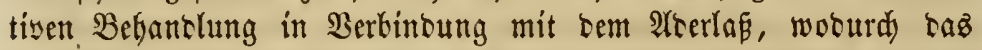
im Bilut enthaltene feine (sift neutralifirt uno unidjäblid gemadjt,

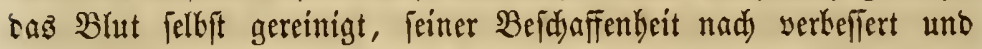
zum Innterhalte einez gejunten uno thätigen Sebenz geeignteter ge= madt wiro.

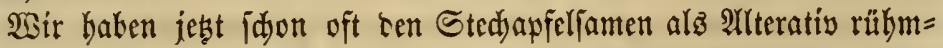
lidjit genannt uno wollen bier wieterholen, daß fein anterez bem Ibierarz̆te ju (3ebote ftehentes Mittel im Etante ift, foldje günjtige

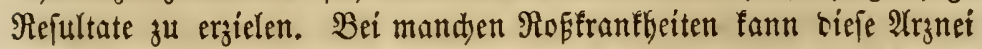
nidjt eriegt werben, bejonterz wenn tiejelten yon einer frantflaften

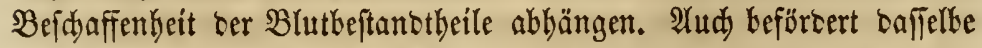

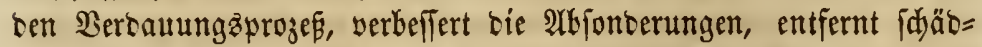
lidje Etoffe yon berjelleen uno wirft alż ftärfenteż Mittel auf bie

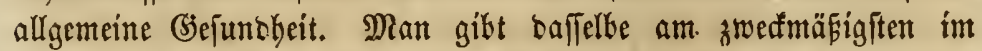
Jutter, womit alle zwei Tage ein Efflöffel voll ober eine balbe Unge yermifidt wirb.

\section{fieber.}

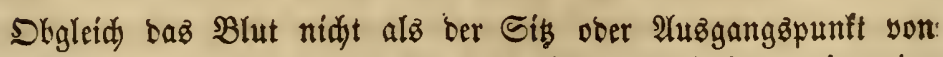
Siranflyeiten angejeben werben barf, to gibt ez bod faum eine ein= sige Ropfrantheit, bei ber baffelbe nidjt meht ober minter beeinfluft 
wiro. Den Sranflyeitsftoff trägt $\mathfrak{E g}$ zuerft nur in fid, uno theilt ibn cann allen Rörpertbeilen mit.

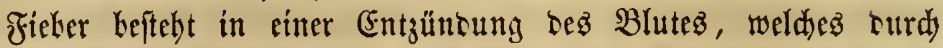
cimen örtlidsen ober allgemeinen Reiz überhist worben ift. Irgenb cin Rörpertbeil wirb gejdyitten, yeritaudyt oder auf anbere Irt lie=

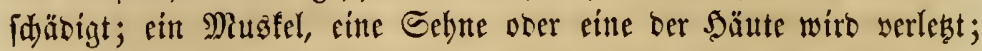
ein Snodyen wirb gebrodyen ober ein Nery zerriffen; Der Sibrper ge= räth ourd) lange Finmirfung oer Rälte in Unoronung; auf irgetto eine $\mathfrak{W}$ sife ift ein ober oer anbere Rörpertheil ftarf verlest morben,

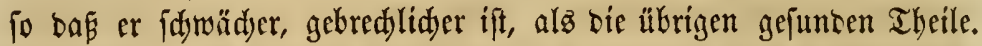
Das Reiben bes Ibeíles vermebrt fid uno wirb idmerbafter; Rei=

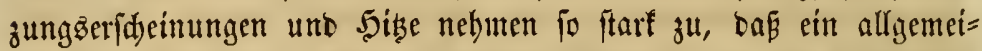
neg Fieber entftebt. In ber äuferen Ratur ift bie J̦ibe gewöbnlid Das Probuft Der Berbrennung oter Reibung. Die Wärme Deż thierifdyen Rörpers entfebt auf eine ähnliche Weife, bod um vieles langjamer als in ber Berbrennung, obgleidy ber Borgang wejentlidy Derfelbe ift. Fieber fommt Daburdy zu Stante, Dap ber Wiäme cr=

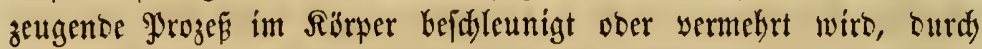

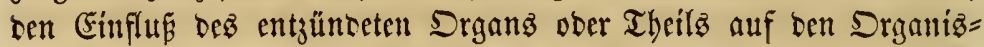

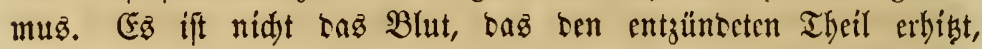

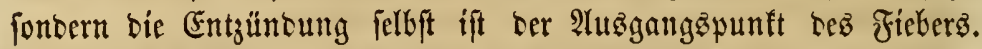

Unter ben im erften Rapitel niebergelegten Srunofäben, weld)e

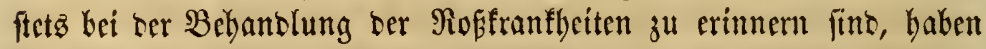
wir gefagt, baf fowohl bei bem Menjdyen, alş bei bem Thiere bei= nabe alle Bejdwerben, was auds immer ibre erfte Urjadye gewefen fein mag, son Sinberniffen ober llnortnungen bes Blutlaufis, soer

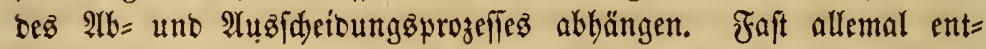
fteken foldye Şinberniffe bez Blutlaufa burd) äupere ober innere Berleb̧ungen. Diefe mögen eine fleine umfdriebene Stelle betreffen ober weit verbreitet jein; aber wenn fie ben freien Blutlauf becin= trädtigen, fo entfteht immer Sibe im betroffenen Ibeil, uno über= baupt Fieber im Drganisimuš.

Die Sdjulter wirs verrenft ober verftaudt, worauf nad einigen Stunoen (sefdroulft unb grofe Şike folgt. Wober biefe Sizge? Sewip nidyt vom Blute. Wäre bie Sdyulter nidyt befdübigt wor= sen, fo würbe baz Blut feinen Rauf fortgejebst baben, ohne irgento eine ungewöbnlide Erfdeinung fu bieten. Äber obne Zweifel ent= 
fitebt bie auferorbentlidye Şike surd) baz bem Blutumlauf entgegen= gejeşte Simbernif. Einige Blutgefäfe uno viele Jaargeräfse fino yerlegt ober fogar zerrifjen worten; uno ergiefen jest ifren Jnbalt in bie umgebenden (3ewebe. Dacurd) entftebt eine Anbäufung, weldye tie freie Blut=Cirfulation binbert.

Frägt Jemant aber, waz Lie Sike verurfadyt? fo antworten wir: bas idnellere Bonftattengeben bes Stoffwed) felz int verlebsten Theile. Die weiden Drgane, die Musfeln, Sebnen, Blutgefäве 4. F. w. fino verftaudyt; in Folge Deffen fliefst mehr Blut in die Icioenoen Theile alz früber, folglid mebr Sauerftoff; ourd befjen Berbintung mit anteren Etoffen die Wärme im Rörper fowobl, als bei ber Berbrennung in ber äuferen Ratur ergeugt woirb. Biel= leidyt ift aud ein Theil oer erböhten Wärme tes leibenten Srganz

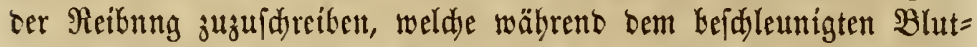

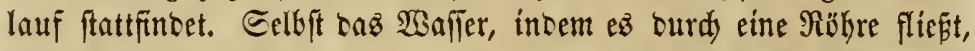
rie mit vielen $\mathfrak{B}$ infeln werjeken ift, erseugt Durd bie Reibung einen merflidjen (3rab särme. Unter ben gebadjten Berbältniffen finten wir im thierifdyen Rürper nidbt nur ganz äbnlidje Zuftänbe, afer aud) eine erböbte Thätigfeit ser mít bem Blutlauf serbunbenen Musfeln, um rie 5inserniffe zu üterwinben, uno befanntlid wiro ourd) Mußfelthätigfeit immer \$särme entroidelt.

Sönnte man ben B!utlauf entweber auf einige Beit aufbeben ober gang in feinem natïrlidyen Gang balten, fo bürfte wobl etmaz Sdmerz sorhanben fein, rod) feine vermebrte $:$ Bärme. Wiro aber unnatür=

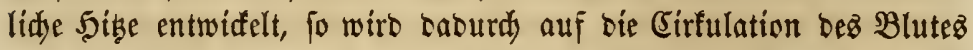
uno bie $\mathfrak{A b}$ fonberungen ber anliegenten Theile ein Ginflup aubige. übt, ber bem som trennenben Dodyt auf bas Del in ter Rampe autz= geübten ganz äbnlid ift; senn nad) bemielben phnfilden (Geleb, wor= nad) Das Del ber Rampe rem brennenden Dodt fufliefst, frömen aud) bas Blut uno bie wälferigen abjonterungen bem leíbenden überbibten Theile zu; uno eben fo, wie bie Flamme fid allen $u m=$ gebenden brennbaren Stoffen mittheilt, wenn man biez nidjt verbin=

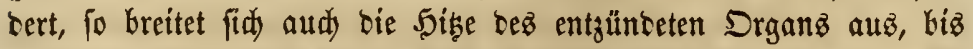
oer gange Drganizmuz yon fieberifjer Jike burdiorungen ift. Foz ift fem Brennen yon bürrem 5̧olz äbnlid - zuerft getwabrt man nur ein flämmdyen, bas wenig Şize erzeugt, aber wie balb if ber

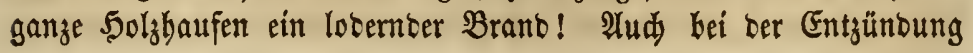


im Siörper mögen wir einen fleinen 2 Ynfang, ein wenig Siţ̨e im Getroffenen Theile finten, aber fandll theilt fid bas Fiteber bem gan= zen Srganiżmuz mít.

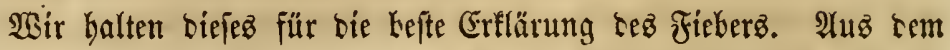
Blute entwidelt fid bie $\mathfrak{B a ̈ r m e ~ n i d j t , ~ b a l i e l b e ~ i f t ~ a b e r ~ b e r ~ T r a ̈ g e r ~}$ ธer $\mathfrak{S a ̈ r m e ~ y o n ~ b e r ~ e n t j u ̈ n b e t e n ~ S t e l l e ~ z u ~ a l l e n ~ a n b e r n ~ \Re o ̈ r p e r t h e i l e n , ~}$ surd) weldye tą $\mathfrak{B l u t}$ frrömt.

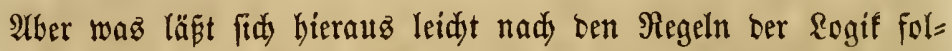

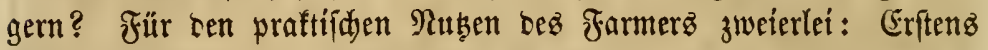

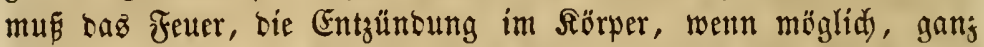
verbütet werben; biefelbe barf gar feinen 5alt gewinnen uno ธa's

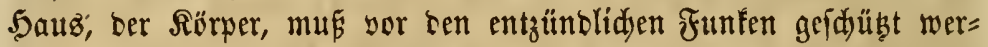
ben. Man fudbe alle urjadien, woourd Entzüntung uno Fister entfteben tönnten, vorfidttig zu verhintern. Daz alte befannte Sprid = wort: "Borjorge verbütet Radjorge," follte in biefer Sinficht ftetz beadtet werben. Benn man eitter אranffeit yorbeugt, Graudst man ihy nidjt mit Befürdftungen entgegen zut fehen. In biejer Bejiehung baben umere Farmer nod) Mandezz zu lernen. Sie follten biefen (Segenftano mit ber grëpten Borfidt unterjuden. Durd eine genaue

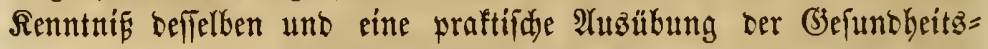
regeln würbe ber Farmer mandiez Thier retten, meldjez jebt zu (5runte geht.

Rönnte man biejenigen, weldye sie $\mathfrak{A}$ uffidyt über Pferte haben, überzeugen, baf wenigftenz brei Biertel ser Beidjwerten, Lenen jeşt

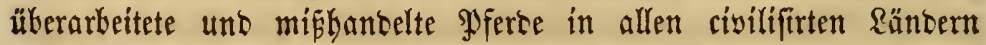

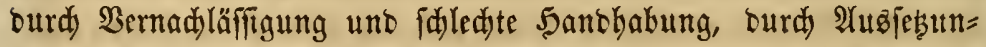
gen und Entbehrungen anbeimfallen, verbintert merben fönten, fo

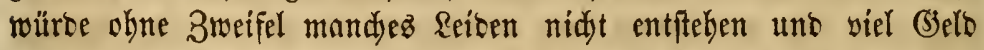
gefpart werben. Unjere Farmer follten lejen uno senfen, follten ibren (beift bilton und benfelten mit ben yon ber 2 siffenidhaft ge=

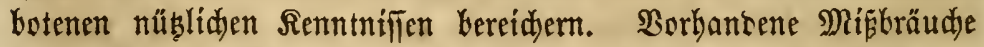
follten fie abidjaffen uno bie Unwiffenden belebren; felbjt menn fie bem Etubium ber Wifienidaften einen Theil ihrer Zeit wirmeten, fusnnte ez ifhen nur zum Bortheil gereiden. Shre AYufmerffamfeit follte aber hauptjädlid auf bie befte Methore ber Bebandlung bez Ihieres geriddet merben unt bezüglid berfeften follten bie yon ber 


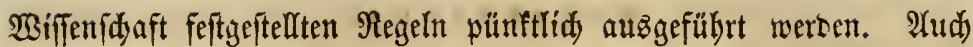
auf bie (3ejuntheitsiregeln harf biel Zeit verwentet werten unt alles, maz bie (S) funcheit uno bie Bebantlung bes treuen Thicres betrift, mup felbjt in fleinlidjen Dingen nad) biejen $\Re$ egeln geleitet werben. Wenn alle Farmer biefem (3egenftante die gebülyrente Aufuerffam=

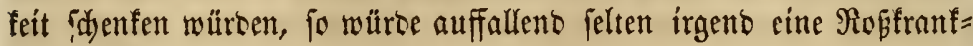
beit vorfonmen.

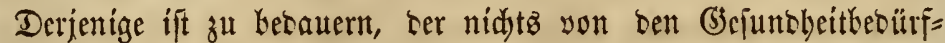
sniffen feines Pfertes verftebt uno wenig veer nídsts yon ber Satur

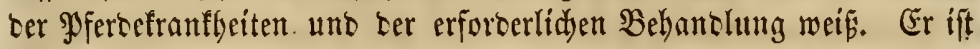
wie ein Mann, ber verjudyt fein biennentez 5auz ju retten. Der

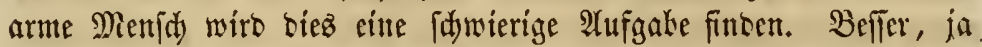
taujenomal befler wäre $\mathfrak{c B}^{\circ}$ gewejen, wenn er ben Bianb bätte ganj serbinbern fönnen. Wie mandsen Farmer gibt es nidyt in biejen gropen Sanbe, weldyer nidytz bayon weís, wenn fein SPferb woncinem ftarfen, heipen Fieber vergebrt wird, biz baffelbe yon ber. Sranfleit ganz zerfötort ift, ber felbit nidit im Entferntejten eine

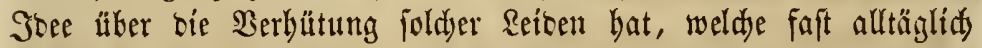
yorfommen uno leidt zu vermeisen fino! Whiro Las Thier eincs folden gedanfenlojen Mannez franf, fo fann geroblynlici ber be= obadytente Senner an Een Symptomen Bernadiäfitgung uno zu=

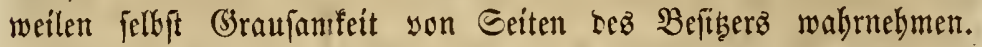

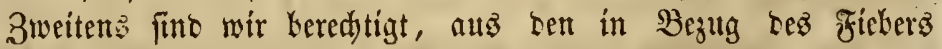
erwähnten Thatfaden zu folgern, on es fogleid mit aller Madyt gesämpft wersen follte. Reine 3eit ift in muslofen Erwartungen, Lafi die Symptome yon felbit veridumin= ben wersen, zu yerlieren. Dem erften Stabium ber Rranflyet, ben allererften Fiebereriducinungen, mup mit ciner energifden, aber in= telligenten Bebandlung begegnet werben. In biejer Beziehung ift bas Fieter ebenfallz sem Branbe ăbntidy. Die tleine beginnenoe. Flamme ift obne viele Mübe zu bämpfen, wiro fie aber vernad)läfigt. ober überfeben, fo mag ber Barano balo eine (5)enalt gewinuen; weldye yon Sunberten nidyt bemeiftert werben fann. Dhne Zmeifel.

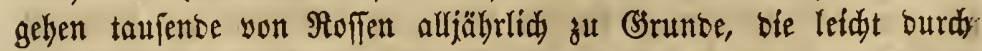
zeitig angewandte $\mathfrak{A}$ rzneimittel gerettet werben tönnten. 


\section{円}

um ein bisziges Fieber mit Erfolg zu behanbeln, mus man breierlei beobad)ten: erftenz ben నörpertheil ober Daz Srgan, weldyez erfranft ift; zweitenz bas $\mathfrak{B}$ (ut, ourd) weld)es bie frantbaften (Erfa)einungen über ben ganzen Srganis̄mus verbreitet werben, und srittens tie Jaargefäpe uno Poren, burdy weldye ber Stoffwed)fel überall im

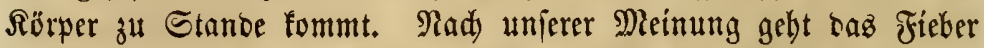
immer aus oem tranfen Srgan bervor. Wir fino jebod nidut alle= mal im Stanoe, ben leibenben Theil zu entbedfen; obne Zweifel ift er írgenowo vorbanden, uno ber Erfolg ber eingeleiteten Bebanclung mag yon ber Entbefung Defifelben abbängen. Der nur zu oft be= merfte idyledyte Erfolg oer Bebanolung bez Fieberz berubt auf zweierlei,

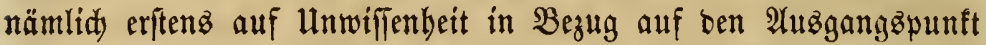

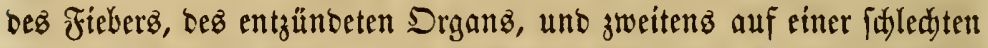

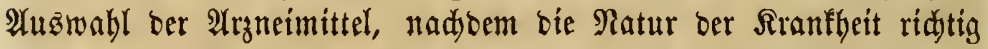
erfannt ift. (5̧ewöbnlid) muf bie Urjadje in mangelbafter Frfennung ber Sirantheit geludat werben.

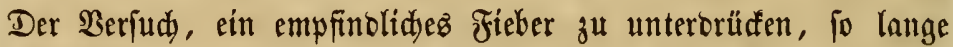
bie Entzünoung cines beionberen Rörpertheils fortbefteht, fo lange ble Duelle, aus oer bie übermäpige Sibe flieft, nidyt serftopft ift, muE notbwendiger $\mathfrak{B e i f e}$ fehlidhlagen. Sold)e BBebanolung fann nidytz bezwedfen; folf ber Strom nid)t mebr fliepen, muś erit bie Duelfe verfiegen. Symptome föninen wir wobl verbeffern ober milbern, aber 10 lange bie Uriad)e berjelben nidyt entbect uno entfernt worben ift, fann feine bleibenoe Befferung eintreten.

Whir baben baber feine unfeblbare Ftebermeoizin, felbit feine be= fonoere Bebandlung, auper ber gegen die Sranfheit geridhteten, won melayer bas Fieber nur als ein Symptom anzuleben ift, anzugeben. Im Allgemeinen fint alterirenoe Mittel bie geeigneten, um $\mathfrak{B l u t t r a n f}=$ beiten zu verbüten uno zu beilen. Buweilen ift die von oenjelben geleiftete Sille auperoroentlid), oa auf beren (sebraud) bie Natur= fräfte ibre gewohnte gefunbe Ihätigfeit wieber fdunelf erhalten. Tlu= fer bem Stectapfelfamen fönnen wir gang befonbers bie fdon oft empfoblene 3ufammenjezung yon Sdjwefel und Sarg empfeblen, bie in manden Rrantlyeiten jenez Mittel bei weitem übertrifft. Die Wirfung beffelben if zwar bin unb wieber langfam, aber immer 
fider, uno fann felsft in ben allergrösten Dofen bem PJerbe nidyt iajaben.

Ridjt felten ift bas Blut bes Roffes in einem folden unbraud baren 3uftano uno bas lymphatifase Syjtem fo unthätig, baj bie - eingegebenen alterirenten Mittel audj in grosen und fadnell wicber= bolten Braben unwirffam bleiben. Unter biejen Berbältniffen ift ein

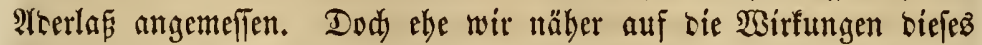
Mittelz singeken, lafat unz bie im Blute surd) Rrantheiten hervor= gebradten $\mathfrak{B}$ eränberungen uno bie Buftänoe, in welden bie $\mathfrak{A}(\mathfrak{n} w e n=$ bung bes 2'berlaffez angemeffen ift, näber betradten.

\section{Dite $B$ I ut.}

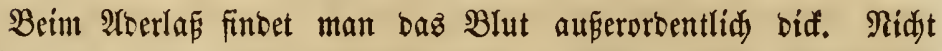
felten hat biejer 3uftano fo überhanb genommen, bá baffellbe gar

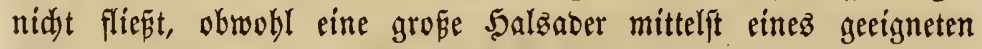
Snftrtmentz gečfint worben ift. Diefe Findifung bes Blutes ent=

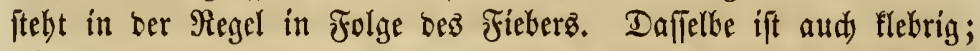

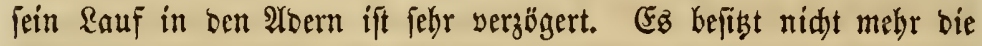
fitrömenten, belebenten (Figenidaften, weld)e ez im gejunoen Zujtante ftets bat.

Difez $B$ lut hat gemöbnlid aine jehr bunfle Farbe. Bei Sranf= heiten bes Rärperz überbaupt wiro baz Blut zuweilen fajt idjwarz

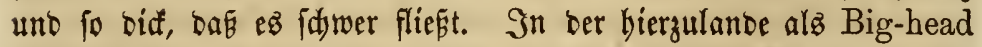

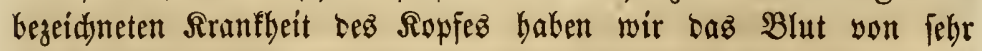
ounfler Farbe gefunben, hin und wiber beinahe idywar.

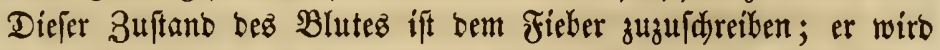
baher bei entzünolidyen Rranfleiten, jowie bei langjam verlaufenden Beid)werben, bie allmälig bie Beftandtheile bez Blutez Gecinträdytigen, bejonters aber bei dronifden Rungenleiben angetroffen. Faft immer

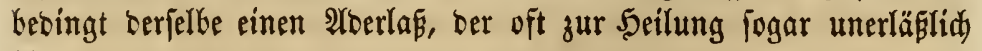
ift.

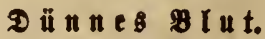

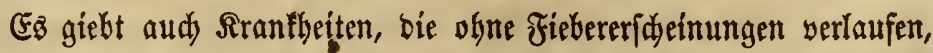
meldye einen ftarfen Ginflü auf bas Blut augüben, baffelbe aber nidjt einbifen, fonbern bünner und wäfferiger madjen. Bu biéen Befdjwerben mus man ben bei einigen \$ẹtben häufig yorfommenten 
Durdffall ober $\Re$ hhe rednen, fowie melyrere antere Srantheiten, bie burd) maffentyafte Entleerungen ben $\Re$ örper allmälig alomagèrn. Die

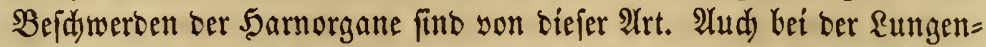

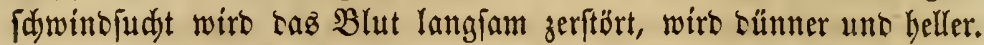

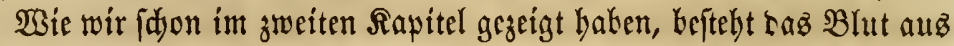
zwei leidyt von einander zu trennenten $\mathfrak{I}$ beilen, sem $\mathfrak{B l u t f u d}$ en uno oem Blutwaffer. Sn ben Rranflyeiten, won welden jebst bie Rebe, ift ber feftere Theil bez $\mathfrak{B l u t e z}$ sermintert, yon weldyem bie rothe Farbe befferben abbängt; taz Blutwaffer bagegen ift im Ueberflus yorban= ben und ertheilt bem Blute die bünne, blafle Beidjaffentheit. Sn biejen Fällen bürfen Blutentziefhungen nidgt vorgenommen werben; im (Segentheil muf man burd) bas allemahrhaftefte Futter, Berwe=

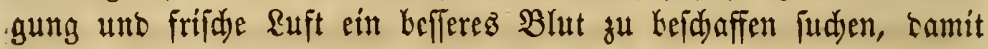
Daffelbe ben Rörper wieber gebärig ernäbren fam.

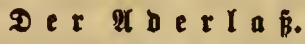

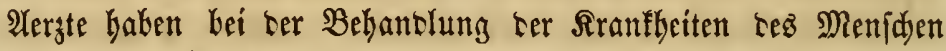

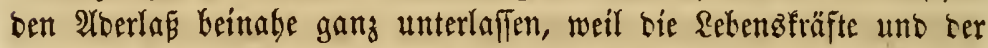

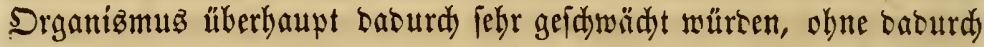

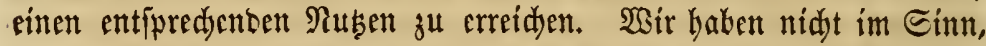

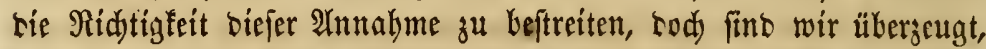

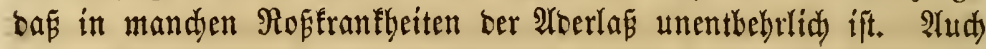
cintige fid Mferbeär

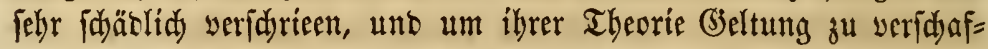
fen, biejelben mit allerlei Edjimpfwörtern belegt. Einter siejer mober= nen Pyerberoftoren, weldyer in ber 1 mgebung yon $\mathfrak{B o f t o n}$ fid eine neutjä̆brige Erfahrung gefammelt haben will, benadjridtigt una,

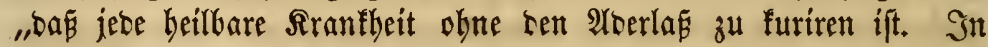
allen Rranfleiten, bei beren Behandlung Ler $2 \mathfrak{r a z}_{\mathrm{z}}$ zu biejem Mittel feine 3ufludjt nabm, wurbe bie Seilung veridpben, und eine grofie, leidjt an ben gefdjwollenen Beinen uno antern allgemeinen Störun=

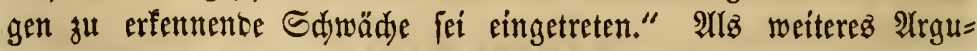

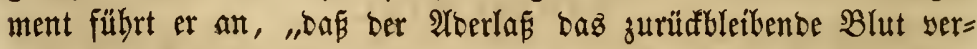
arme unt Beidywerben yeranlaffe, bie ebenfo bebenflidy feien als bie= jenigen, fut beren Seilung er angewant werbe."

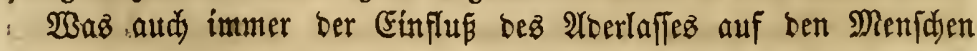

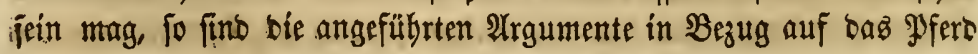


ganz falfa); unto wir fönnen nidjt umbin zu bemerfen, ebe wir näber auf biefen (begenftand eingehen, baß die foeben angefübrte Theorie feine Begrünoung in ser \$raxis jenes 24utors hat, wie er biejelbe in feinem $\mathfrak{B u d j e ~ n i e b e r l e g t . ~ W i r ~ g l a u b e n , ~ b a ~ e r ~ e r ~ n i d j t ~ c i n e ~ e i n z i g e ~}$ son ifm felbft gemadite Rur anführt. Er befudste zwar sintige be= benflidy franfe Patienten, bod) gingen biefe unter feiner Bebandung 3u (Srunbe; und wab anbere Patienten Ketrifft, beren feine (Frwäh) = nung geidicht, ift man gezwungen anjunchmett, $\mathfrak{s a \beta}$ cz ithnen eben= falls jo erging, ober, wenn fie gerettet worben, biez lebiglidy ben $\mathfrak{R a}_{\mathfrak{a}}=$

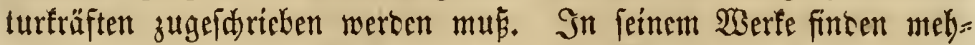

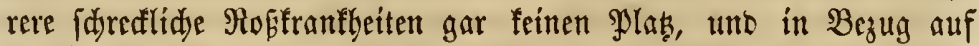

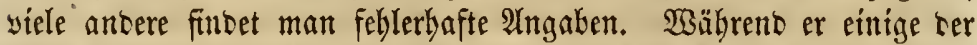
furd)tbariten Reiben faum erwähnt, hat er wieber gegen antere Recepte angefertigt, bie aus zweiuntzmanzig bis adjunbzwanzig verjdiebenen Beftantheilen zufammengefest fint. Für tie 3ubereitung einiger feiner Mittel hat man vierzebn biż fünfzehn Tage nöthig!

Wsir Gaben eigenhänbig mebr alz fünfGunbert Pferben uno Maul= efeln zur 2loer gelaffen, unt befamen in feinem einzigen Faul bie in

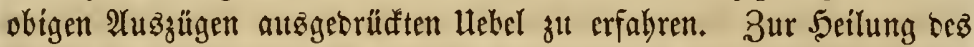

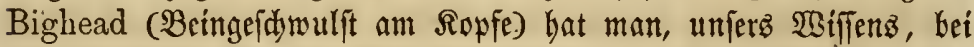

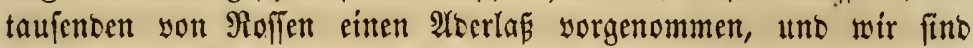
überzeugt, Daß meber ber moberne Rogboftor, nod, fonft Semant biefe Sirantheit obme Bhtentziethungen heilen fann. Alud in sielen an= Dern SiranflyeitžfüUten ift biez Mittel ganz unentbehrlid).

WBenn ber 2lterlas mit ber erforberliden Einfidyt vorgenommen wirb, io folgt nidjt nothmentigerweife eine Blutserarmung. Faft in allen Făllen, zu beren Feilung Blut entzogen werten mus, hat

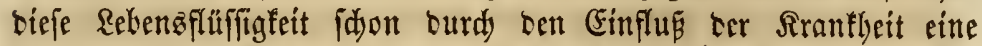
bebeutente Eridjöpfung crfahren. Man finbet biefelbe biad, bunfel, uno bie zur Grmäbrung bes Syfems beitragenten Beitanttbeile fino in vermintorter Duantität vorbanten. Ez wäre vielleidgt zut weit gegangen zu fagen, baj fid bas Pferb um vielez beffer befinben

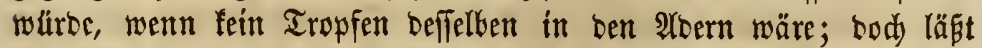
fid) mit ber grösten Sidjerbeit behaupten, bấ

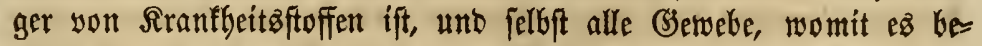
ftänoig in Berülyrung fommt, herunterftimmt uno verfdledtert.

Sierin beftelgt jeood) nidyt bie 5auptidjwierigfeit. Die Saargefäá, 
jene wimzigen Ranäldyen, weldhe bie burd baż Futter bem Riörper.

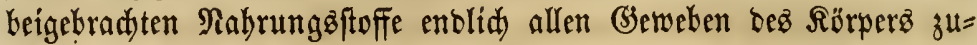
fübren, wersen oft verftopft uno geidlọfen burd bieje Blutbejdaf=

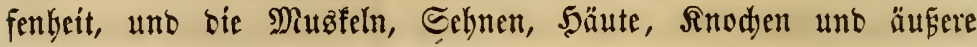
Deffe, in ber That alle Rörpertheile leiten baher aus Mangel an Rabrung, werben balo erjdöpft uno zur Berridutung ither Funftio=

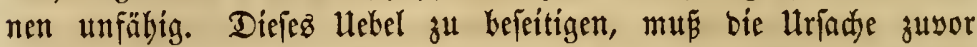
entfernt werben. Daß $\mathfrak{B}$ lut mú geändert und gereinigt werben; neueż, be mergelten treten.

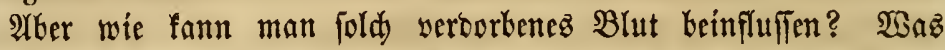
zur Befferung befielten yorgenommen wirb, barf nidt faumfelig aus =

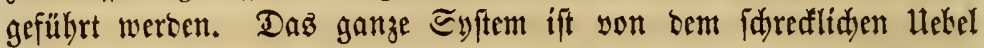
burdionnngen uno wenn man bie natürliden Funftionen nid)t Galo biz zu ibrer gejunten Thätigfeit erhöht, gebt baz Thier ohne 3weifel 3u (Srumbe. Sann man biefe burd) $\mathfrak{A} r r_{3}$ neimittel bezweden? Sel= ten, febr jelten. Selbft wenn ber Magen biz zur hödffen Faflunge= frnft mit Mebizin angefüllt wirt, merft man faum ben Ginflus ber= felben auf baz Blut. Ulterbaupt ift bei biejer Blutbeidyoffenheit bie $\mathfrak{B e r f i n b u n g ~ m i t ~ t e m ~ F u t t e r f a n a l ~ b u r d ~ b i e ~ U n t h a ̈ t i g f e i t ~ t e r ~ S a u g = ~}$ abern faft aufgehoben, fo taf werer Mebizin nod) Rakrungefftoffe in ber zur Crrbaltung ber (3) jutnbheit nothwenbigen Menge auz bem Foutterfanal aufgeiogen uno in ben Blutftrom ergoffen werten.

Daher if ez thöridyt, (Bemsidyt auf bie oberflädlide Bebauptung

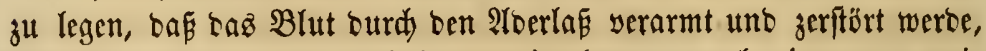
oa biefez fijon sorher gefdah, unt je eher ez burd) ein neuez, mit Nahrungeftoffen fdywer belatenes eriebt werben fann, befto beffer.

Diez fübrt unz jebod) zul einer antern weit wictígeren Betrad)=

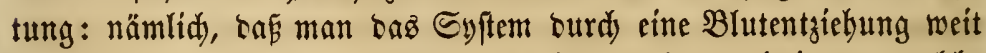
fdunelfer unb fidjerer herunterfitimmen fann, alż butrd irgeno weld)e 2Yrzneimittel. Dft ift ez nötbig, zur Socilung ciner Entgünoung fo= gleidy beren erhöbte Thätigfeit zu bämpfen; waz burd Mesifamente nut allmälig uno langlam, butrd einen tüdtigen 2loerla aber fofort

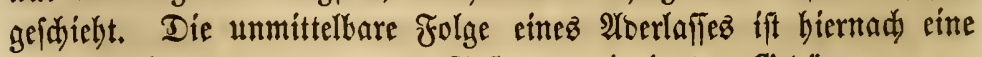
Serunterfitimmung bez ganzen Syjtems ; bie in ben (Sebärmen wur=

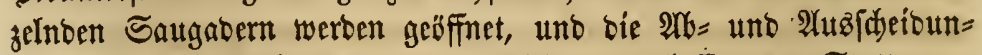
gen gehen überall im Fiörper natürlidjer uno befier von Statten. 


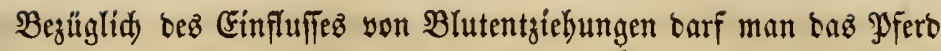
nidjt mit bem Menidyen vergleidyen. Sbgleidi, ber phyifide Srga=

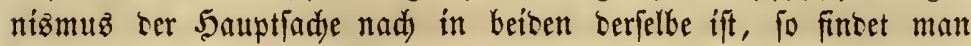

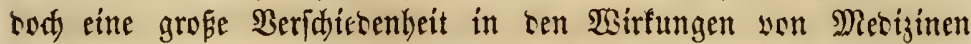
แno jelbft ber alltäglituen Ginflüfle auf siefelben. Finige Mebifa= mente baben beim Pyfere eine beftige Wirfung bie beim Menjaen gan; wirfungąloz̧ fino; wäbreno wieber antere, die auf leşteren alż (3ifte wirfen, beim (3)aule feine beftigen Erjobeinungen verurjad)en,

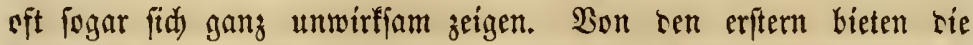
beim Pyfero angewansten Rinimente (oünne Salken) ein Beipiel. शuf cie Saut ber Perion, weld)e diejelben cinreibt, baben fie jaft gar feinen Ginflus, bringen bagegen beim (5aule leid)t die erwartete Wirtung hervor. Die allbefannte Stedapfelpflanje ift ein idslagen=

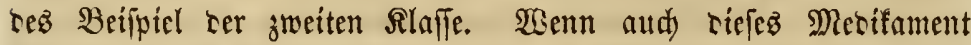
idou in geringen Dutantitäten auf ben Menidien alz furd)tbares (3)ift wirft, fo bemerft man bod) feine Befdwerben beim RoB, felbit

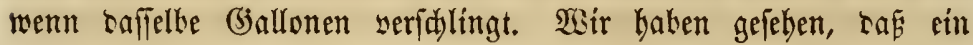
Pfero beinabe zwei Monate lang faft ausjichlieflidy von siejer Pflanze lebte uno intefien viele $\mathfrak{B}$ ujdel ber $\mathfrak{B l a ̈ t t e r}$ uno Inospen veridjlang.

Wir waren idjon wieberbolt zugegen, wenn ein YYuerlá bei einem franfen Menidien sorgenommen wurse, sod) baben wir niemals jol=

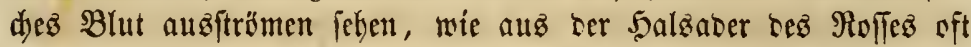
flies̄t, nämlid bid, flebrig uno faft gan' fidwarg. Dem Pfierte ba= ben wir fidon, wir mödten fagen, grofe Fäfler Blut entzogen uno

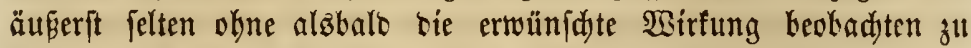

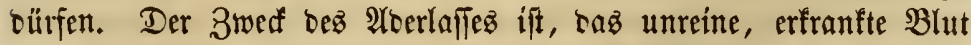
vom Rörper zu entfernen unb bas Syftem überbaupt berabjuftim= men; wenn biejes erreidt ift, mögen $\mathfrak{A}$ raneimittel mit Erfolg ange= wentet werten. In benjenigen Fällen, die fid) turd ein (d)led)tez

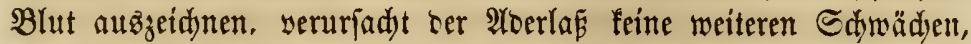
nody in antern Fällen, wenn er yon sen Symptomen angejeigt ift. Sit fdon nabmen wir . $\mathfrak{B}$. ein an Bigheab (

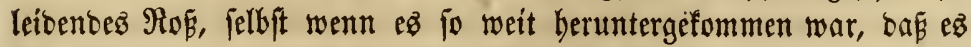
fid) nidft mebr vom (Srunbe aufriduten fonnte, in Behandlung, lie=

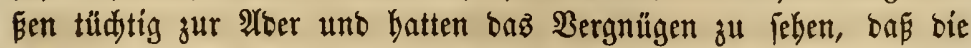
Rräfte bez Patienten nady einigen Tagen zugenommen batten uno bann ftetig wuhjen, biz bie (Se) 


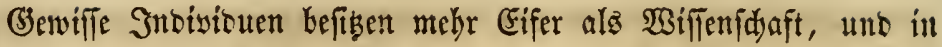

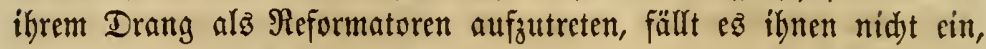
moblbefannte Thatfadien gebörig zu würcigen, nod) neut Theorien burd bie alläglidye Erfabrung zu prüfen. WBir finto fo robl in Reformen intereffirt als antere, bod) müfien fie edter Irt frin. Man

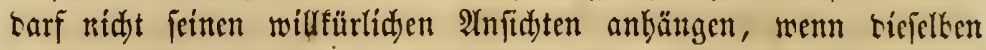
curd) unbeftrittene Ibatjadyen witerfprodyen werten, obgleidy fie bie

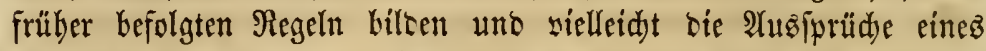
gefeierten Mannes fint. Biern würcen wir bem Prerlaffe entfagent, wenn berfelbe nidyt in ber Behantlung vieler Rofftranffeiten unent= bebrlid wäre. In früberen Zeiten wurte obne Zweifel tiejeg Mittel oft mifbraudst, bod ift bies fein (Srunb, baffelbe sud in gecigneten Fällen zu vermerfen. Diefe Fälle fint nidyt felten, aud nidjt fidwer zu crfennen. Biele Pfertefranfbeiten fönnen burd) antere Dittel nidyt erfolgreid hebanbelt werben.

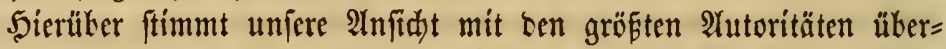
ein. Wir haben గas bödjfte Talent auf unjerer Ecite; um bieję Darzuthun, last uns bie Mcinung von 2 silliam פouatt horen, ser in ber Rofargmeifunte tie allerbödyfte Stelle cinnimmt, uno beffen

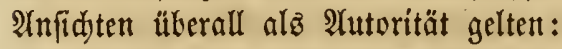

,2Senn ser Entzünoungsprozes in einem vermebrten Zuflup เes Blutes zum leicenten Theil uno einer Blutanfäufung in bemfelben befteft, fo fann man senfelben-leidjt baburd sermintern, tap man bie Blutmenge verfleinert. Entfernt man ben Brennftoff, fo geht

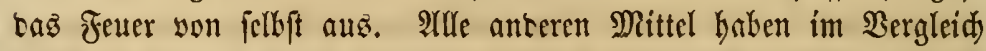

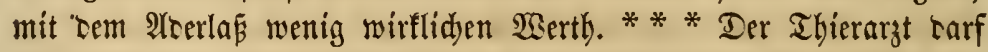

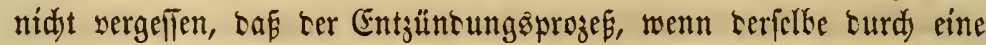
Blutentziehung zum Stillftano gebradyt ober aud nur cinige Beit aufgebalten worben ift, bei feiner $\Re$ üdfebr nidjt mebr bie uriprüngli= d)en, beftigen (Gharaftergüge an fid trägt, zuweilen aber aud nad) rem

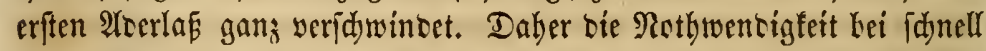
verlaufenten ober keftigen Entzünoungen widtiger Srgane, 3. B. ter

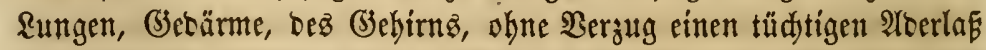
yorzunehmen. Mandes vortrefflidye Pfero gebt zu (3runce, weil bie Blutentziebung ju lang verfdoben wirt ober in zu geringer Duantität ftattfinbet; nie bingegen baben wir erfabren, oaj irgeno

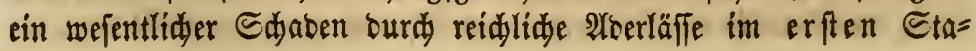


bium einer beftigen Entzünoung verurfadt wurbe. Daż Pfero fann felbft mit Bortheil faft unglaublid) Suantitäten Blut verlieren. Vier Suart baben bei bemjelben weniger Ëinflue alz ein Duart bei einem fräftigen Mann. Unถ ift feine Entzünoung irgeno einez Rörpertbeil's benflear, ob biefelbe aus eimer Berftaudung ober anberen Itradyen entipringt, bei weldyer Blutentziebungen entweter mittelft Sdyröpftöpfe uno Blutegel ober $\mathfrak{A}$ berläffe nidyt bie allerbeften Dienfte leiften."

WBie wir idyon bemerft baben, ift ez nidjt in ber Bebanblung jeser Rrantbeit nothwentig, zur Iloer zu laffen. Nur bei Keftigen, idnell serlaufenten Entzänoungen uno febr veralteten dronifden Befduweroen hat man diejez fräftige Mittel anzumenten. Bur Ber= meibung yon Mif́griffen ift folgente Regel zu beobadjten: Wenn

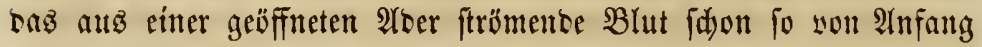
an leidyt fliefst uno bellroth auşifebt ooer bod nur ein wenig bunfel

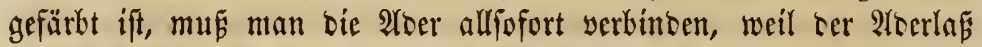
unnöthig ift. Niemalz barf ein 2locrlás fur Beflerung tes allge= meimen 3 uftanteg vorgenonmen werben, wenn nidyt eine Sranflbeit diejez Mittel erfortert. Wirt ein Pfero franf, fo fann eine Blut= entziebung felten idjaben, wenu ber $\mathfrak{A}$ fifall nidjt etwa fu ren fidon befdriebenen gebört, bie suth) mallenbafte Entleerungen bie Rörper= fraft idnell berunterbringen. Wir empfeblen ben Alorlnf nur gegen poldye Reiben, weldye nady unferer Erfahrung diefez Dlittel erfortern, bei welaen bas Blut felbft tutein uno verborben uno bie freic $\mathfrak{B e r}=$ bintung beffelben mit bem Futterfanal, ber Duelle ber Ernäbrung, beinabe sollfommen unterbrodyen ift.

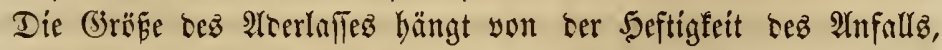
fowie beffen Dauer ab. Selten wirb ber Ropargt ez nötbig finoen,

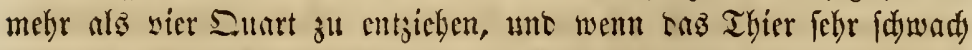
ober ber Siranflyeitzanfall leidyt ift, tann bie Suantitüt fogar auf

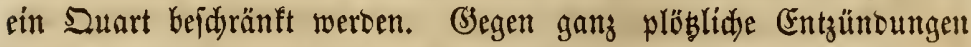

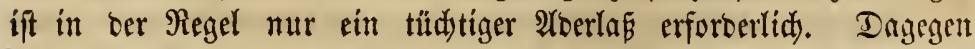
müfโen bei veralteten Befdutwerben, forwie über baz ganze Syftem verbreiteten Rranlbeiten mebrere Aoerläfje eingeleitet werben, bod carf bie auf einmal entogene Duantität niemalz viel betragen. 2rber

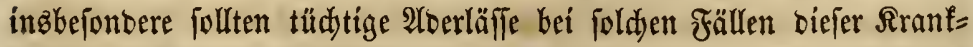
betten in Antwentung gebradt werben, bei benen ber abfliefiende 
Blutfrom febr fajwarg ift, unb bie 2 toer follte nidyt verbunben wer= ben, biz fid baz $B$ lut etwaz beller zeigt, etwa wie baz Blut ber

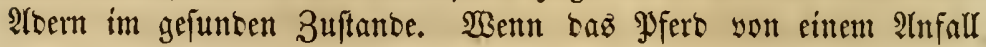
yon Edywintel (blind staggers) ober Maulffemme (lock-jaw) bcfallen

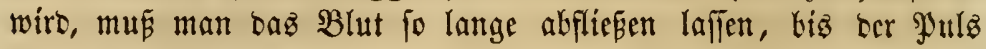
fdjwad) wirb, bie Sinte zittern ober has \$yferb zu blajen anfängt.

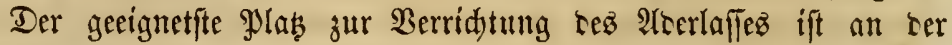

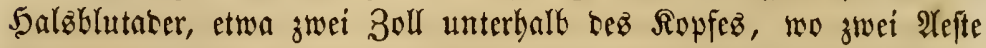
fid) mit einanter vereinigen. Dies ift gerate unterbalb ser bei $t$ wer=

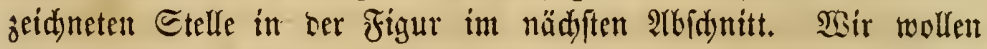

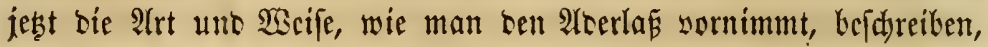
unt wie er won irgent ciner Perfon aud whe Eanjette yorgenom= men werben barf. Daz Berfahren felbit ift cinfad) unt fo Icidjt

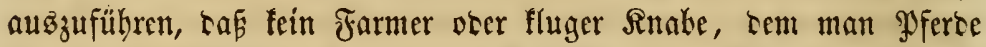
anvertrauen faum, fid yor ber Iluzfübrung beffellen zu fideuen braudyt, wenn er fid son ber $\mathfrak{N o t h y e n t i g f e i t ~ b e f f e l b e n ~ u ̈ b e r z c u g t ~ b a t . ~}$

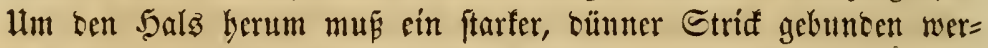
ben, etwa fedis 3oll unterhalb ber Stelle, wo man bie 2 loer ju öff= nen bcabfidtigt, uno jobalo fid bie 5 alzabern mit $\mathfrak{B l u t}$ ftarf gefüllt baben, glättet man taz 5aar über לer 2loer mit Dem befcudteteten

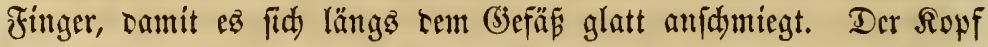

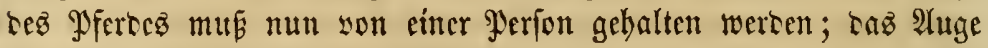
ber Seite, auf welder baz $\mathfrak{B l u t}$ entzogen werten foll, wirb gut be= Deft, ober menn Niemano zur Sä̈lfe vorbanten fein follte, fann man bą̧ 2tuge aud yerbinben. Die Ranzette, weldye man in ber linfen 5ano hält, wiro nun läng ber Ater fo gelegt, baf́ fie gerabe auf

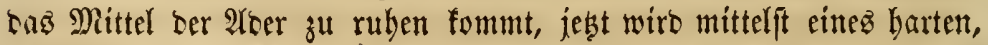

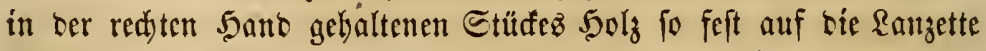

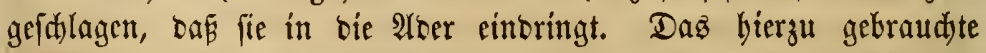

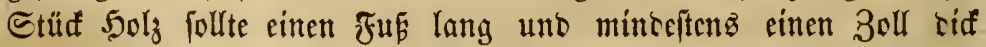
fein. Der bamit ansagefübrte Edjlag harf aber nidjt fo heftig fein, bas aud bie entferntere $\mathfrak{B a n t o}$ ber 2 (ber burdjidnitten wiro, waz bin uno wieber fidon vorgefommen iff. (Bemb̈lynlid folgt hierauf cine Entzüntoung bez yerlebten Theila, bie balo in Citerung über= geht; wegen bem Sitze binter ter 2lber ifít ter Eiter fehr fdjwer zu entfernen. Der Eimidnitt in sie Blutaber mú reidjlid grof fein, bamit bą Blut fo idnell als mëglid) abfliéen fann; baher follte 
man aud eine breite Sanzette benuţen. Wenn eine hinreidente Duantität Blut entfernt worben ift, wiro ser Strid yom balje ge= nommen, worauf baz $\mathfrak{B l u t}$ zu fliefen aufbört. Díe Sisunbränoer werben num zufammengebradyt uno mittelift ciner Stefinabel mit einanoer befeftigt; einige $5 \mathfrak{a a r e}$ aus bem Sdywanz mürifen alzzbann mit Blut beneşt uno feft un bie Steffnabel herumgerwunben werben. Bierunbzmanzig Stunben lang läpt man baz Banza ungeftört. So=

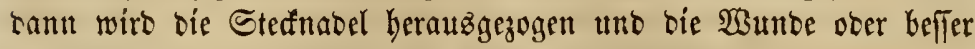
rie Rarbe hin unt wieber mit Epeidyel befeutitet.

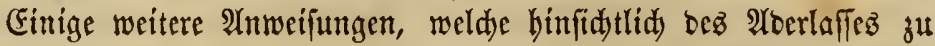

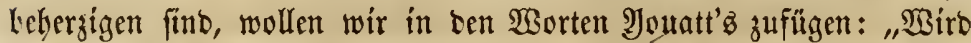

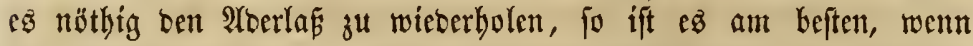
rrei ober vier Stunben jeit ber erften Bhatentziethung idfon ver=

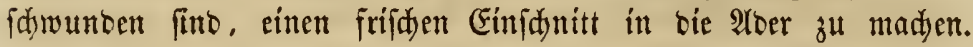

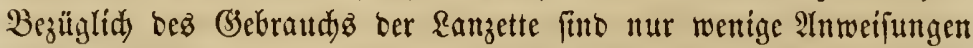
nötbig; biejenigen, weldye genug (Gejdjifflid) feit haben mit berfelben cinen Itberlä zu yollziehen, braudyen wohl feine. Sit bie Spibe nur redft fdarf, fo fann bie Sanzette faum zu breitfdulterig fein; mit einer 2 G6

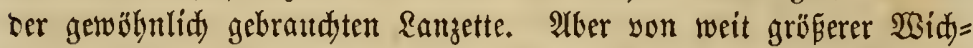
tigfeit, alż bas Snftrument felbjt, ift beffen Sdjärfe uno Reinbeit. Rad) beentigter Dperation muk bafferlee forgfältig gereinigt uno ge= trodtut werben, ba anbers baffelbe in furzer Beit yon ber Feudtig= feit zertört fein wirb."

\section{De r 9 แ $\mathfrak{1}$}

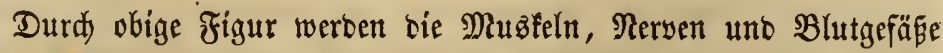
dez Siopfez und dez oberen Theilez dez Jaljez bargeftellt. WBí baben biefelbe bier eingefdjaltet, um bie Stelle, wo ber $\mathfrak{P u l z}$ am

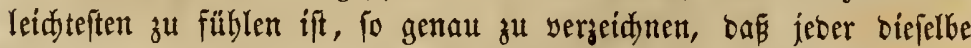
zll finben weís. Wenn man bie Finger auf bie mit w marfitte Stelle legt, wirb man benfellben fogleid mabrnebmen. Arlle $\mathfrak{B} u d d=$ ftaben biż auf $\mathrm{p}$ beziélen fid auf bie Muąfeln.

a Der obere Theil des Nactenbandes.

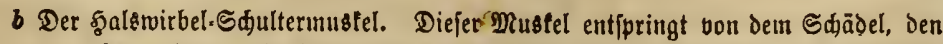

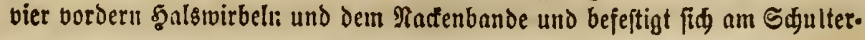




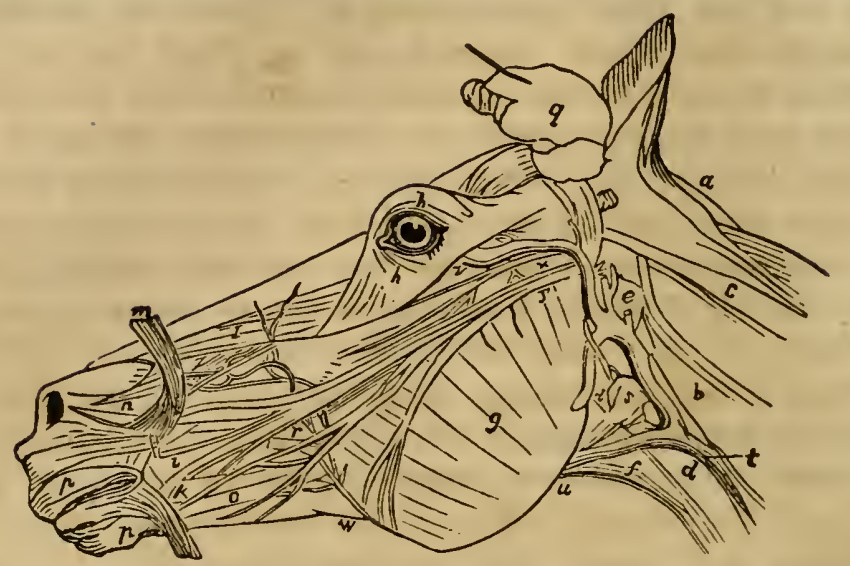

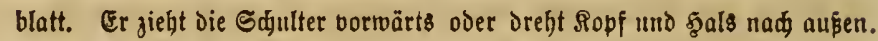
Beun beide Musfelı mirfen, wiro Der Ropf abroürts gezogen.

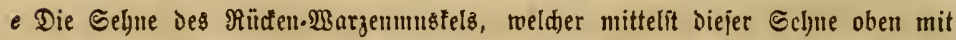

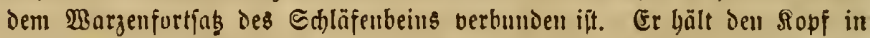
die \$ुöhe, over remu nur einer Der Pinkfelı thätig ift, wiro diejelbe nad Uusett gedrelyt

$d$ Der Bruftbein.fiefermustel. Diejer Muĝtel entipringt dem fnorpel au ber vor.

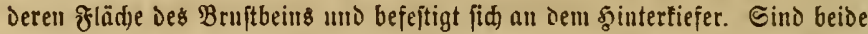

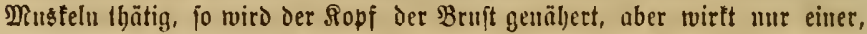

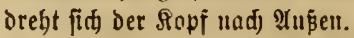

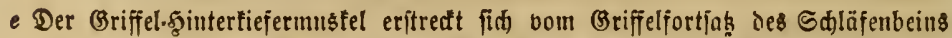

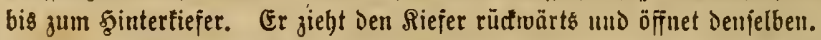

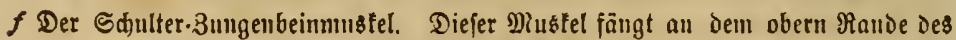
Schulterblattes an unס läuft bis zum 3ungenbein, an oas er fin bejefitigt

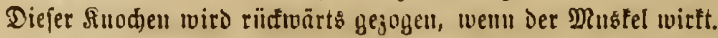

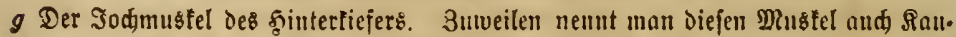

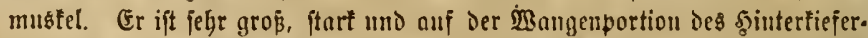
aftes gelagert. Er entftebt an Dent unteren und obern Ibeil Des Jodibogens und endigt an der äuperen જläde des sintertiejeraftes. In Berbindung mit

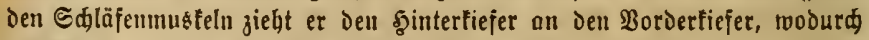
das Raul gejoloffen und das Rauen vollzogen roird.

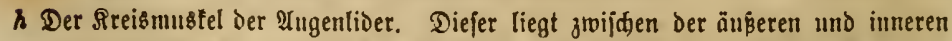
Saut Der Angenlider, mit twelder er imig verbunden ift. Wie der Name an. Deutet, beftebt er ats freisförmigen fofern. Er năbert die 2ugenliber ein.

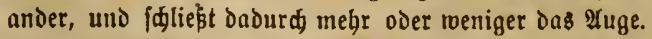

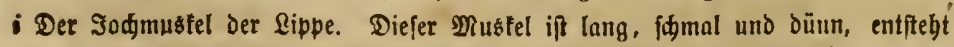
am oberen Sheil ber (sefidtsleifte und geht fidräg nad) unten bis an ben 
Sippenwintel, wo er mit Den Badenmugteln verwadjen ift. (Er ziegt den

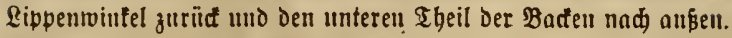

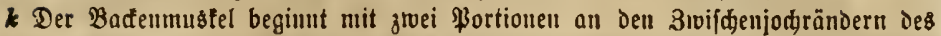
Dber. unb Interfiefers. Die fonern beider ßortionen find an Den Rippen. winteln mit Den Areismunge!n Desీ $\mathfrak{N a n l e s ~ v e r b u n d e n . ~ E r ~ b i l i t ~ D i e ~ G e i - ~}$ tenwand der Maulböble z" bilden und wemn er wirft, wird Diejelbe berengt แIII Das futter zrvifđen Die Badenzäbne gebradt.

Der groje Riefermustel Der Raje. Diejer Mustel fängt am untern Ende Der

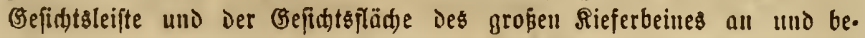
fejtigt fid) an Dem äuperen Rande Des Pajenlods mo an Den obern Rippen.

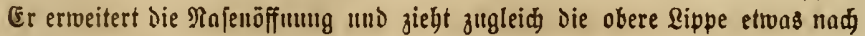
allíen zurïct.

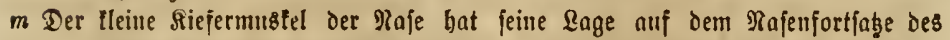

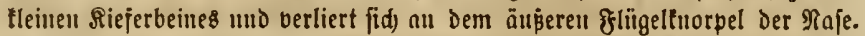
(Fr ermeitert Das \$ajenlod). In Der figur ift er nad oben georeht, un die Darmuter liegenden Blutgefäpe uni Nerven Darzuftellen.

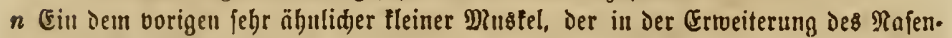
lodís beljilflica ijt.

- Der Siejermuşૈel Der untern Rippe. Diejer entjpringt Dem şintertiejer nuto endigt

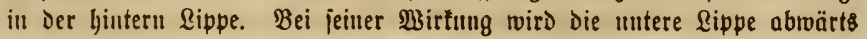
gezogent.

$p$ Der Rrcisıumstel Der Rippen. Er ift ungepaart uno vou Der äuperen und inueren Rippenl)ant eingejtbloffen. Wenn er wirlt, werden Die Rippen einander ge. mäl)ert uno Davurci dos Maul gejdlofien.

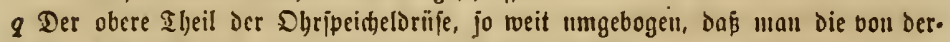

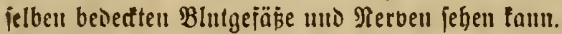

r Der \&u\&fïhrunggnng Der Dhripeidelorïje, wo er Die Bectenfdleimbant Durh. Dringt, un Den Epeitid in Das Mlaul zu ergiésen.

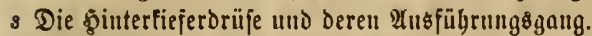

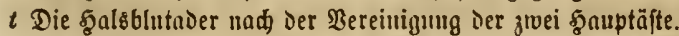

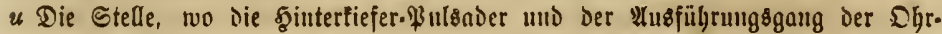
fpeideldrīje juerft unter., Daun innerhalb Des Sinterfieferaites zu liegen lommen.

v (Eine $\Re$ ul\$. und Blutaber, unterbalb Dem Jođbogen verlaufend.

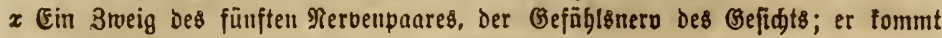
vor ber Olyripeidgelorüfe zum Borfdein.

$y$ Der franptgrweig des fiebenten Rervenpaars, Der Bemegungsinerb Des Befidts;

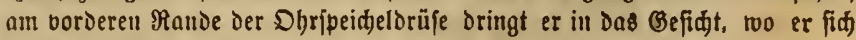
äuserit fein verbreitet.

2 3meige beider Nerven nebit tleinen Blutgefäpen.

Der Pulz bez Pferbez in feinem gejunben, fowie in feinem von ber Rranffeit yeränberten Zuftanbe ift für ben aus̉übenben Pferbeargt yon ber gröften Widtigfeit. Rein anberez Mittel feht ifym fo mie biefez ju Bebote, um bie Bef̧affenkeit bez Syftemz 
bei bem Patienten zu beurtheilen, und nidjtz wirb ihn fitherer zu

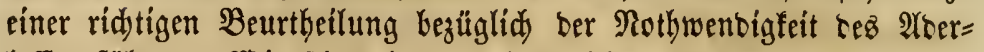

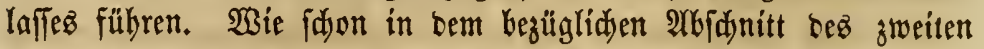

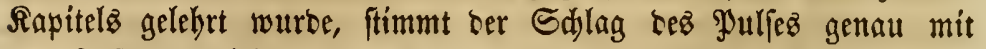

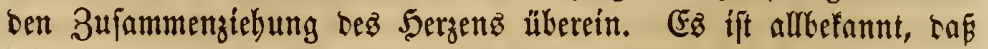
feine bebeutente 2lufregung Des Syftemz ftattinten fann, ob nun biefelbe burd) heftige (Erregungen, tïrperlidje 2inftrengungen, Rrant=

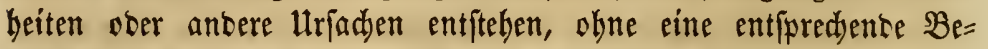
fdleunigung ber Serrathätigfeit zu veruriaden. Diefé fann man mit ber gröften Siderbeit am \$oulfe wahrnehmen, und fo irgend eine Rrantgeit leidjt entbefen unb beren $\mathfrak{B e r l a u f}$ in ten serfdjebenen Stabien ohne Sdywierigfeit beobadyten.

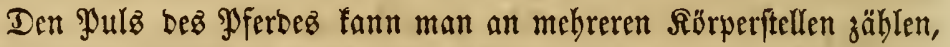

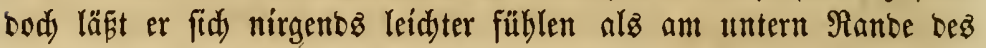
Sinterfieferz, an bem in ber vorbergebenten Figur genau angegebenen

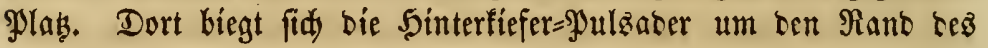
Rnod)enz berum uno läft fid wie einen büntren Etrang anfüblen. Wenn man mebrere Finger fanft tarauf brüft, fann man bie in

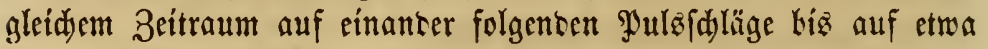

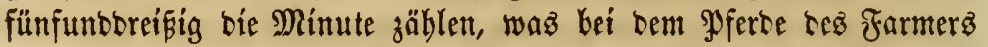
Der gerwäbrlidue, gefunte $\mathfrak{P u l}$ if fommt er aud biz auf viersig ober mebr Edyläge bie Minute.

Wenn man in Refrbüd)ern yom gefunten \$ollz lieft, fo wirb bie Lamit angegetene Zahl ber Sdyläge gemeint. Der 5auptsortheil

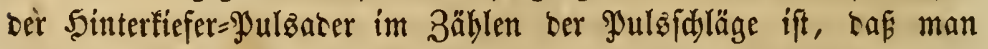
an biejer Stelle nidjt nur bie $2 \mathfrak{m}_{j} \mathfrak{a h l}$ ber Sdjläge, fontorn aud bie Rraft und andern (Eigenfdaften bes \$oulfez beobaditen faum.

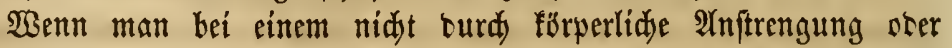

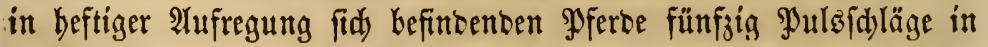
einer Minute zäblen fann, fo ift irgend ein franflyafter 3 uftant sorkanben, uno wenn ber $\mathfrak{p u l z}$ fogar biz auff fiebenzig ober adjtzig fommt, mus ein beftiger Sranflyeits̊anfall bereitz Fortiduritte gemad)t "haben. 2Alz Beipiel fönnen wir ben "Sdjwintel" (blind staggers) anfübren. Englijaje Roß̈ärgte bebaupten bei biejer Rrantheit bundert

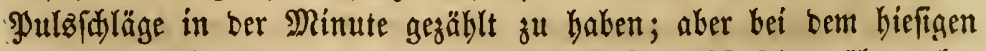

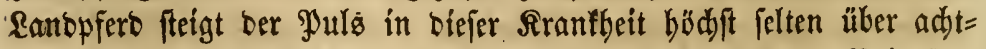
zig, wobei bie Rörverfräfte febłr balb gant zerrüttet fint. Bei Ent= 
züntungen ber \&ungen uno (S̈ebärme fommen nid)t oft mebr benn fiebengig Sajläge auf tie Mimute.

So lange ber Rärper gejunt ift, geht ber gulz regetmäfig unt

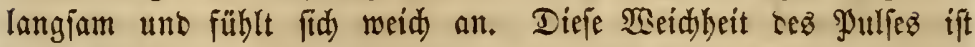

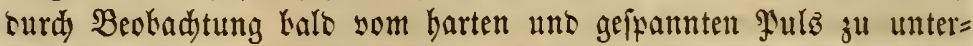

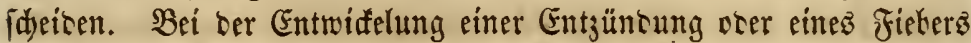

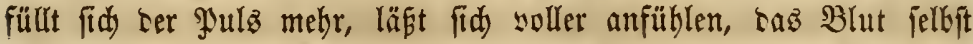

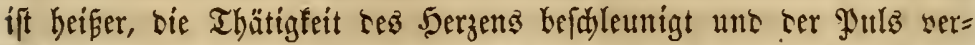

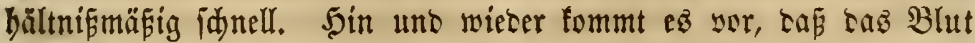
aud) obne bie Fieberaufregung sid witr; Fitber läft fidh aber ftetz an sem fänellen $\mathfrak{T}$ ulz wabrnebmen. Fintet man einen ftarf be= fajleunigten, heftig flopfenten \$uls, fo bat man fid) auf eime Ent= züntoung gefafft zu mad)en; ift aker berfelke hart uno unnadgiebig, fo Kefteht irgent eine hartnädige, seraltete Rranflyeit. Zumeilent trifft man bieje Eigenjdaften za gleidjer Beit am \$ulje an, ein Zeidjen,

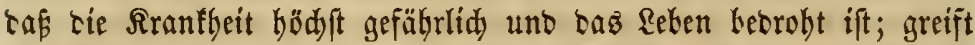
man tann nidjt fogleid) ju emergifden Mitteln, io geht taz Thier,

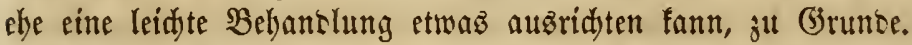

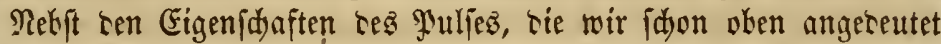
haten, gikt $e$ nod) antere, bie son Pferceärzten mit bejonteren Benenumungen Kelegt worben fimt, weil fie ten Zuftants bes Drga=

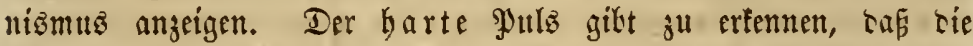
Sergthätigfeit ftart, fogar heftig erbäbt ift, aber shne anserweitige

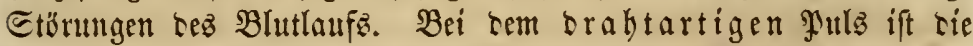

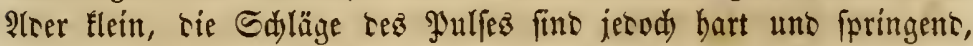

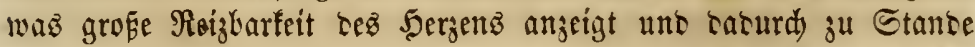
fommt, caf fid tie ber

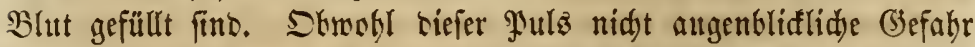
anteutet, io zeigt er cody, Laf sie Rranllyeit idynelle, fühne Fortidritte

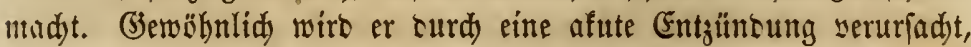

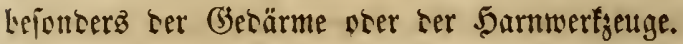

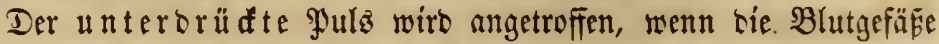

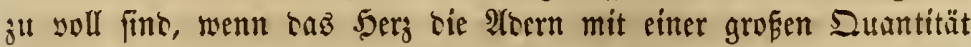

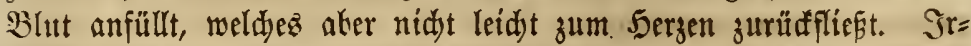

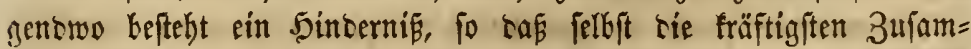
menziebungen $\mathfrak{s e z}$ Serzenz faum im Stande fint, ben langfamen

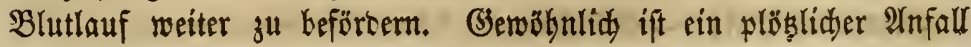




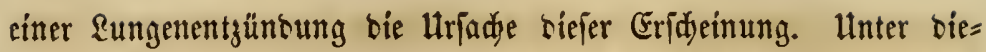
fen llmitänsen wiro nadj einer tüdjtigen, tod nidjt alfzu groêen Blutenţ̦iehung ber Sdjlag bez Pulfez ftärfer. Bei allen biäher

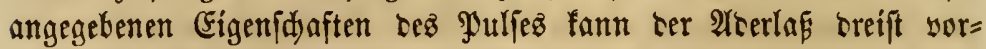
genommen werben.

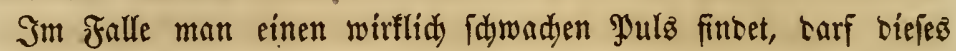
Mittel nidyt gewagt werben; benn terielbe zeigt Edjwäde, Gr=

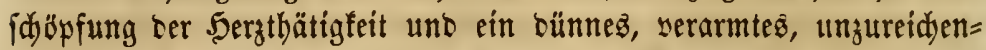
bez Blut an. A̛lle Rranffeiten, weldye baz Enjtem eridäpfen, wer=

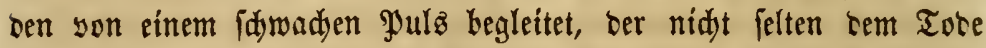
yorangeht. Shier würbe cer 2roerláp ein Moro feun. Stärfente, reizenbe $\mathfrak{A r}_{3}$ neimittel fint erforberlid), um ben $\mathfrak{y a t i e n t e n ~ z u ~ e r b a l t e n ~}$ uno bie erlöfdjenten Rebengfräfte auf'z Reue anzufadjen.

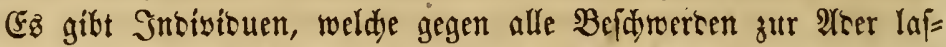
fen, uno andere, bie bei sen beftigften Siranfleiten biefes Mittel

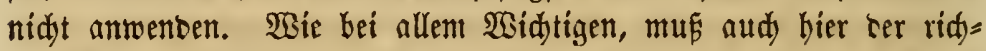

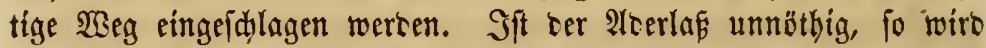
es thöridyt, ja graufam feyn, eine Blutentzilehung vorzunetymen.

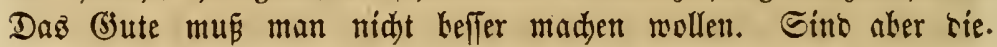
Blutadern ftrobeno mit Blut gefüllt, ift ber $\mathfrak{Y u l z}$ in Folge ber Entzüntung ober bez Fiekers bart, orahtartig ober unter=

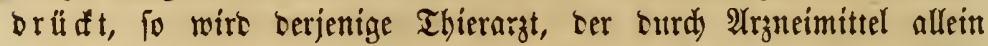

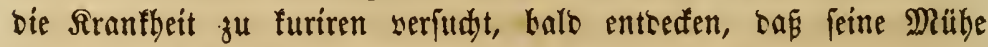
vergeblid ift.

Damit ber Rejer leidter. nadjidlagen fann, wollen wir bier bie veridiesenen 3uftänte bes Sulfes wieberbolen uno mann unt wie biejelben ben 2herlä́ anzeigen:

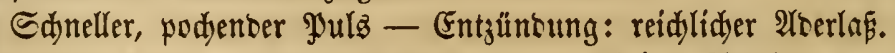

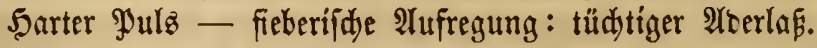

Boller, barter \$̧ulz — langiam yerlaufente Rrantheit : eine mäpige Blutentgílehung mehrere mal in Brwifjenräumen von zefin Tagen zu wieberholen.

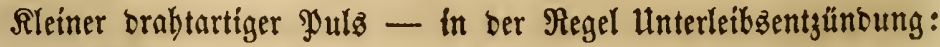
thidytige Blutentziełungen.

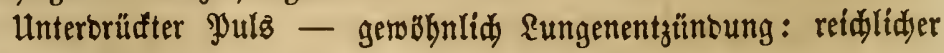
2tberlap.

Sdjwader 
Um ben Puls ridutig zu beurtheilen, muß man mehrere 3uftände

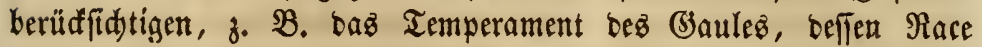

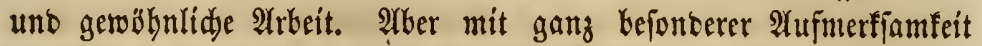

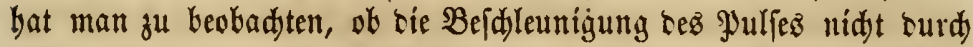

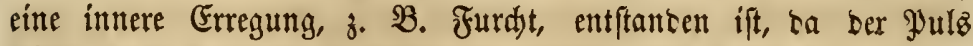
leidyt turd) terartige Einflüfie um adyt big żwölf Sdyläge in einer Minute verjdnellert wirb. Durd Jurdjt fann pogar eine viel befti=

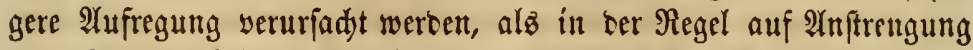
bes Rörpers folgt. Damit man baber in ber Beurtbeilung bez

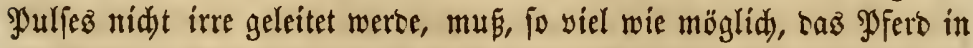
einem rubigen, gelaffenten Zuftant fein. Rathjam ift ez, ben Polz mehreremal zu eraminiren, elye man auz befien Beidjaffenbeit einen

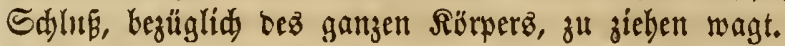

\section{Art un b}

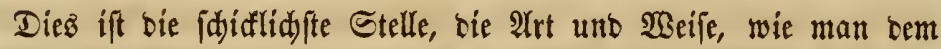
Ojferbe $\mathfrak{A} r$ gneimittel beibringt, näher zu betradten. Beim Eingeben Der Mebizinen fann man fid vier veridiebener Metboben bebienen:

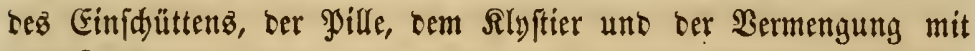
Dem Futter.

\section{D) Cinf由ütten.}

Sm allgemeinen merben bie Mesifamente bem 9 ferbe cingejüŭttet; obgleid) biefe Methore hes Eingebenz in ber Regel obne fabledte Folgen aug̊geübt werten fann, fo ift fie bod) nidyt gant frei yon

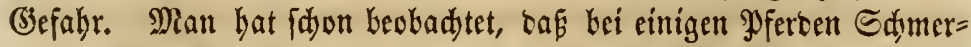
zen yerurjadt, bei antern bleibente Befdnwerben in'z Dafein gerufen uno bei nod antern ber Too idnell herbei gefübrt murbe, ourd

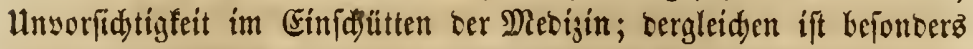

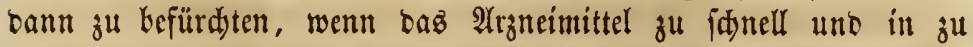
grofén Zuantitäten in's Maul gefdüttet wirb, Da bas Mfer fodann bie fłlüifigfteit nidjt falleunig genug fidluden fann uno ein Theil

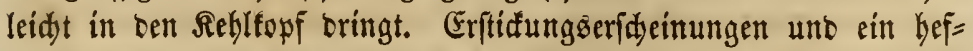
tiger 5uftenanfall fint bie wenigit gefährlidjen Folgen bez Einorin= genz in ben אeglfopf; oft roieberbolt fid ber fo erregte Suften in ל̧artnăđđigen $\mathfrak{2}$ (nfällen.

Diele Folgen fitto jebod leidyt zu vermeiben, wenn man mur jo 
yiel bez Mebifamentez auf cinmal in baz Maul fđjüttet, alz tą Thie: gut falluđen fann. Man barf bie Maulböble beinabe an= füllen, ohne Beidjwerben zu serurfadjen, benn biefe ฐuantität fann ber (Baaul auf cimmal veridlucten. Sin und mieber weigert fid) baz Pferb bie Mebizin zu veridlingen, biz man baffelbe baburd zwingt,

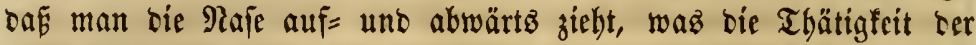
5alämualfeln erregt. Sollte biejez Werfahren nidjt gelingen, jo fann bą Mebifament füglid) in bie Mafenlödyer geidüuttet werben; cod, ba biefe Methooe nod) gefäbrlider ift, alz baz (Einjaütten in bie Munohöble, muF man nur bazu greifen, wenn die weniger gefäbr= lide $\mathfrak{B}$ eife wieberbolt mifflungen ift uno bie Sheftigfeit ber Sirant= beit feinen $\mathfrak{B e r i d j u b ~ g e f t a t t e t . ~ G i n e ~ G a l b e ~ T a f f e ~ s o l l ~ F l u ̈ f i g h t e i t ~}$

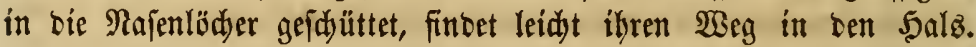
Rommen Symptome bes Erftifenz yor, fo hat man ben Ropf bez Pferbez fogleid) abwärtz zu halten uno ben Berfud) nidjt zu wie= berkolen; senn obgleidy bei ben meiften Pferben in bie Rajenlödjer geid)üttete Flürfigfeiten leidt in ben Sdlund gelangen, gibt ez wicter anbere, bei benen bies immer beftige Symptome verurjadyt. (Jef)t Daz zuerit eingefdüttete ohne Beidyweroen in Den Sdjlunt, fo fann man bas Berfahren in 3wifdenräumen yon einer Minute wieber=

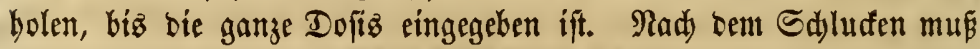
jeteşmal ber Ropf bes PJerbes erniebrigt werben, besor mtan wieber einidüttet, bamit ber weidje (Jaumen, welder burd) bie fehr bohe Etellung Dez Sopfez zulammengeprefst wird, feine natürlidje Sage wieber cinnelymen fann. Der Ropf barf aber audi) nidjt weiter $\mathfrak{e r}=$

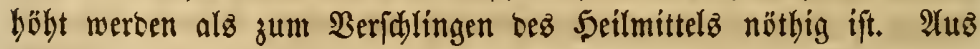

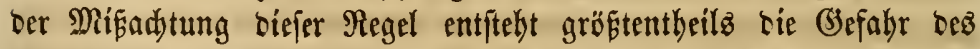
Einfdüttens. Wriro ber Ropf allzumeit in bie Söbe georängt, fo mag baturd) ber Reblfopfeingang binreidjento geöfinet merben, um

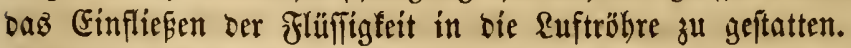

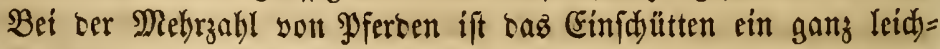

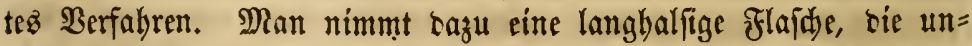
gefäbr ein Duart fafien fann. Dieje füllt man mit ber errwärmten Argnei, wenn ber Flafde in bie red)te Seite bez Maulez, gerabe yor ben, Baden= zähnen. Sierbei mus man eine hobè Stellung einnebmen, am beften auf einer hohen Banf ober אiffe. Mit ber linfen Santo erlyebt man 
jorgfältig Den Ropf Dez Ihierez, uno idüttet mit ber red)ten etwa eime Dbertajle yoll bes Mebifamentez in bie Maulböhle. Wirb cies gut uno leid)t veridludt, was gerwöbnlid ser Fall ift, fo läft man ben Sopf berakfinfen, Lamit Las Thier eine Minute lang bie

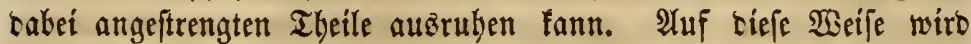
fortgefabren, biz bie Dofiz ganz eingeidüttet ifit.

Fintge einfadye $\mathfrak{A n w e i j u n g e n ~ b e j u ̈ g l i d ~ b e r ~ 3 u b e r e i t u n g ~ b e r ~} \mathfrak{M e}=$ oizin mögen tem angebenten Thterargt yon Rusen fein. Die Flüi jigfeit barf feime Rlumpen, Pulver ober anteren Riecerjalag entbal= ten; benn gerate surd folde werben oft bie gefabrorobentifen $E_{r}=$ ideinungen verurjadyt. Wenn eż nothwentig wirt, eine in Pulser=

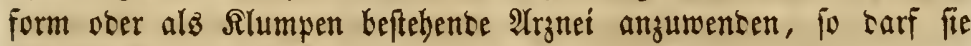
tie als Tranf, foncern mus auf eine anbere $\mathfrak{A}$ rt bem Pferbe beige bradjt werben. Der Borjug Les Cinfdüttens befteht Iarin, Lafi Lie fo eingejwängten Mittel idjneller wirfen, als wenn fie in anterer Form gegeben werben. Die गille läpt fid jwar mit fer gröften Seidjtigfeit eingeben, aber ehe biejelbe im Magen aufgelöf ift, hat

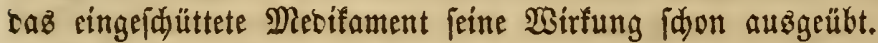

\section{Die Pille.}

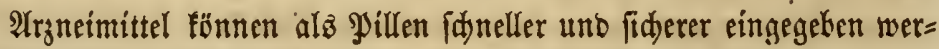
ben, als in ser flüfifigen form, uno in allen dronifden ofer anberen

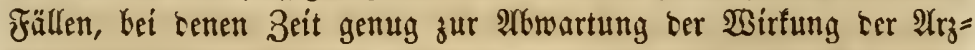
net vorbancen ift, wersienen riejelben ten Borjug. Die Pille wirb caburd bereitet, saf́ man rie geeignete Mecizin mit Miehl uno Wajাer zu einer feften Mafie vermengt uno cann bieje zu einer an= berthalb 3oll langen uno einen 3oll siden Pille ausrollt. Um tie Yille einjugeben, befejtigt man biefelbe am Ence eines sünnen Cte=

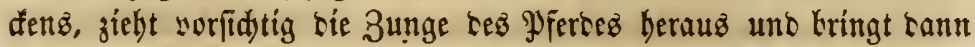
bie ஒille auf rie 3ungenwurgel ober fdiebt fie, went nötbig, nod weiter zurüd. Dlan läpt nun bie Bunge plöblid fahren, woburd

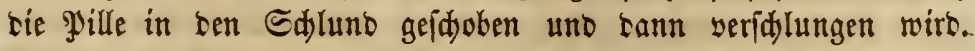
Bei ber Finbringung oer Pille babe man adt, bas fein Theil bes. Saljez ober Mlaules burdy ben Steden bejdäbigt werbe. Sat bie Yerfon, weldye bie Pille eingibt, eine fleine 5anb, fo fann bie Pille: befier mittelft biefer eingebradst werben. 


\section{A $r$ ม}

Die meiften Thierärgte zieben eq yor, die nötbigen $\mathfrak{A}$ ratteimitte!

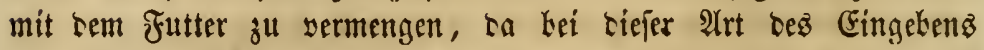
weber Sdyierigfeiten nod) (befabr zu erwarten finb. (Ė gibt jetod) febr viele Seilmittel, bie man auf tieje Weije nidst eingeben faun; aud) ift ciefelbe nidjt anwentbar, wo es gilt, fidnell auf ten Srga= niżmuв einguwirfen. Eine grofe Edwwierigfeit beftebt oft tarin, Dafi mandye Pferte fid bartnäuig meigern sie Mesisin zu freffen. Sebod wirb sas Thier burd) Ien 5unger balo eines Befferen be=

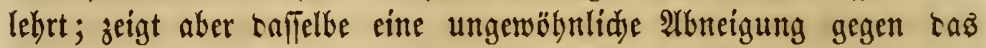
Futter, fo follte man lieber zur ஒJille feine 3ufludt nebmen, als

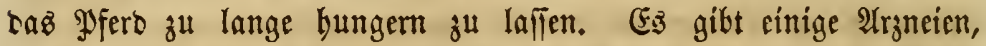

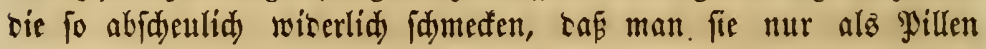
geben follte.

unter allen Berbältnifjen follte man aber serjudjen, bie Metizite im Futter gejdidft zu serbergen. Zuerft fann man biefelbe im un= tern Theil ses Futters verbergen, ober man fügt Infangs nur ganz fleine Portionen bem Futter zu, biz fid tas Pyert etwns an ten

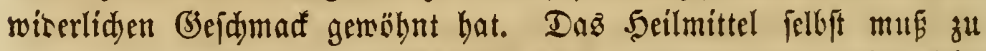
einem feinen Pulver zerrieken uno mit foldem Futter wie Rleie, grobem Mebl, Sädjel ofer Safer sermengt werten.

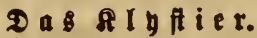

Das Siyftier befteht aแz cinem flüđigen Mesifament, โas man mittelft einer Rlyftierjpribe ober anoern Borridtung in ben Maft=

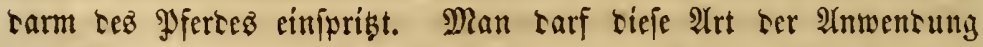
son Metiginen nidyt an cie Stelle ter antern Methore feben wollen, fonbern nur in Berbintung mit antern alsె Shülfsemittel gebraudjen, bejonters bei bartnätiger Stublverftopfung. Bei Rolif, Entzüntung ser (Gebärme, Maulflemme unb anbern Srantbeiten, bei cenen feine Stublentlecrungen erfolgen, bilbet sas Silyftier sas allerbefte Mittel,

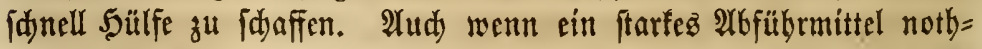

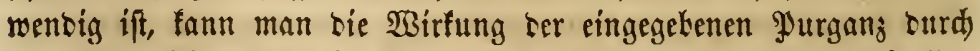
ein gleidjeitiges Slyftier bebeuteno bejdleunigen. So aud) läft (id) bas Slyfter mit Erfolg anmenten, wenn taร Thier an einem Durdjfall leitet. Enclid fann man bei einigen Rrantheiten, z. B.

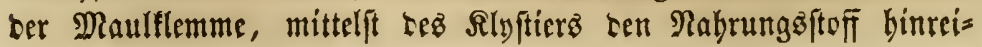


dent in ben Rörper 顿fen, um bas Reben längere 3eit zu er= balten.

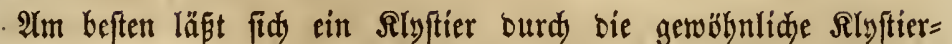

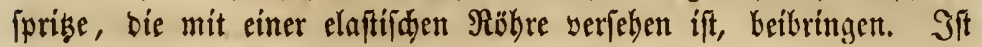
eine joldje nidjt zu bejuaffen, fo fann man ein Rubboun, weldes an beiben Enben offen ift, baju gebrauden. Will man burd lebsteres cin Rlyftier anwenben, fo muj erft bas fleinere Enbe in ben Maft= barm eingefübrt werben uno bie Mebizin ober anbere Flüfifigfeit in Daz erböbte gröfere Enbe gejdyüttet werben, worauf biejelfe in ben Maftoarm fliefit. 2lud fann man eine alte, mit Murslin überzogene leberne Röhre bierzu verwenben. WBoraus aber aud bie Borridtung befteben mag, muf ber in ben Daftoarm eingefübrte Theil worber gut mit Del eingefdmiert worben fein, bamit bie Sd)leimbaut Lez Maftoarmb feine Berleşung erfabre.

Durd) ben Maftoarm fann man aber aud baburd auf ben Dr= ganiṡmus wirfen, baj̃ man ju einem $\mathfrak{B a l l e n}$ formt uno bann mittelit ber Sant fo weit in ben Maftoarm fajebt, als man mit bem Arme reiden fann. 3wifden ben Fingern gebalten, fann ber Ball Durdy ben gut geidmierten 2 rm minbeftenz adjtzehn biż zwanzig 3oll weit in ben Maftoarm geidyoben werben. Wenn bas Thier an Sdylunberengerung, Darmentzün= bung, Maulflemme u. T. w. leibet, fann man bie Rabrungảmittel auf ähnlid)e Weije beibringen. Bur Grbaltung Des Rebenz ift cin poldues Berfahren abjolut nötbig, wenn fein Futter in ben Magen ge=

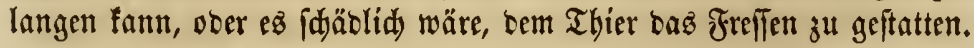

Wir fügen einige yortrefflidje Ilyftiere bei, bie fid fdon mandjez Mal in ber thierärgtliçen Prariz bewäbrt haben: In allen Fällen zieben wir Daz Slyftier bem Ballen für ben Maftbarm yor, aufer wenn es nöthig wirb, bas Pfero burd) ben Maftbarm ju füttern, ba ber aus Futter bereitete Ballen beffere Dienfte leiftet, als flüfifige Fütterunģ่mittel:

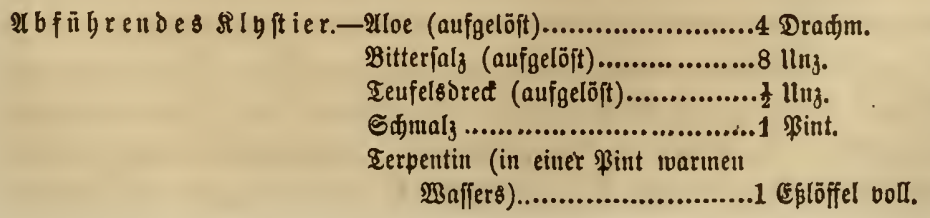


378.

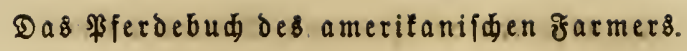

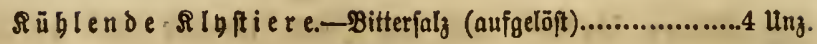
Salyraffer ............................1 Pint.

UImenrinde(slippery-elm) Sdleim $\frac{1}{2}$ Pint.

3 ufammenziehende SIg fitier e.-Laudanum, in einer \$int warmen $\mathfrak{B}$ affers..................1 $\mathrm{unz}$.

Lorbeerenuurzelthee, in einer \$int warmen $\mathfrak{B}$ affers...................1 Iaffenfopf vol.

I a $\mathbf{b}$ bafte $\Re$ I

Ulmeuriude (slippery-elm) Sdleim, mit Sormuehl berdieft. 1 Pint.

Pjeilmurz (arrow-root), mit Rornmebl verdiaft.......................1 Єüke Mild, mit Rorumelgl verbiatt 1 Pint.

Sben angegebene Mittel fino einzeln zum Rlyftier zu gebraudjen.

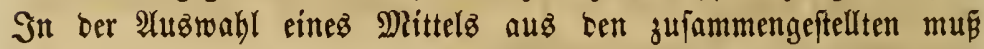

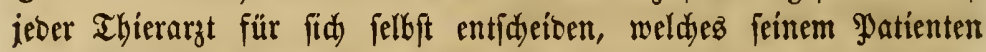
am paffenditen ift.

Die für ben Maftbarm beftimmten Ballen mögen auż ben ange= gebenen Subjtanzen unt Megl beftehen. Sie follten brei 3oll im Durdmenter baben. 


\section{Geefiszefintes sapitel.}

\section{Gifte, giftige Sd)laugen und \$n}

(siftize Subftanzen wirfen nidyt immer bei \$yferoen uno Menjüen

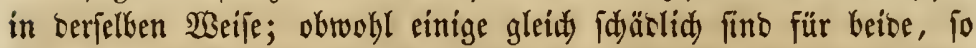
gibt ez aud) (3iffte, weldye bem Mferte unjdäblidy, aber bem Men= iden töbtlid fino, uno umgefebrt gift ez joldje, welde bem Men= iden unjajäblid), aber bem গुferb idjäblid) fino.

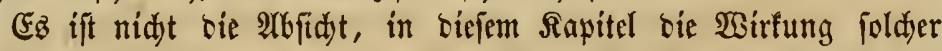
(sifte, weldje allgemein als verberblid) befannt finto, zu beldureiben,

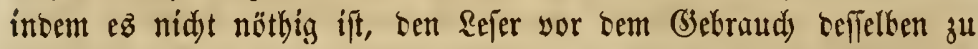

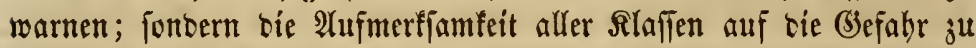

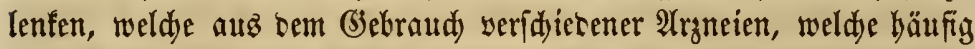

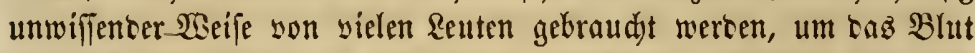
zu reinigen umb tem D:ganiżmus aufalbelfen, entftebt; forwie tie bejten Gẻegenmittel anjufühtren, um foldjen Biften entgegenzumirfen, wenn fie burdy $\mathfrak{B e r f e b e n ~ o b e r ~ a b j i d y t l i d ) ~ e i n g e g e b e n ~ w u t b e n . ~ S S i ́ r ~}$ werben ebenfallz Gelegenbeit baben, bie veridebenen animalifden (3ifte, benen baz \$y Edjlangenbiffe, bie Stidje giftiger Snfeften uno bergleidjen.

Dit bilft bei einem Fall yon Bergiftung nidutz. Daz Gift wirft

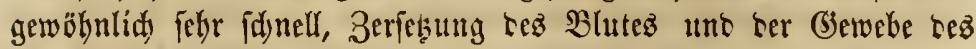

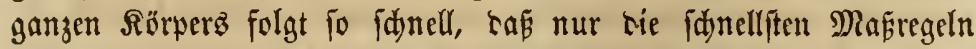

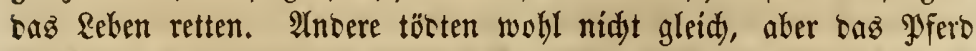
fränfelt uno geht vielleid)t erft Monate lang nadher zu (Brunte. Mandje Fä̈lle dyronijaler Rranffeeten fino bem 2lutor zur Beobad)=

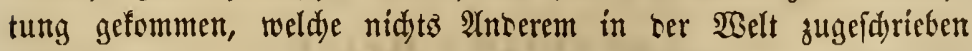
werben fonnten, als bem (Bebraud) giftiger Medizinen. Sold)e Mit= tel wiro ein intelligenter Farmer uno \$oferbeeigenthümer in feiner

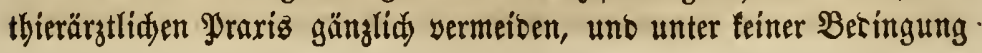




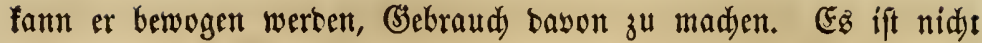
notbwentig, in irgent einem Fall fu foldyen (siften feinte 3 uflud)t fu $^{2}$ nebmen, tenn es gibt cine Menge anterer Mebizinen, weldje ebenjo wirffam fint, unt beren (Sebraud) feine fd)limmen Folgen bat.

Der Fall, baj ein Pfero innerlid) vergiftef wirb, fommt nidyt oft vor, auşgenommen, wie fđon erwäbnt, ourdy gleidygültigen uแt un= wiffentlidyen (Sebraud) gerwiffer fogenannter Scilmittel. Der Snftinft

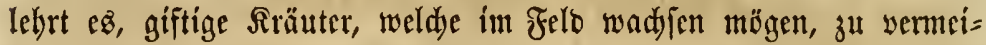

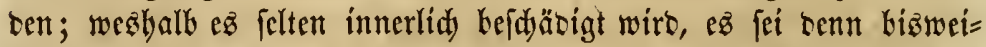
Ien ourd giftige Sräuter uno Ranfen, mit welden feine Naje beim (Srajen in Berübrung fommt. Bielleidft entfpritgt bie gröpte (5)e=

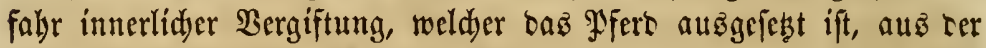

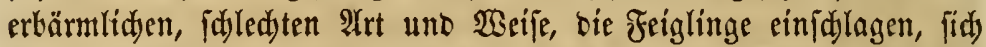
an einem Feinto zu rädyen, baf fie nämlidy fein Pfero vernidjten ober ruiniren.

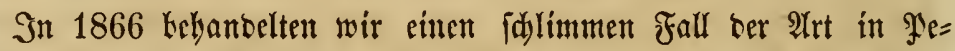
terşburg, Boone Eo., Ry. Ein junges Pferb wurbe burd cinen Hebelthäter aus Radyegefübl gegen ben Eigentbümer wergiftet, intem eine Mifdung an tie Raje gebalten wurte, fo baf bie Raje jur oreifadjen Gröp̃e anjđjwoll, mäbrento bie ganze Sberflädye mit grofien Blajen bebefft war. Die Bebandlung bejtant in 2 Bafdungen mít beifem Salgwaffer uno einem ftarfen 2 bjuס yon (5)elbwurgel (golden seal), momít alle paar Stunben abgewedjelt wurbe. Diejez ver= idaffte in furger Beit Rinterung unt in einigen Tagen war tas Pferb ganz gejunt.

In vielen Diftriften im Sulben unb Sübweften bat aber ber Far= mer siel mebr Uriadje, sie Biffe giftiger Sdylangen, Ineften u. 1. w., als irgento cine antere Uriadje ber Bergiftung zu fürdyten.

Die (Gegenftänte, weldye wir beabjidtigen in ticfem Rapitel ju behanbeln, mögen unter brei Rubrifen gebrad)t merben; nämlich in= nerlidje Bergiftung, Bergiftung ber 5aut unt giftige Ibiere. Das Restere idjlefst bie Biffe giftiger Sdylangen unto bie Stide yon Cfor:

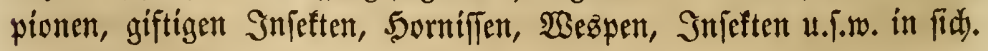

\section{In nerríte ifte.}

Diefes fino die Bsifte, weldye ibren fäbliden Einflus ourdy ben Dagen unb die Eingerocibe, weldye fie einfaugen, bem Drganišmus 
mittheilen. Mandje berjefben töbten ploblidid, finb aber aud fo be=

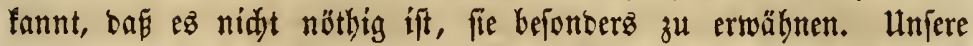
2(b)ifdt ift, gegen ben (B)ebraudy folder zul warnen, weldje langiamer

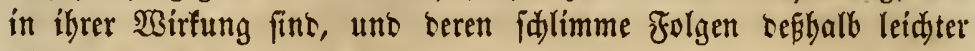
überjeken werben.

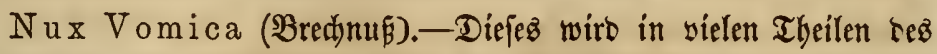
Rantez bäufig zur Blutreinigung uno zur Befürberung ber B̧ejunt: heit im 2(thgemeinen gebraudjt, aber nie ohne wirflidjen Edjaben für

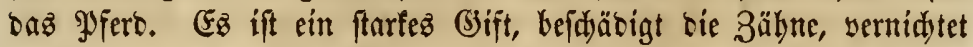
bie Thätigfeit bez Magenż uno Der Berbauungżorgane uno ruft eine allgemeine Unoronung ber Gescärme Gervor. Fine Beitlang mag

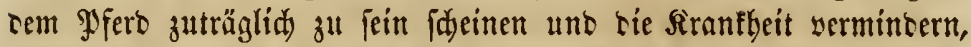

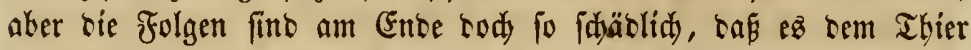

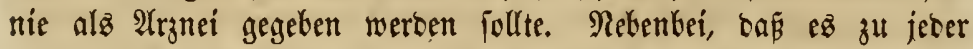
Beit ein unfidteres Mittel ift, if ez aud völlig überfluiffig, intem

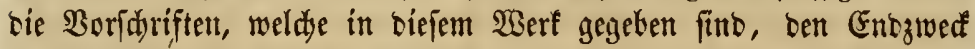
fidjerer uno ohne (Gefabe erreidjent.

Ilnter ben Eymptomen ser Bergiftung aus biejer Urjadye fübren wir folgente auf: Der $\mathfrak{J u l z ~ i f t ~ u n r e g e l m a ̈ ̄ ̄ i g , ~ b a z ~ M a u l ~ u m b ~ b i e ~}$ Bunge ift weî́, Ler Epeidjel fajerig, sie Rajenjijleimbaut purpur=

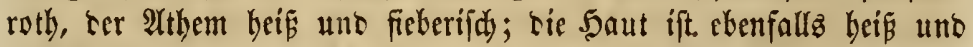
troden, sie 5 aare fint raulh uno fruppig. (Es ift nidt nothmentig, sak alle bieje Eymptome in jesem Fall vorhanten fint, aber einige fino immer zu bemerten, bistweilen fino antere uno fallimmere vor=

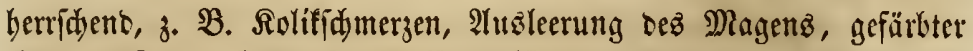
5arn u. f. w. STrämpfe uno Convulfionen mägen folgen, in weldjem Fall ber Too nidit ferme ift.

Das (Gegenmittel in foldem Fall if Fett. Man gebe bem Mferb

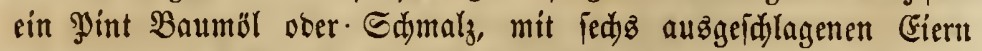
vermifint, um baz Bsift in 2luföjung zu erbalten, uno judbe bann ben Magen fo fannell alz möglíd zu entleeren. Man gebraudje wieberholt baz Rlyftier-ein Duart warmeż, ftarfeż Seifenwafferunt wieberbole ez jebe halbe Stunte, biz bie Entleerung folgt. Radjbem taz Del zwei Stunben gegeben ift, gebe man einen Trant ftarfez Salzwaffer, fo heif alz ez baz tieje $\mathfrak{B e i f e}$ mag es gerettet werben, ferbit wenn die Symptome ber 
Bergiftung ftarf fint; aber ber Eigenthümer roirt überauż glüđlid fein, wenn bie Rraft bez Poferbes nidjt bebeuteno beeinträdjtigt murbe, ober bafferthe fpäter feime farfe Reigung zur Rolif hat.

Im Sabr 1851 hatten wir cinen fehr idhlimmen Fall yon Fifitel in Bebantlung - โaż \$fero gehörte einem 5erm, Ramenz fowler,

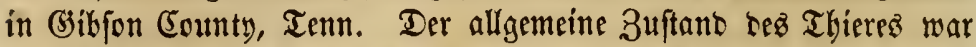
(a)ledjt uno bas $\mathfrak{B l u t}$ iehr unrein. Wäbrend unjerer 2(bwejenbeit uno natütlid) obne unfer $\mathfrak{B i f f e n ~ w u r r e ~ b e r ~ C i g e n t h u ̈ m e r ~ u ̈ b e r r e s e t , ~}$

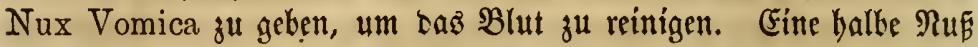
per Ing war bie Dofiz, unb nadjeem neun gegeben waren, ftarb bå arme Thier an Bergiftung am zehnten $\mathfrak{T a g e . ~}$

Spanifde Fliegen (Cantharides, or Spanish Flies).-Diefez

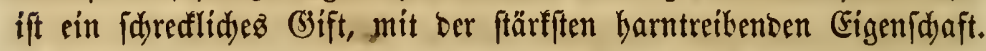
Ez ift unfidyer, felbft wenn ez in ber fleinften Suantität gegeben

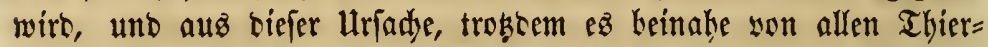
ärz̧ten mit mebre ober meniger $\mathfrak{B o r f i d y t ~ v e r j d y r i e k e n ~ m i r o , ~ m u ̈ f f e n ~ m i r ~}$

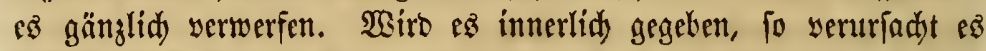

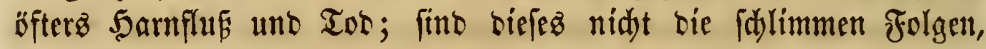
fo findet man gemöbnlid cine feitfitiente sirnutheit ber Sarnorgane, welde fidh nidyt felten auf ben Magen uni bie Eingemeibe aus: sebnt. Ez ift, ob ez in fleinen oter grofen (bjaben gereidgt wirt,

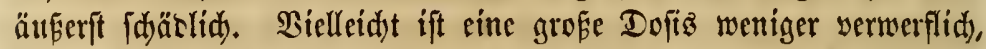
intem fie bas Thier jdynell von feinen Seiben befreit, währent eine fleine $e$ lang $\{a m$ einem qualyollen Tob entgegenführt. Cinte Dradjme töstet baz $\mathfrak{P}$ ferb in furzer Zeit.

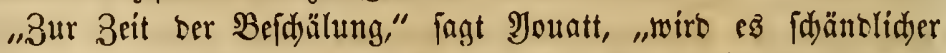
Weife zur Erregung Iem Sengit wie ser Stute gegeben, uno man= d)es werthyolle Seben geht burd biejen gräuliden (Gebraud verloren." wir beftätigen biez uno gehen nod) weiter, intem wir fagen, sá

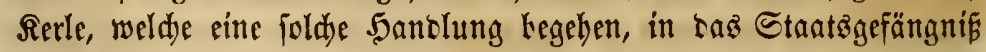
gejdifit werben jolten. 2rker, befrembent genug, veridgreibt tiejer, fonft fo vorfidtige Thierargt ipanijde fliegen (Cantharides) in

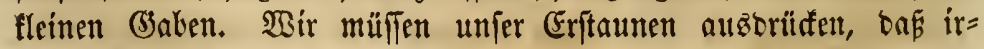
gent eine adjtungżmerthe 24utorität für irgent einen Fall biefes Mittel anempfieblt; unjer Rath für bie Farmer ift: gebraudyt nie fpanifje fliegen unt weifet ben unwiffenben Buriden, welder eud 


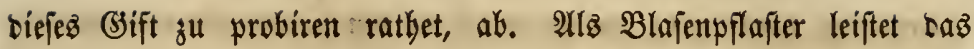
corrofive Riniment allez, waz ipanifdez Fliegenpflafter nur thun

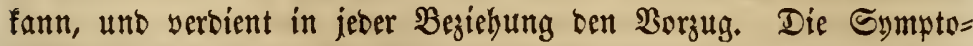
me yon biefer Bergiftung fino ein beifer 2 them, fontelfer uno un=

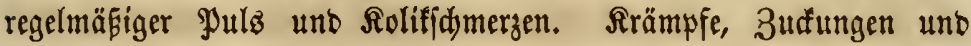
Ioo folgen fduell nad.

Ez ift idwierig, ein (5)egenmittel anzugeben. Wenn bu fold ein Thor warft, beinem Pfero fold) idyredlidyez (sift zu geben, fo fannit bu bir bei einem töbtlidyen $\mathfrak{A}$ ügang fagen, Lafi ou bcin Thier zu (Srumbe gerid)tet babeft. Ein Pint Ricinub $=$ Del (caster-oil), um auf bie Eingerweibe einzumirfen, fedyz frifde Eier, um ber Wirfung Dez Giftes Ginbalt zu thun, uno wieberbolte Rlyftiere mit war= mem Seifenwajler, ift alles, was gethan werben fann; aus̄genom= men, fid zu entid)liefen, nie wieber foldje Thorbeit begeben zu mollen.

Eifenvitriol (copperas, or sulphate of iron). - Diefez ift eitte andere Subftanz, welde biżweilen gegeben wirt, um bem ganzen

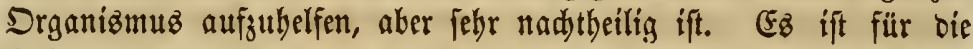
3äbne und ben Magen febr fdäblid, uno follte bei ber Bebanblung von $\mathfrak{P}$ ferbefrantheiten gänjlid, bei Seite bleiben. Sm allgemeinen fino die Sdjwefeljäuren uno falpeterjaurez Supfer, Błlei, Siller uno Zinf (sulphates, acetates, and nitrates of copper, lead, silver and zinc) giftíg für Pferbe - wenigfteno in fold)em (3rat, bap fie nie innerlid) follten gegeben werben, obwobl mandje bason mit be

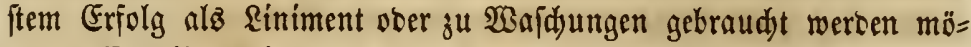
gen. $5 \not{B}$ gibt brei Arten yon Mineralien, meldye alz Mebifamente gute Dienfte leiften, uno beren vorfidtiger (Gebraud bejonters an= empfoblen werben mag. Dieje fint: Eifenoxio, Salomel (jublimirtes Duedfflber) uno falpeteriaures Rali ober Pottajde (oxide of iron, calomel and nitrate of potassium).

A

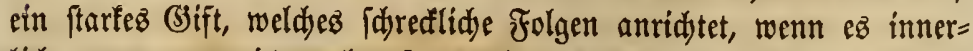
lid) genommen wiro; aber fo töbtlid) $e B$ aud) ift, fo billoet $e B$ in Verbinbung mit anberen Subjtanzen einez ber wertboollyten Rini=

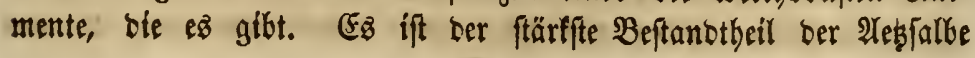


384 Das Pferdebud desి amerifanifden ซึarmers.

(corrosive Liniment), weldye fo oft in ben vorkergebenden Rapiteln anempfoblen ift.

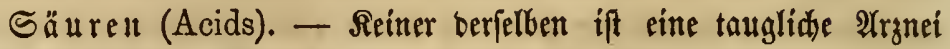
für bag Pferb. Ez gibt Effig=, Zitronen=, Salz=, Sdwefel =, Sal= peter $=$ Weinftein $=$ Rlee = uno Berlinerblau $=$ Săure (acetic, citric, muriatic, sulphuric, nitric, tartaric, oxalic and prussic) - alfe

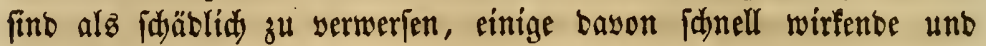
tóstlidue (sifite.

Ilfalien, \&augenfalze (Alkalies) - unb alle ifre Salze mö= gen zu Beiten mit Bortheil angewanot werben, um verfäuerten Ma= gen in Dronung zu bringen, voer alz milbe uno fidjere harntreibenbe Mittel. 3u biefer Rifte gebört jalpeterjaurez Rali (Pottajdy)

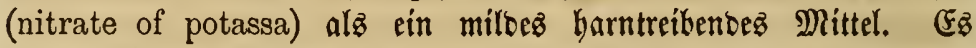
pollte in fleinen Gaben uno nur bei Sranffeiten ber 5arnorgane ge=

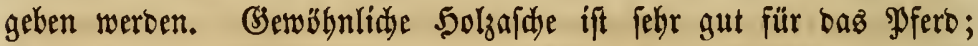
wenn es im Stall fteht, follte erbalten, aber natürlid in geringer Portion. Der Magen bes Pferbes ift zur Säurung uno Säbrung febr geneigt. Säure ber = mebrt biejen 3uftano uno ruinirt Das Pferb, wäbrenb \&augenjalz benjelben bebt uno sem SPfero bilft.

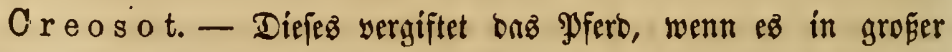
Suantität gegeben wirb, aber zebn Tropfen in warman Waffer ge= geben thun gute Dienjte bei Srämpfen unb Binblolif.

Iabaf. - Diefes Siraut ift cin Bsift, obgleid viele Männer bieje Thatjadye nidyt zu abnen idyeinen. Fr follte bei thierärgtlidjer Bebanolung nidat innerlid gegeben werben, auper bei ber 3 Burm=

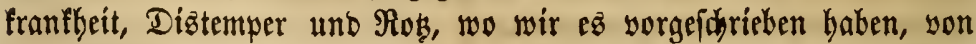

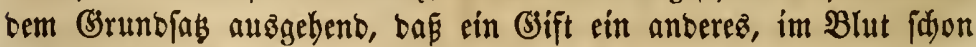
verbreitetes neutralifirt.

Theer (Tar). - Diefe Subftang ift nidyt giftí, follte aber nidyt gegeben werten, eż fei benn, man sermenge fie gut mit Del;

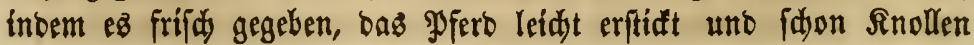


baburd im Magen gebilloet wurben, weldue ben Tob berbei fübrten. Fz bat wertbyolle auflöfente Eigenfdaften, wenn $e z$ mit anseren Subftanzen yermengt ift. Theeröl (oil of tar) pollte nidat gebraudit werben.

Ierpentin (turpentine). - Terpentin ift aus̈gezeidnet, wenn er äuperlid, angewentet wirb, wie $z . \mathfrak{B}$. in Form yon Riniment. Die beften, flüfitgen Galben fonnten nidjt obne Terpentin zubereitet werben, benn es ift ein widjtiger Beftandtheil berfelben. $F_{\mathfrak{B}}$ ift eitl Saut röthentez Mittel uno šffnet bie Poren, fo sap andere $\mathfrak{B}_{e}=$ ftandtheile bes Riniments fo viel befler wirfen fönnen, aber $\mathfrak{e s}$ inner=

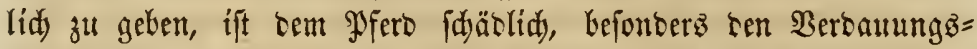
unb Sarmorganent. Terpentinol follte burdjaus nidyt gebraudyt wer= ben. Daz Terpentin anberes.

Bred weinftein (Tartar Emetic). - Diefez mag mit Bor= theil in fleinen (Saben gebraud)t werben, um baż Fieber zu linbern,

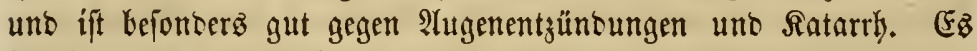
ift ein frarfes Brectumittel, tub in gröpjerer Suantität gegeben, Gat

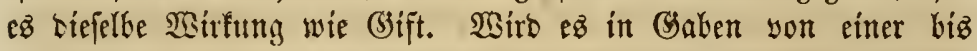
anterthalb Dradume, in Berbinoung mit Salpeter uno Fingerbut

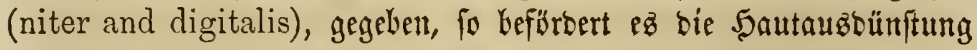

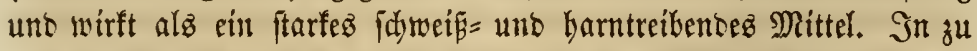

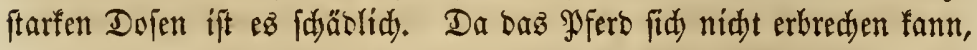
fo ift $\mathfrak{B B}^{\mathrm{B}}$ am fidjerften, wenn man $\mathfrak{B}$ red)weinftein (tartar emetic) mit einigen fleineren Dofen Bitterjalz (salts) gibt.

Croton=Del (Croton Oil). - Srofé Sefabr ift mit bem

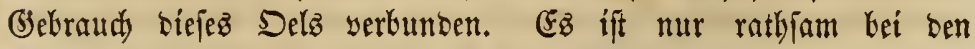
fa)limmiten Fällen yon Berftopfung unb Darmeinztwängung. (FB

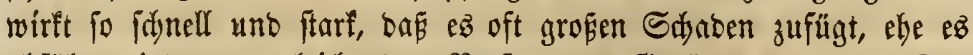
abfübrt, indem $\mathfrak{e}$ leidt bas Beriten ber Gebärme und ben Tod Gerbeifübrt. Die Doftz iff yon 8 biz 10 Tropfen in etwaz war= mem $\mathfrak{W a f f e r , ~ a b e r ~ e z ~ g i b t ~ f e b r ~ f e l t e n e ~ F a ̈ l l e , ~ i n ~ w e l d u e n ~ e i n ~ g e l i n = ~}$

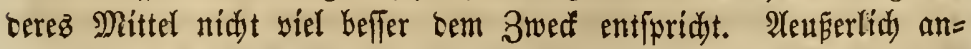
getwanbt, in alfen Fällen, wo man ein wirffames Riniment braudit, 
ift Croton= (sweet oil) vermengt werben, intem man zu zelhn Tropfen Croton= Del (croton oil) vierzig Tropfen $\mathfrak{B a u m a l l ~ n i m m t . ~ M i t ~ e i n e r ~} \mathfrak{B} u$ rffte ober einem Rappen aufgepest uno gut cingerieben, wirft ca fehr gut gegen Rolit, \&ungen= uno Gecbärmentjüntung, Rerventeiten $\mathfrak{u}$. f. w.

Daz Giegenmittel für cine zu ftarfe Dofís Groton=Del (croton

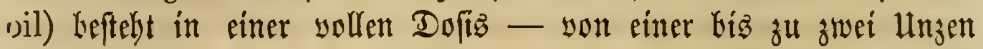
Rautanum (Laudanum), welder in vier Stunten ein balbes \$Pfunt Bitterjalz (epsom-salts) folgen follte.

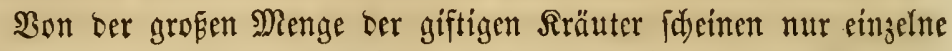
bem Pfero befonberz fääblid zu fein. Es ift in ber That fehr zweifellyaft, ob in unjerm Rano irgeno cine Pflanze wädyjt, surd

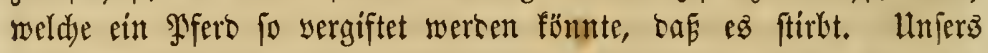

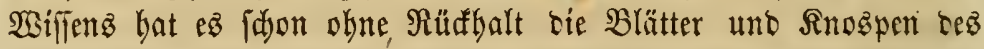

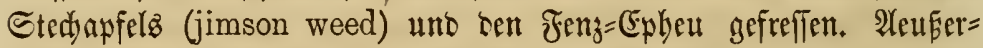

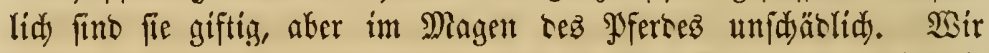

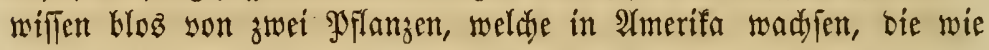
(3ifit mirfen, wemn

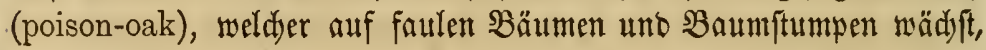

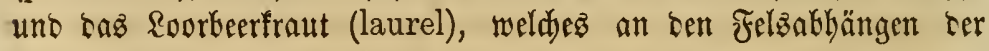

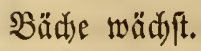

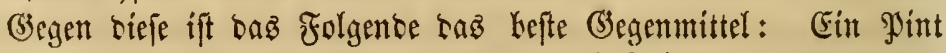

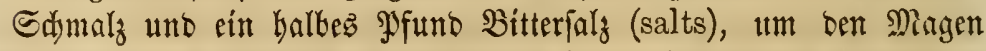
fo idnell alz möglidh żu entleeren, in zwei Stunten fann man etwa Raltwaffer geben.

Iolffiride, $\mathfrak{A}$ dithatten (Belladonna or Deadly Night-

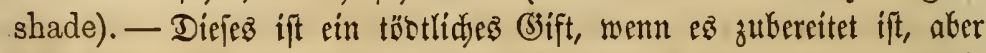

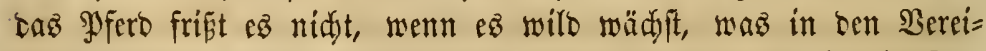

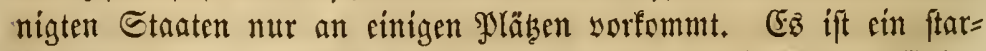
fez Betäutung

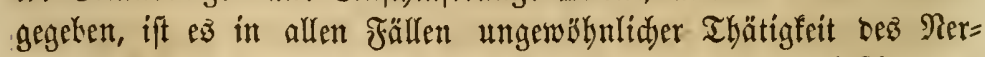

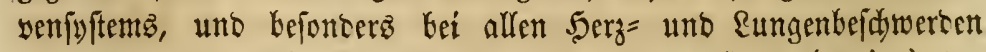
fehr werthyoll. Die babe ift fünf ober fectzo (3ran (grains) ber

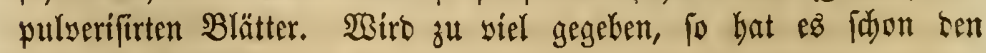
Tob verur[adjt. 


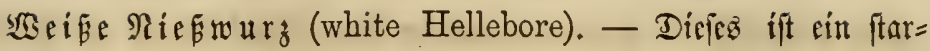
fez (3ift, uno bezbalb febr gefübrlid in ben Sänten folder, welde

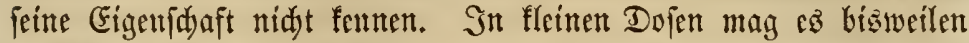
mit Erfolg angewanet, follte aber immer mit ser gröften Borfid)t gebraud)t werten. Es ift ein ftarfes 2(bfübrungsintittel uno febr mirffam. Bei \&ungenfranffeiten, befonters bei-\&ungenentjüncung,

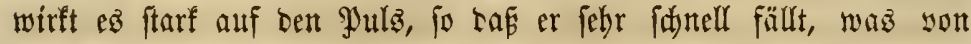
bem Cinflup berrübrt, Ien biejes Mittel auf bas Serz ausitibt, wel= d)es, falls man eine ofer anterthalb Dradjmen (drachm) eintibt, für immer zum Stillftand gebradyt wirt. Fine balke Dradume ift eine grofe Dofis, und cin siertel Dradyme ift fo viel, als obne (Gs= fabr gegeben werben fann. Man jollte nur in ben alfe fidlimmiten Fällen feine 3ufludt zu biejent Mittel nebmen.

Der beryorragentfen Gymptome bei Riefrourg=Bergiftungen fint

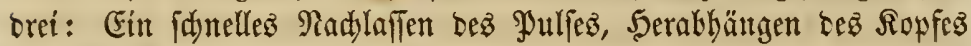
uno Sduaum yor Im Maul.

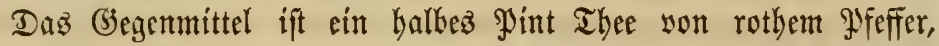
mít ciner balben Unje Raubanum ober ein und einer balben Dradjme Dpium Iarin.

Sdy warje Niefrwurz (black Hellebore). - Diefe, fowie tie

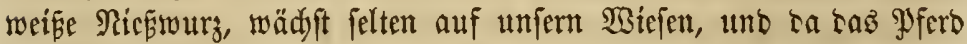
gegent beibe abteigung bat, fo ift wenig (3)efabr für rallelle; aud wiro fie nidyt oft son tem Farmer gebraudyt. Die fdyarze Piefs=

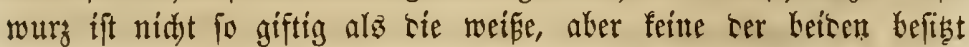
Figenid)aften, weldye Ien innerliden (jebraud redjtfertigen. Für

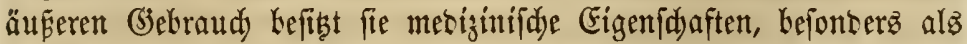

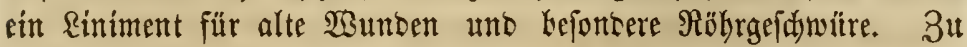
biefem Zwed follte man ben biffen Syrup mit etwas Sdjmals ge= mengt, weldes eine gute Galke gibt, gebrauden; jesod) nur in geringer Suantitüt unto Klos einmal.

\section{(B) ifte, welde burd bie baut einbringen.}

Aebendes Saeffilber= Sublimat (corrosive Sublimate). - Diejes ift ein febr wirffames, reizenbes Bift, uno polute nidit

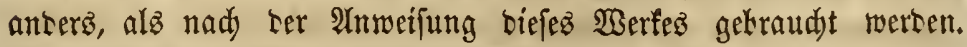
Mit gewifien anberen Subftanzen, welde in einem bejonberen 2 bs= 


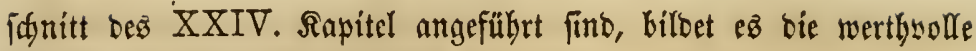
$\mathfrak{A}$ etgalbe (corrosive Liniment).

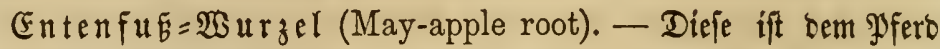
ein (Bift, went fie innerlid) gegeben wirb, und eine verftopfente Medizit, nadjem biejelke ftarf abgeführt hat; wefhalb fie nie

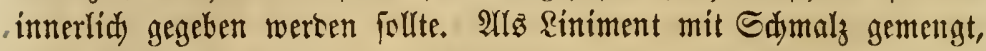
wirft fie gegen Fiftel uno Radenfiftel erfolgreider, als irgent ein anterez Mittel. Der bloṕe Extraft ift für baz PJfero ein ftarfez (3ifit und follte nie unvermengt gebraudit werben.

(3) iftiger Sumad) (Poison Oak, or Running Sumach). -

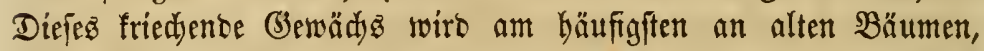
auf Steinhaufen uno bergleiden gefunben. Sbgleid taz \$perd

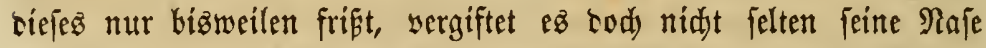
uno Shren uno aud bie Füpe, wenn tiejelken auf ber Weite ta= mit in Berührung fommen, weldes (a)limme Blajen uno grinto

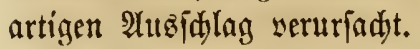

Die Befandung ift folgenbe: Man wajde baffelbe brei= biz vier=

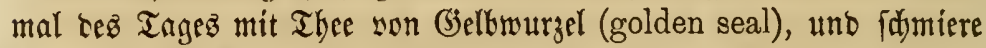
2⿰亻弋 wajaje man bas Fett mit warmem Seifenwaffer at, wajde bie ke= treffenten Theile wicber mit rem âkifub non Belbwurgel (golden seal), uno fahre auf biefe Weseife, fo lange alz nothwentig ift, fort.

Ez gibt veridjebene antere giftíge

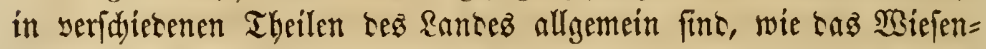

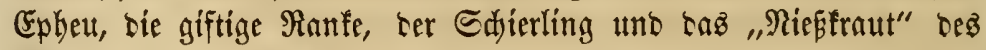
Sü̉enz nebft anteren. Daz lebtgenannte Rraut ift eine grofie ફJlage

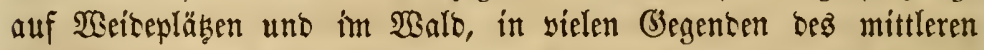
Tenteffee's, wo mandje Fohlen uno Yjerbe in ben Monaten Altguft uno September surd) baffelte faft ruinirt werten.

Die Behandlung bei allen äuferen $\mathfrak{B} e r g i f t u n g e n$ biefer 2 trt ift biejelbe, weldye bei sem giftigen Sumad̆) (poison oak) - Gäufigez

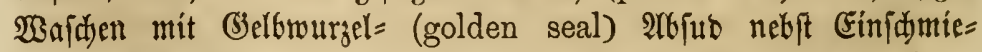
ren bez 2henbz mit altem Sdymalz. Sollte bie Bergiftung, wie ezs

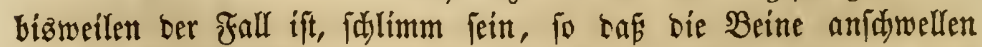
unb bie Gelente fteif werten, fo fann man biefelben mieserbolt mit 
beifem Saljwafler wajden uno mit ben Şänben ober eitter Bürfte gut einreiben.

\section{(B) iftige Ibiere.}

Shlangenbiffe.-Der weftlidje Theil unjers Ranbes ift mit weridjebenen $\mathfrak{A}$ rten yon Sdjlangen uno giftigen Snjeften ftarf beyöl= fert. Mandye ber weftlidyen uno fübweftlidyen Staaten, bejoncerz bie, welde an ben Mifitifippiflue grenzen, fino fehr ramit geplagt. In $\mathfrak{W e f t}=$ Tenneflee, wo wir früher wohnten - ein Rant yoll yon

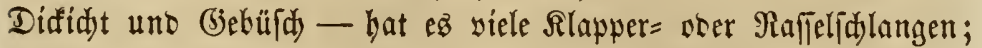
fie finben fid oft im frofraum uno bistweilen felbit unter ber Ibür= idwelle, uno fint fajon in Blodfläujern uno Etällen getöotet wor=

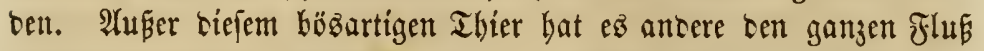
entlang, uno in ber Gegens, Die er in [üblidyer Ridytung ourdyftrömt,

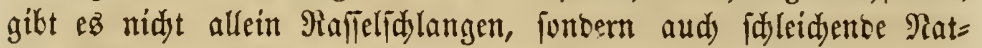
tern, Moccasins, Cotton Mouths uno fdwarge Walferidjlangent.

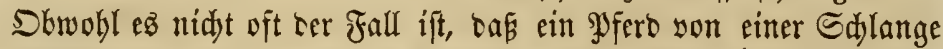

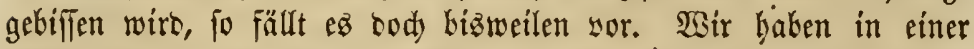

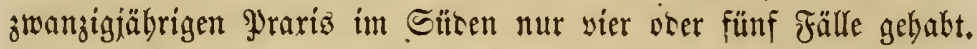
Fajt alle Sd)langen geten jebem Thier eine Sarnung. wenn Daffelbe fid) naben will, und รaв \$jerb verjäunt nie, auf biefelbe zu adyten

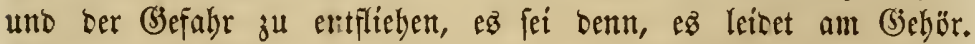
Ille, weldye unbeftreitbar giftig finto, fitto nidyt in gleidjem Mape giftig, incem bas eime (sifif mirffamer wno ftärfer ift als ras anbere. Da aber rie Sualität res (biftes fo ziemlid bie gleid)e ift, fo ift in allen fällen eine uno biefelbe Bebanslung einjuldylagen. Daz gewöbnlidjpte uno wirfjamite (s)egenmittel ift guter; ftarfer Whištyeine balbe Pinte jede balbe Stunde in marmem Waffer mit etwas fauftijdem Ammoniaf (harts-horn) - uno beftändige $\mathfrak{B a j c h e n ~ s e r ~}$ Wunbe mit heifem Saljwaffer. Ein balkez Pfunb Salz follte gleid anfangz gegeben werten. Diefe Bebantlung beilt bas YJiferd, wenn man jofort mit ber Bebanclung beginnt; nadjem aker (bejd) wulft fid) eingeftellt hat, ift fein Dittel zuverläfïg. Starfe Fiterung und Rnodyenfras ftellt fid jebenfallz ein, weldyem :Sabnjinn, Blinobeit, 3ufungen uno ser Tob folgen.

Entoedt man ben Bif fogleid), fo wäre ę befler, man würoe die

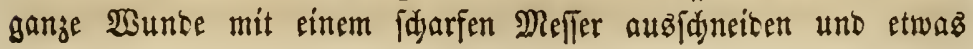


corrofitees \&iniment eingief́en, ober in Ermangelung beflen mag etwas pulyerifittes Sublimat bienen, aker bie vben angefülutte behand=

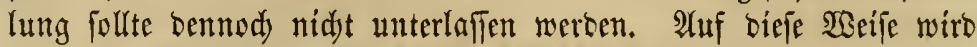
tem (B)ift fräftig entgegengewirft. Ein Fingerfut auf bie Wunbe gebrildt uno feft gebunten, hat fajon oft baz (Jift berausgejogen uno bie (seidiwuljt verbütet.

(3) iftige Spinten.- Spinnen hat man in Menge in jebem. Theil bes $\mathfrak{R} a n b e s ;$ aber nur wentige fint bejonders giftíg, ober bei=

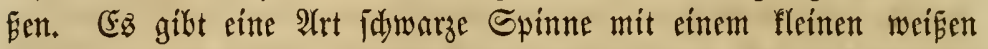

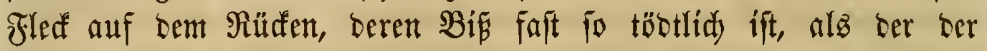

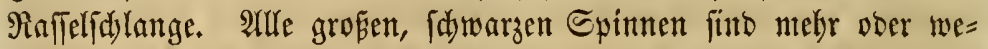

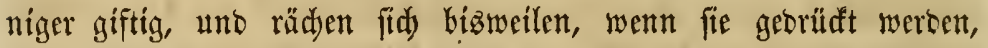

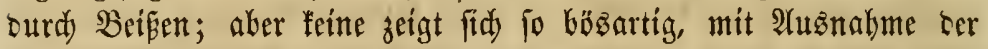
fajrectlidyen Iarantel in ben Ebenen yon Texaz, alz bie fdon er= wähnte. Diez Utngeheuer, beflen Rörper oft zwei 3olf lang wirb, mit Beinen von boppelter Ränge, greift Meniden unt Thiere an,

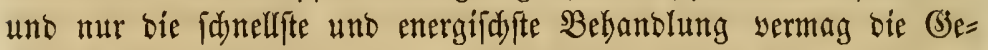
bifi enen zu retten.

Die P̧ferbe leiben burd) bieje Snjeften Gäufiger, alz allgemein an= erfannt wirb. Man findet zuweilen Beffdyulfit an ber Maje ober ben Beinen, waz ber (Eigenthümer gewöbnlid) einer anterent Urjadye

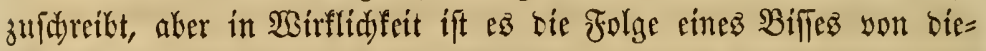

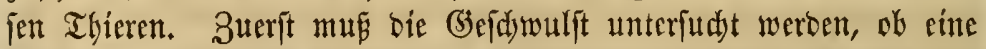

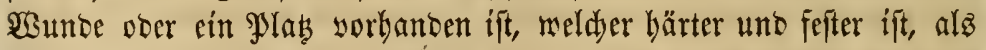
bie 5aut ber Umgebung. WSenn [0, follte man ben Fall bebanteln wie Kei $\mathfrak{B e r g i f t u n g . ~}$

Die Bebandlung ift folgende: Man gebe ein balbes \$int guten Whisty in warmem Sarfer uno einen Theeleffel woll fauftifden

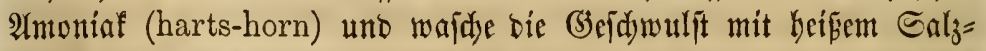

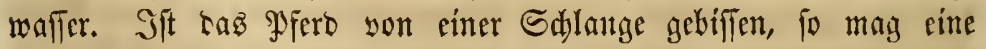

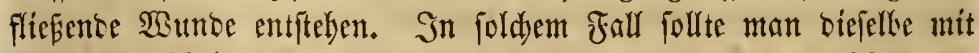
corrofizem Riniment jwei bis brei Iage lang wajdjen, weldes un= feblbar beilt.

Der Sundertfuf (the Centipede). - Diefez if cin giftiger

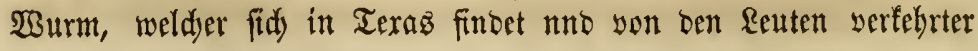


Weife Santa Fe genannt wirb. Er fintet fid bauptfädlid in alten

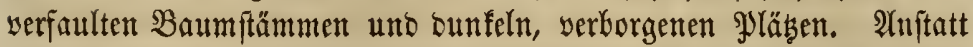

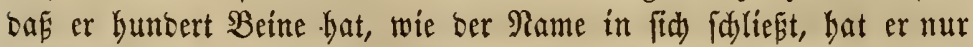

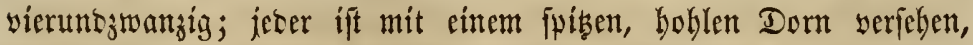
auz weldem $\mathfrak{b a z}$ (3ift,

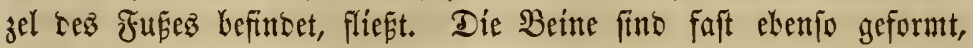
wie bie Sauer bei ciner Edjlange. Diefes giftíge Thier ift nidjt

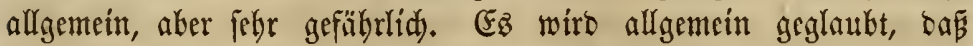

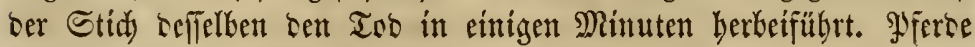
uno Rinovieh werben oft baburd getöbtet.

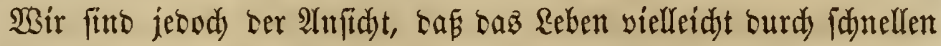

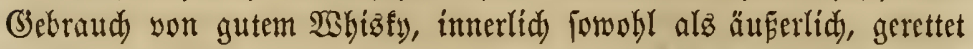
wersen mag. Derfelbe jollte mit ebempo viel fauftifdem Immonial (harts-horn) vermifd)t fein.

Stedento Sforpionen (stinging scorpions). Diefé Thier fomm in benfelben (jegenten sor, wo fid ber 5undertfup (Centipede) finbet. Man trifft Säujern, Etällen, unter bem $\mathfrak{C o l}_{\mathfrak{z}}$ uno in faft allen \&ädern uno Seffunngen. Sie fonmen atı ibrem Berfted mit Blikesfd)utle, fallen über Menfiden ober Thiere her und judden fid unter ber Slet= oung ober ben 5 aaren zu verkergen; werben fie im geringften geftört,

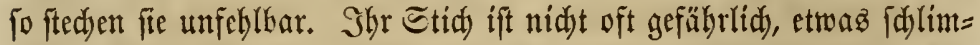
mer alz ber einer $\mathfrak{Z}$ sezpe ober 5ornifle, uno obgleidy or aber $\mathfrak{A} n=$ fang mentig Edymerzen verurfad)t, fo werben biefelben nady einer halben Stunbe fehr heftig.

Die Symptome fint jehr fonterbar. Die erfte Empfintung bez Sdjmerzez wirb unter ber Zunge gefüblt, welde) eine Zeitlang faft be= wegungsloz bleibt. (jeidjwulft uno Sithe zeigen fid in ben Theilen,

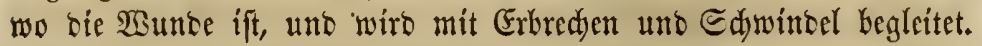
Bei bem Menjajen enten tieje Enmptome oft auf eine gefährliche Wieife, aber meldhe Wirfung ein joldter Etid auf baz Pferb ausübt,

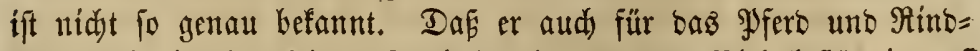
vieh) giftig ift, hat feinen 3meifel; aber wo bas $\mathfrak{B}$ iel beftäntig auf ber $\mathfrak{B}$ seire fid befintet, bietet fid wenig Gielegenteit bar, bie Folgen. zu beubadjten. Sn Teraz ift $\mathfrak{W h i z h y ~ b a z ~ M i t t e l ~ g e g e n ~ a l l e ~ b i e f e ~}$ Ulebel. Wiro Semano won einem Elorpionen geftodsen, fo nimmt 


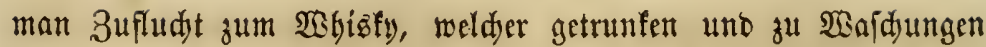
benubs wiro, unb balo Rincerung seridafft. Die Bebantlung ber Sperbe in jolduen Fällen ift siejelbe.

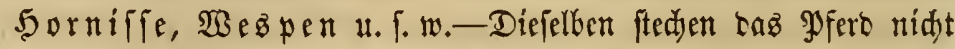

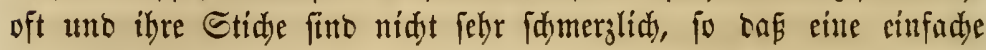
Boridrift zur Rinterung ter Eumerzen genügt. Buerift trüdfe man bas grofe Ente eines Fingerbutez um cen Etidy berum, um einen tiefen Einbrua auf bie Jjaut ju madhen, unb wajde tann rie Etelle

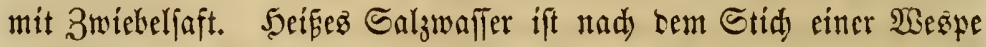
ofer Biene söllig fo gut, als irgeno etwa anteres̄.

In eingelnen Fällen haken Rartoffelfliegen (potato-fly) ntuo Räfer Pferse vergiftet. In riefem Fall idmiere man bie Sherfläde mit Sdmaly, majhe es in zwei Stunten mit Seifenmaffer mieber ab,

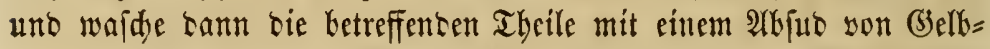

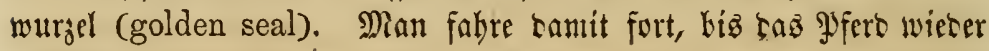
gefunt ift.

Brem jen, Mï đen u.j.w. (gad-flies, gnats \&c.).—Diez ift ber geeignete Wlak, en Gdjaben gewifier. Infeften, weldje jwar nidjt giftig fint, aber yon fom Farmer im Cilsweften nebr gefürdtet werten als Sd)langen u. . w., anjufübren.

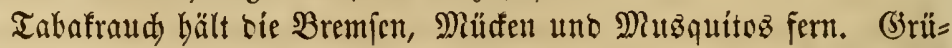
nesె Flohfraut (penny-royal) an Lem Ropf ober unter Iem Zaum befeftigt, treibt fie ebenfalls fort; ober man fann aud sen Rörper unb tie Beine mit einer 5antwoll biefez Rrautes einreiben. Srgeno eines ber riedbencen Sele bält fie fern, wenn foldje Etellen tamit beftridien werben, wo fie fid am liebjten nieberiebett.

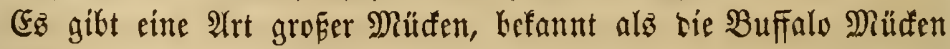
(buffalo gnat), ungefähr ein Drittel gröfer alz bie gewöhnlidue Müute, welde in ton niestigen, fumpfigen Begenten tez Miiffifippi eine grofe Plage für Pferte, Maulejel unb Siridse ftnt, aber antere Thiere nidyt wiel beläftigen. Sie fommen in ben erften marmen $\mathfrak{T} a=$ gen Tez Frübjabrz bei Millionen uno ïberfallen bie Thiere mit mörterijder $\mathfrak{B u t h}$. Sie bebefen tie Seiten, ben \&eib, Bruft, Sals uno Sopf; bie Najenlöder und Shren fint voll von senjelben; werben fie nidt serbintert, fo friedyen fie tie Rajenböblung binauf, 


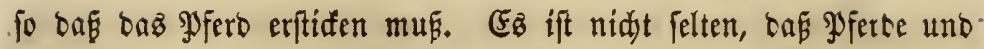
Maulejel burd biefelben getörtet werben. Bielleidyt fünfizigmal bin

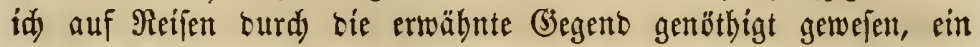
Büjdel Reifig zu nehmen uno fie megzujagen, währent Las \$ferb im yollen 'Trab auf Theer beidmert zu werten, bas einjige Dittel, woburdy man sie golage ferne balten fann.

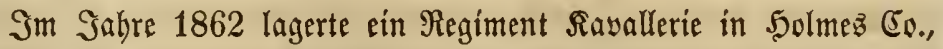
Mifitifitppi, nahe, wo ser Autor tamalz wohnte. Sn einer Radyt wurben fünfunbrreipig Maulejel burdy biefe Müfen vernidjtet - cine That jacte, weldye unz periünlíd) befannt ift.

Säger madjen oft grofé Feuer, Jünten alte Bäume uno tergl.

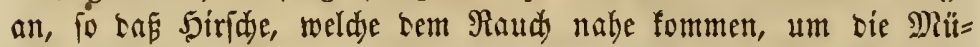

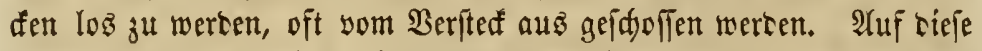
Weife werten oft viele nidjtzabnente Iljiere getöntet. Die Siridje yerla flen alle bie Sümpre, unt. gehen in'ż Snnere, menn bieje Müđen bejonbers läftig fint. Die Buffalo=Müưe beläftigt ben Meniden nie. Der Sdwwarm fommt plöglidy uno seridrvintet auf

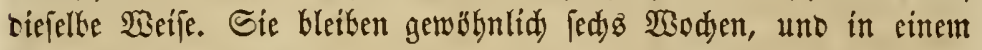
Iag fint fie alle eben fo fajnell wieber verjdmunten, wie fie ge= fommen finto.

Seser Reger auf ten Baummollen=

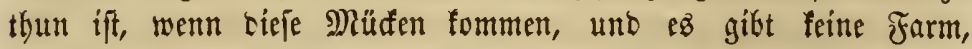
wo nidjt jecen Morgen ein Gimer yoll Theer uno Sdymals in's Felo getragen wirt, wenn biefe Müfen fommen, um \$ofero uno Maulejel bamit einzuldymieren.

Der Bohrourm (the Borer-worm). - Diefé ift bie Earye ober Mate einer baarigen ober molligen Fliege, weldye in Den Efenten yon Teraz fidy fintet, unt ein Sdyrefen Der Pyerte

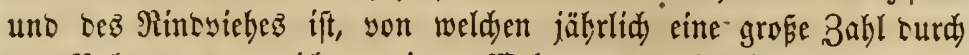

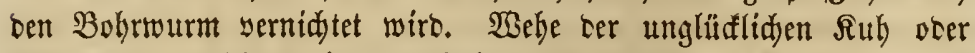

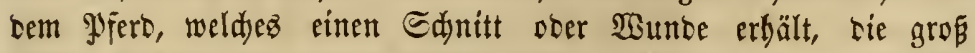

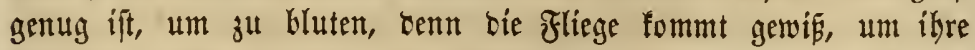

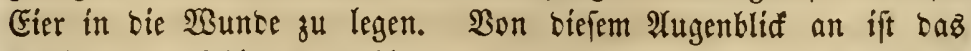

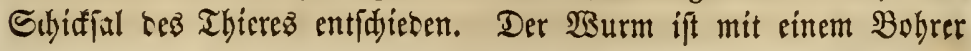




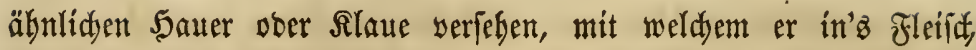
eintringt, bieféz ift ber $\mathfrak{2}$ nfang yon ber $\mathfrak{B}$ efitznahme feiner Beute.

Die Thiere in ben (Ebenen idjeinen alle eime inftinftäbnlidide Furdjt

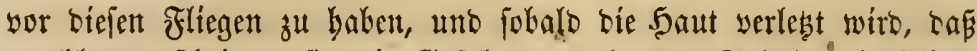
ez blutet, faseinen fie bie befabr zu ahnen. Cobalo bie fliege fommt, läuft baz eridyreftete Thier tavon. Afber gerabe basurd) fam=

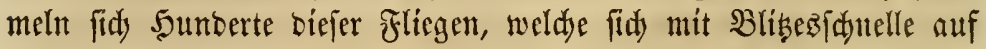

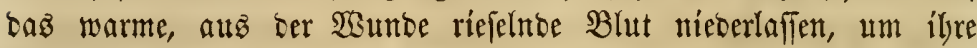

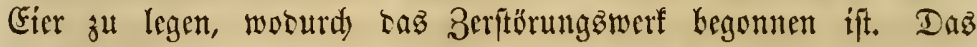
Dpfer hört nur bann z̆ laufen auf, wenn es̃ völlig ermübet ift, unt frengt fid alobann an, bie fdreeflidjen Feinte megjutreiben.

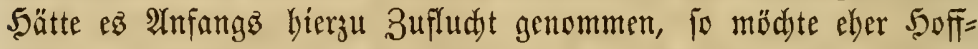

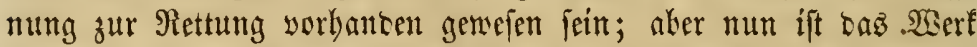
begonnen, baz arme Thier muß́p fid) feinem Edjiffal ergeten, uno taujente yon Maren leben in ter 2 sunbe. Sobald fid ber Ketref=

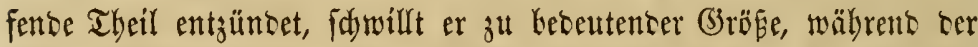

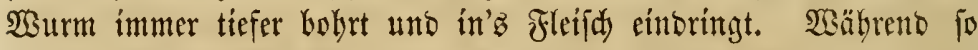

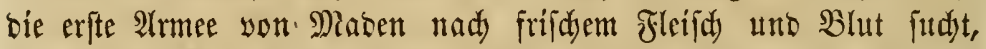
legt bie fliege neue Eier binein, weldye ten vorbergehenten im Eu= den nady Fleifid zur Rabrung folgen. Die 5aut kílbet einen Ead ooer Beutel, weldye sie surdyfreffenten Theile zufammentält, ¿ñ

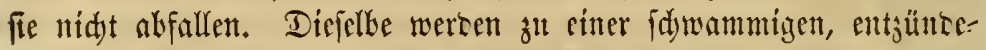
ten Mafie Fleifd, auz weld)en cin efelfafter Eiter flief́t, weldjer

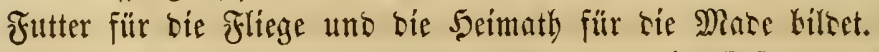

Der Sopf und bie Sdyulter werben am bäufigften angegrifen,

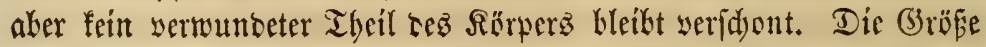

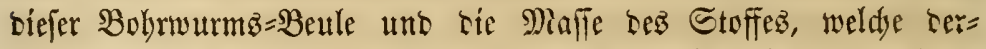

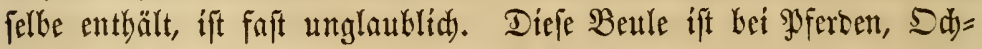

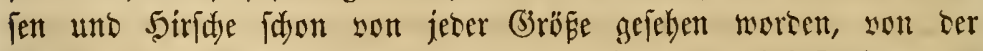

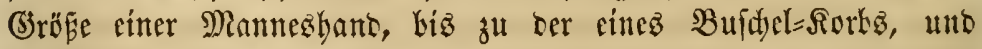

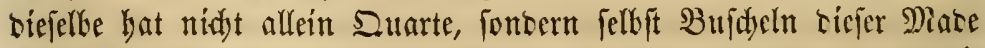
enthalten. Der Tod fommt bem elenten Ibier zur Sülfe und befreít ez you feiner Dual.

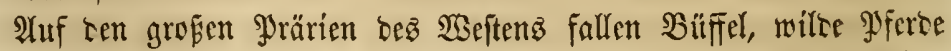

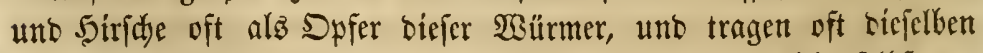

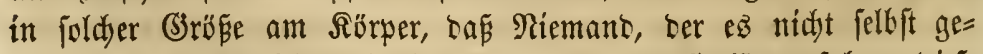
feben hat, bie Berridjte glauben fann. Jaerte Mölfe verfolgen biefe 


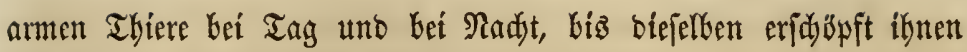
als $\mathfrak{B}$ eute anheimfallen uno verzebrt werben.

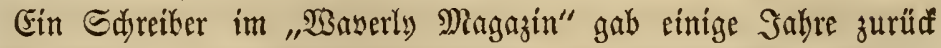
eine getreue, aber traurige Bejd)reibung son ber Berftörung, weldye ser Bobrwurm auridytet, unter ser lleberidyrift "B̉üffelmate". Der

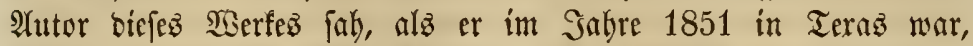
mebrere ser oben bejdricbenen Fälle, obmobl nidyt bie faltimmiten, uno börte bie Reute in ber Gegento oft won ben fdredtlidyen Wir= fungen riefer abidjeuliduen Mlage reoen.

Ez wurbe als fidjerer Tod betradytet, fobald bie Bobrfliege

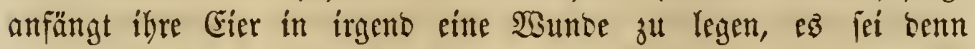
Tas Thier witrbe aufgefangen uno ber $\mathfrak{W u r m}$ burdy fleiffige $\mathfrak{A}$ (n= wenoung yon Ierpentin getöbtet; unt felbft biefes erweist fid nidht

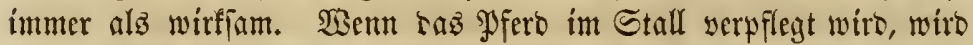
eรี nidyt geplagt, und wenn ez braufen auf irgeno cine Weife ver= wuntet wirt, fo fann ez leidyter eingefangen uno bie Sterfläbye gegen die Jliege geidüht werten, biz bie :

EB wurse bort jugegeben, Daf Terpentin fein fidyerez Mittel in allen Fällen jur Bernidtung โes Bobrwurms fei, uno wenn $\mathfrak{1}$ erfolgreidy fein foll, fo muв ę beftänsig gebraudst wersen, wäbrent bas Thier eingepferdyt ift, bis es wolffommen gebeilt ift. WSir glatt= ben ein Mittel zu befizen, weld)e ben Grforternifien wölig entiprid)t, und weldyez, wenn ein= ober zweintal angetwanot, ben (STuno ter Beule crreidyt uno alle Arten son Ungeziefer fidjer tïstet. Dieję ift ธas corrofime Riniment. Mian fanncise die Beule auf, um bie Diaten zu entflöfen, uns gief̧e eime reidylidue Suantität son rem

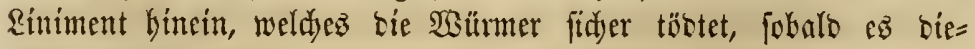
jelten terührt.

Das corroftse Rintment Kefibt Lie Eigenthümlidyfeit,

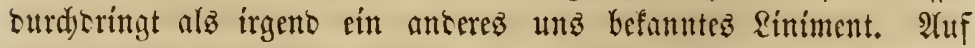

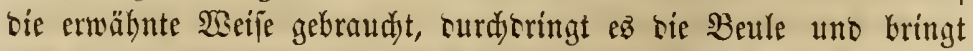
bem gröften Feind ber Sferbe fidueren Tod. P(Hejefen yon feinem

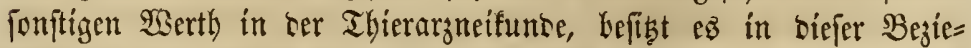
bung einen unidjäbbaren $\mathfrak{W}_{\text {erth }}$ für ben Farmer in Teraz uno in ben fübmeftliden Prärien überbaupt. 


\section{Giebrefintes sapitel.}

\section{fthtterumg und Bebandlungmeife.}

Mit biefem Rapitel beginnen wir bie zweite 2 ebtheilung biefez

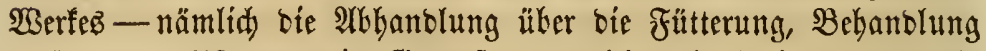

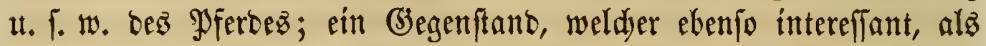

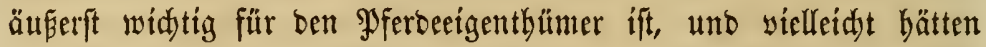

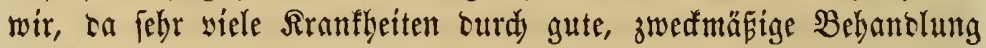
verhütet werben fönnen uno yon berfelben sie biefundheit fowohl

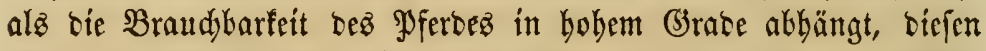

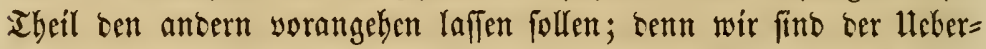

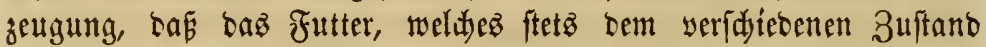
unb bem $\mathfrak{A}$ ther bes Pferbez angemeffen feyn follte, auf bas Blut ulto befien Dualität, fowie auf bas Erzeugen werthyoller Eigen= ¡đaften mehr Einflú ausübt, alz irgeno etwaz anoerez.

Biele Farmer bebanteln, wie fie fagen, ibre glferbe nad einer

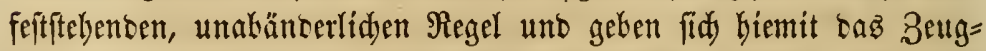

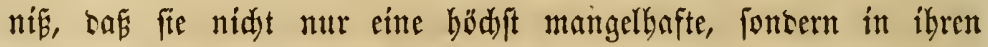

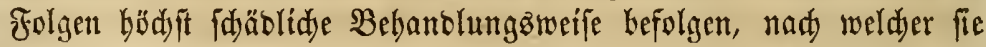
cimmal bas Pfero ganz uno gar tiberfüllen uno fo zu fagen feinen ganzen Srganiżmuz yolffitopfen, uno baz andere Mal bafferlbe Gun= gern uno herabfommen laffen; cin Berfahren, weldję̧, fo lange baš Mferd gefuno ift, yon Bortheil feyn mag, bas aber, fobalo Sirantbcit

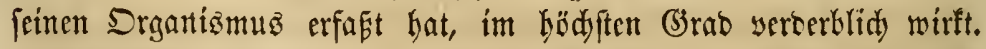

Daz Pfero hat, gerabe fo wie ber Menfd, fu veridjiebenen Bci=

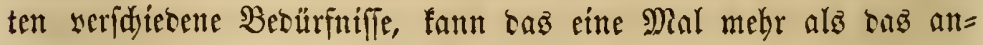
tere $\mathfrak{M a l}$ ertragen, uno feine förperlidjen 3 uftänto fino ourdjaus nidyt immer ein uno biefelten. Mandje Pferbe gcbeiben burd ton

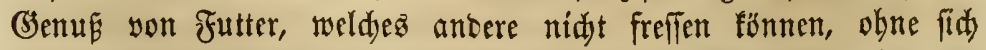
bebeutend zu fajaben; ebenio mag fid ber Rörperzuftand cin und 


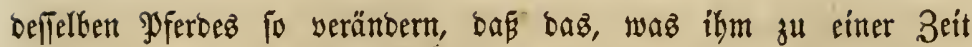
bienlidy ift, zu einer andern burdjaus nidyt verabreidst merben follte; ober ez mag aud) ber Fall fenn, bas ein Thier burd Siranffeit

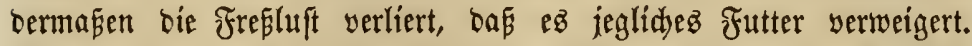

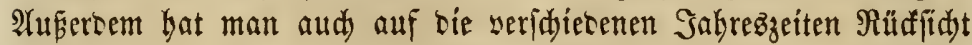
ju nebmen. Der Farmer, welder Winter uno Sommer Daffelbe Futter füttert, wiro wahrnebmen, dafi jein (3efpann zu einer 3eit wohl genährt uno fett uno zur anbern fehr mager, eimmal muthig uno bas anoere $\mathfrak{M a l}$ träge, jest in gutem uno fpäter in (d)led)tem Stande ift.

Man bat aber nidht mur hinfidtlid ber Bebanolungąweife tor

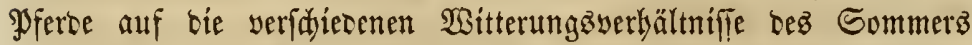

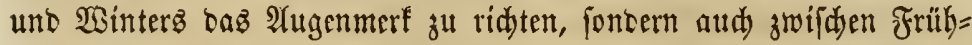
jahr uno Spätjabr ju unterjaeion, uno namentlid auf bie Zeit robyl zu adbten, wo im Frübjabr baz 5aar ausfäult uno im Spät= jabr bafielbe bidster wirt. Der gleidje ilnterfdied mus gemadjt werben jwifden Perioben, wo Las Pferb grofe 2(nftrengungen $z^{4}$ maden bat, uno joldjen, mäbreno welder ez verbältnifmäpig oer Rulye pflegt. Gin Thier, weldes idwer und anbaltend arbeiten mus, hat mehr uno nahrbafterez Futter töthig, als ein anberes, weldbes meiftenz im Stall fteht uno nur nenig gebraudit wiro. Daz für ธaz eine nothwendige Futter würte bem anbern töbtlid ieyn, ober wenigftenz etuftlidye, heftige Riruflbeiten ergeugen, uno viele bei ben Pferben worfommente Befdwerben entiftehen burd) baz Fefthalten an einer Bebandlungšweife, bie, waz immer aud bie Umitänte fint, ein uno biejelbe ift. A̛f ben Farmen baben bie Pfferce som Frübjabr biz Epätjabr fdwere Dienfte zlt leiften, wor=

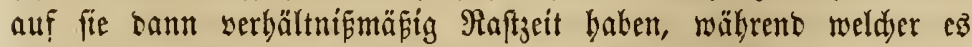

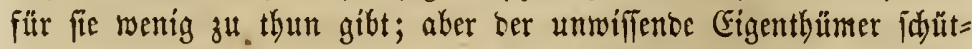
tet aud bann nod bas gleidye fdwere Futter in ben nämlidet Suantitäten bor. Wiro ein foldbe Thier nidyt mager, fo tarf man gewif feyn, baj feine (u)einbare Fettigfeit burd) irgend weldye

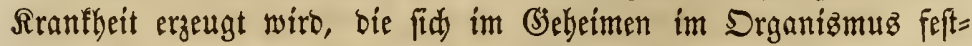
gejest bat.

Das herabgefommene, magere Pfero mup anders behandelt wer= oen, alsె bas fidi im guten Stano befinblidye, muthige, uno benjel= ben Unterfides mus man machen zwifhen einem Foblen uno einem 


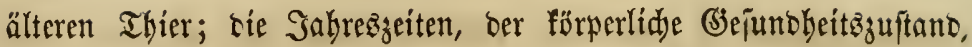
jowie bie Dienftleiftungen fimo verfdieben, weshalb eime vernünftige Bekandlung, fid barnady ridytents, ehenfalls eine verjditedene fein

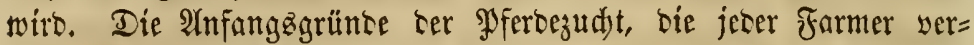
fteken follte, beftehen in einer grüntliden Befanntfdaft mit sen ver=

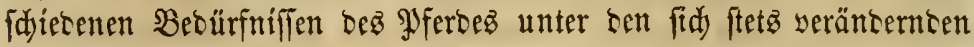

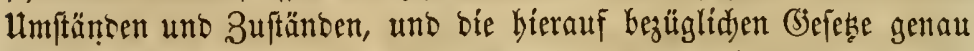

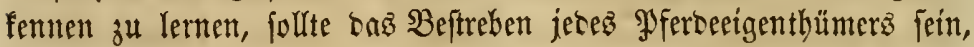
weldjer fein eigenez Snterefie wahren mädje. WBí werten in riefem Sapitel zur $\mathfrak{2}$ ufgabe madjen, hierüber fo viel Ridyt alz möglid ju verbreiten unb einige praftifde, cinfadye 2Tnmeifungen zur Belehrung z̧u geben.

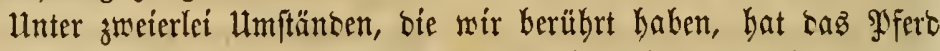
fowohl nabrbafterez alz mehr Ffutter nöthig, wie gewähnlid) - näm=

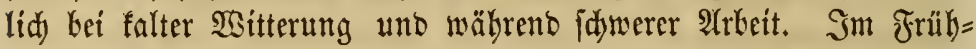

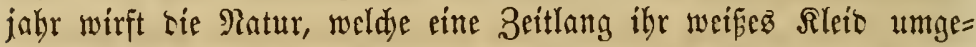

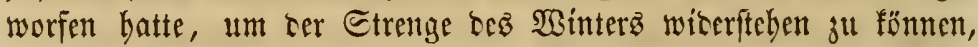
baffelbe ab und erfährt eine surdgängige $\mathfrak{B}$ eränterung. Dies ift ein

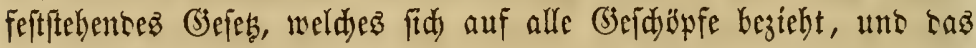

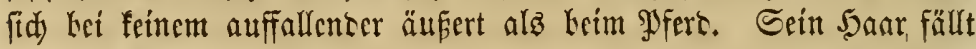
aus, feine 5 aut erletoet eine $\mathfrak{B}$ eränterung, fein $\mathfrak{B l u t}$ wiro versünnt und jelbft feine Berbautung wirb biż ju einem gewifjen (brad ser= äncert. Sein Magen wercaut nidyt mehr jo viel Futter wie im

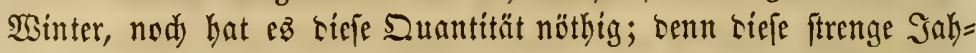
reşzeit mit ifhen bereutenten Forberungen an bie Rebenşfräfte bat fid verabfdiecet, uno alle Thiere becürfen jest weniger Rahrung

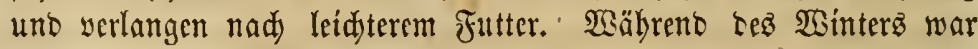
die ganje Ratur beinabe fed) weldjer fid ourd fräftigerez, ermärmentes Futter, fowie burd bid =

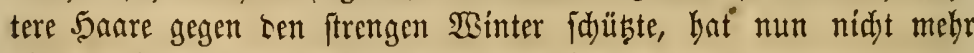
biefe ftarfen, trođenen Eubjtanzen nöthig.

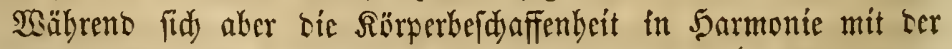

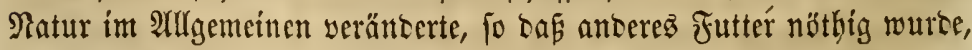
hat die Matur audf) fdon für taffelle gejorgt. Die Felter und

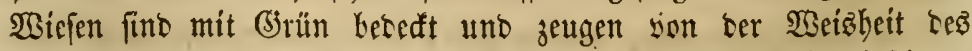
Edjöpferz̄, ter feinen Sireaturen immertar baz nothmentige bejheert.

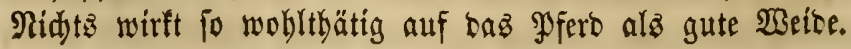


28 e t c

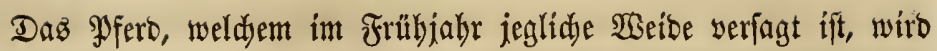
über furs ober lang an ben Daraus entitekenden folgen zu letben

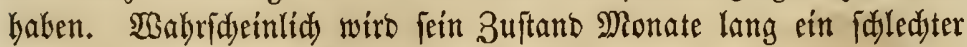
fein; jebod ift eq fo fräftíg gebaut uno

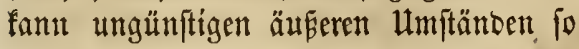
erfolgreidi) wiberfteben, dak ez yon den Durdy baz Entzielen ber wasioe entftante=

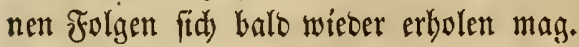
Dás Das Thier, weldeb nidjt auf bie Wetoe fam, fid viel bümmer anjtellt, alz bies fonft ber Fall fein würoe, uno bas

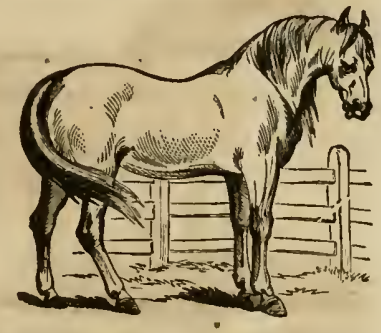
eż fid nad) bem frifden, gewürzigen (3iraz unt nad) bem freien, luftigen Sseibeplags fegnt, bies fann man burd) Beobadjtung leidjt ausfindig madyen.

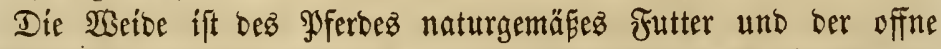

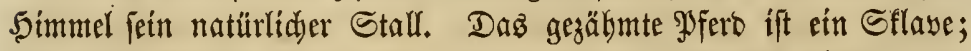

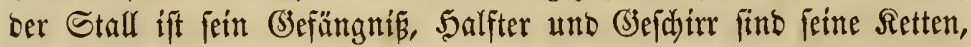
uno vieles für baffelbe zubereitete Fotter ift nidyt im natürliden $\mathcal{Z}^{\mathfrak{t}=}$ ftand und wiro yon bem Iljer nidyt gern gefrefifen, ez fei benn,

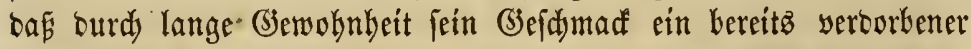

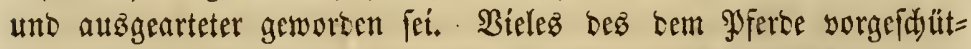
teten Futters, felbit wenn $\mathfrak{e B}$ rein ift, bringt Sithe im Blut bersor uno erzeugt Rranffeiten, io bas wenig Thiere, die nidjtz anderez 3u freflen befommen, ganz und gar von allen Sranflbeitsinmptomen frei fint.

G3egen alle bieje ltebel ift bie 2 Seite ein (S)egenmittel. Sie bietet bem Pferbe fowobl Futter als $\mathfrak{2} \mathfrak{A r}_{\mathfrak{z}} \mathfrak{n}$ ei uno fo fommt

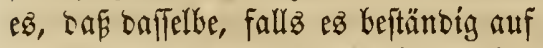
ber 2 seibe ift, felten tranf wirb. Fint = Det eine Reibesweritopjung ftatt, fo wer= ben bie Weibegräfer ben Berbaunugg=

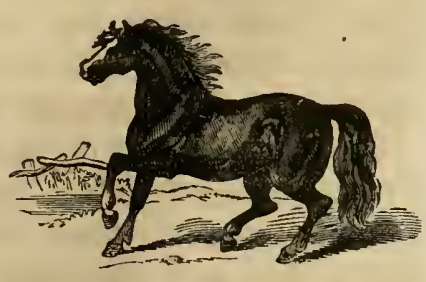
prozés beförbern; benn biefelben belfen ber Berbauung nad); ift baz 5aar frruppig, fo bietet bie 2 seibe baz Saeilmitttel; liegt bie 5aut

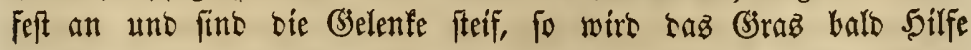
(d)affen, indem 
bie Säfte nad ber Dherflädje beföroert, uno ben unanjebntidjen

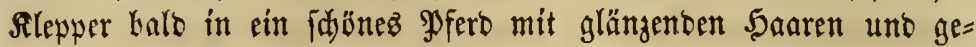
idmerisigen G3elenfen verwandelt.

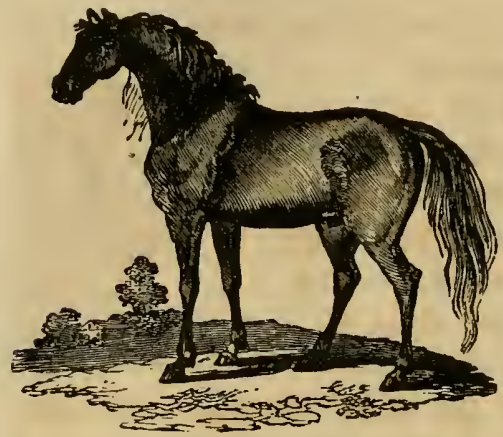

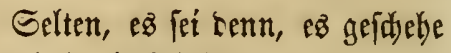
surd) Unglü đof fälle, werten \$perbe, rie ftetż auf ber Wreibe fint, frant, uno Geinabe alle glferbefranflyeiten entifteken in ben Ställen uno fönn=: ten nidit viele Stallpferte wenig= ftens zurveilen auf ber $\mathfrak{W e i b e}$ um= berlaufen, fo wären 5unberttau= iente berfelben frant, währento fie nunmebr in leiblicdem 3 ujtant fint.

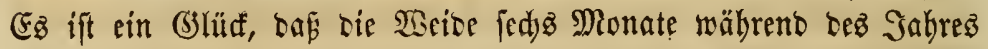
benübt werben fann, bamit ber Sdaden, weldjer in ber übrigen Zeit angeridtet wirb, wenigftenz theilweife mieser aużgebeffert zu werben yermag. Dak baz \$fero burd daz Futter bejdäbigt werben follte, hieju ift gar fein (strund vorhanben, uno bieburd) fommen wir auf bie verfäiebenen $\mathfrak{A r t e n}$

\section{(E) $r$ ä $\mathfrak{e}$ e $r$}

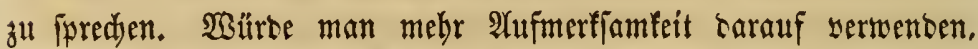
biefelben für ben $\mathfrak{W}$ sintergebraudy zujubereiten, fo mürbe unter ben Farmpferben viel meniger ßranfleit yorfommen. Die veridiedenen

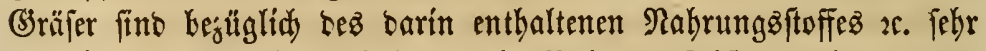

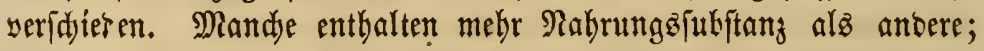
wieber antere eignen fid feb̆r gut als weibegräjer, intem fie im Frïhjahr fdon fehr frübzeitig ber Erbe entipriefen, aber bie 5ibe bez Sammerz nidyt ertragen fönnen unt tarum balo sertorren.

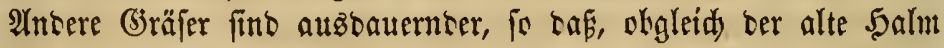
im 2 tuguft ober September ausfterben mag, bie $\mathfrak{W u r}$ gel wieber neue,

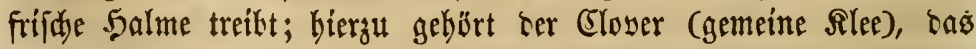

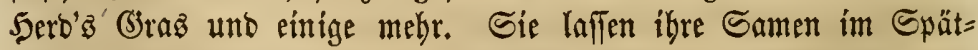

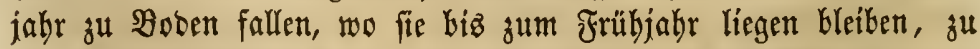
weldjer Beit anfänglich febr fleine Epröß̨lein zum Boridein fommen, bie nad) und nadj aber ftärfer unb entlid zur fäbnen, weidjen

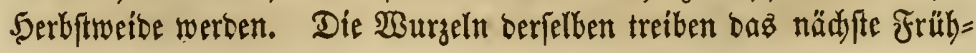




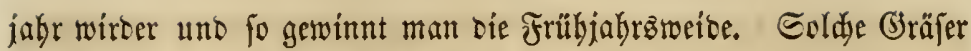
nennt man perennials, $\delta$. $\mathfrak{h}$. mehr alż jwei Gahre dauernse.

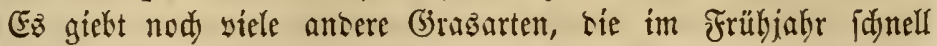
wadyfen, aker nur einjährig finto uno beşhalb aud bie "einjährigen" (annuals) genannt werken. Sie wadjent fantelf aus bem Santen berauz, fterten aber im Epätjahr ab. Eş giebt verfdjebene Arten

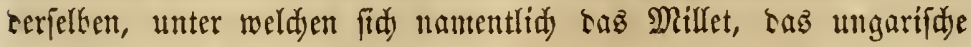

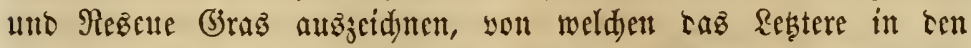

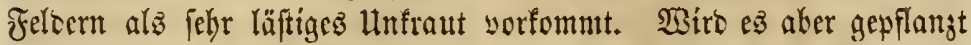
unt fultivirt, fo geceiht eaz ju tem werthyolfiten ber "einjährigen"

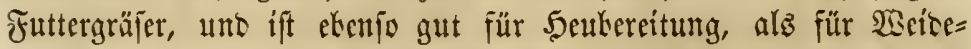

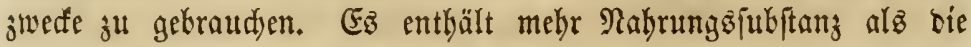
antern uno murbe menigftens bis zum Sab̧r 1860 in ben Baum= wollemftaaten, beren Slima ifm bejonberz zuträglid ifí, febr viel gebaut.

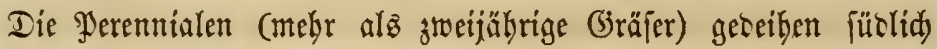
som fünfuntoreisigigften Breitegrab, ber Süngremze son Iennefiee nidjt mebr, benn bort ift ber Boben meiftentz fantig, uno ba auperbem felten yom Sunt biz zum Rowember regnet, fo fterben bie

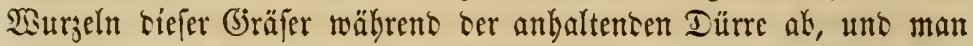

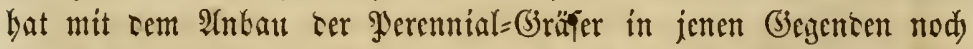
nie (3)tü gchabt, ę fei เenn, man hake fie auf niesrig gelegenez,

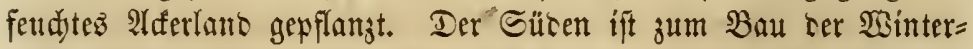

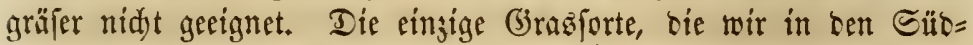
ftaaten mit wirflidem Grfolg haben ankáuen fehen, ift taz STero'z

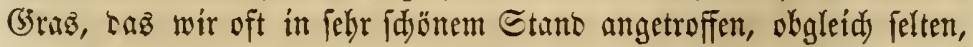
wenn is auf einem anberen Felto als fladjem, feudidem, jüngft urbar gemaditem uferland (bottom lands).

Pörolid) vom fünfuntrreifigften Breitegrad gebcifen bie verjaje=

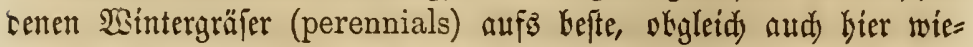

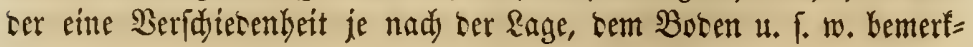
bar ift.

Wir werben in ten folgenden $\mathfrak{A}(\mathfrak{b} ; d)$ nitten sie serfajiedenen, ge=

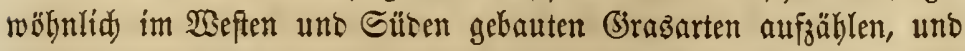

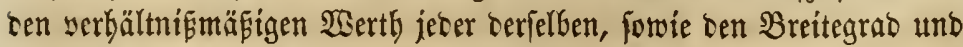
bie Bobenart angeben, wo fie am beften gebeibt.

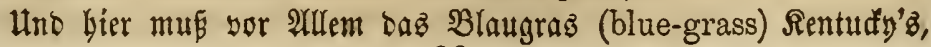


weldyez unter bie beften Grräjer überbaupt gebört und zu Weibezmes

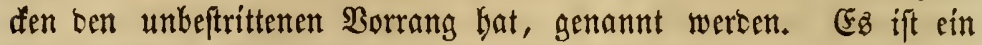
Ileinez, feines (3ras̄, weldyes etwa einen Futí bod wiro, uno cine Menge $\mathfrak{B l a ̈ t t e r ~ n a b e ~ a m ~ B o b e n ~ t r e i b t . ~ D i e ~ S a m e n ~ f e b e n ~ b e n e n ~}$

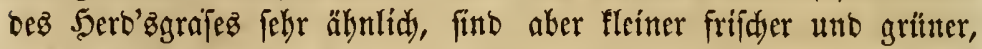
aud) bebedt ez ben Boben febr bidjt mít Unterblättern, was beim

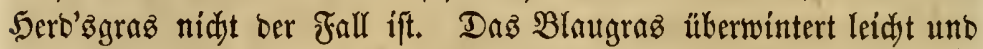
feine $\mathfrak{B} u r g e l n$ fterben unter günftigen lumftänben jabrelang nidjt ab. Im Sommer unb Spätjabr fallen feine febr zablreidyen Samen aus, treiben idnell Sproffen uno überwudtern balo allez, Felter, Weiben,

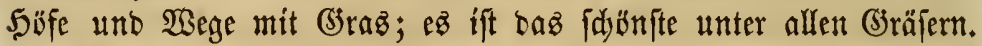
Ebenfo ift es bas nabrbaftefte uno taju febr füp̃, fo bafi alle Biebarten baffelbe nidit nur germe freffen, fonbern attd baburd) ge= Deityen. Im Ralfboben wädist es obne viele Müke, in anberen $\mathfrak{B}_{0}=$ benarten aber fann man yom vierzigften uno füblich vom fünfundoreifigften Breitengrab ge= Deift bieles (stras nidyt mebr gut, uno ba es nidt bod genug wirt, um mit Bortheil Seu Daraus bereiten zu tönnen, io ift líd) alb :Beibegras febr wertbyoll; jebod mag man, um ben Eamen fu gewinnen, im Suni uno Suli bie SSipfel abmähen.

Dent Blaugras am nädffen fteft ber (Slover (gemeiner Rlee), ber weife und rothe, weldyer fo allgemein befannt ift, baj cine Befdrei=

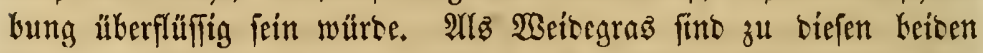
Rleearten Eittwentungen zu madjen; fie wirfen nämlich febr ftarf auf bie Speidyelorüfen unb erzetgen eine bebeutente Speidyelabion= berung unb jomit bas fo unangenebme (j)eifern (slavering or slobbering) ber Pferde. Ulno zwar bat man gegen ben weifen Rlee in biejer Beziehung entfisieben mebr Finwenoung zu macten, als̄ gegen ben rotben; aber man follte weber biefen, nody ben rothen bem Pferbe füttern, währento

Sbgleid) man allgemein glaubt, baf baburdy, baf man sab Pferd auf einer Rleeweibe laufen läft, feiner Stärfe (Fintrag gefdubbe, fo

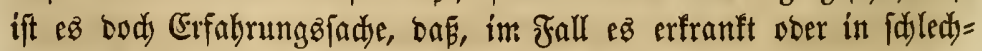
tem 3uftant ift, ifym nidytz fo fekr zum Bortheil wirb, als gerabe foldye 2 seibe; benn in biejem fall wiro ifm bie vermebrte Thätig= feit ber Speidyelorüfe burdyats nidyt fdablidy; fonbern ift ifm im (Segentbeil nüblidy. Der rothe Slee, wäbrent er nidht fo viel Nab= 


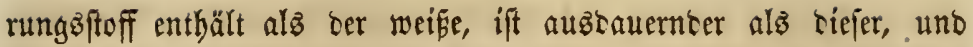

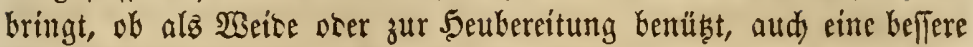
Ernte.

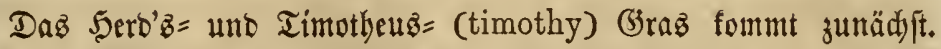
Seins cerjelben ift zu Weibezmeden bejonters gecigntet, uno im all= gemeinen ift ber Ânbau des erferen sortheillyafter, weil $e \mathfrak{b}$ eine er= trägliducre Ernte gift; bas Timotheus̄gras ift unter sen betoen taษ nahrbaftere. Rémes berfelben gibt eine gute, oder wäbrent ber beifen

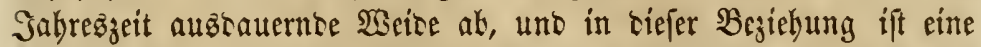
mit Blaugraz bepflangter Morgen io viel werth, alsె brei, bie entwe=

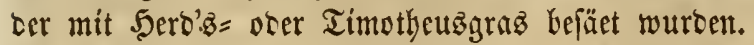

Dies finc alle für Weirezmedfe wertbyolle (5)räjer. Der Rlee ge= reibt in allen Breitegraben nörolich yom fïnfuncoreifigiten, wädjt am beften in reidyen, trodenen, bodjgelegenen Räncereien uno über= baupt überall, ausgenommen im Ganbboben. Daffelbe ift ser Fall mit bem Timotheuşgras, aber tas Sero'g̈gras fommt am beften in feuditen Rieberungen fort.

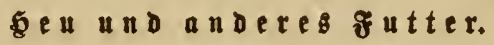

Die $\mathfrak{B}$ eitegräjer finto nidyt bie zur Şeukereitung an tauglidyften,

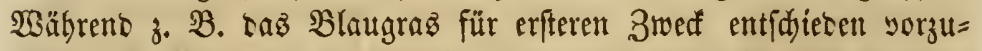

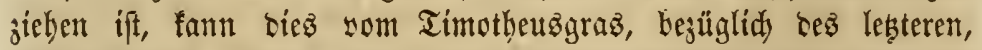

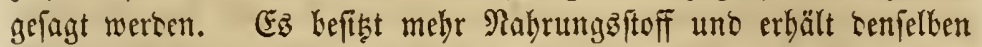
befler, fallz $\mathfrak{x}$ gut eingebradjt mirt, alsె irgeno weldez anberes (3ras. Das nädjitbefte für Seubereitung ift Las Serb'zgras; ca ç aber in feinen Stengeln viel melyr Gaft entbült, weldyer veridyintet,

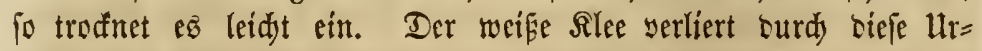
fadje nod mebr als bas Sero'sigras, uno bet rothe Slee mebr als

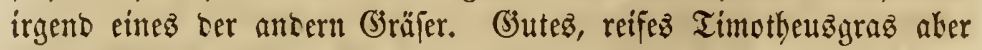
verliert baburdy, baf $\mathfrak{e z}$ ju Seu bereitet wirt, nur etma ein Fünftel

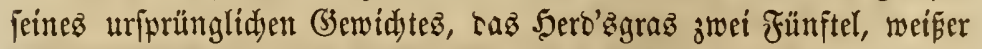
Rlee dic Sälfte und rotber Slee etwa brei Fünftel. Shrer Subftant mady unteridseiben fie fid etwa in rerfelben $\mathfrak{B e i f e , ~ n a ̈ m l i d ~ e t r w a ~ i m ~}$

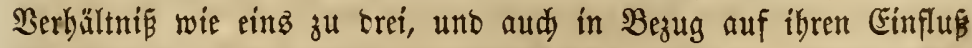
auf bie (3ejunbheit ber Thiere, obgleid bies nidjt mit berfelben (5e $=$ nauigfeit feftgeftelt werben fann, Dürfen fie in ter gleiden Reiben= 


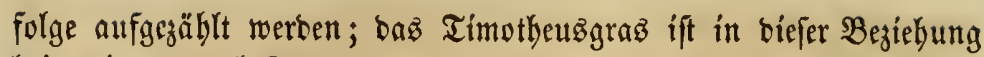
bei weitem am beften.

Biéle ber cinjätrigen (ơräjer fünnen, wenn fie gut zubereitet, zu gutem Futter umgeidanfen werben, fint aber lange nidjt fo werth= yoll alż bí $\mathfrak{B} i n t e r=$ (perennials) Grrä]er. Man nennt fie oft "Sraba," fo lange fie nodj grün, und "5eu," wenn fie getrodnet

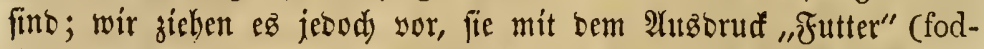

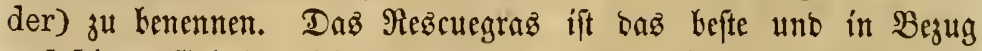

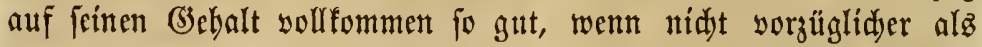

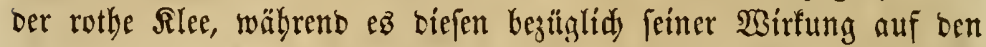

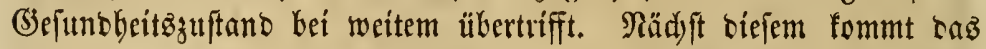

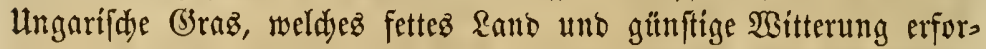

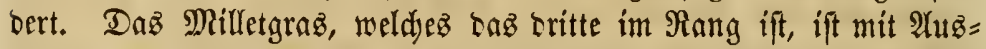
nahme tez Samenz nur um meniges beffer alz $\mathfrak{B a i z e n}=$ boer $\mathfrak{5} \mathfrak{a}=$

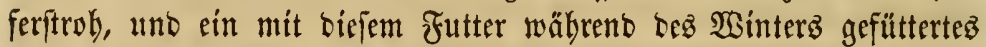
Mfero wiro beinake verbungern.

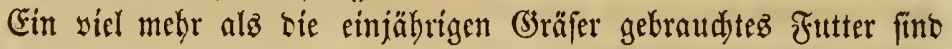

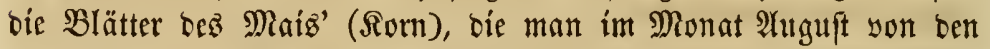
Maizftengeln nimmt, auf bem Felse trofen merben läpt, in Bün=

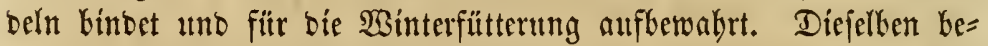
fiben viel Nahrungaftoff ober Subftanz, fino jebod) ber Befuntheit Dez Wferbez und im allgemeinen feinem (Jebeíten fdjärlid). Sie

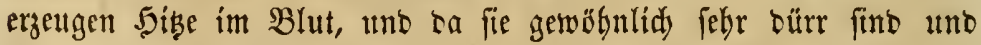
fidy aljo leidyt zu Staub zerreiken, fo fönnen fie aud oem Sdjluno fdjaben. Sn ben Baumwodlenftaaten ift man faft ausfdylieflid) auf biejes Futter angetwiejen, utro man nimmt bort alle Maizblätter jorgfältíg ab, um fie zut trofanen und in bie Sdjeunen $z^{u}$ bringen.

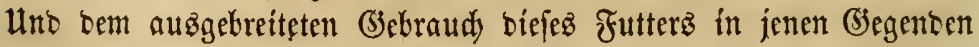

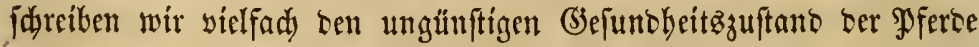

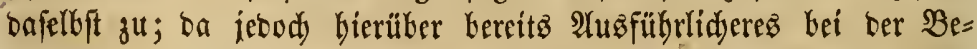
idreibung bes Bighead gefagt wurbe, fo ift es faum nothtg, hier nod) näber barauf einzugeken.

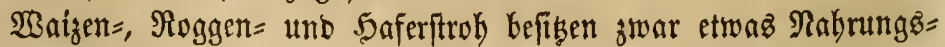
ftoff, etwa ten zwanzigften Theil bes Timotheuzgrafez, finto jebody fo

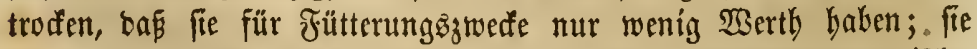

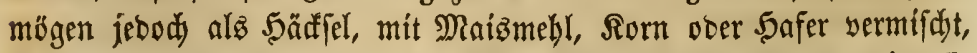
benübst rerben; in irgent einer antern $\mathfrak{B}_{\text {eife }}$ yorgejdüttet, wirb fite 
baz Pferb, weldyez cine entfdjebene Âkneigung Dagegen bat, nur bann freflen, wenn $e z$ burd) ben Şunger ba̧̧ gezwungen wirb.

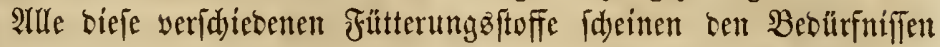
auberer Thiere viel mefr ż entipred)en, alż benen bez Pferbez, benn fie find für baffelbe zu troden uno nelymen wäbreno bes Sauenz bie Speidjelorïfen zu jebr it Aniprud), uno baffelbe gilt yon ben Borridutungen im Magen, burdy weldye bag Futter in ben Futter= brei verwanbelt wirb. Füttert man aber foldacs futter bem Pferb, fo follte es immer gefdnitten, wenigftens eine Etunte lang ange= feudjtet unb mit Maiszmebl, Sorn ober Safer yermengt werben. Sierburd) werben alfe fdäblidjen Cintwirfungen auf bie Drüjen uno Den Sd)lunto yerbiutet.

athe Sorten trodenes Sell follten in terjelben Weife zubereitet werben, unb man fann bic Beit niåst beffer anwenden, alsz bamit,

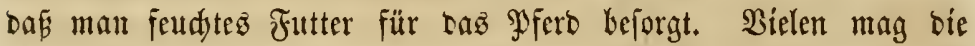

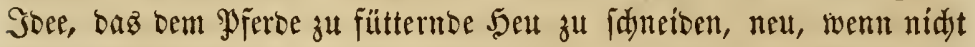
gar läderlid) feín; bat aber eiu Fanmer eimmal einen Winter ben Berjud) Damit gemadjt und sen Zuftand feiner Pferbe fowobl, alsz bie baraus entipringende Eriparnif ju beobadjen (selegenbeit gebabt,

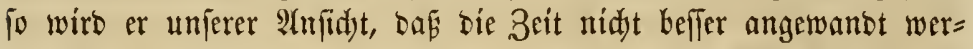
ben fann, wollommen beiftimmen. Secody bürfen Maizftengel uno Daรี, waร wir Futter nenuen, aud wenn bies ridjtig zubereitet wird,

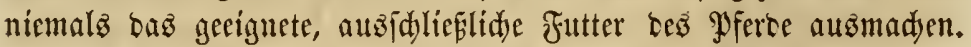
Vor allem hat man barauf ju fchen, Daf bas Selt und Futter gut cingebeimst werte. Das (5ras follte, fo bald es reif ift ocer nod) ein wenig frïter, wenn es blübt uno ebe ez überreif wiro, ge=

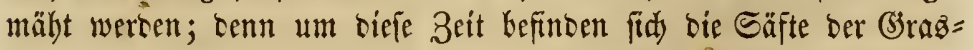
ftengel gerabe in bem 3ufano, Der vorbanben fein muf, wenn gutez,

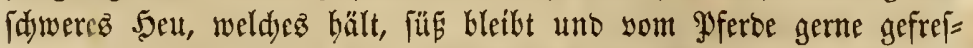
fen wirb, ergielt werben foll. Mäht man bas (Gras zu früb, fo bat

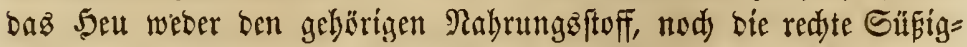

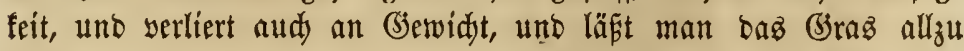
reif werben, fo wirb bas 5eu zäher, holzartiger, uno ift weber fo nabrbaft, nody bem Pferbe fo angenebm, alb wenn es zur erfiten Beit unter bie Sidjel gefommen wäre.

2uferbem ift ę von grofer Widjtigfeit, 5eu uno Futter yor naffer Witterung zu berwabren uno fobalo ez trofen ift, baflelbe in bie 
Sd)eune zu bringen.' Bei Sonnenjidyein miro

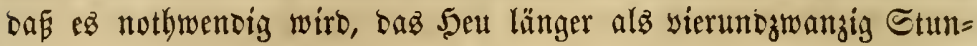

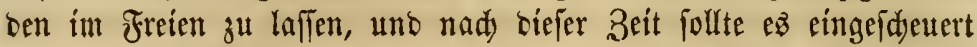

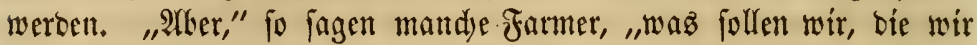
feine Sdjeunen haben, anfangen?" WBir antworten: Der Farmer, weldyer nidyt auf bie einc ober anbere Weife bafür forgen fann, bas

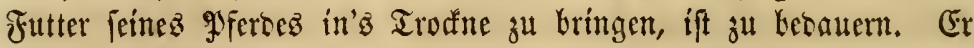
follte gar fein Yfero eignen uno, io balo alz möglich, feinen ganzen

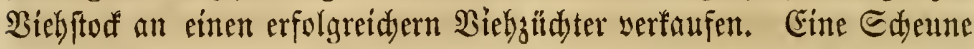
zu haben, ift fo widjtig, als ein Pfero zu befiten, und es ift beitabe

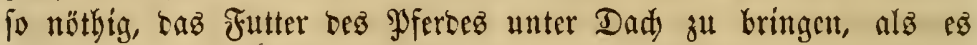
nöthig ifit, bie Speife bes Mienidjen im Irof́nen aufjulbewahren,

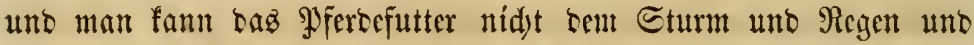

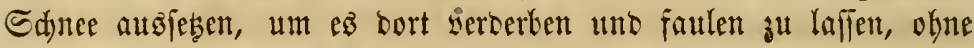

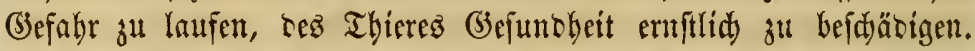

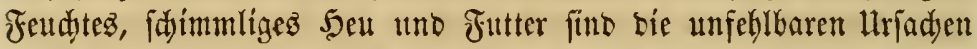
yon Iranflbeiten uno in sielen Füllen mögen sie 5arubejdwerten unter ben \$ferben auf biejen Utebelftano jurüufgefübrt werben.

\section{(3) $t \mathfrak{r} \in \mathbf{i}$ is.}

Es ift nothwentig, bafi bem Pferb Getreibe gefüttert werte unb

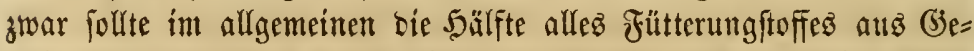
treibefubftangen beftehen, obgleid) es natürlid aud für biefe $\Re e g e l$

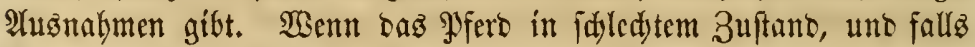
feine (sepundheit nidyt gat ift, ober es nur wenig gebraudt wiro, muß man weniger (b)etrcioe füttern alళ fonft, währeno auf oer an= bern Eeite, fallz bas Thier jojwere, anhaltenbe Dienfte zu leifiten bat, Daffelbe einer gröperen Portion (jetreine bensthigt ift, als unter antern $\mathfrak{l} \mathfrak{n}$ ftänben.

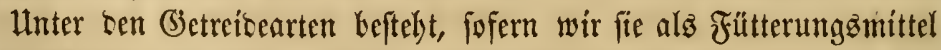

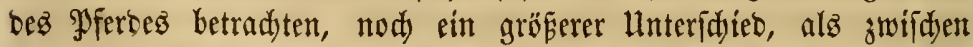

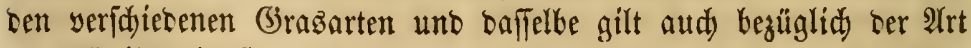

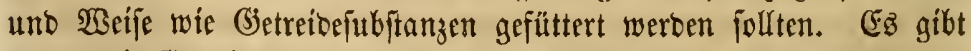
nur zwei Gettreibearten, bie in unjerm Lante in gröferen Dâfen bem Mferbe gefüttert werben, und biez fino 5 afer uno Mais ( bas erftere mirb bauptfäd)lid) in ben nörolidjen Staaten gefüttert,

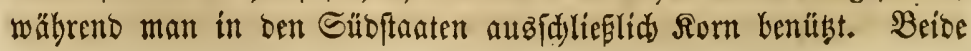


fino . Dem Farmer wobl befannt, uno beibe billoen einen Stapelartifel unferez Randez.

Der Safer ift alż Pferbefutter bem Maiz unter allen Umftänoen bei reitem vorzuzieben. Er ift milloer, versaut leidjter unb erfigt raz Blut nidyt fo febr. Er ift gewöbnlidy nidyt viel mebr alz balb

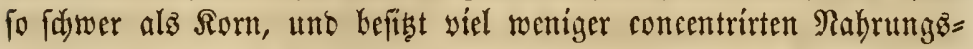
ftoff alz biefes. Sogleidy man biefes Jutter gerabe fo füttern fann, wíe $\mathfrak{x}$ wädj, fo ift mablt unb als Mehl woridyüttet, was neben anderm audy nod eitne Erpparnis ift, benn man bat etwa ein Drittbeil weniger nötlig, als wenn Lie Rörner gefüttert werben. (3efduiegt nämlid leb̧teres, fo faut $D a \mathfrak{s}$ Pferd etwa die Sälfte beriflben unvolfommen uno fie weroen aud im Magen nur theilweife serbaut. Sit aber ber Safer gemablen, fo ift biefem Uebelftand mit cinem Male abgebolfen.

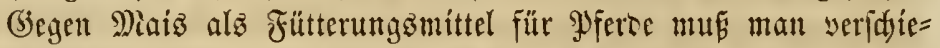
sener Uriadyen wegen Einfpradye thun. Ȩ ift eín fdweres, oas Blut crbiticnses Futter, uno erjeugt eitne Fettanlage, tie weoce son

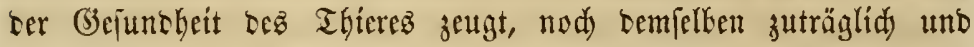
won Sortbeil ifi, uno man barf mit Recjt behaupten, bas Maíz bei Lem Pferbe mebr Siranflyeiten crjeugt, als alleš anbere ungefunbe

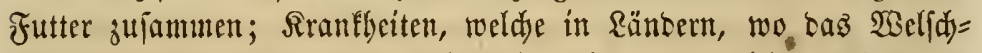
form nidut als P̧ Persefutter gebraudst witt, gar nidjt yorfommen,

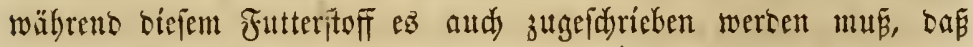

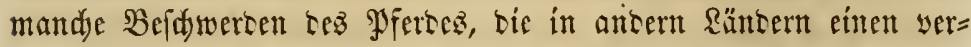
bältniømäşig leidten Berlauf nebmen, in Amerifa fo bögartig uno oft töbtlid) find.

Cin nur mit Welfdjtorn gefüttertes PJfero wiro idwerlid) ie ge= fund fein, benn wenn ser Mais aud für ธas Fettmadjen ter Edyeine

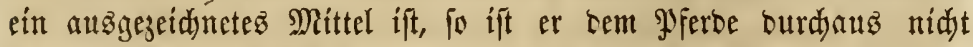

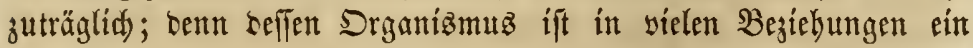
anterer, alz ber tez Sdjweinez, uno bie Wirfungen uno Folgent fawerer Fütterung fint bei beiben ganz uno gar veridfieben. Daz

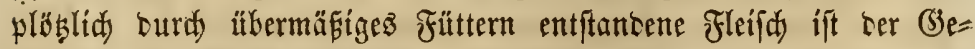
funcheit

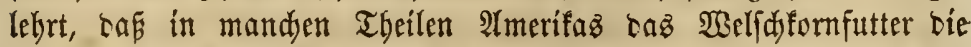
urfache son mebr Sranfleiten unb Befdwerben unter Pferben ift, alz alle anoere llebelftänoe zulammengenommen. Şunoerte junger 
Pferbe uno Foblen, uno viele berfelken ausigezeidjnet fäne Thiere,

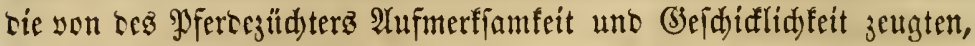
fino fdjon ourd) Welldffornüberfütterung zu (brumbe gegangen.

Uno währeno wir biefez fajreiben, wercen wir burd) eine That= fadje lebhaft an bie lebel erimnert, tie oft baburd) entifteben, Laf́

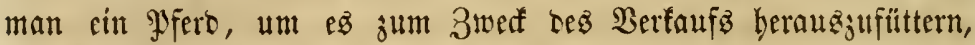
mit $\mathfrak{s o n}$ überfiüllt. Wir wursen nämlid) erjt yor menigen Tagen

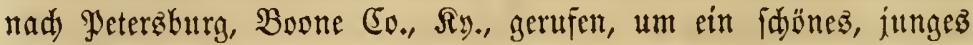
Pfero zu bebanteln, befien Werth man auf breibunbert uno fünf= zig Dollars anjdylug uno weld)es wirflid) aud für riefe Eumme yerfauft wurse uno in wenigen Tagen an ben $\mathfrak{R a ̆ u f e r ~ a b g e l i e j e r t ~}$ werben follte. Daz $\mathfrak{W}$ affer in einem feiner $\mathfrak{2}$ tugen war rahmfarbig, während tas antere teutlid)e Epuren son Erfranfung nadjeres.

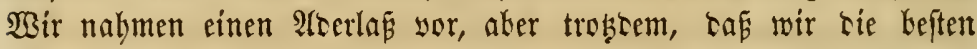
Snftrumente benübęten uno energifd) zu $\mathfrak{B e r f e}$ gingen, gelang $\mathfrak{e g}$ cod) faum, sie Blutaser ju sffinen. Seine Jaut war hart uno bid, wie bie cines bullodjen.

Diefez Wfero litt bereitż zmölf Monate lang an 5antficber, und nummely zeigte saz $\mathfrak{u}$ ehel alle sie Eymptome, meldye fid hei ter

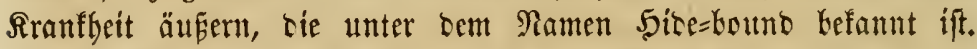
Rieren uno 5arnmerfjeuge waren in berenflider Maeife afficitt, tor

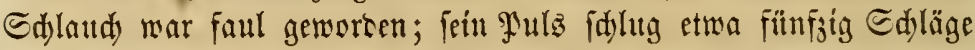
per Minute utto Lod) war haz PFero fehr fett, unb gerate in biejer Thatiadye mufite ber Sils aller biefer llebel gejudtht werten. Das Thier wurce, um fu maden, alle Tage mit Rorn üferfüllt und wir gaben eine Ers

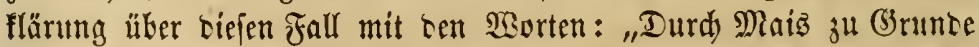

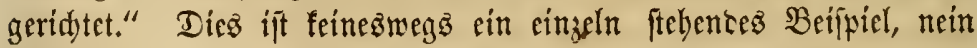

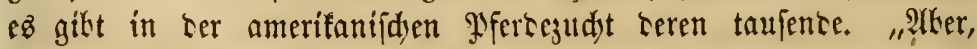

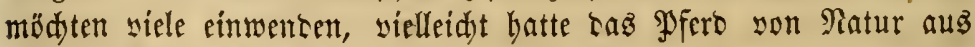

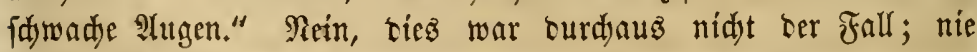

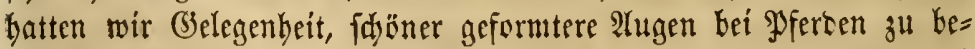
obadjen, alz bieje. Daz lebel entftano einjig und allein burds

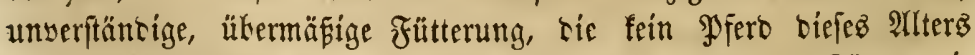
ertragen fann, ohne irgeno weldjen Edjacen zu nehmen. 5ätten wir Das PJero zwei Monate früher zu fehen befommen, io bätte bem Ulebel vielleidyt Einbalt getban werben fünnen. 
Biele werben nun obne 3weifel fragen, ob man benn gar fein Maigforn füttern bürfe, worauf wir entfítiesen antworten - ja -

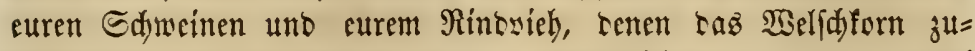

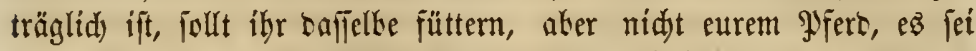

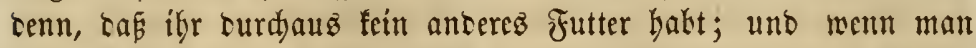
je gezwungen ift, Len \$fersen Maiz vorjuidütten, fo fei bie Suan=

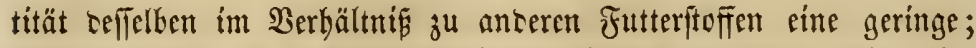
je geringer fie ift, tejto juträglidjer wiro ez für taz Thier fein.

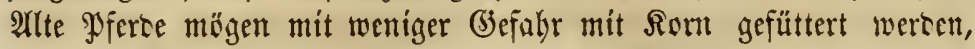

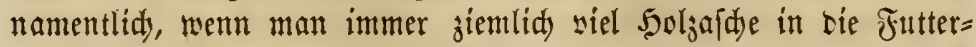

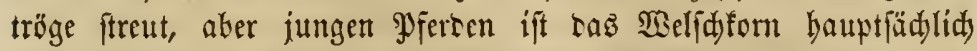
bann entidjecen fidätlid, wenn ibnen sie Rolken sorgeworfen wer=

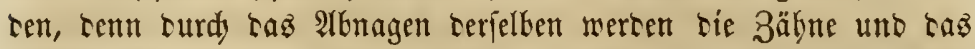

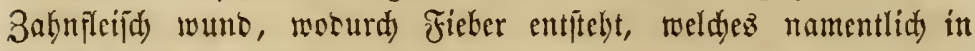

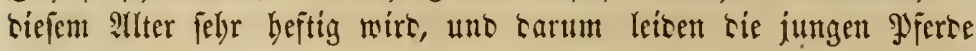
viel melgr alz bie alten Durd) Rornfütterung.

Biele Pyerbe haben tie (bewobnheit, tie Rörner nidgt gebörig zu werfauter, forthern fie nur zu fidroten ober audj biefelleen gerabeju

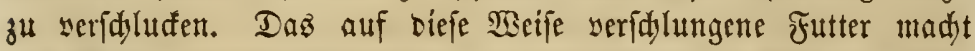
rem Magen unb anteren Bersauungziverf $f_{3} e u g e n$ ju viel ju fdaffen,

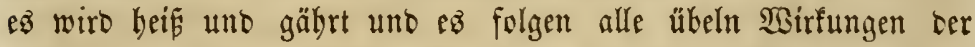
Colif. Nur menige junge, mit Sorn gefütterten \$yferce entgethen

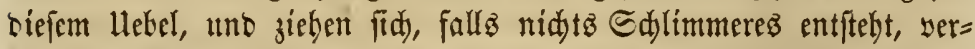

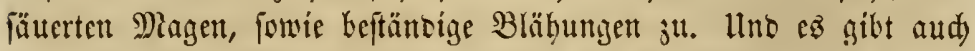

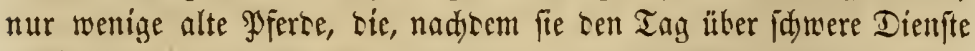
gelcifitet oocr viele Dieilen zurüdfigelegt, mit Wellidetorn gefüttert mer= Den, uno nidjt an Etörungen ser Berraunngsorgane ju leiten ba= bert.

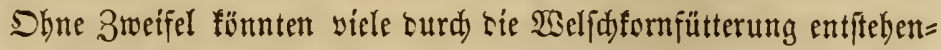
sen Hebel taburd yermiesen werten, dafí man baffelte zu Miehl mablen läßjt, es cine balte Stunte sor ter Fütterung einneşt uno

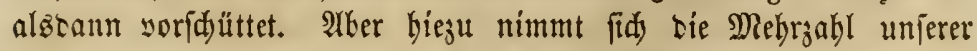
Farmer in biejem gejdäftigen, jantell soramidreitenten Beitalter feine 3eit, uno fie betwahrbeiten samit bas Epridwort: "Er wirft mebr mit tem Röffel herauz, alz er mit ber Edjaufel bereinbringt." WSie

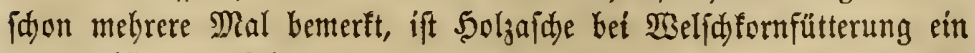
aużgezeidenetez Mittel, benn 


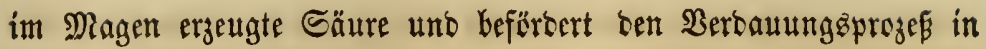
febr zufriebenftellender $\mathfrak{W e i f e . ~}$

(Serfte mag zwar aud), wenn nur bie Sälffte bes vorgcidültteten Futters baraus befteht, benust werben, ę laffen fid jebod gegen ren (sebraud berjelben zu biejem 3wed beinabe fo viele Finwen= bungen erbeben als gegen ben bes Maiz: : Waizenfleie uno Roggen follten mur in geringer Duantität als Pferoefutter gebraucht weroen,

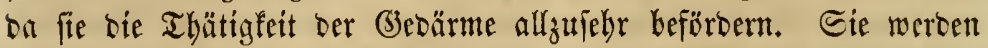
ant vortbeilbafteften mit Safer uno Welfdiformmehl uno Säafel ver= mifdyt uno fo vorgefdüttet.

\section{(5) $r$ ün \& utter für ben $\mathfrak{M}$ inter.}

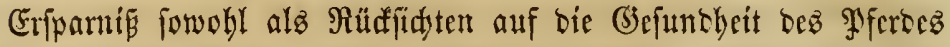
follen jeben Pferberigenthümer bejtimmen, für sen Finterbesarf fo

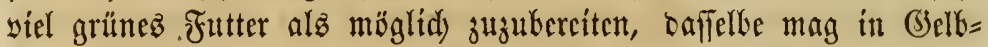

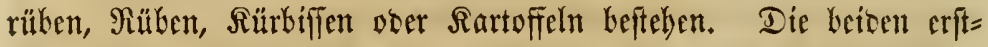
genaunter find bie beften, bas Pferb wirb jebod irgens weldyes grüne Jutter, felbft Rraut uno 2 epfel, mit \&uft freffen uno alle

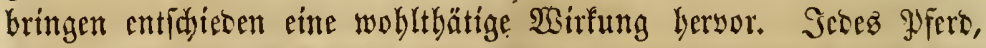
weld)es währent bes Șinters meiftens mit trod̆enen Futterftoffen gefüttert wiro, follte wenigitenz cinmal โeร Tagez grünez . Futter

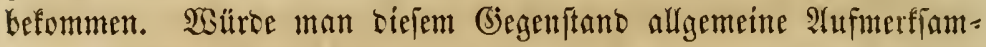
feit idjenten, fo würoe bicrourd ber Entftelyung vieler Siranflyciten yorgebeugt, uno man würce viel mebr fdöne, fette \$ferbe uno Foblen jeben.

Man füttert Rübe fowobl alz Sdyweine bäufig mit Sd)lappfutter (slop), waz ilgnen febr wohl befonmt uno woourdy fie gefund bleiben uno fett werben; uno wer bezitglich feiner Pfferbe ein gleidyes $\mathfrak{B e r}=$ fabren einjalägt, ber wirb fincen, bas bicfelben wobl genäbrt fino und gut aubjeben. Der Irraber futtert fein PJferb mit ber gleidyen Speife, bie er gentef́t, beginnt biermit bereitz bei bem Jüllen uno

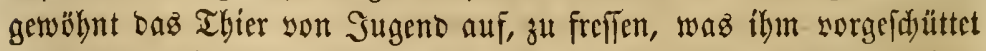

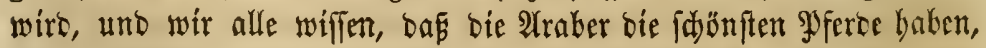
Die $\mathfrak{e}$ gíbt.

3wei (Sallonen Sdylapp (Fett und Salz mit (Semüien, weldye in Denjelben und in 2 Saffer gefocht wurben) wiro ebenjo mobl jur Fütterung beittagen, wie alz 2Yrgneimittel bienen. Füllen tönnen 
nidt nur yon frübeftem 2Yter an baran gewöbnt weroen, foldes Futter 子' freffen, fonoern es wird ibnen aud zuträglid uno sortbellbaft fein.

\section{Stalleinrintung utt Bebandlung im Stall.}

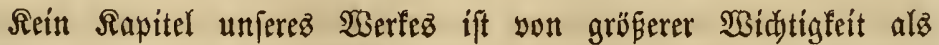
biejes. Die jobreflidan Wirfungen einer fabledten Etalleinridtung

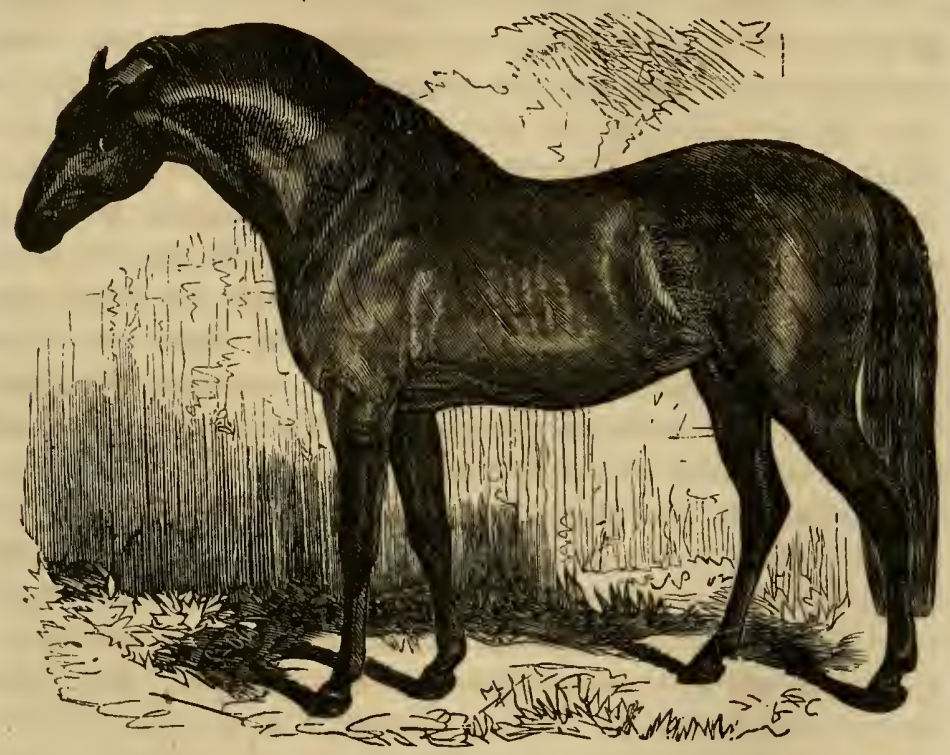

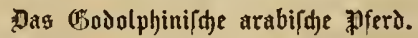

uno Behandlung auf bie (Sejunobeit und \&ebenztraft beż Thteres fint yon fo weit tragenben Folgen, baß fie gar nidyt beredynet werben

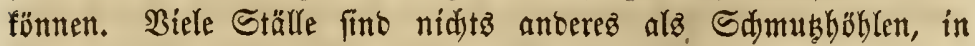
weldyen faulente Subftanzen angebäuft find, wabre $\mathfrak{a} a$ arethe, wo Srantheit and Tod ibre Ernte balten, uno yon ber 2 (nzakl ber bier= ourdh) verurfadsten Srantfeiten uno Uebelfänoen aller $\mathfrak{A}$ rt madyt man (iid) feinen Begriff.

Die Ställe ber Farmer find gewöhnlid in befferem Zuftano als mandye in ben Stäbten und Srtidaften; Denn hier ift ber Aufent=

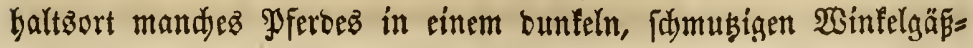




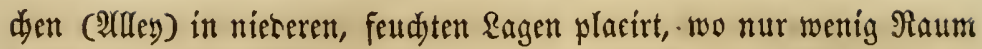
unt nod weniger Ridjt workanten ift, und wo grofe Mifthaufen in und aufer bem Stall fid anfäufen unb die Ruft verpeften. Ratür=

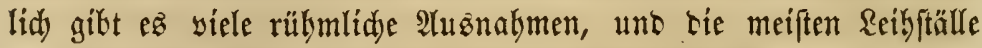
in unjern Stăsten mülfien yon biefem Borwurf freigefprodjen werten. Diefelben fino gembihnlidi gut gebaut, bequem eingeridstet und bie befolgte Methobe ift cine wabrbaft mufterhafte.

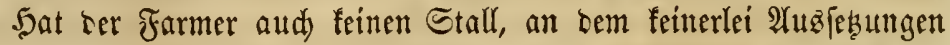
3u madjen mären, fo wirb fein Pyfro beshalb nidyt in sem (3rabe won ben Folgen einer fdylecten Etalleinridutung betroffen, weil $\mathfrak{e B}$

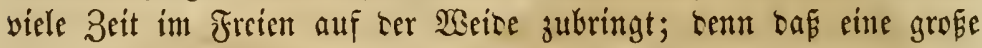
$\mathfrak{A}_{\mathfrak{n}}$ abl Stallungen auf bem Ranbe ebenjo fdjled)t eingeridjtet finto, alz bie Mefthöblen, bie wir im yorbergehenoen âkidnitt bejdricben,

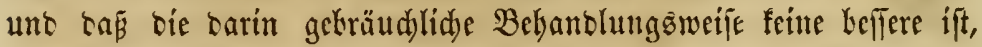
Dies ift leiser nur żu wabr; aber bie Ummftänte, bie Umgebungen fint auf bem Rante meit günftiger. (Jeswöbnlidy finten fid in ber Mähe ber Stalfungen feine anteren (bebäuto vor, weld)e ten Zutritt ber frifden Ruft yerfintern, weşhalb ber Mift fduntl trodfen unb yéle ber verpefteten Dünfte abgefühth werben.

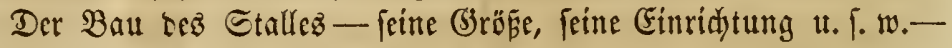

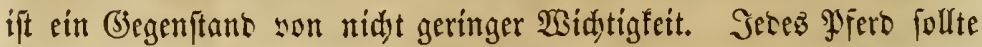
einen bejonberen Etuno haben, weldjer groṕ genug ift, baj esz fid barin umoreben uกt bequem nieterlegen fann; ธenn Pfero nidyt allein in hohem (Brabe, wenn es beftänbig ftehen mus,

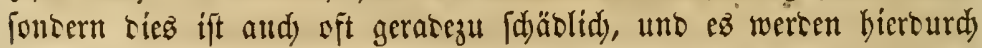
nidyt felten wunte uno angefdyollene Belenfe erjeugt, weldes Hebel öfters in unbeilfare Steifheit auzaratet. Sn vielen Fällen würte cine wäbrend ser 2 rrbeit erbaltene Beidjübigung ober Bselentż obne emftlidje Folgen von felbjt heilen, wenn baz Pferb cinen zum Rieberlegen bequemen Stand bätte; mü ez aber beftän=

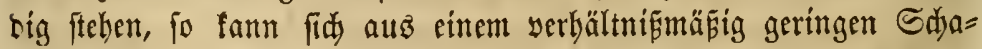
bent eine hartnäđfige, wenn nidjt untheilbare Siranfleit entwideltn, $\delta$. B. Epath, Ringbein u. [. w.

\section{2 i 首 $\mathrm{t}$.}

Ridyt ift zum (Jebeifen unt Whadysthum jeber lebenben Creatur nothwentig; weber thierifaes nod) goflanzenleben fann ohne tiefeș 


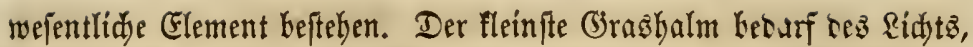
fonft wiro er tie Farbe werlieren und serborren, uno baffelbe Giefes

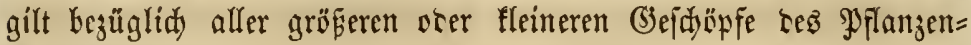
uno Ifierreids.

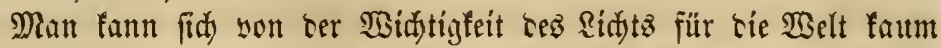
cinen $\mathfrak{B e g r i f f ~ m a d y e n . ~ S h n e ~ R i d y t ~ t o ̈ n n t e ~ f c i n e ~}$ särme erjeugt wer=

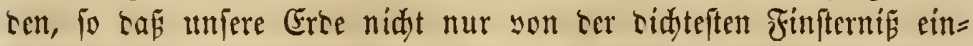
gehüllt märe, fontern audy zu einem grofen Fizflumpen gefriten würce. Ridyt ift tie gebeimnifwolle Madt, welde tie Pflanjen aus ter Eroe bersorgaubert, bie Blumenfnos̄pen öfnet, tie Ihäler mit grïnen Teppidsen kerefft uno auf sen Felrem Frïdte uno Bäume ergeugt, bie 5 ügel uno Berge mit $\mathfrak{s a l}$ sungen Kefleicet uno rie ganje Natur mit nie (dwintenter und sod) ftet fi fid) neränternser Sdyön= beit uto Pradt ükergieft. Ridhts fann obne Ridyt leben, uno fo wabr ez ift, baf fid weter Planjen nod) Ibicre von Ridut ernäbren

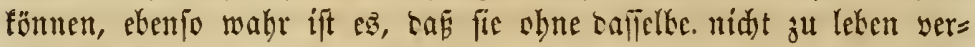

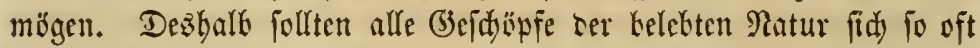

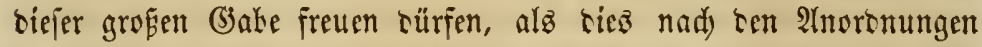
Lez meifen Sdjöpfers möglid ift. Srgento cinem Thier bas Ridjt entzieben, heifst fo viel, als $\mathfrak{e s}$ Bejdäcigungen uno Sranflyeiten aller

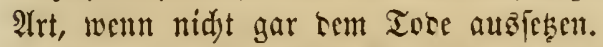

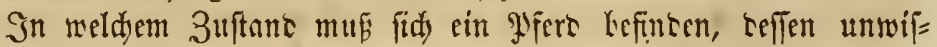
fenter, gleidgültiger oser farger Eigentbïner es einen grofen Theil oer Zeit in einem sunteln, rumpfen Etall fpert? Sann rie Wir= fung eine antere als eine jerftörence feyn? Ia bat fich nod immer surd uniere Erfabrung keftätigt, uno anterer Gierourdy entfitancener oser yeridylimmerter Rrantheiten gar nidyt zut

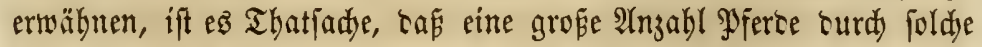
Bebanclung Glint geworten fino, uno biejer Urjade, biejer Bernad)= läfitgung if: ez in yielen Fällen zusufdreiben, wenn bie Pferbe mont= blinb wersen, b. G. Die Monats= ocer Montblintbeit betommen.

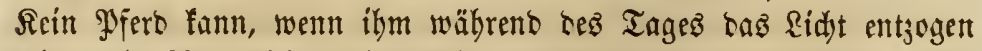
wirt, jein Ilugenlidyt unbejdäbigt erbalten; זenn ba biejez Srgan baju gefdaffen ift, sas sidyt aufjumehmen 2 ., fo wirb baffelbe aud zuerft uno am meiften surd Entziebung diejes Elements notbleiden. Bringt man ein PFers, weldies in einem tunfeln Stall geftanien bat, plöglidy sum Gellen Sonnenlidyt, fo geterbet ez fid wie ver= 
roirt; Beit bingeht, bis es wiecer fo gut fieht wie frulber. So oft fidh Diejer Borfall wieberbolt, wiro ber llebelftano gröfer uno bält länger an. Nad) uno nach, wenn etwas Fieber eingetreten, fest es fid in ben $\mathfrak{A}$ ugen feft, weldye nunmebr weif wersen, uno nun frägt ter

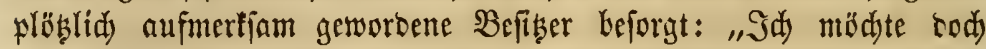

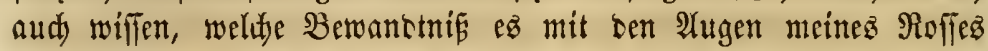

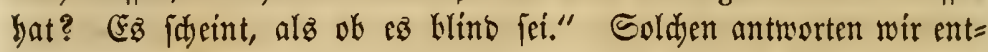

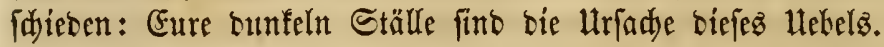

Inweijung zu geben, auf weldye Beife bem Ridht am beften Cin= tritt in ben Stall beridafft werten fann, biez ift nidst möglid; ter Eigenthümer mus bier fein cigenes llrtheil zu Nathe zieben; renn man feine fpecielle Regel aufitellen, ę fei cenn, alle Ctälle wären

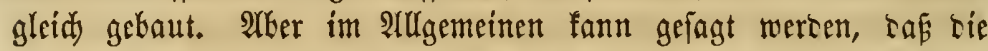
zum Fingang bes Ridjtz beftimmte Deffunng etroas böber fein follte als ber. Sopf bes PJeroes, baf fie eber hinter als yor bemfelben an= gebradyt werten, uno bás ber Stall fo erleudstet werben follte, caf es in semjelben beinabe fo bell ift als im Freien. Sein Stall, bies inag nod binzugefest werben, follte weis getündt (white washed)

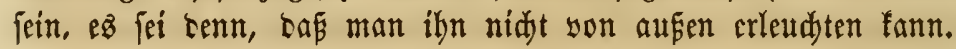

\section{Bentilation un zemperatur.}

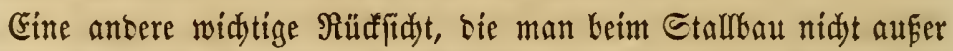
Fdyt laffen barf, beftekt Darin, Borridtungen zu treffen, Dap berielbe ftets gut auzgelüftet werben fiun. $\mathfrak{B a ̈ h r e n t ~ j e t o d ) ~ b i e ~} \mathfrak{B e n t i l a t i o n}$ ein wefentlidtes Erforbernif ift, mup auf rer antern Seite aud) Sorge getragen wersen, เaß โą Pfero sor Rälte geidüht fey. Zug=

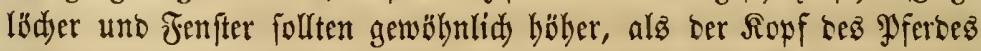
ftebt, an ben Exitenwänoen, bie redyt luftbidyt veridhloffen fein follten, angebradyt werben. Siönnen äber bie Geitenmänbe ces Stalles nidyt biż zur Dede feft seridslofien werten, fo follte man ten gleidyen

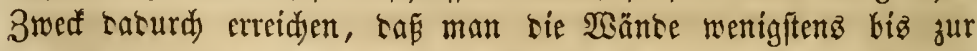

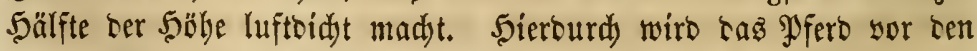

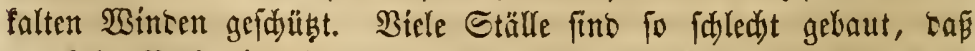
oer falte Nadytwint im :Binter mit aller Seftigfeit burd Fugen und Spalten blafen fann, fo bas daz im Stano befeftigte Thier, das fid feinerlei Bewocgungen madjen fann, gänzlid curdjidjüttelt wirb 
1uno fid nidyt felten Erfültungen, \&ungenbefdwerben ober anbere

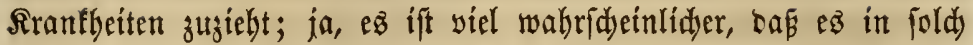
(4) led)t verwabrtem Stalf viel eber eine Frfültung befommt, alsె wenn

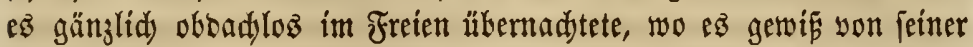
Freíbeit (3ebraud) uno fid) Bewegung madjen roüre, um warm z̆ bleiben.

Auf ber anbern Seite find gegen bumpfe, heife Etälle bie entft= lidgften Cinwenbungen zu erbeben. Eefr falte Witterung ausige= nommen, follte bie Temperatur im Stall nur um zebn ofer zmollf Girab wärmer fein alb im Freien, uno man follte bie Stallungen nur in fo weit verwahren, als baburdy bie falten Sinbe afgebalten merseแ. In ben Stäbten finbet man viel bäuftger alz auf tem Ranbe jene bumpfen, heifen, ber (Befuntheit bes Paferes fo fdübliden Ställe, uno früber traf man biefelben nod) viel bäufiger an, als ge= genwärtig.

Gure in einem feftyerfoloffenen, fleinen Etall cingefdloflente Pुferbe brattuen in furger Zeit alle gute Ruft auf. Sete Runge atbmet eine

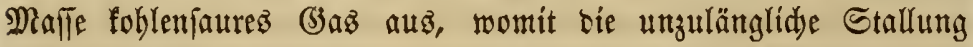
balo bermafien gejdyängert wirb, bafi bie bon ben Thieren einge= atbmete \&uft mit Redjt (sift genannt werben barf. Jebod- - wie viele berartige Stallungen gibt es in ben $\mathfrak{B}$ er. Staaten fowohl, alsె in anbern cistlifitten \&äntern; Stallungen, in weldyen allnädytlich,

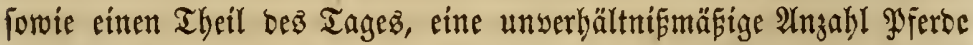

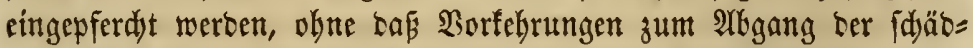
lidyen (3aje, ober zum (Fintritt gefunber, frifder \&uft getroffen werben.

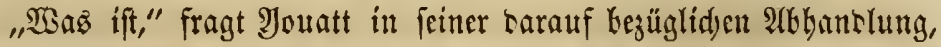
"Die Folge won all Diefem? Ei, ein wentig Nadjenten über sic ge=

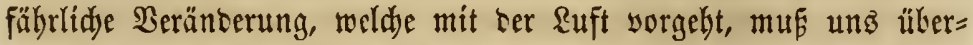

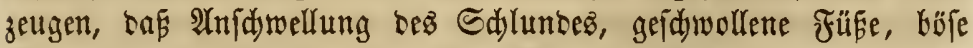

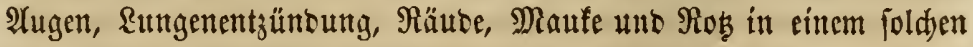
Stall balto auşbreduen müfien."

Th ciner foldyen Stallung berausigentommen uno nad fursem (3)braud) an irgent einen Sfoften gebunsen, wo ez oft ftunbenlang in ber frifdyen, falten \&uft fteben mus, wäbreno ber Serr im 5auje

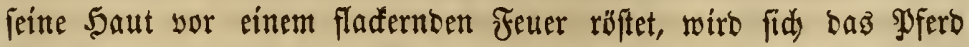
beinabe unfeblbar eine Erfältung zuziebcn. Die Soren fint offen,

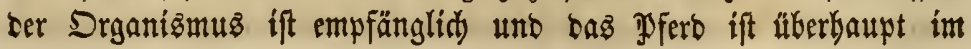




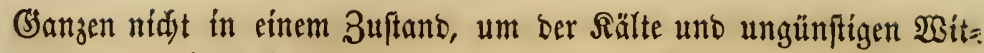
terung zu wiberfteben.

Beim $\mathfrak{B a u}$ eines Stallez follte neben andern Rüaffid ten audy bie

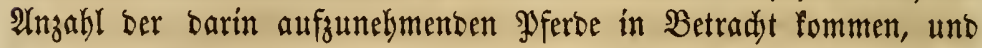
berfelbe follte fo lüftig uno bequem, alz möglidy, gemadyt werben.

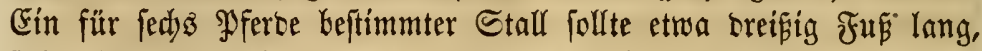

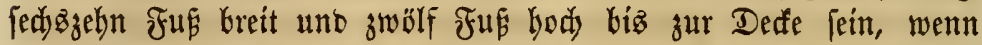
cine foldye angebradjt wirt. Die Deffe porte nidyt bie ganze Breite bes Stallez einnebmen, fontern ez follte cin etro bré Jus breiter

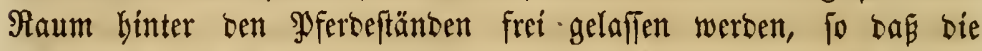
2Yusbünftungen in ben Speidjer entweiden tönnen, uno bort forten

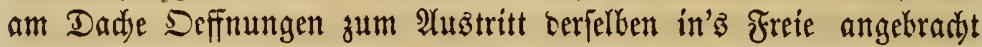
werben. Dięz ift ber zwedmäbigite Plan für bie Erridutung einer Stallung, bie, wenn berjelbe befolgt wirb, fo weit wiro, baj man

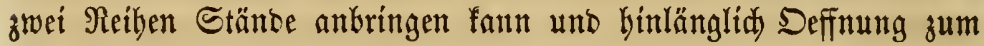
2)

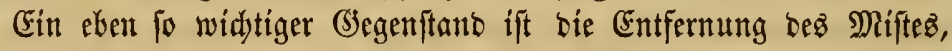
fo wie aller anbern faulenten, unreinen Subjtanzen, bie man unter

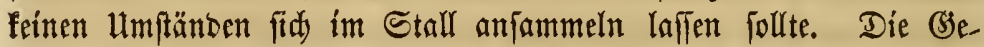

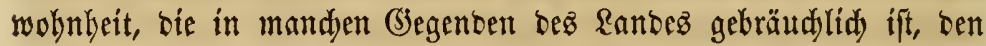
Dünger unter ben Stall zu werfen, follte jogleidy aufgegeben werben.

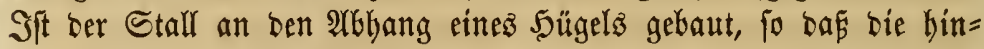
tere Stallwant bäher fteht alz sie yorbere, fo mag es fehr bequem

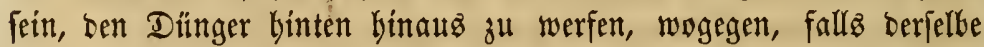
redyt bald yon bort weggebradyt wirb, fidy nid)t

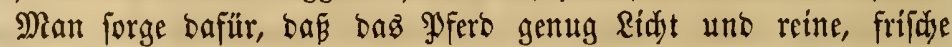
Ruft im Stall erbält, uno man wirb ber Sälffte ber Siranffeiten, bie jeşt unjere PFerbe befallen, vorgebeugt haben. "Bon nidutb," jagt

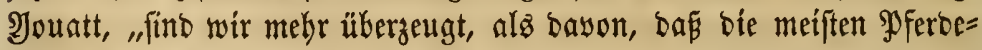
franfleiten und zwar bie fallimmiten uno gefähylidyften berjelben, mittelbar ober unmittelbar auf unzureidjente $\mathfrak{B o r f e b r u n g e n ~ f u ̈ r ~ b e n ~}$

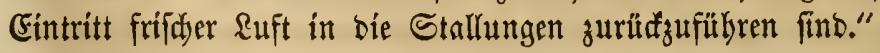

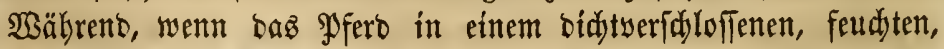
bunfeln Stall eingeidloflen ift, fein ganzer Drganismutz afficirt wirb, bat baz eine ober baz anbere Srgan mehr zu Yeiben, alz bie andern.

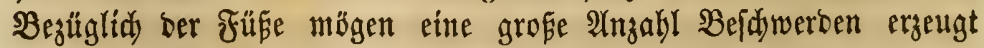
werben, ว. B. - J̧uffäule, Sdjrammen, flẹ́ente Strahlfäule, Maufe, 
Beingefdyulft uno antere berfelben $\mathfrak{A}$ rtt, währeno audy Sautfrant=

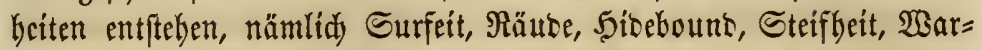
zen uno Ungeżiefer bie Menge. Sebod leiben bie 2Tugen burd) Ent= ziebung ber Ruft uno bez Ridides vielleidjt am meiften, uno bejon=

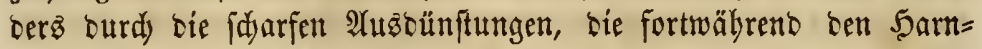
entleeringen uno Düngerhaufen entfteigen, uno $e$ if ift unjere feite

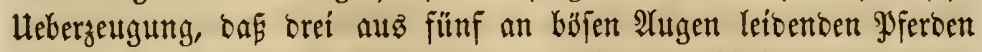
yon biefem Reiben befalfen wurben, weil fie falledjte Stallungen

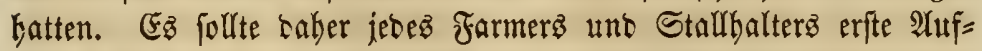
gabe fein, biefe Hebelftäntoe, fallz fie in feinen Stallungen fidy yor= finden, zu entfermen.

\section{รี แล В}

Ałukerbem barf ber Fufboben, auf weld)em baz \$Pferb monate=

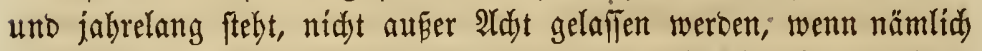
Deffen Befiger an ber (jefundbeit uno Bequemlidjeit feinez Thierez

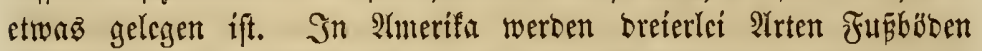

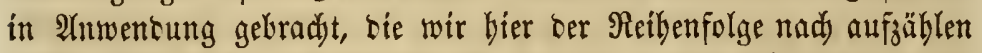
wollen: ben Gro = ober Riezkoden, ben Solz= doer Dielentwoden und baz $\mathfrak{\text { Pflafter. }}$

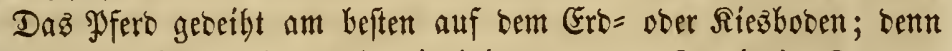
berfelbe ift nidjt fo hart, alsz bie beiben antern, fo wie im Sommer fübler und im $\mathfrak{B i n t e r}$ wärmer alz biefe. Die einzige bagegen ge= madte Ginwenbung ift bie, są ber Sarn, weldyer, wenn er fíd mit bem Mift vermifidt, ein fehr guter Dungleftanttheil iff, verlorent

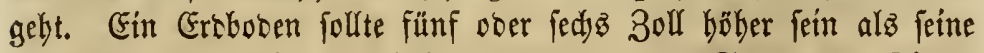
umgebung, uno wirb am beften, went er aus Sant voer feinem Riez bergeftellt wirb. Da ein foldjer Fubboben eben fo fühl alż yer=

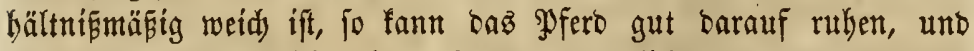

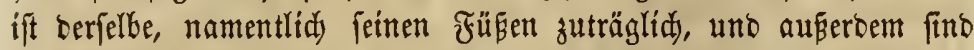
biefe Böben fehr einfad) uno billig. Süblidy yom Shio unt goto= mac trifft man mur felten anbere Etallböben, unt auf ben

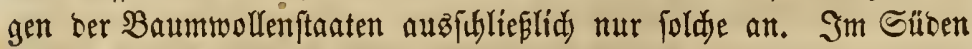
ift man ber $\mathfrak{A}$ nididt, baj fie ter Bsefundbeit viel bienlidyer find, ałs irgento andere.

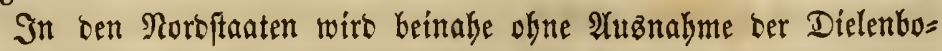

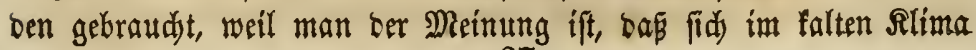


ber Froft in ben aus ber Erbe bereiteten Stallboben feftifebe uno ben Stall feudit uno falt madje. Dieje Rüaffidt bat man aber im Süben, wo $e z$ nur febr felten fo falt wirb, bas die Groe ge= friert, nidjt zu nébmen. Wir baben bejüglidy ber Rorbftaaten nod nidjt genug Erfabrungen gefammelt, um befähigt zu fein, ein $\mathfrak{u r}_{\mathrm{r}}=$

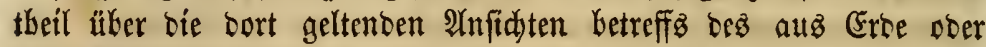
Riés bereiteten Stalfbodens zu fällen. Dielenböben finto fehr harte Etänbe für bie Pferoe, uno wenn fie nidht fehr gut gelegt werben, fo zieht ber Wint burd) bie Fingen und Spalten, fo daf bas \$Fero aud) nidyt warm fteht; aber viele Stallungen im Rorben fino eben mit biejen loje gelegten Böben veriehen, burdy weldje ber winto ganz (d)auerlid beult, 'mag natürlid) bem Pferbe weder angenebm, nod) feiner (bsjunbleit zuträglid) fein faum. 2(utd) befinten fid

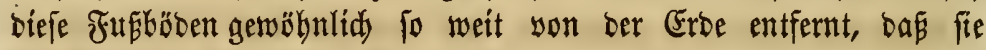
im Sommer febr warm finto.

(S)egen einen gepflafterten Stall läpt fíd, bie bärte beż baburdy getwonnenten Bobens abgeredynet, nidts es einwenten; ba aber biefé 2Yrt $\mathfrak{B}$ b̈ben meiftenz in ben Stallungen ber Stäbte angebradtut wer= ben, wo baz Pyero an baz harte Strafenpflafter getwöbnt ift, fo ift biefez surdjauz nidjt fajäblid, uno aukeroem werben bie Böben vieler grofen Stadtitallungen mit Sägmefl bejtreut, fo bafis bieje

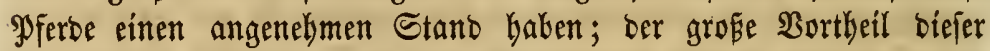
Ställe, ber namentlid) für bie Stäbte von bohem $\mathfrak{B}$ erth ift, ift ber, ba官 fie im Sommer febr fübl find.

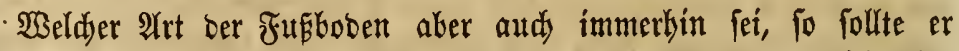
immer eben fein, ba im entgegengejesten fall baz \$fero nidjt be= quem ftehen fann. Soldje Böben, bie son bem Futtertrog an ab= wärtż bängen, fino ganz uno gar untauglidy, uno um atzifinotg fu madjen, wie angenelym ein Pofero in cinem foldjen Stano feht, barf man mur einmal brei voer yier Stunben in aufredter Stellung

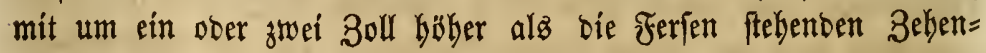
fpizen verbarren.

Woir wieberbolen $e$ s, ber Stalboden follte fo eben uno fo troden als möglid fein, follte reín gehalten und bie Streu oft burd) fri=

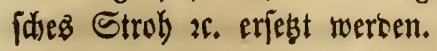




\section{Streu.}

Daż Pferb hat ein gutez, trodeneż Lager im Stano nothmentig uno berfelbe follte nidht nur geräumig genug uno fo eingeridytet fein, bẩ baz Thier fid nad Belleben nieberlegen fann, fonoern $\mathfrak{p}$ Follte fid in bemfelben aud immer ein gutez Rager won Stroh Doer irgeno weldyem anoeren Stoff worfinoen, f. B. Sägmebl, wel= d)ez fid zu biejem Zुwed yortrefflid) eignet. Was man aker aud immer biezu benübt, fo follte in allen Fällen ber nafle uno befdmuste Theil jeben Morgen, uno falls bas Pyerb während bez Iagez im Stand ftebt, aud jeben Albeno entfernt werben. Das yom. Sarn burdnebte Stroh 2c. gebt fehr idnell in Fäulnif über uno ergeugt

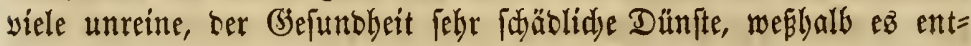
fernt werben follte. In sielen unjerer beften Stallungen geidjebt biez alle paar Stunben, eine Regel, bie ber Radjabmung werth ift.

Die Streu pollte nidjt zu bia fein, fo baj fie bie Füfe bes Thte= res bebeft, ba biefe bieburd erbist werben, waż Entzünoung uno Sranflyeit ergeugt. Zwei 3oll bide Streu, írgent weldjer $\mathfrak{A}$ rt, wirb zu irgend einer Sabreşzeit volufommen genügend fein. Arber bas Rager foute bem Pfero fowohl wäbrent Des Iages alz oes शadjtz gegeben werben, to hapi ez baffelbe benusen fann, ob ez fteht ober liegt, uno man wiro zwifhen einem Pferoe, weldes fortwähreno auf bartem, unbebeftem Stallboben zu fteben hat, uno zwifhen einent anbern, weldjes beftänoig gutes trodenes \&ager benüben fann, einen bebeutenoen Unterfdye wabrnebmen. Zur Wintergizeit wiro hintrei= djenbe Streu viel bazu beitragen, die Uebelftänoe eines nidjt ganz verid)loffenen Dielenbobenz zu bejeitigen, burd beffen Deffnungen

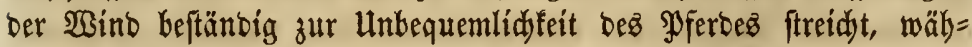
reno biez zu gleidjer Zeit aud) feiner (3)ejunbheit fdabet.

\section{Reintgen แ}

Die Sauptfadje einer guten Stallbehandlung mag in zwei 20 orten bargeftellt werben: "PSerbeftriegel (curry-comb) uno Pferbebürfte." Man fann biefelben nie zu viel gebraudjen, unt felten werben fie fo

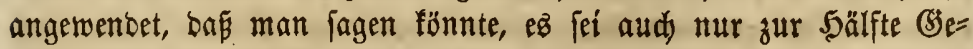
nüge geidyeben. Wenn baz Pfero auf ber Weibe ift, fo wito ez fid an Zaunpfoften, Bäumen zc. felbft ziemlid gut ftriegeln, wäbrend

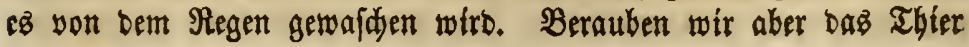


Feiner Freikeit uno fobliepen es in ben Stall ein, fo fint wir ser=

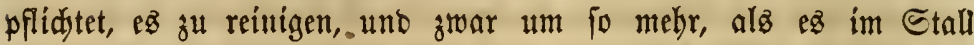

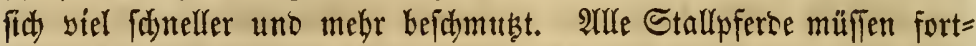
wäbreno geftriegelt, gebürfitet uno gemajden werten, was bei benen, bie viel auf ftaubigen, famusigen $\mathfrak{B}$ egen arbeiten müffen uno oft

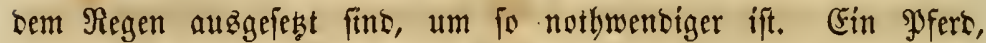
weldes ben ganzen Tag auf einer idmukigen Strape Dienfte zu

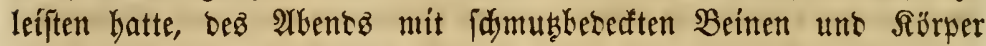
in ben Stall einzujbliésen uno ez bier obne Reinigung biz zum nädften Morgen ober nod länger fteben zu laffen, iff graufam. Riemand bat ein Redt, cin Pferb auf biefe :Beife zu bebnnoeln, uno es wiro ifm bie Reinigung eben fo wohl befommen, als bies bei bem nad)läffigen, gefübllofen $\mathfrak{B}$ efiber ber Fall ift.

Reinlidjeit beförbert aupersem bie (sejuntheit bes Pferbes in bobem Srabe. Der bunfle, oft sumpfe und feudte Stall ift feines: weg geeignet, ber Thätigfeit ber Sattporen Boridub fu leiften, uno $e B$ Dringt ourdy siefe Deffnungen uidt fo viel ölige Flüfigfeit, wenn baz Sfero im Stall gebalten wirt, alв wenn es im Freien umber= laufen fann; nod löfen fid) im Stall bie abgeftorbenen Theildyen ber Sornbaut 2r. fo fdnell uno in fo befriecigenter Weife at. Con=

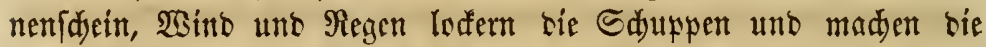
Saut weidy uno auz tiejem (5runte erforbert bas auf ter Weise lebente Pferb nur menig Âfmerfiamfeit in biejer B̧eżiehung. Im Stall aber muj man ber Natur nabbelfen uno ber Striegd, wie bie Bürifte, fo wie im Sommer cin Gimer voll falten Balfers netift

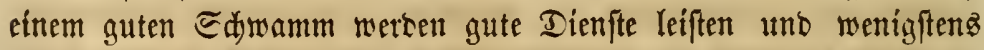
in gewiffem Grabe baż (šefüngnifleben beż Thierez erleidtern. Biele Stallpferbe leiben Keftänbig an Sanutfiebern; Laz Striegeln ift ein ausgezeidnetez Mittel gegen fiefez Hebel; Segenreiz (counter-irritant) und bewirft Frleidyterung.

Der Unterjojieb zwijden eitum Pfero, Laz keftänbig gut gerei= nigt wirt, uno einem antern, weldes man in biefer Şinftht ver= nad)läfigt, ift ein fo bebeutenber, baj man nidit umbin fann, ben= felben fogleid) zu bemerfen. Seber verftänbige : baz Reiben ber Füfe mit ber Sand bie Porenabjonterungen be= beutent beförbert, to baf bas Saar an ben. betreffenten Theilen

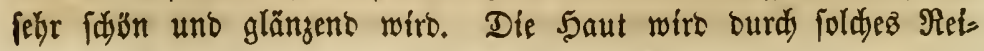




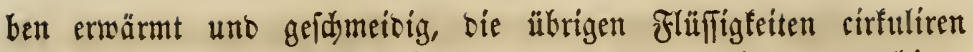
unt bie ganje Sberflădye wiro yon ber Ratur mit ten nöthigen Subjtanjen yeriehen. Bei allen Rrantheiten billoet bas Striegeln

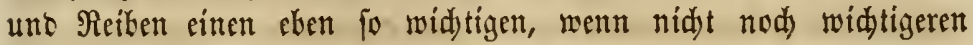

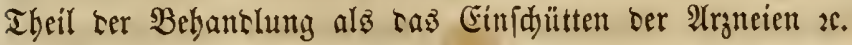

Da biefez ein to wefentlider uno midtiger Theil ber Staltbe=

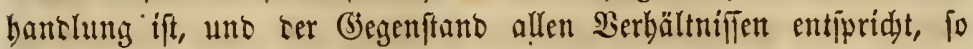

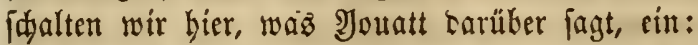

"Då Farmpfert, weldję einen gropen Theil tez Sabres im

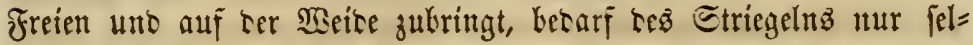
tent uno wirb aud nidjt viel geftriegelt, Lenn sas Thier, weldes bei Tage Dienfte thut uno Radits auf ber Weite ift, braudyt bes

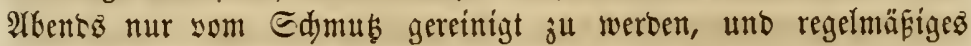
Striegeln res ganjen Rörpers mürte ihm, ba baburd) bie 5aut

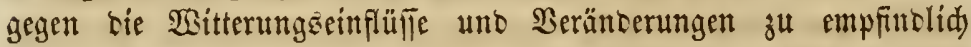
würre, nidjt jegr juträglid) fein. Die Edjuppen, weldje auf ber

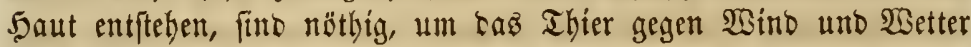

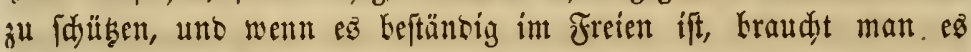
nidjt zu firiegeltr.

"Dagegen ift bei tem Stallpfert, weldjes fdywer gefüttert uno febs

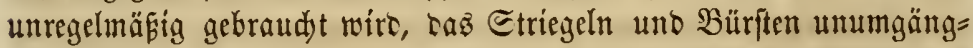
lid) nothwensig; benn baburd) wersen bie 5autporen geöffuet, bie Blutcirfulation miro beförtert, fo sáp fie audy in ben Gliermáent

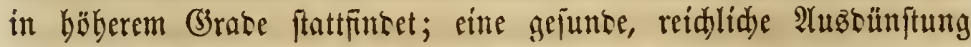
wirb hersorgebradjt, und bas Etriegeln thut in biejer Begziefung

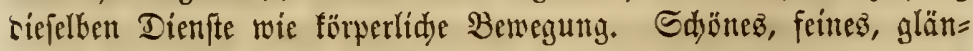
jentes 5aar faum nur surd) żweierlei Mittel ergeugt werben - ent= wecer burd) ummatürlidje Rörperbitse oser fleifiges Etriegeln uno

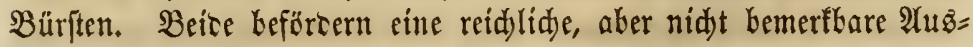
bünftung, ałer währenb baż erftgenannte Mittel biez auf Soften

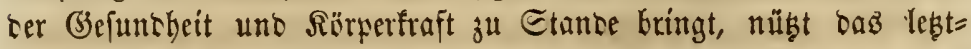
genannte ber Gejuntheit unt regt rie betrefienden Srgane zu neuer

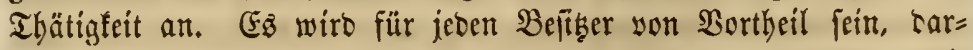
nad) zu fehen, ob haz glänjente $5 \mathfrak{a a r}$ feiner \$perce, worauf er, wie

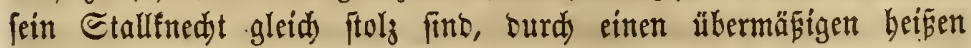
Etall uno allzuldywere Bebefung ober, was nod) am fdäblidften if — burdy ftarfe Getwürze, ober burd elgrlidez Etriegeln uno Bürften 
erzeugt wirb. Das Pferb follte jeben Tag geftriegelt werben unt nebftoem ift es nöthig, baffelbe nad) gejdebener Arbeit zu reinigen. "Iallo bie Witterung günftig ift, follte man fein Pferb im Etall, Fonbern im Freien reinigen, $e \mathbb{B}$ fei senn, Umftänbe fdjreiben ein an=

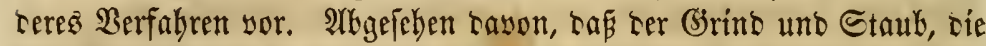
abgetürftet uns abgeftriegelt werten, fid in sen Futtertrögen anjetst,

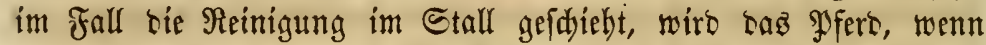

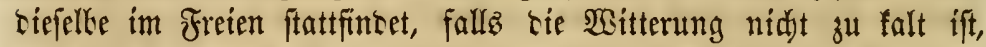
baburd) auperorientlid angeregt uno belebt. Dafür, baj man auf ben Ctriegel, während er gebraudst wirb, ungewöhnlid ftarf brüd,

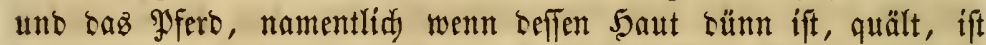
feine' Nothwentigfeit vorbancen. Derjelbe fann im (5)egentheil leidyt aufgejest uno gebraudyt merben, ja bei vielen Pferben braudyt man gar feinen Eiriegel anzuwenben; aud ift ez nidjt. nöthig, tafi bie Borften ber Bürite fo ftrif, ober gar geflifientlid). uneten fint, wie man $\mathfrak{e B}$ oft fincet. Fine weidye Bürfte mit ein wenig mebr Sraft= aufwand wirb eben biefelben Dienfte leiften uno sem SPferb nidyt webe thun. Bei vielen Sferben, bie cine sünme, gejdmeibige Şaut baben, ift weber Striegel nod) Bürfte notbwentig, fonsern bie Rei= nigung mag mit einem Saartud) (hair-cloth) vorgenommen werben.

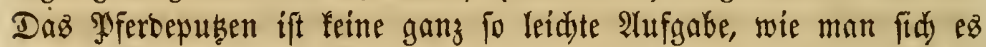

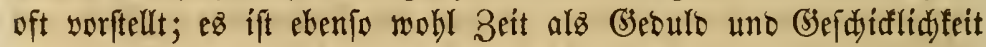
bazu erforterlid. Şenn man mit tem Finger surdy bas Saar ei= nez Pferbez fäbrt, fo fann leidyt ausfintig gemadyt werten, ob taf= felbe gut gereinigt wirb; ber an ben Fingern anflebente Cdymus wiro ben faulen Stallfnedyt verrathen. Bur Beit, wenn taz গুferb sie Snare wedtelt, follten Striegel unb Bärfte fo wenig uno fo leidt als möglid gebraudyt rerben.

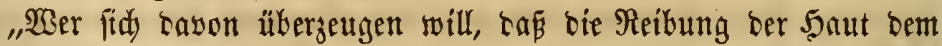
Pferbe febr zuträglid ift, sarf nur einmal beobachten, weldje $\mathfrak{W}$ ir=

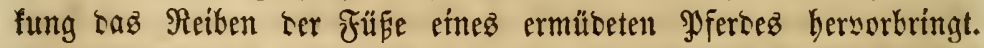
Jebe Frbobung wirb nad) und uad veridwinten, sie fdumerglidye Steiffeit nimmt mebr unb mebr ab, und die Beime erbalten ifre natürlid) Wärme wieber, werben id)ön uno gefdumetsig uno baร Ihier bat fid sffenbar erbolt, frifst bas Futter mit suft uno legt fid) rubig nieber. 


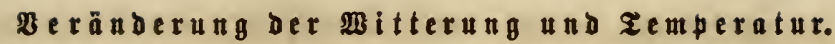

Die Ratur bereitet alle Tfiere, formit aud) bas Pfero auf bie $\mathfrak{B e r}=$ änberungen, weldye bie Jahreszeiten mit fid bringen, yor. Sdyon bie Einridtungen ber Saut find bierzl bienlidy; Die Poren berjel=

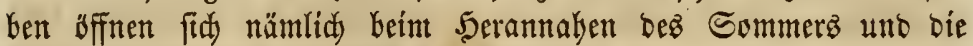

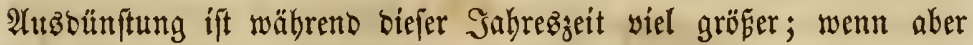
Der Winter yor ber Thüre fteht, fdliefen fid viele biefer Poren wie= ber. $\mathfrak{A}$ uferoem wiro aud im Spätjahr ourd bidteg, langes 5aar (basె Winterbaar) für eine gute, warme Deffe geforgt, weld)e das

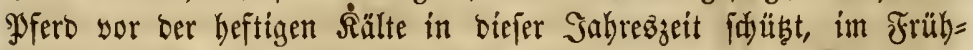
jabr aker, wo biejer Sdub nidjt länger mebr nötbig ift, fallen bieje Saare roiecer auz.

Dieje Beränterungen verurjadyen bem Pferbe nur bödjeft felten Unbequemlidfeiten uno nod) weniger betenflidje Hebel, bagegen ver=

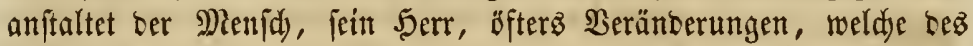
Pferbes (3) jutlobeit uno 3uftand heftig afficiren, 3. B. wenn man bas Thier aแz bem warmen Stall binnus in einen falten Plaķregen bringt, ober faneibentem Norbwint aub]est; ober wenn man bas

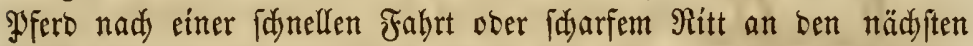
PFoften binbet uno eş bier fteben läst, bis bie Rälte burd alle (Sliermagen ourdgecrungen ift uno bas Pfero yom Froft förmlid geidüttelt wirb; ober wenn man bas Pfero naúf (d)werer Tagesar=

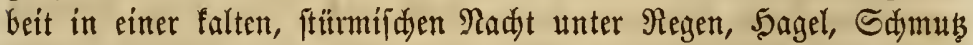

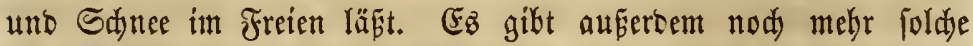
yom Menidyen fu Stande getbradyte $\mathfrak{B e r a ̈ n b e r u n g e n , ~ b e r e n ~ b i e ~ m e i = ~}$ ften nidyis fint, als offenbare Mif́bräudye; aber woir baben feinen Raum biefelben aufzuzăblen unb zu benennen, nur nod) einen, näm=

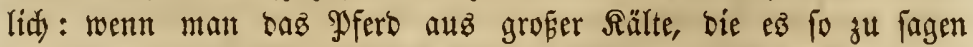
gan; burdobrungen bat, plöblidy in einen warmen Stall bringt.

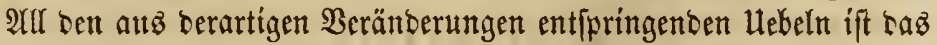
SPfero oft ausigejest uno fällt in Folge bayon oft Rungen=, Saut= uno Jupftranffeiten zum Dpfer. Sönnten wir berartige Umftänbe nidut gan: vermeiben, fo würoen wir mit allen unz zแ (5)ebote ftebenden Mitteln barnady frreben, bem Pferbe allen möglichen Sdub zu verleiben. Mú

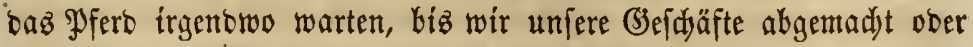
นกร irgenbwo vergnïgt baben, fo würbe einftweílen in cinen Stall zu bringen; fann bies jebod nidjt gefde= 
ben, fo werben wí fowohl burdy Menfdylidyfeit als Selbftinterefie a

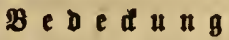

zu verfehen. Beffer fann ein \$ferbecigenthüuer fein (belb nidyt ver=

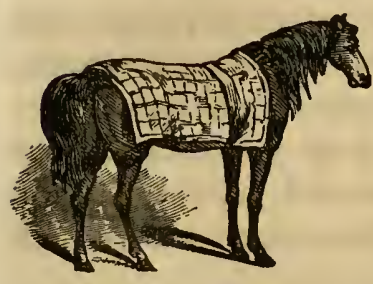
menben, als bafi er bafür gute, bidé, jub= ftantielle Dedfen für feine Pferbe zum (3)e braud in falter, ftürmifater Witterung anidjafft. Ratürlidy mun bie Dedfe mit= telf einem mit einer Edyalle veriebe nen biurt um ben Reib, gerabe binter

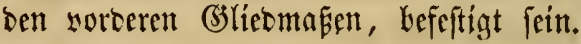

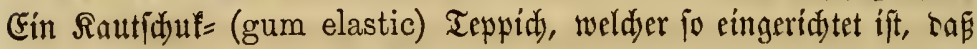
er über bas Pferb fammt (5)efdirr ober Sattel geworfen werben fann,

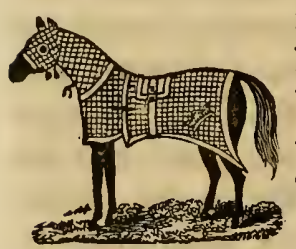
wirb, ba er fowohl das Thier alz bas (seldjirr befoüht, in ftürmifduer Witterung lefre gute Dienfte leiften, unb man fann leicht bie श्Anoronung tref=

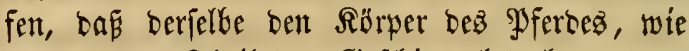

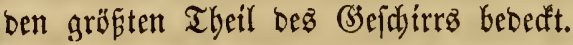

Für bas Reben in wilbem 3uftand, unt felbft

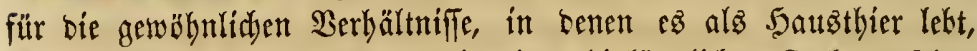

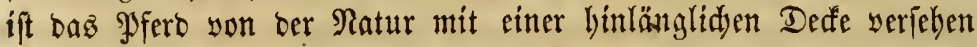
- Feinem 5aar, und nur bam, wenn bas Blut burah faweren Dienft ungewöbnlidy erbibt wurbe, ober wenn ę plöbliduen Tempe raturwedjel. zat befteben bat, ober burd) Siranfleit abgeddwädyt ift, ober wenn bie $\mathfrak{B}$ itterung auserorbentlid falt ift, bat $\mathfrak{e E}$ eine Grtra= bebefung nötbig; benn biejer Sdus ift nur beżhalb erforberlid, um unter gewiffen Berbältniffen zu bienen uno ben ungeiunden (Finflüffen grof̧er und plöblidjer $\mathfrak{V}$ eränberungen entgegenzutwirfen.

\section{Desifettion.}

In allen Stallungen follten mebr ober weniger besinficirenbe Mittel angewant werben, uno zwar mup bie \&uft in grofien Stal=

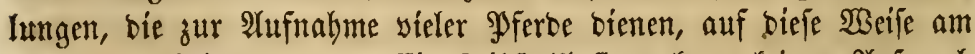
ofteften gereinigt werben. (Fin Reibjtalfbefiser fann feinen 2 (nfpruds auf gute, yerftänbige Bebandlung madyen, ę fei benn, er beşinficire feine Stallungen oft und grïnblid, benn fein Pfero ift. in einem 
jolden Stall, wo viele frembe Thiere $a b=$ uno fugehen, yor $\mathfrak{A n}=$

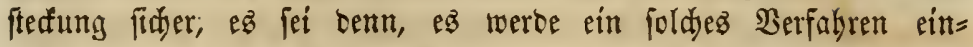
gefdlagen. $F_{3}$ ift für ben Farmer, welder feine \$robufte auf ben Marft in bie Stant bringt, ober für irgenb weld)en Reifenden son

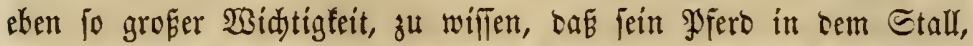

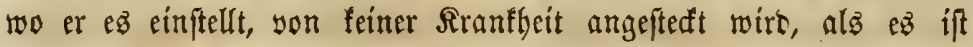
วน wifien, baß wirt.

Rob, 2Burm und Distemper madjen fidy oft in ben Stallungen Daheim, efe bie Stallfnedte irgent etwas dayon wabrnebmen. In Ställen, wo ftüntlid frembe Pferte anfommen uno abgeben, fartn man nie verfidbert fein, sás nidyt ein mit einer anftedenten Srant= beit bebaftetes Thier sarunter gewejen fei. Bielleidyt ftedt ein rogi= ges Dierb, รas auf rieje \$seife in eine Stalfuny gefommen, viele,

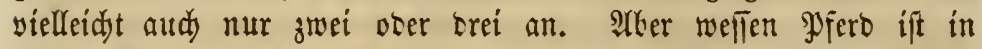
foldjer (jejellidjaft fider? Menn bie geeigneten bezinficirenten Mit= tel getraudit weroen, wiro bie (3iefabr nur jebr gering jein.

Zum Zwede ber Desinfeftion in sen Stallungen gicbt es na= mentlid brei wertbyolle Mittel, uno wir zäblen riejelkent igrem Wertbe naty auf: Tabaaf, Edyefel uno Salf.

Den Iabaf halten wir für bas befte Mittel zur Stall=Desinfef=

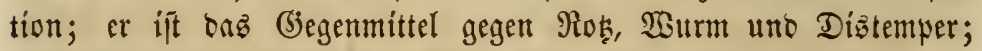
uno menn man benjelben nady ber Anweijung gebraudt, bie in ter 2rbhantlung über tieje Rranfleiten angegeben ifit, fo wiro oer $\mathfrak{B e r}=$ breitung cerfelben Einhalt gethan werben. Giegen jebe anftefente Rranfleit, ob fie bei Menfdyen ober Thieren yorfommt, giebt es ein

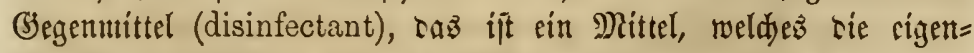
thitmlidyen Ginflüfle ciejer Sranfbeit befler bezwoingt als irgeno eine anocre Subftanj. Desinfeftoren, rie bejüglidy oer bei Ibieren yor= fommenten Sranfleiten erfolgreid) fint, mögen bei Menjaljen ver=

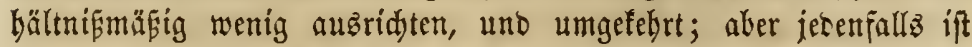
ein gitter Desinfeftor bå befte Mittel gegen bie Rrantheit; uno biefen Grunojas fefthalteno, mag gejagt werben, baf cas befte Mit= tel gegen irgend weldye Epibemie ber betreffente, fidjer wirfente Desinfeftor fei.

Tabaf furirt Robs im erften uno zweiten Stabium, wenn alle

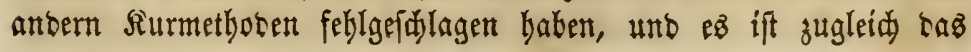


einzzige besinficirente Mittel, auf weldjez man fid) biejer idjred: lidyen Rrantfeit gegenüber yerlafien fann. Cinnige Stängel ober Blătter biées "lunfrautş," melde man wäbreno ber Fütterung in bie Tröge legt, merben auf ben Sejunibeitgajutant ber Pferbe einen

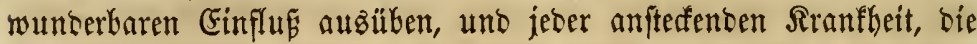
fid) eingerdididen baben mag, entgegenwirfen. Hngleid) mand)en anoern Desimfeftoren werännert ber Tabad die Sualität der mit

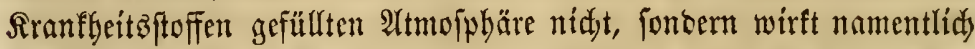
wohlthätig auf ben Drganiżmus ber Thiere, wofelleft bie $\mathfrak{A}$ nftecfung ftattfinbet, insem er bie Suelle bes llebelz zerffërt, ober menigftens

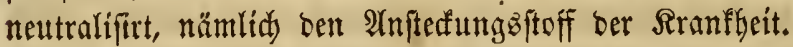

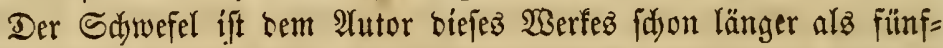
zehn Sabre als ein fehr werthwollez besinfirírenbez Mittel befannt,

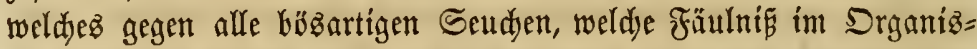
mus erzeugen, erfolgreidy wirft, uno diez ift bie Urjadye, wefbalb ter innerlidje (bebraud in ben yorbergebenten Sapiteln fo oft uno nad haltig empfoklen wuroe. In neuerer 3eit hat man ben Sandefel aud $\mathfrak{a l z}$ Desinfeftor angewantst, intem man mit bemielben bie bes

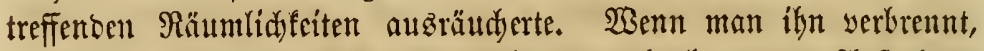
io entfteht Edjwefelgas, weldese, wie man glaubt, gegen 2 nnftefung

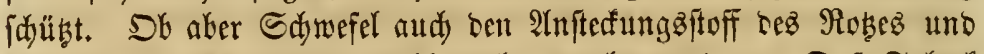

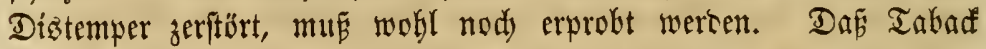
bies yollbringt, bieyon find wir solffommen überseugt, ba wir ten= fellen wieberbolt mit bemi beften Erfolg gebraudyt haben, aus mel= dyer Utradje wir biefes Mittel in allen berartigen Fällen empfoblen haben:

Der $\Re a l f$ ift namentlid als beśinficirentes Mittel, weldes gegen bie fäbäblidjen, aus verwejenben Pflanzenftoffen entfteigenten Dünfte

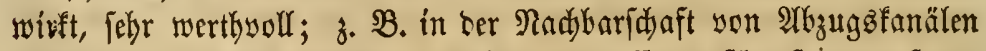
(sewers), ftekenten Pfüben, Mift $=$ uno Compoithanfien $\mathfrak{u}$. F. $\mathfrak{m}$. Ghlorjaurer Ralf (chloride of lime) voer Ralf in jolden Sertlidy= feiten. umbergeftreut, wiro bie $\mathfrak{L} u f t$ in bobem (3rabe reinigen, uno

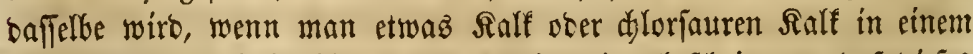

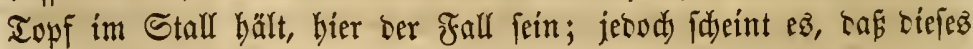
Mittel auf bie Siranffeiten felb́t feinerlé Einflus autübt.

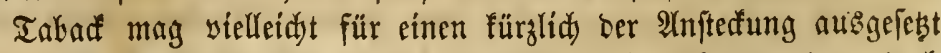
geweejenen Stall als tas einzige Sülfämittel betrachtet werben; bod 


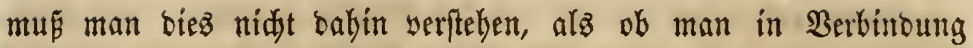
camit nidyt aud Ralf ober Sdwefel benuben buirfe: fie nögen im

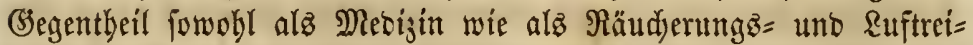
nigungsimittel zu gleidjer Zeit angewant werben. Seber Theil teş

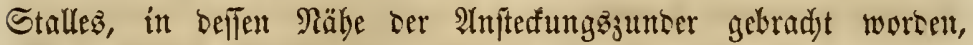
follte tüdtig ntit Tabadg̈brübe abgewajden werten. Flufertem er= jeuge man burd) Daz Berbrennen vieler Tabad'sblätter einen ridyten Dualm uno lege in alle Futtertröge foldye feine Blätter; je feiner Diejelben fins, sejto bejler ift

Tntere Desinfeftrien, 3. B. Rupfervitriol (copperas), Chloro= form, Ienfelozred (assafetida) u. T. w., wutroen von mander Seite anempioblen; aber bie brei hier gentanten fins jerenfalls bie baupt= fächlidaften und die anteren werden mur in bejoutern fällen ge= braud)t.

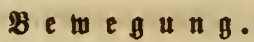

Wenn es immer möglid ift, follten \$rerce auf bie eine ober an= bere Weije täglidy Bemegung baben. Das Farmpfero bat surch

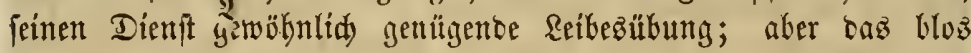
wegen beร̄ Vergnügen gebaltene Stallpfero follte regelmäpaig jecen Tag ins Freie gebradyt uno ifm entweber ourd) Reiten ober Forbren Bewegung veridyafft wetcen, jonjt wetren jeine Beine fteif, uno sie Gelenfe idwellen an, 2 . Berogung beförsert tie Bsejunbeit uno oen Dith tes Ibieres uto ift ofit ras Mittel, worurd Sranfbeiten abgebalten werben. Satünlid follte bie Bewegung eine nur mäfige jein, ba rie joeben bejdriebenen Pjerbe nidyt fähig jino, grofe Stra=

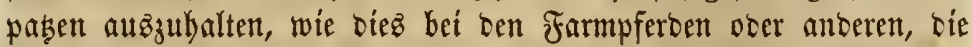
an fdwere 2lrbeit gewöbnt fint, ber Fall ift. Dieje baben zäbe, barte Muşeln, jene aber weidye uno weniger ausbauternoe.

Mít foldyen Pferben, bie eine Beitlang untbätig gewejen, mus mít grofer Sorgfalt werfabren werben, und man barf bie= felben nidit plöblid) ju idure $=$ ren Dienften verwenren, benn foldye Bebandungameife bat (id) idjon burdy febr bebent=

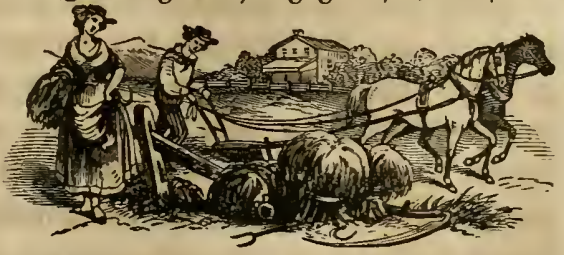
lidue Ulbelftänoe geräddt, unt in vielen Fällen wurben bem Befiser 


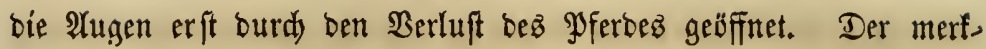
würoige auf Seite 200-202 siefes Buddz beidjriebene fall yon

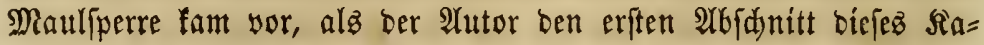
pitelez fajrieb, und zeigt aufz beutlidyfe, waz wir bier mit wenigen Sorten angebeutet haben.

Siele Farmer fadlagen ein bem bort angegebenen ähnlidjes Ber= fabren ein, inbem fie Yjerbe, bie burd)aus nidjt an fdyere Dienta leiftungen gewöbnt fino, ploblid) zu Tatrbiten gebrauden, bie alle Siäfte bes Thieres in 2 Tnfprud) nehmen uno baffelbe ruiniren, uno wenn aud bie Maulfperre nur felten eintritt, fo mögen fie fid

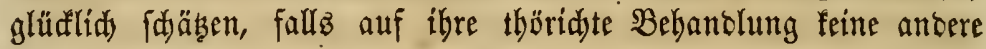
Siranffeit folgt.

Ė war, um auf ben foeben berübrten Falf zurüdfufonmen, ge=

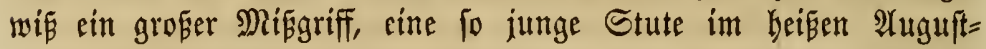
monat zu fo idjwerer 2 trbeit anzuhalten, unt es fonnte vernünfti= germeife gar fein andereb Refultat erwartet werben. Die befte Zeit, baz junge 3ugpfero an bí yon ity geforberte Arbeit ju gewöbnen, ift bas Frühjahr, und zwar hat man gleidy mit bem Beginn beffel=

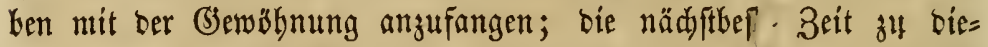
fem 3wefe find bie füblen Tage beż Spätjahrz. Sdjon mand)ez

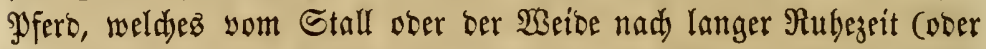
yielleidjt war ez nod gar nidjt gebraudst worben) plöblid ju fdye= rer $\mathfrak{A r b e i t}$ verwentet wurbe, fonute biefertbe nidyt leiften, waz ben Befitser zu ber Meinung veranlaß̧te, er fei im 5antel betrogen wor=

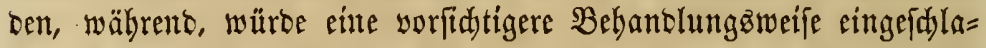
gen werben, bas Thier vielleidyt allen Grwartungen aufż Befte ent=

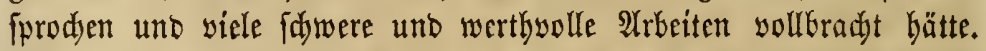

Youatt, obgleid) er fid nidjt fowobl an Farmer alż an anbere

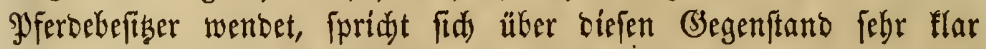
und in befriebigenter $\mathfrak{x s e i f e ~ f o l g e n b e r m a ́ p e n ~ a u s : ~}$

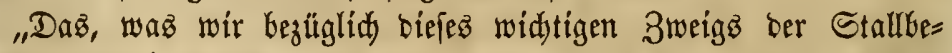

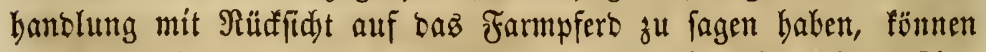
wir furg zufammen brängen. (E⿱ bat regelmäsige aber feine eridjö = pfenben Dienfte zu leiften; $e$ s wirb weoer burd Untbätigfeit in

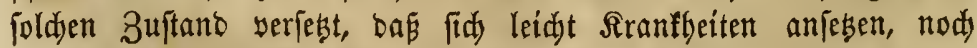

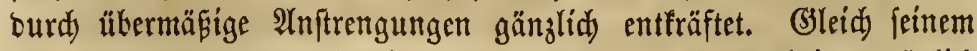

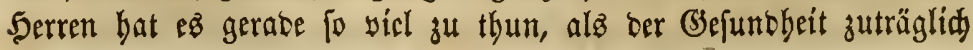




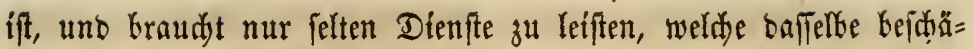
bigen. Die regelmäpig wieterfebrente Irtheit bient, anftatt an ten

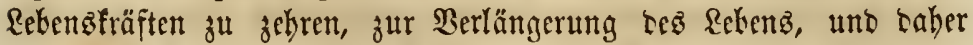
fommt $\mathrm{es}$, bás bie farmpferte fo alt werten, wie man biez felten in ben Stallungen tes Reidyen fintet. Deșhalb bezieben fidh bie

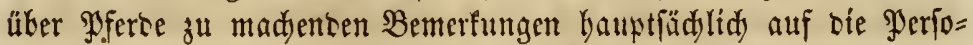

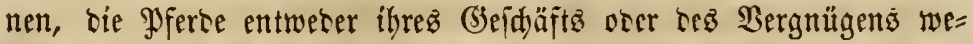

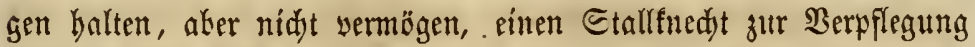
Derjefteen anzuftellen.

"Die erfte Regel, bie mir nieberlegen mödten, ift bie, bá jebem

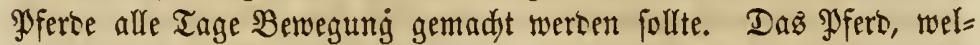

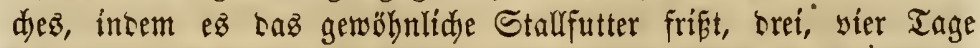
lang untbätíg im Stano fteht, wie bies oft ser Fall ifi, mu年 Sdja= Len nebmen. Fiether, Maufe uno attbere Futufranfleiten mögen fid einftellen, uno wenn man ez nad) siejer in Untbätigfeit verkrad)ten

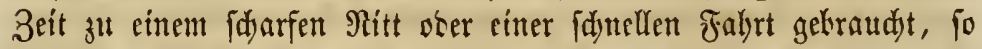

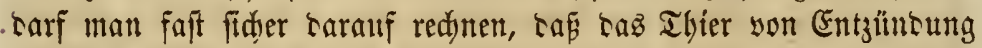
an Rungen ober Fǚnen befallen wirt.

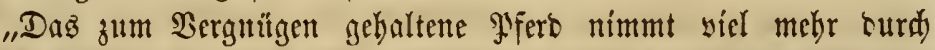
Unthätigfeit alz burd) $\mathfrak{2} r$ teit Sdjacen. Ein im Stall gefüttertez Pfero jollte fid wenigftens jwe Stmusen jesen $\mathfrak{T a g}$ im Freien be=

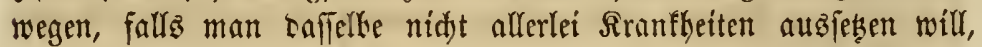
unt man biltse fid nidyt ein, irgetto weldye fitwere Dienftleifungen auf bem Felte ober ber Etrafie bem \$ferbe aufbürcen zu fönnen, ez fei tenn, man habe temirlben genügente uno regelmäß̈ige Bewe= gung yerfdafft; benn Giersurd) alfein wirb faine Energie geweaft uno feitte $\mathfrak{R}$ räfte entroidelt.

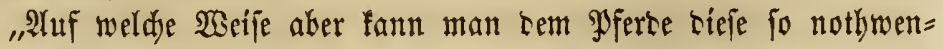
bige Berwegung verjajaffen? Co viel wie mäglid) follte bies som

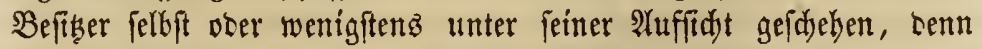
auf bie Berwegung, bie bem Mferse burd) ben Stalfnedyt gemadt wirb, fann man fid) nidyt yerlafien, ba fie entroeber ungentigent ober

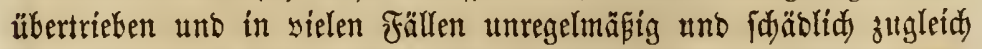
ift, weíl fie yon ben Raunen beffen akbängt, ber baz Yfero Kand= babt unt baffelbe zu feinem $\mathfrak{B e r g n u ̈ g e n ~ o b e r ~ f e i n e n ~ 3 r o e f e n ~ b e n u ̈ b ̧ t . ~}$

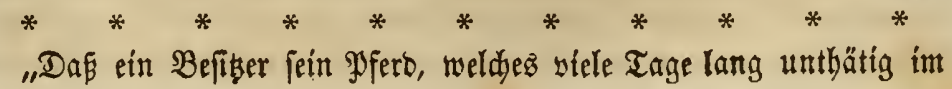


Stalle bes Rofbänblerş geftanben, nadjcem eż burd) Berfauf in antere

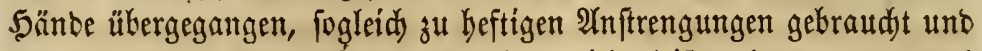
alsoann, wenn baż Rós bie 2 rbeiten nidyt leiften fann, ober nady Dem beftigen $\Re$ itt von Entzünoung befallen wirb, jammert, bies ift ein

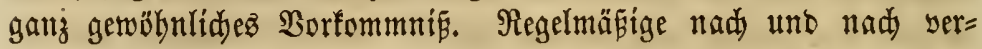
mebrte Beroegung würbe sas Pfero aller $\mathfrak{B a b r j d e i n l i d j e i t ~ n a d j ~ z u ~}$ cinem bödjt werthyollen uno geidäbten gemadjt baben.

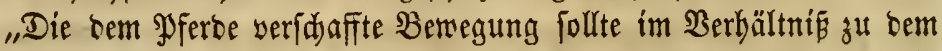
Alter bes Pferbes fteben. Gin junges Pferb bebarf mebr als ein altes; Denn junge Thiere befiken einen Trieb, ber fie zur Thätigfeit anregt; beftig uno gewalttbätig aber tarf bie Berwegung nie fein.

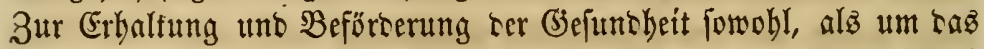

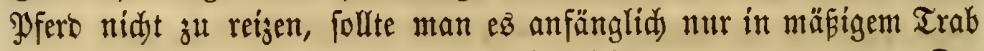
geben laffen unb zu geringeren Dienftleiftungen sermenten. Der fdynelle Trab ober felbit ber Galop mag in Mitte bez Epazierritto

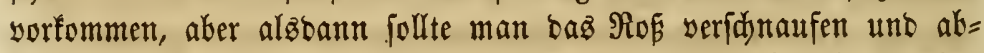
fiiblen Iaffen. Würbe ber Pfertebefiber fein Pferb niemalz Snaben überlaffen uno würoe er sarauf befteben, baf ez in feiner Nadbar=

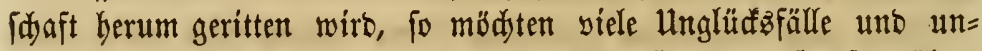
furirbare Sdjäben vermieben werben. Der 5err bes Şaujez über= fiebt alle anbern Theile feines 5̧auşwejens, uno er mag verfidyert fein, baß er Sdaben leiben wirb, wenn er feine Stallungen ver= nad)lâfigt" 


\section{Didftzefintes sapitel.}

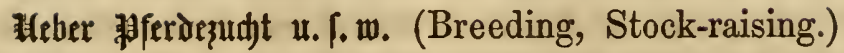

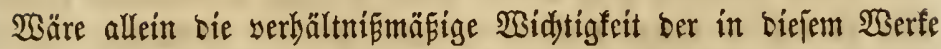

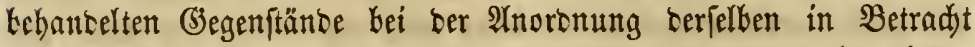
gefommen, fo hätte biejes Rapittel mit Redjt zum erften in biejem Budbe gemadjt wersen bürfen. WBir betradten hier nidjt allein bą junge Thier an und für fỉh, fonbern aud alle bie Uumtänte,

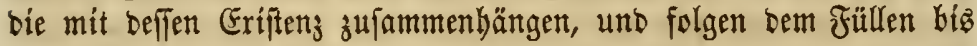
jum $\mathfrak{A}$ lter, wo es ftart unt herangewadjen ift.

Die vorliegento 2 tufgabe ift cinerfét audi) mit fo manderlei Sdywerigfeiten verfnüptt, bas wir biejelte nidjt ohne Bejorgnif unternebmen; benn ein bier begangener Srrthum witre in feitten Folgen fatal Fein unt melbr Sdjaben bringen, als anterşwo gemadjte Mífgriffe. Sobann fitto wir unz wohl be=

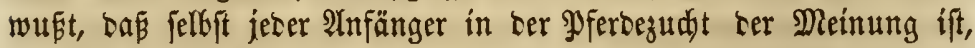

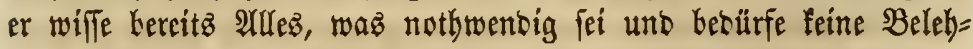
rung mehr. Rein Gegenftant bejdäftigt unjere frarmer mehr bie Molitif etwa aużgenommen - als biejer, uno bie bemélben son

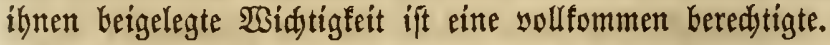

Da aber ber Menjid einmal, jo zu jagen, bieje Sadje auż ben f̧änben Sottes genommen hat, fo follte er audy alle ber Bortheile theillaftig werben, bie ifm burd menfd)lide Erfahrungen geboten werben, wefbalf wir, obgleidy yorausjehent, baj wir uns mandjer

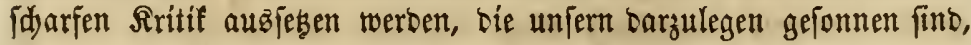
unt unjere $2 \mathfrak{n}$ fidften rubig und flar ausjpredyen werben, fo saf,

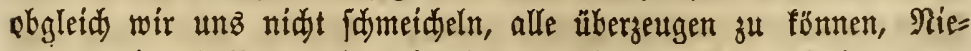
mantben im ltnflaren über biejelben fu jein braudjt. 2 (ud) werben wir nidjt verfeblen, bie Grünbe unb Urjadjen für unjere Meinung 
anzugeben, uno wir fügen bei, bás fid biejelbe auf langjäbrige $\mathfrak{B}_{\mathfrak{e}}$ obadtung uno Erfahrung ftüb̨t.

Sinfiddtlid) ber Pferbezudyt fint gegen viele allgemein üblid) (Ges = bräude entidjiebene Einwenoungen zu madjen. So z. B. verbient

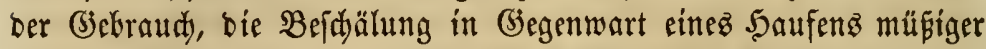
§inaben yorzunekmen, wäbreno ein $\mathfrak{A} u f f e k e r$ bie Bewegungen beż

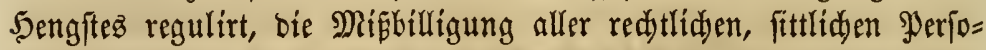
nen. (E⿱ bern aud unnatürlid) und fääblid. A2nbere Thiere fönnen ibre

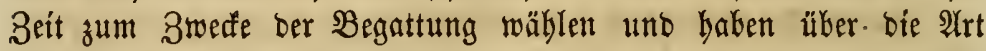

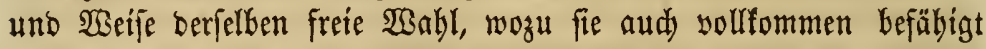
finto, fo ba

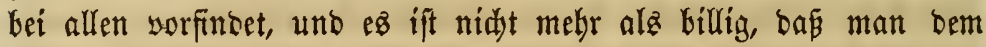
Pferbe biefelbe Freibeit gejtatte.

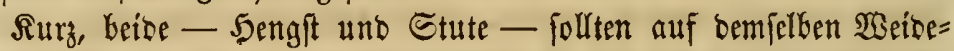
plab zujamment fein, weldyer natürlidy yon ber \&anoftrafie entfernt gelegen fein mus, unb bás ein foldyer leidjt gewäblt werben fann,

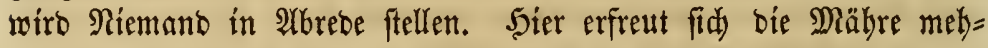

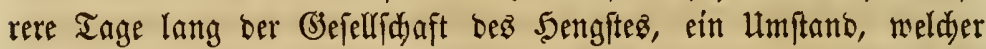

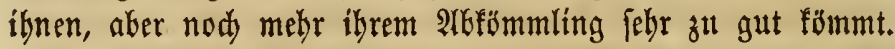

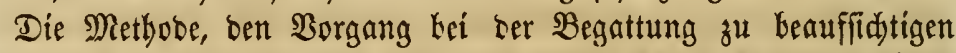

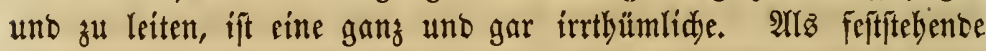

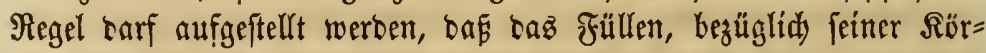
perconftitution und Fäbigfeit hauptfädlid) bem Sengfe, binfidytlidy

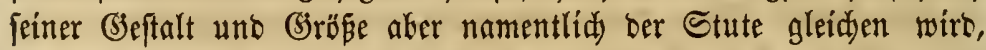
und auf (5rund biefez (jejęez hin empfeblen wir bie oken an=

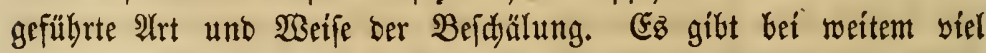

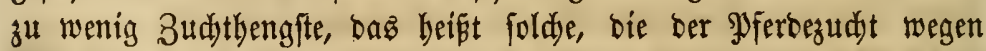

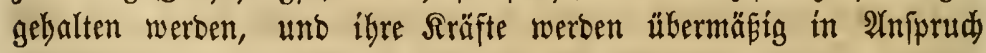
genommen.

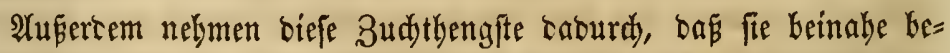
ftänbig in einem bunflen Stall eingefperrt werben uno ibnen zu wenig Berwegung veridafft wirb, Sdjaben; fobann erbigt bas im

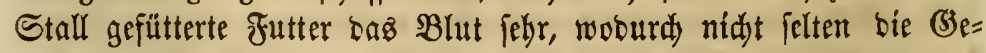

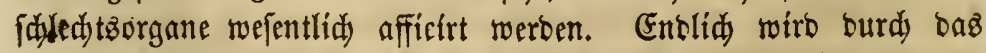
beftänbige Einfperren beewirft, bas ber Sengft wilto, ftörrig und un= lentfam wirb, um fo melbr, als er meiftens yon ber Stute getrennt 


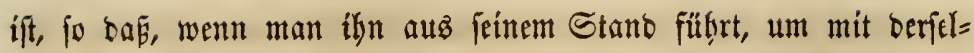
ben zujammengebradyt zul werben, er fid in fieberifjer 2 Uufregung

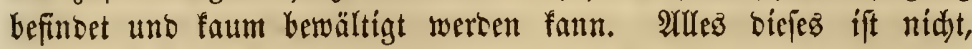
wie $\mathfrak{e s}$ fein follte, und würbe gar nidjt sorfommen, falls man bem Seengit erlauben würoe, beftänoíg mit ber Stute zulammen zu reben; er würbe in biejem Faall viel rubiger, Yenfbarer uno bulojamer fein. Dâs ber Sengft unter ber gemöbnlid) übliden Mettbode feine ber=

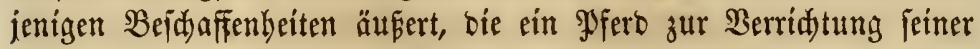
Dienfte haben follte, ifit augenjugeinlid, und bod wiro baz bei ibm zu Tage tretente Temperament mely voer weniger auf bas F̧üllen überigeber.

Ein anterer, feldr oft begangener Srrthum, ten wir berrits bes riiblyt baben, befteht barin, baf man einen und benfelben Sengit jh

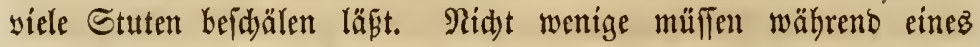

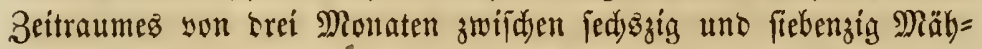
ren belegen, unb baben ofit in einem $\mathfrak{T a g}$ creimal zu bienen; eine Methode, bie aud) bas fräftigite Thier entfräften mus; benn ez̉ wirb bem 5 engit idjon idjaben, wetn er bie Beidjälung einmal bez $\mathfrak{T} \mathfrak{a}=$ gez zu sollbringen hat, uno man jollte biez mutr jeden zweiten $\mathfrak{T a g}$ yon ilgm fortern.

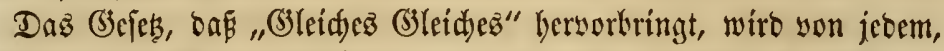
ber über bas Pfero gejd)rieben hat, angefübut, unt jeber 2 nnfänger in ber Pferbeguddt meint, bas er bas fdjon längft wifie uno man barum in $\mathfrak{B} e \mathfrak{u}$ g barauf, wie oft ber 5 engit befdäle, nidjt jo ängft= lid) fein bürfe. Shne Zweifel geidieght bie Entftethung bez Sungen ourd) Bermifdung genilier Suljtangen, zu weld)en beibe Thiere

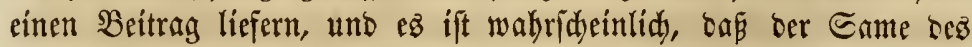

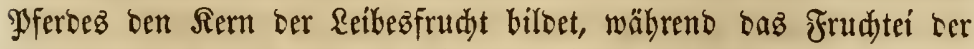
Mähre bas Reben enthält. Dies ift bei allen rothblütigen Ihieren ber Fall.

Ulber fo wahy aud bas vorkergehente ift, fo ift ez eben fo wahr, baf man, um ein befriedigendes Ente zut erreidyen, gut be=

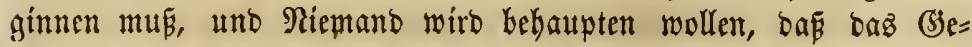
bäube mögliderweife ftarf fein fönne, wenn aud) die Grrunblage

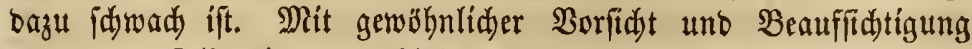
mag man, fatlz ein guter $\mathfrak{A}$ nfang gemadtt ift, beredtigterweife auf

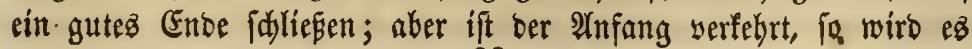




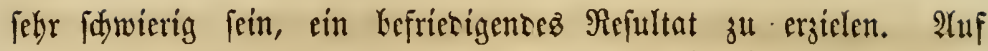

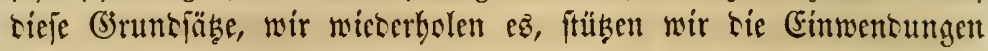
gegen sie unnatürlidłen uno lädserliden (3ebräudue, bie bei vielen

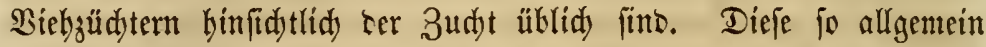

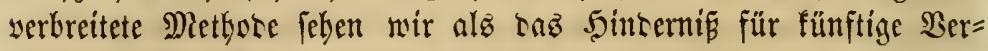
eteltung an; nein nod) melkr, wir fehen in terrelteen sie thatfäd)= lidje Utradje ser becauenzowerthen Entartung tez amerifanijajen Pyfertez, weldye immer mebr überbano nimmt.

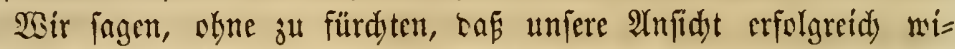

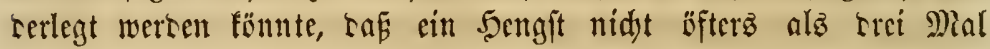

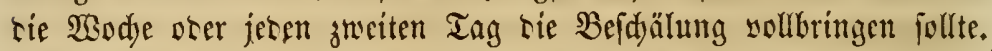
(bridjicht es afters, fo mag zwar Befrudjtung ftattinten, afer ter

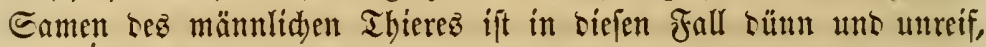
uno wenn ein früllen erjeugt wirt, fo wiro ez grohfnodjig jein uno

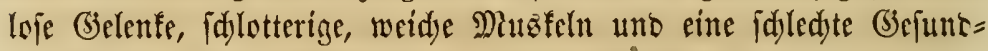

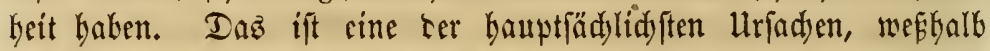

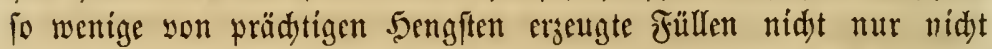
eben fo fdjön wersen alz ticje, fontern in jeber Bezichung weit un= ter fie jul ftelyen fommen, intem fie sfit gar feine ser Sutrlitäten icz Sentgftes erben. Dab unter folden limftänten ergettgte Foblen farn unmöglid, io gut aud immerlyin ser 3uftano ser Etute fein mag, etmaz anterez werten, alż ein fdjwades, elentez Thierdjen.

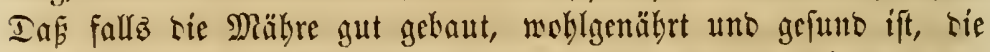

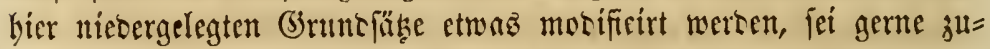

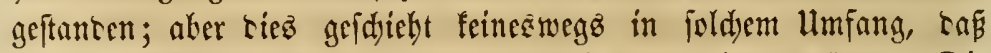
tie Riddtigfeit ticjer \$rinjipien taturdy angefodten würbe. Die wenigen fäsün foüllen, weldje surd) bie Sengite ergengt wersen, fino sie Früd)te ter Begnttung, sie zut einer Beit geidjiekt, in wel=

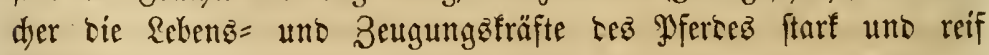
waren.

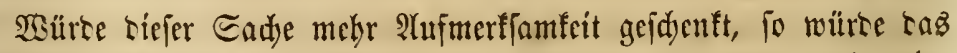
Nidytträgtigmersen ser Etuten viel weniger yorfommen, als siç num nad) Len Erfahrungen Ler Pfertejüdyter ber fall ift, uno ser 3wed ter Paarung wïte treimal fo oft erreidst, alछ unter entge= gengefegten Ulmitänten.

Daz grofe Sinserní, in siejer Beziethung eine fo nothwensigen

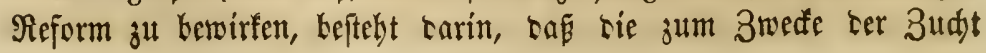


gebaltenen 3udthengite fidy gröstentheils in ben Sänoen poldyer Männer befinten, sie eben fo siel (5elo als möglid vertienen wol= len, uno beren Juterefle es ift, Laf Ier Scngft mährent fer Paa= rungęzeit to siele Befduallungen solubringe alz möglids. 3ufriesen Ianit, auf einige fdöne, son ifren Pyerben ergettgten Foblen bin= weijen ju tönnen, befümmern fid) riefe Reute um rie Beretelung ber Pferberace im allgemeinen burdjau nidjt. Warum follten aud) fie fid mit riefer Frage abgeben; ibre 2Tufgabe ift ja nur einjig uno

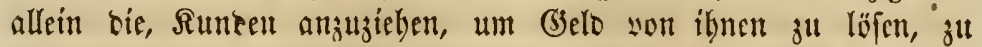
weldyem 3mede alle Mittel angewant wersen unt jelbit, wenn es auf Soften ofr Madbarn uno ibrer Pferbe zu gecueben bat. Wenn nur énige weitere Dollars beraubgeptefst wercen fönnen, fo frägt man nad) sem Hebrigen Durdjaus nidytz. Diefez Syftem ift son

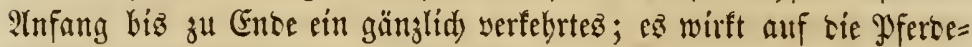
judyt wie eill Meblthau auf rie Pflamjen.

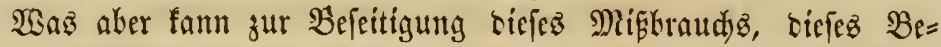

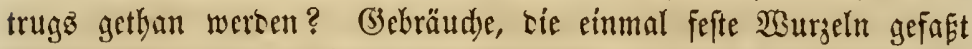
baben, laffen fid) fo lecidst nidyt abfdaffen, uno sennod, fönnte bie= fem. unehrliden Treiben Einbalt gethan merten, fallz unjere Far= ner in sicfer Simfidyt cine entfdiebene Stelfung eimnebmen würcen. 23enn 3. B. cie Rathbaren, irgend weldber (jegent, zujammenteten uno bezitglidye Beidylüje paffiren, fowie betreffente Regeltn aufitellen

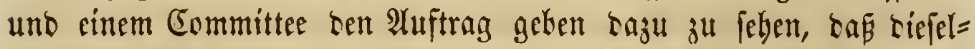
ben ausgefülyrt werten, ober went tiefelben Maṣtegelt yon ben

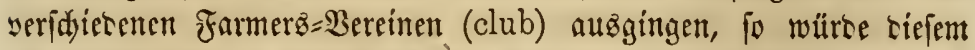
Hebelitano balo in grofem Maf́e abgetyolfen feín. Uebrigenz polute in jetem Etaat ein (3) ejeb befteben, weldes ricfe Mifibräudje auf= hebt; raf ater ein foldyes (5)efes in ten Segislaturen paffiren uno in Sraft treten werte, bies barf nidyt erwartet werben.

In vielen llnterbaltungen, rie wir mit einer grofen $\mathfrak{A}$ (njabl Pfer= tegübter in Rentucfy uno Tenneffe hatten, fanoen wir, sapi fie all= gemein mit ben bier rargelegten $\mathfrak{A}$ fiften übereinftimmten, uno viele fpradyen fid febr beftig gegen ten (Gebraud) aub, einen uno tenfelben Sengit zur Befdälung fo vieler Stuten zuzula fen, webgalb cine nidyt unbeseutente $\mathfrak{A}$ izahl biefer Budffarmer ibre eigenen Sengfte fur $\mathfrak{B} e=$ idälung ifrer Mäbren uno vielleidyt einiger ancerer balten. Mand)= mal foiefen aud) einige Farmer (3) 
ausgezeidnet guten Shengft zu faufen, beflen Dienfte fie alsbann ges meiniduaftlid baben; ein Şlan, welder getwif ber allgemeinen Rach= baltung werth ift.

Intem wir nun auf einen anbern (Siegenftant ülergeben, möd)ten wír nod einmal carauf binweifen, haf fein Sengit mebr alz etwa zwanzig mal wäbreno ber Paarungşzet, uno ní mebr alż jeben anberen Iag zur Stute zugclaften werben follte. Seber Farmer thut feinen Pferben und fomit fidj felbft Sdaben, wenn er e⿱ zu= gibt, bafi man in bebeutensem (Srabe won biejer Regel abweidyt;

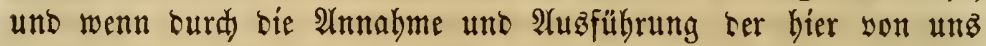
angebeuteten Methobe die Preife für Befdălung erböht werben müften, fo würbe es fid) für ben Farmer wobl lohnen, felbft ben boppelten

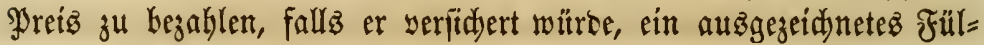
len zu betommen.

\section{Der}

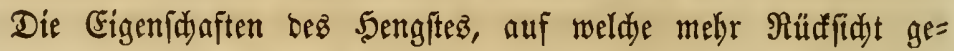
nommen werten mus alż auf alle anberen, fino - bie Ctärfe fei= nes Sörperbaus uno fein Temperament. Die erftere bängt baupt-

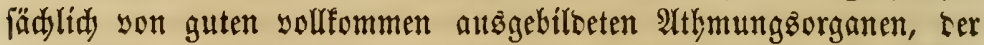
Feftigfeit ter Mubfeln und ber Septalt im allgemeinen ab. Seine

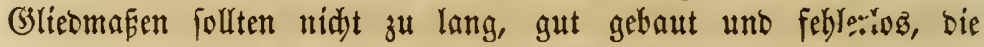
(5)elente oben runb uno gut eingejest fein. Namentlíh mus man

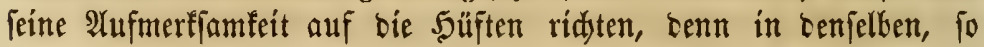
wie ben binteren (Sliebmafen liegt die grofie Stärfe Defball aber barf man nidjt yerfeblen, bie Sdjultern zu unterjuden; biefelben jollten breit, nidyt bod und zugeipist, fonsern an ibren Enoen runo fein.

Für Farmzwedfe in unjerm Ranbe eignet fid baz fedjözelyn Saand ober Fauft bobe PJerb am beften. Gegen foldue, bie siel fleiner ober viel gröfer fittb, müffen, fallz man ben (s)ebraud auf ten Farmen in's 2luge fafit, Einwentungen gemadjt werben. Sft cin Sengit yollfommen ausigebiloet uno fino feine Muşfeln gut ent=

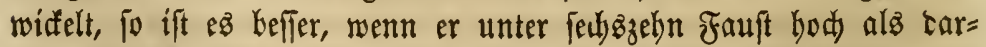
über ift. Auserbem bat man aud nod auf bie Farbe Rädfidt zu nebmen; eine bunfelbraune Farbe Deutet auf Das : Borbandenjein ber

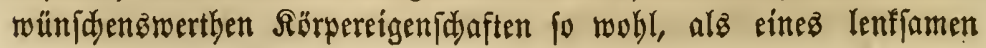


Iemperamentez hín. Die eijengraute Farbe ift bie nädjfe uno bie

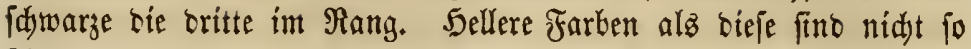
fdäkenşwerth, uno je heller bicielben fint, befto weniger werthyoll

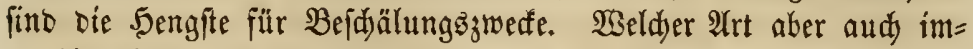

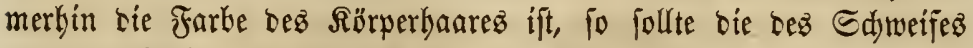

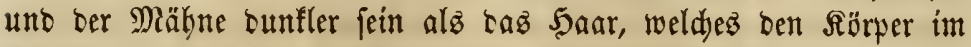
AUgemeinen bebeft, uno man nebme fid yor bem Sengit mit bunf= Iem Sautthaar uno beller Mähne uno Edjweif in 2 d)t. Feinez, glänzenoes, furjez 5 aar zetugt yon gutem $\mathfrak{B l u t , ~ w a ̈ h r e n o ~ g r o b e z ~}$

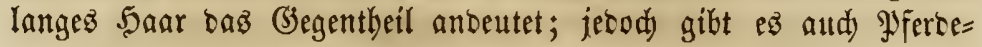
racen, weldae langes 5aar haben uno an senen man burdaus feín Beidjen fintet, yon benten man auf guteż ooer fogenanntez colez Blut fallésen fönnte, bie aber trobbem auserorbentlid) gute Duali= täten entwiđtđeln.

Rein 5engft follte vor feinem vierten Sabre regelmäşig für Zudut= zwecte gebraudjt werten. Zwar mag er jidon in feinem britten $3 a b r$

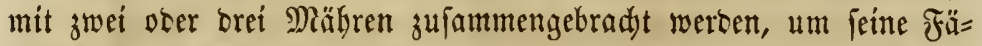
bigfeiten zur Füullenerzeugung zu erproben; mehr alz bieje $\mathfrak{A n}_{3} \mathfrak{a h l}$

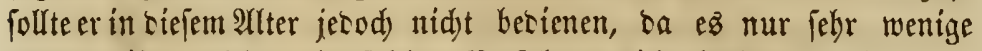
Perbe gibt, welden ein joldes Berfahren nidjt hödjt idjäblid) wer=

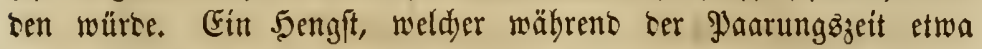
zwanjig Mäbren bejdält hat, wiro in Feinem zwanzigiten Jahr nod ebenio gejunto uno fräftíg uno fähỉ feín, alz ein anterer, yon bem die breifadjen Dienfte erforbert wurben, in feinem zehnten ober zwölften Sabr. Denn Daßj übertriebene Dienftteiftungen in biejer Beżebung

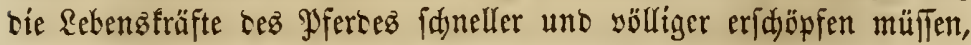
als irgeno ctwaz anterez, ift leidjt einzujeben.

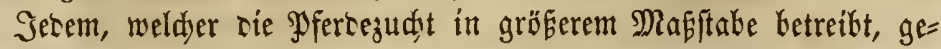
reidjt

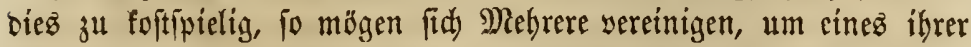

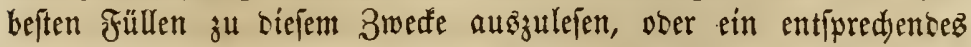
Thter gemeinfdaftlia anjutaufen. Sold)e Berfahnungswneife würbe ohne Zweifel ben nun fo gewöbnlidjen Betrïgereien uno Gelberprei= fungen balo ein Erroe maden, unt auf ber-anberen Seite zur $\mathfrak{B e r}=$ coelung ber $\mathfrak{P}$ ferberace auEerorbentlid) viel beitragen.

Die Sengite unferes Rantes fimb meiftens felfr gut. Man mählt fie gemöbntidy aus ben keften füulfen aus, uno beinake alle, fallz 


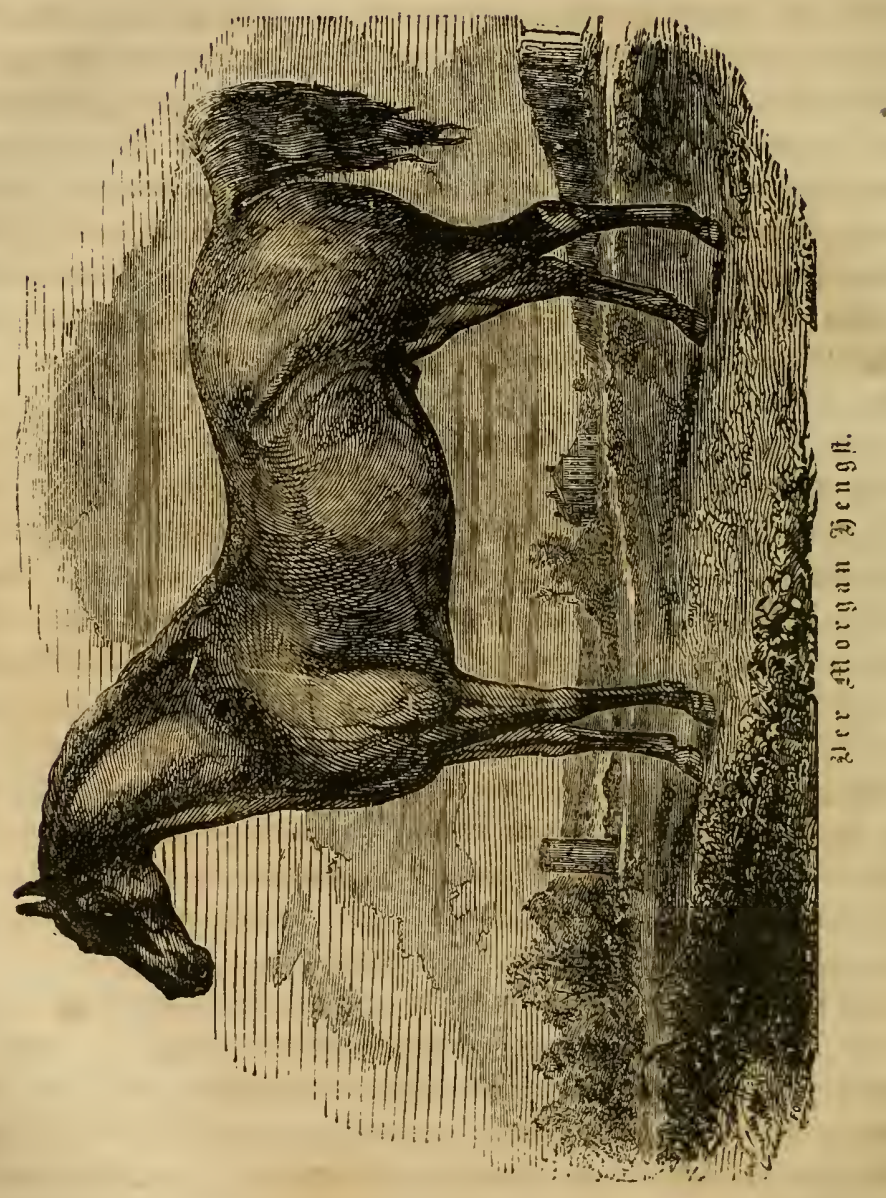


fie nidbt burdy übermäpige Dienflleiftungen abgeidwäd)t werben, er=

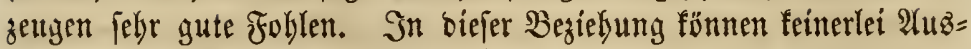
lebungen gemadjt weroen, befto mebr ift aber bie son lutwifienbeit zeu= gento uno veroerblid) $\mathfrak{B}$ erfabrungşweife oer Eigentbünter zu tadeln.

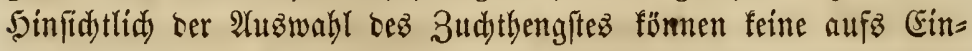
zeltue eingehente, fonbern nur allgemeine Anmeijungen gegeben wer= oen. Der Befitser eines für Zudytzwede gebaltenen Sengltes läjt

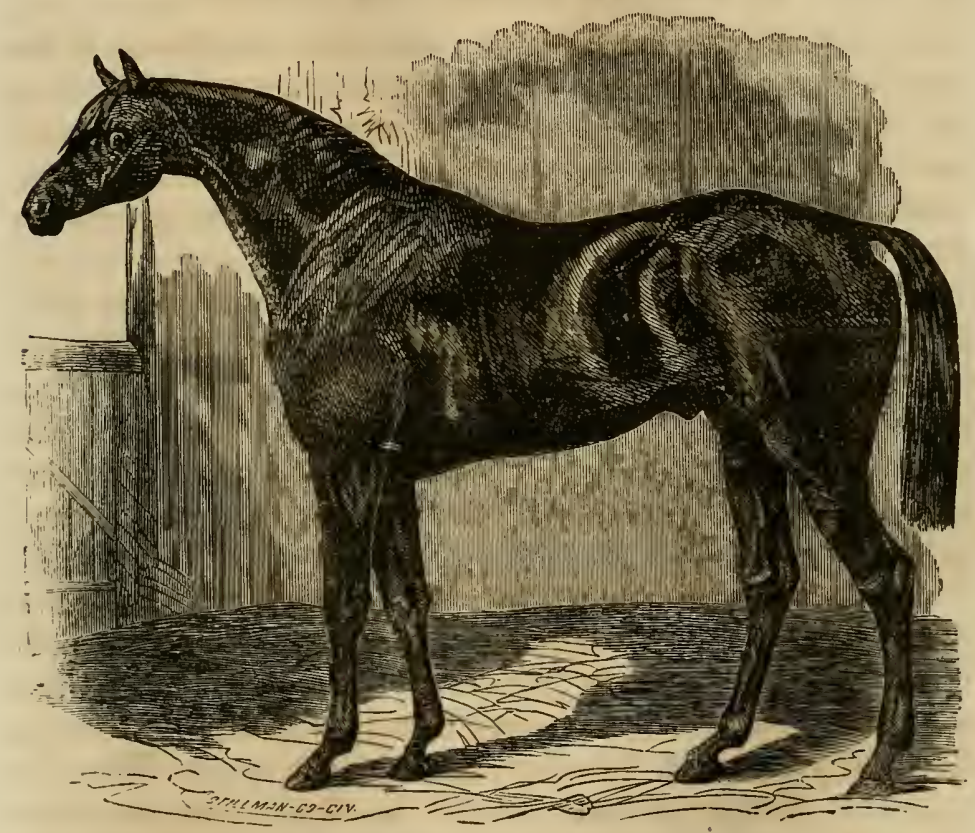

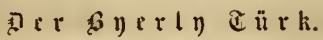

gerobbulid) beflen 2rbftammung uno Dualitäten in sen Beitungen

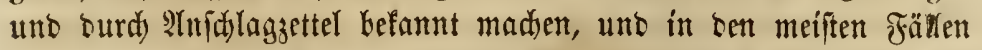
fino bie auf bieje Weife gemadten 2 ngaben oer Wabrbeit gemäf. Die meiften Sengfte ergeugen Füllen, bie am beften für foldye Dienfte taugen, fu weldyen jente am meiften befäbigt fint. Woill man beshalb cin Farmpfero zieben, fo follte man bie Mäbre zu einem Farmbengft bringen, uno ein entipredjenbez Berfahren follte eingefd)lagen merben, falls man ein Reit= ober Chaijenpfero zühten mödyte, benn cin jol= 
dję mus, ba oft fdjnelle Bemegung woin ifm geforbert wirb, anbere Figenidjaften baben alz ein Farmpferb. Neit= uno Ehaifenpferbe follten fid ber (sieftalt nad) ähnlid, leid)t uno gelenfig uno nidjt gröșer fein, alż etwa fünfzebn uno eine halbe Sano hod. Das

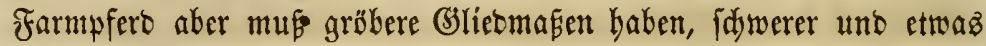
größ̄er fein.

\section{Die Stute, ihre Eigenidaften und Bebanblung.}

Die Eigenifjaften uno Fähigfeiten ber Stute zu verftehen, ift von nidht geringerer Widtigfeit, alz mit benen

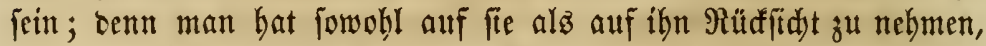
unb eine flare Finfidyt in bie (3ebredyen unt Febler ber Stute, weldye oft ganz anberer Art find als beim Sengft, mögen für ton Büdoter yon weittragenten Folgen fein.

Seber Farmer weif, baj ein Erforbernif einer reidylidjen Ernte guter, tragfähiger Booen, ift. Die Stute mag mit Dem 21+ferlant, in weldes or Samen geftreut wirt, verglidyen werben, uno man fann beinabe mit elonio siel Redyt erwarten, auf idyledtem Boben cine retalidbe Ernte zu crgielen, als man boffen fann, son einer

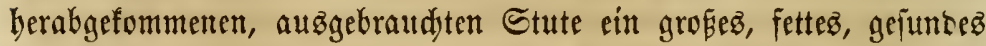
Foblen zu erbalten.

Eine 3uditfute muf namentlid) zwei djarafteriftifde Eigenidjaften baben. Grftenz - eine yollfommen gut geformte Gieftalt, wobei be= fonters auf gebörige Ränge zwifdyen Sitiften uno Sduultern, fowie auf entipredbente Breite bon einer Şüfte zur antern fu fehen ift,

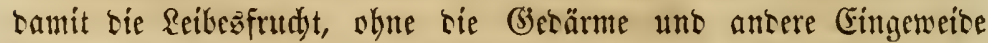
§u trüđen, genügenten Raum habe. Eine fleine, furge Mäbre mit aufgejogenem Baud uno nabe bei einanter ftebenten Süften wiro nie eine gute, zmedfentipredyente Mutterftute jeín.

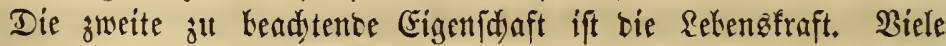
Mäbren ermangeln terfelben in gröferem ober geringerem (srabe,

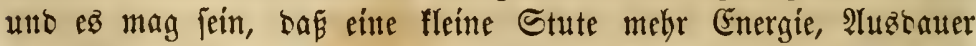
und Retensfraft befist alsె eine größere. Mandye Mäbren fino ab= geftumpft, träge uno ibren Bewegungen febr fdyerfälrig uno lang= fam. Damit fidh biefe Uebelftänte nidjt aud beim Füllen zeigen, bat man einen 5engit fu wählen, ter mebr alsె bie gemöhnlidje $\mathfrak{e}=$ benşfraft uno Energie bat, wäbreno antorieits, falls sie Etute soll 


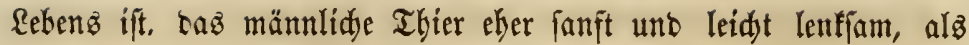
befottbers muthig uno feurig fein jollte.

Sinfidutlid ber (Jieftalt uno (3röffe folltet Thiere, welde in tiejer Begiebung entgegengejeste (Figenfd)aften baben, gepaart werben. Sit alio bie Stute fleimer, fo follte ber 5engit um fo sollommener fein, uno umgefehrt, falls jone cine ziemlia grofe (5eptalt befigt, follte biefer etwas fleiner fein. Sn feinem Fall aber sarf bie Mut=

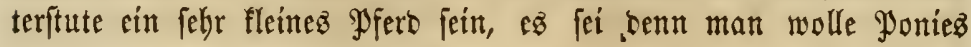
(Pjertdyen, Rlepper) züdyten.

Wir Gaben bereitż auf ben Bortheil aufmerfam gemadjt, welder caraus entipringt, wenn man bie Stute längere 3eit in (S) efellidyaft int bem 5ongit läpt, ein Umitano, weldyer jener mehr zu (5)ute fömmt, alz biejem. Der Naturinftinft wiro oie ridjtige Zeit fer Paarung beftimmen, waz für die Entwidflung bes neuen \&ebens son auferorbentlider Widytigfeit ift. Bei ber gewoblhtid in $\mathfrak{A n}_{\text {s }}$

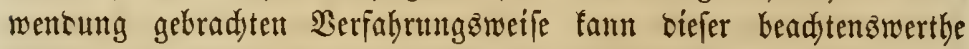

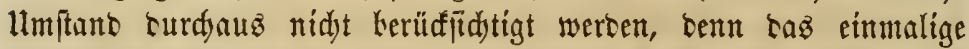
3ufammentrefien ber Gtute mit bem 5engite, oter baf siez einmal innerbalb neun Tagen geldjeft, ties lag surdjaus nidjt in ber $\mathfrak{A b}=$

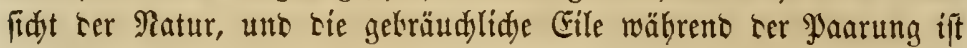

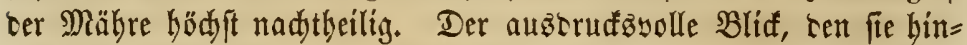
ter fidy wirft, wäbreno man fie wiecer abfübrt, jeigt seutlid an,

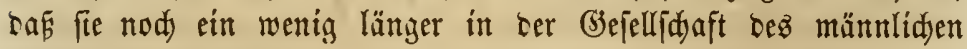
Thieres fein mödte.

Eine gut augigemady[ene unt solfommen entroidelte Mähre mag als 3udtftute gebraudyt wersen, menn fie brei Jabre alt ift, ift fie jerody zu biefer 3eit nody nidyt gebörig entwidelt, fo liegt ez im Intereffe ses Beftzerb, nody ein Sabr zu warten, ehe fie biełu ver= mentet wirt. Mandye Perionen baben es im Bebraud, ein zwei=

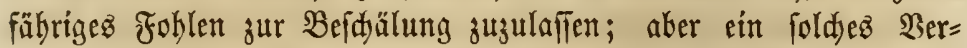
fahren ift ganj unt gar serfebrt uno jwar, weil fid fold junge Miăbren burdjaus nidyt zu Mutterftuten eignen. Daz Trädtigmer= ben unb bie hiermit in Berbintoung fommenben lumftänoe becinträd)= tigen ibre (Seftalt unt Edönbeit bebeutent, wäbrent bie Wirfungen auf ibren Muth uno ifre Rebbaftigfeit nod nad)theiliger fint, uno polde Thiere werten ibr ganges leben lang fanerfällig uno langs fam fein. 
Som zebnten ober zmölften Sabr an, biess tarf als allgemeine Regel aufgeftellt werten, follte man Lie Mäbren nidyt mebr zur 3udt getraudjen; mandje mögen aud nod nad riejer Zeit fdöne, aแsigewadjene Foblen werfen, wilbreno antere bereits sor beriflben nidyt mebr ăm "Foblen" tauglid fint. Diejenigen, weldye jeces Sabr ein Füllen haben, werlieren ibre Rebensträfte am fducluften unt bie, weldye wenig förperlidse Stärfe uno Energie baben, nely=

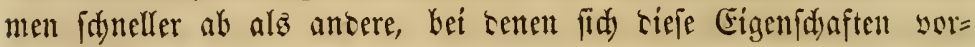
finoen. 3u entfdyetcen, wenn eine Mähre nidyt mebr zur Budd $3 u$ gebraudsen fei, hiełu fino genaue Beobadtungen nöthig uno feime

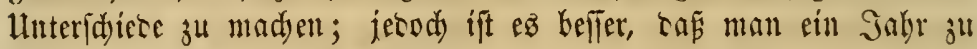

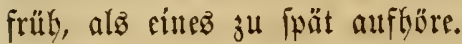

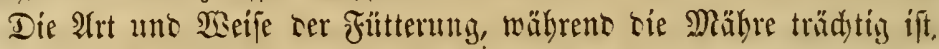

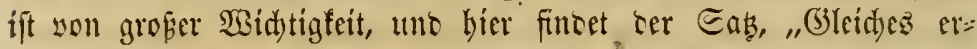
zengt (Sleidess," feite volle 9 mmentung. Wer im 5erbite cine reidje

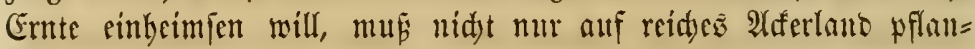

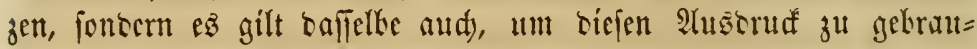

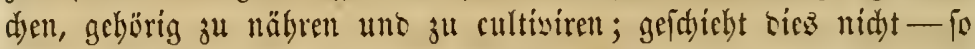
fino rie 5offrumgen auf eine grofe Ernte verigellid. Ebenlo muf

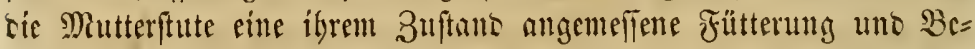
banchung empfangen, fonft ift eš unserftänsig, ein gutez, idyounes

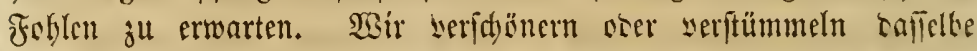

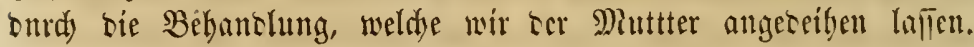

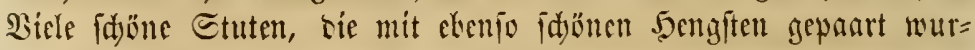
Den, baben nur tefwwegen fleine fränflidye Joblen geworfen, weil fie näbreno ibrer Iräd)tigfeit folect)t Gebantelt wurten, wäbreno auf

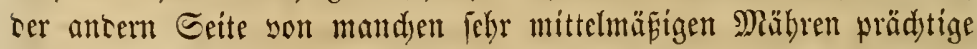
Füllen tasurd) gezogen wurben, saj man fie in ber betreffenden Beit gut fütterte uno ibnen bie nothwenrige $\mathfrak{A}$ ufmerffamfeit id)enfte.

Eine beruntergefommene, balkserbungerte Crute wiro cinen ärm= lidjen Edywäd)ling jur Welt bringen, senn ter förperlidye 3uftano ber Fohlen büngt von rem fer Mutter ats. Daffelte empfängt von jener nidyt allein ธaร \&eben, foncern ber Zuftano ibrer \&ebensftüfte

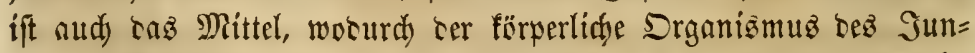
gen - Snod)en, Sebnen, Fled) wirt, unb cie Gejunbbeit ber Mutter fann nidit afficirt merten obne bie entipredsente Rüdwirfung auf bie Reibesffudyt, weil bie 
Berbaung uno Eaftcirfulation bie Mittel fint, moturd biefe er= nübrt roirt. Siaro dic Mutterfute gut gefüttert, fo fommt riez

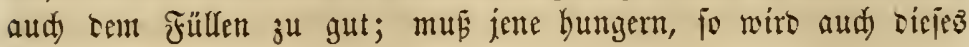
leitert.

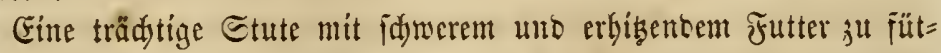
tern, ift ein grofer Srrthum; Senn fie hat feudte, aber nabrhajte Subjtanjen, weldje leidjt vertauten unt โas Mifíten bejörtern, nö= thig. Zur winter= ocer irgento einer anteren Zeit, in welder fie

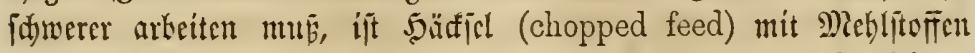

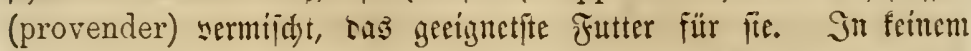

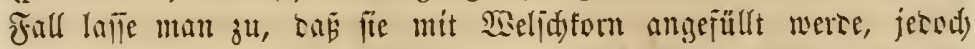

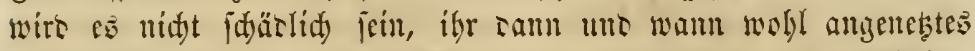

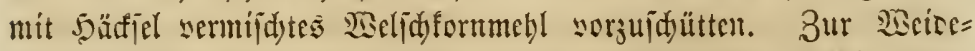

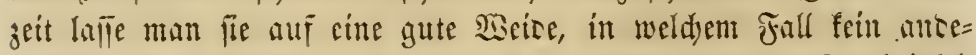

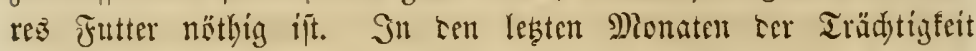

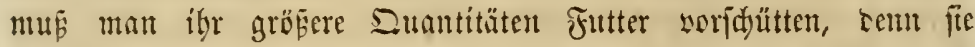

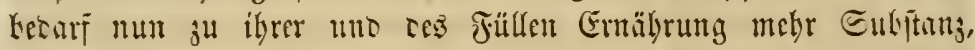
meil sas leţtere immer gröfer wiro uno zu feiner Erbaltung auf

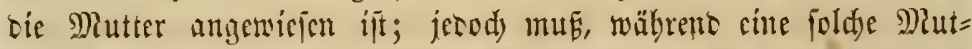
terjtute inmerthin wabl genährt fein follte, gegen eine Jjüttenung, meld)e Soldelütigfeit ergengt, entiffiesene Einwentung gemad)t met=

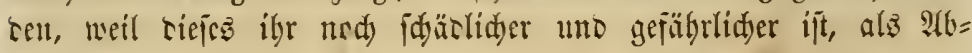
magerumg.

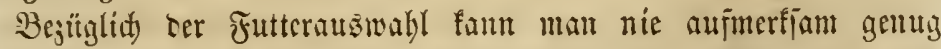
jein, sent wenn je, jo follte zu siejer Zeit bas Jutter nahrbaft,

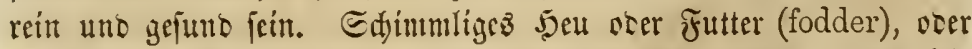

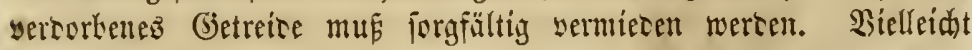

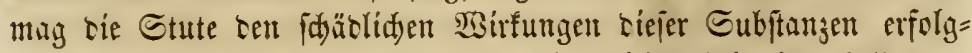

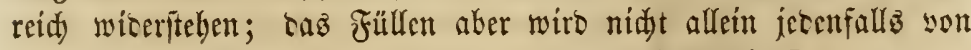

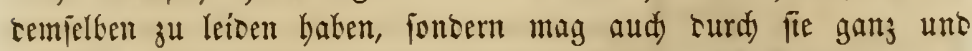
gar ruinirt werten. Taufente Frablen fommen fränflict) zur \$Belt, weil ibre Mautter gę̧wungen waren, daş Reten mit ungejuntent Futter zu friften.

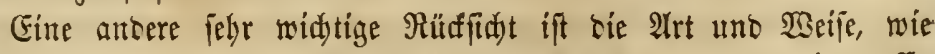

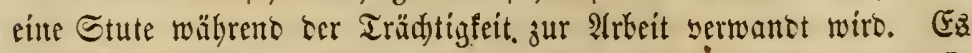

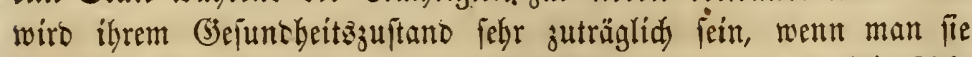

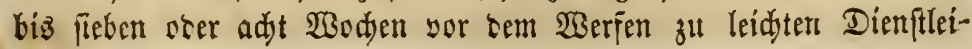


ftungen gebraudft, fu welder Beit feinerlei 9 trbeit mebr yon ibr ge: fortert werben follte, obswohl man igr hie und ba Bewegung ver= (d)affen fann. 2(hnt) follte fie um siefelbe 3eit son antern Thieren abgefondert werben, bamit fie son benielben nidjt bejdäbigt wirt. Zu feiner Beit wäkreno ser Trädjtigfeit barf man ber Miutterftute fdiwere Dienftleiftunget auflegen, und wenn bie Zeit bez Werfens nabe heranfommt, mus fie an einem Sort gehalten werben, wo man

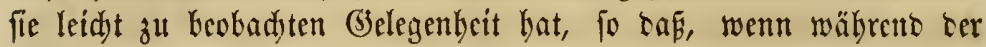

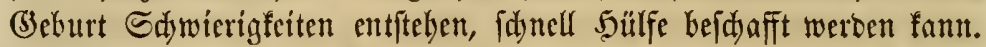

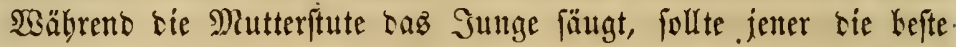
Bebautlung zu Theil werben; ifr Futter mur reidjlid, gefuno uno

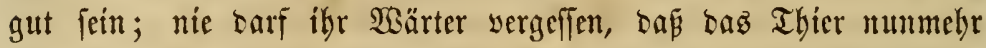
zwei Reken zu erhalten bat, uno bafi bag Sunge an ihren vhncrem abgeid)wäd)ten Rekensfräften zebrt. Şic uno ba mag Rlcien, went möglid), Roggenfléenmanjde (bran-mash) vorgeidjüttet werben uno

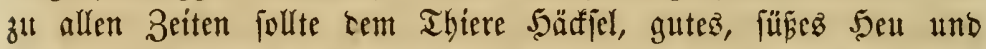
Safer zu Dienften ftehen. Sorm barf nidjt gefüttert werben. Sm Fall 2 Seibe zu baben ift, wiro ihr biefe befler befommen alz irgento

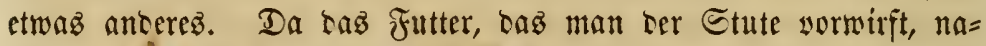

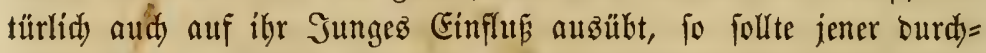

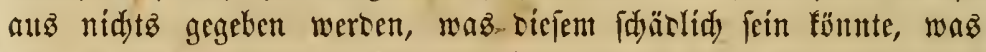
mit einigen Subftanjen orer 2 razneient ter Fall fein may, weldhe ten ftärferen Drganiżmuz ber Stute burd)auz nidyt affiriren.

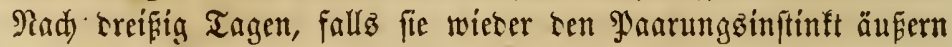
follte, .uno wenn ber Befitier entidlofien fein follte, jedes $S a \mathfrak{d}$ r yon ibr ein Foblen z' zichen, mag fie wieber mit bem 5engft zulammengebradyt werten. Setod) fint ge=

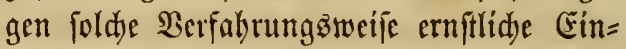
twentungen zu maden; tern wenn immer

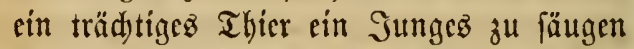
hat, fo verliert bie Milld burd) bie Träd)tigfeit an (Jủte, waz na= türlich bem fäugenten Sungen nadtheilig ift, uno man fann viel beffere Foblen ziehen, wenn man bie Stute nur alle zwei Sahre zur 3udit verwentet.

Die von ber fäugenben Mutterftute geforberten Dienfteifinngen fillten mähreno ber exften fediz Monate nad bem fohlen nur ganz 
leidyt jein, und es jei benn, man babe bejonderz begrüntete urjadyen

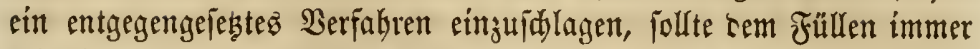
erlaubt rerben, an ber Seite ber Mäbre zu laufen.

\section{Da}

Fallz bas Fohlen woly uno gefunt ift, bebarf eż biz jur 3eit ber $\mathfrak{A}$ bgewöhnung, waz gewöbnlid nad) jedbs Monaten cintritt, feine bejoncere $\mathfrak{A}$ ufmerfjamfeit, jecod) fann in Beług rarau, wie

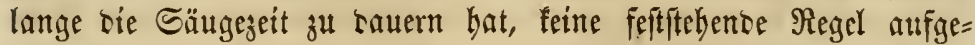
ftellt werben, sa bies surd oen 3ujtant uno die förperlidye Ent= witulung bez jungen Ihicres beftimmt wiro. Sft baffelbe mager uno fduräd)lid, fo follte es einen ober groei Monate, ober in befon= beren Fällen nod) länger alz tie angegebene Zeit an tor Stute faugen, uno jerenfallz carf man sen im Spätjahr geworfenen Foh= len sie Muttermild nidjt entzichen, biż im Frübjahr grünez Futter gewadjen ift. Biele Spätjahrz=Füllen wersen ju früh entwöbnt,

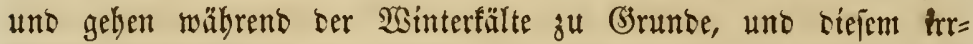
thümliden (Bebraudy ift rie Meinung entiprungen, sap sie im 5erbjt getworfenen Füllen Ien Frühjabrz= Fohlen bei weitem nadyjtïnen, was alleroings riditig ift, fofern jene bie oben angereutete Bebaut= lung, die man eigentlid Mif̧bandlung nennen follte, erfabren. Daz

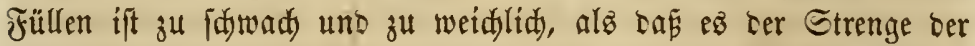
Binterivitterung wicerfteben fönnte, fallz ifm cie Muttermild ent= zogen wirt. Darum follte man ez̉ an ber Stute faugen laffen, biż

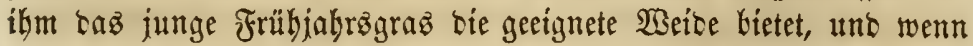

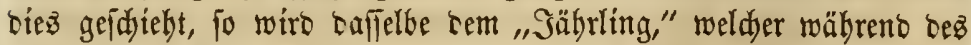
Winterb mit Futter erbalten rourbe, oft voraus fein.

Säbrento ber (5etwöhnung follte sab Foblen an einen fo weit yon

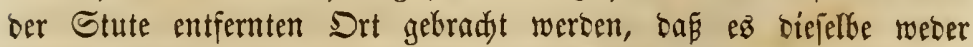
fiebt nod hört. Denn burh biefe Berfabrungäneife wirb fid

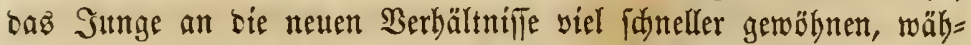

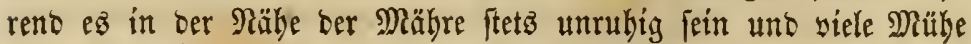
madjen wirt.

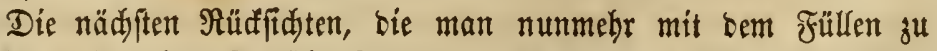
nebmen hat, betreffen fein Futter uno feine 3udjt, uno fwar ifit bies

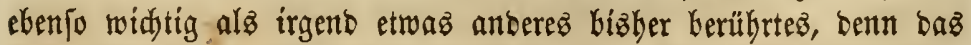
junge Thier wirb fid im allgemeinen nad ber thm wieberfabrenen 
Behanclung geftalten, uno man würte gemín viel weniger mittelmäp̧ige Früllen finten, wenn fie gehörig gepflegt würten, waz aker in unjerem sante leiter nidyt allgemein ter Fall ift. Nur zu oft miro tas junge Thier tas Dpfer grober Bernadjläffigung uno Etra=

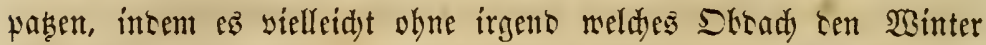

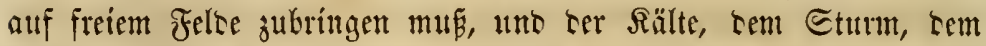
5agel uno bem tiefen Ednee auszefest ift, währent man ihm einen

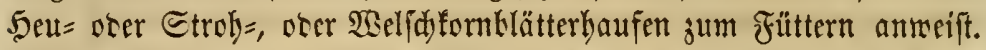

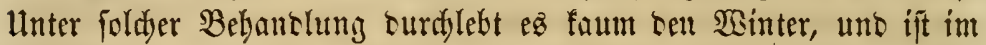

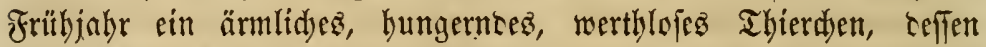
Rebensfañfte einen Stof́ erlitten baken, yon bem fie fith nie wieter crholen fönnen.

Ias if mit taujenten Füulfen im sante ter Fall, und

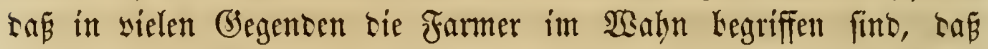

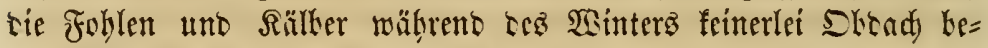
cülftig feien, ta tod gerate fie $\mathfrak{c}$ firts, weldye sor allem antern

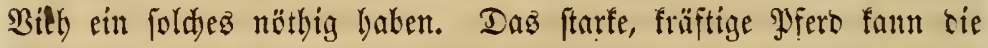
Etrapaken, bie Las Helerwintern im Freien mit fid bringt, viel beller ertragen, unt cody wiro - munterhares Berfabren - nidyt

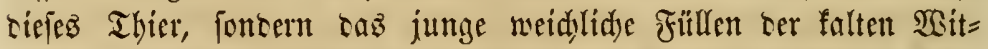

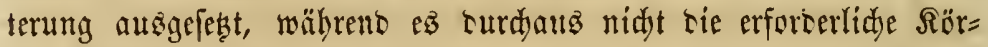
perkefdaffentbeit hat, um Etürmen, Froft uno Sälte ju miberfteben.

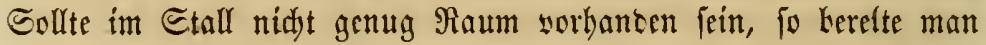
für anderes $\mathfrak{B i e h}$ irgentwo ein Unterfommen uno nehme tas Fob $=$

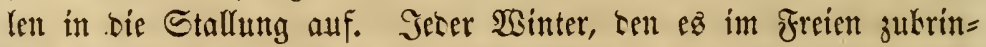

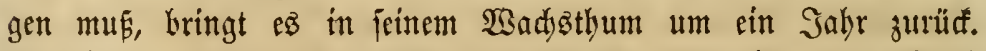
Es nimmt nidyt ou, ift in faledtem Stant, uno zeigt weber Muth) nod) Energie in jeinen Bemegungen, unt ber Farmer flagt alšcann, tiejes mahrnebment, tap or in feinen Erroartungen gan uno gar

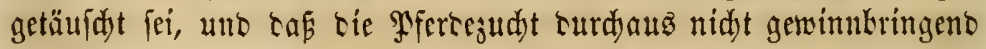

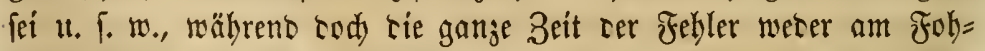
len nod) aut ten altcern Pferten, fontern eingig und allein an itym liegt. Er fdeint ganz uno gar vergefien ju baken, baj fold ein junges Thier eben nodi fehr menig 2lusbauerfähigfeit hat, und

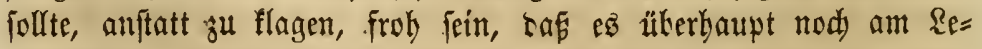
ben ift.

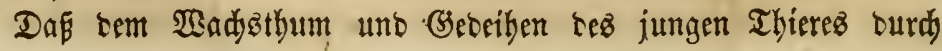


und nad) Ler (Strmöbnung fein Eintrag geidelye, Larauf follte, tem

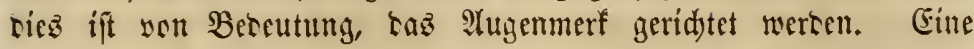
gute, liberale Befbantlung wiro fid reidflid lohnen, uno tad junge Thier hat eine joldye nöthig; fein şleifid) ift jart, feine Inodyen uno (3)tieber fint weidh tute nod) nidht ausigckilcet, uno salfelbe ungün=

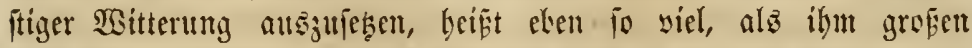
Ed)aten jujufïgen. Die belenfe werten, fallz taz Füllfen nidyt aufmerffam werpflegt wirt, afficirt, idwellen an, sergrö Eern fid $t u=$

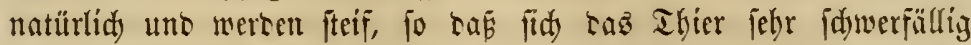
uno ohne Gislenfigfeit kewegt. Die auf rieje Weije serloren gebente Rräfte utno Fäbigfeiten fönnen surd) feinerlei fpätere Pfflege wieser ericht wercen, wäbreno ein Bejtser, weldyer tag Füllen in foldyer

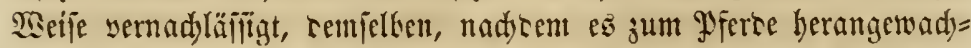

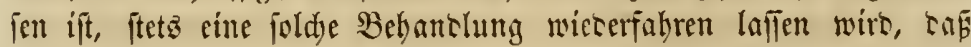

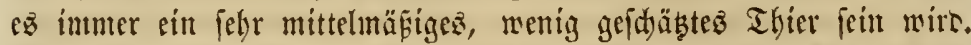
3 vielen, in früteren Sabren fidd entwiffelnten Iranflyeiten, rie

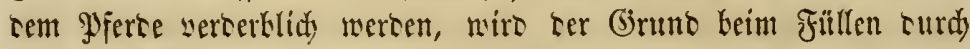

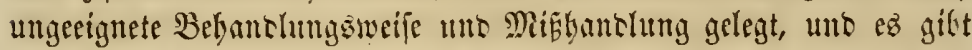

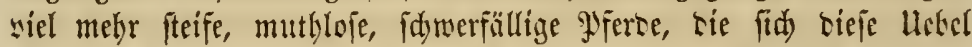

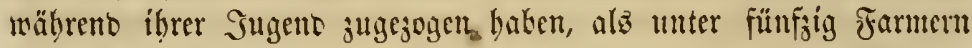

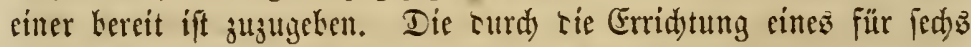
Früllen binlängliden Etalls verur

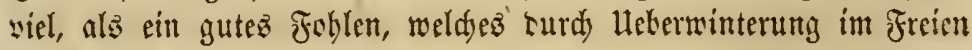
ju Grunte geht, werth ift.

Mebit ber Etallung mú aud tag Futter für taz Fohlen tie

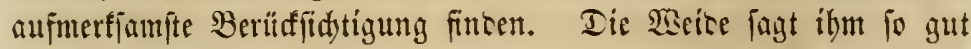

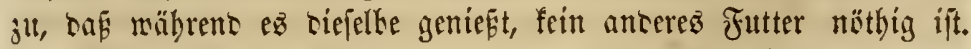
3ur SSintergeit aber bringe man jeses Fohlen in einen bejontern Etano in cinem trofenen, marmen Etall, geke sem Thier gute Etreu, uno verpflege

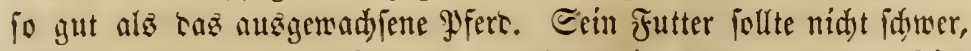

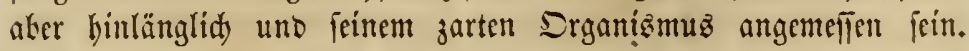

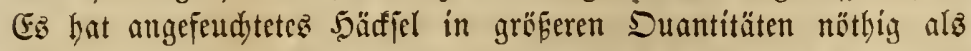

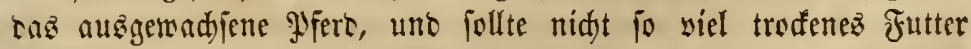

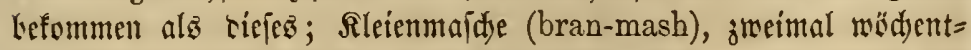

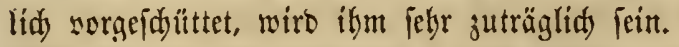

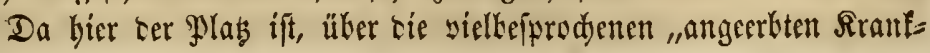


beiten" etwaz zu fagen, fo wollen wir einigez betreff berjelben ein=

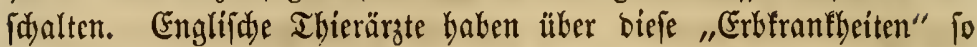
viel gejd)rieben unb benjelben eine io übertriebene Bebentung beige= legt, dấ

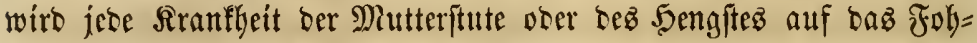
len übertragen, weldees mit ten $\mathfrak{B e f d}$ werten beider behaftet wirb.

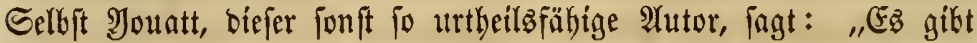
faum eine Iranfleit, yon welder entweber bie Stute ober ber $\mathfrak{5 e n g i t}$ befallen ift, bie fid nidyt auf baz Fohlen in böberem ober geringerem (srabe yererbt. Selbjt bie Frolgen idjledter Behandlung, bie ben ",2lten" zut Theil geworsen, fint am "Sungen" wabraunehmen, uno man hat binlänglidje Beweife, baj fidh Blinobeit, Sartidnaufigfeit,

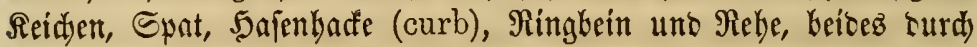

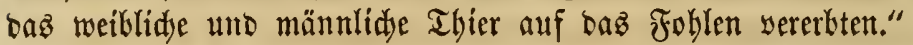

Bsir mollen nidyt entidjeiben, in wie weit fid bicje behauptung

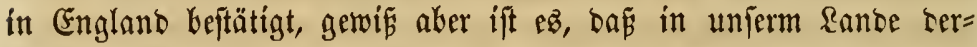
gleiden nidjt sorfommt. Rur fichr felten züdten unjere frarmer son erfranten Thieren, uno ez fommt biez, menigftenz bezüglid tez Şengitez, unter tauljeno frällen nur cinmal sor, währent bie uno ba eine fränllidje Mäbre zur 3uddt benüb̧t werben mag; wollte

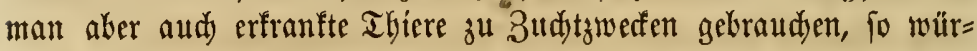
ben fie unjerer $\mathfrak{2}$ nitid)t nady in 2 merifa nur wenige Sungen erget=

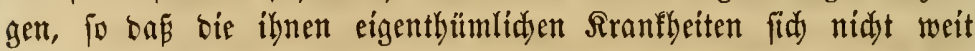
yerbreiten fïnnten.

Dod) glauben wir, Dẫ aud in England die "Erbfrantheiten"

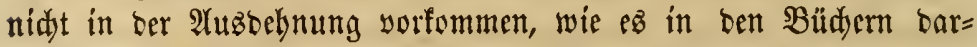

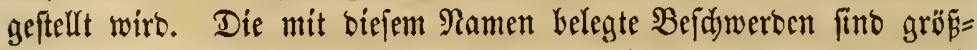
tentheilz foldte, bie in Folge nieberer, feudyter, sunfler Etälle, bie in ben groken Stäbten Englands vft unter ser Eroe angebractst

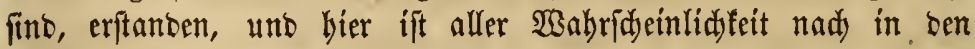

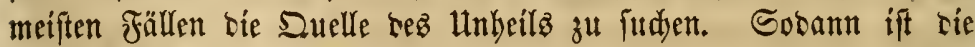

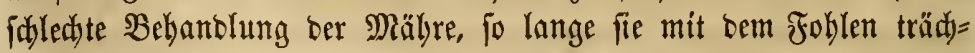

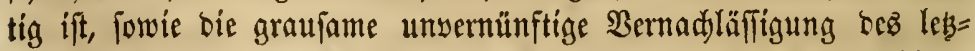

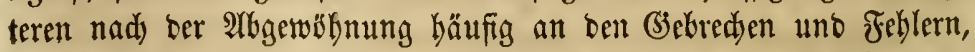
an weldjen bas Pferb währento bes erften Sahrz uno oft feín gan= zez Reben lang leibet, faultb. Sat bie Mutterftute wäbreno ber Trädtigfeit eine einigermaß̧en gute Behandlung erfahren, fo fom= 


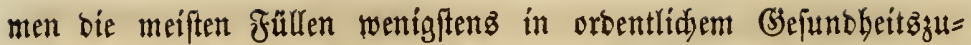
ftand zur Welt; werben fie aber nummebr vernaduläfitigt, mif̧bantelt unt ungitnftiger Witterung ausge alz Daß̧ fid allerlei Sirantbeiten in itgnen entwiffeln.

Alud beí ben Menfdjen fino fogenarnte erblidje Rrantfeiten wohl viel feltener, als man gewöbnlid) anntmmt; wie tenn aber aud im= mer fein mag, fo finto you bem angeblid) in biefer Sinfid)t gelten=

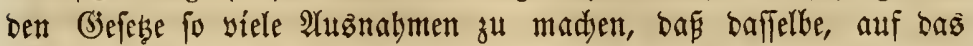
Sfero angerwentet, faum alsె majgebent betradjtet werten barf. Man= dye ber jdjönften Foblen, bie wir je fahen, wurben von fdjwädjlidjen

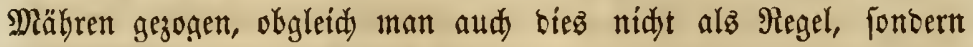
nur alz 2(użnabme aufftellen barf.

So hod wir audy bie 2lutoritäten, bie in biejer Simfidyt yon $\mathfrak{n}=$

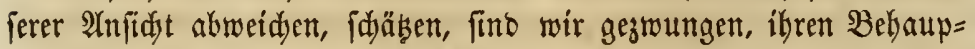

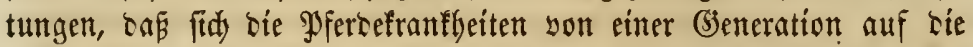
anbere in umunterbrodjener Reibe forterben, entidjieben entgegenzu= treten, und wir fint in biejer Beziebung für bie Bufunft ber ame=

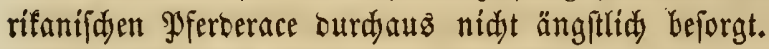

\section{¥ a a $\mathfrak{x} \mathfrak{n} \mathfrak{g}$ (crossing).}

Eine mäß̈ge unt mit Finfidyt geleitete Racenvermifadung mag zur Berebelung ber amerifanifiden PFerbe beitragen, wäbrent, wenn

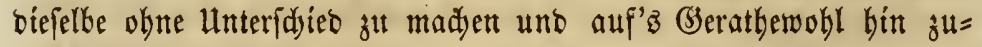
gela fien wirb, fie nur verberblid wirfen fann. Der Gebrautd, bie (Glieber ein unb berfelben Familie zu paaren (breeding in and in), hat fid ourd bie gemadten Erfahrungen fo verberblid errviejen, ba man benferben ohne- SBeiterez verwerfen mußs. Secod barf man

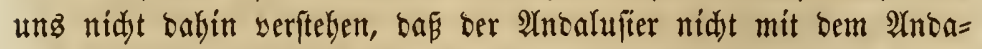
luffer, ber $\mathfrak{A r a b e r}$ nídft mit bem $\mathfrak{A} r a b e r$ gefreuzt werben bürfe, fon= bern wir behaupten nur, dá̈ bie Yferbezudft, bie burd Paarung

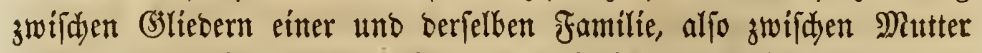
uno Sohn, Sdjwefter uno Bruber zc., Gödfft verberblídy feí. Wenn berartige Berbältniffe zwifden zwei Thieren exiffiren, wiro ber yer= fiänbige PFerbeäüdjter feine Paarung zulatien.

Srgeno meldye Pferberace mag baburd in ihrer Reintheit erbalten und felbft verebelt werben, indem man şlieber berfertben aus entfernt=. ftehenten Familien zu 


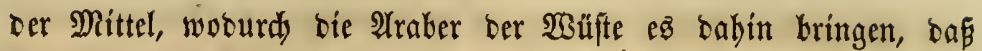
ibre Ctuten allen andern Pferben fo weit überlegen fint, uno ber Inftinft bat bem wilben Pferbe auf ben amerifanifden Ebenen, wel=

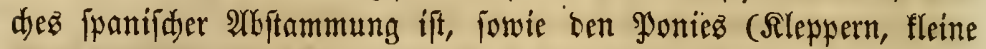
Pferbe) ber Intianer biefelben Dienfte geleiftet. WBir müffen gegen bie Bermifdung von Pferberacen, die bezüglid ber (Seftalt, ber

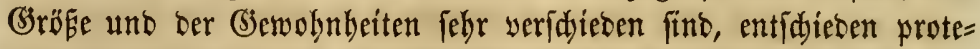
ftiren. Man ntag ben Sndianer=Pony mit bem fdönjten Pferb bez Ranbez, ober jelbjt mit einem $\mathfrak{A}$ raber paaren, und bas Foblen wirb

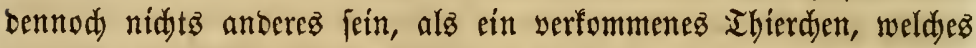
wenige ober feine ber guten (Figenidaften bes 5engitez ober oer Mảhre bat, uno alle mit biejem, "Probuft" päter veranftalteten Mifidungen werben ftets nod mehr entartete Pferbe liefern.

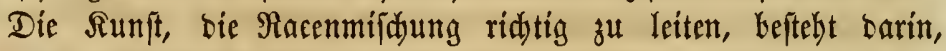
(s)lieber entfernt ftebenter Familien mit einanber zufantmentubringen, rie fid bezüglid ber (Seftalt uno (şroffe 2 . nidjt ganz gleid fint. Se nad ben Eigenidaften ber Mutteritute wiro bas erjeugte Füllen entweber beffer ober geringer werben, als̄ ber mit jener gepaarte Sengft, uno ie näher bie Stute ibrer Dualität nad) Dem Jengft ftebt, je mebr wiro Das Fohlen diefem äbnlid feín. Sft bie Maabre

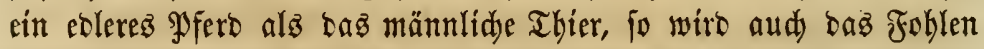
ebler fein als lesteres, aber immerbin unter ber Gtute ftehen; ober umgefehrt, falls ber 5engft beffere Sualitäten bat als bie Stute, fo wirb das Junge lesterer überlegen, jebods wieberum nidyt fo yor= züglid) fein als jener.

Dieje allgemeine Regel aber fann nur 2 (nwentung finben, wenn

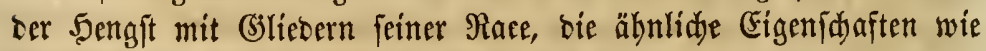
er baben, gepaart wirs. Finben fid im Senglte die vermifidten (Fi= genfdaften veridutedener Racen, fo wirb eine berielben fid oft auf=

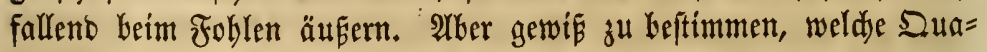
lität bei bem yon einem folden Jengft gezüd)teten Futllen bie sor= berridente fein wirb, ift unmöglid, es fei benn, man wifle, welde Eigenjd)aft im 5̧engft fid bejonbers auşpräge. Bezüglid) ber Stute läst fid ein beftimmteres Urtheil fällen, uno es barf gefagt werben,

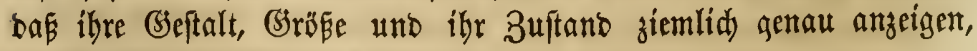
weldyer $\mathfrak{A}$ rt ín Foblen fein wiro.

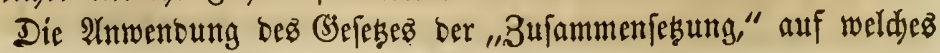


von fo sielen Sdriftifellern fo grofes Sierwidyt gelegt wiro, halten wir für febr zweifelkaft uno nur theilweife gültig. Bon biejer $\Re e=$

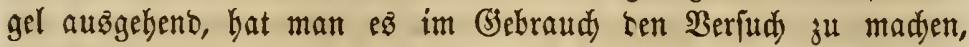
bie Mängel uno Febler tes einen Thieres burd bezüglidye gute $\mathfrak{F}_{\mathrm{i}}=$ genidaften bes anbern bei ber 3udjt aufauwiegen; fo j. $\mathfrak{B}$. fagt man, bafs, falls bie ミstute mangelhafte Atthmungzorgane babe, bie= felbe befto befler beim Sengit entwidelt fein follten; ofer umgefebrt,

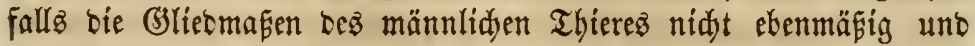
gefällig feien, bie Mähre in biefer Simfidyt befto yorzüglider fein müfle u. T. w.

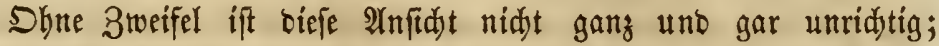
jebod) fitto dic (Sirenzen, innerbalb weldyer man mit eintger (3etwif́= beit biejer Regel gemäs banbeln fann, febr enge gezogen. Eine Mäbre mit bebeutenten Feblern fann niemals, fo ausgezeidnet aud oer mit ibr gepaarte 5engft fein mag, cin fdönes füllen fur $\mathfrak{W e l t ~}$ bringen, fontern um biefen 3wed ju erreiden, bat man eine fabine yollfommen entwidelte uno in gutem 3uftant befinclidje Stute aubi= fuwäblen. Tur:folde weiblidse Ihtere uno feine anbere follten für Budtgrwede gebraudit werben, und wenn antere Berwentung finten, fo follten fie nur zur Maulthierzudjt gebraudt werben.

\section{$\mathcal{R}$ a fi $\mathfrak{r}$ i $\mathfrak{i} \mathfrak{n}$ (castrating).}

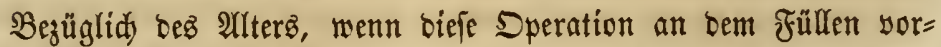
genommen werben follte, fitro bie 2 infichten felbjt bei erfabrenen Sferbezüdjtern fehr getheilt. Die einen glauben, es follte fdon im vierten ober fünften Monat gejdeken, andere meinen, man habe bas Saftriren erft mit Gintritt bes zweiten Rebensjabrs vorzunehmen, uno wieber antere baben ansere, zwifden biejen beiben Ertremen lie= genbe Beitpuntte angegeben. Diefe Meinungigerfditebenteiten grün= ben fid auf einige beridstebene förperlidje Entwidtungen uno Gigen= fdaften, welde für ben Dienjt, für welden man bas junge Thier jpäter braudjen will, alछ̇ nothwentig eradtet werben. So \%. B., fagen uns mandye $\mathfrak{A}$ utoren, cẩ ein für ein Ebaifen= ober- Zugpfero befitimmtes Füllen erft bann serfinnitten werben foll, wann es zwei= ober breimal fo alt ift, als bas für Farmzwedfe beftimmte 26 .

Unfere $\mathfrak{A}$ nfidit nady follte bas Saftriren in allen Fällen febr früh vorgenommen werben, und man follte diefe Speration faum fo lange 
auffidieben, bis baz Foblen vier Monate alt ift. Daf bezüglidy ber

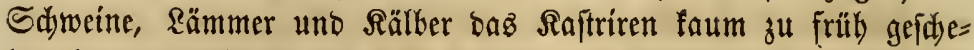
ben fann, barïber finto wir solffommen im Rlaren uno iman fënnte

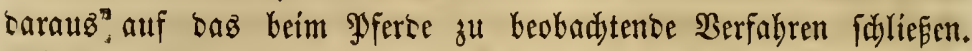
Mit bem Beginn โez zweiten Sahrez erreidyt ez bie für Budutżwecte erforberlidye Reife, und oft zeigen feine Berwegungen 2 . fidon zu

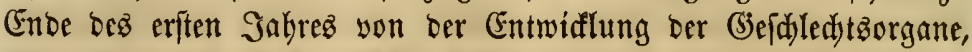

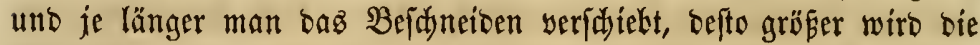
(S)efabr.

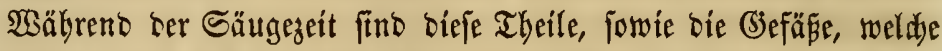
jene mit $\mathfrak{B l u t}$ verfeben, nod) flein, weăbalb bie Blutung, fowie ter

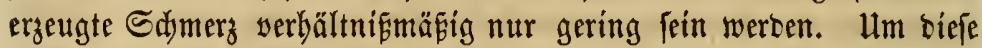
Zeit wiro baz Raftriren beshalb weber jefr fdymerzhaft, nod) mit bedeutentem Blutserluft verbunden feln, aus seldyen (3ründen alä= bann baz Berzapfen fowobl alz baz Brennen (clamps or scarring) unnöthig fint, benn $e z$ wird vollfommen genügen, ein wenig feines Salz uno Terpentin zu appliciren, uno irgetto Semanto, welder eín Sd)wein ober Sdjaf yerdjuetben fann, ift aud im Stanbe, ein Pfero

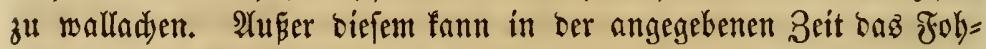
len audj fehr leidjt gehandbabt werben uno zwar obne (3efabr zu laufen, ikm burd) Rieberwerfen 2 ., waz mit bem fdjon mebr ber= angewadjenen Thiere gefdehen muE, Sdjaten zuzufügen.

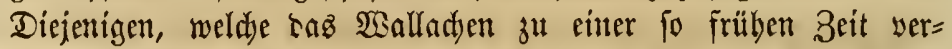

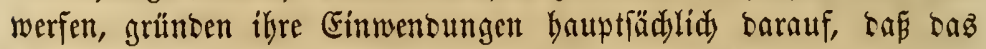
fidon frübscitig faftrirte Pjerb nie fo fdobn, solftommen entwidfelt und muthig werbe, als wenn main bie Dperation längere Beit bin=

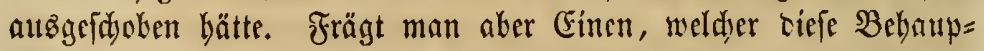
tung auffitll, in wie weit biefelbe burdy feine Erfahtung beftätigt werbe, fo bleibt er gemöbnlid cine befricsigente ântmort idjuldig.

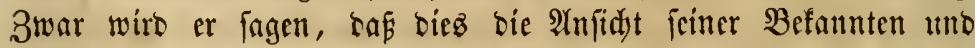
Radjbarn fei, bie audj er theile; aber jene halten eben audj nur an oerfelben feft, weil antere fid in gleider $\mathfrak{B e c i f e ~ a u s g e f p r o d j e n ~ b a b e n , ~}$ und am Enoe wiro man gewahr, bas biefe weit verbreitete Meinung lebiglid) auf nid)tż, aloె auf "lleberlieferntng". gegrünbet ift, son ber Riemano weí, wober fie gefommen. Shinfidytlidy dez Mutthez, wel=

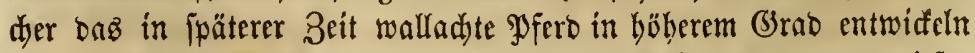
foll, fei einfad gejagt, daj baz männlidje Thier nur bann biejen 


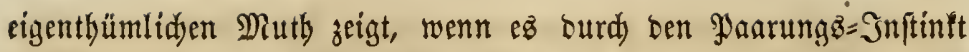

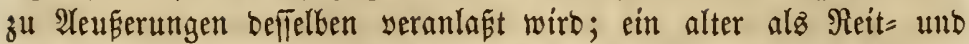
Chaifenpferb benübter Sengit aker ift einez ber jdwerfälligiten, ener= gielofeften (3efdöpfe, die man fid benfen fann.

Fine anbere gegen unfere $\mathfrak{A}$ fif bas, wenn man baz yon แmb empfohlene Berfabren einjallage, ez febr febr fdwierig fei, bas fïr 3 udtzmede am beften tauglide Füllen

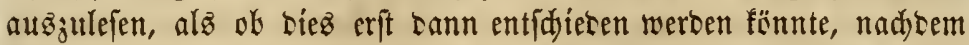

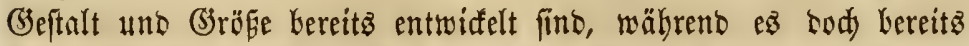
vor ber (5)burt (wenigitenz zum grofen Theil) beftimmt bätte wer= ben follen, uno zwar curd) gebörige Berüdfithtigung oer Eigenfdjaf=

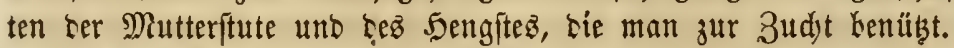

Unjere eigene Erfabrumg uno Beobaditung hat unż, okgleid) bie=

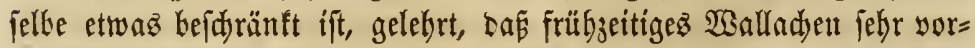
theillyaft ift. Wir erinnern uns sieler Fälle, wo ein foldjes $\mathfrak{B} e r=$ fabren sem Sadjsthum unb ber volfommenen Entwidelung yon auszezeidneten (Figenidjaften burdjaus nidyt binoerlid war, uto bieje unfere $\mathfrak{A}$ nfidt wirb son vielen intelligenten und erfolgreidjen Yferoe= zühtern, mit benen wir über biefen Begenftand rebeten, unterftübt. Aud) englipde Thierärste werben mebr und mebr von ben Borthei= len eines jolden Berfahrenb übergeugt, uno mandje fpredjen ganz

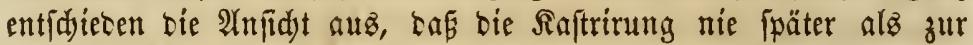
Zeit ber $\mathfrak{A}$ bgewöbnung gefdeben follte, ba bie Mild) ber Stute als Borbengungänittel gegen Entzünoung und Fieber biene.

Der unerfabrene Dperateur fommt oft Laburd, bafí er bie 5oben, welde nod nidyt yom Unterleibe, wo fie yor uno oft aud) längere 3eit nad) oer (beburt find, in ben Sodenfact berabgefommen fint, in grofie Berlegenbeit. Bei manden Foblen verbleiben biejelben bis jum erften uno zwciten Sabr im Unterleib, um weldje Zeit fie alz= cann in ben Sobenfact berabrutidsen. Sann man fie beim Raftri= ren bier nidt finben, fo tarf man nur in sie am Reib befindidye Seffinung einbringen, wo man bie Soben etwa zwei 3olr weiter nad) Innen finben wirb, und biefelben entweber mit ben Fingern ober einem eijernen, gebogenen, mit einem sappen umwidfelten Roffel entfermen fann.

Se älter bas Fohlen wirb, befto fatwieriger unb gefäbrlicher ift

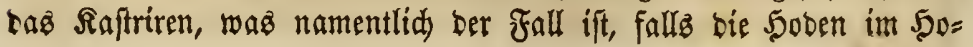




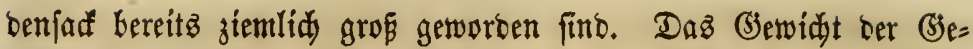
bärme in Verbinbung mit ben beftigen Beewegungen bes jungen Ihie res uno Ien Säken, bie eż nady ber Dperation madyt - bies ift

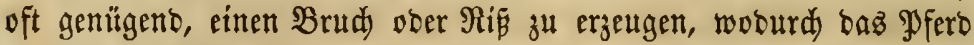
für immer ruinirt wiro, wenn es nidyt fogleid ftirbt. SUd ift ir.

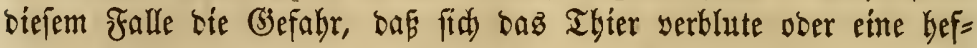
tíge Entzünoung entjtebe, viel größer.

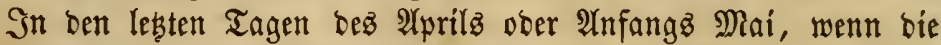
Weibe reidjlid junges, frifdes (3̧ras bietet, ift bie geeignetjte 3eit

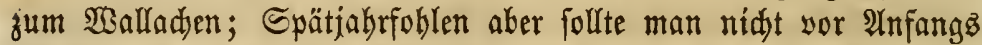
Sttober, voer biz bie beife Sitterung vorüber ift, walladjen. Sat man Utradje ju glauben, bap bas Thier yon ben Fliegen zu leiben Gaben werbe, fo reibe man bie Theile mit ein wenig Terpentin ein, woourd diefe läftigen Sneften abgebalten werben, wäbreno ę nur menig fdmersbaft ift uno bod auperorbentlid) zur Seilung beiträgt. Sollten, wäbreno bas Füllen nod wuno ift, falte Regen eintreten, To hat man baffelbe fammt ber Stute in eimen guten Stall unter= fubringen.

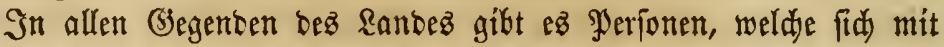
ber Bolfitehung biefer Speration abgeben utto beren Dienfte leidjt erlangt werten fönnen, waż, fallż baz Saftriren lange binaugige= fdoben wurbe, immerbin empfeblensimerth ift.

Diejenige Methooe, weldje yor etwa breiffig biz vierzig Sabren in Englano eingefübrt uno unter bem Namen "Torsion" (Drebung, Binoung) befannt ift, ift Gauptiäd)lid) bann, fallz baz Füllen idyon berangemadjen ift, anbern Sperationen vorjuzieben, unb wiro von Yjouatt folgentermapen befdrieben:

"Man madjt gleidnie bei antern Sperationen einen (Finjanitt in ben Sobenjacf; fobann fap̧t man bie Blutater (artery) mit einer eigens Lazu verfertigten Zange unt brebt fie fed) ober fieben Mal berum. Eie febrt, fobalo man fie mieber fahren läft, in ifre tha= türlide Rage zurïaf, ohne baf́ bie ß3inoungen (coils) aufgebreht würon, weşbalb baz Bluten jogleid nad)läst. Nunmebr entfernt man bie 5oben und entftebt nidyt nur fein faules Fleifa), fon= bern ez ift aud fonft feine (Sefahr yorkanben, wäkrend baz bei andern Dperationżmethoden fo fdymergbafte Brennen vermieben wirb. Die :3unde wirb gut beilen." 


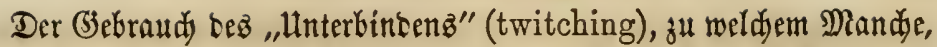
um ciner unangenehmen $\mathfrak{A r b e i t ~ e n t h o b e n ~ z u ~ f e i n , ~ s f t e r s ~ g r e i f e n , ~ m u ß ~}$

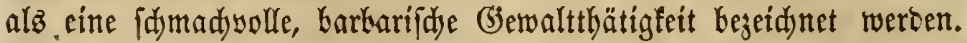
Man unterbintet nämlid cen 5obenjaf mit einer bünnen, aber ftar= fen Sdnur, fo caf die. Cirfulation gänjlid aufgeboben wirb, ziebt bie Sdyur, wenn nöthig, won Zeit zu Zeit an uno befümmert fith

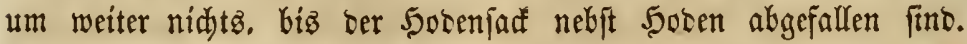
Durdy diefes graujame Berfabren werben sem bebauerngivertben Tbiere nidyt alfein ungebeure Edmerzen verurfacht, foncerm er er=

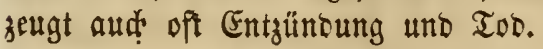

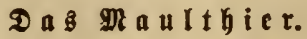

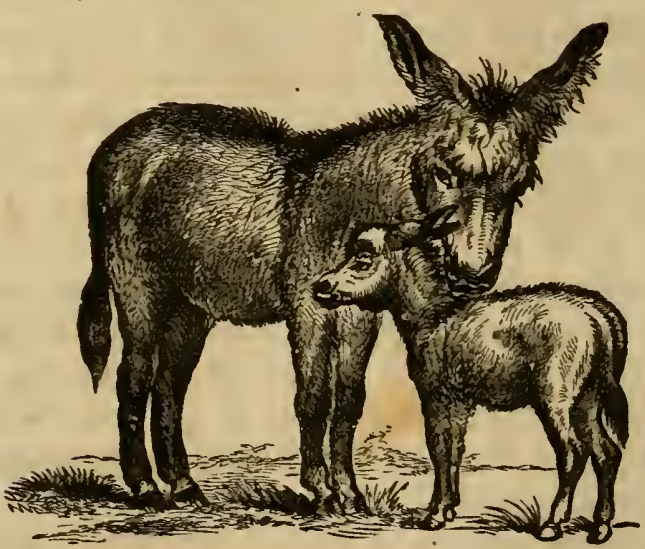

Die Maulthiergudyt wirb in unferem Ranbe in ausgebebntem Mapjtabe betrieben. In Sentudy uno Tenneffee ziebt man jäbrlich

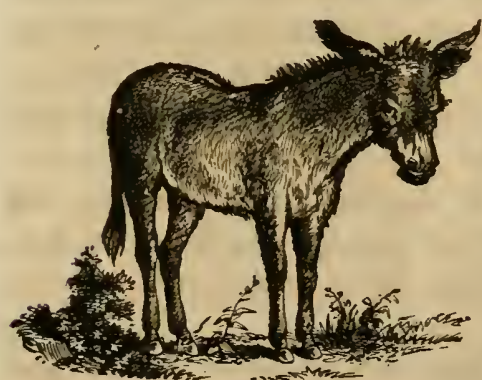
taufende Maulthiere für sie füt = lidjen Märfte, benn Erfabrung hat gelebrt, bas tieje Thiere auf ren Baumwollen=Plantagen viel kefier fortfommen als die Pperbe. Sie fino aนตือauernoer, arbeiten mit weniger Sdwierigfetten, ertragen bas Rima beffer uno werben. burdy die Bermad)läffigung ber Neger und anberer nidgt fo leidt befdäbigt. 2uperbem frift bas 


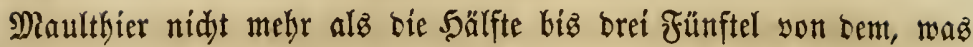
ein Pfero becarf, was,, went bas futter theuer ift, berüffidtigt werben carf.

शud ift

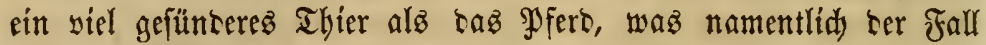
ift, wenn beibe auf ren SPlantagen โez Sübeng ju leben baben, wo= bin tie meiften Pferbe aus anbern Staaten eingefübrt merben. Sin= fidytlid) Les Dienftes fann ein Maulthier nidyt allein ebenfo fdwere Arbeit serridyten, fonsern cauert aud mebr als coppelt fo siele Sabre aus, alb fein ftolzer Nebenbubler. Die ourdjfdunittlide Dienjt= zeit bes $\mathfrak{P f e r c e s}$ beträgt - mit bem tritten Sahre anfangent - zetn Sabre, und obwobl mande Pferte bebeuteno länger gute Dienfte leiften, fo gibt ez bod ebenio viele, weldye fdjon vor tem breigebnten Sakre bienftunfähig fint. Die surdyfdnittlidye Dienftjeit ofe Maul= thiers aber beträgt fünfunszwanzig Sabre; mandymal ztwar wiro fdon mit tem zmanzigften Sabre untauglid, bfters aber leiftet es

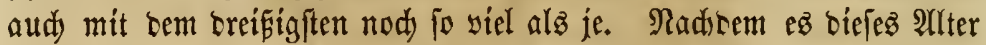

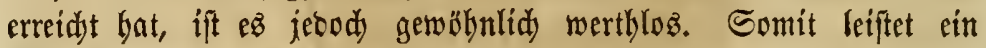
Maulthier wäbreno feines Rebenz fo viele Dienfte als zwei gewöhn= lidje Pferbe, wäbrent die Soften feiner Fittterung jäbrlid yon fünf=

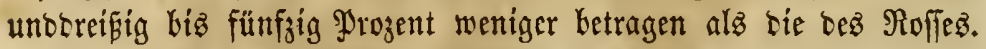

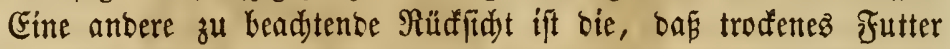
uno ungemaklenes (3etreitse sem פanltbier am zutrïglidyten ift, und bas gerabe bas Umgefebrte beim \$ferse ber Fall ift, womit wir sen sejer in sen sorkergebenten siapiteln befannt gemadjt baben. Das Futter bez Pुferbes follte alles gefdynitten uno gemablen, feudyt uno nidst fduer feitt, tno Welfdforn ift ifm obne Bmeifel (d)̈blid), na= mentlid) wenn es baflelbe som Rolben abnagen mus. (Serabe saz (3)egentbeil ift mit rem Maulthier ter Fall. Rorm, fein Rieblings= futter, übt, fo weit man erfabren fonnte, feinerlei fääbliduen Finflus aนf calielte aus uno nidyts ift ifm zuträglidjer als trodenes Seu, falls es gut uno füs ift. Dies ift natürlid) zu berîdfídtigen, um To melyr, alz nidyt allein saz Futter an uno für fid), fonbern aud bie.

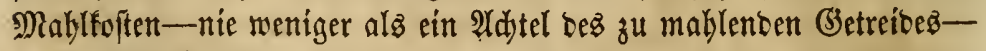
iil Âridylag fommen.

Die Soften, ein Maultbier im Sabr 1860 zu überwintern, wurben

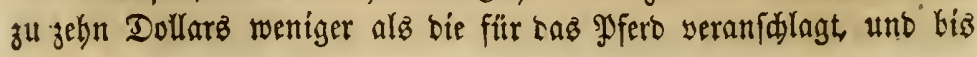


zum 'Jahr 1866 wiro biefer lunteridjed wohl auf nidjt weniger alz

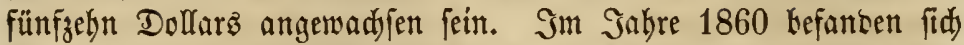
etro eine halbe Mitlion Maulthiere in sen $\mathfrak{B}$ ereinigten Staaten, curd) beren $\mathfrak{B e r w e n o u n g}$ anftatt ter Pferbe allein burd) bie Heber= minterung fünf Millionen Dollars erfpart wurten. Dicfe Gripar=

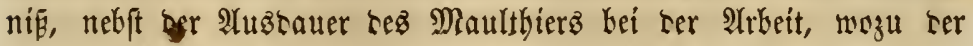
Umitanto fommt, bas es feltener son Rranfheit befallen wirb und nod) einmal fo lang zu Dienjten tauglidi ift als baz Yjero, geben

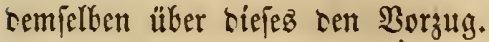

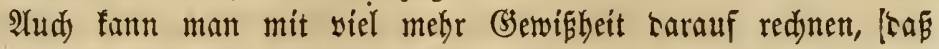
eine Stute yon einem männlidjen Ejel träd)= tig wiro, als yon einem 5engft, und es ereignen firts im erften. Fall wäbrend ber

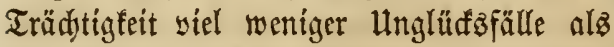
im zweiten. Seber "马üudter" hat erfaharen, Dáp $\mathrm{ezz}$ yiel weniger Mübe foftet, ein Maul=

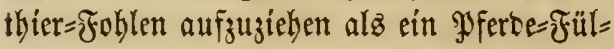

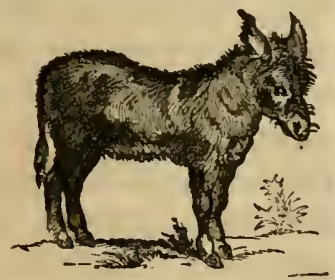
len. Sobann bat man aud) zu berürfididtigen, das faft jebe fleine, unaniehnlidje Mähre beinabe ebenio gut zur Maultbierzudyt vertwen= bet werben fann alż eine fajüre, cble Stute. Daz Sunge mag zwar flein und gebrängt gebaut Tein, ift bef̧halb aber niduts befto= wentiger ebenjo werthyoll; ja, cin foldes Thier ift wegen feiner grö=

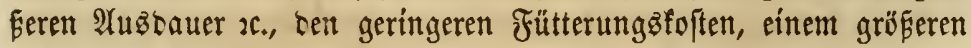
sorjuziehen.

Eine Mäbre, weldje einmal mit einem Maulthierfüllert träd)tig war, follte nie wieber mit einem 5engft gepaart werben, ba ihr

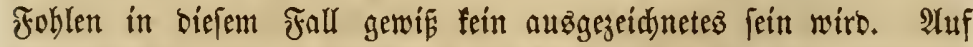

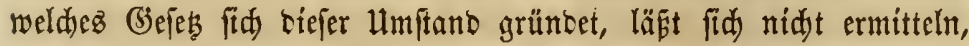
bás es aber Erfahrungşadje ift, fant nidjt wiserlegt werten.

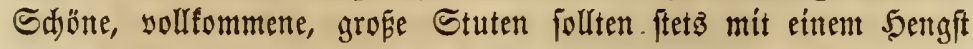
gepaart werben, währent rie übrigen, son senen man $\mathfrak{R a d} j_{j} u d j t$ gewinnen will, zur Maulthierjudjt gebraudjt werben mögen.

Das Maulthier eignet fid nidjt bloz befier für bie genob̈hnlidien auf ber Farm erforberlidjen Dienftleiftungen, fonbern ift aud alz Bugthier, baz auf ben. Strápen grope Eaften fortberwegt, unb na= mentlid zum Treiben ber Mafdjinen, Sem Pferbe yorzuzieben, und 
ez wirb in biefen $\mathfrak{A}$ rbeiten "sfterz beinabe nody einmal fo lange

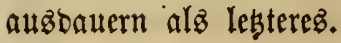

Dis Mieinung, die früher allgemein unt aud beute nod, weit verbreitet ift, baf baz Maulthier niemalz yon Rrantheit befallen

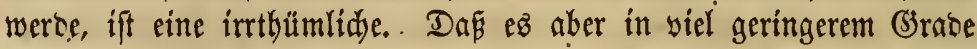
ben manderlei Befdwersen unterworfen ift, biez ift whe Bweifel wahr, weldje Thatjadje wir, ta unfere Beobadjtungen uno Erfah:

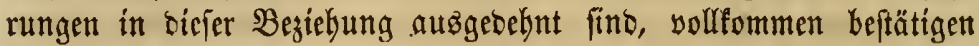
fönnen. Dody haben wir aud ermittelt, bas bas Maulthier yon

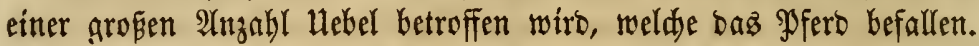

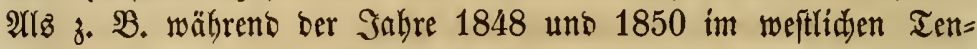

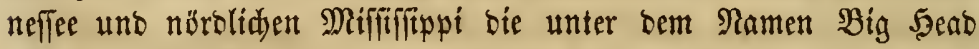
befannte Rranfleit ungeheure $\mathfrak{B e r h e e r u n g e n ~ a n r i d f t e t e , ~ f i e l e n ~ i t h r ~}$ taujenbe Maulthiere in jenen (Segenden zum Spfer, und baffelte war in antern Sübftaten ter Fall. EGenfo baben wir wieberholt

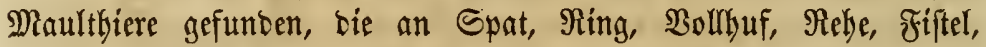

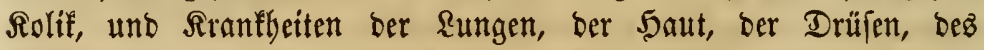
5alfez unt oer 5arnorgane 2 . litten, 'und vielletdet fint fie nidut

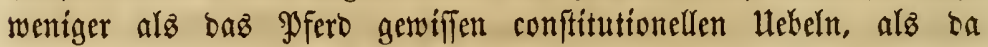

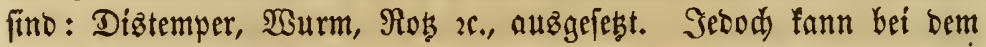
erfrantten Maulthier viel leidjter einte Rur betwerfftelligt merben als beim Mferbe.

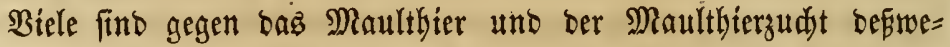
gent mit einem unbegrünbeten $\mathfrak{B} o r u r t h e i l$ erfüllt, weil fie in ter

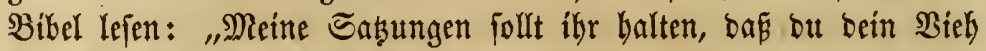
nidyt lafleft mit allerlei Thieren zu idjaffen haben;" woraus man

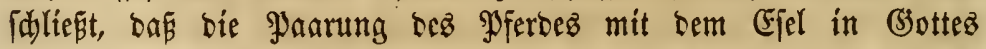
Wort verboten jet. Sebod bezieft fid biejez (B)efes nur auf einen

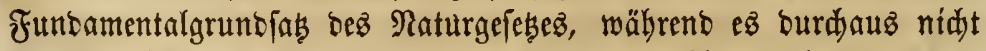

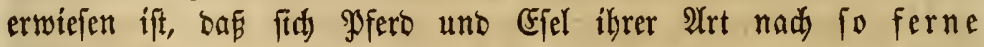
ftehen, bas man baffelbe aud auf fie anzumenten babe. Die Paa rung yon gatl unb gar ferne ftebenden Thiergattungen aber war immer entweber ganz uno gar frudtloz, ober $e z$ wurben baburd effelhafte Mífgeburtent ergetggt. Dap bas nidht bei bem Maultbier, obgleid) ez nidht ferbit "zeugen" fann, ber Fall ift, beeweift feine Eri= ftenz, waz allein fobn ein hinreidyenber Beweiz ift, bas ez in ber Ihierwelt youffommen Beredjtigung hat; wollen wir aber nadh 
befien Braudbarfeit urtheilen, fo muв ihm unter ben 5austthieren ein bober Rang angewiejen werben.

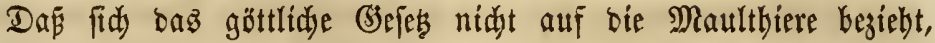
bies geht beutlid) genttg bervor, bas baffelbe in ber Bibel mebrere

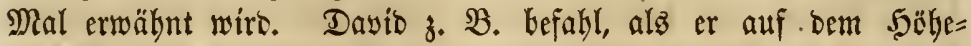
punft jeiner fönigliden Madjt ftano, eintigen feiner Diener: "Neb= met mit sud eurez 5erm Sinedyte uno fest meinen Sohn Salomon

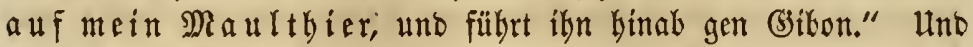
Salomo empfing alş der reidje, mäd)tige నiönig unter anbern Din=

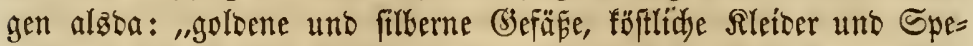

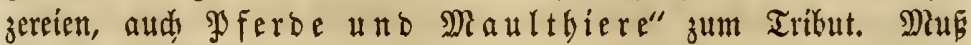

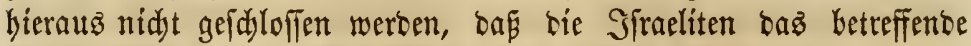
Berbot nidjt auf baz Maulthier bezogen?

Darauf, wå mit biefem Gefeet näher gefagt werben follte, näher einzugeben, liegt nidyt in unjerer arbfidyt, fonbern wir wollen bloz

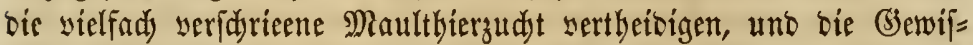

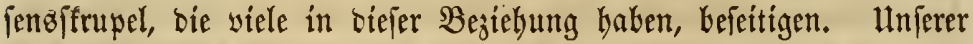

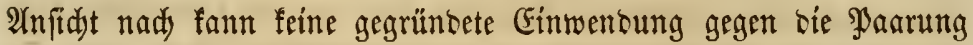
oer Stute mit bem. Gel auf biejen Grount hin gemadyt werben, unt jeoer Büd)ter follte, fallz $\mathfrak{e}$ in in jeinem Snterefle liegt, fid ungeideut ntit ber Maulthierzudyt abgeber.

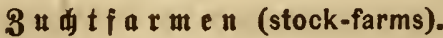

Unter biejer $\mathfrak{H e b e r j d j r i f t ~ w i t n j d e n ~ w i r ~ e i n i g e ~ a l l g e m e i n e , ~ a b e r ~ b a ̈ d j i t ~}$

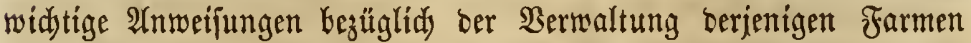

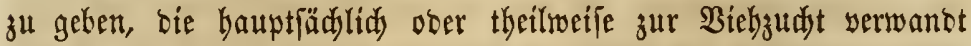
werben, uns werben ung in benjelben namentlidy auf bie \$oferbe= uno Maulthierzuddt begieben.

Fin grofer Fefler auf joldyen Farmen ift ber, baf entweder gar

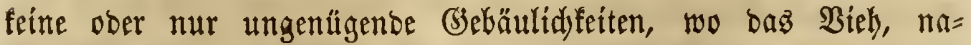
mettlidid bie jungen Fư̈llen, bei ungünftiger Sitterung ein Unter= fommen finten fönnten, yorhanben finto; benn es ift ebenio noth=

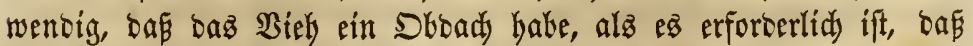

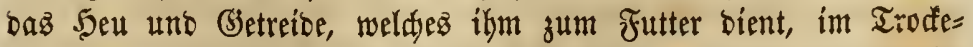
nen aufbewahtht werbe. Bezüglitid ber Stallung haben wir unż im

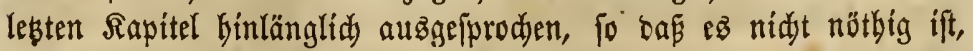
bier nody weiterez einzujijalten. 
2rber nebft ben trodenen unt bequemen Ställen für ben Winter= gebraud, follten aud) gentügente $\Re a ̈ u m l i d$ feeiten zubereitet werben, in weldyen fid) alle jungen Wferbe uno Maulthiere wäbrento ber falten Frühjahrż = uno Spätjahröregen aufbalten fönnen, uno zwar follte biefez Sbrady auf bem Weiteplats felbft, oter tody fo angebradit

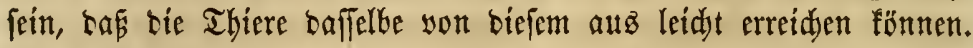
Ein foldyer Stallraum, ber zwanzig Suabratfuk groß ift, genügt,

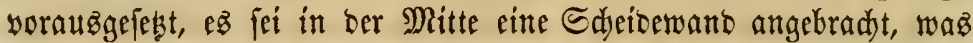
immer ber Fall fein follte, um zwamzig Füllen unterzubringen; an jeter Seite tönnen zefn ganz bequem ftehen. Die Erridytung eintez foldyen "Edjuppen" fant obne grofe Roften uno in fehr eimfadjer

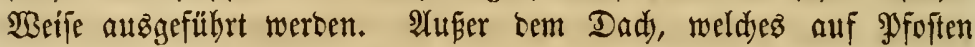
ruht, sie mif Eteine geftellt fint, ift nur nody sin Bretterseridilag

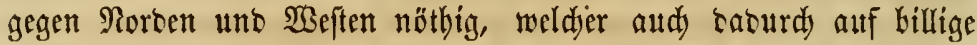
Weife erjeģt werben mag, baj man an bie betreffenten Stellen Bün= bel Roggen= oder $\mathfrak{W e i z e n f t r o h}$ neben uno aufeinanter ftellt, uno biefe surdy Bretter, weldje wagredyt zol beiben Seiten ber Dadjpfoiten an= genagelt mercen, befeftigt. Die Edjeiberwanto in ber Mitte follte aus einer Futterranfe beftehen, in weldyer bejtänbig Stroh ober beu

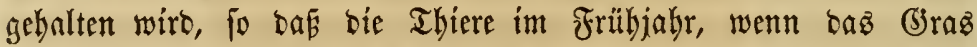
nod) flein ift, voer im Spätjahr, wenn es wenig grünez Futter gickt, nidjt Mastgel zu leiben haken. Utnter ben Raufen follten zutr

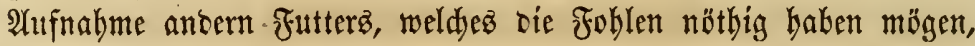
Futtertríge angebradyt jein.

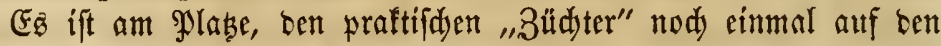
franflaften 3 uftano bez Maulez junger Thiere wäbrento sez $3 \mathfrak{a b}=$ tกenz aufmerffam zu madjen, unt gerabe in biefen Futtertrögen mag

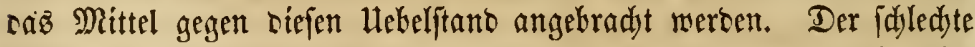

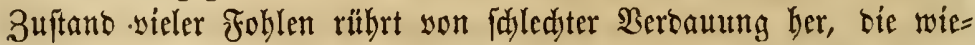
Derum burd wunkez unt entzünbetez Munt = und Zahnfleifd ser=

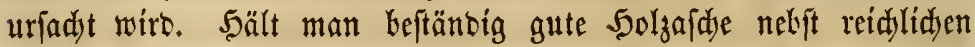
Dutantitäten Salo in biefen Trögen, fo wiro Gierburd) biejem $\mathfrak{H e b e l}^{2}$ uno ben für baz Foblen barauz entftelyenben Sdjmerzen yorgebeugt; audj mag Edjwefel zum gleiden 3mefe mit fohr gutem Erfolge

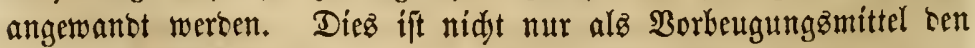
taujenbfaden Betrag ber baburd) yerurfadyten Soften werth, Fonbern ez werben aud Ungeziefer aller 2 rrt baburd) fern gebalten. 
2luf vielen Farmen giebt $\mathfrak{e z}$ nur wenige Sdattenkäume uno niddt

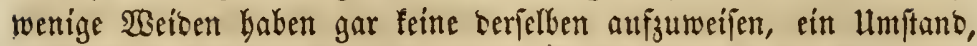
meldyer ben Pferbegüdter um fo mehr veratlanien follte, Sduppen, wie fie oben bejdrieben wutroen, zu erridten. Zur Bequemlidjeit uno zum Sisoblergehen bez Biehz uno namentlidy ter Füllen, ift ein

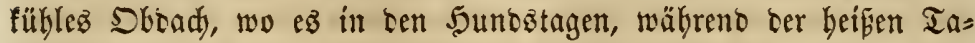
geszeit, sor ben brennenten Sonnenfrahlen Sdy fintet, burdjaus erforberlid, uno wo Bäume fein foldjes bieten, ift ez nothwentig,

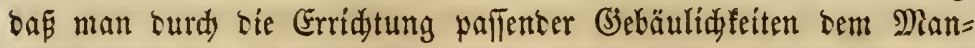
gel abbelfe.

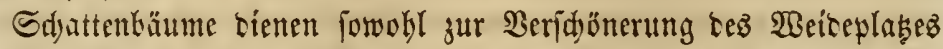

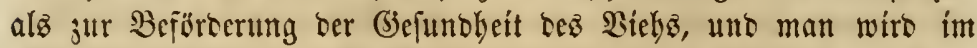
Spätjahr zwifden rinem Foblen, weldes eine gut Geidattete WSeite

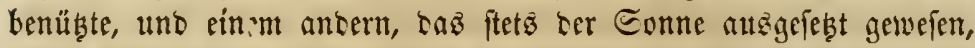
cinen beceutenten Unteridjied wahrnebmen, benn has junge Thier fann nidjt beftänoi, unter ben fengenten Eonnenftrablen leben, obne entfräftet uno fatwad) zu werben. Eine ber erften Esitridstungen, für tie man tef̧̧alb auj einem Wesceplats, weldjer feine Edyatten=

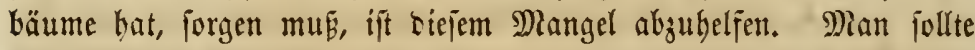
in veridiecenen Theilen oefielben - wo, bas wiro bem intelligenten Farmer surd) bie Bobenart, Sertlidfeit 2 . angesentet - junge Bäume pflanjen, uno jwar fino die fdjwarzen 5eufdredenbäume (black locust trees) für siejen 3wefi vorjujichen. Sie gereihen

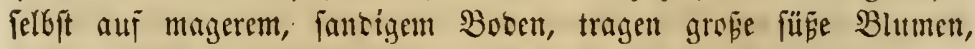
meld)e, fowohl wie bie Blätter, tem $\mathfrak{B i e l}$ gejuno fint, uno tą Ģrazs, weldjes unter benfelben wädyft, ift üppiger uno wiro yon sen

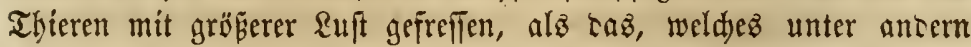
Bäumen gerciht. Reid) Rieberungen mag man mit Bufferaborn= bäumen (sugar-maple) beịebeen, währeno an Fllifîen ober Bäd)en Lin weiten gepflangt merten mögen. Der Socuft wädjt fehr fanell uno alfe biefe Bäume gewähren viel Sdyatten uno fino aupertem

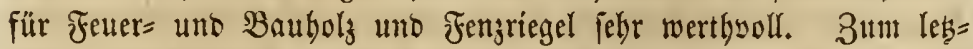

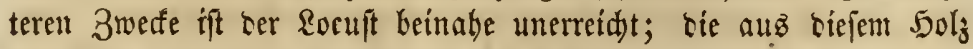
angefertigten Riegel werven ein Sahrbunbert lang Dienjte leiften.

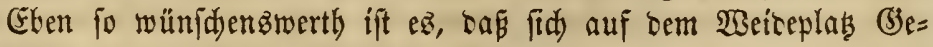

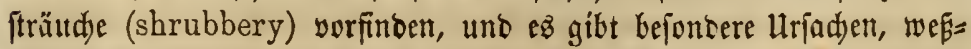
balb jelkft Stauben (briars) auf mageren 2HbGängen unb an ben 
Rlüften 2 . hin gepflanzt werben follten. Die Brombeerftaube (blackberry) bereidjert bent Boben fo fajnell alz ein befanttez Mittel,

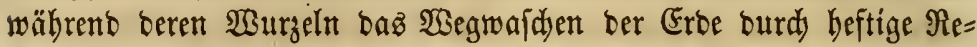

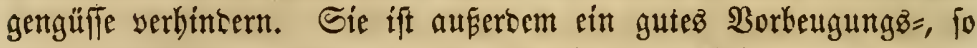

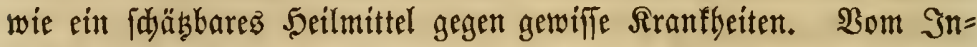
ftinft belebrt, fudjen bie Pferbe, forwie anbere Thiere in betreffenden

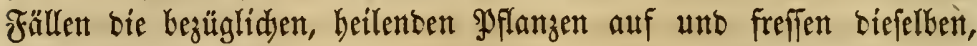
unb auf bieje $\mathfrak{B e i f e}$ werben bie Blätter mebrerer $\mathfrak{B a ̈ u m e , ~ S t a u b e n ~}$ 27. werthyolle $\mathfrak{A}_{\mathfrak{r}}$ neimittel, waż, wie gefagt, audd yon benen ber Brombeerftatbe gejagt werben barf. Diejeltbe ift ein wertbyollez

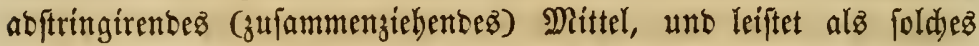
veí beftigem Durdjfall (scours), bem bie Fohlen in ben eriten $\mathfrak{W B}_{0}=$ d)en కez Frühjahtra, uno woburdy fie fo fehr herunterfommen uno abmagern, oft ausigezeidnete Dienfte. Sobald baz Thier yon ten Blättern 2 . ber Brombeergeftrüpps freffen fann, veridjwinbet biefes

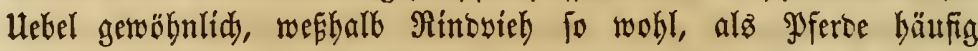
bayon geniefen. Natürlid jollten sieje Stauten nidht ben ganzen Weiteplat überwudyern, nod) ben reidjten Theil beffelben eimneh= men, fortbern nur an joldyen Drten gebulbet werben, bie wir be= zeidjnet haben. Sie ganz auszurrotten, liegt nidyt im Sntereffe tes Farmers, namentlidy went in Betradyt gezogen wirb, bás fie eine föftlide $\mathfrak{I} a$ felfrudyt liefern.

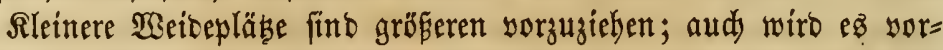
theillyaft fein, baz Sieh cinmal auf biefem uno haz anbere mal auf

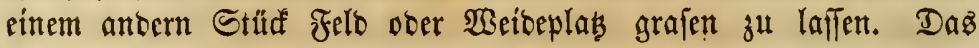

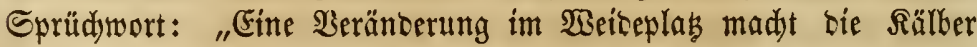
fett," ift alt uno abgebrofden, aber nidjts befto wentiger wahr umb läśt fid aud) auf Laz Foblen anwenden. Siebft tem wiro bas betreffente Stülf Felb ba\& Sahr hinburd) aud megr Futter liefern,

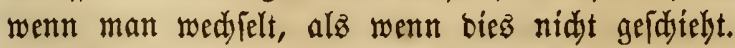

Sann man bie $\mathfrak{A}$ norbnung treffen, fo follten bie Foblen gleidjen

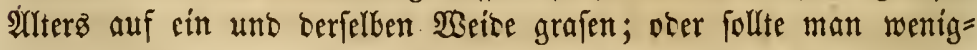

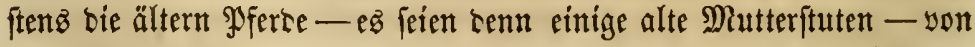

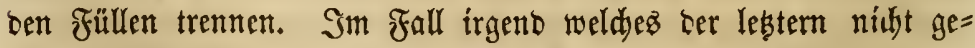
beiht, fontern in idjedjem 3uftand ift, möge ez ber Farmer yon ben anbern trennen, um bie Urjadye bez Hebelfítandes zu ermitteln uno bann zutr gecigneten Bebandlung fdreiten. Wenn eine $\mathfrak{A}$ trabl 
Füllen miteinanter auf ein unb bemfelben $\mathfrak{B}$ eitoplats grajen, werten bie jüngern uno fidwädern berfelben oft yon bem ältern uno ftär= fern míf̧antelt, worauf man in allen Fällen wobl zu adten uno Sorge zu tragen bat, Laf bie jüngeren Foblen gut veriorgt werben.

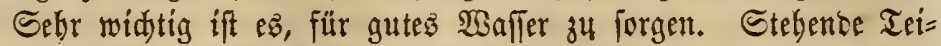
d)e uno Sd)mulzpfüben eignen fid für 3udtffarmer nidt, bent sie=

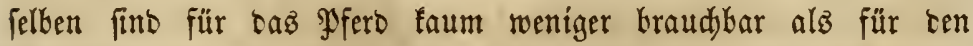
Menjajen, unb viele Foblen fränfeln nur teşhalb, weil fie feir an=

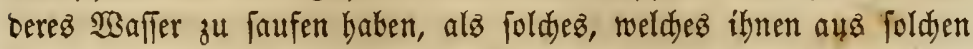
"Raden" geboten wirb; berjenige Farmer, weldjer einte Duelle ober einen fliesenten Bady auf feinem $\mathfrak{B}$ Beibeplag hat, tarf fid glüaflid idäzen. Sif jebod feines yon beiben yorbanben, fo follte fogleidy ourd) einen guten mit Settenpumpen verietenen Brumen, an mel= dyem ein grofer Trog angebradjt ifit, Eriak geidjaft werben. Siünft=

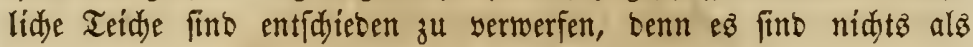
Sdjmub=Raden, die zu allerlei Rranfleiten Beranla|jung merben.

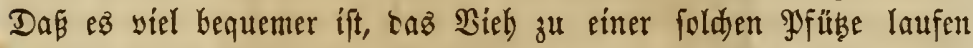

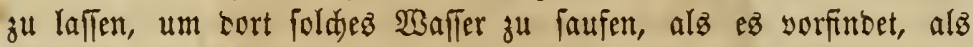

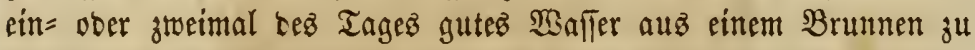
pumpen, biez wî̄en wir wohl; wer aber wähnt, er habe fid hier=

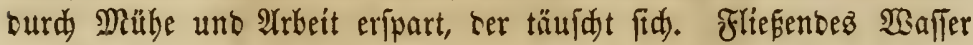

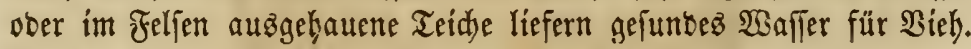

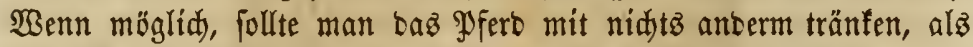

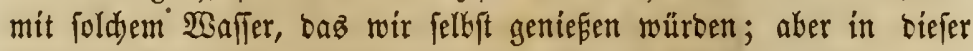
Sinfidyt fino unjere farmer im allgemeinen fekt gleidgültig, uno

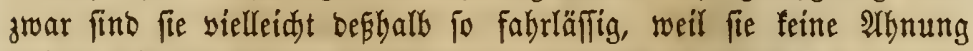

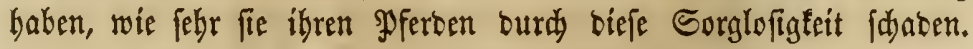




\section{Denturzefintes sapitel.}

\section{Aterlimale ieg Alter und Der gthisbandumgen.}

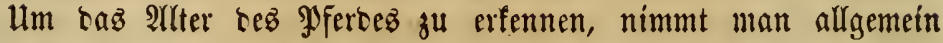

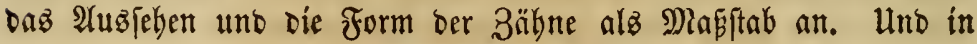

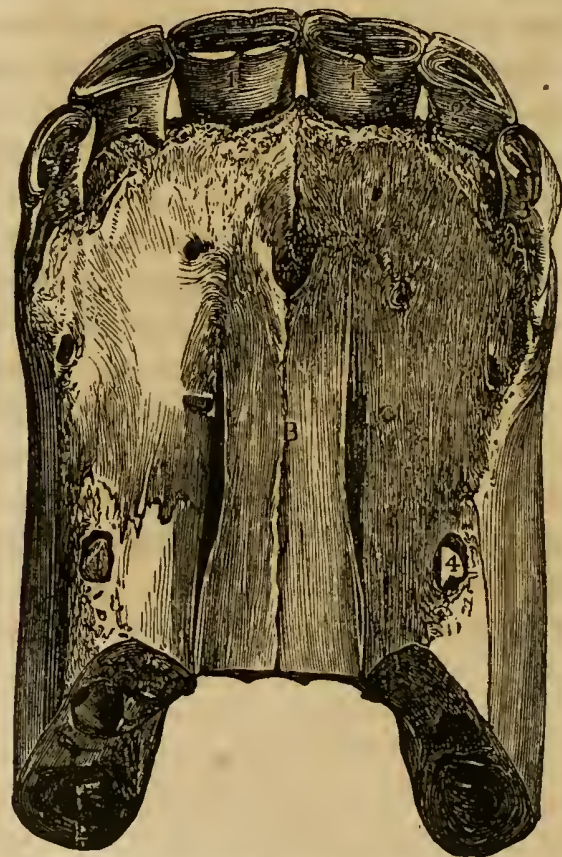

Der \#anen eines oreijäl)rigen Toblen.

B, Borberer Riefertnoden.

11, Mittlere, permantente, beinabe ausgerwadjfue Ectgeidezäbne (nippers).

22 Rildyägne, abgentiigt.

3 3. Cedmildzäbne, an welden nod der Sern (kernel, or mark) z" fchen ift.

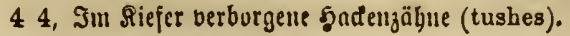


Berbintung mit andern 1 mitänoen, bezüglidy welder fid ber erfah = rene Wferoekefitger wo möglidi) genau unterrídten wirb, fanm man,

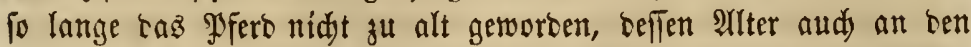
Zähnen erfennen. Die brcierlei $\mathfrak{Y} r t e n$ Zähne; bie man im PFerbe = rad)en sorfinbet, wurben nebit 9 ingabe iferer Ramen im 2. unb 10. Rapitel beidjrieben.

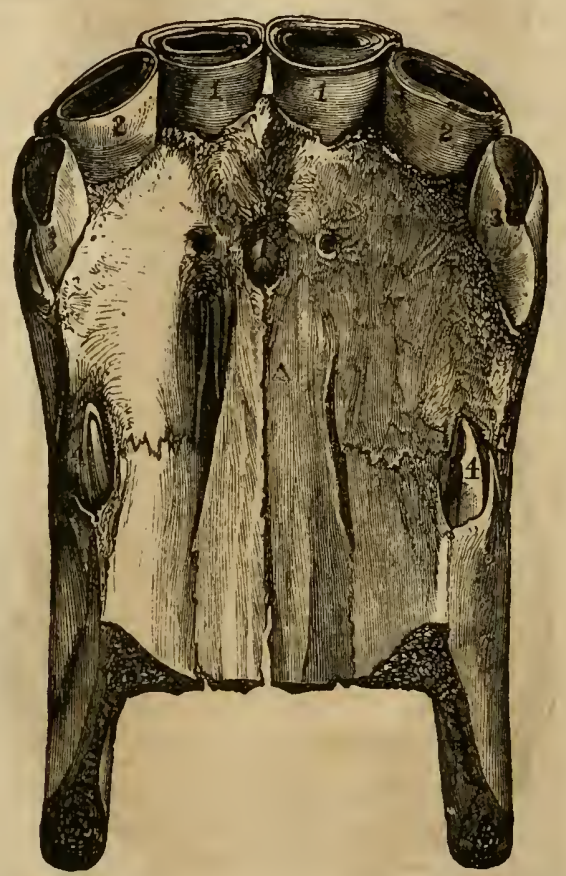

Der Kadjen eines vier und ein balbes $3 a b r$ alten poferdes.

A, Borderer Rieferfnodenen.

11. Mittlere, ziemlin abgenü̈şe Sthneidezähne.

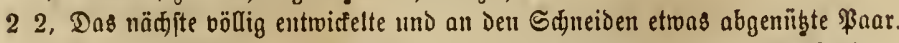

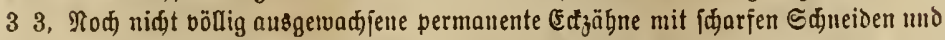
jebr Dentlidjem Rern.

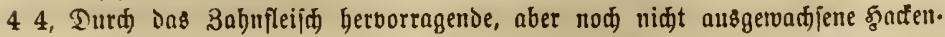
zäbue.

Sier baben wir nur nod auf bie verifjiedenen $\mathfrak{B}$ eräntoerungen, bie mit ber 3eit mit ben Pfersezähnen vorgeken, uno auf bie veridie=

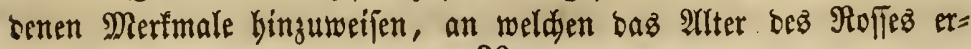


lannt werben fann. DaB̉ Pुferb bringt adjt Badenfähne (grinders, or molars), zwei auf jeber Seite ofen uno unten, mit auf bie $\mathfrak{B e l t , ~}$ ober ez zeigen fid) hiefelken zwei ober trei Tage nad bem Werfen. Benn vier Edneite = oter Borterzäbne, zwei im Sber $=$ und zwet

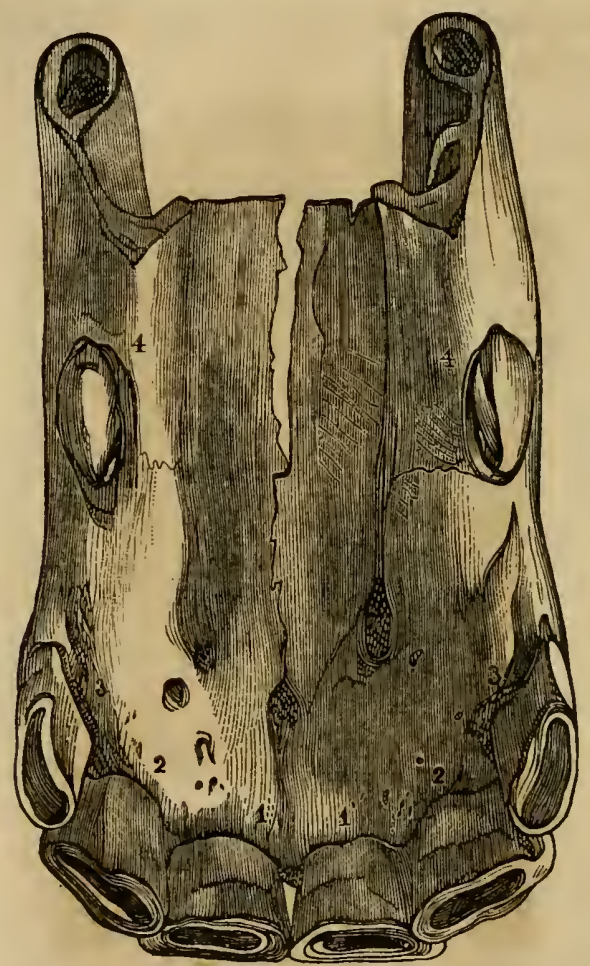

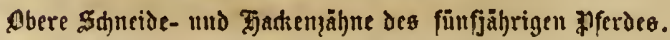

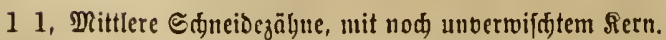

22 Die Diefen zunädjt ftehenden Єdnueidezägne, mit nod oentlidjer hervörtretendem Rern.

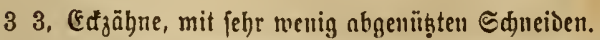

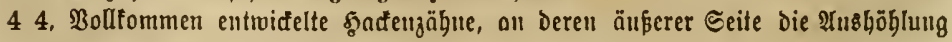
nod) Deutlidy wabrzunebonen ift.

im Ilnterfiefer, wollig burdyz Zabufleifd getwadjen fint, bann if taz Jüllen zebn ober zwolf Tage alt; uno wenn nod) vier weitere her= anşgemadyen fint, einer altf jecer Seite, bie anbern in beiben Rie= 


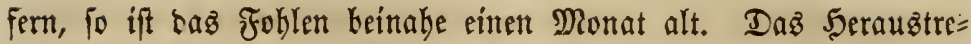

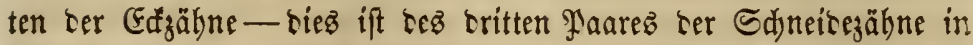
jebem Riefer, zeigt ein $\mathfrak{A} l t e r$ yon etwa adt Monaten an. Mit bem

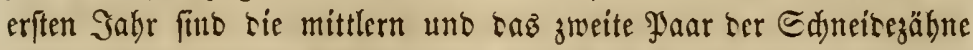
fo abgentibt, basi fie beinabe gant eben fint, waz mit bem Ed̆zahn,

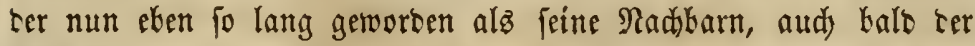
Fall ift.

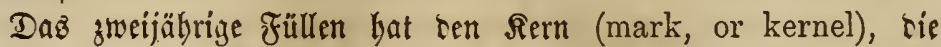
sunfle, harte Subftang in ser Mitte ser Bnhulrone, ganz unt gar

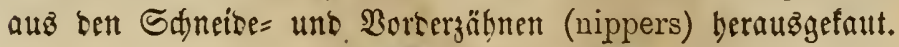

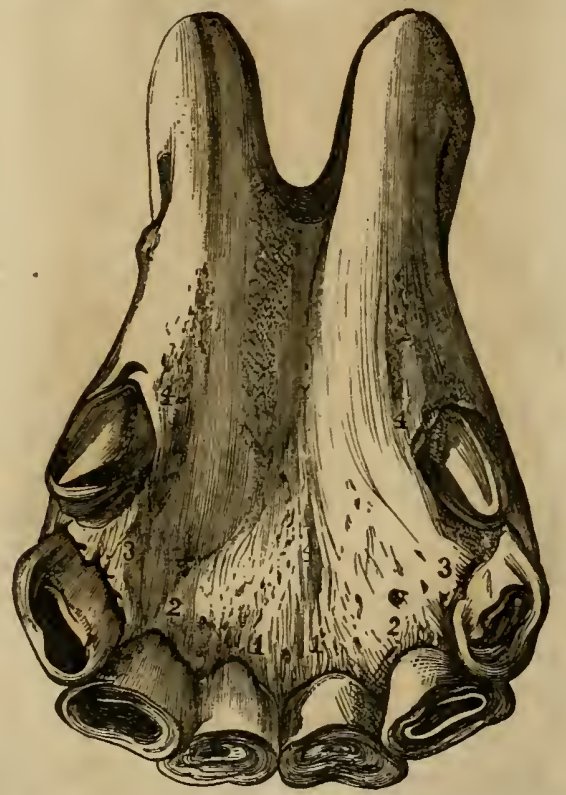

Untere Sadneide- แแd Ģakenzähne eines fünfjäbrigen pferdes.

1 1. Mittlere Sđ̆nei內ejäbne, deten Rern beinabe abgenüb̨t ift.

22 , Die dempelben zumädff ftehenden Ednneidezäbue, mit theilweije abgenühtem Rern.

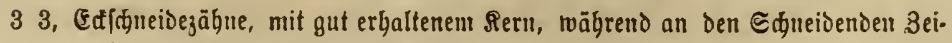
Weri der $\mathfrak{a b m u k z u n g}$ bemertbar find.

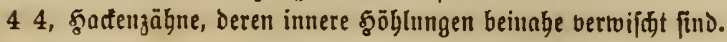

Biäher leifteten bie Mildyähne bem Thiere alle erforberlidjen Dienfte, nunmebr aber ift ez anterer, fefterer unb in jeter Beziebung sauer= 
hafterer benöthigt, und biefür forgt bie Ratur, inbem fie biefe Mild)= zätne burd permanente erietst, und zwar beginnt biefe "\{łuzfrattung"

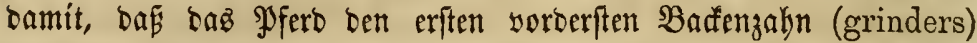
befommt. Da jebod) biefe $\mathfrak{B a f f e n z a ̈ h n e ~ z u ~ w e i t ~ z u r u ̈ a ~ i m ~ \Re a d j e n ~}$ angebradt fint, fo muf mon aud fernerhin zur Bejtimmung bez

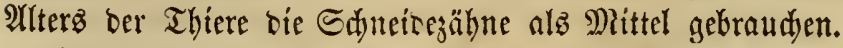

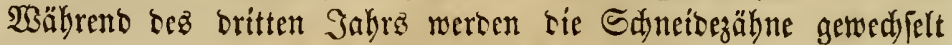
(shedded, shifted), uno biz bicịis yollentet ift, ift baz mittlere Paar

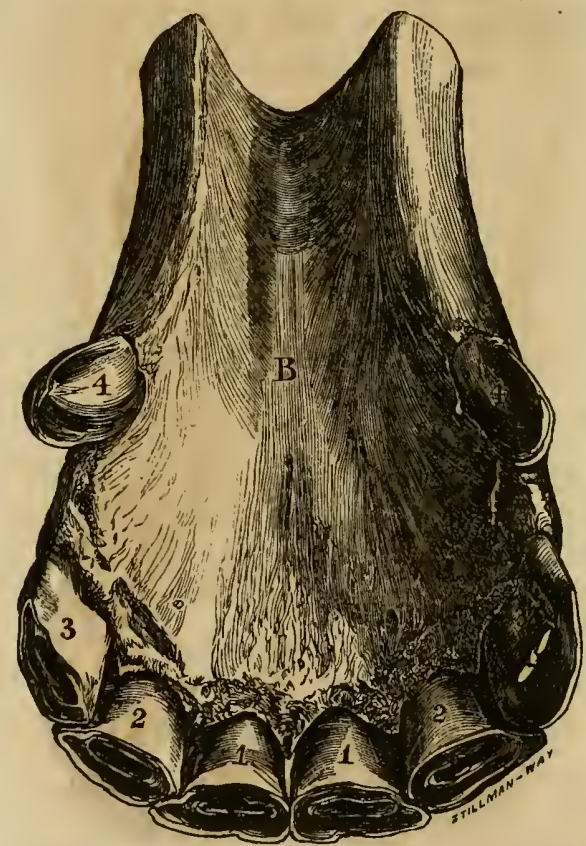

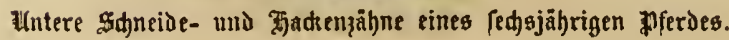

B, Der llnterfiefer.

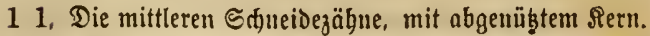

2 2, Die denjelben zunähjt jtehenden Shmeidezähme, mit theiltweife abgenügtem Rern.

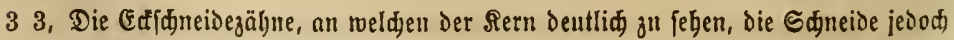
bedeutend abgenitbt fino.

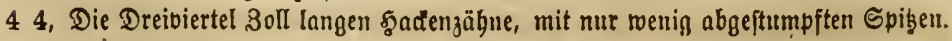

berfelben beinahe auzgetwadjen. (Sieke baz Billo, weldes bie Zähne bez oreijährigen Fobjlen barftellt.) 


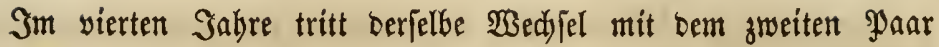
ber Sdyneibegähne ein und gegen bas (Enbe beffelben unt mit 2 Yn= tritt bes fünften fommen bie 5aden= ober Zaumzähne beutlid zum Boridjein.

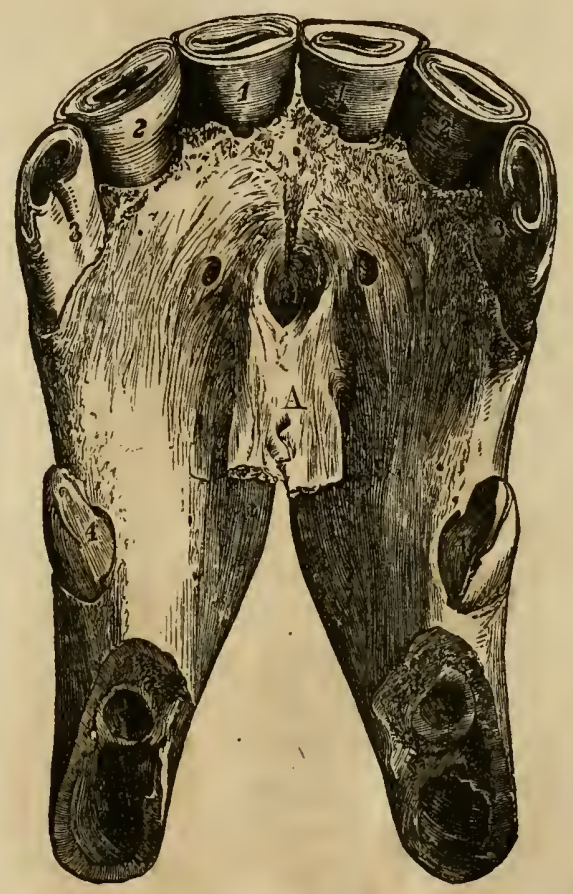

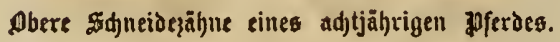

A, Borderer Rieferfnodjen.

11. Mittlere Sdneidezälnue, fo abgenügt, Daß fie ziemlid eben finto.

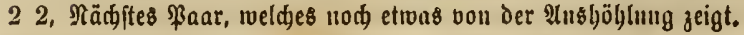

3 3, Edjidneidezäbue, an soeldjen Der Rern (mark or kernel) nod) Deutlid) zu jeben ift.

4 4, รูađenzähne, die meb̆r abgenüßgt find als bie im Inntertiefer bes jechsjäbrigen Pferdes.

Mit bem fünften Sahr ift Der Radyen bez $\mathfrak{P f e r b e z ~ m i t ~ b e r ~ y o l l = ~}$ ftänoigen 2 (ngahl Zähne (a full mouth) veriehen, uno mit bem jedjften find bie Sdjneidezäbne bez Untertiefers bermaßen abgenübst, 


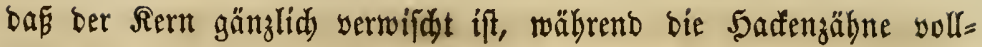
fommen aug̈gemad) jen fint.

Mit bem fiebenten Sabre ift an Den Eđfähnen beż Dberfieferz ein Şaten Vemerffar, währeno ber Sern bes zweiten Paarz ber Sdyneibegäbne gäuzlid) verwifdyt ift und an Den Sacfenzäbnen beut=

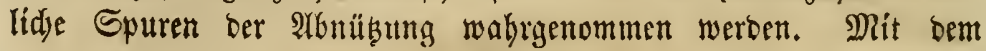

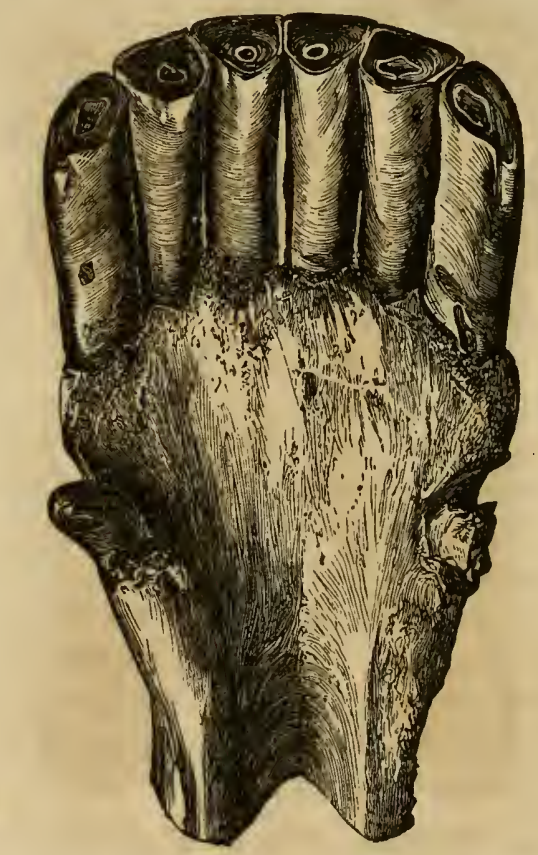

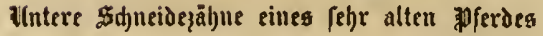

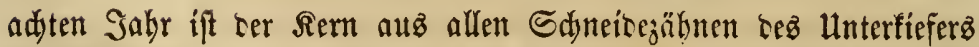
abgenügt uno tritt Derjelbe im mittleren Paar ธes Soberfieferz viel weniger beutlich berwor, ober berifelte ift bei bem Pferee, bas nur im Stall gefïttert wirb, autd gänzlid veridywunden.

Wăhrend bez neunten Gabrz wito bas̄, waz etwa yom Rern in bem mittleren Paar bez Sberfiefers übrig geblieben ift, abgenüht,

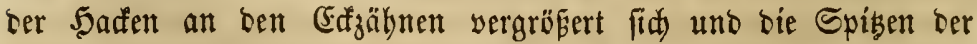

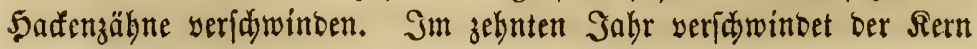


son bem zweiten Paar ber Saneibezäbne am Sberfiefer uno im elften ber an ben Gifzähnen. Mit bem zrölften Jahr werben alle Rrenen ber Borbergäbne im Unterfiefer breiefig unt die Saafenzäbne fino febr abgenübt.

Se älter taz Pfero wirb, befto mebr nübt fidy auth baz Zahn=

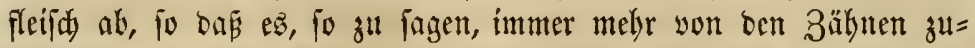
rüdtritt uno bieje fehr weit vorfteken. Daz Bilto auf oer yorberge= benoen Eeite ift eíme getreue, nady ber Ratur entworfone Beidunung

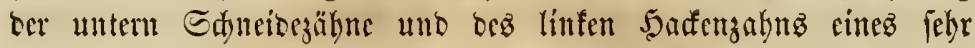
alten Piertes. Der red)te Sadfenjahn ift, wie zu feben, auşgefallen.

Radjocm bas Pfero bas adjte Sabr erreidyt hat, fanm man nur

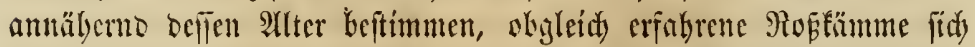

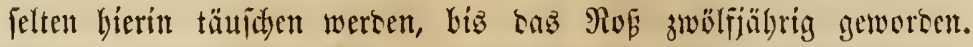
Bon zwölften Sabr an aber tönnen wir, aufer rapi febr lange

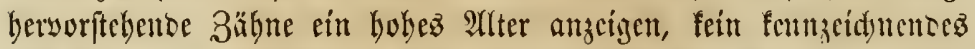
Merfinal mebr angeben. Mit sen Bäbnen mandyer Pforte gebt, nadjem fie bas neunte Jabr crreidyt, nur febr wenig Serïnocrung wor uno wir haben jebn oecr jwölf febr alte Roffe gefelen, nads

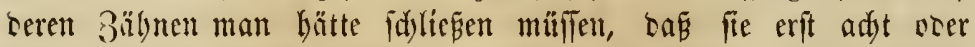

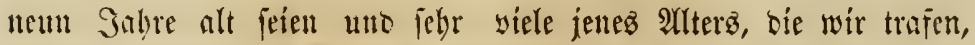
batten nic Sacfen an ton Eafjübnen.

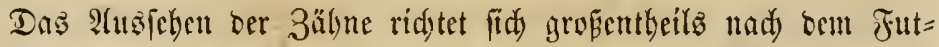

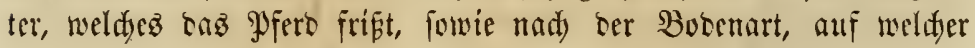
baffelbe gewadyen, nady ocm Slima und ber Beidaffenteit bes San= Des, in weldyem bas Piero lebt, uno bergleidyen Untitänoe. Pierce, weldye ftetż auf Weibe laufen, bie auf fantigem Boben angelegt ift,

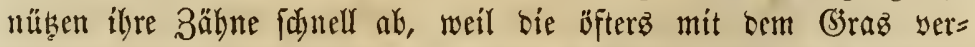
miftyten Sanbförner beftänoig zermalt werben, wosurdy ben Zähnen

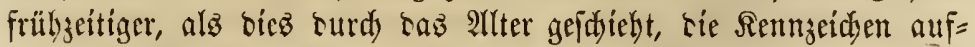

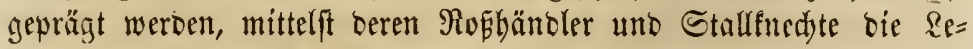
benbjabre ber Pferde bejtimmen, fo baß̧, fallz man in biejen Fällen

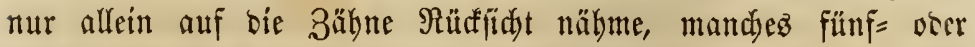
fechsjährige Pfero zefnjäbrig genannt werden müste.

Utn ben Ufern bes Mififippt und feiner Rebenflüfie freffen hun= berte Sferbe beinabe bas ganze $\mathfrak{a} a \mathfrak{l}$ bas in ben 4 fermünoungen wadjente Rohr (cane), woburdy die Sdjeibezäbne bermanen zer= brödeln uno abnüben, oaß feine fuyerläjfigen Rennjeidyen, nady wel= 
den man bas 2 Iter beftimmen fönnte, wabrzunebmen find, unb bie Edjäbne biefer Pferbe haben, gleidy benten ber eben angefübrten, feine Sacfen.

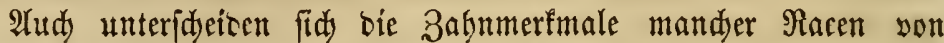
benen anberer welentlidy. Bei ben Pony, z. B., finbet fid felten ein

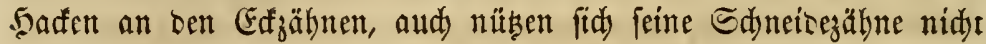
To fdunell ab, alz biez gewöhnlid) ber Fall ift. Ebenfo fdrumpft

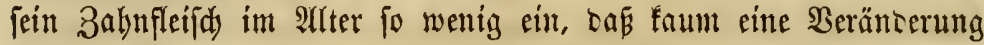

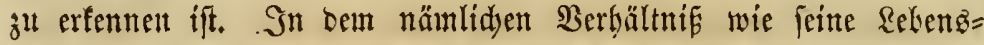
bauer étte viel grö̋̈ere if̣t, alż tie anoerer. Pferte, erbalten fid and) reine Zähne länger. Diefe Bemerfungen mögen audj in gemif = fen Brate auf Pferde verfdyiedener Form und Rörperbildung ange= wanot werben. Die Bäbute grof́er, fnodiger Thiere beuten auf ein viel böherez $\mathfrak{A}$ lter hin, alछ̇ biejenigen fleinerer, gebrängter gebauten, uno ebenoaffelbe ift mit Pferben ber Fall, bie beftäntig im Stall gefüttert werben, gegenüber Denen, weldye die meijte Beit auf or Tocibe laufen.

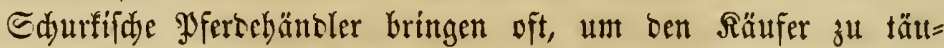
id)en unb zH betrïgen, an ben untern Sdjueibezäbnen fitnjtlidje Mertmale an. Dieje aub Englano ftammente Betrügerei wirt you Pouatt folgendermafen beiduricben:

"Man nennt biejen Betrug nady sem Sdurfen, ser senfelben ju= erit benübte, 'Bifdopen' (bishoping). Daz adjt= ober meunjäbrige Pfero wiro niebergeworfen und nun meifelt man mit einem (5rasir=

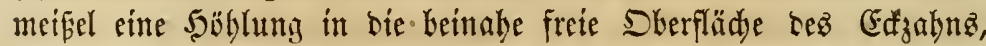
bie bejüglid ter (j)eftalt uno form bem Rern (mark or kernel)

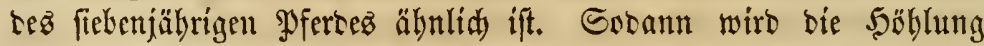
mit einent glübeno gemadten Eifen gebrannt, fo bap ein permanen= ter, fdwarger Flefen entfteht. Sefterz wiro aud nod baz nädjfte Paar ber Sdynirezäbne ein wenig gebrannt. Unwwiffende werben

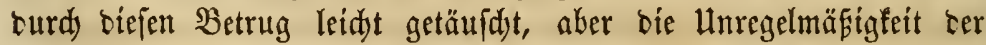

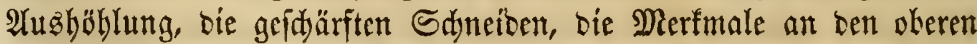
Sdjneibezäbnen in Berbinbung mit anbern allgemeinen Rentzeidjen, fönnen einen aufmerfjamen $\mathfrak{B e o b a d}$ ter niemals irre fübren."

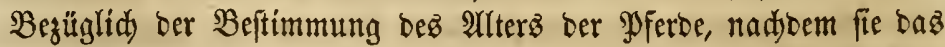
ad)te Sabr zurüfigelegt baben, fagt Derielbe $\mathscr{A}$ utor: "Die Sadfen=

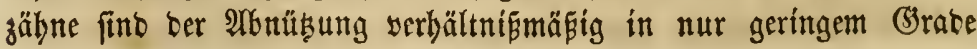


auछgefest, weil, เa เaż Futter fo zu fagen, über biefelben in ben Sdiluno geft, fie nur geringer Reibung aubgejest fint. Deshalb fann man aus ber mit itnen yorgebenben Beränberung, obgleid) fie gewöbnlidy in ter yon uns befdriebenen Meife ftattintet, nidyt mit

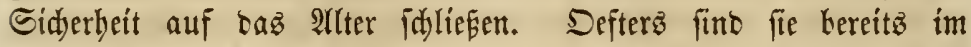
adyten Jahre ftumpf, mandymal aber aud nod im adtzefnten ganj gut erbalten. Die obern Sadfenjäbne, obwobl fie sie jüngeren fino, nübent zuerit ab.

"(Siebt nadyem es bas adje Sabr nodj überidyritten bat, nod) beftimmen fann? Es giebt weldse, nad) tenen es ermöglidst ift, rie Rebens= jabre febr alter Pyferbe wenigftenz annäberno zu erratben, foldye Senngciden, yon benen man mit einiger Siderbeit Sdylüfle zieben fönnte, fint aber nidis mebr worbanten, unt man fann yon mun an feine Bermuthungen nur auf sie Keftalt ber Bäbne grünten. Mit rem adjen Sabre find biefelben oyal; je älter aber tas Pyerd wirb, refto mebre abgentingt werten bie 3äbne, unb jwar zeigt fid ciefe Abnübung nidft jowohl in ber Diffe als in ber Weite ter 3ăbne, fo Laf tas Dyal fürjer wirt, tie Zähne yon einander abjteben, uno teren Enten abgeruntet fint. Mit oem vierten Sabre ift ries an ben mittleren Edjetoezäbnen seutlid wabrzunetymen. Mit bem zebnten wirb bab Doal ser anbern fürzer; mit tem elften fino bie

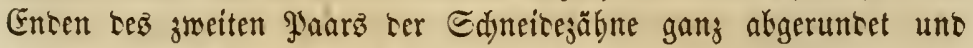
mit sem breizebnten zeigt fid Daflelbe an ben Edfidneibezähnen. Mit bem vierzebnten Sabr werten bie Rerne ber mittleren Edyei= bezäbne etwaz oreiectig; mit bem fiebenzebnten haben alle biefe Form. Mit bem neunjebnten sagegen find bie Efen mieber abge nügt uno dí mittleren Zähne fino wieter oval, nur baf́ daş Doal

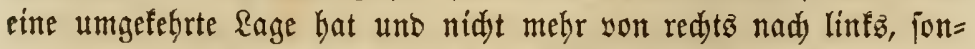
bern yon aupen nad innen liegt, uno mit bem zwanjigiten baben alle Zähne diejelbe (3eftalt. Diez ifi die Anjidyt einiger europäi= fdyen Thierärste, weldye Serr Bercibalf zuerit in oer englifiden Spradye bargeftellt hat.

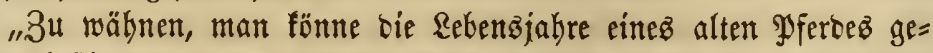
nau beftimmen, wäre Thorbeit, benn obgleid) bie son uns nieberge=

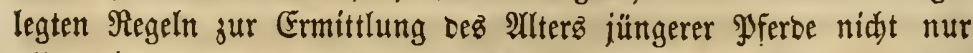
allgemeine, jonbern aud geridtlidge Beltung baben, fo mup dod 
zugeftanten werben, เá audi fie nidjt in allen Fällen anwentbar fino. Die im Stall gefütterten Wferbe nithen ten Siern (marls

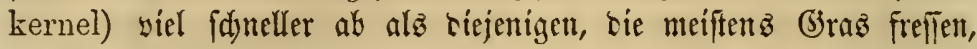
unt ber "STrippenbeíber" (crib-biter) mag fijon int erften ober

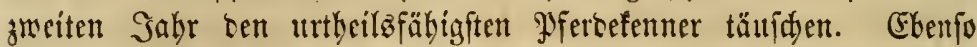

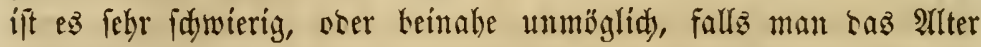
bes Pferses yom erften Miai an geredjuet, beftimmen wollte, zu

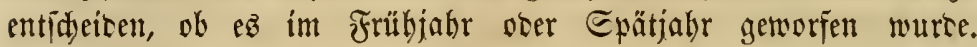
Mit sem neunten orer zebhnten Sabte finto bie Träger (bars), Theile

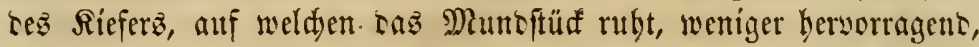
unt in rem Berbältnifí, als fie fleiner wercen, fann man auf höbe=

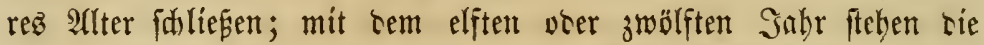

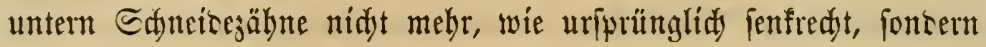
fdiéf, ober gar wagredyt unt fitto gelb, uno zwar bephalk, weil sie=

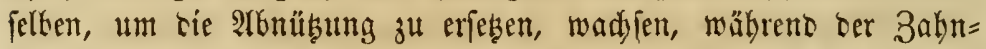

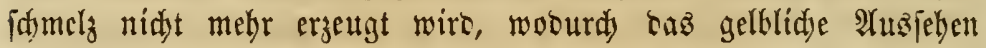
entitetyt."

\section{Die $\mathfrak{E}$ ippen.}

Die Rippen meifen jwar feine Merfmale auf, nadh tenen man

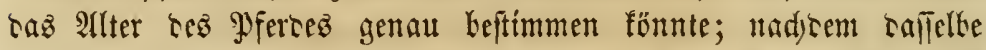
jerod adyt ocer neun Sabre alt gemorten, fajrumpfit bie Sherlippe etwa zufammen und wiro fleiner, wäbrent fid rie untere serlïn= gert, horabbängt, oft in ter Form ciner Rofosinufifdale (cocoanut-

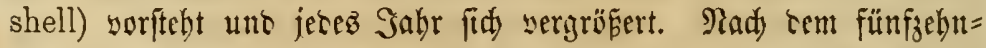
ten Gahre haten bie Rippen gemöbnlid ein jebr rumjeliges uno ju=

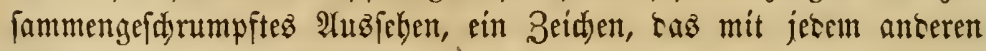
Rebensiakr mehr hervortritt.

\section{Die $\mathfrak{g}$ a a $\mathrm{r}$.}

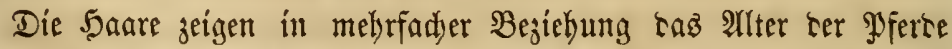
an. Sit caffelbe zwifhen zekn unt zwölf Gahre alt, fo wersen bie

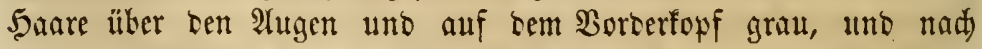
uno nad) weis; nebft cem verbreiten fid bieje entfärbten 5aare auf bie umliegenten Theile, uno mit sem fünf̧eshnten, Jahre ift tiejes

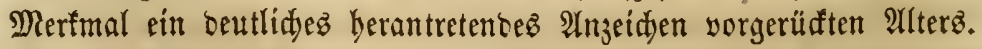
Radyom taz Thier bas zmölfte Sahr zurüfigelegt hat, uno fis zum 


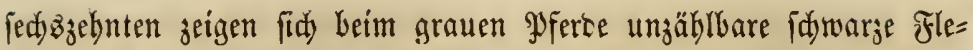

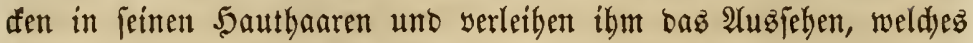

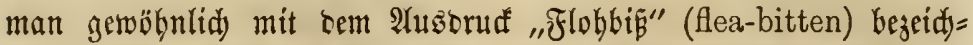
net. Diefe eigenthümlidje Eridjeinung zeigt fid nur felten bei einem Pofero unter zwölf uno jeften yor bem fünfzelynten Sabr. Diefe Dunfeln Fleffen verlieren fity nidyt, fontern werben mit jebem Sabr größ̨er.

\section{Der $\mathfrak{u}$ terfiefer (chin).}

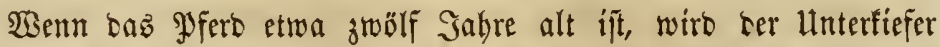
(chin) fpistig und an feinem Ente fajarf und effig; ein Merfmal,

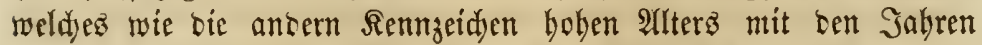
ftürfer bervortritt. Bur felken Beit wiro bie sen Rieferfnoden um=

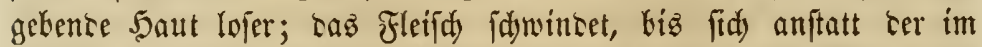

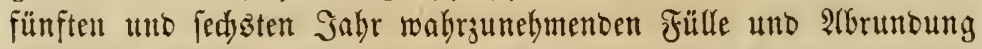

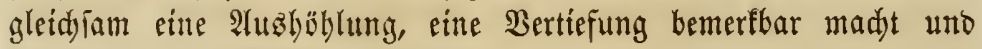
tie Ranten tes Riefers yorftehen.

\section{D i e $\mathscr{A}$ น}

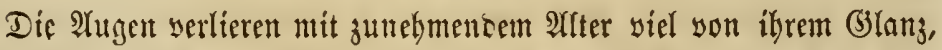
ter $\mathfrak{A}$ ugball wiro fladyer, mandje ber $\mathfrak{A}$ ugenfleden (humors) ver= idjwincen uno die 2 uggengöble mirb tiefer.

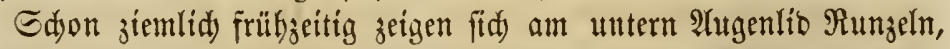

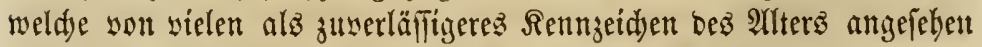
werben, als bie an ben Zübnen zu bemerfente Merfmale; ja mandje

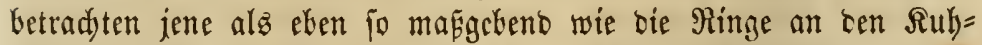

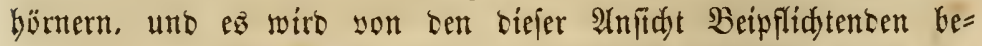
Gauptet, bas fid bieje Runzeln mit bem britten Rebensjałhr bez

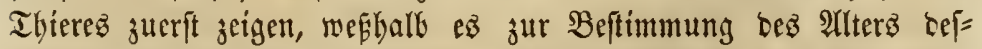
felben nidjt weiteres alz Bäblung berfelben betürfe, zu weldjer Zahl man brei absiren müije. Daṕ biefe 2 Anfid)t bie ridjtige fei, barüber

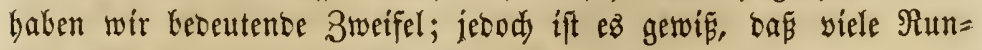
jeln Merfmale hohen Alterz fint.

\section{Die mínand}

Sebr viele Perfonen behandaln bie Pferbe in einer $\mathfrak{B}$ eif́, bá einem ber Geranfe fommt, jene \&eute wähnen, biefe Thbiere feien 
aub Eifen gefdaffen. Wie wenig Menfd)lid)feit und wie viel Brutalität uno Unbarmbergigfeit viele Mentđ̆en ben Thieren gegenüber zeigen, uno wie wenig bie taujente fidy bieber beziebenten Rebren

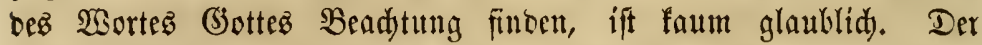
rurdy Mifighanolung bem Pferbe jugefïgte Sdaben verminoert befien Werth oft um ein Drittbeil, uno ift zugleid) Uriadje unjäbliger in feinen Nadtömmlingen berwortretenter llebel; uno gerabe biez ift einez ber bauptfäd)lidyfen binterniffe, die fidy ber Berebelung rer amerifanifden Sferbe entgegenftellen, wäbrent, nad) ben Zeugniffen europäifjer Ibierärjte, in Guropa nody viel mebr unbeil in oiejer Ridutung aus cicjer Suelle entipringt.

Selten mur wiro ber Mutterftute oder bem Foblen yon ben Far= mern eine fowobl jur Beförterung iGrer (3ejuntbeit zuträglide, als ben Sntereflen Ies Befigers entppredsente Bebandung zu Ibeil, uno bie Entfräftung, Reicen uno Rranfbeiten oer Tlyiere, rie burd idylectste

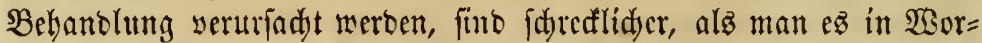
ten aug̉jurrüten sermag; senn man barf treift fagen, sap etwa fieben Bebntel aller Hebel, yon senen saz Pfero in civilifirten Rän= Dern befallen wirs, entweser mittelbar ober unmittelbar bie Früctste ber $\mathfrak{B}$ ernadjläffigung uno Brutalität oer Mienjduen fint. Mandje elenbe, abgemagerte Fullen würoen fett, gejuno, gut entwidelt uno mutbig geworben fein, Gätte man auf bie Mutterfute während ocr Irädtigfeit bie erforoerlidye Eorgfalt verwenbet. WSie viele fdyöne Füllen werben für iły ganzez Rebenlang serfrüppelt ooer wenigitent theilmeife in ifrem werth geidmmälert ourdy bie ifnen orer ter Etute zugefügten Mighandlungen! Uno wie viele nüblidue Pfertse werben ourd) bie gleidje Urjadye in cinten fdyledsten 3uftano gefradyt, yon oem fie fid nur fetr langlam erbolen!

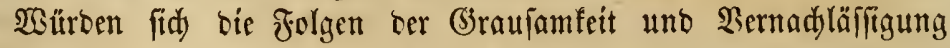
allein auf bą betreffenoe Ibier bezieben, fo bätten wir mandje unferer $\mathfrak{B}$ orwürfe zurülfhalten mögen; biez ift jeoody nidyt ber Fall, Denn bie $\mathfrak{B}$ irfungen ber Mighbanolung erftrecten fich oft nidyt nur auf bie gange Rebensizeit bes Míbhanbelten, fonbern aud aud auf Deffen 2rbfömmlinge. Wirb sie Mutterftute wäbrento ber Trädtig= feit brutal uno graujam bebanoelt, fo ift ibr Foblen ein fduädyli=

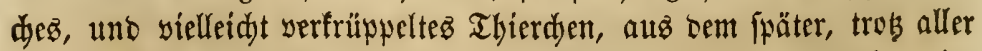
barauf werwanbten Pflege, nie ein eblez Pfero wirt. Somit wirb 
bie Race, anftatt fortwälyend yerebelt, ftetig, fo zu fagen, veridjled)= tert. Erft nad) Sabren uno Generationen famn unter ben günftig= fiten 1 miftänoen ber basurd) yerurjadyte Sdjaben ausgeglidjen werben.

Sncem wir nut cine $\mathfrak{i t n} \mathfrak{z} a \mathfrak{b l}$ ber allgemeinften Mif́bräudje an=

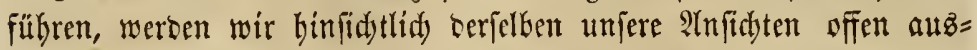
ipredyen uno nidyt verbeblen, für biejelleen (Srünte anzuführen.

\section{uebermä íges $\mathfrak{A}$ r beiten.}

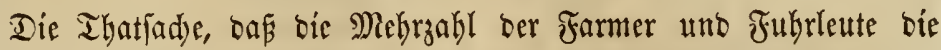

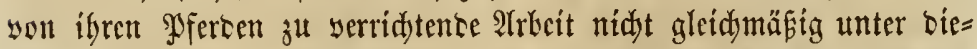
jelben yertbeilen, ift befrembent. Man fintet eben fo oft ein jdina=

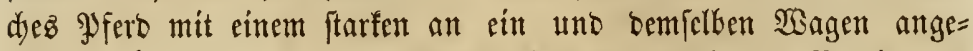

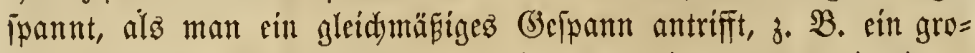

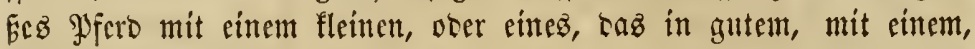
weldjes in idyledtem Stano ift.

EGen fo menig beaditet man baz (bewidyt ber Rabung ober ben

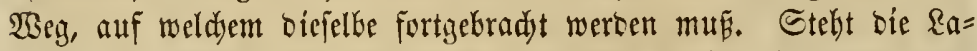

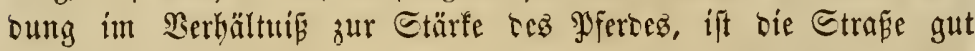
ober idyled)t, bergig ocer etern, mun man burd) Iteferfelo fahren voer faum sic Randftrafe benübt werten? Diefe uno äfnllidje Fra gen follten geftellt unt beantwortet werten. Wie oft aher gefdjebt biefez? "Recidte Rabung uno idnelle Fahrten," riejer beadtens=

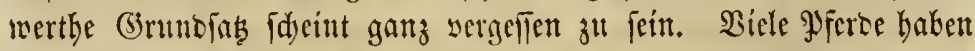
fid) burdy übermäßige 2tufterngung ruinirt, intem fid bie Folgen

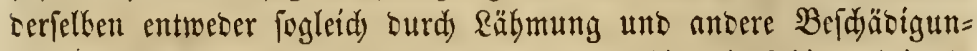
gen oter fpäter ourdy Entfräftung ăuperte, biz bie Thiere beinabe werthlos waren.

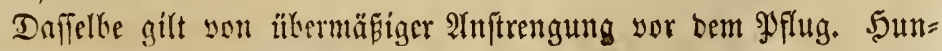

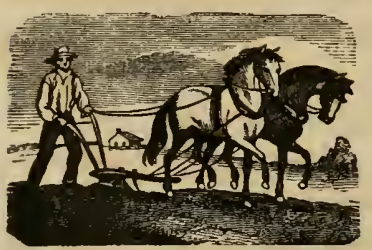
Derte mal baben wir cin flcinez Pferb

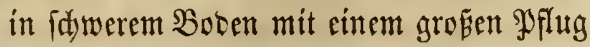
Hfliigen ichen, währeno zur $\mathfrak{B}$ erridbtung

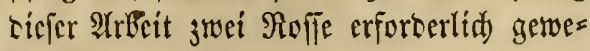
fen wären, unt namentlid fann man ber= gleid)en bäufig im Eüben, wo beinahe

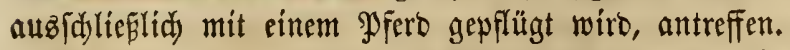

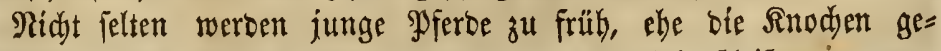
bärtet unt bie (J)lente feft geworben fino, ju Dienfiteifungen ver= 
want. Wirto bem jungen Thiere, weldyes feine solle Rraft unt

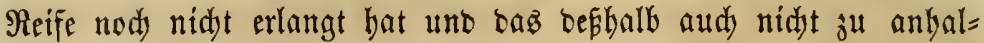
tenten beftigen $\mathfrak{A n f t r e n g u n g e n ~ f a ̈ b i g ~ i f t , ~ m e b r ~ a u f g e b u ̈ t o e t , ~ a l s ~ e z ~}$ ju leiften im Stance ift, fo muf fid) ber Cigentbümer barauf gefáft madyen, baj ber geringite Shaben, ben fein Thter nebmen tann, in angeidwollenen Beinen uno Belenfen uno lebenslänglider Steif= beit beftebt. Zwar follte bem Spferbe fobn frübseitig mäpige $\mathfrak{B}_{e}=$ wegung veridyafft werben; fu idweren anjtrengenten $\mathfrak{A}$ rbeiten jollte man ez jebod yor bem vierten Jabr nidjt benïben.

Dor gröpte Diefbraud in biejer Beziebung ifit ter, trädtigen Mäh=

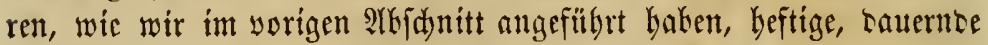
Inftrengungen zuzumutben, senn zwei \&eben auf ein mal zu gefäbr= sen, ift eine foimpflide (3ctwalttbätigfeit.

PSferte, meldye entmeder eitte Beitlang im Stall geftanten ober auf oer Weise gelatfen baben, follten nidyt plöblich, fontern nad) uno nad) zll idwerer Arbeit verwant wersen. Sterủber baben wir ung jeond im fiebenzebnten Rapitel in Iem mit "Bewegung" üter=

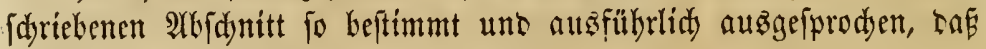
nidytō mebr nötbig ift, alв Len Refer barauf z" verwcifen.

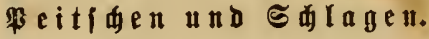

Man folle benfen, bas Pferb habe, ohne tas unjdulbige Spfer

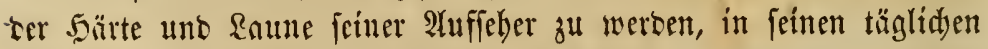
müh[amen Dienflleiftungen genug Strapajen auszubalten; nidbts sefto weniger ift $\mathrm{eB}^{\mathrm{B}}$ erftaunlid, wie bie Thiere oft yon gebanfenlofen ober aud bözwilligen Menfdyen auf'z fdimpflidjite mighbanbelt wer=

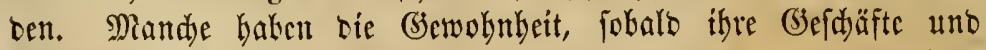
Berridytungen fid nidjt, nady ifrem $\mathfrak{B}$ illen geftalten, ibren Unwillen an bent ftummen, wiberifantlofen Bieb auşula fen. Biele fducinen ç für cinte ber angenclymiten Bergnügungen zu balten, rie besau= ernswerthen Ibiere zu quälen, uno fie fönnen ourdjaus nidyt mí einem Pfero umgeben, obne baffelbe ibre Bosbeit uno Straufamfeit surdy Stöfe, Sd)läge uno anbere Brutalitäten füblen zu laffen.

Gelbft viele befler gefinnte Männer fenten feine anbere Mittel, cin wiberipenftiges Pfero zun (schorjan, ober cin raftlofes zum

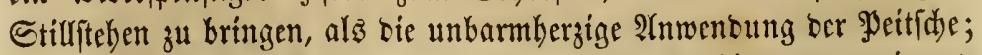
baben aber foldye linmenfdyen, yon benen wir sorbin rebeten irgent 


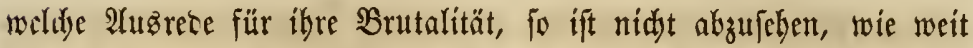
fie mit bem Miffbraud ifrer (siewalt geben werben. Wir baben

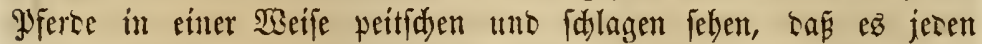
auf menid)lides (sefübl $\mathfrak{T n}$ fprud Madjenten fdausern müste.

Etwa zur 3eit, um weldye wir riefez $\mathfrak{B e r f}$ zu fdreifen anternah= men, fahen wir einen bieker bejüglidsen Fall. Eine junge Stute war mit einem alten $\mathfrak{P}$ fero zum $\mathfrak{A}$ dern verwentet worten, eine $\mathfrak{A} r=$ leit, bie fie burdjaus nid)t gemohnt wat. Jenez war in feinen Bewegungen äuferft langfam, rieje febr fdnell. Sie legte fidh in'z (5) fidyirr, lief rüftig soran uno fdleifte oen fdyeren, für zwei gyferte beftimnten Pflug beinabe allcin, biz ilyte Rräfte nadiliefen unt fie eine 3eit lang aus Erídoppfung fid weigerte, yorwärts ju geben. Finer ber Itafers̆leute, über sie sermeintlide Störrigfeit bes berau-

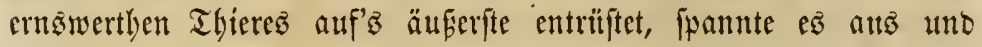

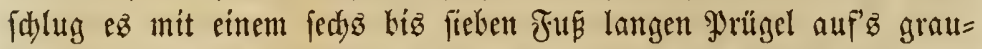

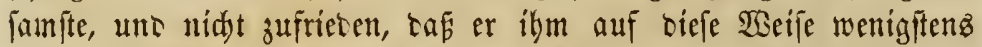
lumbert Edyläge werfebte, ftief́ er es nod wobl fünfjig mal mit feinen mit fdweren Etiefeln bewaffneten Füpen. Die Maăbre batte (đ) on längere Beit ben Paarungsimftinft geäufert (in season, Rauf= jeit) แno war, wie alle Etuten unter nämlidyen Berbältnif|en viel= leid)t befonserş wiserfäultig; jesod) ser brutale Serl fannte rie befonderen Itmftänbe nid)t, nod) befümmerte er fid carum. Das SFfero hatte aus Reibeşfräften gearbeitet, unb oer Fehler lag weniger ât ifm, als in ten Unt|tant, baf́

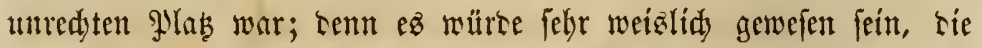
Etute zu biejer Beit entweber yon ber Arbeit ju befreien ober fie

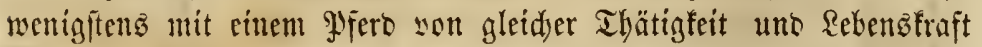
jufammen ju fpannen. Sene foredfidse Misfbandlung madte oas Thier auf längere Beit für jeglid)e Dienftleiftung untauglid), went $\mathfrak{e z ̇}$ nidyt baburd gänglidi ruinirt wurbe, unb $\mathfrak{e}$ bat nun fdon Monate lang beftän rig abgenommen.

Dergleidyen 2 uftritte fint feincồnegs felten; nein fie fönnen leiter jübrlid kei tauienten gezäblt werten. Nie erbolen fid bie Pferce son ben Wirfungen foldjer Mifbandlungen wollfommen. Wir erin= nern แกะ eines fđönen, jungen Foblens in Tenneflee, weldes, weil คริ unvermögent war, eine fdwere \&abung cinen fteilen Şügel hin= aufzuzieben, unbarmbergig gepeitít murbe. Die grofen, Mannôfinger 


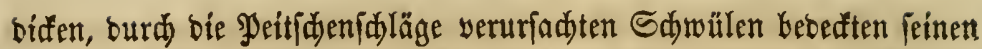
ganzen Rörper. Esz wurbe fehr frant, nahm yon Tag zu Tag ab, bizz ez beinabe werthloz war. Gerabe yor tiejem Borfall war baz junge \$fero für einhundert uno fünfzig Dollars verfauft worben, nad) fed) : Monaten aber würoe Riemano fünfaig bafür gegeben baben.

Biele Sferbe find fapn burd einen plobstid verfesten, ein Rebenz= vrgan treffenten Sajlag getöbtet morben. So $3 . \mathfrak{B}$. erinnern wir

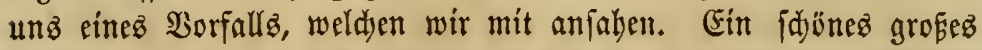
Pfero erbielt einen heftigen Slag gerabe hinters $\$$ hr, und fanf todt

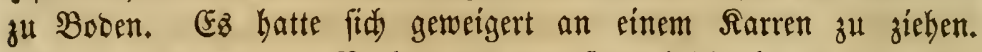

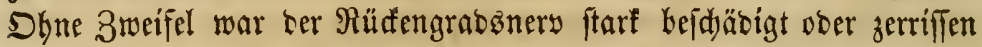
worben - ein traurigez Rejultat, baz burd) einen ভajlag auf baz oberite (Sentofgelent leidt herbeigefülyrt werben mag.

B̉ei ber Züudtigung einer trädttigen Mä̆bre zeigen viele Männer

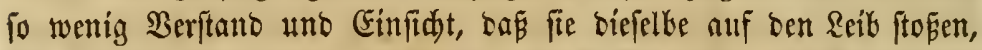

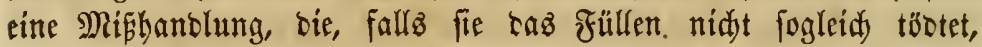
bemielben mehr ober weniger permanenten Sdyaben zufügen wirb.

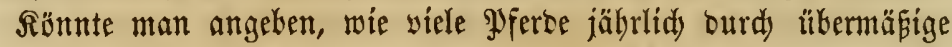
Injttengungen uno graulame 3üd)tigung zu (Srunte geridjtet wer= ben, fo würbe Sebermann Larob ftaunen; jebenfallz beläuft fid ber baburd bem Ranbe verurjadjte $\mathfrak{B}$ erluft auf Gunberttaufente Dollarz.

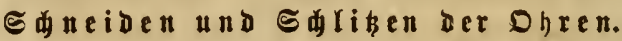

Diefer unfinnige uno graujame (jebraud wiro glüaflidjerweife

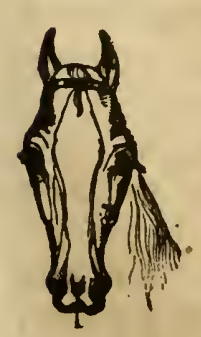
nur nod) felten atägeübt unt geräth immer mehr in fduledjen Ruf. Dod gab eż eine 3eit, zu welder jeres

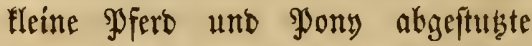
ober bejdnittene Dhren hatte. (5)e= genwärtig aber fieft man foldde Thiere nur nody felten.

Der angeblidje Zmeaf biefer Ber=

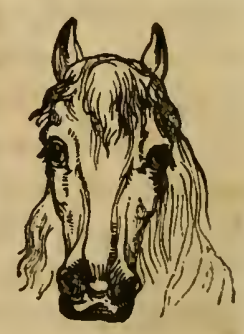

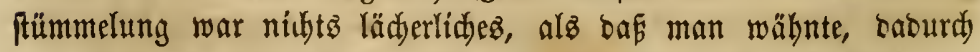

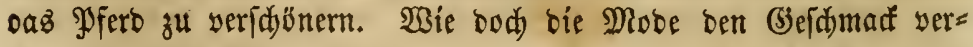
berben fann! Mandye Farmer find yon ber Sudjt befallen, allen ibren Saustgieren bie Shren zu befdneiben. Die bez Sunbez 
mu็ffen turz zugeftubt fein; weber bie bebauernsiwerthe Sd)efe, nod ber gebulbige Dab werben verijont, und bie Dhren fer Edweine

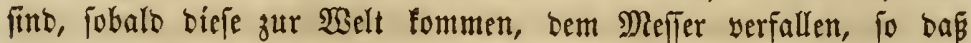
ibr Ropf, fallz fie fich ein fdweinifdes Bergnügen in einer Pfübe madjen wollen, ja feinterlei Sdy gegen ren Edyumb batse.

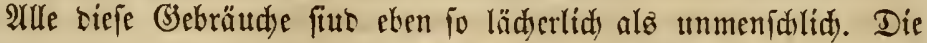
Ratur bat bie Thiere mit Diefen Drganen auggerü= ftet, saunit oer innere Theil bes Dhrz ธaburd gefdubt uno mittelft berfelben Flie= gen, Staub u. f. w. fern= gebalten werten; was aber nod) widtiger ift als cies, ift ter llmftand, tá rie

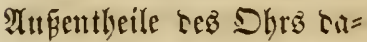
zน rienen, ben Sdjall auf= zufangen unt alfo zum

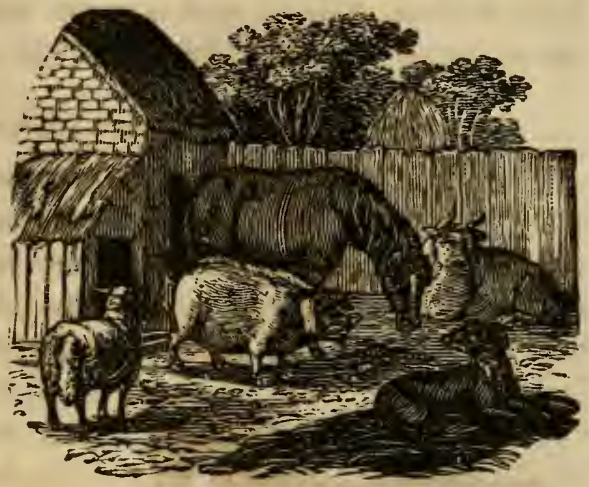
bören" exforterlid) fint. Wenn man alfo rie ftummen 5auşthiere,

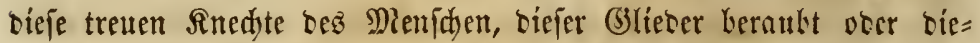
felben yeritümmelt, fo becinträdytigt man rag (5)hör uno febt cie Dhrtrommel (tympanum), biefe feine, empfinclide 5aut mebr ober wentiger ber Rälte, nafier Sittertug, Etattb, Fliegen น. F. m. aแz,

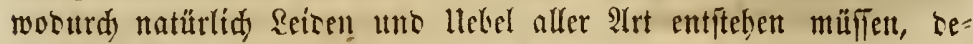
ren Serteifübrung eine ganz tno gar unterufene ift.

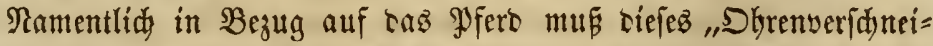
ben" als ein ganz gejdmadtofes Berfahren, nidhts zแ fagen yon ser babei auछggeübten Giraulam= feit, bezeidnet werben. Ií Shren gebören zu feinem idjön= ften Sdumtaf. Shre veridie= benen Stellungen zeigen reffen Mbfidten uno Temperament beutlid) an; find fie nad) $\mathfrak{B o r}=$ märtż geridjtet, fo beuten fie auf Heberrajaung ober Sdured;

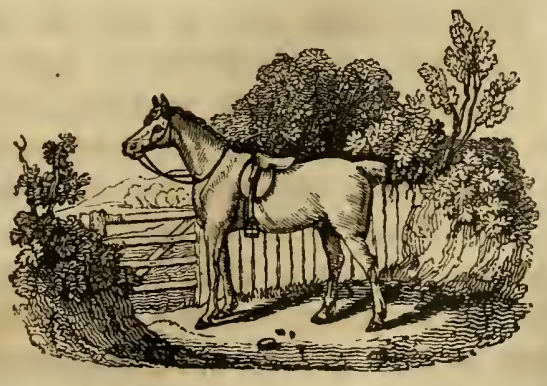

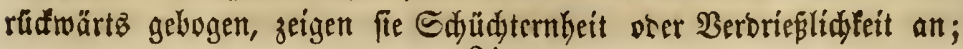


merben fie aber ganz zurüd, auf bas G3enid gelegt, fo bebeutet biez

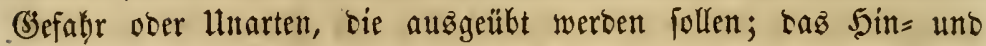
Setbewegen berjelben zeigt Willigfeit uno (5eboriam an, uno wenn • fie zu beiben Seiten berabbängen, fo ift taz \$fero entweber febr

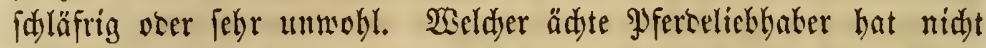

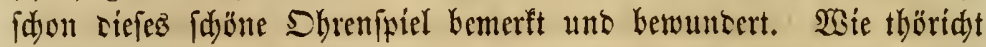
ift es resbalb, biejes Srgan entweber auf bie bier angegebene, ober bie im adyten Rapitel beidyriebene Weife zu serunftalten.

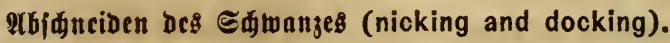

Die Mote ift in ser That ein graujamer, berglojer Iyrann; uno riez ift wabr, ob bas Spfer berfelben zur menidhliden Familie orer zu sen Ilieren gehört. Fg giebt aud) beutzutage in umjerem sanbe nod) Stuber, die in rem :Babn befangen fino, baf alleż, waz fie benügen, yon ben son andern gebrauditen Dingen fid unterfdeiren

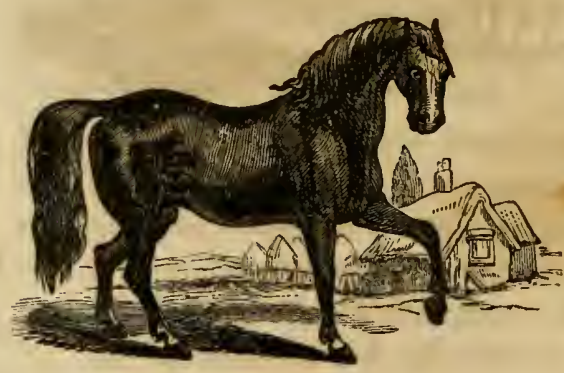
müffe. Shrer alkernen Mei= numg, (notion) nad) bat ter weife Sdyopper nidytz redyt geidaffen, wenigitens nidyt foldes inz Reben gerufen, was ibrem Befdomad ange= meffen ift. Sie wollen besi= balb an ben sollonmenten Rreaturen $\mathfrak{B e r b e f f e r u n g e n ~ a n = ~}$ bringen, fowie fte ithen yon ibren launigen Einfüllen ober ihrem franfbaften (3efdymad cingegeben werben, uno beghalb plagen fie tie unglüaflidyen in ibre Sänte fallenten Thiere beftünoig.

Ier Ifumädytige fand obne Shren uno bie. Pferte mit furgen Sdweifen ju fdaffen, uno

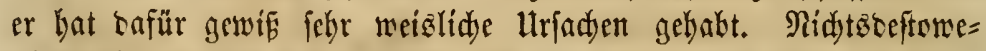
niger aber mollen ricie "ভd)öpfunguerbefferer" weifer fein als Gott uno sergnügen fid unter anterem aud tamit, in graujamer 2scife Die Edwänze ter Pferbe abufdunciten, uno zwar ift man nidyt $r a=$ mit zufrichen, einen Theil rerfelben zu entferten, fo saf sab Thier beinabe gar feinen (s)ebraud von feinem Sdjmeif madyen fann, fon= bern ser übrig gebliebene "ऽdymanjftumpen" wirb aud) nod) an veridjie: benen Stellen bermafen geldnitten, sap sie Musfeln, mittelft teren 
ber Shweif auf= uno abgebohen werten fant, für immer zerftört

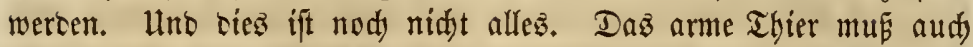
nod) mit an bem Sdyweifbar aufgebuntenem Sdyanj fiteben, tutb

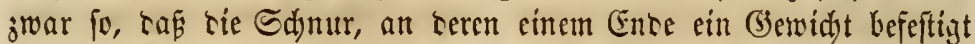
ift, liber eine an ser Deffe angebradjte Rolle läuft, worurdy bas ser=

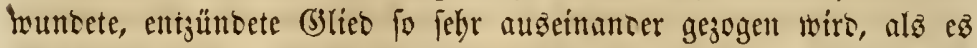
rie Snodhen zu ertragen im Stante fino; und in biefer Stellunis,

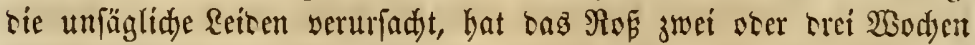
ơ verbleitert.

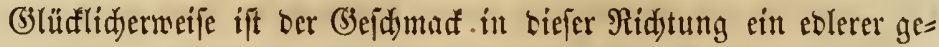

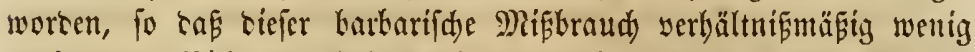
vorfommt. Nid)t nur baben fid serftänoige uno gefüblvolfe Mä̈nner son foldyer Berfintumlung mit Miserwillen abgewanot, fonbern bie= felbe wiro gegenwärtig felbit felten yon unjern Startitusern verlangt. Auf tem Rante ift weter nicking nod) docking gebräud)lid, unb wir boffen, sap bie Beit nidyt ferne ift, in ber man fid keiber nur

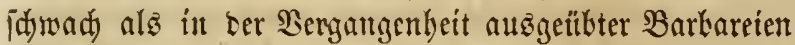
crinnert. Shren, Mähne, Borberbaar, Sdyweif, alles riejes geböt jum Sdymuf tes Pfertes uno an feinem serjelben fann tie Raume bes Micniden eine wirflidye

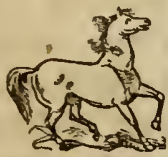
Berbefferung antringen.

\section{פEettrennen (racing).}

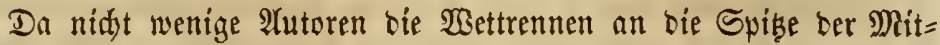
tel, weldye fie zum 3wefe ber Pferbevereblung auffiellen, gepebt baben, to witro ez viclen unferer \&ejer auffallent erjoeinen, biejelben

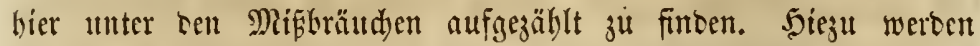
mir jecody weber surd) eitlez Streben nad) Sriginalität, nody ourd' Raume, fonbern burd tie fefte Hebergeugung veranlafit, tafi bie Wett= rennen zu ten gröften uno nadytbriligften Mifbräudjen gebören, te= nen bie Pferte in unferm Tagen aubzefeţt fint.

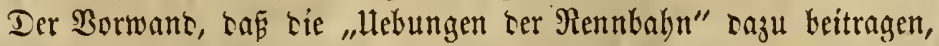

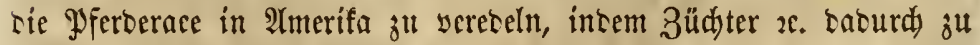
grö̈̈eren Anftrengungen angefpomt werten, berubt auf einem grofien Grrthum, benn biejer Sdyeinbemeis entbält - wenigitenz fann man

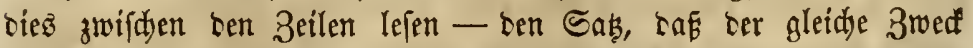
entweber gar nidht, ober cod grögtentheilas nidyt auf anbere Weife 


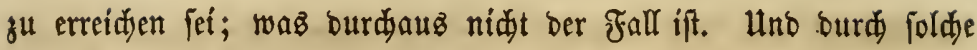
Durdyaus nidyt fídjfaltige Bemeife will man einen Uebelftano bers theitrigen, welder, yon anterem gänzlid) abgeieben, die unausbleib=

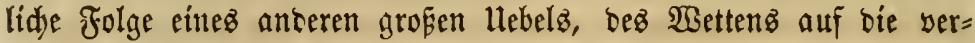
fuiebenen $\mathfrak{B e t}=\Re e n n p f e r b e$ ift.

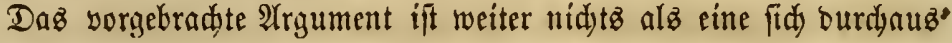
auf feinerlei Thatfadyen zu gründenbe Behauptung. WSir fino über=

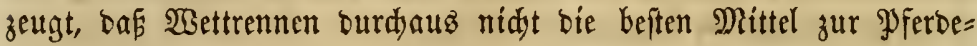
racenvereslung fino, uno glnuben, bap jeber benfente fittlidye Mann allez möglidue zur Bejeitigung oiefez Mípbraudz thun follte.

"Alber," - fagen bie Bertheibiger ber $\mathfrak{B e t t r e n n e n , - ~ " S p o r t s m e n ~}$ (Epieler von Profeffion; hier: Reute, bie fid) mit ter 3udt biefer Rennbafupferbe abgeben, um atz itnen (berwinn zu zieben) baben

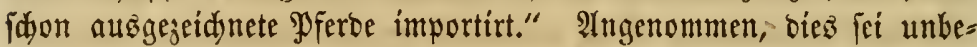
ftreitbar wabr, fo ift anoerfeits aud wiecer getwif, ons auf cin edlez,

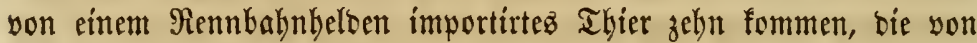
Männern eingefülyrt wurten, welde lebiglid) nidjts mit ben Wett= rennen zu thun baben wollen, uno biefelben alz gänzlid serwerflich baritellen. Diefe lesteren unb nidht jene "Spieler" fint eš, die etwa fwei Drittbeile ber auf Rennbabnen gebraudsten Pferce entweder importirt ober gejüdtet baben. Die Rennbahnbelsen Kaben ein au= Berorbentlidje Talent, alle ungewöbnlid fanellen Pferoe ju ermit= teln, uno wo fie immer eins fincen, faufen fie $\mathfrak{e z}$, breffiten $\mathfrak{e z}$ für

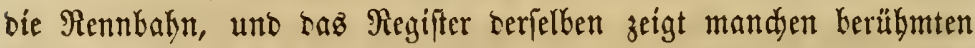
গamen biejez ober jenez Serrn, yon dem gejagt wiro, er habe baz

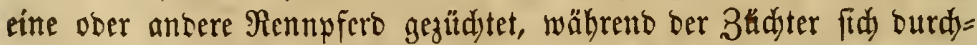
aus nidjt gejdmeidjelt füblt, feinen Namen in foldjer Berbinoung genannt zu Fehen.

(3ileid) allen Spielern baben auty bie Rennbahn=Sportzleute genug

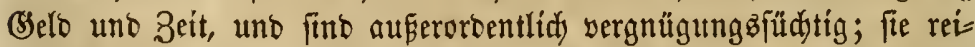
fen viel uno haben bie Belt gefehen. Biele fteken im Dienfte reictjer Seute von ocrielben 3unft uno baben die $\mathfrak{A}$ ufgake, die Farmen oer beften Pferbeghtidter zu befudyen uno bort ben Pferbeftod zu befidtigen. Finben fie thei biefer Hmidjau nun ein jungez Pferb, weldez ver=

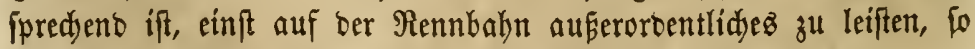
wiro $e$ fo fogleid aufgefauft uno fürz Bettrennen breffirt.

Wir find in ben lebsten zwanzíg Gabren mit biefer Rlaffe Dens 


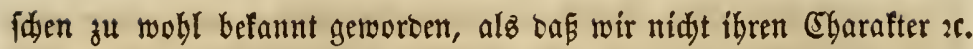
bätten fennen lernen follen. Zu fagen, bá fic ober bie burd fie zu Stance fommenten Settrenten bie Beredlung ber Pferbe beabjidtigen,

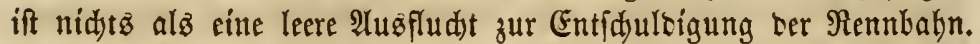
Ridjt (Finer auz hundert biejer Männer benft an bie Beredlung ber Pferoe; nod) fint fie eintes folden (bedantenz fäbig. WSaz fragen fie

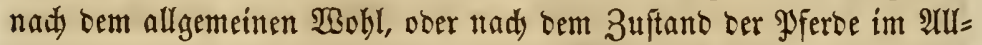
gemeinen, wenn fie nur einen guten Renner finten, ihn auf bis Rennbabn bringen unt auf benfelben wetten fönnen. Die Wett= rennen werten in ihren bänten nidytz anberes als auferortentlid aufregente Spiele, bei Lenen anftatt ber Sarten, Leż Ballż, ber Eroupe u. f. w. baz \$ferb gebraud)t wirb. (5)elb unb nidjtz anderez ift ber bauptfädlidfte 3wed, bas 2 Setten bie Sudt uno Das Spiel

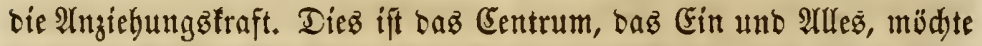
man jagen, bie Seele ter ganzen Rennbahn=24faire, uno würte biejez entfernt, fo fragten jene philanthropifden 5erren wenig Larnadj; ob baz Wettrennen ferner beftünoe ober nidt.

Sdyon Der Cbarafter, Laz Reben, bie Sitten ber meiften Renn= bahnbelden wizeripredyen ter $\mathfrak{A n n a b m e , ~ d a f i ~ f i e ~ b i e ~ \Re a c e n v e r e d l u n g ~}$ zu bezmefien fid beftreben, aufż unwiterlegbarfte. Wer bejudt benn bie 2 Settrennen? Wier kringt fie ju Stante? Ez gejdieht utjerer Beobadtung nad etwa folgentermafen: Srgeno welder Remubabn= Sportzman fentet cinem feiner Mebentubler, welder ebenfallz Renn=

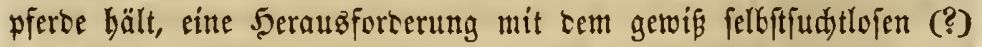

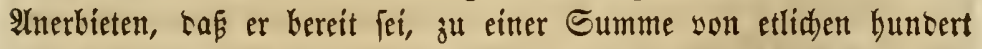
ober taulent Dollarż, bie tem Befiter bez genwinnenten Poerbez ge= geben werben follen, etwas beizutragen. Ilno diefe feine Syerren fint - Fehr unternebmente, wohlthätige uno wadere Epieler yon Yrofeffín, bie fid bie rühmenswerthe 2 Uufgabe gejegt baben, die \$ferberace bez Lanbez zu verebeln! Weld ein preiżwüroigez Unternebłen, weldy Erelmuth, weldje Selbfterleugnung! Sebodh ser gewinnente foll eine [djöne Summe Belo cinfteden, unt vielleidt bringen beibe ibr Sdjäfden inz Trođne. Ahb, baz ift bie Triebfeber, oer gewaltige

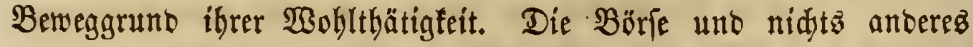

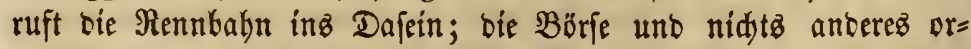
ganifitt baz ganze $\mathfrak{W}$ ettrenu=Unternehmen!

Diefe Sherren, bie fin fo angeftrengt um গgferbevereblung bemüben, 
laffen nun nadj allen Seiten Einlabungen ergeken uno rufen yiele Reute zu[ammen, bie fith am Bettrennen vergnügen follen. Itno nidjt vergeblid); baffelbe loct eine ungeheure Menge 3uidhauer an.

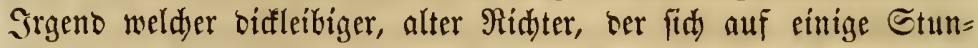
ten won feinem Champagner uno feinem $\mathfrak{x}$ Giffipiel (Rartempiel) loz̉gemunten hat, ift bei siejer bödft widtigen Begebenbeit ber $\mathfrak{B o r}=$ fiber. Rur fold eine widtige Sadje vermag ibn jäbrlid einmal yon feiner \$feife zu trennen utto feime (3)idjt zu vergefien. Iic Spielhöllen ber umliegenten Stäbte fino leer, weil jeber Edurfe,

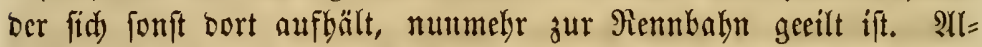
lenthalken wiro gewettet; Riemant, von sem fein gefleireten Stub̧er, ser mit Sunberten uno Taulenten um fid wirft, bis zu sen armen

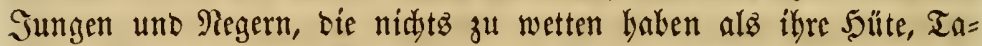

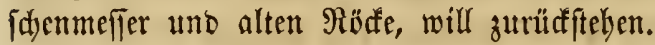

atber bie profeffionellen Epieler madjen unter jener Menge auf ber Rennbahn nur bie Minterheit aus. Atle ETenten ber ganten $\mathfrak{l} m=$ gend find zufammen gefommen. Sebes verrufene 5aub, jece Sauf=

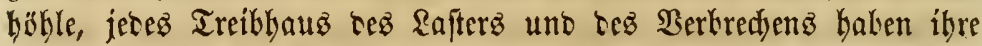
Bertreter geianot. Spieler, groittituirte, Ruppler, Bertrauensัmämues, Iajdentiebe, Edmwintler aller $\mathfrak{A}$ rt, Räuker, Diebe, Ginbred)er unt bergleidjen treffen hier zujammen. Unto ju weldem 3 wed ? Siele

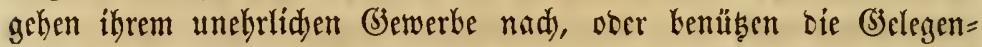
heit, fid alz bie barzuftellen, sie zu sem mto jenem zu gebraud)en feien, währent ber weniger entifttlidyte Zuldyauer feinen anbern 3 weaf hat, als zwei ooer mebrere ftumme, Ketauernstwerthe Thiere auf einer zwei veer brei Meilen langen $\mathfrak{B a b}$ - waz aud) bie Folaen uno $\mathfrak{B}_{e}=$ \{däbigungen hierson fein mögen-aufz äuşerfte angetrieben, zau fehen

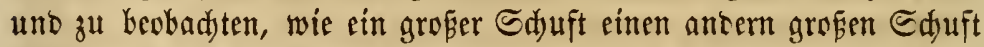
plüntert, weld) lesterer wieberum einen andern grofen, minter fajarf= finnigen Sduft um bie Summe beidimintelt bat, bie er bem erften abgeben muई

Die immer mebr zunehmende $\mathfrak{A}$ ufregung ift ungeheuer, und viele erfolgreidy Wettente ideinen nur teşbalb gewomen zul baken, um ben Tafdjentieben bie Beutel zu füllen. Stemit aker entigt ter

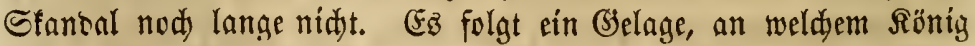
Alffobol bas Scepter fülyrt uno viele Berebrer fintet. Die luftige Menge ladjt uno trinft uno madjt Wiłze; bie Bedjer (djäumen uno 
Die Ropfe werten umnebelt. Tlle Sdumergen uno Sorgen find ver= geflen, fo lang Das "(3)clo circulirt uno oer Ednapps überfliept." Entlid) fängt eín cayaliemmäpiger Sauforuber Speftafel unto Etreit an, weldyer vielleidjt mit einem Moro entiget unb - ter Borbang

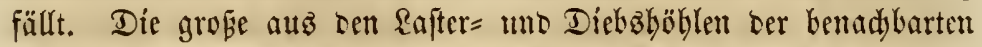

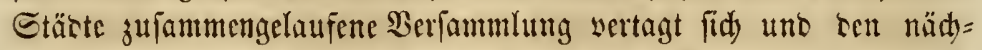
ften Tag werben it allen Beitungen die Sisuner uno Errungen=

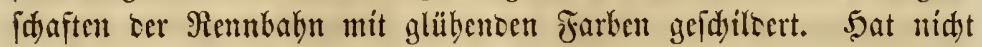

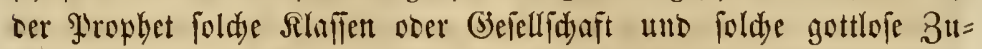
fammenfünfte in $\mathfrak{A}$ uge gebabt, alz er jene erniten Worte nicces= farieb: „Ilno baben Sarfen, Paalter, Paufen, PJeifen tmo Wein

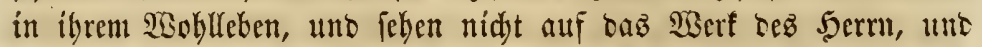

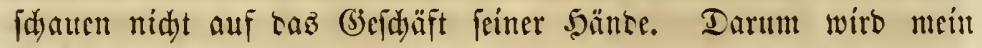
Bolf müfịen weggeführt wereen unveriebeng, uno werben feine Serr= lidyen Sunger leiben mo fein Pobbel Durft leiten."

Bielleidyt ift baz im vorbergebenten Bill, fallz anyewant werten follte, etwas grelf gejeidjnet; jetod) müf|en wir cntfdiesen gegen alle wettrennen Einfpradye einlegen, onn fie fint

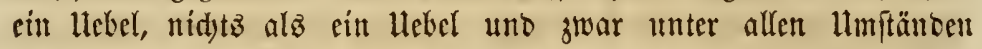
uno immer cin llefel. Die Remnbahn oarf wohl alo eine antere Art Spielbölle bezeidynet werten. Wie bereitz gelagt, ser Finwant, daf weranftaltcte Settrennen zur Pferceyerebelung beitragen, ift ganj uno gar falid, uno wenn nidyt zur Erreidyung biefez 3weffez er= folgreidsere Mittel angewenbet wäroen, fo bätten wir nur febr soenig

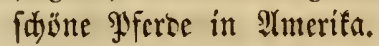

Rennbahnpferbe find bem Farmer nidjt nüblidy. "Er bat feinerlei

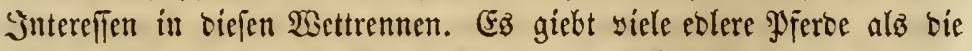
fino, weld)e man in oer Rennbafin finbet. Wie verbält es fid benn

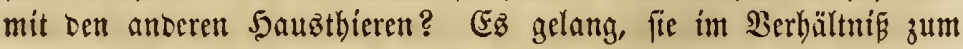
Pferbe viel mebr zu yerebeln als bicfez, uno zwar obne fo aupier=

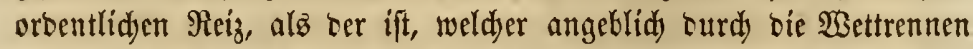
veranlafit witt. Intelligente, unternebutenbe Serren (uno beren 3abl ift nidt gering) haben idönes Rinbvieb, Sdjafe uno Sdjweine im= portirt, weldye Thiere beutzutage bezüglid) ber betreffenben wäniduens=

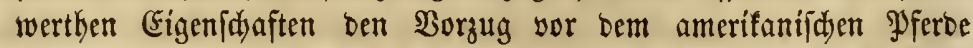
baben. Sa man mag fid wobl bie Frage ftellen, ob uniere Roffe ridht langlam aber befto gewiffer von Jabr zu Jabr mebr aubarten; 


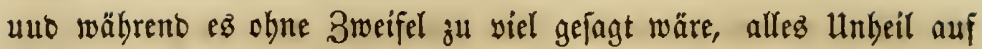
Redunung ber Rennbahnen ju idyreiben, fo fonn nidyt geläugnet werben, baj fie vieles berielben verurfad)en.

Sein Pfert, weldes einen zwei bis orei Meílen langen $\mathfrak{W e g}$ auf'в alleräuferfte angetrieben wirb, fann nadher als Foblentergeuger ju$^{4}=$ yerläjifg fein, benn bei foldem Rennen werben yon ben \$üften tie beftigiten 2Injtrengungen geforbert unt biejellen bebefen bie Зeu= gungöorgane, weldye vielleidyt bei jebem Sisettrenten geftört unt be= idäbigt werben, uno an ben ergeugten Foblen fino bie folgen ber Samenftörungen, welden ber Sengft ausgejest gerefen, beutlid wabr= junebmen. Arlz eitte Regel Larf, fo weit unjere Beobadtungen ge= ben, aufgeftellt werten, bá gegen ben auf ber Rennbabn benübten Sengft zu Bejbälz̧weden unter allen alloem bie alletmeiften Gin= wenoungen zu erbeben finb. Mag er audy yon cer erelften Plbitam= mung fein, fein Arbfömmling wiro faum je feine Eigenid)aften erben, uno neun aus zehn ber von ifm ergeugten Foblen werben bezüglid oer Sualität weit unter ibm fteken. Die THzabl fdylotteriger,

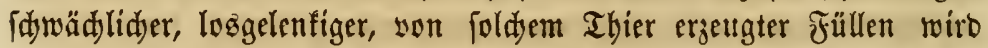
jecen, weldyer einige Beobadtungen anfellt, in Staunen fetsen.

Die Befeitigung biefer Uebel watroe menigitens theilweije au Stante fommen, ftünte nidt eine Edyierigfeit im $\mathfrak{B e g e}$ unb biefe

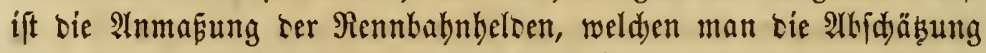

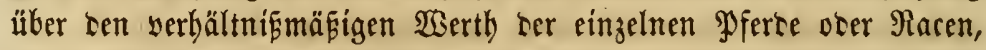
io zu fagen, burd ftillidweigente Hebereinftimmung faft allgemein

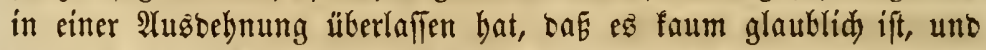
Daf́ aus biefem Umftano Sdaben entiteben muf́, liegt auf ser Sand. Diefe Reute finto unfäbige uno unwüroige Riduter, unt, menn man bie Wabrbeit fagen wifl, siejer $\mathfrak{A}$ Wfgabe surdjaus nidt gerwadjen. 'Sürben fie nidyt im Sisege geftanten baben, fo bätten andere, beflere, von exleren (Stunbjäben geleitete Männer es unter= nommen, bie nöthigen Dualificationen ebler Pferte bam Bolfe beut= lid) zu maden, uno würben für bie $\mathfrak{B e r e b e l u n g ~ b e r ~ a m e r i f a n i f d e n ~}$ Pferberace viel mebr gethan baben, als biz jegt geidefen ift.

Jebod wurte in biejer Ridutung auf ebrlidem, gefeblidem $\mathfrak{W e g e}$ bereitz febr viel geleiftet, uno immer ift man nod) beftrebt, kefieres uno sollommeneres zu ergielen. 2Tuf ben veridiecenen-lantwirtb=

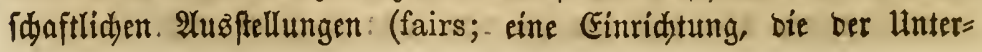




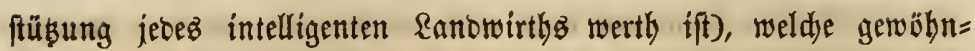

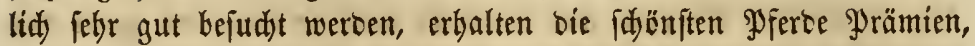
wå bie 3üd)ter ermuntert unb zu erneuten 2 (nffrengungen anjpornt. Settrennen fino heutzutage nidyt melor fo febr beliebt, wie in frü= berer Zeit, eine Beränberung ber sffentlidjen Meinung, bie man nur mít groper foreube begrüßen fann, uno bie zu ber 5offnung bered)tigt, bas bie Rennbalyn, wenn aud) nidyt ganz bejeitigt, in ter 3ufunft nur yon folden bejudte werben wirt, sie feinen 2 nniprud) auf bie $2 d j$ tung reipeftabler Seute madjen fönten.

Die $\mathfrak{B e t t r e n n e n ~ w u r t e n ~ u n z ~ y o n ~ E n g l a n t o , ~ w o ~ f i e ~ a l s ~ e i n e ~} \Re e=$ liquie frülberer barbarifden Zeiten eriftiren, übermadjt, aker felbut bort

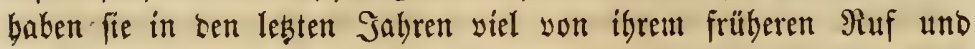

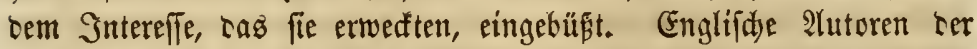
(J)egenwart fübren tie Rennbahn nur alz ben Sportżleuten ge= börento an, tno obgleid) fie alle ein wenig vorfidtig fint, Lamit biefe Serren ja nidjt beleibigt wersen, jo beuten fie bod) inbireft

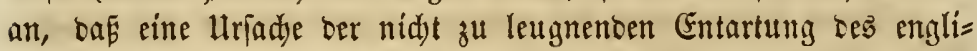
fdjen syferbez in ben $\mathfrak{B e t t r e n n e n ~ g e f u d d t ~ w e r b e n ~ m u ̈ i ा e . ~}$

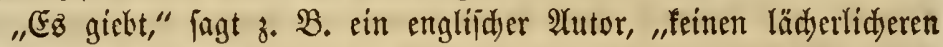
(3ebraud tez englijaen $\mathfrak{B o l f e z}$ als ben, uniere zwei= und Dre $i$ jä hrige n Wferbe zu Mettrennen zu verwenten, ober bie Thiere überbaupt in gebraudyen, ehe ibre (Stlieber uno Gelenfe feft uno ibre Mu\&feln uno Sräfte im Aflgemeinen entwiafelt fint. For= Dern wir yon unfern Rojen zu früh fd)were 2(nftrengungen, fo werben fie nidjt ben fedjfen Theil io alt werben alz baz lestgese maunte 9Jfero" (baflelbe wurbe zweiunofedysoig Jabre alt).

Atudy in unjerm Rante werben beinabe alle Remnpferbe ju jung

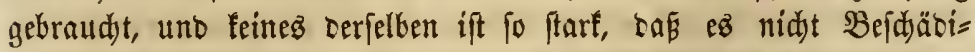
gungen erlitte, weldye ez für Bttdity wede weniger werthwoll, wenn nidyt gar untauglid) madt. Dẩ Daffelbe aud) in Englano ter

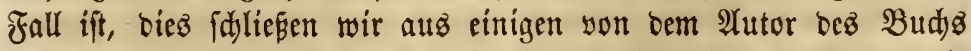
"Daß Thierreide" (Animal Kingdom) gemaditen Bemerfungen, wel= der zwar binfidytlid) ber $\mathfrak{A}$ uffinoung ber Urfaden biefer Entartung etroaz zu zögern fdheint. Ueber leģtere (bie Entartung) jagt er: "Ez barf wohl angenommen werben, bas in jebem Sahrzebnt in Englano: mehr $\mathfrak{P f e r b e}$ fertben alz in irgeno einem andern Rano in zelyn Mal fo langer. Zeit, Felogüge ausgenummen." Daz englifd) 


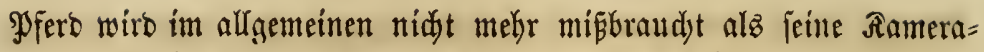
ben im übrigen Europa, und vielleidyt nidjt fo viel; es gíebt be $=$

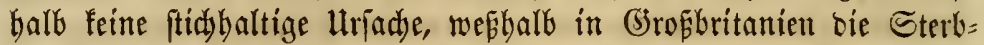
lidffeit unter ben Pferben $u$ mo viel gröfer fein follte, alz anterz = wo, ez fei benn, man beadste ben llmitano, dap cort fdjon won

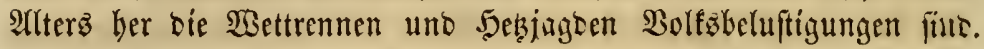
WSenn irgenowo, fo follten in Englano bie vielgepriefenen $\mathfrak{B}$ ortlyeile

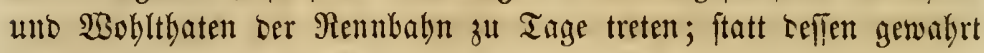
man aber gerabe baz Ge Gegentbeil.

Ein anberer woblbetaunter veterinärifidser Edyrifttiftler Englanta

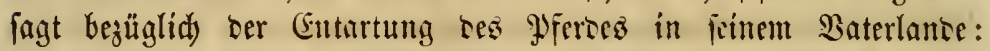

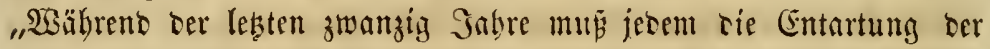
balb= uno 3weibrittelblütigen (one-half and three-parts-bred) zum Berfauf aügebotenen Pferce aufgefallen fein." llno gerabe biefe

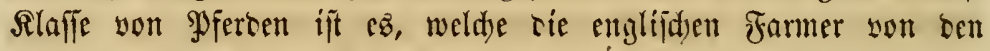

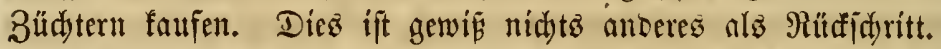

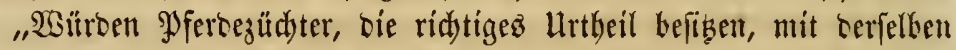
2lufmerffamteit bie Place uno Gejtalt ber zu paarenoen Ibiere beo= badyten, um barnady ibre Mañnabmen zu treffen, wie biez yon Serrn $\mathfrak{B a f e w e l l} b_{e}$ jilglid) feiner Sdjafe geidjah), fo würten fie, wie

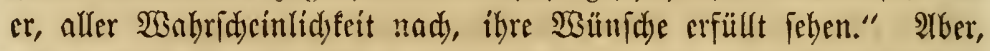

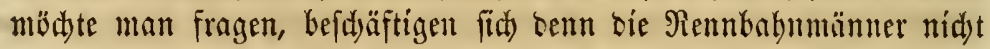
gerabe tamit; ift bies, wie fie sorgeken, nidyt ifgr Fad)? Und sod laffen fie fid) Durd) Den Edyufzitdster übertreffen?"

"Ilnjere Mennpferce," fagt YJouatt, "finto nod) eben fo fdunell als

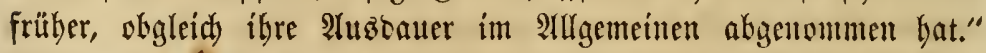

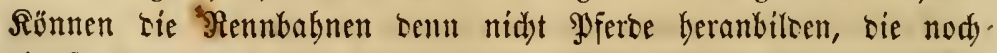
ebenfo aušcauterno fint alż in früherer Zeit? Wenn bież ter fall ifit,

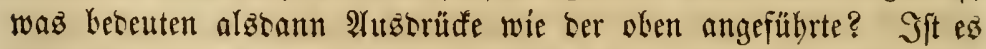
nidut flar, Iaf daz ganze Renubahniyftem, fo weit tie Bercoclung Dez Pferbes in Betradt fommt, nidytz taugt, in ber That eine foldye Sdjante ift, bá fein redytlid) Senfenter Mann bamit verbunden fein fann?

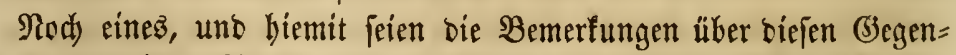

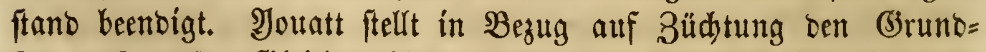

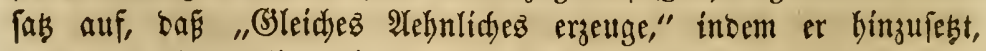
"Dape ber 2 (btömmling bie Dualifieationen entweber im allgemeinen, 
ooer gemijdt, erken würbe." Wie bie Sejer bereits willen, ftimmen wir riejer umfaj|enten Bebauptung ourdjaus nidyt bei. Âtngenom=

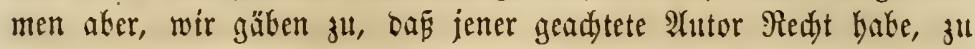
weldyer folgerung, fo fragen wir, mus man notbiwentigerweije fom=

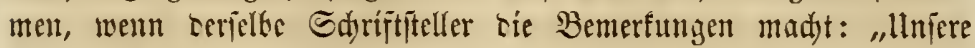
Rennpferte baben fid beceutento sermincert." "llujere Sagt= nno Mietbpferte fino nidht mekr fo gut als frïber;" "unjere 3 ug = แn Ehaifenpferte fino Dagegen werthyoller geworsen." Die "Renner" uno teren $\mathfrak{A}$ ftümmlinge "entarten alio," ibre Zabl wiro "geringer," "fie fino nict)t melyr io gut als frither," wäbrento Pyferbe, bie ju

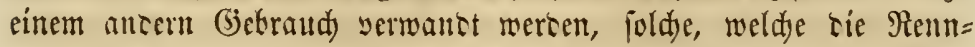
babnbelcen unbeadytet uno bem Farmer "̈berlajen, "wertbyoller" iversen.

3eigt biejer 3ug aแร ber (s)

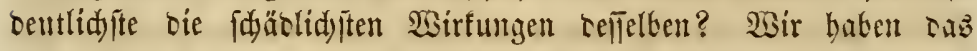

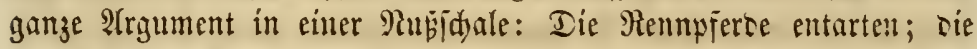
Jarmpferte werben veresclt.

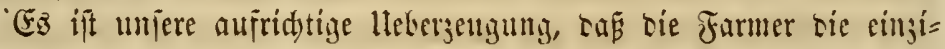
gen im Rante fino, weldic sic erforoerlidye Jutelligenj, lluternet)= mebmungsigeit, sen fittliden Charafter uno Das gebörige PInjeben

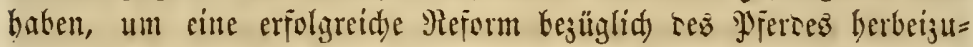
fübren. EB fommt Laber ibnen, als d)araftervollen Männern ju,

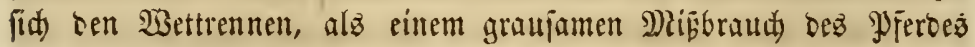
uno feiner $\mathfrak{A} b$ fömmlinge, entidieben entgegenjujesen. 


\section{Z̉wanzigftes}

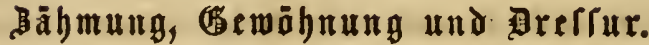

\section{3 å}

Die Beit, in weldjer man mit ber Bäbmung beginnen follte, wire yon ben Poferbegüdyterm felten benübt. Sie baben, wie fie fagen, To viel zu thun, baf fie biefen (befdjäft, ibrer Meinumg nad), un= möglid) bie nothyendige Alufmerffamfeit fajenfen fönnen, unb eż ift Thatjadje, baj nidjt wenige berielten bicjez widjtige Departement

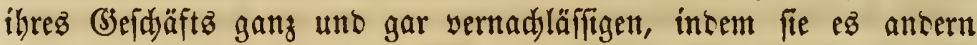

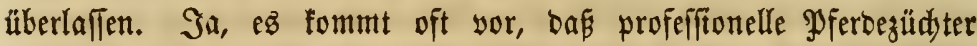
nidjt einmal bas "Ëüttern" ihrer Thiere beauffidjtigen, viel wentiger fid) um bie Zähmung unb (Benwöhnung ifrer Fuüllen befümmern. Soldje Mänter fint für ben widjtígen Berufşżweig, bem fie oblie=

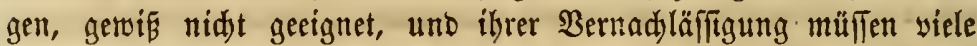
beftelyente Hebel zugeidrieben werben.

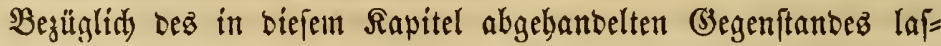

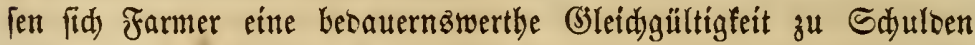
frmmen. Dem F̧üllen täglid Futter, uno einmal wödentlid Salz

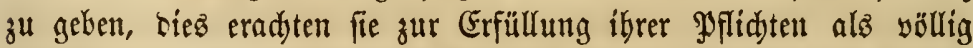
binlänglid, unb befïinmern fid nidyt weiter um bie jungen Thiere, biz fie alt genug fint, um zur arrbeit verrwentoet zu werben, um weld)e 3eit bas Fohlen vielleidyt um zwantig ober breisig Dollarz wentiger bes $\mathfrak{B}$ erthes verfauft wiro, den es einbringen würse, wenn es breffirt wäre. Taufende goferdesüldter verlieren eher jähr= lid) bebeutenbe Summen, alż bá fie fid ber mit ber Dreflur yer= bunbenen Rübe untergiehen.

Selten nur fintet man in unjerm \&anbe einen Mann, bem.ę ermftlid) barum zu thun ift, bie beften Methoben ber PSerbegälgmung 
uno Dreffur fennen zu Iernen. Der gemöbnlidje, wir bätten beí=

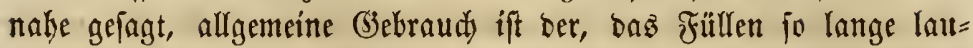
fen żu la|jen, bis man baun, mit einem rubigen, alten \$ferbe zufammengejpannt, auf ein= mal zur Hnterwerfung z̆ zwingen. Diefes Berfahren ift, bab we= nigite gefagt, ein jehr verfehrtes, bas nidft felten tem antern Pferoe, fowie bem Fubrmann gefäbrlid, wiro, nod) błterz aber bas junge Thier befdäbigt. शhud ift bieje Methobe surdjaus teine erfolg= reidye; betn ez fann nur yon wenigen Fohlen, sie auf folde $\mathfrak{M}_{\mathfrak{a}}=$ nier "gervöhnt" fint, gejagt werben, fie feien "gutt" gewoübnt. WSie

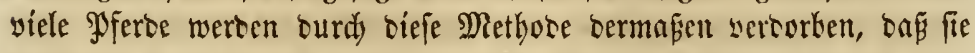
entweber unzuverlaffig voer ganz uno gar für Diemftleiftungen un= tauglid werben! Hno diefe Folgen werben fid gerabe fo lange zei=

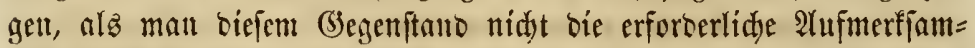

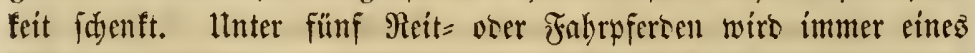
entweber für Reit= ober Fanbrgebraud beim Gemöhnen verborben. Der idrefflidje "Miauliperr=Frall," beffen im fietenten Sapitel er=

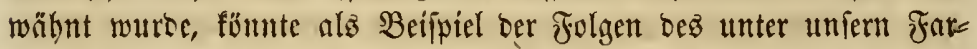
mern fo gewöbnhliden geonenfenlojen $\mathfrak{B} e r f a b r e n z$ aufgeftellt werben.

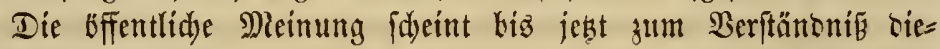
fez (jegenftantez nod) nidjt sorbereitct ju jein, was wohl mehr

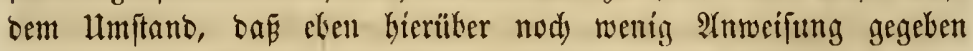

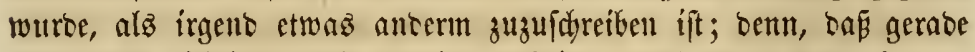
über biefe widjtige Sadje wenige Edjriften worhanden, utto bie vor= banbenen nur theilmeife bem Farmer zugänglich fint, ift cine unbe= ftreitbare Thatiadje. $2 \mathfrak{B a ̈ h r e n}$ ez gar fein Bud giebt, weldjez über

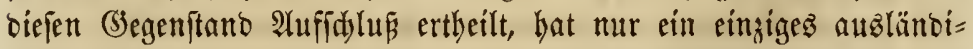

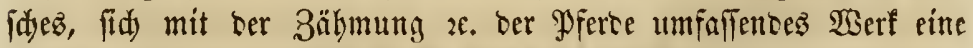

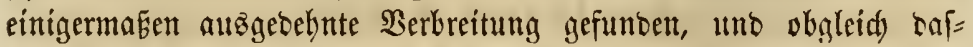
felbe viele wertboulle $\mathfrak{A}$ trweifungen ertheilt, uno in manden Fällent als Slutorität aufgeftellt werben mag, fo papt es tody im alfgemei= nen nidbt für amerifanifdye $\mathfrak{B}$ erbältniffe. In Folge befien bat bei= nahe Jebermann jeine eigene Metbobe, bie fid yon ber aller Rad)= barn unteridyeiset, io baj man vergeblid) nad) einem allgemeinen Syjtem umfieft. Sebod) ift weniger gegen bie vorherridente $\mathfrak{B e r}$ fáiebentheit ber Methooe, alz gegen ben allgemeinen Mangel aller Methode im eigentlidyen Sinn bez Wortez einzumenten. Wrée viele 
Sunberte baben wir angetroffen, bie ber PFerbe $=$ Dreffur aud) nids: bie mintefte 2 uffmerffamfeit fidenften, uno meldye, fallz fie auf bie Widjtigfeit ber Sadje aufmerffam gemadyt wurben, gleidggültig ant= worteten: "Nun - bie alte Weife ijt mir völlig gentigent; fie wurbe in Egren gelyalten, alz id nod) cin Sinabe mar, uno gefällt mir auferorbentlid) gut."

Ecit ben Rebzeiten jenez fabelhaften 2 se wobners" wurbe in ber 5andhabung ber \$yferbe wenig Fortiduritt gemadjt, obwohl, biez fei mit Bergnügen zugeftanten, ba uno bort unternebmente Männer z̆u ibrem uno ber betreffenten Csummunen Bortbeil Reformen angeftrebt uno wohl mudy bezmedt baten. Wee= nige, ober feiner biejer 5erren aber bat jeine Erfahrnengen tor WSelt

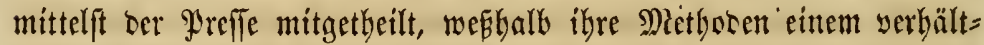

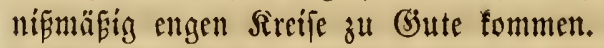

Rönnte man ben burd) unridtige (șewöbnung unt Dreffur bem Rante jährlid) zugefügten Sdjaben in Biffern barftellen, fo würte

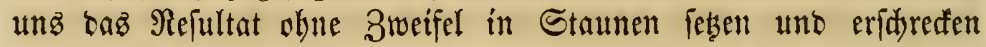

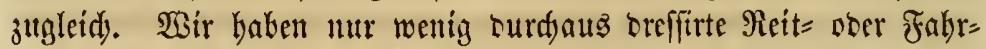
pferbe, utto zwar ift ber Grunto biezu in ber feftgeftellten Thatfadye zu finben, baf man bie für Drefīur geeignetfte Zeit unbenübst vor=

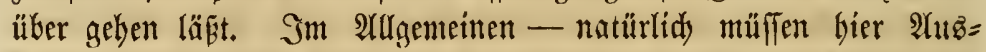
nabmen gemadjt werten - gelten bei ber Dreffitur bez früllens tie

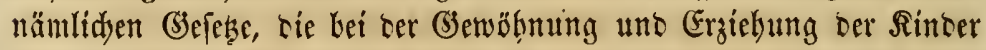
angewanot werben. Uno fo wie bie weifeften Grgieher belyaupten, man fänne mit ber $G_{3} r_{j} i c h u n g$ nie zul früh beginnen, fo ftellen er=

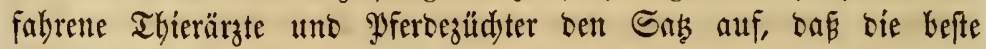

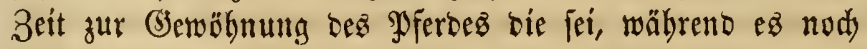

\section{(E) i i}

ift. Man fange fogleidy mit ber Ģewöbnung an uno lafie nidyt fünf Iage nadj bem $\mathfrak{B}$ erfen yorilbergehen, ohne baz junge Thier

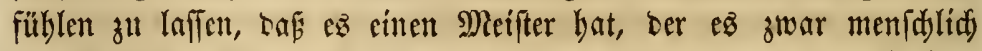
bebrndeln wirs; bem ez aber audj geborjam fein mup. Rie jage man sem Früllen Sdyreden ein uno bod) hat man baffelbe zu con= trolliren. Sier

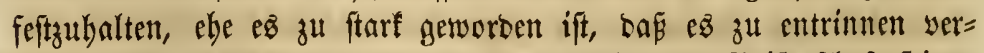
mag. Die Zeit, in welder baß̧ junge Thter oer Meifterfadaft feinç 


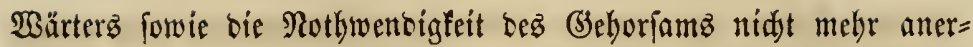
fennt, follte nie fommen. Niemand follte erlaubt merben, Daflelke

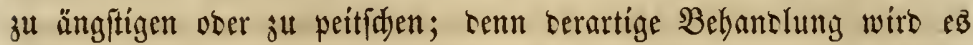

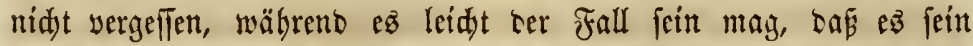

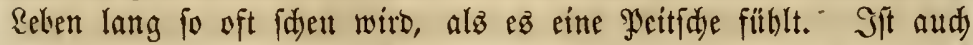

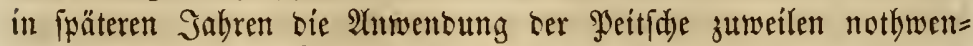
rig, fo follte ein in zartem Âtler ftehentes Foblen gar nidyt wifien, ba

भlle Tage follte man ein jungez Füllen handhaben, anfajien uno mit Iemjelben umgelben, biż alle Edjüdternbeit uno Edjente ver=

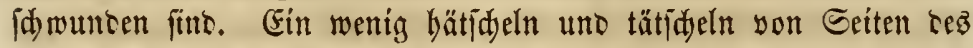
Wärterz wiro bas junge Thier bald febr zutraulid madjen. Das

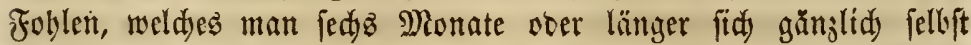
überläfit, ohne temfelben nabe zu fommen, uno daz feinen 5 errm เuนr als einen Ummenjojen fennt, yor bem

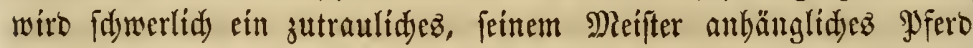

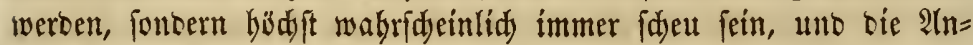
lagen zul allen oft fo roberwärtigen, wenn nidyt gefährlidyen $\mathfrak{u n a t =}$ ten tez Yfertes werten in früber Stgento erzeugt.

Ein midjtiger, aber wie ez fajeint, yon ben Wferbezüdytern unke=

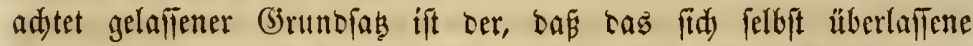

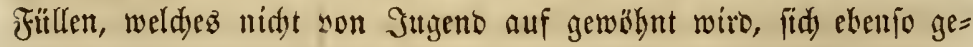

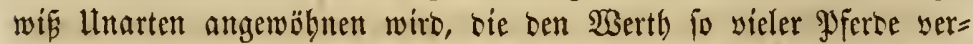

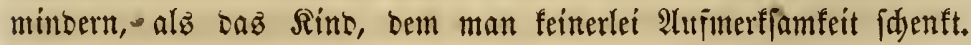

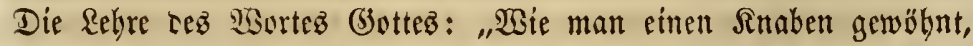

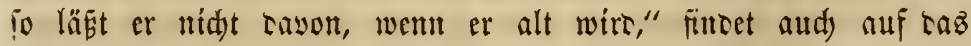

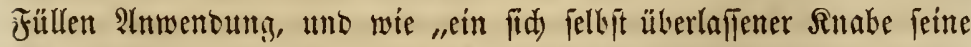
Mutter idjänbet," fo madjt ein fith felleft itberlafiente Foblen feinem berrn Mübe uno sielleidyt vicle ermítlidye Mäbe.

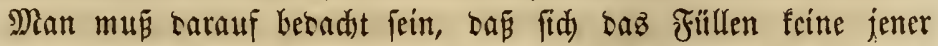
Inarten angerwöhnt, bie fo viele Poferoe werthlos madyen und ruini= :en. Fallz aller Energie barauf hinjuwirfen, bá nidjt feft eingewourgelt finb, unb bas Ibier nodj jung ift, wieder ablegt. Derjentige Pferbełüudter -utto $\mathfrak{B a ̈ r t e r , ~ w e l d j e r ~ n o d y ~ n i d y t ~} g e=$

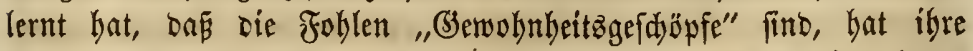
Matur nod) nidjt erfannt, nod) fid bamit befapt, ibre Gigenthüm=- 
lidifeiten fernen zu lernen. Saledyten (Semobnbeiten mun entwe: ber vorgebeugt, ober tiejelben müfien wieber abgelegt werten, unc bier wiro ber Pferdezüdyter hauptfädylidy bie Wabrbeit bes Eprid)=

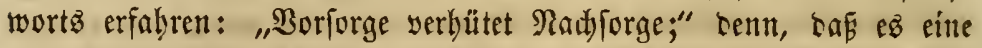

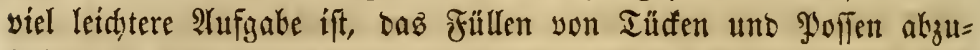
balten, fo

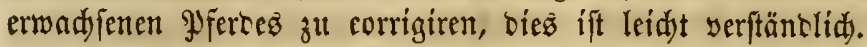

Reinerlei fpäter angewante Mäbe wiro die Bernadyläftgung in ber Jugeno aufrögen. Sowie bie Jugento tie Saatzeit fürs \&eben ift, wäbreno meldaer oer Charafter gebilbet uno Renntnifje gefam melt werben müffen, fo ift โaв "Joblenalter" Ias geeignetfte zur (S)evöbnung uno Dreffur für fünftige Dienftleiftungen. Daz orei= ober vierjährige ungewöbnte uno nidyt trefiftre Pfero ift tem wilten Snaken zu sergleidyen, weldyer nidjt meip, was ez heift, bem Sater (3)boriam zu leiften. Wie fint beice fo unwifient, faul, ftarrföpfig, ungebuloig! Wise ftreben fie fid) wiber alle Regel unb Sinfdrän= fung, fo milo uno vernünftig bielelben aud) fein mögen? Rernen nid) siele, febr viele Pefere die fpäter fo liaftig werbenten Unarten,

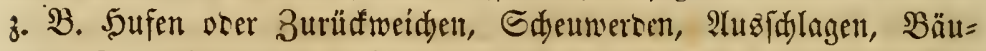
men, Dayonlaufen, Rogreifen, fortwährente Unrube u. f. w., fo lang fie nod jung fino? Der Farmer bejablt für bie Bernadylaffifgung feiner jungen Thiere in ter That theuer.

Seber PJerbezüdter follte ourd) Beobadtungen ermitteln, wofür feine Fưflen am Bejten taugen, ơu welden Dienftleiftungen fie fünf= tig yorgugzineife zu gebraudjen fein retben, uno ift er über bicfen Punft cimmal im Reinen, fo follte fid bab ganze Berfahren bei ber Drefitur uno (Sewöbnung carnad einridten, uno zwar fann bies it

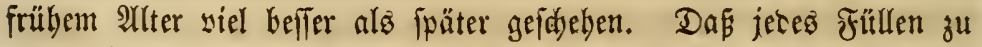
ben Dienjten, zu weldyem es feiner Beidyaffentheit nad) am beften geeignet ift, treffirt und gewöbnt werten fann, bies barf als Regel aufgeftellt werben. Wir mögen feine (berwobnbeiten uno fein Tem= perament bilben utto formiren, feine Bewegungen beberridjen, es (sseborjam uno Unterwerfung lebren unb anthalten, jeben von ibm geforberten Dienft obne meiteres zu leiften. Wer fid bie Diübe rimmt, bas junge Ibier zu belebren uno ju breffiren, ber wiro fid beinabe in allen fällen ein frommes, zakmes, yon Unarten freies SPferd beranzuzichen. 
Sieine (3)elegenteit, bie zur Ģerwäbnung fid bietet, follte man vorübergehen laften, unt biez̧ mögen aud fheinbar wenig beceu=

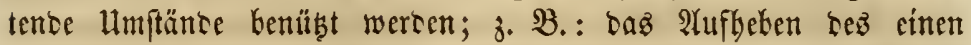

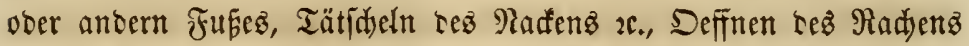

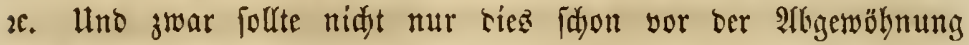
ber Mutterffute atsege zu thun. Man mag ben Zaum fürjer idnallen uno baz (jebín anlegen, nur follte bie Stange cine fleine fein uno nup man bie= felbe jorgfältig bantbaken, bamit feine Bejdäbigung Leß Radjens

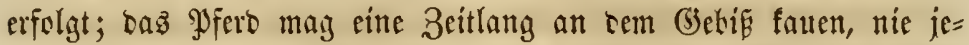
bod) follte es am Zaum berumbefübrt weroen, went ifm terielbe taz erfte Mal angelegt wirc. Sit eimmal etważ gewöbnt, waż nad orei= biż yiermaligem 2tnlegen ber Fall fein wito, fo fann man ez aud) ein wentig berumfübrett, und zwar jetesmal ét wenig länger. Die paar erften Mal follte taz Füllen zur Eeite ser Mutteritute heruntgeführt werben, jocann mag man es ein wenig Ginter uno entlidy eínige Sdyritte sor terjelben bergelyen laffen.

Man barf ein Fiullen nid)t alfufrüh feftbintoen, whs wenn bie Beit ju biefem Theil ser Drefiur gefommen ifi, fo follte man, $\mathfrak{n a}=$ mentlid wenn taż junge Thier allein zu ftelhen hat, eine gute, frarfe

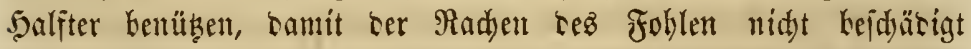
werte. Man fei ifm gegenüher fo gütig unt milte alz möglid,

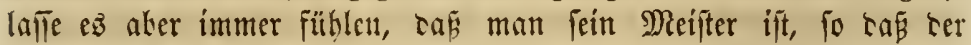

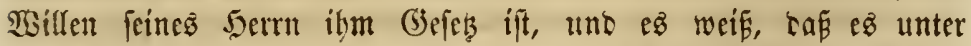

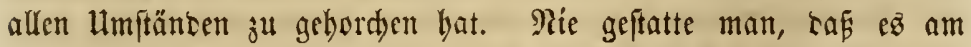

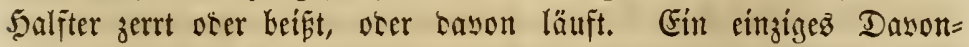
latuen mag heinahe ber Ruín tez Mjertes jein. Secenfallz werben Monate forgamer Mithe zur Berwifidung ber baburd serurjadten

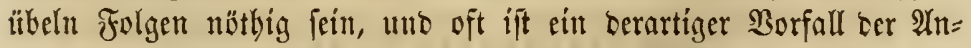

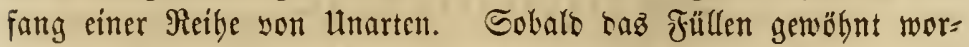

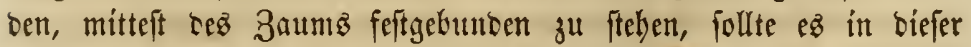
Etellung etwas läırger alş anfänglid verbleiben.

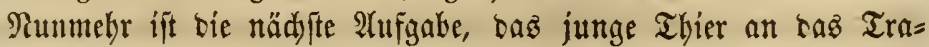
gen bes Sattelż ju getwöbnen, woju ein fleiner gebraudyt werben follte, welden man'leidft uno ruhig auf ben Rüfen legt uno wies = ber abrimmt, obne bie (3)urte zu idinallen, und mit biefem $\mathfrak{B e r f a h}=$ 
ren fo lange fortfäbrt, biz bas Thier feinerlei Furd)t mebr zeigt, in weld)em Fall alzbann bie Sattelgurte befeftigt werben fann. Sft fein fleiner, tem Thiere paffender Sattel yorkanben, to wirb ein

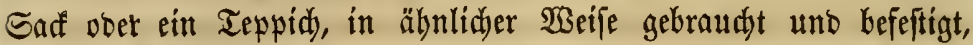
biejelben Dienfte leiften uno beinahe ebenio zwectentiprediento fein.

Derjenige, weldher baz Fohlen füttert, ifít bie geeignete Yoeron, bas

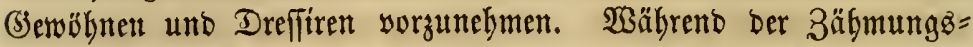

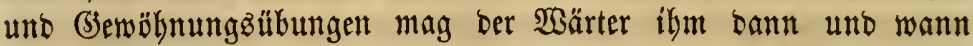
ein Stüfdyen $\mathfrak{B r o t}$ 25. żu freffen geben, wooburdy bag Thier zutrau= líd) wiro uno bemerft, wer ifm etwas gibt, was bie $\mathfrak{A}_{\text {ufgabe fels }}$ erleiátert. Erift bann, wemn bas junge Thier völlig zalym ift, fo bás es fid yor ben Menjdyen burdjaus nidyt melhr fürdjtet uno man es mit ber grösten Freiheit anfaffen uno handbaben $\mathfrak{k} a n n$, ift

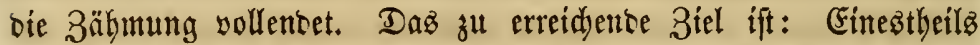
fein ganzes 3utrauen zu gewsinnen uno anoerntheil's, es gleid bar= an zu geswöbnen, augenblíflídyen (bieborjam zu leiften. Sat man

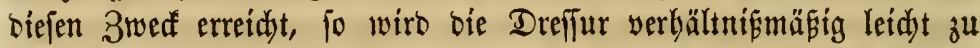
Stanbe gebradyt werben fönnen, und man barf feiner fünftigen Braudjbarfeit verfitdert fein. Daf bie (S)ewb̈hnutg fo oft nidjt ge=

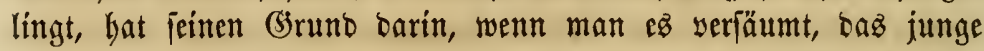

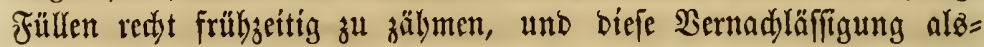
Daun jpäter burch rauke und barte Behandlung aufzutwiegen be=

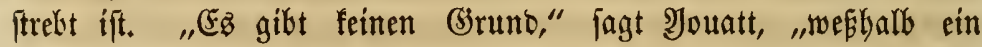
Pferbezüd)ter einen feiner Snedte fo ohne alle Hmitände uno plög = lid) entlaffen follte, als wenn fid berfelbe (Jiraufamfeit ober aud) nur 5ärte unb Raubeit gegen bie jungen IViere zu Sdultoen fom=

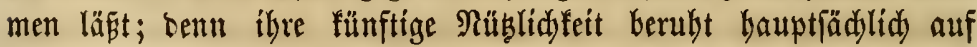

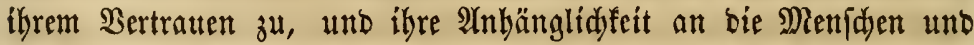
bem barauz berworgebenten, augenbliffliden biekorfam."

\section{2 a cinjäbrige รัoblen.}

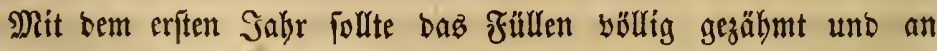
bie Salfter, ben Zaum, den Sattel, forwie die übrigen Theile dez Sperbegeidjirrz gewöknt fein. CEz follte, ob am Salfter ober am Zaum gefühtht, willtig folgen unt, wenn allein ooer mit anteren Pferben irgentwo feftgebunben, ftillftelgen. Sft bieje (sorumblage ge= legt, fo wirb bab, waz beguglid ber Dreffur fernerbin zu thun if, 
obgleid) man nod) mandje Sdywierigfeít zu überwinten haben wirb, in ber natürliden Sronung ber Dinge wie son felbft folgen.

Daz Füullen follte mandymal mit einem alten, rubigen Yjerbe an bie Seite ber $\mathfrak{W a g}$ gentoeidjel feitgebunten merben, wo man es in bie= fer Wseife etwa eine halbe Meeile mitlaufen läp̆t. Sft da einigemal

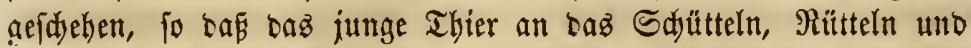

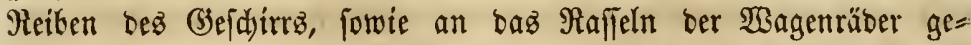
wöhnt ift, fo mag man baz Geipann zu einem leidten Trab auf ebener Strafe antreiben. Durd) foldye Dreffur miro Das Foblen

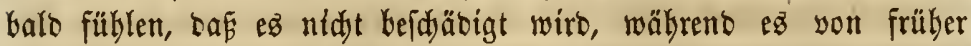

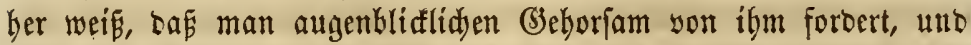
wiro bå Geben unt $\mathfrak{E} a u f e n$ yor bem $\mathfrak{B a g e n}$ als eine feiner Dienft= serridjutugen betrad)ten lermen.

(Elye ez jebod) vor oen Wagen geppamt werben fantn, muk gelekrt werben, fidj burd) bie Bügel leiten zu laffen. Dies fann sm beften gefdeben, intem man bas alte Pferb aus = uno bas junge

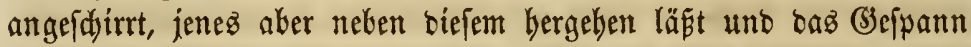
in biefer $\mathfrak{B e i f e}$ cine Zeitlang umbertreibt. Zunäd)ft fann man nún bas alte Pfero logstinben uno mit bem ourdy bie Bügel geleiteten Fillten allein umbertreiben, inbem Semano sormen neben igm ber= geht. Diefe Hebung follte fo lange fortgefegt merben, bis baz junge Thier im (bebraud) 2 . Des (bejdjirs breffirt ift und fid $\mathfrak{n a}=$ mentlidy an bie Reitung ber Zügel gerwöbnt hat. Sit ez in biefer Bieife binlänglid gewöhnt, fo mag man ezs yor ben $\mathfrak{B a g e n}$ fpan= nen, indem man die Deidjeln (shafts) mebreremal vorfidtitg an

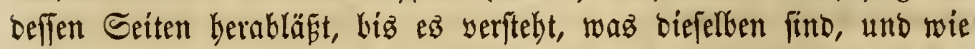
wenig ez Utratde bat, fid yor benfelben zu fürditen.

Soweit gefommen, mag ein Rabriolet ooer S5ig (buggy or gig),

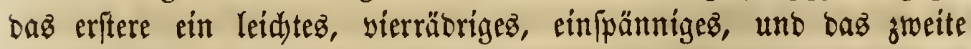

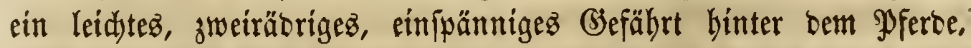
währeno (Gefäbrt gejpannt ift, hergeidoben werben. Nady einer Wreile wer= ben bie 3ugriemen (traces) befeftigt uno nun fährt man zum erfen= mal mit bem Foblen, währeno baz alte Pfero neben ifh bergeht, langfam herum. Man treibe zuerft bas alte Pfero an, roorauf baz junge yon felbjt folgen wiro und follte man bemjelbent nidjt erlau= ben anzulfalten, bis es augen[djeinlíd ermübet ift. Woäbrento bies: 


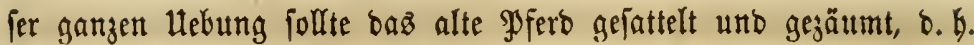
zum Reiten parat fein. Bicht baz Foblen gern an, fo laffe man benjenigen, ber y ornen bie Reitung ühernommen, baz alte \$Fero bem jungen ein wenig voranfübrent uno vergrö̋ere nad uno nậ bic

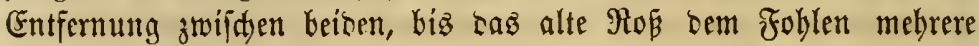
Rängen (lengths) sorauz ift. Shue daz alte Jjferd anjukalten, laffe man ben bethülfen nun baffelbe befteigen uno fortfabren, ben

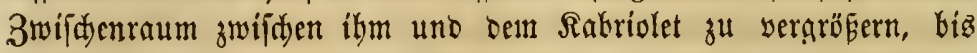
baz alte Pfero fem jungen entolid) ganz aus bem (Gepifdt fömmt!

Diefez Berfahren follte auf ebenem Boben und mit einem fehr

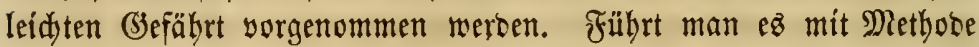

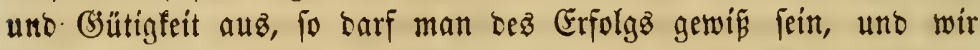

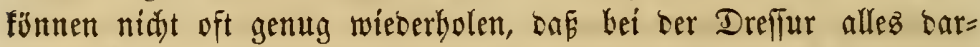
auf anfomme, einerjeitz gelince uno anbererpeitz mit Feftigfeit zu verfabren, utro fid nie Şärte veer gar (3raufamfeiten zu Edjulben

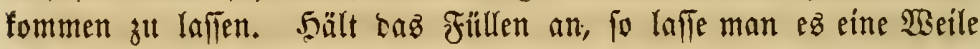

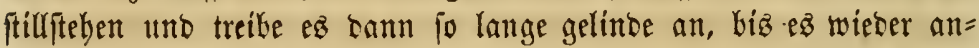
ziebt. Diez follte es aber fajon theilweife gelehrt werben, fo lange baz alte Pfero nod an feiner Seite ift, fo wie aud bas bufen

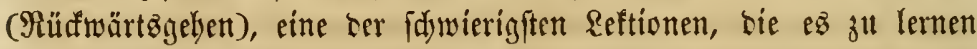

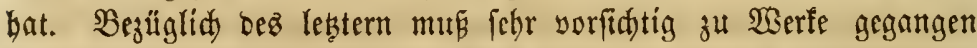

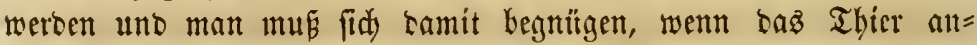

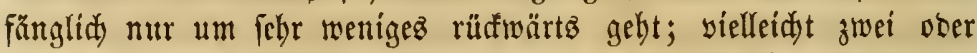

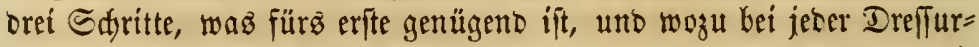
Uebung ein anterer Sdyitt Ginjufommen fann, biz caz Pyero ab= geridutet ift fll "huten."

2Ute biefe Uebungen fino bagu beftimmt, bas Thier an ben (Bes=

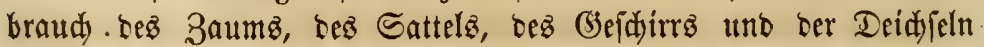
Dez Rabrioletz und an bie burd sie Bügel bewerfftelligte Reitung zu gemöhnen, uno bie Zähmung zu vollenden, ehe ez Etärfe ober

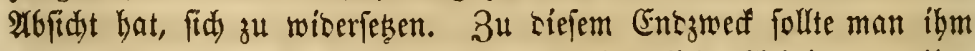
bäufige Hebung yeridaffen, obne jebod) eigentlidie 2arbeit yon ibm gu forbern, fo lange ez nod) io jung uno zart ift.

\section{Das ztucia ährige go glen.}

Bom zmeiten biz britten Sabr follte man fortfahren, oaz Füflen

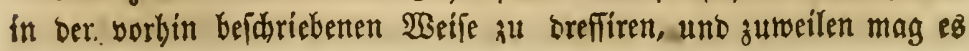


gebraudt werben, wobei tas Thier jetod) nie mebr alż brei biż vier Meilen auf einmal zurüdlegen follte. Beim Bergabfabren Darf man nie vergeffen, ben Rabjdub einjulegen, wäbreno bergauf ber Jubr= mann nebenber geben folute, fo tap das Pfero nur bas (jefäbrt za zieben bat.

Diefe 3eit ift aitd bie paflidyfte, baz Thier zujureiten. Ein etro jebn = ober zwölfiäbriger Snake mag auf= uno nad einer Weile wieber abjizen. Becim erfitmaligen $\mathfrak{A}$ uffiteigen follte man fei= nen $\mathfrak{B e r j u d}$ mad)en, baz Ibicr herumbureiten, fonbern man barf bier, wie bei set ganjen Dreffur nur fdrittweife vorangeben. Die=

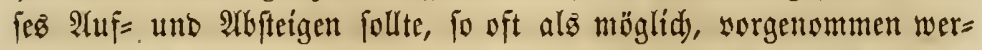
ten, aber in feinem Fall tarf man irgeno Jemant etlauben, auf Daz PJferb zu fpringen, fonbern ser אabbe, weldyer aufifbt, follte entweter yon Semantoen unterftübt werben ober auf irgeno weldyer Grböbung fteben, utto fid fo forgfältig als möglid auf ben Rüden เes PJerses nieserlaffen; sent folde Pfetce, benen gegenüber man

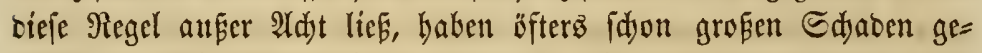
nommen. Die Rittenmirbel fino nod nidyt fo ausigewadjen uno feft, wie beim ältcren Pferbe, webhalb, fallz man geftattet, Dafi Per=

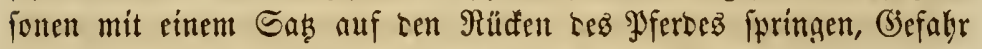
worbanben ift, saf cafjelbe surd bie unter bem Ramen "Senfrüden" (sway-back) befannte Bermuftaltung für fein ganjeg $\mathfrak{R} e b e n$ mísge= faltet wiro. (Eiclse srittes Rapitel). Das Füllen follte nidst allein ser 3äbmung ull Albridutung wegen, fonbern aud) rebbalb oft ge= ritten werten, um $\mathfrak{e B}$ an bie Gtrafie und die Gegenftänte, bie sort trifft, zll gewölonen.

\section{(5) e to ถี}

Sm Fall biez in ben sorkergebenben $\mathfrak{A b j d y}$ itten angegebene, auf $\mathfrak{B e m u n f t g r u ̈ n}$ en uno Erfabrung bafirte Berfabren igftematifich aus: gefübrt wurte, fo wirb her farmer mit her Gewöbnung ober $\mathfrak{A} b=$ ridjtung zur $\mathfrak{U}$ rbeit, biejem für viele fo fduredliden Sdyreffgeipenft,

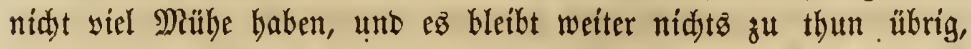
als ons junge Pfero, fobalo bie ridatige Beit bazu gefommen, zur Irbeit zu verwenben, uno es̄ nad) unb nad) zu beftänoigen Dienft= leiftungen zu gewoblyen. (Ez ift jebod) zu bebauern, baj nidyt alle Farmer bie Jabre, in welden baż 3ähmen am leidjteften yolnbradjt 


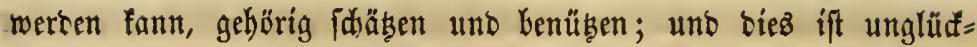
lidjerweife bei ber Miehrzahl berfelben in ben $\mathfrak{B}$ er. Staaten ber Fall;

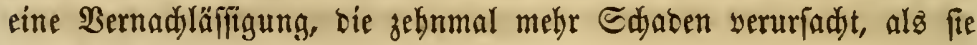
fiid) benfen.

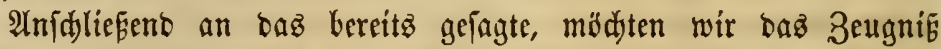
Youattz binjufügen, welder fagt: "Man follte mit ber 2OHrid)=

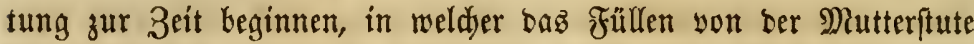
angerwbłhnt wirb;" uno an einer antern Etelle: "Man follte daz Fritlen frïbseitig anfaflen unb bantbaben; ${ }^{*} *$ es an bie 5 alf $=$ ter gewsibnen, wenn ez berumgefühth wiro ober angebunten ift. Siervon lyängt bas gute Temperament bes gyerbes uno feine Renf" barteit in viel bäberem Grabe ab, alz die Yfertezüudter miffen."

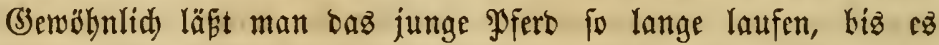

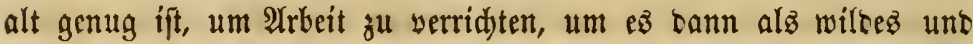
unartig geworbenes Thier abzurídten. Eold ein Pfero wirb nur bödjif felten zahm und fromm werben, in Folge sefien mandje friner beften Fäbigleiten wenigftens theilweife unentwiffelt bleiben. Dis

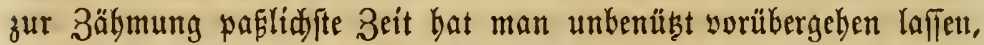
um fid) nummehr mit sem willoen, burdaus nidft an (sehorfam ge= wöbnten Foblen abjumühen. Son 2્Alterz her fino unfere farmer

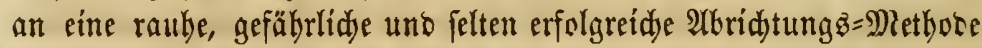
gewäbnt, nämlidid bie: bem willten Gerangewadjenen Füllen plög= líd) baz (befdjirr überzuwerfen, einen $\mathfrak{S a g e n ~ z u ~ p p a n n e n ~ u ก ~}$ fo lange zu treiben, bis ę̧ fdnaubent und mít Edjaum bededt yor lauter Erifdeppfung unfreimillig gehordft.

(3llitfliderweife haben sie intelligenteren unt befier unterridteten

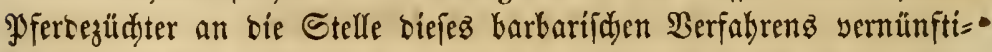
gere und milsere Metbocen gefest, bie berühmtefte uno bei weitem bie erfolgreidffte unter allen ift

\section{Die Metbode Mareb's.}

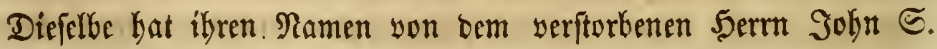
Rarey yon Frantlin Co., Dhio, meldyer fie zuerft einfübrte uno welt= berübmt madjte. Die Erfahrung biefez 5jerrn im Dreêiren junger

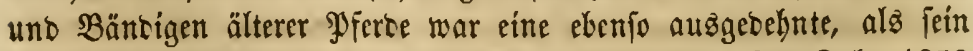
Erfolg sin auferoroentlider genannt werben tarf. Im Sabr 1858 
reifte er nad Englano und madjte bort foldeż 2Yuffeken, baß man fagt, bie burd) feine Borftellungen uno Reftionen ergielten Einnab= men feien nidbt weniger alBz $£ 25,000$, ober $\$ 120,000$ getwejen.

Dab bier beigefügte Bilb fillt bie von 5errn Rarey empfoblene Salfter nebft feirer gewabnlidien Arbridutungęftange (breaking-bit) Dar. Die 5alf= ter ift aus Reber verfertigt uno einem gewöbnlidien Ropfgeitell ähnlid, nur etwaz leidter. Da an ben शajenriemen ein $3 \ddot{u}=$ gel befeftigt ift, fo fann man baz Foblen leidyt leiten, uno genügt berfelbe

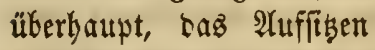
uno Reiten ausgenommen, zu allen 3wedten. Die Methobc, ourdy weldye biefe 5yalfter in einen jebr ztwed=

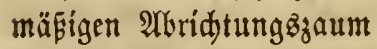
umgerwanbelt wirb, ift eine febr einfadye, inoem man nichts พveiteres ชน thun bat, alb irgeno weld)e

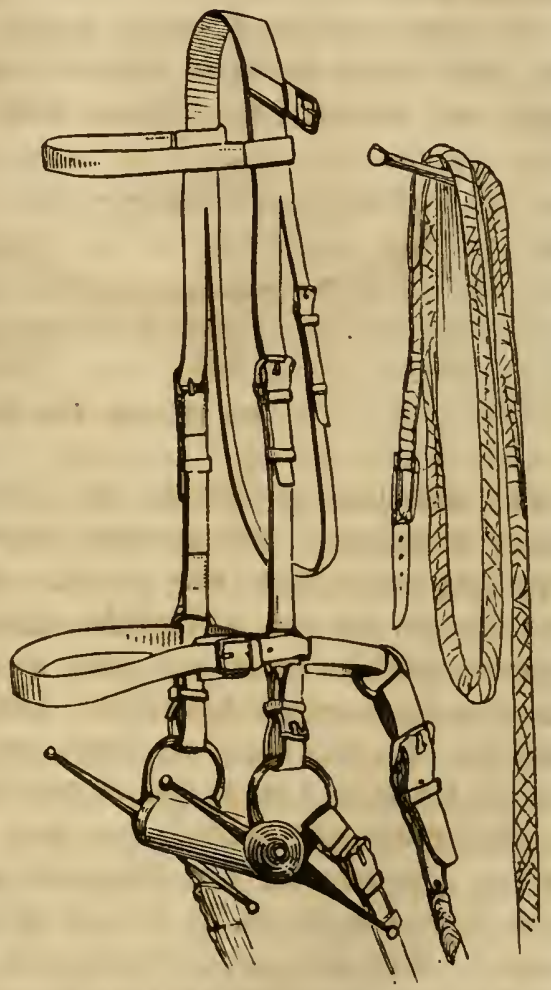
Stange (bit) an bie Sei= Gerrn karen' Galfter oder saum für füllen.

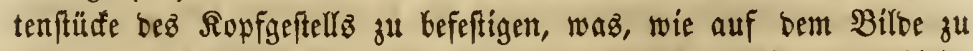
jehen ift, burd zwei fleine, mit Sdnallen veriebene Riemen gefdieht.

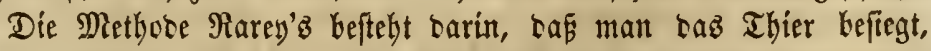
inbem man ez zeitweilig bez (b)ebraud e⿻⺀ füblen ไǟt, madtloz ift, uno bef̧balb jeber Forberung nadzufommen bat. Doer mit anberen Sorten: Diefe Methobe ift bas fyftematifade und ftrenge Berfabren, ourd weldyes bas wilbe unabgeridtete Thier in febr furger 3eit oreffitt wiro uno alle wefentliden Reftionen - alfez, 
was früber vernad)läffigt worben, lernt. Alls Mittel, wilbe unt unartige Pyferbe zu zäbmen, fteht biefelbe ohne Zweifel unübertroffen ba, tuto bie Reidytigfeit, womit fie aubgefübrt werben fann, thre jdnellen Sirtungen uno igr beinabe beftänoiger Erfolg bezeidnen fie als einen widytigen Fortjdritt in Ser Pferbebreffur. Reine \$er = fon, weldye diefes Berfabren burdjaus verfteht, würbe bereit fein, raflelbe nit anoeren früber übliden Metboden ju vertaufden.

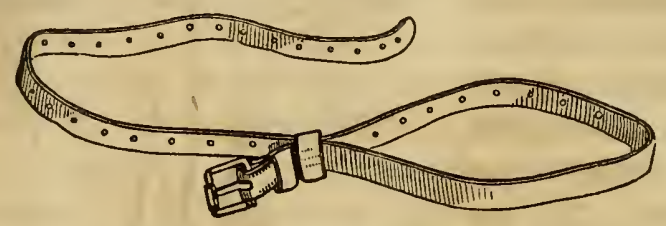

Der Rarey'个he Ftuteriemeu.

Daz erfe, waż zu gejdehen bat, ift natürlid, bem Ffferbe die Salfter überzumerfen, waz ourdjaus nidyt in alfen Fällen fo leidht

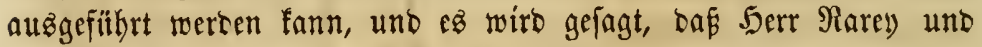
feime Cdjüler, um bies zu bezweden, vfterz zum (sibbraud gewiffer Arzeneien gegriffen baben, uno zwar wirb bas yon ifuen befolgte Berfabren folgenberweife befdrieben: "Man reibe ein wenig Rüm= melöl (oil of cumin) auf rie 5and uno näbere fith bem Yjferbe

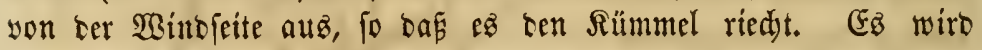
auf Diefe Wseife nidyt fdwierig fein, gan nake an โas Rop beran= zutreten, uno man bat nun (3)legenbeit mit ber Sand fanft über

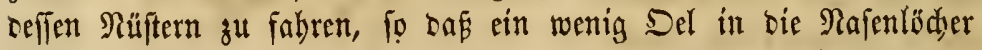

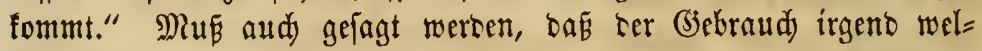

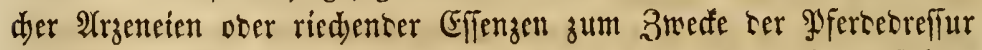
son fehr zweifelbafter Zwedimäfigfeit ift, fo mag man bod) zugeftelyen, baf biefelben willen Thieren gegenüber, benen auf andere 2 eife (d) led)= terbing nicyt beizufommen ift, zuläffig finc. Wrber man barf bie Frage robl erbeben, ob foldye Mittel bem Pferce nidut fdäblid fint, uno angenommen, bies fei nidyt ber Fall, fo find fie von zul flüd $=$ tiger Wirfung, um bebeutenten Werth zu baben, unb fer Befizer follte fid auf biefelben uno bie saburdy bewirften Rejultate nidyt allgu yertrauensyoll verlaffen, fonft mödyte în fein tofloeb, unbän= biges Pfero unverfehens grofer (3efahr aubieben. 


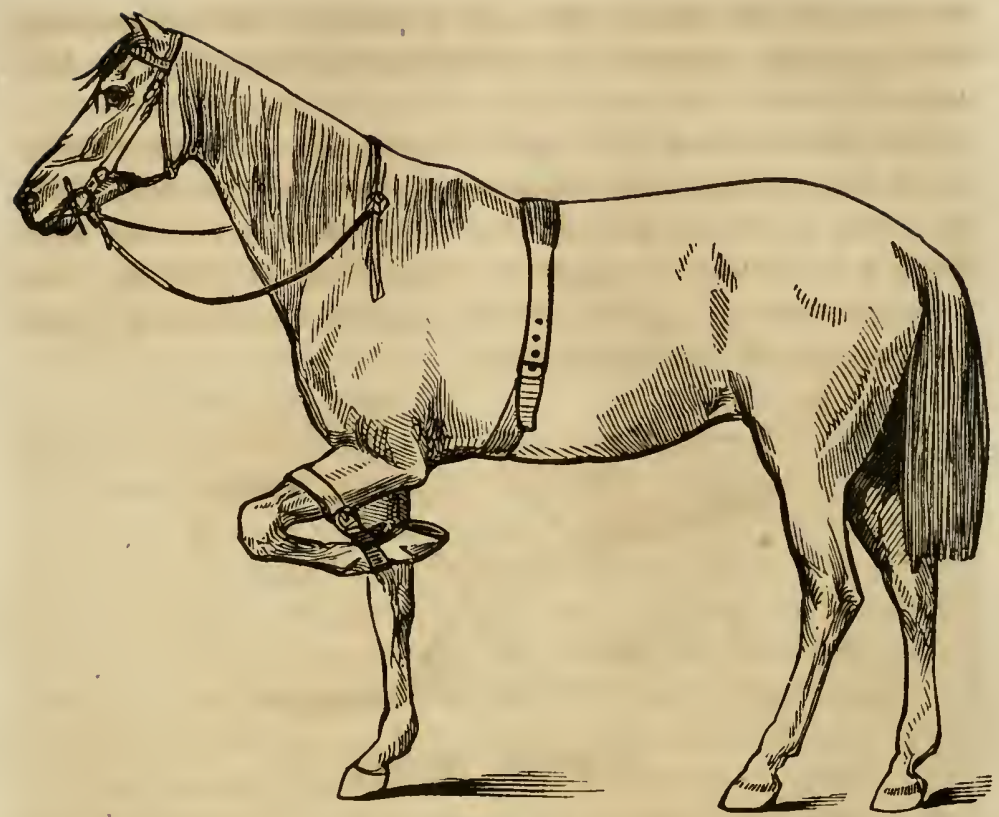

Gebraud des ginieriemens.

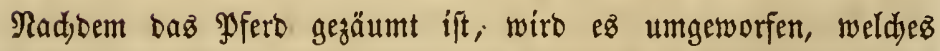
mittelft jweier Riemen obne (Siefabr geidjeben fann. Der erfte follte ftarf, won biffem Reber, zwei Fur lang uno wenigitenz zwei 30 Ul weit fein, und ift berjelle auf bem Bilde fo gut bargeftellt, baf eine weitere $\mathfrak{B}$ ejabreibung überflüffig ift. Etwa zwangia 3oll son ber Sdnalle follte ber Riemen zufammengeidnallt werben. Run bebt man ben linfen Fuß Des Thteres auf, während ein Stehilfe baffelbe am 3aum feftbält, und ziebt ben Riemen über bas Rnie ber, indem man ifn unten über baż Feffelgelenf unb ben $\mathfrak{A}$ fel uno oben bizz

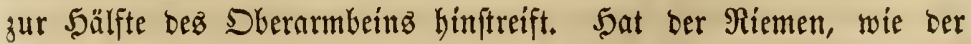
auf bem Bilde bargeftellte, eine grofe Sd)leife, fo wirb berjelbe erft feftgejdnall, nadjoem ber Fus aufgeboben ift. Da bas Thier nun= mebr auf orei Füben fteht, to if ez unvermögeno, aufer mit ben Bäbnen, irgend weldez Unbeil anzuftellen. In biejer Stellung laffe man $e z$ yon fünf biż zethn Minuten fteben, uno wenn ber Rnie= riemen ben Fus niddt ziemlid) nabe zum Rörper bält, fo ziebe man 
benfelben an uno funalle ifn enger zujammen. Daz nebenftebenbe Bild zeigt ben (Sebraud) beż Sinieriemenz bei biejer Methobe beut= líd) an.

Der zweite Riemen jollte fed)z Fuß lang uno an einem Enbe mit einem anbertbalbzolligen, feftangenäbten Ring verieben fein. Wirb er jebod in Berbinbung mit bem (5)urt gebrad)t, wie eş 5erm Rarey's Mode war, fo braudit er nidjt fo lang zu fein, und jeben= fallz wito eine gute leberne Sd) mäfíger fein alż ein eiferner Ring.

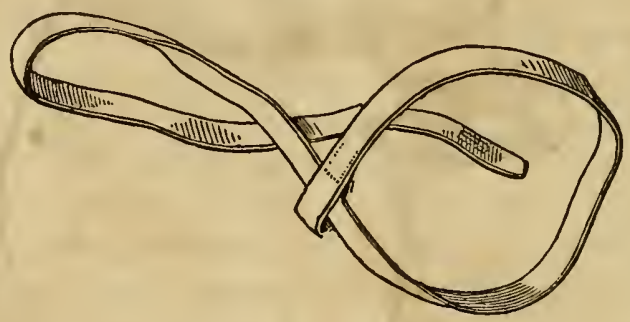

Der Rarey'f fhe Sufrritmen.

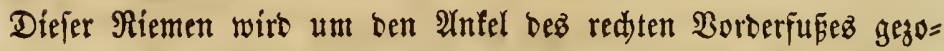
gen, inbem man baz eine (Enbe burd) bie Saleife freift, unb yon bem Bänbiger, ber auf ber linfen Eeite freht, feft in ber 5amb ge= balten und zwar fo, baj man bieje Riemen über bie Sdulltern her= laufen läp̧t. Nunmebr wirb berfelbe frrafi angezogen, woourd) baz

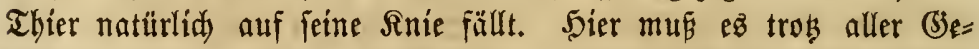
genanitrengungen, fallz ber (bebilfe am Zaum feitthält unt ber Bän= biger ben über bie Sdultern laufenden Riemen feft angegogen bält,

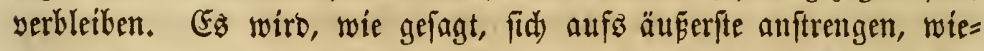
ber aufautommen, insem man jecod) feinen Sopf nieberbält uno feinen

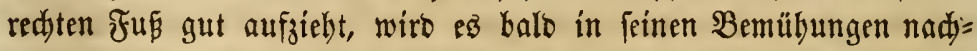

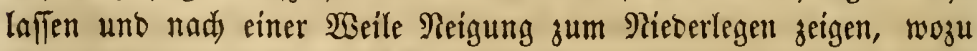

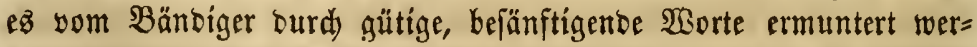
ben follte; uno wäbrent er mit ber einen Sand verjudft, ez auf bie linfe Seite Gerüber zu ziehen, follte er es auf ber andern reiben unb bätiddeln.

Der Gehjilfe follte ben Rapf dez gyferbez auf bie redjte Seite brehen,

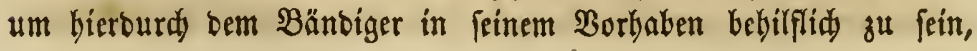


นnס wenn es nieberliegen will, es endidi zwingen, fid auf bie linte

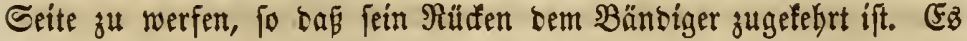

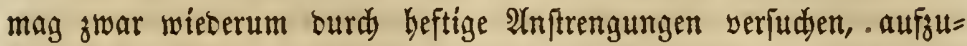
fommen; fallz aber fein Ropf auf bem Booben uno ber linte Fuf zurüdigebalten wiro, wíro es ben $\Omega$ ampf balo aufgeben.

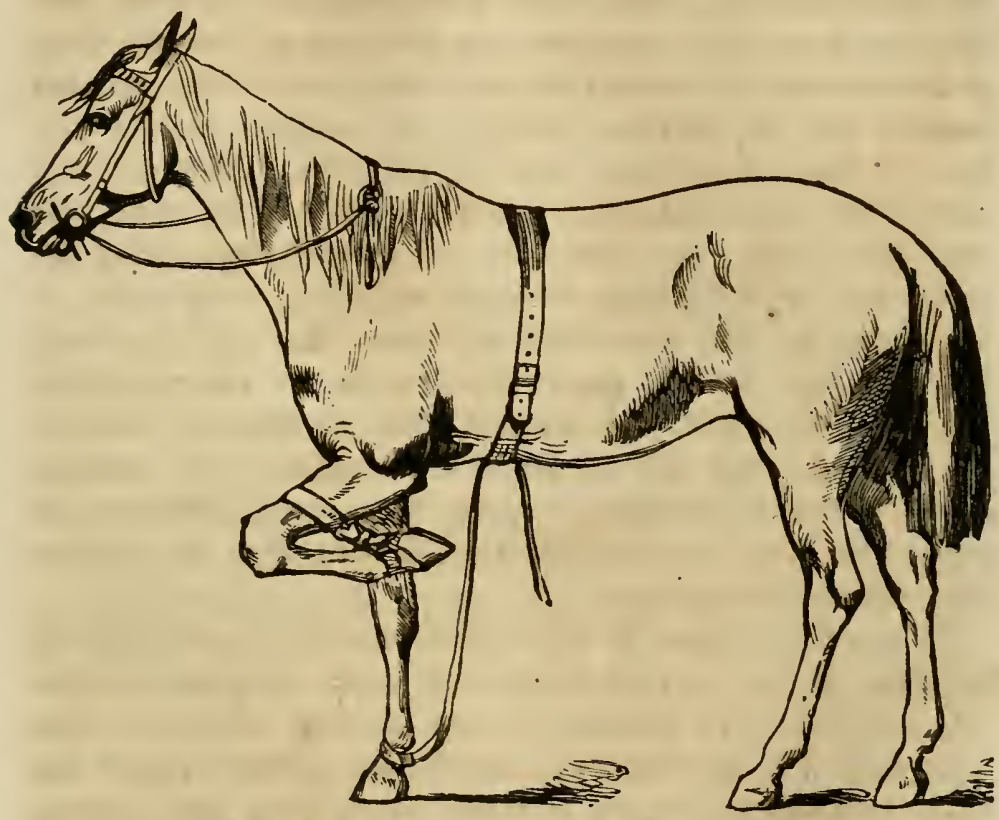

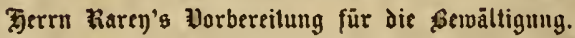

Wir haben bizber baż Berjahren alz yon zmei Mlännern aużge= fübrt befdrieben, weil hierburdy baffelbe fo einfady uno leidst wirs, bas fein intelligenter Farmer ober Farmarbeiter yon gewöhnlider Stärfe uno Energie fid zu fürdyten braudit, einen Berjud mit ber Rarey'dyen Metbobe fu maden. Serr Rarey felbit aber nabm in feinen Borftellungen unb Unterrid)tbftunben nie ben Beiftand eines

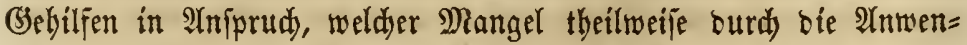
bung ber (3)urt, wie ez auf ben Bilbern ( 5.505 u. 507) bargeftellt ift, erjest wurbe. Daz lestere biejer $\mathfrak{B i l}$ toer zeigt unz bie gange von biejem $\mathfrak{B a ̈ n o i g e r ~ z u m ~ Z a ̈ h m e n ~ b e n u ̈ b t e ~ B o r r i d j t u n g , ~ u n o ~ m a n ~ w i r o ~}$

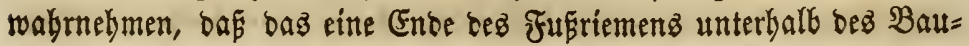


des burd) bie (s)urt gezogen ift. Derfellbe wiro gerate hinter bem (s)ürtel gefást, in bie Sano gefdilungen uno feftgebalten, wäbreno

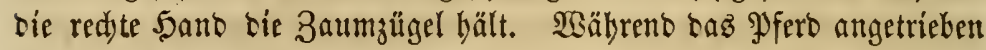
wiro, ein wentg sorwärtz z̆ geben, was nur in büpfenter $\mathfrak{w e i f e}$ gefdelyen fann, wiro ber redte Fuf plöblid) zur (B)urte aufgezogen uno bier feitgebalten, worauf bab Thier natürlịd) auf feine Snte

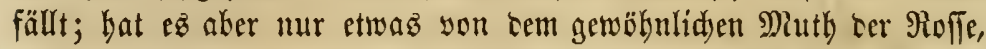
fo wiro es mit ben bintern (bliesmafen bejtig um fid fallagen, uno nunmebr muß ter Bändiger energif un vorfidtíg zugleid fein, intem er feine beiben Sänte, wie oben befdrieben, benübt uno auf=

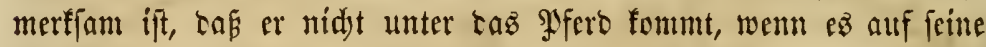

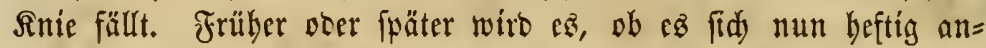
frrengt uno um fid fallägt, oter rubig auf jeiten Finien bleikt, er= fdäpft uno froh feín, niecerliegen zu tönnen. Der red)te 3ügel muß ftraff angezogen werten, bamit fein Ropf in ber entgegengefesten Ridjtuttg getreht wirt, uno vielleidt fann tor Bäntiger tenfelben aud) nod) ein menig auf bie antere Seite treben. Ein muthiger, energifder Mann, namentlid, nadjeem er ein wentig Erfahrung ge= fammelt hat, wird ez yorgiehen, bie Zähmung ohne ben Beifitano einez Ge Gebilfen worjunebmen.

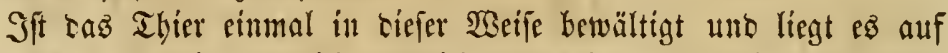
ber Eeite, fo wirb ez nid)t fogleid \&uft jeigen, fid wieser ju erhe= ben, uno nun ift bie goltene 3eit jum Şanteln gefommen. Das

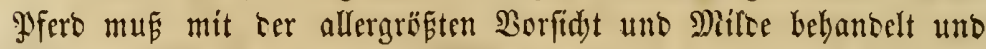

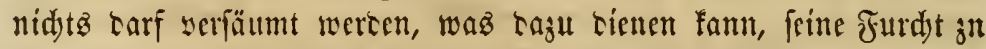
befdrwidtigen uno feine furd)thare Âtfregung, sic as oft am ganzen

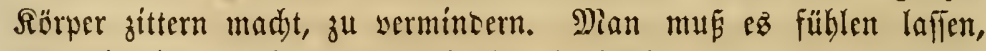

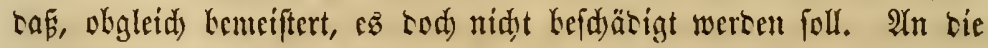
Stelle ber Furdjt muf Bertrauen, an bie Etelfe feimer Unarten unb Störrigfeit 3abmbeit und Folgfamfeit treten. Der Bäntiger ftreidjle Ropf uno Radfen, tätfdjle Edjultern uno Rüafen, unt fađTe, mäbreno er fortwäbrento zu tem Thiere in gütigem Tone fprid)t, feine Shren, Beine, Füpe unb alle Theile bez Rörperz an. Nun mag er fíd auf tas Thier fescen, fid berumbreben unb carauf nieberliegen. Ie mehr Bervegungen uno veränterte Etellungen er yornebmen fann, Defto beffer ift $\mathfrak{e}$ s.

Nunmehr follte bem Thier ter Sattel leidjt uno fanft aufgelegt 
werben, fo baf bie Steigbüget an betben Seiten bes Baudjes ber=

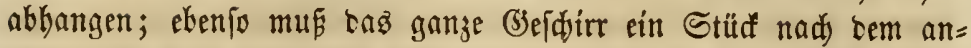
sern, unt fallz man biefe gebraudyt, audb bie Retten angelegt wer= ben. Radisem man biemit etroa eine balbe Stunce fortgefabren, und baz Thier feinerlei Furdyt mebr äufert, mögen sie Riemen $0=$

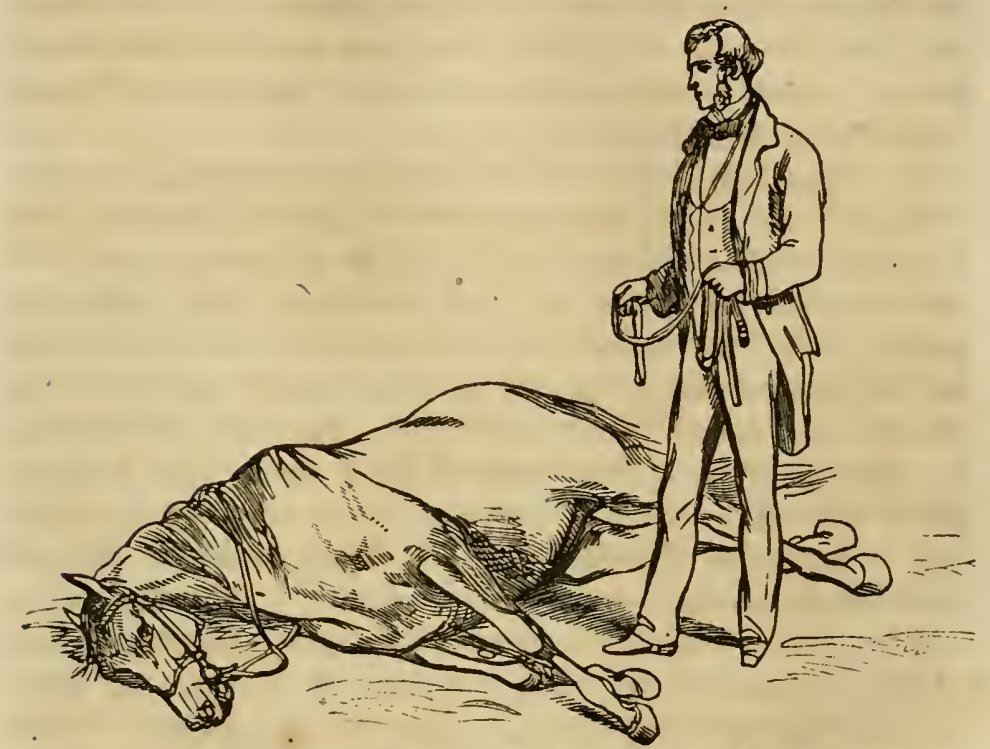

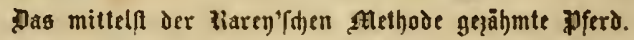

wie ber 'Sourt, wenn ferfelfe getraudit wurbe, entfernt werben, uno man mag bas PJferb eimuntern, wieter aufjufteten. Biele Perionen

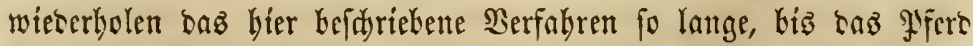
fid söllig fügen gelernt hat unt auf $\mathfrak{B}$ efebl felbit auf bie Sinie fällt uno fich auf die Seite legt, mit weldyen llebungen fo lange fortige=

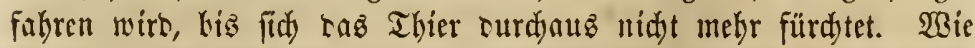

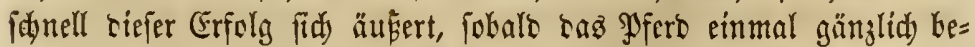
wältigt ift, ift erftaunlid). Mit 2 nwentoung ser gebörigen 2 ufmerf= famteit uno (Sebulo fann es bahin gebrad)t werben, baf 5az Pfero aufz genaufte folgt; jesod ift ơ fold) solffänoiger Bäbmung öfters wodyenlange Arbeit erforberlidy.

Mandje ziehen, währeno bas Pferb auf bem Boben liegt, bie Deidj= feln (shafts) besె Cabrioletz (buggy) an befien F̈lanfen bin uno Ger 
uno fabren mit bem (3)efäbrt um saffelbe berum. Stebt bą Thier wieber, fo mag ber Cattel fadte auf beffen Piüden gelegt werben. Räpt ez fid ties nidjt gefallen, fo mup man taz ganze Berfabren wieberbolen unb zwar fo oft, biz $\mathfrak{e z}$ zuläst, baf nidyt allein ber Sattel, fonoern audy alle antorn Theile bes (befduirro angelegt wer= ben fönnen. Mian jollte nur ein Gtild beffelben nad) bem anbern bem Pferd auflegen, und fobalo es nur sor einem berielben fdeut, muß es wieber niebergelegt uno bie oben befdriebenen lebungen wieber burdjgemadit werben.

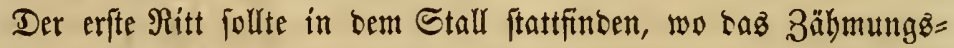
verfabren ftattgefumben, uno zwar mag ein Sinabe, fobalo fth bas Pferb erboben bat, auffitsen, uno follte tiefer mit jenem einige Male im Stall kertmgefübrt werben. Diefe llekung mus afterz mieberlyolt

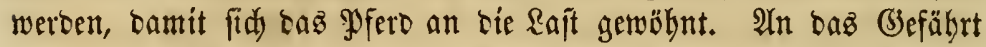
follte

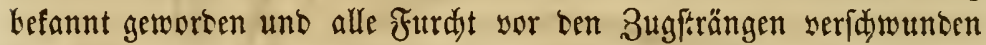

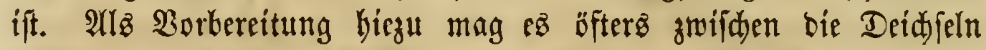
gefübrt und diefelben offters an feinen Flanfen auf= und abgezogen,

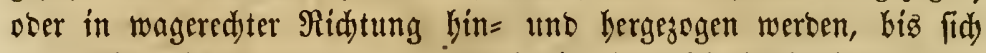

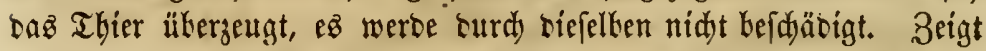
es Sheu ober Sdühternbeit, fo mieberbole man bie Hebung fo lange,

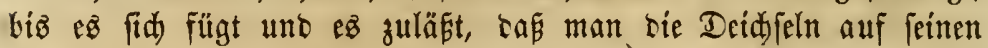

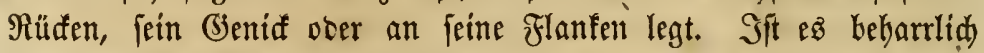
ftarrinnig, furdytiam ober fidets, fo fdnalle man wieber ben Borber= fü auf uno wieserbole baz Berfabren. Range wiro ez unter foldjer Dreffur nidst anfeben, bib bas Pfferb bewältigt, willigen Geborfam leifitet.

Bor allem gilt $e \overline{\text {, }}$,o lange mit jeber Utbung fortzufabren, biz Mübe uno $\mathfrak{A}$ rbeit mit Grfolg gefrönt werten. Wurte oas Thier gleid) 2 Anfangz solffommen bewältigt, fo wirb man päter verbältnifs= mäfig wenig mebr Mübe baben; ift jecod jenes nidjt gefdeben, fo wiro bie Dreffur etwa längere Beit in 2 niprud nebmen. Nie ver= geffe man bie Regel, mit Ler grö́stmögliajten Milloe unwanbelbare Jeftigfeit zu paaren. Nie greife man ju barten, graufamen Mafre= geln, fonbern fei wäbreno deż ganzen $\mathfrak{B e r f a b r e n o ~ g u ̈ t i ́ g ~ u n o ~ g e l i n o c , ~}$ indem man fid erinnert, bap bierburd mebr ausgeridjtet wirb, als burd) (Semalttbätigfeiten. Radbem bas (S)efdirr aufgelegt worben, 
mag fid ber (3iehülfe binter Das Pfero ftellen unb an ben Strängen zieben, to baf bie Sdjultern bes Thieres einen leidyten Druf empfitt= ren, uno hat $e$ fid biefez gefallen laffen, fo fann es] yor ein $\mathfrak{C}_{\mathfrak{a}}=$ briolet (buggy) gefpannt werben.

Gite antere alz bie bier angegebene Methobe, um baz Pjerb mit bem (3iebraudy ber Deidjfel befannt zu madjen, ift bie bei ber Dreffur

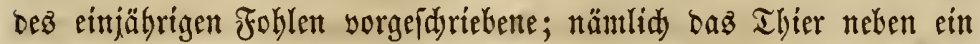
an ras Cabriolet gejpantes, febr zabmes Pfero zu binden und fo lange mit beioen herumzufahren, biz oas unabgeridgtete neben oem breffirtent rubig bergeht. Sft biejez bezwedft; fo fpannt mant bas nod nid)t gewöhnte Pfero ein uno läß̨t bas anbere, an biefez feftgebun= ben, neben bemielben bergeben. Nod) eime anoere ba uno bort ge= bräudjlidue Methode beftefyt barin, ons nidyt afgeridjtete Pfero an

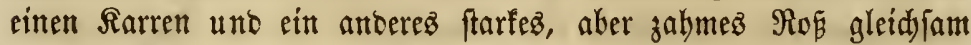

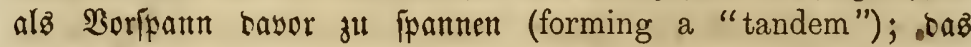

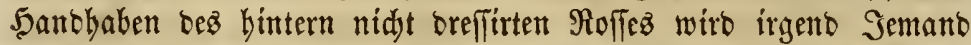
gernitg zu fdaffen maden. Nadj einer Weile mag onz Thier abge= gejpannt uno yor bem Füllen bergefübrt werben, inbem man bie betreffente (Entfernung nad) uno nad) vergrösert, bis ber "Rebrling" gewahr wirb, bag er redit wohl allein geben fant, in weldyem Fall man bas andere Syfert ganz entfernt.

Sobalo matt mit bent Dreflur= Berfahren begonnen, follten täglidbe Uebungen gebalten wersen, bis bas Pfero solffommen abgeridtet ift; bat man es eimmal angeipannt, to ift eB zroefmäfig, ziemlid biel mit bemjelben berumjufabren. (5ż fint energijhe Mafiregeln erfor= Derlid, um bem Ibiere bie Meifteridaft uno oie Rotbrentoigfeit ber Unterwerfung zu keweijen. Nie follte man fid oer mübesollen Dref=

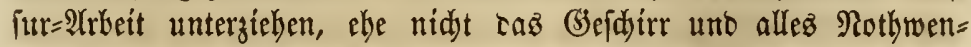
bige in gutem Zuftand bejd)afft und zum augenblidfid)en (Bebraud) zured)tgelegt ift. Sit bies vorkanben, uno bat man mit ben Utebun= gett begonmen, fo Galte man erft bann bamit inne, wetn ber 3wed erreidyt ift. Die bei ber Unmeijung für bie Dreffur bes jungen

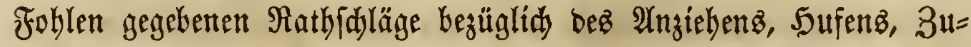
rü̆fhaltens bes $\mathfrak{W a g e n z}$ beim Bergabfahren $2 c$., fino aud) bier gültig uno jollten ifrem ganzen lumfange nady ausigefübrt werben, wobei zu beadten, dafi je ftärfer bas Ihier ift, if mebr es ertragen fann. 
Eż ift natürlid nidjt nöthig, ein bereits berangewadhjenes Pfero in eben bem (Srabe zu fdonen wie ein zartez Foblen.

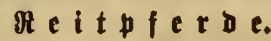

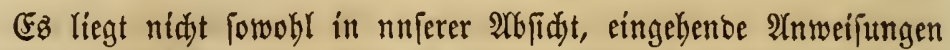

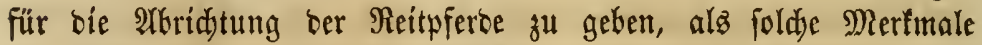

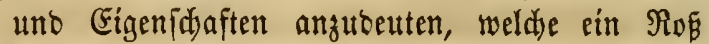

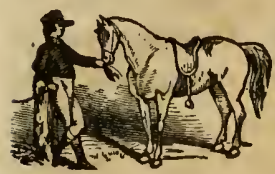
bejonders für diejen Zwed befähigen. Mandje Roffe fino yon Ratur aus mit folduen Dualitä= ten ausgerüftet, fie treten leidyt auf, berwegen fid)

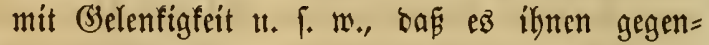
über nur eintiger Bentffidstigung uno Dreffur betarf, um fie zu aubzgezeiduneten Reitpferben zu madyen. Uno zwar giebt in biejer

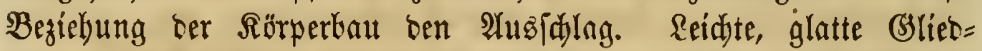

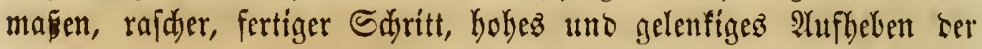

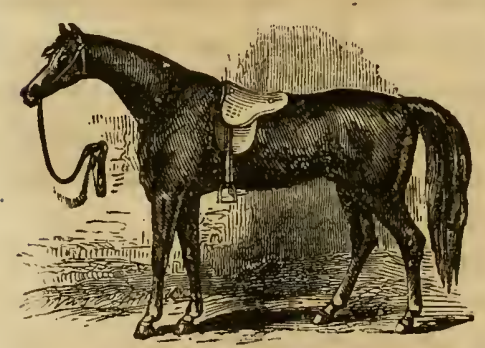
Filibe, Shiften, bie fich yom obern Enoe berjelben gegen ben Sdyweif binzieben, nicoeryebaltener uno gut eingefester Sdymeif, fino bie Merf= male eines guten Reitpferbs, unt follte aud nur einez berielben sor= banben jein, fo lobint ez fid ber

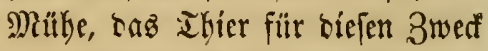
abzuridyten. Bicle fonft febr werth=

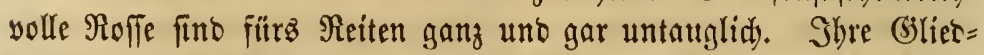
mafen fino lang uno grob gebaut; $\mathfrak{e s}$ feblt ifunen an (belentigfeit uno Sdnelrigteit; ibre Bemegungen fino langfam uno fduwerfällig, uno fie fdjleifen bie bintern (sliesmafen gleidjam in febr unke= holfener Manier nady. Sobe pribe Sdultern tmo Scüften mit bodjgeistem, beinabe mit sem Rüfen eben ftethentem Edjweif -

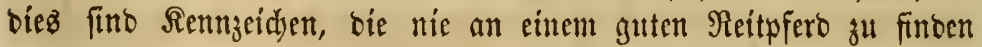
fino.

(53 giebt in unjerm Rante eine 2Yrt 3elter (pacing horses), die

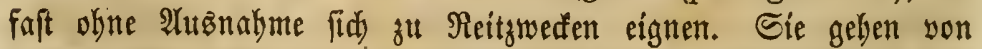
Jugent auf, ofne tazu abgeridytet zu fein, im Pap (pace), uno gwar halten fie biefe Bangart beftändig ein. Pferbe, bie nidd, um biefen $\mathfrak{A}$ uzorud zu gebraud)en, "natürliđe Dafgänger" fino, werben 
oft abgeridytet im Paß́ zu geben, inbem man einen furgen Zügel auf bie rechte Seite ber Stange (bit) uno an ben Steigbügel befe= fitigt, io baj ber Ropf auf bie Seite gezogen wiro, fo oft das Thier einen Sdyritt madt. Der= felbe 3wed mag erreidyt werben, inbem man ben redyten 3aum= zügel ftraff angieht, woourdy fidty daz PJFero in (đ)aufelnoer $\mathfrak{M a}=$ nier wormärts bemeģen wiro. 2(ud) bat man idyon anoere Mit= tel angewant, um tas eime ober anbere Pofero ful cinem Pạ̧gän= ger zu madien; jecody werben foldy fünitlid) ju eittem eigen= thiumlidien (song abgerichtete

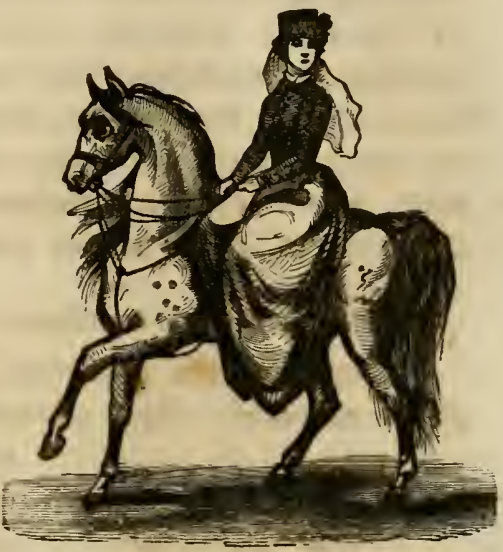

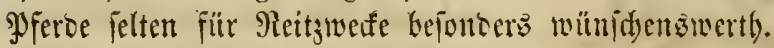

Fin anberer febr angenebmer (bong, weld)en mon Keituabe jetez Pferb mit fleinen, glatten Beinen uno Füfen uno einem raidyen, energifden Sdyitt lebren funn, ift ter fog. Fudstrab (fox-trot); Díez geidjebt, inbem man saz Pfero nady uno nad zu raid)erem (b)anty als Sdyritt antreibt, ifm aber nie erlaubt jut traben. Hebt man das Thier fortwäbreno uno forgfältig in biejem (Sang, fo wiro ithm berielbe endliat zur (Bemohntheit.

Fïr Cayalleriepferte uno Irmeezmedfe überbaupt wäblt man am liebften sie, weldye won $\mathfrak{N a =}$ tur aแร gute Traker finto, ein (5)ang, weldyer ber erforterlidyen bebeutenten ?(njtrengung, nad) bem Sdyritt, am angeme五njten ift. Diejenigen, of fie nun civilifiert fino ober nidit, wel= de ben meiften Theil ber Zeit im Sattel zubringen, treiten, auper Sduritt, Irab uno (Sal= lopp, ifre Pferbe felten zu ei= nem anbern Gang an. Ein

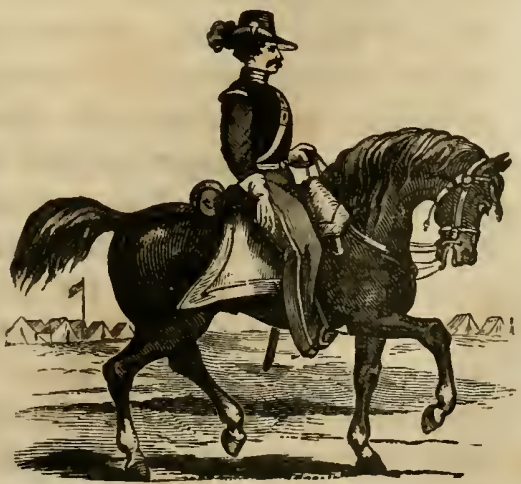

33 


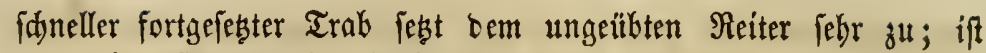
man biefe (Bangart jebod) einmal geroobnt, fo zieht man fie wäh $=$ reno längeren Reifen allen anbern yor. E:z wiro gefagt, baß Giene=

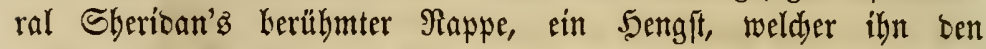

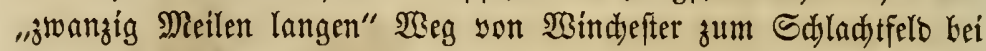
Spequan Ereef bradje, einez ber barttrabendften Pferbe fei, bie je ein Mann geritten, uno eines, weldes mandyem profeffínollen Reit=

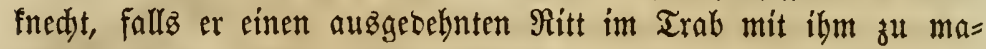
dyen bätte, z̧u fdhaffen madjen mürbe.

\section{(c) a if $\mathfrak{n}$ f $\mathfrak{e} \mathfrak{r} \boldsymbol{e}$ (Horses for the Buggy and Carriage).}

Die amerifanifden Farmpferse wersen gewöbnlid für seridfiecene 3mede vertwentet. Man gebraudyt fie yor bem (Eabriolet (buggy)

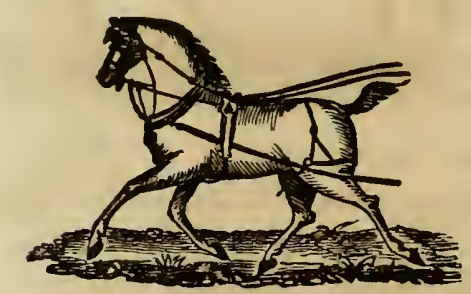

tulb ber Ehaife (carriage) fowobl alb zum Reiten und Pflügen und yor Dem Wagen. Edyere Arbeit auf bem Felo ober ber Strafie madyt ein $\mathfrak{P f e r d}$ fum Reiten weniger taug= lid), uno nur felten ift ein Farm= pfero aud ein gutez Ehaijenpfert.

Dod) wiro eit mit fdäner Form uno glatten (bliesmafen auģgerü= ftetez Yferb vor einem Cabriolet 2 . immer gelenfiger unt idneller fein alz sin grobfnodigez.

Die grofer Roffe find nidyt bie beften Chaifenpferoe. Diefe foll= ten, obswohl 5abhe utto Ränge nidjt fehlen tarf, leidjt uno gebrängt grhaut fein, ibre (s)licoma feln feft fein, uno siefe $\mathfrak{A r t}$ Pferbe follten ftetz für Cabriolet= und Chaifengebraud) auszewählt meroen. (Gz ift biefe frorm einerfeitz cie fdönfte, wäbrento anderfétż \$ferte, weldye fie befitien, nidjt we=

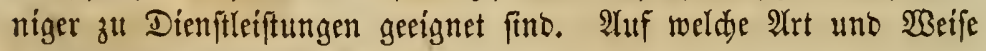
Fohlen für biefen 3 wed zu brefïren find, biełu wurnen in ben vor=

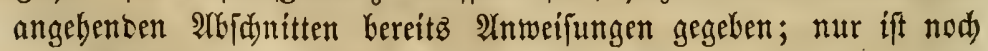

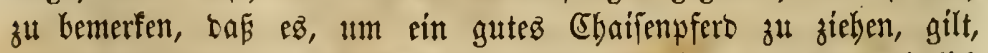
baffelbe in beftäntiger Uebung zu halten. YFerbe, weldye gerwb̈hnlid miteinanter zieben, follten bfterz ihren slabs wedjeln, indem bas cine einmal an biefe, Dab andere an jene Seite gefpannt wirb, wo=

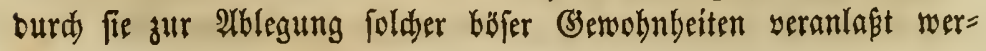


oen, in bie Pferbe, weldye ftets auf ein uno terfelben Sette geben, oft verfallen.

\section{3 u g bfer be (Draught Horses).}

Diefez fint sie fdwerften, ftärfften Rolle, bie fidy burdy grofe Beine uno Füne, fowie ourd ftarfe Belenfe uno Musfeln auşzeid $=$ nen follten. Natürlid) fann bei folden Eigenjuaften son Edunelligy= feit ber Berwegung nidyt bie Rete fein.

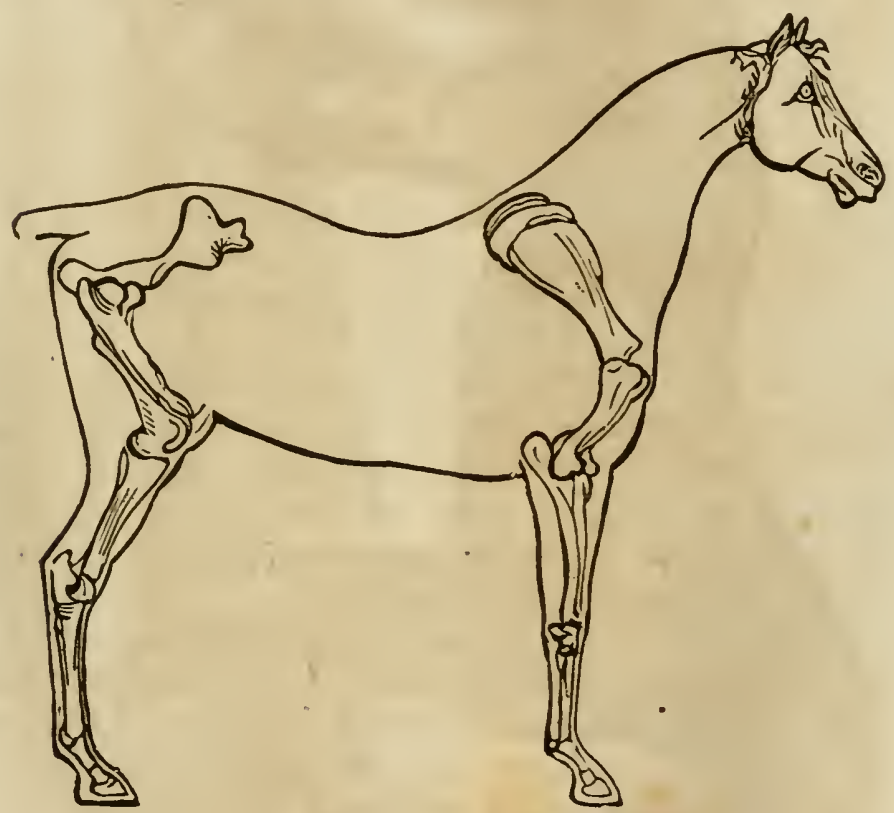

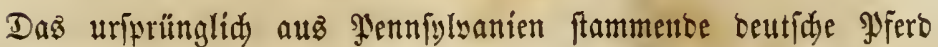
(dutch horse) ifí tas in biejem \&anbe für fdwere frudyten am meiften gebraudste, uno befist zur A̛şfübrung berartiger Dienftlei= ftungen ausigezeidunete Figenidyaften.

Die Sdulter (Sdyulterblatt, fiebe 13, in Billo auf Seite 24) bes 3ugpferbes follte nidht in to fdjiefer Ridtung (slanting direction)

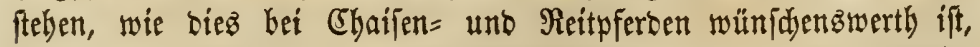
Damit bas నummet einen fo grosen Theil ber Sdulter als möglid berübrt unb bas (Setwidat ber saft auf biefelbe gleidmäfig vertheilt 


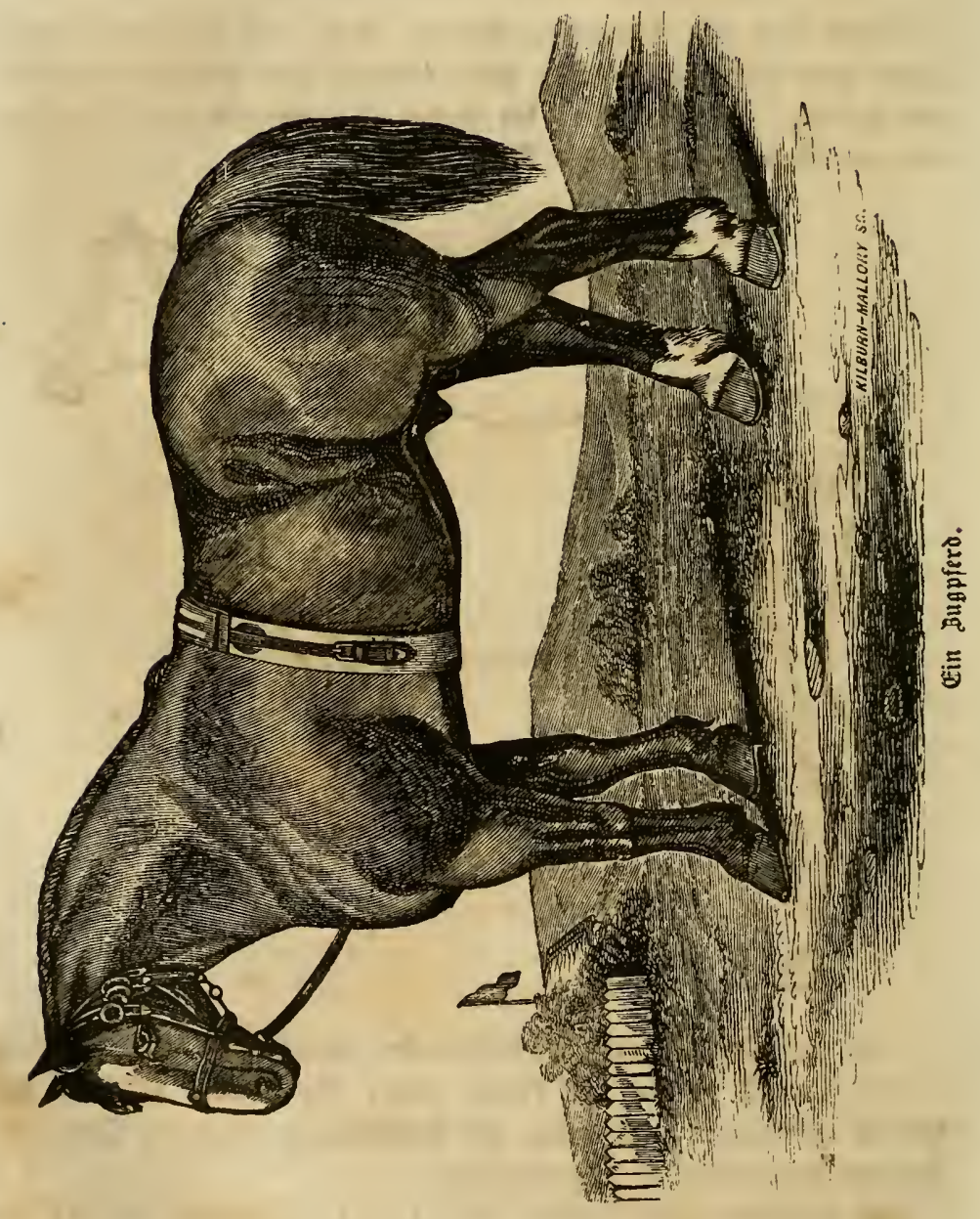




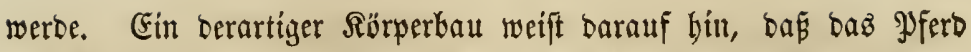
für fanelle Berwegungen nidjt taugt uno nur als ftetiges, fdwer= fälliges 3ugthier zu gebraud)en ift, uno bejüglid bes bier gejagten fonnte ber Rünftler beim Entrourf oer auf ber gegentüber ftebenten

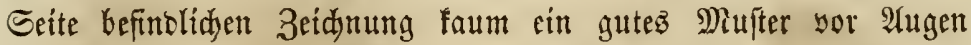
gebabt baben. Fine fotefftehente Situlter ift eine wejentlide Ei=

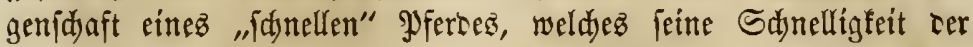
Bemegungen erbalten foll. Daz Bilo auf Seite 515 zeigt bie sage ber Rnodyen ber yorberen unb binteren (Bliebmafen, und wiro un= fern Rejern obne 3weifel bebülflid) jein, bie bier gemadten Bemer= fungen beffer zu verfteben.

\section{Roadsters (B fer de für $O$ m nibuffe re.)}

Unter biejer $\mathfrak{B}$ ezeidnung wollen wir eintigez über Pferbe, bie yor Dmnibuffen, Reiferwägen, Poftutiðuen ober alż Reitpferoe für lange

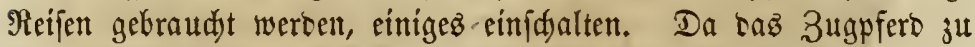
fdwer uno langfam ift, fo eignet ez fid) für bieje 3wedfe burchauz

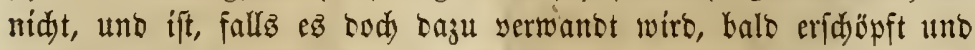
bienftuntauglid. Dagegen ift taz Ro mí fleinem, aber ziemlid

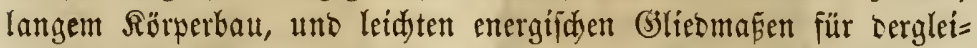
d)en Ditenfte am jwedtmäp̈igften. Eine Gellere Race für biejen 3wed als bie burd bie Sireuzung ber arabijdyen mit ber ancalufitiden gezüdteten Pferbe ift nidyt befannt. Der. Moabfter follte nidat über= mäpig fett fein, bagegen follte er barte, gerrungene Mubleln, gutge= formte Glieber unt solle, runoe Belenfe baben, und fein FrtE uno Ienfel follte fich yon ter. Zebe an in einem sisinfel von fünfunc= vierzig (Bracen rüđ̛̣ärţ dieben.

Jene Pferbe mit langen Rörpern uno furzen Beitten fino für rie= jen (siebratt) surd)ats nidjt geeignet, foncen bei ben zu biejem Zwed taugliduen Pferden follte bie Ränge Des Rörperz mit Derieni= gen Ler Beine im Serbältmí̄ fteben. Ebenio fino gegen mandye langbeinige Thiere entidiebene Fintwentungen zu madjen. Daffelbe gilt yon Rollen, beren Beine in ber Räbe ber $\mathfrak{A}$ enfel ebenjo um= fangreidy fino alz nabe am Seib, beren Belente zu fletr uno flad, uno beren $\mathfrak{A}$ enfel allzu jenfred)t ftehen, wäbreno Der Fuf runo uno flumpig (clumped) ift. Pferbe mit fold)em (słlieberbau befigen nidyt bie

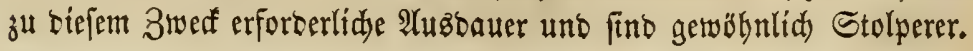


518 Das Pferdebud dez ameritanifden §armers.

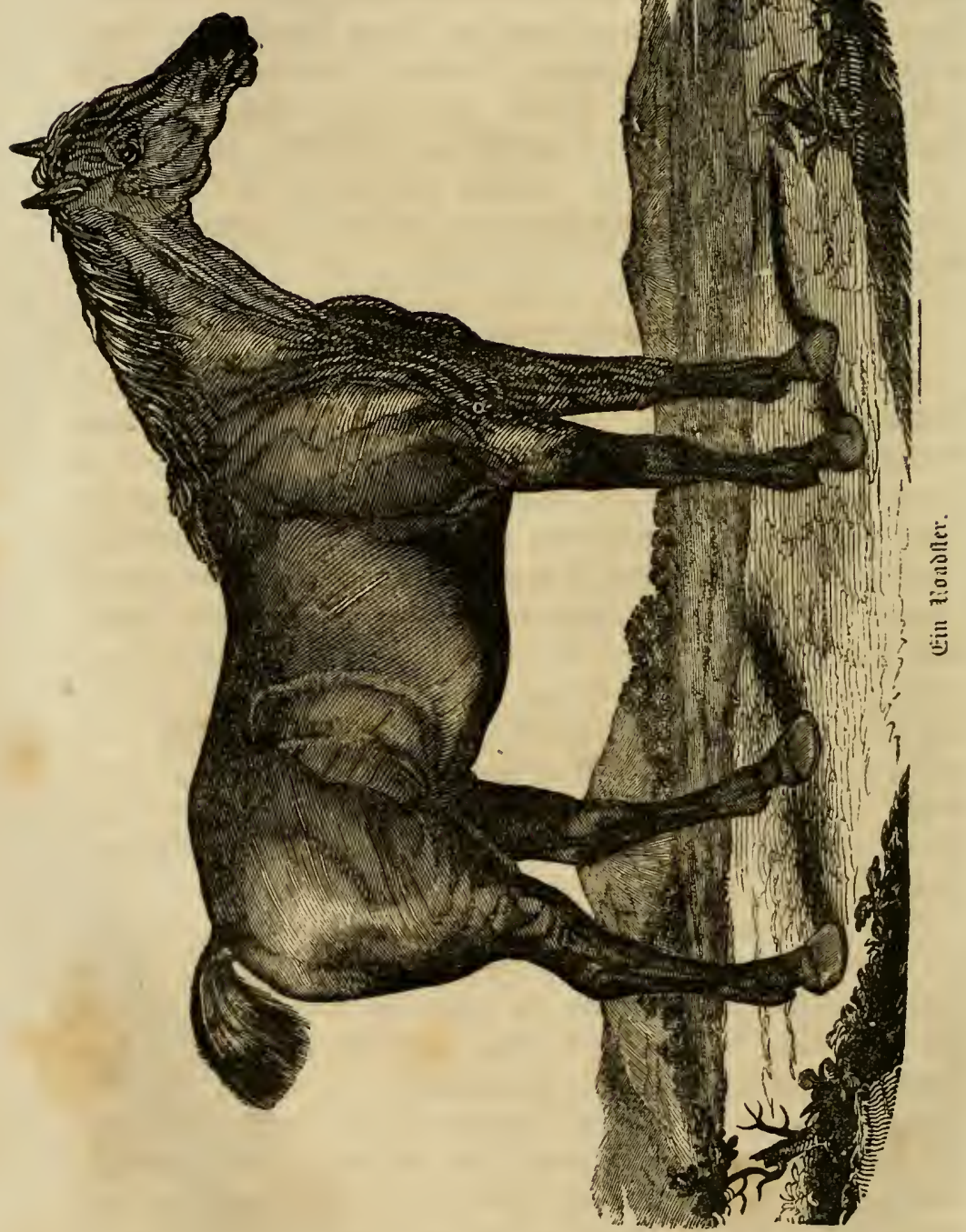


Der frieblid auşebente Roabfter auf ber anbern Seite bat au=

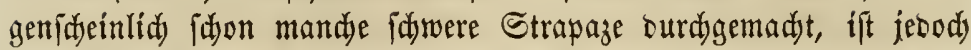
immer nody zu neuen Dienftleiftungen bereit, fallz fie geforbert wer= ben. Er ift einez ber am ftärfften gebauten Thiere biefer Rlafle.

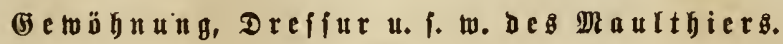

Sierüber ift ęs nicht nöthig, yiel zu fagen, tonn baz Maulthier

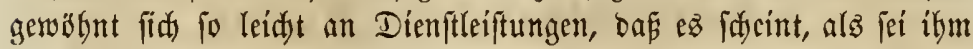

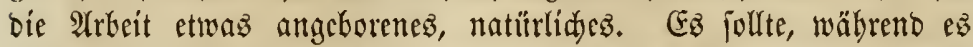
nod) eit Filllen ijt, jum (Sebraudy ber Salfter, tmo wenn verlangt, ju sem tes Sattels, oreffirt werten. Mebr als bies ift yor tem

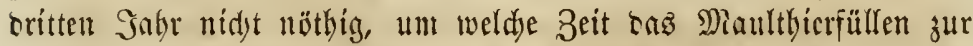

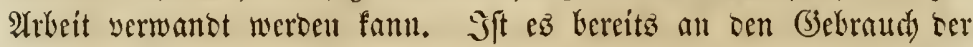
Salfiter gewöbnt, fo fann man es jogleidy mit eimem alten Pfero ober Maulthier yor einen 2 agen oocr Pflug ipannen unt es wirt nad) einer Iagezarbeit ebenjo gut gewöbnt fein alz mand)

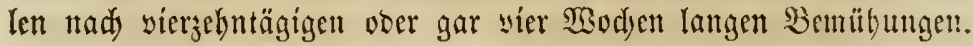

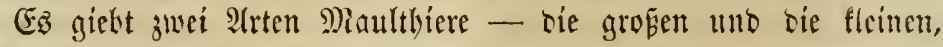

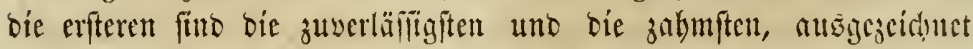
für 3 ugthiere, wäbrend mandye yor ber Chaije uno scm Błแggy? trefflictue Dienfte leiften. SSir fönnen uns fein feineres Gerpann benfen alv ein paar fobün, fdwaze Maulthierc mít aufigebunbenem

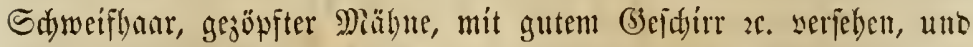
sor eine foine Shaije gcipannt. Derartige Thicre worcen, auf sieje Weije bermusgepttht, im Siloen, wo fie febr belicbt fint, viel ge= brautht. Sie fino viel zuverläffiger alz Jjerte. Mandye fino für

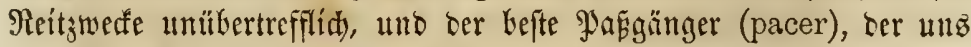
je unter die Alugen gefommen, war ein rotbbraumes Maultbier in (bibjon County, Tenneffee. Die fleinen Maultbiere find auboan=

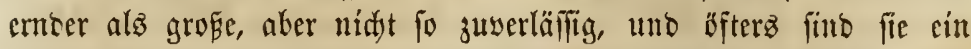

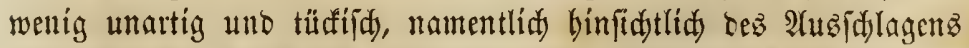

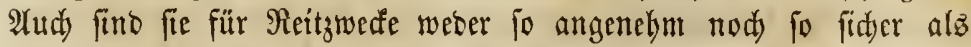
bie gröferen. Für gewöbnlidje Farmarbeit jebod finb eg bie werth= volfiten Thiere, bie man findet, und ein fleines, gebrungen gebautes Maulthier wirb yor bem Pflug melyr leiften alz bas befte Thier, weld)es irgend ein Farmer aufzubringen vermag. 


\section{Simunozmanzigftes sapitee.}

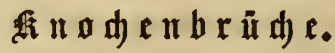

Selten nur formmen bei'm Pferoe Beinbrüdje yor; menn bież je= Dod) ber Fall ift, fo ift es gewöbntid die Süfte ober bie Säaffe,

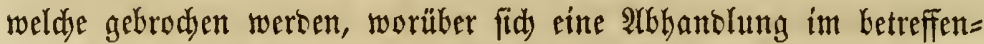
oen $\mathfrak{A}$ bjdjnitt

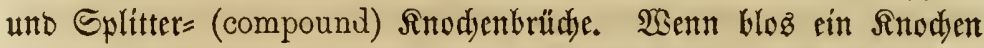
gebrodyen ift, ohne geiplittert zu fesn, fo ift biez ein einfader Brudj;

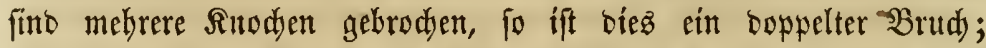
unt ift cin ooer mebrere Sinodien fo gebrodien, Daf. Splitter ent= ftanten uno bie untiegenten Bänter zerrifien wurben, fo nennt man bícz einen Splitterbrudy.

\section{ธ西范}

Buweilen werben bie Sdjäbelfnoden gebrodhen, unt in folden Fäl=

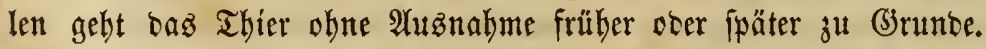

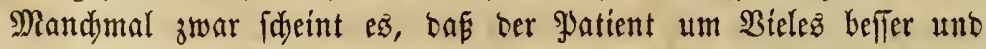
mieber ou Dienfteiftungen tauglidy fey; jebody ift immer Gefahr

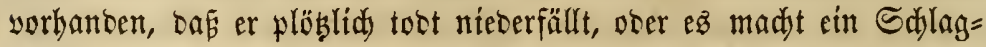
flus (apoplexy) feinem Reben ein Enoe. Die Rentzeidyen foldyer

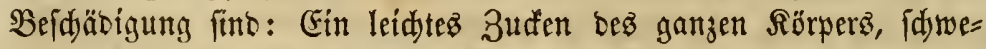

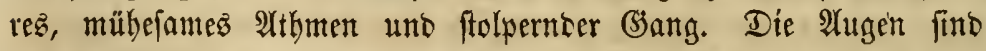
ftets entweber beinabe ober ganz geidjlofien, ber Ropf uno bie Rip= pen hängen herab uno ber Speidel flieşt oft. reidylidy aแż bem

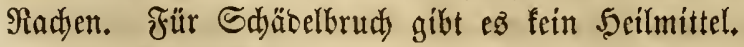

Derartige Beidäbigungen fommen bäufiger yor, als ez fíd unjere Farmer vorftellen. Die Uriad)e berfelben ift gemöbnlid ein keftiger, von einem zornigen Fubrmann auf ben $\mathfrak{s}$ opf gefüfrter Sdlag, wel= 
det bem Befiter ein merthyollez Thier foftet. Beruriajajen aber ber=

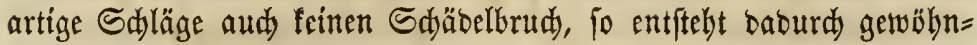

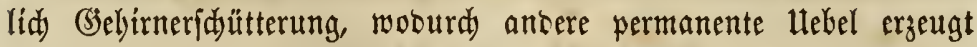

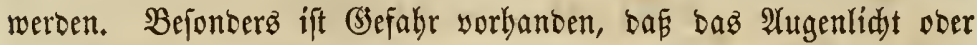

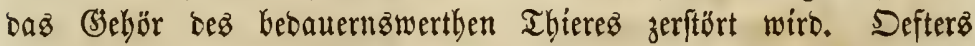
¡djon waren wir unfreiwilliger 3 uj jauter, wenn Pferbe über ben

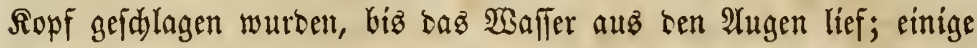
Monate Darauf faken wir biefe Thiere mit mildjigen (milky) $\mathfrak{A}_{\mathfrak{H} g e n,}$ unt fpäter entftand bie unter bem unridtigen Ramen "Mono= Blinbkeit" befannte Rranfheit. Nidjt wenige Sgferbe werben burd jold) grau [ame Mi

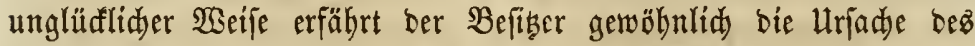
Uebelftanoez nidjt, obgleidh er bie Folgen ber Brutalität nur zu balo wahrnimmt.

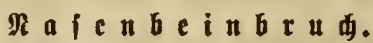

Mandje Seute find bejüglid) igrer Pferbe aukerorbentlid nadjläF fige Beobadter. Wir baben Thiere mit Rafenbeinbrüdeu gejeben, burd) weldye fie förmlid entiftellt wurben, wäbreno ber Eigentlyümer über ben angeridteten Edjaten augenflyeinlidy ganz unt gar unwiF feno war. Rajenteinbrïde Geilen gewöbnlid yon felbit, ez fey benn, Dar ber gebrodjene Sinodjen bebeutend nady Snnen gebogen ift, in

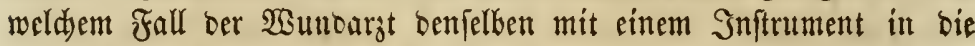
redjte Rage zu bringen bat. Sft ber gebrodjene Sinodhen jebod) aubz= wärtz gebogen, fo mag er mit ber 5and eingejest werben. Wenn man heifez Salzwafier applizít, io wiro baburd bas Fieber io= wohl alz bie Sdjmerbłaftigfeit verminbert.

\section{(B) b}

Die Rippen werben oft burd einen fayweren Fall auf bie Seite

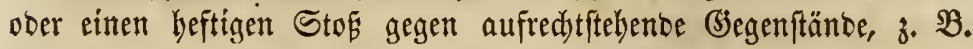
Moften zc. gebrodyen. Dieje Fälle fommen jebody felten yor, uno werben nodj feltener entbeft, ez fei benn, baß zu gleidyer Zeit ein Brud der Rücfenwirbel eintritt. Die englif den Thierärgte beridten nur yon sinigen Fällen. Mit 2 (uşnahme ber $\Re u k$ e, bie man bem

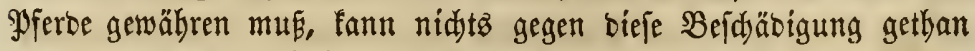
werben, unb wenn bie inneren Drgane nidyt verlebt fint, fo mag baz Pferd wieber gefund werben. Rann man ben Sit beg Brudib ermit= 
teln, fo forten bie betreffenden Theile tüdotíg mit beísem, mit ziemlid

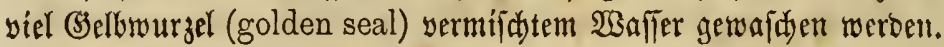

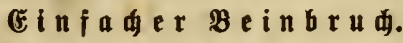

Mandymal fommt Beinbrud yor uno zwar entweber in Folge yon

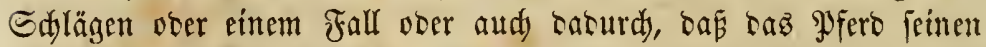

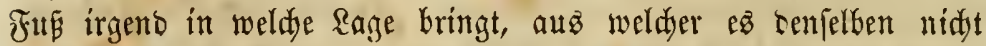
mebr leidyt befreien faum. Die Utrādje bez Beinbruddz zu ermitteln, ift weniger widftiger, als jut verftehen, wie berfelke geheilt wernen fort. (Ein Beinbrud) ift immerbin ein bebenflider Sdyaben, weldjer bie fofor= tige 2 humerffamfeit und energifdes Einid)reiten erforbert, wäbrent ge=

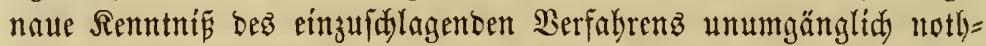
mentig ift; unt beshalf, wetl umferm frarmern biefe Renntmif abgely, geben fie ein \$yferb mit gebred)enem Bein fogleidy hoffnumggloz auf

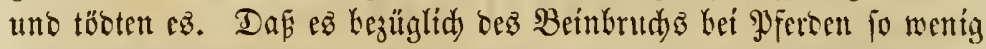

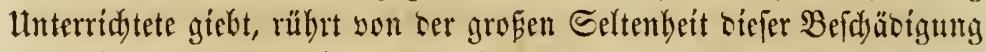

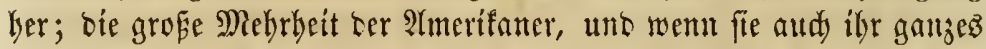

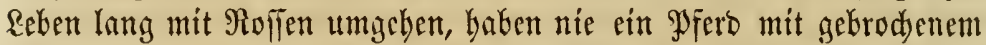
Bein gejeben, utho jollte bies autd ein ocer tas antere Mal eines igrer

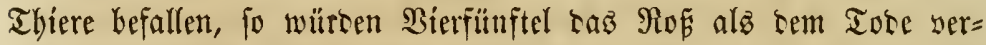

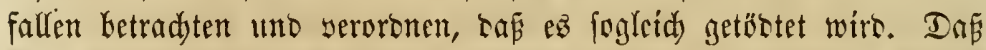
man unter feitun Umetänden einen Sceinbrudy am gyerte beilen

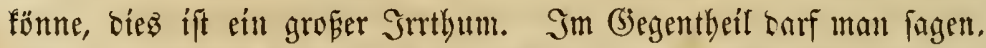

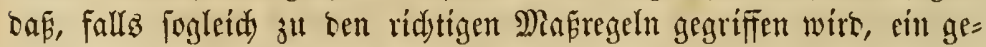
brodenez Bein gebeilt mersen fastn. Freillid) foftet es siele Miübe,

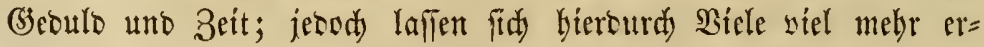

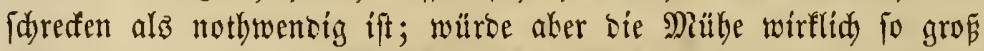

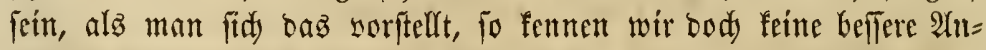
wentong ber 3eit als bie, weldye mit Bemühungen, einen Brudi ju beilen, jutgebrad)t wirr.

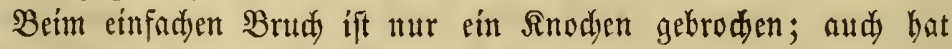
weder Berrüfung nod) Splitterung ftatigefunden. Daz Paferb fann

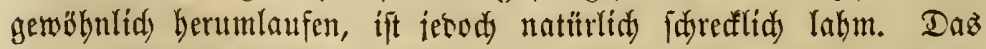
Bein follte mit Streifen yon ftarfem, geftärftem Tud yerbunten unto auf ben Brudh follte lofe Baummolle gelegt werben. In ben meiften Fällen legt fidd bas \$fero gar nidht nieder, fondern bleibt mebrere Tage

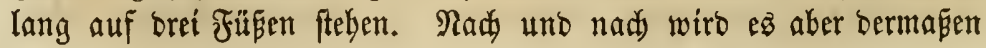


mübe, malz zugegeben weroen, fonbern ber Eigenthümer mü [ogleidy $\mathfrak{2} n=$ ftalten zur Unterftübung bes PSferbez treffen, jonft mödjte biejez Rie=

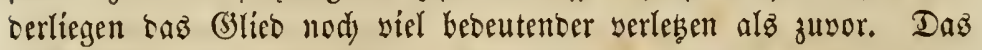

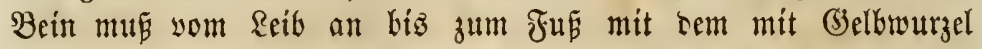
(golden səal) vermifidten Saljwaller tüd)tig gewafdjen werben, fo,

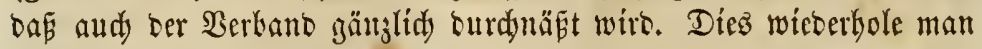
währeno ber erften vier ober fünf Tage vier= ober fünfmal täglid, la fle bamit allmäblig nad), bỉz man ganls bamít aufbört. Der Berband mus jeben antern Tag afgenommen und aufz neue angelegt werten, und im Fall bie wunte Etelle anjdinillt uno bas gyero

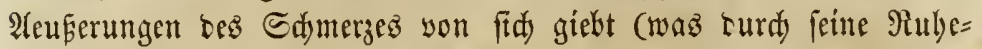
loftgfeit angezeigt wirt), io follte bie Binde nur einige Etunten auf

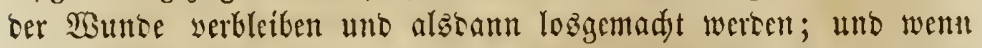
ber Berkano abgenummen ift, fo wajdje man sen Fus mit bem oben angegebenen Saljwajier reidjlidu.

Sit ber Brudy cin coppelter ober Epritterbrudy, fo wiro fid baz PFero gewübnlid) auf sie Seite legen, uno mus aufgeridjtet werben,

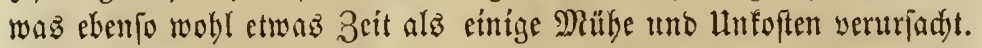

Daz biefez ber erfite Edyritt in bem zu beokadjenten Berfahren iff,

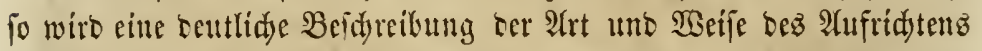

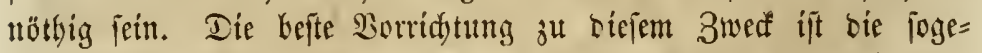
nannte Edjlinge (sling), welde ket einfadyen uno Doppelbrüden

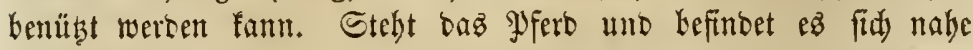
beim Stall, fo fann man es in Denjelben fübren uno einige ftarfe

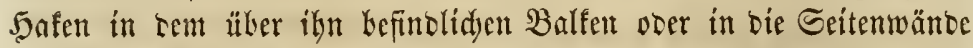

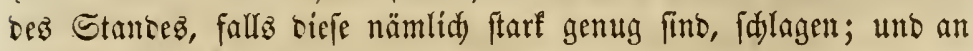
biejen bafen wiro sie Sajlinge aufgehängt.

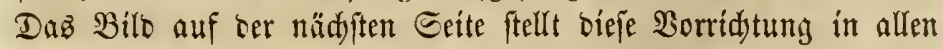
ibren Theilen tar; jerod fann audy cine einfadjer angefertigte $\mathfrak{V e r}=$ wenoung finben, fallz eine berartig zufammengefeste nidjt hergeftellt. werben faun. Diefe Mafddine mag entweter auв $\varsigma_{a}$ ober Segeltud) gemad)t werben, und fint vier $\mathfrak{Y}$ Jarb hinlänglid. Man näke bie Enoen febr feft zufammen, fo bas haz boppelte Tud etroa

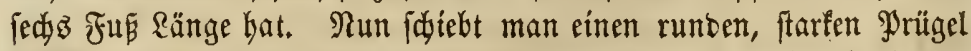
auz Kartem 50 ol burd je einz ber Tudjenben uno befeftigt ein ftarfez Seil an bie Enben beż einen, unb eín anterez an bie Enden bez 
anbern Soügelż, uno groar fo feft, bap bieje Seile nidht auछgleiten fönnen. Beibez biejer Seile follte etma zmölf Fus, alfo die eine Eeite eines jeben, menn aufwärtż gezogen, etwa fedjz Fuß lang fein. Díe alfo angefertigte uno zuredit gemadyte Sdylinge wito nun unter bas Pferb gebradyt; fodann jicht man ein anteres boppeltez Scil ourdy bie an bie Prügel befeftigten, Forwie burd) cinen $\Re$ ing, ber an ben

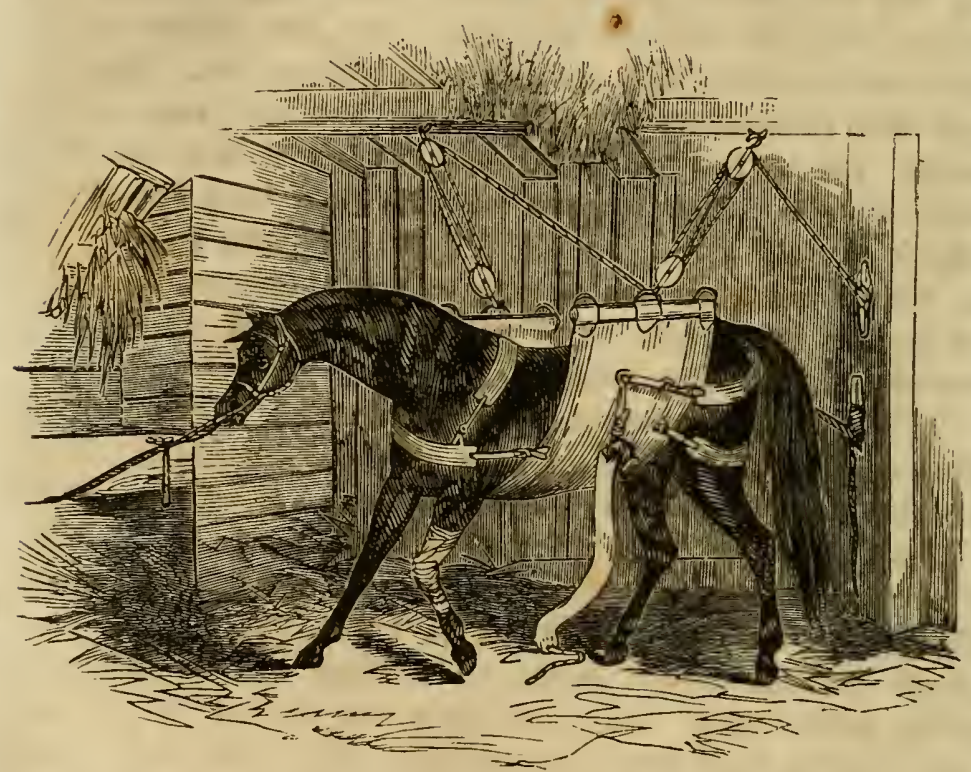

eingefdlagenen Safen angebradjt wirb; befeftigt baffelbe juerft an oer einen uno bann an ber anbern Geite uno zwar fo, baj ber

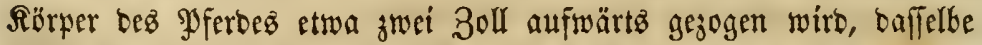
icsod) immer nod auf ben Füfen ftelyen fann. (5z wirb balo ler= nen, falls feine vorberen Glicomafen febr ermübet merben, in ter Sdlinge auşuruben. Dan hat tas Thier mittelft einer guten, ftarfen Salfter feft

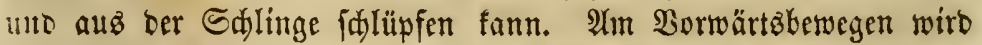
$\mathfrak{c}$ ourd bie Srippe verhinbert. Sit fein Borberbein gebroden, fo wirb ę veriud)en rüfwärtz zu geben, unt umgefebrt, wenn ber Brud all sen hintern (3)liebmafen ftattgefunten, wirb $\mathfrak{e B z ~ f i d ~ v o r m a ̈ r t z ~ b e = ~}$ wescut wollen. Betces muß serbïtet mersen. Bielleidt bridst eín. 
Syerb ein Bein, während ę eine bebeutenhe Streffe yom Stall ent= fernt ift, in weldjem Fall man ein

\section{(ङ) e $\mathfrak{r}$ ü fิ (frame)}

aufzuld)lagen hat. Ein foldes fann in ber (J)efduwincigfeit mittelft

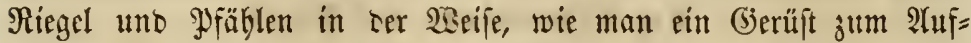
bängen toster Sdyweine berftellt, angefertigt wersen. Ga fint adjt

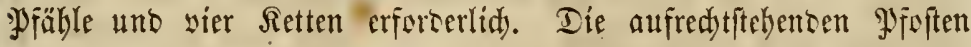
werten an keiten Exiten tes Thieres angebradjt, unto ungefähr adjt

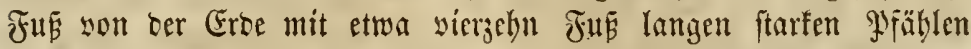

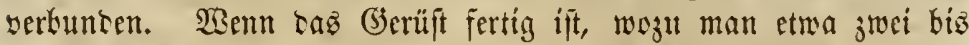
brei Etunden braudt, fo finto fünf biz fed) g Mann erforterlid, um

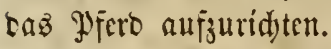

Sebt miro bie bereits befdyrichene Edylinge (sling) unter bas glert gebradyt, unt ntan wirft tas Exil über bie Wrähle, weldfe zu beiten Eeiten an ben Proften fejtgemadyt fint. Diefe Plfoften foll= ten sornen uno hinten etwa fedjz fous auseinanser fteben uno io

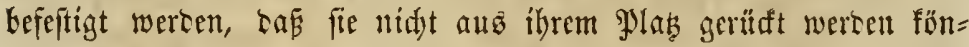
nen. Ein Mann ftelle fid) an sen Sopf uns ein anterer an sen Sd)weif bes Pfertes, uno einer an je ein Ente tez Eeiles, weld

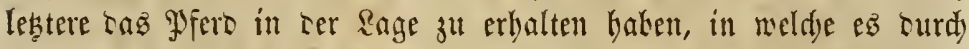
bie Ânftrengungen ser antern gebradyt wurbe. Es ift frine geringr 2rrbeit, uno miro sen Männetn am Rapf uno Edyweif viele Mühe

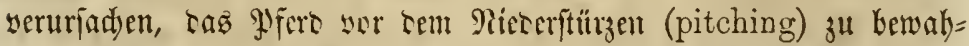
ren. Sobald es theilweife crlyoten ift, wirb ein guter Puaf am Eeil Das Thier yollents auf sie Beine bringen. Wahrideinlid) wiro eine Weile etwas unrubig fein unb lošreífen wollen, was natürlidy vergindert wersen muf uno vormen mittelfit einer ftaten 5alfer uno hiuten mittelft querüber genagelter, ftarfer Eparren geidjelgt. Thuf Dem (B̉erüft hat man ein ftarfes Dad) anjubringen, tho sornen ift

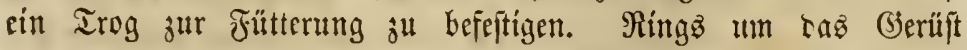

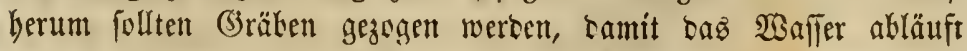
uno oer Pratient autd) im Regenwetter troden fteht.

Eine anbere $\mathfrak{2}$ norbmung, bie getroffen werben mag, wenn bas (S)erüft uno bie Edhlinge nidyt bejdaffit werben fönnen, ift unter bem Namen 


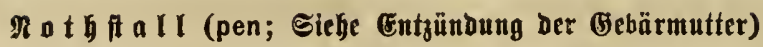

befantut. Sino alle biefe Alnoronungen ausgefübrt, fo fino wir nunmebr für

\section{Dic Einridtung bes Beins}

fertig. Sift Der Brud ein boppelter (compound), uno fint bie

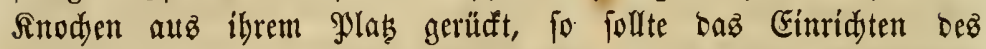
Beinz nody sor bem 2 (ufridyten bez Pferbes gefdeben, uno fogleid, nadjoem bas Unglüd gefdeben, follte bas verwunbete Bein mit beifem Seifenwaffer gut gewaiduen werbet. Man mag in bie= jent Waffer burdunäpte Sappen um bie Wunbe binten und zwanzig

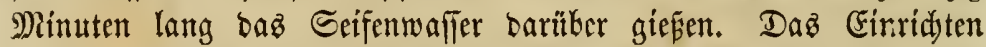
gefdiebt baburd), daf man einen Strif um bas gebrodjene Bein binbet, benfelben um einen SPfoften ober anbern feft ftebenden (siegen= ftand fdylingt uno fo lange Daran zieht, biz tos Bein eingeridytet ift, waz man burdh einen fanften Drud mit ber Şano ermitteln fann. Nunmebr foluten bie erften Rappen yon cimer PJerion entfernt werben, wäbrent eine andere ben $\mathfrak{B e r b a n d}$ juridjtet. Derielbe wiro aus orei 3oll weiten Etreifen ftarten Tuds, weldye in eine warme flebrige Diffung (adhesive mixture), bie man burdy bas Sd)mel= zen gleidyer Theile verdidfen Ierpentin (burgundy pitch), Bienen= wad) (beeswax) uno Talg (tallow) anfertigt, getaudst weroen.

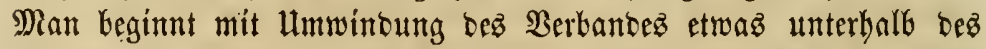
Brudues, lege vier ober fünf 3oll yom Enbe ber Binbe aufwärtsి am Bein und umwiffle biefez Ente, samit ez fefthălt; lege etwaz lofe Baumwolle über ten B̧rud uno umminbe biejelbe feft mit ber Binbe; laffe die Streifen bez Berbants mit jeber \$Bindung unge= fähr eimen 3oll vorfteben uno umwidłle das Bein fo weit oberballb

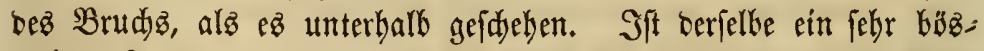
artiger, fo mögen grüne, nah) Der frorm bes Beinez gebogene $50 l ;=$ ftüdduen mit einer andern in bie flebrige Mafie getaudten $\mathfrak{B}$ inbe fo

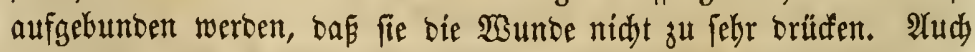

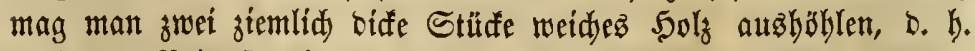
nad) bem Bein formiren, uno bie Enoen bünn funeiben, fo bak fie an bemjelben gut anliegen und biefe Stüde mittelft bes mit ber

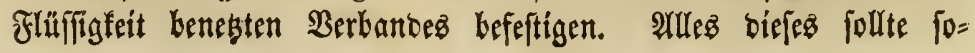


balo als möglid gefdeben, worauf baz Seil yom Fú lożgebunten wirt.

\section{Ве}

Das sein follte mit ber heífen, aus Salzmafler uno Gelbwurgel (golden seal) beftebenden Mifdung wäbrent ber brei eriten Tage alle paar Stumben uno aud) fpäter Dann unb wann tủdtig getwa= fiten werben.

Sat ber Beinbrud) über bem Sinie ober Sprunggelenf (hock-joint) ftattgefunoen, oder wenn beide Sinorben unterbalb bes einen ober andern biejer (Sielente gebrodjen fint, mödten wir rathen, falls man ez tem Pुfero einigermajen erträglid madyen fann, baffelbe zwei Wodyen lang liegen zu laffen. Zwoar fann man bas (3erüft errid)= ten, aud) follte man bem Patienten unter allen Umftänben cin $D \mathfrak{b}=$

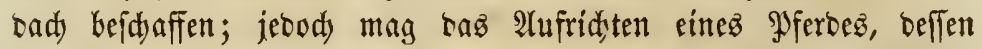
Bein fefr íblimm gebrodyen ift, auserorbentlid) gefäbrlid werben; auferbem fann bie Cinridjtung nidjt fo gut auszgefülyrt werben, wenn baż Thier ftebt, als wenn falls กas Thier auf bem Booen liegt, ras obere ift, fo ift ez nidyt nötbig viel zur Unterftỉbung bez Şatienten ou thun, uno einige fo zuredtgelegte Bünod Strob, Laf oer Fuf Darauf ruben famn, mö= gen genügen. Sft aber ber verwuntete Fus ber untere, fo mú gerabe unterbalb ber $\mathfrak{B}_{\text {unde eine }}$ Bertiefung gegraben werben, in weldye man Strob wirft, bamit ber verwunbete Theil ein gutez rager babe. Bon Zeit zu Zeit bat man nadjureben, ob Las Bein anid)willt, in weldem Fall ber Berbano loşzubinoen uno leidgter angelegt werben mus. Sebod fdureitet man biezu bloz im äuperften Fall, menn nämlid) saz balo äufern wirs, bat man das Bein forgfältig uno wieberbolt

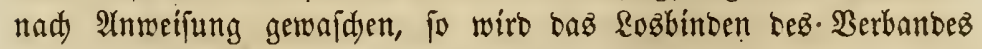
nidyt nöthig wercen. Im Fall ber Beinbrudy im Winter ftattfinbet, fo kringe man bas Pferb unter allen llmftänden in ben Stall ober bic Sheune. Sein Bein mag vorberbanb, fo gut $\mathfrak{e B}$ gebt, verbun= ben uno gefdindelt werben, worauf man bas \$Pferb yorfiditig auf eimen nieberen Sdylitten bringt, uno fo in bie Sdueune ober Stall führt, wo es warm uno angenehm ift. Steht baz Thier nod, 
nadjeem ez daz Bein gebrodien, fo führe man uno nelyme bas ganze $\mathfrak{B e r f a b r e n ~ b i e r ~ y o r . ~}$

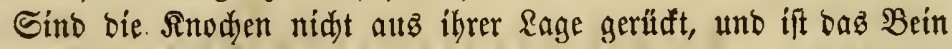
nidyt frumm geworben, fo genügt bas $\mathfrak{A}$ uflegen ber in bie flebrige

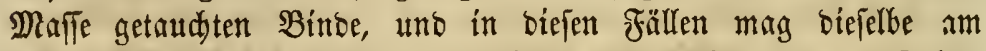
britten Tage abgenommen uno wieber angefeuditet unb aufgelegt werber.

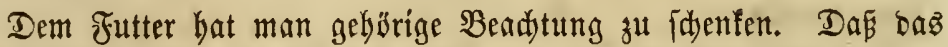

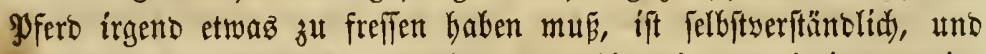

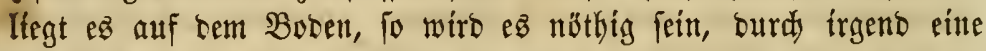

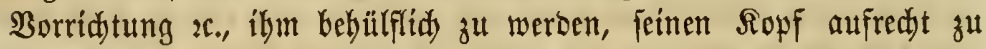
balten. Man mag ifm baz gewöbnlidje Futter geben, Säaffel, Seu ober 5 afer, aber fein Sorn.

\section{Die 3 eit d a er Der $\Re \mathfrak{u}$.}

Die zur Iur erforberlidje Zeit wiro in verfajiebenen Füllen ver=

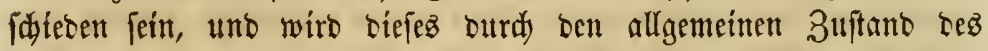

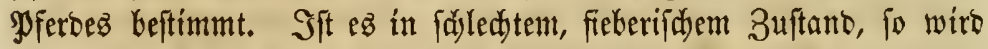
es wahridyeinlid nidyt mit bem Reben bavon fommen; benn bas

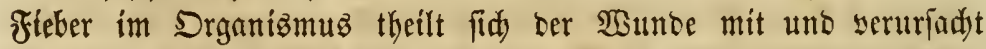

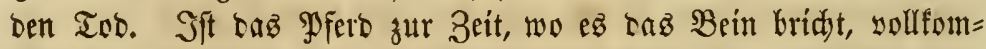

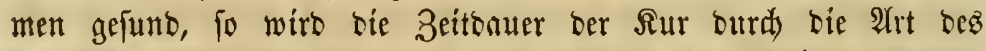

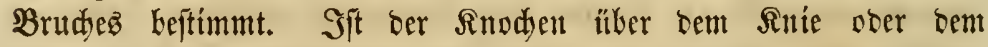
Sprunggelent gefroden, fo wiro man zur 5eilung einen Mlonat mebr gebraudden, alz wenn ber Brud unterbalb bez Siniez ober Sprunggelenfz ftattfintet, uno ein boppelter Butd, wenn ber Snođen gantz abgebrodjen uno aus feiner gewöbntidjen Rage verfdyoben ifi, erforbert breimal fo lange Zeit zutr Sur alz eín gewöbnlidyer, einfad)er Brud. Sebenfallz fann ein Beinbrud nidjt unter einem biz bret Monaten geheilt werben, und mandimal gebt nod) einmal fo viel Zeit vorüber, ehe baz Pfero zu Dienjtyerridjtungen touglid

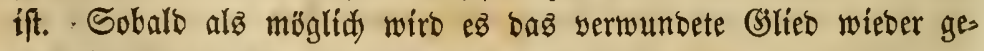
braudien, unb follte Gíezu nidht aufgeforbert werben. 


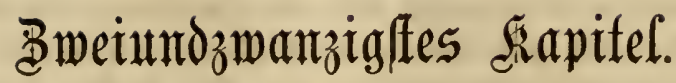

\section{(⿻)}

EB war eine traurige Nothmentigleit, als man bie Pferbe zum

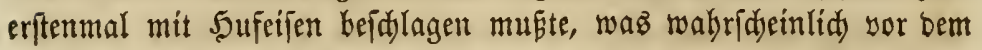
zwölften ober treigebnten Sahrbunbert nidat geidjah. Bor biejer Zeit wurben bie Wferte níd) beidlagen, batten aud feite Gien nö= thig, La ter yom Edjëper verlichene Edjus

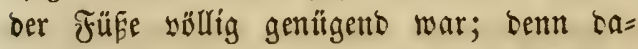
malz, als alfeż nod) in natürlidem Buftanto war, war ber hornige 5 uf tem Zwed gan;

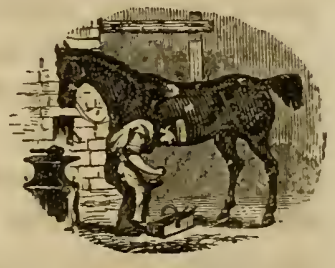
utto gar entipred)eno; heutzutage aber, wo allez fünftlid) jubereitet

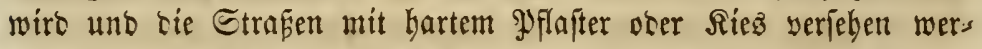
ten, hat bas Pfert eine Befleicung bes 5 Tufes nöthig.

Bielleid)t wurte ten

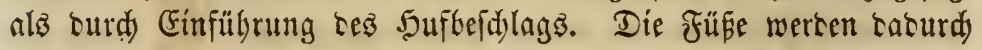
bejdärigt uno oft ruinit, who aupertem werben taturd) aud nod) anbere Rebensorgane afficirt unt gerathen in franthaften 3uftant. Sbrwobl aber bie burd ben 5ufteidlag verurjadten $\mathfrak{H e b e l}$ zablreid

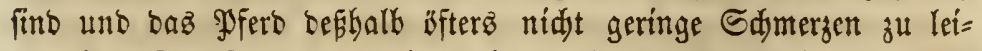

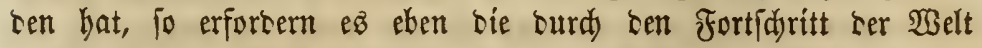

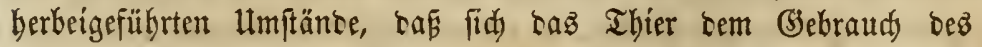
Memiden füge. Hnjere 2afbiddt ift, in biejem Rapitel auf sie unnis= thigerweife burd) sen Sufbejdlag Kerbeigeführten $\mathfrak{l}$ ebel zu verweifen uno $\mathfrak{A}$ neitung zu einer praftifden Methobe bez Bejdlagenz zu geben.

3u allen Zeiten bat man fid mit biejem Giegenftand befaßst, uno

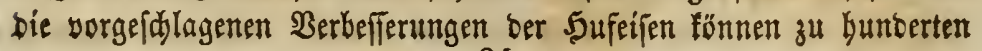


gezäblt werten; troberbem hat man aber wenig wirfliden Fortiduritt

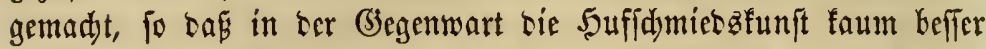

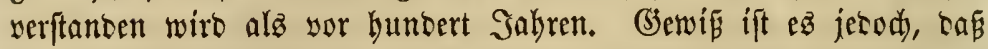
bie gewöhnlidy burdy ben Shffeid)lag erzeugten Hebel nidst fowohl

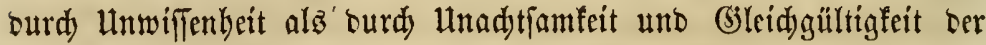
Artbeiter yeranlafst werden. Sn einem Werf "üher Das Pfers" finto

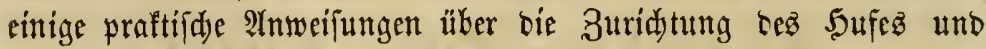

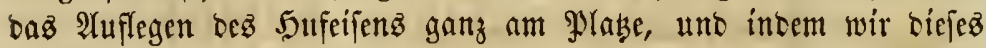
thun, werben wir zuerft anfiuthren, was Youatt über biejent (Jegen= ftano jagt, benn Befferes fönnten wir nidjt Kieten, uno würten im

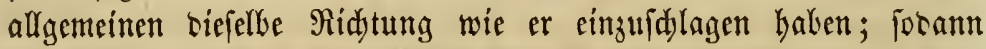
nber werten wir foldhe praftifde $\mathfrak{A n w e i f u n g e n ~ g e b e n , ~ b i e ~ i n ~ b i e f e r ~}$ Begziebung namentlid) für bic amerifanifa)en $\mathfrak{S e r b a ̈ l t n i f f e ~ u n o ~} \mathfrak{u m}=$ ftänbe, unt bie Zuftänte ber Pferbe in unjerm Lanbe paffent fint. "Die Zeit, wann man mit bem Sufbeidlag begonnen bat, fann nidjt genau beftimmt werben. WBillyelm ber Eroberer fübrte benjel= ben in Englano ein.

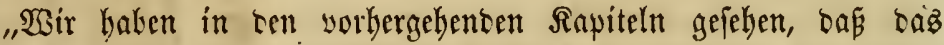
Sufeijen, währeno ten barten Straßen fo nothwentigen Sdyut verleitht, aud bie $\mathfrak{u r}=$

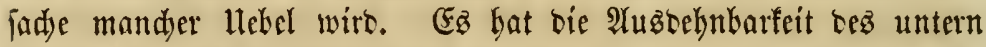

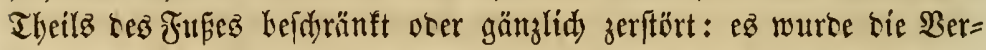
anlafiung fur Zufammenzichung (contraction), obwobl biejelbe nidyt

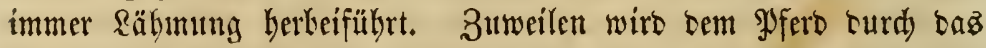

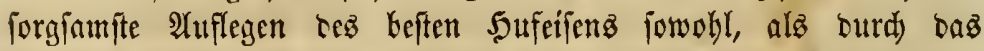

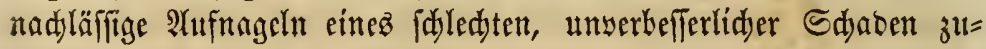
gefiugt.

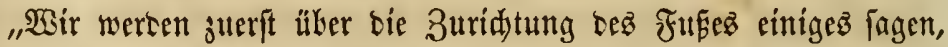

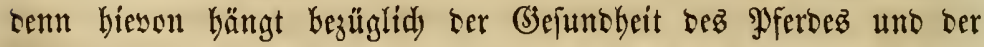

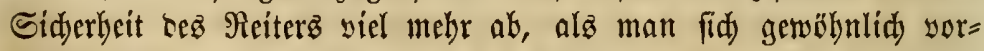

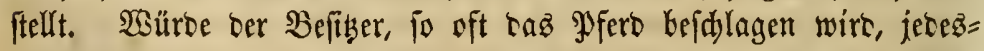
mal felleft mit zur Edymieos geben, fo bürfte er biedurd mebr

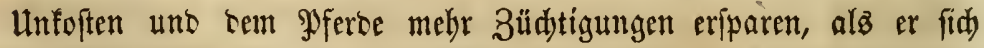
einbilbet, yoraugereiest er verftebe bie Sadje felbft, wiorigenfallzz

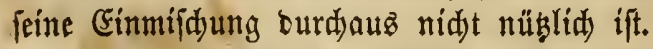

"Зुuerft muß bas alte Eijen abgenommen werben, wobei zu bead)= ten ift, Dás Daffelbe baburd) befeftigt worben, daf man burd die 


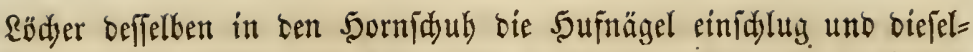

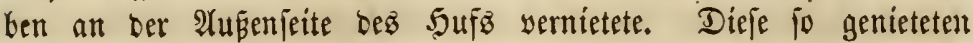
Nägel müffen vorerjt adtfam aufgeridtet werten, woju fid ber Sdmieb aber jelten Zeit nimmt, fonoem nadoem er taz Gijen mit bem $\mathfrak{W e r f}_{j}$ eug ein wenig losgemadyt uno einen ober zwei ber umge=

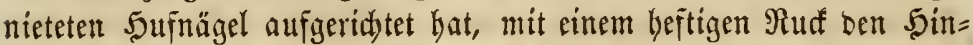
tertbeil uno mit einem antern sen yorbern befielben abreift. Dutd)

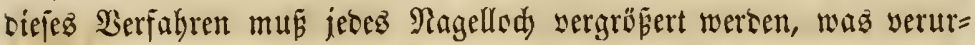

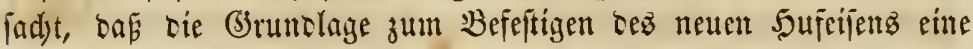
um fo viel lofferere uno unjuverläfijgere wirs, nid)tz ju jagen $c \mathfrak{a}=$

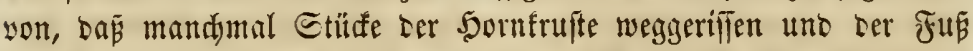
anberweitig bejdäbigt witb. Dap bem Prerbe ourd bie mit foldter (3) walttbätigfeit auछgefül)te Borbereitung für ben Beia)lag feine ge= ringen Shunerzen vertrjadjt weroen, bies zeigt es Durd Zưfen und

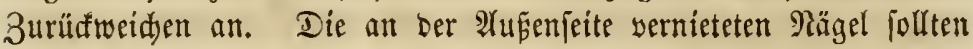
immer forgfältig aufgeridtet werben, und wenn ber fun bes Pfer= Des bejonsers weid und empfindlid, ober falls baffelbe labm ift, 'o follte jecer Nagel forgfältig ausgezogen werben. Durd) Das ge=

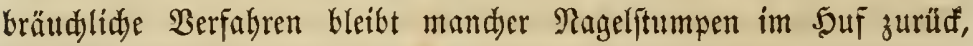
woourdy mandjez päter berwortretento Ulebel uno viele Befducroen bervorgerufen werben.

"Sobalo bas alte Eijen abgenommen ift, rajpelt ber Sdymied die Santen Der 5uffrufte ab, wogegen, aud wenn biez mit ideinbarer

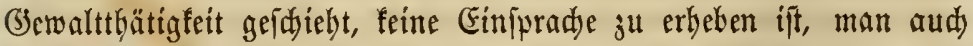

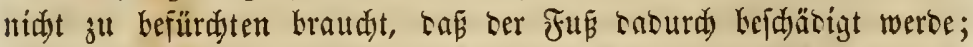

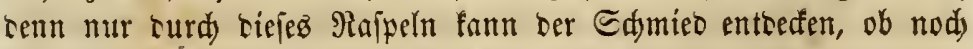
Nagelitumpen in ten Rödjern.ftecten, währent ju gleid)er 3eit ber Theil ser Sirute entfernt wiro, in weliben fid Sano, Staub 2e. feft= gejetgt bat.

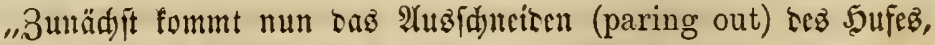

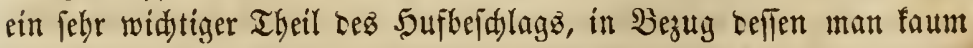
genaue, in allen Fällen anwenbbare Regeln aufitellen famt. (5) twís

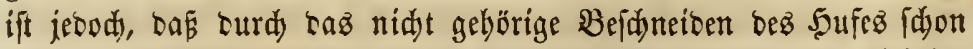
wiel mebr Shaben angeridatet wurbe, als menn berjelbe zu viel be=

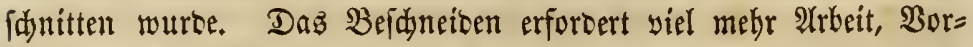

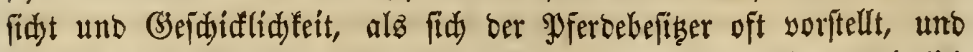
ber Sdymied, falls man ibn nidyt beobadytet, wiro fid getwöbnlid 
fo menig Mäke bamit madyen als möglid, uno ber Theil bes Şuf-

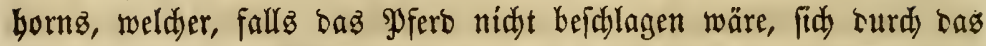
(Seben abnüzen würbe, wäch/t yon einem Monat zum anbern, biz bie Claftizität ber Soble zerftört ift uno fie fid nidyt meiter nach unten aušbehnen fann. Steburd weroen, abgefeben bayon, bap bie Funftionen ber Soble zerftört werben, mandjerlei lebel, menn nidyt fogleid, fo bod ipäter herbeigefübrt, als oa find: Gallen, Bollkuf,

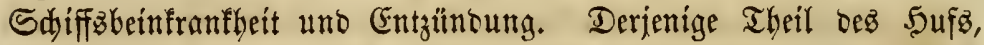

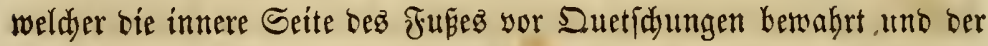
Soble zugleich Raum zum Wadjen giebt, follte nidht abgeidnitten werben. Uno wie fann man ermitteln, wie biel abgefdnitten wer= ben foll? Ein ftarfer Druf mit bem Daumen auf bie betreffenten Theíle wiro ben Sdymieb belebren. Da bas Wirfeifen (butteris),

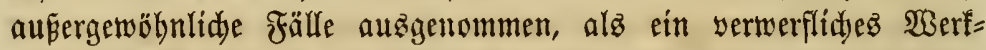
zeug in feiner refpeftabeln Echmiebe mebr gebraud wirb, fo fduci=

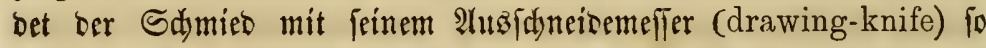
biel son bem Sufeifen ab, biz tie Soble ben Drut bez Daumenz nadgiebt, jebod nur um febr weniges. Sicourd wirb bie erforber= lidue 5ornlage auf ber Soble verbleiben.

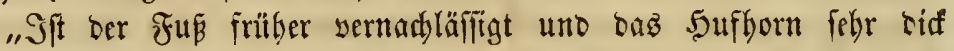
geworben, fo muj ber Eigentbümer feine Ginipradje erbetien, wenn ber Sdymieo bie harte Eubftanz mittelif eittes glübeno gemadjten

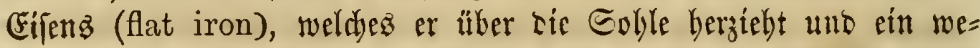
nig sarauf ruben läft, zu ermeidsen judt. Sft bie Soble wirflid febr diaf, fo fann diefes raube uno facinbar barbarifde Berfabren feimen Shaben anridaten; man barf bafielte jebod nie zula falla ber Şuf regelmäetg bei jebem Beidblag befdnitten wirb. Wie viel Şorn abgefdnitten werben mus, um bie ridytige Diffe ber Soble zu bezweden, biefez ift bei veridjiebenten Ilieren serfdícoen.

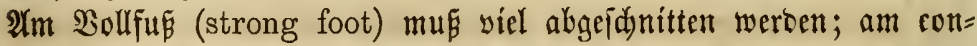
caven mag fo viel abgenommen wersen, bis bie Goble einem mäfí gen Druf nachgiebt, uno som Plattfúp (flat foot) hat man nur wenig auszuidneiben, währeno man yon einem fauligen (pummiced) $\mathfrak{F u p ~ n u r ~ b i e ~ a b b a ̈ n g e n o e n ~ F e k e n ~ a b n e b m e n ~ f o l f t e . ~}$

"Ift ber Sdumied mit dem Bejdneiben beinabe fertig, fo wiro ez ratbjam fein, benjelben genau zu beobadyten, fonft wirb er sie Rrufte bermafen befdneiben, bafi fie mit ber Soble beinabe eben ift, wo= 


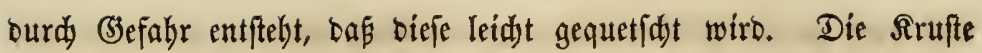
jolute ringz herum ganz eben, jebody etwas böber alz bie Soble fein.

"Ebenjo bat man feine 2Yufmertfamfeit auf bie innere Ferie zu

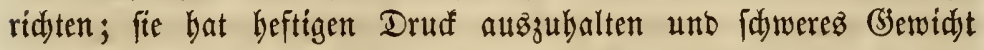
ju tragen, unt ba bie Sornwänte (aud) Suartiere, Tradten; eng= lifd) quarters) an jenem Theil nidjt bejonbers ftarf fint, fo nübt (id) Der Suf bort aud) fdneller ab als fonftwo; witrbe man beǵbalb bier eben fo viel Sufforn abfdnetben, als an ber äuferen Ferje, fo würoe bie innere niebriger fein als biefe. Der Sdymteo follte bas Befdneiben ber Ferfe barum genau nad) ber Tlbnübung berjelben einridgten uno auferorbentlid) yorfidtig fein, oaf siefelbet sollfom= men eben werben.

"Wenn fid ber Rejer erimnert, wag über ben 3wed und bie Funt= tion ber (Fffitreben gejagt wurbe, fo wirb er leidjt erfennen, bafí bem Sdymicb Cinfalt gethan werben mus, zu viel Sornjubitanz zwifhen ben Ferjen herausjaj

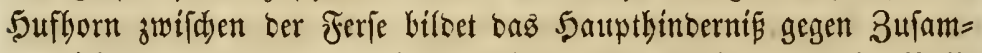

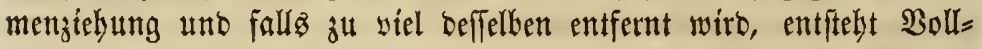
buf. Der zwifden ber ßiegung (inflection) ber Eeffitreben uno bem Strahl (frog) liegende Theil ber Ferfe follte faum mit bem Mefler berübrt soerben, unt man follte bier nur bie berabbängenden Sorn=

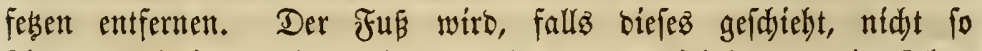
fajön uno frei aub̧eben, aber ben Strapajen viel länger wiberfteben fönnent.

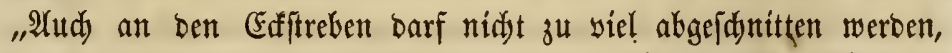
uno jwar muf man biefelben snidyt allein an ifrer erften Biegung, fonoern audy ba, wo fie fidh an ber Seite bes Strablz binzielen,

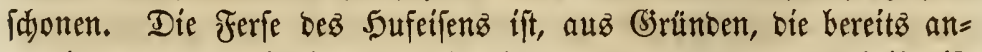
gegeben worben, beftimmt, theilweife auf ber Jerfe und theilweife auf ber Gaftrebe bez Fufes zu ruben. Sft bie Gefftrebe fdwady und flein, to follte man zu foldyen Dasregeln greifen, die beren

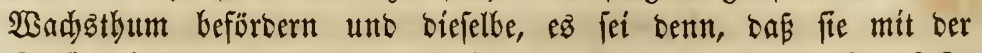
Rrufte eben geworben, faum mit bem Meffer berübren. Der Rejer wiro fid ber bereitz gemad)ten Bemerfung erinnern, oas nämlid,

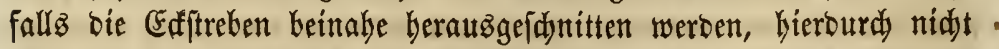
alfein bas Sinderníf gegen 3ujammenziebung entfernt wirb, fondern. 


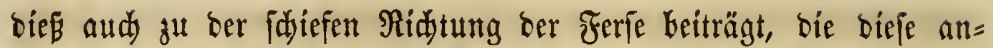
nimmt, wenn fie nidyt won ber Edfftrebe unterftübt wiro.

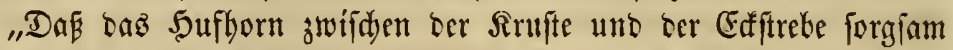
auşgéd)nitten werben follte, iff einleudjento; uno jeber, ber mit

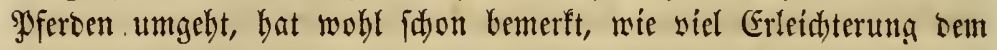

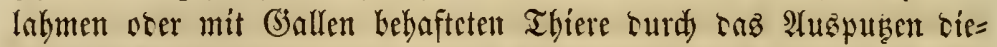

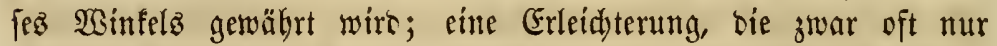
zeitweilig ift, weil, wenn baz 5 ufforn wieber gewadyen, fo bą vom Eifen gebrüưt wirb, fidy bie Sdymergen wieber einftellen.

"TSie siel ooer wie wentig yom Strabl abgeidnnitten weroen foll,

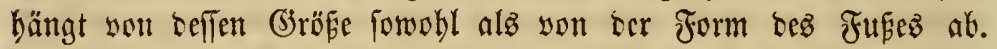
Dapi terfelbe io weit hersorftehen foll, ba tiefer fteht alz baz Gifen, bierauf wuroe bereitz aufmerffam gemadyt.

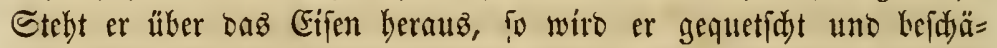

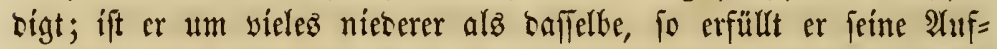
gabe nidyt. Die Kerabbänhenten, zerfesten Theile, uno namentlid bie burd) Strablfüule erzengten, follten entfernt meroen; aber wie viel ber Strabl befidnitten werten mus, biez ridutet fid ganz uno gar nady rem angegebenen (jorustojat.

„STierauz geht hersor, baß cin 5uffidmiés zur Grfütung feiner 2)

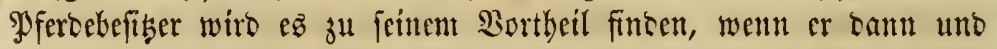
wann zur Sdymiebe geht, und oen unadjtamen, oter faulen, ober eigenfiunigen (J)efellen juredttweift, unt sem guten uno fleişigen ein

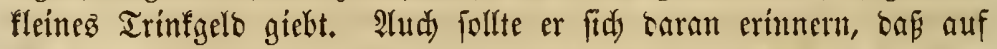

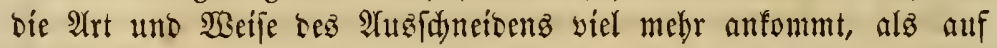

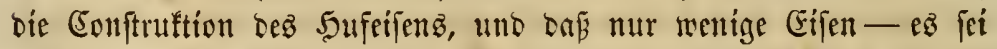

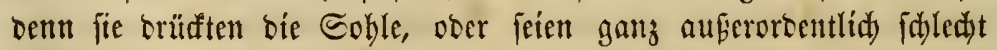

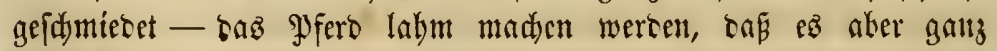

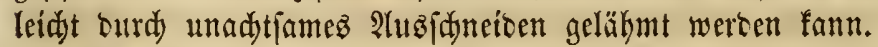

\section{Das Aufregen des}

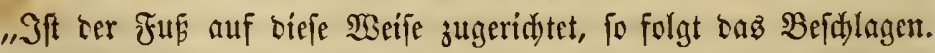
Der Edymico follte ein bem Fufe paffendes Eiffen, ober wenigitents

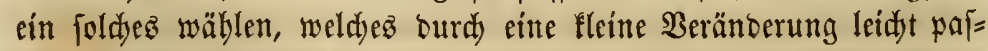
feno gemadyt werben fann. Mandjmal wirb er, namentlids wetn er

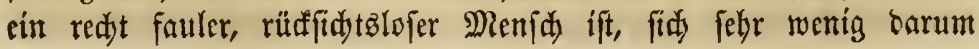




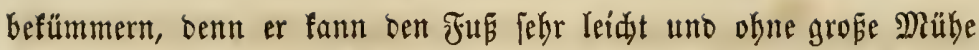
nad) ber (b)eftalt bes Eifenz formiren. Mit bem bufmefier

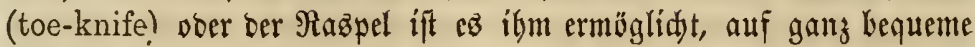

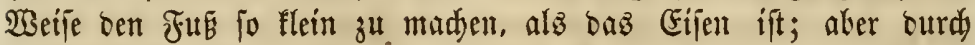
jold) gewiifenlojes und gleid)gültíges Berfahren wiro bie Sirufte ba, wo bie Rägel burdygeidlagen werben, bebeutent sünter, und bic (Gefahr, baj bie Soble gebrüatt unt gequetidgt werbe, um vicl ver=

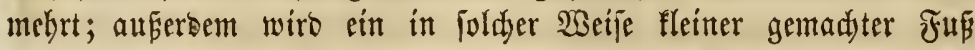

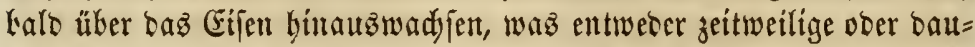
erttoe Rähmung hersorbringt.

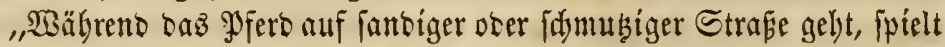
fid) oft Sdymus uno Santo zwifden baz Eifen uno ben Jusu; falla nut bajfelbe gantz flady auflïge, würoen sieje Subjtanjent bort bleiben, rie

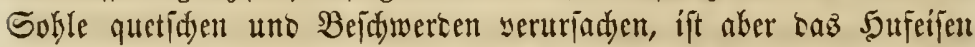

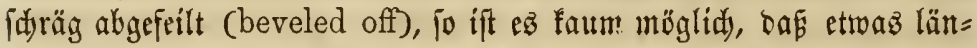
gere 3eit unter bemielben bleiben fann, fonbern bie Sanbförner $x$.

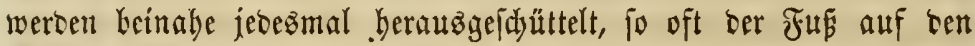
Boben gejegt wirt.

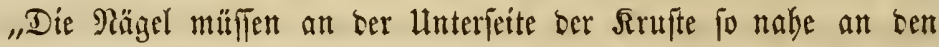

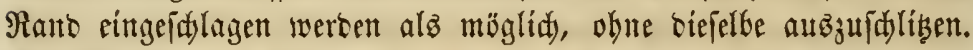
Der Sdymies ifit p̈fters nicht bereit, ein jold) fajräg geidymiebetes Eijen anzufertigen, weil befen Butereitung mehr Zeit uno Mühe erforbert als ein flactez unt weniger idrägez. Er twiro jebod) bieje Einwensungen nidyt madyen, went ibm ber gyjerbetefiber bebeutet,

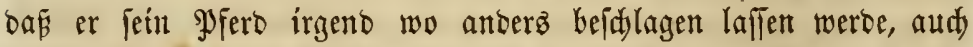
willig fey, - waz nifft mebr alz billig ift - etwaz mebr für ein Eifent żu zahlen, befien $\mathfrak{A}$ nfertigung größ̈ere Fertigfeit uno mehr Beit erforbert.

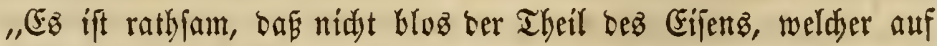
ben $\mathfrak{B}$ ooen aufigejegt wirb, genau eben gemadyt werbe, fonbern audd, dafí bie Rrujte glatt gerajpelt uno bem Eifent angepaft werbe, waz, went ez auf bie redyte Wseife gethan werben joll, biel Zeit unto Geidjifflidffeit erforbert. Die Sdymiebe haben eine nete Methobe er= funoen, mittefft berer fie bie Srufte, ofne fid fo fehr zu bemulthen, eber madyen. Sie jajneiben biejelben eben io gut alż eż geht, uno ap=

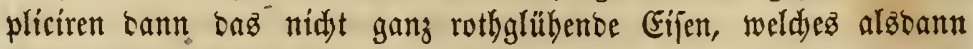
bie erböbten \$untte an ber Srufte brennt, die baburd Dem 5and= 
wertżmann angezeigt werben. Man bat gegen biefez Berfabren yon vielen Eeiten idjon entfdiedene Einfpradje ertoben; es ift jebod nidjt ber ridjtige (Jebraud), fondern ber Mifbraud, weldjer bier zu tabeln ift. WBíro bas Sufeifen nidft zul glïhend gemadjt uno bleift eg nidjt zu lang auf bem Fun liegen, fo wirb taffelbe burdi biefe Manier tem Sou fo genau augepaff, wie ez fonft nidut möglid wäre, wäbreno baz \$ferb nidjt bejdäbigt wiro. Wiro jebody basె

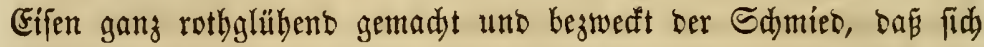
baffelbe fo ju jagen felbjt in rie gehörige sage brenne, wäbrent vorker wenig ober feine $\mathfrak{B}$ orbereitungen mit bem Meffer gemadyt wurten, fo wirb bie Sike forwohl ben gefühllojen, als ben empfint =

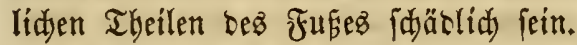

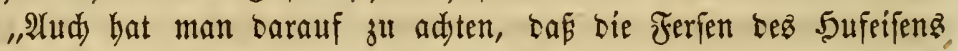
nidjt allguweit auscinanber ftehen. $\mathfrak{B a z}$ immerhin bejüglid bes

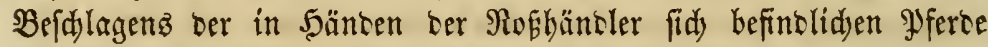
(Gebraud) festn mag, unb obgleid man in Sonton fid bejtrebt, bem

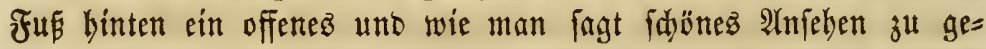

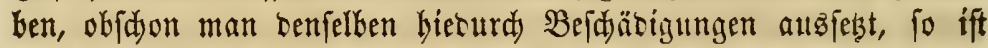

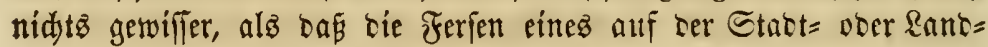
ftrafe benübten Pferbez faum zu gut befdübt feyn fönnen. Sudjt man biefen Miangel ber Ridutbejdübung ber Ferien aud taburdy

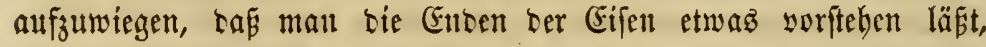
To wiro bacurdy tod ber 3wef nidjt erreidt, und ez mag bies bie urfade zu Unheil fein. Dehnt fid aber tas 5ufeifen nadj Innen fo weit als möglid obne ben Strahl zu berühren aus, fo wiro bie Eafe zwifdjen ben Eeffreben (bars) uno Der Sinufte"bejdütigen.

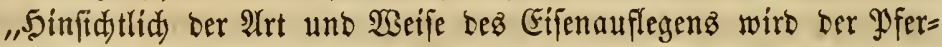

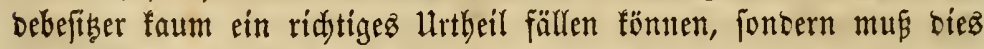
bem Edjmiebe überlaffen, er follte nur barauf jehen, baf baffelle nidyt fatwerer fey, als es zu ben zu verridjenben Dienftleiftungen erfor=

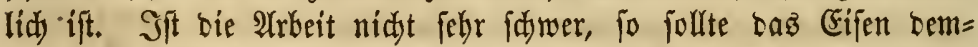
nad) leid)t und in beffen Runbung ein wenig Stahl mit eingefdmie= bet feyn. Ferner hat ber Eigenthümer barauf zu adjten, baj bie ge= braudten ఇägel fo flein, uno beren fo wenige und. fo weit won ber

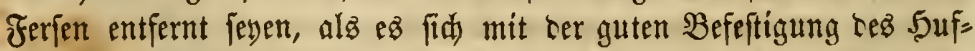

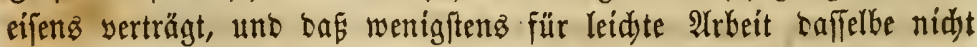
fo auserorbentlidy feft aufgenagelt werbe, wie biez oft gejdiefl uno 
bie Spizen ber Nägel nidjt fo weit oben am Şuf zum Boridein fommen, wie biegs gewöbulidy ber Fall ift.

\section{Etalten (calkins).}

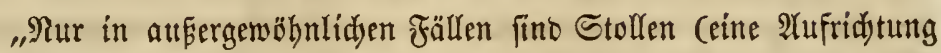
ber Ferfen ain (Fijen) an ben Eifen ber Boroerfüpe nöthíg, $3 . \mathfrak{B}$.

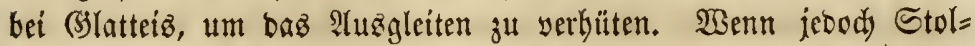
len angebradyt werben, fo follte dies auf beiten Seiten bez Gijens

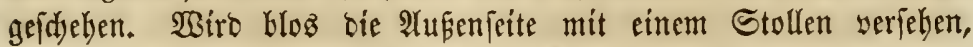
wie bies nur ju oft ber Fall ift, fo fann bas (biewidyt unmöglich gleidumäş่ auf bem Fufe ruben, waz notbwentig ben einen ober andern Theil beflelben bejdäsigen imuE. Wenn auf irgent etwas, fo foute ser Pferbecigenthïmer auf biefen lädyerlidyften aller Sdymieb=

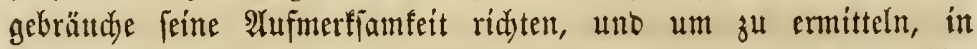
weldyer Iage fid ein mit einfeitigen Etollenei an bejulagenes Thier befinben muह́, barf man nur eine Biertelftunte mit einem auf ei= ner Seite erböhten Stiefel ober $\sigma_{d y b}$ umberlaufen. Gs fann biefer (3)braudy nidat einmal für Jagrzwede entidulbigt werben; benn

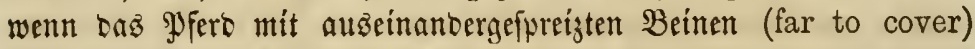
ober auf bartem, fiefeligem Gruno traten uno galopiren mus, wiro ibm rie ourd) Las cinfeitige Etolleneifen berbeigefübrte unverbält=

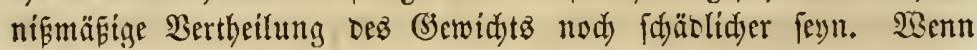

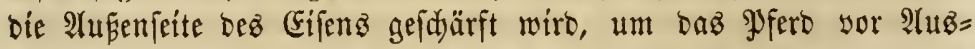
gleiten zu befdüben, fo folute entweber ber Juf an ber betreffenden Stelle etwas mebr abyenommen, oder tas antere Gnoe bes Eijenz mit einem oiden nidyt zugeppisten, eben to bohen Stollen verjeben fenn. Heber bie Stollen an ben Eifen für bie bintern B̧liecmafien werben wir fogleid fpred)en.

\section{Nafe (clip).}

,TSenn ein Theil ber obern Sufeifentante ein wenig aufwärts ge= bogen ift, fo bas er fid an ten untern Theil der Suffrufte anflam= mert, fo beï̈t man biez eine Sufeifen= Raje. Diefelben finto, da fie zur Befeftigung bes Sufeijens bienen, febr nüblid), oa anbern Fatls

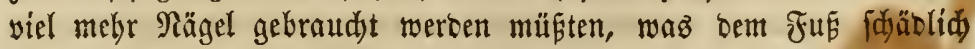
wäre. Das für bas 3ugpferb beftimmte Sufeifen follte aut bem Theil, weldyer auf ben Borberbuf (toe) zu liegen fommt, eine 2afe 
baben unt bei bem Eijen, mit weldyem baz Thier bejdlagen wiro,

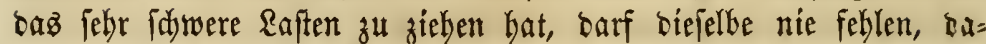

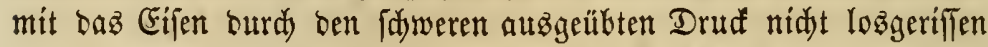

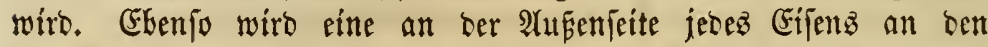
Iradjten (quarters) angebradjte Raje zur Befeftigung deffelben bien=

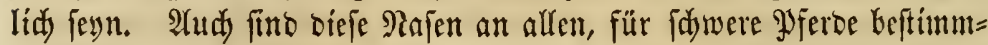
ten Eifen, jowie für alle die nothwenoig, bie heftig ftammfen ocer

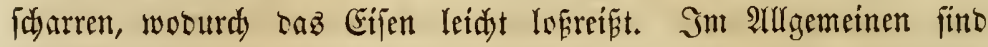
bieje Rajen jebod) nichts anderez als nothmentige Hebel, ba burd) fie bie Sirufte, weldye fortwährento wädjt, gerritaft wiro, tmo man follte bieielben eben beşwegen nur sanu gebraud)en, wenn bies un= umgänglidy nöthig ift. 2(m Shufeifen tes für sie Sago benthten Sferbez fint an ben Eeiten feine Rafen erforberlidy, eine am $\mathfrak{B o r}=$ berbuf (toe) ift hinreidyetto.

\section{Das $\mathfrak{s u f e i f e n ~ D e r ~ s ̧ i n t e r f u ̈ ̈ e . ~}$}

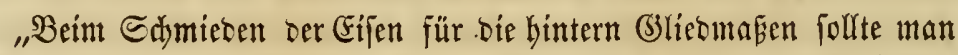
fid) erínmern, da Dienfte zu leiften habell, uno baj, wenn baz lopirt, ofer in irgeno einer anbem (b)angart, auerer sem Edyritt, geft,

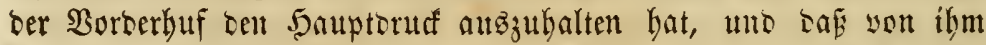
auz sie Forthewegung meiftens bewerfftelligt wirt. Deähalb follte

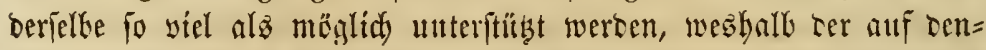

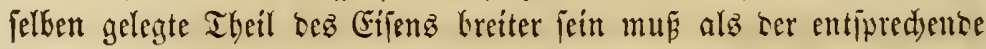
Theil bez Eijenz ber Borterfüpe. Rebitoem wit' hiecurty, sa ber

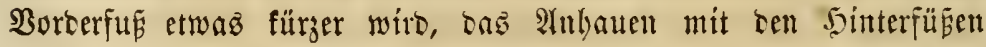
(over-reaching), wenn nitht ganz werbindert, io bods :ermintert,

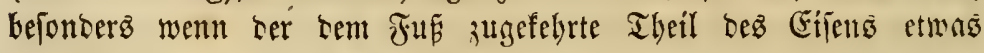
weiter ift, alz ber bem Booen zugefebrte. Die untere Shufeifenfante

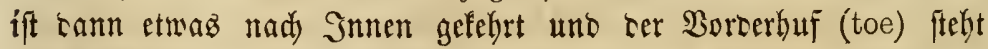
ein wenig üker siefelte beraus.

"Der Şinterfus ift nidft gang fo geftaltet wie ber sorbere. Gr ift an ben Tradten (quarters) aufredter und baz Gifen mus diefeltbe

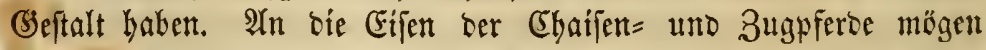
Stollen angebradyt werben, woburd) eż bem gyferbe ermöglidjt wirb,

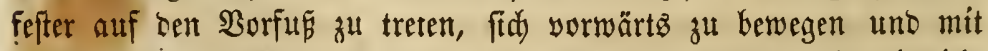

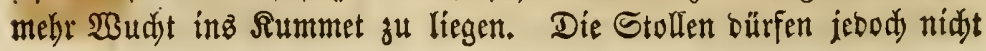




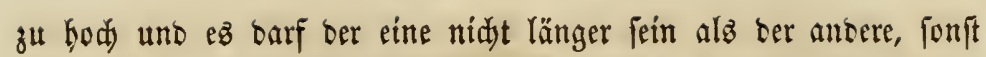

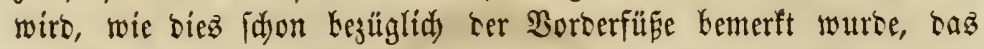
(3) widyt nidjt gleidmäpig vertheilt, baz sen einen ober antern Iheil

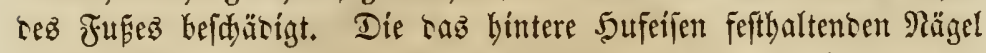
mögen näber bei ben Ferien eingeidlagen werben, alz biez aut bem

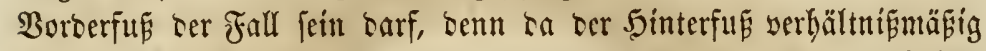

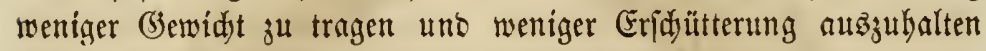

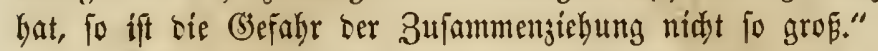

\section{Beridiedene פufeifen=Sorten.}

Die folgente 3eidnung ftellt bie ridutige form tes rediten 5 uf = eifenz bar uno zeigt bie obere uno untere Eeite befletken. Die Dher=

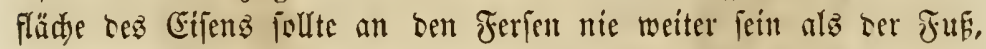

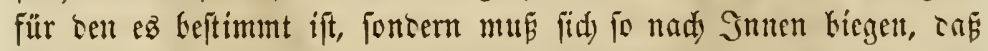
ez genau fo läuft wie die innere Dherfiäde ter 5uffrujte. Iie innere bälfte follte coneay geidymietet wersen, fo bá bie innere

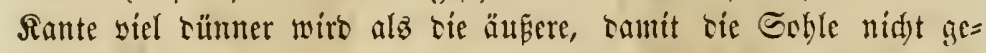
brüăt wito uno Santförner, bie zwifden Eifen uno Fup fommen, feinen Edjaten anridjten mögen. Daş Giien für ein Yifero mittler

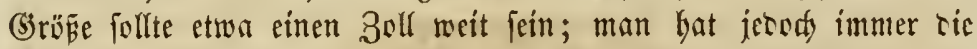

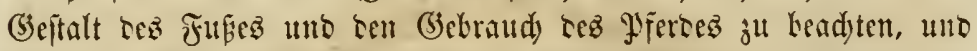

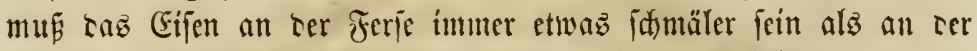
Iradjte (quarter), baffeltbe jollte burd) einige nabe kei sem Borter= buf eingefdlagene Rä̈gel feftgehalten merten. Drei södser an ser

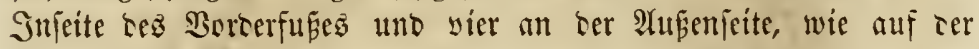
3eidnung zu fehen fint, fint binreidjent, uno bei \$ferten, sie nur zu leidter Artbeit gekraudyt werben, fann man einen ocer zwe Rägel

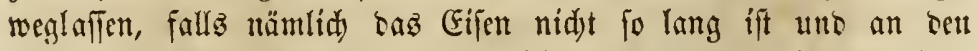

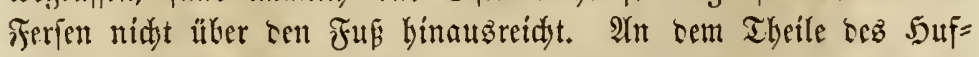

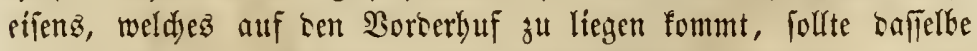
etwas aufwärtz gehämmert uno fo bie "Nafe" angefertigt werben,

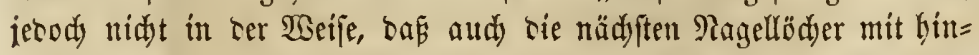
aufgebümmert werden. Sit bie Strape mit (Slatteiz kededt, ober überhaupt jajlüpferig, fo müifen Stollen angebrad)t werben, unb bie=

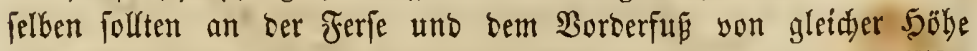
fein. Derjenige am Borberfuß follte ftäglern fein und an bas Eifen angeiduweifst werben. 


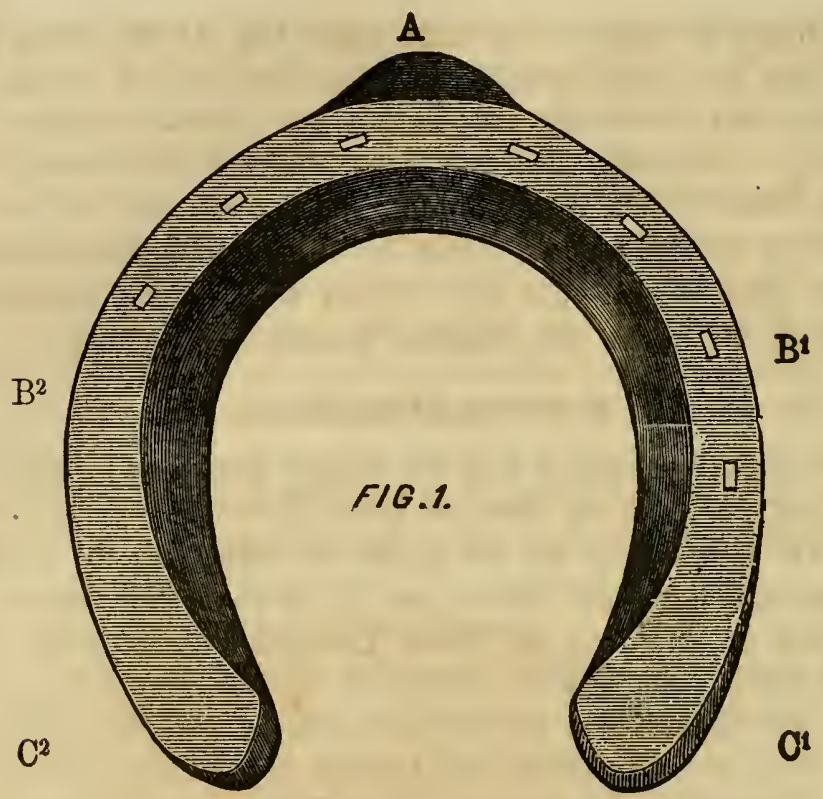

A

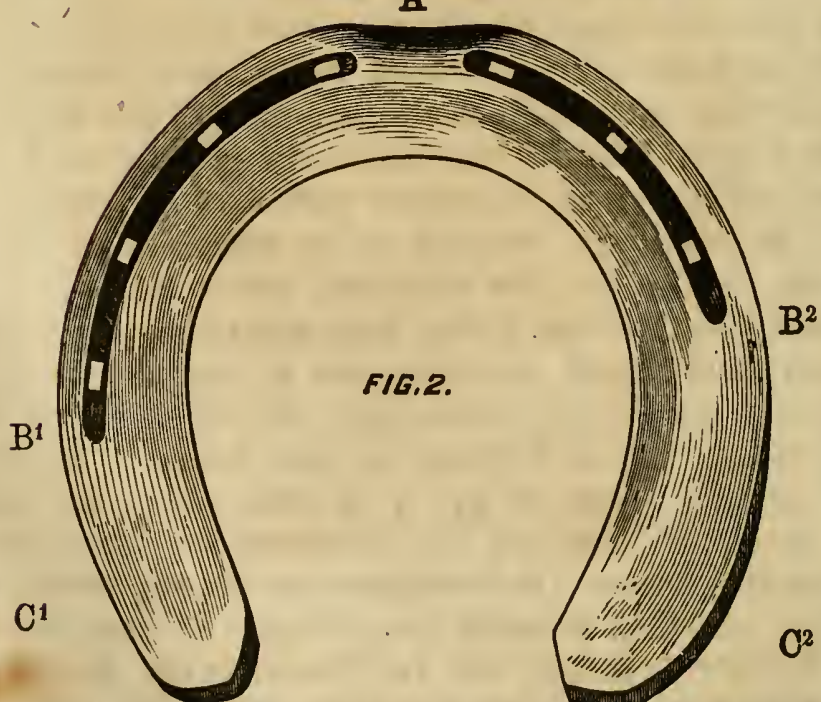

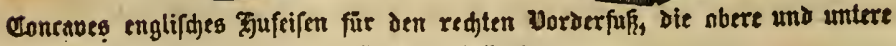
:SSteite darftellend. 


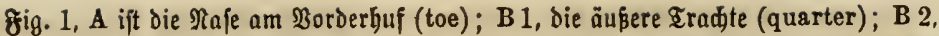

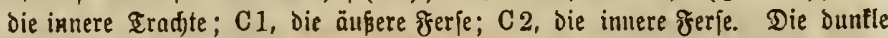
Gdattirum bezeidnet die concabe Sberfläd)e, unto zroar ift Das Eifen concao angefertigt, um es leidter zu maden unt die Soble voum Druct zu befreien.

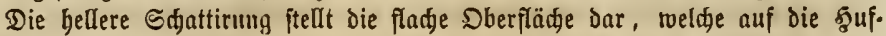
trufte zul liegen foummt.

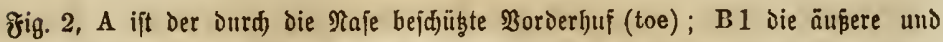
B 2 die innere Iradjte; $\mathrm{C} 1$ bie äupere und $\mathrm{C} 2$ bie inuere gerfe; Der Gellere Sdyatten zeight Den Dem Boben zugetegrten Theil Des Eijens, welder fo weit an Den ferjen als am Borderbut ift. Die ountler fajattirte \&inie bezeidyut die

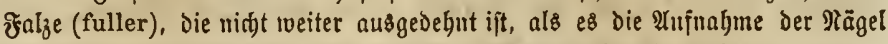

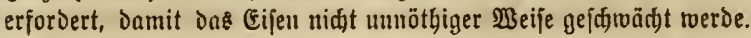

Die folgende 3eidnung ftelft bas Ringhufeifen (bar-shoe) Dar,

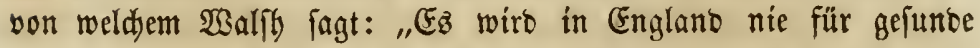

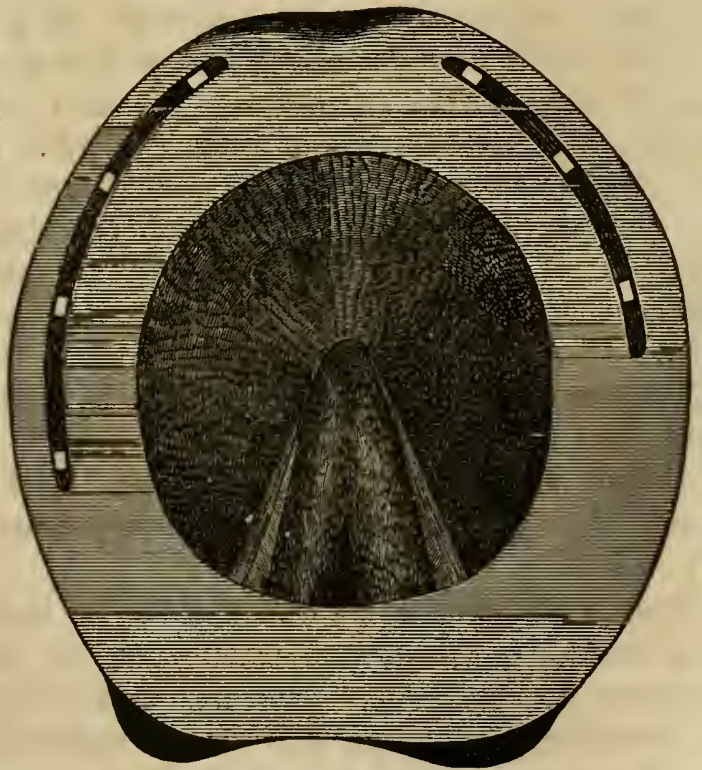

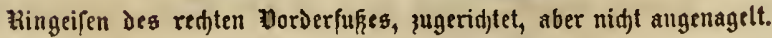

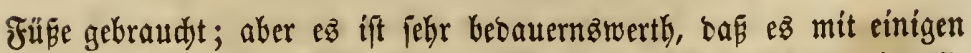
2rbänoerungen nidyt allgemein eingefübrt werben fann, womit alle geaen bas gemöbnlide Şufeifen erbobenen Einwensungen wegfallen 
würben. Diefez Ringeifen befteht aus einem eifernen Ring, welder

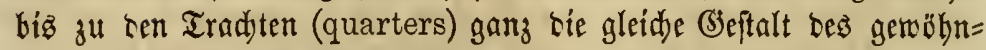

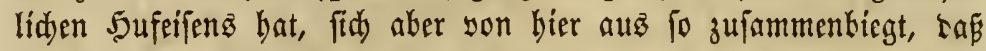
sie Enben, weldye zufammengejdmeist werben, fid treffen.

"Daffelbe wiro gegenwärtíg gerabe zu sen entgegengefesten 3wedfen verwandt, mofïr man bas gewöbnlidje (Gijen gebraudjt. Das eine

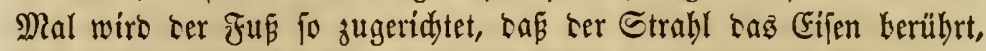
wäbreno sie Ferfen frei uno fo son allem Druaf befreit finto. Daz antere Mal fommt ber Ctrabl nidht mit tem 5 ufeifen in $\mathfrak{B} e r u ̈ h$ rung, weldyes in biejem Fall allein auf ser Rrufte unt bem Eefftre=

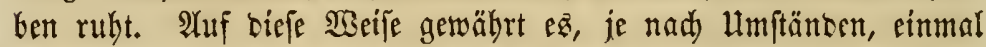

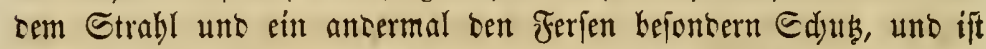

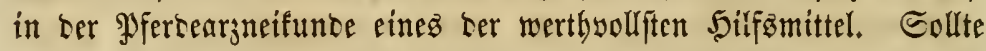
Der Strabl über bie Rimfte yorfteben, fo mag baz Gifen, La wo erfteren bededt, verbältnifmäsig sünner gejdmienet uno fo ben Strabl fowohl alz ber Sirufte angepast werten, fallz

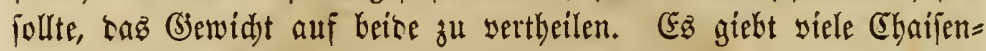

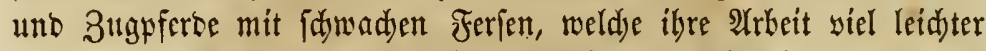
scrridten fönnten, went fie immer mit tem Ringeifen Kefdlagen

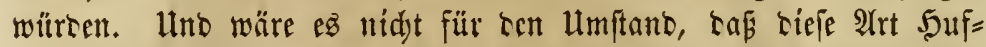

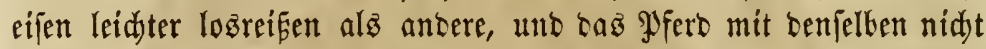
To feft auftreten fann, fo wäre es rathjam, zumeilen aud Mieth=

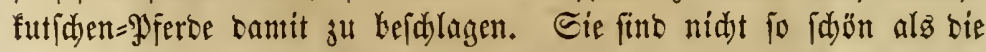
andere Sorte, werten audy für Zeiden eriftirenter Hebel angefehen

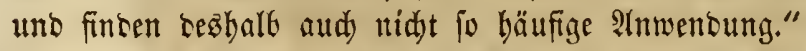

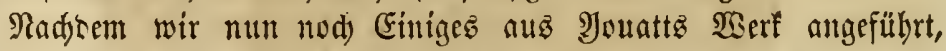

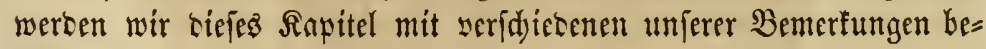
[ablięeren.

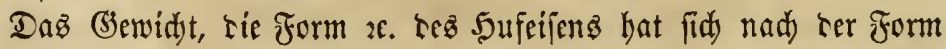

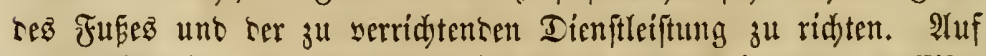

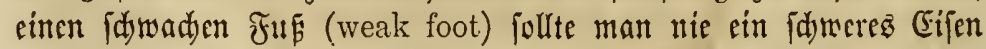
auflegen, nody jollte irgento weldes \$ferb ein uno haffeltbe Eifen länger als einen Monat tragen. Llno bier ift ter Mlab, ben Mfertecigen= thümer barauf aufmerfjam zu maden, nie mit einem Edjmicte einen

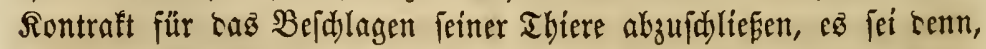

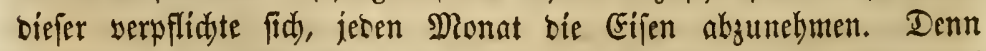

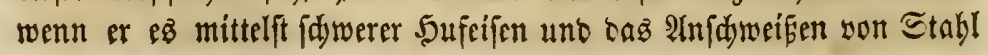




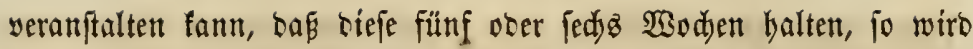

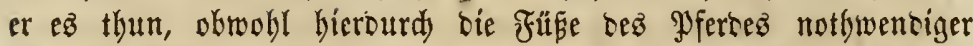

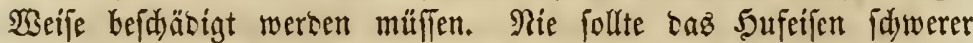
feitt, als eร zur Berridtung ber geforterten Dienftleiftuttgen erforcer=

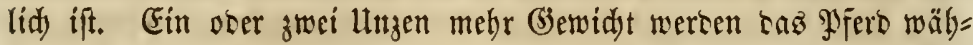
renb einer fdweren. Tagezarbeit viel mürer madyen alz biez ber Fall wäre, wenn bas Gijen bie ridjtige Sdywere hätte. Ies̆balb madjt

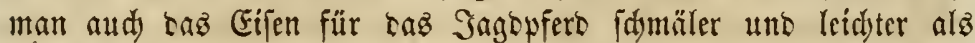

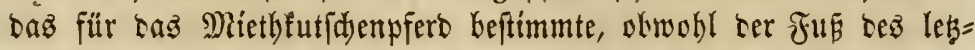

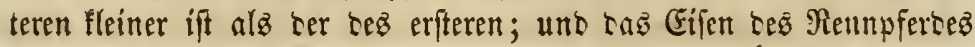

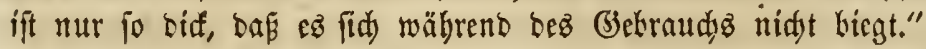

Die bicr gemadten Bemerfungen fino in jetem Rante anwentbar und fönnen im 2rllgemeinen nidjt wohl verbeflert werten; ofgleid wir in mandjen Beziehunget,, wie aus Folgentem bersorgeft, son Ient

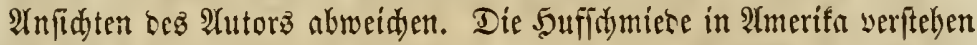
im Allgemeinen ifbr Sanowerf beffer, fint aud) forgfïltiger, als bies

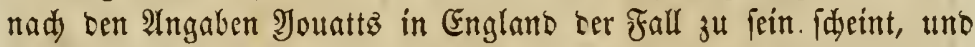
es zeigt fit namentlid in ben leşten Jabren unter ibnen ein er= freulidyes Bejtreben, fid in ibrer Sunft zu vervolffommnen. Maudhe begeben zwar beutzutage nod) Srrtbümer; tie gröften in ber Pferbe=

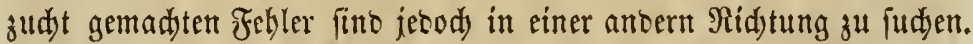
Berfteben aud einige Suffdmiebe ihr 5anomerf nidt, fo madjen bieje bod) nur eine geringe Minberbeit aub.

Der 5uftefdylng erforbert viel aufmerfjamfeit, uno fint zur be= friebigenten $\mathfrak{A}$ (นี

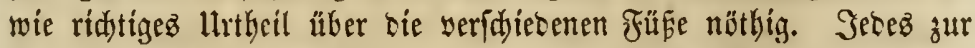

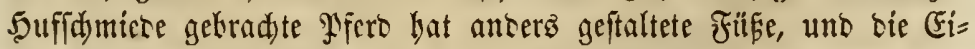
jen müffen nad) biejen veridiebenen formen forobl, alz audy ber

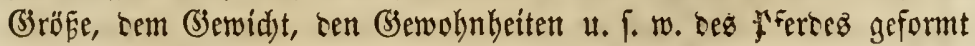
werben. Namentlid, bat man bie (3röß̈e ber \$ferte zu Kerüfifiti= gen, bent fleite, leidte Thiere betürfen surdjaus nid)t fold fdwerer 5ุufeijen alsె grofe Zugpferbe.

Fin harter, fpröber 5ouf erforbert fein fo meitez 5ुนfeifen alz ein weid)er, fauliger (pummiced). Ein von ben Sdymieben begangener Febler befteht harin, baj fie swifden ben in ben Borberidjub einge=

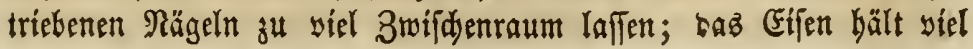


befier, wenn bier bie Rägel nidft fo weit außeinanter ftehen, benn biefer Theil bes Sufez ift der ftärffite.

Die wäbrend dez Binters gebraudjten Eifen jollten Stollen, bie im Sommer gebraudeten jebod feine haben; aud follte an lebteren

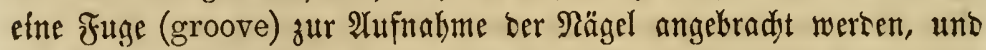
die Ferfen biefer Gifen fönnen etwaz biferer gejdmiebet werben, fo

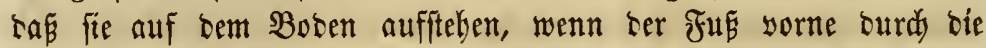
Rägel etras erthoben iff. Für mit Găllen voer Suffäule, ober beitoen

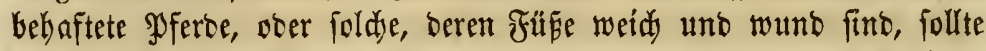
man einen Filziftreifen in Form ser Sirufte zufdneiben uno biefen

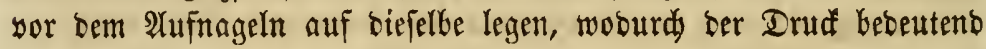
yermintert wirt.

\section{Befdneiden ber $\mathfrak{g}$ ufe.}

Der bei ter Soufbefdneioungl gewöbnlid begangene Febler beftelt barin, bá man zu viel an ber Ferre ullo zu wenig am

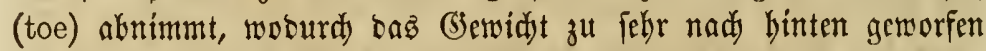

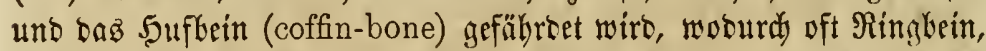

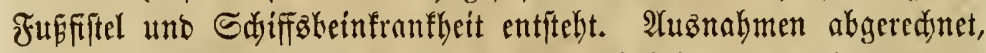
follte yon bem Borberhuf (toe) ein Drittheil mekr abgenommen werben als yon ber Ferie, weil baz 5ufborn fid am leștern Theil

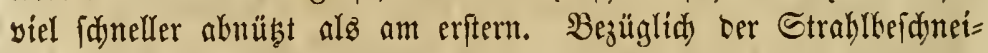

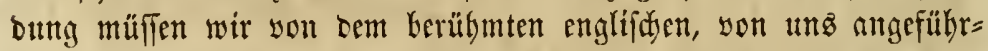
ten ভdyriftifteller etwaz abweiden. Gr follte nämlid) wenigitenz um einet Drittel Die Eiffitreben (bars) ju beiren Seiten tes Strabla follten gar nidjt

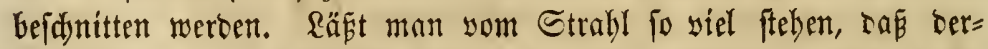

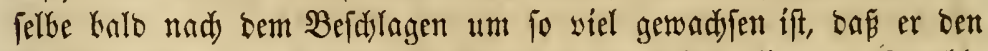
Boben berührt, fo hat baz unmittelbar über ibm legende Strahl= bein (shuttle-bone) und bie mit iłm in $\mathfrak{S e r b i n d u n g ~ f t e h e n d e n ~} \mathfrak{i n o =}$

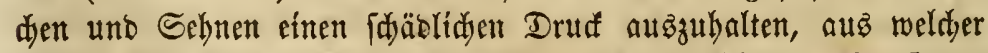
urjadje fadwere Siranlfleiten entftanden fint, weldje ber Sunft ber beften IGierärz̧ fpotteten.

\section{A b nel men ber}

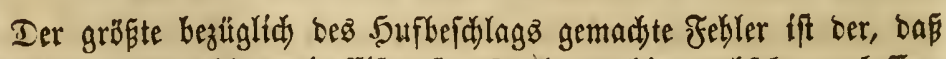
bie Farmer werfeblen, bie Eifen fo oft alo nöthig wedjeln zu laffen. 


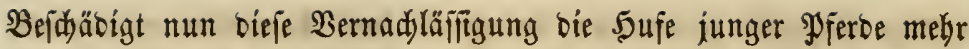
als bie ber alten, weil bie ber erfteren fajneller wadjen, jo ifit ez

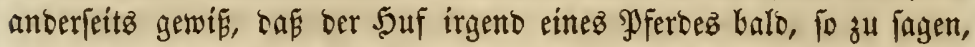

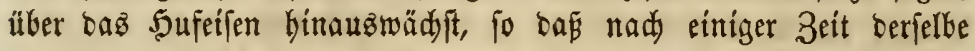

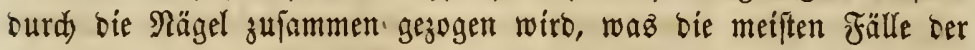
unter bem Ramen Vollhuf (narrow heel) befannten Rrantbeit ber=

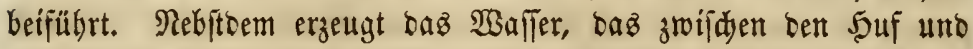

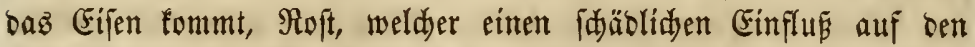
F̌⿰氵 entfteher.

\section{Mie lange die gujelien gebraudt merben tönnen.}

Mandje Pferbe mögen eín unto déejelben Eifjen länger tragen als

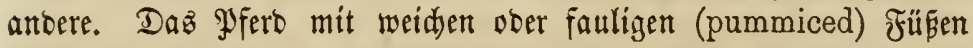
poilte alle viersig bis fünfunbsierzig Tage bejdlagen werben; bie

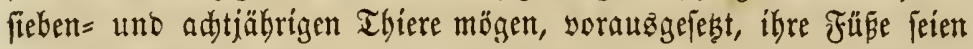
gut, bie Shufeifen fedszzig ober fiebsig Tage tragen, uno alte Pferbe, beren Füne nie bejdäbigt worben, fönnen alle orei Monate bejdla = gen wersen. Diez ifit jebod bie länglte Beit, bie ein Shufeifen auf bem 5 uf bleiben follte. Sunge gyferbe bagegen, welde nod) nie be= fajlagen wourten, jollten bie Eijen nie länger als viersig Tage tragen.

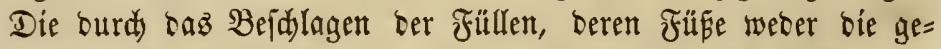

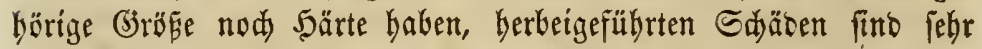
zablreidy. Füllen follten inur einen fleinen Theil bez Gahrez be= fajlagen fein; nod follten fie mit (Eijen verjehen werben, ehe fie we= nigitenz bré Sahre alt geworoen, uno felbfit bann ift bas Bejdalagen nod) nidjt ratbjam. 2Anfanga WSinter mag man bem breijährigen Frülten Gijen auflegen, bie im Frühjaghr abgenommen werben, yon weldyer Zeit an man baz junge Thier biż zum nädjten Serbjt ohne Eijen laufen läp̧t.

AUten PFerten, namentlid allen, jungen gyerben, follten fo oft uno

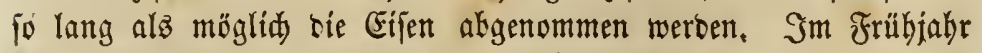

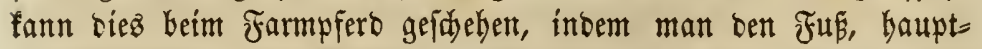
fäblid bie Ranten oer Rrujte beidneibet, uno wenn biefelbe uno antere nad unten geridtete Theile anfangen fid abzunüben, jo be= nest man fie gut mit Terpentin, weldyer mittelfit eines barüber ges

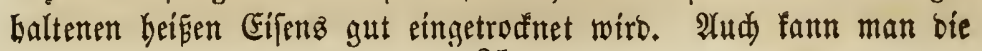
35 
flüffige $\mathfrak{A}$ ebjalbe (corrosive liniment) ftatt Terpentin gebrauden.

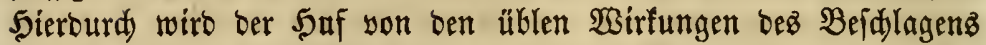
befreit uno mander Rrantbeit yorgebeugt. FFüße, weldye lange be $=$ fidlagen waren, werben oft, ba fie febr weid) fint, burd) bas $\mathfrak{A}(b=$ nebmen ber Eifen, forwie Durd) ben harten Boben bejdäbigt. EGenjo bred)en bie 5ufe, fallz fie nidit orbentlid bejdnitten uno augigepust werben in einer S⿱Secife, bak bie Soble ben Boben berührt, woourd) bem Pyerbe bei jebem Sdyritt beftige Sdymergen verurjadjt werben.

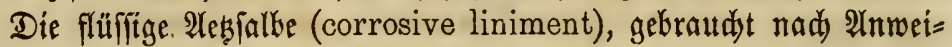
fung in bem Rapitel über Medizinen, wiro ben Şuf balo beilen uno bärten, und barf biefe Mebizin oft an benfelben applicirt werben, woburdi vielen Siranfleiten, \&. B. Souffäule, Baallen, Maufe und Strablfäule, yorgebeugt wirb. 


\section{Dreiundzmanzigftes sapitel.}

\section{ฟ \\ (Vices and Unsoundness of the Horse.)}

\section{I. $\mathfrak{u} \mathfrak{n} \mathfrak{a} \mathbf{t} \mathfrak{n}$.}

Das פ̧ero bat, wie fein Meifter uno Serr, ber Men[u, ausige zeidnete Eigenjdaften fowohl als Felylex; benn obwohl es einez ber ebelifen, wenn nidjt bas ebelfite Thier ift, fo finbet man bod aud siele Hnarten an ihm. Die meiften berfelben gebören ber ganzen Pferberace an, während einige nur bei einzelnen $\mathfrak{a}$ rten zu finben fino. Mand)mat laffen fid biefe Unarten (vices) auf natürliche Trlagen zurüdfübren, offters jebow fino biefelben bie Folge un=

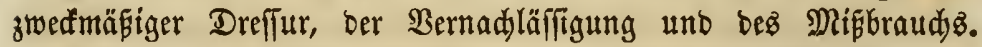
Fine verfebrte (Gewöhnungamethode bringt beim Sperbe wie beim

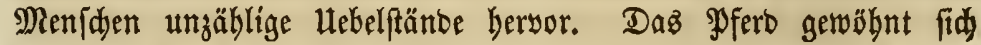
leidst und yon Sugend auf ltnarten aller $\mathfrak{A}$ rt an, weşbalb man es frübseitig zäbmen, controlliren uno meiftern follte; benn je mebr Unarten ein Pferb äufert, befto mehr verliert es am $\mathfrak{B e r t h}$, und ber unwiffende Räufer wirb oft betrogen, weil er biefelben nidat redjtzeitig zu entbeden vermag. Dap ein \$yerb "yoll allerlei Unar= ten" leid)t gebänbigt uno bas man iłm bie Tüde leidt abgewöh $=$ nen fönne, biez ift ein weitverbreiteter groper Jrrthum; benn wenn ez fdon fdyer ift, einen alten Sund neue Poffen zu lebren; fo ift es nod) viel fdwerer, ein altes Spfero yon Tüden abubringen; ja, bies ift in ber That eine fo fdwierige atifgabe, baf fte faum je aubgefübrt werben fann. Man muj beshall bebadyt fein, bas Füllen" zu bänotgen, uno wenn dies nidyt gelingt, fo fint alle 


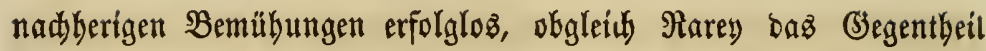
behauptet.

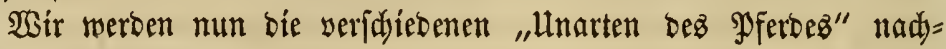
einanber betraditen.

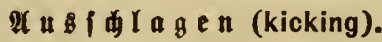

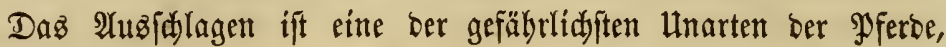

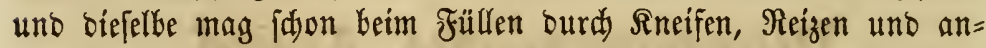
Dere Pladfereien, beren fith Sinaben uno Roffnedyte oft $\mathfrak{z}$ Sdjulben fommen laffen, hervorgerufen werben. Daz erwadjene \$ferd, ezz fei benn, $p$ habe biefe üble Gewolnhleit fdjon frülge angenommen, wiro

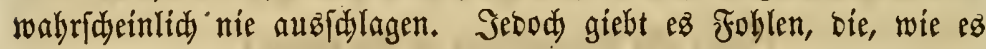
仯eint, natürlidye 2 tnlagen zu biefer unart baben. Sie fidlagen nad) Sebermann unb nad) jebem in ibre Räbe fommenten (Begen=

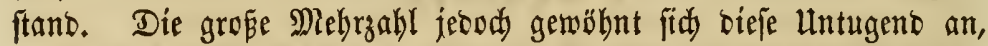
indem fie burd unwifiente, unadjtjane, gleidgülttige \&eute bazu ge=

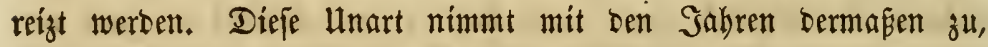

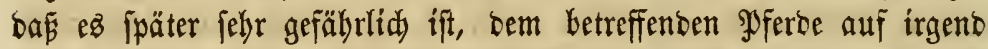
eine $\mathfrak{B e i f e}$ und yon írgend einer Seite fid zu nähern, uno alle

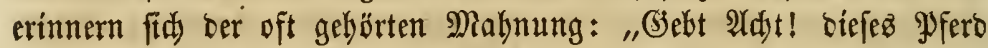

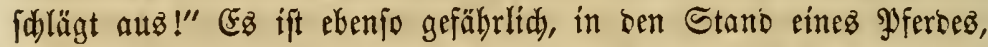
baz auzjollägt, zu treten, alz ez ift, baffelbe anjugefdirren ober zu putsen, ober es audj mur, wenn angeidjirrt, zu berïbren. Mandse Pferbe fajlagen wobl nad) andern Pferben, aber nidjt nad) Men=

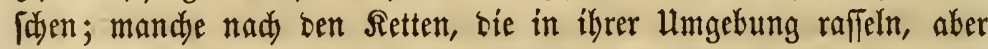
nidjt nad andern Igeilen bes G̈efdirrz. Mandje verbalten fid gand rulfig, wenn mur eine Perjon auffist, wollen aber zwo auf oem Thiere reiten, fo fillägt es binten uno sorm aufs beftigfte auz.

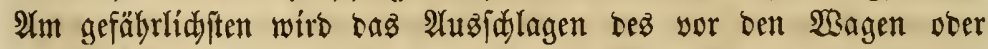
bie Chaife. gefpannten Pferbes, worïber Yुouatt fagt: "WSegen ber geringften Unbequemlidjeit am Reibe ober ben Sintertheilen fajlagen mandje פyferoe ganz wütheno aus uno zeridmettern nidjt nur ben

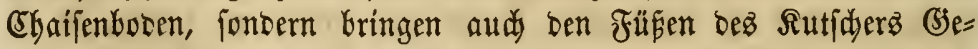
fahr; und zwar fino bie Pferbe, weldje im Stall raftloz fino, in biefer Sinfidut bie heftigften. und gefäbrlidjften. Sollten bie Zügèt

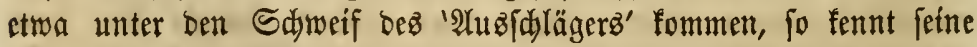

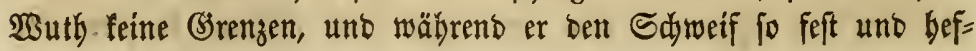




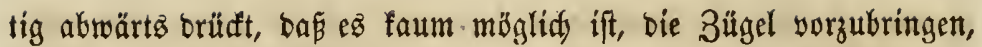

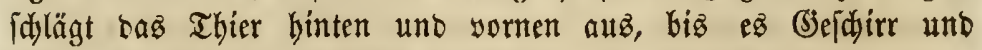
\$agen jertrümmert hat."

Ein joldez Pfero für Den (J)ebrautd zu halten, ift nidat alfein bödft unyorfidtíg, fortoern aud verbredjerifdy.

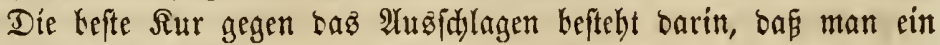
feftez bünnes Eeil an bas Edjweifhar bindet, daffelte zmifdjen ben Sinterbeinen Durdyzieht, am Unterleib binlaufen läpt, und $c$ az, fehr ftraff angezogen, am $\mathfrak{s u m m e t , ~ o b e r ~ e i n t e m ~ a n o e r n ~ u m ~ b e n ~} 5$ alz

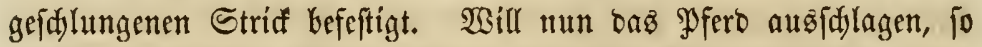
wiro bas fert angegogene Seil fo fehr an feinem Edjweif zerren

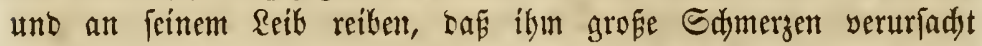
werben, bie zulatien.

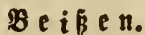

Entfpringt biefe unartige (Jemobhnbeit aud in ben meiften Frällen aus natürlidjer $\mathfrak{A}$ nlage, fo wirb fie body ourdy bie yon Sinaben uno

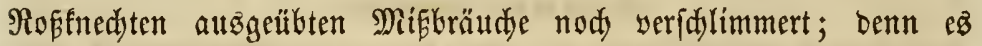
würbe wohl nur jebr menig Pferte geben, bie "beifen," wenn nidjt

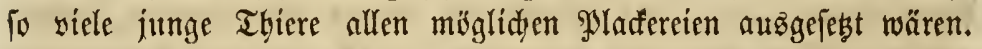

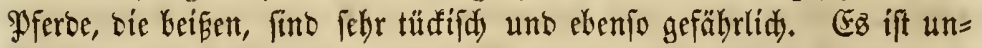
möglidy, mit Sidjerheit in ihren Stand zul gethen woer fie zu ftriegeln,

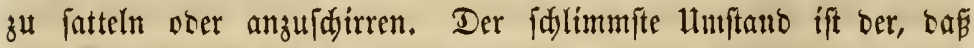

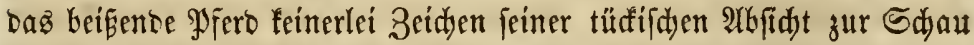

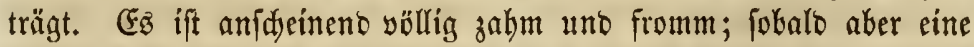

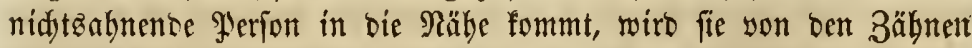

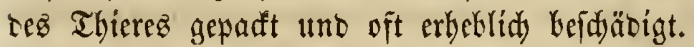

Ein 5engft, weldyer "beif́t," if ein auteroroentlidy gefährlidyez

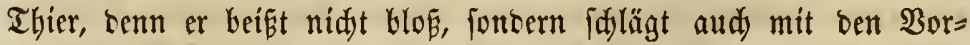

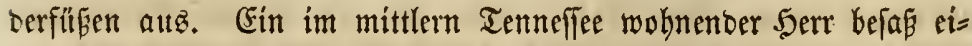
nen mit biejer Unntugend bebafteten 5engit. Finez $\mathfrak{T} a g e z$ ging er in ben Stall, um benielben zu füttern, unb alz er längere Beit nidyt zutüuffelyrte, futdjte ihn feine Famille auf uno fand ihn toot unter

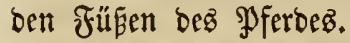

Dieje Unart fann nur baburdy furirt -werben, bas man bem Thjer, fo- oft es Semanten beist, einen feiner- Borberzäbue 'aubj falägt: 


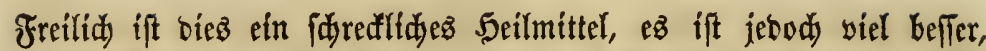

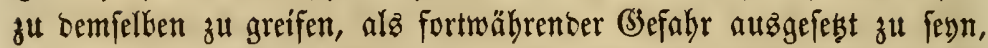
fumal ba bag Mittel erfolgreidy wirft, benn $e$ ga giebt wobl weníge Pferbe, bei benen ez nötkig wirts, megr alz zwei Zähne - einen oben uno einen unten - zu entfernen, ebe fie biefe Hnart ablegen.

Profeffor Stemart fagt in feinem Wert "Stable Economy," bá

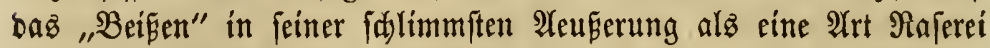
(insanity) bezeidinet werben miifie.

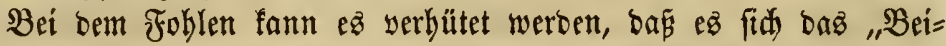

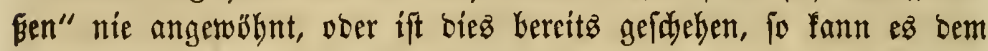
ju $\operatorname{ng} \mathfrak{e}$ Thier aud wieber abgerwähnt werben; und bá biez ge=

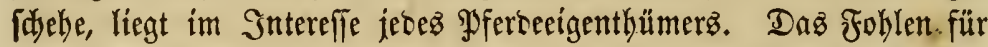
biefe ober irgento eine anbere llnart zu züdjtigen, führt nidyt zum

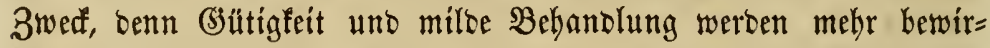
fen alz Züdtigungen. Man fehe bazu, bấ $\delta a z$ junge Thier nidyt

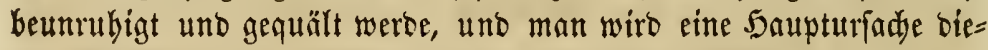
fer beläftigenoen, gefäbrliden ltntugeno entfernt baben.

\section{$\mathfrak{B}$ ä u $\mathfrak{m}$ c n (rearing).}

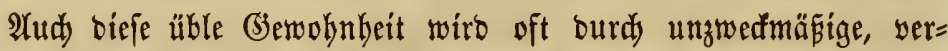

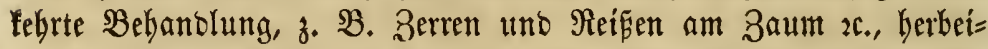
gefülyrt. $\mathfrak{W a z}$ aber audj immerhin bie veranlaffende uráade fein mag, fo ifi es immerbin eín beläftigentoer, gefäbrlider Fefler, burd)

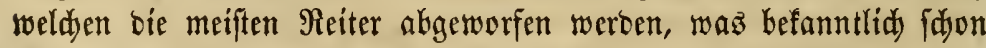
oft mit bem Tode endigte. Bänmt fid ein yor ben $\mathfrak{W a g e n ~ o b e r ~}$

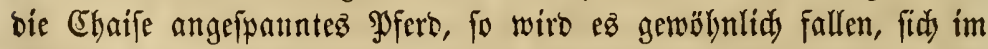
(Gejedirr uno ben Deidjeln voer ber Deidjel verwirren uno wahr=

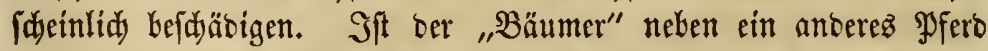
geipannt, fo wiro biefez, wenn nidyt bejdäbigt, fo bodj furdtram und ideu merben. Mandje Pferbe Gäumen fid jebesimal, fo vft fie zu hufen baben. Der Räufer follte fidd, ehe er ben Poferbehandel

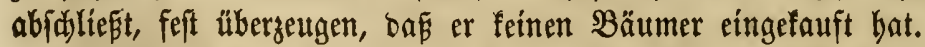

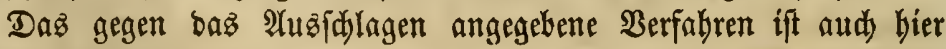
aแछ่\}แfüluren.

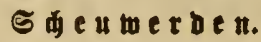

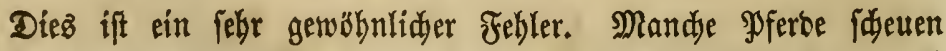
beinahe yor jebem Bsegenftanto, ober werben fogar furdtfam, aud 
wenn nidtż zu bemerfen ift. Defterz wirb baz Sdyeuwerben burdh

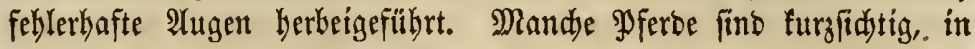
Fyolge beffen fie bie Begenftänoe erft fehen, wenn fie benfelben fo

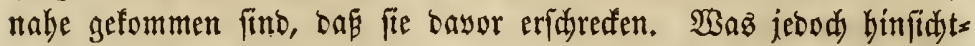
lid) ber anbern Unatten gejagt wurbe, gilt audy hier, baßi nämlid

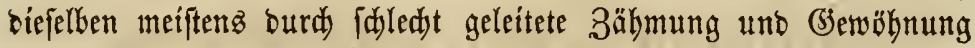

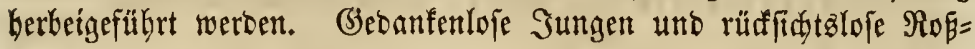

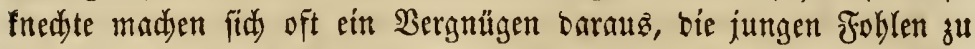
eridgrefen, fo oft fie benjelben nahe fommen, unto hat fid baz frül= len eiumal angewöbnt, fajeu zu weroen, fo wiro ihm biefe Untugeno immer anthätgen. Eine Rabifalfur gíbt es nid)t; fontern $\mathfrak{e b}$ gilt, burd) miltoe und gütige Behandlung baz Uebel romogglid zut ent= fernen, und wenn bieburdy tor 3 weef nidjt erreidyt wirt, fo fann man auth mit antern Mitteln nidjts bewirfen.

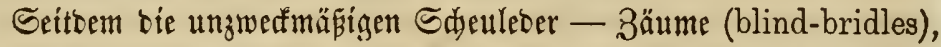
nidjt mebr gebraudjt werben, giebt ez nidyt mebr fo siele fajeute Soferbe als früher.

Daz Pfero zeigt gewöbnlid. burdy Seiteniprünge, oder ittoem es sorwärtz rennt, ober burd Sdjeutwerben bie in ihm erregte Jurdyt an. Springt es zur Seite, boer yorwärts, fo ifit am meiften Gefahr yorhanoen, benn biefes geht gewöbnlid bem Dayonlaufen

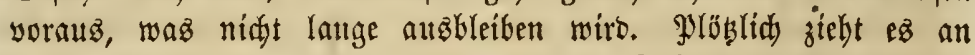
und rennt mit einer (bewalt fort, baf ber Futhrmann oft vergeblidy

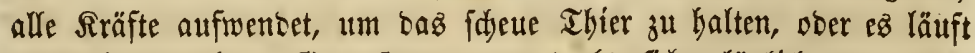
gegen irgento einen (jegenftano, ober sregt fid plöblith uno wirft oaz (3efährt um. Daz Sdyeuwerben tift weniger gefährlid als be=

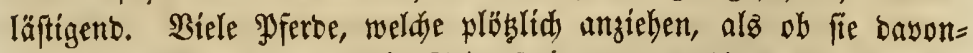
laufen wollten, ober auf bie Seite fpringen unb fder werben, gehen nie burd, aker yon allen fann bież nidjt gejagt werben.

\section{Da b}

Einem einntal Dayongelaufenen Pfero ift nifit mely zu trauen; und ein PFero, baz einmal mit einem Wogen ober einem Cabriolet (buggy) burdging, follte nie wieber yor bą nämlidje (Sefähtht ge=. fpant werben. Rod wirb es in ben meiften Fällen ratbjam fein,

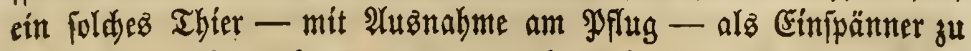
gebrauden. Man fann 
fpannen; weiter aber follte ihm baz $\mathfrak{B}$ ertrauen nidht gejdenft wer= Den. Dá baz ভdeumerben bas Dayonlaufen erzeugt, hieran mus

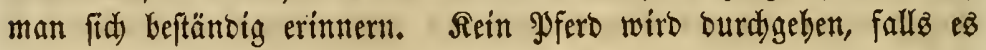
nidjt ideu wirb.

\section{Störrigfeit un $\mathfrak{b u f e n ~ ( b a l k i n g ~ a n d ~ b a c k i n g ) . ~}$}

Diefe üble Geswobnheiten fino fo fdylimm ober fdylimmer als ir= gent weldye andere Unarten, und zwar madjen fie bie bamit behaf=

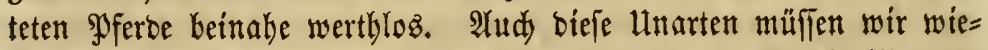
berum nidjt jowohl ber natürlidyen 2 lnlage ober tem Mutbroillen bes

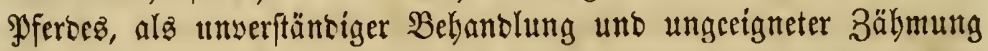

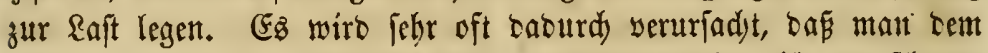

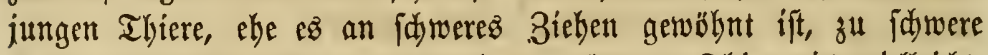
\&aften aufbürbet. Då übermäßjig angeftrengte Thier wiro vielleidjt,

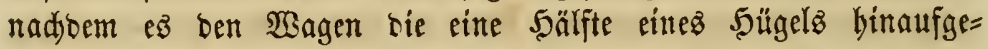
fidleppt bat, fo eridjöpft, Las es nidjt mebr weiter fann uno zu

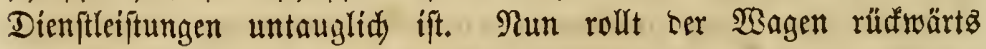

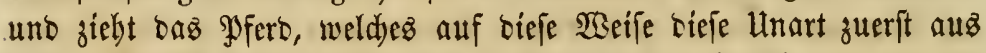
Noth lernt, uno fid biejelbe fpäter angewöbnt, mit fid dy.

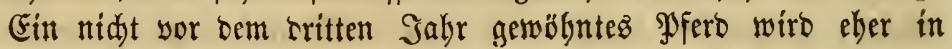
diefe Untugent verfallen alz einez, mit beflen Zäbmung früber be= gonten wurbe.

Ratürlid fann man fid) auf ein folddes PJfero nie verlaffen; benn wenn man feiner Dienfte am meiften benöthigt ift, leiftet ez biefelben

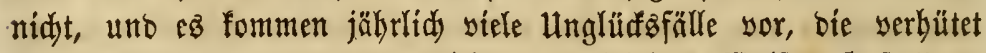
werben fönnten, wenn man nidjt unsorfidutiger $\mathfrak{S e i f e ~ " S o u f e r " ~ z u ~}$ oft gebraudyte; benn viele Perfonen bentiben, trob aller Woarnung

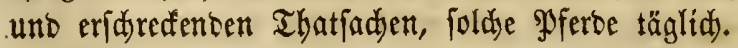

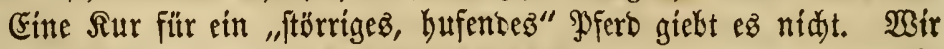
haben bie serjajebenften Mittel ohne Erfolg anwenden jeben, und

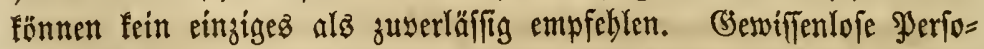
nen wollen zwar im $\mathfrak{3 e f t h ~ g e h e i m e r ~ S u r m i t t e l ~ f e i n , ~ b i e ~ f i e ~ b e n ~}$

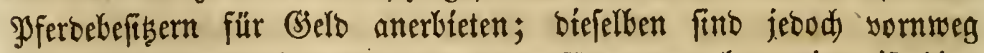
nid) tze werth und jeber Dollar, ber bafür ausgegeben miro, if hin= aużgetworfen. Dieje "S̋ekeimmittel" verfaufenoen Taujenbtünfter

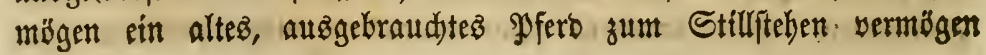


fönnen, werben aber nie in ibrem \&eben einen "alten ftörrigen 5ufer" kergaufmärts bringen.

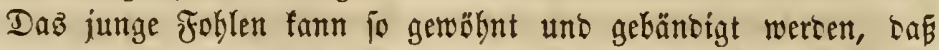

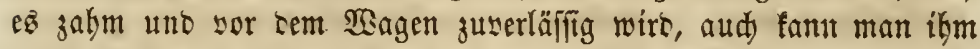
Tüdfe uno Poffet uno mande llnarten abgeröbnen, niemalz aber

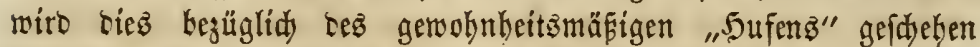
tönnen.

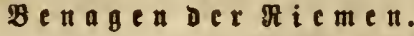

Mit ciejer idarenbringenbent (Setwohnheit fino meiftenz junge Pferte uno Maulthiere behaftet, wäkreno fth sas alte Pjero tiefelke jelten zu Cdulton fommen läft, obgleid Maulthiere oft mäbreno ibrez ganjen Rebens sie Riemen kenagen. Rutrmittel: Bejtreide tie Riemen mit einem Canennepfeffer = oter Takad=?tbjut.

ßei ín a d der

Mandye Pferce ftehen nie ftill, foncern find fortwäkreno unrubig, "eifen an ter 5 alfter unb breden oft log. Diez muß in beinabe allen Fällen unjwedmäátger Drej̄ur uno unridtiger Bebandlung Desె nod) ganz jungen Foblen zur Raft gelegt werten. Snaken ver=

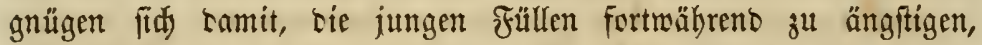

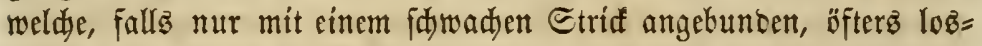
reifen, waz fie, fo balo es einmal gelernt ift, fpäter serjudjen, wenn fie an ser Salfter feftgebunten fino, uno gelingt riez groei ober breimal, fo ift sie üble Gerwobnheit eingeniftet. Das einzige bage= gen anzumentente Mittel if eine fo ftarfe Salfter zu bejdaffen, tab fie nidjt zerrifien werten fann.

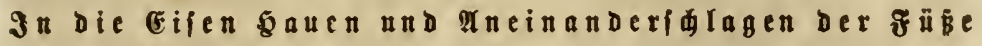
(overreaching and interfering).

Dieje Febler bes PJerces follten vielleidyt nidjt fowohl unter ben Unarten als unter ten (5) ebred) en angeführt wercen. Daz erjtere (in bie Eijen Sauen, aud) Inhauen) rübrt yon vermebrter Rerben= thätigfeit in ben bintern (3)liebmafen ber. Der Norberbuf (toe) besె

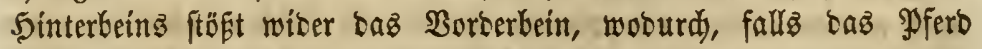
befdlagen ift, ein unangenebmes (S)räufd entiteht; woher ber $\Re a=$ men - in bie Eijen bauen - berfommt. Rebft ber Unannebmlid=

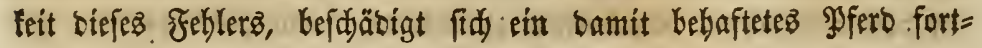




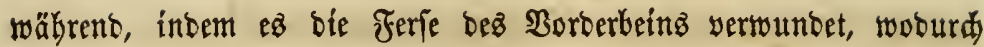
oft ernftlidye Rähmung entftebt.

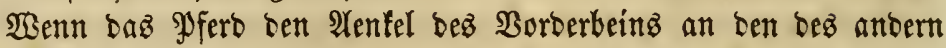
Borberbeins ftöft, to Keift man biez $\mathfrak{A}$ (neinanberfalagen (interfering), unb bei foldyem Pferb werben bie Innenfeiten ber 2Yenfel fort=

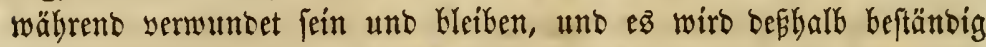
anbalten uno hinfen. Pferbe, Deren Bruft febr enge ift, uno beren Borberfübe bejbalb nake bei einanter fteben, fino siefien Sebrecten viel mebr ausgejebt als antere.

3ur Berbütung bieję Hebelz fann man siel beitragen, intem man bie Sufe an ber Snnenfeite gut auşpubt uno bie Sufnägel nidyt an oer Rrufte vorftehen läpt; ganz uno gar aber fönnen

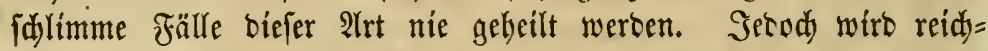

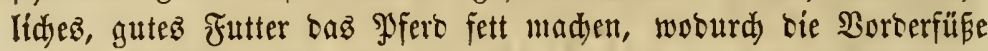

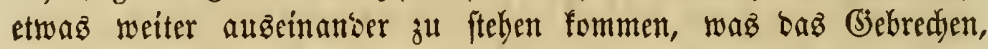

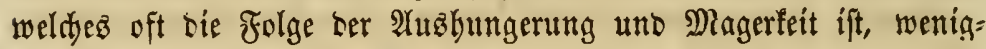
ftens theilweife Gebt.

\section{Sto $\operatorname{tp} \in \boldsymbol{r} \mathfrak{n}$ (stumbling).}

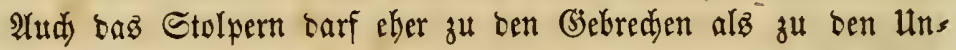
tugenoen geredinet werten; $\mathfrak{E}$ entipringt aus einer eigenthümliden

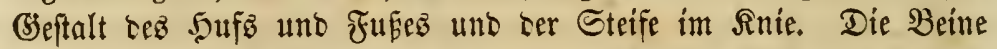

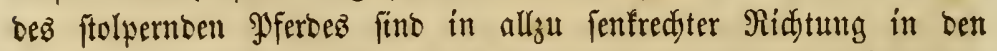
Suf eingejest, fowie etwa ein Pfoften in ben Boben. Gin Stol=

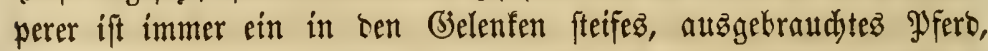
weldyes nur yor Dem Bangen uno bem Pfluge Dienfte verridyten fann. Gin Surverfabren fann gegen biefez (5iebrechen nidyt angege= ben werben, uno wehe bem Mann, weldyer es verfucht, auf einem "Stolperer" zu reiten; jebenfalls follte er fein seben verfidjern laf= fen, ebe er ben Ritt unternimmt.

\section{Fe h $\mathfrak{l} \in \mathfrak{r}$ (unsoundness).}

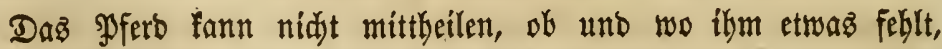

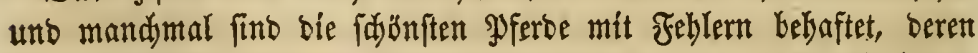
Sorfjandenjein audy ben beften Sennern entgebt. Defbalb ift es unjere 2Nbficht, auf einige ber am meiften worfommenten Biebredyen

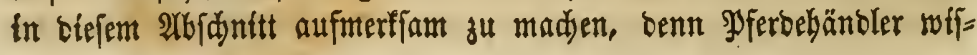




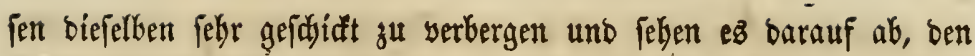

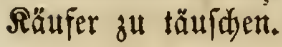

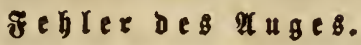

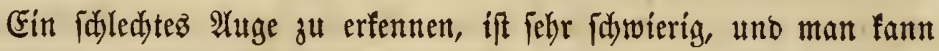
biezs, wenn ïberhaupt, im Somnenlidyt aun beften auşülbren. Man

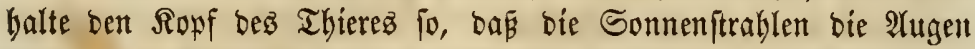
treffen; iftes nidht ganz hell uno flar, fo wiro biez burdy bie in baffeltbe faheinenbe Sonne angezeigt. Eine antere Methobe, bas

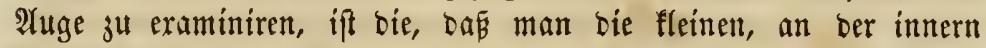

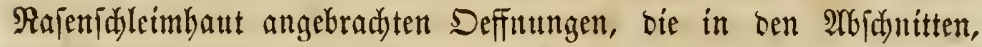
wellye som $\mathfrak{A}$ uge und "Blino Staggers" handeln, beidyrieben wur=

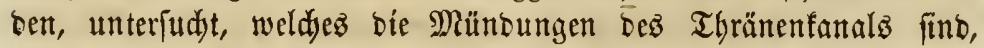
burdy weldyen bą $\mathfrak{T}$ tgentwaffer abgefübrt wirb. Dieje Deffumngen

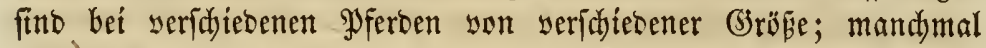
fint fie nur to grof wie ein Steffnadelfopf, manditmal meflen fie

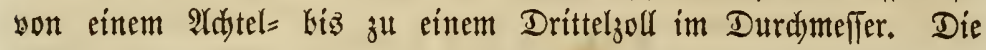

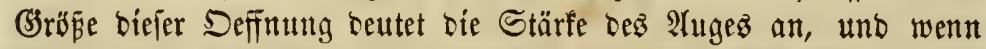

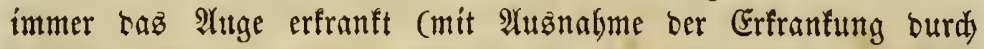
Sdjläge voer anberweitige Beiduäsigungen), ober burdy Sranfleit blint geworben ift, fo werben die Deffintungen fehr flein fein, uno in ben meiften son unz unterfudten fälllen (eßs fino beren beinahe fünfGunbert) waren diejelfen nidht größ̄erer alż ein Stefnabelfopf, wäGrent in vier yon unz wäbreno bez lebten Monats (2̂uguf 1866) in Peteräburg unteriudten Fañllen bieje Deffnungen in ber

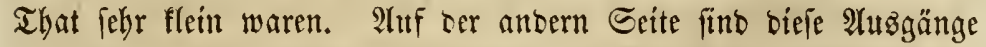
bagegen bei PFerben mit guten, hellen, ftarfen $\mathfrak{A}$ tugen meiftenz im= mer groß̈; uno barf bieje Regel alz eine allgemeine aufgeftelft wer=

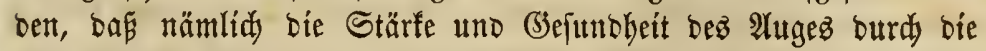
(3rräpe biefer Deffinungen angezeigt ift.

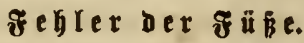

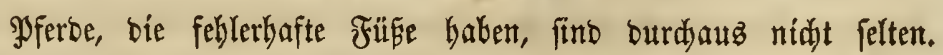

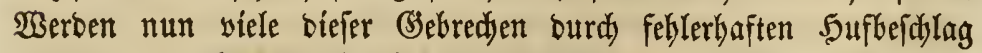

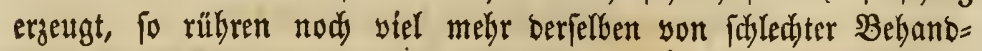
lung im Stall ber, inbem man bie Thiere in Räffe unt Sdymuts felben läpt. Dielenboben finto, bauptfädlta im Sommer, ben Früsen 


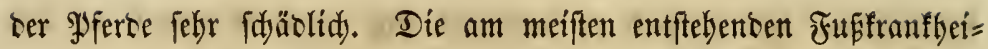
ten find: Şuffäule, Baallen, Strahlfäule, Maule, Sdyrammen, weldje Dann wieberum viele andere Hebel hervorrufen. Die Shuffäule hat

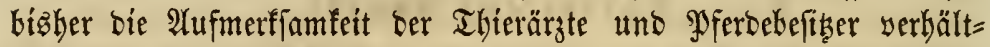

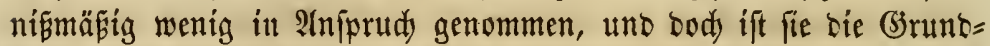
lage aller antern Fttfbejd)werben. SHuf̈äule (audd "pumiced feet" genannt) wurbe kereitz bejdrieben. Dieje Srantheit ift ourdi einen

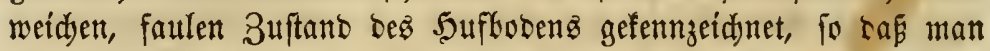

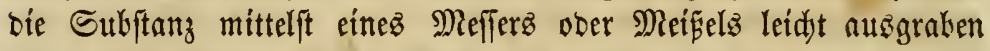

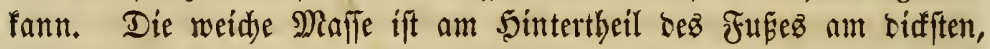

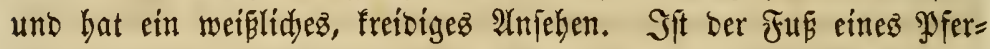

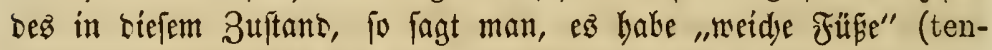
der-footed), was fîd burd) Ien eigenthümlidjen Edjritt beż Thierez

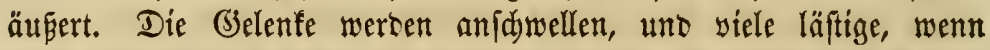
nidjt unbeilbare Befdyerben fino bie Folge. Rie vergeffe man, ba Suffäule eine emftlidye Siranfleit uno bef̧halb ein grofer Fehler ift.

\section{gebrer der}

Die 5̧aut vieler $\mathfrak{Y}$ ferbe ift yoll yon flénen Sduppen (scurviness), fo dás ez niddt möglid) ift, fie rein zu halten. Man fann faum je mit ber 5and über bie 5authaare fahren, ohne bas biefelbe yoll Staub und Sdymuts wirb. Wenn man bez Morgenz fo viele siejer

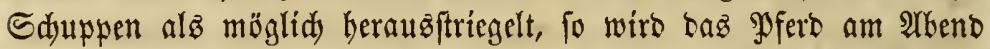
wiecer ebenfo fdumutig uno ftaubig fein alş zusor. Mandumal bält siejer Zuftano Monate unt felbjt Sahre lang an. Die 2Tnfidyt vieler

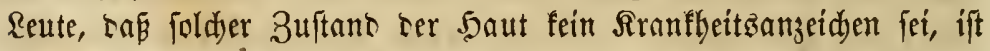
cin Srrthum;

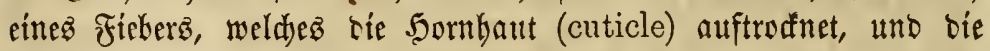
5aut am ganzen Rörper versiát. Die Siranfheit mag zwar bloz in

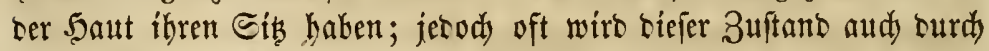

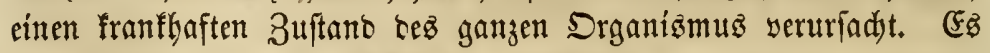
ift ber $2 \mathfrak{n}$ fang anterer ernftlidjen Sranffeiten uno kejdä̌rigt nament=

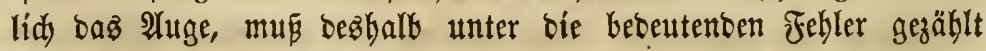
werben.

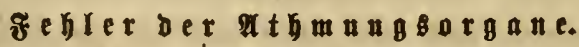

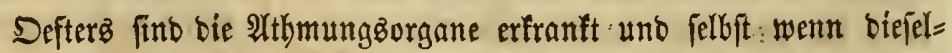

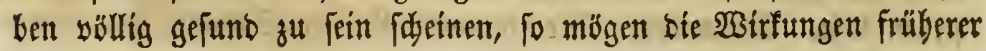


Sranfbeiten nody, obgleid in mildoer frorm, vorhanben fein, twaz ben

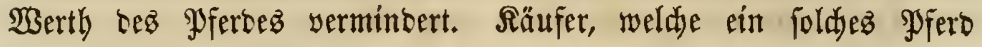
einbanteln, find betrogen. Finige ber dyronifden, Durd) (3ebredien

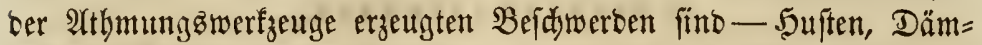

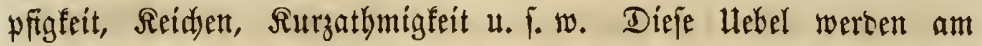
fiduerften baburd) entoedt, indem man bas Thier längere Zeit idnell Gerumreitet ober mit ihm berumfäbrt. Sit ez an biefen Drganen erfranft, to wiro fid biejes im Artbmen zeigen. Trodenes, ftaubiges

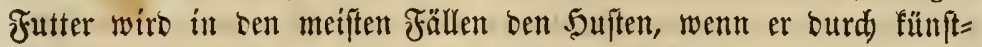
lidje Mittel ober fonft etwas einige Beit zurüffigebalten sourbe, zum Borfajein bringen. Man prüfe tą zu faufenoe Pfero genau, ebe man $\mathfrak{e z}$ cinbancelt.

\section{รéter des}

Unverbaulidjfeit unb (sebärmsftörungen fino bei bem Pferbe oft yorfommenoe Hebel; bie biedurd) erzeugten beftigen Symptome geben jebod idnell sorüber; nidt aber bie Jolgen biejer Sirantbeiten, in= bem burds tiejelben bie Beroanungzorgane oft aejdwäd)t weroen. Biele Pferbe find mit bäufizen Rolifanfällen behaftet, weldye suth nidyts anteres serurjadyt wersell, als ourd, bie Unyolfommenteit

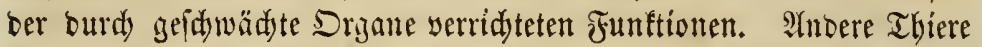
fino beftändig mit miloercu ober beftigetem Durdfall behaftet. Mandtumal wirb baz gefteffene Futter unveroaut entleert, fo baj etwas ober eine ziemlidye Partie

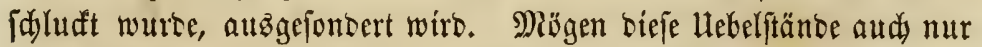
yon zeitweiliger Erfranfung ber (sebärme herrübren, fo fönnen bod aud bleibenoe Sdjäben zu (3runbe liegen.

\section{Die $\mathfrak{g}$ arnorgane.}

Die Sarnorgane beż Pferoes erfranten bäufiger als írgend weldje andere Theile feines Rörpers. Entzünoung berjelben mus entweber bald gebeilt werben, oder wirb ben Too berbeifübren. WSiro fie aber aud) furirt, fo laffen foldye Entzünounggftanfbeiten bod) faft immer mebr ober minter erbeblidje (Sebred)en zurüd, f. B. Şarnzwang, woller Salaud), Blutharmen, Shleimbamen, weifer ober falfiger 5arn, Sarnflǘ, Berbaltung beż 5̧arns น. \%. w. Sn manden Făl= len fint bieje Befdwerben nur zeitweilig uno veridywinden wieber 
mit ber fie verurfadjenben Rranffeit, febre oft aber baften biefe Hebel bem Ibier aud fein ganzes Reben lang an.

\section{ร}

Es giebt aufer ben genannten nod) viele anbere \$Pferbefebler; ba

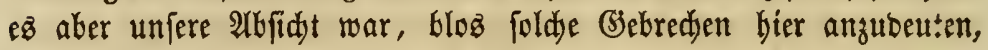

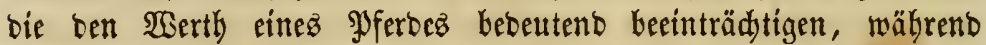
fie zugleid) nidyt allgemein verftanden werben, fo mag baz Sbige genügen. Esz ift faum nöthig, ben Refer yor vffen baliegenden Feb = lem zu warnen, aber ifn auf bie gelheimeren, verftedteren aufmerf= fam zu madjen, biez haben wir alż unfere Mflidyt eradjtet. (Semiffe Siranflyeiten fint burdy fo auffalfende Eymptome gefennzeidnet, ba aud) ber Uuterfahrne faum irre geführt werben fain; f. $\mathfrak{B}$. Ring= bein, Spat, Irantheit bes Grriffelbeinz (splint), Flufigallen, Boll= huf, gefdwollene Beine, Big=head u. f. w. YUlle biefe Franfbeiten mûffen alz gröfere ober geringere Fefler bezeidynet werben, find je= bod) fo wobl befannt, baß eine näbere Beidureibung berfelben unno"s= thig märe. 


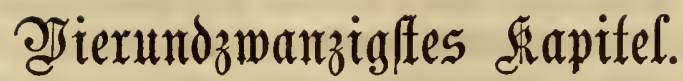

\section{mezepte zur ârzmeibereitung.}

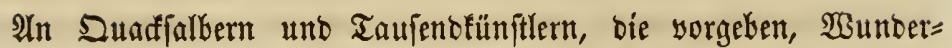

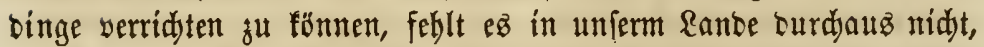
wobl aber an einer binreidenten $2 \mathfrak{n} \mathfrak{z} \mathfrak{a b l}$ wirflid befäbigter $\mathfrak{T}$ hier= ärzte, bie im Stanbe fint, bie SSferbefranffeitent ridjtig zu behanbeln; obgleid fid ba uno bort ein tüdtiger Pferbeboftor fintoet, waz $n a=$ mentlid in ben Stäbten, weldje in biefer Sinfidut beffer werforgt find alz baz \&anto, ber Fall ift. Secod) werben audy bort (in ben Stäbten nämlid) nody heute im Âlgemeinen bie veralteten als un=

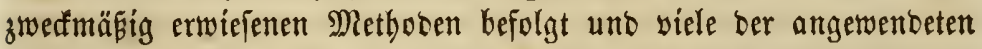
Debijinen erweifen fid als erfolglos; benn wenn biefelben aud bie Folgen ber Siranlfheit pịt entfernen, fo verfehlen fie bie Urfadjen

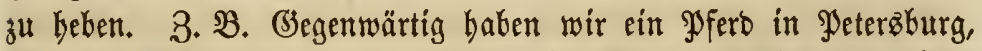
Rig. in Behandung, an weldem sin Mann, weldjer fidi) einen

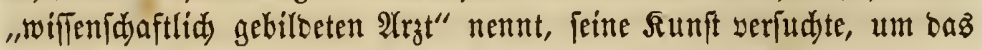
mít einem angeidwollenen $\mathfrak{B}$ ein behaftete $\Re$ of zu furiren. Range

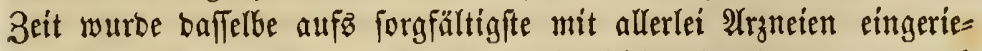

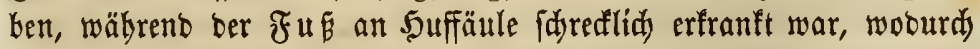
die Beingefdyulft beryorgerufen wurbe. (Jegen bie $\mathfrak{u} r=$ fadie ber Rrarfleit wurbe nidjt eingeldyritten, ja, man erfannte bie felbe nidjt einmal.

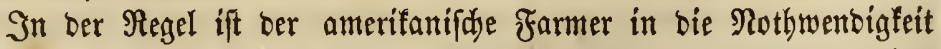
verfebt, feine erfranften Thiere jelbjt zu belyanbeln, pber fie ofne

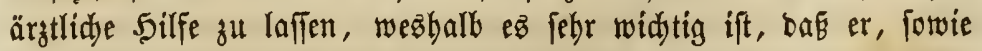
jeber \$ferbebefiker, fidy nid)t allein mit allen gewöbnlid vorfommen= ben Sranffeiten, fonbern aud) mit ben anzumenbenden Mebizinen

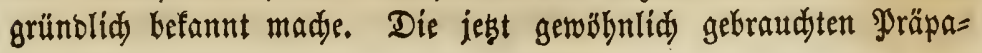


rate find bem Farmer meiftens unbefannt uno auperoem aud oft fdywer zH befommen. Dies ift nidht, wie es fein follte. Die baupt= jäd)lidyiten uno wirfiamften Seilmittel fino einfady, fömen leidht beidaafft werben, uno ift ber Stebraud berfelben ourdyaub nidyt ge= fälyrlíd.

Die bier bejdriebenen Medizinen, fo wenige aud angegeben wer= ben, uno to allgemein befannt fie audy fint, find erprobt unb baben fit) entweder einzeln ocer in Berbinbung mit einanber alz febr er= folgreidy Gewiejen. Sisir wersen in Rïrze bie sazu verwanten Sub=

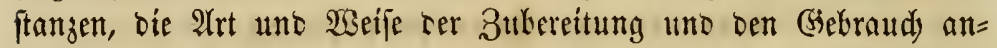

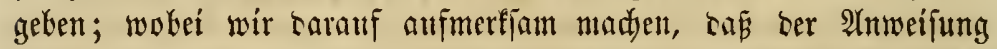
für bie Bereitung fowobl alz nem (jebraud) rie gettaufte 2Utufmerf= famfeit gejdjenft wersen jollte.

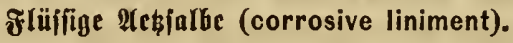

I.

Man nebme ein halbez Pint Terpentin (turpentine), giep̃e den: felben in eine gute, ftarfe Flaidye uno mildye eine Unze fein pulyes

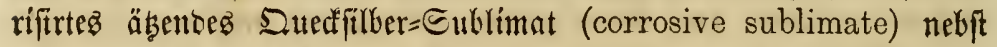
ciner Unje (S) mmi=Sampher (gum camphor) barunter; fodüttele bie Mifdung gut wto laffe fie vienunzwanjig Stunten fteben, nady, weldyer Zeit fie gebraudyt werten fann.

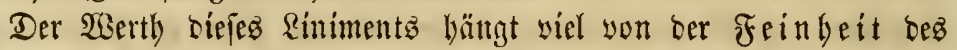
geftofenen ätzenten Duedfilber=Suhlimatz ab, weshalb baffelbe in einem 2 (potbefermörjer fo feín alz möglid gemadyt werben follte; ez nur mit einem Sammer za zerflopfen, ift ourdjaus ungenügend.

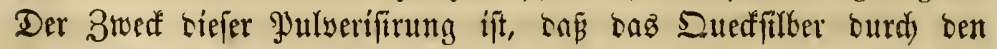
Terpentín gebörig uno fdnell aufgelöf werbe. Nurr wentige flüffitg= feiten löfen diefes Sublimat auf, uno wir beamprutuen, die Ent= becfung gemadyt zu baben, baß biez burd) ben Ietpentin zu Stande fommt. Sit aud) bas äbente Duedffilker=Sublimat alo eins ber ftärfften Bsifte befannt, fo ift $\mathfrak{e s}$ in Serbinbung mit rem Ierpentín bod) eine ber erfolgreidjfen Mebiginen, weldye je älter, befto beffer wiro. Wát find überzeugt, ing) Riniment ift. (Ez bringt burd) alle Sinternifje zum Sits ber

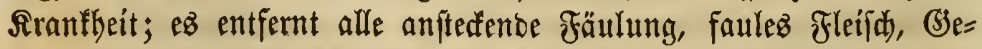
fdy whr= Materie uno willoes Fleifd; beilt alte, laufenoe Wunben und 


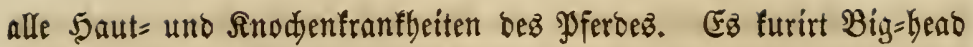
uno Big= Saw, Maufe, Strablfäule, Shywämme, angeidumollene

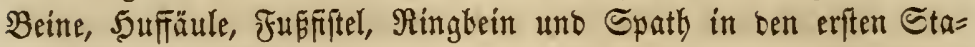
sien biejer Srantheiten.

Bei Meniden bat bieję siniment fđjon äfters jente beläftigenten Beidywerben, bie unter bem Ramen Grinto (scald-head) uno fledte (tetter) befannt fint, furitr, mú aber in biejen fä̈llen mit groper Borfidit uno barf nie sor bem zebnten Sahre angewants werben.

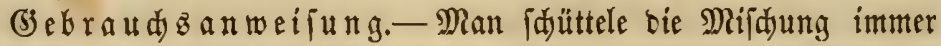
tüd)tig, ehe ber Stöpfel abgenommen wirb, gief́e baz siniment, ba

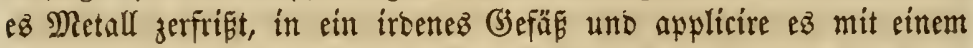
zujammengelegten, weidjen Sappen. Bei allen Sinodjentrantfeiten muE bie Mesizin mittelft eines beif́gemaditen Eifenz tühtig einge= trodinet werben, inbem man baffelbe nabe über bie betreffenten Theile

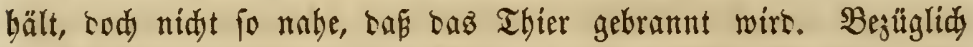

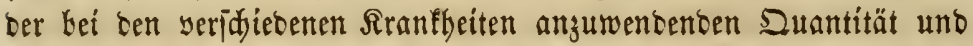
(3) lide 2 trweifungen gegeben.

Vorfidt

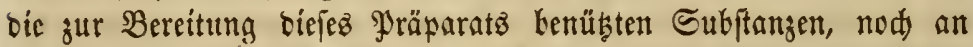
baflelbe felbit fommen fönnen, benn wenn baz Riniment genofien

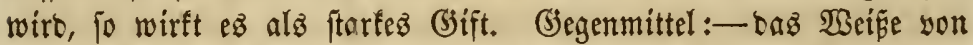
Ëtern. Die 5änbe aber, fallz bie 5aut nidjt wunto 2 . i it, werben

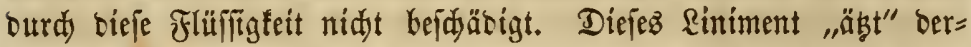

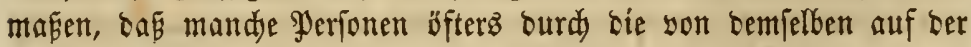

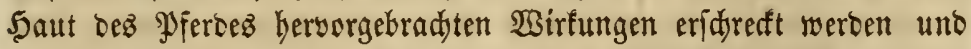

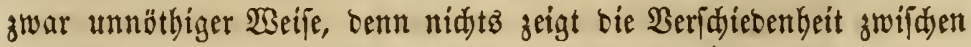

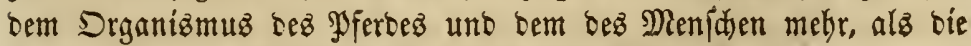

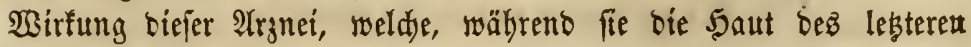

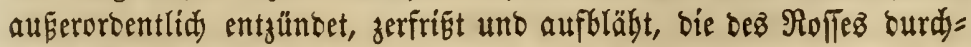
aนs nidjt bejdäbigt.

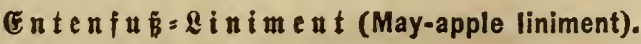

III.

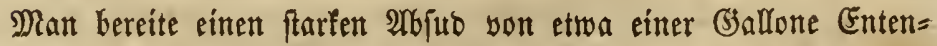

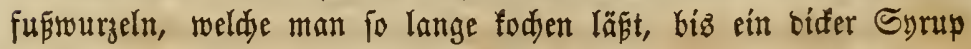
entfifteht, ben man aber nidt anbrennen lajien barf. Währento bíe 
Maffe nod) fodjt, mifdje man ein Biertheil foyiel alten Sped ober Sdjmalz barunter, indem man fortwährent gut rïbrt, nebme ben

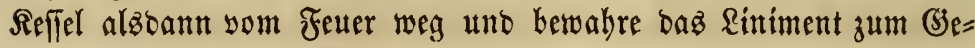
braud) auf.

(3) $\mathfrak{e b r a}$ d) gen (Jejd) würe uno Beulen, wo fid Materie angefammelt hat, aud bei Fiftel und Geneniffiftel in zweiten Stabium, b. h. wenn bie Ei= terung begonnen bat. Dieje Rranfleetten werben in biejem Stabium immer burdy Daz Entenfußs=?iniment furirt. Es wirft zmar lang aber, wenn ridjtig gebraudst, fider; entzuntoet bie 5aut, bie ę auf=

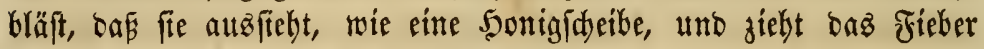
fowobl als ben Eiter auf bie Sherfläd).

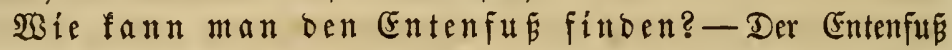
(engl. may-apple; lat. podophyllum peltatum) fommt int ben mitt= leren uno weftlidjen Staaten Morsamerifa's bäufig yor, uno wädýt auf reidyen 5odjebenen, wo bie Birfe (birch) und ber 3ưferahorm (sugar-tree) fortfommen, fowobl alz in ben meiften 1 ferläntern. Die Pflattze wirb etwa einen Fus hod) und bat einen glatten, run= Den Stengel, weldyer oben öfters zwei Zweige treibt, zwifden weldyen fid bíe Blume befintet. Sfit ber Stengel nidht gegabelt, fo haben bie

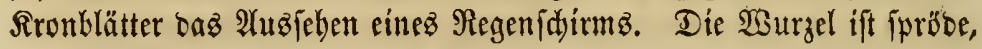
yon weiś=brauner Farbe, uno verzweigt fid etwa einen 3oll unter bem $\mathfrak{B o d e n}$, wo fie fid in vicle (3aabeln theilt. Der Stengel er= facint zeitig im Frübjabr uno ftirbt etwa im Suni ab. Die $\mathfrak{s u r =}$ zeln follten nidjt getrofnet, fonbern gleid) benübt werben, benn bas Trodnen beraubt fie gemb̈bnlid) ibrer medizinifden Siraft. Man fam bie goflanze beinabe immer das ganze Sahr hinourdy finton.

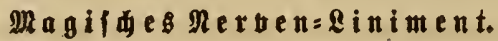

III.

Man nelgme sinte ftarfe Flafde, weldye aht Unzen bält unb fülle fie mit

Siridjhorngeift (spirits of hartshorn)

Sdivefeläther (sulphuric ether). $.1 \frac{1}{2} \mathfrak{l n} \mathfrak{z}$.

Ierpentingeift (spirits of turpentine) $1 \frac{1}{2}$,

Baumöl. $\frac{1}{2} n$

Relfenö̆ . $\frac{3}{4}$ chloroform $\frac{1}{2}$ " 
uno faüttle die Mafle gut, fo ift baz Riniment bereitet. Die fla ide follte immer gut jugeftöpfelt werten und zwar wo möglid mit

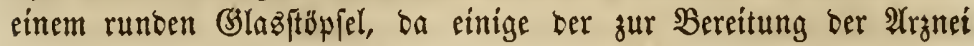
verwittoeten Subftanzen febr flüdjtig fint. Audy foulte fie entweber an einen bunfeln Sort ooer gut utmwidelt aufberwakgt werben, weit Ridyt bie Rraft ber Mesizin idjwädst.

(B) $\mathfrak{b} \mathfrak{a} \mathfrak{a}$ d) $z \mathfrak{a n w}$ eifung. - Diefes Riniment wiro, wie fdon fein Rame anteutet, gegen Nervenleiben gebraudyt, uno ift in feinen Wirfungen jebr bejänftigeno uno beruhigent; es linbert bic Sdamer=

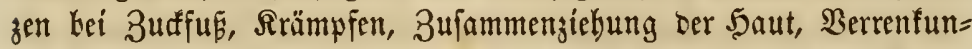

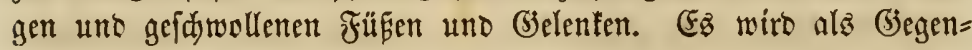

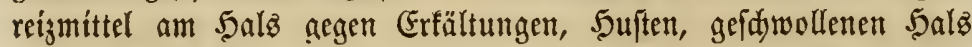
3. und gegen Bronditis uno \&ungenentyünoung in ter Begeno ber

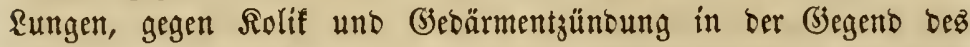

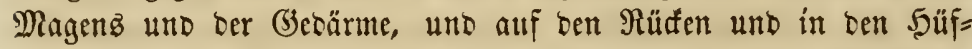
ten, gegen Rranffeiten ber Rieren uno 5arnorgane eingerieben.

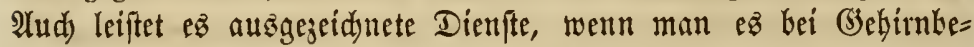
¡dyerten auf bie Simfdale cinreibt. STSenn frühe genug applicirt,

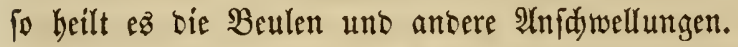

Diefez Riniment wirb aud bem Menfdjen gegen veridiebene Rer=

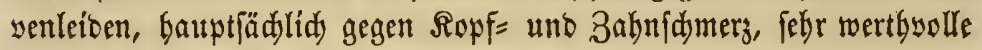
Diemite leiften.

\section{Mercurial=ober $\mathcal{Q}$ uedilber=salbe.}

IV.

Man nehme eine Duantität Dueffitlber (metallic mercury), bie fo grof ift wie eine Erbfe uno ebento yiel Joo (iodine) unt eine

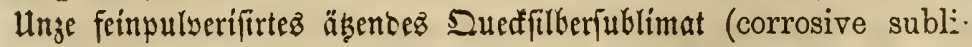
mate), uno mifdje bieie Subjtanzen gut mit zwei Eflöffel vol Sdmaly, biz díe ganze Mafie yolffommen vermengt ift.

(3) $\mathfrak{b r a}_{\mathfrak{a}}$ banweifung. - Diefe Salbe furitt Strablfäule (thrush), Sdyrammen uno Fuffififel, aber $\mathfrak{n} i$ d andere Fuffrant= beiten. Sie furirt beinabe alle Sauttrantbeiten, o. B. Räube, Sur=

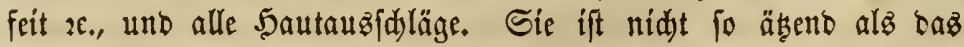
corrofite Siniment, und beshall in Fällen, wo milloe Behandlung

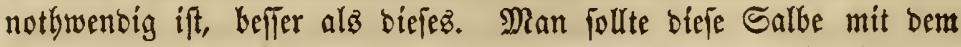
Finger ober einem raulfent $\mathfrak{a} a p p e n$, ober einer Bürfte gut in bie 5aut 


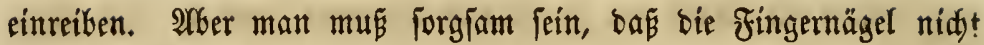

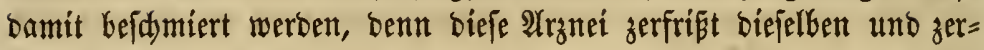
ftört fie oft ganz.

\section{S d to efelfalbe (sulphur ointment).}

$\mathrm{V}$.

Man nehme eine halbe Unze rotken Duedfillbernieberidjlag (red

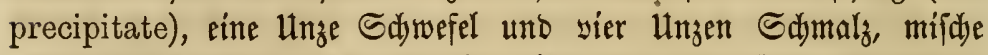
bieje Subftanzen gut uno berwahre bie Salbe zum (bebraud) auf.

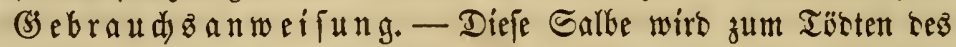

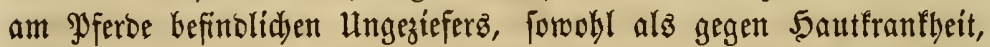

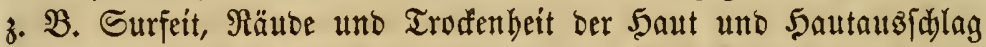

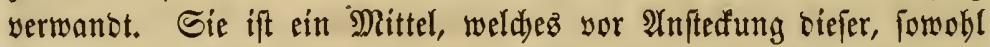

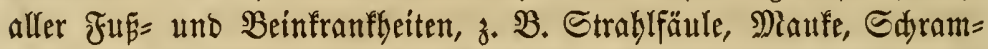
men uno Fuffiftel bewabrt. 2(ud) wiro fie mit Erfolg gegen nidjt jebr folimme Sdjrammen 2 ., auf bem Rüfen utmo Sdultern ange= mandt, uno ift überbaupt ein unfdäb̧bares Seilmittel, weldę in jebem Stall zum Giebraud yorräthig fein follte.

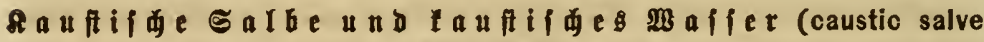 and wash).}

VI.

Diefe werben yon ber gewöbnliden fauftifden Pottajde, bie überall

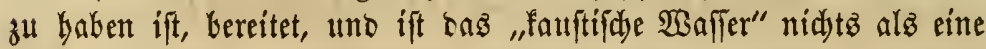
ftarfe Rauge, bie yon Pottaidhe uno SGafler bereitet wiro.

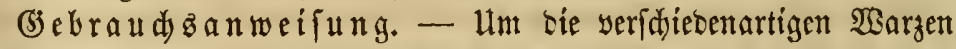

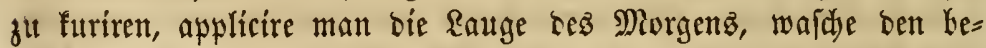
treffenten Theil ant 2 fbend wieber ab und applícire bie $\mathfrak{R} a u g e$ wie=

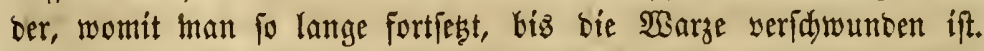
Will man eine Blutwarze entfernen, fo foutte man nad) $\mathfrak{A}$ nwendung

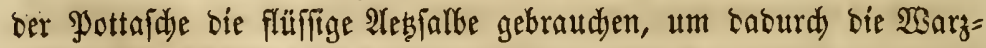
wurzeln zu zerftören fowie bie WSunbe zu Keilen. 5at man es mit eitner Saatwarge (seed wart) zul thun, fo beftreid)e man bie Theile

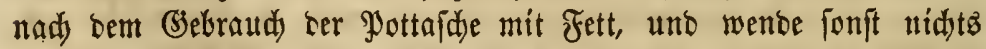
an. Beim (bebraudy ber fauftifden Sottafdye mus man forgfam fein, bas nidjt anbere Rörpertheile, als bie zu behanbelnten, bamit befledt -werben, inbem fonjt immer bie 5aare jerfrefien werbent und 
eine $\mathfrak{B}$ unde entfebt. Damit biez nidjt gefidehe, mag man bie Theile um bie $\mathfrak{2}$ arze mit Fett gut beftreidjen.

Die faufififde Salbe wirb bereitet, inbem man fein pulyerifirte 5olzfoble (charcoal) mit ber Rautge vermifatt, und fie wirb in äbn= lider $\mathfrak{2}$ eife wie bie Rauge gebraudd, ift aber biefer vorzugieben, in= tem man. leidt)t verbüten fann, andere Särpertbeile mit berjelben $\mathfrak{z}^{\mathfrak{u}}$ beflecten.

Profelfor Dale'serfifues Pferdu VII.

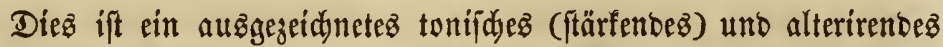
(Mifdungżyeränberung bervorbringent) Mittel, über beffen (Sebraud in ben betreffenden 2(bjanitten 2Inweifungen gegeben wurben.

\section{Salpeter= ธã $\mathfrak{u} \mathfrak{r} \in$ (nitric acid).}

VIII.

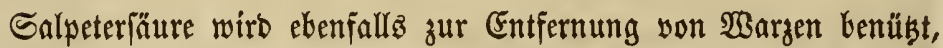
muß aber mit auserorbentlider Sorgfalt gebanobabt weroen. Ein Stülf Reber ober biffer \$appendedfel, in welden ein Rodh geidnitten wirb, gerabe io gró alz bie $\mathfrak{B a r z e}$ wiro über fie bergelegt, worauf man ein wenig Säure fehr jorgfältíg mit einer fleinen Bürfte ober sinem Räppden appliritt. Die Theile unterbalb ber Warze follten gut mit Ralf beftridjen werben, bamit bie Säure, weldje binabträü feln mag, biejelben nidyt zerfrist. Man jollte bie Salbe alle zmölf Stunben fo lange anwenben, biz bie $\mathfrak{B a r}_{\mathrm{g} e}$ zerftört ift, uno nadj=

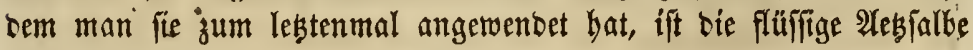
zu gebrauden.

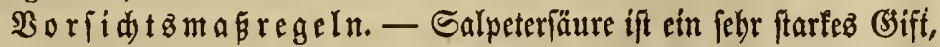
unb wenn fie auf bie 5aut bes Menjwen gebradtt wirb, bringt fie Blajen unb böżartige $\mathfrak{B u t n d e n ~ h e r v o r . ~}$

\section{Distemper = MR it t $x$.}

IX.

Man nebme cinen Eplöffel woll Sdiefpultwer, ebenfoviel Sdutwetne idmal uno Sdymierieife (soft soap), uno zwei Eslöffel voll Theerr

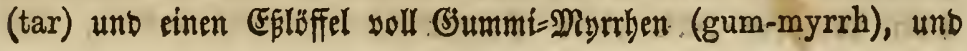


mija)e biefe Subftanzen gut untereinanber. Dieje Mafie wirb für

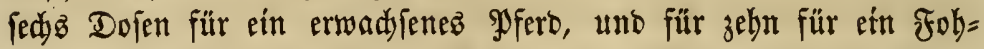

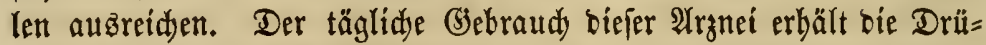

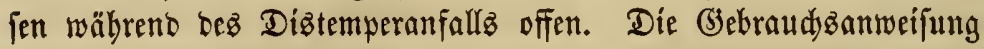

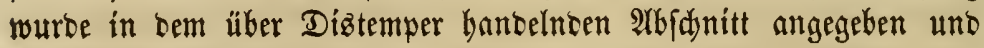

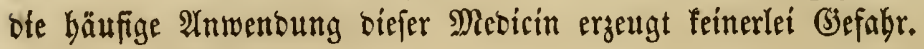

\section{A и в п to a ficr (eye-wash).}

$\mathrm{x}$.

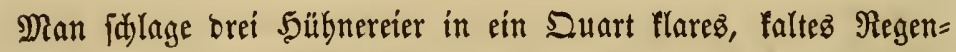
waffer, und rübre die Mafle, bis fie gut gemifdut ifit, fodde fie alö = baun über einem nidjt zu grofent Feuer, wäbrent man yon Zeít zu Beit barinnen rübrt, faütte eine $\mathfrak{H}_{\mathfrak{z}} \mathrm{e}$ Binfvitriol (sulphate of zinc, or white vitriol) baju und la life daz (Janze bierauf nod eine Weile foden, worauf sie $\mathfrak{A}$ rznei für ben (bebraud fertíg ift. Sn biejem

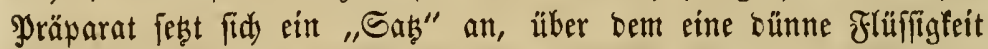

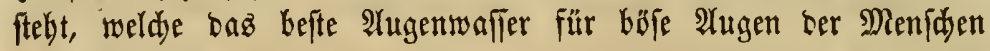
voer Thiere ift.

Der auf baz entzündete 2 quge bei $\mathfrak{R a d j t ~ g e l e g t e ~ " S a g " ~ w i r o ~ b a s ~}$ Fieber жc. bis Morgen entfernt baben. Man fann temelelben bem Pfero auffeben, inbem man ifm eine mit eirrem Sod) (bamit bas gefunde 2 ugge gebraudits werten fann) verietgente Rappe über ben

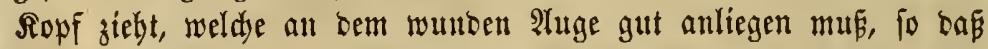
ber Sas bez Präparatz feitgehalten wiro. Etrwa ein Efflöffel Des= felben wirb in ein bünnes Stüld Muslin gewiffelt, gut mit bem

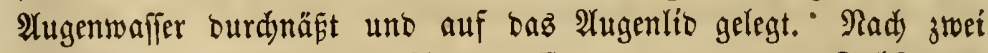
vber brei $\mathfrak{T} a g e n$ follte bas 2lugentwaffer yon ben anbern Subftanzen abgegoffen uno in einer Flafde zum fermeren (Gebraud) aufbetwaftst werben. Wenn man baż Waffer zwei ober breimal burdjeiket, fo wiro es gang frei yon ber (Eifettigfeit und flar, uno bält fid felyr lange. Der aus den übrigen Subjtanzen beftebente Sab̧ ift für die

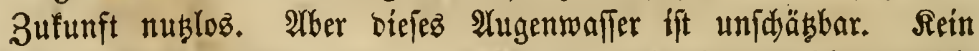

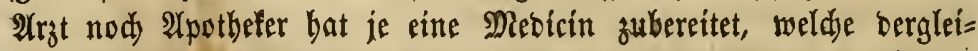

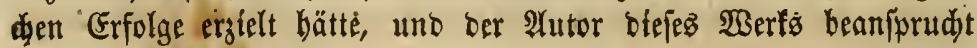

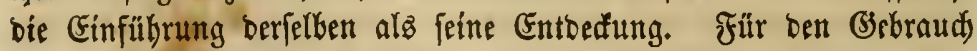
beim Mertiden follte biefes AYugenwaffer yerbünnt werben; aud 
fann ber "Sağ" beim Meniden mit gutem Erfolg angerwentbet werber.

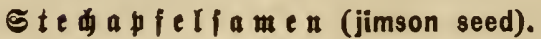

XI.

Der Stedfapfel (lat. datura stramonium) if eine wobfbefannte (3iftpflanze, bie überall wädjt. Sein Same wirb alz PJerbearznei gebraudt, benn, obwobl berjelbe bem Meniden Bift ift, wirtt er bei

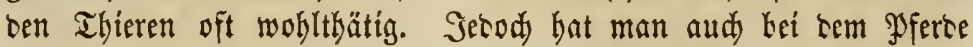
voridutig zu fein, weil ber Sted)apfelfamen leidjt feine 2 ugen be= fajäbigt, obruobl fid mandje Roffe fajon Wodjen uno Monate lang yon ber Stedjapfelpflange getährt haben, obne Sdjaten zut erleiten, unb Rindsieh, Sdafe uno (3eisen füttern fid Laran, ohne beein=

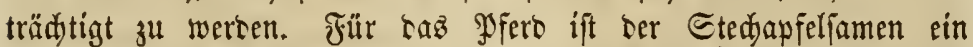

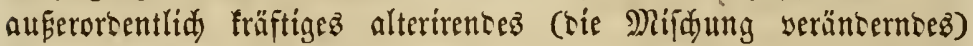
Mittel. GB ift abfübreno, fajweís= uno barntreikeno, uno wirft auf

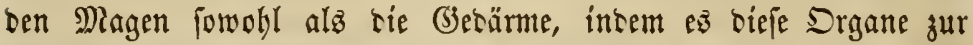
Erfüllung ifrer Funftionen anregt. Es theilt fid fehr fodnell bem Bhate mit, oringt curd bie 5autporen uno erjeugt rege, gejunbe

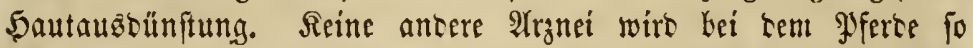
fänell Etörungen uno Entzïntungen ter 5arnwerf unt Keilen. Stedapfeliamen barf mit Redjt bie widjtigfte Pyferbe=

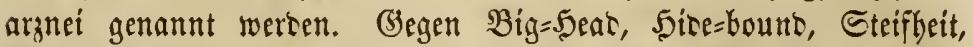

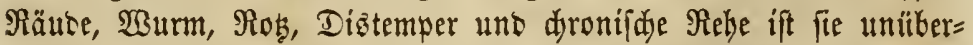
troffen. Sn allen Fătlen, wo gen uno bie erfrantten $\mathfrak{B e r c a u u n g s w e r f}$ geuge in Dromung zu brin= gen, ift Mittel wirft to prompt uno erfolgreid. Dhne Stedjapfel fönnen weder Big=5eab, nod Sicebount, nod) Steiffeit furirt weroen.

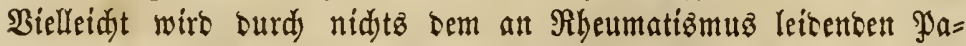

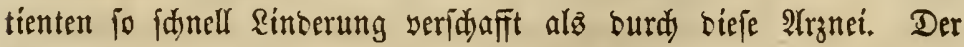
Stedapfeliamen jollte in ben Monaten Sftober uno Rovember ein= gefammelt werben.

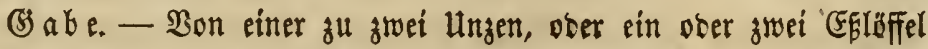
yoll alle zwei ober brei Tage, je nad) Der Seftigfeit ber Rrantbeit, bíz sier Dofen eingegeten wurben. Rad einem 3wifdenraum yon 


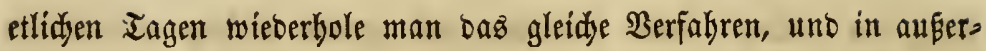
orbentlidjen Fällen mag jeben $\mathfrak{T} a g$ eine Dofe gegeben werben.

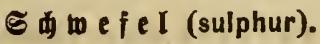

XII.

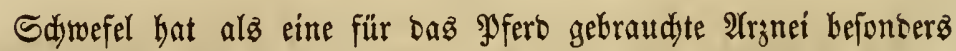

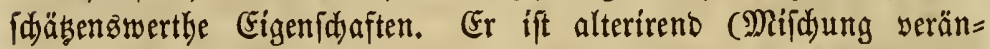
Derno), führt milbe ab, berwahrt yor 2 (niftefung, beilt bie Entzün=

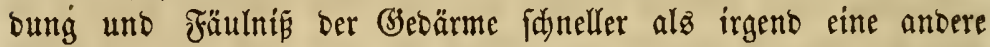
Mebicin, uno wirft auf bic Saugabern uno lymphatifajen (biefäßje jebr woblthätig. Er ift berubigend (sedative) und harntreibent. Die woflthätigften $\mathfrak{B}$ irfungen jedod) ergeugt er auf ber 5aut und im Saar, indem er bie Soren sffnet unt bie ölige Flüfifigfeit auf

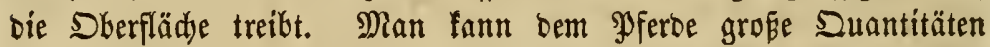

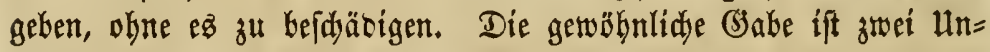
zen jeben $\mathfrak{I} a g$, woer sier Unzen jeben andern $\mathfrak{T a g}$.

\section{$\mathfrak{B} \mathfrak{a} \mathfrak{z}$ (rosin, or resin).}

XIII.

5arz ift eir milldes harntreibendes Mittel uno beefhalb fegr werth= woll, benn ez giebt viele harntreibende $\mathfrak{A}$ rganeien, bie, weil fie feffr

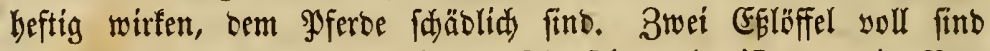

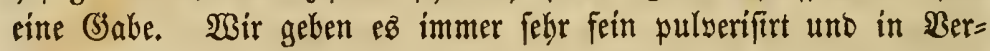
binoung mit Sdywefel. Es wirft auf bie Rieren unb Jarnblaje, und reinigt ben Saarn fidjerer alo irgent cin anberez unz befanntez Mittel, wirft aber jehr langjam.

\section{ธ मabe ober ङ horse's leg).}

XIV.

Der Sdjorf, weldyer fidh an ben $\mathfrak{A} u$ fenjeiten ber yorberen und

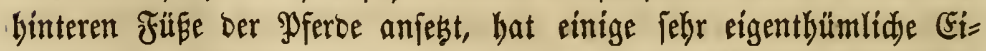
genidjaften, auf bie man erft neuerbingz aufmerffam wurbe. (B)e=

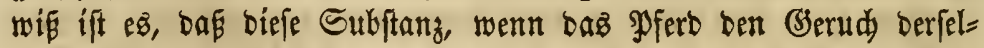
ben einathmet, ober wenn ez biefelbe frift, ober fie ihm in bas Dhr gelegt wirn, einen fehr betäubenten Einflus auf bas Thier ausübt, 
und zwar tauert biefe fonberbare Wirfung mebrere Stunten. Wír bem Pferbe etwa ein Ibeeloffel yoll biejer Subjtanz eingegeben, fo lintert biefelbe die bei manden Sranfleiten yorberridente Span= nung toe Srganiżmus in wenigen Mimuten, uno ift befballb bei Maulperr=Fällen febr wertbyod. Die Sirfungen find ftaunenerre= gent. Cin Theeloffel woll - pulverifirt - ift eime (Sabe uno follte mit eimer grofen Dofe Bitterfalz gegeben werben. Sbgleid) diefe Sdjabe etwas bitter unb wiberlid fdmedt, fo frifit fie bas Pferb jebr geme, unt wenn man bie Sände mit Ierfelben einreibt, und fie unter feine Raje bält, fo ftebt ftille. Sft reibt ez jeine Rafe an Dem Sdjorf bez Borberfues, was obne Zweifel son irgent weldyer angenebmer, wohlthätiger Wirfung ift. Die Ratur bat wabrideinlid) für bieje Subftanz ge= forgt, um irgent ein Besürfnís bez Pferces zu befriebigen, ober irgent eines jeiner Seiben zu linbern. WBir find ber $\mathfrak{A}$ fitidt, baf

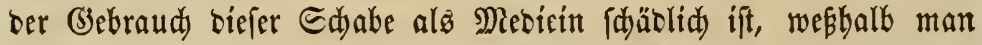
fie mur ipärlid benüben jollte. Mandje baben fie für Zäbmung willer Pferbe, die eben erfít eingefangen worben, benüst, und aud) wir haben berartige Berfudbe gemadyt, rathen aber yon sem (Be= braud) ganz entidieben ab. 



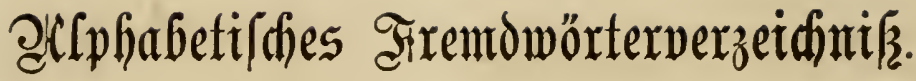

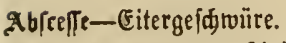

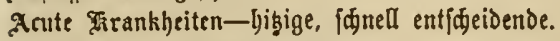

Affaire-Borfad, Begebenbeit.

Afficirt-angegriffen, franthaft gereizt.

Alterativ-ein Miijüungsoveränderndes Mittel.

Ammoniak-Alaunerde.

Anatomie-3ergliederungstunft.

Animali(h)-thierija.

Axparat-Borridjtung, Gerăth.

Appliciren-anwenden, gebrauめem

Argument-Beweis.

Rtmofphäre-Quft., Dunfttreis.

Rutor-Berfaffer.

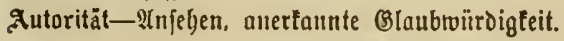

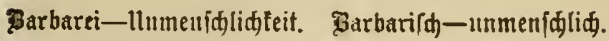

รูBrondien-Ruftröl)renäfte.

Ģronditis-Entjïnoung Der Ruftröbrenäite.

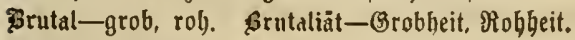

รุiliös-gallüđtitig.

Cientral-im Rittelpuntt befindlid.

Centrum-Mittelpuntt.

Oirculation-llmlauf, Ireisumlauf.

Claffifirirung_Eintbeilung.

Clima-Erogegeno, Ruftbejøaffenheit.

Chankrös-frebsgejđginürartig.

Charakter-eigenthümlidje Rennzeiden, Sinnesart.

Charakterifiren-bezeidinen.

Concav-hohl, flad bertieft.

Confiften-Beitano.

Conftitution-2eibesbejdaffenbeit. Confitutionell-in der Reibesbejdaffenbeit liegend.

Conftruction-3ujammenfeģung, Bauart, Anordnung.

Controlliren-übermaden.

Corrigiren-verbefiern. 


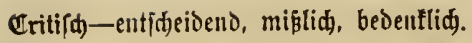

Cultiviren-aubauen, ausbilden, fortfegen, üben.

Departement-2(btbeilung, Fad), (Bejdäftştreis.

Desinfektion-Reinigung bon Anftectungsftoffen.

Diät-Roft, Fütterung, Lebensoronung.

Direkt-unmittelbar.

Dolis-Babe, Arzneigabe.

Dreflur-2bridtung. Drefirren-abridten.

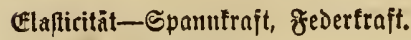

Element-BrumDitoff.

Energi (h-thatträftig, fraftuoll.

Excrement-2lustecrung, Stublgang.

Epidemie-Gende. Epidemi/d-Eeudenartig.

Elien?-Siraftwajier, Sraftitoff.

Extrakt-iie aus einem Stoff ausgegogene Rraft.

Zatal-[d)lium, verbängniß̧soll.

Fermient-(Bäl)ritofi.

Formation-Bildung, Beftaltung. Wormiren-bilden, geftalten.

Funktion-Berridtung.

Barantiren-hafter, gutfagen.

(5aftrifa)-Den lluterleib betreffent.

Beles-Bseromuenes, Diafjaft, Sülze.

Generation-QIbjtammung, Beidled, Radjtommenjajaft.

Indirekt-mittelbar.

Inftiukt-Naturtrieb.

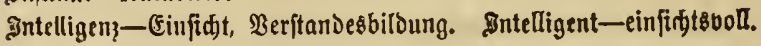

Drritation-2Inrcizung, Erregung.

踪aftriren-beridjneiden.

zitarrb-\&lupfieber.

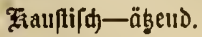

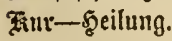

Tokal一örtlid).

2tanier-2Irt und Meife, Rebensart. .

Ataterie-Stoff, Eiteritoffi.

Etrreurialin-Argneien, die Duedfilber enthalten.

Attethode-Berfabrungsart, Lebrweife.

sttikroskop-Bergrößserungs̊glas.

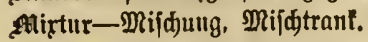

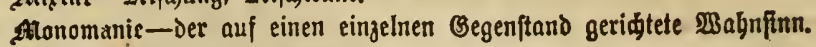

stotto-Dent, Sinu., Wabliprud. 
Ueutralifiren-bie eigenthümliden Eigenidaften greier Rörper durd Berbinoung

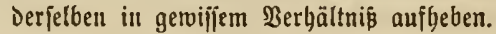

normal一io, roie etroas jein foll, voridriftsmäpig, mujtermäpig.

Operatian-Sgeilberfabrell, Soirtung, Berridtung.

Drgan-Mertzeug.

Organifirt-eimridteu, belebert, befeelen.

Drganismus- Sörperbau.

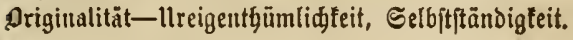

Daal-eiruno.

Jamphlet-grluginrift.

Jarat-bercitrillig, jertig.

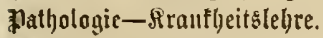

Fatient-ier Rranfe.

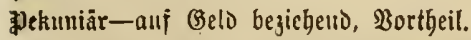

Jerutanent-bleibent, Dauerub.

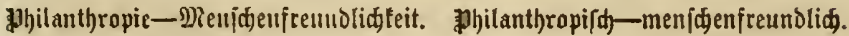

3hilo[ophi[d-wiffenijuaftlid, weisbeitsliebeno.

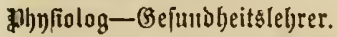

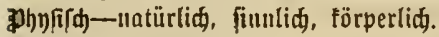

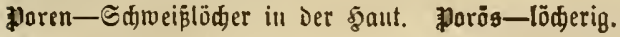

Jortion-Iheil.

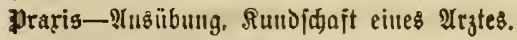

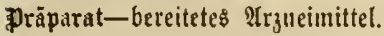

Drakti[d-ansübend, anmendobar.

Jrimār-uriprïuglid.

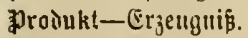

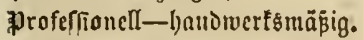

proportion-Berlıältmí.

Droftituirte-Entelyrte.

Joteptiren-mideriprectien, einreden.

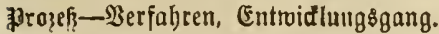

Znluerifirt-verfeinert, fein geftopent.

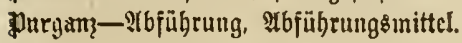

Dualifikation-B\&fähigun!

Dnalitä-CEigenjळaft, Bejめaffenheit.

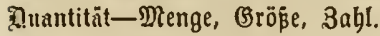

hace-?trt.

Kadikal-bon (3rund aus; ;. B. beilen oder verbeffern.

Reduciren-verrilgern, auflöjen, zurīđfübren.

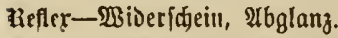

Reform-llmbiloung, Berbefierung.

Aieforma:or-Berbefierer, Ulmbilder.

thegulirt-regelu, oronen. 
RePpehtabel-phrenwerth, adtungsooll.

kefultat-Ergebniß, Erfolg.

Ruiniren-zu (5runde ridten.

Sektion-3rgliederung oder Deffnung, Ib/đnitt.

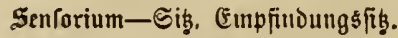

Serōs-blutwäfiferig, Dem Blutwaifer äbnliđ.

Sppecifífh-eigenthümlid, verbältuiß̄mäsig.

Stadium-Berlaujzzzeit einer Srantbeit.

Struktur-3ufanumenfïgung, Einriøitung.

Stupis-dunm, ftumpifinuig.

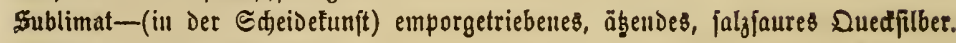

Solvitanz-Stoff, Beftantitheil.

Symmatrie-Ebemma

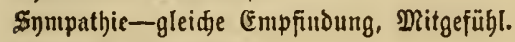

Sinmptom-2Äzeidien.

Sinmptomatifd)-anzeigend, zu Srantheit\&zeiळen gehörend.

Snjfem-das zujammen gebörige (Bauze. Snftematifh-wiffenfhaftlid, bündig, ge. oronet, zujammengeitellt.

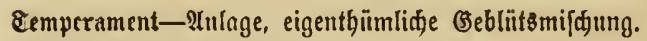

Cemperatur-Wärmegrad der Ruft.

Ehrorie- Rebre, roiffenjajaftidje Renutniß.

Iuberkel-franfhafter Snoten im Rörper, bejouders in Den \&ungen.

Enphös-nerbenfieberartig.

Dentilation- Quftzug.

Beterinärifd-thierarzneilid).

Volumen-llmfang, didf, ftarf, Band.

Walladen-beridneiden, veridguittene Pferde. 


\section{Detphabeti/dhes Inthaltsperzeidnitz.}

\begin{tabular}{|c|c|}
\hline & \multirow{4}{*}{ 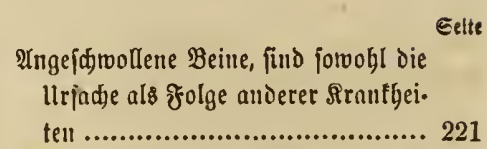 } \\
\hline & \\
\hline & \\
\hline 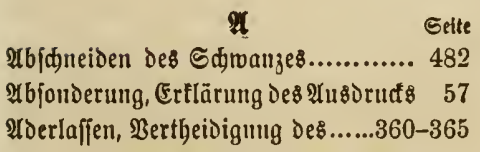 & \\
\hline \multirow{2}{*}{$\begin{array}{l}\text { De nidft bie gleiden wie } \\
\text { beim MRenfdert........... 363 }\end{array}$} & \multirow[t]{2}{*}{ the } \\
\hline & \\
\hline & \\
\hline & शlugefdrwoll \\
\hline & \multirow{2}{*}{ 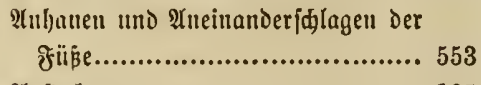 } \\
\hline & \\
\hline & Ariftedfung..................................... 125 \\
\hline 2 & \\
\hline & \\
\hline $\begin{array}{l}\text { " witnd } \\
\text { "Beljan }\end{array}$ & \\
\hline & \multirow{2}{*}{ 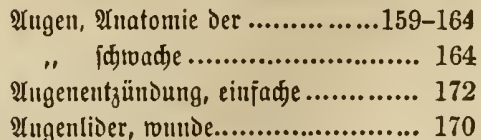 } \\
\hline & \\
\hline \multirow{2}{*}{ " Durd die Rippen angedeutet..... 474} & Ágenuaffer.................................... 56 \\
\hline & \multirow{2}{*}{ 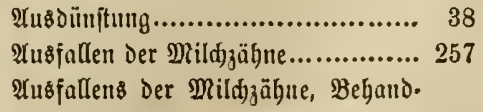 } \\
\hline \multirow{2}{*}{ Augen angedeutet............... 475} & \\
\hline & \\
\hline Altalien & 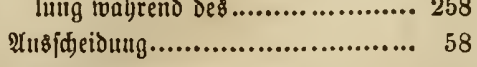 \\
\hline \multirow{2}{*}{ 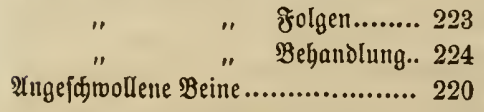 } & us[ð]lagen ............................... 548 \\
\hline & wie es fid das Pferd an. \\
\hline & \\
\hline
\end{tabular}




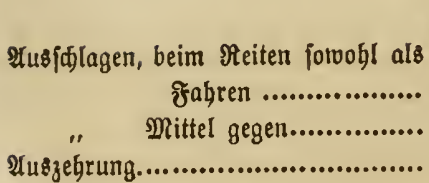

\section{$\mathfrak{B}$}

Baudfpeidjeldrüfe....................... 66

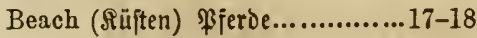

Bevectung .................................. 424

Bebandlung im Stall..................... 411

Beíkent ..................................... 549

Belladouma............................... 386

Beugefelne .............................. 41

Bewegung, Notbwendigleit Der ........ 427

Borfint be 3 üglid) Der...... 428

Dountt ïber................. 428

Big Head, (Sejwidjte Der Sirmutlleit.... 69 Ilnwiffenlyeit bezïglid Der

Rranflbeit................. 70

Ulrjactjel1.....................71-74

Symptome .................. 75

Behaindlung.................. 76

Bebandlung in früberer

Beit .......................81-83

Blaje, Entzïndumg...................... 334

" Stein in............................ 337

Blaues uno flebriges Ddjenfleiijd..... 32

Blinddarm............................64, 316

Blinobeit, veruriadgt ourdy ভdjlagfluß 244

Blind Staggers......................... 113

\begin{tabular}{|c|c|}
\hline " & $\begin{array}{l}\text { Bo Dieje Sranffeit } \\
\text { borfommt........... } 113\end{array}$ \\
\hline - & $\begin{array}{l}\text { Ulnwiffenlyeit bezüglidg } \\
\text { Des .................... } 114\end{array}$ \\
\hline " & $\begin{array}{l}\text { Qäderlidje } \text { afnfidgten } \\
\text { über................... } 114\end{array}$ \\
\hline " & wirflide llrfađen des 115 \\
\hline " & Enmptome De\$......... 117 \\
\hline & $\begin{array}{l}\text { Die frübere Behand. } \\
\text { lungstweife des...... } 119\end{array}$ \\
\hline " & $\begin{array}{l}\text { Die ridtige } \text { Begand. } \\
\text { lung des............... }\end{array}$ \\
\hline
\end{tabular}

Seite

Blut, Rraufbeiten Des................. 374

. Beftandtheile des.................. 42

Blutyarnen, Bebandlung Des.......... 329

Bluffuden .............................. 42

Bobrwurm................................ 393

Edyrecten vor................. 393

" Beule verurfacht ourd....... 394

". Bebaudlung Des............. 395

Bösartige Geude ......................... 282

" " Eymptome ........... 282

" " grall .................. 283

Bref)ueinitein ............................ 385

Bremien .................................. 392

Brondjien ............................... 57

Bronchitiš................................. 289

Brudi ies Edjüdel\$..................... 520

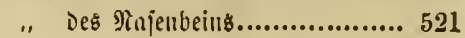

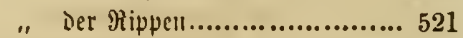

" Der Beine.......................... 522

, Eiuridutung ies $\mathfrak{B e i n s . . . . . . . . . . . ~} 526$

"Bel)andlung der Brudjwunde... 527

Brüdige รูufe............................. 100

" " Utraddent der.............. 100

" " Belyandlung Der......... 101

". "Beitonuer Der §ur...... 103

Brufit, Sirunflleitcu Der.............288, 289

Buffalo.Müưten .......................... 392

Sdprectell vor......... 392

Edjug vor.............. 393

\section{(c)}

Ehloroform .......................314, 319

Corrofives \&iniment.................... 560

Creosot ................................... 384

Croton Del.............................. 385

2

Dabonlaufen............................. 551

Desinfeftion ............................... 424

Diffe\& $\mathfrak{B l u t}$.............................. 359

Dielenbodent in Ställen................. 421

Distemper ............................... 153

153 


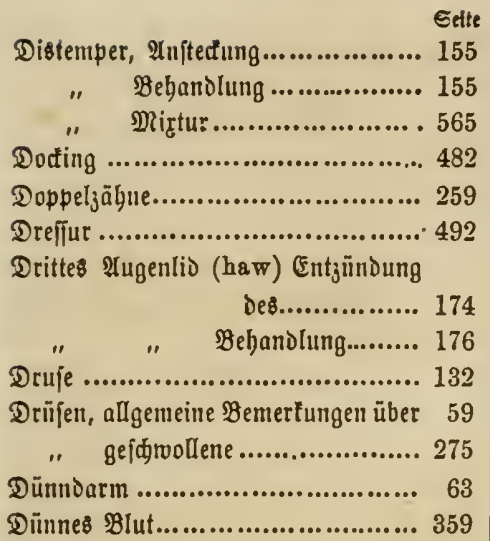

\section{(5)}

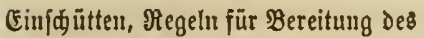
" einzujüüttenden Trantes 375

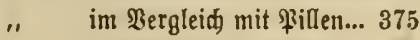
" Ilıgwectuāpigige Inwen. Dung ................... 373 Befte Methode Des....... 374

Eijenbitriol ............................. 383 Eitergallen............................ 235 Gireiß̄, Mirtung Deffelben anf die . Rub́teln .................. 31

" Farbe Des..................... 32

Engländer und Эanfee............... 143

Entenfuß.\&iniment ................... 561

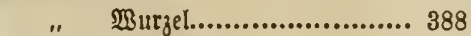

Futgündung Der (sedărme............. 307

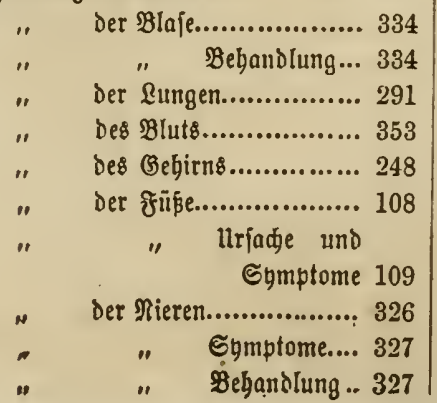

Entgündung und Beriten Des (Brimm. Setie Darms................. 318 1. Bluten Des Raftoarus 320 Epidermis............................. 35 Ertältungen.......................... 270 " Ilrjaden :Der.............. 271 " Borbeugungen gegen.... 272

\section{$\dddot{\mho}$}

falljudt.............................. 247

Jajern (Segnen. f̧ibern)............. 31

fobler ................................. 547

J̃effelgelent ............................. 26

Jjettzunalyme bermebrt nidgt Die STrạt Des Pferdes.............. 31 Wirtungen auf รूaut und saar .................... 31

₹eudtigteitsbebälter §. Eprunggelenf\$ 189 Befめ̆äذigungen u. Beríten Der...... 189

Fieber, Urjachen แแD Borbeugungen gegent ..................... 355

Bebandlung Des............... 358

Jiftel, Mrjade Der..................... 180

, Behandlung Der................. 181

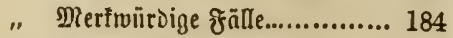

" Frïhere Beljandlunggrveije.... 185

fleifdbant........................... 37

₹luв̈gallen............................. 191

" IIrfade u. Bebanolung 191-192

รlup̣trämpfe find jebr bäufig.......... 208 Der Nerben, gaut und MRเి๋teln ............ 208

flüfïge Aleģalbe..................... 560

froblen, Das einjäbrige............... 502

pollte zu Dem bon igm gefor. Derten Dienfit dreffirt werden 496 3eit Der Ågewöhnung........ 445 Rranfbeiten Der................ 343 BebondIung Der Siranfbeiten 345 follten ein gutes Dboacy zur ueberwinterung baben ...... 446 Ererbte Sranlbeiten Der..... 447 


\begin{tabular}{|c|c|}
\hline \\
\hline & \\
\hline \multicolumn{2}{|l|}{ 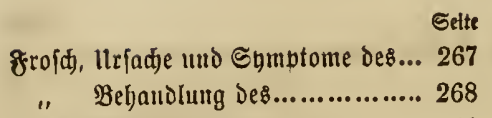 } \\
\hline Finfe, $\mathfrak{A}$ tnatomie ber.................... 40 & \\
\hline " fellerbafte ....................... 555 & \\
\hline Futter, befte Gräfer für.................... 403 & \\
\hline " Subereitung....................... 405 & \\
\hline fotterballen.................................. 377 & \\
\hline " aแ18 maร beftehend......... 377 & \\
\hline follte je nadid ber 2 lrbeit 2 . & \\
\hline ftärfer ober leidfter feil 396 & \\
\hline " (Einwenoungen gegen $\mathfrak{B}$ elyd. & \\
\hline & \\
\hline (B) & \\
\hline ................ 324 & \\
\hline .................... 324 & \\
\hline Belganditung ................ 325 & \\
\hline (3anglien .................................53-54 & \\
\hline (Gebärmutterentzïnoumg................. 337 & \\
\hline Gedärme, $\mathfrak{A}$ natomie der................. 309 & \\
\hline Entzünbung der.............. 310 & \\
\hline Symptome Der................ 310 & \\
\hline (s)eörmsentzinnourg.......... 310 & \\
\hline ". Bebandlung ................... 312 & \\
\hline
\end{tabular}

Bebirn, Anntomie Des. .51-53

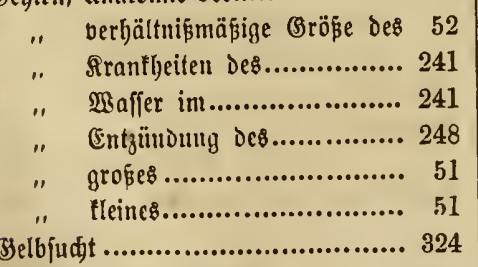

"1 Befandlung..................... 325

Betröpe.................................. 65

(Betreide, @uantität fiitr Die Fiitterung der $\mathfrak{a f e r d e . . . . . . . . . . . . . . . . . ~} 406$ verl)ältnī̄mäßiger $\mathfrak{B e r t h ~ ๖ . ~}$

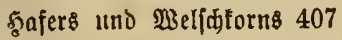
(Bervöbnung ............................... 492 Bifte, giftige Sdjlangen, Injeften 2c. 397

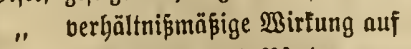
MReniden und $\$$ fferde........ 379 als Irgneien.................... 379 (3ifte, welde burdh bic ફ̧aut einorin.

gett ............................ 387

1" thierifite ......................... 389

Biftiger Sumadt......................... 388

(Biftige Epintuen......................... 390

(Sla\&auger............................... 173

(Bräjer, Bemerfingen über............. 400

" verhältnißßäß̈iger $\mathfrak{B e r t h}$ Der 401

Brimmoarm ............................... 64

" Entzültoung und Berften Des........................ 318

Behandlung............... 319

33rose Ulnteridenfelbein.............. 27

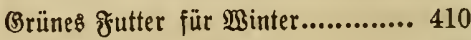

Grub, Bejdreibuty Des................. 62

\section{$\mathfrak{g}$}

ફ̧aаre, Bemertungen über...35, 39, 40,474

รูnargefäße ................................ 43

Haematura.............................. 329

ફ̧abmenfpat (\$̧al)nentritt).............. 209

Sig̨ Des .................... 210

Symptom Des̊.............. 210

Mirfungen, wie fie fidy bei Der Geftion Darftellen 210

รjals........................................ 58

„, Srantheiten des.................... 270

" ange[dyollener ................... 275

Sarit, blutiger............................. 329

" dicter, fifleimiger.................. 329

". . Enaltiger............................... 330

". Berhaltung deß \$ูarn\$1.......... 333

§ูarnflu| .................................. 328

\$arnorgane .........................67, 557

รูarmberftopfunt ........................... 333

\$̧arz......................................... 568

\$̧ajenbacte................................. 193

รูaut, gunttion Der..................... 35

„ Sranfbeiten Der.................. 213

" Der frerje ............................. 217

" Fettbrüjen der....................38-40

§̧autmuttetl................................ 37

छäute ..................................... 34 


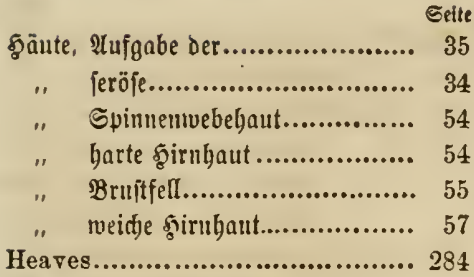

5aengit, Beidreibung Des geeigneten Budthengites.................. 436

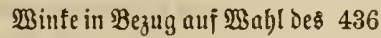
f̧erz, Lage Des............................ 47

" Fimttion ies....................... 47

". Stranflyeiten des..................... 347

รen Dnju eignenden Bräjer......... 403

Hide-bound .............................. 229

Itriade und Beł̆andlung 229-230 छirnbaut, farte.......................... 54 รुorubaut

" $\quad$ Sunttionen Der............... 36

". Des Magens.................. 61

§orniffe, Da§ Sted)en Der............... 396

รูufbejdlag, lltiprung des................ 529 cin nothrendiges llebel... 529 Joutatts Anweifung pür... 530

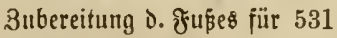
İuflegen Deร Eijens...... 534

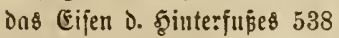
veridfiedene Fुufeifen...... 539 Rirtgeijen.................. 547 \{buebymen Der รุufeifen... 544 รูแน์. 26

" Farbe, in ge[undem 3uftand.... 103

, Bejdneiden der..................... 544 รูแกีäule 103

, Ulrjactje Der..................... 103

" Folgen Der....................... 103

Enmptome der................. 104

Bebandiung Der............... 104

5.undertfuß ................................... 390

\$uften................................... 278

Itrjade Deళ.................279-280
Sुulten, Bebandiung des

Selte 280

\section{3}

In die Eijen bauen und Ineinander. joflngen der gïüe.................. 553 Iutenter Iffter.......................... 320

Iunge Pferoe erfranten leidter als alte. 169

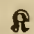

Siatarrb................................ 132

Raftriren, waun vorgmehmen........ 451

Berfahrungsmethode....... 454

" befte Эabre禾eit für......... 454

" Ilnterbinden (twitching)... 455

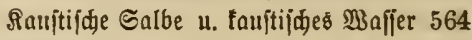
Rebldoeftel ............................. 56

Rebltopi................................. 56

Reiden (Bellows, Heaves)............ 284

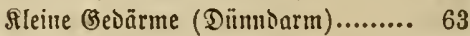

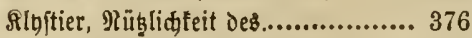

. Bebrandisantweijung .......... 377

Inoden, Be[djreibung Der.............. 25

" Des Sopfes..................... 27

., Der Giutern B̧liedmaßen..... 27

" Der vorbern Bliedmaßen.... 26

Rolif ........................................ 303

" Reunzeiden Der.................. 304

Srämpfe................................. 203

Sranflyeiten Der Ptugen und Bebano.

lung derjelbell........... 159

Der Reber u. Şarnorgane 322 jumger Foblent................ 353

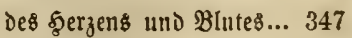
Der 3äbne u. Des Mlaules 254 Deई fुalfes..................... 270 der Bruft uno der \&ungen 288 Der Şautt.................... 213 Des Mlagens und Der Bes: Därme .................... 300

Rreislauf De\& Blutes.............43, 44, 349

Siteuzung der zu derfelben falnilie ge. Görenden $\$$ Fferde.............. 18 


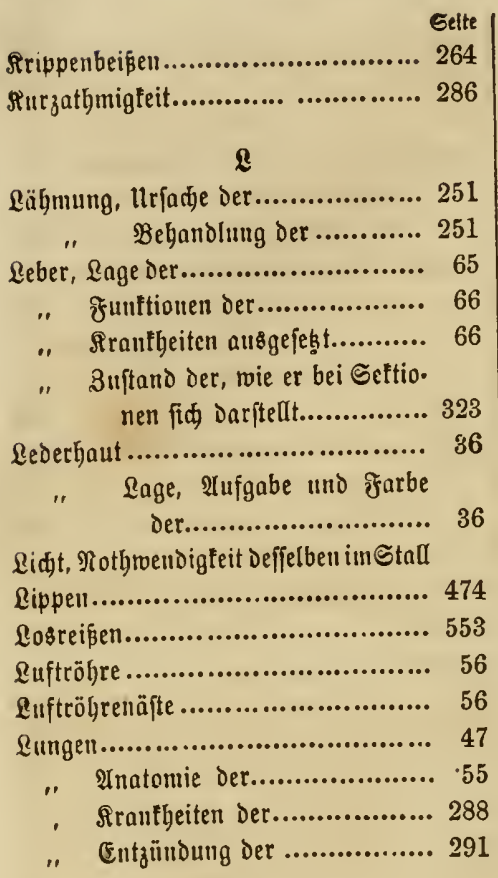

\section{$\mathfrak{B}$}

Mrageil, 2Hatomie Desి......

, Sranthyeiter de\&................ 302

" Größe und foähigteit Desి...... 302

, Alufgabe Degీ.................... 302

". Zehler De8...................... 557

PRageumund ............................ 60

MRagen und (Gedörme, J̧eh̆ler Deş..... 557 Magenfaft .............................. 62

Magilđes Merbenliniment, 3ubereitung Des.................... 562

(B)ebrauch Debิ................. 563

MRahnung an Pferdeeigentbïmer...... 145

Malignant epidemic................... 282

" " $\quad$ " Enall................ 200

Mtaftdarm............................... 64

" Entzünonng 1. Bluten des 320

" Bebandlung 320

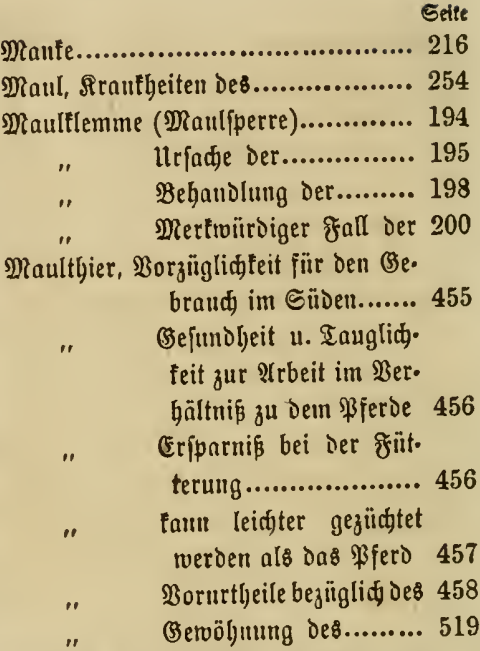

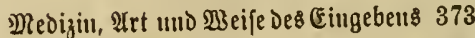

Merfmale des $\mathfrak{A}$ Iterş.................... 468

Merfurialfalbe ........................ 563

3ubereitung Der........ 563

(Gebrauch Der............ 563

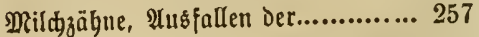

Behandlung

wäl)rento des 258

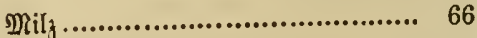

, $\mathfrak{B e r g r o ̈ \beta e r u n g ~ D e r . . . . . . . . . . . . . . . . ~} 335$

Mijbyandtungen Der $\mathfrak{P f e r d e . . . . . . . . . . . . ~} 475$

llebermäß̆gę Â 2 rbeiten...... 477

¥eitjden und Sblaget...... 478

Sduteideu und Sdilizen der

Dhren ....................... 480

Mondblindbeit........................... 170

Musfteln, Afnatomie Det............... 30

" (Empfinifautfeit und Quali.

tät ber....................... 31

\section{$\Re$}

Ragen an Den Riement.................. 553

Mafe am \$ुufeijen........................ 537

शa[enföblen, Junftionen Der.......... 56

Nerben, für Bewegung................. 53 
Stite

Rerben, Srantheiten o. Nerbenfiftem 224

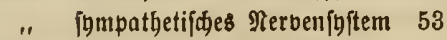

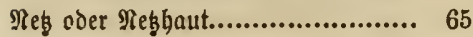

Nicking ............................... 482

Nierell................................ 67

, Fumflionen ber.................. 67

" Entzündung ठer................. 326

Nux vomica............................ 383

Dळfenfpat und $\mathfrak{B l u t i p a t . . . . . . . . . . . . . . ~} 188$ i) " Bebantlung 190 Dhren, Berleģstng der................ 237

" Folgen folder Bełdädigungen 237

", wunde.......................... 238

" zeigen das Temperament alt.. 481

\$aaruurg ..............................449

Pacer.................................... 14

Panniculus carnosus................. 37

ßaß̧äuger............................ 14

Pferd, Borbemerfungen über Das..... 11

, Srantheiten Des................ 14

, Entartung de\$................. 15

, Rebensoawer Des................. 18

" .eit........................... 512

, Ehaifen.......................... 514

, Sెug................................ 515

, Dmuibus......................... 517

, llinarten des...................... 547

" Fehler Des̊..................... 547

Bjerdegudt ............................ 431

" Einmendung gegen übliche Gebräuçe bei Der...... 432

" Der şengit follte fid mebr im freien berwegen uno nicht jo oft in $\mathfrak{A}$ [1prud genomment werden.432-433

Bie eine Reform in Der ßfproegudt au betvirfen 434
Pförtner................................ 60

\$ille.
Bithatell

\$leurefie ................................ 298

Pneumonia.............................. 291

ßodjen ................................. 349

," Beifpiel bes์..................... 350

, Bebandlung de\$................. 351

\$oren................................ 35

, ซुuntion Der................... 48

अuls, man hat demiflben Aufmert.

famteit zu jфhenten............ 369

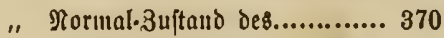

" Beränderumgen Des............... 370

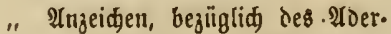
laffes

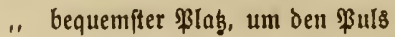
子u füblen.

\section{$\Re$}

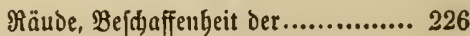

" Urfade und Enmptome der... 226

, 9 Inftectung bon................. 227

" 3eitbaner der Sुeilung.......... 227

, Bebanblung Der............... 227

, wie Anftecfung ju verbüten.... 228

Recepte zur $\mathfrak{A}$ rgneibereitung, die in

Diejem $B$ ứ angegebenen........... 559

Rebe, die bezügliđge, gemöbnliçe $\mathfrak{a}$.

fitht irrig............................ 108

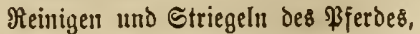
Rotbmendigteit des........ 424

.. शुonatt über.................... 421

". pollte romöglich im frreien gefdeben.................. 422

Rei

Reitpferde, welde $\$$ ferde fid am beiten

Ђiezu eignen........................ 512

Rete mucosum........................ 37

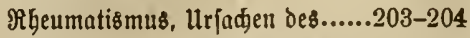
merțürdige fölle... 204 Behandlung des...... 208

Rippen............................... 29

Roaring ............................. 286 

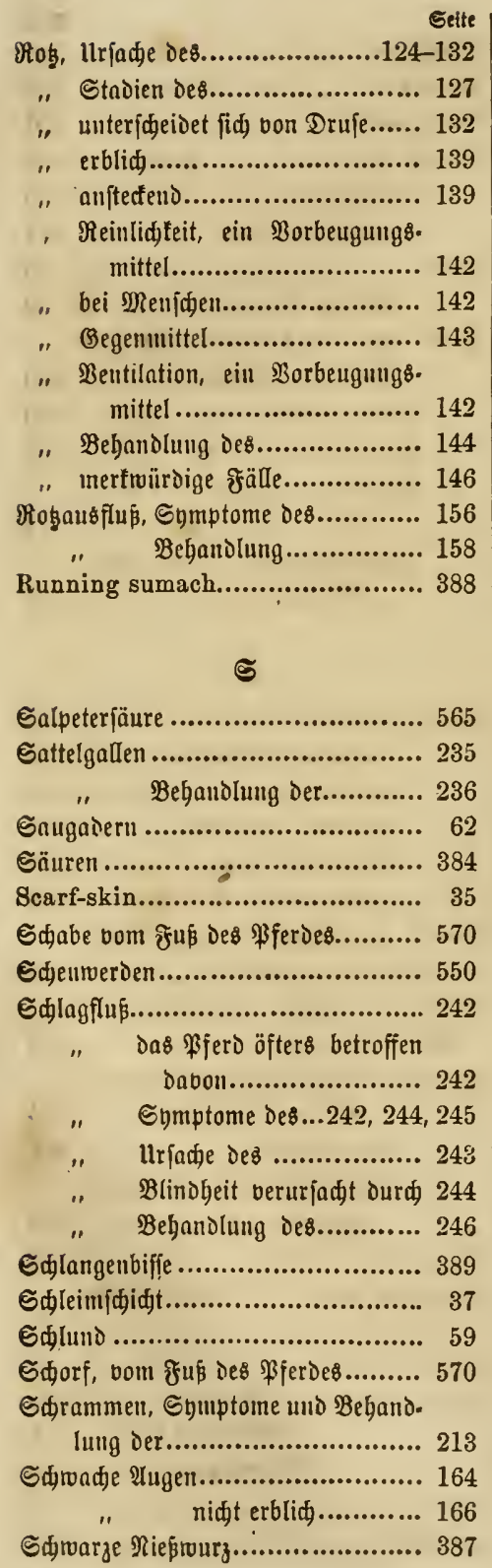

Sdywarzer Staar....................... 173

Sdivefel ................................. 568

Sdivefeljalbe, 3ubereitung Der........ 564

" Bebrautd Der............ 564

Sdjwei

Segnen, founttionen Der................ 33

Sit-fasts ............................... 235

Storbut Der Bäbne....................... 261

Strophell1.................................... 352

Epanijळe જfliegen........................ 382

Epinnen, Biffe boll..................... 390

Spinnenuebehaut......................... 54

Sprunggetenf ............................. 26

Staar...................................... 172

Stalleinridtung........................... 411

Starrframpf (DRaultlemme, MRaul(perre) .................... 194

Ulrfadje des................. 195

Behandhung des.......... 198

Merfwïrdiger fall voul 200

Stedapjelfamen, (3ebraudj Des.....77, 567

Stediende Gforpionell.................... 391

Steiflyeit ................................ $23 \mathrm{C}$

Stein in Der Blaje, Entftegung des... 331

." Symptome des..................... 331

" Behandlung de8................... 332

Steingallen ................................ 105

" Ulnwiffertheit bezüglidy der 105

" Bebandlung Der............ 106

, F̈älle Der..................... 106

Steinquetidungen........................ 108

Steiphaden ............................... 197

Stollen aın รูufeifen..................... 537

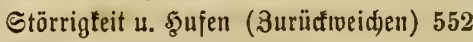

Strabl, Berleşungen des................ 107

Strahlfäule............................. 215

" Borbengung Der............. 215

", Bebandlung Der............. 216

Strell .......................................... 419

Stumpfaugen ............................. 264

266

" Fälle....................... 266

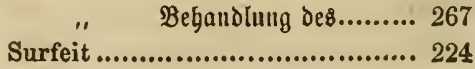


Sette

Surfeit, llrjache uno Shmptome des 224

Bebandlung\$rweife Deş...... 225

Gympatbetijules Banglieninitem......

\section{I}

Tabad 384

Semperatur der Ställe................. 414

" Beränderungen........... 423

Terpentilt............................... 385

Ibeer ................................. 384

Thorough-pin ........................ 197

Thumps............................... 349

., Beifpiel....................... 350

, Bebandlung................... 351

\$olltir[dje ............................. 386

Tïrt................................... 167

Twitching............................ 455

11

Ueberzäbne. 259

Ulnartell. 547

Angewöbnung, wern noळ jung 495 Ilngegiefer, Lrjadae, Bebandlung...... 238 Unterbinden............................ 455 Ilnteriđentelbein, Das groß̧e........... 27

\section{3}

Bentilation der Ställe. 414

Bergrö̈́perung Des \$̧erzens............. 348 Berleģuแg Der Dhren.................. 237

BoЩfuß ............................... 107

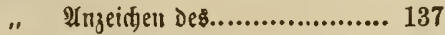

" Bebandlung Des................ 107

Botarmbein........................... 26

218

Bahnfinn 252

Błaffer im Behitn. 241 Bafferidjeu 247

Warbles 235 WBarzen

Bepđreibung Der. 231

"

Bebandlung Der... खeide รัü̉e (fiebe รูuffäule).

Beide, Bemertungen ïber............. 399

" die bejte $\mathfrak{A r}_{j}$ nei ..................399

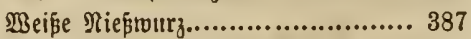

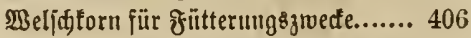

" idjlimme Mirtungen des (Be. braudjs boll............... 407

Wespen ................................. 392

Wettremuen ............................. 483

Widerrijt, Cntzïnoung Des (i. Fifitel)

Mindtolif.................................316

Bebandlung der............ 817

Wind [augen.............................. 264

Wirbelīänle.............................. 53

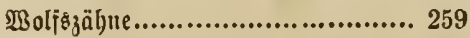

$\mathfrak{B} u$ ue $\mathfrak{A}$ ugenlider.................... 170

" " Bebandlung der... 170

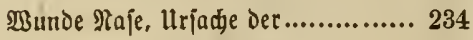

" " Bebandlung Der......... 170

$\mathfrak{1}$ urm................................. 147

Ionatf' \$Bejđreibung Diefer

Sirantheit................... 148

Urfacje der[elbell.............. 152

" Bebandlung derjelben........ 153

Mutb............................... 247

\section{3}

3agnen..............................256-260

3ähıung ............................. 492

" bejte నeit fïr bie............. 494

" bejte Metbode für Die....... 495

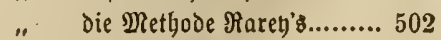

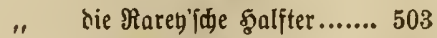

" Der Rareb'jul Rnieriemen... 504.

" $\quad$ (Febrauc voll $\mathfrak{A}$ rzuei bei... 504

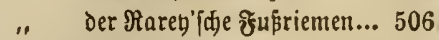

3ähne, Sranflyeiten Der.

. Sujtand in veridjiedenem Alter 464

bi\$ 474

, fünitlidje Buridjtung Der...... 472

. F̧aulen Der...................... 260

" Sforbut ber................... 261

Sellengervebe Der Beine................. 220 


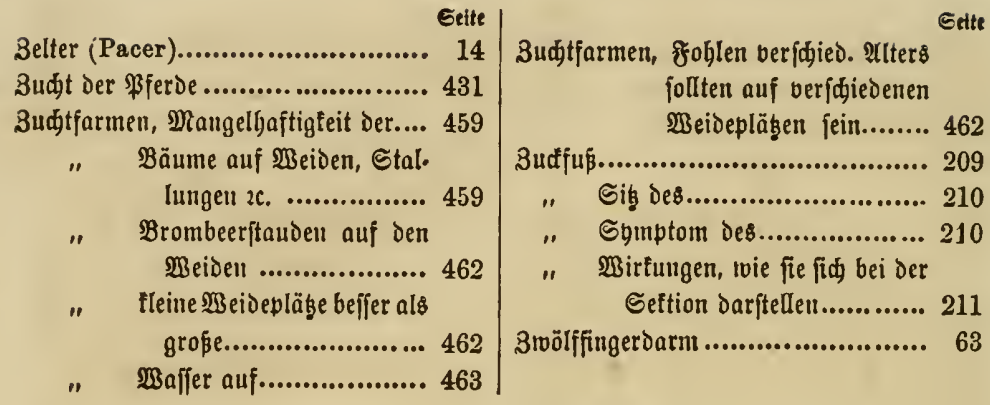




\section{Petrgabe dex Sinnptome}

der

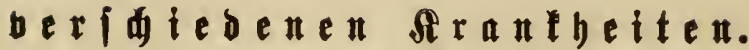

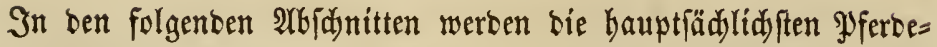
franfheiten mit 2 (ngabe ser Symptome überfiddtlid aufgeführt. Die lebteren fino ihrer Reithenfolge nad), b. b. To angegeben, wie fie fid nad) einanber äufern uno aljo bie veridjebenen Stabien ber Rrant= beit fenrzeidjnen. Die Biffern geben bie Seiten an, wo bie betref=

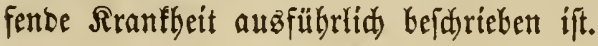

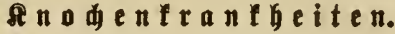

(Seite 69-95.)

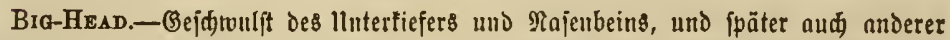

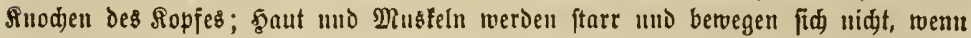
man an Den Rippen ziel)t; beftändige Saläjrigteit wälyrend des Steljens; Abmagerung;

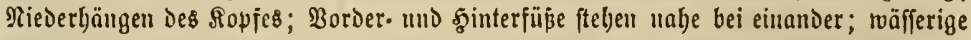

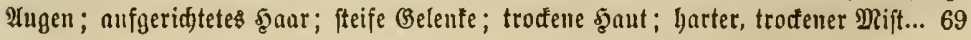

SwInNex, oder Entgünoung Der Sdulter: Entgünoung. Şiģe uno \&abmbeit iu ber

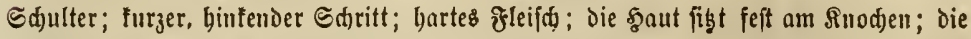
Sdulter fdrumpft eiu und wird rumzelig; Der \$atient jögert, (id) niederzulegen; endlid)

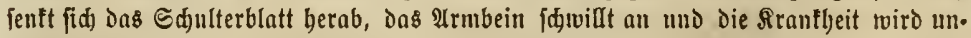

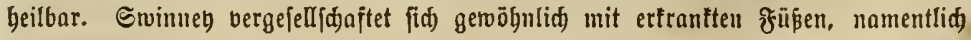
mit ફ口uffäule

Bia sHodLder:-BBeridlimmerte Sáulterentzündung (swinney). (Siehe den vor. bergeljenden $\mathfrak{r}^{(b j}$ djuitt.).............................................................. 84

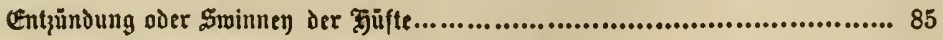

Verrenkte oder gebrod) frile

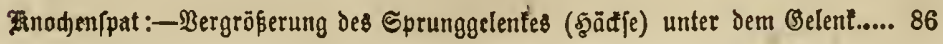


Ge/djmollene Gjädhe, àder siprunggelenk 89

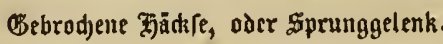
90

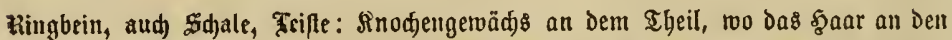

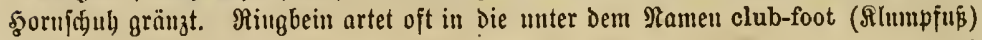
befannte Sirantheit aus.

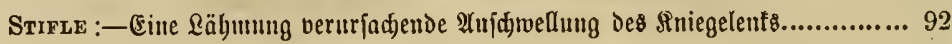

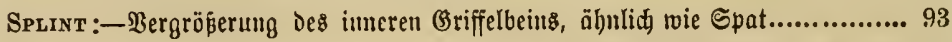

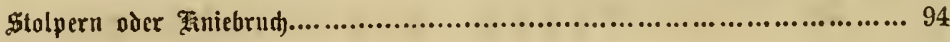

Sitnknüttell ........................................................................ 98

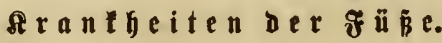

(Seite 96-112.)

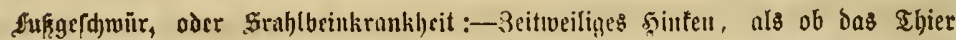

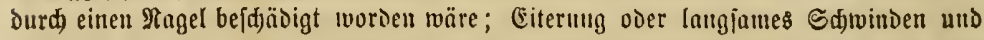

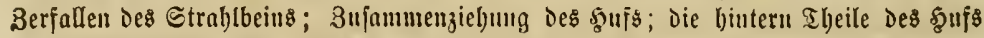

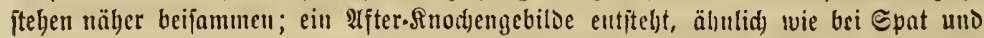

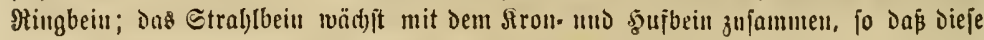
Drei endlidy eine Majie bilden und mit einumber inmer megr anjaluellen............... 96

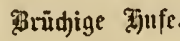

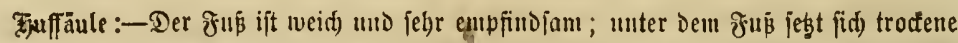

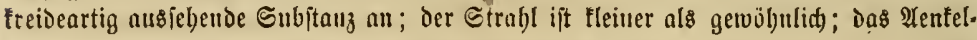
gelent ift angeidguollen; ; turzer Sdyritt; bintender Bang...................................103

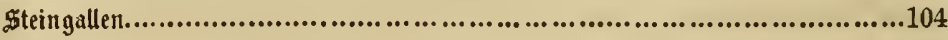

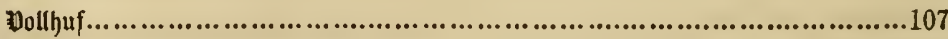

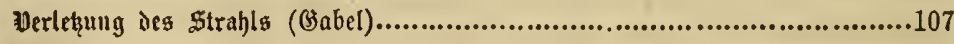

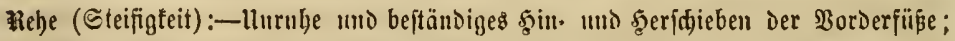

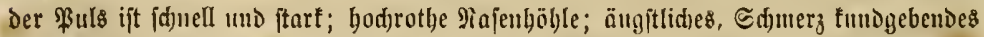

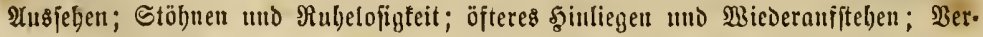

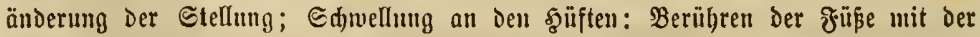
Raje 108

\section{Rrantlociten Der Drüịen= un๖ Rajenbäute.}

(Seite 113-158.)

Buind-Stagaens:- Wirtlidje oder (đjeinbare $\mathfrak{B}$ linoheit eines $\mathfrak{A}$ (uges, mandjmal aud)

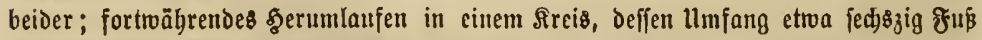

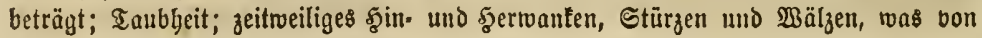


zmanzı Mimuten bis eiue Etunde Dauert; Die Rrämpfe nehmen an ફुeftigteit zu und wiederbolen fid, öfters; Stöhnen, 3uđungen und milde Sprünge, die mit nnbefdreib. lidjer ફ̊gftigfeit ausgefübrt roerdelt

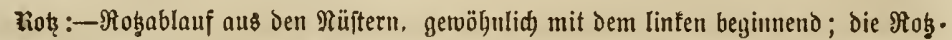
abfonderun!̧ twir twäfferig und fleberig; Die Duantität berjelben wird mit Dem ₹oct.

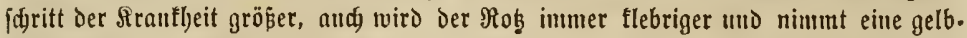

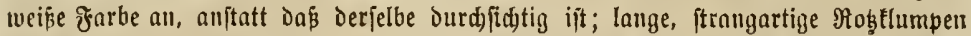

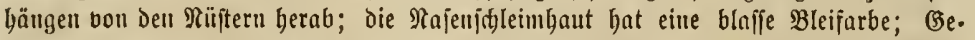

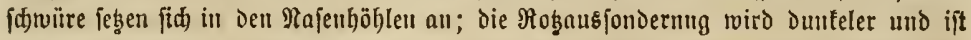

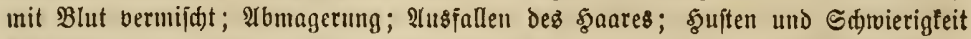

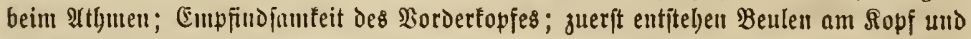
bem Gefidft und Dutu aul gauzen Siörper.

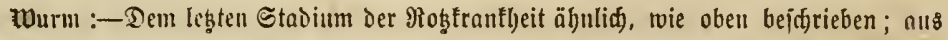

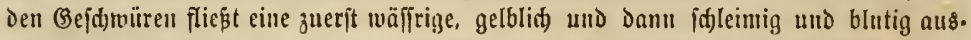

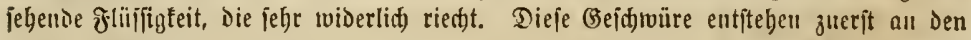

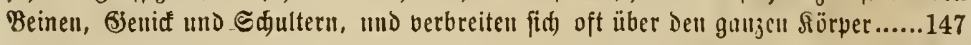

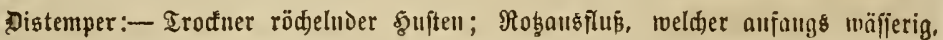

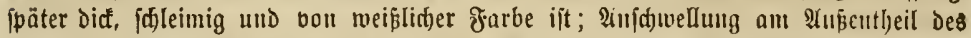

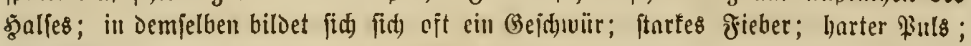

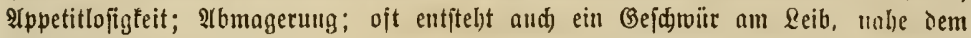
Sdlaud. 153

Koถุausfluß̧. 156

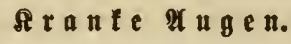

(Geite 159-179.)

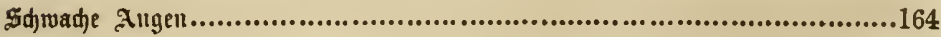

Inunde Augenlider......................................................................170

Atondblindbeit................................................................................ 170

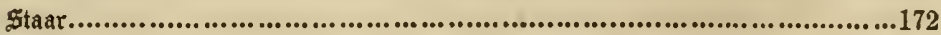

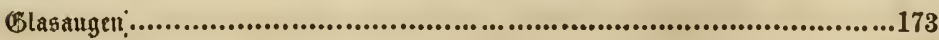

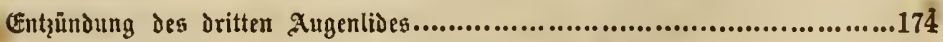

\section{Rranfleiten ber Masteln und Sebren.}

(Seite 180-212.)

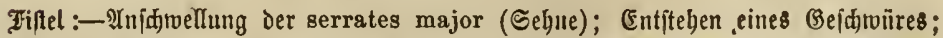

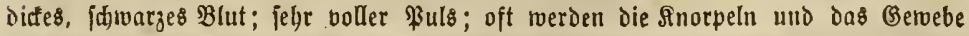

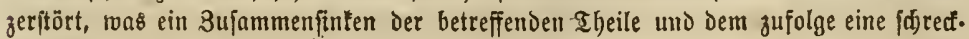
lides $B_{B}$ erunftaltung erzeugt..................................................................180

Gertidkfiftel (Poll-evil) ...................................................................187 


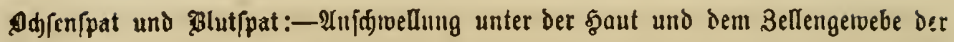
\$äätfe............................................................................. 188

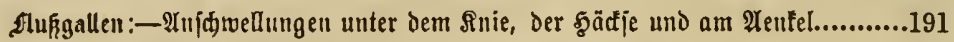

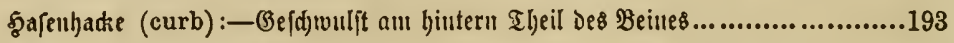

Diphadkn (Steiplacten, thorough pin):- Eitue weide Gejdwulft auf ber innern

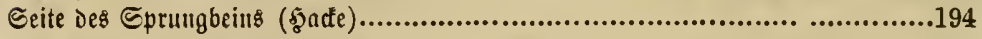

Ataulklemme (Maulperre, Starrframpf; lock-jaw):-Die Dlusteln find ftraff;

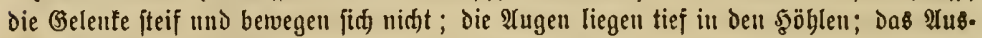

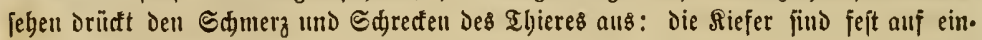
ander gèrüdt.

2tugkclkrämpfe:-3ữen Der Muśtelı an ben Beinen u.f.w. 202

Rheumatismus:-Entzünoung Der Gehnen แแo Belente, namentlid bie Der şüfte und Sdultern...................................................................20

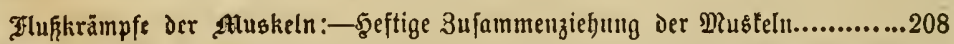

Gुabnenโpat:-Das Bein toiro trampfhaft, viel höher als gewöhulid, mit eiuer plög̨. liden 3 3ututu emporgebobell........................................................211

\section{Rranfbeiten ber $5 a$ ut ud ber Dhren.}

(ङeite 213-240.)

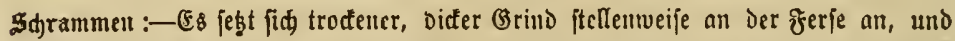
greift un fid , bis die gauze Oberfläbe zu einer feiten Mafie von B̈rind und şaren geworden ift; Suden in Den betreffenden Iheilen......................................213

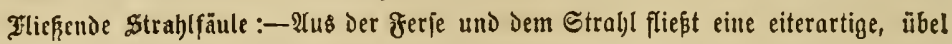
riedende olüfígfeit.

Atatke:-Die Symptome fino Denen ähnliø, die fid bei Der Strablfäule zeigen, mit

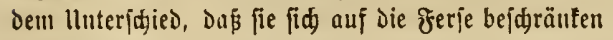

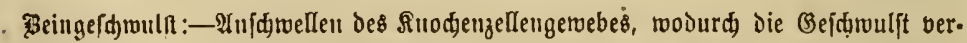

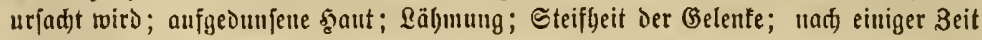

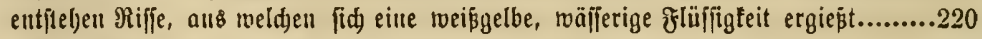

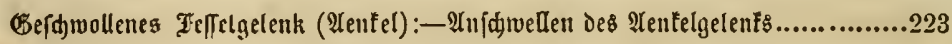

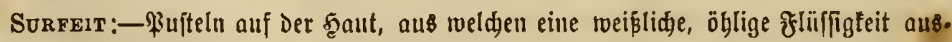

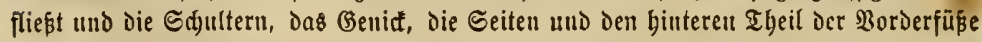
bebectell .224

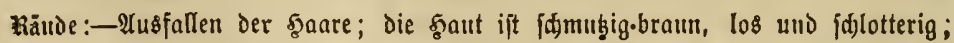

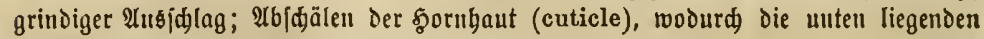
Iheile roh und blutig werden; Brenten und ฐuten...................................226

HIDE-BOUND .229

Steifhsit:- Trodene, zu[ammengezogene Şaut; iteife Belente; Musteln uno Sebnen werden jteif und idjeinen zujammengezogen zu feill .280 


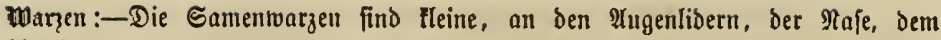

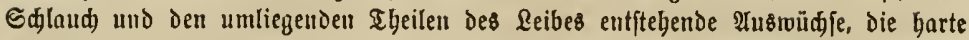

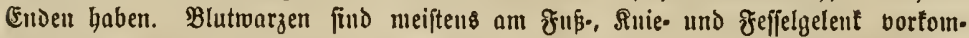

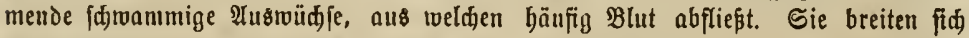
jebr leidst ans, uno find öfters febr rob, wund mo blutend.

vunde nafe. 234

Sattelgallen:- Der Rücten des Pferdes ift uuno geritten uns roh; mandumal entfiteben Beuleri, Die Eiter nusjondern 235

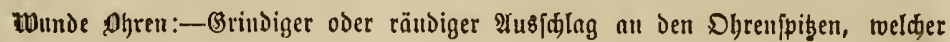
fic von bier abwärts aแsocbut. 238

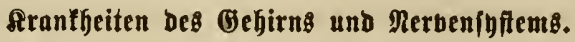

(Seite 241-253.)

Waffer im Gehirn

241

Sid)ląfluk:-Sdywindel und tolle, heftige Benegungen; idfwanfender, ftolpernder

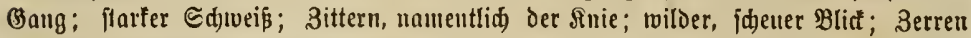

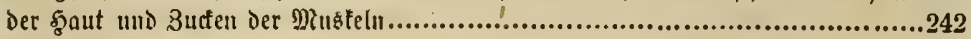

Walferftheu, wuth.........................................................247

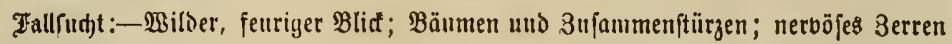
und 3uctent

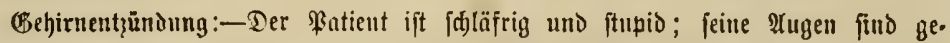

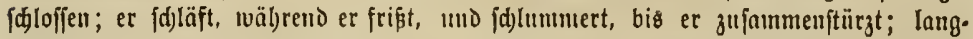

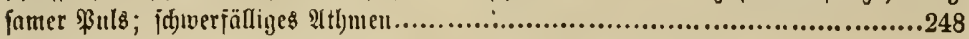

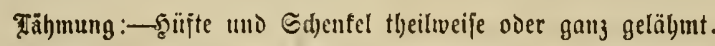

Wahnfinn:-Einfältiges (Bebal)ren; hermmid)weifender Blid; nubezrwingbarer Sdjedt bei getwiffem (Seräujक), Erblicten getuiffer garben $11 . f .10$. .252

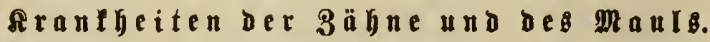

\section{(Scite 254-269.)}

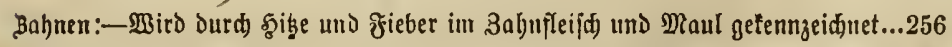

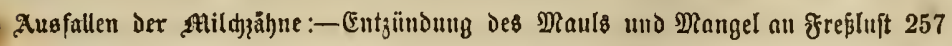

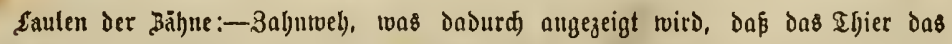

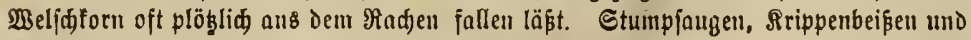
Bindjaugen mögen auf diefe urfacte zurï̈gefïbrt werden.........................260

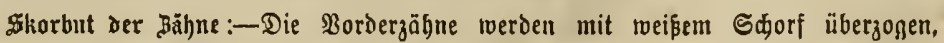
wodurd Das 3abnfleif und der Riefer entzündet werden..............................261

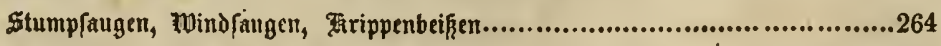

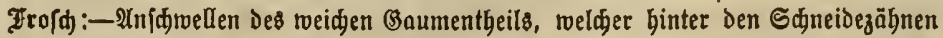
in Der obern $\mathbb{R}$ undwand liegt 
Srantbeiten des galfes.

(Seite 270-287.)

Erkăltumgen.

Gerdumollene Driifen

Geldimollener gals

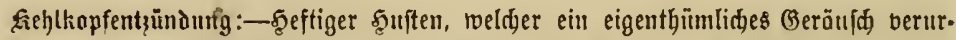

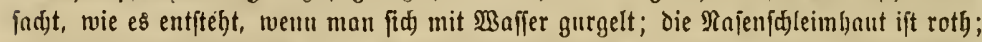

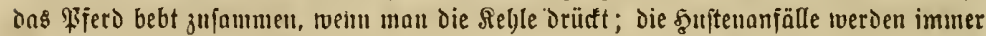

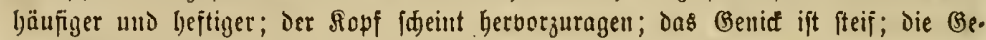

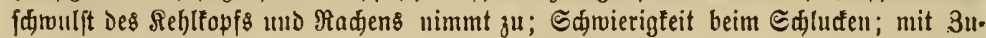

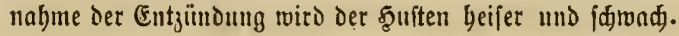
.275

ริ) .278

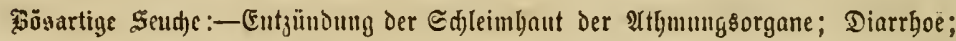

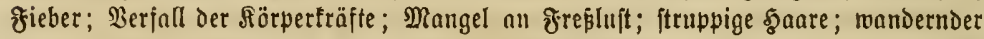

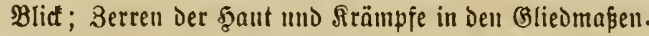
.283

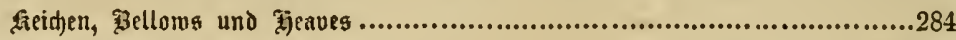

\{funţatbmigkeit.....................................................................28

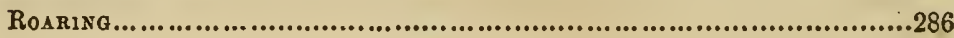

\section{Sranffyeiten Der Bruft und Der Rungen.}

(Seite 288-299.)

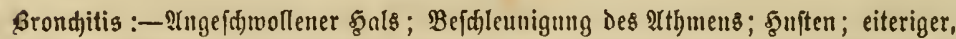

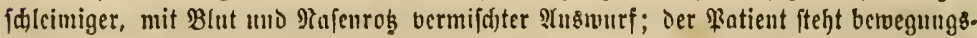

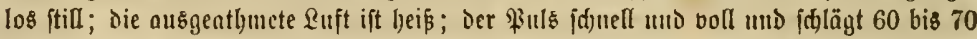
Mal in Der Minute; Die Majeufdaleinthant ift tiefroth; bält man Das Ohr nahe zum

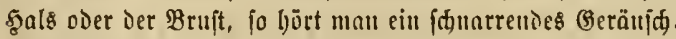

.289

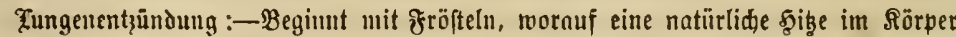

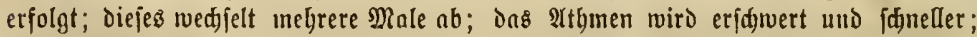

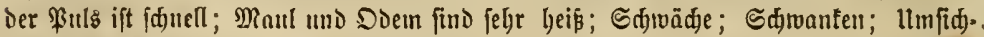
jळlagen; Stölynen

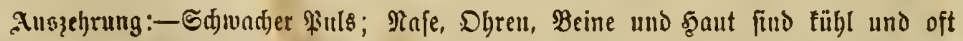
eisfalt; Majenldjleimlyaut vou blaffer, aldggraner farbe; Doem beiß uno felje übel.

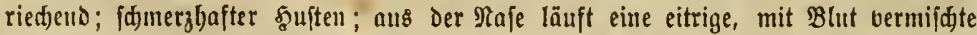
flüffigteit .294

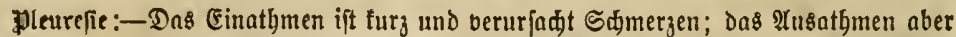
gefdiegt nur wenig ober nidit idneller als wie im gejunden 3uftand; 2itbembolen -

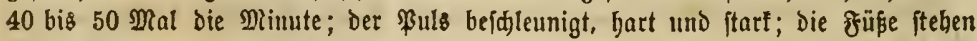
nabe beifammen; Der Ropf ift vorrwärts geftrectt. 


\section{Arantbeiten bes Mageng ber (Bebärme.}

(Seite 300-321.)

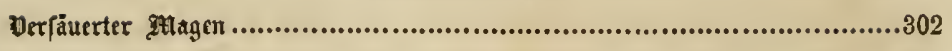

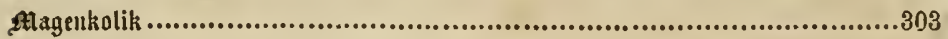

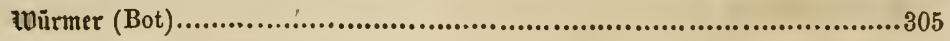

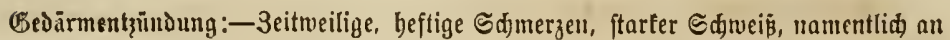

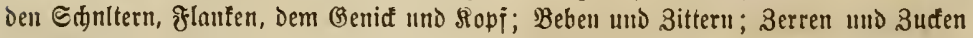

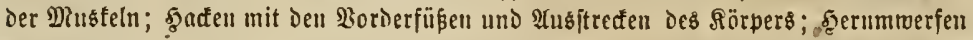

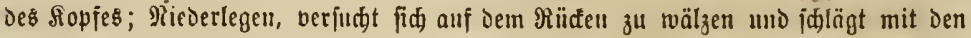
Borderfï̈вen gegen die Bruft, fpringt plöglid vieder anf, legt feine Dhren zuriữ, läuft f

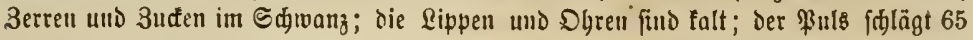
bi\& $80 \mathbb{M}$ al bie $\mathbb{R}$ imute..........................................................................308

mintokalik 316

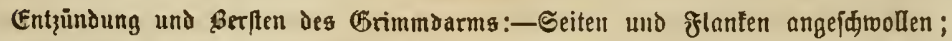
ftarte $\delta$ fieber; aukerordentlidje Edimerzen...............................................318

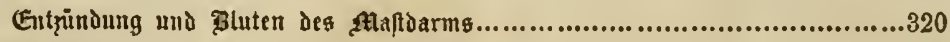

thunder und judkender fffter....................................................... 320

\section{Sranfyeiten Der Reber und Garnorgane.}

(Seite 322-346.)

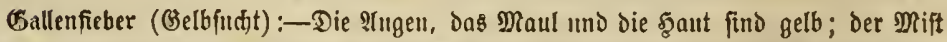
ift hart, Dunfel und wird in fleinen Ballen abgefondert; Der f̧arn hat eine dunfelbraune

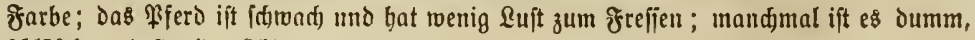

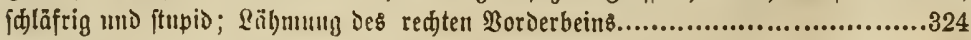

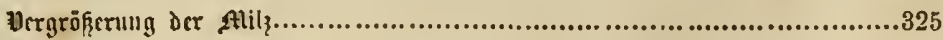

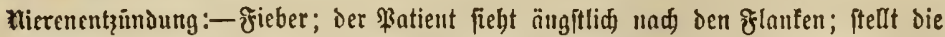
\$ुinterbeime reit nuseinander, legt fich fehr ungern, empfindet Sdimer; beim llmotehen

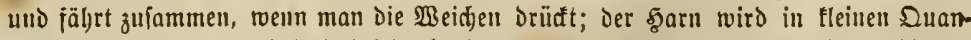
titäten uno mit groper Sdpwierigfeit abgelaffen, und ift getwöbnlid bodjroth und blutig;

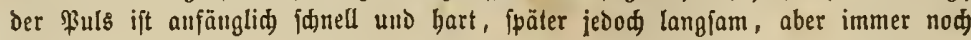
bart .526

B⿹

Bgluthantert.................................................................................3 329

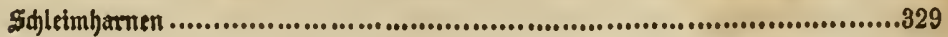


Wrifer ober kalkiger J్jarm.

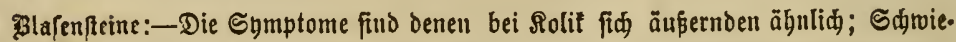

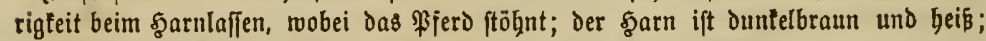

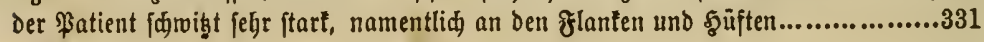

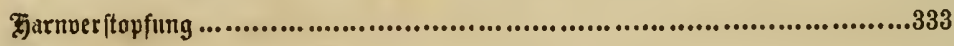

ģ

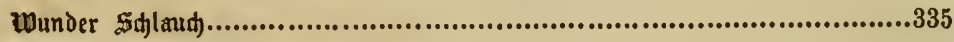

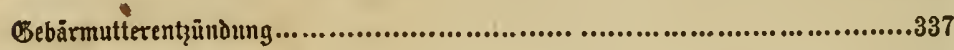

Sânkankeiten junger fohler..........................................................343

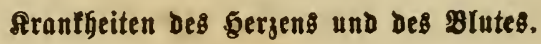

(Seite 347-378.)

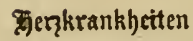
.848

pood)en (Thumps)

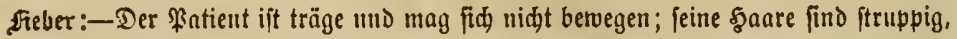

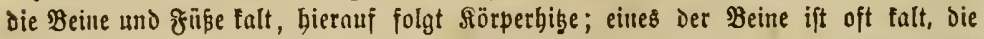

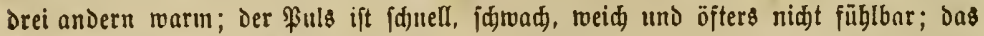

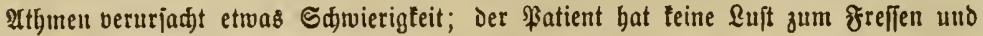
ift fefre bartleibig.............................................................................353

gidkes ģ

פDimueg g glut............................................................................359 






\section{.}


